\title{
JaA
}

Energy

Information

J U L Y 1996

Administration

Annual

RECEIVED

JUL 232996

Energy
Review

1995

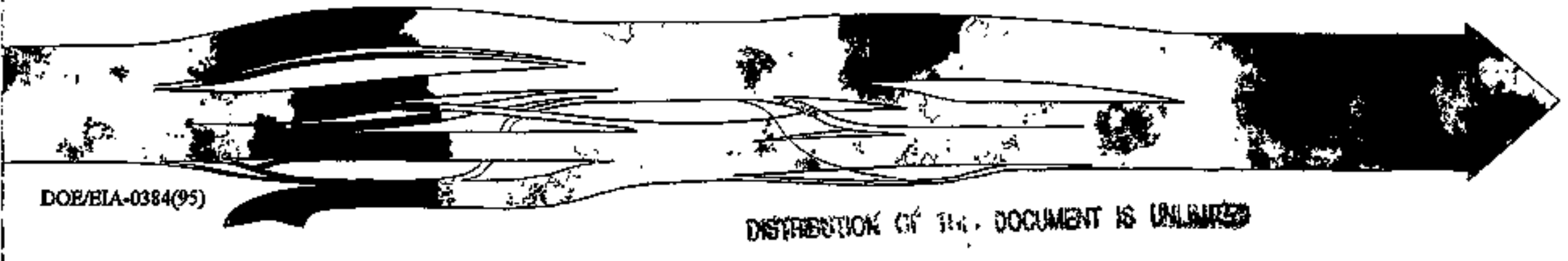




\section{Annual Energy Review 1995}

The Anntual Energy Revlew ( $A E R$ ) presents the Energy Information Administration's historical energy statistics. For most series, statistics are given for every year from 1949 through 1995. The statistics, expressed in either physical units or British thermal units, cover all major energy activities, inciuding consumption, production, trade, stocks, and prices, for all major energy commodities, including fossil fuels, electricity, and renewable energy sources.

Publication of this report is in keeping with responsibilities given to the Energy Information Administration (EIA) in Public Law 95-91 (Department of Energy Organization Act), which states, in part, in Section $205(a)(2)$ that:

"The Administrator shall be responsible for carrying out a central, comprehensive, and unffed energy dato and information progrom which will collect, evaluate, assemble, analyze, and disseminate data and information..."

The AER is intended for use by Members of Congress, Federal and State agencies, energy analysts, and the general public. EitA welcomes suggestions from readers regarding data series in the $A E R$ and in other ElA publications.

Related Publication: Readers of the $A E R$ may also be interested in EIA's Monthly Energy Review, which presents monthly updates of many of the data in the AER. Contact on National Energy Information Center for more information.

\section{Electronic Access}

Wost of the data to the AEF are also available electronically. For more Information about elecironic access to the AER, please refer to the tiside back cover of this report or contact EIA.

\begin{tabular}{|c|c|}
\hline \multicolumn{2}{|c|}{ intemet Addresses } \\
\hline $\begin{array}{r}\text { E-Mail: } \\
\text { Wortd Wide Web stie; } \\
\text { Gopher Sile: } \\
\text { FP Site: }\end{array}$ & $\begin{array}{l}\text { infoctr ola.doe.gov } \\
\text { hltp:/hww.eia.doe,gov } \\
\text { gopheri/gopher.ela.doe.gov } \\
\text { fto:/ftp.ela, doe,gov }\end{array}$ \\
\hline
\end{tabular}

Released for Printing July 3, 1996

GPO Stock No.; 061-003-00962-0

\section{Ordering Information}

This and other ELA publications may be purchased from the Superintendent of Documents, U.S. Govemment Printing Office.

Telephone and tax orders should be directed to:

Superinterdent of Documents

U.S. Govemument Printing Office

Main Order Desk

202-512-1800

Fax: 202-512-2250

8 a.m. to 4:30 p.m., eastern time, M-F

Mail orders should be directed to:
U.S. Government Pinting Office
P.O. Box 371954
Pittsburgh, PA 15250-7954

Alternatively, copies of the 1995 edition of the Annual Energy Review may be obtained by use of the order form in the back of this publication.

Complimentary subscriptions and single issues are avajlable to certain groups of subscribers, such as public and academic libraries; Federal, State, loctal, and forejgn governments; ELA survey respondents; and the medig. For further information and for answers to questions on epergy statistics, please contact ELA's National Energy Information Center. Address, telephone numbers, and hours are as follows:

\author{
National Energy Information Center, EI-231 \\ Energy Information Administration \\ Forrestal Butlding. Room 1F-048 \\ Washington, DC 20585 \\ 202-586-8800 \\ Intemet E-Majl: infoctr(ieeja.doe.gov \\ TTY: For people who are deaf \\ or hard of hearing: 202-586-1181 \\ 9 a.m. to 5 p.m., eastern time, M-F
}

Cover: Artst's rendition of U.S. total energy flow.

Printed with soy ink an recycled paper 


\title{
Annual Energy Review 1995
}

\author{
July 1996
}

\author{
Energy Infomation Administration \\ Oftice of Energy Markets and End Use \\ U.S. Department of Energy \\ Washington, DC 20585
}

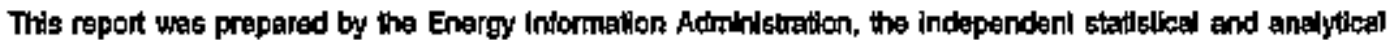

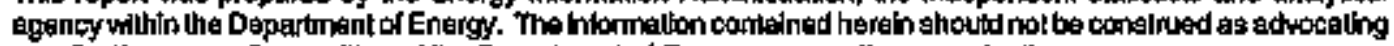
or reflecting any potcy posillon or the Depariment of Energy or any olher orgarizalion. 


\section{DISCLAIMER}

Portions of this document may be illegible in electronic image products. Images are produced from the best available original document. 


\section{Contacts}

The Annual Energy Review (AER) is prepared by the Energy Information Administration. General information may be obtained from W. Calvin Kilgore, Director, Office of Energy Markets and End Use, 202-586-1617, Lynda T. Carlson, Director, Energy End Use and Integrated Statistics Division, 202-586-1112; and Katherine E. Seiferlein, Chief, Integrated Statistics Branch, 202-586-5692. Questions and comments conceming the contents of the $A E R$ may be referred to Samuel E. Brown, 202-586-5103; Barbara T. Fichman, 202-586-5737; Alethea K. Jennings, 202-586-9160; or the following subject specialists:

Major Energy Developments in $1995 \ldots \ldots \ldots$. . . . . . . Barbara T. Fichman

202-586-5737

Analyticat Summaries $\ldots \ldots \ldots \ldots \ldots \ldots$ Barbara T, Fichman

$202-586-5737$

1. Energy Overvlew . . . . . . . . . . . . . Samuel E. Brown

2. End-Use Energy Consumption . . . . . . . . . . . . . . Samusl E. Brown

Manufacturing Energy Corsumption Survey ........... Mark A. Schipper

Fesidential Energy Consumption Suvey . . . . . . . . . . . . . . . . Mlchael $T$. Laurence

Residential Transportation Energy Consumption Survey . . . . . . . . . . Ronald Lambrecht

Commercial Buildings Energy Consumption Survey . . . . . . . . . Martha M. Johnson

3. Financial Indicators . . . . . . . . . . . . . . . . . Samuel E. Brown

Financlal Reporting System . . . . . . . . . . . . . Jon A. Rasmussen

$202-586-5103$

$202-586-5103$

$202-586-1196$

$202-586-2453$

$202-586-4062$

202-586-1135

Energy Resources

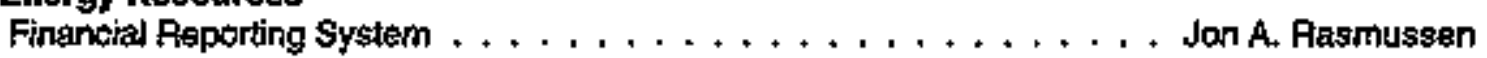

Petroleum and Natural Gas . . . . . . . . . . . . . . . . . Robert F. King

Coal . . . . . . . . . . . . . . . . . . . . Richard F. Bonskowski

Urantum . . . . . . . . . . . . . . . . . . . . . L Luther L Smith

5. Petroleum . . . . . . . . . . . . . . . . . . . . . Robert G. Harper, III

Prices $\ldots \ldots \ldots \ldots \ldots \ldots \ldots \ldots$ Ellzabeth $K$. Scott

Charles W. Finer

6. Natural Gas $\ldots \ldots \ldots \ldots \ldots \ldots$ Carol J. Jones

7. Coal $\ldots \ldots \ldots \ldots \ldots \ldots$. . . . . . . . . . . . . . . . . . . .

$202-586-5103$

$202-586-1449$

202-586-1449

202-586-4787

202-426-1132

$202-426-1140$

202-586-9176

$202-586-1258$

$202-586-6610$

$202-586-6168$

202-426 -1153

6. Electriclty

Generation and Fossil Fuel Consumption and stocks . . . . . . . . Melvin E. Johnson

Imports and Exports . . . . . . . . . . . . . . . . . . John W. Makens

Sales and Prices . . . . . . . . . . . . . . . . . . . Stephen E. Cakpedis

Net Summer Capabtlity . . . . . . . . . . . . . . . . . . . . . Karen McDantel

Noncolncidental Peak Load . . . . . . . . . . . . . . . . . John W. Makens

Emissions and Environmental Equipment . . . . . . . . . . . . . . . John G. Colligan

Nonutitly Power Producers . . . . . . . . . . . . . . . . . Betty L. Williams 


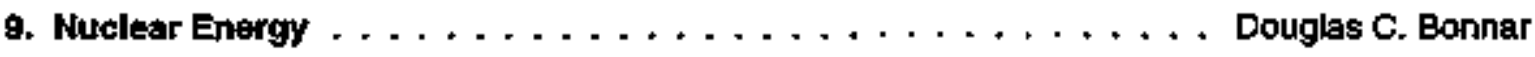

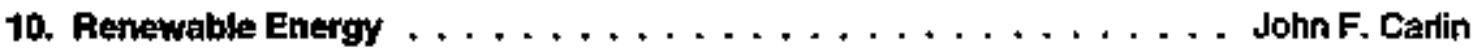
Residential Energy Consumption Survey . . . . . . . . . . . . . . . . Michael T, Laurence

11. International Energy . . . . . . . . . . . . . . . . Michael J. Grillot

Nuclear Electricity Generation . . . . . . . . . . . . . . . . . Douglas C. Bonnar

$202-586-6577$

$202-426-1249$

12. Environmental Inticators

Greenhouse Gases ........................ Arthur D. Fypinsk

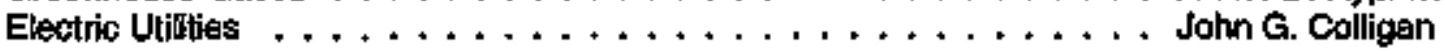

\section{Aftention All Readers:}

\section{We Are Hoplng To Hear From You!}

The Energy Information Administratlon welcomes comments from readers abott the Annual Energy Review (AER). We would like to hear about any aspect of the $A E R$ that can be improved so that we can enhance the usefulness of the report. If you have suggestions about improving the oontent or format of the $A E R$, please direct them to Barbara T. Flchman via any of the following toutes:

$$
\text { Telephone: } \quad 202-586-5797
$$

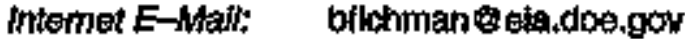

\section{Fax: $\quad 202-5 B 6-0016$}

Malling Address: Bahara 'T. Fichman, El-635

Energy Information Administration

Forrestal Building, Room 2F-02t

Washington, DC 20595 


\section{Preface}

This fourteenth edition of the Annual Energy Review (AER) presents the Energy Information Administration's historical energy statistics. For most series, statistics are given for every year from 1949 through 1995. Because coverage spans four and a half decades, the statistics in this report are well-suited to long-term trend analyses.

The $A E R$ is comprehensive. It covers all majof energy activities, including consumption, production, trade, stocks, and prices, for all major energy commodities, including fossil fuels and electricity. The $A E R$ also presents Energy Information Administration (ELA) statistics on renewable energy sources. In the past, ElA's consumption series have included about half of the renewable energy used in the United States, the amount consumed by electric utilities. Last year, for the first time, usage by other consumers was integrated into ELA's historical consumption series for 1990 forward. Incorporation of non-electric utility data into U.S. energy consumption adds about 3 quadriltion Bhu to the total.

This year's report introduces four new tables:

- Table 3.13, "State Govemment Severance Taxes, 1985-1993," supplies data on effective energy severance taxes per volume of crude oll, natural gas, and coal and on energy severance taxes as a share of all taxes.

- Table 3.14, "Companies Reporting to the Financial Reporting System, 1975-1994," is a grid displaying which major U.S. energy compantes reported to the Financial Reporting System (FRS) in each year from 1975 through 1994 (the most recent year for which FRS data are avaitable).

- Table 4.9, "FRS Companies' Expenditures for Oit and Gas Exploration and Development by Region, 1977-1994," presents, for the first time in this report, data on FRS companies' expenditures for exploration in Canada, Europe, and other reglons.

- Table 10.9, "Electric Power Industry Net Generation by Selected Renewable Energy Resources, 1949-1995," presents data on renewable energy use by electric utilities and nonutility power proilucers side by side in the same table to allow the reader to compare them directly.

For the most part, fuel-specific data in the $A E R$ are expressed in physical units, such as barrels, cubic feet, and short tons. The integrated summary data in Section 1 are expressed in Btu. The Btu values are calculated by using the conversion factors in Appendix A. Statistics expressed in Btu are valuable in that they allow for comparisons among different fuels and for the calculation of integrated summary statistics, such as U.S. consumption of energy.

The AER emphasizes domestic energy statistics. Accordingly, Section 1 through 10 and 12 of this report are devoted to U.S. statistics, while Section 11 is reserved for most of the international statistics, such as world production of energy. The one exception is trade data. For example, Table 5.4, which presents statistics on petroleum imports by country of origin, is found in Section 5 . To keep table and figure titles in Sections 1 through 10 and 12 concise, "United States" is usually not specified. Readers interested in more detailed international data than are presented in the AER should consult EIA's International Energy Annual.

Publication of the AER each year is in keeping with responsibilities given ElA in Section 205(a)(2) of the Department of Energy Organization Act, Public Law 95-91. The report is intended for use by Members of Congress, Federal and State agencies, energy analysts, and the general public. ElA welcomes suggestions from readers reganding its energy data series. To make a suggestion or to obtain specific information regarding the contents of the $A E R$, readers may call any of the subject specialists listed as contacts on the preceding pages.

Printed copies of the 1995 edition of the Annual Energy Review may be obtained by using the order form in the back of this publication or by contacting the U.S. Goverument Printing Office or the National Energy Information Center, as listed on the inside front cover of this report. Most of the data in this report are also available electronically. For more information about electronic access to the $A E R$, please refer to the inside back cover of this report. 



\section{Contents}

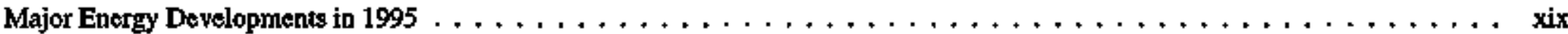

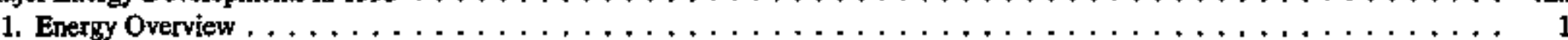

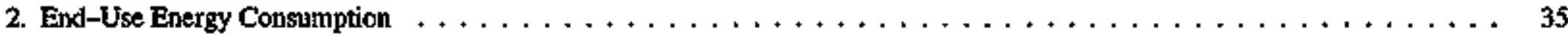

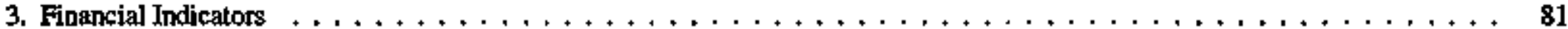

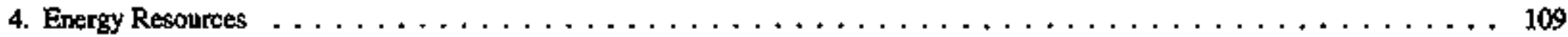

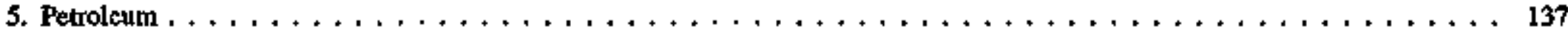

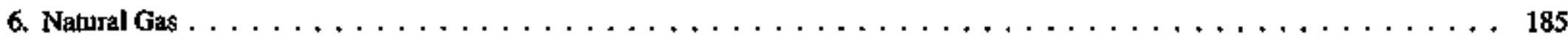

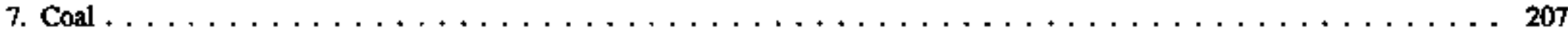

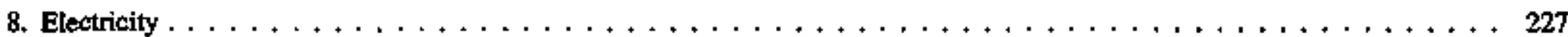

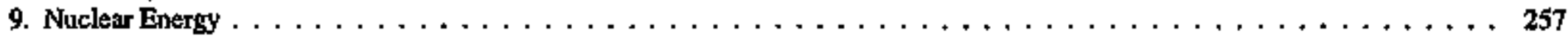

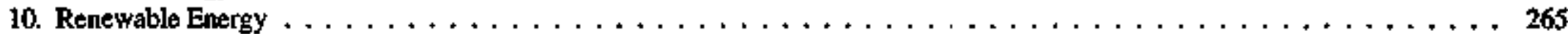

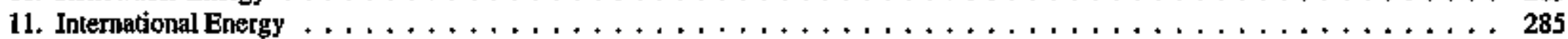

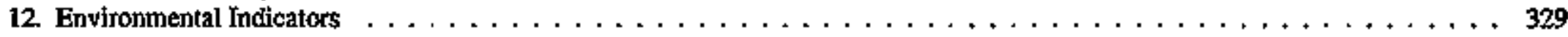
Appendices
A. Themal Conversion Factors $\ldots \ldots \ldots \ldots \ldots \ldots \ldots \ldots$
B. Metric and Other Physical Conversion Factors $\ldots \ldots \ldots \ldots \ldots \ldots \ldots \ldots \ldots \ldots$

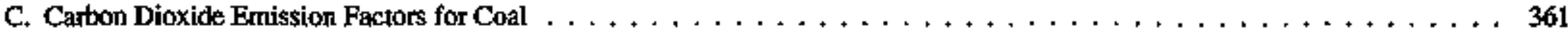

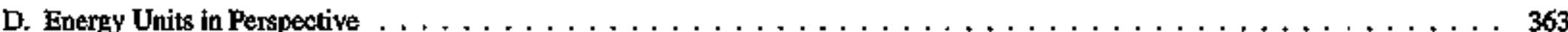

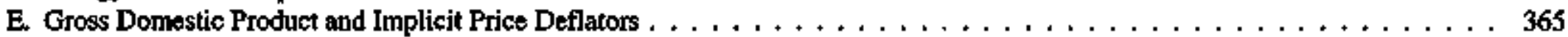

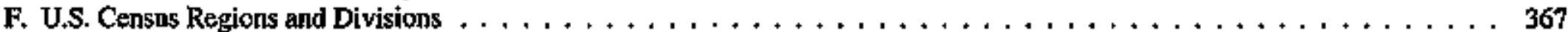

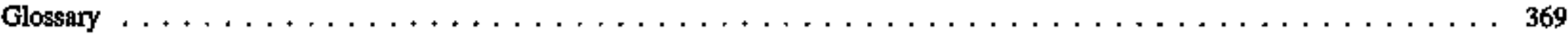
Diagrams

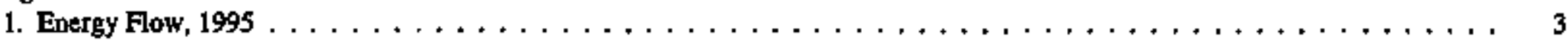

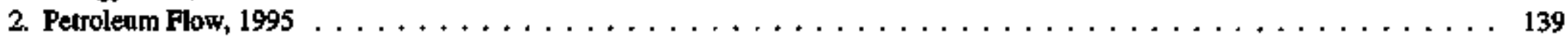

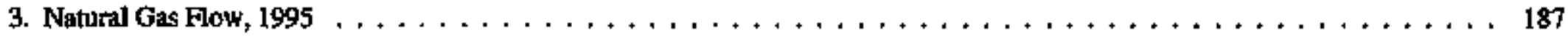

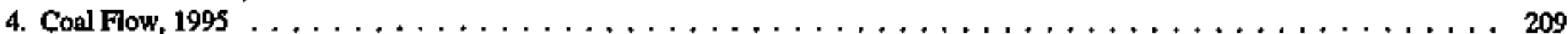

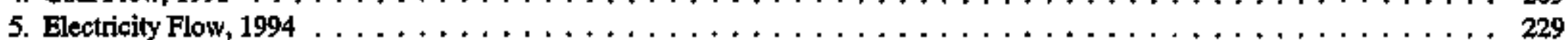


1. Energy Overview Page

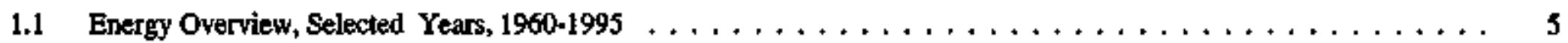

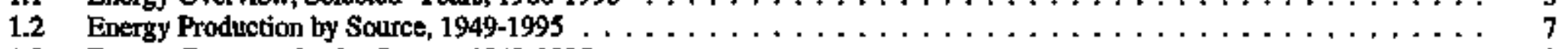

1.3 Energy Consumption by Source, $1949-1995 \ldots \ldots \ldots \ldots \ldots \ldots \ldots \ldots$

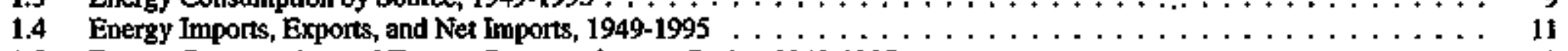

1.5 Energy Consumption and Energy Consumption per Capita, 1949-1995 $\ldots \ldots \ldots \ldots \ldots \ldots \ldots$

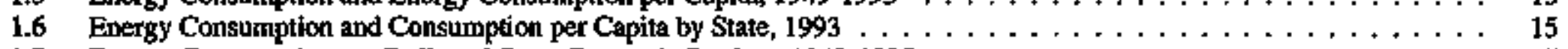

1.7 Energy Consumption per Dollar of Gross Domestic Product, $1949-1995 \ldots \ldots \ldots \ldots$

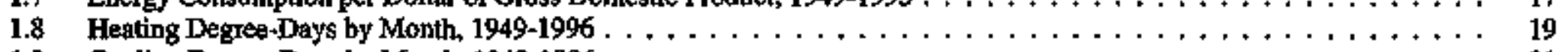

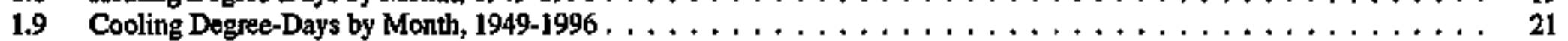

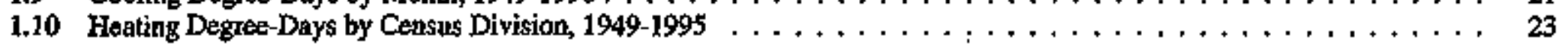

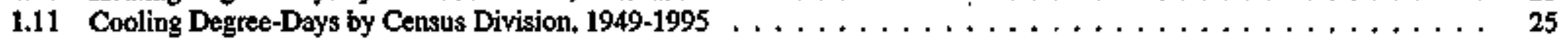

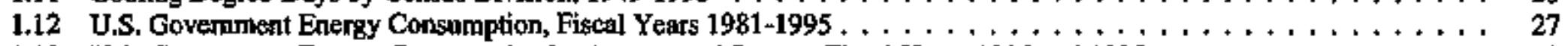

1.13 U.S. Government Energy Consumption by Agency and Source, Fiscai Years 1985 and $1995 \ldots \ldots \ldots$

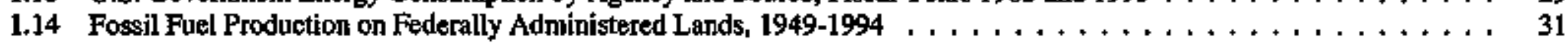

1.15 Fossil Fuel Consumption for Nonfuel Use, 1980-1995 . . . . . . . . . . . . . . . . . . . . . . . . . . . 33

\section{End-Use Energy Consumption}

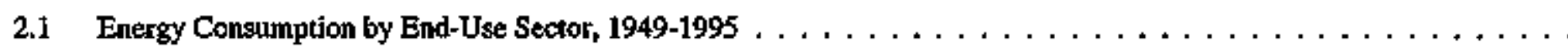

2.2 Manufachuring Energy Consunntion Measures, $1991 \ldots \ldots \ldots \ldots \ldots \ldots \ldots \ldots \ldots$

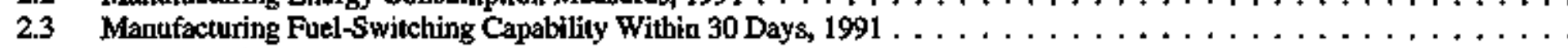

2.4 Manufacturing Energy Intensity by Industry, 1985, 1988, and $1991 \ldots \ldots \ldots \ldots \ldots \ldots$

2.5 Offsite-Produced Energy Consumed for Heat and Power by Selected Industry Group, 1974-1991 . . . . . . . . . . .

2,6 Manufacturing Sector Inputs for Heat, Power, and Electricity Generation by Energy Soturce, 1991 . . . . . . . . . . . .

2.7 Manufacturing Sector Inpets for Heat, Power, and Electricity Generation in 1991 by

Energy Management Activity Present From $1989-1991 \ldots \ldots \ldots \ldots \ldots \ldots$

2.8 Manufacturing Sector Inputs for Heat, Power, and Electricity Genecation by Technology, $1991 \ldots \ldots \ldots$

2.9 Household Energy Consumption by Census Region, Selected Years, 1978-1993 . . . . . . . . . . . . . . . . 55

2.10 Household Energy Consumption and Expenditures by End Use and Energy Source, Sejected Years, 1978-1993 . . . . 57

2.11 Household Energy Consumption and Expenditure Indicators by Census Region and Vintage of Honsing Unit, $1993 \quad \ldots \quad 59$

2.12 Households With Selected Appliances, Selected Years, 1978-1993 . . . . . . . . . . . . . . . . . . . 61

2.13 Type of Heating in Occupied Hoasing Units, Selected Years, 1950-1993 . . . . . . . . . . . . . . . . . . 63

2.14 Household Motor Vehicle Data, 1983, 1985, 1988, 1991, and $1994 \ldots \ldots \ldots \ldots$

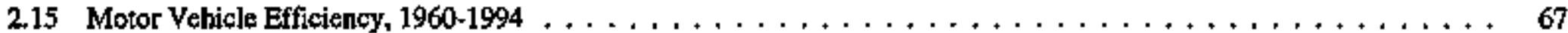

2.16 Motor Vehicle Registratjons and Motor Fuel Consumption, 1960-1995 . . . . . . . . . . . . . . . . . . . . 69

2,17 Cornmercial Buildings Characteristics by Energy Source, Selected Years, 1979-1992 . . . . . . . . . . . . . . . 71

2.18 Commercial Buildings Consumption by Energy Source, Selected Years, 1979-1992 $\ldots \ldots \ldots \ldots$ 


\section{Tables (continued)}

2. End-Use Energy Consumption (continued)

2.19 Commercial Buildings Expenditures by Energy Source, Selected Years, 1979-1992 ～. . . . . . . . . . . . . . 75

2.20 Commercial Buildings Energy Consumption and Expenditure Indfcators, Selected Years, 1979-1992 . . . . . . . . 77

2.21 Commercial Buildings Energy Intensities by Building Characteristic, $1992 \ldots \ldots \ldots \ldots$

\section{Financial Indicators}

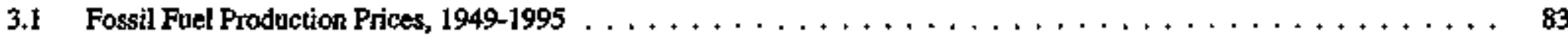

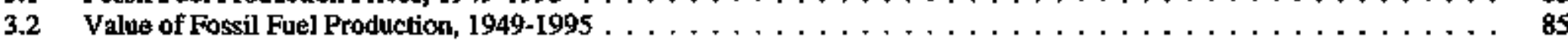

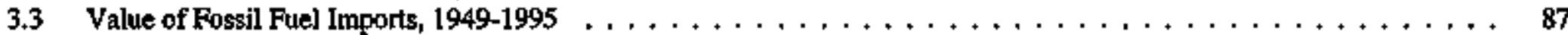

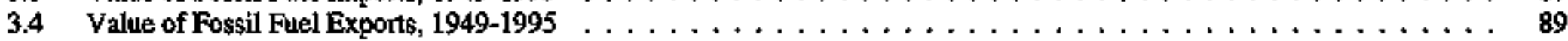

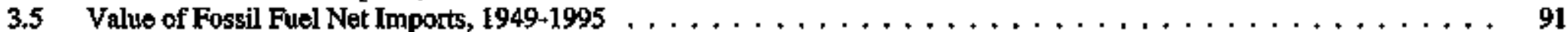

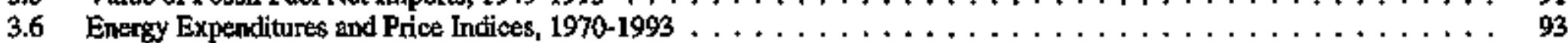

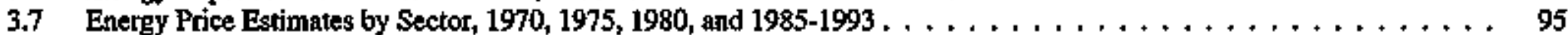

3.8 Energy Expenditure Estimates, 1970, 1975, 1980, and 1985-1993 . . . . . . . . . . . . . . . . . . . . . . . 97

3.9 FRS Companies' Operations, Selected Statistics, 1975-1994 . . . . . . . . . . . . . . . . . . . . . . . . . . 99

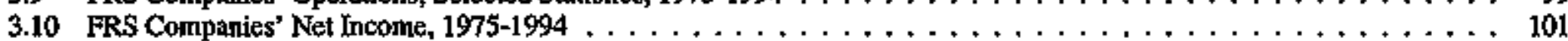

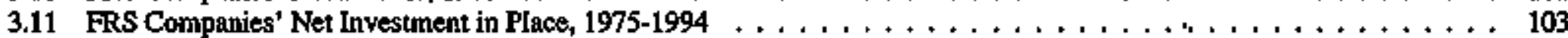

3.12 FRs Companies' Additions to Investment in Place $1975-1994 \ldots \ldots \ldots \ldots \ldots \ldots$

3.13 State Government Severance Taxes, $1985-1993 \ldots \ldots \ldots \ldots \ldots \ldots$

3,14 Companies Reporting to the Financial Reporting $\$ y s t e m, 1975-1994 \ldots \ldots \ldots$

\section{Energy Resources}

4,1 Undiscovered Recoverable Resource Estimates for Petrolenm, 1987 and $1994 \ldots \ldots$

4.2 Crude Oil and Natural Gas Field Counts, Cumetlative Production, Proved Reserves, and Ultimate Recovery,

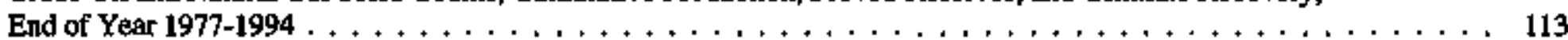

，4.3 Oil and Gas Drilling Activity Measurements, $1949-1995 \ldots \ldots \ldots \ldots$. . . . . . . . . . . . . . . . . 115

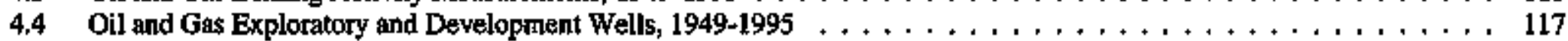

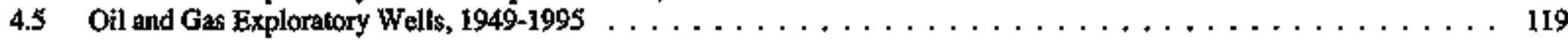

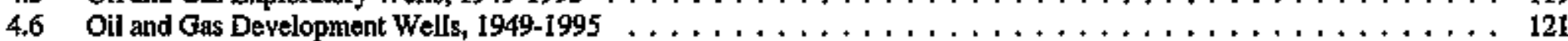

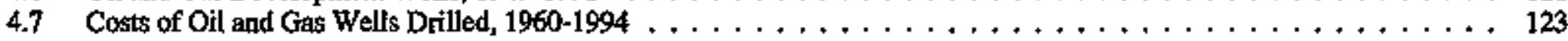

4.8 U.S. Exploration and Development Expenditures, Gross Additions to Proved Reserves, and Production of Liquid and Gaseous Hydrocarbons by FRS Companies and U.S. Industry, 1975-1994 . . . . . . . . . . . . . . . . . . . 125

4.9 FRS Companies' Expenditures for Oll and Gas Exploration and Development by Region, 1977-1994 . . . . . . . . . 127

4.10 Liquid and Gaseous Hydrocarbon Proved Reserves, End of Year 1949-1995 . . . . . . . . . . . . . . . . . . . 129

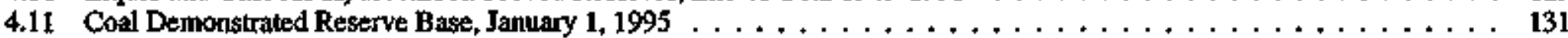

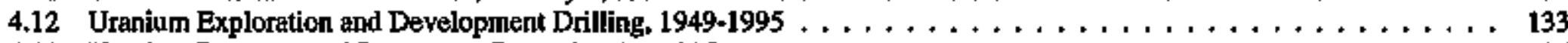

4.13 Uranium Reserves and Rescurces, December $31,1995 \ldots \ldots \ldots \ldots$ 
Tables (continued)

5. Petroleum Page

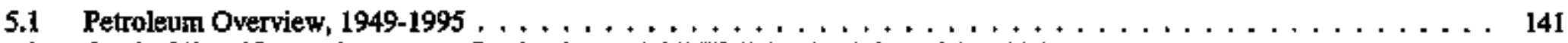

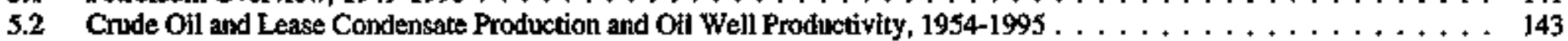

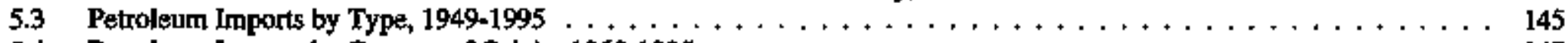

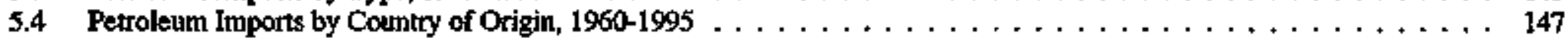

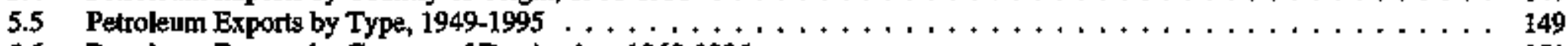

5.6 Petroleum Exports by Country of Destination, $1960-1995 \ldots \ldots \ldots \ldots \ldots \ldots \ldots \ldots$

5.7 Petrolenm Net Imports by Country of Origin, $1960-1995 \ldots \ldots \ldots \ldots \ldots \ldots \ldots$

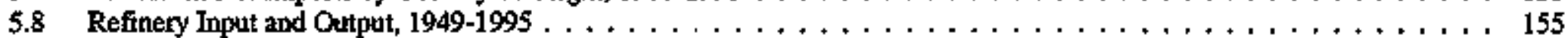

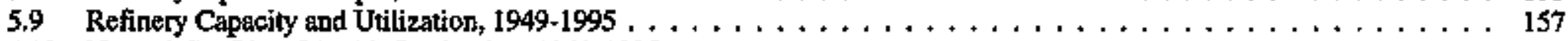

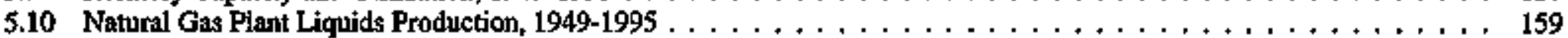

5.11 Petroleum Products Supplied by Type, 1949-1995 . . . . . . . . . . . . . . . . . . . . . . . . . . . . 161

5.12. Petroieum Products Supplied to the Residential and Commencial Sector and the Industrial Sector, 1949-1995 . . . . . . 164

5.126 Petroleum Products Supplied to the Transportation Sector, Electric Utilities, and Total, 1949-1995 . . . . . . . . . 165

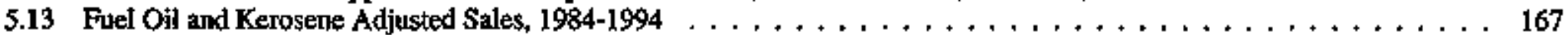

5.14 Petroleum Primary Stocks by Type, End of Year $1949-1995 \ldots \ldots \ldots \ldots \ldots \ldots \ldots$

5.15 Strategic Petroleum Reserve, $1977-1995 \ldots \ldots \ldots \ldots \ldots \ldots \ldots \ldots$

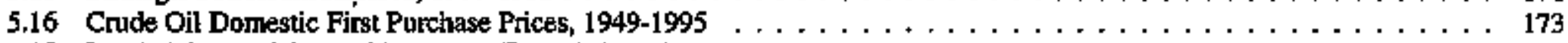

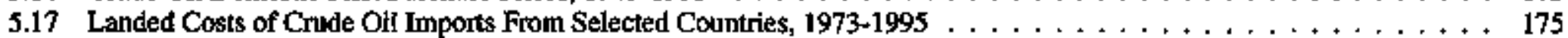

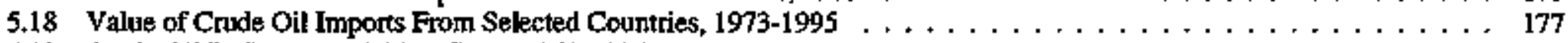

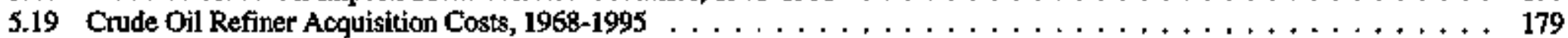

5.20 Refiner Sales Prices and Refiner Margins of Selected Petroleum Products, 1980-1995 . . . . . . . . . . . . . . 181

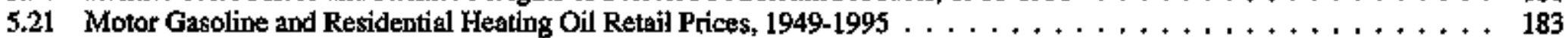

6. Natural Gas

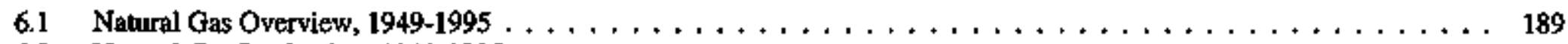

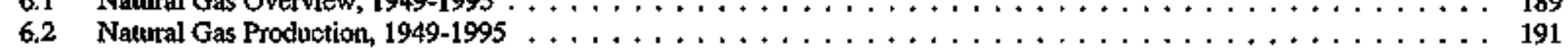

6.3 Natural Gas Imports, Exports, and Net Imports, 1949-1995 . . . . . . . . . . . . . . . . . . . . . . . . 193

6.4 Natural Gas Gross Withdrawals by State and Location and Gas Well Productivity, 1960-1995 . . . . . . . . . . . . . . 195

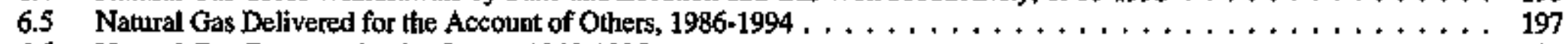

6.6 Natural Gas Consumption by sector $1949-1995 \ldots \ldots \ldots \ldots \ldots$

6.7 Natural Gas in Underground \$torage, End of Year $1954-1995 \ldots \ldots \ldots \ldots$

6.8 Natural Gas Wellhead and Import Prices, $1949-1995 \ldots \ldots \ldots \ldots \ldots$

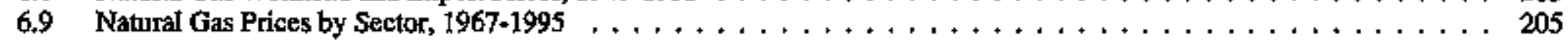

7. Coal

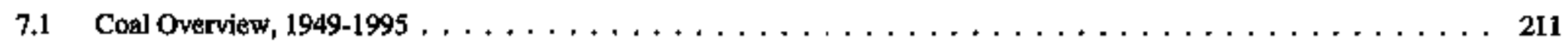

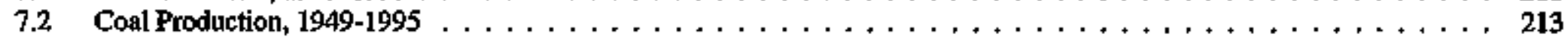




\section{Tables (continued)}

7. Coal (continued) Page

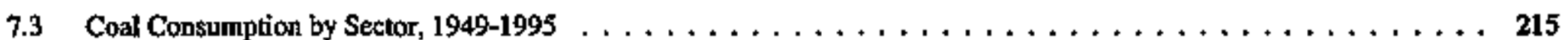

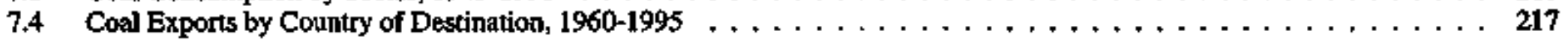

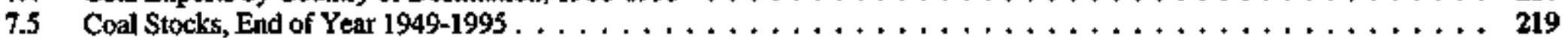

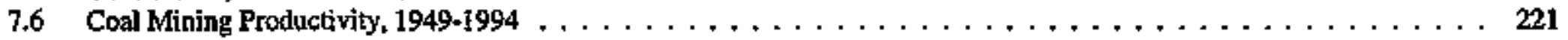

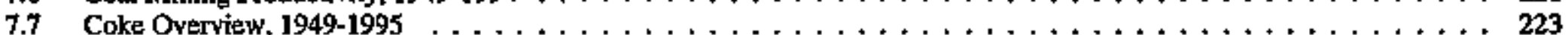

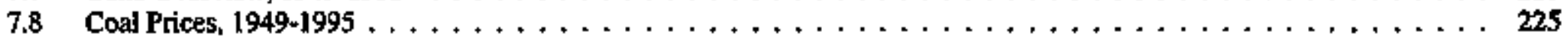

\section{Electricity}

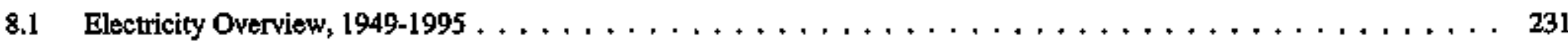

8.2 Electric Power Industry Net Generation and Net Summer Capability, 1992-1994 . . . . . . . . . . . . . . . . . . 233

8.3 Electric Utility Net Generation of Electricity by Energy Source, $1949-1995 \ldots \ldots \ldots \ldots$

8.4 Electric Utility Net Generation of Electricity by Prime Mover, 1949-1995 . . . . . . . . . . . . . . . . . . . . . . . 237

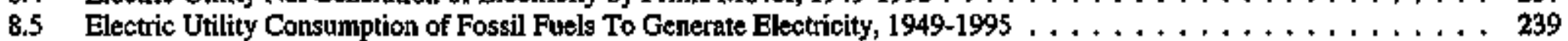

8.6 Electric Utility Retail Sales of Electricity by End-Use Sector, 1949-1995 . . . . . . . . . . . . . . . . . . . . . . 241

8.7 Electric Utility Demand-Side Management Programs: Peakload Reductions, Energy Savings, and Costs, 1989-1994 . . . 243

8.8 Electric Utility Net Summer Capability, End of Year 1949-1995 . . . . . . . . . . . . . . . . . . . . . . 245

8.9 Electric Utility Noncoincidental Peak Load by Region, 1986-1994 . . . . . . . . . . . . . . . . . . . . . . . . . 247

8.10 Electric Utility Stocks of Coal and Petrolentm, End of Year 1949-1995 . . . . . . . . . . . . . . . . . . . . . 249

8.11 Retail Prices of Electricity Sold by Electric Utilities, $1960-1995 \ldots \ldots \ldots \ldots \ldots$

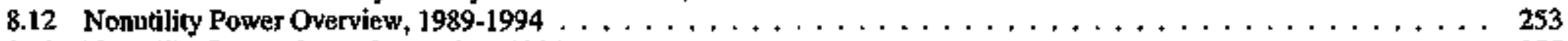

8.13 Nonutility Power Gross Generation, $1994 \ldots \ldots \ldots \ldots \ldots \ldots \ldots$

\section{Nuclear Energy}

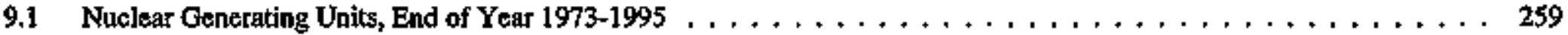

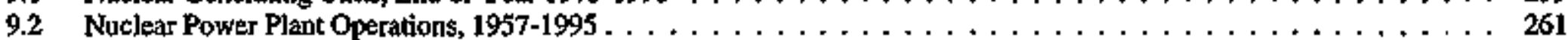

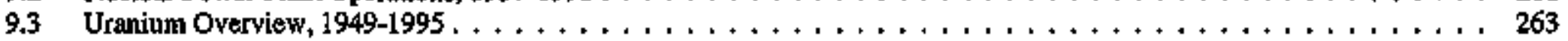

\section{Renewable Energy}

10.Ia Renswable Energy Consumption by Source, $1990-1995 \ldots \ldots \ldots \ldots \ldots \ldots$

10.1 b Renewable Energy Consumption by Sector, $1990-1995 \ldots \ldots \ldots \ldots \ldots \ldots$. . . . . . . . . . . . . . . . . . . 267

10.2 Wood and Waste Energy and Alcohol Fuels Consumption by Sector and Census Region, Selected Years 1981-1995 . . . 269

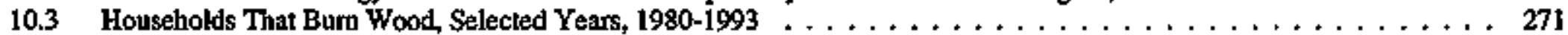

10.4 Solar Thermal Collector Shipments by Type and Trade, 1974-1984 and 1986-1994 . . . . . . . . . . . . . . . . . 273

10.5 Solar Thermal Collector \$hipments by End Use, Market Sector, and Type, $1994 \ldots \ldots$. . . . . . . . . . . . . . 275

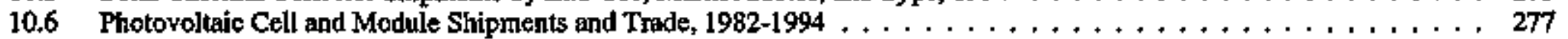


10. Renewahle Einergy (continued) Page

10.7 Photovoltaic Cell and Module Shipments by End Use, 1989-1994 . . . . . . . . . . . . . . . . . . . . . . 279

10.8 Electric Power Indusiry Net Summer Capabitity and Net Generation of Electricity by Selected Renewable

Energy Resources, 1949-1995 . . . . . . . . . . . . . . . . . . . . . . . . . . . . . . . . 281

10.9 Electric Power Industry Net Generation by Selected Renewable Energy Resources, 1949-1995 . . . . . . . . . . 283

\section{Finternational Eneray}

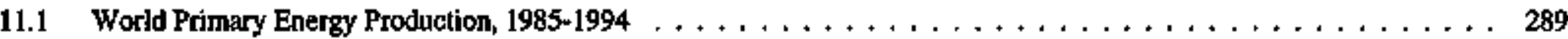

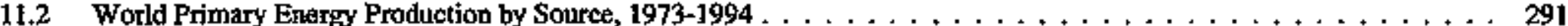

11.3 World Crude $O$ il and Natural Gas Reserves, January 1, $1995 \ldots \ldots \ldots \ldots \ldots$

11.4 World Rotary Rigs in Operation, 1982-1994 . . . . . . . . . . . . . . . . . . . . . . . . . . . . . . . . 295

11.5 World Crude Oil Production, $1960-1995 \ldots \ldots \ldots \ldots \ldots \ldots \ldots \ldots \ldots$

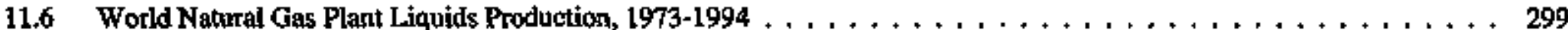

11.7 World Crude Oil Prices by Selected Type, $1970-1996 \ldots \ldots \ldots \ldots \ldots \ldots$

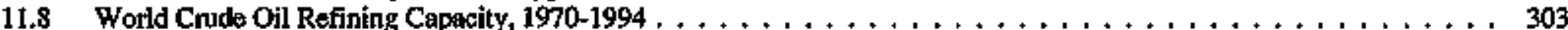

11.9 World Petroleum Consumption, $1960-1994 \ldots \ldots \ldots \ldots \ldots \ldots$

11.10 Petroleum Stocks in OECD Countries, End of Year $1973-1994 \ldots \ldots \ldots \ldots \ldots \ldots$

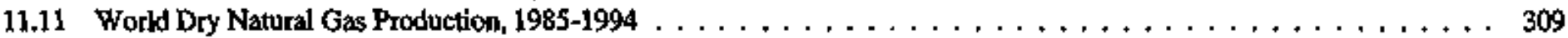

11.12 World Dry Natural Gas Supply and Disposition, $1993 \ldots \ldots \ldots \ldots \ldots \ldots$

11.13 World Dry Natural Gas Consumption, $1980-1994 \ldots \ldots \ldots \ldots \ldots \ldots \ldots \ldots$

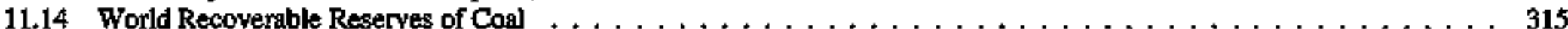

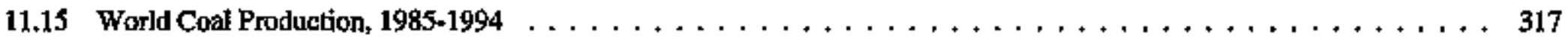

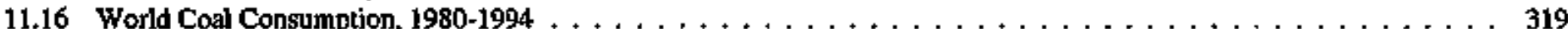

11.17 World Net Generation of Electricity by Type, $1993 \ldots \ldots \ldots \ldots \ldots \ldots \ldots$

11.18 World Electrical Installed Capacity by Type, January $1,1994 \ldots \ldots \ldots \ldots \ldots \ldots \ldots$

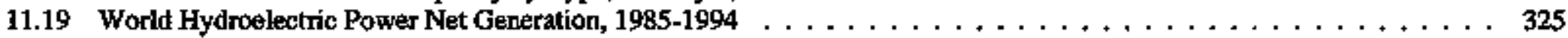

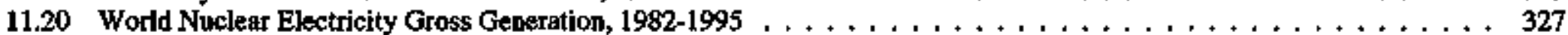

\section{Environmental Indicators}

12.1 Estimated Enissions of Greenhouse Gases by Gas, $1985-1994 \ldots \ldots \ldots \ldots \ldots \ldots$

12.2 Carbon Dioxide Emissions From Fossil Energy Consumption by Sector, 1980-1994 . . . . . . . . . . . . . . . 333

12.3 Carbon Dioxide Emissions From Energy Use by Sector, $1994 \ldots \ldots \ldots$

12.4 Methane Emissions From Anthropogenic Sources, 1985-1994 . . . . . . . . . . . . . . . . . . . . . 337

12.5 Emissions From Fossil-Fueled Steam-Electric Generating Units at Electric Utilities, 1985-1994 . . . . . . . . . . . . 339

12.6 Installed Nameplate Capacity of Fossil-Fueled Steam-Electric Generators for Electric Utility Plants With

Environmental Equipment, $1985-1994 \ldots \ldots \ldots \ldots \ldots \ldots \ldots \ldots \ldots \ldots$ 


\section{Tables (continued)}

Appendix A. Thermal Conversion Factors Page

A1 Approximate Heat Content of Petroleum Products . . . . . . . . . . . . . . . . . . . 343

A2 Approximate Heat Content of Crude Oil, Cuude Oil and Products, and Natural Gas Plant Liquids, 1949-1995 . . . . . . 344

A3 Approximate Heat Content of Petroleum Product Weighted Averages, 1949-1995 . . . . . . . . . . . . . . . . . . 345

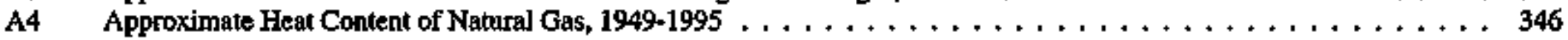

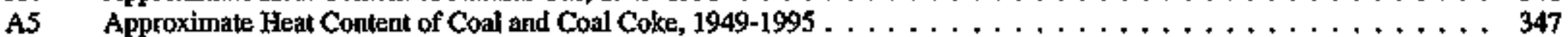

A6 Approximate Heat Content of Cosl by Type, $1949-1995 \ldots \ldots \ldots \ldots \ldots \ldots \ldots$

A7 Approximate Heat Rates for Electricity, $1949-1995 \ldots \ldots \ldots \ldots \ldots$

Appendix B. Metric and Other Physical Conversion Factors

B1 Metric Conversion Factors $\ldots \ldots \ldots \ldots \ldots \ldots \ldots$

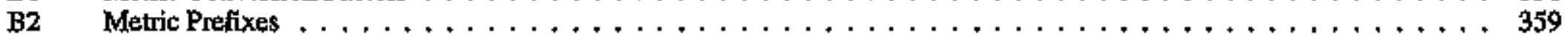

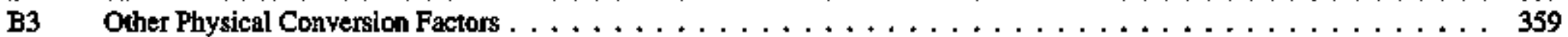

Appendix C. Carbon Dioxide Emission Factors for Coal

C1 Average Carton Dioxide Emission Factors for Coal by Coal-Consuning Sector, 1980-1994 . . . . . . . . . . . 361

Appendix D. Bnergy Units in Perspective

D1 U.S. Daily Per Capita Consumption of Energy by Type, 1975, 1985, and 1995 . . . . . . . . . . . . . . . 363

D2 Energy Equivalents $\ldots \ldots \ldots \ldots \ldots \ldots \ldots \ldots$

Appendix E. Gross Domestic Product and Implicit Price Deflators

E1 Gross Domestic Product and Implicit Price Deflators, 1949-1995 
1. Energy Overview

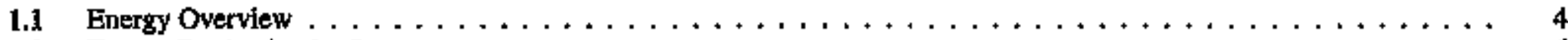

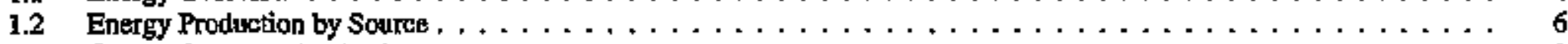

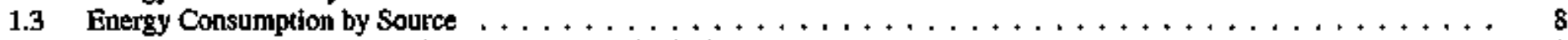

1.4 Energy Imports, Exports, and Net Imports, $1949-1995 \ldots \ldots \ldots \ldots \ldots \ldots \ldots$

1.5 Energy Consumption and Energy Consumption per Capita, $1949-1995 \ldots \ldots \ldots \ldots \ldots \ldots \ldots$

1.6 Energy Consumption and Consumption per Capita by State, $1993 \ldots \ldots \ldots \ldots \ldots \ldots$

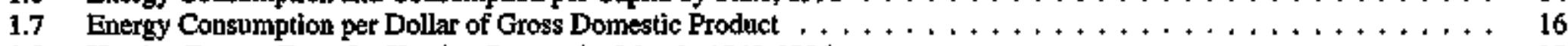

1.8 Jeating Degree-Days for Heating Seaton, by Month, $1949-1996 \ldots \ldots \ldots \ldots \ldots \ldots$

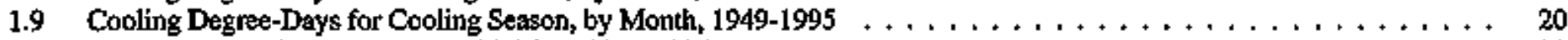

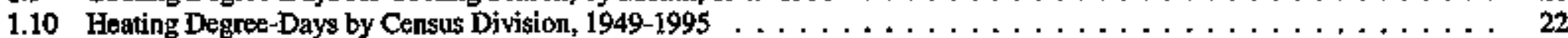

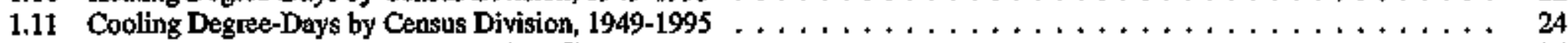

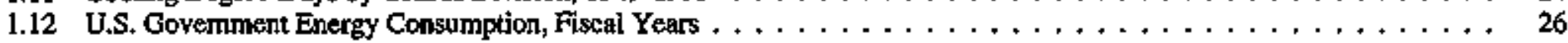

1.13 U.S. Government Energy Consumption by Agency and Source, Fiscal Years $\ldots \ldots \ldots \ldots \ldots \ldots$

1.14 Fossil Fuel Production on Federally Administered Lands $\ldots \ldots \ldots \ldots \ldots \ldots$

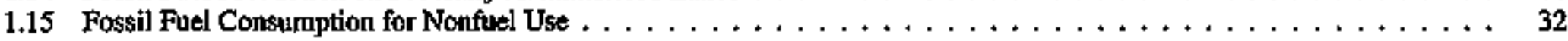

\section{End-Use Energy Consumption}

2.1 Energy Consumption by End-Use Sector, $1949-1995 \ldots \ldots \ldots \ldots \ldots \ldots \ldots$

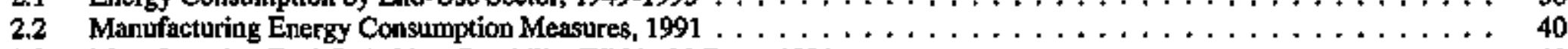

2.3 Manufacturing Fuel-Switching Capability Within 30 Days, $1991 \ldots$

2.4 Manufacturing Offsite Energy Intensity Change by Industry Group, 1985 to $1991 \ldots \ldots \ldots \ldots$. . . . . . . . . . . . . 44

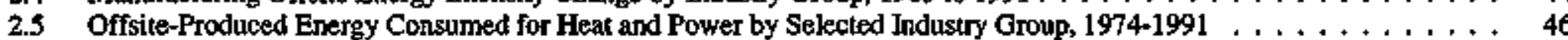

26 Manufacturing Sector Inputs for Heat, Power, and Electricity Generation, $1991 \ldots \ldots \ldots$

2.7 Manufacturing Sector Isputs for Heat, Power, and Electricity Generation in 1991 by

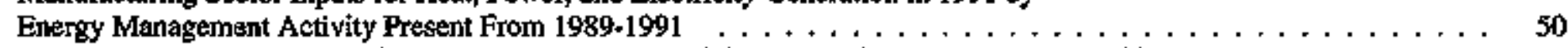

2.8 Manufacturing Sector Inputs for Heat, Power, and Elsctricity Generation by Technology, $1991 \ldots \ldots$

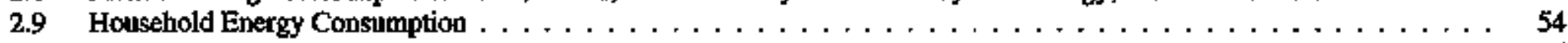

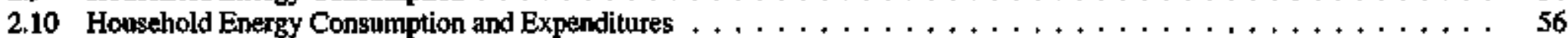

2,11 Household Energy Consumption and Expenditure Indicators by Census Region and Vintage of Housing Unit, 1993 . . 58

2.12 Households With Selected Appliarces, 1980 and $1993 \ldots \ldots \ldots \ldots \ldots \ldots \ldots$

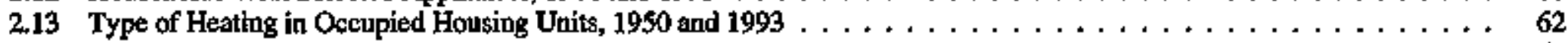

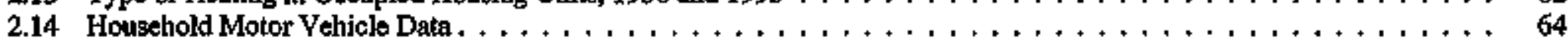

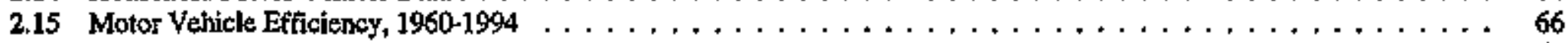

2.16 Motor Vehicle Registrations and Motor Fue] Consumption, 1960-1995 . . . . . . . . . . . . . . . . . . . . 68

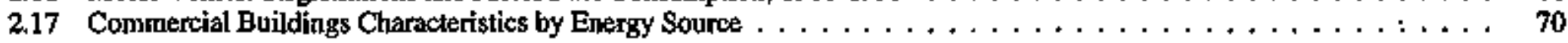

2.18 Commercial Buildings Consumption by Energy Source $\ldots \ldots \ldots \ldots \ldots \ldots \ldots$ 
Figures (continued)

2. End-Use Energy Consumption (continued)

2.19 Commercial Buildings Expendiures by Energy Source $\ldots \ldots \ldots \ldots \ldots$

2.20 Commercial Buildings Energy Consumption and Expenditure Indicators, Selected Years, 1979-1992 . . . . . . . . . 76

2.21 Commercial Buildings Energy Intensities by Building Characteristic, $1992 \ldots \ldots \ldots \ldots \ldots$

\section{Financial Indicators}

3.1 Fossil Fuel Production Prices $\ldots \ldots \ldots \ldots \ldots \ldots$

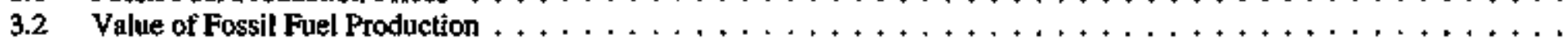

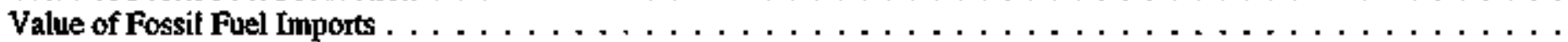

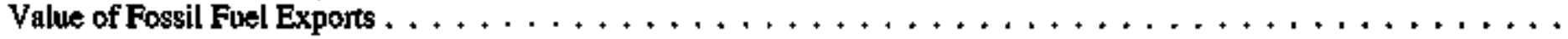

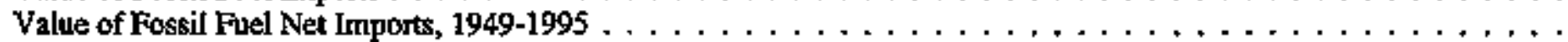

88

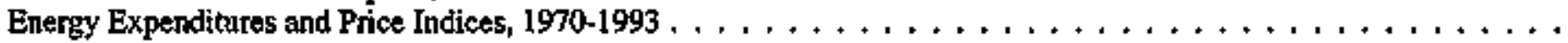

Energy Price Estimates by Sector, 1985-1993

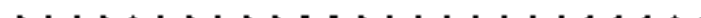

92

94

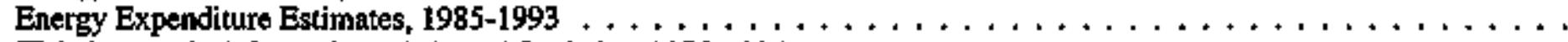

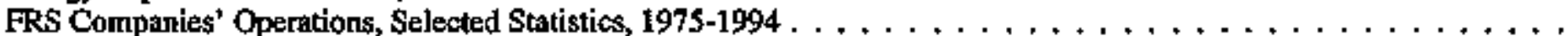

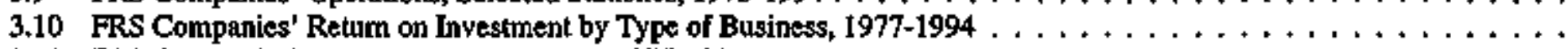

3.11 FRs Companies' Net Investnent in Place, 1975-1994

3.12 FRS Companies' Additions to Investment in Place, 1975-1994

3.13 State Government Severance Taxes, 1985-1993

\section{Energy Resonrces}

4.1 Undiscovered Recoverable Resource Estimates for Petroleurn . . . . . . . . . . . . . . . . . . . . . . .

4.2 Crude Oil and Natural Gas Field Counts, Cumulative Production, Proved Reserves, and Uitimate

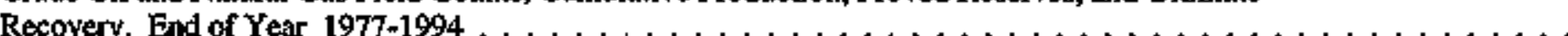

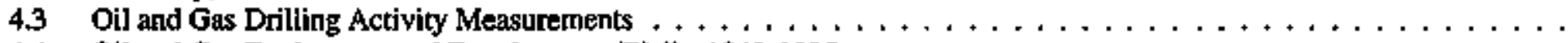

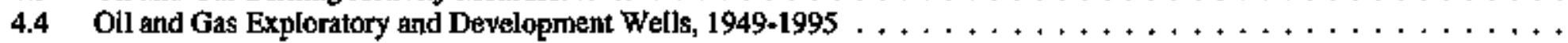

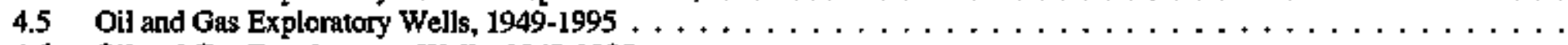

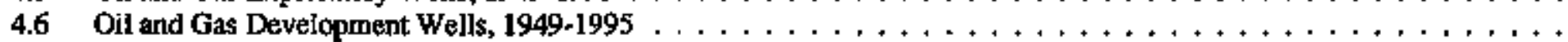

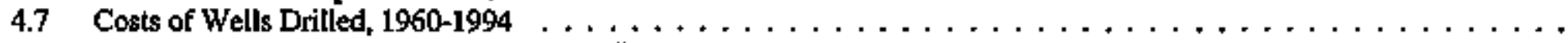

4.8 U.S. Exploration and Development Expenditures, Gross Additions to Proved Reserves, and Production of Liquid and

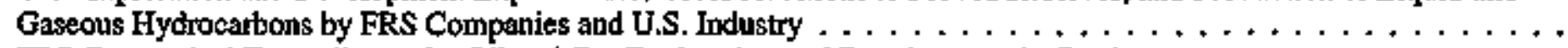

4.9 FRS Companies' Expenditures for Oil and Gas Exploration and Development by Region . . . . . . . . . . . . .

4.10 Lquid and Gaseous Hydrocarbon Proved Reserves, End of Year . . . . . . . . . . . . . . . . . . . . .

4.11 Coal Demonstrated Reserve Base, January $1,1995 \ldots \ldots \ldots \ldots \ldots \ldots \ldots \ldots$

4.12 Uranium Exploration and Development Drilling, 1949-1995 . . . . . . . . . . . . . . . . . . . . . .

4.13 Uranium Reserves and Resources, December $31,1995 \ldots \ldots \ldots \ldots \ldots \ldots \ldots \ldots$ 


\section{Figures (continued)}

5. Petroleminn Page

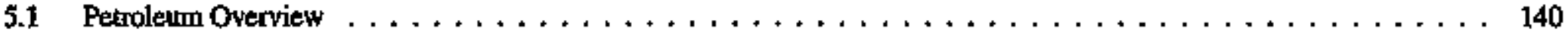

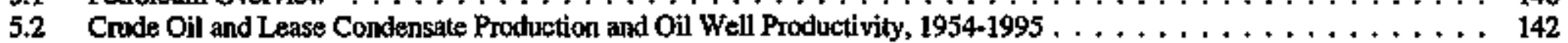

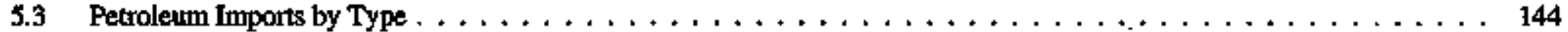

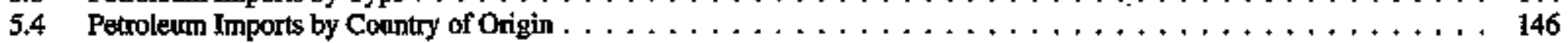

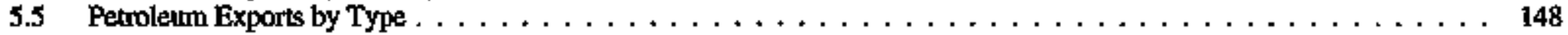

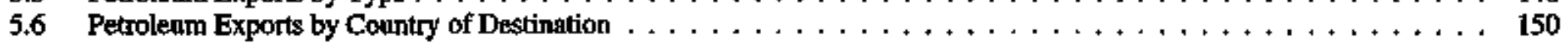

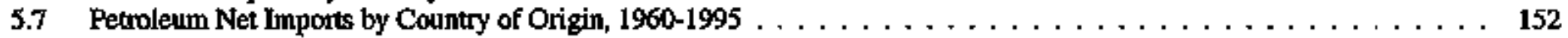

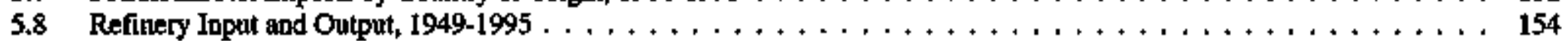

5.9 Refinery Capacity and Utilization, $1949-1995 \ldots \ldots \ldots \ldots \ldots \ldots$

5.10 Natural Gas Plant Liqujis Production $\ldots \ldots \ldots \ldots \ldots \ldots \ldots$

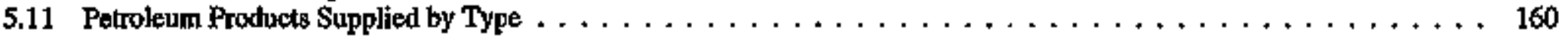

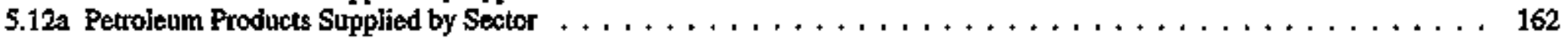

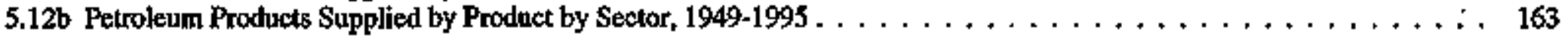

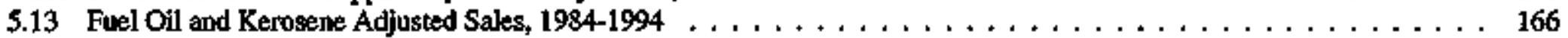

5.14 Petroleum Primary Stocks by Type, End of Year $\ldots \ldots \ldots \ldots \ldots \ldots$

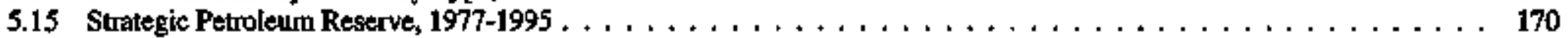

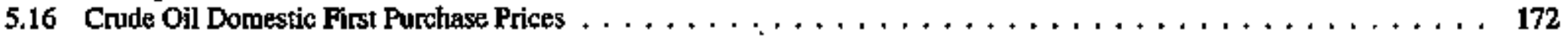

5.17 Landed Costs of Crude Oll Imports From Selected Countries . . . . . . . . . . . . . . . . . . . . . . 174

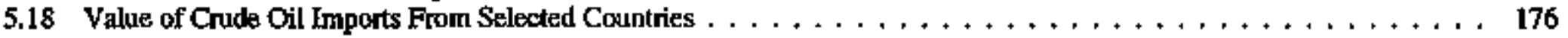

5.19 Crude Oil Refiner Acquisition Costs, $1968-1995 \ldots \ldots \ldots \ldots \ldots$

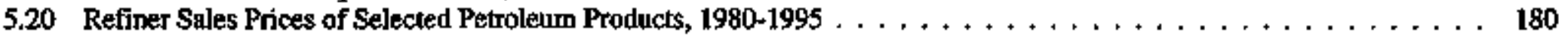

5.21 Motor Gasoline and Residential Heating Oil Retail Prices . . . . . . . . . . . . . . . . . . . . . . . . 182

\section{Natural Gas}

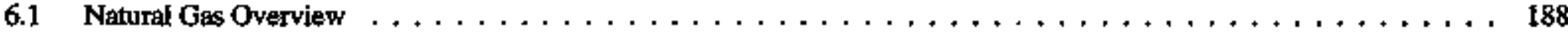

6.2 Natural Gas Production, $1949-1995 \ldots \ldots \ldots \ldots \ldots \ldots \ldots$

6.3 Natural Gas Imports, Exports, and Net Imports . . . . . . . . . . . . . . . . . . . . . . . . . 192

6.4 Natural Gas Gross Withdrawals by State and Location and Gas Well Productivity, 1960-1995 . . . . . . . . . . . . . 194

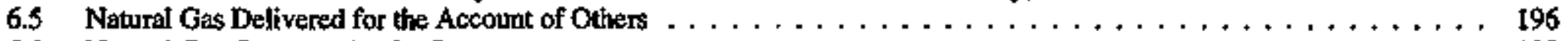

6.6 Natural Gas Consumption by Sector $\ldots \ldots \ldots \ldots \ldots \ldots \ldots$

6.7 Natural Gas in Undergrotund Storage, End of Year $1954-1995 \ldots \ldots \ldots \ldots$

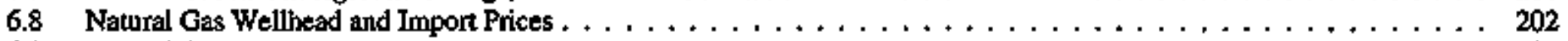

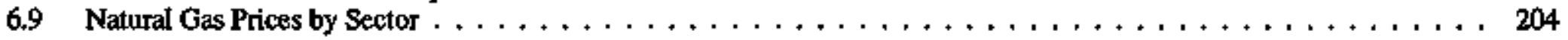

7. Coal

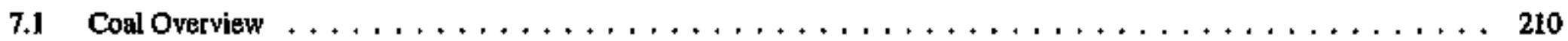

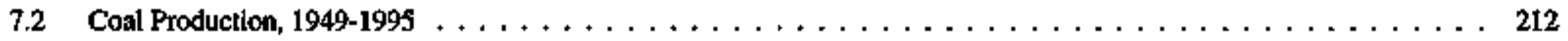




\section{Figures (continued)}

7. Coal (continued)

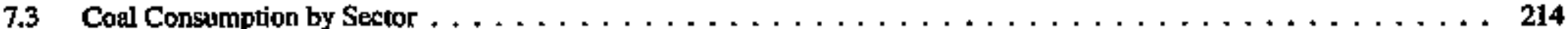

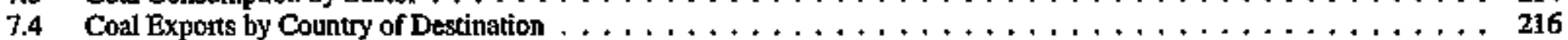

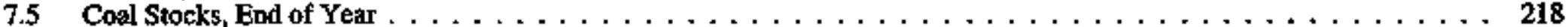

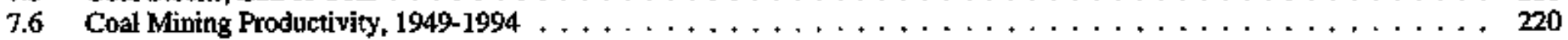

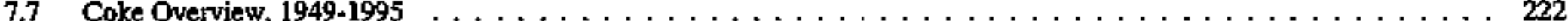

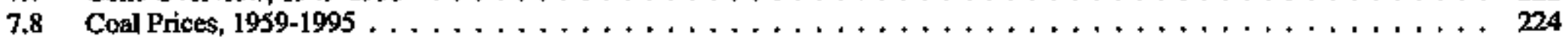

\section{Electricity}

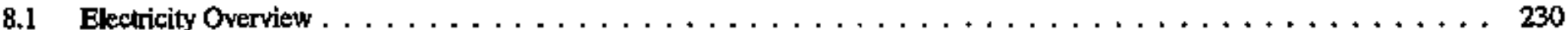

8.2 Electric Power Industry Net Generation and Net Summer Capability, $1994 \ldots \ldots \ldots \ldots$

8.3 Electric Utility Net Generation of Electricity by Energy Source . . . . . . . . . . . . . . . . . . . . . . . . . 234

8.4 Electric Utility Net Generation of Electricity by Prime Mover $\ldots \ldots \ldots \ldots$

8.5 Electric Utility Consumption of Fossil Fuels To Generate Electricity . . . . . . . . . . . . . . . . . . . . . . . 238

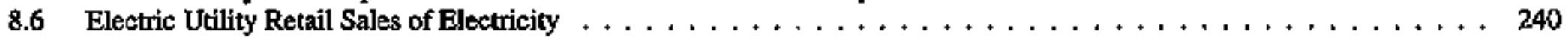

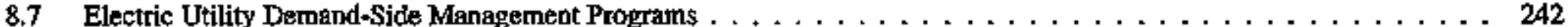

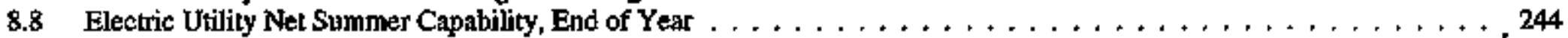

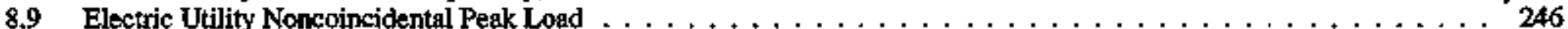

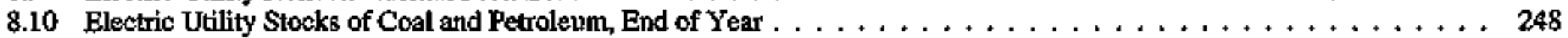

8.11 Retail Prices of Electricity Sold by Electric Utitities, 1960-1995 . . . . . . . . . . . . . . . . . . . . . . . . . . . . 250

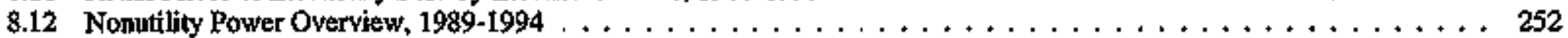

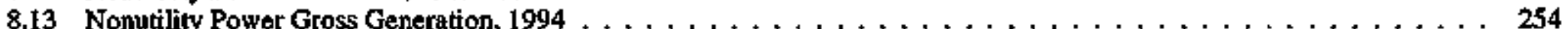

\section{Nuclear Energy}

9.1 Nuclear Generating Units, December 31, $1995 \ldots \ldots \ldots \ldots \ldots \ldots \ldots$

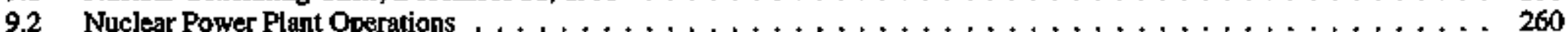

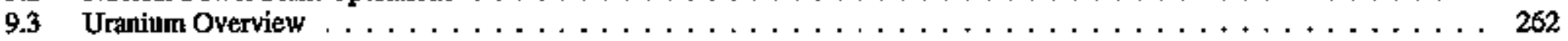

\section{Renewable Energy}

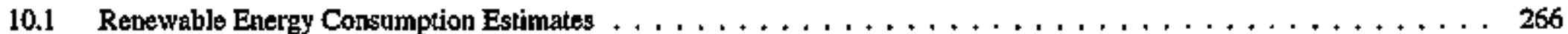

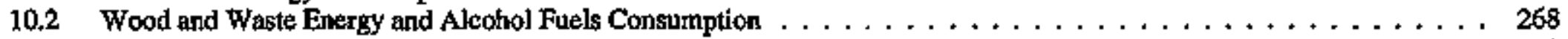

10.3 Honseholds That Bum Wood, Selected Years, $1980-1993 \ldots \ldots \ldots \ldots \ldots$

10.4 Solar Thermal Collector Shipments and Trade, 1974-1984 and 1986-1994 . . . . . . . . . . . . . . . . 272

10.5 Solar Thermal Collector Shipments by End Use, Market Sector, and Type, $1994 \ldots \ldots \ldots$

10.6 Photovoltaic Cell and Moduje Shipments and Trade $\ldots \ldots \ldots \ldots \ldots \ldots \ldots$

10.7 Photovoltaic Cell and Module Shipments by End Use, $1994 \ldots \ldots \ldots$ 
10. Renewable Energy (continued) Page

10.8 Electric Power Industry Net Summer Capability by Selected Renewable Energy Resources . . . . . . . . . . . 280

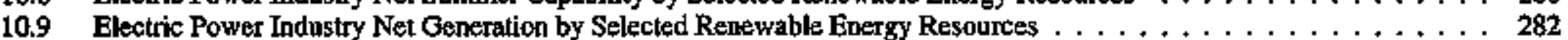

\section{International Energy}

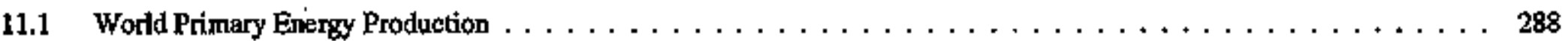

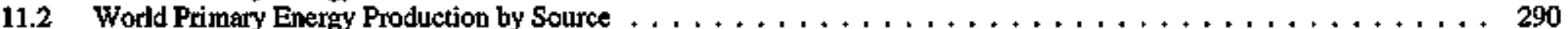

11.3 Word Coude Oil and Natural Gas Reserves, January 1, $1995 \ldots \ldots \ldots \ldots \ldots$

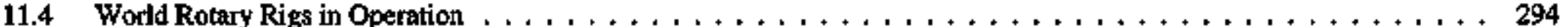

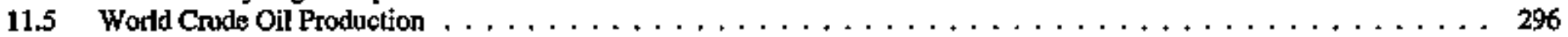

11.6 World Natural Gas Plant Liguids Production $\ldots \ldots \ldots \ldots \ldots \ldots \ldots \ldots$

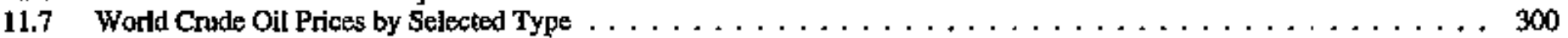

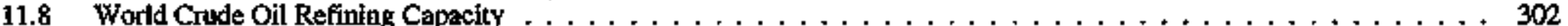

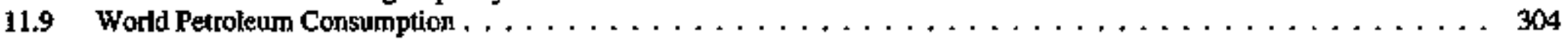

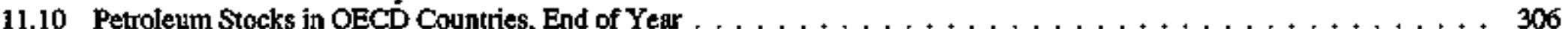

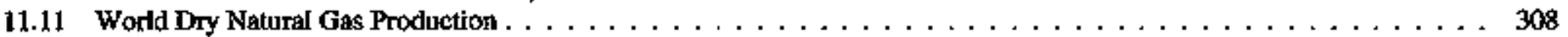

11.12 World Dry Natural Gas Supply and Disposition, $1993 \ldots \ldots \ldots \ldots \ldots \ldots$

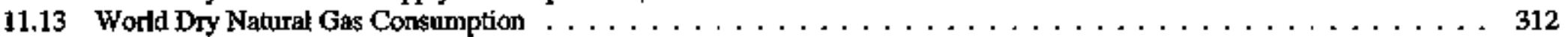

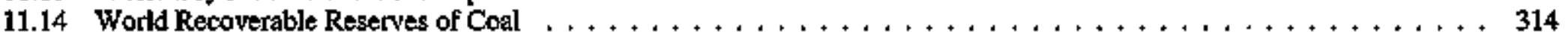

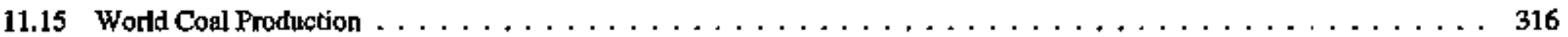

11.16 World Coal Consumption. .

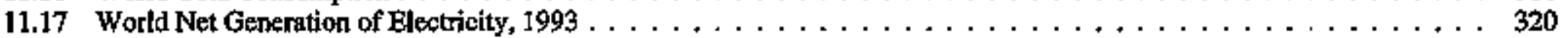

11.18 World Electrical Installed Capacity by Type, January $1,1994 \ldots \ldots \ldots \ldots$

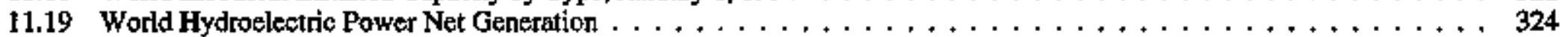

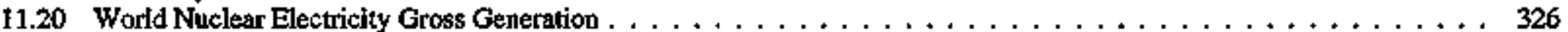

\section{Environmental Indicators}

12.1 Estimated Emissions of Greenhouse Gases $\ldots \ldots \ldots \ldots \ldots \ldots$

12.2 Carbon Dioxide Enissions From Fossil Energy Consumption by Sector, 1980-1994 . . . . . . . . . . . . . . . . 332

12.3 Carbon Dioxide Emissions From Energy Use by Sector, $1994 \ldots \ldots \ldots$

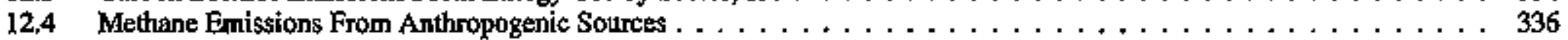

12.5 Emtssions From Fossil-Fueled Steam-Electric Generating Units at Electric Utilities ～. . . . . . . . . . . . . . . 338

12,6 Installed Nameplate Capacity of Fossil-Fueled \$team-Electric Genterators for Electric

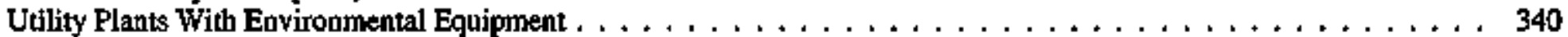

Appendix F. U.S. Census Regions and Divisions

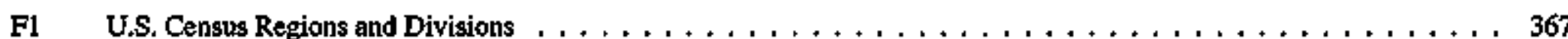




\section{Major Energy Developments in 1995}

\section{Energy Demand Sets Another Record}

A reviving domestic economy, generally low energy prices, a heat wave in July and August, and urousually cold weather in November and December all contributed to the fourth conseculive year of growth in U.S. total energy consumption, which rose to an all-time high of almost 9I quadrillion Btu in 1995 (1.3).* The jacrease came as a result of increases in the consumption of natural gas, coal, nuclear electric power, and renewable energy. Petroleum was the primary exception, and its use declined by only 0.3 percent. (Integrating the amount of renewable energy consumed outside the electric utility sector into U.S. total energy consumption boosted the total by about 3.4 quadrillion Btu, but even without that integration, U.S, total energy consumption would have reached a recond level in 1995.)

Petroletm. Electric utilities' preference for other energy sources and somewhat higher prices for cnude oil in 1995 led to the small decrease in petroleum consumption (5.12b). Petroleum consumption declined 0.02 million barrels per day from the 1994 level to 17.70 million barrels per day in 1995. A 33-percent decline in electric utilities' consumption of petroleum, as well as a 1.7-percent decline in industrial consumption, more than offset consumption increases of 1.7 percent and 1.8 percent in the transportation sector and the residential and commercial sector, respectively (5.12a and 5.12b).

Of the major petroleum products, residual fuel oil showed the greatest decrease in consumption (5.11). Residual fuel oil consumption felt 17 percent to 0.85 million barrels per day, due to electric utilities' preference for other energy sources, in part to comply with environmental regulations. Consumption of jet fuel also declined, down 1.3 percent to 1.51 million barrels per day. In contrast, consumption of motor gasoline, which consistently accounts for the largest share of all petroleum products supplied, rose 2.5 percent to 7.79 million bartels per day in 1995. The improved economy contrituted to an increase in distillate fuel oil consumption of 1.3 percent to 3.20 million barrels per day. Consumption of liquefied petroleum gases rose 1.1 percent to 1.90 million barrels per day.

"Numbers in parentheses indirate ralated tablos. Annual data aro the most recent avallablo; they frequently are preliminery and may be revised in future publications. Percentages and nunbers in text are calculated by using otata in the tables.
Natural gas. Consumption of natural gas in 1995 rose 4.0 percent to 21.6 trillion cubic feet (6.6). Increased dentand in all sectors except residential was responsible for the growth. The industrial sector alone consumed 9.8 triltion cubic feet of natural gas in 1995.

Coat. Consumption of coal in 1995 rose 1.1 percent to 941 million short tons (7.3). The increase occurred primarily at electric utilities, where 88 percent of the coal was consamed.

Electricity. Electricity sales of 3.0 trillion kilowatthours were 2.4 percent above 1994 sales (8.6). Sales to the residential sector rose 3.5 percent, and sales to the industrial sector rose 0.3 percent. Electricity sales to the commercial sector rose 4.0 percent.

Renewable energy. Renewable energy consumption rose 9.3 percen to 6.9 quadrillion Btu, the highest on record and an 8-percent share of total energy consumption (10.1a and 1.3). Conventional bydraelectric power, consumed primarily at ejectric utilities to generate electricity, accounted for 3.5 quadrillion Btu, half of the renewable energy total (10.1a). Biofuels (fuelwood, wood byproducts, waste wood, municipal solid waste, manufacturing process waste, and alcohol fuels) accounted for 2.9 quadrillion Btu of consumption. Biofuels were consumed by all sectors and were the primary form of renewable energy consumed by the transportation sector. Consumption of geothermal energy (in the form of grid-connected electricity) totaled 0.4 quadrillion Btu. Solar energy is used primarily by the residential and commercial sector, which consumed 0.06 quadrillion Btu in 1995, and by the industrial sector, which accounted for 0.01 quadrillion $\mathrm{Btu}$. Wind energy is used primarily by the industrial sector, which accounted for 0.04 quadrillion Btu in 1995.

Energy intensity. The energy intensity of the economy, when measured in terms of energy consumption per dollar of gross domestic product (GDP), declined in 1995 for the fourth year in a row (1.7). About 13 thousand Btu of energy were consumed for each chained (1992) dollar of GDP in 1995, compared with about 19 thousand Btu per chained (1992) dollar in the early 1970's. The energy intensity of the economy declined during the 1970's, 1980's, and 1990's due to increases in energy efficiency, conservation, the expansion of the service 
sector, and the shift toward less energy-intensive industries. The Energy Policy Act of 1992 mandates additional energy efficiency standards that may further lower the energy intensity of the economy.

\section{Energy Production Reaches a Record Level}

U.S. total energy production in 1995 rose 0.8 percent to 71.2 quadriltion Btu (1.2). Most of the increase was attributed to increased production of renewable energy and nuclear electric power. Production of renewable energy rose 0.6 quadrillion Btu to 6.6 quadrillion $\mathrm{Bta}$ and production of nuclear electric power rose 0.4 quadrilion Btu to 7.2 quadrillion Btu. In contrast, production of the three major fossil fueis in 1995 was below 1994 levels. Coal production fell 0.2 quadrillion Btu from the 1994 level to 21.9 quadritlion Btu, natural gas production fell 0.04 quadrillion Bto to 19.23 quadtillion Btu, and crude oil (including lease condensate) production fel] 0.3 quadritlion Btu to 13.8 quadrillion Btu (the lowest level in 41 years).

\section{Nuclear electric power production rose to an all-time high.}

Coal and natural gas production each accounted for a greater share of the U.S. total than did crude oil. Coal production accounted for 31 percent of the U.S. total and dry natural gas production accounted for 27 percent, while crude oil production accounted for 19 percent.

Crude off and natural gas exploration. Exploration for crude oil and natural gas is closely tied to market conditions. In 1995, the continuing low price of crude oil reversed a modest upturn in domestic exploratory activity, which, in 1992, had fallen to the lowest levels in at least 44 years. The number of rotary rigs in operation fell from 775 in 1994 to 723 in 1995 (4.3). Exploratory wells drilled fell from 3.6 thousand to 3.5 thousand (4.5). However, the percentage of successful exploratory wells drilled rose from 38 percent in 1994 to 44 percent in 1995 (4.5).

Petroleum production. Crude oil production dropped to 6.5 million barrels per day, down 2.0 percent from the level in 1994 (5.1). However, average output from U.S. refineries in 1995 tose to 16 million barrels per day (5.8). Motor gasoline, at 7.4 million bartels per day, was by far the most prevalent product. The refinery utilization rate was 92 percent, the second highest rate in 22 years $(5.9)$.
Patroletm stocks. At year end, the Strategic Petroleum Reserve held 592 million barrels of crude oil (5.15), enough to replace petrolenm net imports for 75 days. Privately held stocks of crude oil totaled 302 mitllion barrels (5.14). Privately held stocks of petroleum products totaled 668 million bartels.

Natural gas production. Gross withdrawals of natural gas in 1995 totaled 24 trillion cubic feet, and dry gas production totaled 19 tritlion cubic feet (6.2). U.S. total gross withdrawals include a small but growing amount of methane produced from coalbeds. In 1994, gross withdrawals of coalbed methane totaled about 851 billion cubic feet, ${ }^{\ddagger}$ an amount equal to 5 percent of U.S. total dry production. However, the rate of increase in coalbed methane reserves slowed after 1992, when Federal tax incentives for new coalbed methane wells expired. In 1994, coalbed methane reserves declined for the first time since data collection began in 1988. Caalbed methane reserves accounted for 6 percent of U.S. natural gas total reserves in 1994.

Coal production. Domestic coal production in 1995 totaled $1,030 \mathrm{mil}$ lion short tons $(7,1)$. Production of western coal rose to 488 million shont tons, 47 percent of the total (7.2). The growth in westem coal was due in part to environmental concems that led to increased demand for low-sulfur coal, which is concentrated in the West. In addition, surface mining, with its higher productivity, is much more prevalent in the West.

Cost stocks. Year-end 1995 coal stocks remained at the year-end 1994 level of 169 milition short tons (7.5). Electric utilities held threefourths of the coal, and coal producers and distributors held most of the remainder:

Nuclear eloctilc power production. In 1995 , nuclear eltctric power production rose to an all-time high. Nuclear electricity net generation in creased 5.2 percent to 673 billion kilowalthours, the highest ever, and the nuclear portion of domestic electricity net generation rose from 22.0 percent in 1994 to a record 22.5 percent in 1995 (9.2). The 1995 capacity factor of 78 peroent also was the highest ever recorded. However, the number of operable nuclear generating units remained at 109, two fewer then the number in 1990 and 1991 . One unit, Watts Bar 1, was licensed for startup in 1995, but construction on the remaining six units holding construction permits had been halted or canceled. The year-end 1995

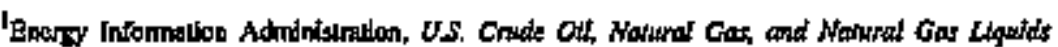
Resenves I994 Avrsual Report, DOBEElA-0216(94) (Washlogton, DC, Oetober 1995), p. 34. 
net summer capability of operabie units temained at the year-end 1994 leve] of 99.1 million kilowatthours, 0.5 million kilowatthours below the peak capability recorded in 1990 and 1991.

Hydroelectric power production. Conventional hydroelectric power production at electric utitities (which excludes hydroelectric pumped storage) rose from 247 billion kilowatchours in 1994 to 296 billion kilowatthours in 1995 (8.3). Hydroelectric pumped storage (total production at pumped storage facilities minus the energy used for pumping) was a negative 3 billion kilowathours. The amount of electricity generated from renewable energy (excluding hydroelectric power) at electric utilities fell from 9 billion kilowattours in 1994 to 6 billion kilowathours in 1995.

\section{Energy Net Imports Decline}

U.S. net imports of energy fell to 17.8 quadrtllion Btu in 1995 , a decrease of 3.9 percent from 1994's record level $(1,4)$. Changes in the trade volumes of both petroleum and coal led to the decline. Petroleum net imports decreased 1.8 percent to 16.9 quadrillion Btu and coal net exports increased 27 percent to 2.1 quadrillion Btu. Natural gas net imports rose 4.4 percent to 2.6 quadrillion $B t w$.

Crude oil net imports (including imports for the Strategic Petroleum Reserve) rose to an all-time high in 1995 of 7.1 million barrels per day (5.3 and 5.5), but net imports of petroleurn products fell 32 percent to 0.7 million barrels per day. The petroleum products registering the bighest volumes of net imports in 1995 were unfinistred oils, motor gasoline, and residual fusel oil. Petroleum coke was the primary net export.

\section{Crude oil net imports rose to an all-time high in 1995 of 7.1 miltion barrels per day.}

U.S. net imports of petroleum totaled 7.9 million barrels per day in 1995 (5.7). Members of the Organization of Petroleum Exporting Countries (OPEC) supplied 4.2 million barrels per day, over half of the total. Net imports from Venezuela, Saudi Arabia, and Nigeria were 1.5 milfion barrels per day, 1.3 million barrels per day, and 0.6 million barrels per day, respectively.
The remaining 3.7 mitlion barrels per day of U.S. petroleum net imports came primarily from Canada, which supptied 1.3 million barrels per day, and Mexico, which supplied 0.9 miltion barrels per day. The United Kingdom supplied 0.4 million barrels per day.

U.S. dependence on foreign suppliers of petroleum decreased by 1.0 percentage point in 1995 (5.7). Net imports from all countries fell to a 44.5-percent share of petroleum consumption. Dependence on thet imports from $O P E C$ members alone fell 0.2 percentage points to a 23.7-percent share of petroleum consumption.

Although petroleum domizated U.S. trade in energy, imports and exports of other energy sources played an important role:

- Natural Gas. Natural gas net imports roso to 2.6 trillion cubic feet, due primarily to increased netimports from Canada (6.3). Trade with Canada was facilitated by the completion of the Iroquois transportation system in January 1992. Canadian natural gas exports to the U.S. market rose 5.7 percent to 2.7 trillion cubic feet. U.S. exports to Camada decreased 38 percent to 33 billion cubic feet.

- Coal. Coal rernained the primery U.S. energy export. Coal exports rose 24 percent to 89 million short tons in 1995 , rebounding from the 1994 level, which was the lowest in 15 years (7.1). Coal exports to almost all countries increased. Japan, Carada, and faly remained the three largest foreign purchasers of U.S. coal.

- Electriolty. Net imponts of electricity totaled 37 billion kilowathours in 1995 (8.1). Electricity net imports contributed only a strall share of U.S. olectricity consumption.

\section{Energy Prices Remained Low}

Although the U.S. refiners' real ${ }^{2}$ composite acquisition cost of cnude oil rose to $\$ 16.03$ per barrel, tp from $\$ 14.85$ in 1994 , the cost remained well below the high costs of the 1970's and 1980's.

The and-use prices, excluding taxes, of most petroleum products also increased in 1995 (5.20). The average price of all types of motor gasoline rose from 74 cents per gallon in 1994 to 77 cents per gallon in 1995. Aviation gasoline, kerosene-type jet fuel, residual fuel oil, and

"Rest (tallation-adjusted) proces ant exptessed in chained (1992) dollars. 
No. 2 diesel oil average pices, excluding taxes, also increased. In contrast, the average prices per gallon, excluding taxes, of kerosene, propane, and No. 2 fuel oil declined in 1995.

The average wellhead real price of all categories of natural gas fell 17 percent to $\$ 1.48$ per thousand cubic feet (6.8). Lower costs of producing and transporting natutal gas benefited consumers. The average price, in real terms, paid by residential consumers was down 7.5 percent from the 1994 price. Corresponding prices paid by the commercial, electric utilities, and industrial sectors were down 10 percent, 14 percent, and 15 percent, respectively (6.9 and E1).

The average real price of bituminous coal and lignite at the minemouth fell to $\$ 17.67$ per short ton, down for the sixteenth year in a row (7.8).
The real price of coal at electric utilities, where most coal is consumed, was $\$ 25.20$ per short ton, down from $\$ 26.70$ per short ton in 1994 .

The weighted average real price of electricity to all sectors declined slightly to 6.4 cents per kilowatthour in 1995 (8.11). The average real price of electricity sold to the residential sector, where prices have usually been the highest, was 7.8 cents per kilowatthour, down 2.5 percent from the real price in 1994. The commercial sector price feli 1.4 percent to 7.2 cents per kilowatthour in 1995. Industrial cus* tomers continued to pay prices that were favorable compared with prices in other sectors. In 1995, the real price of electricity sold to Industrial users was 4.4 cents per kilowathour, down 4.3 percent from the price in 1994. 


\section{Energy Overview}

\section{Production}

Historically, three fossil faels have accounted for the bulk of domestic energy production, which by 1995 totaled 71 quadrillion Btu (1.2).* Coal accounted for the largest share of domestic energy production in 19491951 and, after a long hiatus, again in 1982 and in 1984 through 1995. In the interim, first crude oil and then natural gas dominated domestic production. In 1995, coal production totaled 22 quadriltion Btu. Dry natural gas production totaled 19 quadrillion Btu and crude oil production totaled 14 quadrillion Btu. Natural gas plant liquids accounted for another 2.4 quadrillion Btw.

Net generation of electricity by electric utilities increased throughout the 1949-through-1995 period (8.1), registering only two year-to-year declines (during the 1982 recession and again in 1992). However, the rate of growth of electricity net generation slowed during the 47-year period. From 1949 through 1979 , the annual growth rate averaged 7.1 percent, whereas from 1980 through 1995 , the anrual growth rate averaged 1.8 percent. After the mid-1970's, coal and nuclear fuels provided increasing shares of fuel input for electricity generation, displacing substantial quantities of petroleum and, to a lesser extent, natural gas (8.3).

Hydrotectric genemation (conventional and purnped storage) accounted for over 1.4 quadrillion Bu of electricity in 1949 and from the 1970's through 1995 usually provided about 3 quadrillion Btu per year (1.2). However, in 1988, the second year of drought, hydroelectric generation totaled only 2.3 quadrillion Btu. In 1995, it totaled 3.2 quadrillion Btu.

Other renewable entergy sources also contributed to the domestic energy supply. Biofuels, a category which includes wood and waste, contributed 2.9 quadrillion Btu to the 1995 total (1.2). Geothenmal, solar, and wind energy combined contributed 0.5 quadrillion Btu. Renewablo energy production (including conventional hydroelectric power and excluding hydroelectric pumped storage) totaled 6.6 quadrillion Btu, 9.3 percent of U.S. total energy production.

Numbers in parentheses indicale related tables. Annual data are the most recent

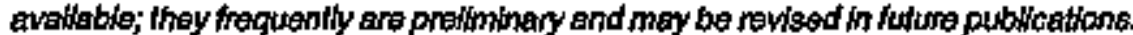
Percentages and nwhlosis in text are calculeted by using data in tho tables.

\section{Consumption}

Energy consumption more than doubled during the 1949-through-1973 period, increasing from 30 quadrillion Btu in 1949 to 74 quadrillim Btu in 1973 (1.3), and the U.S. economy grew at about the same rate. The domestic energy market was dominated by rapid growth in petroleum and natural gas consumption, which more than tripled thring the period. After the 1973 oil shock, energy consumption fluctuated, influenced by dramatic changes in oil prices, changes in the rate of growth of the domestic economy, and such factors as concerns about the effect of energy use on the environment. The post-1973 low point of energy consumption, 71 quadrillion Btu, occurred in 1983 following a period of very high oil prices. The highest level of energy

\section{Indicators of Energy Intensity}

The relationship between totat enercy consumplion and real gross domesilc product (GDP) is a tradilionat Indicetor of the energy intenesity of the econorny. In 1970, 20 thousand Btu of energy were consumed for each chained (1992) dollar of CDP (1.7). Hicher enexgy prices in the earty 1970 's led to increases in energy efilciency and a signilicant resinucturing of the energy-Intenstive activilies of the mansfacluring seckor. In 1985, the energy Intensity of the economy as a whole fell betow 14 tbousend Eitu per chained (1992) dollar, where tit remained through 1995.

A secorid indicator of energy intensity is per capila consumplion. Througheout the 1960's and early 1970's, the growth of end-use entergy consurnetion was greatar than the growth of the paputation (1.5). Per capita consurmpllon roes from 212 million titu in 1960 to a poak of 286 million Btu in 1973. Therestter, per capita consumption Irended downward to as low as 226 milion Btu in 1993 . In the 1990's, low pelmoleum prloes encouragad energy use, and enct-use energy consumption rose to 264 minllion Btu per capita In 1995.'

'The Inelusten of non-electido consumption of renewrabis enaroy in the lotals of U.S.

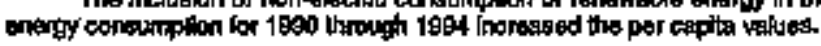


consumption, 91 quadrillion Btr, ${ }^{2}$ occurred in 1995, following several years when oil prices were low.

The composition of demand after 1973 reflected an increasing emphasis on electricity generated by coal, nuclear, and renewable energy sources and on non-efectric utility use of renewable sources. In 1973, petrolenm and natural gas accounted for 77 percent of total energy constumption; by 1995 , their share had declined to 63 percent. ${ }^{3}$

\section{Energy Prices in a Volatile Market}

Since the mid-1970's, changes in fossil fuel prices have become more frequent and more pronounced (3.1). Prior to the oil embargo of 1973 . 1974, the composite teal price ${ }^{4}$ per million Btu of crude oil, aatural gas, and coal had declined to a post-World War II low of $\$ 1.03$ in 1968 and 1969. In 1974, however, the real price rose to $\$ 1.76$ and eventually peaked at $\$ 4.17$ in 1981 after a second round of crude oil price increases. Thereafter, overproduction of crude oil began to affect energy prices and, when crude oil prices plunged in 1986, the composite real price of the major fossil fuels fell to $\$ 2.05$. In 1995, the composite price was $\$ 1.39$, the lowest in 22 years.

Throughont the 1949-through-1995 pariod, changes in the real price of oil dominated movements in the composite index. The real price of oil trended downward between 1959 and 1970 and then rose sharply in 1974 and again in 1979 through 1981. Thereafter, in the face of shrinking demand and excess production, price trends reversed sharply. Precipitous declines in 1986 and 1988 brought the real price of crude oil in 1988 to $\$ 2.52$ per million Btu, the lowest level since 1973 . In 1989 , the price rose to $\$ 3.05$. In 1990 , the Iraqi invasion of Kuwait contributed to an increase in crude oil prices to $\$ 3.69$ per million $\mathrm{Btu}$. In 1991, however, the ability of producer's to supply replacement oil, coupled with a worldwide economic recession that depressed petroleum demand, led to a decrease in crude oil prices to $\$ 2.93$ per million Btu. In 1995 , the real price of oil was $\$ 2,35$ per million Btu.

${ }^{1}$ U.S. totol anergy tonsomplion in 1990 through L9gS wins roughly 3 quodrillion BCU bigher dac to the expanded coverage of non-electric utility use of renowable tanergy. Even without the additional ronewabls energy consumption, however, $1995 \mathrm{U} . \mathrm{S}$. Lotal ontrigy con sumptien was the highest an record.

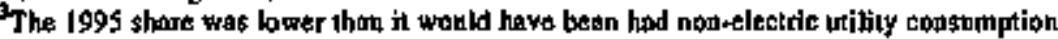
of renewable energy nol been included in U.S. totol energy consumption.

${ }^{4}$ Reall (inflintion-adfusted) prices are expecessed in shntmed (1992) dellars.
Prices of coal and natural gas were much less volatile than those of oil. Coal markets are generally less vulnerabie to snpply disruptions than are oil markets, where the output and pticing policies of the Organization of Petroleum Exporting Countries (OPEC) were a major influence during much of the 1973-through-1995 period. Natural gas prices were subject to substantial State and Federal regulation. Throughout the 1970's, regulation dampened the response of natural gas prices relative to the oil price movement. However, the weakening of crude oij prices after 1985 was severe enough to trigger declines in the prices of the other fossil fuels, particularly that of natural gas. In 1995 , the real price of crade oil per million Btu of $\$ 2.35$ was 56 percent below the 1985 price (3.1). The real price of natural gas was 53 percent lower, and the real price of bituminous coal and lignite was 43 percent lower, than their respective prices in 1985.

\section{Ghanging Patterns of Trade}

From 1958 forward, the United \$tates consumed more energy than it produced, and the difference was met by energy imports $(1.2,1.3$, and 1.4). Net imports of energy (primarily petroleum) grew rapidly through 1973, as demand for cheap foreign oil eroded quotas on petroleum imports. The oil embargo of 1973-1974, coupled with the increase in the price of crude oil, interrupted growth in petroleum net imports; nevertheless, they climbed to a peak of 18 quadrillion Btu in 1977 (1.4). That year, U.S. dependence on foreign sources of petroleum reached an all-time high of 47 percent (5.7). A second round of price increases in 1979 through 1981 suppressed demand for forejgn oil. In 1985, petroleum net imports totaled 9.0 guadrillion Btu, and U.S. dependence fell to 27 percent of consurmption (1.4 and 5.7). Subsequently, petroleum net imports increased every year through 1989 , when U.S. dependence on forejen sources of petroleum reached 42 percent of consumption. In 1995, the fifth consecutive year of low cride oil prices, petroletm net imports rose to 17 quadrilion Btu and U.S. dependence on them equaled 45 percent-the second highest level in 18 years.

Natural gas trade was limited to border countries until the advent of shipping natural gas in liquefied form in the late 1960's. In 1995, natural gas net imports reached the record level of 2.6 quadrillion Btu (1.4).

Throughout the 1949-through-1995 period, the United States was a net exporter of coak (1.4). In 1995, coal net exports totaled 2.1 quadrillion Btu. 


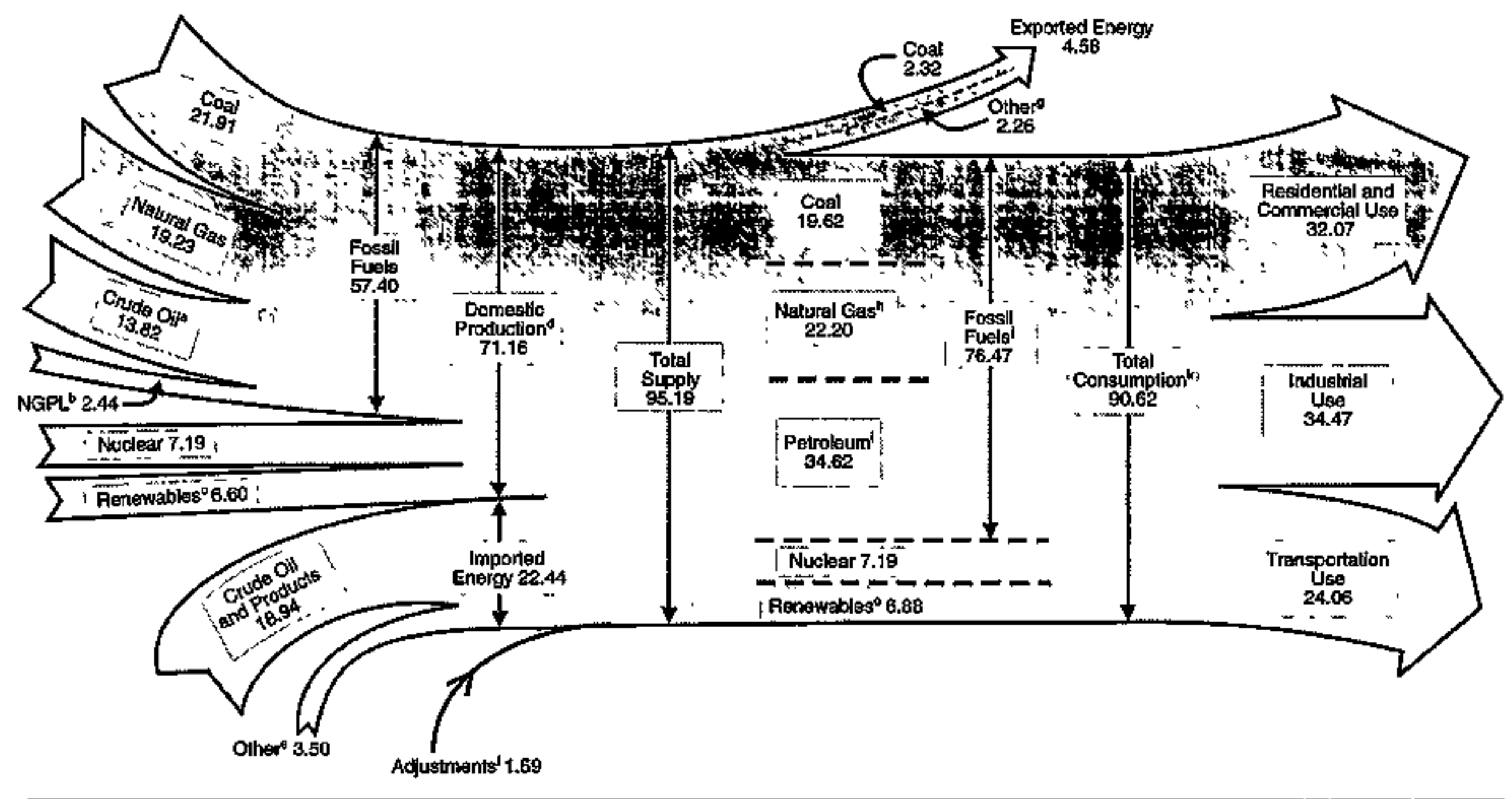

*1nesudos lease condengette.

b Naturel gesplantilicuida.

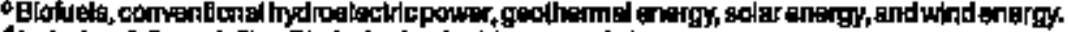

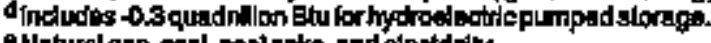

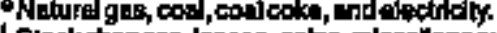

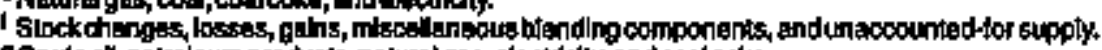

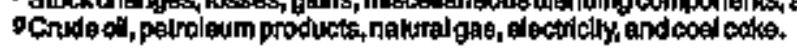

hindudes aupplementel gacencus fugls.

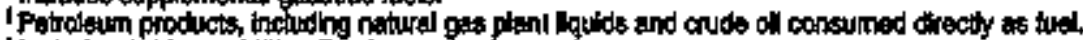
Inciudes 0,03 quadrilliap Bifu for coal coke net imports.

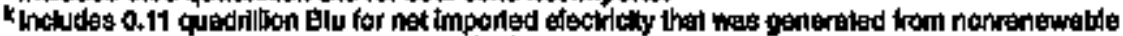
energy sarces and +0.03 cusadrition Buy for twdroelectric pumped storage.

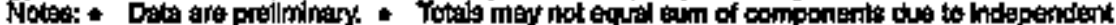
roundint

Sounces Tables 1.1 ind 2.1. 


\section{Figure 1.1 Energy Overview}

\section{Ovenview, 1960-1995}

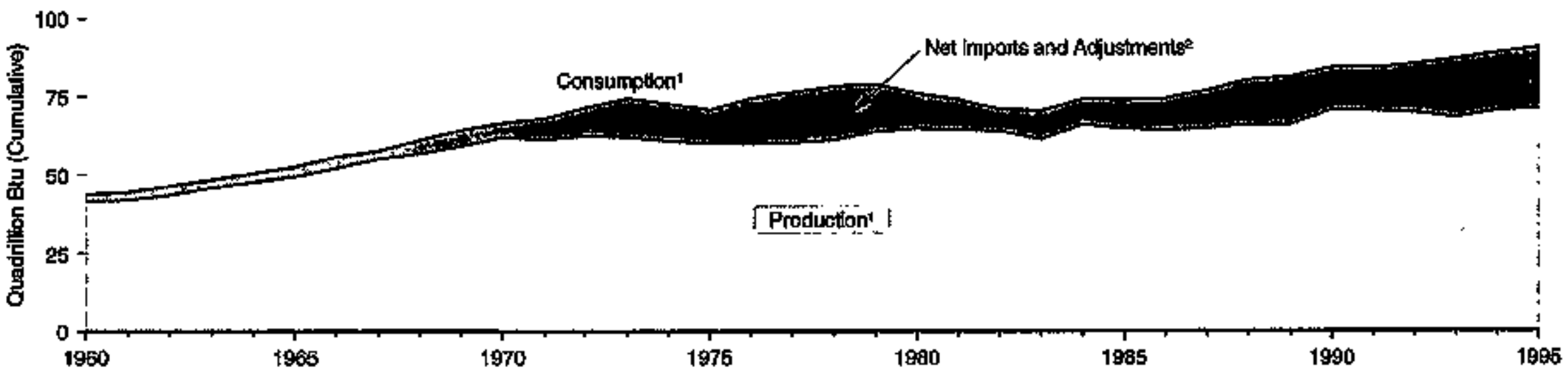

\section{Overview, 1995}

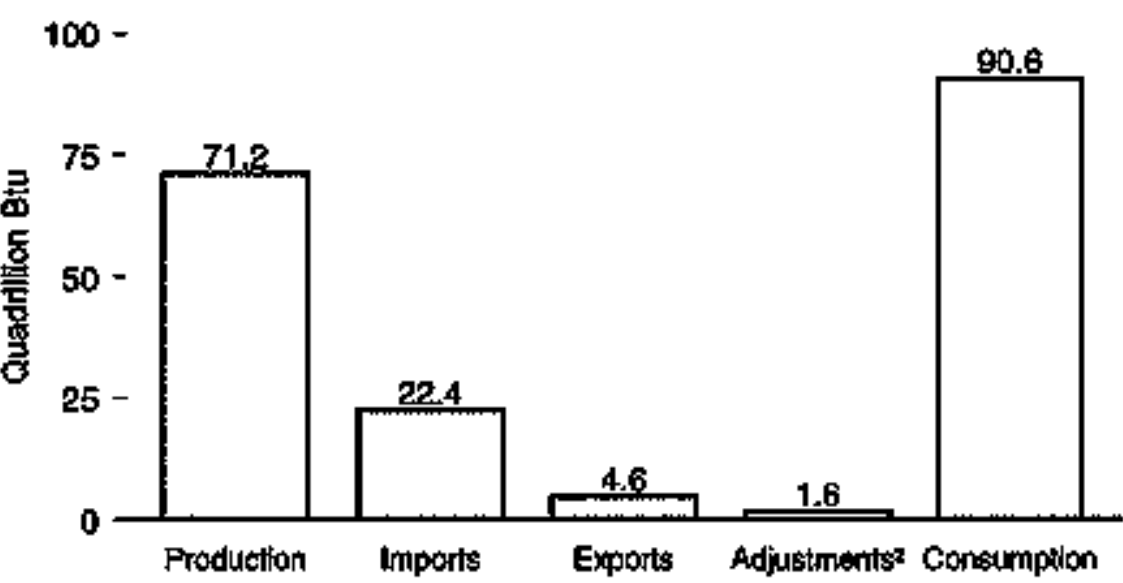

1 There is a decontinuthy th Itis ilme sertes betwaen 1989 end 1990 due to the expended coverage of non-electic uillihy use of renewable energy beglenth in 1980.

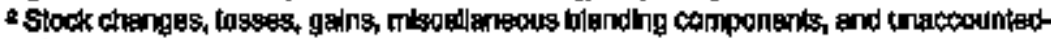
for supply.

\section{Energy Flow, 1995} (Quadricon Biti)

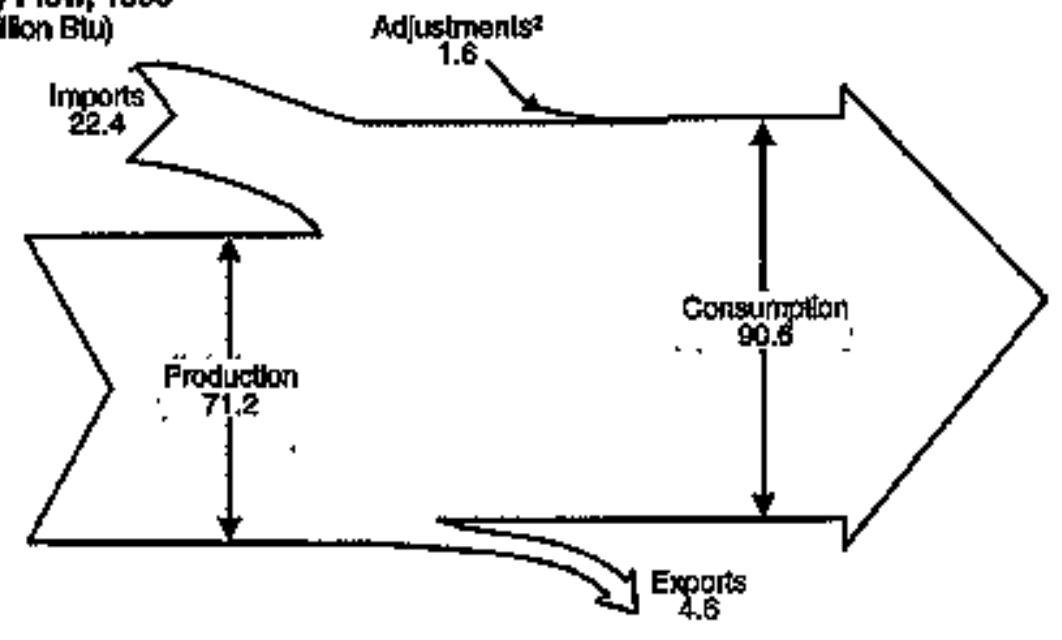

Nola: Date tor 1985 are preliminary Source: Table t.1. 
Table 1.1 Energy Overview, Selected Years, 1960-1995

\section{(Cruadrillion Btu)}

\begin{tabular}{|c|c|c|c|c|c|c|c|c|c|c|c|c|c|c|c|c|c|c|}
\hline Aelwhy thad Enargy Fource & 1060 & 1970 & 1980 & $198 \mathrm{gt}$ & 192 & 1089 & 1904 & to05 & 1090 & 1997 & 1980 & 1090 & 1090 & 1091 & 1992 & 1009 & 1904 & $1995 \mathrm{~F}$ \\
\hline 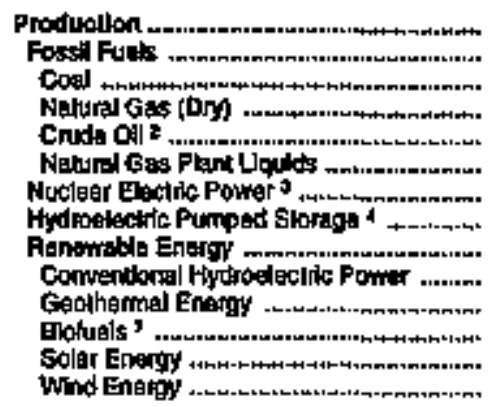 & 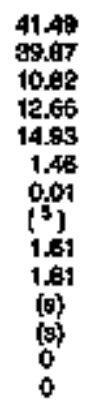 & $\begin{array}{l}62.07 \\
59.19 \\
14.61 \\
21.57 \\
20.40 \\
2.51 \\
0.24 \\
13) \\
2.65 \\
2.65 \\
0.09 \\
{[(9)} \\
0 \\
0\end{array}$ & $\begin{array}{l}64.76 \\
59.01 \\
10.60 \\
19.91 \\
19.25 \\
2.25 \\
2.74 \\
15.5 \\
3.01 \\
2.00 \\
0.11 \\
601 \\
0 \\
0\end{array}$ & $\begin{array}{l}54.42 \\
58.59 \\
10.39 \\
19.70 \\
18.15 \\
2.31 \\
3.01 \\
{[5]} \\
2.89 \\
2.78 \\
0.12 \\
(9) \\
0 \\
0\end{array}$ & $\begin{array}{c}62.98 \\
57.45 \\
18.64 \\
18.32 \\
18.34 \\
3.19 \\
3.13 \\
6.7 \\
3.57 \\
3.97 \\
0.10 \\
18 \\
0 \\
0\end{array}$ & $\begin{array}{r}61.26 \\
54.42 \\
17.26 \\
16.59 \\
18.39 \\
3.18 \\
3.20 \\
15) \\
3.56 \\
3.53 \\
0.13 \\
69 \\
0 \\
(9)\end{array}$ & $\begin{array}{c}65.95 \\
58.95 \\
19.72 \\
18.01 \\
18.85 \\
2.97 \\
3.55 \\
(5) \\
3.58 \\
3.39 \\
0.16 \\
0.01 \\
0 \\
\text { (\$) }\end{array}$ & $\begin{array}{l}54.97 \\
5.54 \\
19.33 \\
16.98 \\
18.99 \\
2.94 \\
4.15 \\
(3) \\
3.18 \\
2.97 \\
0.90 \\
0.04 \\
0 \\
(8)\end{array}$ & $\begin{array}{c}54.35 \\
58.59 \\
16.61 \\
16.54 \\
18.39 \\
2.15 \\
1.47 \\
15.5 \\
3.30 \\
3.07 \\
0.22 \\
0.01 \\
0 \\
\text { (4) }\end{array}$ & $\begin{array}{l}64.5 \\
57.17 \\
20.14 \\
17.14 \\
17.67 \\
2.22 \\
4.91 \\
(5) \\
2.69 \\
2.69 \\
0.23 \\
0.02 \\
0 \\
(0)\end{array}$ & $\begin{array}{c}68.10 \\
57.87 \\
30.74 \\
17.60 \\
17.28 \\
2.26 \\
5.66 \\
15) \\
2.57 \\
2.33 \\
0.22 \\
0.02 \\
0 \\
(3)\end{array}$ & $\begin{array}{l}5.13 \\
5.47 \\
21.35 \\
17.65 \\
16.12 \\
2.15 \\
5.60 \\
15) \\
2.90 \\
2.77 \\
0.20 \\
0.08 \\
0 \\
(5)\end{array}$ & 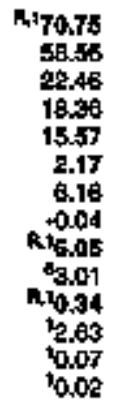 & 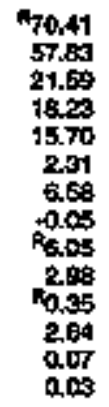 & 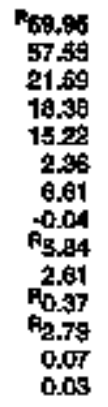 & 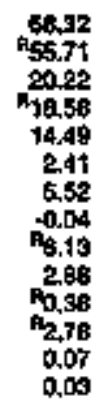 & 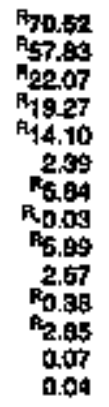 & $\begin{array}{l}71.16 \\
67.40 \\
21.91 \\
18.23 \\
18.62 \\
2.44 \\
7.16 \\
-0.09 \\
6.80 \\
3.20 \\
0.55 \\
2.94 \\
0.04 \\
0.04\end{array}$ \\
\hline 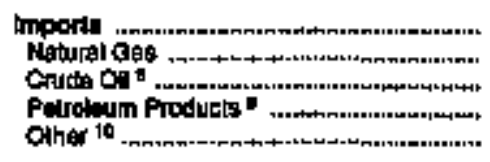 & $\begin{array}{l}4.23 \\
0.16 \\
2.20 \\
1.00 \\
0.07\end{array}$ & $\begin{array}{l}6.39 \\
0.85 \\
2.91 \\
4.88 \\
0.07\end{array}$ & $\begin{array}{r}15.97 \\
1.01 \\
11 .+9 \\
3.48 \\
0.31\end{array}$ & $\begin{array}{r}13.97 \\
0.90 \\
9.94 \\
3.30 \\
0.42\end{array}$ & $\begin{array}{r}12.09 \\
0.95 \\
7,42 \\
3.36 \\
0.36\end{array}$ & $\begin{array}{r}12.03 \\
0.94 \\
7.08 \\
3.57 \\
0.44\end{array}$ & $\begin{array}{r}12.77 \\
0.96 \\
7.50 \\
4.13 \\
0.49\end{array}$ & $\begin{array}{r}12.10 \\
0.95 \\
6.91 \\
3.90 \\
0.54\end{array}$ & $\begin{array}{r}14.44 \\
0.75 \\
\$ .00 \\
4.20 \\
0.49\end{array}$ & $\begin{array}{r}16.78 \\
0.09 \\
10.07 \\
4.10 \\
0.61\end{array}$ & $\begin{array}{r}17.59 \\
1.30 \\
11.09 \\
4.72 \\
0.52\end{array}$ & $\begin{array}{r}18.96 \\
1.39 \\
12.60 \\
4.57 \\
0.40\end{array}$ & $\begin{array}{r}18.99 \\
1.55 \\
12.77 \\
4.35 \\
0.39\end{array}$ & $\begin{array}{r}18.89 \\
1.80 \\
12.5 \\
3.79 \\
0.44\end{array}$ & 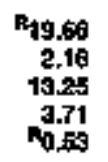 & $\begin{array}{r}21.64 \\
2.40 \\
14.75 \\
3.78 \\
80.63\end{array}$ & $\begin{array}{l}A_{22.71} \\
A_{2.69} \\
A_{15.34} \\
A_{3.91} \\
A_{0.79}\end{array}$ & $\begin{array}{r}2 ., 44 \\
2.80 \\
15.74 \\
3.20 \\
0.70\end{array}$ \\
\hline 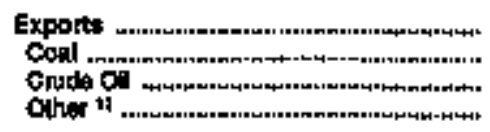 & $\begin{array}{l}1.49 \\
1.09 \\
0.43 \\
0.03\end{array}$ & $\begin{array}{l}2.85 \\
1.94 \\
0.56 \\
0.18\end{array}$ & $\begin{array}{l}3.72 \\
2.42 \\
1.16 \\
0.14\end{array}$ & $\begin{array}{l}4.35 \\
2.94 \\
1.28 \\
0.12\end{array}$ & $\begin{array}{l}1.63 \\
2.79 \\
1.73 \\
0.11\end{array}$ & $\begin{array}{l}3.72 \\
2.04 \\
1.57 \\
0.11\end{array}$ & $\begin{array}{l}3.90 \\
2.15 \\
1.54 \\
0.11\end{array}$ & $\begin{array}{l}4.23 \\
2.44 \\
1.66 \\
0.14\end{array}$ & $\begin{array}{l}4.08 \\
2.26 \\
1.67 \\
0.14\end{array}$ & $\begin{array}{l}3.85 \\
2.09 \\
1,69 \\
0,19\end{array}$ & $\begin{array}{l}4.42 \\
2.50 \\
1.71 \\
0.18\end{array}$ & $\begin{array}{l}4.77 \\
2.64 \\
1.84 \\
0.99\end{array}$ & $\begin{array}{l}4.91 \\
2.77 \\
1.92 \\
0.31\end{array}$ & $\begin{array}{l}5.22 \\
2.85 \\
2.13 \\
0.24\end{array}$ & $\begin{array}{l}5.02 \\
2.69 \\
2.01 \\
0.39\end{array}$ & $\begin{array}{l}1.35 \\
1.98 \\
2.12 \\
0.27\end{array}$ & $\begin{array}{r}4.12 \\
1.69 \\
1.99 \\
0.28\end{array}$ & $\begin{array}{l}4.59 \\
2.32 \\
1.99 \\
0.27\end{array}$ \\
\hline 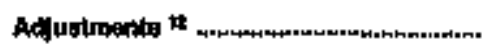 & -0.43 & -137 & -1.05 & -0.06 & -0.67 & 0.94 & -0.76 & t.24 & -0.44 & 0.09 & 0.96 & tor & -0.67 & $F_{0.27}$ & P0.65 & n.1.51 & $8,0,3,2$ & 1.59 \\
\hline 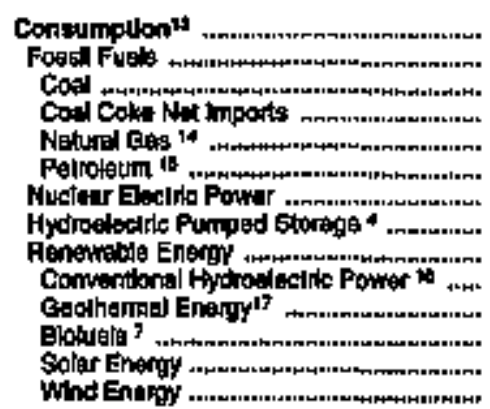 & 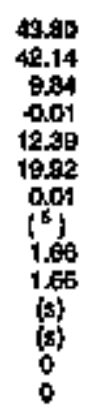 & $\begin{array}{l}65.49 \\
63.52 \\
12.20 \\
-0.08 \\
21.79 \\
20.52 \\
0.24 \\
15) \\
2.07 \\
2.65 \\
0.01 \\
(15 \\
0 \\
0\end{array}$ & $\begin{array}{l}75.93 \\
69.09 \\
15.42 \\
0.04 \\
20.39 \\
34.20 \\
2.74 \\
15 \\
3.23 \\
3.12 \\
0.11 \\
(5) \\
0 \\
0\end{array}$ & $\begin{array}{l}7.59 \\
67.76 \\
15.91 \\
-0.02 \\
10.00 \\
31.00 \\
3.01 \\
(3) \\
3.23 \\
0.11 \\
0.12 \\
(8) \\
0 \\
0\end{array}$ & $\begin{array}{l}70.05 \\
64.04 \\
15.32 \\
0.02 \\
18.51 \\
30.23 \\
3.13 \\
15 . \\
3.68 \\
3.57 \\
0.10 \\
(8) \\
0 \\
0\end{array}$ & $\begin{array}{l}70.52 \\
63.20 \\
15.89 \\
0.02 \\
17.96 \\
30.05 \\
8.20 \\
15.1 \\
4.03 \\
3.90 \\
0.13 \\
(8) \\
0 \\
(\$)\end{array}$ & $\begin{array}{c}74.14 \\
68.68 \\
17.07 \\
0.09 \\
18.67 \\
31.06 \\
.55 \\
6 \\
3.07 \\
3.00 \\
0.16 \\
0.01 \\
0 \\
(s)\end{array}$ & 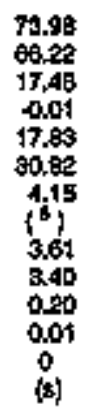 & $\begin{array}{l}71.30 \\
68.15 \\
17.25 \\
-0.02 \\
16.71 \\
82.20 \\
1.47 \\
(6 .) \\
3.69 \\
3.45 \\
0.25 \\
0.01 \\
0 \\
(5)\end{array}$ & $\begin{array}{c}76.69 \\
69.63 \\
10.01 \\
0.01 \\
17.74 \\
32.67 \\
4.91 \\
(t) \\
3.36 \\
3.12 \\
0.20 \\
0.02 \\
0 \\
(6)\end{array}$ & $\begin{array}{c}80.22 \\
71.68 \\
18.95 \\
0.04 \\
18.55 \\
39.22 \\
5.68 \\
5 \\
2.80 \\
2.86 \\
0.12 \\
0.02 \\
0 \\
\text { (s) }\end{array}$ & $\begin{array}{c}9 t .33 \\
72.55 \\
18.99 \\
0.09 \\
10.39 \\
34.21 \\
5.69 \\
51 \\
8.10 \\
2.69 \\
0.20 \\
0.02 \\
0 \\
(5)\end{array}$ & 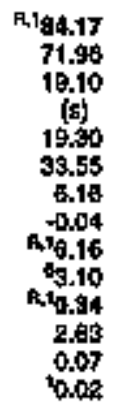 & 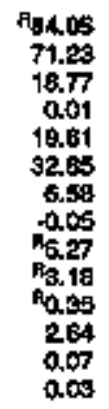 & 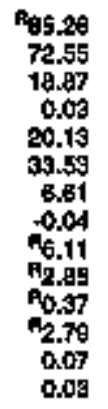 & 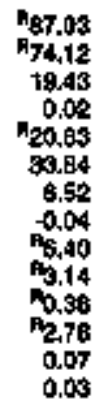 & 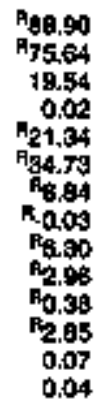 & $\begin{array}{r}90.62 \\
70.47 \\
19.62 \\
0.03 \\
22.20 \\
39.60 \\
7.19 \\
0.09 \\
6.019 \\
3.46 \\
0.39 \\
2.94 \\
0.07 \\
0.04\end{array}$ \\
\hline
\end{tabular}

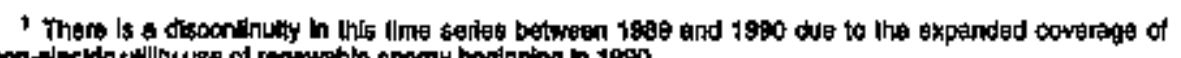

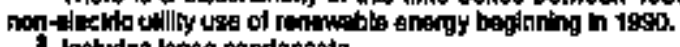

Mnctudes lesise condenteate.

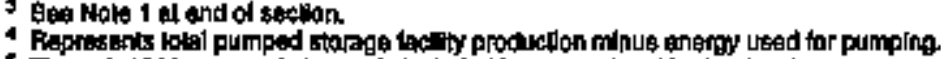

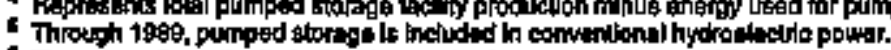

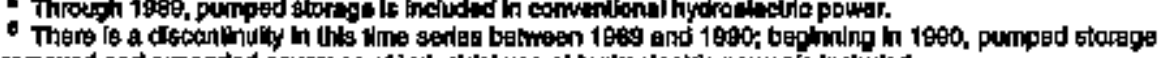

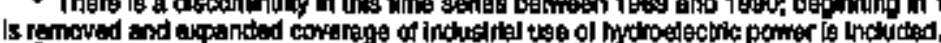

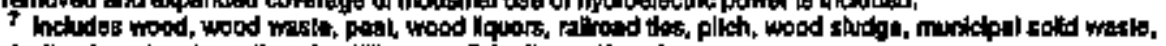

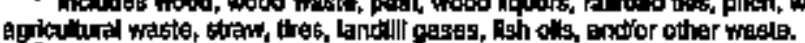

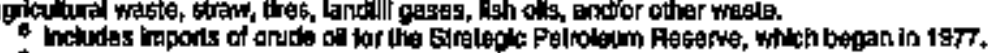

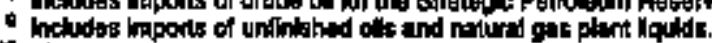

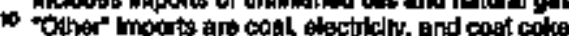

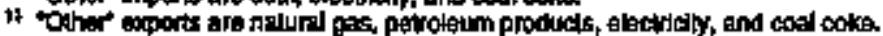

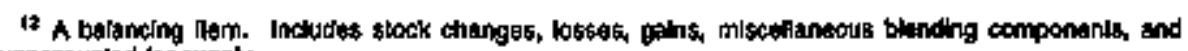
uraccounked.har suppty.

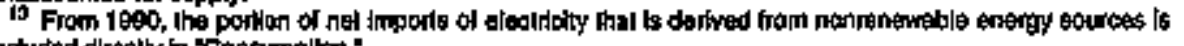
Inctuded disectly in "Contumplikn:"

is Includids supplemantal gaseous luals.

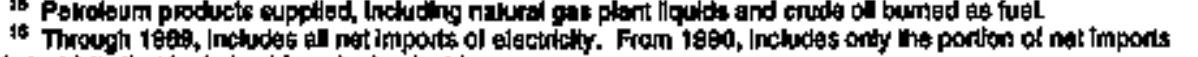

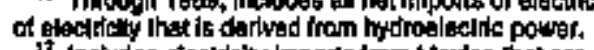

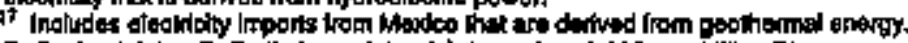

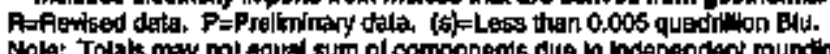

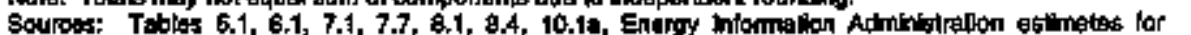

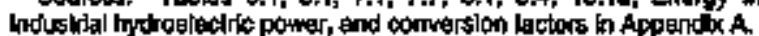


By Sourke, 1949-1995

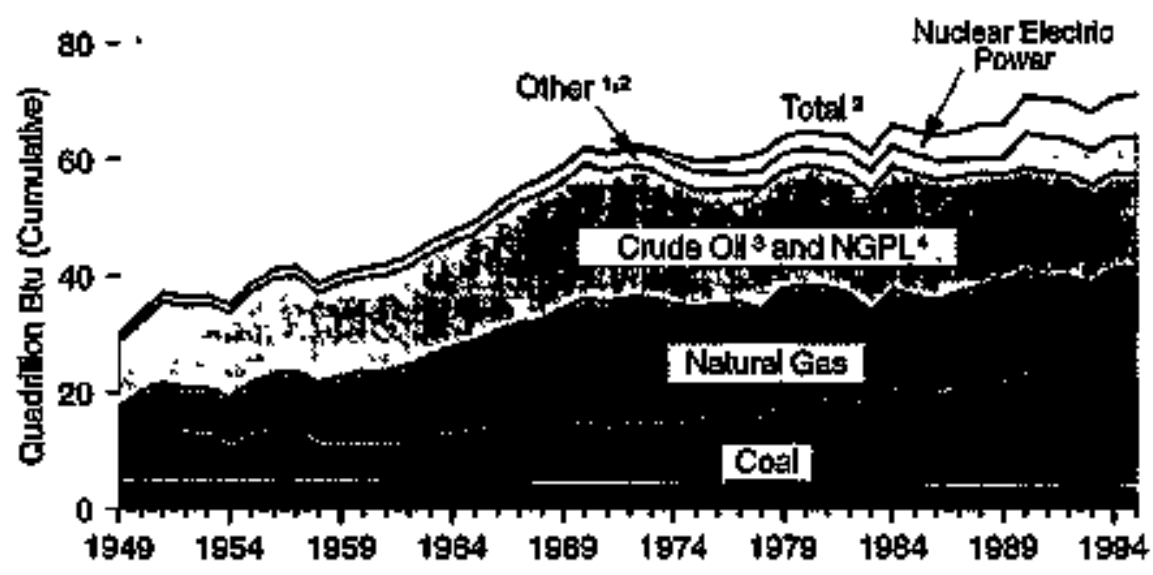

By Source, 1995

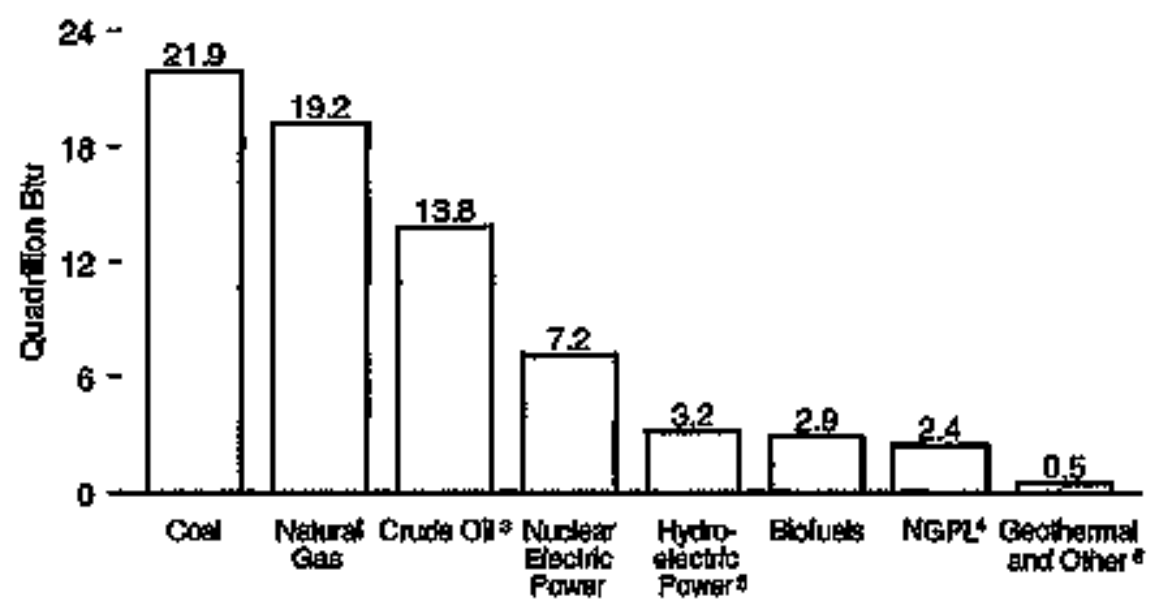

' Ohere" ts renewable energy end pumped-storage mydroelecitc power.

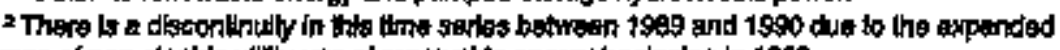

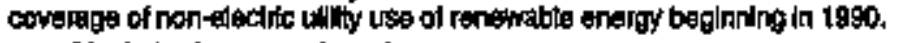

1 Inchudias Itase condensiate.

' Nalurel gas plenk llouldo.
By Malor Source, 1949-1995

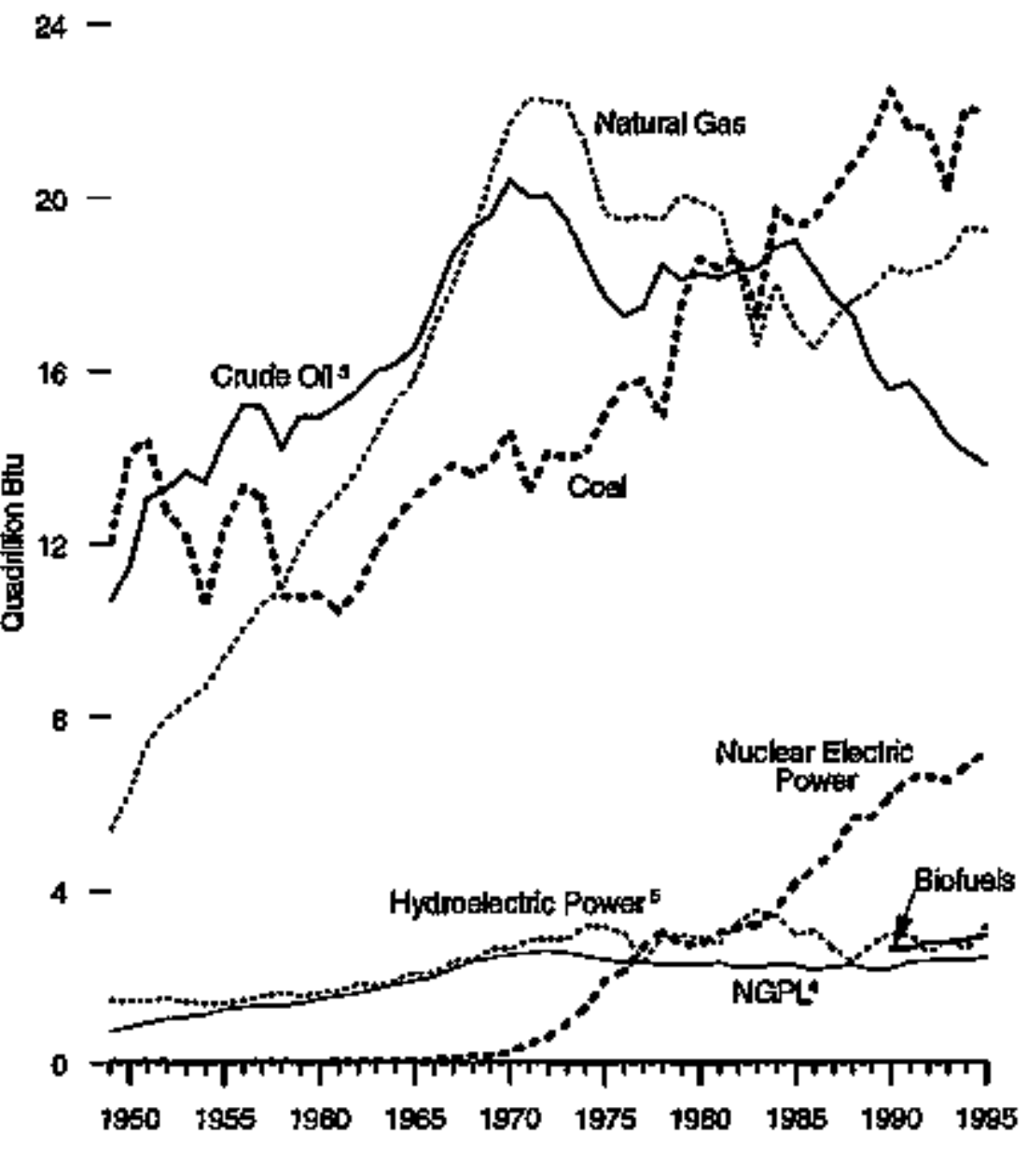

6 Comentionel and pumped storage hydroelectro power.

6 "Other" is sotar onergy and wind energy.

Nole Because vertical scales tiller, graphs should nox bo compered.

Source: Tohle 12 
Table 1.2 Energy Production by Source, 1949-1995

(Quadrillion BAu)

\begin{tabular}{|c|c|c|c|c|c|c|c|c|c|c|c|c|c|c|}
\hline \multirow[b]{2}{*}{ Your. } & \multicolumn{5}{|c|}{ Forsfl Fuels } & \multirow[b]{2}{*}{$\begin{array}{l}\text { Nuwlenr } \\
\text { Eloolrio } \\
\text { Powor? }\end{array}$} & \multirow[b]{2}{*}{$\begin{array}{c}\text { Hydroetecirlc } \\
\text { Pumpad } \\
\text { slorage }\end{array}$} & \multicolumn{6}{|c|}{ Peptwable Energy } & \multirow[b]{2}{*}{ Tot:여 } \\
\hline & conl & 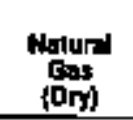 & Cnde & $\begin{array}{c}\text { Notumed } \\
\text { Gins } \\
\text { Pingit } \\
\text { Liquids }\end{array}$ & $\begin{array}{l}\text { Totil } \\
\text { Fot:il } \\
\text { Fuols }\end{array}$ & & & $\begin{array}{l}\text { Conventored } \\
\text { hydronisetrio } \\
\text { Poumer }\end{array}$ & $\begin{array}{c}\text { Govihermul } \\
\text { Enwigy }\end{array}$ & B Elotuals * & $\begin{array}{l}\text { Solar } \\
\text { Enorgy }\end{array}$ & $\begin{array}{c}\text { Wind } \\
\text { Entergy }\end{array}$ & $\begin{array}{c}\text { Toital } \\
\text { Renewrable } \\
\text { Endirgy }\end{array}$ & \\
\hline 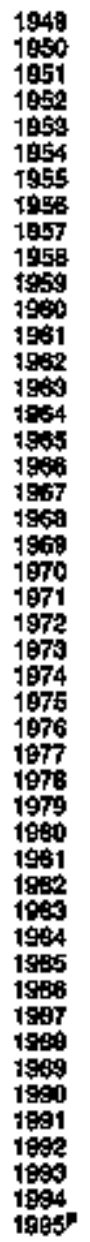 & 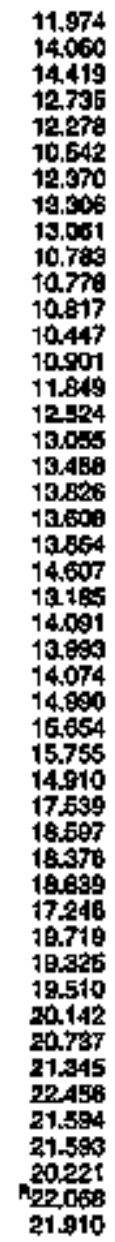 & 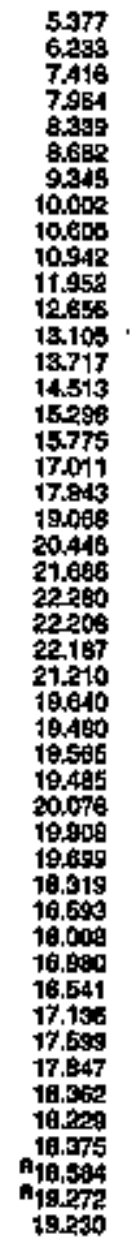 & 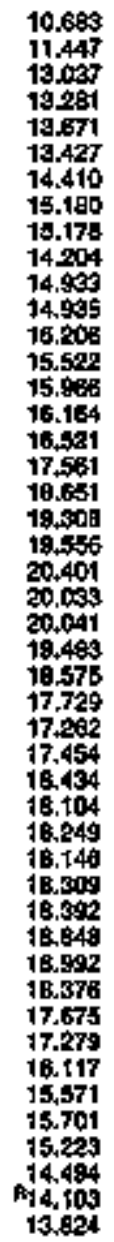 & 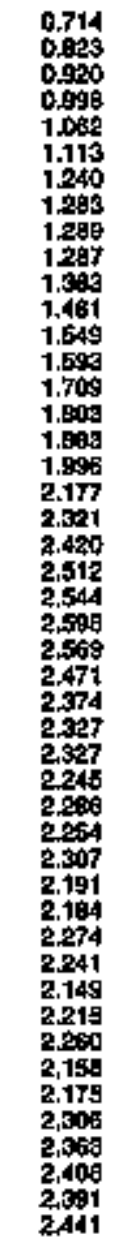 & 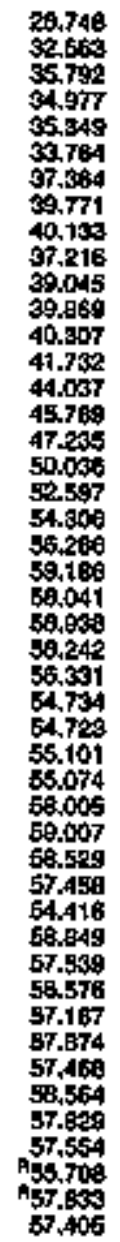 & 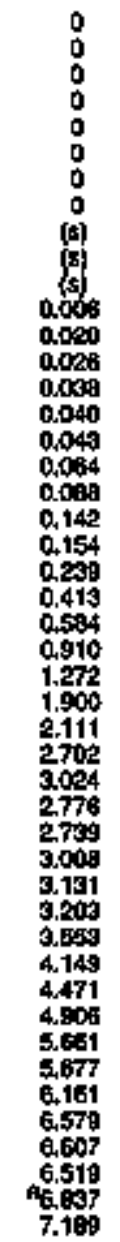 & 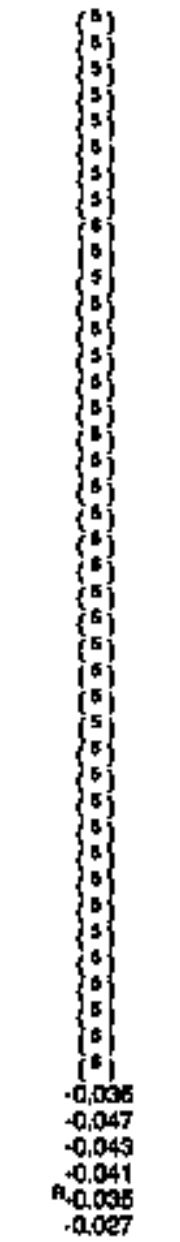 & 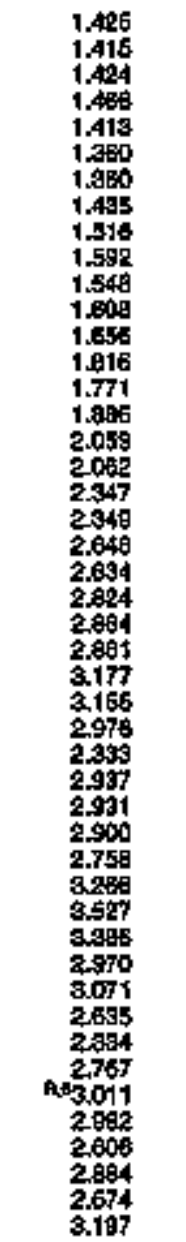 & 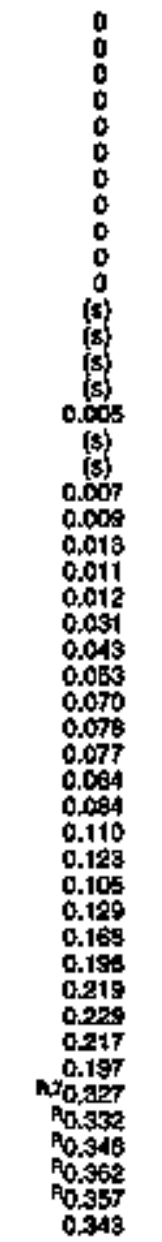 & 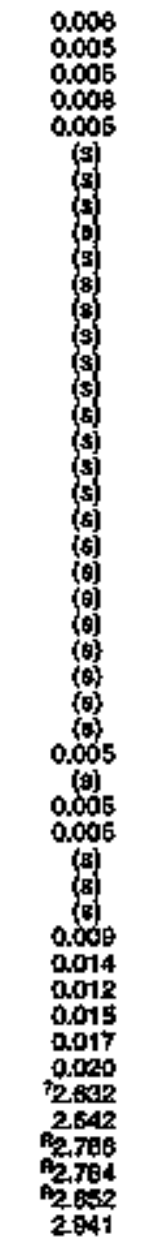 & $\begin{array}{l}0 \\
0 \\
0 \\
0 \\
0 \\
0 \\
0 \\
0 \\
0 \\
0 \\
0 \\
0 \\
0 \\
0 \\
0 \\
0 \\
0 \\
0 \\
0 \\
0 \\
0 \\
0 \\
0 \\
0 \\
0 \\
0 \\
0 \\
0 \\
0 \\
0 \\
0 \\
0 \\
0 \\
0 \\
0 \\
0 \\
0 \\
0 \\
0 \\
0 \\
0 \\
0.067 \\
0.069 \\
0.060 \\
0.060 \\
0.060 \\
0.07\end{array}$ & 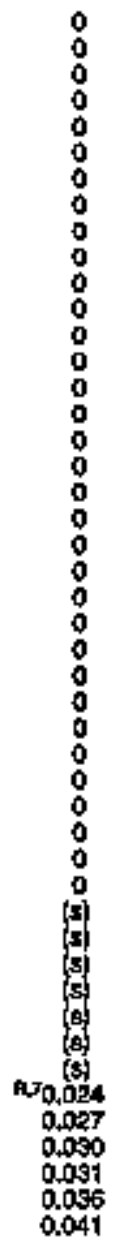 & 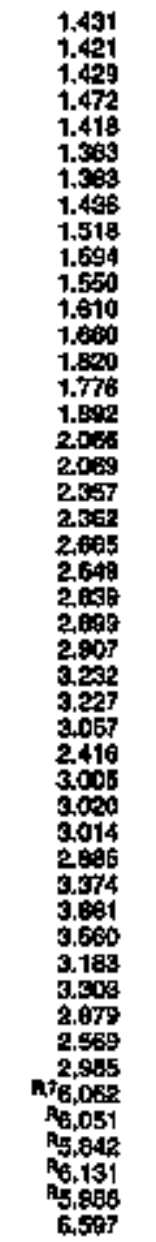 & 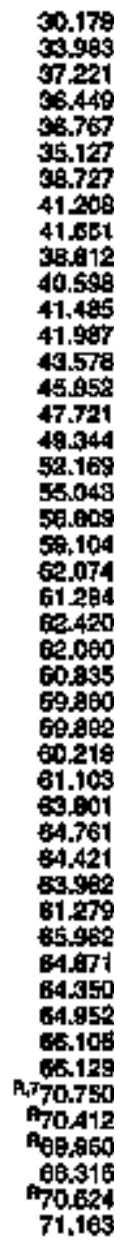 \\
\hline
\end{tabular}

1 helutes levas condensila.

2 Sat Nole 1 al ind of sodion.

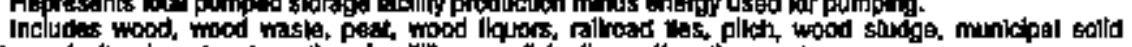

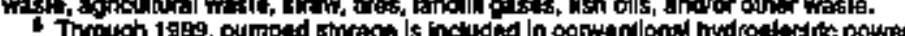

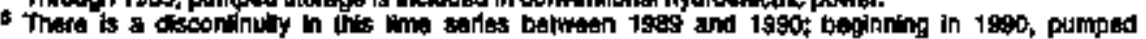

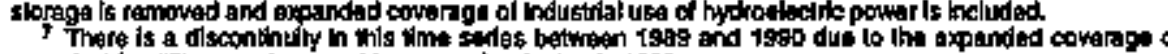

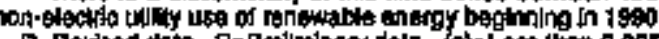

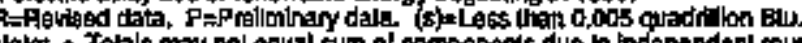

Bou 0 To

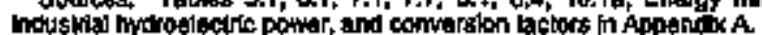




\section{Figure 1.3 Energy Consumption by Source}

Production and Consumption, 1949-1995

$100-$
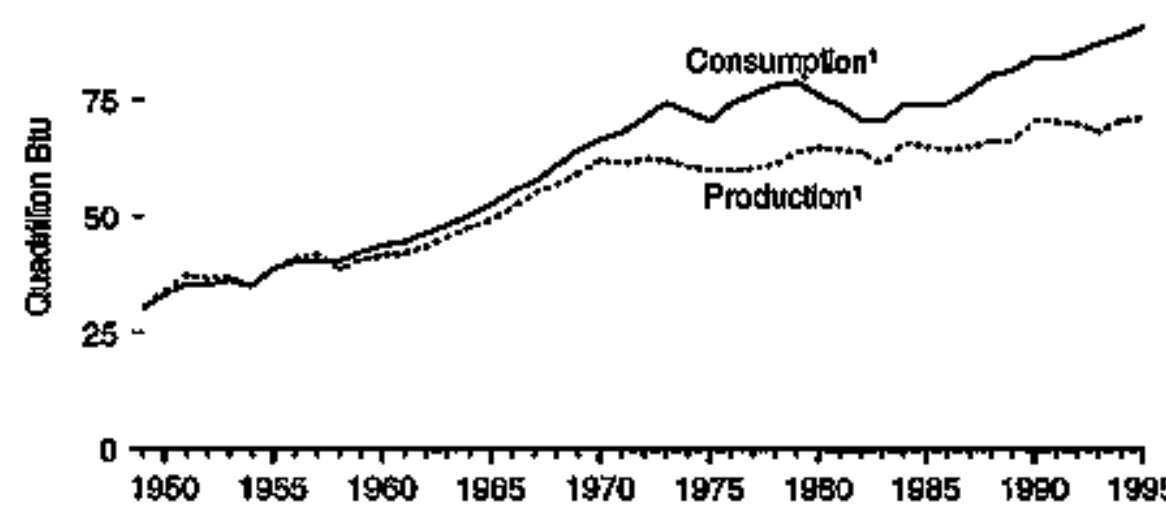

\section{By Sourco, 1995}

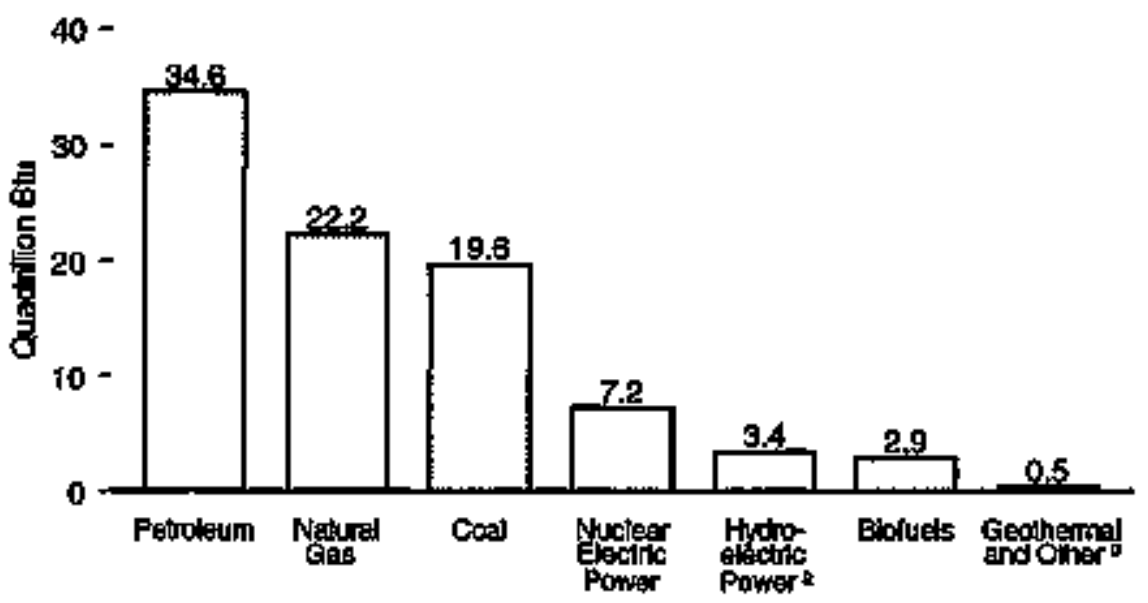

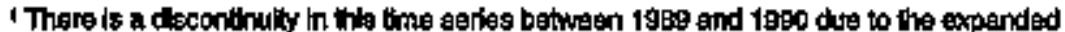

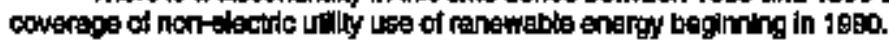

2 Conwantional and pumped-storage mydrostectric power.
By hajor Solmce, 1949-1995

$40-$

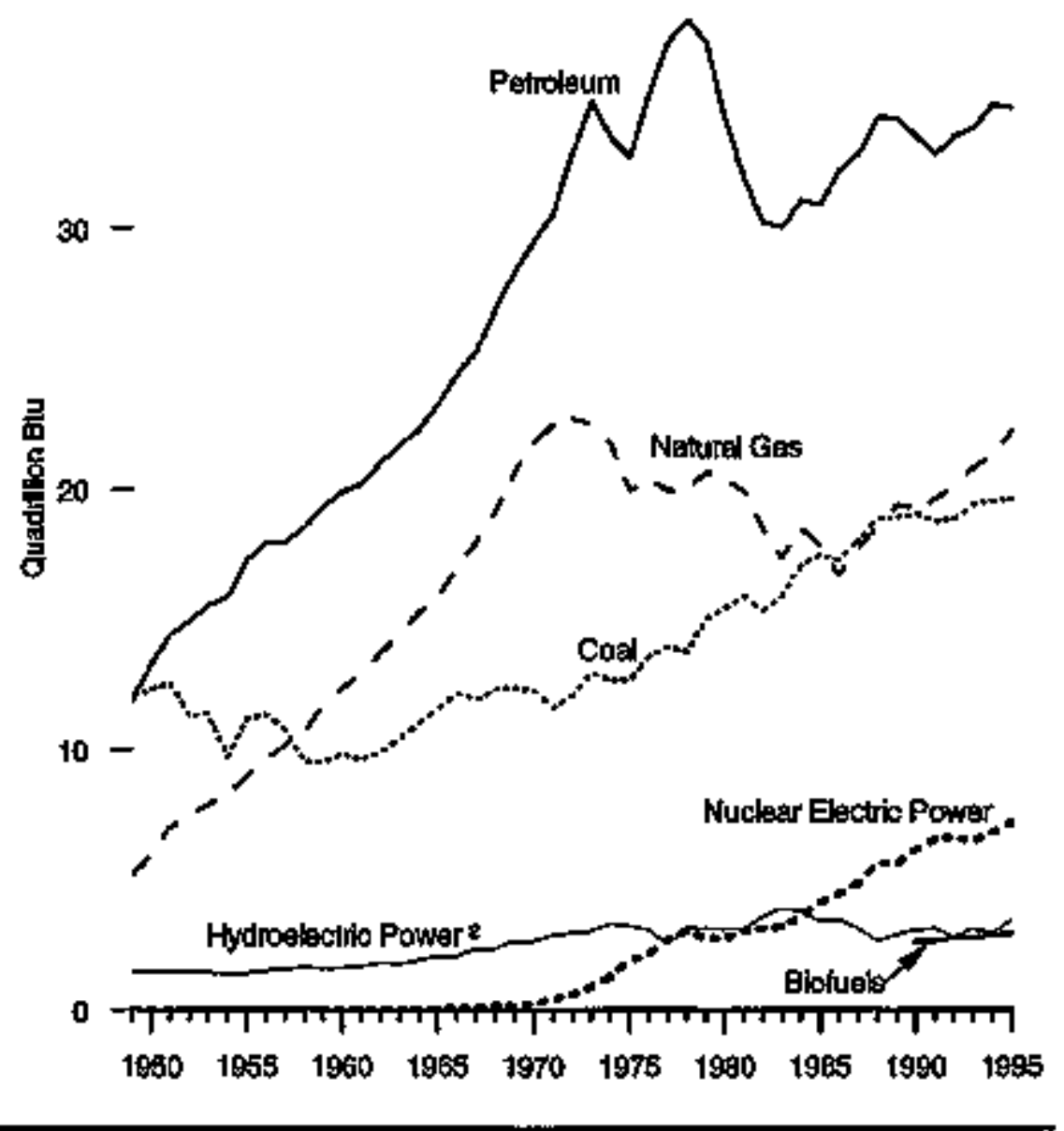

3 "Other" is soler energy and whot energy.

Noler Because wertical sceles difier, graphs shoutd nol be compared.

Souncess Thobles 12 and 1.3 . 
Table 1.3 Energy Consumption by Source, 1949-1995

(Quadirillion Btu)

\begin{tabular}{|c|c|c|c|c|c|c|c|c|c|c|c|c|c|c|}
\hline \multirow[b]{2}{*}{ ver } & \multicolumn{5}{|c|}{ Foasill Fuate } & \multirow[b]{2}{*}{$\begin{array}{l}\text { Nucloser } \\
\text { Electio } \\
\text { Powwir } \\
\end{array}$} & \multirow[b]{2}{*}{$\begin{array}{l}\text { Hydroolooutio } \\
\text { Pumped } \\
\text { Storages }\end{array}$} & \multicolumn{6}{|c|}{ Rentawabte Energy } & \multirow[b]{2}{*}{ Totel' } \\
\hline & Gonal & $\begin{array}{c}\text { Cosl Coks } \\
\text { Net } \\
\text { imports }\end{array}$ & $\begin{array}{c}\text { Metural } \\
\text { ses } 1 \\
\text {. }\end{array}$ & Petrotend 2 & $\begin{array}{l}\text { Totel } \\
\text { Fos:sll } \\
\text { Futs: }\end{array}$ & & & 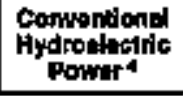 & $\begin{array}{l}\text { Geotheralal } \\
\text { Enterg: }\end{array}$ & Elotunats & $\begin{array}{l}\text { Solar } \\
\text { Energy }\end{array}$ & $\begin{array}{c}\text { Mind } \\
\text { Energy }\end{array}$ & $\begin{array}{c}\text { Total } \\
\text { Ronowablo } \\
\text { Energy }\end{array}$ & \\
\hline 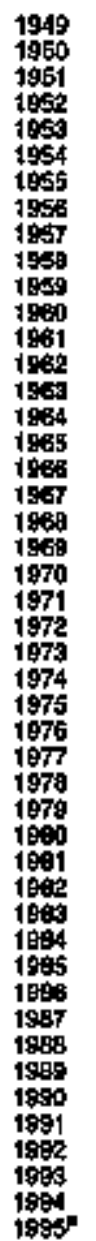 & 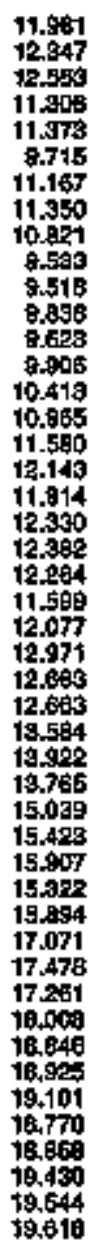 & 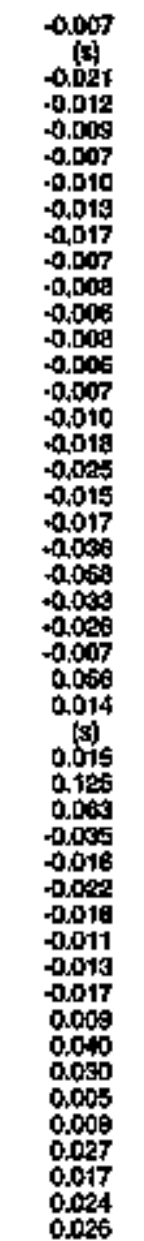 & 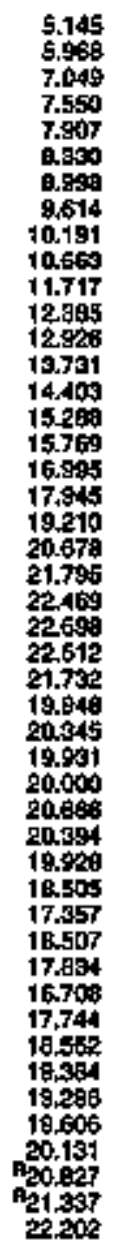 & 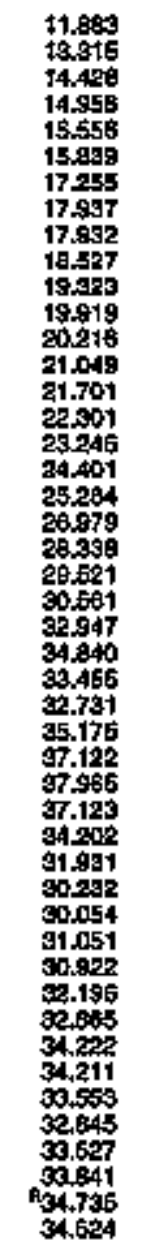 & 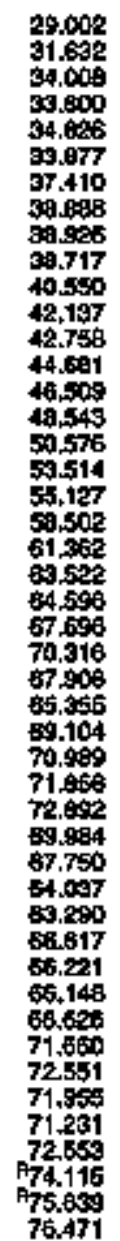 & 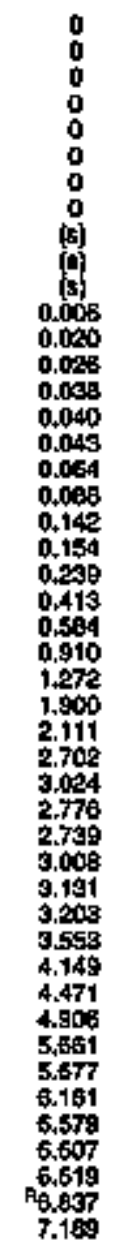 & 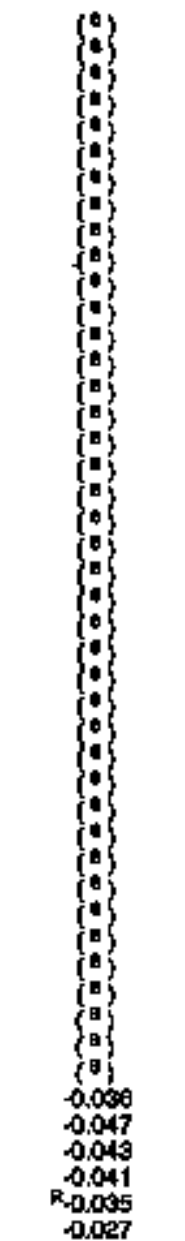 & 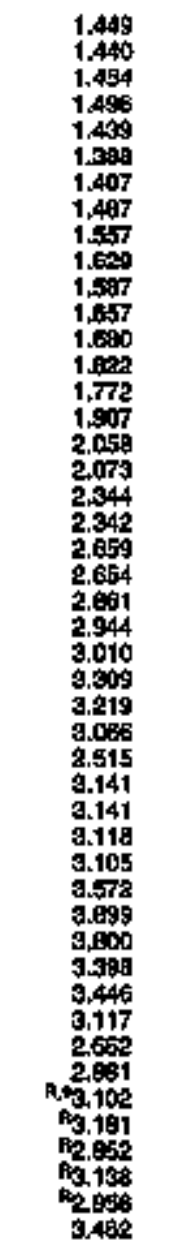 & 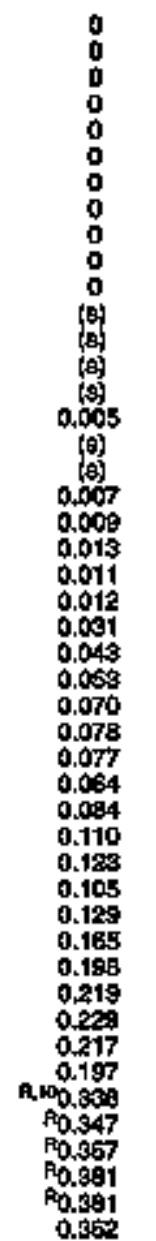 & 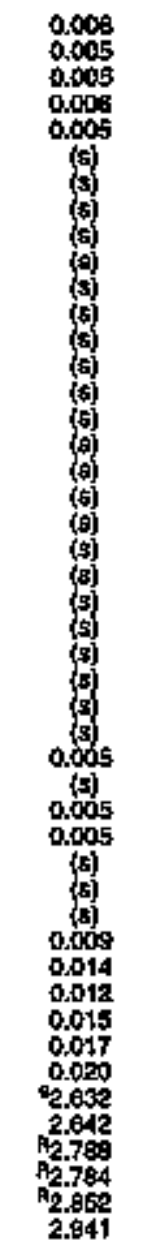 & $\begin{array}{c}0 \\
0 \\
0 \\
0 \\
0 \\
0 \\
0 \\
0 \\
0 \\
0 \\
0 \\
0 \\
0 \\
0 \\
0 \\
0 \\
0 \\
0 \\
0 \\
0 \\
0 \\
0 \\
0 \\
0 \\
0 \\
0 \\
0 \\
0 \\
0 \\
0 \\
0 \\
0 \\
0 \\
0 \\
0 \\
0 \\
0 \\
0 \\
0 \\
0 \\
0 \\
0067 \\
0.069 \\
0.060 \\
0.069 \\
0.060 \\
0.074\end{array}$ & 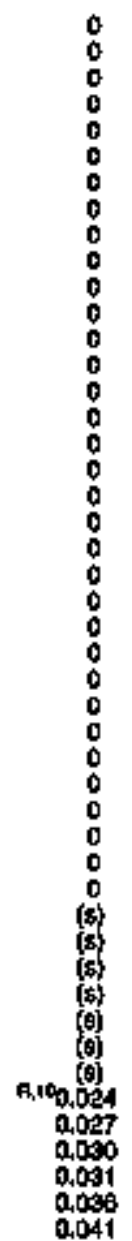 & 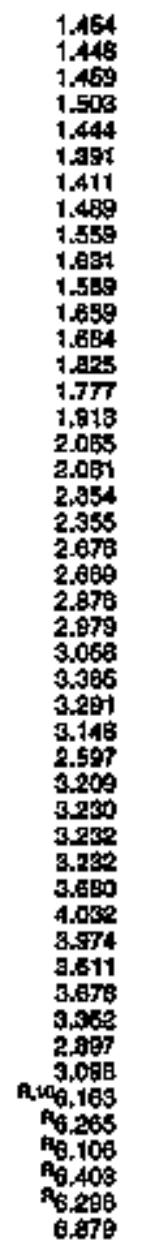 & 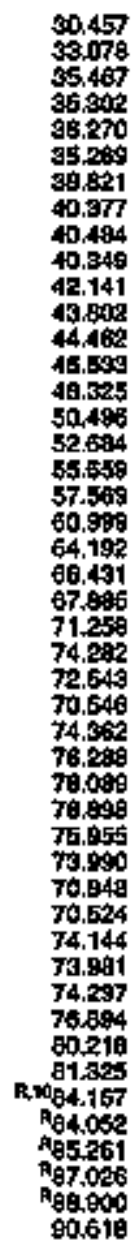 \\
\hline
\end{tabular}

1 hochudes supplemental gaseonos tuets.

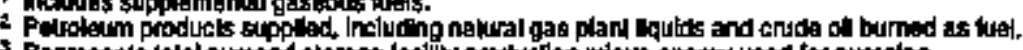

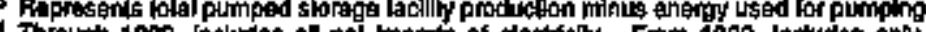

a the

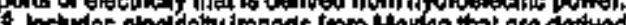

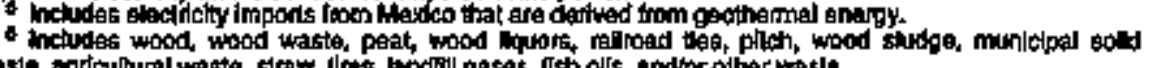

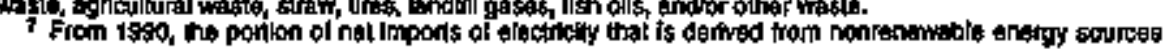

is theluded drecly' in the Tolad,

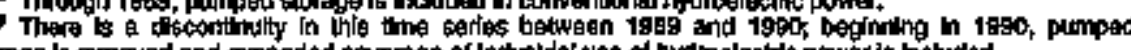

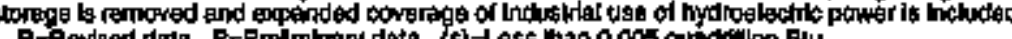

(a)

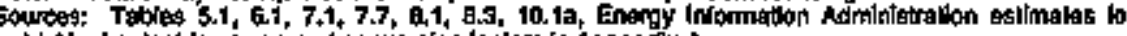

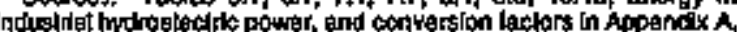


Figure 1.4 Energy Imports, Exports, and Net Imports, 1949-1995

\section{Energy Imports}

$25-$

急 10 -
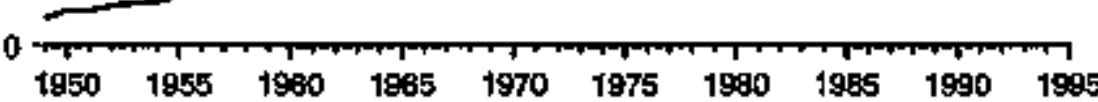

\section{Energy Exports}

$6-$

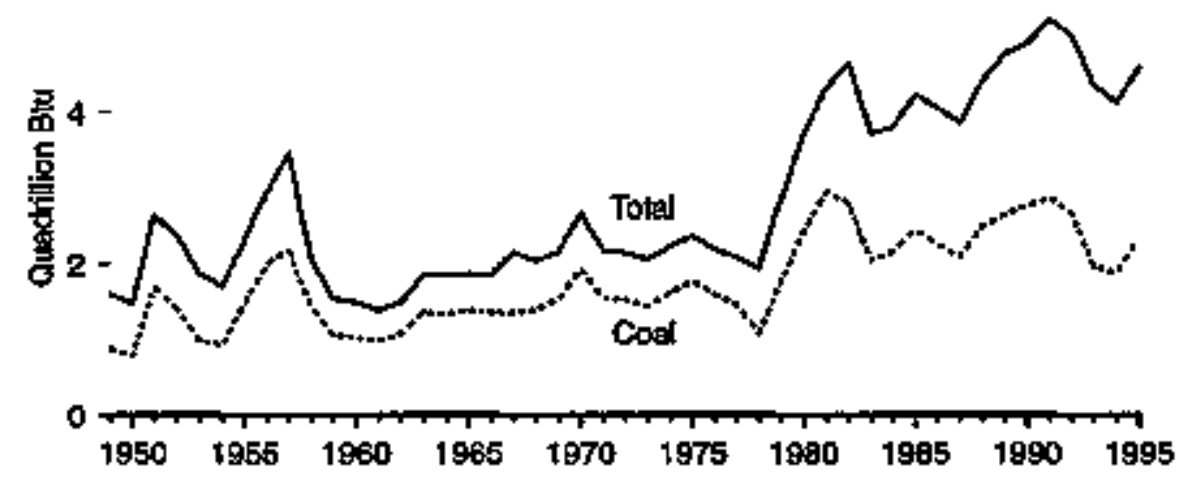

\section{Energy Net Imports}

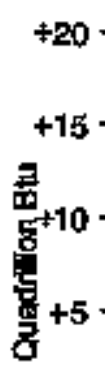

$+20-$
$+15-$
$+10-$
$+5-$

0

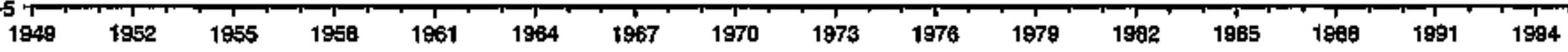

Noles! - Negal we not Imports are nel exporta, = Because vertical aceles differ, graphs

Source: Tatse 1.4 ahou'd not be compared. 
Table 1.4 Energy Imports, Exports, and Net Imports, 1949-1995 (Quadrillion B(t)

\begin{tabular}{|c|c|c|c|c|c|c|c|c|c|c|c|c|c|c|c|}
\hline \multirow[b]{2}{*}{ Year } & \multicolumn{5}{|c|}{ Inports. } & \multicolumn{5}{|c|}{ Exporty } & \multicolumn{5}{|c|}{ Not Imports 4} \\
\hline & Casi & $\begin{array}{c}\text { Natural } \\
\text { Gat } \\
(\mathrm{Dry})\end{array}$ & Peiroleunit 2 & OAhar ${ }^{3}$ & Totel & Cod & $\begin{array}{c}\text { Nabural } \\
\text { Gas } \\
\text { (Iny) }\end{array}$ & Patroleum & Othar ${ }^{3}$ & Told & $\cos$ & $\begin{array}{c}\text { Mature } \\
\text { Gas } \\
\text { (Dry) }\end{array}$ & Putroloum 2 & Other ${ }^{3}$ & Tolal \\
\hline 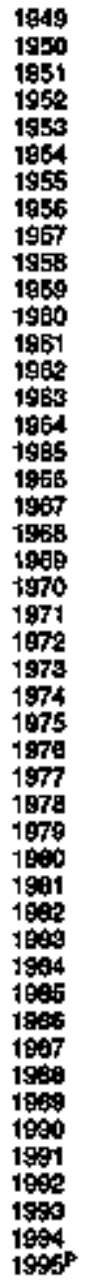 & 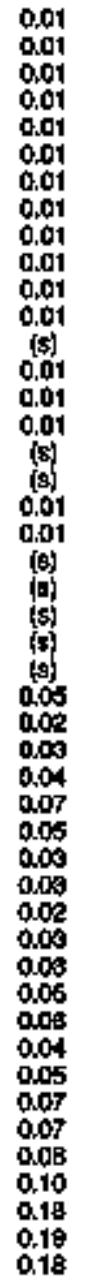 & 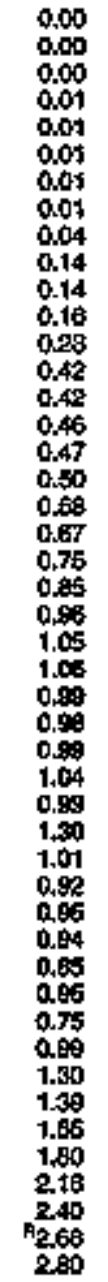 & 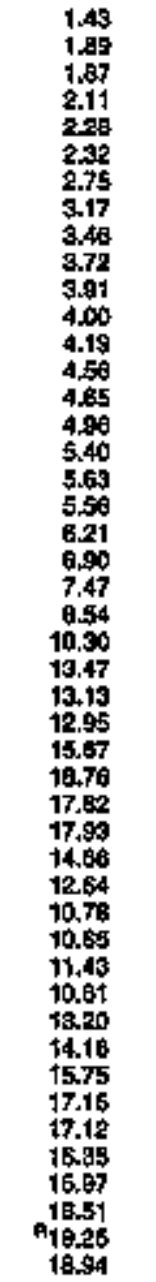 & 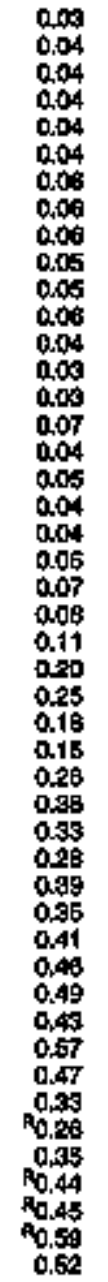 & 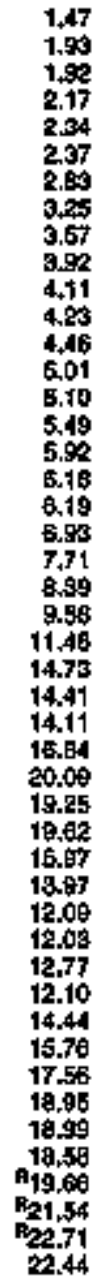 & 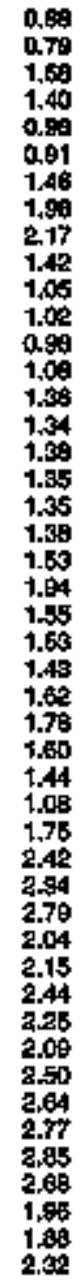 & $\begin{array}{l}0.03 \\
0.03 \\
0.03 \\
0.03 \\
0.03 \\
0.03 \\
0.03 \\
0.04 \\
0.04 \\
0.04 \\
0.03 \\
0.01 \\
0.01 \\
0.02 \\
0.02 \\
0.02 \\
0.03 \\
0.03 \\
0.08 \\
0.10 \\
0.05 \\
0.07 \\
0.08 \\
0.08 \\
0.08 \\
0.08 \\
0.07 \\
0.07 \\
0.06 \\
0.05 \\
0.06 \\
0.03 \\
0.06 \\
0.05 \\
0.08 \\
0.06 \\
0.06 \\
0.06 \\
0.06 \\
0.07 \\
0.11 \\
0.09 \\
0.49 \\
0.02 \\
0.14 \\
00.16 \\
0.16\end{array}$ & $\begin{array}{l}0.68 \\
0.64 \\
0.89 \\
0.91 \\
0.94 \\
0.75 \\
0.77 \\
0.91 \\
1.20 \\
0.58 \\
0.45 \\
0.48 \\
0.37 \\
0.38 \\
0.44 \\
0.43 \\
0.39 \\
0.41 \\
0.05 \\
0.45 \\
0.48 \\
0.55 \\
0.47 \\
0.47 \\
0.49 \\
0.40 \\
0.44 \\
0.47 \\
0.51 \\
0.77 \\
1.00 \\
1.18 \\
1.26 \\
1.73 \\
1.57 \\
1.54 \\
1.06 \\
1.67 \\
1.69 \\
1.74 \\
1.94 \\
1.02 \\
2.19 \\
2.01 \\
2.12 \\
1.99 \\
1.99\end{array}$ & $\begin{array}{l}0.02 \\
0.01 \\
0.03 \\
0.02 \\
0.02 \\
0.01 \\
0.02 \\
0.02 \\
0.03 \\
0.02 \\
0.02 \\
0.02 \\
0.02 \\
0.03 \\
0.03 \\
0.06 \\
0.06 \\
0.08 \\
0.06 \\
0.08 \\
0.08 \\
0.11 \\
0.07 \\
0.06 \\
0.08 \\
0.06 \\
0.08 \\
0.00 \\
0.06 \\
0.06 \\
0.00 \\
0.09 \\
0.08 \\
0.00 \\
0.05 \\
0.06 \\
0.00 \\
0.00 \\
0.00 \\
0.70 \\
0.10 \\
0.20 \\
0.11 \\
0.11 \\
0.13 \\
00.09 \\
0.10\end{array}$ & 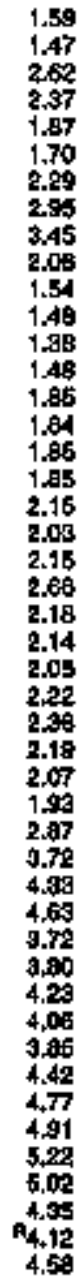 & 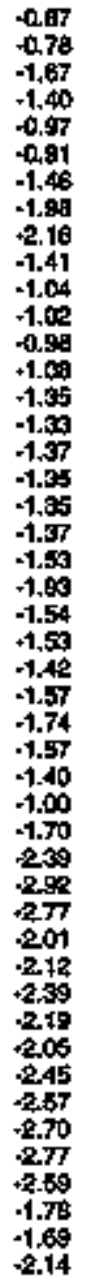 & 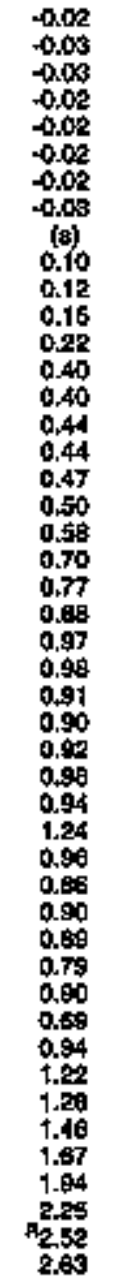 & 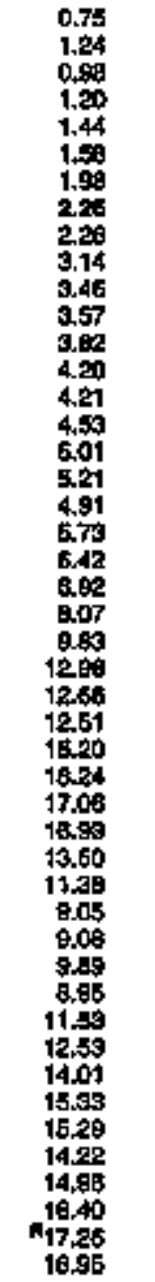 & 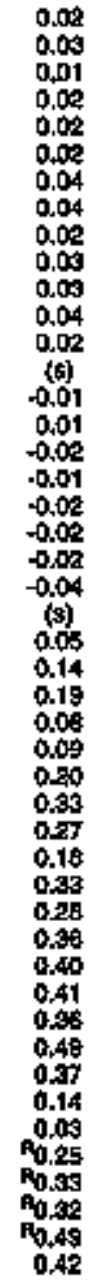 & 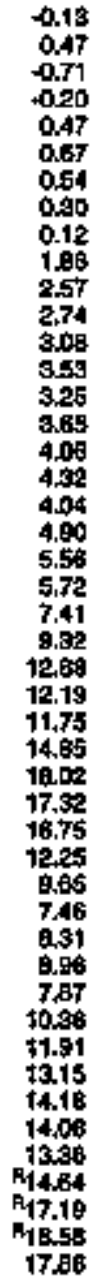 \\
\hline
\end{tabular}

I Net Importh = inponts minus axponts.

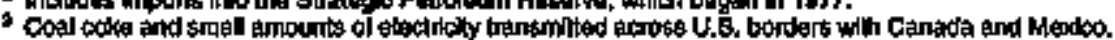

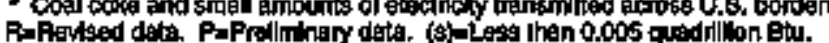

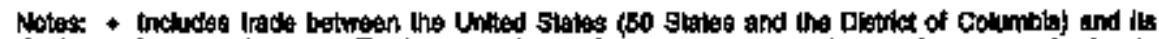

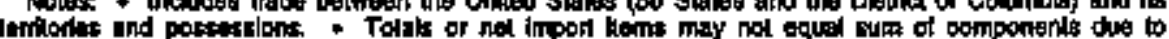

Sources: Tebles S.1, 6.5, 6.1, 7.1, 7.7, end 0.1, and converalan fectors in Appendix A. 


\section{Figure 1.5 Energy Consumption and Energy Consumption per Capita, 1949-1995}

\section{Energy Consumption}

$100-$

$90-$

$60-$

$70-$

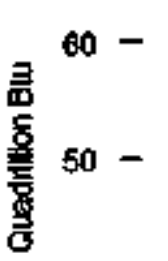

$40-$

3)

$20-$

$10-$

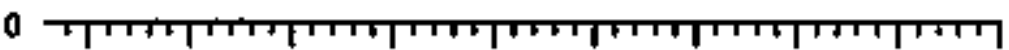

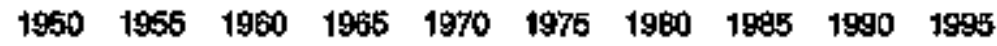

\section{Energy Consumption per Capita}

$400-$

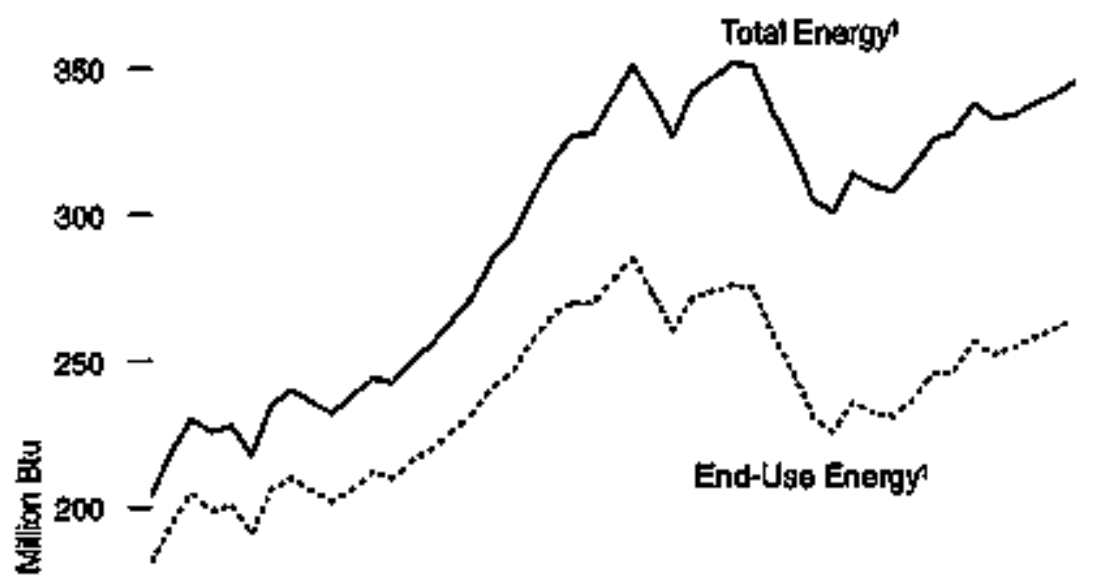

$160-$

$100-$

50-

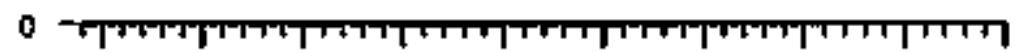
$\begin{array}{llllllllll}1950 & 1955 & 1960 & 1965 & 1970 & 1975 & 1980 & 1985 & 1990 & 1995\end{array}$

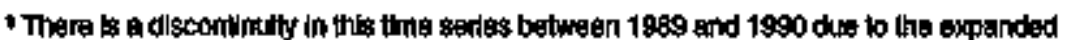

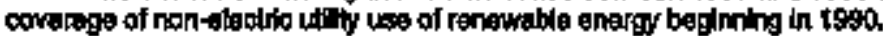

Source: Table 1.5. 
Table 1.5 Energy Consumption and Energy Consumption per Capita, 1949-1995

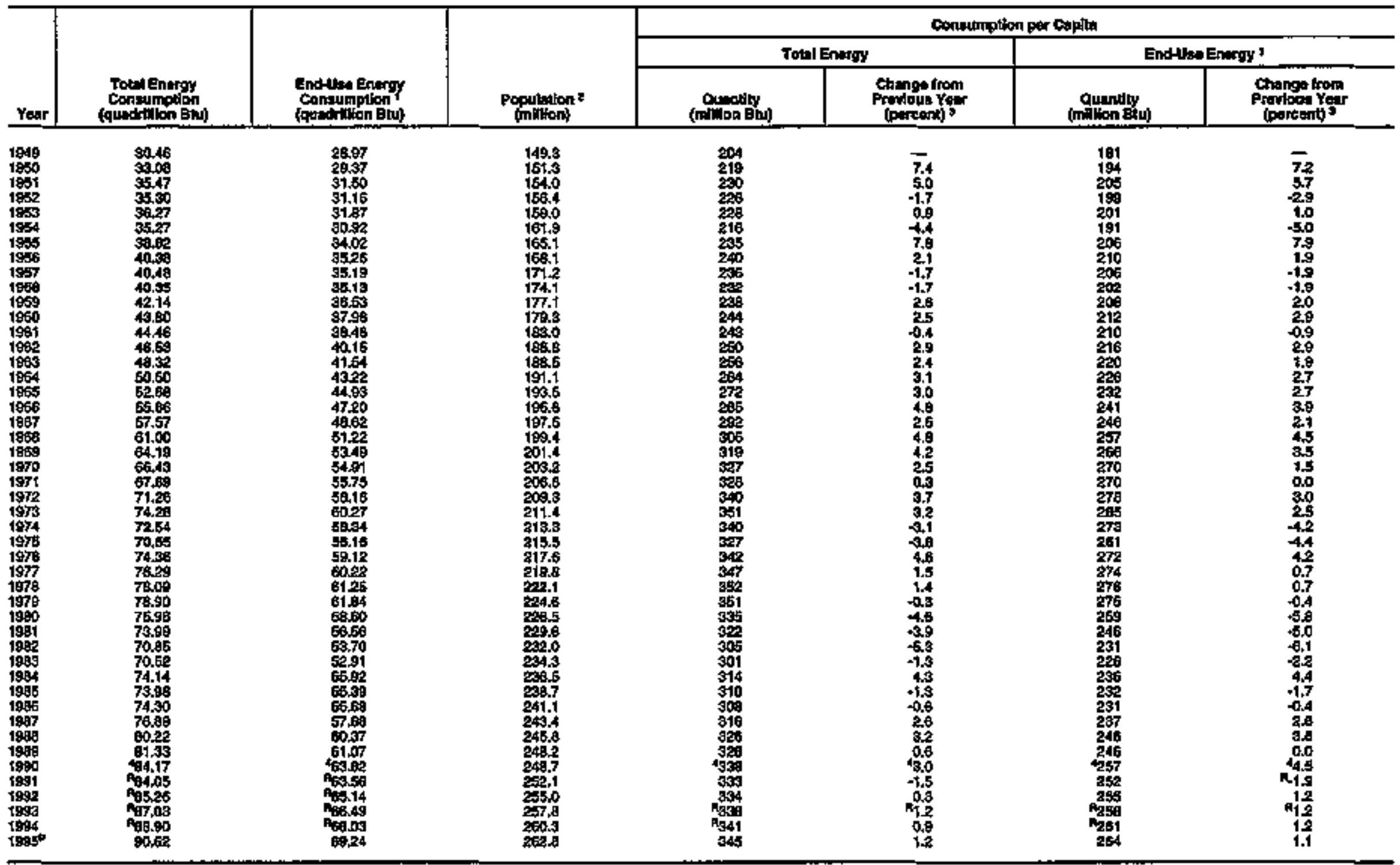

I Enduss energy conaumpalon is lotal anergy consumplon fose looses haured in the generalon,

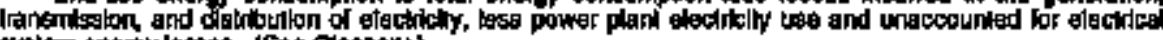

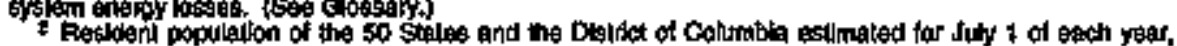

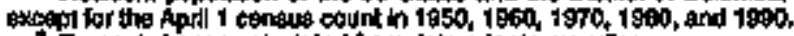

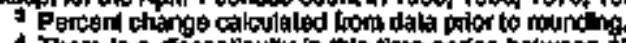

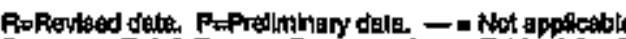

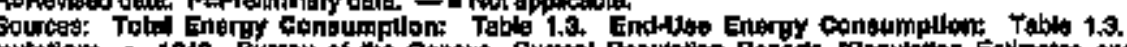

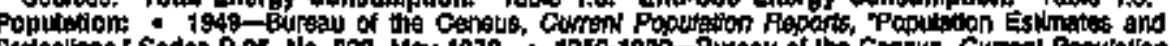

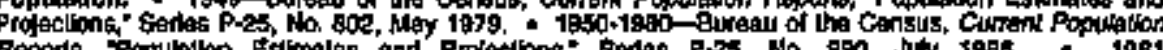
A

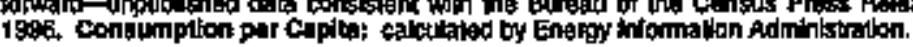




\section{Consumption}

12 -

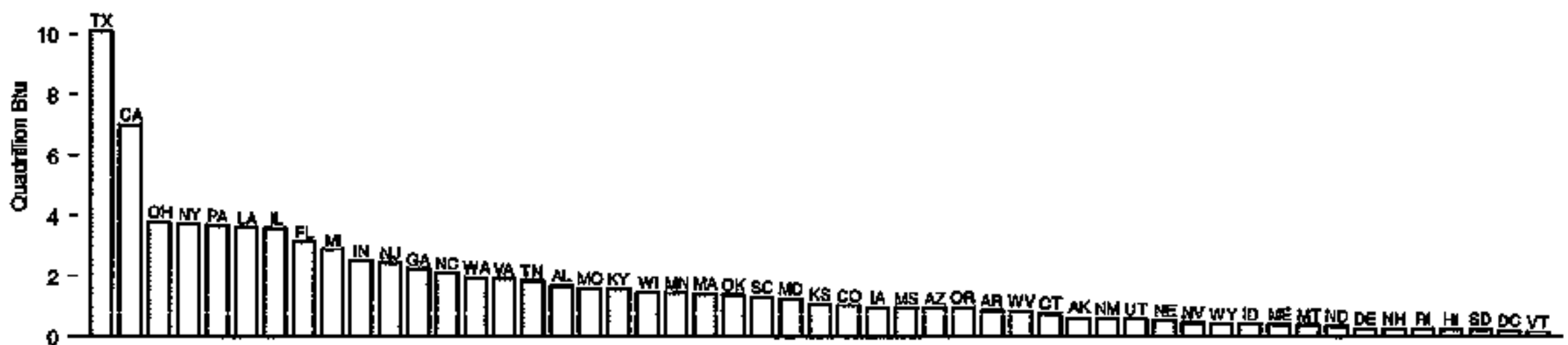

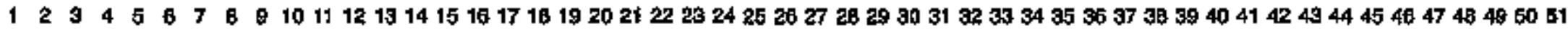
Consumption per Capita

Ranking by Slate

$$
1.2-
$$

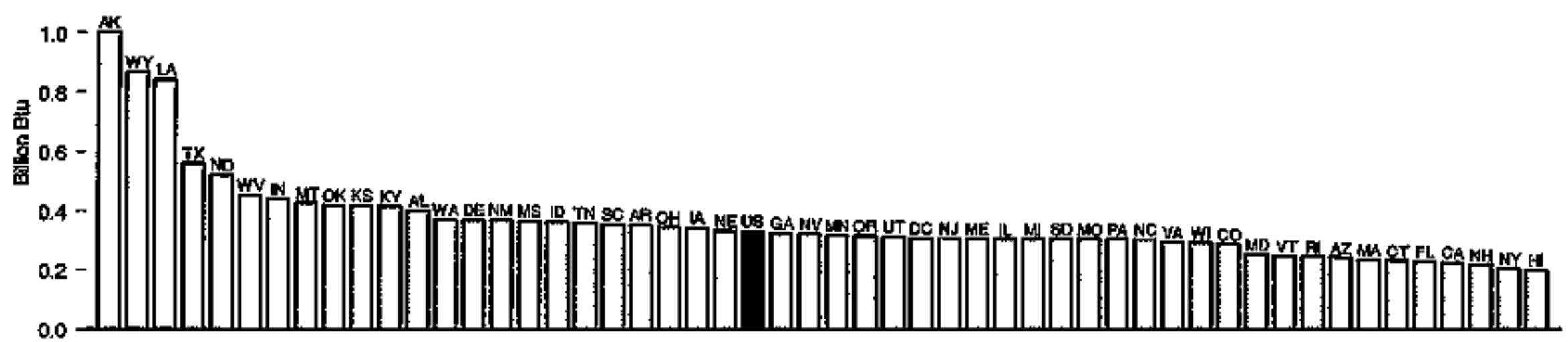

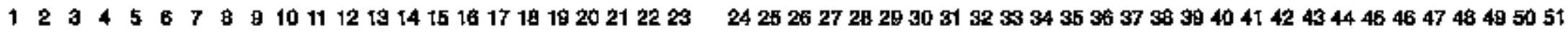
Panking by Slate and U.S. Average 
Table 1.6 Energy Consumption and Consumption per Capita by State, 1993

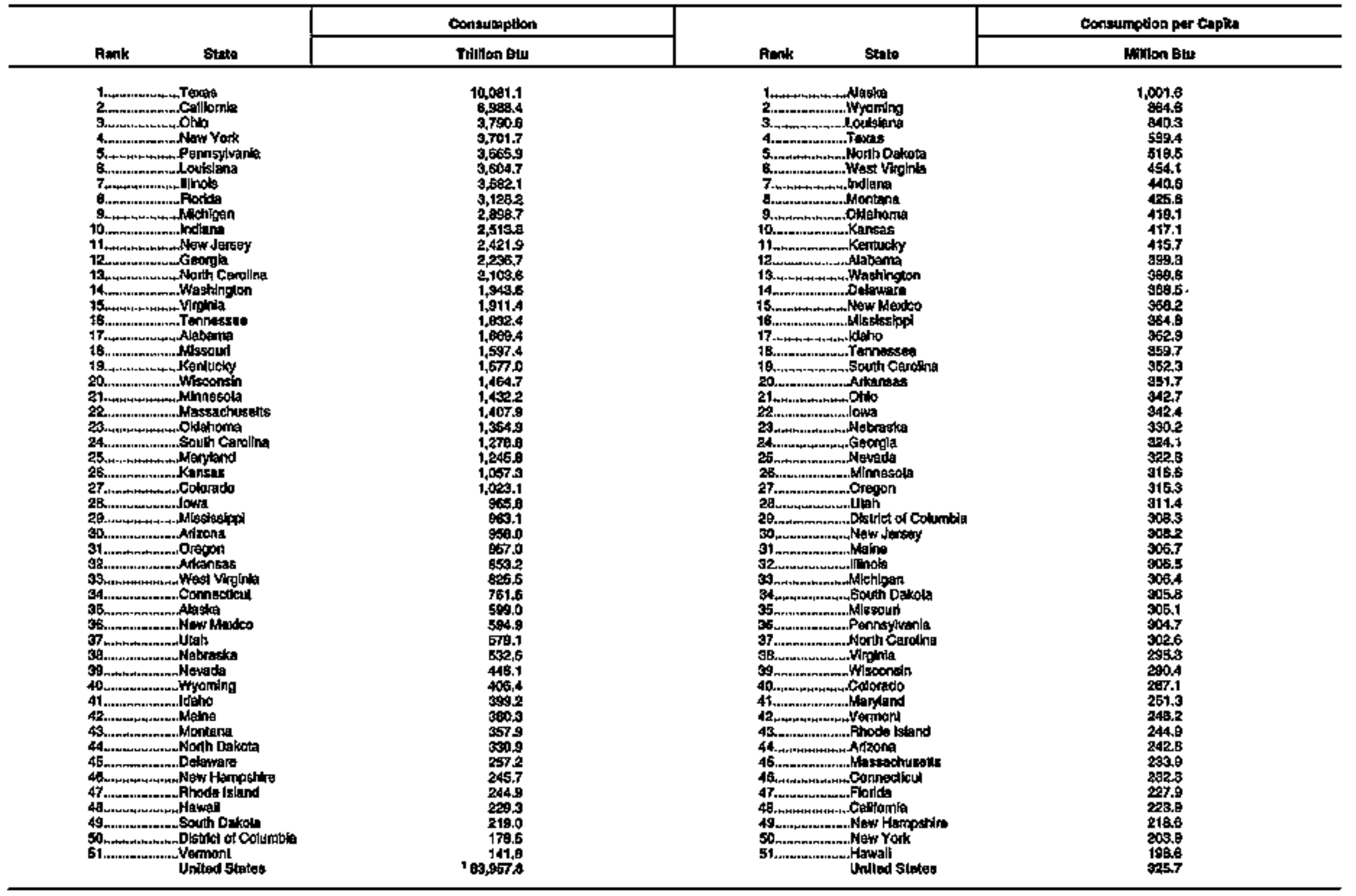

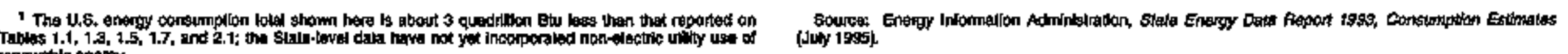

rengewatole ginengy. 
Enargy Gonsumption, 1949-1995

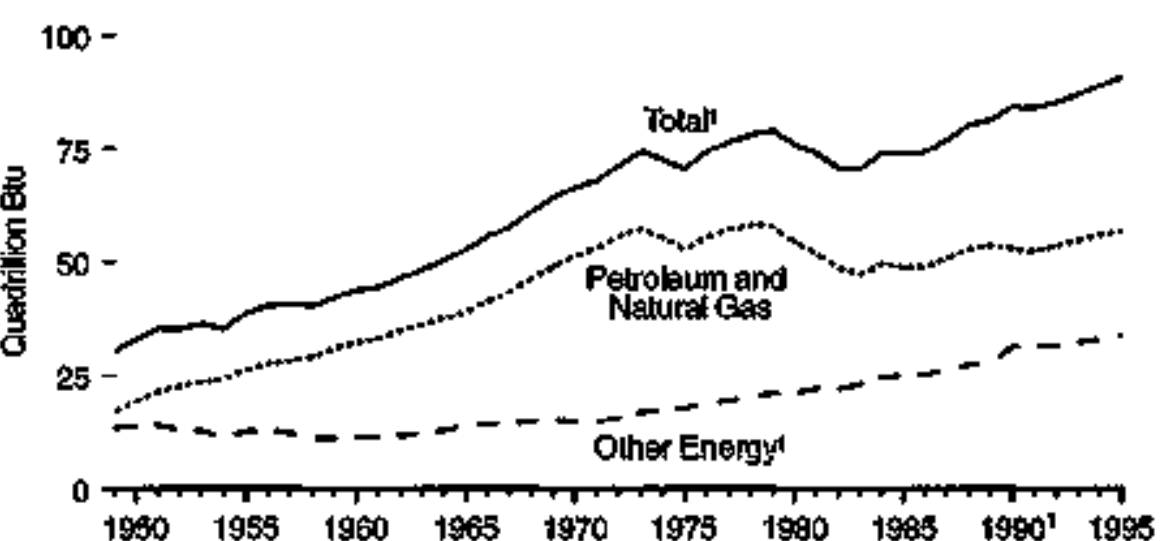

Energy Consumption per Dollar of Gross Domestic Product, 1959-1998

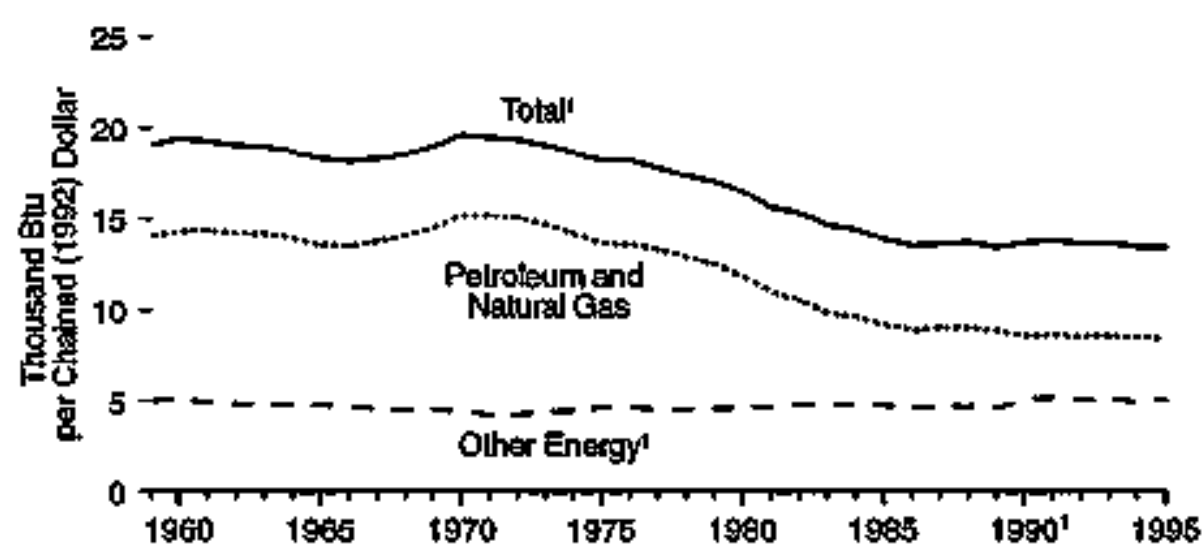

Total Energy Consumption per Dollar of Gross Domestio Product, Change from Previous Year, 1960-1995

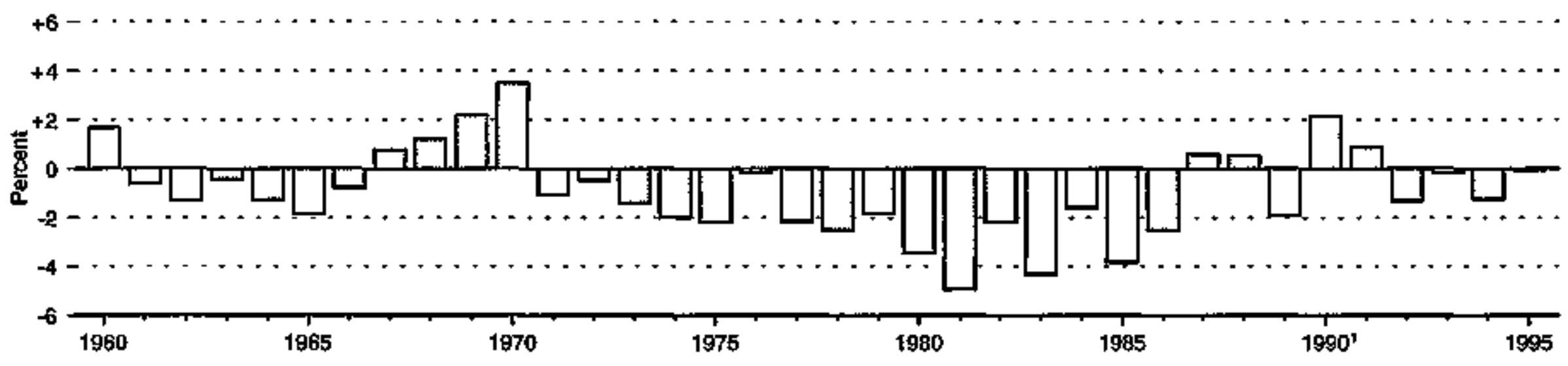

1 There is a decontinuly in this time serles between 1989 and 1990 due to the expanded coveraye of non-etedilc utithy use of renewable anergy beginiting in 1980.

Sourres: Table 1.7. 
Table 1.7 Energy Consumption per Dollar of Gross Domestic Product, 1949-1995

\begin{tabular}{|c|c|c|c|c|c|c|c|c|}
\hline \multirow[b]{3}{*}{ Yoar } & \multicolumn{3}{|c|}{ Enorgy Contumption } & \multirow{3}{*}{ 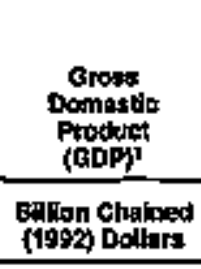 } & \multicolumn{4}{|c|}{ Energy Consuanplion par Dolatur of GDP } \\
\hline & $\begin{array}{c}\text { Petroleum } \\
\text { and } \\
\text { Metirdal ans }\end{array}$ & $\begin{array}{c}\text { OAther } \\
\text { Energy }\end{array}$ & Total & & 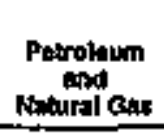 & $\begin{array}{c}\text { Othas } \\
\text { Envingy }\end{array}$ & Totat & 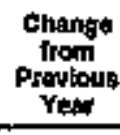 \\
\hline & \multicolumn{3}{|c|}{ Dusdriation Bu } & & \multicolumn{3}{|c|}{ Thousund atu par Chained (1992) Dollur } & Percent 2 \\
\hline 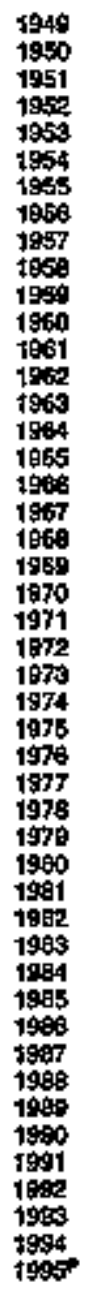 & 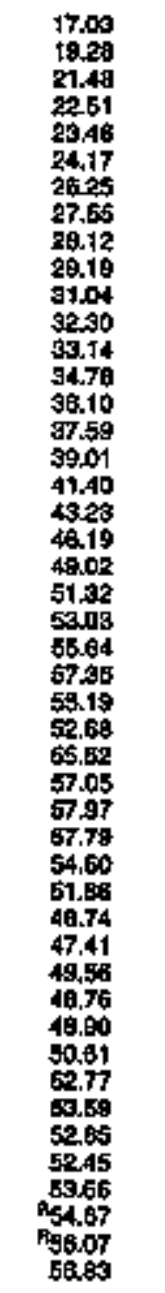 & 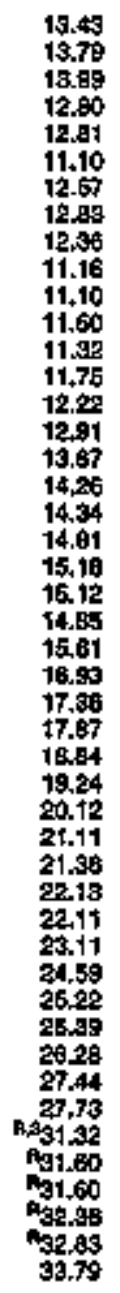 & 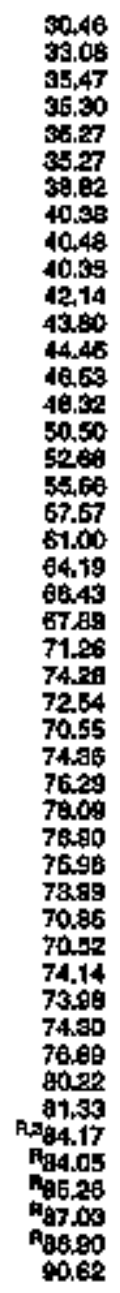 & 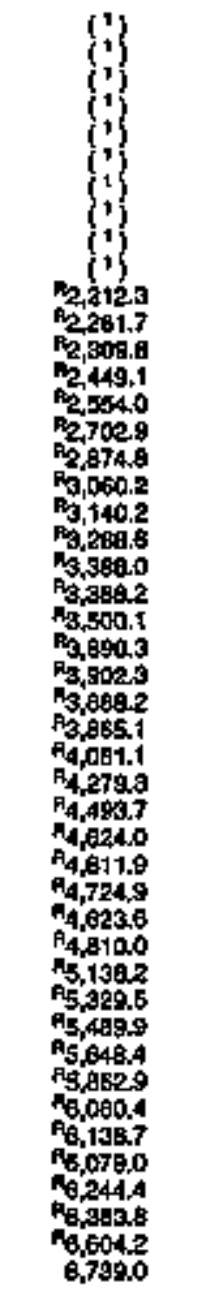 & 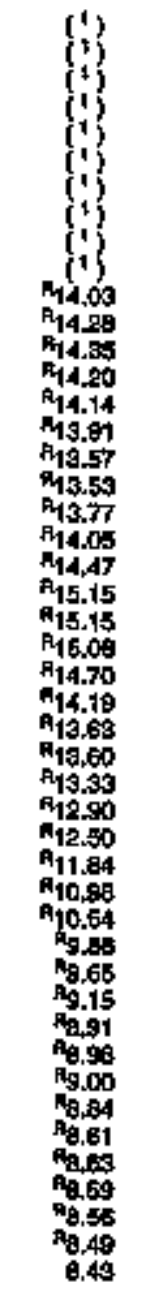 & 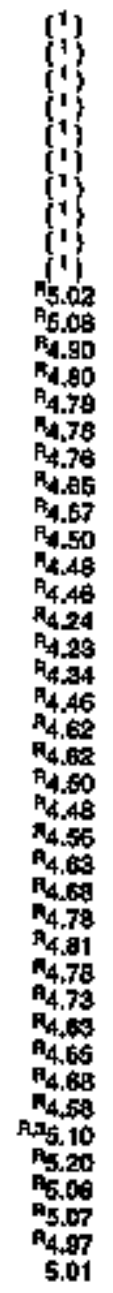 & 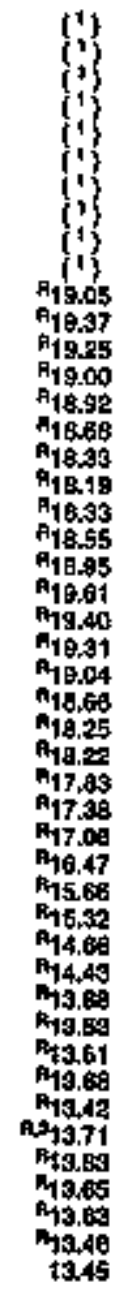 & 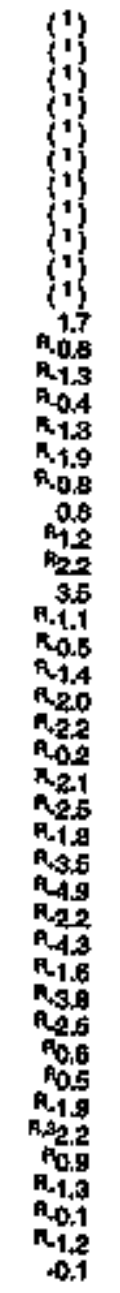 \\
\hline
\end{tabular}

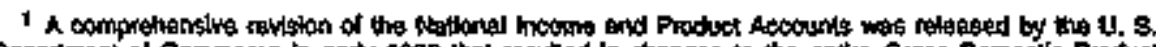

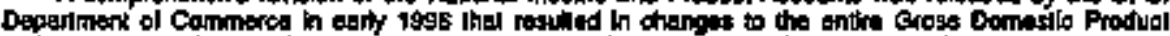

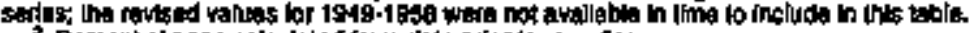

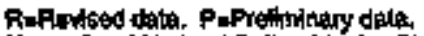

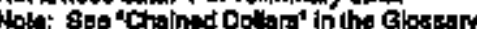

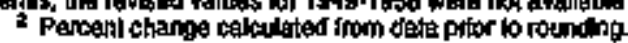


Figure 1.8 Heating Degree-Days for Heating Season, by Month, 1949-1996

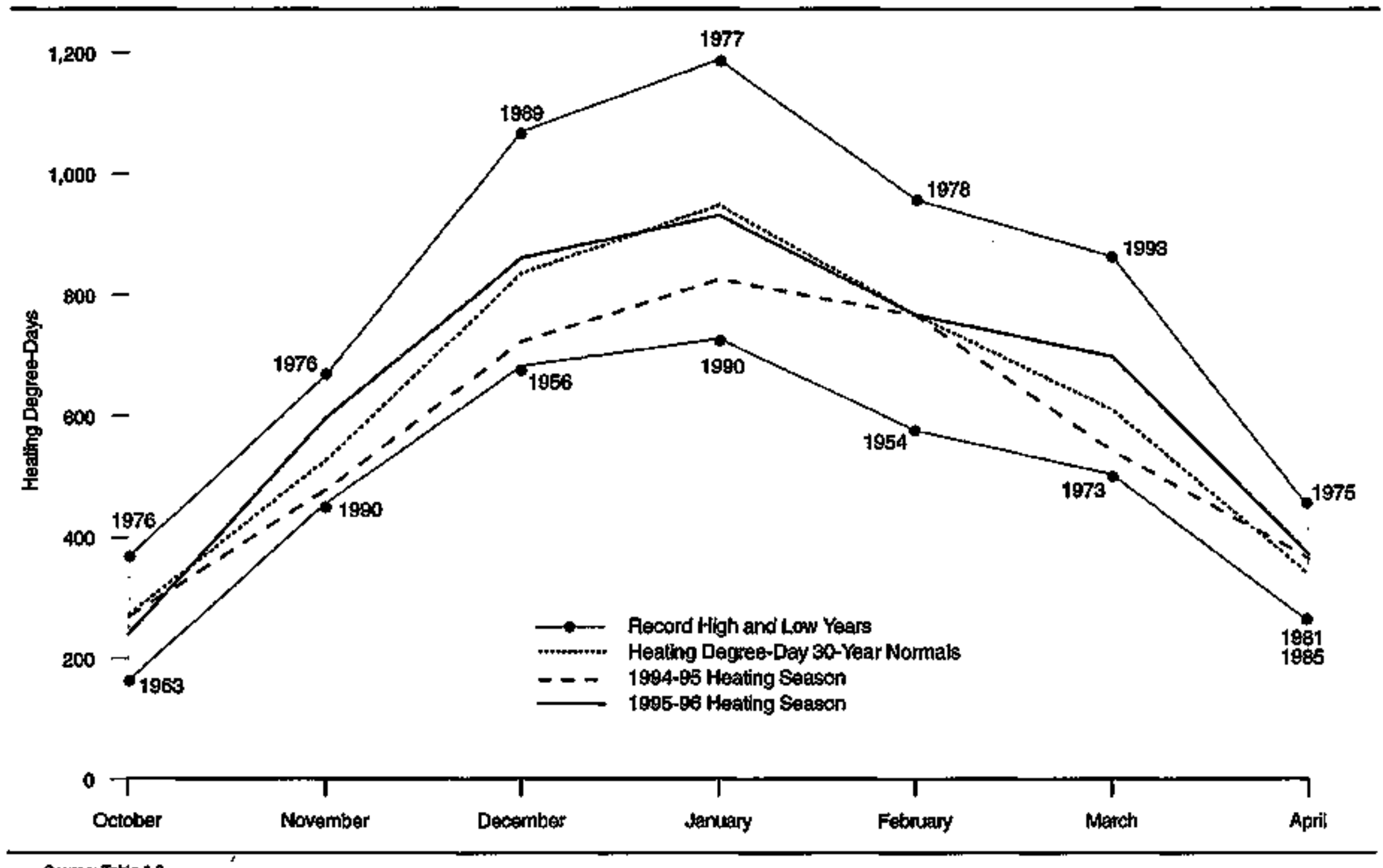

Sourcer Teble t,B. 
Table 1.8 Heating Degree-Days by Month, 1949-1996

\begin{tabular}{|c|c|c|c|c|c|c|c|c|c|c|c|c|c|}
\hline Year & Junuary & Fibruacy & Harch & April & $\mathrm{May}$ & pune & July & Auxgust & septersber & Delober & Movinger & Dreamber & Toted \\
\hline 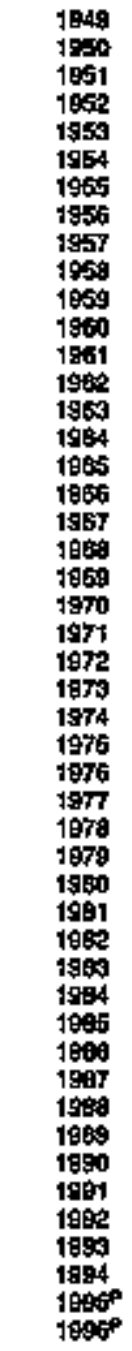 & 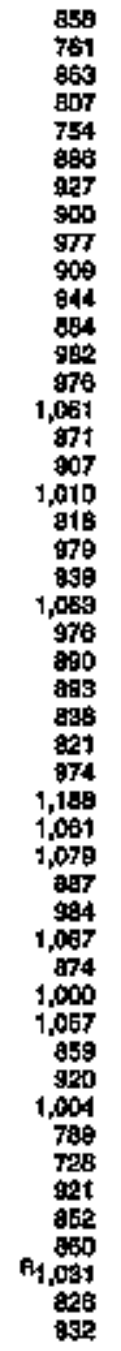 & 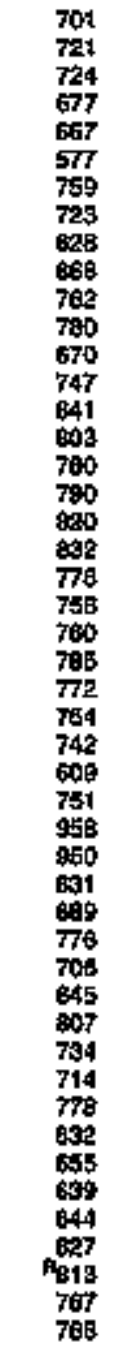 & 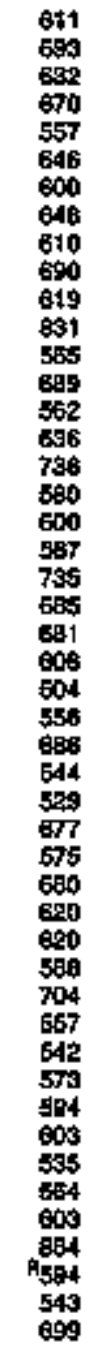 & 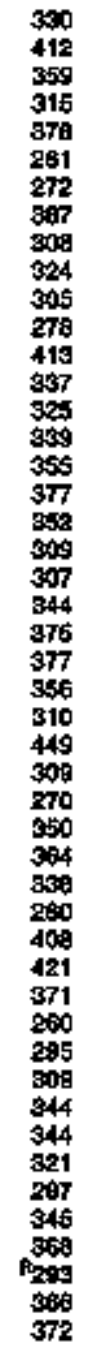 & 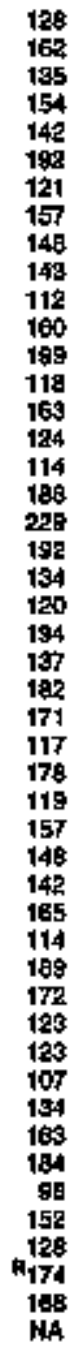 & 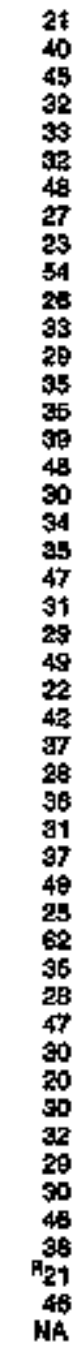 & $\begin{array}{r}7 \\
11 \\
8 \\
5 \\
5 \\
8 \\
4 \\
10 \\
6 \\
7 \\
4 \\
7 \\
5 \\
14 \\
8 \\
5 \\
11 \\
6 \\
8 \\
5 \\
7 \\
1 \\
10 \\
7 \\
6 \\
6 \\
5 \\
8 \\
6 \\
7 \\
8 \\
5 \\
5 \\
7 \\
6 \\
7 \\
5 \\
9 \\
6 \\
8 \\
5 \\
6 \\
6 \\
14 \\
11 \\
66 \\
13 \\
149\end{array}$ & $\begin{array}{r}9 \\
18 \\
17 \\
11 \\
11 \\
11 \\
6 \\
14 \\
16 \\
8 \\
6 \\
11 \\
7 \\
19 \\
18 \\
22 \\
14 \\
14 \\
17 \\
14 \\
9 \\
8 \\
12 \\
12 \\
9 \\
13 \\
13 \\
19 \\
13 \\
11 \\
15 \\
10 \\
11 \\
19 \\
5 \\
7 \\
17 \\
16 \\
13 \\
5 \\
14 \\
10 \\
7 \\
24 \\
99 \\
18 \\
11 \\
11 A\end{array}$ & 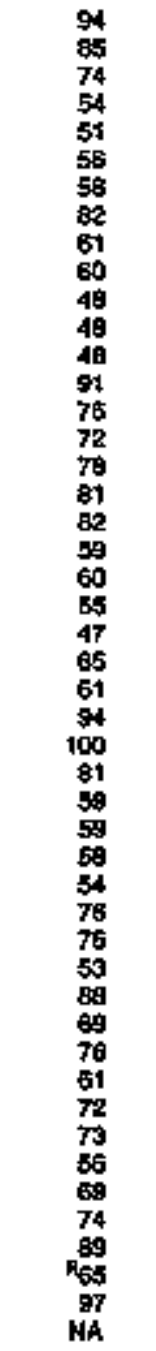 & 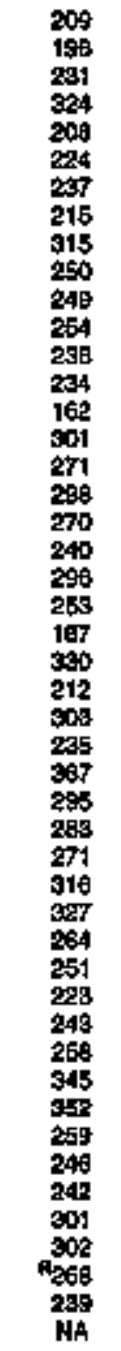 & 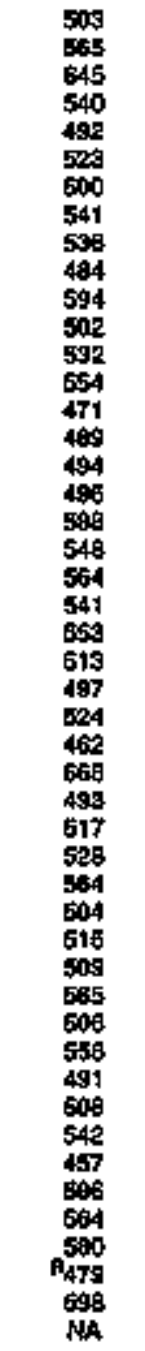 & 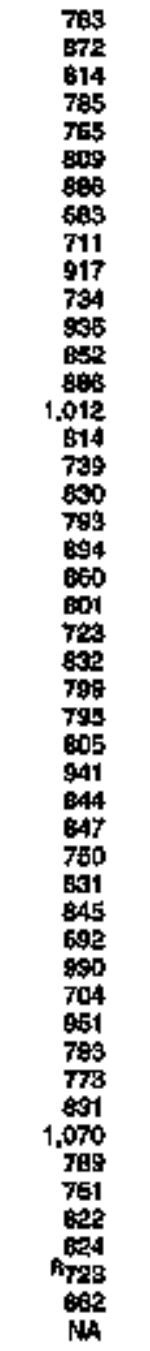 & 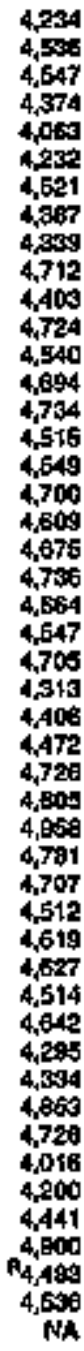 \\
\hline Mormakr & 948 & 789 & 611 & 3339 & 150 & 36 & 7 & 13 & 69 & 271 & 5289 & 838 & 4.576 \\
\hline
\end{tabular}

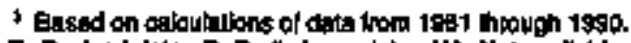

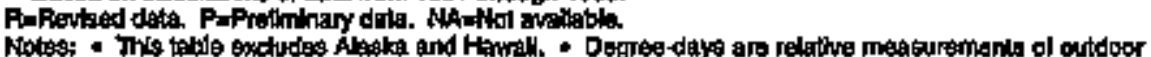

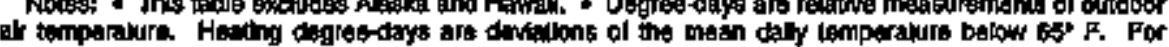

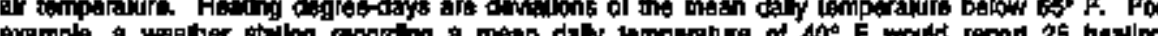

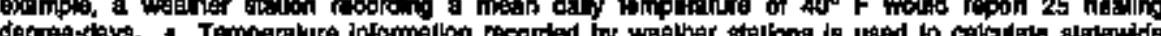

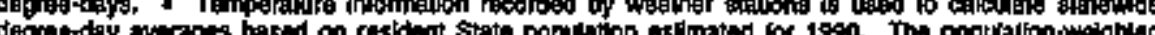

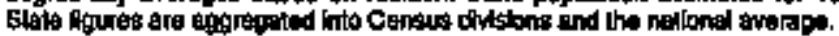

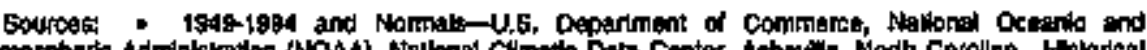

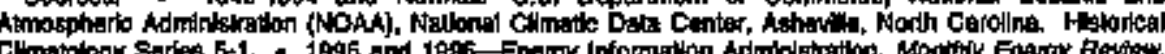

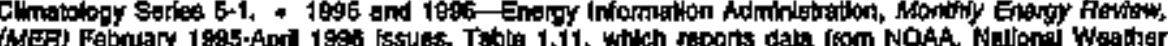

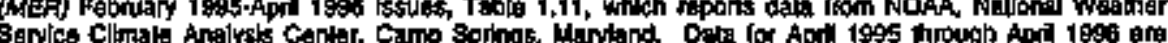

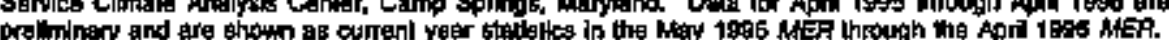

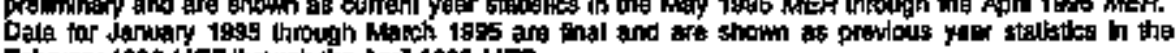

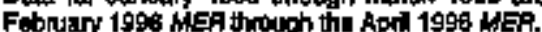




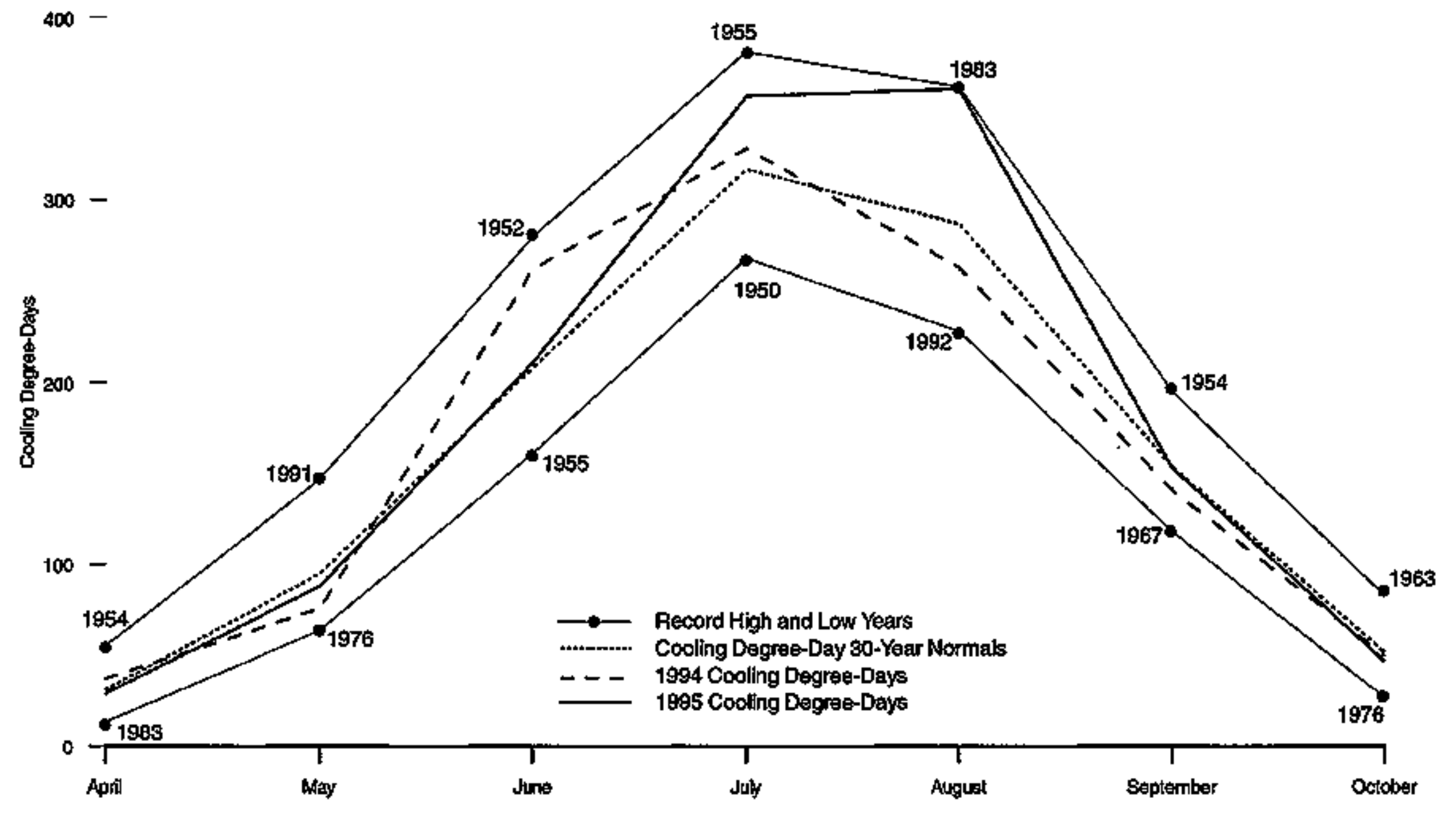

Source: Tabila 1.9 
Table 1.9 Cooling Degree-Days by Month, 1949-1996

\begin{tabular}{|c|c|c|c|c|c|c|c|c|c|c|c|c|c|}
\hline Yonr & Jonuary & Fobruny & March & Aprid & thy & Wino & Juby & Auqugt & Soptomber & Oetpotir & Novemntber & Despamber & T螘 \\
\hline 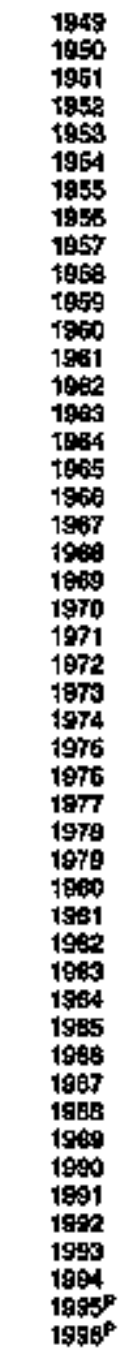 & 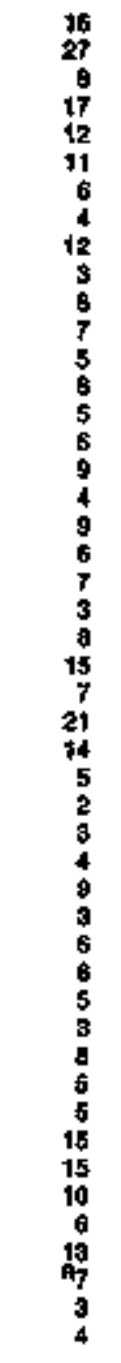 & $\begin{array}{r}14 \\
12 \\
5 \\
8 \\
8 \\
12 \\
7 \\
12 \\
17 \\
1 \\
12 \\
4 \\
9 \\
15 \\
5 \\
3 \\
7 \\
5 \\
5 \\
3 \\
4 \\
4 \\
7 \\
6 \\
3 \\
6 \\
11 \\
11 \\
5 \\
1 \\
4 \\
4 \\
6 \\
10 \\
5 \\
6 \\
5 \\
10 \\
7 \\
5 \\
7 \\
14 \\
9 \\
10 \\
5 \\
89 \\
5 \\
9\end{array}$ & $\begin{array}{r}14 \\
18 \\
15 \\
15 \\
25 \\
11 \\
20 \\
14 \\
13 \\
6 \\
13 \\
6 \\
29 \\
99 \\
22 \\
14 \\
10 \\
12 \\
24 \\
9 \\
4 \\
10 \\
10 \\
20 \\
24 \\
20 \\
14 \\
23 \\
21 \\
10 \\
13 \\
13 \\
10 \\
21 \\
9 \\
14 \\
22 \\
17 \\
13 \\
13 \\
19 \\
21 \\
19 \\
15 \\
11 \\
110 \\
14 \\
7\end{array}$ & $\begin{array}{l}27 \\
21 \\
22 \\
20 \\
25 \\
55 \\
45 \\
45 \\
23 \\
33 \\
27 \\
31 \\
37 \\
20 \\
25 \\
49 \\
37 \\
42 \\
28 \\
48 \\
32 \\
33 \\
33 \\
22 \\
35 \\
18 \\
29 \\
24 \\
27 \\
35 \\
31 \\
32 \\
23 \\
52 \\
26 \\
13 \\
24 \\
39 \\
33 \\
23 \\
29 \\
30 \\
29 \\
42 \\
29 \\
19 \\
937 \\
29 \\
20\end{array}$ & 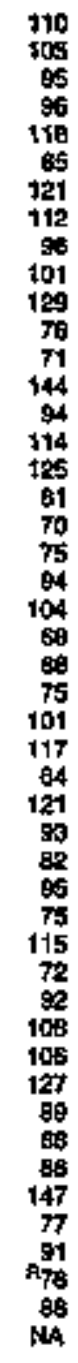 & $\begin{array}{l}253 \\
201 \\
198 \\
200 \\
263 \\
241 \\
161 \\
285 \\
243 \\
167 \\
228 \\
215 \\
195 \\
204 \\
213 \\
214 \\
179 \\
201 \\
208 \\
204 \\
200 \\
201 \\
244 \\
174 \\
236 \\
173 \\
203 \\
208 \\
212 \\
216 \\
167 \\
199 \\
247 \\
185 \\
193 \\
293 \\
199 \\
291 \\
244 \\
219 \\
208 \\
234 \\
235 \\
170 \\
297 \\
0262 \\
211 \\
19\end{array}$ & 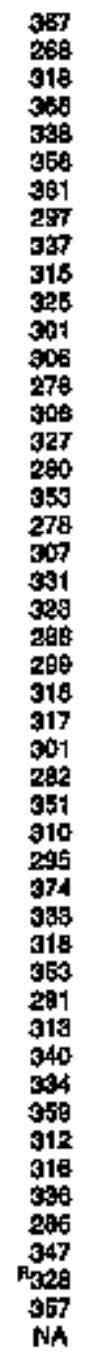 & 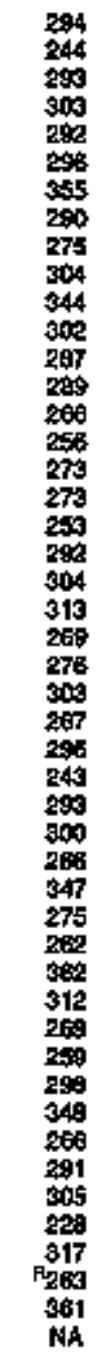 & 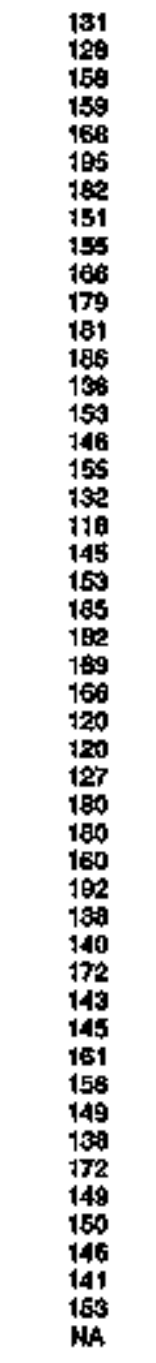 & $\begin{array}{l}70 \\
78 \\
65 \\
38 \\
58 \\
60 \\
50 \\
66 \\
30 \\
53 \\
64 \\
59 \\
47 \\
44 \\
93 \\
42 \\
48 \\
43 \\
45 \\
58 \\
48 \\
48 \\
77 \\
44 \\
66 \\
40 \\
95 \\
27 \\
44 \\
58 \\
53 \\
45 \\
43\end{array}$ & $\begin{array}{r}12 \\
9 \\
7 \\
10 \\
11 \\
9 \\
10 \\
9 \\
13 \\
18 \\
18 \\
15 \\
12 \\
7 \\
11 \\
17 \\
19 \\
12 \\
12 \\
7 \\
8 \\
6 \\
12 \\
9 \\
21 \\
10 \\
12 \\
8 \\
15 \\
19 \\
11 \\
19 \\
12 \\
15 \\
12 \\
99 \\
25 \\
28 \\
14 \\
18 \\
13 \\
16 \\
8 \\
18 \\
11 \\
120 \\
8 \\
14\end{array}$ & $\begin{array}{r}10 \\
4 \\
11 \\
4 \\
7 \\
4 \\
6 \\
11 \\
5 \\
6 \\
5 \\
5 \\
7 \\
3 \\
2 \\
9 \\
6 \\
4 \\
9 \\
4 \\
4 \\
9 \\
17 \\
8 \\
4 \\
5 \\
5 \\
4 \\
6 \\
5 \\
6 \\
5 \\
5 \\
11 \\
5 \\
15 \\
4 \\
8 \\
8 \\
6 \\
5 \\
8 \\
9 \\
7 \\
4 \\
95 \\
6 \\
14\end{array}$ & 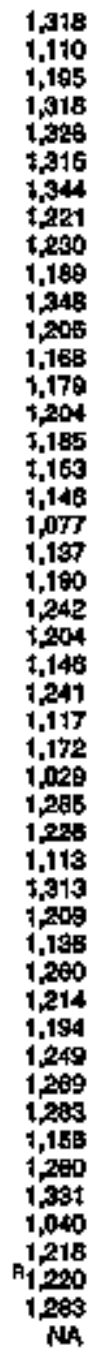 \\
\hline Hompals 1 & 7 & 7 & 16 & 31 & gs & 200 & 317 & 287 & 154 & 59 & 13 & 7 & 1,163 \\
\hline
\end{tabular}

I Based on caldodations of date from 1951 through 1990.

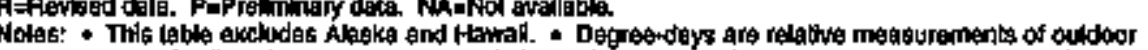

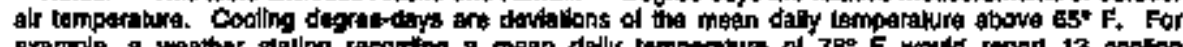

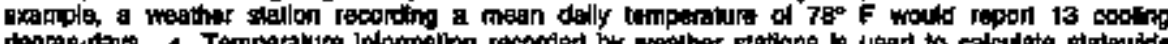

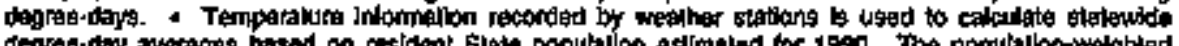

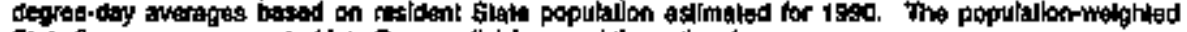

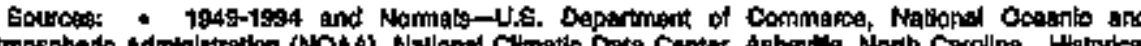

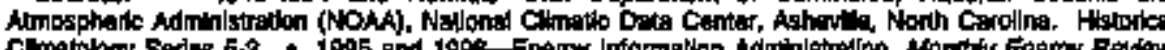

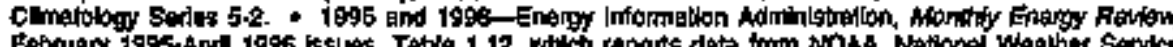

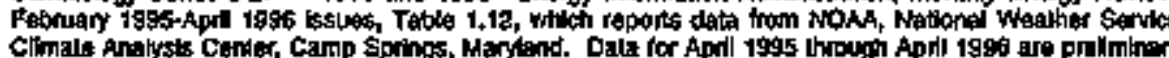

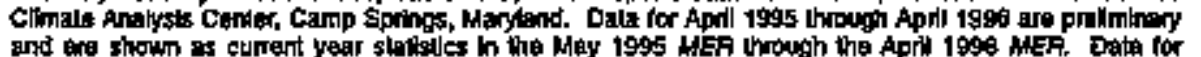

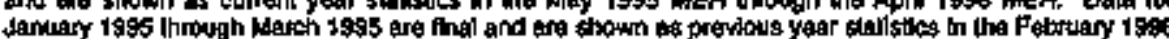
MEA through tho Apd 1998 NGA. 
Figure 1.10 Heating Degree-Days by Census Dlvislon, 1949-1995

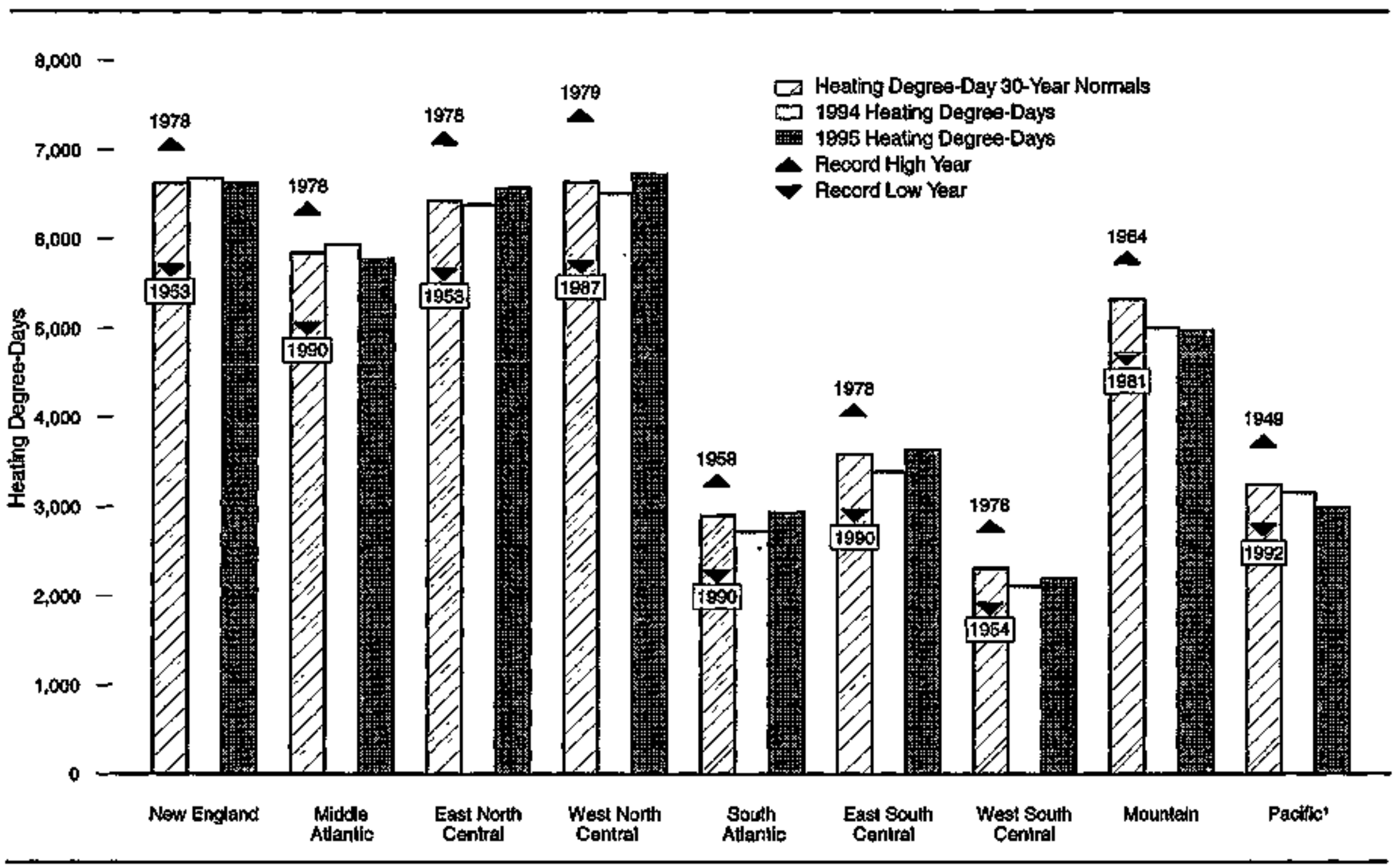

1 Excludes Alaska and Hawill.

Notex See Appendix F for Cengus divistons.

Source: Talto 1.10 . 
Table 1.10 Heating Degree-Days by Census Division, 1949-1995

\begin{tabular}{|c|c|c|c|c|c|c|c|c|c|c|}
\hline Yor & Engtend & $\begin{array}{l}\text { Mlodlo } \\
\text { Atloafle }\end{array}$ & $\begin{array}{l}\text { Eack North } \\
\text { Central }\end{array}$ & $\begin{array}{l}\text { Wesi Norm } \\
\text { Ceniral }\end{array}$ & $\begin{array}{l}\text { South } \\
\text { Adontios }\end{array}$ & $\begin{array}{l}\text { Exst sounh } \\
\text { Ceritral }\end{array}$ & Wopt Soulh & Hountiple & Paciller & $\begin{array}{l}\text { Unithed } \\
\text { Etroteat }\end{array}$ \\
\hline 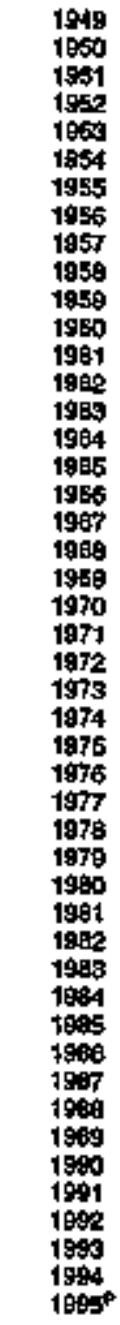 & 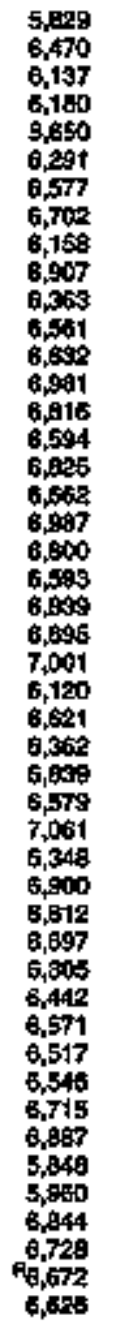 & 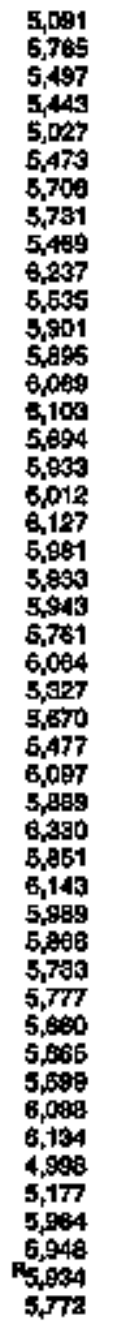 & 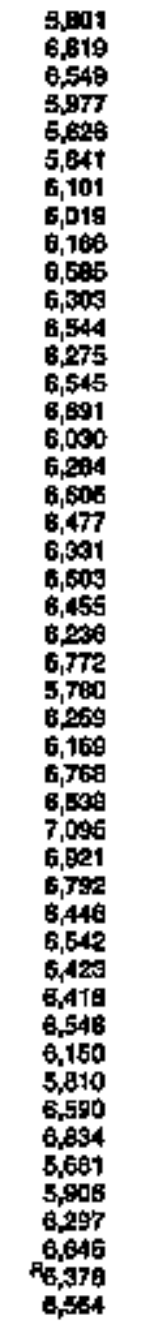 & 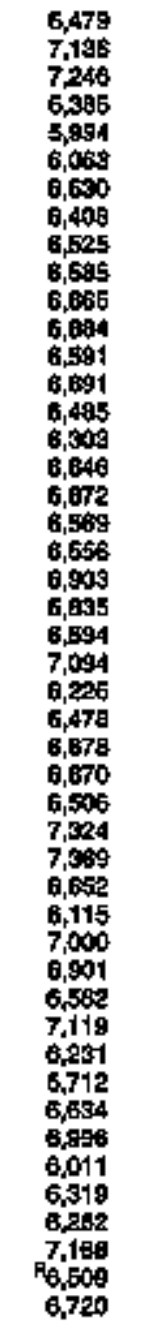 & 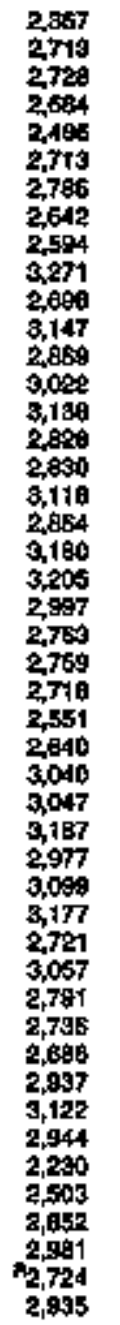 & 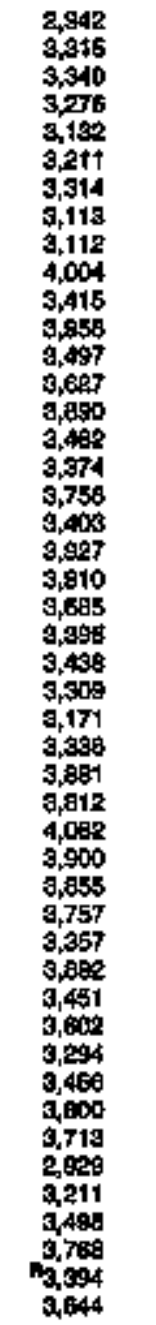 & 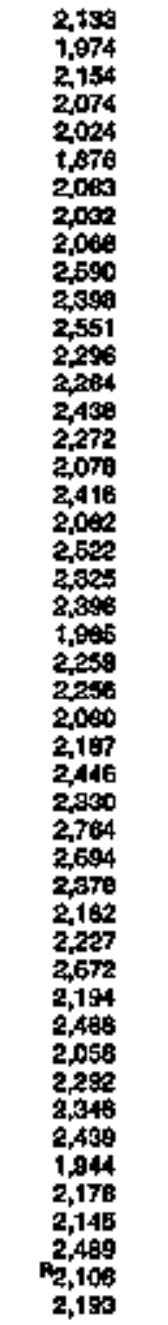 & 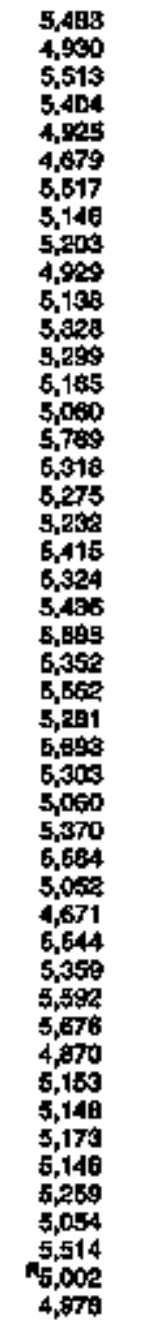 & 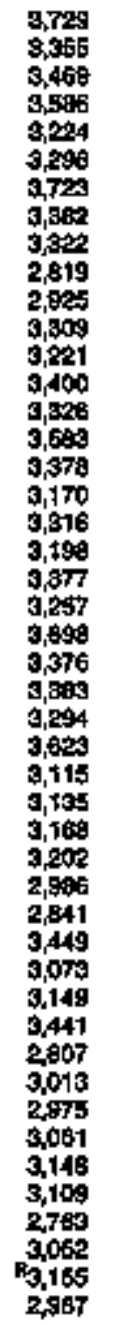 & 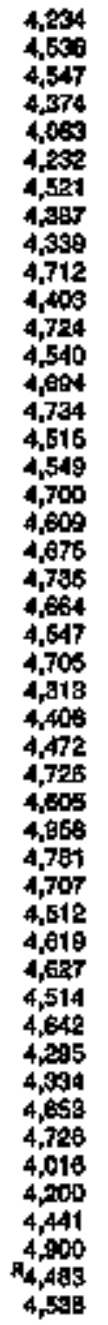 \\
\hline Normaigl & 0,621 & 6,839 & 0,421 & 0,695 & 2,696. & 3,699 & 2,308 & 6,321 & 0,246 & 4,076 \\
\hline
\end{tabular}

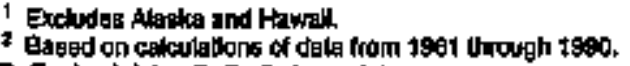

A-fiowised dela. P=Frelmhary tra

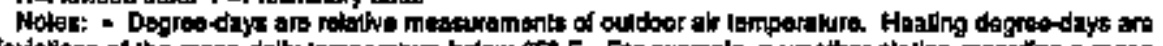

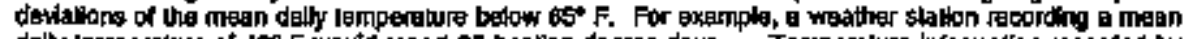

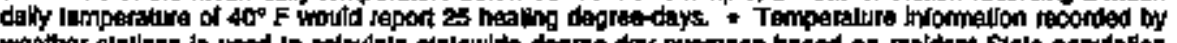

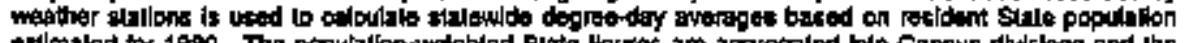

nelbonal avenge. - S10 Appendlax F for Consirs dittalons.

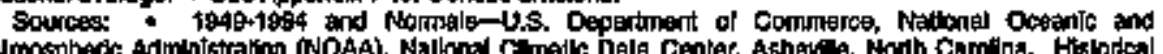

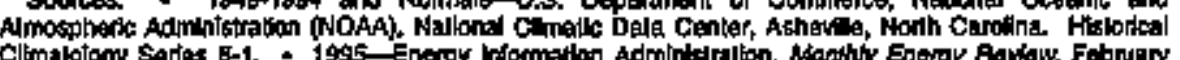

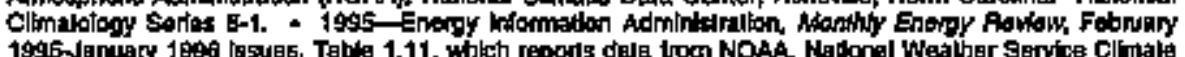

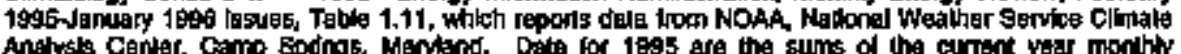

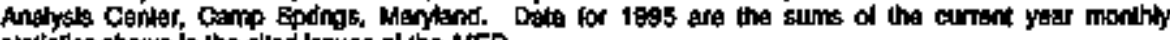

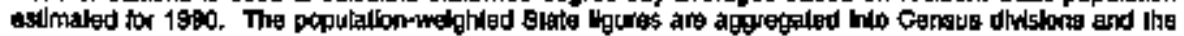




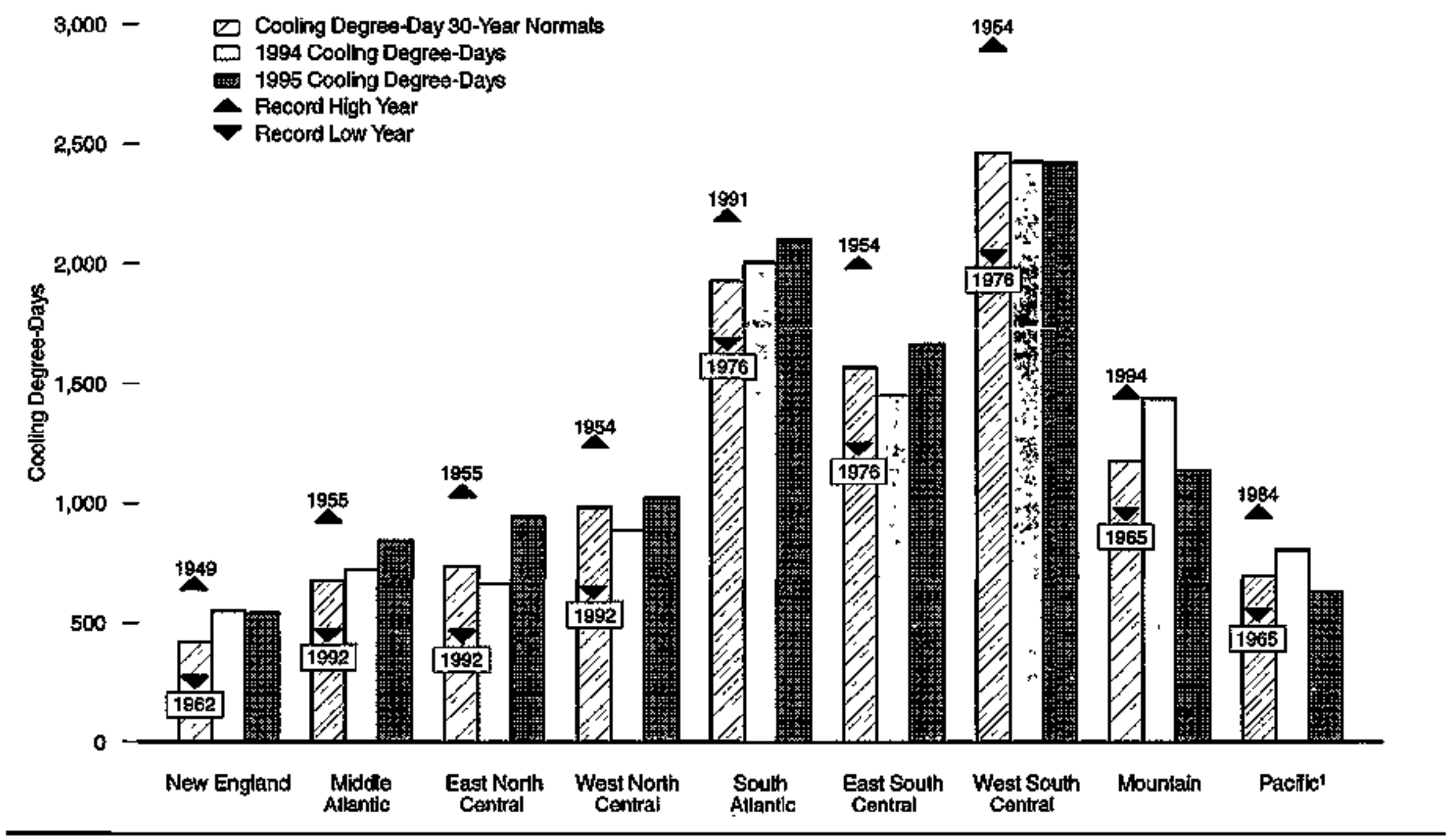

I Exdudas Alastica and Haweal.

Note: Sate Appendlx F tor Census divilant.

Source: Table 1.11. 
Table 1.11 Cooling Degree-Days by Census Division, 1949-1995

\begin{tabular}{|c|c|c|c|c|c|c|c|c|c|c|}
\hline Yeer & Englew & $\begin{array}{l}\text { Matdile } \\
\text { Atlandia }\end{array}$ & $\begin{array}{c}\text { Ehat Noxth } \\
\text { Contral }\end{array}$ & $\begin{array}{l}\text { Wost Nonth } \\
\text { Cantral }\end{array}$ & $\begin{array}{l}\text { Sounth } \\
\text { Anterito }\end{array}$ & $\begin{array}{c}\text { East south } \\
\text { Central }\end{array}$ & $\begin{array}{c}\text { West South } \\
\text { Conmiral }\end{array}$ & Mountaln & Purillo 1 & $\begin{array}{l}\text { Inilad } \\
\text { stotios }\end{array}$ \\
\hline 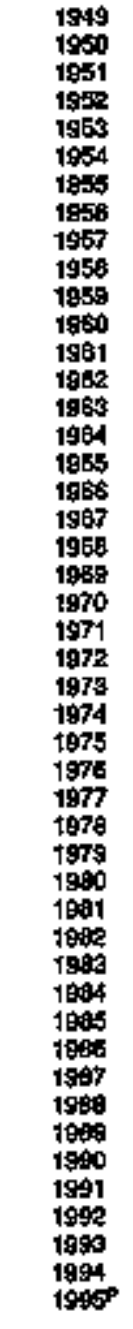 & 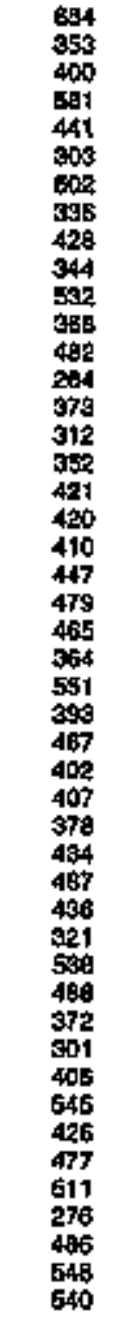 & 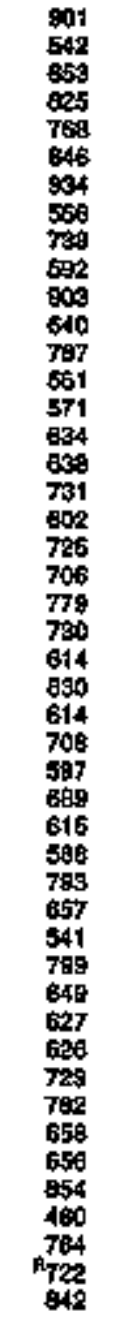 & 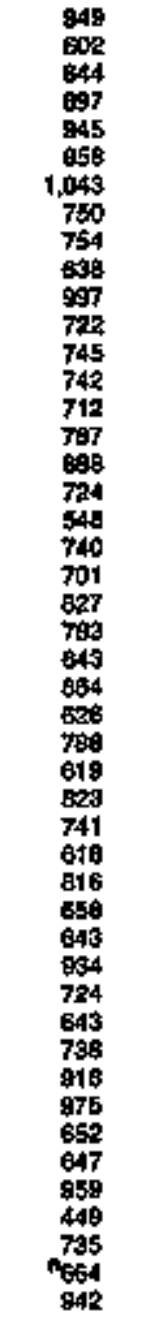 & 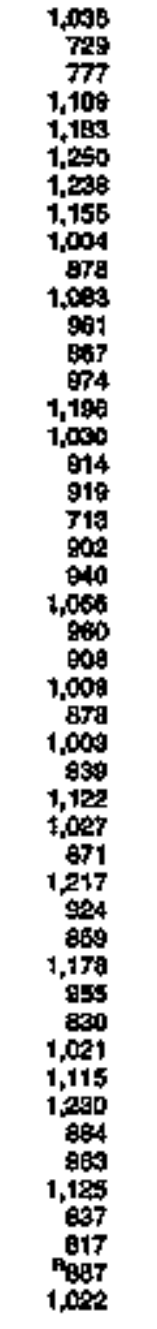 & 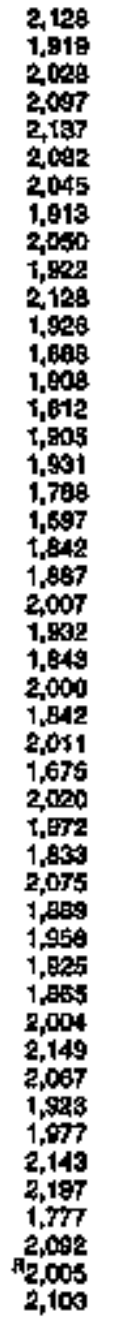 & 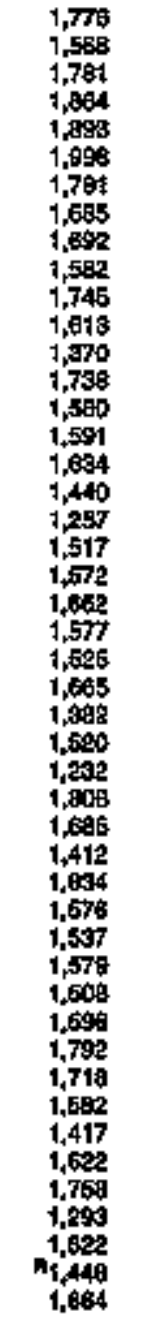 & 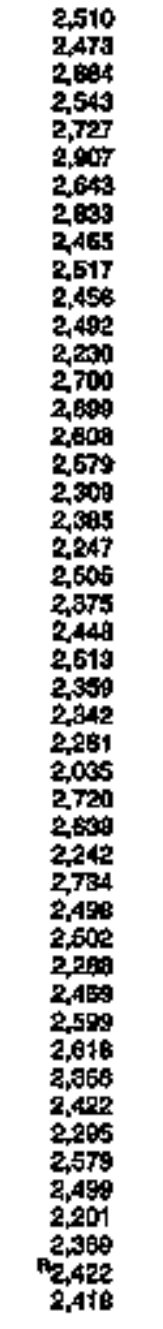 & 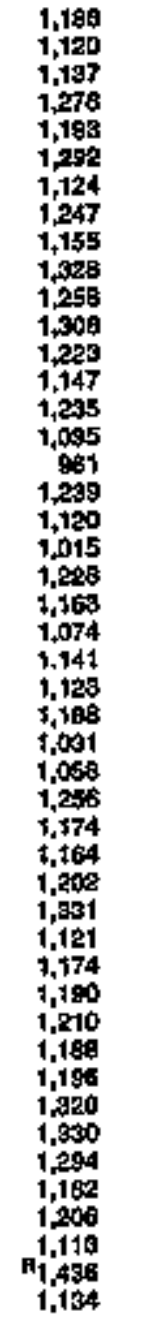 & 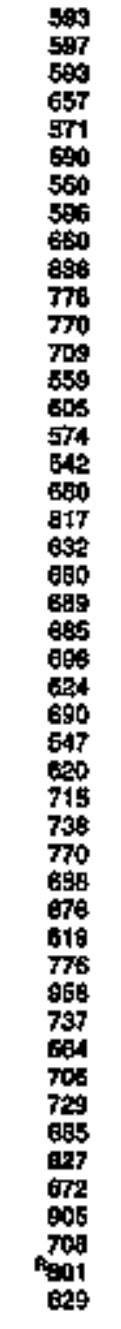 & 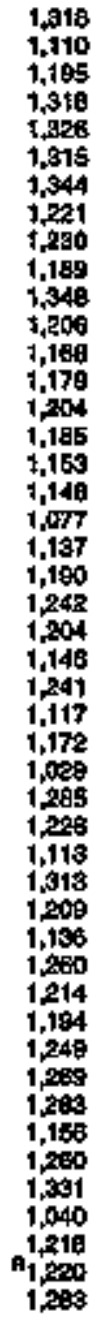 \\
\hline Nomals? & 421 & 675 & 736 & 981 & 1,926 & 1,565 & 2,460 & 1,174 & 694 & 1,199 \\
\hline
\end{tabular}

I. Exclutes Akatho and Hower.

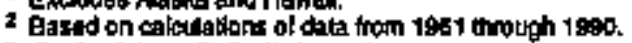

Pefieviogd dole. PxPrellininary date.

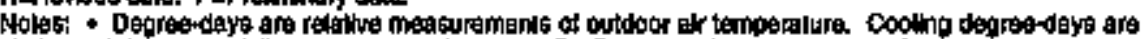

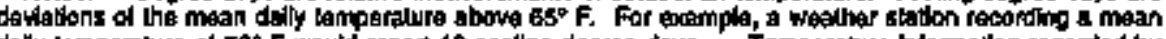

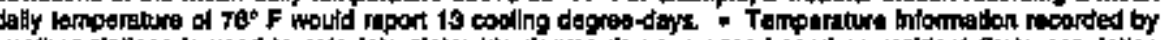

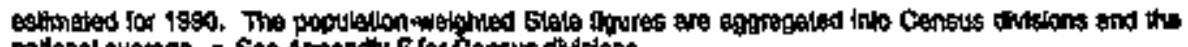

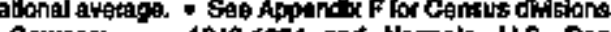

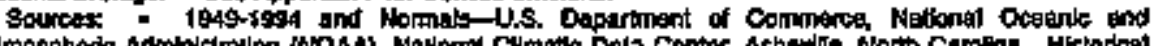

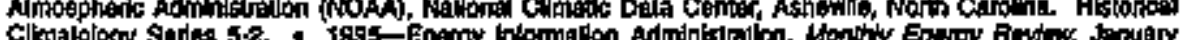

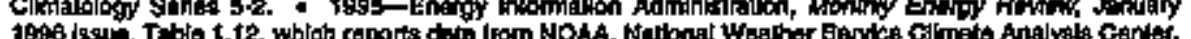

Cema Sptrigs, Mantand. 


\section{Figure 1.12 U.S. Government Energy Consumption, Fiscal Years}

\section{Total and U.S. Department of Defense, 1981-1995}

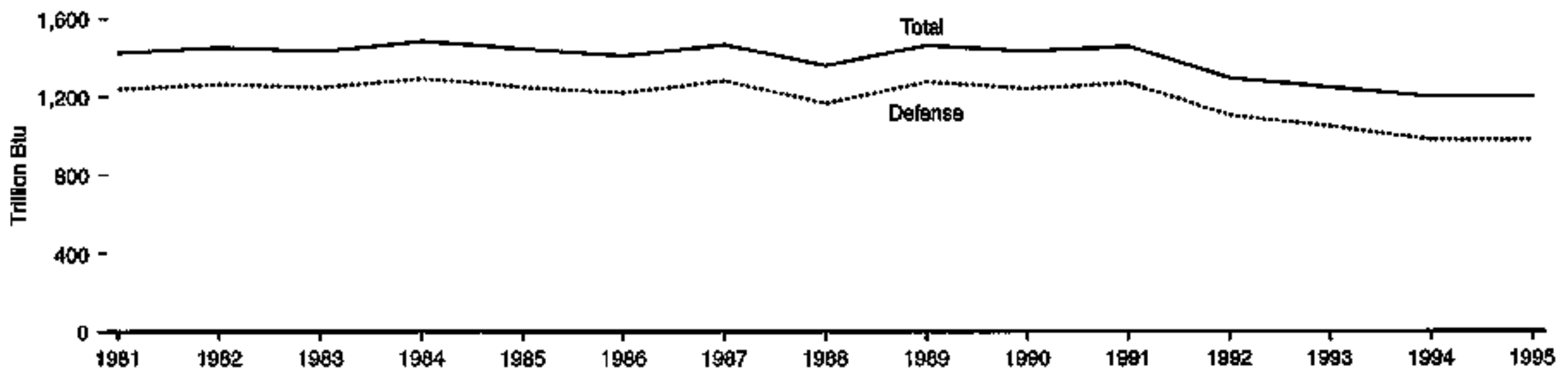

Top Fout Consuming Agencles, 1995

By Miejor Energy Source, 1981-1905
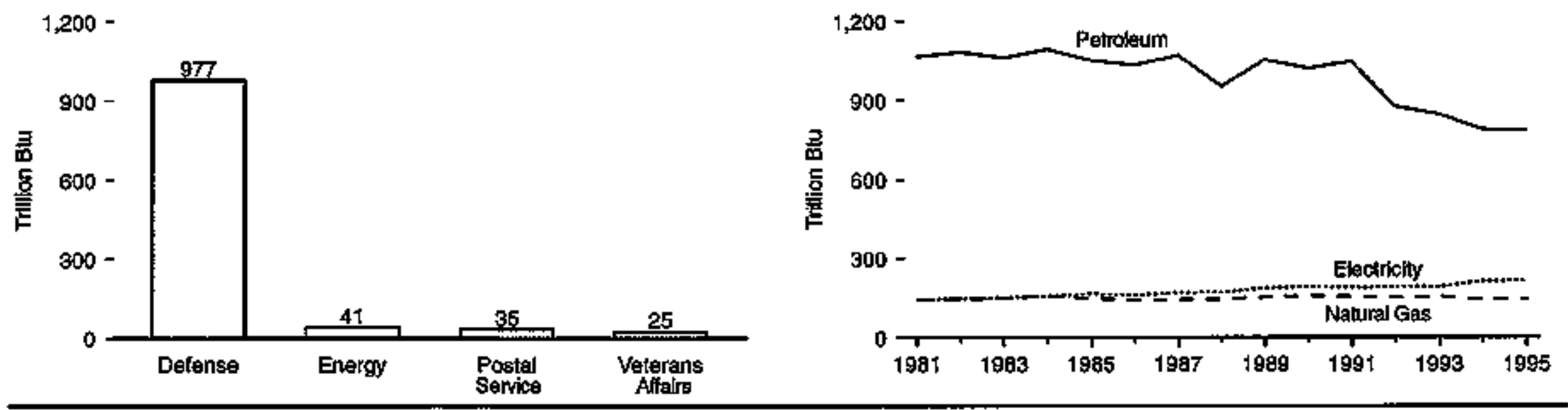

Noles: - The U.S. Govemmenl's tlecal year num from October 1 through September 30. - Becense vertlcal scales ditier, graphs should not be compared.

Solice: Table 1.12. 
Table 1.12 U.S. Government Energy Consumption, Fiscal Years 1981-1995 (Trillion B(u)

\begin{tabular}{|c|c|c|c|c|c|c|c|c|c|c|c|c|c|c|c|}
\hline Gabory & 1다여 & 1982 & 19gas & 19E4 & 1995 & 1986 & 1997 & 199: & 1989 & 1990 & 1991 & 1982 & 1695 & 1994 & $1095 \mathrm{~N}$ \\
\hline 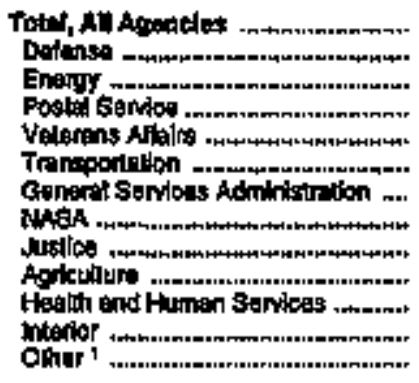 & $\begin{array}{r}1,424.2 \\
1,238.5 \\
47.3 \\
27.8 \\
24.0 \\
15.0 \\
19.0 \\
10.0 \\
5.4 \\
7.9 \\
6.7 \\
7.6 \\
11.1\end{array}$ & $\begin{array}{r}1,451.4 \\
1,264.5 \\
49.0 \\
27.5 \\
24.2 \\
19.1 \\
18.1 \\
10.1 \\
5.8 \\
7.6 \\
6.4 \\
7.4 \\
11.6\end{array}$ & $\begin{array}{r}1,431,8 \\
1218.3 \\
49.5 \\
26.5 \\
24.1 \\
19.4 \\
18.4 \\
10.3 \\
5.5 \\
7.4 \\
6.2 \\
7.7 \\
10.8\end{array}$ & $\begin{array}{r}1,492.5 \\
1,292.1 \\
51.8 \\
27.7 \\
24.0 \\
19.8 \\
18.2 \\
10.6 \\
6.4 \\
7.9 \\
6.4 \\
8.4 \\
10.7\end{array}$ & $\begin{array}{r}1,405.5 \\
1250.5 \\
159.3 \\
27.8 \\
25.1 \\
19.5 \\
17.3 \\
10.6 \\
8.2 \\
0.4 \\
7.0 \\
7.8 \\
50.7\end{array}$ & $\begin{array}{r}1,410.1 \\
1,222.8 \\
49.9 \\
28.0 \\
25.0 \\
19.4 \\
14.0 \\
11.2 \\
8.0 \\
6.0 \\
6.2 \\
6.9 \\
11.3\end{array}$ & $\begin{array}{r}1,405.6 \\
1,280.5 \\
48.2 \\
28.6 \\
24.9 \\
19.0 \\
13.1 \\
11.1 \\
6.1 \\
7.2 \\
6.6 \\
6.6 \\
11.6\end{array}$ & $\begin{array}{r}1,359,8 \\
1,16 ., 8 \\
49.8 \\
29.6 \\
28,3 \\
18,7 \\
12.4 \\
11.2 \\
9.4 \\
7.8 \\
6.4 \\
7.0 \\
16.5\end{array}$ & $\begin{array}{r}1,469.7 \\
1,274.4 \\
43.9 \\
30.3 \\
26.2 \\
18.5 \\
72.7 \\
12.1 \\
7.7 \\
6.7 \\
6.7 \\
7.1 \\
15.3\end{array}$ & $\begin{array}{r}1,433.0 \\
1,241.7 \\
43.4 \\
30.6 \\
24.9 \\
19.0 \\
14.2 \\
12.3 \\
7.0 \\
9.6 \\
8.0 \\
7.4 \\
15.1\end{array}$ & 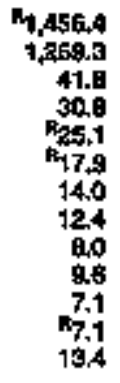 & $\begin{array}{r}A_{1}, 285.4 \\
1,104.0 \\
44.4 \\
31.7 \\
25.3 \\
A_{18.4} \\
13.0 \\
12.5 \\
7.5 \\
9.1 \\
6.0 \\
7.0 \\
13.8\end{array}$ & $\begin{array}{r}P_{1}, 247.9 \\
1,049.9 \\
43,6 \\
39.7 \\
25.7 \\
A_{20,7} \\
14.1 \\
12.4 \\
8.1 \\
9.3 \\
8.1 \\
7.6 \\
14.7\end{array}$ & 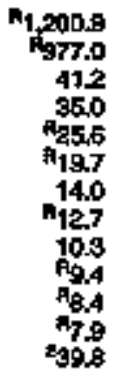 & $\begin{array}{r}1,201.1 \\
97.0 \\
41.2 \\
35.0 \\
25.4 \\
18.4 \\
13.7 \\
124 \\
10.3 \\
9.4 \\
6.4 \\
7.9 \\
42.1\end{array}$ \\
\hline 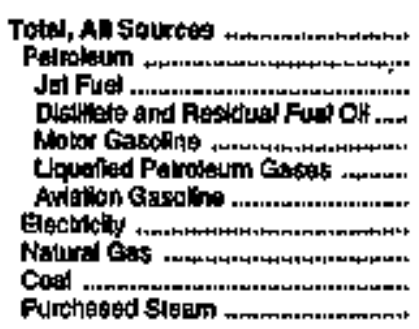 & $\begin{array}{r}1,924.2 \\
1,055.1 \\
653.3 \\
351.3 \\
59.2 \\
3.7 \\
4.6 \\
144.5 \\
142,2 \\
6.1 \\
6.2\end{array}$ & $\begin{array}{r}1.451 .4 \\
1.0827 \\
672.7 \\
349.4 \\
53.1 \\
3.9 \\
3.6 \\
147.5 \\
146.2 \\
68.6 \\
6.2\end{array}$ & $\begin{array}{r}1,431.9 \\
1,061.1 \\
673.4 \\
329.5 \\
51.5 \\
4.0 \\
26 \\
151.5 \\
117.9 \\
82.4 \\
9.0\end{array}$ & $\begin{array}{r}1,492.5 \\
1,009.0 \\
693.7 \\
342.9 \\
51.2 \\
4.1 \\
1.9 \\
165.9 \\
+55.4 \\
65.3 \\
10.1\end{array}$ & $\begin{array}{r}07,445.5 \\
1.052 .9 \\
706.7 \\
280.8 \\
50.5 \\
4.0 \\
1.9 \\
9165.7 \\
9149.1 \\
64.0 \\
13.8\end{array}$ & $\begin{array}{r}1,410.1 \\
1,032.3 \\
710.9 \\
271.5 \\
46.3 \\
3.9 \\
1.4 \\
159.1 \\
141.4 \\
68.9 \\
13.5\end{array}$ & $\begin{array}{r}1,465.5 \\
1,059.5 \\
702.3 \\
319.4 \\
43.1 \\
4.0 \\
1.0 \\
169.7 \\
145.4 \\
67.0 \\
13.7\end{array}$ & $\begin{array}{r}\mathbf{7 5 9 . 6} \\
958,3 \\
617.2 \\
384.7 \\
11.2 \\
3.2 \\
6.0 \\
171.1 \\
114,9 \\
80.2 \\
31.9\end{array}$ & $\begin{array}{r}1,469.7 \\
1,054.4 \\
781.7 \\
245.1 \\
41.1 \\
5.7 \\
0.8 \\
199.3 \\
151.9 \\
48.6 \\
20.6\end{array}$ & $\begin{array}{r}1,433.0 \\
r, 00.0 .5 \\
730.4 \\
244.1 \\
37.2 \\
8.3 \\
0.5 \\
192.4 \\
167.1 \\
44.2 \\
18.9\end{array}$ & 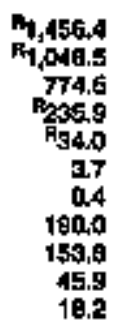 & $\begin{array}{r}r_{1.295 .4} \\
r_{370.0} \\
R_{60.28} \\
r_{205.1} \\
3.5 \\
6.1 \\
1.0 \\
101.5 \\
151.2 \\
51.8 \\
22.8\end{array}$ & 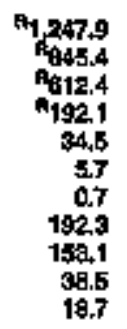 & 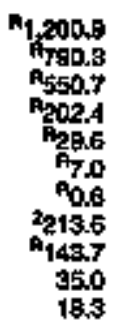 & $\begin{array}{r}1,201.1 \\
768.4 \\
650.1 \\
202.1 \\
29.5 \\
6.2 \\
0.5 \\
225.5 \\
144.4 \\
35.0 \\
70.0\end{array}$ \\
\hline
\end{tabular}

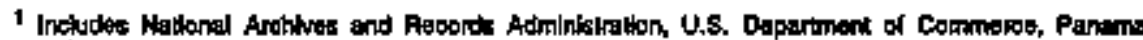

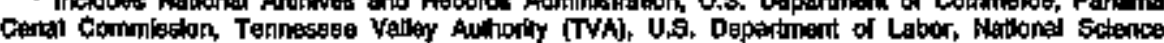

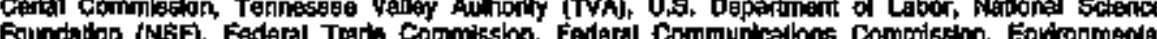
Protection Agency

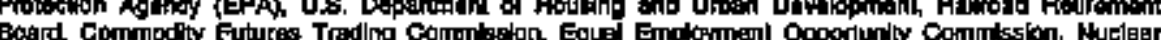
Hegutory commitsin U.

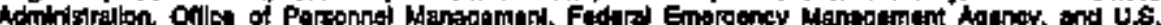
Inlorration Apency.

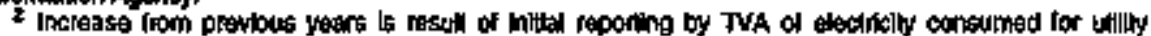
sintion senvice tss.

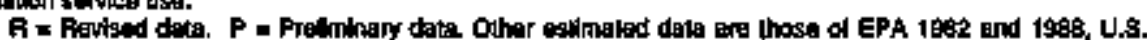

Deparnaen of Trasury 1962 and 1983, and NSF 1990, 1989, and 1990

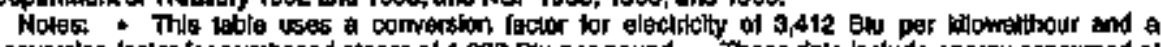

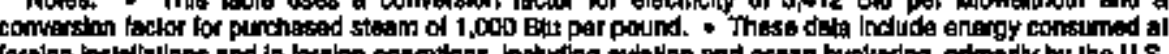

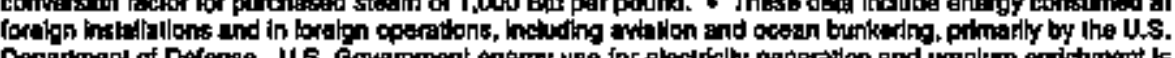

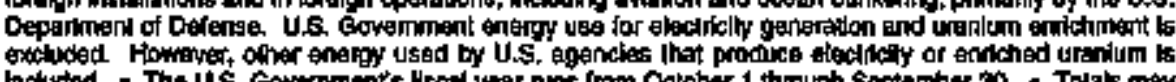

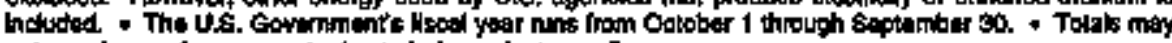
nol equal sum of componeris due to hadependenl rounting

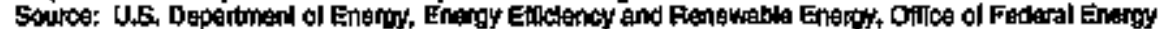
Mtanagamanl Programs. 


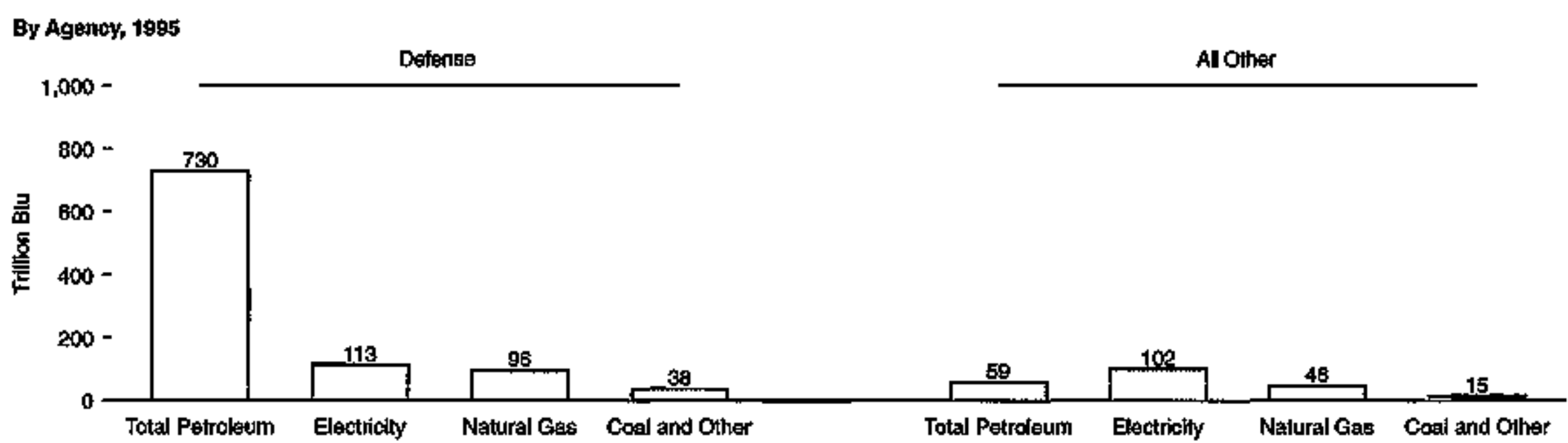

By Source, 1985 and 1995

$1,600-$

回 1985 . 1995

$1,200-$

喜

兽 800 -

$400=$

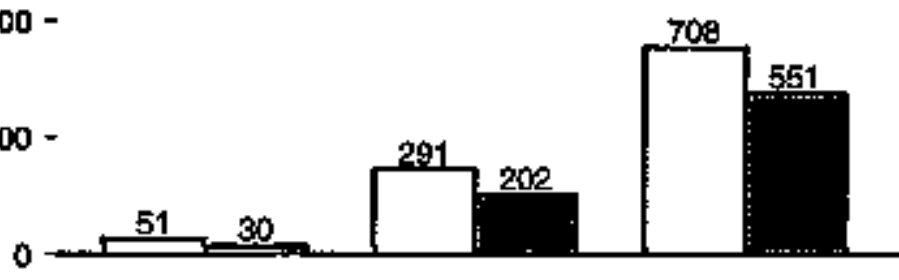

Motor Casoline Distillate and Jet Fuel and Residual Fuelo:s Aviation Gas

Totel Petroleum Electricity

Natumat ........


Table 1.13 U.S. Government Energy Consumption by Agency and Source, Fiscal Years 1985 and 1995 (Trillion Btu)

\begin{tabular}{|c|c|c|c|c|c|c|c|c|c|}
\hline \multirow[b]{2}{*}{ Agoney } & \multicolumn{5}{|c|}{ Patrotoum } & \multirow[b]{2}{*}{ Eecotrioly } & \multirow[b]{2}{*}{$\begin{array}{c}\text { Nadumat } \\
\text { Gea }\end{array}$} & \multirow[b]{2}{*}{$\begin{array}{c}\text { Coal } \\
\text { and Ophor }\end{array}$} & \multirow[b]{2}{*}{ Tots 1} \\
\hline & $\begin{array}{l}\text { Molor } \\
\text { Gessolino }\end{array}$ & 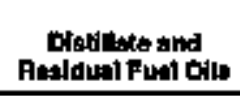 & $\begin{array}{c}\text { Jot Furl } \\
\text { and } \\
\text { Avbation Gas }\end{array}$ & Oher: & Tows & & & & \\
\hline 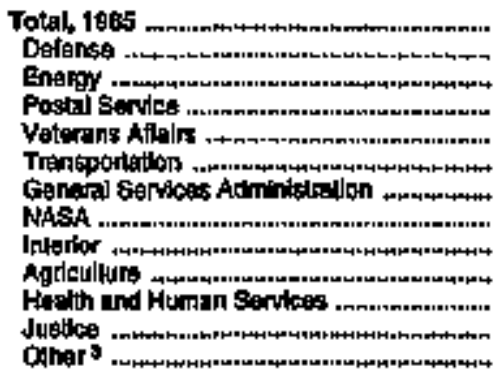 & $\begin{array}{r}50.5 \\
25.4 \\
1.5 \\
9.9 \\
0.5 \\
1.3 \\
0.1 \\
0.3 \\
4.0 \\
1.8 \\
2.2 \\
0.4 \\
2.9\end{array}$ & $\begin{array}{l}250.8 \\
25.0 \\
3.6 \\
3.1 \\
2.8 \\
8.0 \\
1.1 \\
0.6 \\
0.9 \\
0.4 \\
1.6 \\
2.1 \\
2.1\end{array}$ & $\begin{array}{l}707.6 \\
60.3 \\
0.5 \\
0.0 \\
0.0 \\
5.5 \\
0.0 \\
1.6 \\
0.1 \\
0.1 \\
0.1 \\
0.0 \\
0.4\end{array}$ & $\begin{array}{l}4.0 \\
2.3 \\
0.2 \\
0.2 \\
0.0 \\
0.0 \\
0.0 \\
0.0 \\
0.5 \\
0.1 \\
0.8 \\
0.1 \\
0.0\end{array}$ & $\begin{array}{r}1,052.9 \\
892.1 \\
5.7 \\
19.2 \\
2.8 \\
11.8 \\
1.2 \\
2.7 \\
5.2 \\
2.4 \\
4.6 \\
2.6 \\
5.4\end{array}$ & $\begin{array}{r}t 65.7 \\
101.1 \\
19.8 \\
9.8 \\
7.2 \\
3.8 \\
10.3 \\
5.8 \\
1.6 \\
1.2 \\
1.5 \\
2.5 \\
9.0\end{array}$ & $\begin{array}{r}149.1 \\
10,4.4 \\
6.9 \\
4.5 \\
13.9 \\
0.9 \\
3.9 \\
2.6 \\
1.5 \\
4,2 \\
1.4 \\
1.9 \\
1.9\end{array}$ & $\begin{array}{r}7.0 \\
51.0 \\
21.0 \\
0.5 \\
1.3 \\
0.0 \\
2.5 \\
0.3 \\
0.1 \\
0.4 \\
0.2 \\
0.1 \\
0.4\end{array}$ & $\begin{array}{r}1,445.5 \\
1,250.6 \\
52.3 \\
27.6 \\
25.1 \\
19.5 \\
17.3 \\
10.8 \\
6.4 \\
8.2 \\
7.8 \\
7.0 \\
10.7\end{array}$ \\
\hline 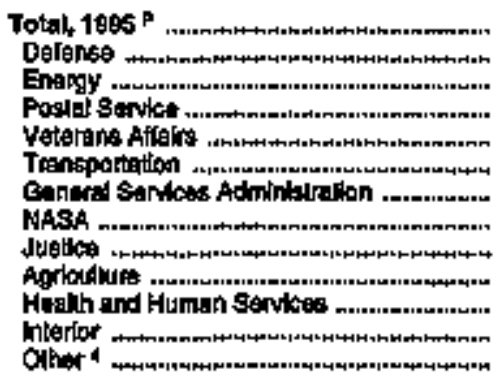 & $\begin{array}{r}29.5 \\
4.3 \\
1.2 \\
11.2 \\
0.3 \\
0.6 \\
0.1 \\
0.3 \\
2.5 \\
4.8 \\
0.2 \\
2.1 \\
2.2\end{array}$ & $\begin{array}{r}200.1 \\
18.3 \\
2.4 \\
3.2 \\
1.4 \\
5.7 \\
0.3 \\
0.6 \\
0.5 \\
0.6 \\
1.3 \\
1.3 \\
2.0\end{array}$ & $\begin{array}{l}550.7 \\
540.8 \\
0.4 \\
0.0 \\
0.0 \\
5.7 \\
0.0 \\
1.4 \\
0.8 \\
0.2 \\
0.0 \\
0.2 \\
1.8\end{array}$ & $\begin{array}{l}0.2 \\
2.1 \\
0.4 \\
0.0 \\
0.0 \\
1.2 \\
0.0 \\
0.0 \\
0.0 \\
0.2 \\
0.3 \\
2.0 \\
0.0\end{array}$ & $\begin{array}{r}76.5 \\
729.5 \\
4.3 \\
14.3 \\
1.0 \\
15.3 \\
0.3 \\
2.3 \\
3.8 \\
5.6 \\
1.7 \\
5.5 \\
0.2\end{array}$ & $\begin{array}{r}215.6 \\
113.3 \\
17.1 \\
14.0 \\
8.9 \\
4.1 \\
9.1 \\
6.9 \\
2.6 \\
2.1 \\
3.4 \\
1.8 \\
32.4\end{array}$ & $\begin{array}{r}144.1 \\
8.9 \\
8.0 \\
6.0 \\
13.6 \\
0.9 \\
2.9 \\
3.0 \\
3.6 \\
1.6 \\
3.3 \\
0.5 \\
\mathbf{3 . 0}\end{array}$ & $\begin{array}{c}53.0 \\
39.4 \\
10.0 \\
0.8 \\
1.3 \\
0.1 \\
1.4 \\
0.2 \\
0.2 \\
0.1 \\
0.0 \\
0.1 \\
0.5\end{array}$ & $\begin{array}{r}1,201.1 \\
97.0 \\
41.2 \\
35.0 \\
26.4 \\
18.4 \\
13.7 \\
12.4 \\
10.3 \\
5.4 \\
8.4 \\
7.9 \\
48.1\end{array}$ \\
\hline
\end{tabular}

1 Inchules Iquefied pelrolamm genses and other.

Inctudes pinchased sisam, eojal, and olles.

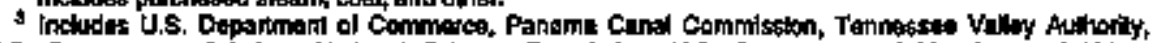

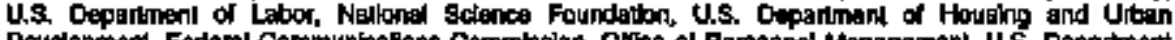

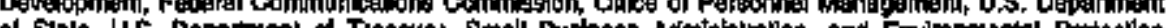
Agricy.

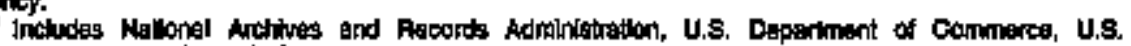

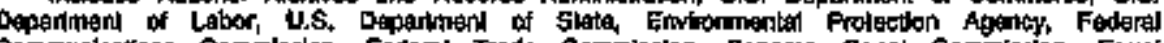

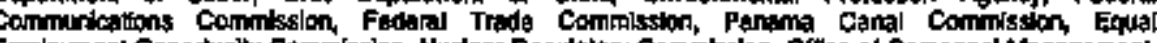

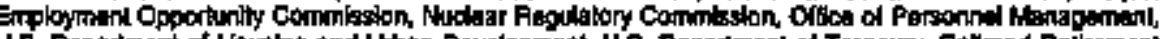

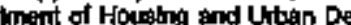
Agancy.

$R=$ fintsed data P=Preliminary dela

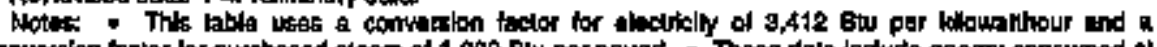

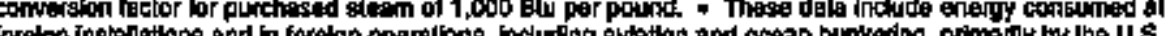

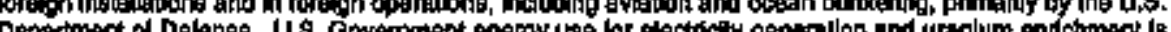

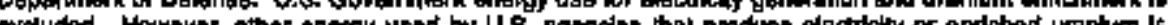
axpluded. The

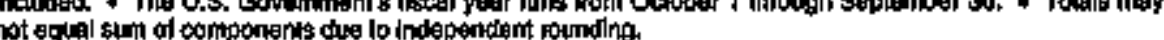

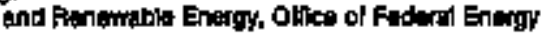

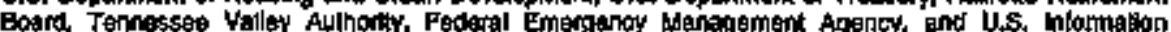




\section{Total, 1949-1994}

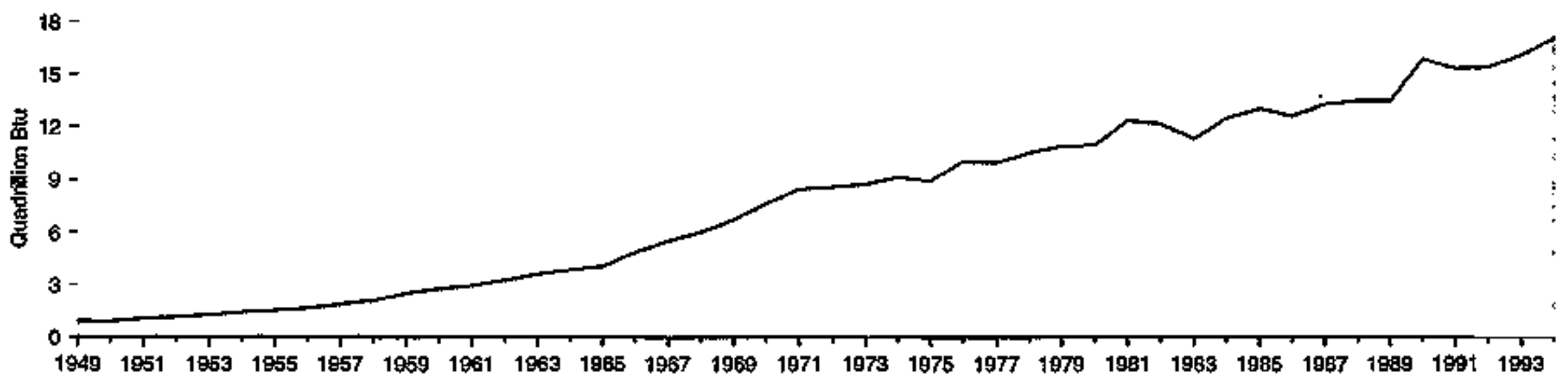

\section{By Source, 1949-1994}

$$
8-
$$

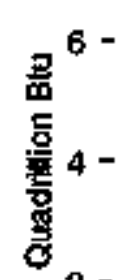

2 $\begin{array}{lllllllll}1950 & 1965 & 1960 & 1965 & 1970 & 1975 & 1960 & 1985 & 1990\end{array}$
Production on Federal Lands as Share of U.S. Total Production, by Souroe, 1994

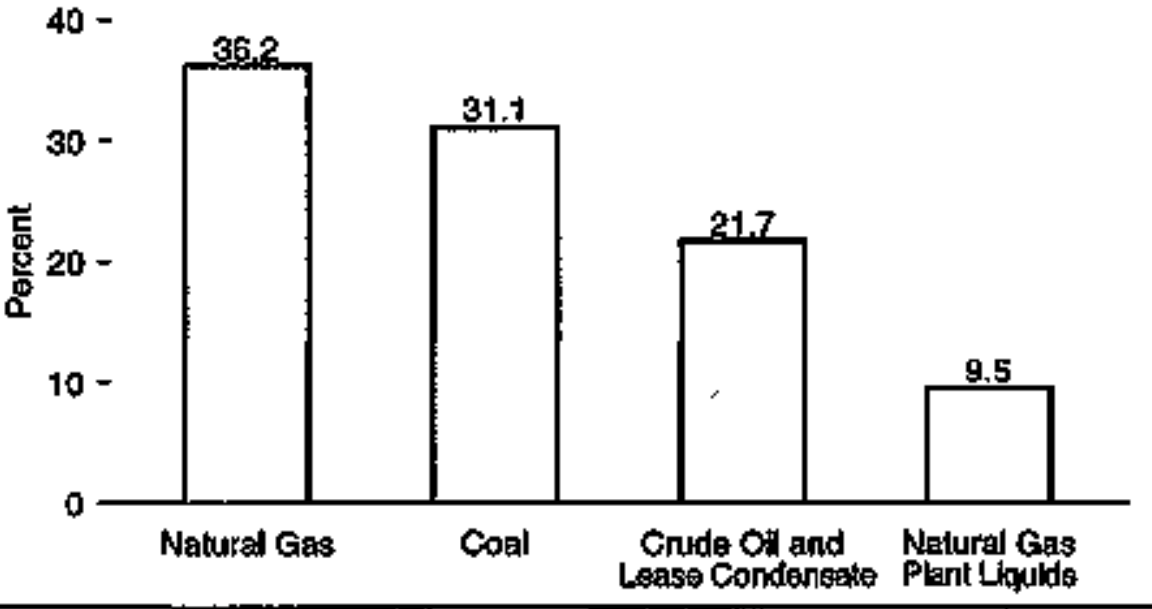

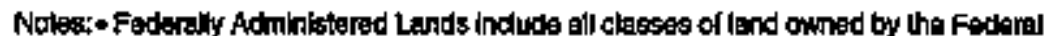

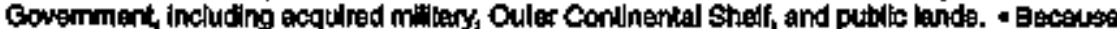

Wertical scales olfier, graphs should not be compared.

Sounces: Tutlo 1.14. 
Table 1.14 Fossil Fuel Production on Federally Administered Lands, 1949-1994

\begin{tabular}{|c|c|c|c|c|c|c|c|c|c|c|c|c|c|c|}
\hline \multirow[b]{2}{*}{ Year } & \multicolumn{3}{|c|}{ Grude ofl and Lanen Condinathe! } & \multicolumn{3}{|c|}{ Netural Gax Plaxx Lisuida z } & \multicolumn{3}{|c|}{ Naturat Gas* } & \multicolumn{3}{|c|}{$\cos 14$} & \multicolumn{2}{|c|}{ Toted } \\
\hline & $\begin{array}{l}\text { Maliasp } \\
\text { Barroto }\end{array}$ & $\begin{array}{c}\text { Oundifillon } \\
\text { But }\end{array}$ & $\begin{array}{l}\text { Percentk } \\
\text { us. Totols }\end{array}$ & $\begin{array}{l}\text { Maling } \\
\text { Germeto }\end{array}$ & $\begin{array}{c}\text { Cuedifilion } \\
\text { Estu }\end{array}$ & $\begin{array}{l}\text { Porthent } \\
\text { U.S. Totals }\end{array}$ & $\underset{\text { outh fout }}{\text { Typh }}$ & $\begin{array}{c}\text { Quadrillon } \\
\text { Bwo }\end{array}$ & $\begin{array}{l}\text { Percent } \\
\text { U.s. Total } 1\end{array}$ & $\begin{array}{c}\text { Hillon } \\
\text { shart Tons }\end{array}$ & $\begin{array}{c}\text { Oundrillon } \\
\text { ate }\end{array}$ & $\begin{array}{c}\text { Perctert } \\
\text { L.s. Total } 5\end{array}$ & $\underset{\text { Btud }}{\text { Oundrillow }}$ & $\begin{array}{l}\text { Parcent } \\
\text { U.S. Toidl }\end{array}$ \\
\hline 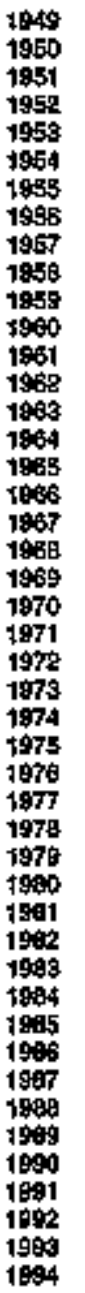 & 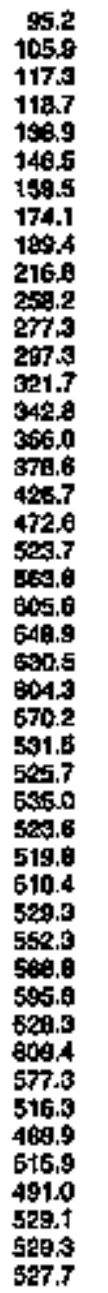 & 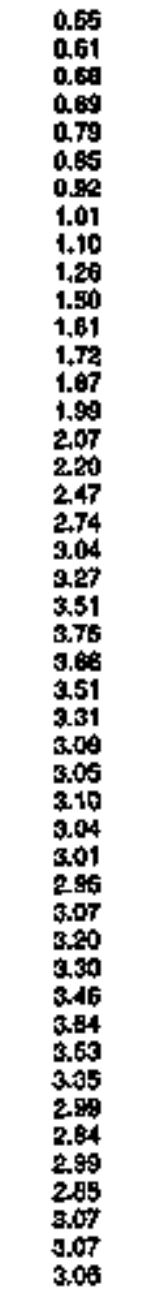 & $\begin{array}{l}5.2 \\
5.4 \\
5.2 \\
5.2 \\
5.8 \\
6.3 \\
8.4 \\
6.7 \\
7.2 \\
1.9 \\
10.0 \\
10.8 \\
11.3 \\
12.0 \\
12.5 \\
12.8 \\
19.3 \\
14.1 \\
14.7 \\
15.7 \\
16.7 \\
17.2 \\
18.8 \\
16.2 \\
10.0 \\
17.8 \\
17.4 \\
17.7 \\
17.8 \\
16.5 \\
16.7 \\
18.2 \\
18.9 \\
17.5 \\
17.9 \\
18.3 \\
18.2 \\
10.2 \\
18.8 \\
17.3 \\
17.8 \\
19.2 \\
18.1 \\
20.9 \\
21.2 \\
21.7\end{array}$ & $\begin{array}{c}4.4 \\
4.4 \\
5.3 \\
55.5 \\
5.7 \\
6.1 \\
6.0 \\
6.4 \\
6.6 \\
8.0 \\
9.5 \\
11.9 \\
13.5 \\
15.3 \\
16.0 \\
15.5 \\
14.3 \\
15.9 \\
20.1 \\
18.7 \\
19.9 \\
40.6 \\
54.0 \\
56.7 \\
54.9 \\
61.9 \\
69.7 \\
57.2 \\
57.4 \\
25.9 \\
11.9 \\
10.5 \\
19.3 \\
66.0 \\
14.0 \\
25.4 \\
26.6 \\
23.3 \\
29.7 \\
97.0 \\
45.1 \\
50.9 \\
72.7 \\
70.7 \\
64.4 \\
60.0\end{array}$ & $\begin{array}{l}0.02 \\
0.02 \\
0.02 \\
0.02 \\
0.03 \\
0.03 \\
0.03 \\
0.03 \\
0.03 \\
0.04 \\
0.04 \\
0.05 \\
0.05 \\
0.07 \\
0.07 \\
0.07 \\
0.06 \\
0.06 \\
0.09 \\
0.05 \\
0.08 \\
0.17 \\
0.22 \\
0.23 \\
0.22 \\
0.25 \\
0.24 \\
0.23 \\
0.23 \\
0.10 \\
0.05 \\
0.04 \\
0.09 \\
0.00 \\
0.05 \\
0.10 \\
0.10 \\
0.09 \\
0.09 \\
0.14 \\
0.17 \\
0.18 \\
0.28 \\
0.27 \\
0.24 \\
0.23\end{array}$ & 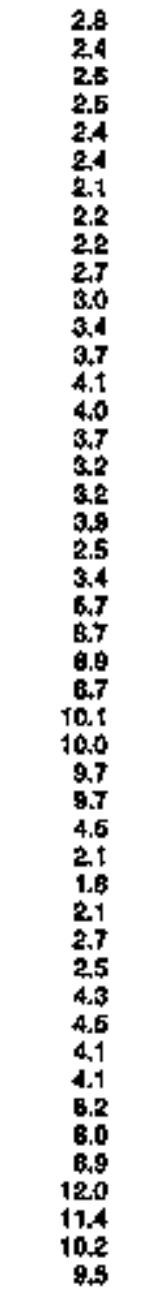 & 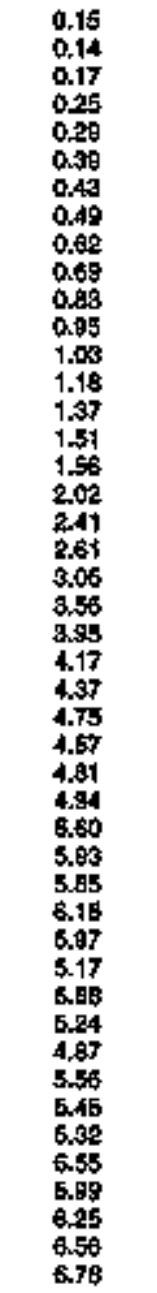 & 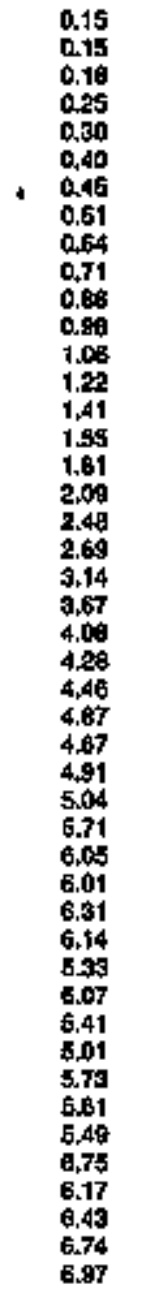 & 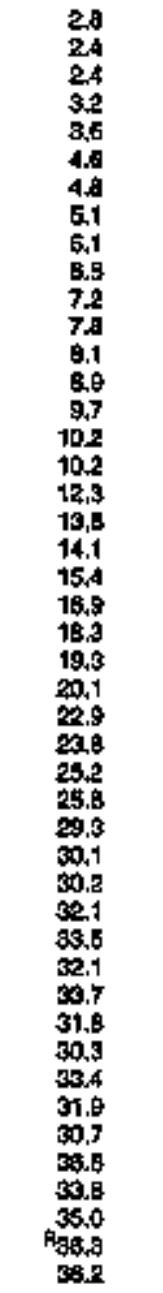 & 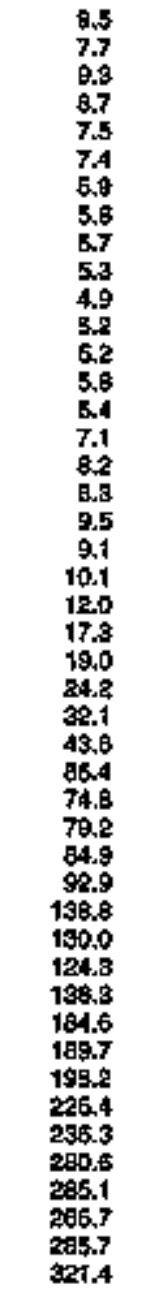 & 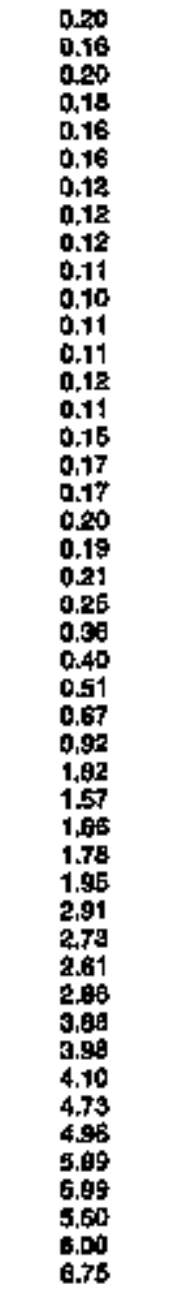 & $\begin{array}{l}2.0 \\
1.4 \\
1.5 \\
1.7 \\
6.5 \\
1.8 \\
1.3 \\
1.1 \\
1.1 \\
1.2 \\
1.1 \\
1.2 \\
1.2 \\
1.3 \\
1.1 \\
1.4 \\
6.6 \\
1.6 \\
1.7 \\
1.5 \\
1.8 \\
2.0 \\
3.1 \\
3.1 \\
4.1 \\
5.3 \\
6.7 \\
12.0 \\
10.7 \\
11.8 \\
10.8 \\
11.2 \\
16.1 \\
15.5 \\
15.9 \\
15.2 \\
20.8 \\
81.3 \\
21.2 \\
23.7 \\
24.1 \\
27.3 \\
26.6 \\
26.7 \\
30.2 \\
31.1\end{array}$ & 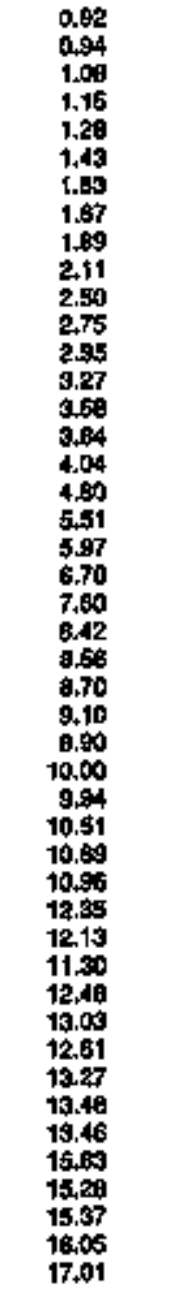 & 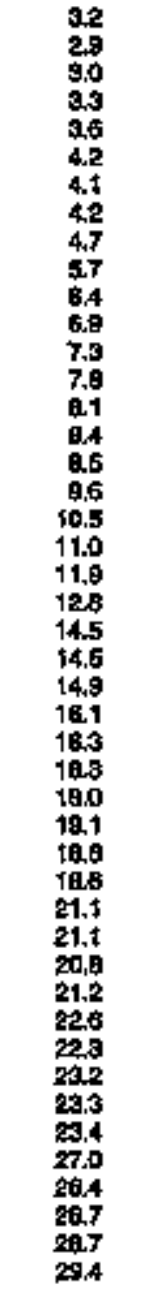 \\
\hline
\end{tabular}




\section{Figure 1.15 Fossil Fuel Consumption for Nonfuel Use}

\section{Tolat, 1960-1995}

6-

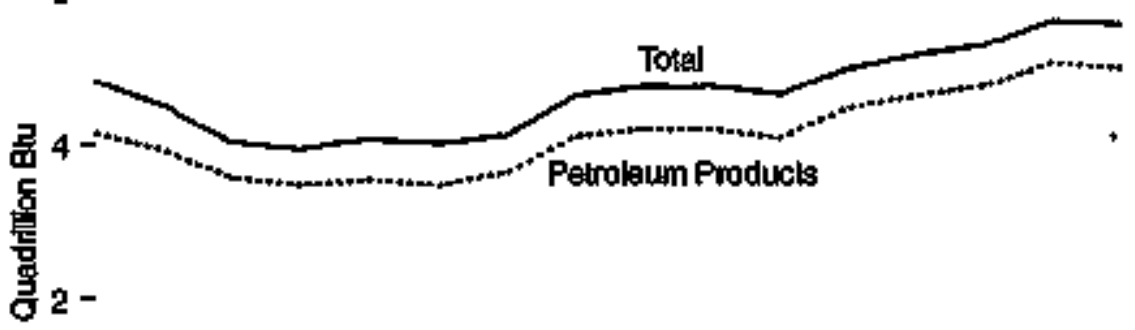

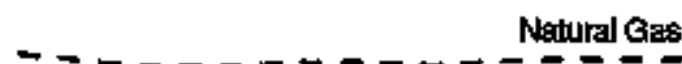

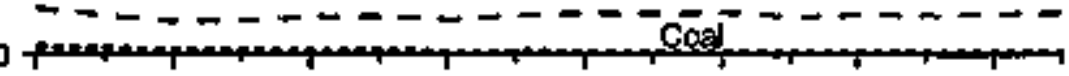
1980
1982
1984
1986
1986
1900
1992
1894

\section{By Fust, 1985}

$6-$

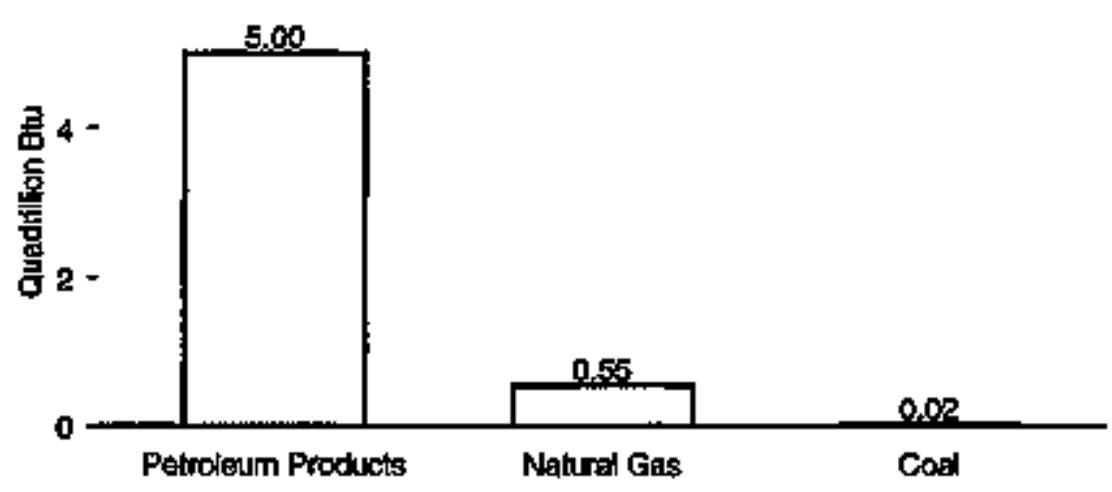

As Share of Total Energy Consumption, 1990-1985

B -

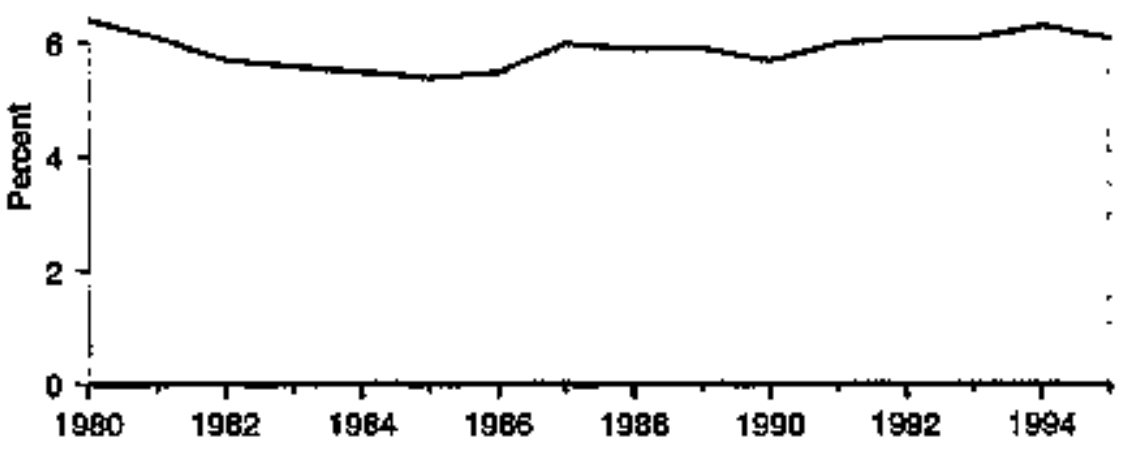

By Petroleum Produkt, t995

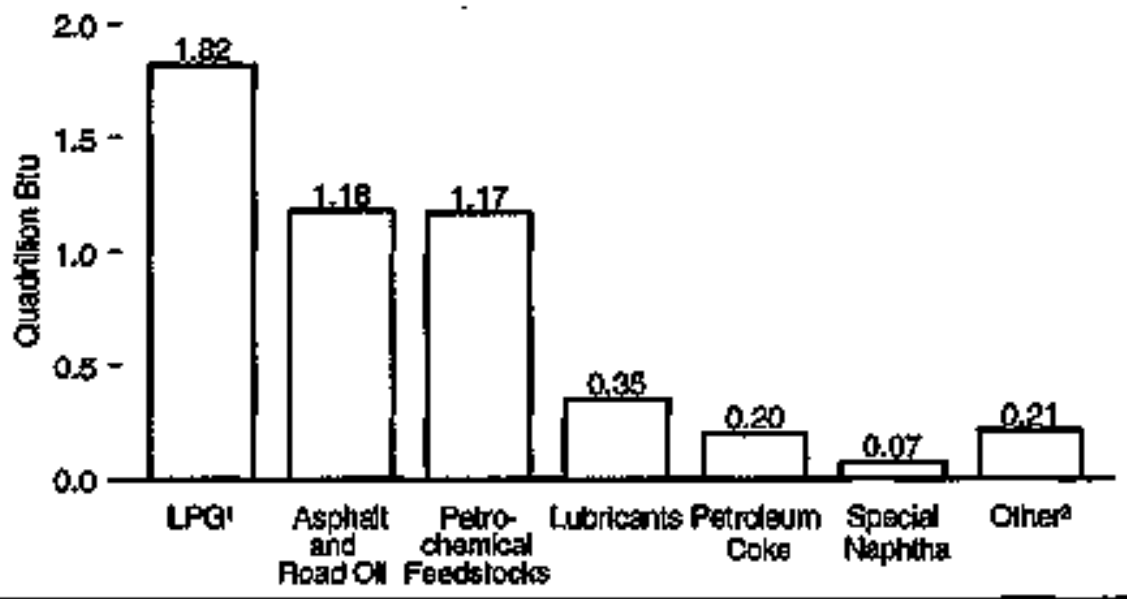

Note: Because verical sceles offifer, grepho should nol be compered, Source: Tabla 1.15.

1 Liqueded peiroloum gaves.

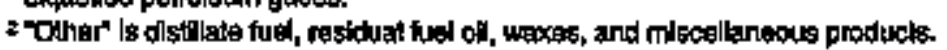


Table 1.15 Fossil Fuel Consumption for Nonfuel Use, 1980-1995

\begin{tabular}{|c|c|c|c|c|c|c|c|c|c|c|c|c|}
\hline \multirow[b]{2}{*}{ Yoar } & \multicolumn{8}{|c|}{ Potroleum Produtets } & \multirow[b]{2}{*}{$\begin{array}{c}\text { Notural } \\
\text { Gas }\end{array}$} & \multirow[b]{2}{*}{ Conk } & \multirow[b]{2}{*}{ Totat } & \multirow[b]{2}{*}{$\begin{array}{l}\text { Percent of } \\
\text { Total Energy } \\
\text { Connumption }\end{array}$} \\
\hline & $\begin{array}{c}\text { Asphsil } \\
\text { ond } \\
\text { Rosd on }\end{array}$ & $\begin{array}{l}\text { Uqualled } \\
\text { Pettoleuth } \\
\text { Gasea }\end{array}$ & Lubeicams & $\begin{array}{c}\text { Potro- } \\
\text { themicend } \\
\text { Poedstotece }\end{array}$ & $\begin{array}{c}\text { Peiroleam } \\
\text { Coke }\end{array}$ & $\begin{array}{l}\text { Specifos } \\
\text { Nephthed }\end{array}$ & Other 1 & Toiv & & & & \\
\hline \multirow{3}{*}{$\begin{array}{l}1980 \\
1981 \\
1985 \\
1983 \\
1984 \\
1985 \\
1985 \\
1997 \\
1988 \\
1909 \\
1990 \\
1994 \\
1995 \\
1993 \\
1994 \\
1995 \mathrm{P}\end{array}$} & \multicolumn{12}{|c|}{ Physical Unils } \\
\hline & $\begin{array}{l}145 \\
126 \\
125 \\
135 \\
149 \\
155 \\
154 \\
170 \\
171 \\
165 \\
164 \\
168 \\
166 \\
173 \\
176 \\
177 \\
\end{array}$ & $\begin{array}{l}291 \\
290 \\
259 \\
267 \\
260 \\
258 \\
269 \\
318 \\
340 \\
345 \\
368 \\
404 \\
411 \\
444 \\
498 \\
496\end{array}$ & $\begin{array}{l}50 \\
58 \\
51 \\
59 \\
57 \\
65 \\
47 \\
59 \\
50 \\
59 \\
60 \\
59 \\
54 \\
58 \\
189 \\
67\end{array}$ & $\begin{array}{c}259 \\
258 \\
160 \\
159 \\
144 \\
143 \\
180 \\
170 \\
174 \\
172 \\
159 \\
203 \\
214 \\
214 \\
214 \\
2224 \\
207\end{array}$ & 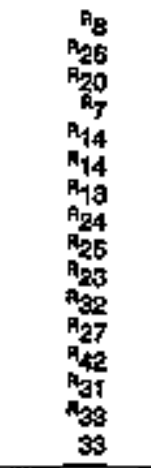 & $\begin{array}{l}37 \\
27 \\
25 \\
30 \\
10 \\
30 \\
24 \\
29 \\
20 \\
20 \\
20 \\
17 \\
20 \\
20 \\
15 \\
13\end{array}$ & $\begin{array}{l}58 \\
54 \\
48 \\
45 \\
38 \\
38 \\
41 \\
40 \\
45 \\
44 \\
40 \\
48 \\
35 \\
35 \\
97 \\
39\end{array}$ & 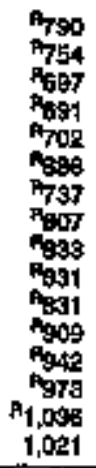 & 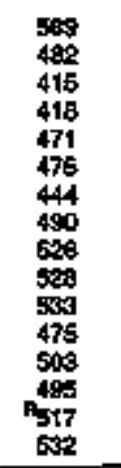 & $\begin{array}{l}2.8 \\
2.3 \\
1.5 \\
1.4 \\
1.6 \\
1.8 \\
0.9 \\
0.8 \\
0.8 \\
0.7 \\
0.8 \\
0.7 \\
0.8 \\
0.8 \\
0.8 \\
0.8 \\
\end{array}$ & $\begin{array}{l}= \\
= \\
= \\
= \\
= \\
= \\
= \\
= \\
=\end{array}$ & $\begin{array}{l}= \\
= \\
= \\
= \\
= \\
= \\
= \\
=\end{array}$ \\
\hline & \multicolumn{12}{|c|}{ Quadition Obu } \\
\hline 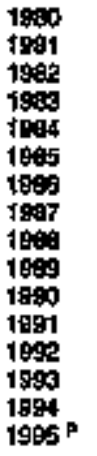 & $\begin{array}{l}0.85 \\
0.85 \\
0.03 \\
0.00 \\
0.99 \\
1.02 \\
1.09 \\
1.18 \\
1.14 \\
1.10 \\
1.09 \\
1.08 \\
1.10 \\
1.15 \\
1.17 \\
1.10\end{array}$ & 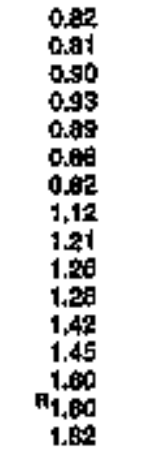 & $\begin{array}{l}0.35 \\
0.34 \\
0.31 \\
0.32 \\
0.35 \\
0.32 \\
0.29 \\
0.35 \\
0.35 \\
0.35 \\
0.37 \\
0.39 \\
0.34 \\
0.34 \\
0.35 \\
0.35\end{array}$ & $\begin{array}{l}1.43 \\
1.39 \\
0.89 \\
0.80 \\
0,91 \\
0.91 \\
1.02 \\
1,00 \\
1.00 \\
1.00 \\
0.92 \\
1,15 \\
1.20 \\
11,21 \\
1,20 \\
1.17\end{array}$ & $\begin{array}{l}0.05 \\
0.15 \\
0.12 \\
0.04 \\
0.08 \\
0.08 \\
0.08 \\
0.14 \\
0.15 \\
0.14 \\
0.19 \\
0.15 \\
0.28 \\
0.18 \\
0.20 \\
0.20\end{array}$ & $\begin{array}{l}0.19 \\
0.14 \\
0.13 \\
0.16 \\
0.21 \\
0.16 \\
0.13 \\
0.14 \\
0.11 \\
0.11 \\
0.11 \\
0.09 \\
0.10 \\
0.10 \\
0.00 \\
0.07\end{array}$ & $\begin{array}{l}0.34 \\
0.32 \\
0.28 \\
0.25 \\
0.24 \\
0.22 \\
0.21 \\
0.23 \\
0.24 \\
0.25 \\
0.23 \\
0.25 \\
0.21 \\
0.20 \\
0.22 \\
0.21\end{array}$ & $\begin{array}{r}4.14 \\
3.93 \\
3.57 \\
3.47 \\
3.55 \\
3.47 \\
3.64 \\
4.41 \\
4.09 \\
4.01 \\
4.09 \\
4.49 \\
4.65 \\
4.78 \\
0.07 \\
5.00\end{array}$ & $\begin{array}{l}0.60 \\
0.50 \\
0.43 \\
0.43 \\
0.49 \\
0.45 \\
0.46 \\
0.50 \\
0.54 \\
0.54 \\
0.65 \\
0.49 \\
0.50 \\
0.61 \\
0.53 \\
0.55\end{array}$ & $\begin{array}{l}0.09 \\
0.07 \\
0.04 \\
0.04 \\
0.04 \\
0.05 \\
0.02 \\
0.03 \\
0.02 \\
0.02 \\
0.02 \\
0.02 \\
0.02 \\
0.02 \\
0.02 \\
0.02\end{array}$ & $\begin{array}{r}4.83 \\
4.50 \\
4.04 \\
3.94 \\
4.06 \\
4.01 \\
4.14 \\
4.54 \\
4.76 \\
4.77 \\
4.68 \\
5.00 \\
5.10 \\
5.31 \\
1.56 \\
5.57\end{array}$ & $\begin{array}{l}0.4 \\
6.1 \\
5.7 \\
5.6 \\
5.5 \\
6.4 \\
6.5 \\
6.0 \\
5.9 \\
6.9 \\
5.7 \\
6.0 \\
6.7 \\
6.1 \\
8.3 \\
8.1\end{array}$ \\
\hline
\end{tabular}

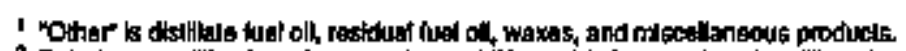

2 Petroleurn - million bamels; notural gas - biton cubla lant and cost - matllon short bona.

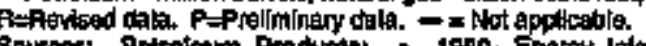

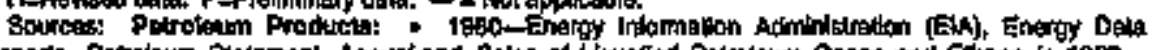

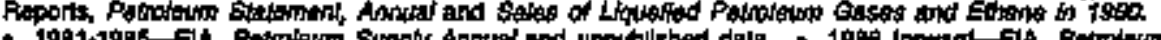

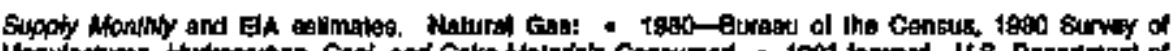

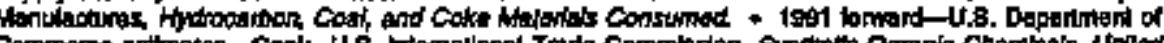

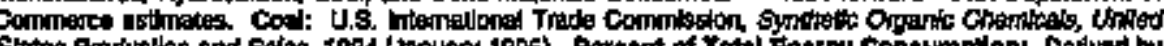
stotes Prow disting toten by ketel conaumplion on Table y.a. 


\section{Energy Overview Notes}

1. Data on the generation of electricity in the United States represent net generation, which is gross output of electricity (measured at the generator terminals) minus power plant use. Nuclear electricity generation data identified by individual countries in Section 11 are gross outputs of electricity.

2. Table 1.14 Sources: Coal: 1949-1980-U.S. Geological Survey, Coal, Phosphate, Potash, Sodium, and Other Mineral Production, Royalty Income, and Related Statistics, June 1981. 1981 forward-U.S. Mirerals Management Service, Mineral Revenues-The 1992 Report on Receipts from Federal and Indian Leases, and predecessor annual reparts.
All Other Data: 1949-1980-U.S. Geological Survey, Oit and Gas Production, Royalty Inceme, and Related Statistics, June 1981; Department of Erergy, Office of Naval Petroleum and Oil Shale Reserves, unpublished data; and U.S. Geological Survey, National Petroleum Reserve in Alaska, nnpublished data, 1981-1983-U.S. Minerals Mansgement Service, Mineral Revenues-The 1983 Report on Receipts from Federal and Indian Leases, and predecessor annual reports; Department of Energy, Office of Naval Petroleum and Oil Shale Reserves, unpublished data; and U.S. Geological Survey, National Petroleum Reserve in Alaska, nnpublished data. 1984 forward-U.S. Minerals Management Service, Mineral Revenues-The 1992 Report on Receipts from Federal and Indian Leases, and predecessor annual reports; Department of Energy, Office of Naval Petroleum and Oil Shale Reserves, unpublished data. 


\section{End-Use Energy Consumption}

\section{Types of Consumption Data}

The Energy irformation Administration pubalshes two sels of siatistics on end-use energy consumpition. The first set, based on surveys difected to suppliars and markelers, provides continuous series for the years 1949 through 1995 and allocates U,8. total energy consumption to one of three end-use sectors; infustriat, residential and commeroiat, or transportation. The second set, based on surveys ditected to end-users of energy, provides detalied intormation on the types of energy consumed and the energy-related characterisilics of maryfacturing establishmenls, commercial bulldings, households, and household vehiches.

\section{End-Use Energy Overview, 1949-1995}

Industriat. Energy consumption by the industrial sector increased throughout the 1960's and in 1973 reached 32 quadrillion Btu. Of the three end-use sectors, the industrial sector proved to be the most responsive to the turmoil in energy markets after the 1973-1974 embargo (2.1). * In 1979, industrial consumption of energy reached the then-record level of 33 quadrillion Bu. In the early 1980's, a stagnant economy restrained industrial consumption, which declined to a 16year low of 26 quadrillion Bu in 1983, In 1988 and 1989, economic growth spurred demand for energy in the industrial sector, and industrial energy consumption in 1989 rose to 29 quadrillion Btu. Despite slow economic growth in the early 1990's, industrial energy consumption trended upward. In 1995, industrial consurnption of energy reached 34 quadrillion Btu, the highest level recorded.

Residential and commerotal. Mach of the growth in energy consumption during the 1949-through-1995 period occurred in the residential and commercial sector (2.1). Residential and commercial consumption leveled off in response to higher energy prices in the late

* Wumbers in parentheses indicate rotaled tables. Annual data ans the most recent avatiable; they frequentily are presisndnary and may be revised in future publicalions. Percentagss and numbers in toxt ars caloufated by using dats in the tables.
1970 's and early 1980's, but lower prices in the 1986-through-1995 period played a role in boosting residential and commercial energy consumption to the record level of 32 quadrillion Btu in 1995.

Transportation. Energy consumption by the transportation sector was primarily petroleum consumption. Over the 47 -year period, the transportation sector's consumption of petroleum more than tripled, but growth was slower during the 1980's than in previous decades. In 1995, consumption of petroleum in the transportation sector totaled 24 quadrillion Btu, also a record level.

\section{Consumption of Energy for Manufacturing in 1991}

The U.S. manufacturing sector consumed an estimated 20 quadrillion Btu' of energy in 1991. Naturall gas accounted for 6.1 quadrillion Btu, a 30-percent share of total energy consumption (2.2). Net electricity ${ }^{2}$ accounted for 2.4 quadrillion Bar, a 12-percent share, and coal consumption accounted for $\mathbf{2 . 0}$ quadrillion Btu, a 10-percent share. Fuel oil consumption of 0.6 quadrillion Btu accousted for a 3.0-percent share.

Of all the industries, the petrolenm and coal products industry was the largest user of energy in 1991, consuming 6.0 quadrillion Btn. At 5.1 quadrillion Btu, the chemicals and allied products industry was the second largest user. Together, the two industries accounted for mors than half of the energy consumed in the manufacturing sector.

Because the manufacturing sector accounts for a large share of total U.S. energy consumption, manufacturers' ability to cope with fluctuations in energy supplies and prices by switching to alternative sources of energy plays a significant role in the Nation's energy security. Fuel

IThe manufacturing sector is composed of estabtistoments that use mechtonical or chemical processes to iringtorm raw materials into intermodints or final prodocts. It does sol include the remainder of the industrial sector (coastroction, mining asricultural, fithing, and forestry sstabilsbments) or electric utilitles. The 20 qundriltion Btw toid ls the pribsary cousunpwion of energy, it inctudes ebergy cossumed to produce hent and power and to generate electicity. as woll as sources of enorry consumed as petrochemieal feedstocks and raw matoriat inpuls. but it excludes byproduct fuels produced from other energy souress.

Net electricity is obtained by summing purchases, transfers is, and generation from noncombusilble renewable resources, minus quantities sold and trassierrod out. It excledos

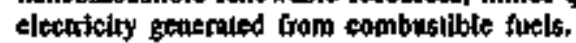


switching to alternative sources of energy plays a significant role in the Nation's entrgy security. Fuel switiching capability in 1991 was deternined for frve major energy sources: natural gas, purchased electricity, coal, residual fuel oil, and distillate fuel oil (2.3).

Residual fuel oil registered the largest vatue (45 percent) for switchable consumption as a percentage of actual consumption, indicating substantial fuel-switching capabilitjes. In addition, 20 percent of distillate fuel oil consumption could have been supplied by other sources. It is estimated that about 99 thousand bartels per day of fuel oil (residtha! and distillate combined) consumed could have been switched to nonpetroleum sources.

Natural gas registered the largest absolute amount of total switchable consumption. Of the 5.5 quadrillion Btu total of natural gas consumption, 1.9 quadrillion Btu (35 percent) could have been switched to other sources. Of the $\mathbf{1 . 2}$ quadrillion Btu of coal consumed, 0.5 quadrillion Bth (45 percent) were switchable. Very little (less than 3 percent) of the 2.5 quadrillion Btu of purchased electricity consumed by manufacturers in 1991 could have been switched to other sources if manufacturing output were to be maintained.

\section{Household Uses of Energy in 1993}

In 1993, household energy consumption totaled 10 quadrillion Btu and energy consumption per household averaged 104 million Btu (2.9). Household energy consumption is strongly influenced by climate. Households in the West and South consumed the least amount of energy in 1993, an average of 76 million Btu per household in the West and 88 million Btu per household in the South. Consumption in the colder climates was higher in 1993; households in the Midwest averaged 134 million Btu per household and those in the Northeast 122 million Ba per household. Many other factors influence consumption, including the fact that houses in the Northeast and Midwest tend to be larger and oIder.

Energy consumed by households can be attributed to four primary applications: space heating, atr conditioning, water heating, and appliance operation (2.10). In 1993, space heating was the most prevalent application of energy consumed by households and accounted for 5.3 quadrillton Btu. Natural gas was the primary source of energy for

${ }^{3}$ The capability of U.S. manufacurers to swluch fuels within 30 days, wing only existing squdpment and kecping production output consiant space heating and provided the main source of heat in 51 million households (2.11). Natural gas was also the primary source of energy for water heating (2.10).

\section{Natural gas was the primary source of energy for space heating and provided the main source of heat in 51 miltion households in 1993.}

About 2.4 quadrillion Btu were sused to operate appliances and, as would be expected, olectricity was the major source of energy for that application. Refrigerators, color televiston sets, ovens (regular and microwave), and clothes washers were the most common household appliances (2.12).

Electricity was essentially the only source of energy used for air conditioning. Although air conditioning accounted for only 4.6 percent of household energy consurntion, it accounted for 9.1 percent ( $\$ 11.3$ billion) of total household energy expenditures of $\$ 124$ billion (2.10).

The cost of energy used to operate appliances totaled $\$ 56$ bitlion in 1993 , and the cost for space heating was $\$ 40$ billion. Energy expenses for water heating came to about $\$ 17$ billion.

\section{Improvements in Passenger Car Efficiency, 1973-1994}

Because motor gasoline consistently accounts for the largest share of all petroleum products supplied (5.11), motor gasoline consumption has a significant effect on U.S. dependence on foreign sotures of crude oil. Following the oil embargo in the mid-1970's, concerns about U.S. dependence on foreign oil led to interest in improving motor vehicle efficiency.

In 1973, average annual mileage exceeded 10 thousand miles per passenger car (2.15). The average futel rate of passenger cars, which make up a sizable proportion of the U.S. motor vehicle fleet, was 13 miles per gallon. That measure of fuel efficiency had dectined for the previous several years. 
In 1973 and 1974, however, crude oil supply interruptions and rising prices led to public concem over the continued availability of motor gasoline. The immediate effect of higher prices was a decline in mileage to an average of 9.6 thousand miles per passenger car in 1974 (2.15). At the same time, the average frel rate of the passenger car fleet began to improve. It increased throughout the $1970^{\prime}$ 's and $1980^{\prime} \mathrm{s}$, peaking at an average of 21.7 miles per gallon in 1991. In 1994, the fuel rate was 21.5 miles per gallon. The Federal Corporate Average Fuel Economy standards, which required automobile manufacturers to meet fleet fuel-rate minimum averages, played a major role in the increase in fuel rates.

\section{Energy Consumption by Household Vehicles in 1994}

In spite of the recent rapid growth in the number of minivans and sport-utility vehicles owned by U.S. households, the average on-road fuel efficiency of the household vehicle fleet rose from 15 mites per gallon in 1983 to 20 miles per gallon in $1994(2,14)$. In 1994, nearly 85 million househoids owned or had access to at least one vehicle. The 157 million household vehicles traveled a total of 1.8 trillion miles, up from 1.2 trillion miles in 1983.

In 1994, household vehicles consumed 87 billion gallons of unleaded motor gasoline and a quantity of leaded motor gasoline too small to be accurately measured. Consumption in 1991 was 81 billion gallons, of which 96 percent was unleaded. In 1983, by comparison, 59 percent of the 79 billion gallons consumed was unleaded. The average price of motor gasoline was slightly lower in 1994 than in 1983. According to household survey data, unleaded motor gasoline averaged $\$ 1.16$ per gallon in 1994, down from $\$ 1.22$ per gallon in 1983 .

\section{Energy-Related Characteristics of Commercial Buildings in 1992}

Commercial buildings are those which house mercantile, service, office, ecucation, and other activities. In 1992, there were approximately 68 bitlion square feet of commercial floorspace in the United States (2.17). The largest amrount of commencial floorspace, 25 billion square feet, was found in the South and accostnted for 36 percent of the U.S. total. On the basis of the amount of commercial floorspace in which a given energy source is consumed, electricity was the most prevalent. Electricity was an energy source for almost 67 billion square feet of commerciai floorspace. Natural gas was also comumonly used and supplied energy for 45 billion square feet. Fuel oil, district heat,' and propane were consumed in smaller, but still significant, amounts in commercial buildings.

On a Btu basis, electricity and natural gas were the most common sources of energy in commercial buildings (2.20). In 1992, 2.6 quadrillion Btu of electricity and 2.2 quadrillion Btu of natural gas were consumed in commercial butldings. Consumption of district heat totaled 0.4 quadrillion Btu and consumption of fuel oil totaled 0.3 quadrillion Btu. (Propane also supplied small amounts of energy tn commercial buildings, but propane data were not collected in 1992.)

Of the $\$ 72$ billion spent on energy for commercial buildings in 1992 , by far the largest amount went for electricity (2.20). Electricity expenditures came to $\$ 58$ billion, whereas expenditures for natural gas came to $\$ 9.9$ billion. Expenditures for district heat were $\$ 2.9$ billion and expenditures for fuel oil were $\$ 1.4$ billion.

Adsiticl heal is stenm or hoc waler that circolates from a central plant ox utility. 


\section{By End-Jas Sector}

$40-$

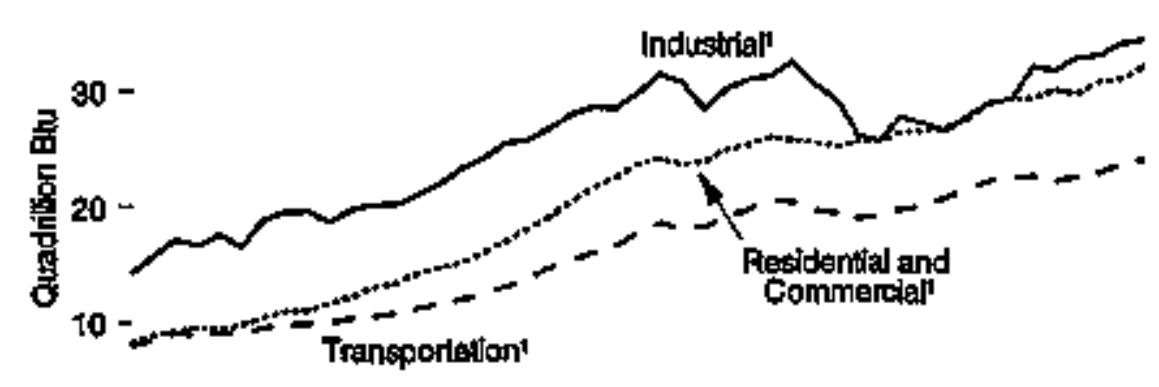

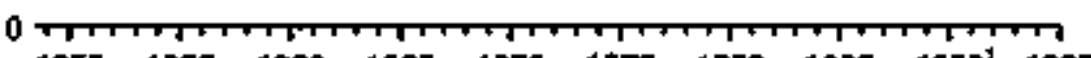
$\begin{array}{llllllllll}1950 & 1955 & 1960 & 1965 & 1970 & 1975 & 1980 & 1985 & 1990 & 1995\end{array}$

\section{Industral Sector}

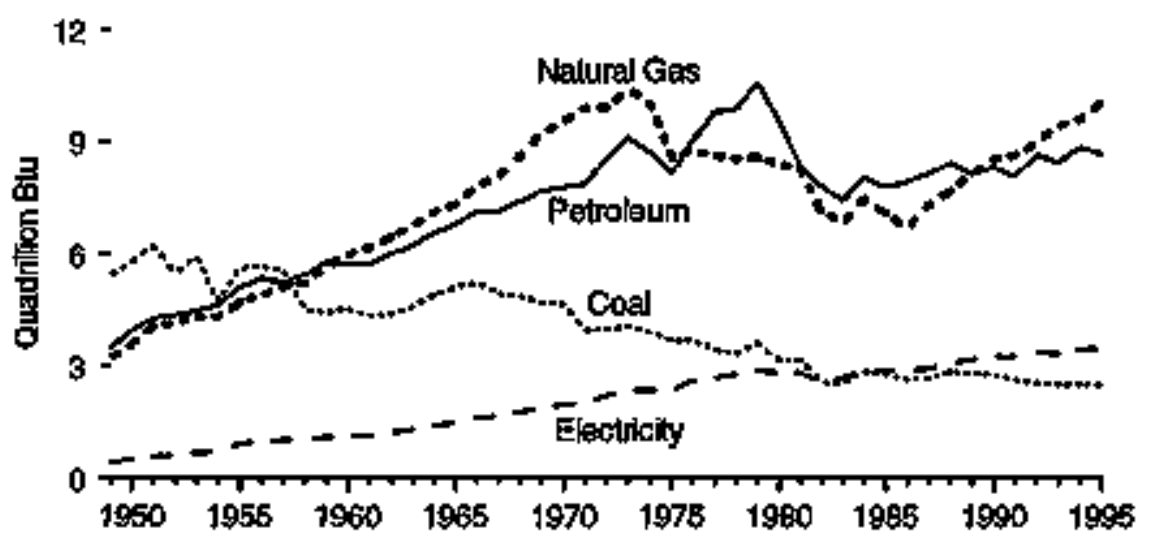

\section{Fesidentlal and Commercial Bector}

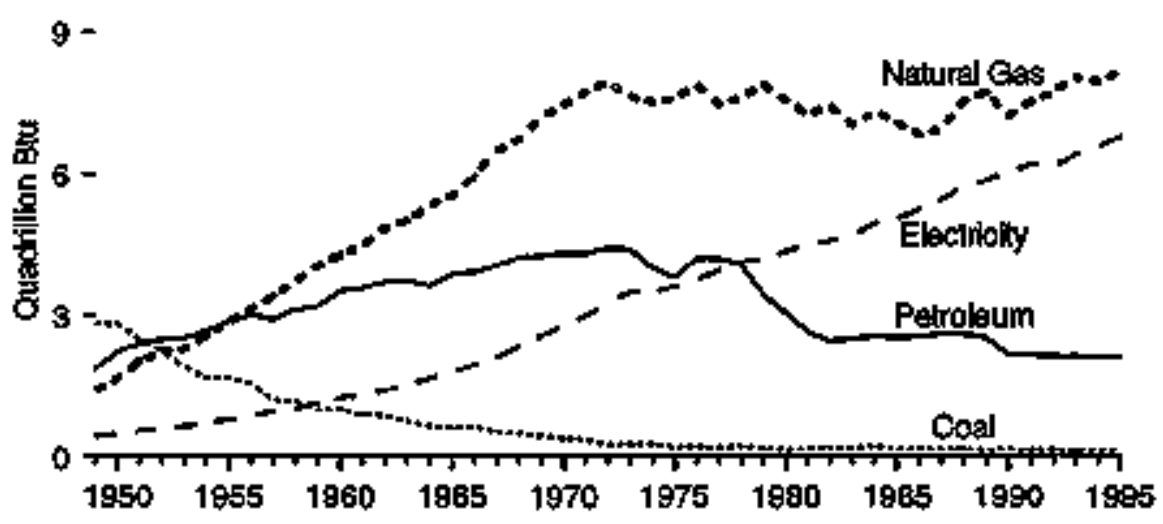

Transportaklon Sector

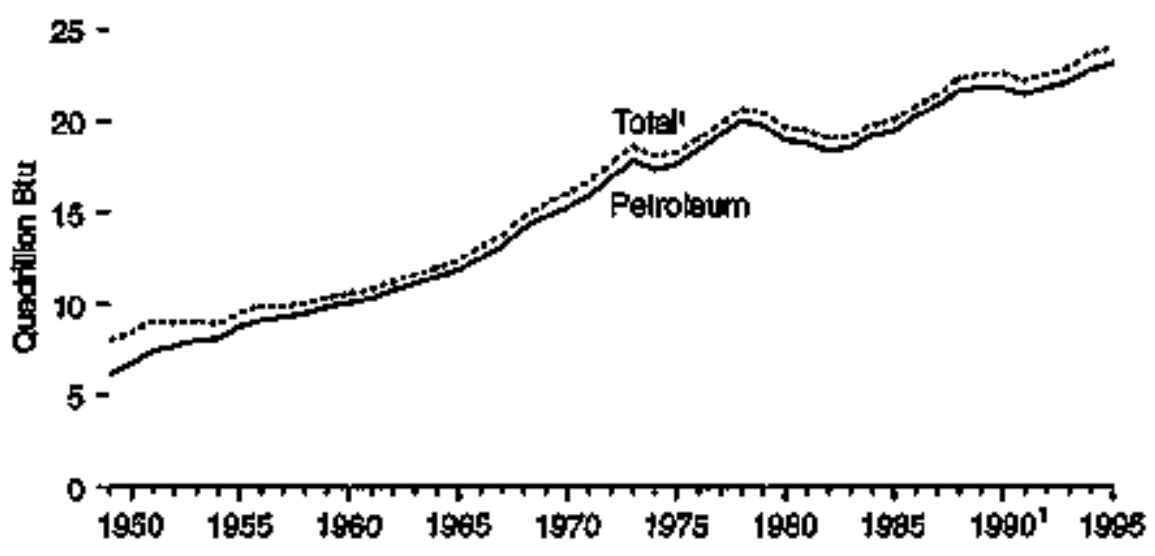

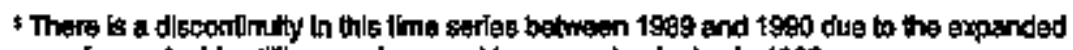
coverage of non-etectite uillty use of renewable energy begining In 1990 .

Nole: Beceuse verticel scales differ, graphs should not be compared, Source: Table 2.1. 
Table 2.1 Energy Consumption by End-Use Sector, 1949-1995

(Quadrittion Btu)

\begin{tabular}{|c|c|c|c|c|c|c|c|c|c|c|c|c|c|c|c|}
\hline \multirow[b]{2}{*}{ Veor } & \multicolumn{6}{|c|}{ Regidenilal and Comprerciell } & \multicolumn{6}{|c|}{ Inclustrlat : } & \multicolumn{2}{|c|}{ Trensportation } & \multirow[b]{2}{*}{ Toket 3} \\
\hline & Coot & Natural & Pesroloim & Electricliy & Lobaes 2 & Totals & Cool & $\begin{array}{l}\text { Malurel } \\
\text { Gow } 1\end{array}$ & Pouroleum & Eleosidalty & Loyses 2 & Tolel an & Petroloum & Totol & \\
\hline 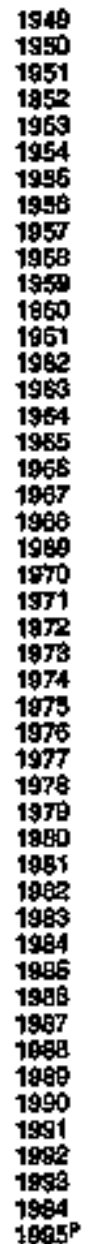 & 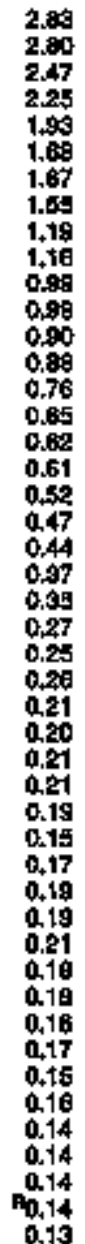 & 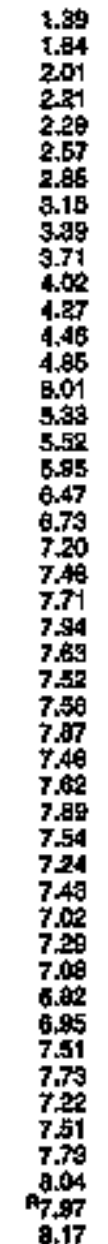 & 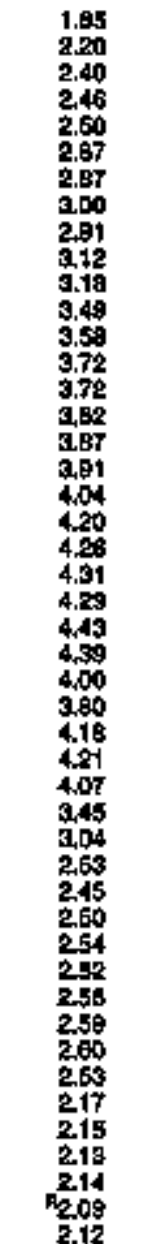 & 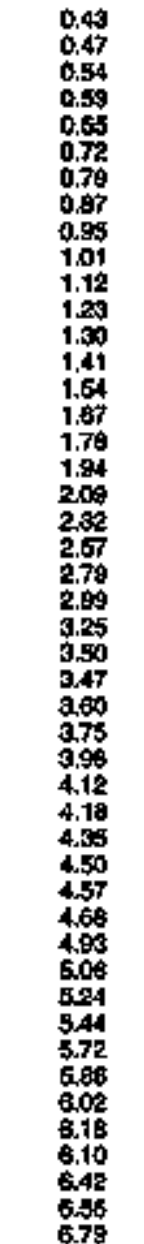 & 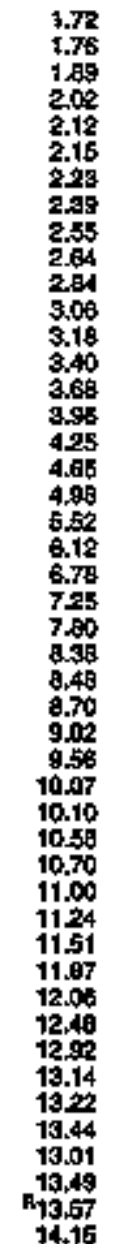 & 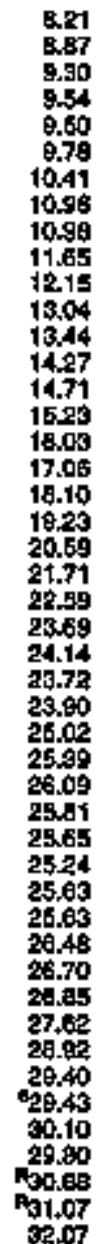 & 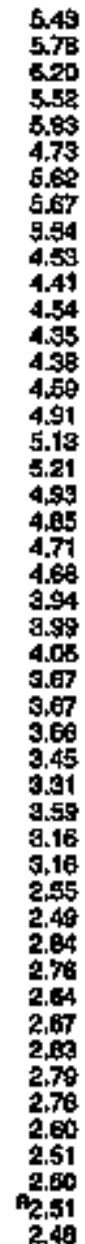 & 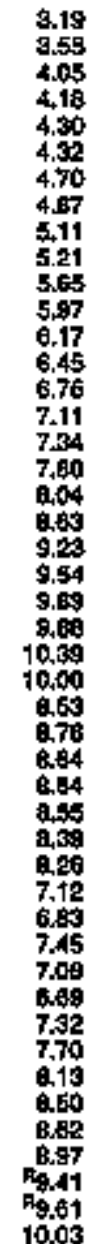 & 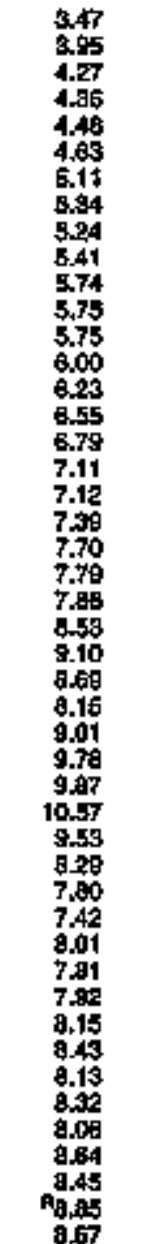 & 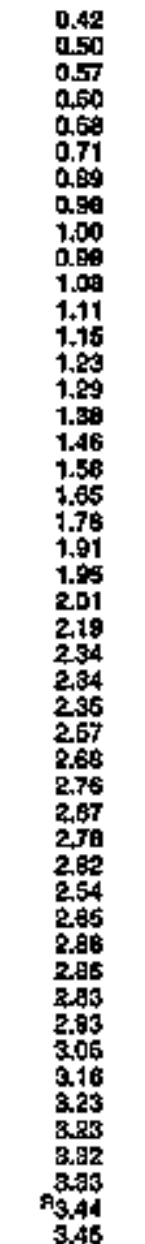 & 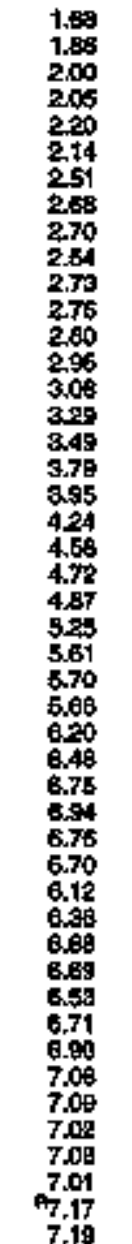 & 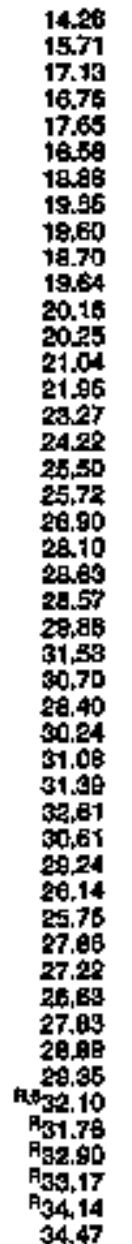 & 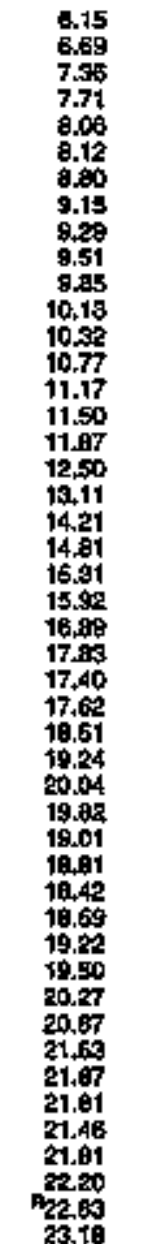 & 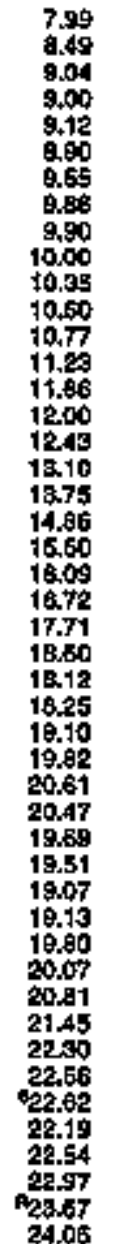 & 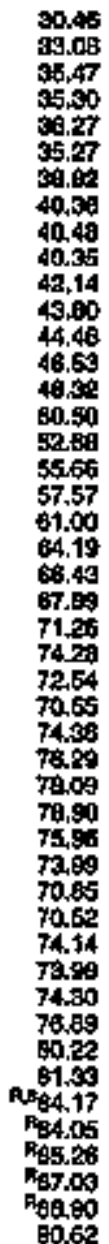 \\
\hline
\end{tabular}

1 hourdes supplemantal naturei pas.

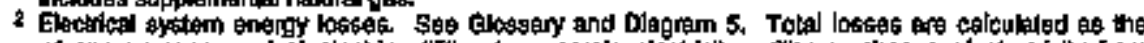

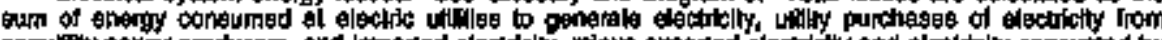

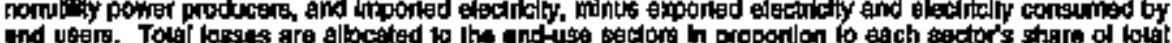

Wisofichly. uga.

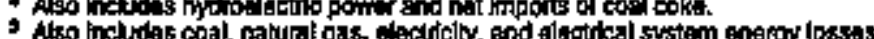

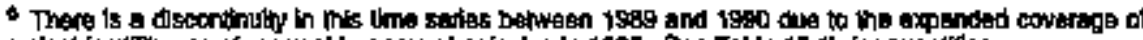

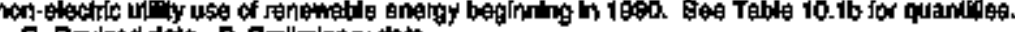

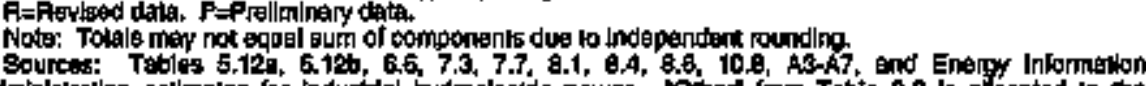

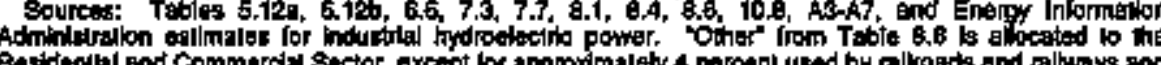

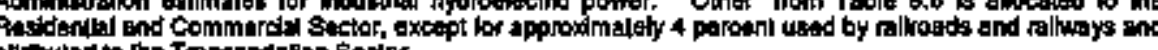
alinuled to the Transportaron sector. 
By lndustry and Type of Consumption

$$
24-
$$

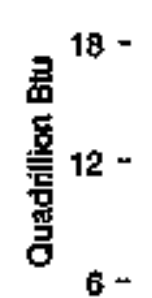

Ofisite-Produced Energy to Produce Haat, Power, and Electrichy" Total Energy Consumed to Produce Heal, Powex, and Electrioty 2

firnary Consumption of Energy ${ }^{3}$

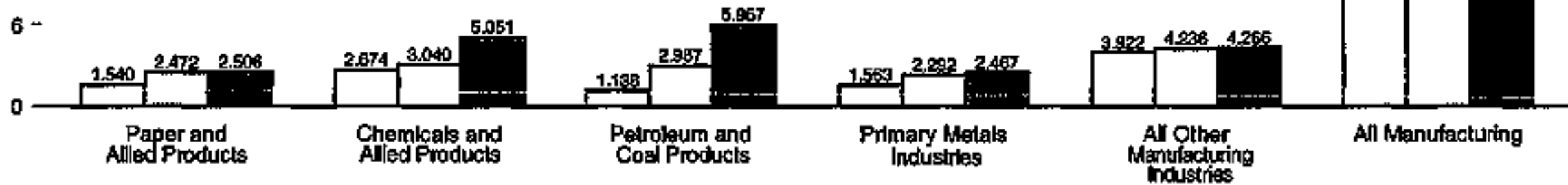

Prtmary Energy Consumption by Industry

Primary Energy Consumption by Source

$40-$

莺 20 -

$30-28$

$10-$

0

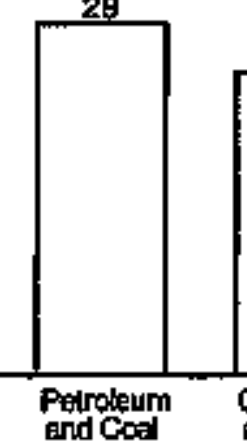

25

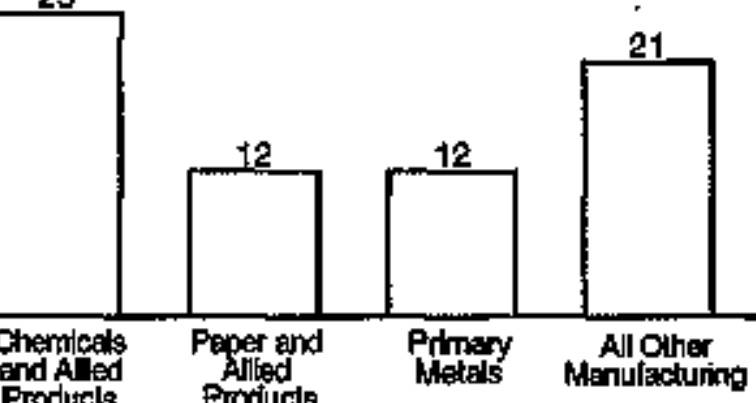

$10-$

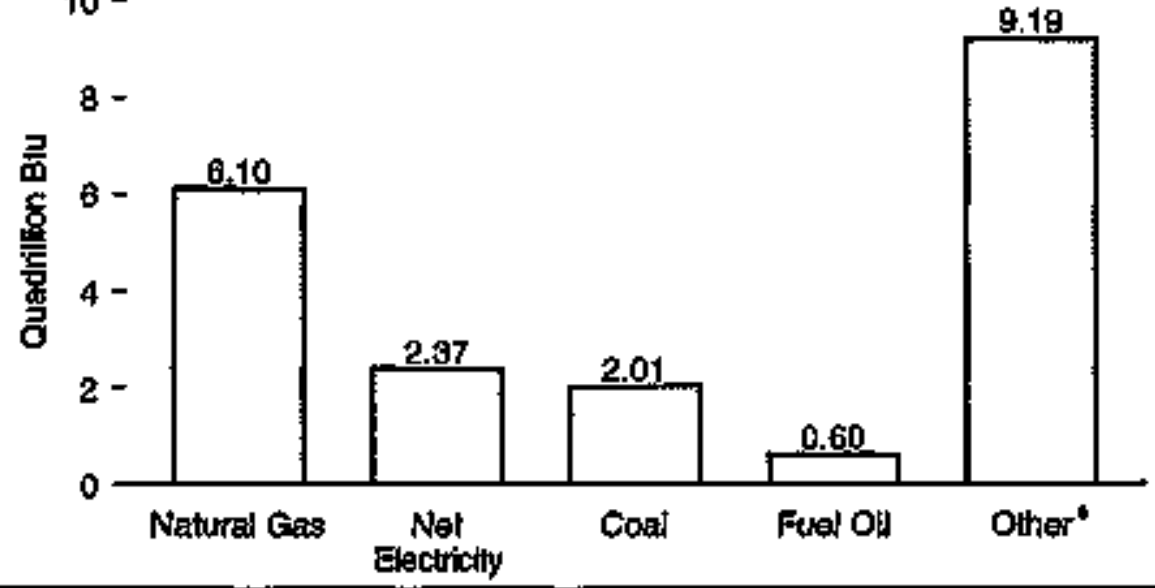

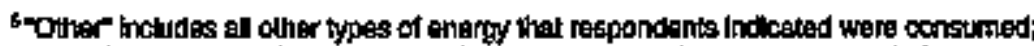

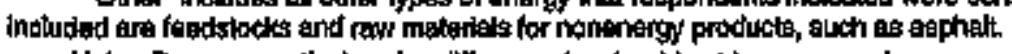
Note: Because vertical scalos differ, graphs should not be companed.

Source: Table 22

' Eneroy thal was produced ofistie and then acquired by purchese or ranstar and consimed onsthe tor the production of heat or powter.

2 insiludes by produel anarey.

I includes teedstocks; does not Inciude by-product tuets.

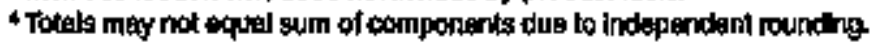


Table 2.2 Manufacturing Energy Consumption Measures, 1991

(Quadirilion Btu, Except as Noted)

\begin{tabular}{|c|c|c|c|c|c|c|c|}
\hline Type of Consumption end Solectod Industutis & Not Elootriklty & Fu혀 에 & Nahiral Gág & Cabl & Other 2 & Tolv & Parkent \\
\hline 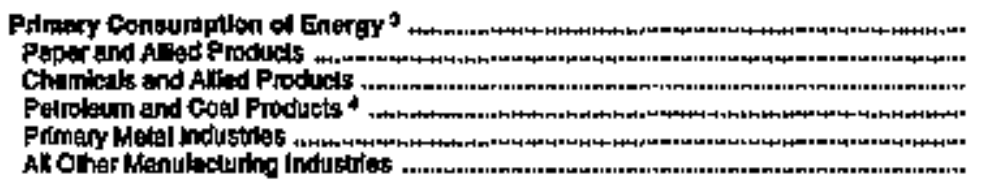 & $\begin{array}{l}2.370 \\
0.201 \\
0.440 \\
0.105 \\
0.499 \\
1.125\end{array}$ & $\begin{array}{c}0.000 \\
0.165 \\
W \\
\text { o.08s } \\
W \\
W\end{array}$ & $\begin{array}{l}6.068 \\
2.2 \% 7 \\
0.708 \\
W\end{array}$ & $\underset{W}{\mathbf{W}}$ & $\begin{array}{r}0.166 \\
w \\
w \\
w \\
w\end{array}$ & $\begin{array}{r}20.257 \\
2.506 \\
5.051 \\
6.067 \\
2.407 \\
4.266\end{array}$ & $\begin{array}{r}100 \\
12 \\
25 \\
99 \\
12 \\
21\end{array}$ \\
\hline 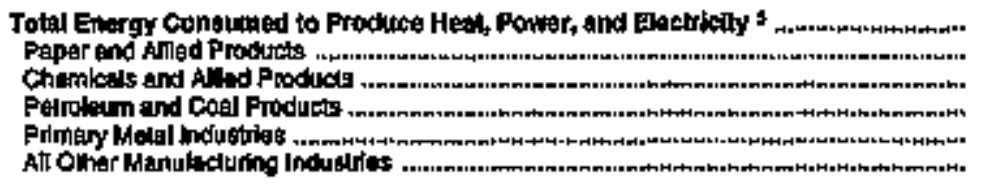 & $\begin{array}{l}2.370 \\
0.004 \\
0.440 \\
0.105 \\
0.499 \\
1.125\end{array}$ & $\begin{array}{l}0.553 \\
0.165 \\
0.060 \\
0.106 \\
0.044 \\
0.176\end{array}$ & $\begin{array}{l}5.508 \\
0.546 \\
1.689 \\
0.838 \\
0.686 \\
1.765\end{array}$ & $\begin{array}{r}1.184 \\
0.295 \\
0.253 \\
W \\
W\end{array}$ & $\begin{array}{l}5.4 t 4 \\
1.269 \\
0.519 \\
W \\
w \\
w\end{array}$ & $\begin{array}{r}16.027 \\
2.472 \\
3.040 \\
2.997 \\
2.292 \\
4.236\end{array}$ & $\begin{array}{r}100 \\
16 \\
20 \\
20 \\
15 \\
29\end{array}$ \\
\hline 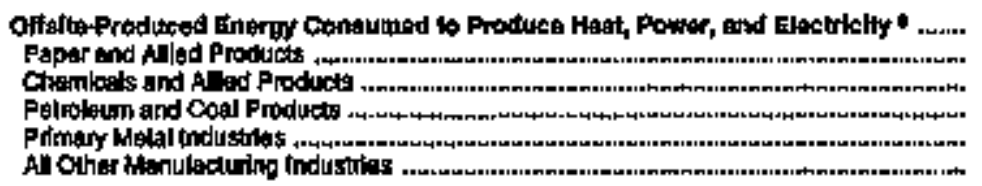 & $\begin{array}{l}2.451 \\
0.2912 \\
0.474 \\
0.114 \\
0.502 \\
1.139\end{array}$ & $\begin{array}{l}0.485 \\
0.165 \\
0.059 \\
0.041 \\
0.044 \\
0.176\end{array}$ & $\begin{array}{l}5.492 \\
0.648 \\
1.685 \\
0.098 \\
0.086 \\
1.769\end{array}$ & $\begin{array}{r}1.175 \\
0.292 \\
0.249 \\
W \\
0.046\end{array}$ & $\begin{array}{c}1.234 \\
0.313 \\
0.227 \\
W \\
0.285 \\
w\end{array}$ & $\begin{array}{r}10,637 \\
1,540 \\
2.874 \\
1,138 \\
1,560 \\
3.922\end{array}$ & $\begin{array}{c}100 \\
14 \\
25 \\
11 \\
14 \\
30\end{array}$ \\
\hline
\end{tabular}

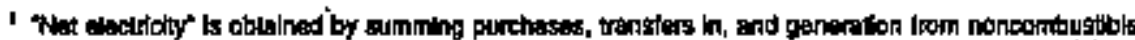

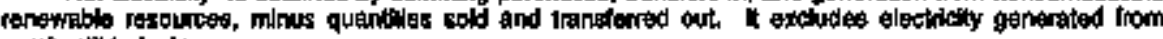

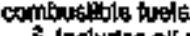

2 Incledes alf ther types ol eneroy that respondents indfoated mere consumed.

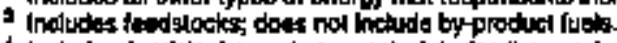

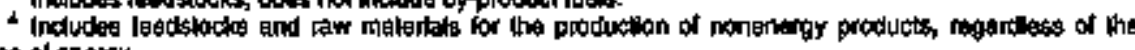

tyos al energy.

Induster by-product energy.

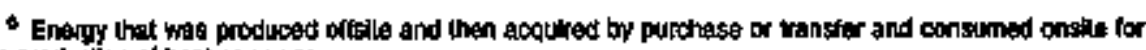
the production ol heal or pown.

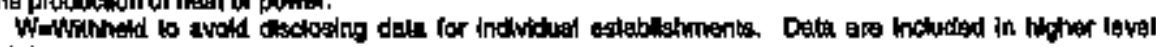
Iolals.

Notes Totals may nol exuat aum of components dus lo indepandant rounding.

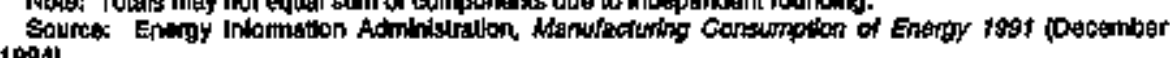
1994). 

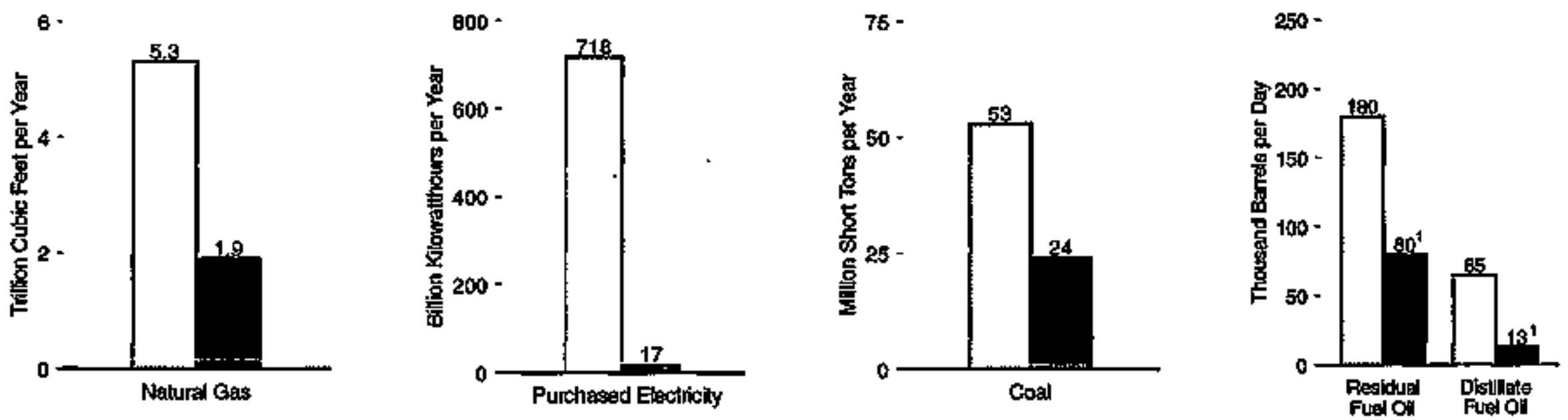

DAclual Constumption $\square$ Total Switchable

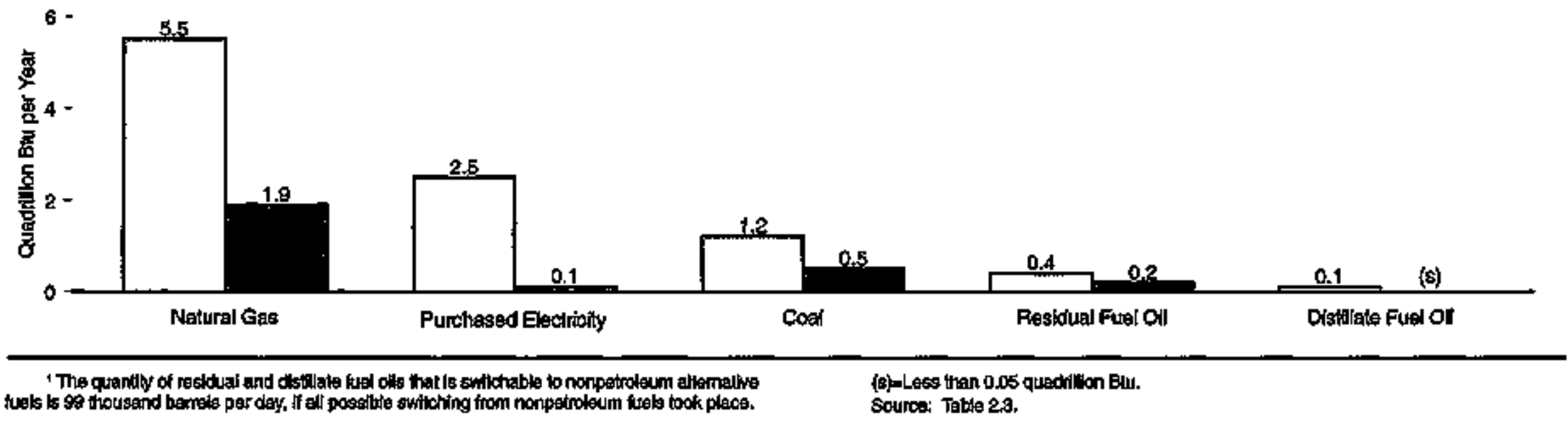


Table 2.3 Manufacturing Fuel-Switching Capabllity Within 30 Days, 1991

\begin{tabular}{|c|c|c|c|c|c|c|c|c|c|c|}
\hline \multirow[b]{2}{*}{$\begin{array}{l}\text { Messiura of } \\
\text { Canatumption }\end{array}$} & \multicolumn{2}{|c|}{ Notural Gas } & \multicolumn{2}{|c|}{ Purchusad Electridoly ? } & \multicolumn{2}{|c|}{ conl } & \multicolumn{2}{|c|}{ festodual Fuod on } & \multicolumn{2}{|c|}{ Oisultise Fues On } \\
\hline & $\begin{array}{l}\text { Bution } \\
\text { Cubic } \\
\text { Feet } \\
\text { Pen Yous }\end{array}$ & $\begin{array}{c}\text { Cundrilion } \\
\text { Btu } \\
\text { parYur }\end{array}$ & $\begin{array}{l}\text { Mlaton } \\
\text { Klowat:- } \\
\text { horst: } \\
\text { peqr Yeptar }\end{array}$ & $\begin{array}{c}\text { Guadililon } \\
\text { Btu } \\
\text { parYoat }\end{array}$ & $\begin{array}{l}\text { Thoputand } \\
\text { shoit } \\
\text { Tons } \\
\text { par Yoer }\end{array}$ & $\begin{array}{c}\text { Oundrillion } \\
\text { Bqus } \\
\text { per Yoir }\end{array}$ & $\begin{array}{l}\text { Thausend } \\
\text { Eamels } \\
\text { per Dey }\end{array}$ & $\begin{array}{c}\text { Oundtalon } \\
\text { But } \\
\text { part Yons }\end{array}$ & $\begin{array}{l}\text { Thousand } \\
\text { Eurnds } \\
\text { per Doy }\end{array}$ & $\begin{array}{c}\text { Quodrllion } \\
\text { Btu } \\
\text { per Yor }\end{array}$ \\
\hline 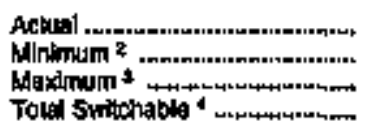 & $\begin{array}{l}5,345 \\
6,495 \\
5,097 \\
1,600\end{array}$ & $\begin{array}{l}5.505 \\
3.590 \\
6.064 \\
1.916\end{array}$ & $\begin{array}{r}718,4 \mathrm{gD} \\
701,47 \mathrm{~B} \\
766,887 \\
17,003\end{array}$ & $\begin{array}{l}2.451 \\
2.398 \\
2.017 \\
0.056\end{array}$ & $\begin{array}{l}53,039 \\
29,423 \\
68,006 \\
23,610\end{array}$ & $\begin{array}{l}1.181 \\
0.655 \\
1.314 \\
0.526\end{array}$ & $\begin{array}{r}100 \\
100 \\
663 \\
80\end{array}$ & $\begin{array}{l}0.414 \\
0.299 \\
1.289 \\
0.185\end{array}$ & $\begin{array}{r}65 \\
52 \\
561 \\
513\end{array}$ & $\begin{array}{l}0.139 \\
0.111 \\
1.171 \\
0.008\end{array}$ \\
\hline
\end{tabular}

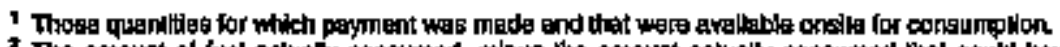

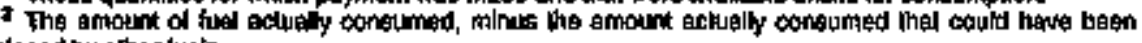
replacad by other Wuly.

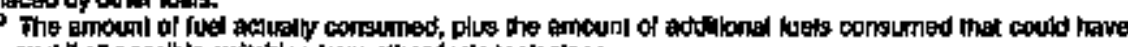

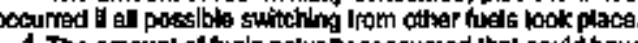

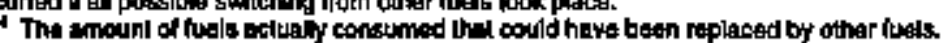

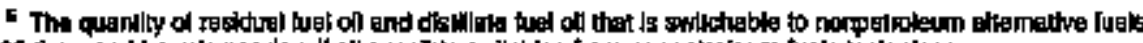

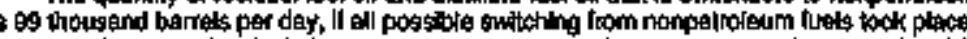

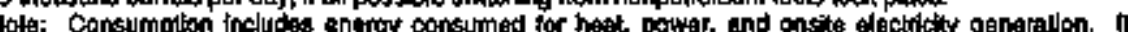
(1)

Soum 


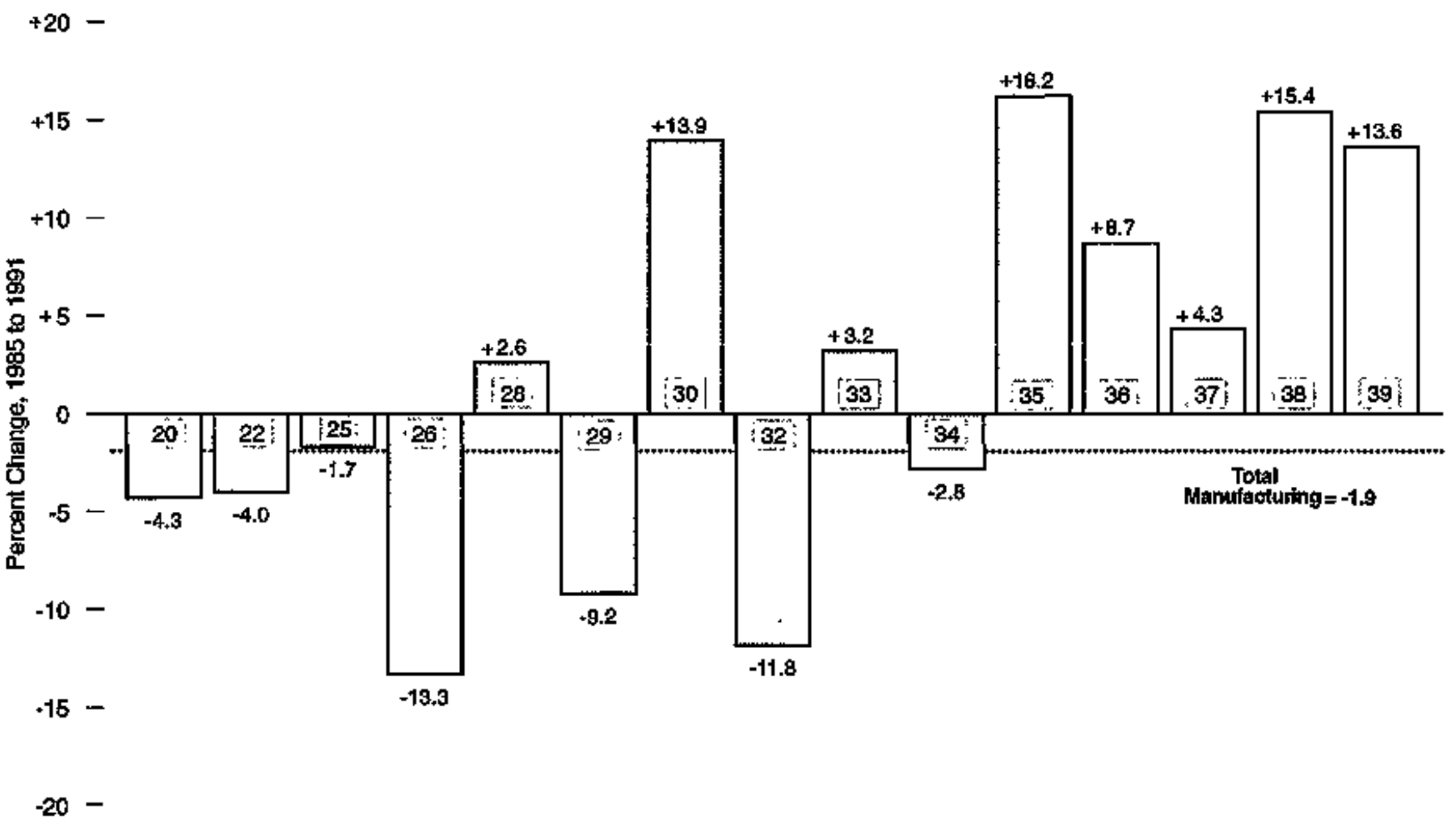


Table 2.4 Manufacturing Energy Intensity by Industry, 1985, 1988, and 1991

\begin{tabular}{|c|c|c|c|c|c|c|c|}
\hline \multirow{2}{*}{$510^{2}$} & \multirow[b]{2}{*}{ Mejor Gicoup and lndasting } & \multicolumn{3}{|c|}{ 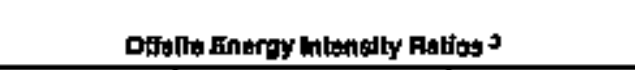 } & \multicolumn{3}{|c|}{ Otislio Exergy linonsily Charge ' } \\
\hline & & 10 & t969 & 1991 & thes to 1998 & 1955 lo tgs & 10601001 \\
\hline $\begin{array}{l}20 \\
34 \\
29 \\
23 \\
24 \\
25\end{array}$ & 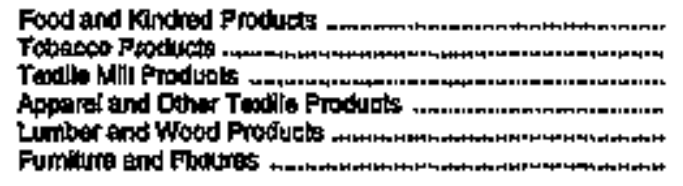 & $\begin{array}{l}2.53 \\
\text { NA } \\
4.48 \\
\text { NA } \\
1,37\end{array}$ & $\begin{array}{l}2.79 \\
\text { MA } \\
4.94 \\
\text { MA } \\
\text { MA } \\
1.48\end{array}$ & $\begin{array}{l}2,64 \\
\text { NA } \\
4.67 \\
\text { NAA } \\
1,99\end{array}$ & $\begin{array}{c}10.1 \\
\text { MA } \\
-1.1 \\
\text { MA } \\
\mathbf{0 . 2}\end{array}$ & $\begin{array}{l}4.3 \\
N / 4 \\
-4.0 \\
N A \\
N A \\
+1.7\end{array}$ & $\begin{array}{c}6.3 \\
\text { NA } \\
\text { NA } \\
\text { NA } \\
6.1\end{array}$ \\
\hline $\begin{array}{l}28 \\
2621 \\
2831 \\
27 \\
28 \\
2819 \\
2897 \\
2879 \\
2979 \\
29 \\
2941 \\
30\end{array}$ & 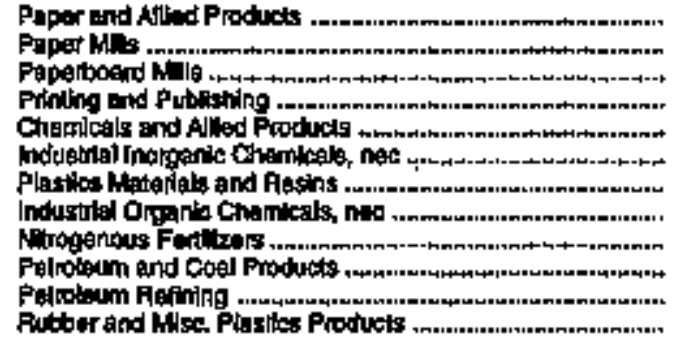 & $\begin{array}{r}12.27 \\
24.27 \\
36.39 \\
\mathrm{NA} \\
11.85 \\
19.06 \\
10.21 \\
22.68 \\
79.86 \\
7.63 \\
7.75 \\
3.04\end{array}$ & 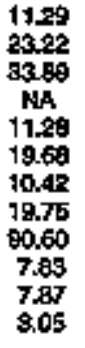 & $\begin{array}{r}19.90 \\
26.63 \\
36.47 \\
114 \\
11.65 \\
21.14 \\
9.90 \\
21.01 \\
11+.64 \\
6.38 \\
6.63 \\
2.68\end{array}$ & $\begin{array}{r}9.0 \\
4.3 \\
6.7 \\
6.7 \\
4.8 \\
4.1 \\
-2.0 \\
12.6 \\
13.4 \\
-2.4 \\
-1.3 \\
-0.5\end{array}$ & $\begin{array}{r}-19.3 \\
-9.7 \\
+9.7 \\
N A \\
2.6 \\
-10.6 \\
4.1 \\
7.3 \\
-39.8 \\
-9.4 \\
-11.0 \\
18.9\end{array}$ & 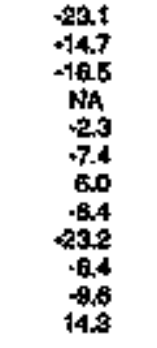 \\
\hline $\begin{array}{l}31 \\
32 \\
3041 \\
33 \\
3312 \\
34 \\
34\end{array}$ & 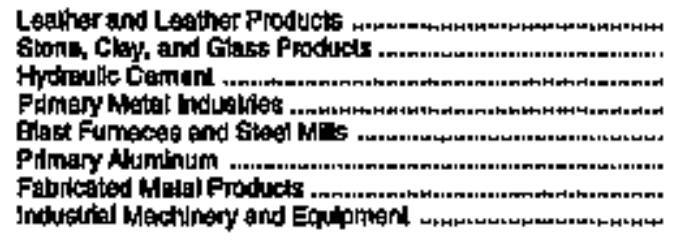 & $\begin{array}{r}\text { MA } \\
15.52 \\
61.04 \\
13.84 \\
22.32 \\
45.21 \\
2.19 \\
1,20\end{array}$ & $\begin{array}{l}\text { MA } \\
18.39 \\
78.06 \\
13.66 \\
28.21 \\
4.11 \\
2.33 \\
1.10\end{array}$ & $\begin{array}{l}\text { NA } \\
17.35 \\
80.89 \\
19,40 \\
21.45 \\
37.94 \\
2.24 \\
1.00\end{array}$ & $\begin{array}{r}\text { NA } \\
-5.6 \\
3.7 \\
1.9 \\
+.0 \\
9.1 \\
6.8 \\
7.8\end{array}$ & $\begin{array}{r}\text { NA } \\
-11.8 \\
-7.2 \\
3.2 \\
1.6 \\
18.1 \\
2.8 \\
16.2\end{array}$ & $\begin{array}{r}1.4 \\
-5.8 \\
-11.3 \\
1.9 \\
8.4 \\
7.7 \\
3.8 \\
9.0\end{array}$ \\
\hline$\underset{36}{36}$ & 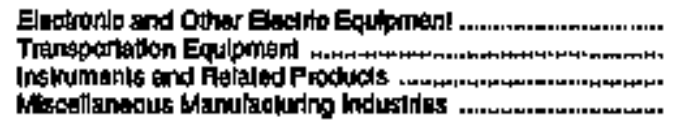 & $\begin{array}{l}1.15 \\
1,04 \\
1,05 \\
1.25\end{array}$ & $\begin{array}{l}1.21 \\
0.97 \\
0.91 \\
1.27\end{array}$ & $\begin{array}{l}1.05 \\
1.00 \\
0.99 \\
1.09\end{array}$ & $\begin{array}{r}-4.0 \\
6.8 \\
13.2 \\
-1.5\end{array}$ & $\begin{array}{r}8.7 \\
4.3 \\
15.4 \\
18.6\end{array}$ & $\begin{array}{r}12.9 \\
-2.7 \\
2.5 \\
14.9\end{array}$ \\
\hline- & 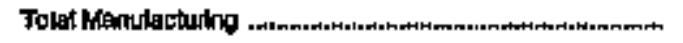 & 4.35 & 4.20 & 4,44 & 2,1 & $\cdot 1 . \theta$ & 4.1 \\
\hline
\end{tabular}

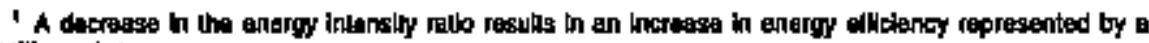
poefthe value.

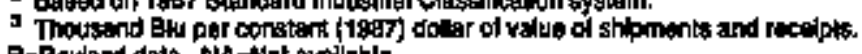

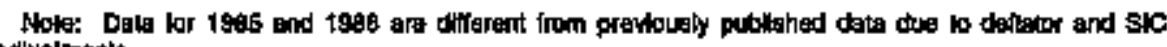

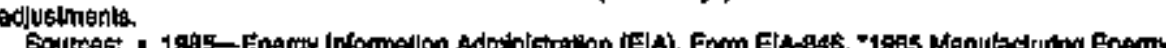

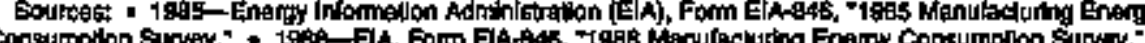

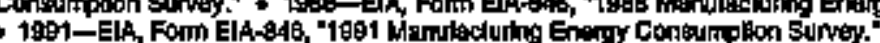


Total Manufacturing

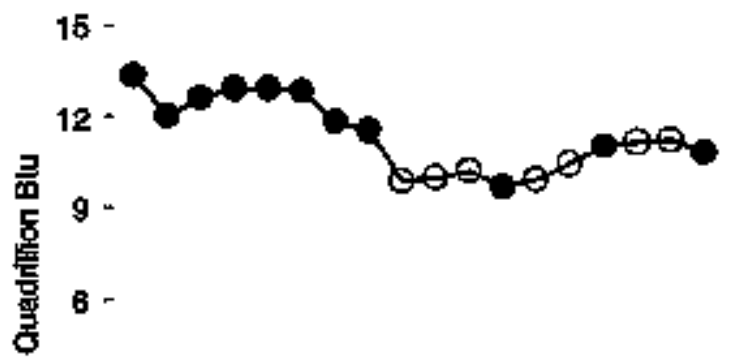

3 -

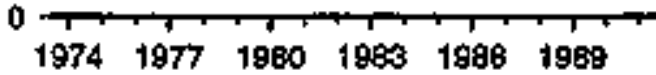

SIC 29: Petroleum and Coal Products

3
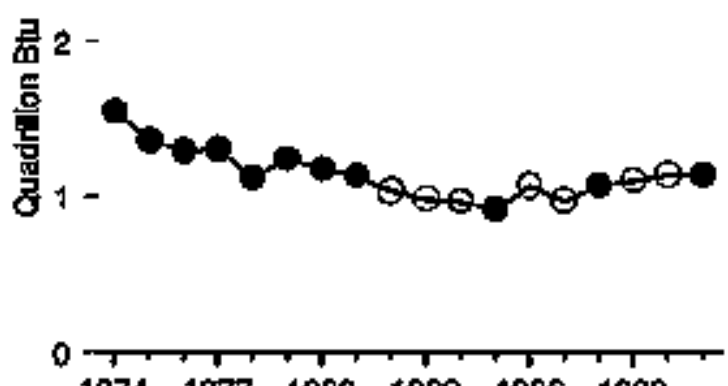

$\begin{array}{llllll}1974 & 1977 \quad 1980 & 1988 & 1986 & 1989\end{array}$
SIC 26: Paper and Allied Products
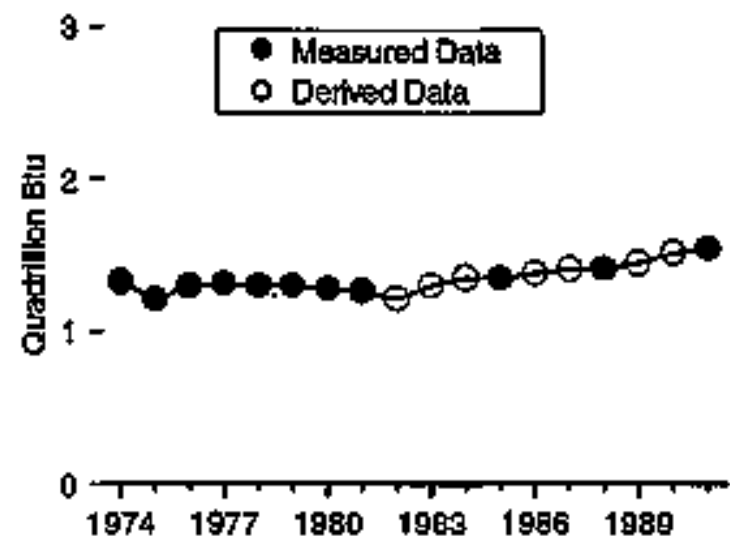

SIC 32: Stome, Clay, and Giass Products

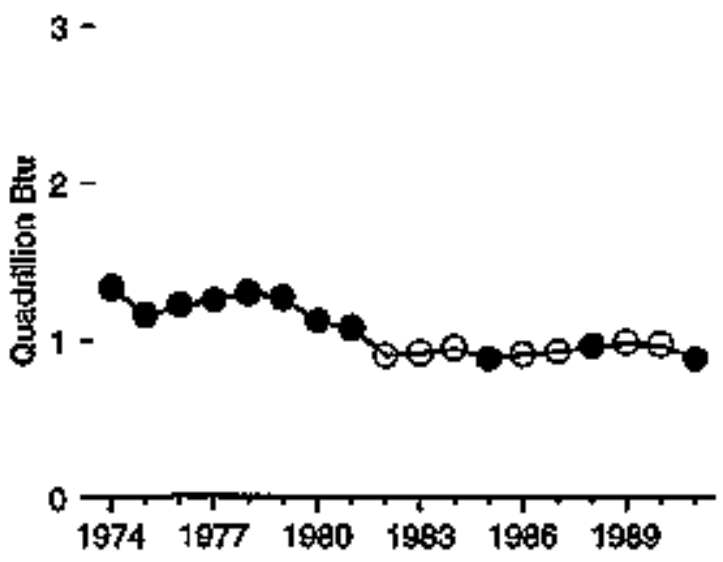

Sic 28: Chemicals and Allied Producte

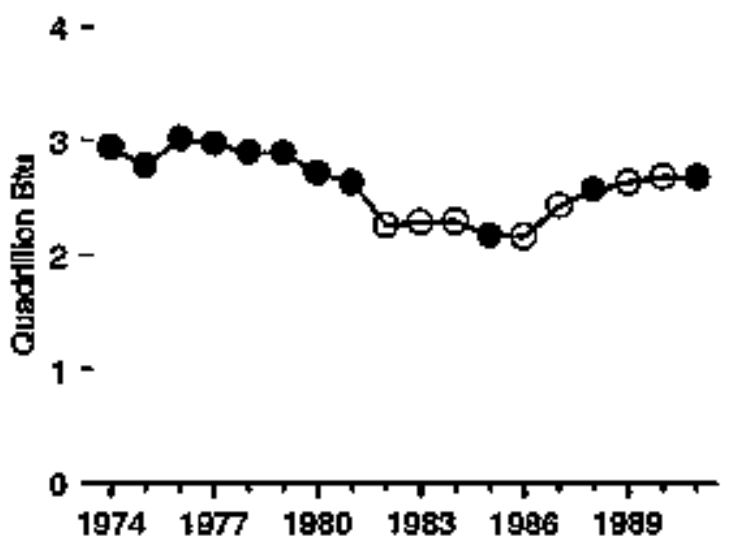

SIC 33: Primary Metal industries

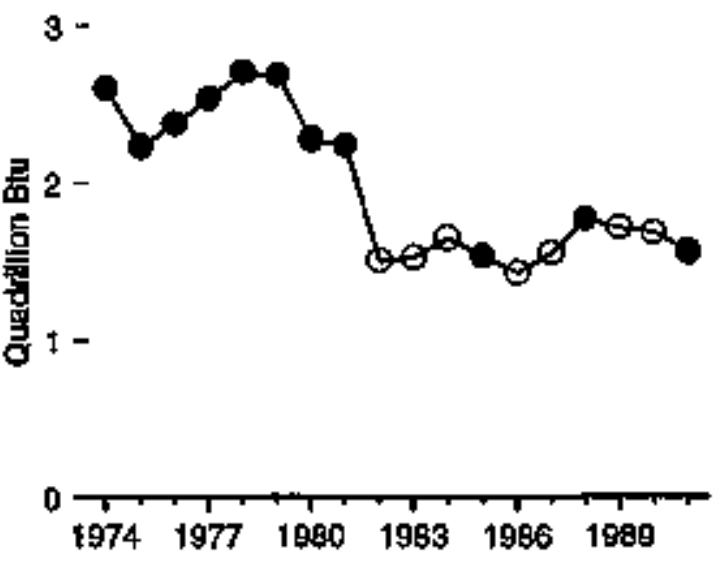


Table 2.5 Ottsite-Produced Energy Consumed for Heat and Power by Selected Industry Group, 1974-1991 (Trillion Btu)

\begin{tabular}{|c|c|c|c|c|c|c|c|c|c|c|c|c|c|c|c|}
\hline \multirow[b]{2}{*}{ ver } & \multirow{2}{*}{$\begin{array}{c}\text { Daba: } \\
\text { Source: }\end{array}$} & \multicolumn{14}{|c|}{ Indugtry troup by sic code 1} \\
\hline & & $\operatorname{stc} 20$ & skin & $\operatorname{sic} 28$ & sic za & $81 c 29$ & $\operatorname{sic} 30$ & $\operatorname{sic} a z$ & sic 33 & stec 34 & stc 35 & $\operatorname{sicas}$ & $\operatorname{sic} 37$ & Dther: ${ }^{2}$ & total \\
\hline 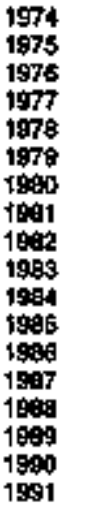 & 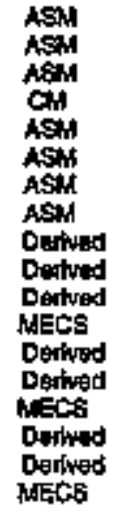 & 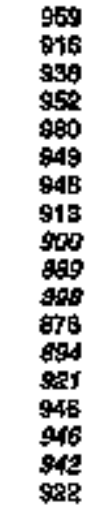 & $\begin{array}{l}323 \\
307 \\
329 \\
399 \\
327 \\
315 \\
295 \\
298 \\
258 \\
274 \\
265 \\
247 \\
258 \\
378 \\
276 \\
280 \\
278 \\
272\end{array}$ & $\begin{array}{l}1,327 \\
1,210 \\
1,298 \\
1,308 \\
1,301 \\
1,300 \\
1,278 \\
1,268 \\
1,210 \\
1,299 \\
1,340 \\
1,340 \\
1,379 \\
1,402 \\
1,409 \\
1,446 \\
1,514 \\
1,540\end{array}$ & $\begin{array}{l}2,997 \\
2,780 \\
3,017 \\
2,979 \\
2,905 \\
2,609 \\
2,717 \\
2,650 \\
2,259 \\
2,285 \\
2,295 \\
2,170 \\
2,167 \\
2,496 \\
2,689 \\
2,630 \\
2,648 \\
2,674\end{array}$ & $\begin{array}{r}1,545 \\
1,307 \\
1,292 \\
1,500 \\
1,103 \\
1,245 \\
1,179 \\
1,137 \\
1,045 \\
960 \\
065 \\
9,17 \\
1,068 \\
972 \\
1,070 \\
1,105 \\
1,100 \\
1,139\end{array}$ & $\begin{array}{l}247 \\
227 \\
297 \\
272 \\
261 \\
248 \\
220 \\
2209 \\
2051 \\
280 \\
206 \\
211 \\
202 \\
200 \\
251 \\
259 \\
255 \\
235\end{array}$ & $\begin{array}{l}1,350 \\
1,1509 \\
1,220 \\
1,252 \\
1,300 \\
1,266 \\
1,122 \\
1,077 \\
907 \\
916 \\
945 \\
076 \\
909 \\
591 \\
959 \\
978 \\
970 \\
877\end{array}$ & $\begin{array}{l}2,604 \\
2,235 \\
2,300 \\
2,599 \\
2,711 \\
2,689 \\
2,277 \\
2,241 \\
1,507 \\
1,529 \\
1,650 \\
1,507 \\
1,431 \\
1,560 \\
1,773 \\
1,720 \\
1,090 \\
1,965\end{array}$ & 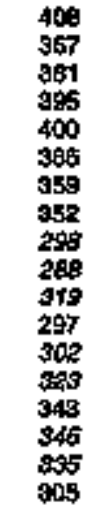 & $\begin{array}{l}367 \\
359 \\
390 \\
340 \\
351 \\
359 \\
334 \\
325 \\
278 \\
257 \\
268 \\
241 \\
243 \\
351 \\
278 \\
284 \\
277 \\
238\end{array}$ & $\begin{array}{l}251 \\
207 \\
239 \\
249 \\
255 \\
250 \\
240 \\
245 \\
218 \\
229 \\
295 \\
209 \\
219 \\
407 \\
215 \\
217 \\
215 \\
196\end{array}$ & $\begin{array}{l}375 \\
348 \\
380 \\
390 \\
390 \\
385 \\
344 \\
309 \\
493 \\
307 \\
395 \\
325 \\
3999 \\
348 \\
350 \\
358 \\
352 \\
318\end{array}$ & $\begin{array}{l}681 \\
575 \\
594 \\
810 \\
617 \\
592 \\
559 \\
548 \\
496 \\
499 \\
510 \\
450 \\
502 \\
598 \\
816 \\
617 \\
612 \\
581\end{array}$ & 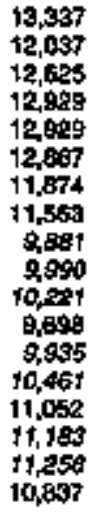 \\
\hline
\end{tabular}

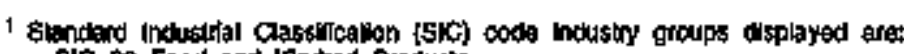
SIC 20 Food and Kindred Products

Fic 26 Paper and Alled Products

sic at Charaleals and Mild Products

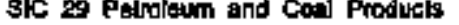

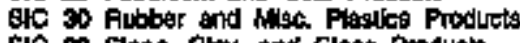

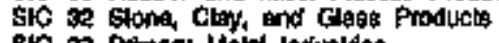

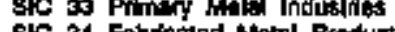

SkC 34 Fabricaled Makil Prodtuats

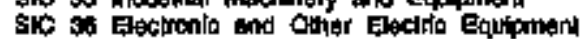

SIC 37 Transportolon Equpmen.

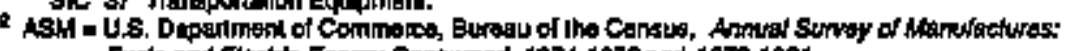

Fugts and Elocts Enary Consumad, 1974+1976 and 1978-198\%".

Condachos: Fuals and

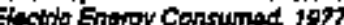

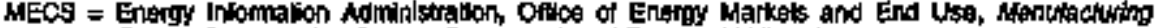

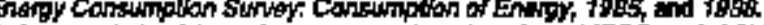

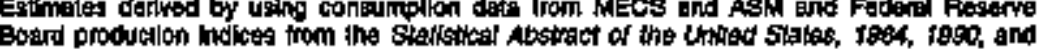

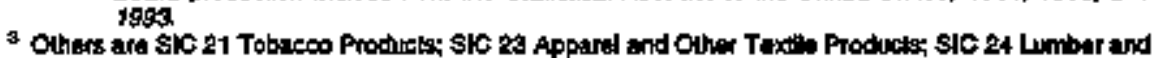

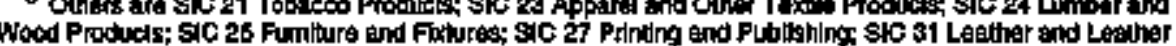

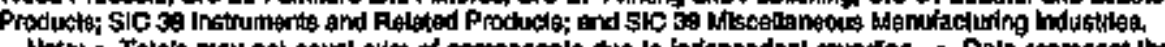

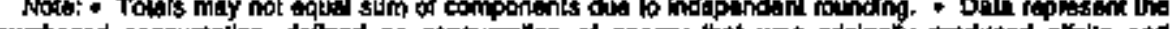

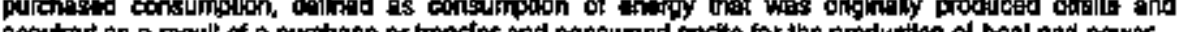

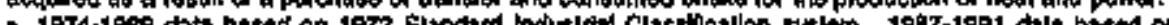

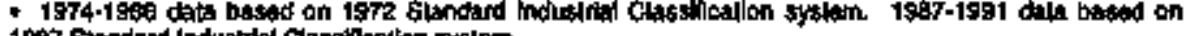

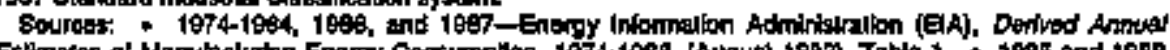

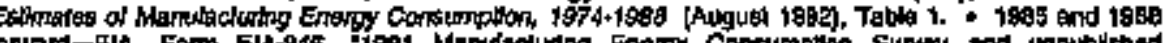

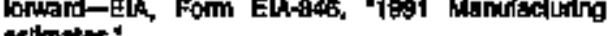




\section{Figure 2.6 Manufacturing Sector Inputs for Heat, Power, and Electrlcity Generation, 1991}

\section{By Selected End Users}

Process Healing

Machino Ditre

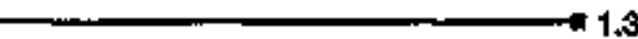

FaclityHVAC1

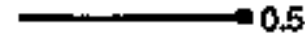

Electrocherrical Processes

Facility Lighiting

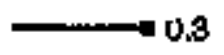

Process Cooling and Reitigeralion

$$
\rightarrow 0.1
$$

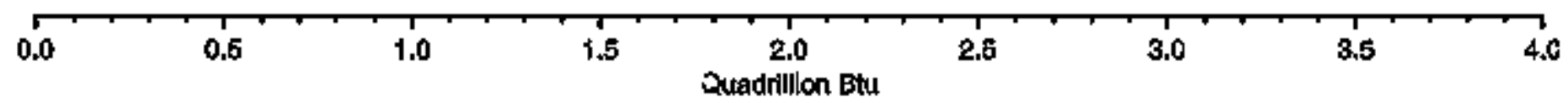

\section{By Energy Sourte}

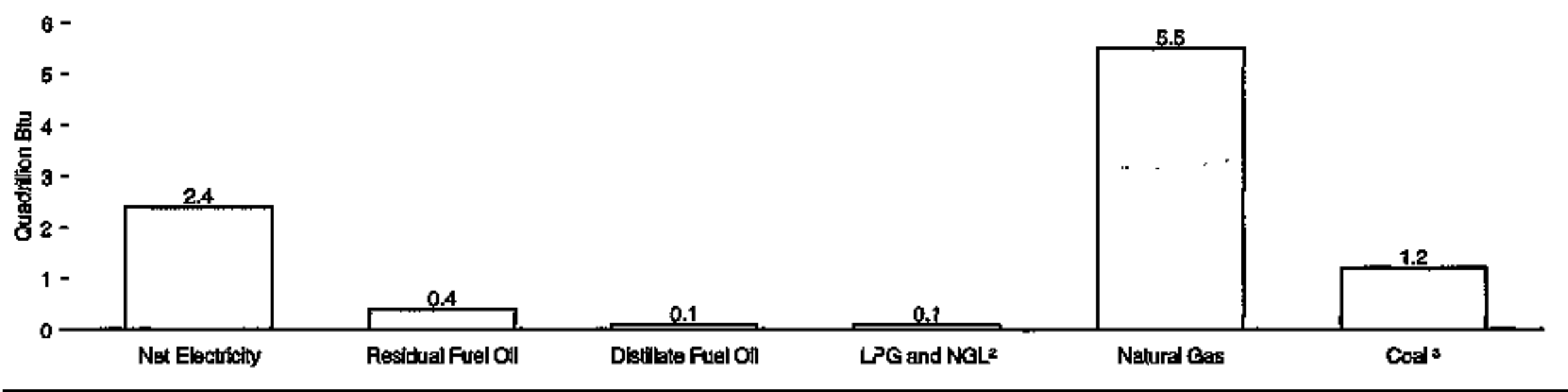

THeating, ventillation, and air condlioning.

$\checkmark$ Exchufing coal coke and breoze.

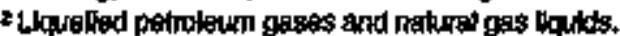

Source: Thole 2.6. 
Table 2.6 Manufacturing Sector Inputs for Heat, Power, and Electricity Generation by Energy Source, 1991

\begin{tabular}{|c|c|c|c|c|c|c|c|}
\hline & $\begin{array}{l}\text { Net } \\
\text { Elestrictly, }\end{array}$ & $\begin{array}{l}\text { Fieskduel } \\
\text { Fuel ofil }\end{array}$ & $\begin{array}{l}\text { Distulater } \\
\text { Fued onts }\end{array}$ & LPQ AHdNGL" & Noturel Gest & 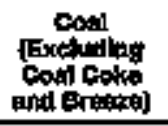 & Tola|s \\
\hline Enduso Gutegory & $\begin{array}{c}\text { Mition } \\
\text { Kalownthoss }\end{array}$ & \multicolumn{3}{|c|}{ Thousand Barrels } & $\begin{array}{l}\text { Balllon } \\
\text { Cuble Fet }\end{array}$ & $\begin{array}{l}\text { Thiputund } \\
\text { short Tons }\end{array}$ & \\
\hline 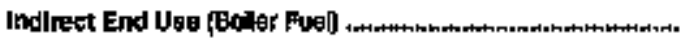 & $W$ & 47,000 & 6,050 & $4, \mathbf{9 2 6}$ & 2,037 & 80,473 & \\
\hline 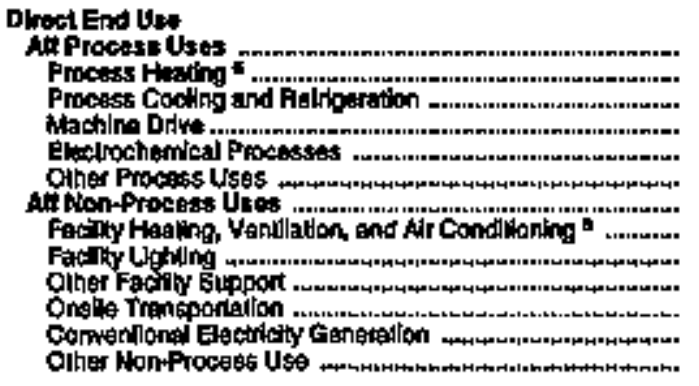 & 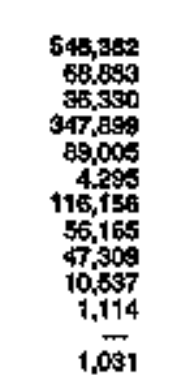 & $\frac{17,342}{16,959}, \frac{5}{353}$ & 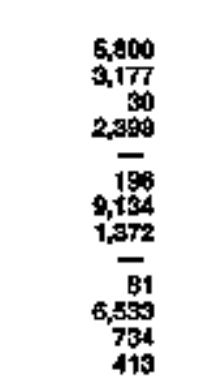 & $\begin{array}{r}16,908 \\
12,704 \\
18 \\
4,053 \\
- \\
5,93 \\
5,105 \\
791 \\
\frac{62}{62} \\
4,242 \\
41 \\
30\end{array}$ & 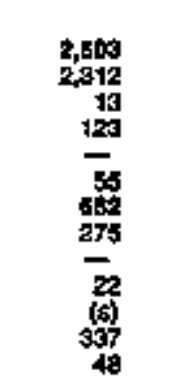 & 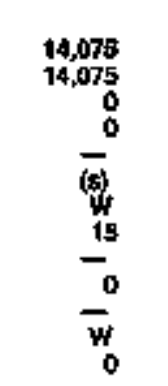 & \\
\hline Find Uad Not Rieported .... & $\boldsymbol{w}$ & 399 & 2,101 & 1,026 & 124 & $\mathbf{w}$ & \\
\hline \multirow[t]{2}{*}{ 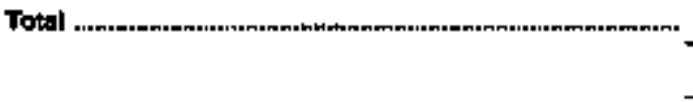 } & 694,702 & 65,007 & 23,065 & 27,970 & 6,345 & 69,035 & \\
\hline & \multicolumn{7}{|c|}{ Tatlon Bw } \\
\hline 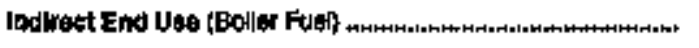 & $\mathbf{W}$ & 296 & 40 & 18 & 2,000 & 69 & $w$ \\
\hline 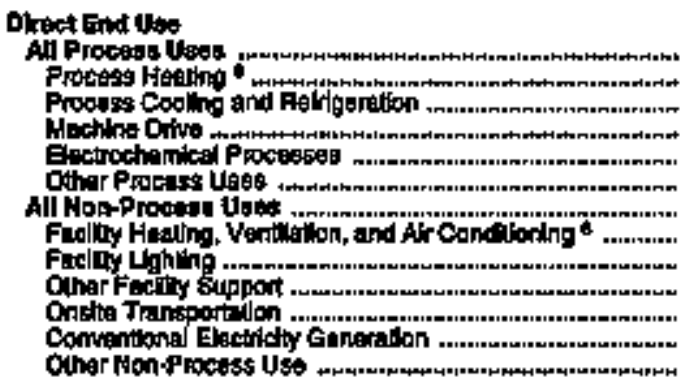 & $\begin{array}{r}1,994 \\
295 \\
124 \\
1,197 \\
304 \\
15 \\
394 \\
198 \\
164 \\
35 \\
4 \\
-4 \\
4\end{array}$ & $\begin{array}{l}109 \\
107 \\
(5) \\
\frac{2}{(s)} \\
\frac{4}{4} \\
\frac{w}{w} \\
\frac{2}{w}\end{array}$ & 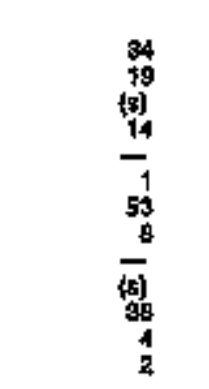 & $\begin{array}{c}64 \\
49 \\
(5) \\
19 \\
\frac{(5)}{19} \\
3 \\
-6) \\
16 \\
(4) \\
(5)\end{array}$ & 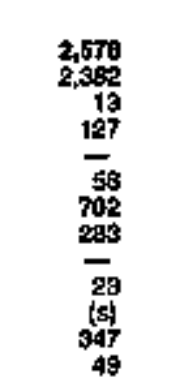 & $\begin{array}{c}314 \\
314 \\
0 \\
0 \\
\frac{0}{(s)} \\
w \\
(8) \\
\frac{1}{0} \\
\frac{w}{0} \\
0\end{array}$ & $\begin{array}{r}4,509 \\
3,700 \\
137 \\
1,346 \\
304 \\
702 \\
w \\
400 \\
161 \\
w \\
65 \\
w \\
w\end{array}$ \\
\hline 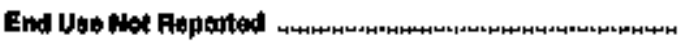 & $w$ & 2 & 12 & 4 & 128 & $w$ & $w$ \\
\hline 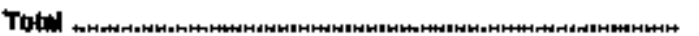 & 2,370 & 414 & 130 & 105 & $\mathbf{5 , 5 0 0 6}$ & 5,164 & $\mathbf{9 , 7 1 6}$ \\
\hline
\end{tabular}

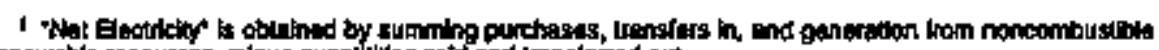

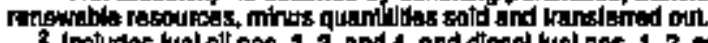

? Inturdes hual oll nos. 1, 2, and 4, and dteset tual nos. 1, 3, and 4.

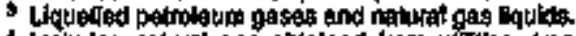

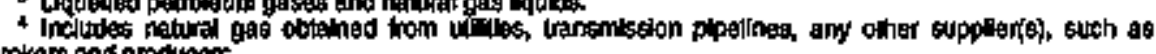

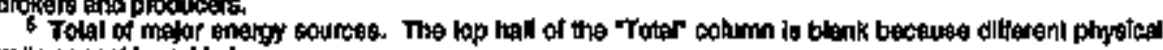

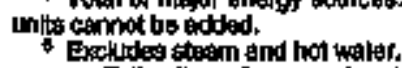

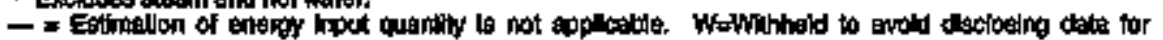

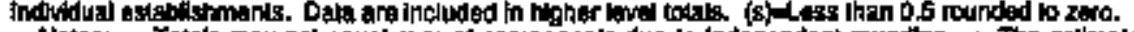

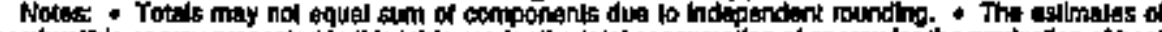

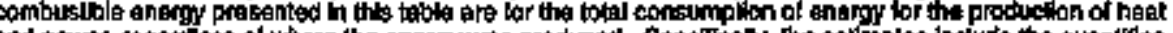

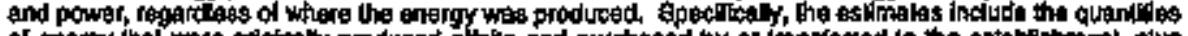

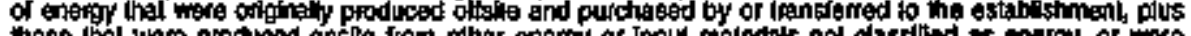

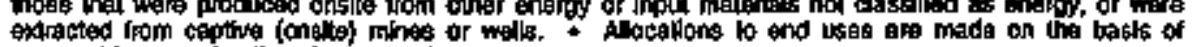

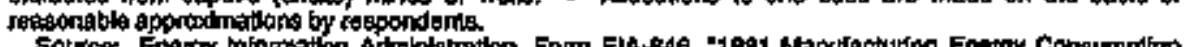

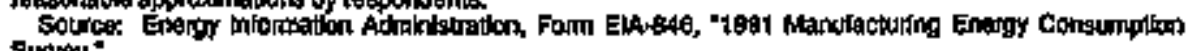
survey. 


\section{By Manegement Activlty}

15 -

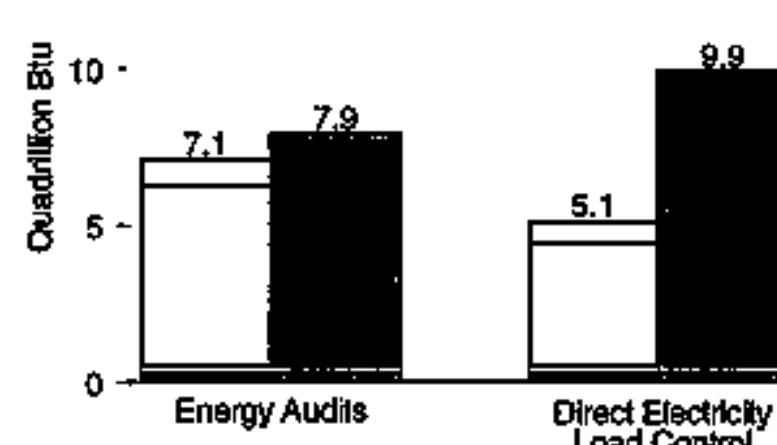

Equipment installation or Potrofit for the Primary Puppose of Improving Energy Efficiency Affecling:

15 -

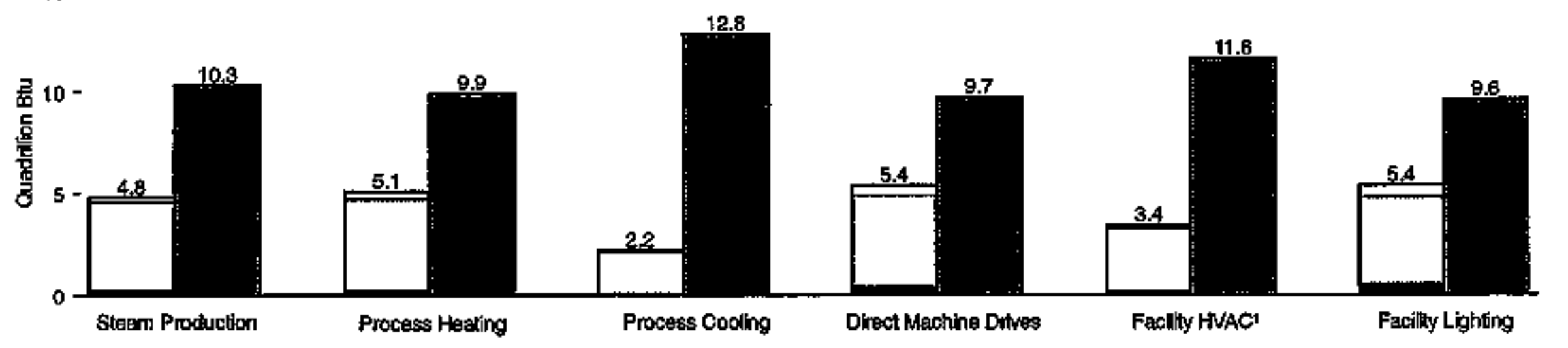

1 Heating, ventilitton, and alr contiftioning.

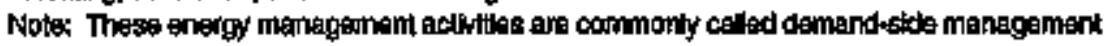

Bolh Types of Sponsor

Self or Third Party Sponsor Onty

Uillyysupplor Sponeor Only

No Acinily

18.9

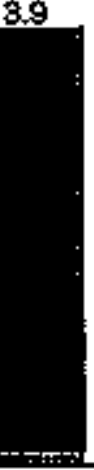

Stancty Generation

Program

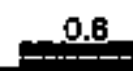

Equipment

Fetoales

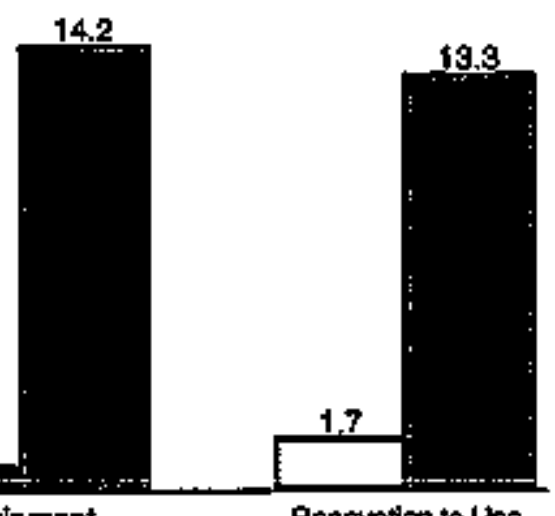

Piencuation to Use

Difierent

Energy source

programs when conducted by ubilly or supplier.

Sourcex Table 2.7. 
Table 2.7 Manufacturing Sector Inputs for Heat, Power, and Electricity Generation in 1991 by Energy Management Activity Present From 1989-1991

\begin{tabular}{|c|c|c|c|c|c|c|c|c|c|c|c|c|c|}
\hline \multirow[b]{2}{*}{ Spanoorahlp 1 } & \multirow[b]{2}{*}{$\begin{array}{l}\text { Energy } \\
\text { Auditi }\end{array}$} & \multirow{2}{*}{$\begin{array}{l}\text { Dlreact } \\
\text { Elootricity } \\
\text { Load } \\
\text { control }\end{array}$} & \multirow[b]{2}{*}{$\begin{array}{l}\text { Spocied } \\
\text { Aate } \\
\text { Sochadite } 2\end{array}$} & \multirow[b]{2}{*}{$\begin{array}{l}\text { Standby } \\
\text { Genteraion } \\
\text { Program }\end{array}$} & \multirow[b]{2}{*}{\begin{tabular}{|c|} 
Equipmont \\
Robitites
\end{tabular}} & \multicolumn{6}{|c|}{ 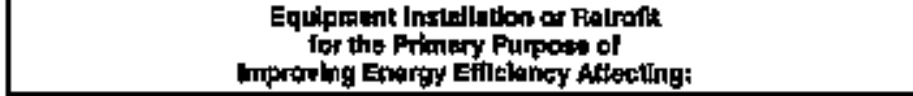 } & \multirow{2}{*}{ 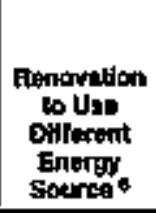 } & \multirow[b]{2}{*}{ Other? } \\
\hline & & & & & & $\begin{array}{l}\text { Stown } \\
\text { Production? }\end{array}$ & $\begin{array}{l}\text { Processs } \\
\text { Heatiog }\end{array}$ & $\begin{array}{l}\text { Processs } \\
\text { cooting }\end{array}$ & $\begin{array}{l}\text { Dirock } \\
\text { Itoching } \\
\text { Drikes }\end{array}$ & $\begin{array}{l}\text { Faenlly } \\
\text { HVAC's }\end{array}$ & 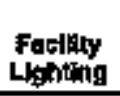 & & \\
\hline & \multicolumn{13}{|c|}{ Ourdellion Btu } \\
\hline 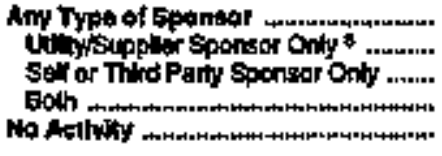 & $\begin{array}{l}7.089 \\
0.539 \\
6.757 \\
0.799 \\
7.544\end{array}$ & $\begin{array}{l}5.085 \\
0.585 \\
3.858 \\
0.098 \\
\$ .941\end{array}$ & $\begin{array}{l}6.517 \\
3.539 \\
1.289 \\
1.370 \\
1.599\end{array}$ & $\begin{array}{r}1.139 \\
0.766 \\
0.918 \\
0.008 \\
13.694\end{array}$ & $\begin{array}{r}0.783 \\
0.568 \\
0.095 \\
0.108 \\
14.244\end{array}$ & $\begin{array}{r}4.757 \\
0.200 \\
4.360 \\
0.198 \\
10.269\end{array}$ & $\begin{array}{l}5.146 \\
0.209 \\
4.517 \\
0.419 \\
0.691\end{array}$ & $\begin{array}{r}2.212 \\
0.089 \\
2.059 \\
0.004 \\
12.015\end{array}$ & $\begin{array}{l}5.354 \\
0.951 \\
4.511 \\
0.493 \\
9.672\end{array}$ & $\begin{array}{r}3.484 \\
0.175 \\
3065 \\
0.167 \\
11.603\end{array}$ & $\begin{array}{l}5.405 \\
0.516 \\
4.285 \\
0.002 \\
0.622\end{array}$ & $\begin{array}{r}1.593 \\
0.045 \\
1.025 \\
0.120 \\
13.373\end{array}$ & $\begin{array}{r}0.376 \\
0.058 \\
0.271 \\
0.049 \\
14.051\end{array}$ \\
\hline \multirow[t]{2}{*}{ 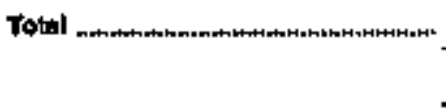 } & 15007 & 15.0 .27 & $15.0 \times 7$ & 16.027 & 15.027 & 16,027 & 15.027 & 75,087 & 16,027 & 15.027 & $\$ 6.027$ & 15.027 & 150027 \\
\hline & \multicolumn{13}{|c|}{ Paccent } \\
\hline 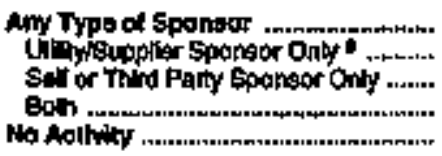 & $\begin{array}{r}47.1 \\
3.5 \\
383 \\
53 \\
62.9\end{array}$ & $\begin{array}{r}3.9 \\
3.6 \\
25.6 \\
4.4 \\
66.2\end{array}$ & $\begin{array}{r}49.4 \\
26.2 \\
8.4 \\
8.7 \\
66.6\end{array}$ & $\begin{array}{r}7.5 \\
1.2 \\
6.4 \\
0.3 \\
9.6\end{array}$ & $\begin{array}{r}6.2 \\
3.9 \\
0.6 \\
0.7 \\
94.8\end{array}$ & $\begin{array}{r}31.7 \\
1.3 \\
290 \\
1.3 \\
63.3\end{array}$ & $\begin{array}{r}34.2 \\
1.4 \\
30.1 \\
2.8 \\
65.8\end{array}$ & $\begin{array}{r}14.7 \\
0.5 \\
13.7 \\
0.6 \\
8.9 .3\end{array}$ & $\begin{array}{r}3.6 .6 \\
2.3 \\
3 \times .0 \\
3.3 \\
64.4\end{array}$ & $\begin{array}{r}220 \\
1.2 \\
20.4 \\
1.2 \\
772\end{array}$ & $\begin{array}{r}36.0 \\
3.4 \\
20.5 \\
4.0 \\
64.0\end{array}$ & $\begin{array}{r}11.3 \\
0.3 \\
10.1 \\
0.8 \\
98.7\end{array}$ & $\begin{array}{r}2.5 \\
0.4 \\
\pm .8 \\
0.3 \\
97.5\end{array}$ \\
\hline 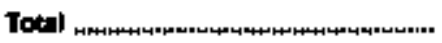 & 100.0 & 100.0 & 100.0 & 1000 & 100.0 & 1000 & 100.0 & toodo & 100.0 & $\$ 000$ & 190,0 & 100.1 & 100.0 \\
\hline
\end{tabular}

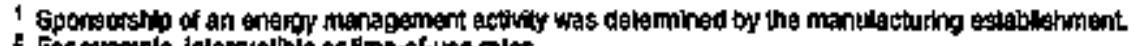

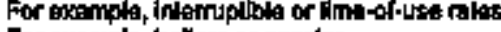

For exempla, boiless or nozrates.

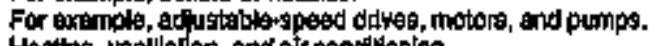

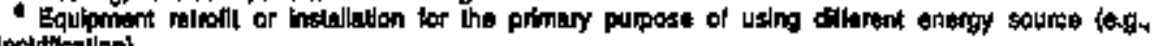
Alecittiteailon).

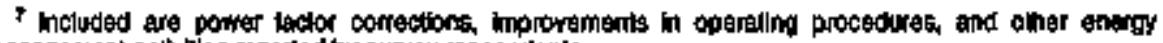

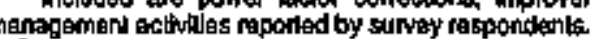

B these conducted by utilly or appliter

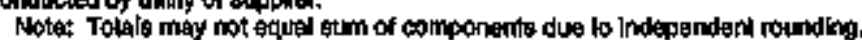

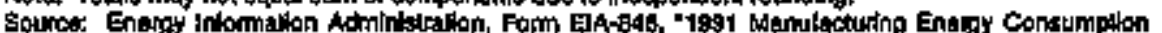
survay." 
Either No Presence or Presence of Energy-Hebled Technologies, by Aegion

$$
\text { g - }
$$

$$
\text { 蛋 }^{6-}
$$

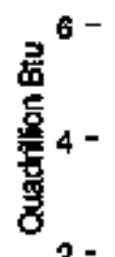

E. None CW One or More Technologles$$
\mathbf{0}
$$

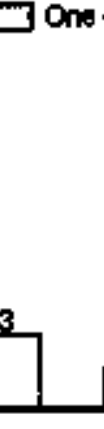

arlheast

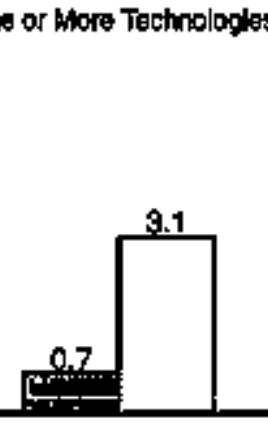

Medinest

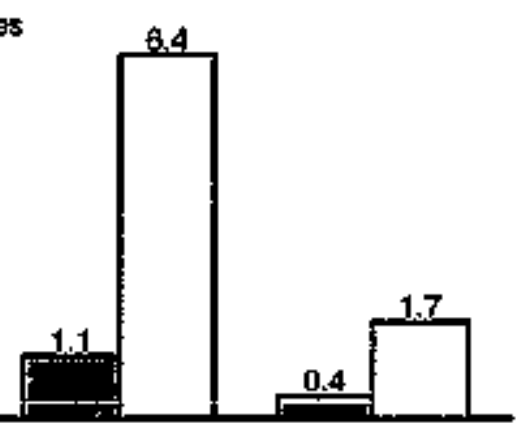

South

\section{Energy-Related Technologies by Tecinnology Type}

$12-$

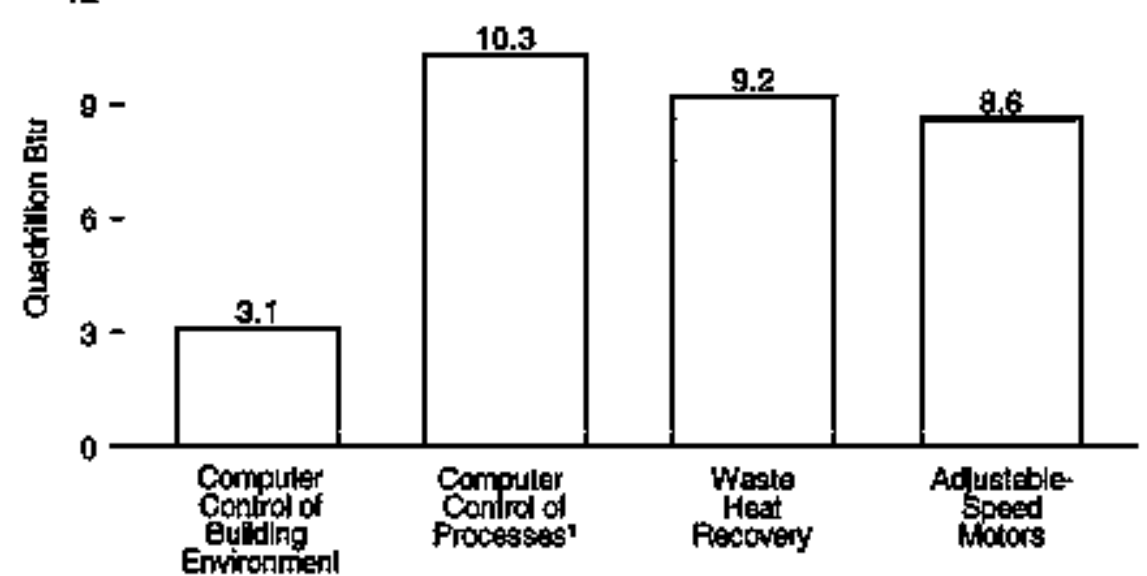

Energy-Related Technologles by Technology Type by Region

6-

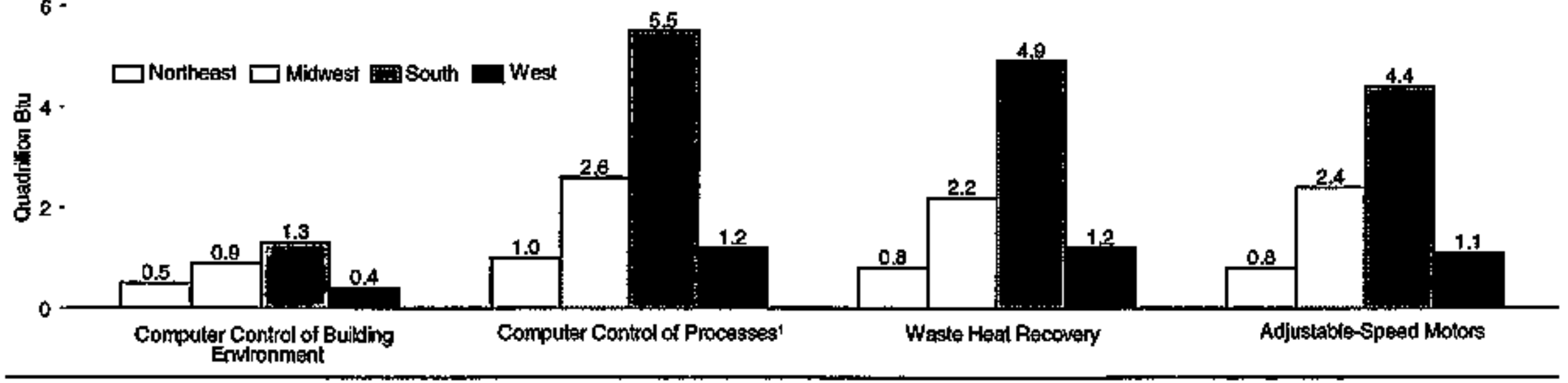

1 Or mejor energy+using equipment.

Notes: - Seg Appendla F lor Census reglons. • Because vertical ecales differ, graphs

sinoult not be compered.

Source: Table 2.g. 
Table 2.8 Manufacturing Sector Inputs for Heat, Power, and Electricity Generation by Technology, 1991

\begin{tabular}{|c|c|c|c|c|c|c|c|}
\hline \multirow[b]{2}{*}{ Census Roglon 1} & \multirow[b]{2}{*}{ Total } & \multirow[b]{2}{*}{$\begin{array}{c}\text { Ho Prasence } \\
\text { of seleoled } \\
\text { Texhnologlas }\end{array}$} & \multirow[b]{2}{*}{ 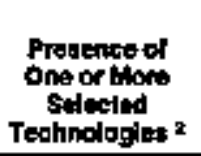 } & \multicolumn{4}{|c|}{ Typos of Gonoral Energy-rinteded Teabnologias } \\
\hline & & & & 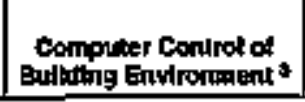 & 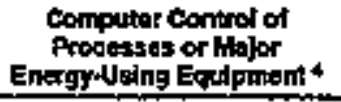 & $\begin{array}{l}\text { Wasiotiont } \\
\text { Recowery }\end{array}$ & $\begin{array}{c}\text { Adjustablo-Speed } \\
\text { Molore }\end{array}$ \\
\hline & \multicolumn{7}{|c|}{ Duadillion Bat } \\
\hline \multirow[t]{2}{*}{ 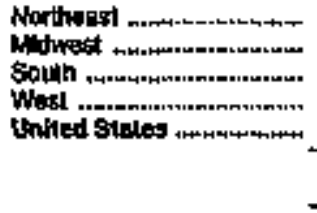 } & $\begin{array}{r}1.685 \\
3.9 .958 \\
7.507 \\
2.052 \\
15.002 \\
\end{array}$ & $\begin{array}{l}0.352 \\
0.703 \\
1,078 \\
0.393 \\
2.518 \\
\end{array}$ & $\begin{array}{r}1.280 \\
8.130 \\
5.479 \\
1.689 \\
12.510 \\
\end{array}$ & $\begin{array}{l}0.473 \\
0.942 \\
1.280 \\
0.408 \\
3.085\end{array}$ & $\begin{array}{r}1.033 \\
2.770 \\
5.463 \\
1.205 \\
10.300 \\
\end{array}$ & $\begin{array}{l}0.628 \\
2.219 \\
4.991 \\
1.160 \\
9.150 \\
\end{array}$ & $\begin{array}{l}0.791 \\
2.355 \\
4.385 \\
1.112 \\
0.679\end{array}$ \\
\hline & \multicolumn{7}{|c|}{ Papsant } \\
\hline 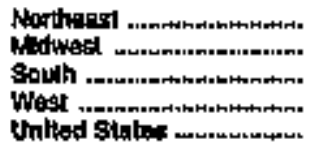 & $\begin{array}{r}10.8 \\
25.5 \\
60.0 \\
13.7 \\
100.0\end{array}$ & $\begin{array}{r}14.0 \\
27.5 \\
42.8 \\
18.2 \\
100.0\end{array}$ & $\begin{array}{r}10.2 \\
25.0 \\
51.4 \\
13.3 \\
100.0\end{array}$ & $\begin{array}{r}16.4 \\
30.5 \\
40.9 \\
13.2 \\
100.0\end{array}$ & $\begin{array}{r}10.0 \\
250 \\
58.0 \\
12.0 \\
100.0\end{array}$ & $\begin{array}{r}9.0 \\
24.2 \\
53.8 \\
12.9 \\
100.0\end{array}$ & $\begin{array}{r}9.2 \\
27.3 \\
50.6 \\
12.9 \\
1000\end{array}$ \\
\hline
\end{tabular}




\section{Consumption by All Householda, Selected Years, 1978-1993}

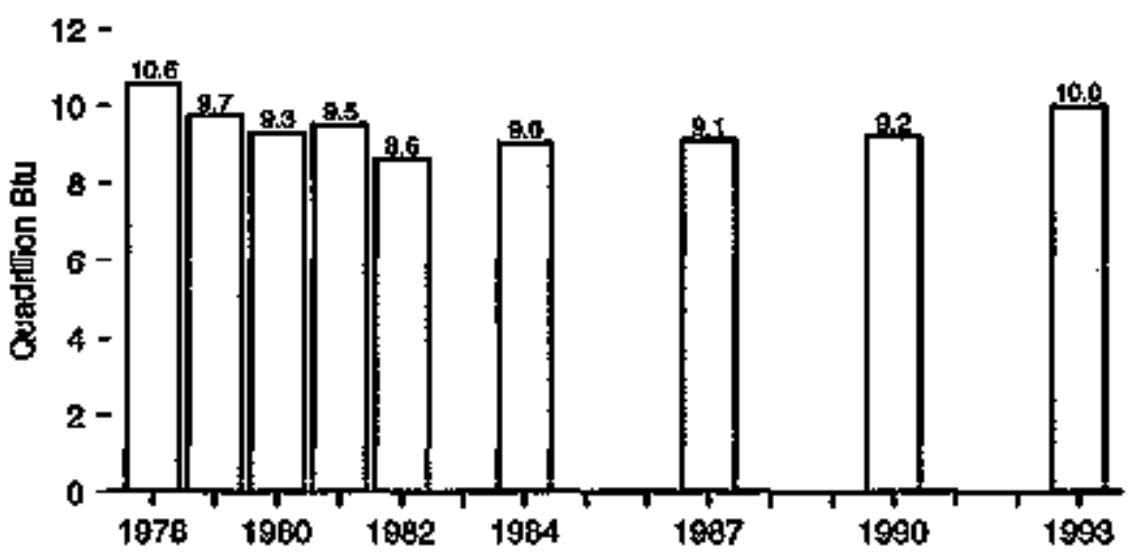

Consumption per Household, Selected Vears, 1978-1993

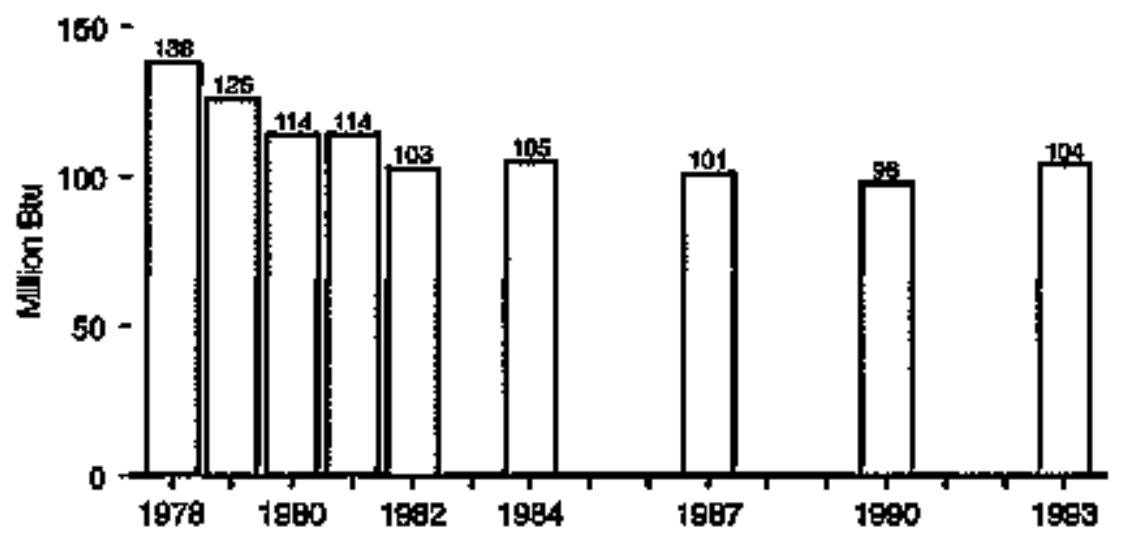

Consumption by All Househalds, by Census Rieglon, t99s

4 -

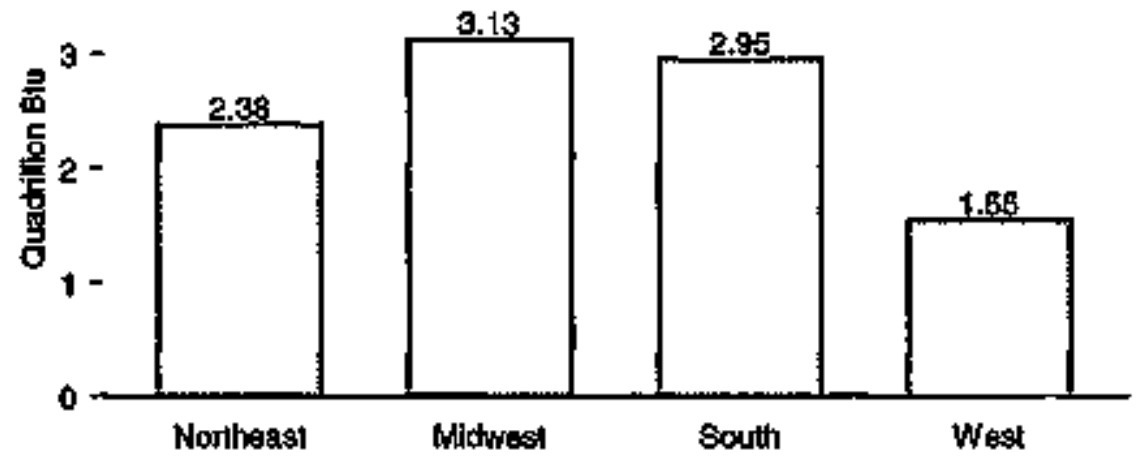

Consunftion pet Household, by Gonet:s Aogion, 1993

$150-$

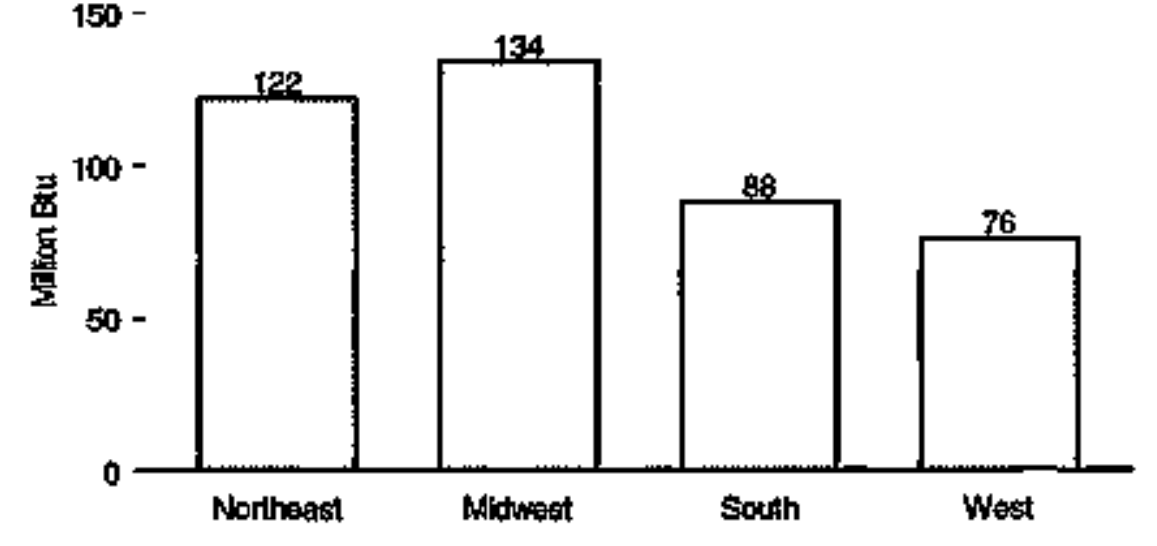

Notes: - No data ace avallabla tor years nol shorm. Data for 1978 through 1994 are for Aprl of the year shown throught Merch of the followhy yer, date 10r 1897, 1990 , and 1993 aro for the calender year. "Beceuse vaitical scales differ, graphs should nol be conpared. 
Table 2.9 Household Energy Consumption by Census Region, Selected Years, 1978-1993

(Quadrillion Bu, Except as Noted)

\begin{tabular}{|c|c|c|c|c|c|c|c|c|c|}
\hline Censua Proglon i & $19 \%$ & 1979 & 1960 & 1sst & inta2 & 1984 & 1987 & 1090 & 1993 \\
\hline 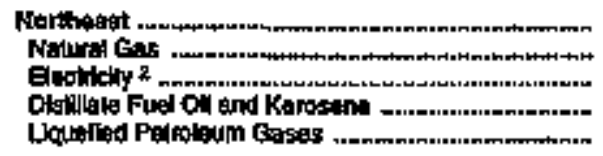 & $\begin{array}{l}2.69 \\
1.14 \\
0.39 \\
1.30 \\
0.00\end{array}$ & $\begin{array}{l}2.50 \\
1.05 \\
0.39 \\
\$ .08 \\
0.06\end{array}$ & $\begin{array}{l}2.43 \\
0.92 \\
0.39 \\
1.09 \\
0.03\end{array}$ & $\begin{array}{l}2.47 \\
1.06 \\
0.42 \\
0.06 \\
0.00\end{array}$ & $\begin{array}{l}2.50 \\
0.99 \\
0.58 \\
0.79 \\
0.02\end{array}$ & $\begin{array}{l}2.09 \\
0.90 \\
0.41 \\
0.99 \\
0.05\end{array}$ & $\begin{array}{l}2.37 \\
1.03 \\
0.44 \\
0.07 \\
0.02\end{array}$ & $\begin{array}{l}2.30 \\
1.09 \\
0.47 \\
0.79 \\
0.02\end{array}$ & $\begin{array}{l}2.79 \\
1,11 \\
0.47 \\
0.76 \\
0.09\end{array}$ \\
\hline Consumption per Howatheld (malion Guly) ............. & 185 & 145 & 138 & 138 & 128 & 125 & 124 & 120 & 122 \\
\hline 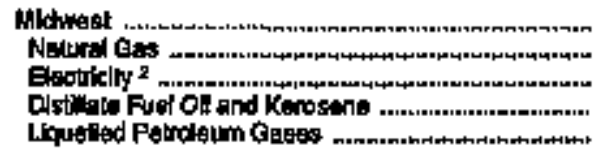 & $\begin{array}{l}3.70 \\
2.59 \\
0.600 \\
0.48 \\
0.12\end{array}$ & $\begin{array}{l}3,46 \\
2,45 \\
0.59 \\
0.94 \\
0.10\end{array}$ & $\begin{array}{l}2.92 \\
2.02 \\
0.60 \\
0.16 \\
0.15\end{array}$ & $\begin{array}{l}3.12 \\
2.24 \\
0.57 \\
0.17 \\
0.13\end{array}$ & $\begin{array}{l}2.80 \\
1.76 \\
0.57 \\
0.15 \\
0.11\end{array}$ & $\begin{array}{l}2.60 \\
1.98 \\
0.58 \\
0.73 \\
0.13\end{array}$ & $\begin{array}{l}2.73 \\
1,69 \\
0,81 \\
0.78 \\
0.13\end{array}$ & $\begin{array}{l}2.81 \\
1.89 \\
0.68 \\
0.13 \\
0.13\end{array}$ & $\begin{array}{l}3.19 \\
2.07 \\
0.74 \\
0.18 \\
0.19\end{array}$ \\
\hline Consumpilion per Housahold (millian Bexi) .................. & 100 & 160 & 199 & 147 & $12 a$ & ras & 129 & 122 & 134 \\
\hline 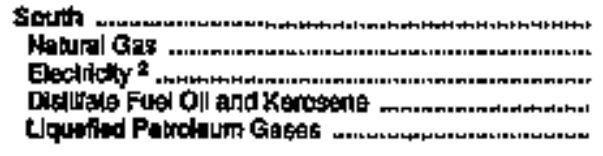 & $\begin{array}{l}2.45 \\
0.58 \\
1.00 \\
0.32 \\
0.15\end{array}$ & $\begin{array}{l}2.300 \\
0.91 \\
0.97 \\
0.28 \\
0.14\end{array}$ & $\begin{array}{l}2.59 \\
1.11 \\
1.06 \\
0.27 \\
0.15\end{array}$ & $\begin{array}{l}2.46 \\
1.16 \\
1.08 \\
0.16 \\
0.12\end{array}$ & $\begin{array}{l}2.46 \\
1.13 \\
1.05 \\
0.17 \\
0.12\end{array}$ & $\begin{array}{l}2.60 \\
1.15 \\
1.08 \\
0.16 \\
0.12\end{array}$ & $\begin{array}{l}2.61 \\
\$ .09 \\
\$ .12 \\
0.17 \\
0.12\end{array}$ & $\begin{array}{l}2.60 \\
1.09 \\
1.30 \\
0.11 \\
0.10\end{array}$ & $\begin{array}{l}2.95 \\
1.18 \\
1.51 \\
0.19 \\
0.19\end{array}$ \\
\hline Consumption Der thuselkald (mallon Biu) ............... & 99 & 92 & 96 & $\theta 9$ & 89 & 息 & 64 & 81 & 80 \\
\hline 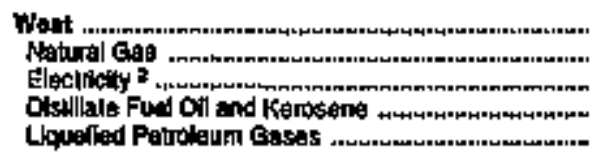 & $\begin{array}{l}1.54 \\
0.85 \\
0.48 \\
0.08 \\
0.08\end{array}$ & $\begin{array}{l}1.47 \\
0.89 \\
0.47 \\
0.09 \\
0.04\end{array}$ & $\begin{array}{l}1.30 \\
0.99 \\
0.41 \\
0.04 \\
0.04\end{array}$ & $\begin{array}{l}1.47 \\
0.09 \\
0.40 \\
0.09 \\
0.04\end{array}$ & $\begin{array}{l}1,39 \\
0.89 \\
0.42 \\
0,03 \\
0,04\end{array}$ & $\begin{array}{l}1,45 \\
0.51 \\
0.47 \\
0.04 \\
0.03\end{array}$ & $\begin{array}{l}1.42 \\
0.88 \\
0.48 \\
0.08 \\
0.08\end{array}$ & $\begin{array}{r}1.51 \\
0.92 \\
0.54 \\
0.04 \\
0.02\end{array}$ & $\begin{array}{l}1.55 \\
0.01 \\
0.56 \\
0.05 \\
0.04\end{array}$ \\
\hline 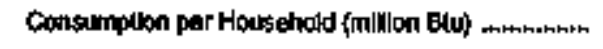 & 110 & 100 & $\theta$ & $\$ 0$ & 84 & 8 & 79 & 76 & 76 \\
\hline 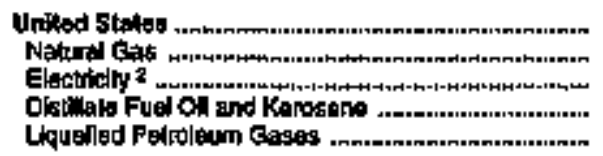 & $\begin{array}{r}10.58 \\
5.58 \\
2,47 \\
2.19 \\
0.39\end{array}$ & $\begin{array}{l}9.74 \\
5.31 \\
2.42 \\
4.71 \\
0.31\end{array}$ & $\begin{array}{l}9.32 \\
4.94 \\
2,46 \\
1.55 \\
0.35\end{array}$ & $\begin{array}{l}9,51 \\
5,39 \\
2,49 \\
1,33 \\
0.31\end{array}$ & $\begin{array}{l}8.62 \\
4.77 \\
2.42 \\
1.14 \\
0.99\end{array}$ & $\begin{array}{l}9.04 \\
4.88 \\
2.48 \\
1.28 \\
0.31\end{array}$ & $\begin{array}{l}9.13 \\
4.63 \\
2.76 \\
1.22 \\
0.32\end{array}$ & $\begin{array}{l}0.02 \\
4.06 \\
3.09 \\
1.04 \\
0.20\end{array}$ & $\begin{array}{r}10.01 \\
5.27 \\
3.89 \\
t .07 \\
0.30\end{array}$ \\
\hline 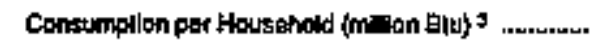 & 198 & 125 & 114 & 114 & 103 & 105 & 101 & 9s & 104 \\
\hline
\end{tabular}

1 Soe Appendix $F$ tor Census roglons.

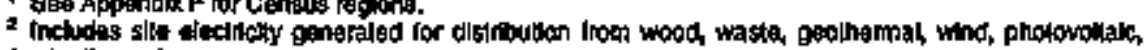
and woler thempht enerTy.

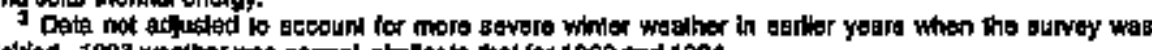

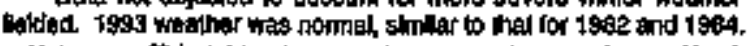

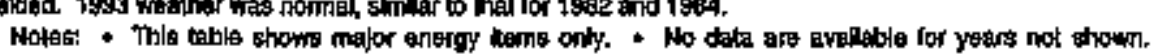

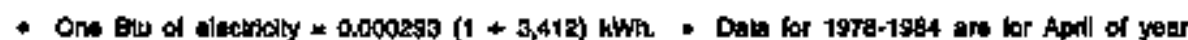

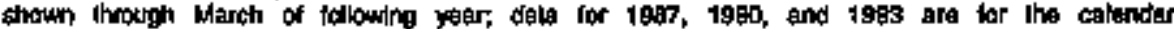
year. - Totals maly not equal sum ol components due ko hopendert rounding.

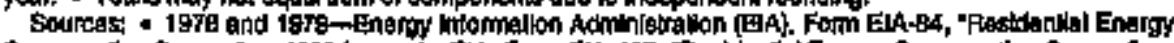

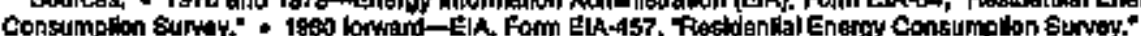




\section{Consumption by Enorgy Source, 1993}

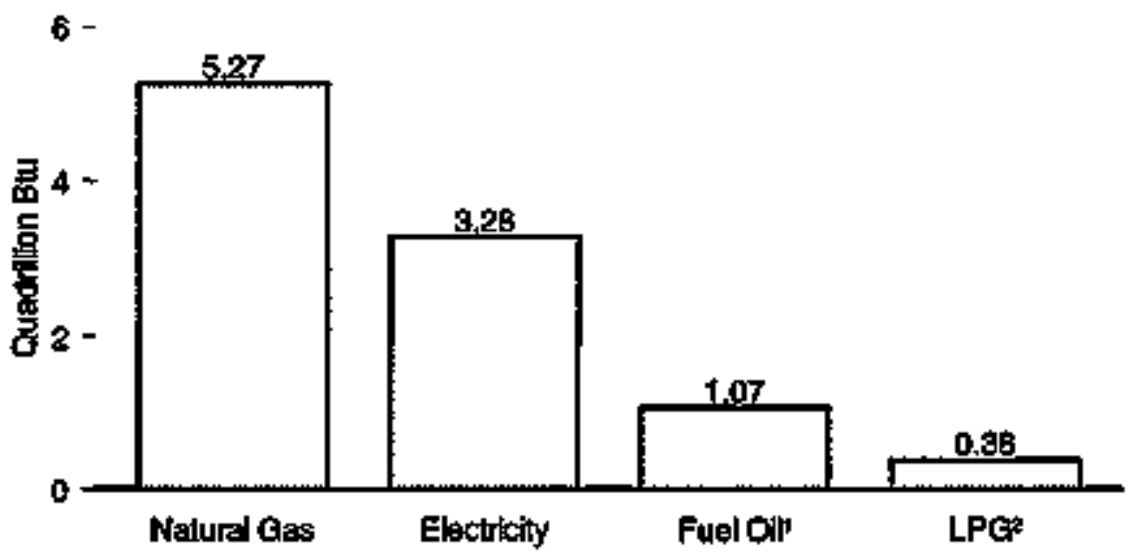

Consumpilon by End Use, 1993

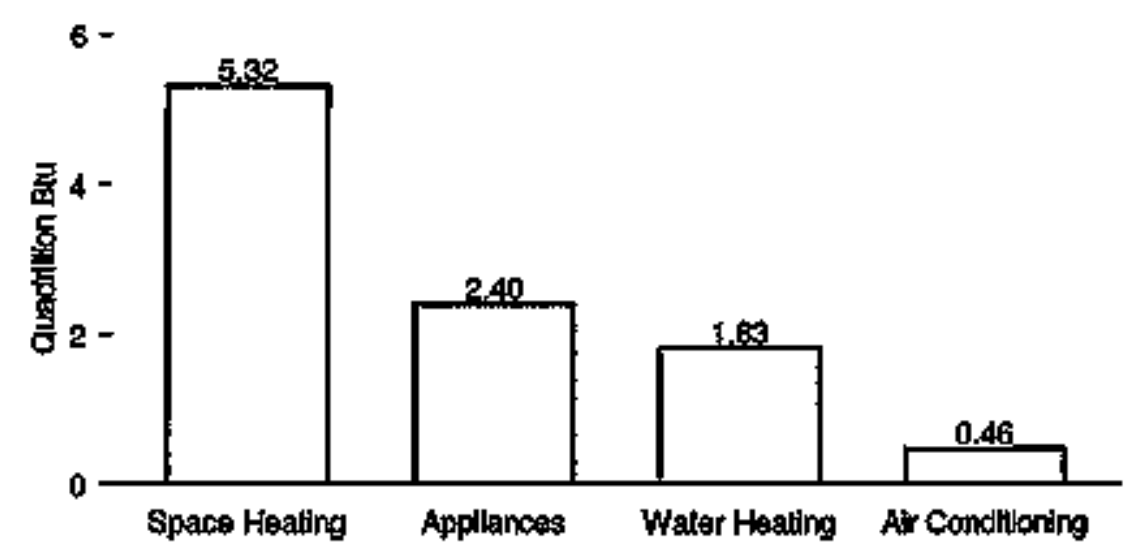

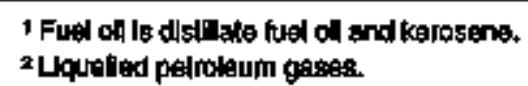

$\checkmark$ Nominal dollers.
Expendilures, Selected Yoars, 1978-1998

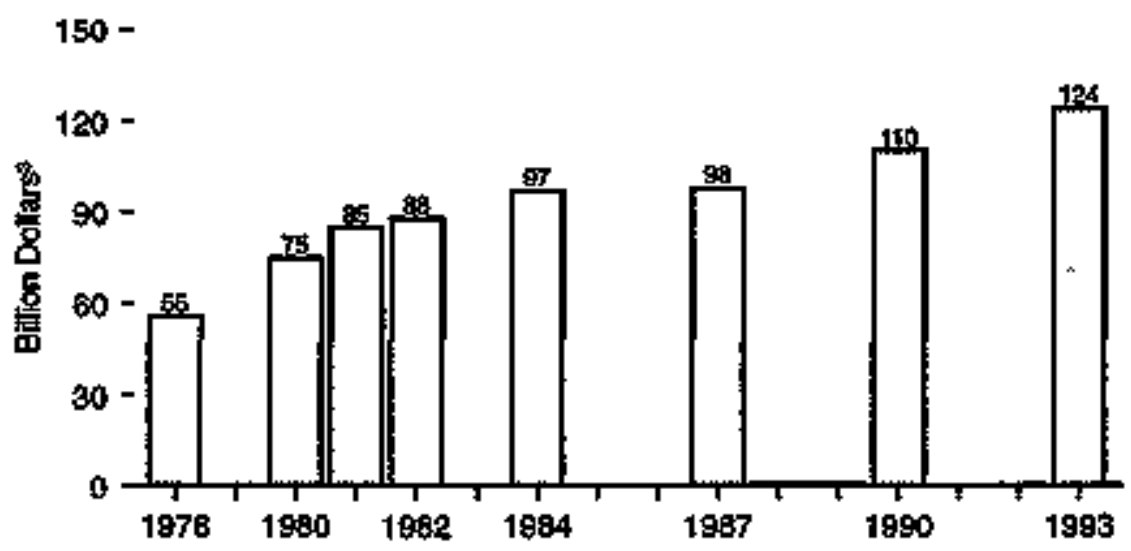

Consumpilon for Space Heatins, 1993

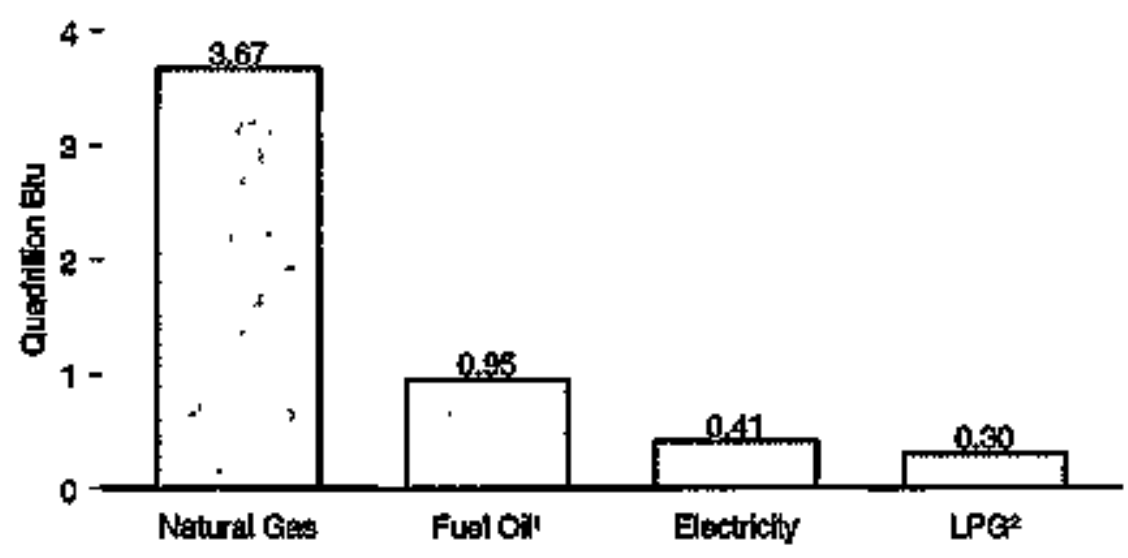

Noles? - No dala are avellable for years not shown. - Because vartleal scales difier, graphs should not be compared

Sounce: Table 2.10. 
Table 2.10 Household Energy Consumption and Expenditures by End Use and Energy Source, Selected Years, 1978-1993

\begin{tabular}{|c|c|c|c|c|c|c|c|c|c|c|c|c|c|c|c|c|}
\hline \multirow[b]{2}{*}{ Yoar } & \multicolumn{4}{|c|}{ spece theasing } & \multirow{2}{*}{$\begin{array}{l}\text { ANC to } \\
\text { Electir- } \\
\text { telty }\end{array}$} & \multicolumn{4}{|c|}{ Water Heating } & \multicolumn{3}{|c|}{ Applaneans? } & \multicolumn{4}{|c|}{ Told 2} \\
\hline & $\begin{array}{c}\text { Nalurd } \\
\text { Gay }\end{array}$ & $\begin{array}{l}\text { Electry. } \\
\text { ethyt }\end{array}$ & $\begin{array}{l}\text { Fuef } \\
\text { ont? }\end{array}$ & LFE" & & $\begin{array}{c}\text { Nutural } \\
\text { Gats }\end{array}$ & $\begin{array}{l}\text { Electit. } \\
\text { olty }\end{array}$ & $\begin{array}{l}\text { Fu } \\
\text { OH } 5\end{array}$ & LPG: & Natcorat & Electst & EPE : & $\begin{array}{l}\text { Nohurad } \\
\text { Gex }\end{array}$ & $\begin{array}{l}\text { Electrit. } \\
\text { oby }\end{array}$ & $\begin{array}{l}\text { Fual } \\
\text { oft' }\end{array}$ & LPG \\
\hline \multirow{3}{*}{$\begin{array}{l}1979 \\
1990 \\
1999 \\
1998 \\
1984 \\
1997 \\
1990 \\
1998\end{array}$} & \multicolumn{16}{|c|}{$\begin{array}{l}\text { Consumprion } \\
\text { (quadfiltion Btul) }\end{array}$} \\
\hline & 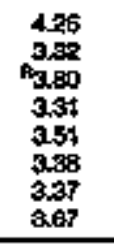 & $\begin{array}{l}0.40 \\
0.28 \\
0.90 \\
0.27 \\
0.30 \\
0.28 \\
0.30 \\
0.41\end{array}$ & $\begin{array}{r}2.05 \\
1.32 \\
R_{1.12} \\
1.05 \\
R_{1.11} \\
7.05 \\
m_{0.38} \\
0.65\end{array}$ & $\begin{array}{l}0.23 \\
0.25 \\
0.22 \\
0.19 \\
0.21 \\
0.22 \\
0.19 \\
0.30\end{array}$ & $\begin{array}{r}0.31 \\
0.32 \\
0.33 \\
0.30 \\
\mathbf{0 . 0 . 3 3} \\
0.44 \\
0.48 \\
0.46 \\
\end{array}$ & $\begin{array}{l}1.04 \\
1.24 \\
1.10 \\
1.00 \\
1.10 \\
1.10 \\
1.15 \\
1.31 \\
\end{array}$ & $\begin{array}{l}0.29 \\
0.31 \\
0.34 \\
0.33 \\
0.32 \\
0.31 \\
0.34 \\
0.34\end{array}$ & $\begin{array}{c}0.14 \\
0.24 \\
+0.20 \\
0.00 \\
0.15 \\
0.17 \\
0.11 \\
0.12 \\
\end{array}$ & $\begin{array}{l}0.08 \\
0.07 \\
0.05 \\
0.08 \\
0.08 \\
0.05 \\
0.08 \\
0.05\end{array}$ & $\begin{array}{l}0.28 \\
0.38 \\
0.49 \\
0.39 \\
0.35 \\
0.34 \\
0.39 \\
0.29 \\
\end{array}$ & $\begin{array}{r}1.46 \\
1.56 \\
1.59 \\
1.59 \\
1.53 \\
1.72 \\
1.91 \\
0.09 \\
\end{array}$ & $\begin{array}{l}0.03 \\
0.04 \\
0.03 \\
0.04 \\
0.04 \\
0.04 \\
0.03 \\
0.03\end{array}$ & $\begin{array}{l}5.58 \\
4.94 \\
5.39 \\
4.77 \\
4.98 \\
4.08 \\
4.86 \\
5.27 \\
\end{array}$ & $\begin{array}{l}2.47 \\
2.45 \\
2.48 \\
2.42 \\
2.48 \\
2.76 \\
3.09 \\
3.28 \\
\end{array}$ & $\begin{array}{l}2.10 \\
1.55 \\
1.30 \\
1.14 \\
1.26 \\
1.28 \\
1.04 \\
1.07 \\
\end{array}$ & $\begin{array}{l}0.33 \\
0.35 \\
0.35 \\
0.29 \\
0.35 \\
0.38 \\
0.28 \\
0.39 \\
\end{array}$ \\
\hline & \multicolumn{16}{|c|}{$\begin{array}{l}\text { Expend wures } \\
\text { (balllon dollers' }\end{array}$} \\
\hline $\begin{array}{l}1978 \\
1990 \\
1987 \\
1988 \\
1984 \\
1987 \\
1990 \\
1989\end{array}$ & $\begin{array}{l}11.49 \\
12.00 \\
17.09 \\
18.55 \\
20.08 \\
18.05 \\
18.59 \\
21.98\end{array}$ & $\begin{array}{l}3.58 \\
3.71 \\
4.60 \\
4.45 \\
5.71 \\
5.53 \\
5.16 \\
8.65\end{array}$ & $\begin{array}{r}\text { B.06 } \\
10.69 \\
0.09 \\
\text { B.84 } \\
8.51 \\
6.95 \\
7.42 \\
\text { A.24 }\end{array}$ & $\begin{array}{l}1.05 \\
1.00 \\
1.04 \\
1.60 \\
2.00 \\
1.05 \\
2.01 \\
2.01\end{array}$ & $\begin{array}{r}9.97 \\
5.07 \\
5.06 \\
6.05 \\
1.37 \\
9.77 \\
11.49 \\
11.30\end{array}$ & $\begin{array}{l}2.06 \\
4.70 \\
4.93 \\
5.06 \\
5.89 \\
8.02 \\
6.69 \\
0.09\end{array}$ & $\begin{array}{l}3.15 \\
4.54 \\
6.32 \\
5.50 \\
8.44 \\
8.45 \\
7.21 \\
7.59\end{array}$ & $\begin{array}{r}0.55 \\
1.80 \\
1.83 \\
0.75 \\
1.09 \\
0.94 \\
0.03 \\
\mathrm{P}_{0.74}\end{array}$ & $\begin{array}{l}0.58 \\
0.59 \\
0.53 \\
0.57 \\
0.58 \\
0.50 \\
80.65 \\
0.58\end{array}$ & $\begin{array}{l}0.93 \\
1.71 \\
2.50 \\
2.42 \\
2.31 \\
2.00 \\
2.08 \\
1.98\end{array}$ & 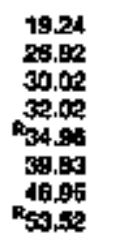 & $\begin{array}{r}0.25 \\
0.40 \\
0.37 \\
0.47 \\
0.54 \\
0.48 \\
0.48 \\
0.48\end{array}$ & $\begin{array}{r}15.30 \\
10.30 \\
24.60 \\
27.06 \\
A_{29.78} \\
26.15 \\
77.28 \\
32.04\end{array}$ & $\begin{array}{r}29.69 \\
40.14 \\
45.90 \\
41.48 \\
R_{54.48} \\
61.58 \\
71.54 \\
91.08\end{array}$ & $\begin{array}{r}9.62 \\
12.49 \\
11.99 \\
9.59 \\
9.60 \\
7.21 \\
8.25 \\
6.96\end{array}$ & $\begin{array}{r}1,68 \\
2.69 \\
2.74 \\
2.72 \\
03.12 \\
2.61 \\
3.14 \\
3.01\end{array}$ \\
\hline
\end{tabular}

NO $=$ Ar conditoniting

A small amount of naturel gar used tor alr condidoning is hetuded in "Welural Gas" under "Toxal"

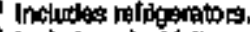

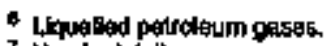

7 Mominal daltars.

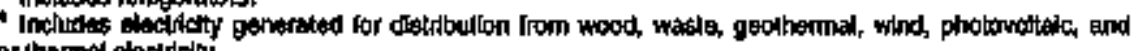

solar tharmot clactrile-ly.

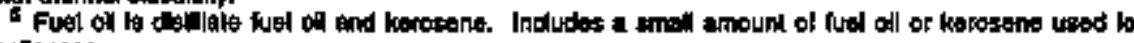
2,8. - One But of electrichly $=0.000203(1+3,412)$ kWh. - Tolats may not equal sum of components dke to indapardant roundirg

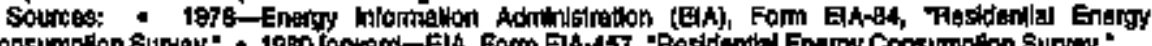
apponass 
Figure 2.11 Household Energy Consumption and Expenditure Indlcators by Census Region and Vintage of Housing Unit, 1993

\section{Consumplion of Main Heating Fual}
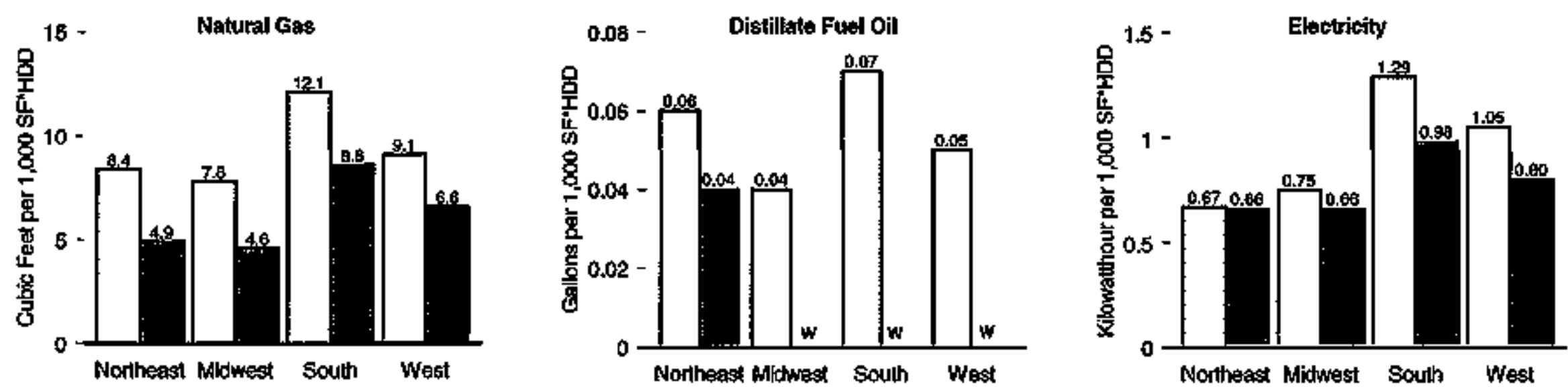

Expenctutures for Main Heating Fuel

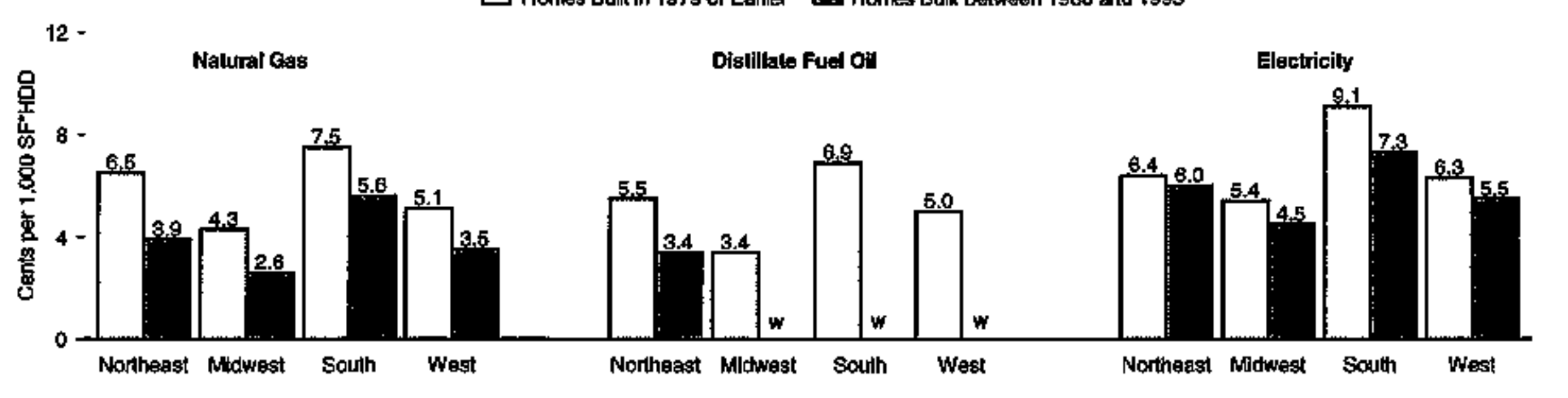

Whate withold beceuse fewer than to housing unlls were semplad. Sptuck: Table 2.11. Seg Appenctix F for Census reglons.

Nove: SF"HDD=Bquare follege VImes heating degreo-days. 
Table 2.11 Household Energy Consumption and Expendifure Indicators by Census Region and Vintage of Housing Unit, 1993

\begin{tabular}{|c|c|c|c|c|c|c|c|c|c|c|}
\hline \multirow[b]{3}{*}{ Source and hitdicator (Un'ta) } & \multicolumn{8}{|c|}{ Centus feglont 1} & & \\
\hline & \multicolumn{2}{|c|}{ Northequt } & \multicolumn{2}{|c|}{ Llkweat } & \multicolumn{2}{|c|}{ South } & \multicolumn{2}{|c|}{ Weat } & \multicolumn{2}{|c|}{ LkHited Stater } \\
\hline & $\begin{array}{l}\text { Eultito } \\
\text { 1979 or } \\
\text { Eardilur }\end{array}$ & $\begin{array}{c}\text { Búll } \\
\text { Bekweis } \\
\text { 1990-1999 }\end{array}$ & $\begin{array}{l}\text { Bunk in } \\
1979 \text { or } \\
\text { Extiter }\end{array}$ & $\begin{array}{c}\text { Bult } \\
\text { Betwripun } \\
19 \mathrm{~B}-1993\end{array}$ & $\begin{array}{l}\text { Butit to } \\
\text { 1979 or } \\
\text { Eeriler }\end{array}$ & $\begin{array}{c}\text { Buill } \\
\text { Between } \\
\text { 19ak-1993 }\end{array}$ & $\begin{array}{l}\text { Ouph In } \\
\text { 19r9 on } \\
\text { Earilier }\end{array}$ & 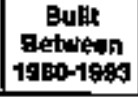 & $\begin{array}{l}\text { Buin In } \\
1970 \text { or } \\
\text { Eanllex }\end{array}$ & $\begin{array}{c}\text { Budd } \\
\text { Befturén } \\
\text { 19:0-19os }\end{array}$ \\
\hline 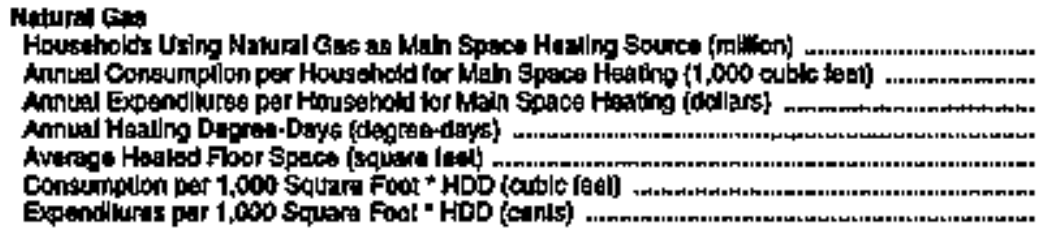 & $\begin{array}{r}8.2 \\
83.2 \\
640 \\
5,749 \\
1,718 \\
84 \\
8.4\end{array}$ & $\begin{array}{r}1.3 \\
54.9 \\
440 \\
6,056 \\
1,0.46 \\
4.9 \\
3.9\end{array}$ & $\begin{array}{r}14.4 \\
0.1 \\
513 \\
5,585 \\
1,809 \\
7.6 \\
4.3\end{array}$ & $\begin{array}{r}2.5 \\
70.9 \\
396 \\
6.694 \\
2.207 \\
4.6 \\
\mathbf{2 . 6}\end{array}$ & $\begin{array}{r}9.7 \\
60.9 \\
378 \\
3,277 \\
1,575 \\
121 \\
7.5\end{array}$ & $\begin{array}{r}3.3 \\
46.7 \\
300 \\
2,574 \\
1,80.2 \\
8.6 \\
5.6\end{array}$ & $\begin{array}{r}9.8 \\
43.5 \\
241 \\
3.151 \\
1,10.9 \\
0.1 \\
5.1\end{array}$ & $\begin{array}{r}2.5 \\
40.8 \\
251 \\
3,698 \\
1,649 \\
6.8 \\
9.5\end{array}$ & $\begin{array}{r}41.8 \\
72.8 \\
445 \\
4.859 \\
1.657 \\
9.0 \\
5.5\end{array}$ & $\begin{array}{r}9.8 \\
542 \\
993 \\
+598 \\
1,058 \\
6.0 \\
9.7\end{array}$ \\
\hline 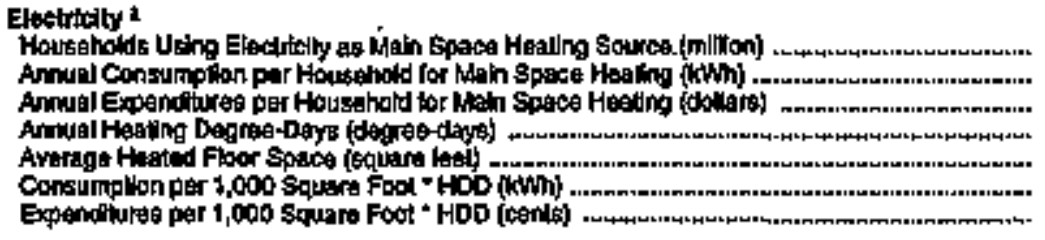 & $\begin{array}{r}1.5 \\
5,499 \\
5927 \\
6,065 \\
1,368 \\
0.67 \\
6.4\end{array}$ & $\begin{array}{r}0,7 \\
6,137 \\
557 \\
6,076 \\
7,536 \\
0.56 \\
6.0\end{array}$ & $\begin{array}{r}1.7 \\
5,215 \\
589 \\
6,445 \\
1,695 \\
0.76 \\
6.4\end{array}$ & $\begin{array}{r}1.2 \\
5,561 \\
376 \\
5,894 \\
1,407 \\
0.66 \\
4,5\end{array}$ & $\begin{array}{r}7.5 \\
4,395 \\
311 \\
2,451 \\
1,990 \\
7.29 \\
9.1\end{array}$ & $\begin{array}{r}7.1 \\
3,638 \\
271 \\
2,484 \\
1,597 \\
0,99 \\
7,3\end{array}$ & $\begin{array}{r}\text { 3. } \\
4,682 \\
279 \\
0,943 \\
1,124 \\
1.05 \\
6.9\end{array}$ & $\begin{array}{r}1.8 \\
0,127 \\
214 \\
3,008 \\
1,290 \\
0.80 \\
5.5\end{array}$ & $\begin{array}{r}14.3 \\
5,001 \\
354 \\
3,693 \\
1,030 \\
1,0.02 \\
7.2\end{array}$ & $\begin{array}{r}10.7 \\
8,020 \\
291 \\
3,157 \\
1,476 \\
0,84 \\
62\end{array}$ \\
\hline 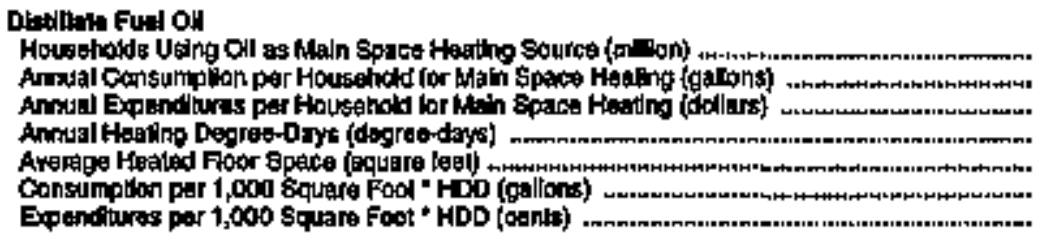 & $\begin{array}{r}6.3 \\
653 \\
505 \\
6,908 \\
1,613 \\
0.08 \\
5.5\end{array}$ & $\begin{array}{r}0.7 \\
655 \\
505 \\
5,511 \\
2,28.4 \\
0.04 \\
3.4\end{array}$ & $\begin{array}{r}1.3 \\
690 \\
592 \\
7,747 \\
2,249 \\
0.04 \\
3.4\end{array}$ & $\begin{array}{l}w \\
w \\
w \\
w \\
w \\
w \\
w\end{array}$ & $\begin{array}{r}1.4 \\
516 \\
494 \\
3,952 \\
1,946 \\
0.07 \\
5.9\end{array}$ & $\begin{array}{l}w \\
w \\
w \\
w \\
w \\
w\end{array}$ & $\begin{array}{r}0.4 \\
535 \\
549 \\
5,900 \\
2,009 \\
0.00 \\
5.0\end{array}$ & $\begin{array}{l}w \\
w \\
w \\
w \\
w \\
w \\
w\end{array}$ & $\begin{array}{r}9.4 \\
635 \\
571 \\
5,841 \\
1,865 \\
0.05 \\
6.2\end{array}$ & $\begin{array}{r}0.8 \\
5,82 \\
483 \\
6,322 \\
6,222 \\
0.04 \\
0.4\end{array}$ \\
\hline 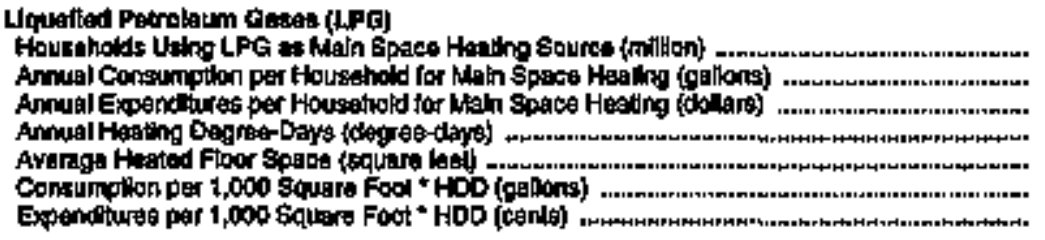 & $\begin{array}{l}\mathbf{w} \\
\mathbf{w} \\
\mathbf{w} \\
\mathbf{w} \\
\mathbf{w} \\
\mathbf{w} \\
\mathbf{w}\end{array}$ & $\begin{array}{r}0.1 \\
606 \\
609 \\
7,075 \\
1,667 \\
0.05 \\
6.2\end{array}$ & $\begin{array}{r}1,4 \\
1,001 \\
760 \\
6,039 \\
2,134 \\
0,07 \\
6.1\end{array}$ & $\begin{array}{r}0.3 \\
707 \\
664 \\
6.694 \\
1,908 \\
0.05 \\
4.2\end{array}$ & $\begin{array}{r}1.8 \\
425 \\
406 \\
2,827 \\
1,291 \\
0.12 \\
11.1\end{array}$ & $\begin{array}{r}0.5 \\
485 \\
417 \\
3,039 \\
1,436 \\
0.10 \\
0.4\end{array}$ & $\begin{array}{r}0.2 \\
697 \\
791 \\
0,459 \\
1,559 \\
0.00 \\
7.7\end{array}$ & $\begin{array}{r}0.1 \\
432 \\
128 \\
4,550 \\
1,398 \\
0.07 \\
6.7\end{array}$ & $\begin{array}{r}3.5 \\
692 \\
681 \\
4,624 \\
1,546 \\
6.09 \\
7.3\end{array}$ & $\begin{array}{r}1.1 \\
641 \\
106 \\
4,980 \\
1,824 \\
0.07 \\
6.1\end{array}$ \\
\hline
\end{tabular}

I See Appenulix F bor Cenass reptons.

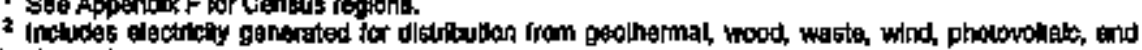

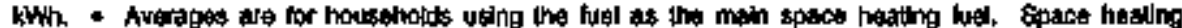

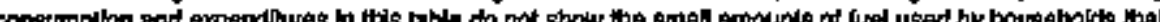

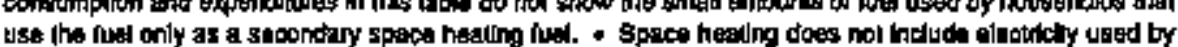

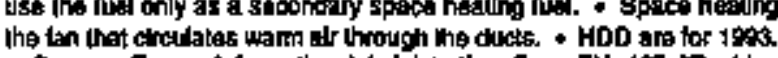

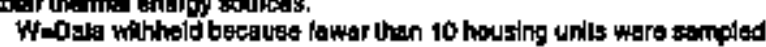

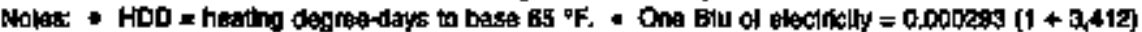

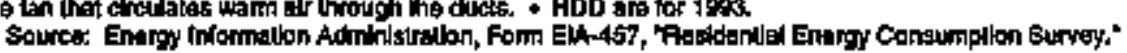




\section{Figure 2.12 Households With Selected Appliances, 1980 and 1993}

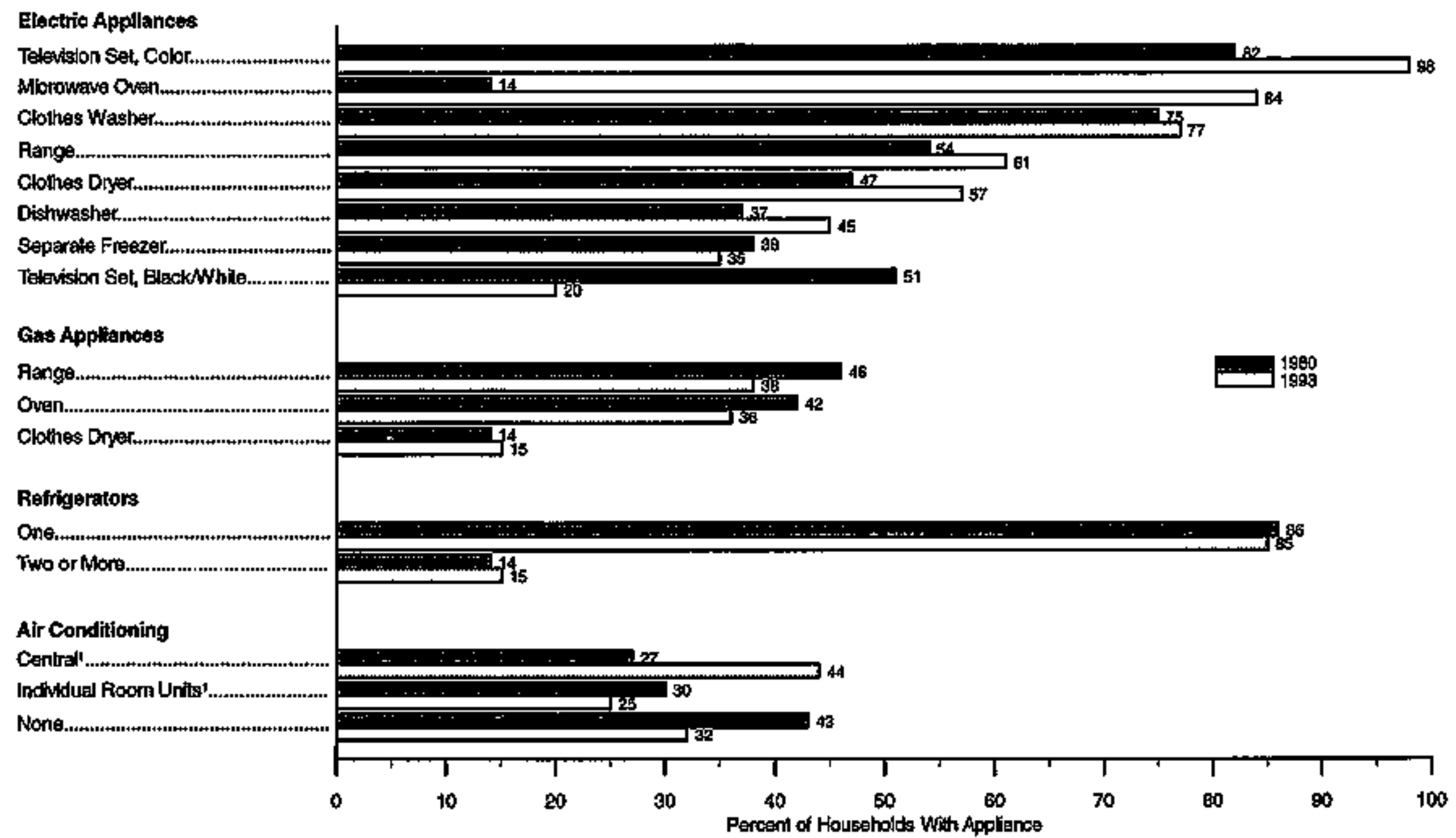

'Househalds wth both central exd hodidural room units are coxunted only under "centreal,"

Source: Table 2,12. 
Table 2.12 Households With Selected Appliances, Selected Years, 1978-1993

\begin{tabular}{|c|c|c|c|c|c|c|c|c|c|c|}
\hline \multirow[b]{2}{*}{ Appilanow } & \multicolumn{9}{|c|}{ Pwrount of Houschinds: } & \multirow{2}{*}{$\frac{\text { Chargat }}{1990101993}$} \\
\hline & 197a & 5979 & 1500 & 1991 & $1 \operatorname{sen}$ & 1894 & 19.57 & 1900 & 1998 & \\
\hline Total Houssholds ...nomm & 100 & 100 & 100 & 100 & 100 & 100 & 100 & $\$ 00$ & 100 & - \\
\hline 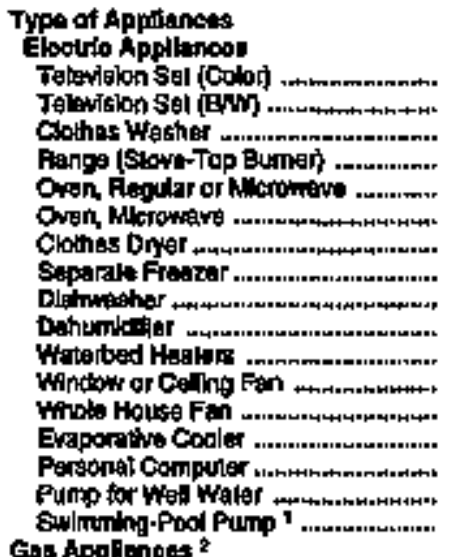 & 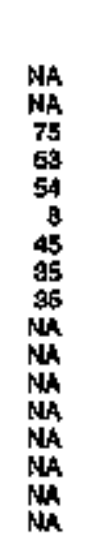 & $\begin{array}{l}\text { NA } \\
\text { NA } \\
\text { NA } \\
\text { MA } \\
\text { NA } \\
\text { NA } \\
\text { NA } \\
\text { NA } \\
\text { NA } \\
\text { MA } \\
\text { NA } \\
\text { NA } \\
\text { NA } \\
\text { NA } \\
\text { NA } \\
\text { NA } \\
\text { NA } \\
\text { NA }\end{array}$ & $\begin{array}{c}89 \\
51 \\
75 \\
54 \\
59 \\
14 \\
47 \\
59 \\
37 \\
9 \\
\text { NA } \\
\text { NA } \\
\text { NA } \\
4 \\
\text { NA } \\
\text { MA } \\
4\end{array}$ & $\begin{array}{r}89 \\
40 \\
74 \\
54 \\
59 \\
17 \\
45 \\
30 \\
37 \\
9 \\
\text { NA } \\
\text { NA } \\
\text { NA } \\
4 \\
\text { NA } \\
\text { NA } \\
4\end{array}$ & $\begin{array}{r}85 \\
47 \\
72 \\
58 \\
59 \\
24 \\
45 \\
37 \\
38 \\
5 \\
\mathrm{MA} \\
28 \\
8 \\
4 \\
\mathrm{NA} \\
\mathrm{MA} \\
\mathrm{a}\end{array}$ & $\begin{array}{c}88 \\
43 \\
74 \\
54 \\
63 \\
34 \\
45 \\
37 \\
38 \\
9 \\
10 \\
35 \\
8 \\
4 \\
\text { NA } \\
\text { NA } \\
\text { NA }\end{array}$ & $\begin{array}{c}93 \\
36 \\
76 \\
57 \\
79 \\
61 \\
51 \\
34 \\
43 \\
10 \\
54 \\
46 \\
9 \\
3 \\
\mathbf{3} \\
\mathbf{N h} \\
\mathbf{N A}\end{array}$ & $\begin{array}{c}96 \\
31 \\
76 \\
76 \\
68 \\
68 \\
79 \\
59 \\
35 \\
45 \\
12 \\
16 \\
51 \\
10 \\
4 \\
16 \\
15 \\
5\end{array}$ & $\begin{array}{c}98 \\
20 \\
77 \\
71 \\
61 \\
91 \\
94 \\
77 \\
35 \\
45 \\
9 \\
12 \\
50 \\
4 \\
3 \\
23 \\
13 \\
5\end{array}$ & 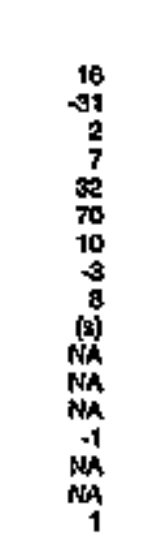 \\
\hline 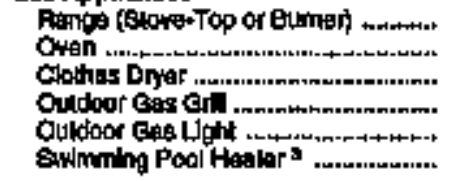 & $\begin{array}{l}48 \\
47 \\
14 \\
N A \\
2 \\
N\end{array}$ & $\begin{array}{l}\text { MA } \\
\text { MA } \\
\text { MA } \\
\text { MA }\end{array}$ & $\begin{array}{r}46 \\
42 \\
14 \\
0 \\
2 \\
2 A\end{array}$ & $\begin{array}{r}41 \\
49 \\
16 \\
9 \\
2 \\
\mathrm{NA}\end{array}$ & $\begin{array}{r}47 \\
42 \\
18 \\
11 \\
4 \\
M A\end{array}$ & $\begin{array}{r}46 \\
48 \\
16 \\
13 \\
1 \\
1\end{array}$ & $\begin{array}{l}43 \\
41 \\
15 \\
20 \\
1 \\
1\end{array}$ & $\begin{array}{l}12 \\
41 \\
16 \\
26 \\
1 \\
2\end{array}$ & $\begin{array}{r}3 a \\
38 \\
16 \\
29 \\
1 \\
1\end{array}$ & $\begin{array}{r}9 \\
6 \\
1 \\
20 \\
-1 \\
N A\end{array}$ \\
\hline 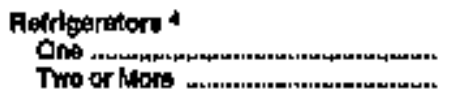 & 19 & $\begin{array}{l}\text { MA } \\
\text { MA }\end{array}$ & 85 & $\begin{array}{l}87 \\
13\end{array}$ & $\begin{array}{l}85 \\
13\end{array}$ & $\begin{array}{l}88 \\
12\end{array}$ & $\begin{array}{l}8 \times 6 \\
14\end{array}$ & $\begin{array}{l}64 \\
15\end{array}$ & $\begin{array}{l}\text { 95 } \\
15\end{array}$ & $\begin{array}{r}-1 \\
1\end{array}$ \\
\hline 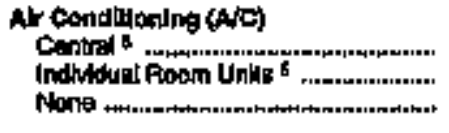 & 34 & $\begin{array}{l}24 \\
31 \\
46\end{array}$ & $\begin{array}{l}27 \\
30 \\
43\end{array}$ & $\begin{array}{l}27 \\
31 \\
42\end{array}$ & $\begin{array}{l}28 \\
30 \\
40\end{array}$ & $\begin{array}{l}30 \\
30 \\
40\end{array}$ & $\begin{array}{l}36 \\
30 \\
36\end{array}$ & 39 & $\begin{array}{l}44 \\
25 \\
32\end{array}$ & $\begin{array}{r}17 \\
-5 \\
-11\end{array}$ \\
\hline Portable Kerosene Howlere & (的) & MA & (\$) & 1 & 3 & 5 & 8 & $\mathbf{s}$ & 2 & 2 \\
\hline
\end{tabular}

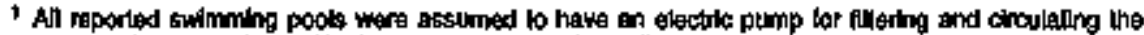

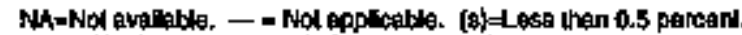

wajar, oxcept lor 1 sao when a tilaring syshm was mode axplatt.

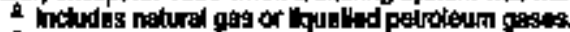

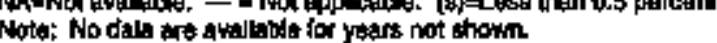

3 incudes natura gas or iqualid peiroteurn gases.

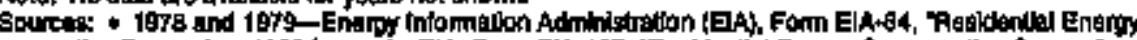

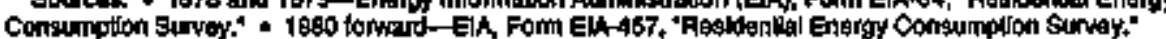

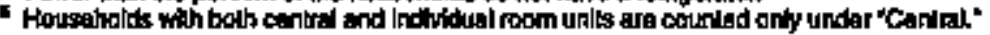




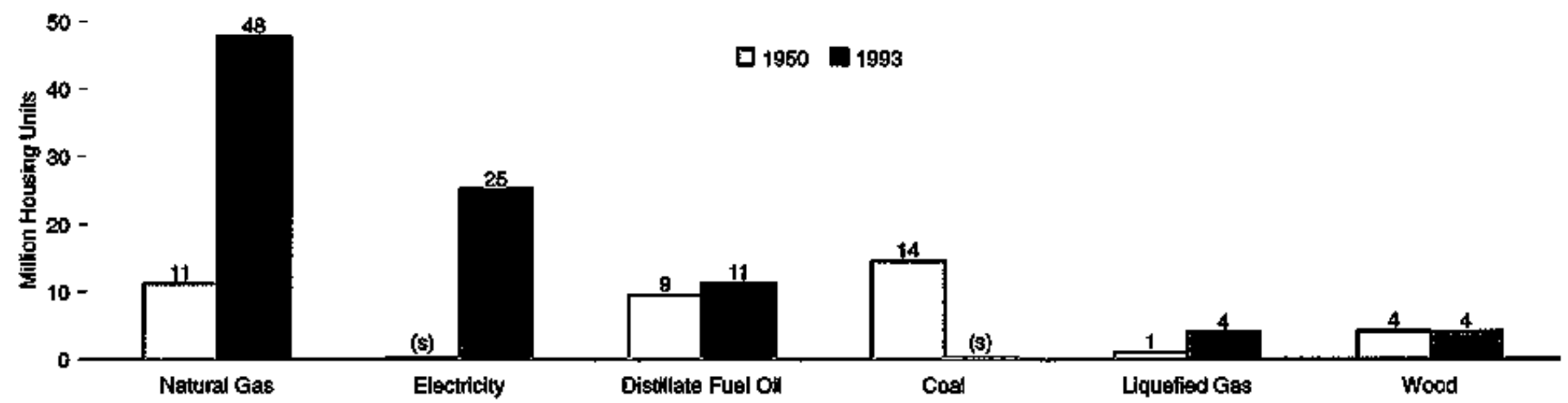

60.

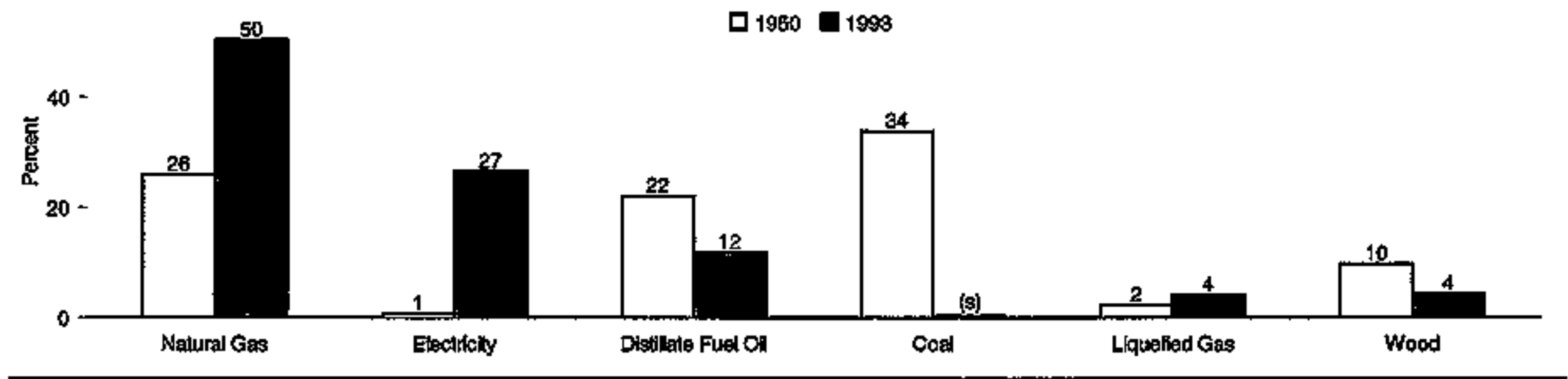


Table 2.13 Type of Heating in Occupied Housing Units, Selected Years, 1950-1993

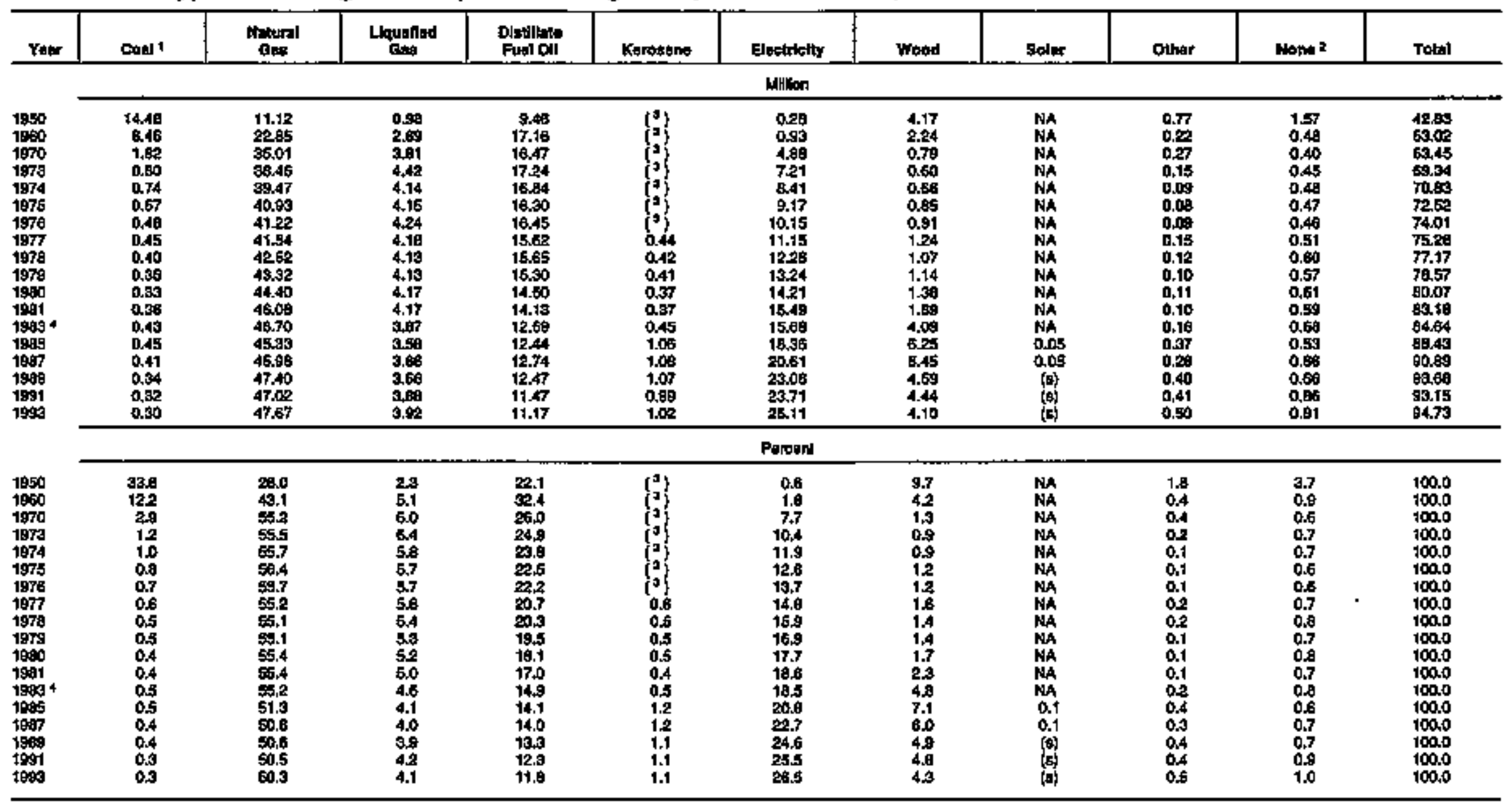

2 Inctides cosel coter.

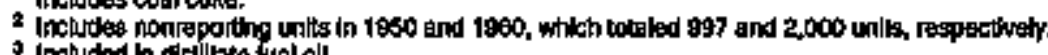

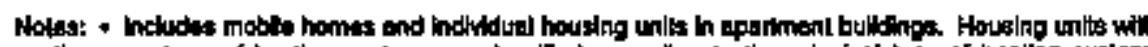

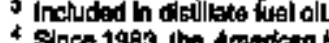

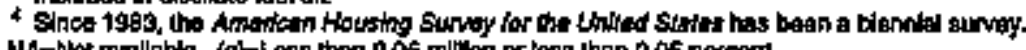

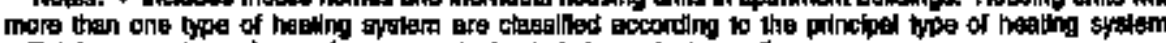

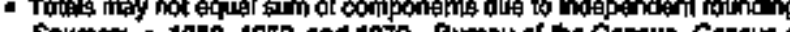

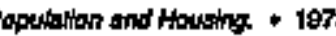

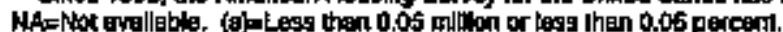




\section{Figure 2.14 Household Motor Vehicle Data}

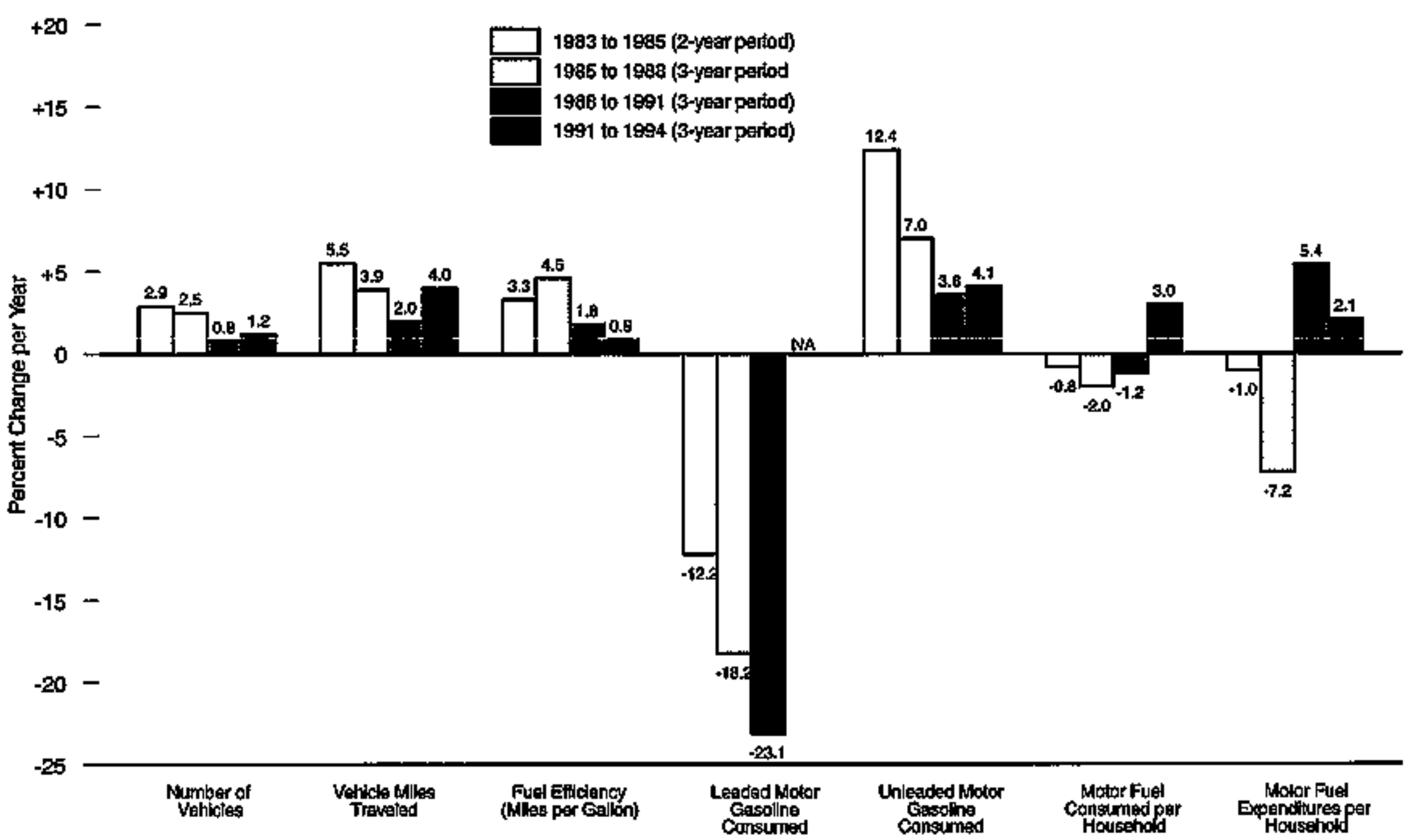

Nolex The percem changes are of al heome catecorles; they are shapte averane enmual

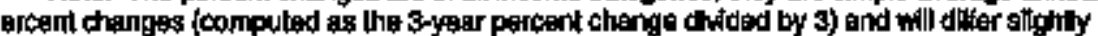

NAsuNol Avalkablo.

pircent changes (computed as this 3-year porcent

Source: Tabke 2.14. 
Table 2.14 Household Motor Vehicle Data, 1983, 1985, 1988, 1991, and 1994

\begin{tabular}{|c|c|c|c|c|c|c|c|c|c|c|c|c|c|c|c|}
\hline \multirow[b]{3}{*}{ Inht of vipasine } & \multicolumn{15}{|c|}{ Fondily Inecme } \\
\hline & \multicolumn{5}{|c|}{ Lesa than $\$ 20,000$} & \multicolumn{5}{|c|}{$\$ 25,000$ or Hors } & \multicolumn{5}{|c|}{ All Incoms Categorie: } \\
\hline & $19: 3$ & 19995 & 1998 & 1999 & 1894 & 1963 & 1995 & 1986 & 1999 & 1894 & 1983 & 1985: & 1948 & 1991 & 1994 \\
\hline Householts with Vatieles (millont) & 42.9 & A3.5 & sB.s & 36.5 & 34.5 & 30.5 & 34.5 & 12.2 & 48.2 & $50 \mathrm{~s}$ & 724 & 77.7 & 81.3 & 84.8 & 84.9 \\
\hline 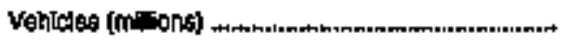 & 66.7 & 65.4 & 58.7 & 52.7 & 500 & 68.0 & 759 & 88.8 & 90.5 & 104.8 & 129.7 & 137.3 & 147.5 & 151.2 & 156,8 \\
\hline 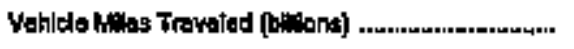 & 589 & 587 & 50 & 488 & 550,4 & 630 & 786 & $\operatorname{sen}$ & 1,114 & 1,2428 & 1,219 & 1,353 & 1,511 & 1,800 & 1,793 \\
\hline 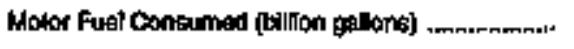 & 40,8 & 382 & 31,4 & 28.0 & 28.3 & 39.9 & 45.7 & $\mathbf{5 1 . 0}$ & 56.0 & 62.3 & 80.5 & 83.0 & set & pe.8 & 80.6 \\
\hline 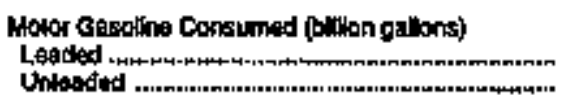 & $\begin{array}{l}10.2 \\
20.8\end{array}$ & $\begin{array}{r}13.6 \\
24.2\end{array}$ & $\begin{array}{r}6.4 \\
25.7\end{array}$ & $\begin{array}{r}1.8 \\
24.7\end{array}$ & $\underset{24.7}{0}$ & $\begin{array}{l}13.2 \\
25.3\end{array}$ & $\begin{array}{l}11.0 \\
\text { aa. }\end{array}$ & $\begin{array}{r}5.8 \\
44.8\end{array}$ & \$.6 & $\underset{60.3}{C}$ & $\begin{array}{l}32.4 \\
46.5\end{array}$ & $\begin{array}{l}24.6 \\
578\end{array}$ & $\begin{array}{l}11.1 \\
698\end{array}$ & $\begin{array}{r}3.4 \\
7.5\end{array}$ & $\begin{array}{r}9 \\
07.0\end{array}$ \\
\hline 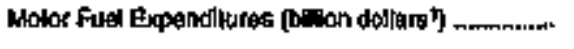 & 48,1 & 44,8 & 30.7 & 31.7 & 326 & 17.3 & 54.3 & 50.3 & 68.6 & 72,1 & 95.4 & 90.1 & 81.4 & 99.2 & 104.7 \\
\hline 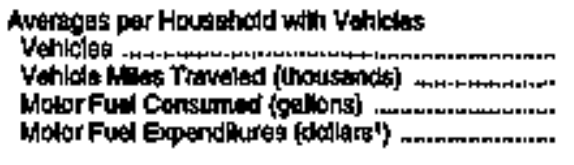 & $\begin{array}{r}1.6 \\
18.7 \\
950 \\
1,121\end{array}$ & $\begin{array}{r}1.6 \\
19.6 \\
1,009\end{array}$ & $\begin{array}{l}1,0 \\
14,1 \\
807 \\
709\end{array}$ & $\begin{array}{r}1.4 \\
13.4 \\
797 \\
869\end{array}$ & $\begin{array}{r}\$ .5 \\
16.8 \\
918 \\
943\end{array}$ & $\begin{array}{r}2.1 \\
20.7 \\
1,305 \\
1,562\end{array}$ & $\begin{array}{r}2.1 \\
22.2 \\
1,326 \\
1,676\end{array}$ & $\begin{array}{r}2.1 \\
22.7 \\
1.205 \\
1.191\end{array}$ & $\begin{array}{r}2.0 \\
23.1 \\
1,160 \\
1,382\end{array}$ & $\begin{array}{r}2,1 \\
24,7 \\
1,2399 \\
1,433\end{array}$ & $\begin{array}{r}1,8 \\
10.6 \\
1,097 \\
1,300\end{array}$ & $\begin{array}{r}1.8 \\
17.4 \\
1,079 \\
1,274\end{array}$ & $\begin{array}{r}1.8 \\
180 \\
1,014 \\
090\end{array}$ & $\begin{array}{r}1.8 \\
1.98 \\
979 \\
1,161\end{array}$ & $\begin{array}{r}1.9 \\
21.1 \\
1,067 \\
1,234\end{array}$ \\
\hline 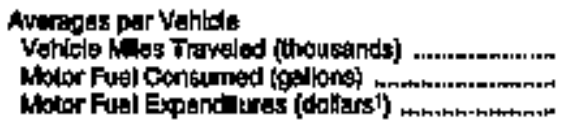 & $\begin{array}{c}8.8 \\
612 \\
722\end{array}$ & $\begin{array}{l}9.0 \\
585 \\
685\end{array}$ & $\begin{array}{l}0.4 \\
50 \\
504\end{array}$ & $\begin{array}{l}1.3 \\
510 \\
602\end{array}$ & $\begin{array}{l}10.6 \\
545 \\
628\end{array}$ & $\begin{array}{l}10.0 \\
631 \\
751\end{array}$ & $\begin{array}{l}10.7 \\
690 \\
7 \% 5\end{array}$ & $\begin{array}{l}10.8 \\
574 \\
567\end{array}$ & $\begin{array}{l}11.8 \\
688 \\
676\end{array}$ & $\begin{array}{l}11.8 \\
594 \\
688\end{array}$ & $\begin{array}{c}0.4 \\
621 \\
736\end{array}$ & $\begin{array}{c}9.9 \\
611 \\
722\end{array}$ & $\begin{array}{r}10.5 \\
559 \\
5 \$ 50\end{array}$ & $\begin{array}{l}10.6 \\
548 \\
650\end{array}$ & $\begin{array}{l}11.4 \\
578 \\
669\end{array}$ \\
\hline 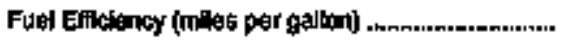 & $\$ 4.4$ & 16.3 & 17.5 & 18.1 & 19.5 & $\mathfrak{i s . \theta}$ & 便息 & 18.8 & 18.8 & 20.0 & 16.1 & 16.1 & 18.3 & 19.3 & 18.8 \\
\hline 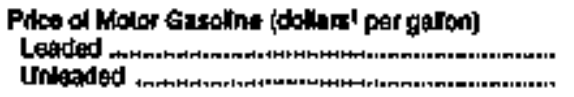 & $\begin{array}{l}1.14 \\
1.22\end{array}$ & $\begin{array}{l}1.11 \\
1.20\end{array}$ & $\begin{array}{l}0.90 \\
0.99\end{array}$ & $\begin{array}{l}1.10 \\
1.18\end{array}$ & $\begin{array}{r}0 \\
1.15\end{array}$ & $\begin{array}{l}1.14 \\
1.22\end{array}$ & $\begin{array}{l}1.11 \\
1.21\end{array}$ & $\begin{array}{l}0.50 \\
1.00\end{array}$ & $\begin{array}{l}1.10 \\
1.19\end{array}$ & $\begin{array}{c}0 \\
1.16\end{array}$ & $\begin{array}{l}1.14 \\
1.22\end{array}$ & $\begin{array}{l}1.11 \\
1.21\end{array}$ & $\begin{array}{l}0.90 \\
1.00\end{array}$ & $\begin{array}{l}1.10 \\
1.19\end{array}$ & $\begin{array}{r}Q \\
1+16\end{array}$ \\
\hline
\end{tabular}

1 Nanthal dolers.

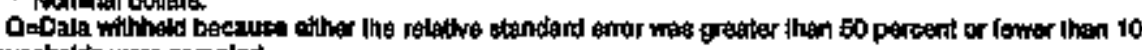
households whe sapipled.

Noles: + Inciuded are alstornoblus, stalon wagons, passunger vans, carpo vans, motor homes, pickup

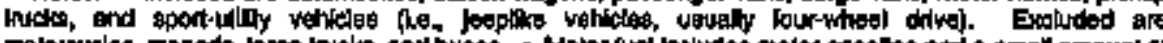

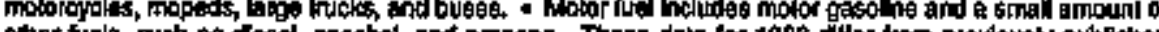

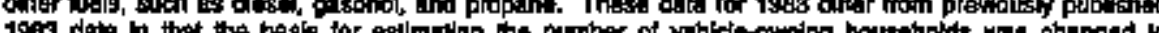

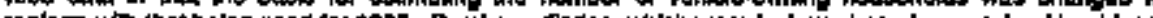

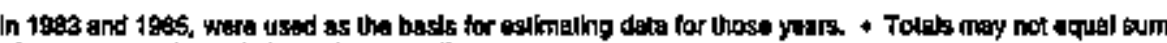

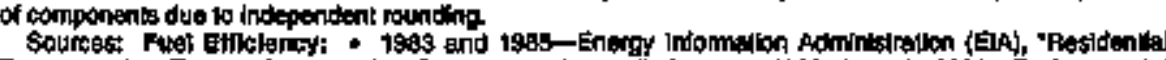
Transportation Enengy Consumplion Burvey" purchase diantes. * 1ses hrough 1994-Emirommenta

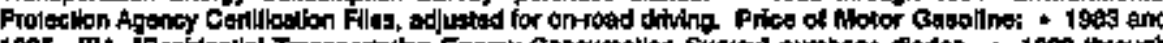

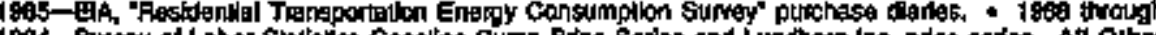

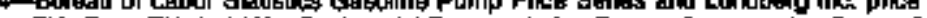
Dates EK, Form EA-ETSAC, "Pestidental Taneportalon Energy Conaumplion Surrey." 
Miflesog

15 -

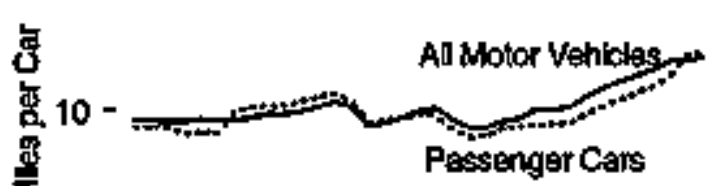

5 -

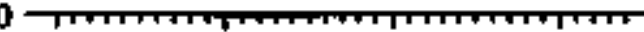

$1980 \quad 1970 \quad 1980 \quad 1990$

\section{All Motor Vehicles Efficiency}

175

韋

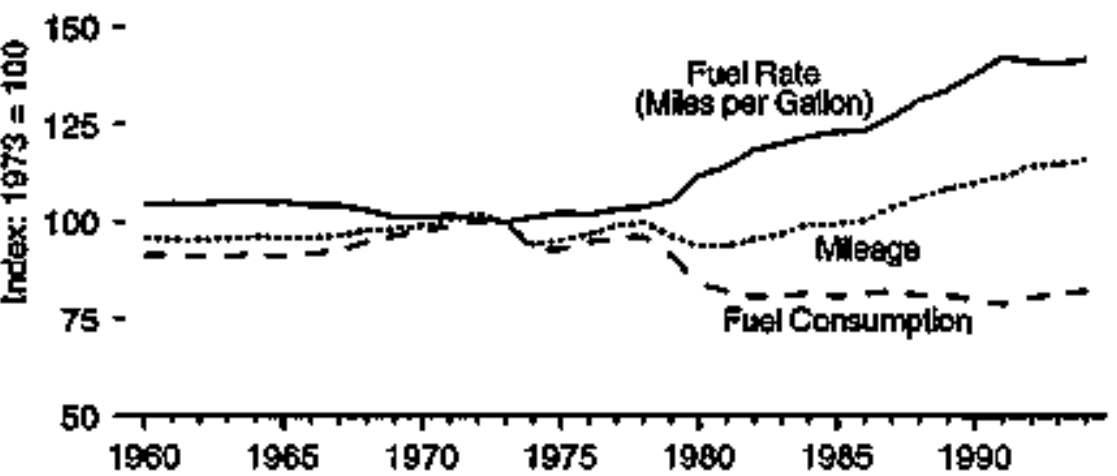

\section{Fuel Rata}

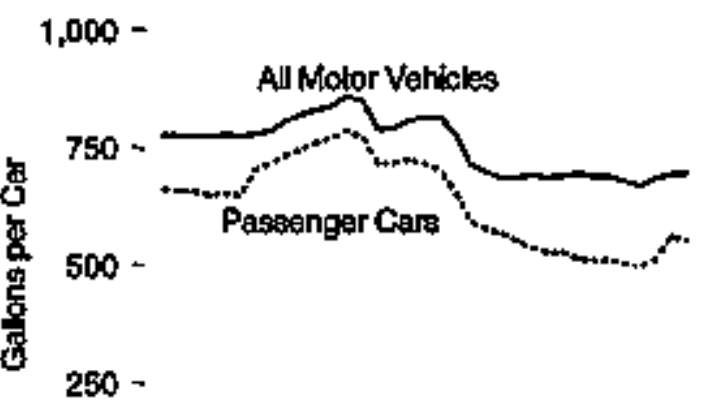

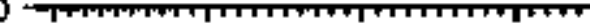
$1960 \quad 1970 \quad 1960 \quad 1990$

\section{Passenger Car Efflciency}

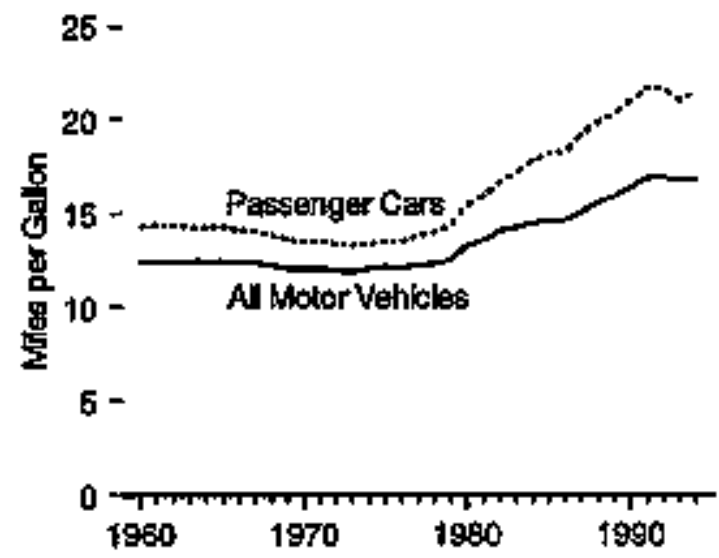


Table 2,15 Motor Vehicle Efficiency, 1960-1994

\begin{tabular}{|c|c|c|c|c|c|c|c|c|c|c|c|c|}
\hline \multirow[b]{3}{*}{ Vear } & \multicolumn{6}{|c|}{ Puspengar Cars 1} & \multicolumn{6}{|c|}{ A1 Botor Vahielas: 2} \\
\hline & \multicolumn{2}{|c|}{ Mloage } & \multicolumn{2}{|c|}{ Fuel Constumpidon } & \multicolumn{2}{|c|}{ Fuel Rate } & \multicolumn{2}{|c|}{ Mlowgon } & \multicolumn{2}{|c|}{ Fuel Cenntumptian } & \multicolumn{2}{|c|}{ Fuclation } \\
\hline & $\begin{array}{c}\text { Miles per } \\
\text { Gort }\end{array}$ & $\begin{array}{c}\text { Index } \\
1973=0 \\
10000\end{array}$ & $\begin{array}{l}\text { Gellons } \\
\text { per Crat }\end{array}$ & $\begin{array}{c}\operatorname{madex}_{\operatorname{tg73}} \\
100,0\end{array}$ & $\begin{array}{l}\text { Mabos } \\
\text { per } \\
\text { sillon }\end{array}$ & $\begin{array}{c}\text { kdax } \\
1975=0 \\
100,0\end{array}$ & $\begin{array}{l}\text { Wiles per } \\
\text { Vehreto }\end{array}$ & $\begin{array}{l}\text { Index } \\
1073 \text {. } \\
\text { t100.0 }\end{array}$ & $\begin{array}{l}\text { adolons: } \\
\text { per Veltita }\end{array}$ & $\begin{array}{c}\text { Indax } \\
1073 a \\
1000\end{array}$ & 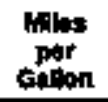 & $\begin{array}{c}\text { Indax } \\
1973 \\
100.0\end{array}$ \\
\hline 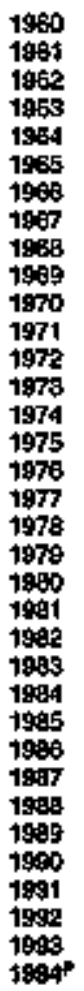 & 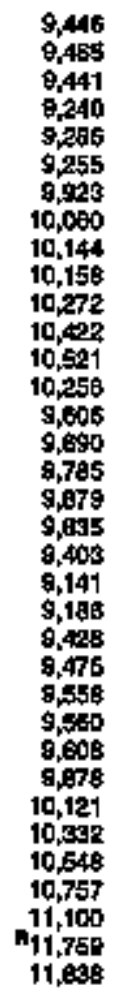 & 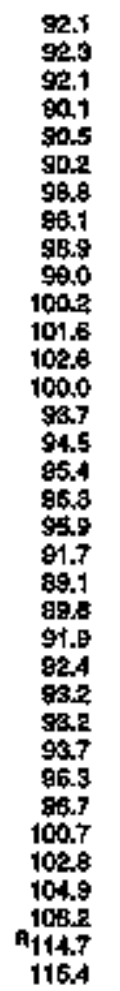 & 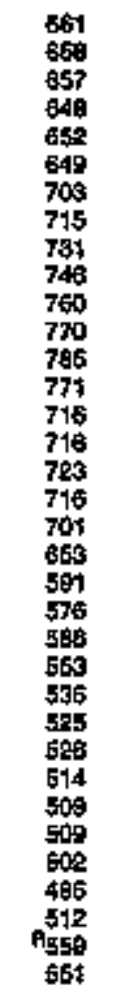 & 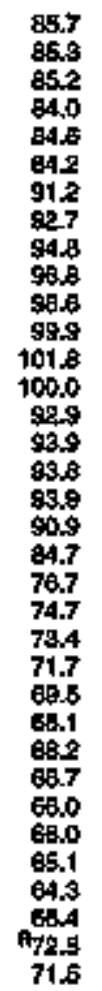 & 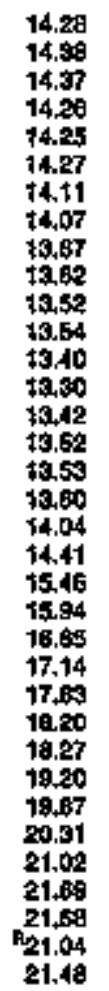 & 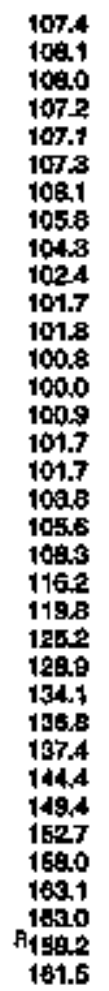 & 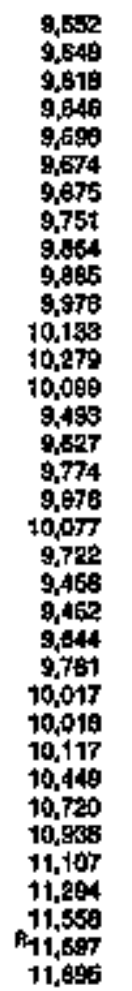 & 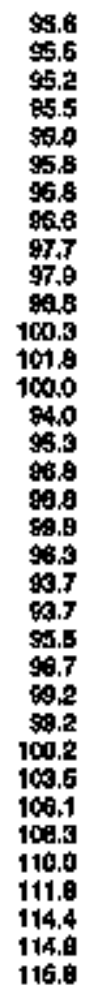 & 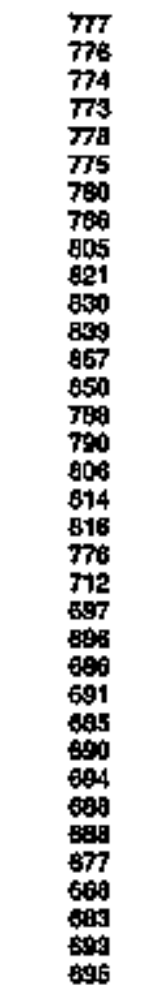 & 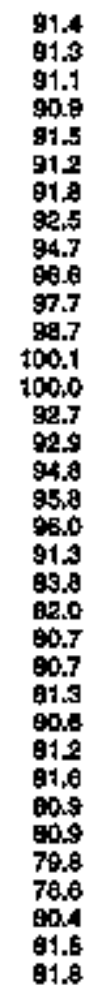 & 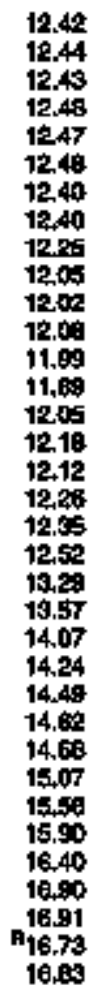 & 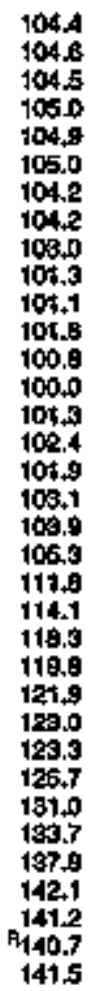 \\
\hline
\end{tabular}

Froll 1900 o 1965 , passengar cars categany otso betude motorgyetes.

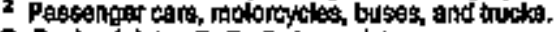

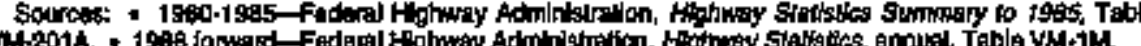
PeRenksed data PaPrelininacy data, 


\section{Motor Vohielo Registrations}

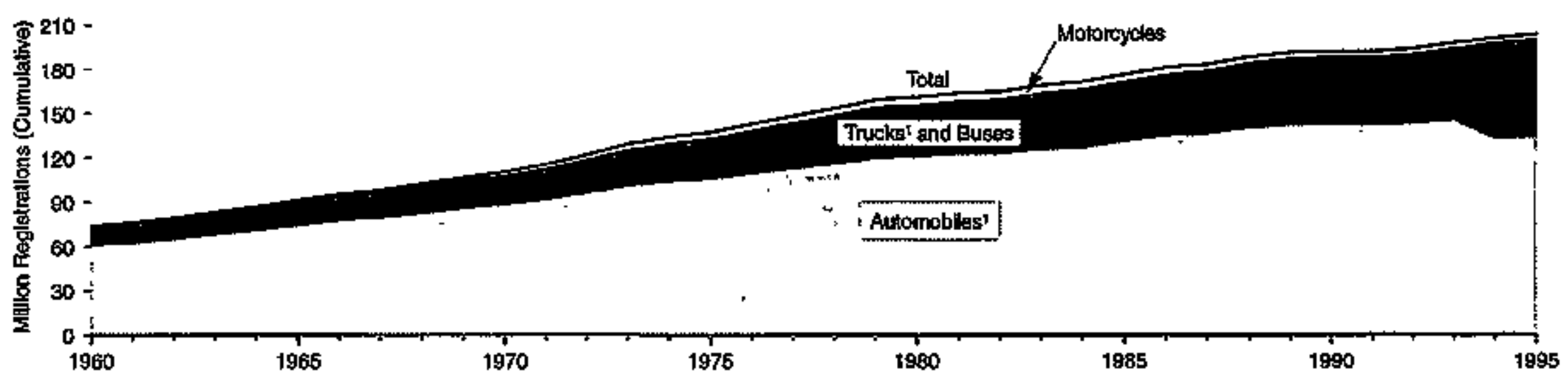

Molor Fuel Consumption

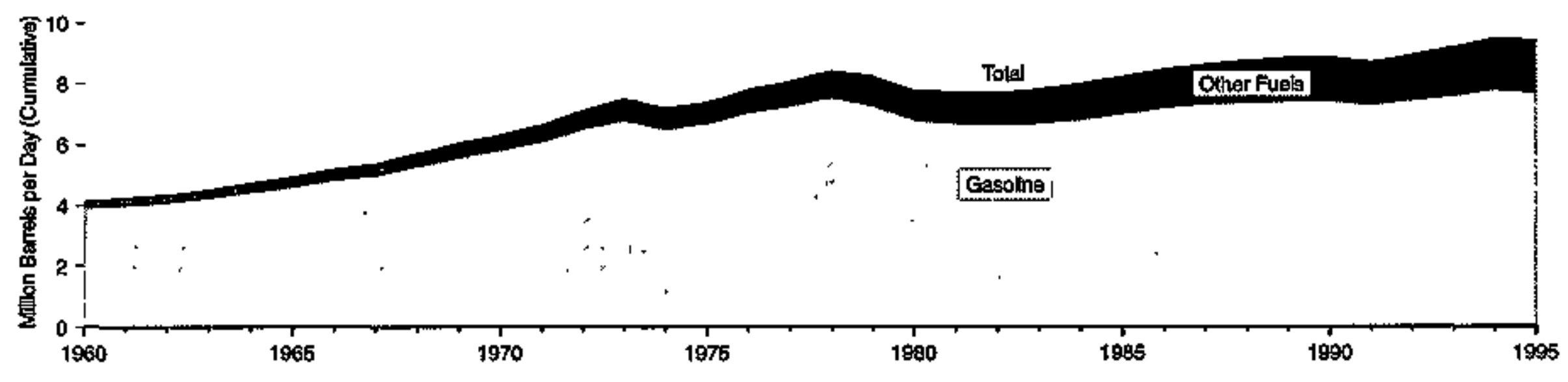

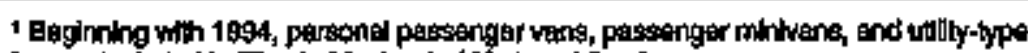
watcies ere included in "Trudks" insteed of "Automobles."

Source: Tabre 216 . 
Table 2.16 Motor Vehicle Registrations and Motor Fuel Consumption, 1960-1995

\begin{tabular}{|c|c|c|c|c|c|c|c|c|}
\hline \multirow[b]{2}{*}{ Yoar } & \multicolumn{5}{|c|}{$\begin{array}{l}\text { Wolor Vehicte Fegtstrallonts } \\
\text { (millom) }\end{array}$} & \multicolumn{3}{|c|}{$\begin{array}{l}\text { Motor Futs Conaumption } 1 \\
\text { (thougend beards per day) }\end{array}$} \\
\hline & Autamobilies: & Motorytites & Buses & Trucke & Tothal & Gasctine $z$ & Other Fusis 3 & Total \\
\hline 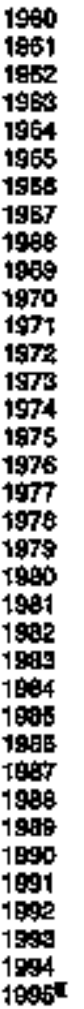 & 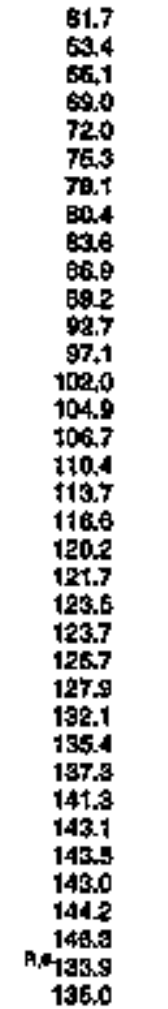 & 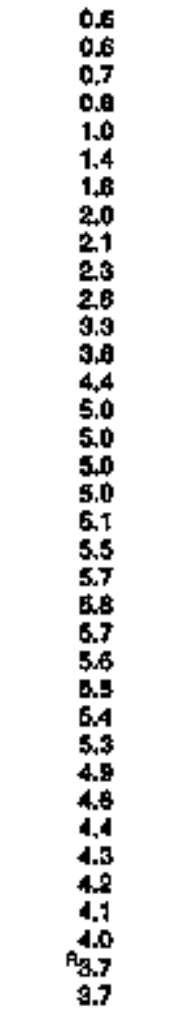 & 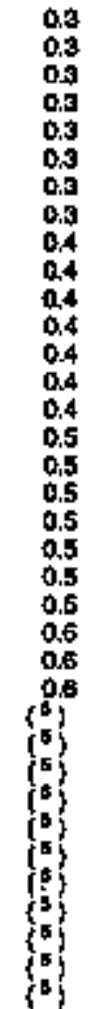 & 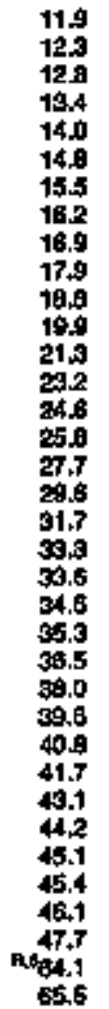 & 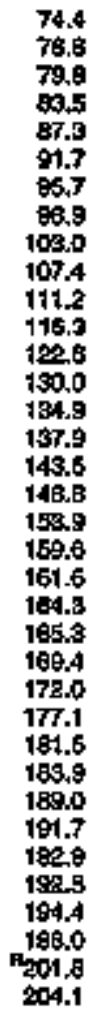 & 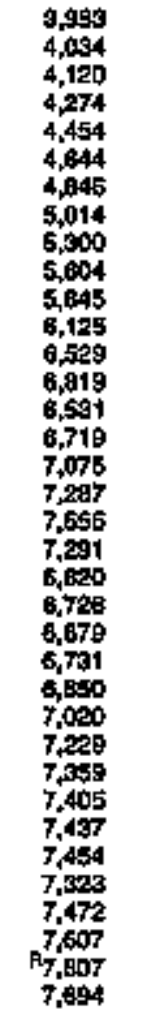 & 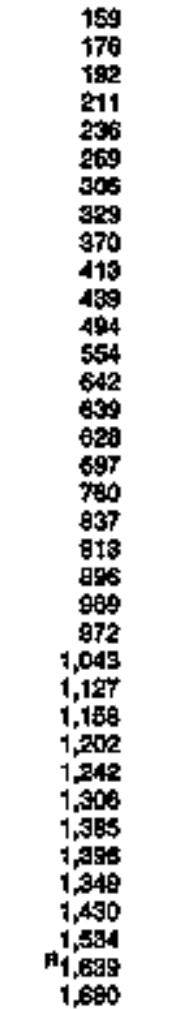 & 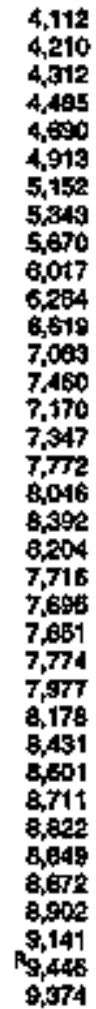 \\
\hline
\end{tabular}

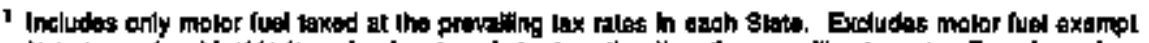

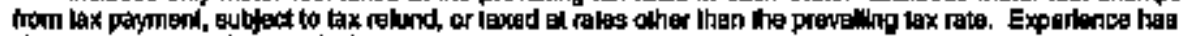

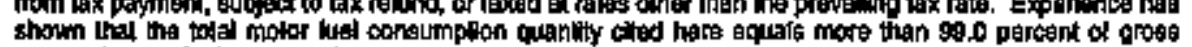
reporised motor tued consumplon.

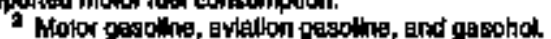

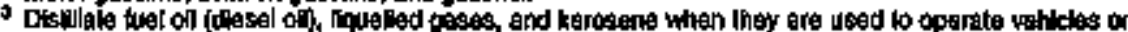
hilghways. Excludas fell frod begining in 1808

Excludes lossas alonred for eveporation, handing alc

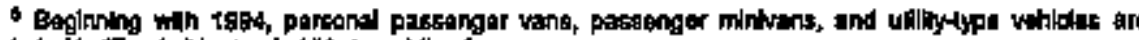
loctuded in "Trucks" Instead of "Aulomobilles."

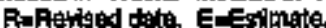

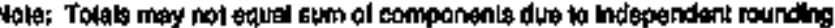

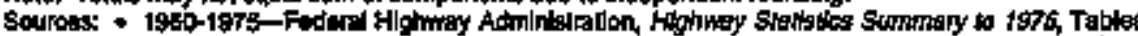
includted in Irucks. 


\section{Figure 2.17 Commercial Buildings Characteristics by Energy Source}

\section{By Census Region, 1992}

$75-$

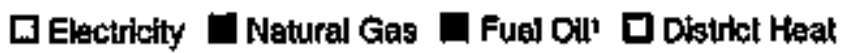

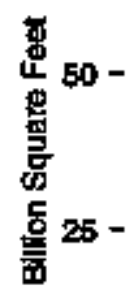

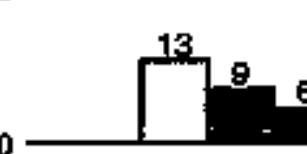

Northeast

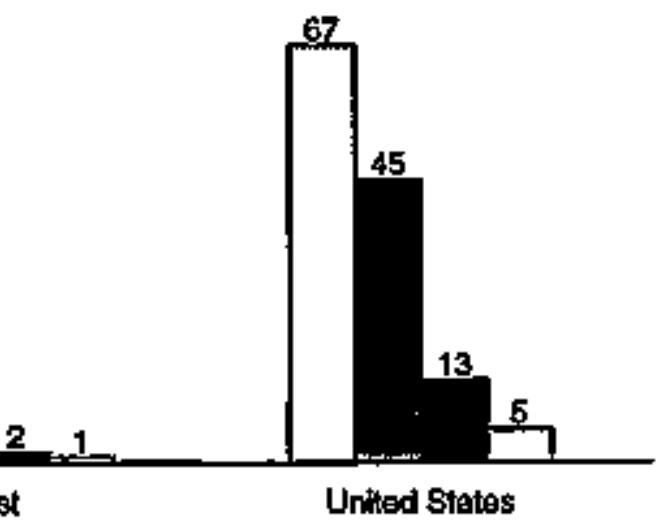

\section{By Survey Year}

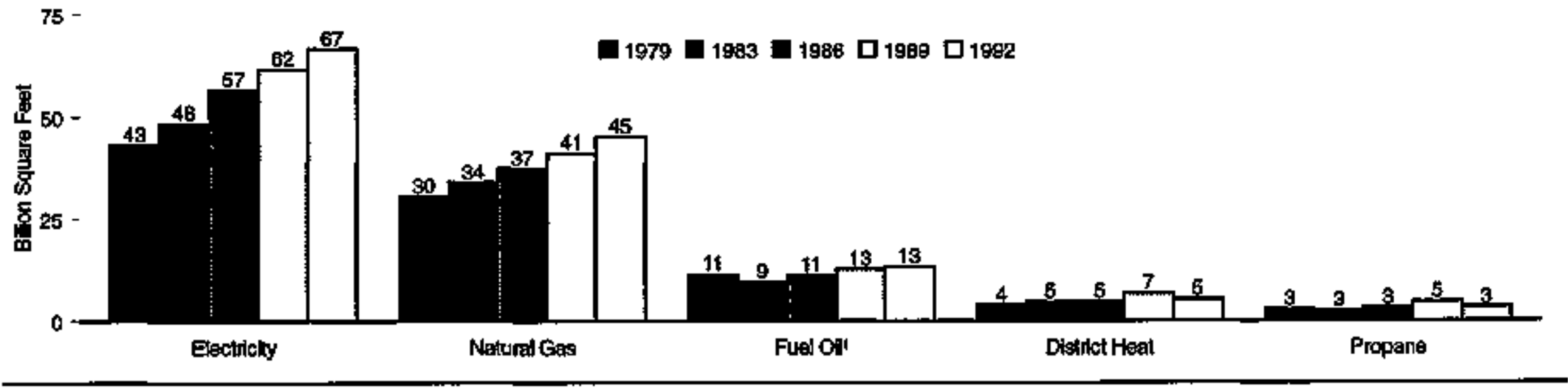

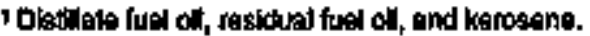

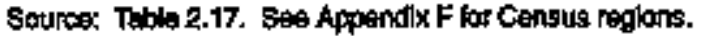


Table 2.17 Commercial Buildings Characteristics by Energy Source, Selected Years, 1979-1992 (Billion Square Feet)

\begin{tabular}{|c|c|c|c|c|c|c|c|c|c|c|c|c|}
\hline \multirow[b]{2}{*}{$\begin{array}{l}\text { Energy Sourse } \\
\text { utd Yop }\end{array}$} & \multicolumn{3}{|c|}{ Square Footspo Culegory } & \multicolumn{4}{|c|}{ Principel Buldeling Acthrty } & \multicolumn{4}{|c|}{ Census Aeglon' } & \multirow[b]{2}{*}{ Builinge } \\
\hline & $\begin{array}{c}1,001 \\
10 \\
10,000\end{array}$ & $\begin{array}{c}10,001 \\
10 \\
10,0,000\end{array}$ & $\begin{array}{c}\text { Over } \\
100,000\end{array}$ & $\begin{array}{l}\text { Merentila } \\
\text { and } \\
\text { sonice }\end{array}$ & Offieg & Edtetilion & All & Northest & Midimest & South & West & \\
\hline 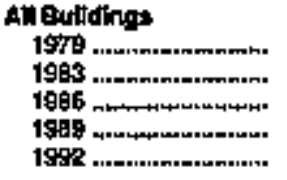 & $\begin{array}{r}9.21 \\
9.20 \\
13.07 \\
19.32 \\
14.50\end{array}$ & $\begin{array}{l}20.85 \\
22.35 \\
25.34 \\
2838 \\
28.51\end{array}$ & $\begin{array}{l}13.44 \\
17.88 \\
18.79 \\
21.54 \\
24.84\end{array}$ & $\begin{array}{r}9.98 \\
10.32 \\
12.91 \\
12.97 \\
12.40\end{array}$ & $\begin{array}{r}6.95 \\
8.31 \\
9.55 \\
11.200 \\
12.32\end{array}$ & $\begin{array}{l}5.97 \\
604 \\
729 \\
806 \\
8.47\end{array}$ & $\begin{array}{l}20.63 \\
24.80 \\
29.56 \\
30.94 \\
34.60\end{array}$ & $\begin{array}{r}9.60 \\
10.25 \\
11,83 \\
13.07 \\
13.40\end{array}$ & $\begin{array}{l}14 . n 0 \\
15.25 \\
16.00 \\
15.96 \\
17.28\end{array}$ & $\begin{array}{l}18.68 \\
16.61 \\
19.40 \\
22.04 \\
24.59\end{array}$ & $\begin{array}{r}6.16 \\
7.36 \\
10.94 \\
11.64 \\
12.62\end{array}$ & $\begin{array}{l}43.55 \\
49.47 \\
59.80 \\
63.18 \\
67.88\end{array}$ \\
\hline 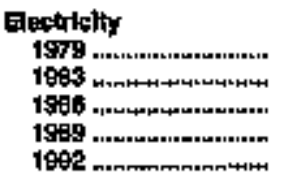 & $\begin{array}{r}8.99 \\
8.26 \\
12.49 \\
12.71 \\
14.05\end{array}$ & $\begin{array}{l}20.76 \\
21.79 \\
25.58 \\
27.68 \\
27.89\end{array}$ & $\begin{array}{l}13.41 \\
17.68 \\
16.50 \\
21.28 \\
24.61\end{array}$ & $\begin{array}{r}9.82 \\
10.24 \\
12.71 \\
12.38 \\
12.39\end{array}$ & $\begin{array}{r}6.98 \\
8.57 \\
5.50 \\
11.80 \\
12.32\end{array}$ & $\begin{array}{l}5.97 \\
6.09 \\
720 \\
8.07 \\
8.47\end{array}$ & $\begin{array}{l}20.29 \\
29.78 \\
27,10 \\
29.34 \\
32.37\end{array}$ & $\begin{array}{r}9.46 \\
9.99 \\
11,43 \\
13.39 \\
13.24\end{array}$ & $\begin{array}{l}14.15 \\
14.69 \\
15.69 \\
15.70 \\
18.91\end{array}$ & $\begin{array}{l}13.49 \\
16.29 \\
18.75 \\
21.29 \\
23.98\end{array}$ & $\begin{array}{r}6.11 \\
7.24 \\
10.85 \\
11.32 \\
12.42\end{array}$ & $\begin{array}{l}43.15 \\
46.35 \\
66.51 \\
61.58 \\
66.55\end{array}$ \\
\hline 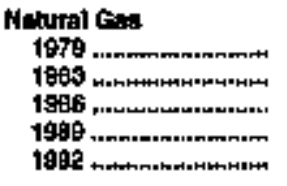 & $\begin{array}{l}5.58 \\
5.58 \\
7.03 \\
7.39 \\
8.09\end{array}$ & $\begin{array}{l}14.41 \\
14.8 \% \\
18.15 \\
17.41 \\
19.11\end{array}$ & $\begin{array}{l}10.60 \\
13.50 \\
14.09 \\
16.30 \\
17.96\end{array}$ & $\begin{array}{l}7.68 \\
7.80 \\
8.74 \\
8.70 \\
9.38\end{array}$ & $\begin{array}{l}4.61 \\
5.50 \\
5.73 \\
7.29 \\
7.86\end{array}$ & $\begin{array}{l}4.17 \\
4.45 \\
5.52 \\
6.64 \\
6.85\end{array}$ & $\begin{array}{l}14.13 \\
10.09 \\
17.28 \\
16.19 \\
21.01\end{array}$ & $\begin{array}{l}6.75 \\
6.95 \\
6.95 \\
6.62 \\
6.56\end{array}$ & $\begin{array}{l}11.81 \\
12.79 \\
12.42 \\
12.81 \\
13.84\end{array}$ & $\begin{array}{r}7.77 \\
9.17 \\
10.43 \\
11,68 \\
13.41\end{array}$ & $\begin{array}{l}4.15 \\
5.08 \\
7.59 \\
9.15 \\
9.29\end{array}$ & $\begin{array}{l}30.48 \\
33.94 \\
37.26 \\
41.14 \\
45.10\end{array}$ \\
\hline 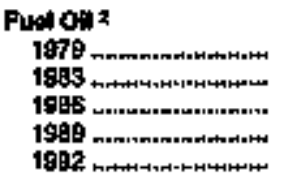 & $\begin{array}{l}1.82 \\
1.91 \\
1.71 \\
1.52 \\
1.75\end{array}$ & $\begin{array}{l}4.73 \\
3.35 \\
3.97 \\
4.49 \\
3.89\end{array}$ & $\begin{array}{l}1.75 \\
1.83 \\
5.39 \\
6.59 \\
7.57\end{array}$ & $\begin{array}{l}2.00 \\
1.50 \\
2.42 \\
1.82 \\
2.11\end{array}$ & $\begin{array}{l}1.76 \\
1.59 \\
1.75 \\
2.91 \\
3.60\end{array}$ & $\begin{array}{l}2.20 \\
1.43 \\
x .60 \\
2.21 \\
1.84\end{array}$ & $\begin{array}{l}5.28 \\
4.69 \\
5.14 \\
6.67 \\
5.67\end{array}$ & $\begin{array}{l}4.41 \\
4.21 \\
5.09 \\
5.13 \\
5.59\end{array}$ & $\begin{array}{l}2.07 \\
1.77 \\
2.04 \\
3.20 \\
2.64\end{array}$ & $\begin{array}{l}2.97 \\
2.94 \\
2.52 \\
2.84 \\
3.58\end{array}$ & $\begin{array}{l}1.04 \\
0.60 \\
1.38 \\
1.43 \\
1.58\end{array}$ & $\begin{array}{r}11.40 \\
5.41 \\
11.01 \\
12.60 \\
13.27\end{array}$ \\
\hline 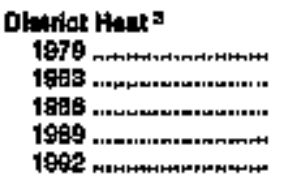 & $\begin{array}{c}a \\
0 \\
0.10 \\
0.15 \\
0.15\end{array}$ & $\begin{array}{l}1.17 \\
1.39 \\
1.49 \\
1.89 \\
1.65\end{array}$ & $\begin{array}{l}2.64 \\
3.16 \\
3.04 \\
4.55 \\
6.56\end{array}$ & $\begin{array}{c}0 \\
0 \\
0.18 \\
0 \\
0.15\end{array}$ & $\begin{array}{l}1.19 \\
1.25 \\
1.45 \\
2.32 \\
1.71\end{array}$ & $\begin{array}{l}0.40 \\
0.45 \\
0.89 \\
1.13 \\
0.69\end{array}$ & $\begin{array}{l}1.98 \\
2.48 \\
2.18 \\
3.02 \\
2.79\end{array}$ & $\begin{array}{l}1,26 \\
1.37 \\
1,38 \\
2.24 \\
1,50\end{array}$ & $\begin{array}{l}1.69 \\
1.99 \\
1.60 \\
+.61 \\
1.60\end{array}$ & $\begin{array}{l}0.65 \\
0.95 \\
0.71 \\
1.58 \\
0.98\end{array}$ & $\begin{array}{l}0.99 \\
0.69 \\
0.74 \\
1.25 \\
0.81\end{array}$ & $\begin{array}{l}3.8 B \\
4.84 \\
4.63 \\
6.58 \\
5.34\end{array}$ \\
\hline 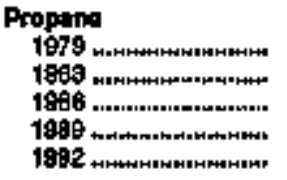 & $\begin{array}{l}0.68 \\
0.55 \\
1.09 \\
1.04 \\
1.04\end{array}$ & $\begin{array}{l}1.21 \\
0.89 \\
1.61 \\
1.05 \\
1.37\end{array}$ & $\begin{array}{l}0.93 \\
1.07 \\
0.52 \\
1.71 \\
0.99\end{array}$ & $\begin{array}{l}0.03 \\
Q \\
0.64 \\
0.91 \\
0.74\end{array}$ & $\begin{array}{c}0.14 \\
0 \\
0 \\
0 \\
0.21\end{array}$ & $\begin{array}{l}0.47 \\
0.35 \\
0.37 \\
1.14 \\
0.47\end{array}$ & $\begin{array}{l}1.58 \\
1.54 \\
2.10 \\
2.62 \\
1.97\end{array}$ & $\begin{array}{l}0.44 \\
0.47 \\
0.78 \\
1.07 \\
1.04\end{array}$ & $\begin{array}{l}0.73 \\
0.44 \\
0.68 \\
1.08 \\
0.59\end{array}$ & $\begin{array}{l}1.40 \\
1.59 \\
1.85 \\
1.74 \\
1.51\end{array}$ & $\begin{array}{c}0.23 \\
0 \\
0.42 \\
0 \\
0.28\end{array}$ & $\begin{array}{l}2.80 \\
2.53 \\
3.21 \\
4.69 \\
3.98\end{array}$ \\
\hline
\end{tabular}




\section{By Consus Region, 1992}

$3.0-$

口Electricky $\square$ Natural Gas $\square$ Fuel Oil1 $\square$ District Heat

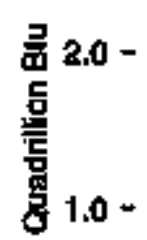

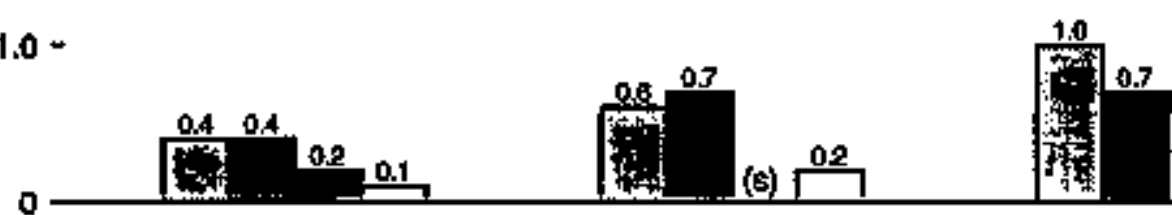

Northeas:

Mikwest

South
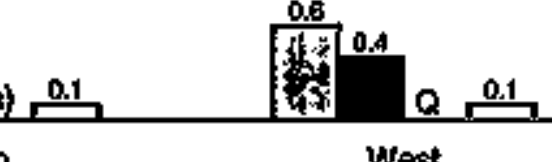

West

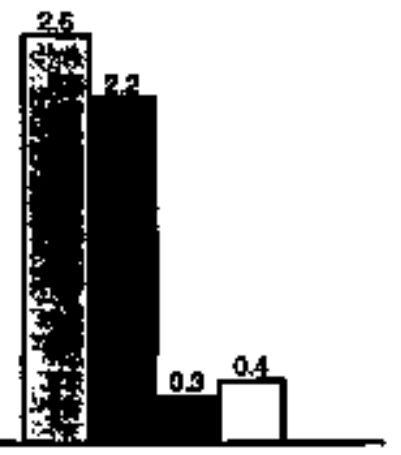

Uniled Stales

By Struey Year

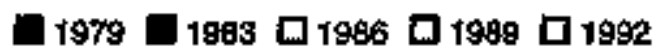

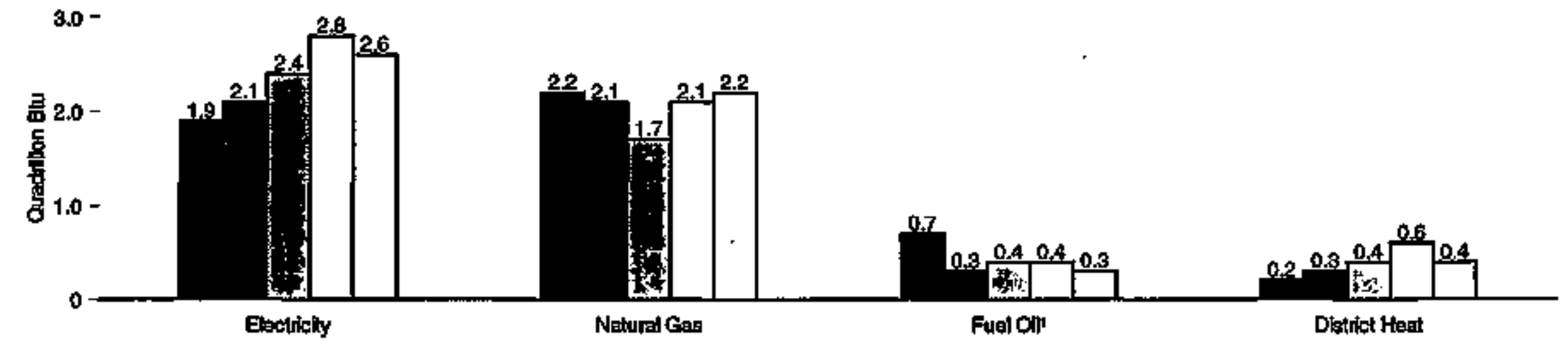

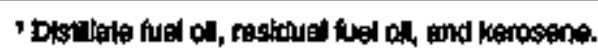

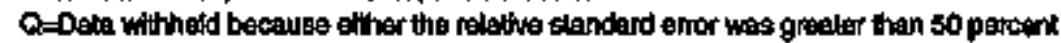

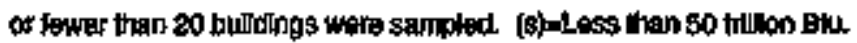

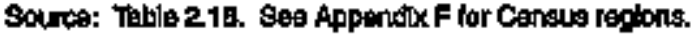


Table 2.18 Commercial Buildings Consumption by Energy Source, Selected Years, 1979-1992 (Trillion Btu)

\begin{tabular}{|c|c|c|c|c|c|c|c|c|c|c|c|c|}
\hline \multirow[b]{2}{*}{$\begin{array}{c}\text { Enargy source } \\
\text { and Yaur }\end{array}$} & \multicolumn{3}{|c|}{ Squor Foglegp Catpgony } & \multicolumn{4}{|c|}{ Prtioffpal Butding Activity } & \multicolumn{4}{|c|}{ Ennaus pogton' ' } & \multirow[b]{2}{*}{ Balding: } \\
\hline & $\begin{array}{c}1,001 \\
\text { to } \\
10,000\end{array}$ & $\begin{array}{c}10,001 \\
\text { to } \\
100,000\end{array}$ & $\begin{array}{c}\text { Ower } \\
100,000\end{array}$ & $\begin{array}{l}\text { Morounilto } \\
\text { snd } \\
\text { sanises }\end{array}$ & Otfice & Eduzavan & All & Mortheses & Niturast & Sath & Wast & \\
\hline 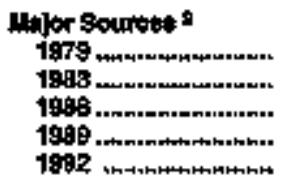 & $\begin{array}{l}1,255 \\
1,242 \\
1,279 \\
1,259 \\
t, 260\end{array}$ & $\begin{array}{l}2,202 \\
1,935 \\
2,000 \\
2,402 \\
2,301\end{array}$ & $\begin{array}{l}1,500 \\
1,646 \\
1,506 \\
2,127 \\
1,002\end{array}$ & $\begin{array}{r}944 \\
912 \\
905 \\
1,048 \\
892\end{array}$ & $\begin{array}{r}601 \\
1,018 \\
1,008 \\
1,200 \\
1,247\end{array}$ & $\begin{array}{l}511 \\
490 \\
504 \\
704 \\
607\end{array}$ & $\begin{array}{l}2,689 \\
2,519 \\
2,391 \\
2,800 \\
2,714\end{array}$ & $\begin{array}{r}1,297 \\
850 \\
1,037 \\
1,354 \\
1,090\end{array}$ & $\begin{array}{l}1,096 \\
1,021 \\
1,595 \\
1,659 \\
1,578\end{array}$ & $\begin{array}{l}1,695 \\
1,450 \\
1,459 \\
1,649 \\
1,625\end{array}$ & $\begin{array}{r}526 \\
582 \\
1.126 \\
998\end{array}$ & $\begin{array}{l}4,565 \\
4,628 \\
4,977 \\
5,768 \\
5,490\end{array}$ \\
\hline 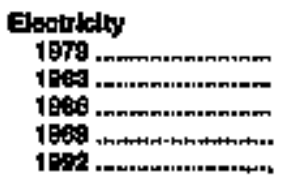 & $\begin{array}{l}429 \\
499 \\
654 \\
572 \\
566\end{array}$ & $\begin{array}{r}972 \\
909 \\
927 \\
1,145 \\
991\end{array}$ & $\begin{array}{r}600 \\
759 \\
809 \\
1,058 \\
1,050\end{array}$ & $\begin{array}{l}381 \\
126 \\
538 \\
550 \\
444\end{array}$ & $\begin{array}{l}424 \\
509 \\
841 \\
701 \\
704\end{array}$ & $\begin{array}{l}163 \\
158 \\
179 \\
217 \\
215\end{array}$ & $\begin{array}{r}001 \\
1,041 \\
1,0055 \\
1,225 \\
1,226\end{array}$ & $\begin{array}{l}425 \\
324 \\
490 \\
686 \\
410\end{array}$ & $\begin{array}{l}590 \\
873 \\
504 \\
609 \\
525\end{array}$ & $\begin{array}{r}689 \\
801 \\
887 \\
976 \\
1,004\end{array}$ & $\begin{array}{l}227 \\
331 \\
510 \\
604 \\
560\end{array}$ & $\begin{array}{l}1,900 \\
2,129 \\
2,390 \\
2,770 \\
2,600\end{array}$ \\
\hline 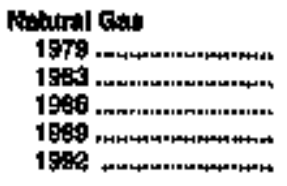 & $\begin{array}{l}646 \\
644 \\
465 \\
568 \\
572\end{array}$ & $\begin{array}{r}09 \\
809 \\
715 \\
1,017 \\
1,017\end{array}$ & $\begin{array}{l}532 \\
597 \\
599 \\
670 \\
586\end{array}$ & $\begin{array}{l}422 \\
307 \\
392 \\
417 \\
381\end{array}$ & $\begin{array}{l}272 \\
365 \\
250 \\
230 \\
369\end{array}$ & $\begin{array}{l}214 \\
246 \\
254 \\
323 \\
291\end{array}$ & $\begin{array}{r}1,208 \\
1,158 \\
079 \\
1,096 \\
1,115\end{array}$ & $\begin{array}{l}448 \\
278 \\
244 \\
963 \\
354\end{array}$ & $\begin{array}{r}5.097 \\
979 \\
749 \\
831 \\
747\end{array}$ & $\begin{array}{l}470 \\
593 \\
496 \\
498 \\
697\end{array}$ & $\begin{array}{l}255 \\
311 \\
311 \\
391 \\
376\end{array}$ & $\begin{array}{l}2,174 \\
2,091 \\
1,723 \\
2,073 \\
2,174\end{array}$ \\
\hline 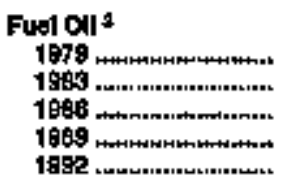 & $\begin{array}{c}177 \\
85 \\
114 \\
10 t \\
86\end{array}$ & $\begin{array}{l}272 \\
140 \\
208 \\
170 \\
111\end{array}$ & $\begin{array}{r}231 \\
80 \\
121 \\
85 \\
75\end{array}$ & $\begin{array}{r}103 \\
13 \\
105 \\
76 \\
85\end{array}$ & $\begin{array}{r}107 \\
75 \\
39 \\
43 \\
47\end{array}$ & $\begin{array}{r}107 \\
61 \\
100 \\
71 \\
60\end{array}$ & $\begin{array}{l}394 \\
155 \\
194 \\
167 \\
108\end{array}$ & $\begin{array}{l}285 \\
172 \\
270 \\
287 \\
104\end{array}$ & $\begin{array}{r}100 \\
28 \\
6 \\
61 \\
20\end{array}$ & $\begin{array}{r}237 \\
104 \\
86 \\
60 \\
48\end{array}$ & $\begin{array}{c}26 \\
0 \\
0 \\
0 \\
0\end{array}$ & $\begin{array}{l}661 \\
914 \\
442 \\
367 \\
272\end{array}$ \\
\hline 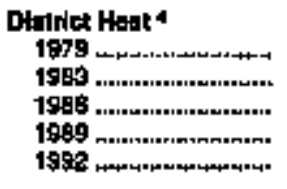 & $\begin{array}{c}0 \\
9 \\
0 \\
19 \\
0\end{array}$ & $\begin{array}{r}61 \\
69 \\
159 \\
259 \\
102\end{array}$ & $\begin{array}{l}158 \\
204 \\
243 \\
315 \\
236\end{array}$ & $\begin{array}{r}a \\
0 \\
12 \\
0 \\
0\end{array}$ & $\begin{array}{r}6 \\
71 \\
167 \\
100\end{array}$ & $\begin{array}{r}27 \\
21 \\
97 \\
0 \\
19\end{array}$ & $\begin{array}{l}108 \\
164 \\
248 \\
310 \\
264\end{array}$ & $\begin{array}{r}64 \\
84 \\
94 \\
179 \\
183\end{array}$ & $\begin{array}{r}98 \\
141 \\
196 \\
159 \\
103\end{array}$ & $\begin{array}{r}9 \\
34 \\
81 \\
198 \\
70\end{array}$ & $\begin{array}{r}0 \\
30 \\
51 \\
121 \\
51\end{array}$ & $\begin{array}{l}201 \\
289 \\
482 \\
585 \\
435\end{array}$ \\
\hline 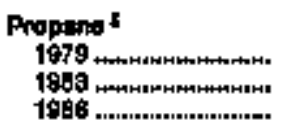 & $\begin{array}{l}23 \\
20 \\
44\end{array}$ & $\begin{array}{l}16 \\
12 \\
10\end{array}$ & $\begin{array}{l}5 \\
2 \\
1\end{array}$ & $\begin{array}{r}10 \\
6 \\
17\end{array}$ & $\stackrel{0}{0}$ & $\begin{array}{l}2 \\
2 \\
3\end{array}$ & $\begin{array}{l}29 \\
24 \\
42\end{array}$ & $\stackrel{Q}{Q}$ & $\begin{array}{r}16 \\
7 \\
19\end{array}$ & $\begin{array}{l}16 \\
21 \\
26\end{array}$ & $\begin{array}{r}10 \\
0 \\
0\end{array}$ & $\begin{array}{l}43 \\
34 \\
B 3\end{array}$ \\
\hline 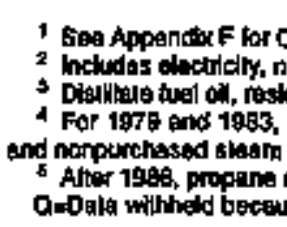 & regh & 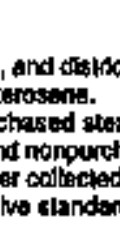 & $\begin{array}{l}1060 \\
\text { wat wate } \\
\text { wh }\end{array}$ & Ind 1092 , & ma & 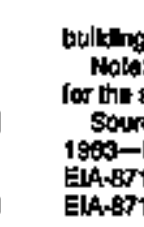 & $\begin{array}{l}\text { Comisesta } \\
\text { Comm }\end{array}$ & 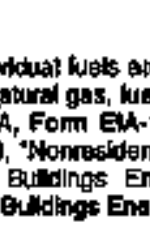 & 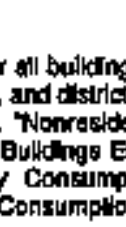 & 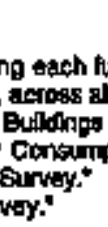 & 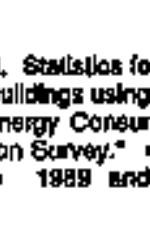 & 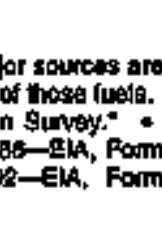 \\
\hline
\end{tabular}




\section{Figure 2.19 Commercial Bulldings Expenditures by Energy Source}

\section{By Census Region, 1992}

$60-$

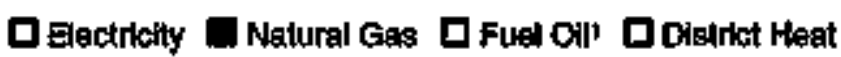

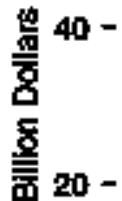

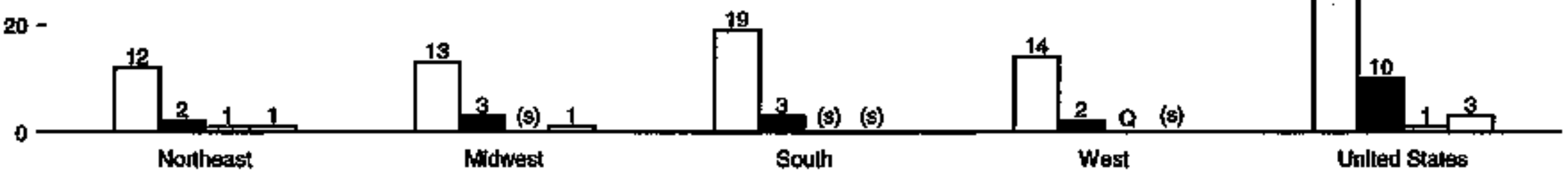

\section{By Survey Year}

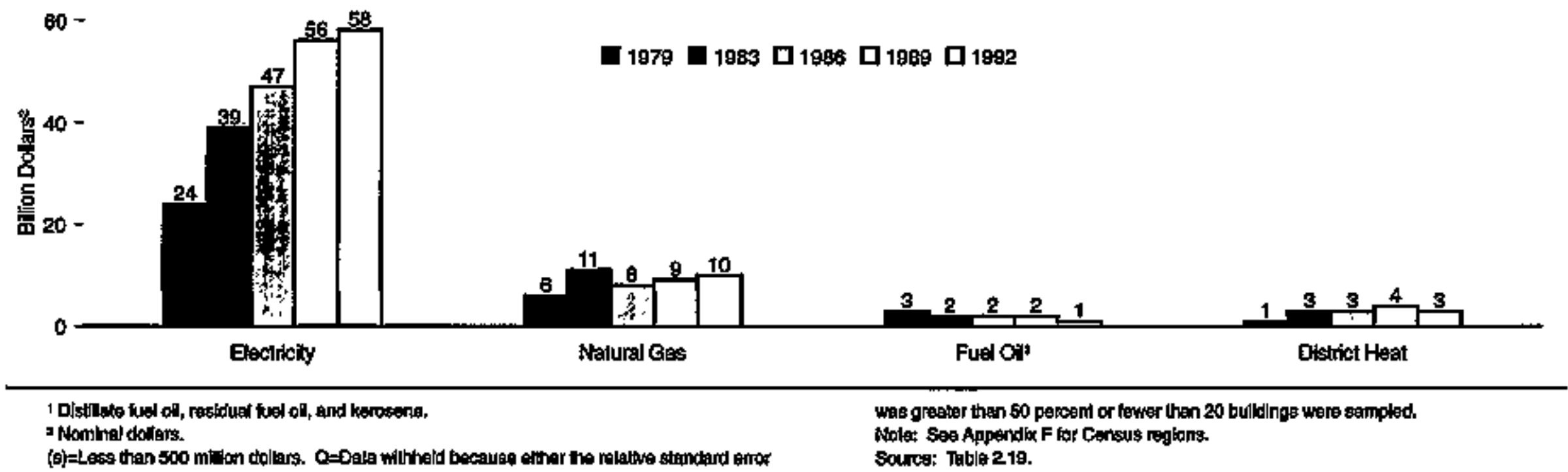


Table 2.19 Commerclal Buildings Expenditures by Energy Source, Selected Years, 1979-1992

(Million Dollars')

\begin{tabular}{|c|c|c|c|c|c|c|c|c|c|c|c|c|}
\hline \multirow[b]{2}{*}{$\begin{array}{l}\text { Enorgy Soures } \\
\text { nid Yelur }\end{array}$} & \multicolumn{3}{|c|}{ 8qume Foolng Caingory } & \multicolumn{4}{|c|}{ Prinolpat 日úlding Aotivity } & \multicolumn{4}{|c|}{ Consustagion 2} & \multirow[b]{2}{*}{ Autidings } \\
\hline & $\begin{array}{c}1,001 \\
100 \\
10,000\end{array}$ & $\begin{array}{c}10,001 \\
\text { to } \\
100,000\end{array}$ & $\begin{array}{c}\text { Ovar } \\
\text { toopopo }\end{array}$ & $\begin{array}{c}\text { Mortankile } \\
\text { sendives }\end{array}$ & OHlos & Educetion & Olhtor & Northenest & Mldweat & Soulh & West & \\
\hline 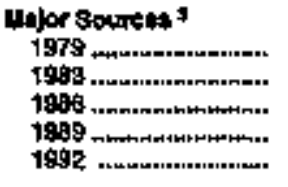 & $\begin{array}{r}0,587 \\
19,081 \\
17,411 \\
17,472 \\
19,554\end{array}$ & $\begin{array}{l}15,120 \\
20,970 \\
20,512 \\
29,949 \\
29,479\end{array}$ & $\begin{array}{r}9,699 \\
19,589 \\
19,296 \\
24,411 \\
24,794\end{array}$ & $\begin{array}{r}6,384 \\
9,058 \\
13,091 \\
13,527 \\
12,907\end{array}$ & $\begin{array}{r}7,498 \\
12,614 \\
14,763 \\
18,323 \\
10,102\end{array}$ & $\begin{array}{l}3,051 \\
4,785 \\
5,702 \\
6,589 \\
7,399\end{array}$ & $\begin{array}{l}18,729 \\
27,8902 \\
26,004 \\
32,390 \\
33,423\end{array}$ & $\begin{array}{r}9,405 \\
12,396 \\
14,269 \\
17,505 \\
16,226\end{array}$ & $\begin{array}{l}10,651 \\
19,009 \\
15,710 \\
16,489 \\
16,967\end{array}$ & $\begin{array}{l}10,106 \\
17,868 \\
17,725 \\
21,769 \\
2,, 843\end{array}$ & $\begin{array}{r}3,424 \\
7,174 \\
12,805 \\
15,098 \\
15,795\end{array}$ & $\begin{array}{l}30,595 \\
56,451 \\
60,219 \\
70,226 \\
71,821\end{array}$ \\
\hline 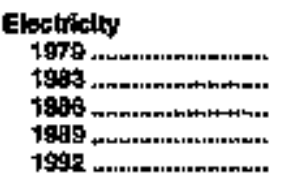 & $\begin{array}{r}5,939 \\
8,389 \\
14,167 \\
19,684 \\
14,072\end{array}$ & $\begin{array}{l}10,5 \% 4 \\
58,779 \\
18,046 \\
22,770 \\
20,103\end{array}$ & $\begin{array}{r}6,789 \\
13,169 \\
18,003 \\
18,349 \\
20,585\end{array}$ & $\begin{array}{r}4,656 \\
7,602 \\
10,784 \\
11,115 \\
10,589\end{array}$ & $\begin{array}{r}5,662 \\
9,651 \\
12,884 \\
15,757 \\
15,5611\end{array}$ & $\begin{array}{l}1,956 \\
0,995 \\
3,608 \\
4,351 \\
5,546\end{array}$ & $\begin{array}{l}11,299 \\
19,401 \\
19,915 \\
24,679 \\
25,999\end{array}$ & $\begin{array}{r}6,408 \\
5,408 \\
10,806 \\
13,188 \\
12,250\end{array}$ & $\begin{array}{r}7,009 \\
11,354 \\
10,899 \\
11,697 \\
12,745\end{array}$ & $\begin{array}{r}7,760 \\
14,576 \\
14,856 \\
16,409 \\
19,097\end{array}$ & $\begin{array}{r}2,493 \\
6,103 \\
10,576 \\
12,649 \\
10,527\end{array}$ & $\begin{array}{l}20,751 \\
99,470 \\
47,188 \\
5,949 \\
67,619\end{array}$ \\
\hline 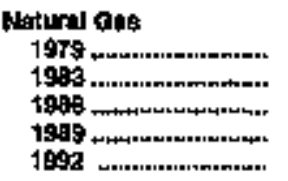 & $\begin{array}{l}1,804 \\
3,800 \\
2,502 \\
2,924 \\
3,059\end{array}$ & $\begin{array}{l}2,854 \\
4,486 \\
3,543 \\
3,760 \\
4,695\end{array}$ & $\begin{array}{l}1,355 \\
3,071 \\
2,289 \\
2,520 \\
2,218\end{array}$ & $\begin{array}{l}1,201 \\
1,904 \\
1,706 \\
1,997 \\
1,899\end{array}$ & $\begin{array}{r}728 \\
1,998 \\
1,178 \\
1,126 \\
1,618\end{array}$ & $\begin{array}{r}557 \\
1,347 \\
1,189 \\
1,309 \\
1,271\end{array}$ & $\begin{array}{l}3,304 \\
6,223 \\
4,290 \\
4,866 \\
5,114\end{array}$ & $\begin{array}{l}1,320 \\
1,874 \\
1,472 \\
1,807 \\
2,014\end{array}$ & $\begin{array}{l}3,547 \\
5,172 \\
3,400 \\
3,381 \\
3,011\end{array}$ & $\begin{array}{l}1,255 \\
2,575 \\
1,958 \\
2,258 \\
2,589\end{array}$ & $\begin{array}{r}692 \\
1,721 \\
1,604 \\
1,724 \\
1,879\end{array}$ & $\begin{array}{r}5,014 \\
11,449 \\
9,355 \\
9,204 \\
9,901\end{array}$ \\
\hline 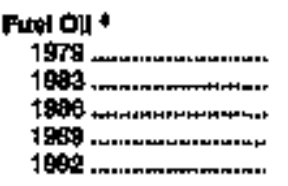 & $\begin{array}{l}798 \\
690 \\
616 \\
592 \\
516\end{array}$ & $\begin{array}{r}t .177 \\
947 \\
970 \\
802 \\
681\end{array}$ & $\begin{array}{l}650 \\
625 \\
473 \\
378 \\
328\end{array}$ & $\begin{array}{l}457 \\
\$ 16 \\
516 \\
450 \\
312\end{array}$ & $\begin{array}{l}443 \\
501 \\
104 \\
298 \\
245\end{array}$ & $\begin{array}{l}396 \\
397 \\
410 \\
391 \\
277\end{array}$ & $\begin{array}{r}1,450 \\
895 \\
801 \\
828 \\
580\end{array}$ & $\begin{array}{l}1,149 \\
1,541 \\
1,272 \\
1,225 \\
108\end{array}$ & $\begin{array}{l}569 \\
189 \\
270 \\
310 \\
192\end{array}$ & $\begin{array}{l}932 \\
589 \\
394 \\
241 \\
257\end{array}$ & $\begin{array}{r}116 \\
75 \\
116 \\
0 \\
9\end{array}$ & $\begin{array}{l}2,765 \\
2,102 \\
2,060 \\
1,002 \\
1,400\end{array}$ \\
\hline 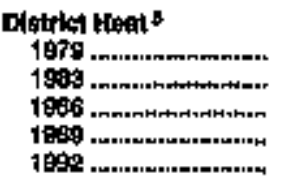 & $\begin{array}{r}0 \\
0 \\
0 \\
1+1 \\
0\end{array}$ & $\begin{array}{r}355 \\
767 \\
963 \\
1,551 \\
1,680\end{array}$ & $\begin{array}{r}\text { eds } \\
1, \mathrm{egs} \\
1,630 \\
2,165 \\
1,698\end{array}$ & $\begin{array}{l}9 \\
0 \\
8 \\
0 \\
0\end{array}$ & $\begin{array}{r}405 \\
604 \\
607 \\
1,207 \\
726\end{array}$ & $\begin{array}{r}169 \\
167 \\
519 \\
0 \\
315\end{array}$ & $\begin{array}{r}650 \\
1,673 \\
1,506 \\
2,042 \\
1,751\end{array}$ & $\begin{array}{r}144 \\
977 \\
609 \\
1,206 \\
970\end{array}$ & $\begin{array}{r}5,5 \\
1,045 \\
1,170 \\
1,081 \\
1,069\end{array}$ & $\begin{array}{l}169 \\
329 \\
516 \\
810 \\
492\end{array}$ & $\begin{array}{r}124 \\
275 \\
294 \\
0 \\
360\end{array}$ & $\begin{array}{l}1,267 \\
2,627 \\
2,620 \\
3,067 \\
2,901\end{array}$ \\
\hline 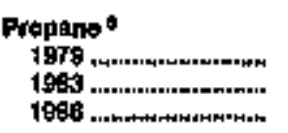 & $\begin{array}{l}129 \\
+90 \\
370\end{array}$ & $\begin{array}{r}80 \\
109 \\
163\end{array}$ & $\begin{array}{l}27 \\
14 \\
10\end{array}$ & $\underset{140}{58}$ & $\begin{array}{l}0 \\
0 \\
0\end{array}$ & $\begin{array}{l}10 \\
12 \\
80\end{array}$ & $\begin{array}{l}153 \\
222 \\
389\end{array}$ & $\underset{9}{0}$ & $\begin{array}{r}76 \\
62 \\
131\end{array}$ & $\begin{array}{r}91 \\
201 \\
201\end{array}$ & $\begin{array}{r}47 \\
0 \\
0\end{array}$ & $\begin{array}{l}225 \\
313 \\
543\end{array}$ \\
\hline 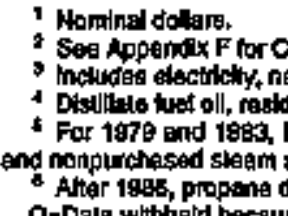 & res & ollas & $\begin{array}{l}1986 \\
x+w 9 k\end{array}$ & 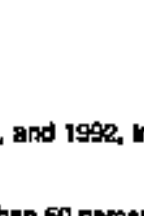 & 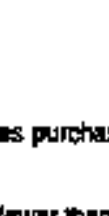 & 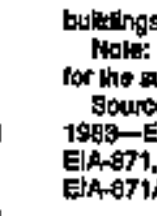 & onteside & 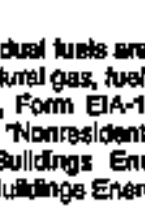 & 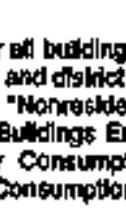 & 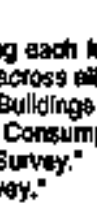 & 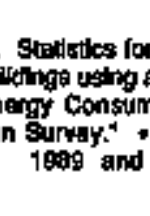 & 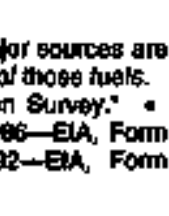 \\
\hline
\end{tabular}




\section{Constumption}

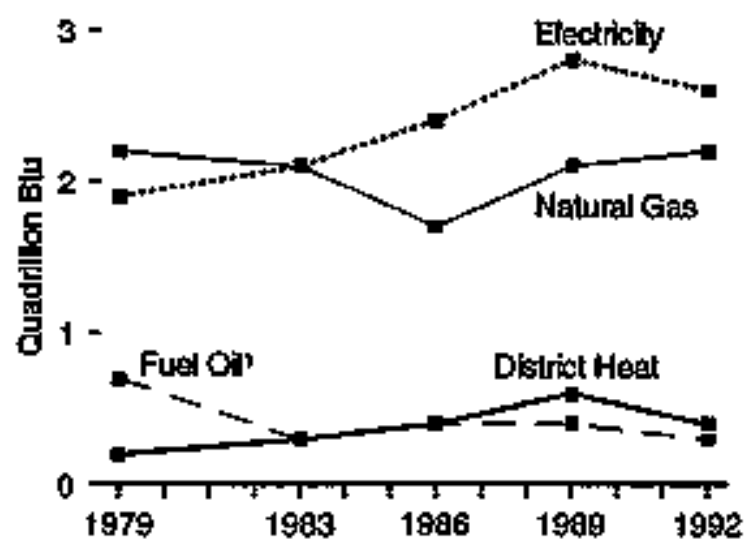

Expondilitures

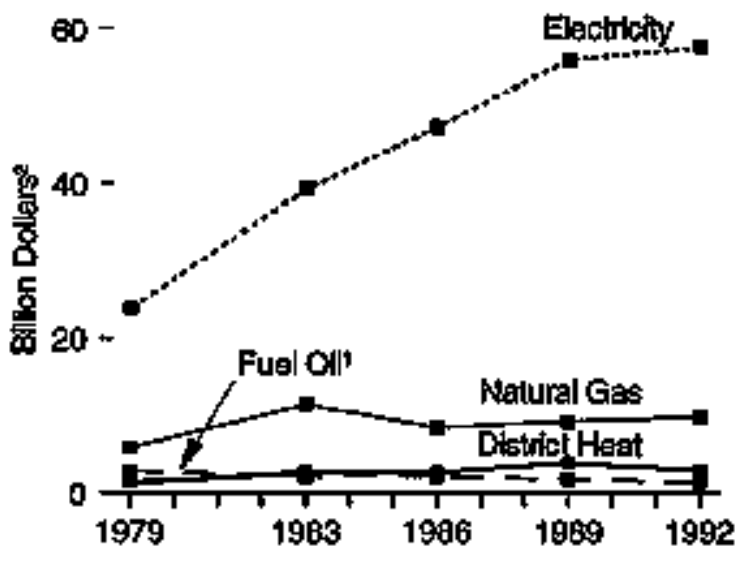

Consumptlon per Square Fool

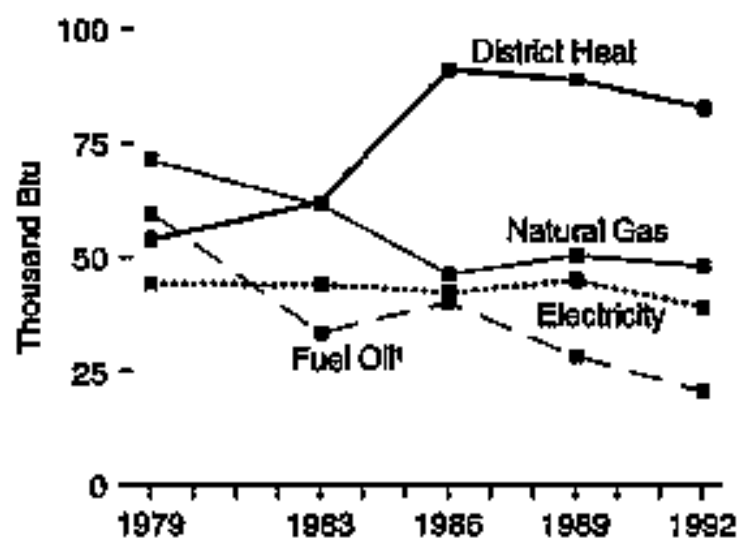

Expenditures per Square Foot

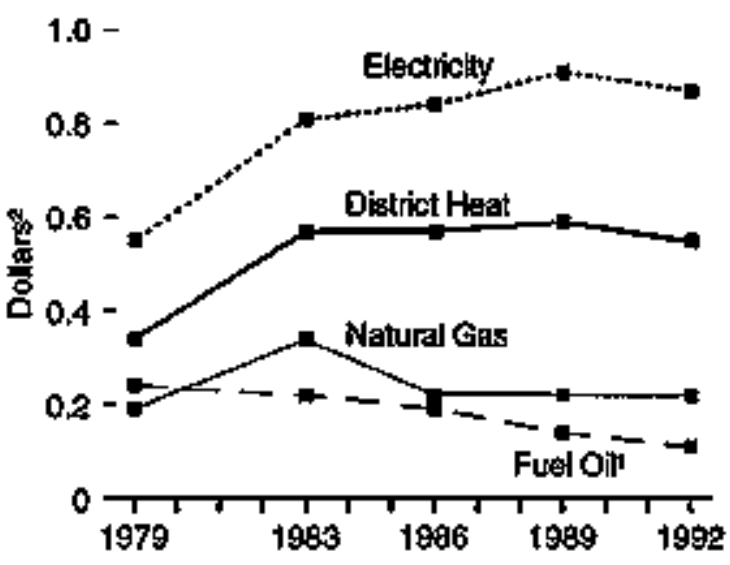

Constumption per Employes

$75-$

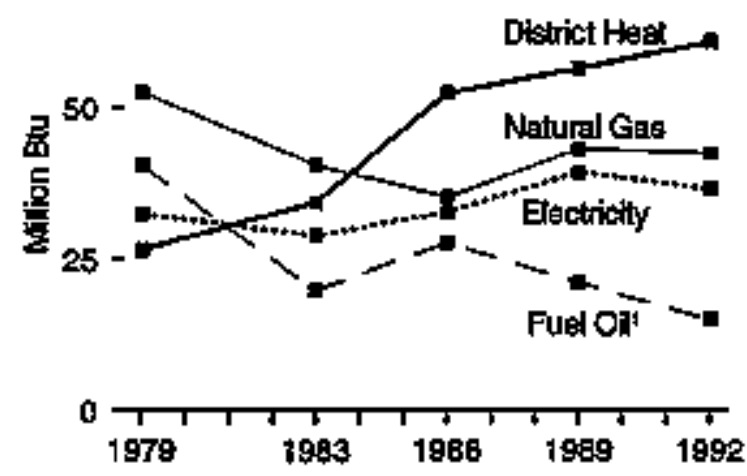

Exponditures por Milion Btu

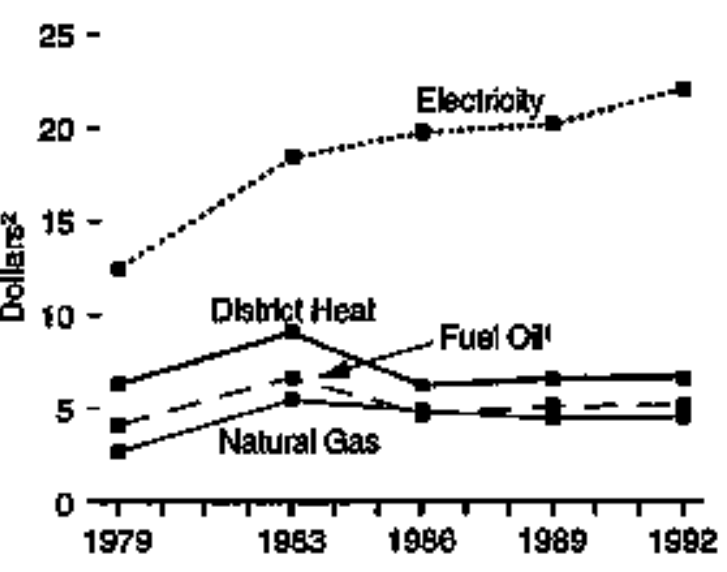

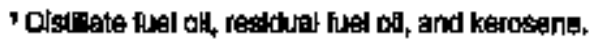

* Nominal dollaris.

- Because vertical ecalos otiter, glaphs should not be compared.

Noles: - No data are ayaliablo for 1980-1962, 1964-1985, 1987-1998, and 1990-1991.

Source: Table 2,20. 
Table 2.20 Commercial Buildings Energy Consumption and Expenditure Indicators, Selected Years, 1979-1992

\begin{tabular}{|c|c|c|c|c|c|c|c|c|c|c|c|}
\hline \multirow[b]{2}{*}{$\begin{array}{c}\text { Energet Sourto } \\
\text { side Yos: }\end{array}$} & \multicolumn{3}{|c|}{ Buflding Charactoritalks } & \multicolumn{4}{|c|}{ Exteksy Coctertimption } & \multicolumn{4}{|c|}{ Enargy Expondilureeg } \\
\hline & $\begin{array}{l}\text { Numbar of } \\
\text { Bulldings } \\
\text { (thoutgands }\end{array}$ & $\begin{array}{c}\text { Total } \\
\text { square } \\
\text { Fent } \\
\text { (inllont }\end{array}$ & 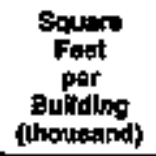 & $\begin{array}{l}\text { Tatal } \\
\text { (Inlilon } \\
\text { Bt(u) }\end{array}$ & $\begin{array}{c}\text { Pex } \\
\text { Exilking } \\
\text { (millon } \\
\text { Bta) }\end{array}$ & $\begin{array}{c}\text { Per } \\
\text { Square } \\
\text { Foot } \\
\text { (thaughofd } \\
\text { Blu) }\end{array}$ & $\begin{array}{c}\text { Por } \\
\text { Emplonyed } \\
\text { (million } \\
\text { Bhal }\end{array}$ & $\begin{array}{l}\text { Trolal } \\
\text { fmbllon } \\
\text { dollerty }\end{array}$ & $\begin{array}{l}\text { Por } \\
\text { Gulding } \\
\text { funoulary } \\
\text { dollars'] }\end{array}$ & $\begin{array}{c}\text { Por } \\
\text { Squitt } \\
\text { Fool } \\
\text { (dollars') }\end{array}$ & $\begin{array}{c}\text { Par } \\
\text { Mollon Bru } \\
\text { (doplerst) }\end{array}$ \\
\hline 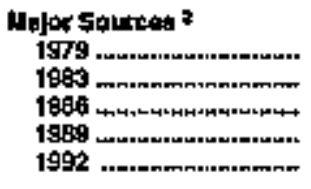 & $\begin{array}{l}3,073 \\
3,186 \\
4,159 \\
4,528 \\
4,606\end{array}$ & $\begin{array}{l}43,548 \\
49,471 \\
58,196 \\
63,184 \\
67,976\end{array}$ & $\begin{array}{l}14.2 \\
16.5 \\
14.0 \\
14.0 \\
14.5\end{array}$ & $\begin{array}{l}5,000 \\
4,858 \\
5,040 \\
5,780 \\
5,490\end{array}$ & $\begin{array}{l}1,630 \\
1,626 \\
1,213 \\
1,278 \\
1,142\end{array}$ & $\begin{array}{r}115.0 \\
98.2 \\
65.6 \\
97.6 \\
80.0\end{array}$ & $\begin{array}{l}85.0 \\
65.7 \\
66.6 \\
61,8 \\
\pi .1\end{array}$ & $\begin{array}{l}33,821 \\
65,764 \\
60,762 \\
70,806 \\
75,621\end{array}$ & $\begin{array}{l}18.0 \\
17.6 \\
14.6 \\
15.6 \\
14.9\end{array}$ & $\begin{array}{l}0.78 \\
1.13 \\
1.04 \\
1.12 \\
1.05\end{array}$ & $\begin{array}{r}6.75 \\
11.48 \\
12.06 \\
12.24 \\
13.08\end{array}$ \\
\hline 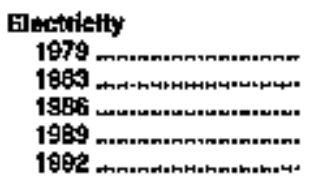 & $\begin{array}{l}3,001 \\
0,050 \\
3,065 \\
4,294 \\
4,611\end{array}$ & $\begin{array}{l}43,163 \\
48,327 \\
58,508 \\
61,663 \\
66,525\end{array}$ & $\begin{array}{l}14.4 \\
15.8 \\
14.3 \\
14.3 \\
14.4\end{array}$ & $\begin{array}{l}1,909 \\
2,129 \\
2,390 \\
2,779 \\
2,609\end{array}$ & $\begin{array}{l}698 \\
697 \\
608 \\
648 \\
508\end{array}$ & $\begin{array}{l}44.2 \\
11.1 \\
42.3 \\
46.0 \\
39.2\end{array}$ & $\begin{array}{l}32.4 \\
28.0 \\
38.7 \\
39.8 \\
36.6\end{array}$ & $\begin{array}{l}23,761 \\
39,279 \\
47.186 \\
55,949 \\
67,619\end{array}$ & $\begin{array}{r}7.9 \\
12.0 \\
11.9 \\
13.0 \\
12.6\end{array}$ & $\begin{array}{l}0.65 \\
0.81 \\
0.84 \\
0.51 \\
0.87\end{array}$ & $\begin{array}{l}12.46 \\
18.45 \\
19.74 \\
20.17 \\
22.09\end{array}$ \\
\hline 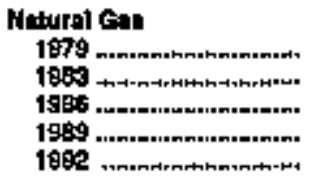 & $\begin{array}{l}1,904 \\
1,904 \\
2,214 \\
2,420 \\
2,657\end{array}$ & $\begin{array}{l}30,477 \\
33,935 \\
37,263 \\
41,143 \\
44,894\end{array}$ & $\begin{array}{l}16.4 \\
17.8 \\
16.8 \\
17.0 \\
16.0\end{array}$ & $\begin{array}{l}2,174 \\
2,091 \\
1,729 \\
2,073 \\
2,174\end{array}$ & $\begin{array}{r}1,167 \\
1,058 \\
778 \\
857 \\
818\end{array}$ & $\begin{array}{l}71.3 \\
61.6 \\
46.5 \\
60.4 \\
49.3\end{array}$ & $\begin{array}{l}62.5 \\
40.6 \\
35.2 \\
43.2 \\
42.6\end{array}$ & $\begin{array}{r}5,814 \\
11,449 \\
8,555 \\
9,204 \\
0,001\end{array}$ & $\begin{array}{l}3.1 \\
6.0 \\
3.8 \\
3.8 \\
3.7\end{array}$ & $\begin{array}{l}0.19 \\
0.34 \\
0.22 \\
0.2 .2 \\
0.22\end{array}$ & $\begin{array}{l}2.67 \\
5.47 \\
4.85 \\
4.44 \\
4.65\end{array}$ \\
\hline 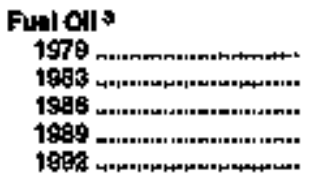 & $\begin{array}{l}641 \\
141 \\
534 \\
581 \\
560\end{array}$ & $\begin{array}{r}11,397 \\
8,400 \\
11,005 \\
12,600 \\
13,215\end{array}$ & $\begin{array}{l}17.8 \\
21.3 \\
20.5 \\
21.7 \\
23.6\end{array}$ & $\begin{array}{l}691 \\
314 \\
442 \\
357 \\
272\end{array}$ & $\begin{array}{r}1,003 \\
714 \\
627 \\
811 \\
487\end{array}$ & $\begin{array}{l}69.7 \\
39.4 \\
10.1 \\
28.3 \\
20.4\end{array}$ & $\begin{array}{l}40.5 \\
19.8 \\
27.7 \\
21.0 \\
15.1\end{array}$ & $\begin{array}{l}2,765 \\
3,102 \\
2,089 \\
1,802 \\
1,400\end{array}$ & $\begin{array}{l}4.3 \\
4.8 \\
3.9 \\
3.1 \\
4.5\end{array}$ & $\begin{array}{l}0.24 \\
0.22 \\
0.19 \\
0.14 \\
0.11\end{array}$ & $\begin{array}{l}4.06 \\
6.68 \\
4.88 \\
5.11 \\
5.14\end{array}$ \\
\hline 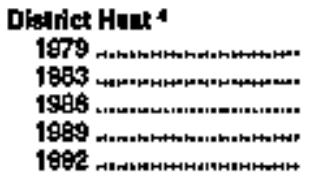 & $\begin{array}{l}47 \\
69 \\
77 \\
89 \\
85\end{array}$ & $\begin{array}{l}6,722 \\
4,643 \\
4,625 \\
6,676 \\
5,245\end{array}$ & $\begin{array}{l}79.0 \\
72.9 \\
59.7 \\
67.0 \\
65.4\end{array}$ & $\begin{array}{l}201 \\
209 \\
425 \\
585 \\
436\end{array}$ & $\begin{array}{l}4,267 \\
4,590 \\
5,4,46 \\
6,964 \\
4,586\end{array}$ & $\begin{array}{l}54.0 \\
02.1 \\
91.2 \\
0.0 \\
02.0\end{array}$ & $\begin{array}{l}26.6 \\
34.4 \\
58.4 \\
6.8 \\
60.0\end{array}$ & $\begin{array}{l}1,267 \\
2,627 \\
2,620 \\
3,857 \\
2,801\end{array}$ & $\begin{array}{l}26.9 \\
41.2 \\
33.8 \\
39.3 \\
30.7\end{array}$ & $\begin{array}{l}0.34 \\
0.57 \\
0.57 \\
0.59 \\
0.65\end{array}$ & $\begin{array}{l}6.30 \\
\$ .10 \\
6.91 \\
6.59 \\
6.67\end{array}$ \\
\hline 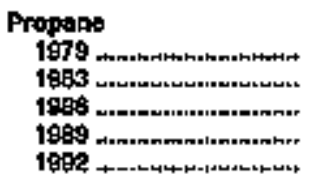 & $\begin{array}{l}214 \\
191 \\
344 \\
348 \\
397\end{array}$ & $\begin{array}{l}2,797 \\
2,562 \\
3,213 \\
4,685 \\
3,093\end{array}$ & $\begin{array}{r}13.1 \\
13.4 \\
9.3 \\
13.5 \\
10.1\end{array}$ & $\begin{array}{l}43 \\
34 \\
63 \\
N A \\
N A\end{array}$ & $\begin{array}{c}202 \\
176 \\
184 \\
N \alpha \\
N \alpha\end{array}$ & $\begin{array}{c}15.5 \\
13.1 \\
19.7 \\
\text { NA } \\
\text { NA }\end{array}$ & $\begin{array}{r}12.9 \\
2.8 \\
17.5 \\
\mathrm{NA} \\
\mathrm{NA}\end{array}$ & $\begin{array}{l}225 \\
313 \\
543 \\
N A \\
N A\end{array}$ & $\begin{array}{l}1.1 \\
7.6 \\
1.6 \\
N A \\
N A\end{array}$ & $\begin{array}{l}0.08 \\
0.12 \\
0.17 \\
\text { NA } \\
\text { NA }\end{array}$ & $\begin{array}{l}5.19 \\
9.29 \\
8.69 \\
\text { NA } \\
\text { NA }\end{array}$ \\
\hline
\end{tabular}

1 Monintal cholanto.

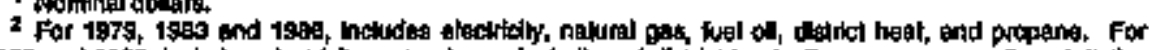

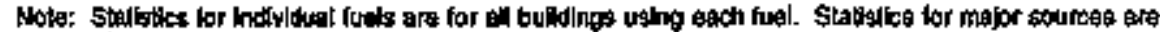

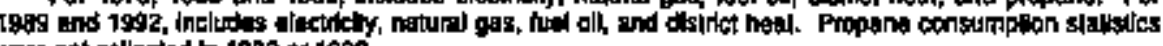
ware nos collected in 1998 or 1002 .

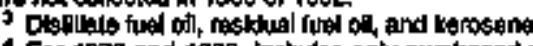

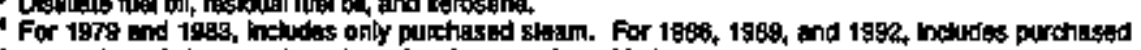

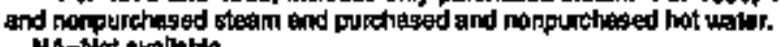

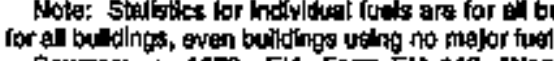

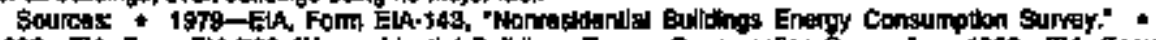

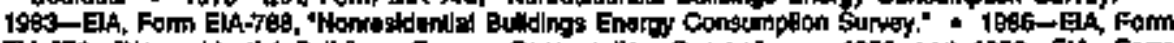

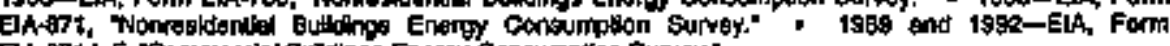

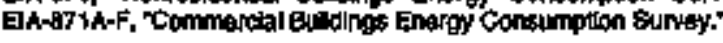

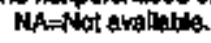



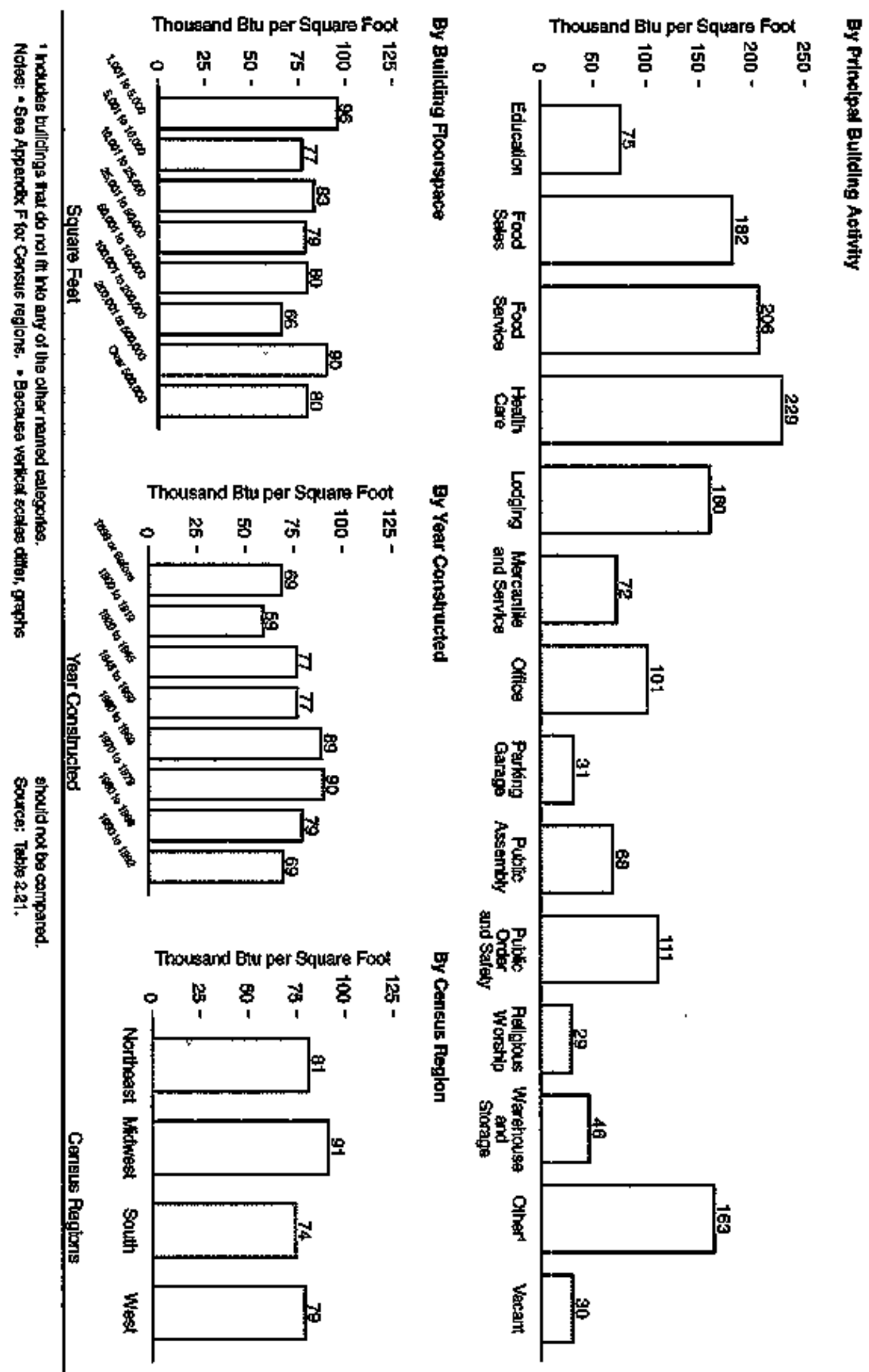
Table 2.21 Commercial Bulldings Energy Intensities by Building Characteristic, 1992

(Thousand Btu per Square Foot)

\begin{tabular}{|c|c|c|c|c|c|c|c|c|c|c|}
\hline Bullding Chamectartatic & $\begin{array}{l}\text { Spove } \\
\text { Hiniting }\end{array}$ & Cooling & Vemlitestan & $\begin{array}{l}\text { Water } \\
\text { Heating }\end{array}$ & LLㅏ.ghting & Cooking & Ratirlgerallon & $\begin{array}{c}\text { Ofitte } \\
\text { Equipment }\end{array}$ & other' & End Usea \\
\hline 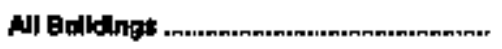 & 29.2 & 6.8 & 2.5 & 12.8 & t7.1 & 3.3 & 20 & 30 & 6.3 & 80,9 \\
\hline 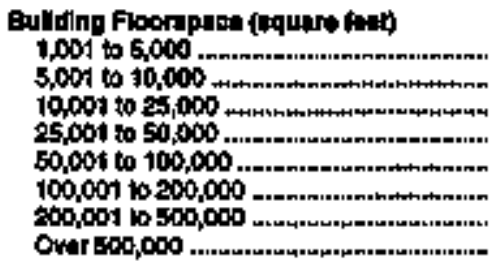 & $\begin{array}{l}34.3 \\
27.7 \\
36.0 \\
25.9 \\
31.5 \\
21.8 \\
25.9 \\
21.0\end{array}$ & $\begin{array}{l}8.3 \\
8.2 \\
6.2 \\
6.7 \\
6.5 \\
5.7 \\
6.9 \\
6.9\end{array}$ & $\begin{array}{l}2.8 \\
2.0 \\
1.6 \\
2.1 \\
2.5 \\
2.5 \\
3.4 \\
3.2\end{array}$ & $\begin{array}{r}14.0 \\
13.6 \\
15.4 \\
10.5 \\
10.0 \\
6.9 \\
15.9 \\
10.4\end{array}$ & $\begin{array}{l}17.1 \\
13.4 \\
18.4 \\
19.4 \\
17.6 \\
17.3 \\
24.3 \\
21.3\end{array}$ & $\begin{array}{l}6.0 \\
5.1 \\
2.5 \\
2.3 \\
1.5 \\
1.3 \\
3.5 \\
3.5\end{array}$, & $\begin{array}{l}5.6 \\
2.0 \\
2.8 \\
1.7 \\
1.7 \\
1.0 \\
0.9 \\
1.1\end{array}$ & $\begin{array}{l}2.7 \\
2.4 \\
2.7 \\
2.4 \\
2.0 \\
3.0 \\
4.3 \\
4.4\end{array}$ & $\begin{array}{l}3.2 \\
2.7 \\
3.4 \\
9.1 \\
6.5 \\
4.5 \\
5.8 \\
7.9\end{array}$ & $\begin{array}{l}95.9 \\
77.1 \\
69.4 \\
76.6 \\
79.7 \\
60.2 \\
50.1 \\
79.8\end{array}$ \\
\hline 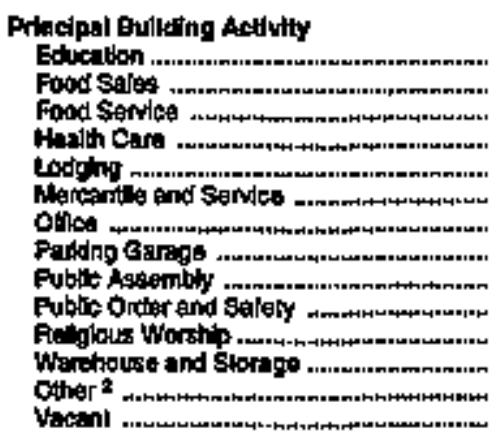 & $\begin{array}{c}40.2 \\
21.3 \\
28.7 \\
50.1 \\
51.2 \\
24.6 \\
39.2 \\
7.4 \\
21.9 \\
44.3 \\
17.4 \\
18.2 \\
71.2 \\
14.4\end{array}$ & $\begin{array}{c}6.2 \\
12.8 \\
35.3 \\
19.3 \\
20.9 \\
3.4 \\
11.4 \\
0 \\
4.5 \\
4.6 \\
1.9 \\
1.9 \\
0.1 \\
1.4\end{array}$ & $\begin{array}{l}1.3 \\
4.5 \\
6.2 \\
6.5 \\
3.4 \\
2.1 \\
6.1 \\
0.5 \\
1.4 \\
1.0 \\
0.8 \\
0.2 \\
5.9 \\
0.8\end{array}$ & $\begin{array}{r}7.2 \\
11.9 \\
24.8 \\
72.4 \\
41.5 \\
14.8 \\
11.0 \\
31 \\
8.8 \\
31.2 \\
32 \\
5.6 \\
23.0 \\
2.7\end{array}$ & $\begin{array}{c}15.5 \\
27.9 \\
18.5 \\
25.7 \\
20.0 \\
18.7 \\
18.9 \\
180 . \\
26.3 \\
24.3 \\
.9 .8 \\
13.9 \\
32.3 \\
5.7\end{array}$ & $\begin{array}{r}0.9 \\
6.6 \\
77.8 \\
16.8 \\
4.4 \\
1.5 \\
1.4 \\
0.4 \\
2.2 \\
2.1 \\
0.7 \\
0 \\
0.6 \\
0\end{array}$ & $\begin{array}{r}0.8 \\
84.1 \\
11.3 \\
8.3 \\
1.6 \\
1.2 \\
0.3 \\
0.0 \\
0.7 \\
0.0 \\
0.3 \\
1.1 \\
0.1 \\
0.1\end{array}$ & $\begin{array}{c}0.5 \\
0.9 \\
0.3 \\
0.5 \\
1.0 \\
2.2 \\
11,1 \\
0.0 \\
0.4 \\
0.3 \\
0.1 \\
1.1 \\
2.4 \\
0.1\end{array}$ & $\begin{array}{r}2.7 \\
11.5 \\
3.1 \\
29.9 \\
14.1 \\
3.6 \\
7.6 \\
10.4 \\
2.7 \\
2.9 \\
1.9 \\
3.7 \\
19.7 \\
0\end{array}$ & $\begin{array}{r}79.2 \\
181.5 \\
200.1 \\
228.5 \\
180.1 \\
71.9 \\
101.2 \\
31.3 \\
69.0 \\
110.6 \\
29.0 \\
15.9 \\
163.2 \\
29.9\end{array}$ \\
\hline 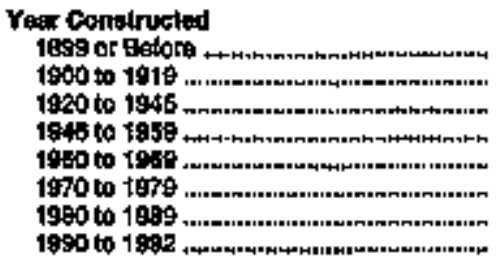 & $\begin{array}{l}39.9 \\
30.7 \\
37.2 \\
28.5 \\
29.5 \\
29.2 \\
20.5 \\
20.3\end{array}$ & $\begin{array}{l}6.0 \\
3.7 \\
6.9 \\
5.3 \\
6.1 \\
6.2 \\
6.1 \\
6.9\end{array}$ & $\begin{array}{l}0.9 \\
0.8 \\
1.5 \\
2.0 \\
2.8 \\
2.8 \\
3.2 \\
3.6\end{array}$ & $\begin{array}{r}11.6 \\
9.4 \\
11.9 \\
12.0 \\
16.1 \\
12,5 \\
12.6 \\
7.9\end{array}$ & $\begin{array}{r}7.1 \\
8.3 \\
0.5 \\
16.4 \\
21.6 \\
20.7 \\
18.8 \\
17.0\end{array}$ & $\begin{array}{l}4.2 \\
2.5 \\
3.2 \\
2.0 \\
3.2 \\
4.2 \\
3.3 \\
2.1\end{array}$ & $\begin{array}{l}1.3 \\
0.5 \\
1.4 \\
1.5 \\
2.0 \\
2.3 \\
3.0 \\
1.7\end{array}$ & $\begin{array}{l}2.1 \\
1.4 \\
1.6 \\
2.3 \\
3.3 \\
3.1 \\
4.4 \\
4.9\end{array}$ & $\begin{array}{l}1.6 \\
2.0 \\
3.3 \\
7.1 \\
4.7 \\
7.1 \\
5.5 \\
4.7\end{array}$ & $\begin{array}{l}68.5 \\
59.1 \\
76.6 \\
76.6 \\
69.2 \\
90.0 \\
79.3 \\
69.3\end{array}$ \\
\hline 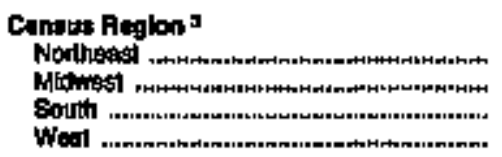 & $\begin{array}{l}34.7 \\
39.3 \\
21.3 \\
20.0\end{array}$ & $\begin{array}{l}4.6 \\
5.3 \\
6,4 \\
6.2\end{array}$ & $\begin{array}{l}1.3 \\
2.2 \\
2.7 \\
3.8\end{array}$ & $\begin{array}{r}13.6 \\
14.3 \\
11.2 \\
12.2\end{array}$ & $\begin{array}{l}14.7 \\
17.4 \\
17.1 \\
10.8\end{array}$ & $\begin{array}{l}3.6 \\
4.0 \\
2.5 \\
3.4\end{array}$ & $\begin{array}{l}1.7 \\
2.0 \\
1.7 \\
2.7\end{array}$ & $\begin{array}{l}2.7 \\
2.9 \\
3.0 \\
3.6\end{array}$ & $\begin{array}{l}4.3 \\
6.0 \\
6.2 \\
5.1\end{array}$ & $\begin{array}{l}61.3 \\
91.9 \\
74.3 \\
72.1\end{array}$ \\
\hline
\end{tabular}

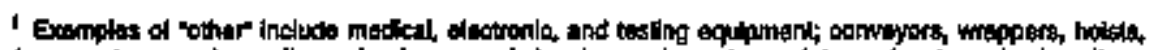

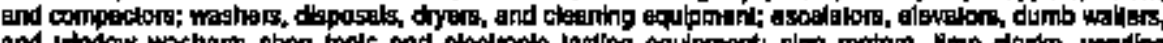

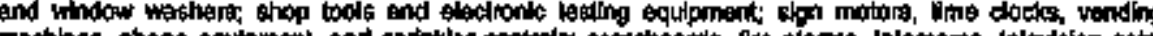

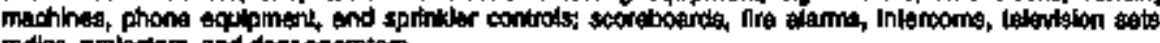
Modos, propectors, and door cperators.

Soe Appendax P far Cunsus regitans.

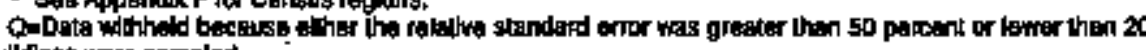
bulkings ware samplad.

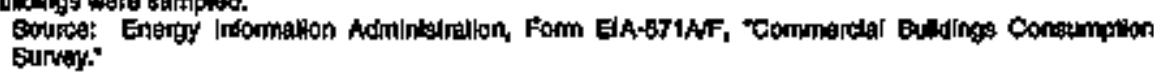





\section{Financial Indicators}

\section{Fossil Fuel Prices Down From Record Levels}

From the 1959 level of $\$ 1.25$ per million Btu, real prices' of fossil fuels ${ }^{2}$ trended downward to a low of $\$ 1.03$ in $1968(3.1)$.* Thereafter, prices began to escalate, sometimes abruptly. In 1974, the composite price of fossil fuels jumped from the 1973 level of $\$ 1.12$ to $\$ 1.76$, surpassing the 1959 level for the first time and registering the largest year-to-year increase (57 percent) of the 1959-to-1995 period. The peak of $\$ 4.17$ was reached in 1981. Thereafter, the price declined each year through 1988, plunging 36 percent in 1986 alone. Although ptices recovered somewhat in 1989 and 1990, they then declined to a 22-year low of \$1,39 in 1995.

Crude oil was the most expensive of the fossil fuels over the entire period, with the exception of anthracite in 1975 through 1977. At its peak in 1981, the real price of crude oil reached $\$ 8.31$ per million Btu, more than triple the price of natural gas and more than quadrupte the price of nonanthracitic coal.

\section{Energy Expenditures Rose in 1993}

The energy expenditure measure is the product of energy consumption and energy prices. In 1993, although energy prices declined, end-use energy consumption increased 2.1 percent (1.5). As a result, nominal expenditures rose 4.4 percent to $\$ 493$ billion (3.6).

Nominal end-use expenditures of $\$ 226$ billion for petroleum products accounted for 46 percent of total energy expenditures in $1993(3,8)$. Expenditures for natural gas showed the largest year-to-year percentage increase. The 1993 total of $\$ 76$ billion was $\$ 7.6$ billion (11 percent) above the 1992 total. Expenditures for coal were $\$ 28$ billion. Sales of electricity (net of expenditures by electric utilities for most

\footnotetext{
'Real (infotion-adjusted) prices are expressed in shained (I992) dollass.
}

${ }^{2}$ Crude ofl, naxural gas, and eval.

Wumbers in parentheses indicate related tables, Annuld data are the most recent avallable; they frequently are preliminary and may be revised in tuture putilicalions. Fercentages and numbers in lexd are celculated by using data in the tables. fuels used to generate electricity) totaled $\$ 168$ billion. Nuclear fuel and biomass fuels used at electric utilities accounted for $\$ 3.7$ billion.

\section{Energy Industry Financial Performance}

In 1994, the 24 major energy companies included in the Financial Reporting System (FRS) ${ }^{3}$ accounted for $5 I$ percent of U.S. crude oil and natural gas liquids production, 43 percent of dry natural gas production, and 17 percent of coal production (3.9). They also accounted for 66 percent of refinery capacity. The FRS companies continued to play a significant role in the U.S. economy. In 1994, their sales equaled 10 percent of the $\$ 4.3$ trillion in sales of the Fortune 500 largest U.S. industrial corporations. ${ }^{4}$

Despite the decline in crude oil prices-the nominal composite refiner acquisition cost of crude oil of $\$ 15.59$ per barrel in 1994 was the lowest since 1988 (5.19)-the FRS compantes' net income rose to $\$ 17$ billion (3.9). Low crude oil prices restrained net income from domes. tic petroleum and natural gas production, which totaled $\$ 4.8$ billion in 1994 and contributed to a decline in net income from foreignt petroleum and natural gas production, which declined $\$ 1.2$ billion to $\$ 4.0$ billion in 1994 (3.10). Net income from domestic refining and marketing rose from $\$ 1.7$ billion to $\$ 1.8$ billion in 1994, but net income from foreign refining and marketing decreased, from $\$ 3.2$ billion in 1993 to $\$ 2.0$ billion in 1994. Net income from the noninergy line of business rose dramatically from $\$ 2.7$ billion in 1993 to $\$ 6.2$ billion in 1994 due to profits from chemical manufacturing, particularly petrochemical manufacturing.

FRS companies' additions to investment in place totaled $\$ 39$ billion in 1994 , down from $\$ 40$ billion in 1993 (3.12). Petroleum and natural gas accounted for $\$ 31$ billion of the 1994 total. Additions to investment in domestic petroleum and natural gas production exceeded additions to investment in foreign production.

3The FRS collecls financiul data trom the mator epergy-prodteing compondes. See Tałle 3.14 at end of sectlon for a llst of the U.S. energy companies reporting to the FRS. Enery Infarmation Administracion, Perfarmance Profilas of Mafor Entorgy Prodicers 1994, DOE/ElA-0206(94) (Washington DC, Jantary 1996), p. 3. 


\section{Pricea, 1949-tges}

兽

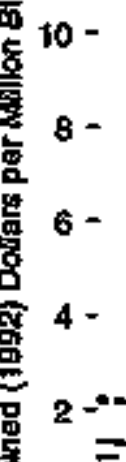

2 =-O- - - -

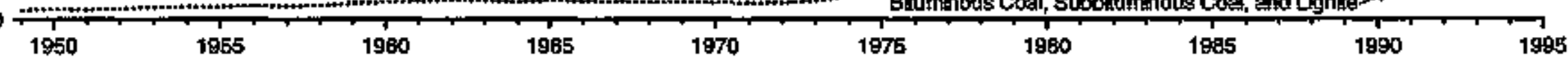

\section{Fossll Fuet Composite Prlce, Change from Prewlous Year, 1950-1995}

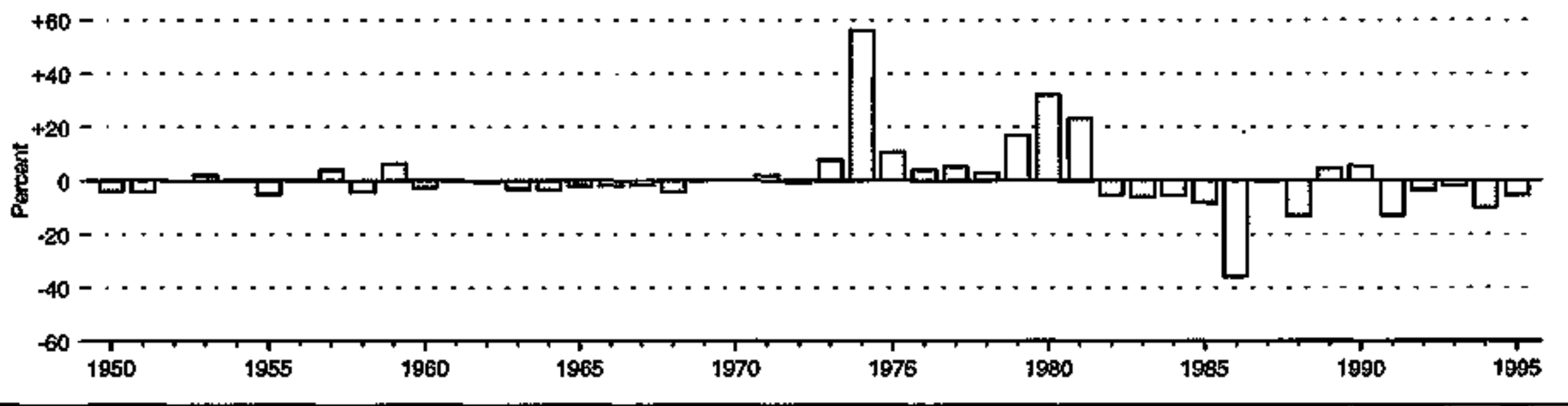

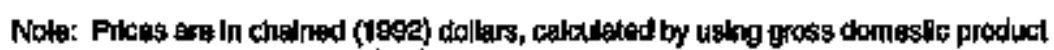

Sourog; Tabte $\mathbf{3 . 1 .}$

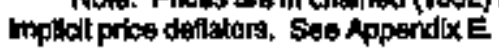


Table 3.1 Fossil Fuel Production Prices, 1949-1995

(Dollars per Million Btu)

\begin{tabular}{|c|c|c|c|c|c|c|c|c|c|c|c|}
\hline \multirow[b]{2}{*}{ rex } & \multicolumn{2}{|c|}{ Arute on 1} & \multicolumn{2}{|c|}{ Bustural Cas 2} & \multicolumn{2}{|c|}{ 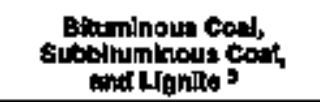 } & \multicolumn{2}{|c|}{ Anthemellen 4} & \multicolumn{3}{|c|}{ Fossll Fuel Compodtos } \\
\hline & Alominal & Ragls & Nornalnal & Ron ${ }^{*}$ & Homine & Ro: 1t & Nominal & Rosit & Nomines & Aseale & Percent Change \\
\hline 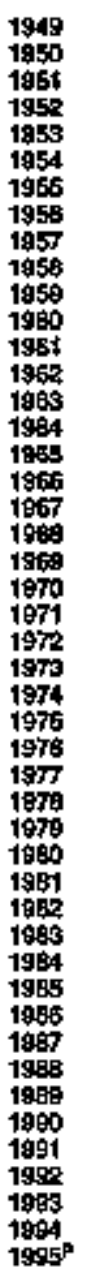 & 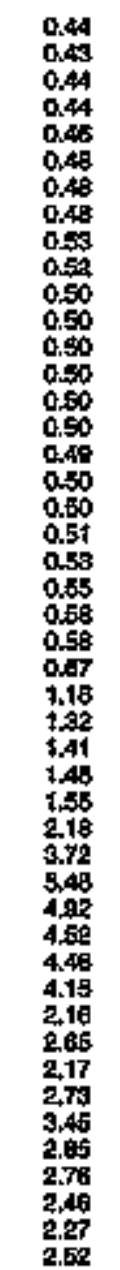 & 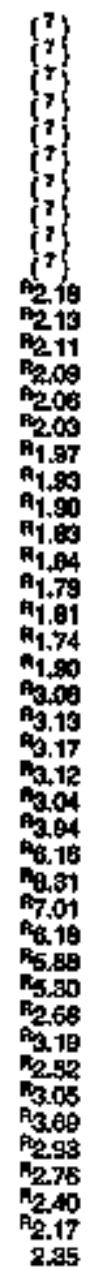 & 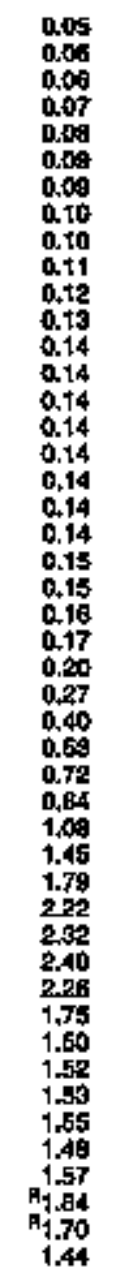 & 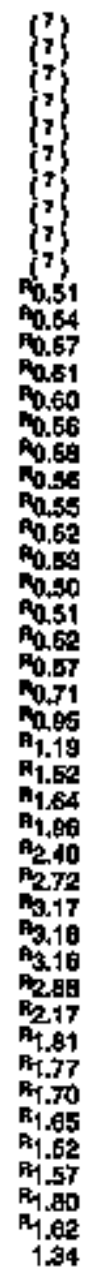 & 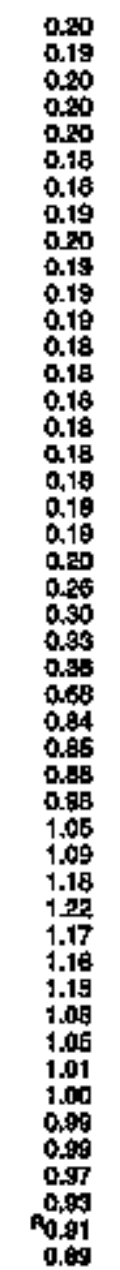 & 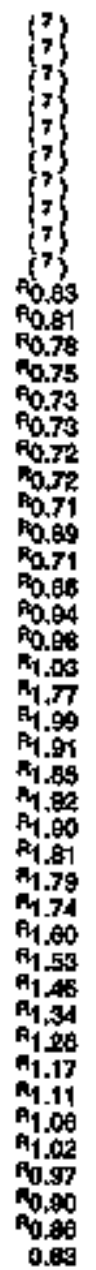 & 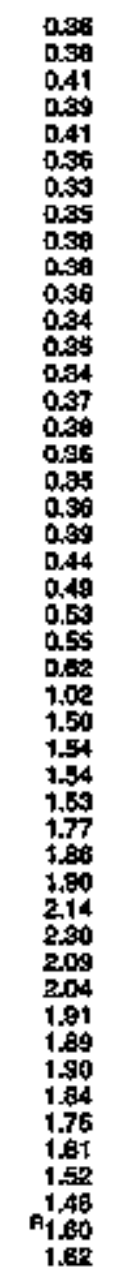 & 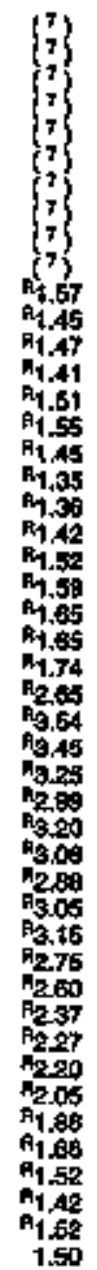 & 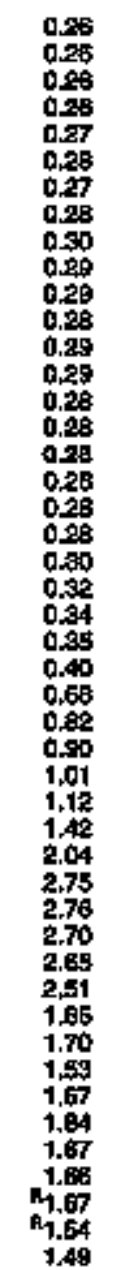 & 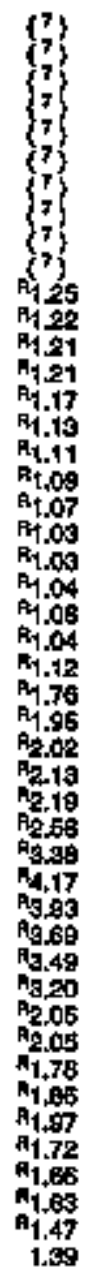 & 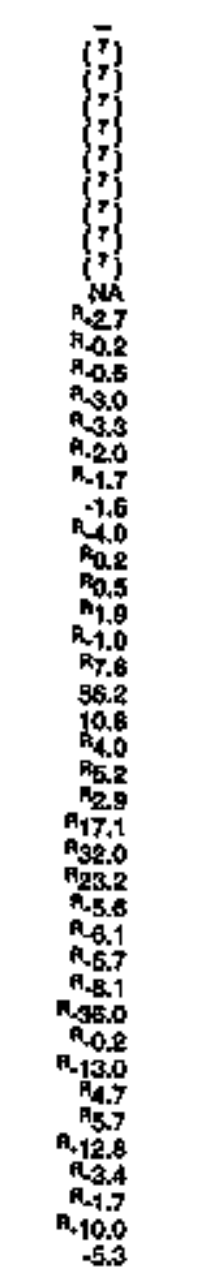 \\
\hline
\end{tabular}

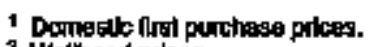

2 Wilhoid pitces.

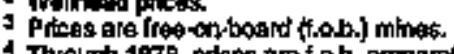

- Dare

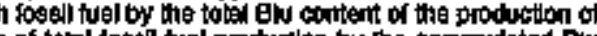

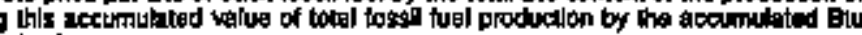

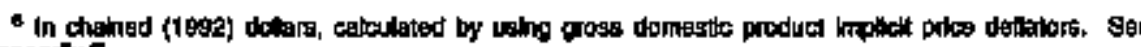
Appondixe.

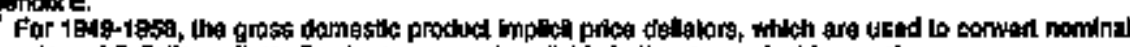

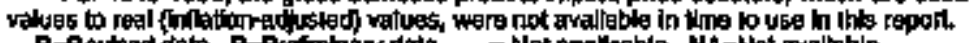

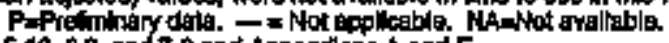

contanl of total tosstif ivel prodtution. 


\section{Figure 3.2 Value of Fossil Fuel Production}

\section{Overvlew, t949-1995}

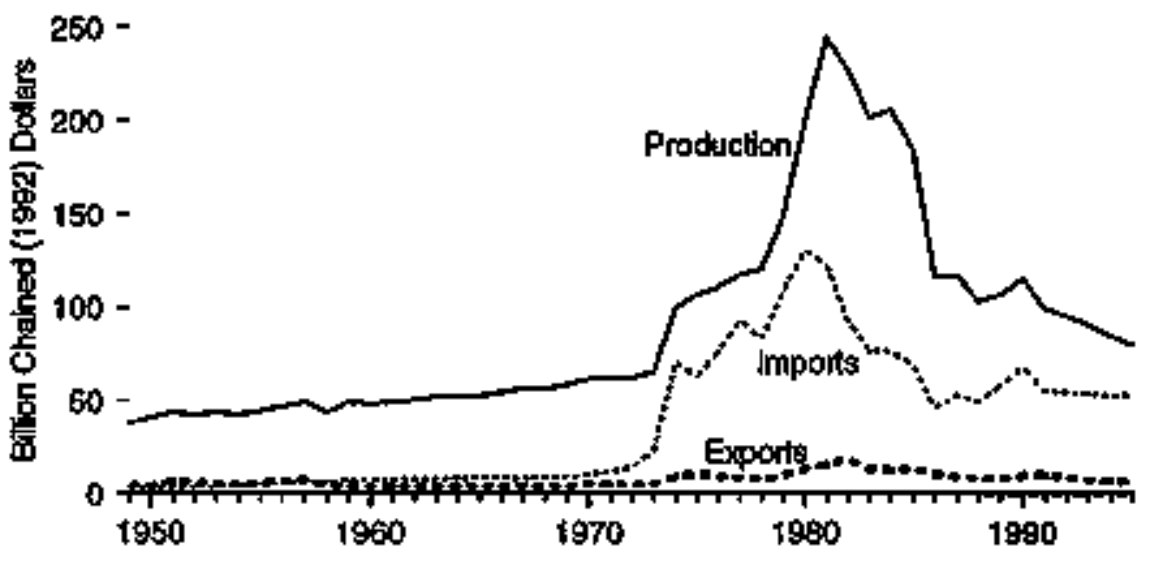

Overvkew, 1995

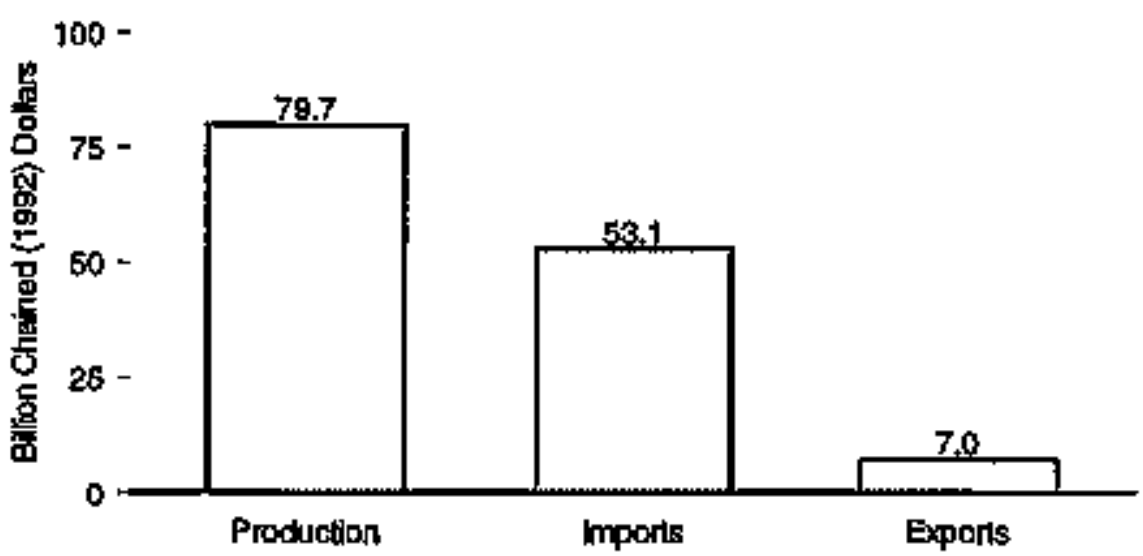

Noles: * Ftogs ara in chalned (1902) ctollars, calculdated by using grose domesilc product inpincle prices deflators, See Appendtx E. * Because verlieal seales ditier, gaphs shoutd not
Proctuction by Fual, 1949-1995

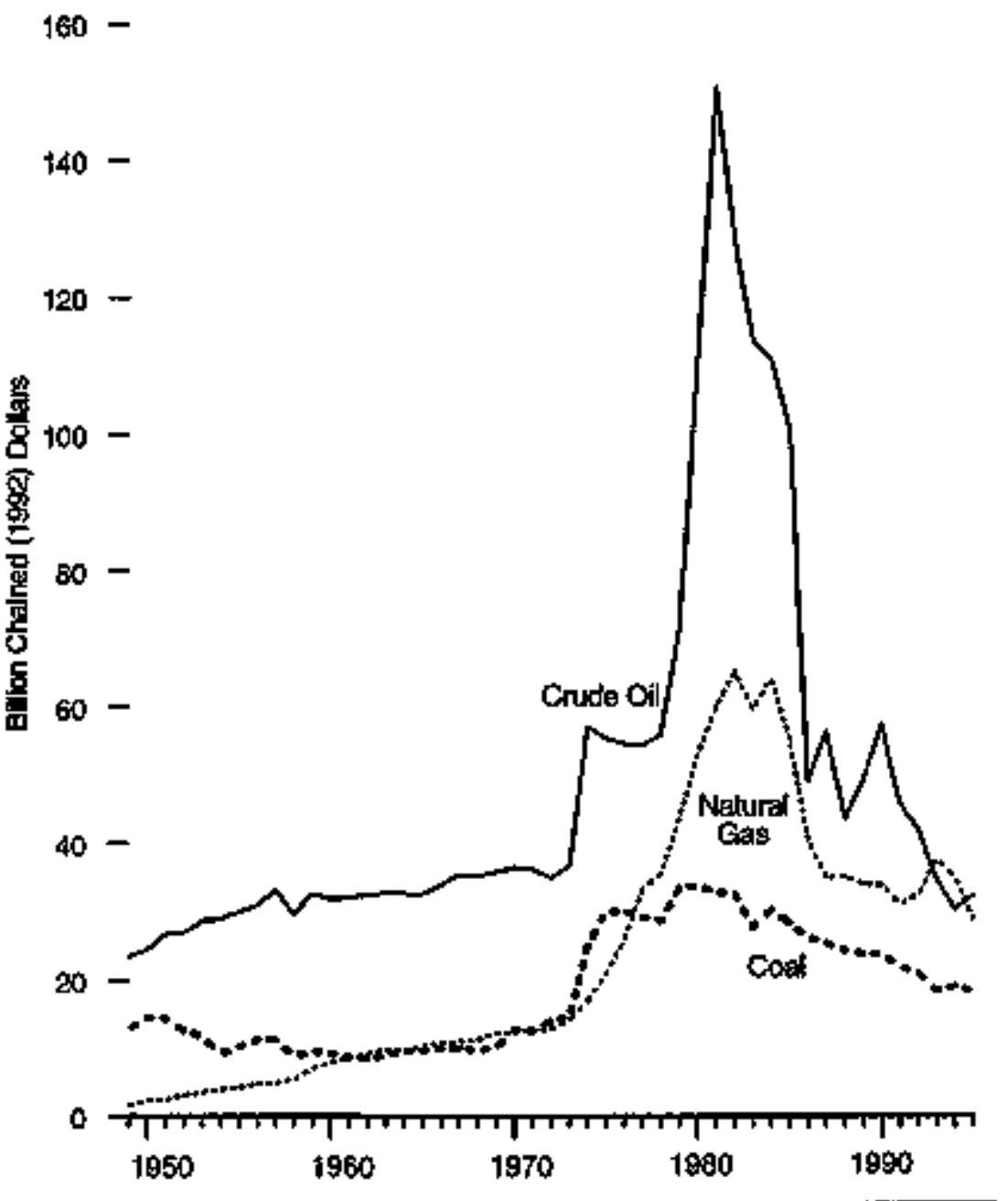

be compared.

Scurces: Tables 3.2, 3.3, and 3.4 . 
Table 3,2 Value of Fossil Fuel Production, 1949-1995

(Bt|lion Dollars)

\begin{tabular}{|c|c|c|c|c|c|c|c|c|c|c|c|c|}
\hline \multirow[b]{3}{*}{ Year } & \multirow{2}{*}{\multicolumn{2}{|c|}{ Crudy on 1}} & \multirow{2}{*}{\multicolumn{2}{|c|}{$\begin{array}{c}\text { Noluted Gas } \\
\text { (Mitarkated PToduction) }\end{array}$}} & \multicolumn{6}{|c|}{ Cond } & \multirow{2}{*}{\multicolumn{2}{|c|}{ Total }} \\
\hline & & & & & \multicolumn{2}{|c|}{$\begin{array}{l}\text { Bhuminang Cpal, } \\
\text { subbiluminous Cosal, } \\
\text { and Lignitos }\end{array}$} & \multicolumn{2}{|c|}{ Anihraolis } & \multicolumn{2}{|c|}{ Total } & & \\
\hline & Nomiknt & Font 2 & Nomtney & Feat 2 & Hominal & Regal 2 & Mlominal & F(日) $)^{2}$ & Noninal & Fon: 2 & Nominat & Rocy 2 \\
\hline 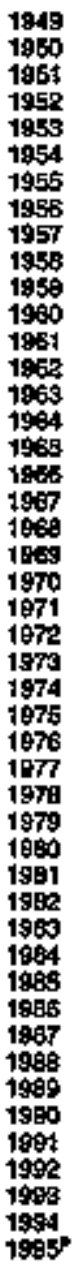 & 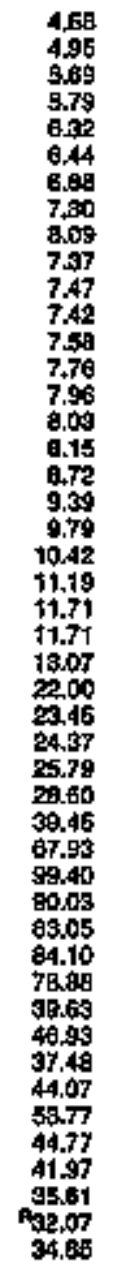 & 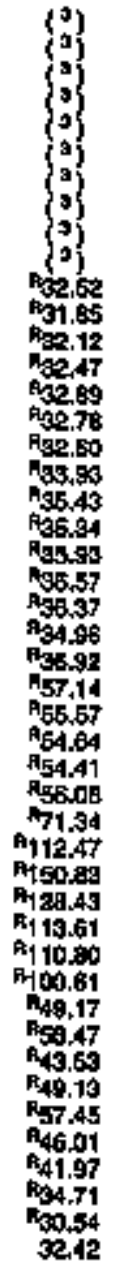 & 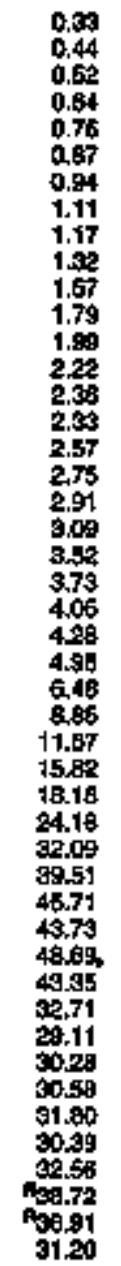 & 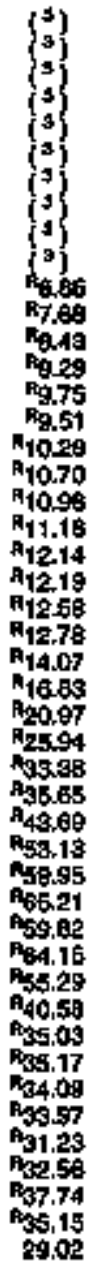 & 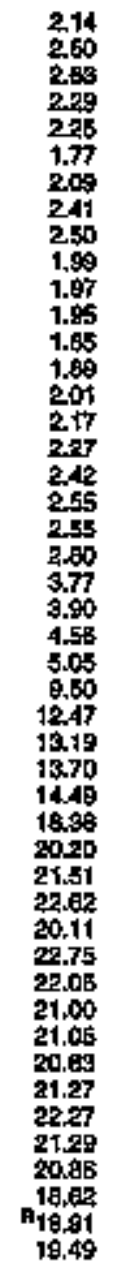 & 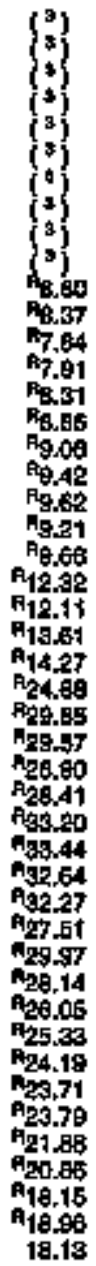 & 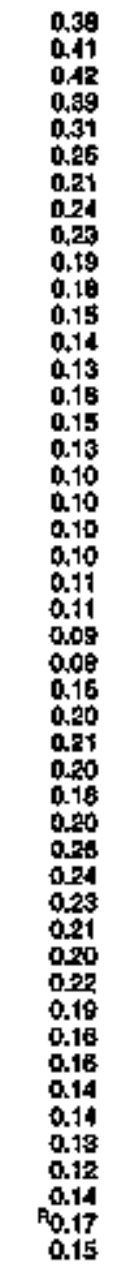 & 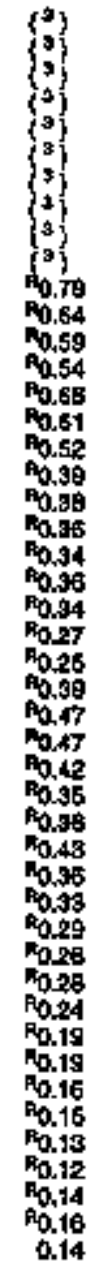 & 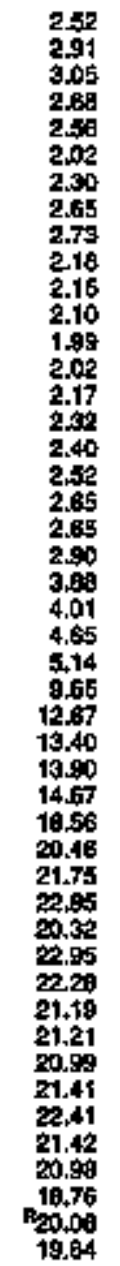 & 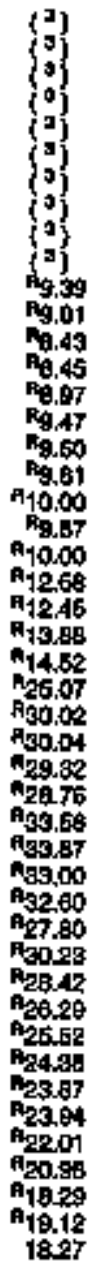 & 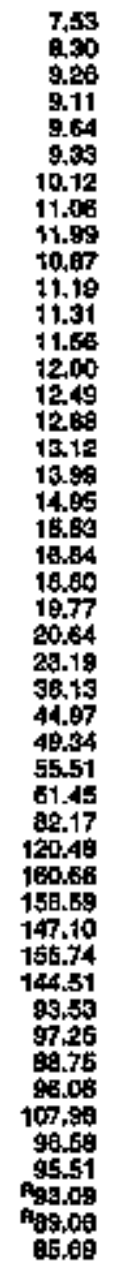 & 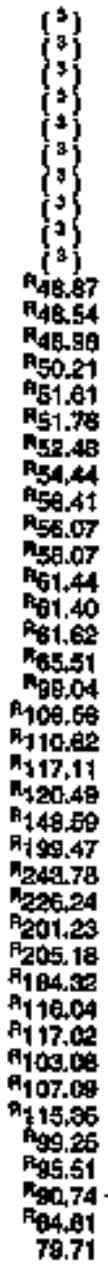 \\
\hline
\end{tabular}

Incaudes tease candensallo.

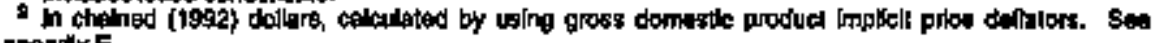
AppendixE.

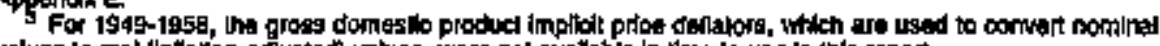

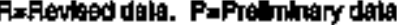




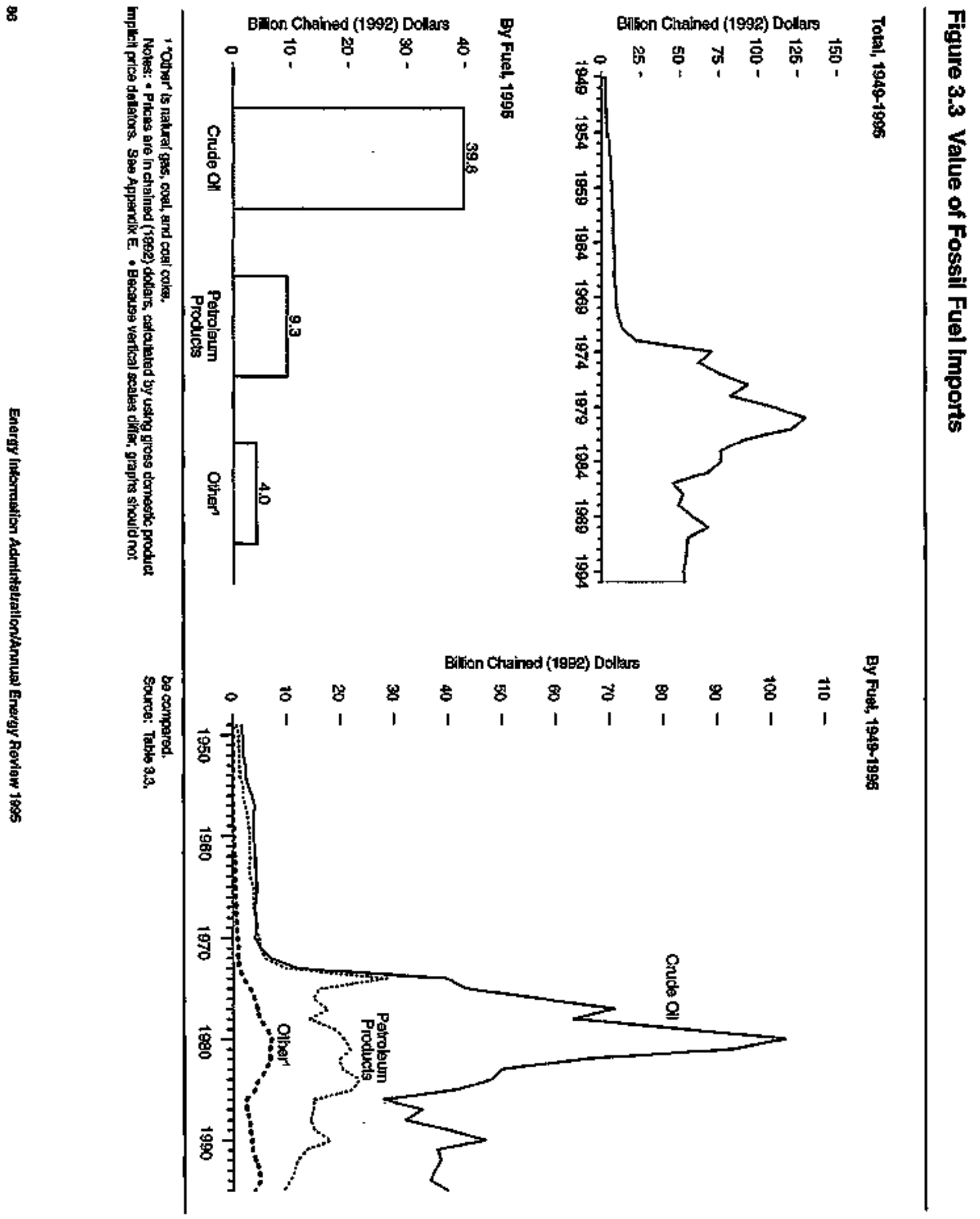


Table 3.3 Value of Fossil Fuel Imports, 1949-1995

(Billion Dollars)

\begin{tabular}{|c|c|c|c|c|c|c|c|c|c|c|c|c|}
\hline \multirow[b]{2}{*}{ Yeer } & \multicolumn{2}{|c|}{ Conal } & \multicolumn{2}{|c|}{ cost conse } & \multicolumn{2}{|c|}{ Naturat Gan } & \multicolumn{2}{|c|}{ Cruds on } & \multicolumn{2}{|c|}{ Petrolaum Procturits } & \multicolumn{2}{|c|}{ Tolal } \\
\hline & Mornand & Aval2 & Nominel & Reat 2 & Norninat & Real 2 & Notand & Rion' 2 & Nominal & Fenil2 & Nominat & fios 2 \\
\hline 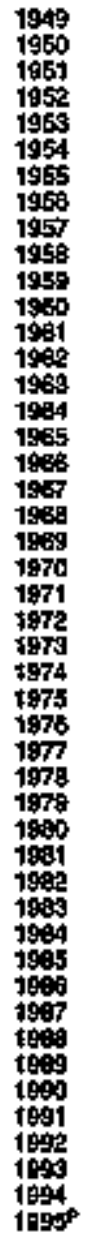 & 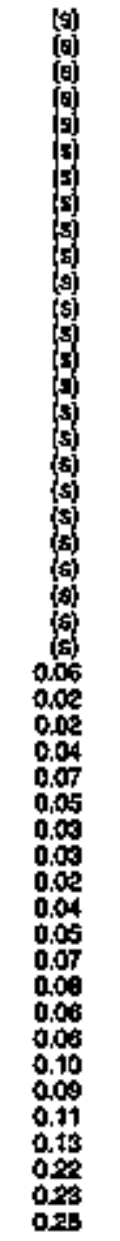 & 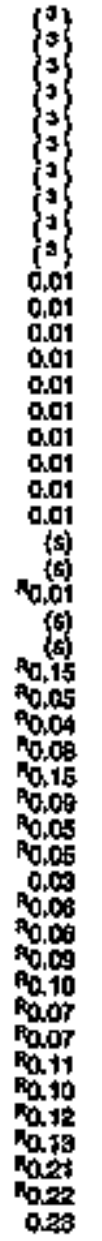 & 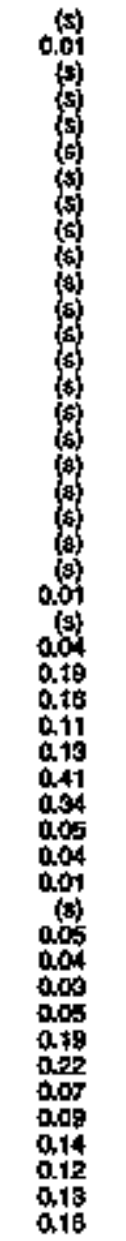 & 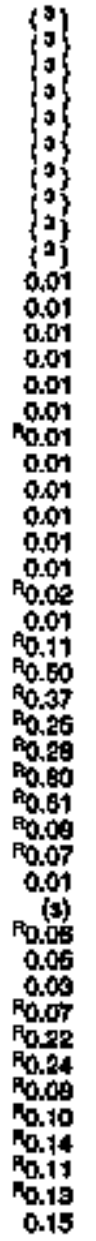 & 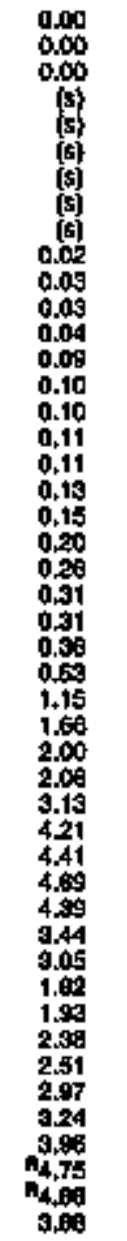 & 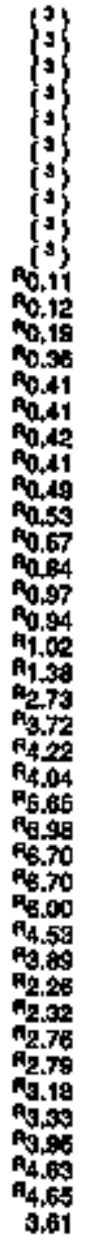 & 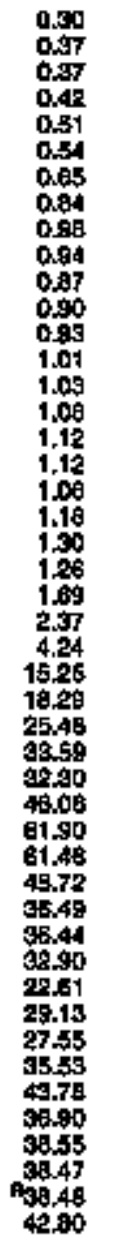 & 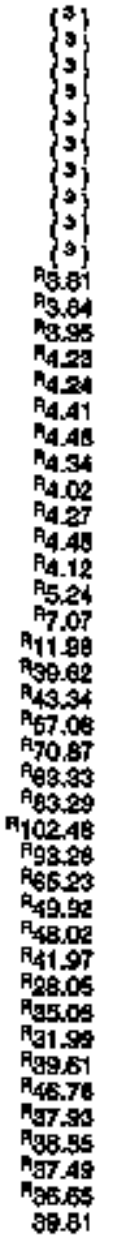 & 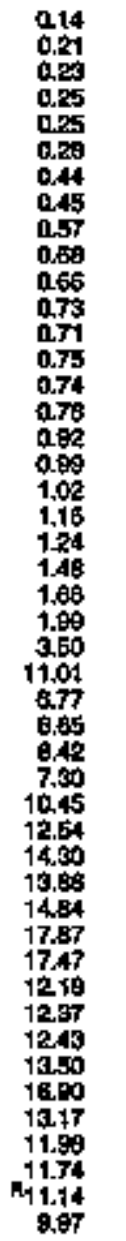 & 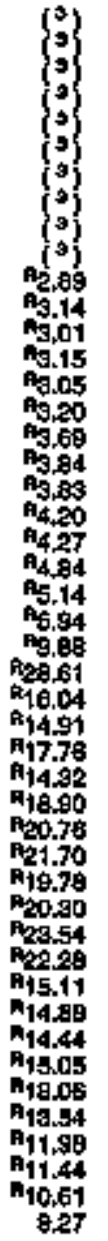 & 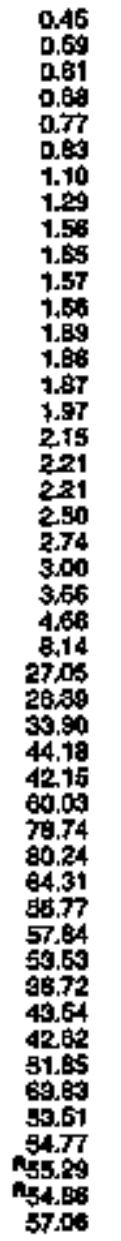 & 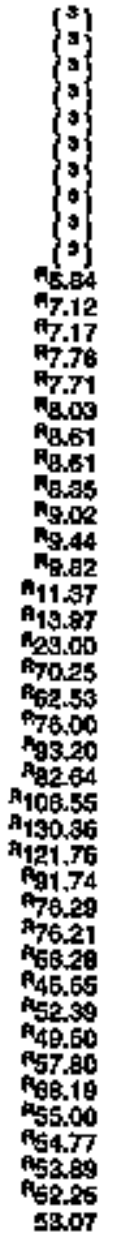 \\
\hline
\end{tabular}

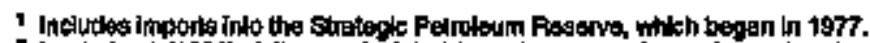

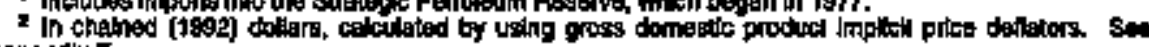

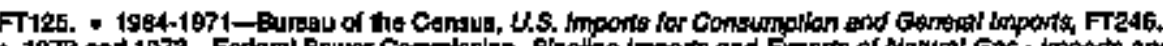

Append F E E

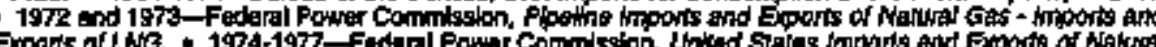
Exports of Nakcoke

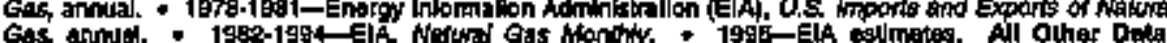

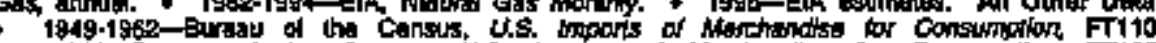

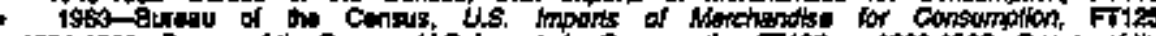

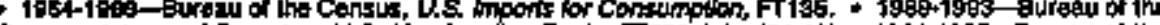

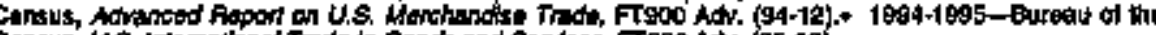

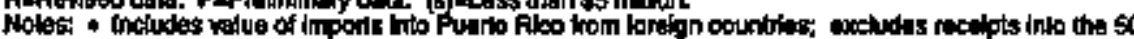

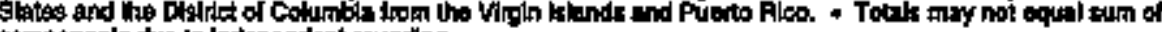

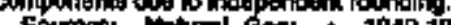

con

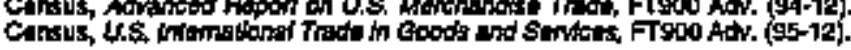




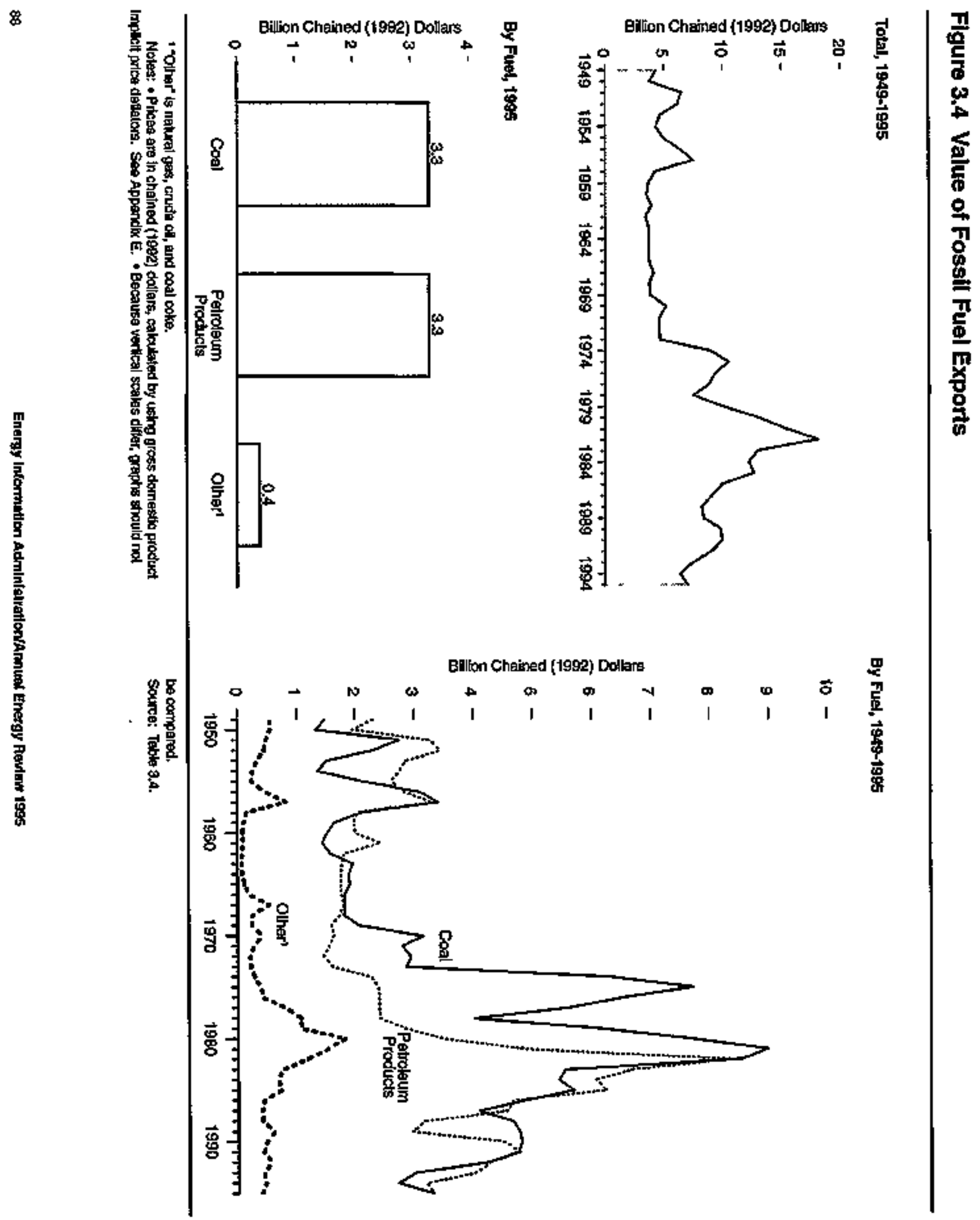


Table 3.4 Value of Fossil Fuel Exports, 1949-1995

(Billion Dollars)

\begin{tabular}{|c|c|c|c|c|c|c|c|c|c|c|c|c|}
\hline \multirow[b]{2}{*}{ Yeor } & \multicolumn{2}{|c|}{ Con } & \multicolumn{2}{|c|}{ Conl Coks } & \multicolumn{2}{|c|}{ Hanum teat } & \multicolumn{2}{|c|}{ Enuteoll } & \multicolumn{2}{|c|}{ Petrolenm Products } & \multicolumn{2}{|r|}{ Totel } \\
\hline & Homingl & Real 1 & Nominow & Real & Nonthell & Ranl 1 & tominnl & Real 1 & Homlnes & Real 1 & Nomins & Reed" \\
\hline 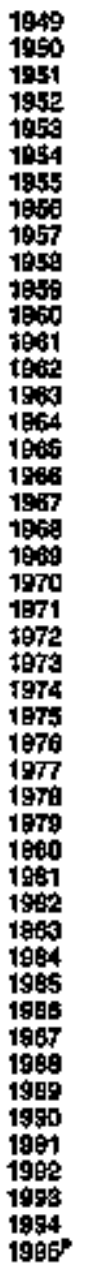 & 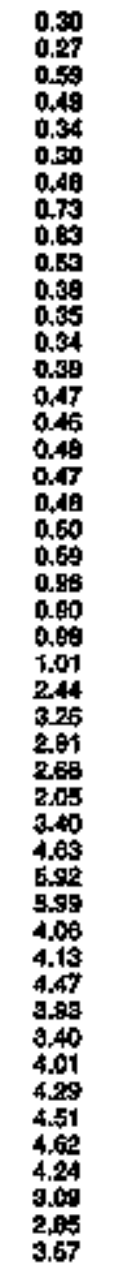 & 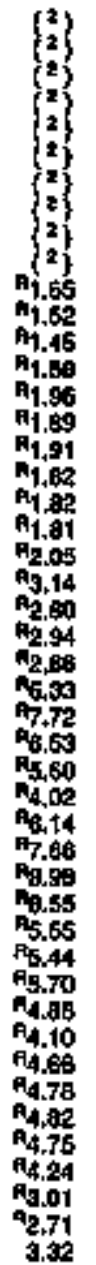 & $\begin{array}{l}0.01 \\
0.01 \\
0.02 \\
0.01 \\
0.01 \\
0.01 \\
0.01 \\
0.01 \\
0.01 \\
0.01 \\
0.01 \\
0.01 \\
0.01 \\
0.01 \\
0.01 \\
0.01 \\
0.02 \\
0.02 \\
0.02 \\
0.02 \\
0.04 \\
0.08 \\
0.04 \\
0.09 \\
0.03 \\
0.04 \\
0.07 \\
0.07 \\
0.07 \\
0.05 \\
0.09 \\
0.13 \\
0.07 \\
0.06 \\
0.05 \\
0.07 \\
0.09 \\
0.07 \\
0.05 \\
0.00 \\
0.00 \\
0.05 \\
0.05 \\
0.04 \\
0.06 \\
0.04 \\
0.05\end{array}$ & 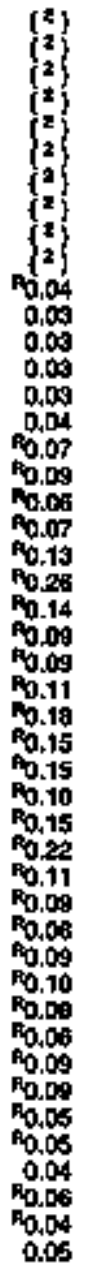 & 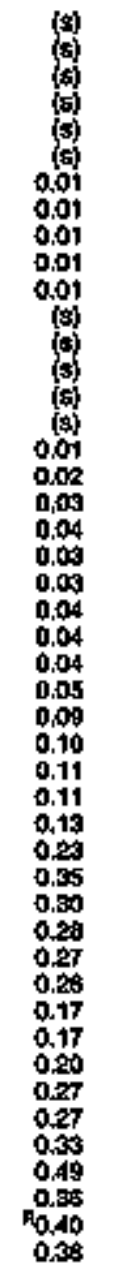 & 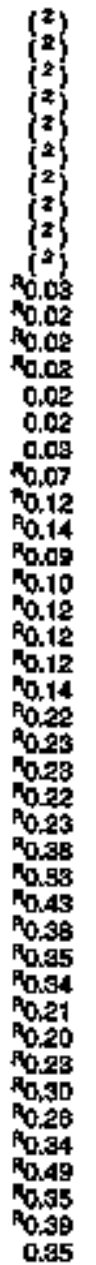 & 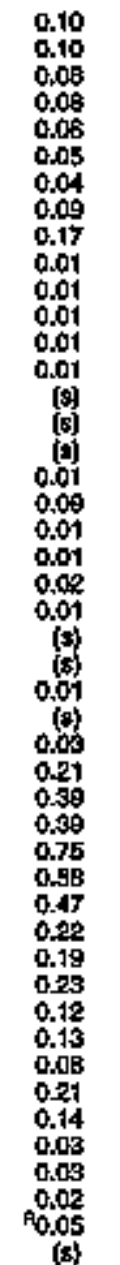 & 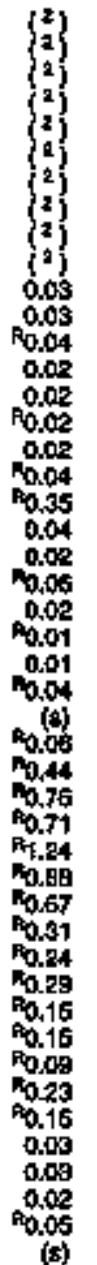 & 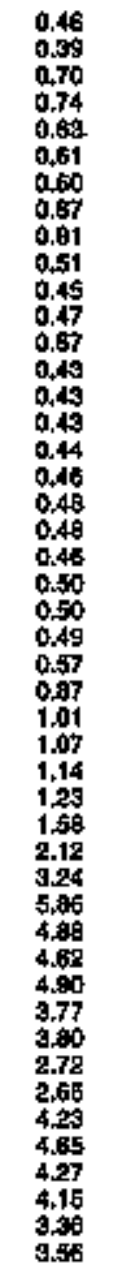 & 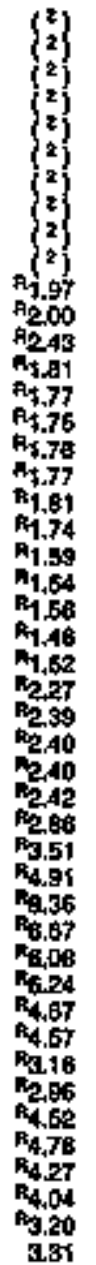 & 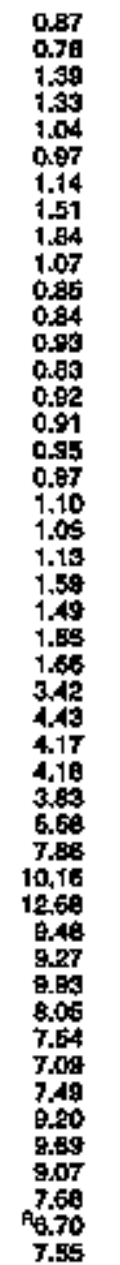 & 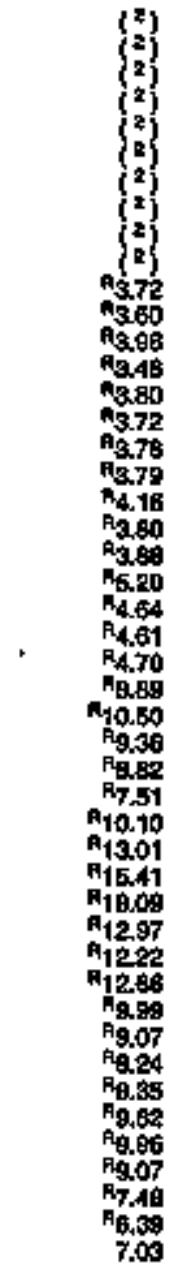 \\
\hline
\end{tabular}

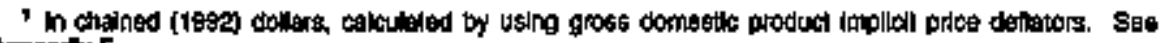
Appingdix E.

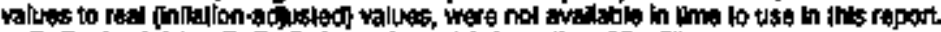

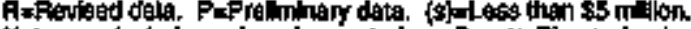

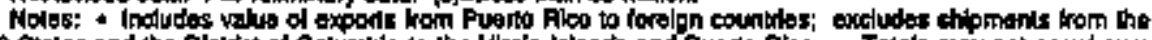

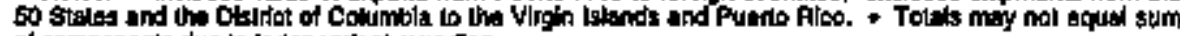
of corponents due is independent rounong.

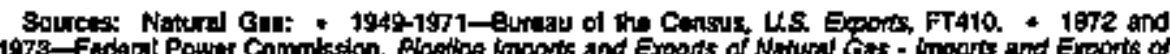

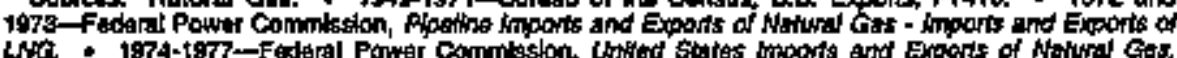

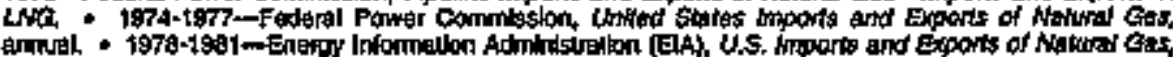

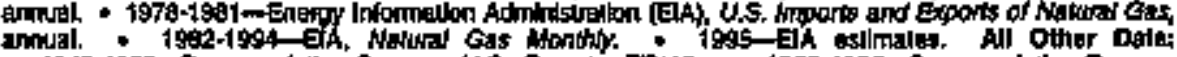

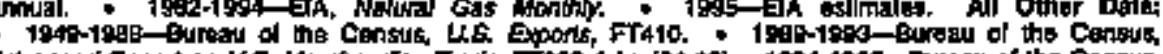

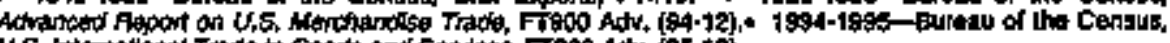

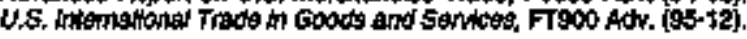




\section{Value of Fassin Fuel Not imparts}

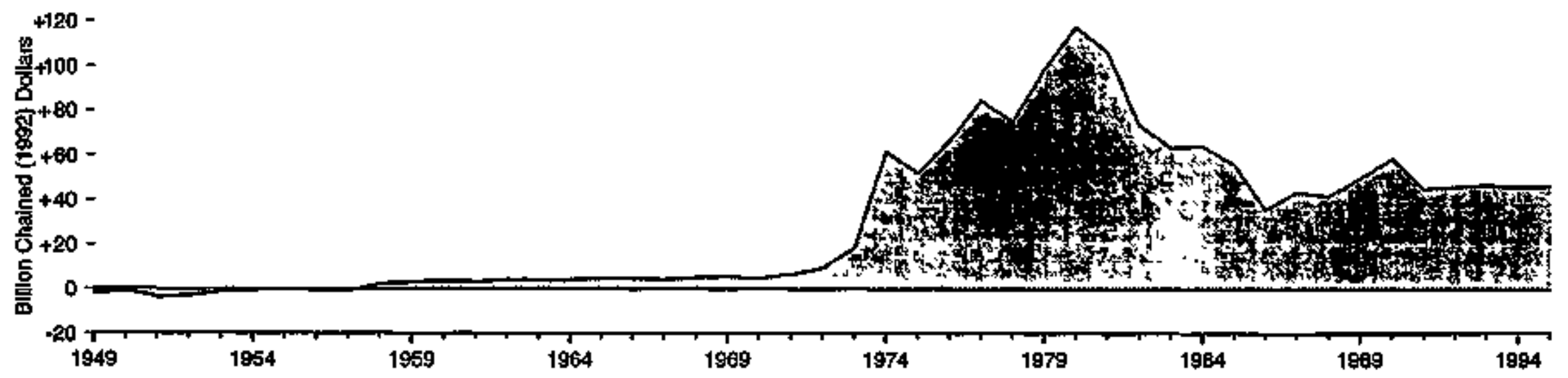

\section{Value of Fostsil Fued Net Imports by Fued}

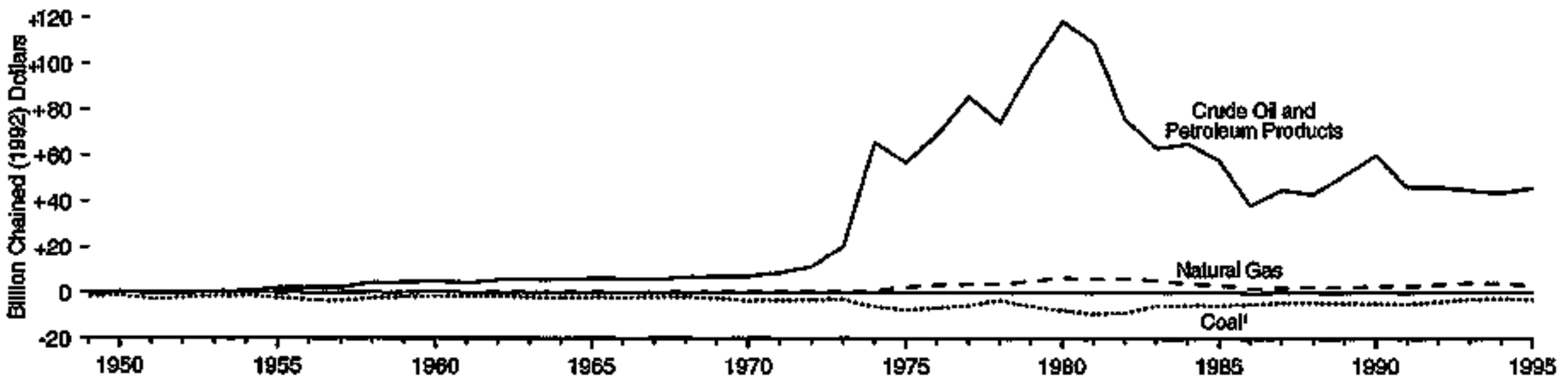

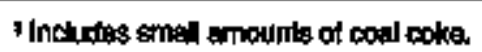

Notes: * Negalive not luports are not exports. * Prices are in cha'ned (1992) dollaxs, calcufoled

by usthg gross dormestic product impilett price delialors. See Appendlx E Soureot Tabla 3.5. 
Table 3.5 Value of Fossil Fuel Net Imports, 1949-1995

(Betlion Dollars)

\begin{tabular}{|c|c|c|c|c|c|c|c|c|c|c|c|c|}
\hline \multirow[b]{2}{*}{ Year } & \multicolumn{2}{|c|}{ Cost } & \multicolumn{2}{|c|}{ cal coks } & \multicolumn{2}{|c|}{ 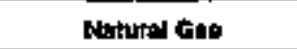 } & \multicolumn{2}{|c|}{ Crude 여 } & \multicolumn{2}{|c|}{ Patealaum Products } & \multicolumn{2}{|c|}{ Tokal } \\
\hline & Nomkinal & Pall & Hominat & Feal ' & Nomplonat & Fieal' & Norrinat & Rasd 1 & Nominal & Pegal 1 & Narranal & Bemal ${ }^{*}$ \\
\hline 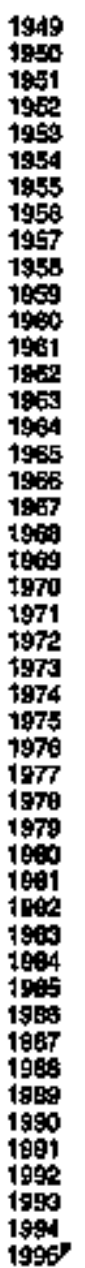 & 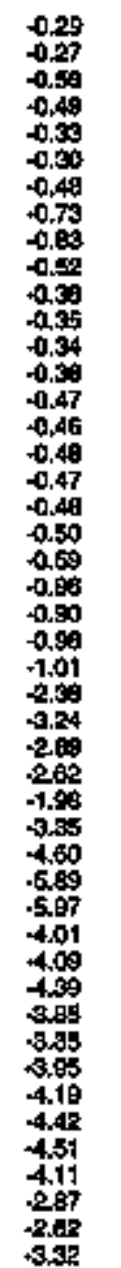 & 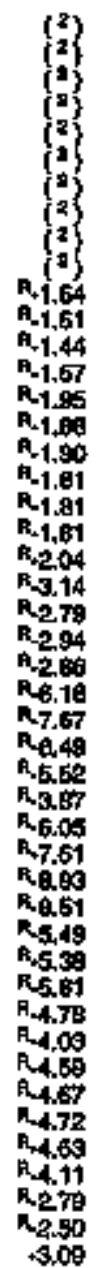 & 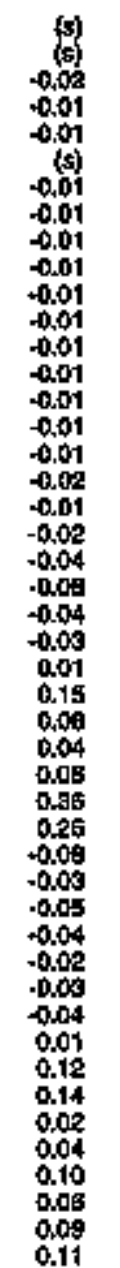 & 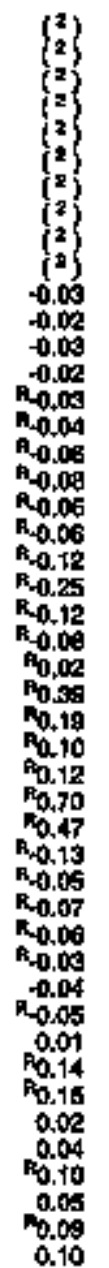 & 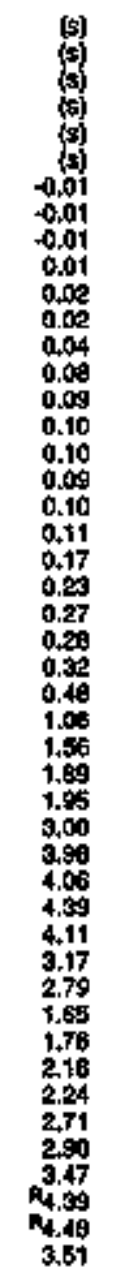 & 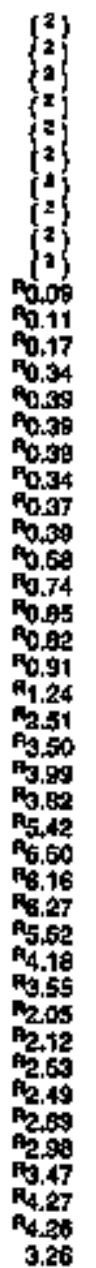 & 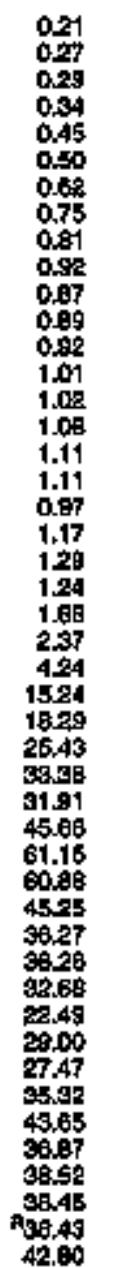 & 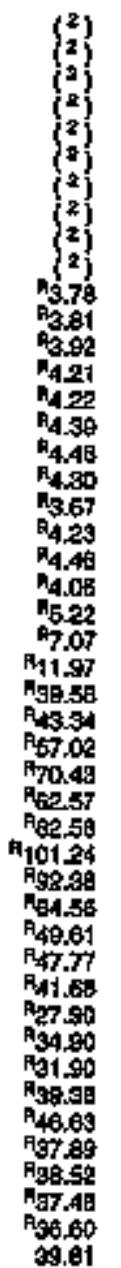 & 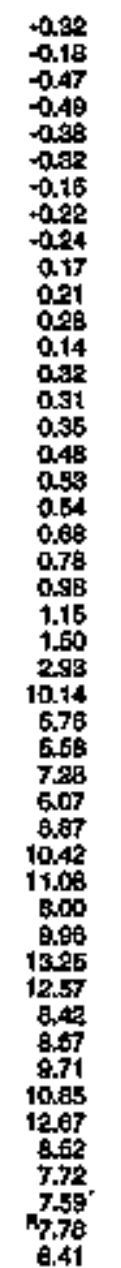 & 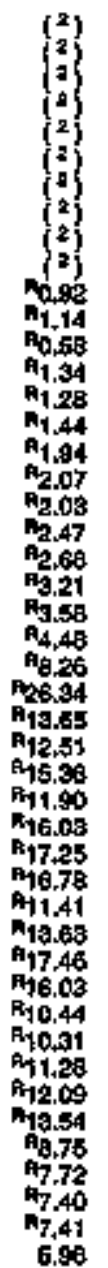 & 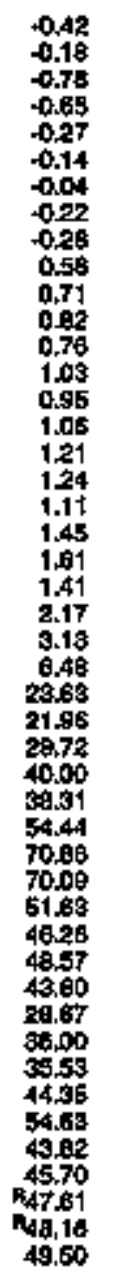 & 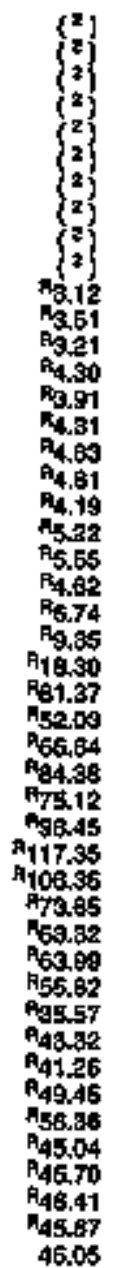 \\
\hline
\end{tabular}

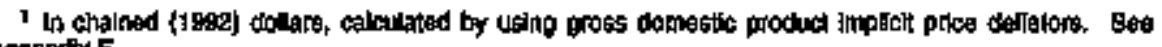
kpondik E.

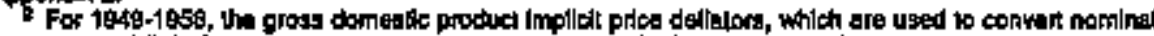

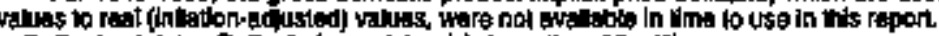

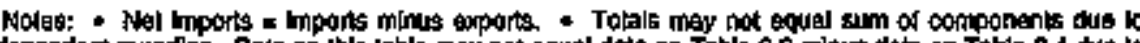

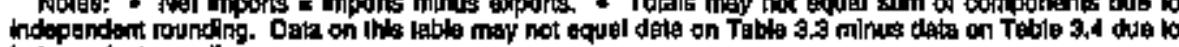
indepandert round

Souncest Tebles 3.3 and 3.4 .

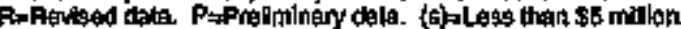




\section{Figure 3.6 Energy Expenditures and Price Indices, 1970-1993}

Energy Expendltures

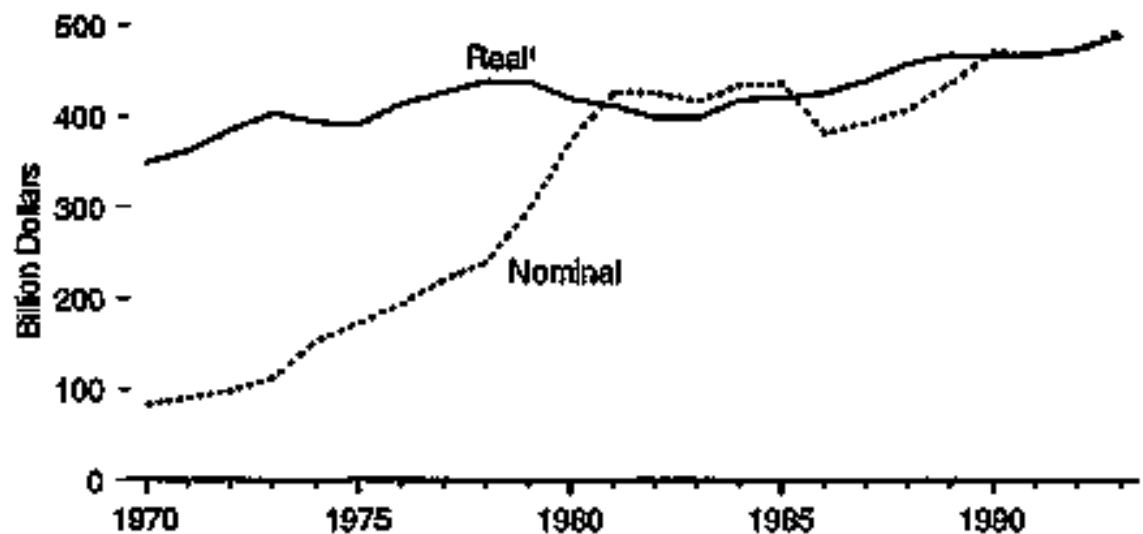

Energy Expenditures as a Share of Gross Domestic Purchases

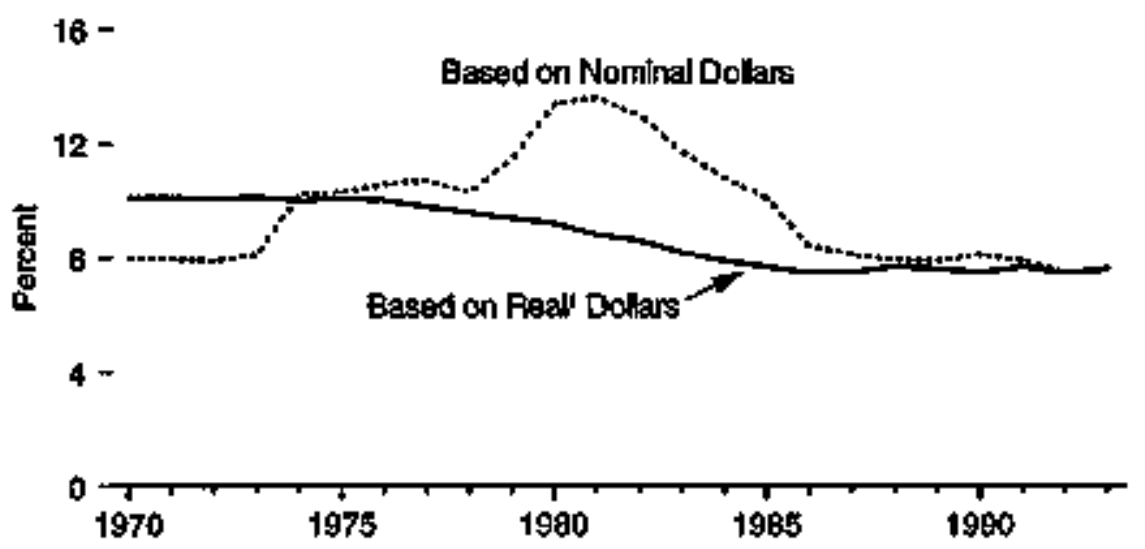

\section{Energy Price Indicas}

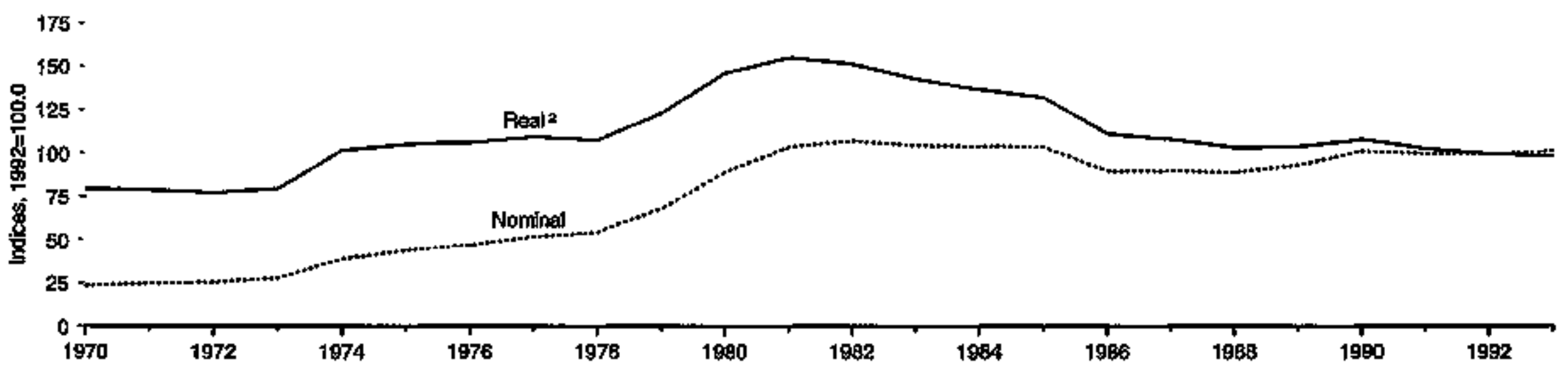

* For explanation, see Tabla 3.8, footnote 4.

Source; Tames 3.6 . 
Table 3.6 Energy Expenditures and Price Indices, 1970-1993

\begin{tabular}{|c|c|c|c|c|c|c|c|c|c|}
\hline \multirow[b]{2}{*}{ Yost } & \multicolumn{2}{|c|}{ Energy Expendiburs: } & \multicolumn{2}{|c|}{ Gross Domestis Purohuses ' } & \multicolumn{2}{|c|}{ 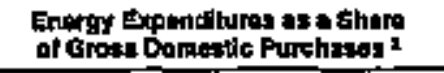 } & \multirow[b]{2}{*}{ 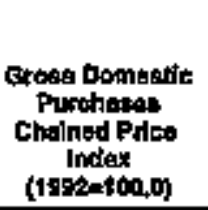 } & \multicolumn{2}{|c|}{$\begin{array}{l}\text { Energy Expendiures } \\
\text { Chalned Price Inolicas at }\end{array}$} \\
\hline & 泉lllon bollart & $\begin{array}{l}\text { Bpilish Chained } \\
\text { (1959) Dollars' }\end{array}$ & Gillen Dollus: & 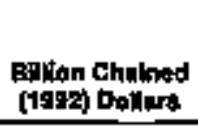 & 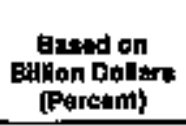 & 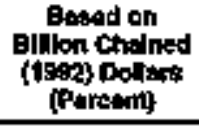 & & $\begin{array}{c}\text { Momintal } \\
(1902=100.0)\end{array}$ & $\begin{array}{c}\text { Pa: } \\
\text { (t992 }=100.0)\end{array}$ \\
\hline 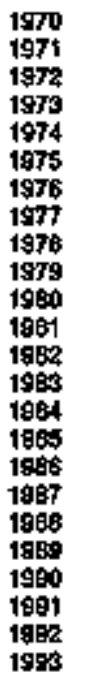 & 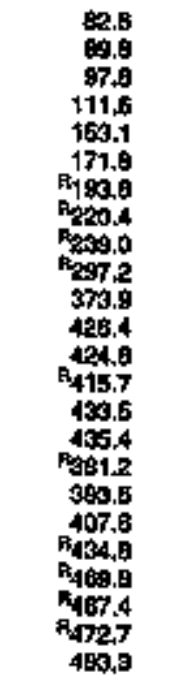 & 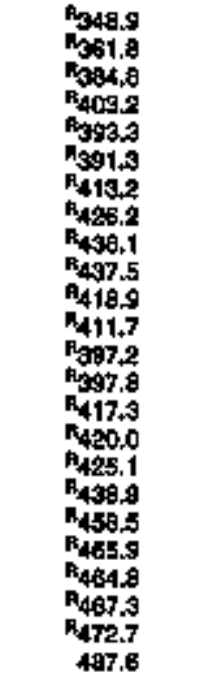 & 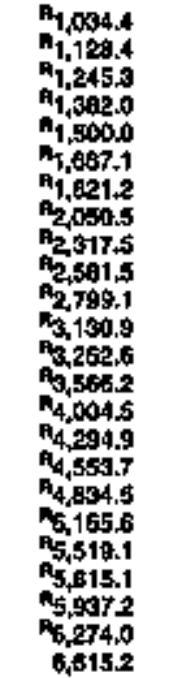 & 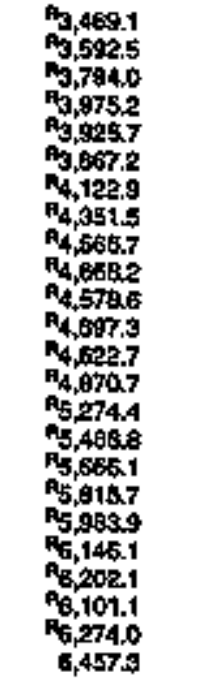 & 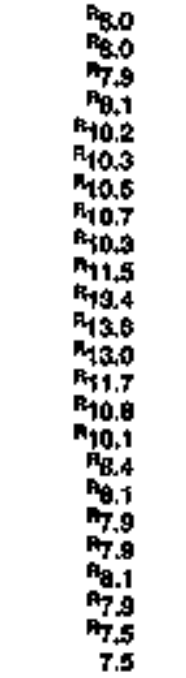 & 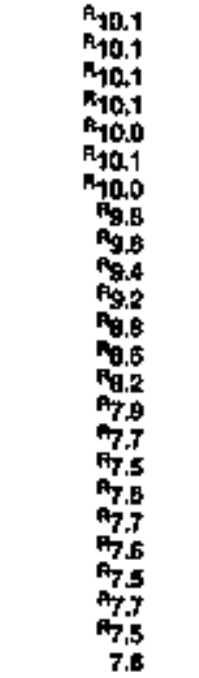 & 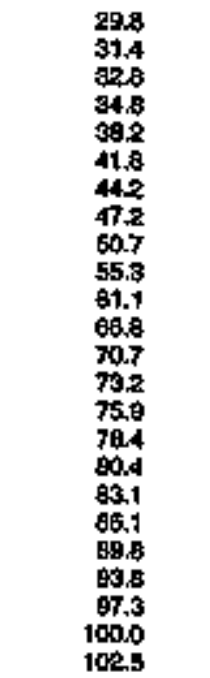 & 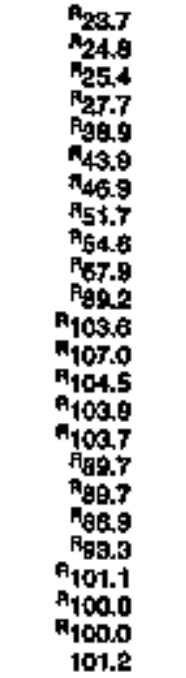 & 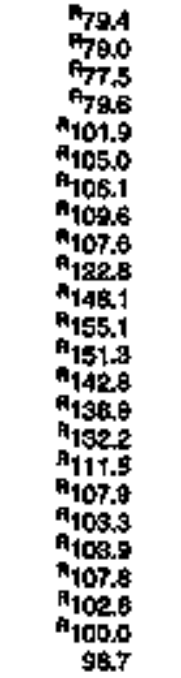 \\
\hline
\end{tabular}

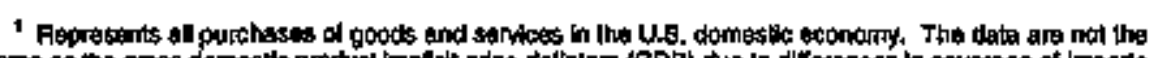

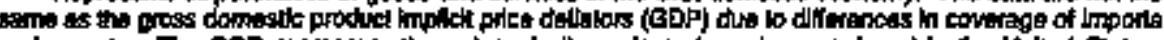

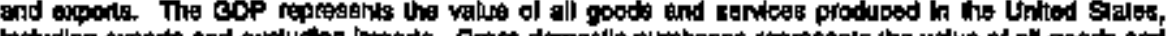

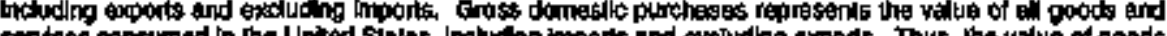

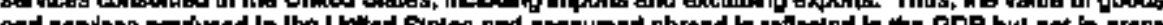

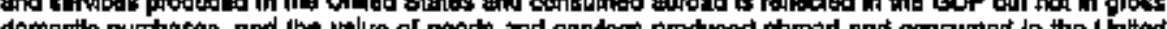

Chastalons basad on unrounded data.

The nominal chaingdenefgy index is batsed on the same methodolowy as used for the chained energy

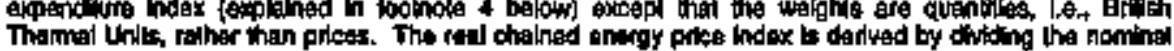

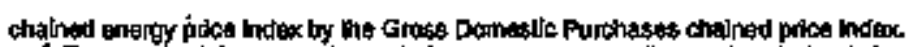

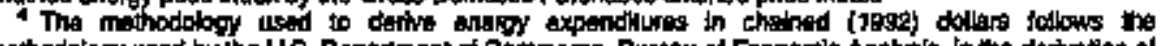

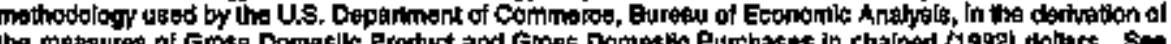

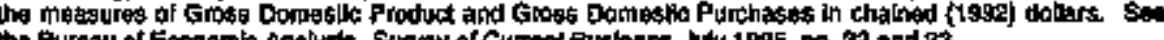

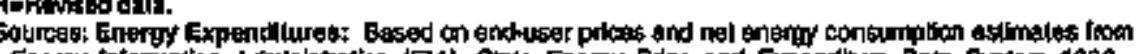

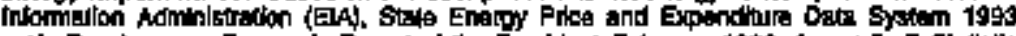

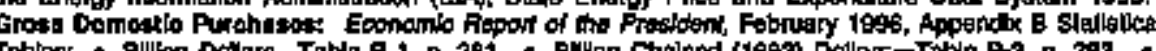

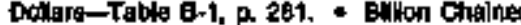

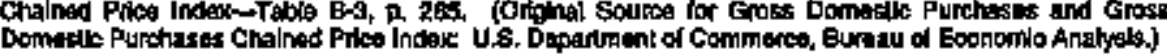




\section{Figure 3.7 Energy Price Estimates by Sector, 1985-1993}

\section{EndHose sertor}

15 -
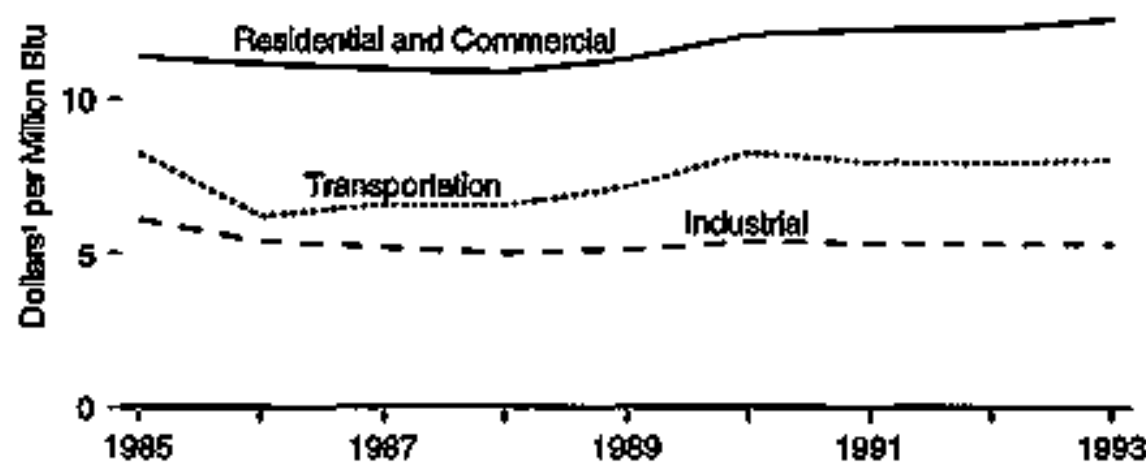

\section{Inxustrital Sobtor}

$20-$

趸 15 -

둥

10 -

5 - Pelroleum Products

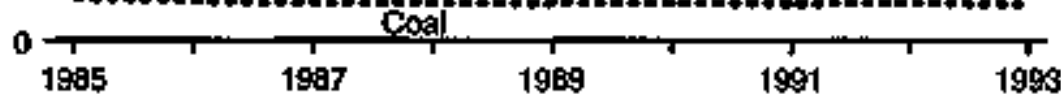

Residuntlal and Commertial sector

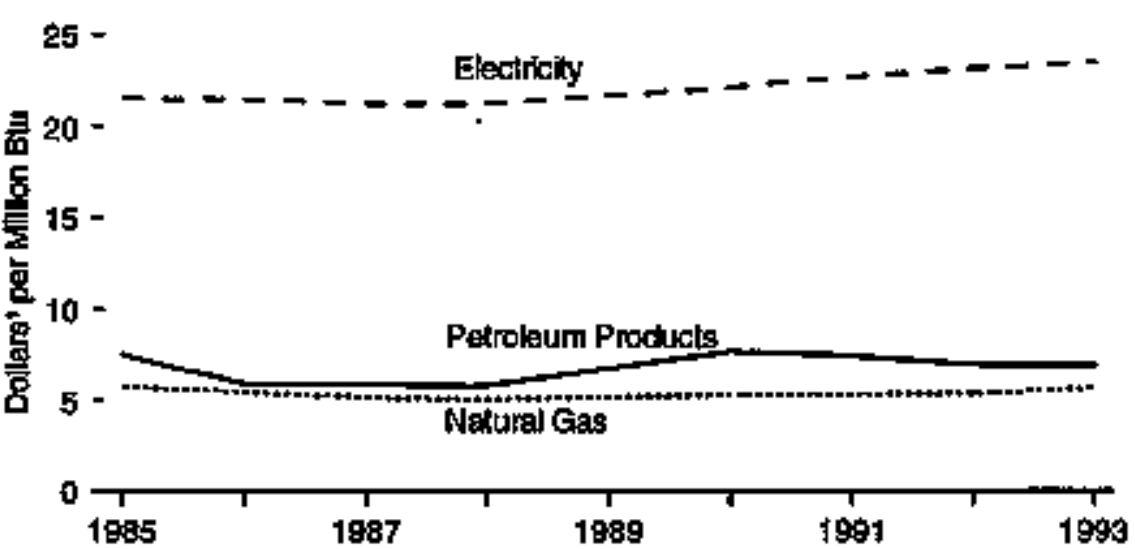

Eloctric Utilitios

6-

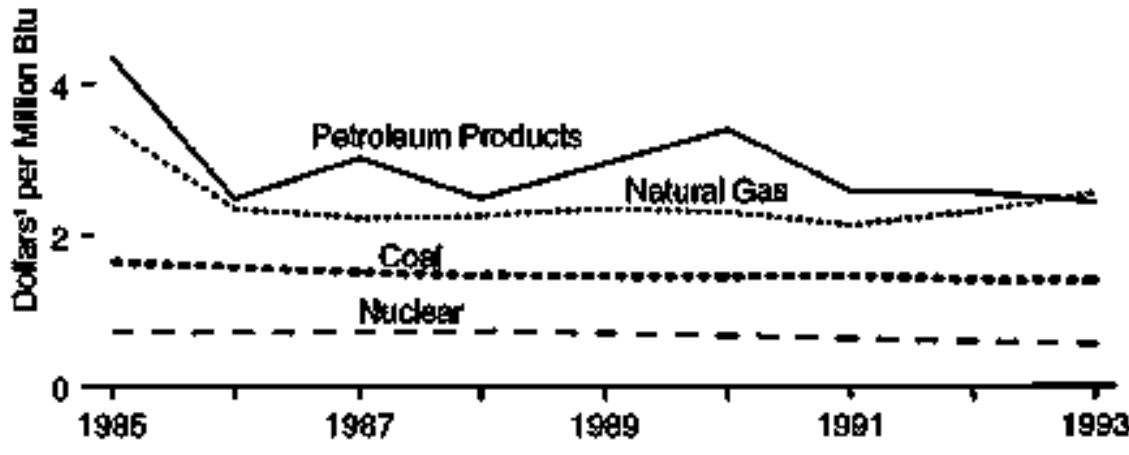

1 Nomlnal doulars.

Note: Ceceuse verticel scales difler, glaphis should not be comparad

Source: Table 3.7. 
Table 3.7 Energy Price Estimates by Sector, 1970, 1975, 1980, and 1985-1998 (Dollars' per Maltion Btu)

\begin{tabular}{|c|c|c|c|c|c|c|c|c|c|c|c|c|}
\hline Steotor & 1970 & 1976 & 1900 & 1sts & 1998 & ty & 1008 & $19: 9$ & 1980 & 1991 & 1982 & 1893 \\
\hline 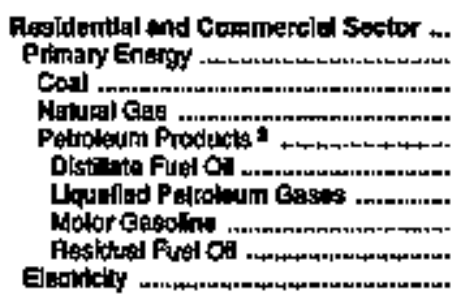 & $\begin{array}{l}2.07 \\
1.08 \\
0.73 \\
0.98 \\
1.38 \\
1.34 \\
1.98 \\
2.88 \\
0.45 \\
6.99\end{array}$ & $\begin{array}{r}3.99 \\
1.97 \\
1.76 \\
1.69 \\
2.99 \\
2.66 \\
3.81 \\
4.60 \\
1.91 \\
50.21\end{array}$ & $\begin{array}{r}7.66 \\
4.56 \\
2.10 \\
3.50 \\
6.56 \\
6.86 \\
7.50 \\
9.77 \\
4.72 \\
15.85\end{array}$ & $\begin{array}{r}11.37 \\
6.12 \\
2.37 \\
6.73 \\
7.47 \\
7.32 \\
9.02 \\
0.05 \\
4.50 \\
21.50\end{array}$ & $\begin{array}{r}11.14 \\
5.49 \\
2.29 \\
5.42 \\
5.89 \\
5.70 \\
6.51 \\
6.77 \\
2.70 \\
21.45\end{array}$ & $\begin{array}{r}10.99 \\
5.7 \\
200 \\
6.12 \\
5.87 \\
5.49 \\
6.49 \\
7.22 \\
3.79 \\
21.19\end{array}$ & $\begin{array}{r}10.90 \\
5.17 \\
1.97 \\
5.09 \\
5.78 \\
5.49 \\
8.36 \\
7.33 \\
2.52 \\
21.19\end{array}$ & $\begin{array}{r}11.31 \\
5.49 \\
1.99 \\
5.16 \\
6.72 \\
6.20 \\
9.92 \\
8.93 \\
2.99 \\
21.94\end{array}$ & $\begin{array}{r}12.09 \\
5.78 \\
2.17 \\
5.28 \\
7.67 \\
7.86 \\
10.59 \\
9.18 \\
3.41 \\
2.12\end{array}$ & $\begin{array}{r}12.28 \\
5.71 \\
R_{2} .88 \\
6.30 \\
7.40 \\
6.80 \\
10.65 \\
9.96 \\
2.51 \\
22.70\end{array}$ & $\begin{array}{r}12.29 \\
5.66 \\
A_{2.18} \\
5.36 \\
6.97 \\
5.38 \\
10.09 \\
0.07 \\
2.68 \\
20.16\end{array}$ & $\begin{array}{r}12.56 \\
5.55 \\
2.7 \\
5.69 \\
6.89 \\
5.24 \\
10.04 \\
9.39 \\
2.75 \\
23.48\end{array}$ \\
\hline 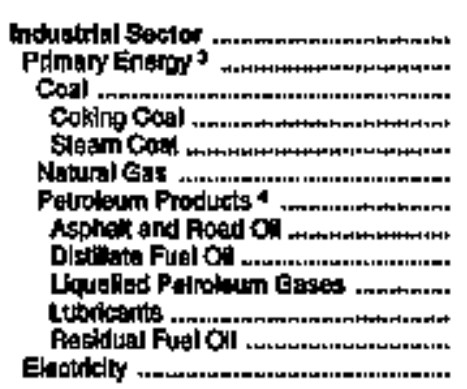 & $\begin{array}{l}0.03 \\
0.60 \\
0.45 \\
0.45 \\
0.44 \\
0.31 \\
0.98 \\
0.68 \\
0.72 \\
1.10 \\
6.09 \\
0.46 \\
2.99\end{array}$ & $\begin{array}{l}2.20 \\
1.66 \\
1.50 \\
1.85 \\
1.29 \\
0.95 \\
2.41 \\
1.99 \\
2.23 \\
2.51 \\
7.48 \\
1.91 \\
5.07\end{array}$ & $\begin{array}{r}4.71 \\
3.77 \\
1.87 \\
2.10 \\
1.56 \\
2.58 \\
5.69 \\
3.68 \\
5.54 \\
5.10 \\
14.98 \\
3.69 \\
10.41\end{array}$ & $\begin{array}{r}0.09 \\
4,49 \\
1.89 \\
8.03 \\
1.01 \\
3.87 \\
6.40 \\
4.77 \\
5.10 \\
1.06 \\
17.61 \\
4.24 \\
14.57\end{array}$ & $\begin{array}{r}5.40 \\
3 ., 63 \\
1,80 \\
1.90 \\
1,75 \\
9.20 \\
4.60 \\
4.44 \\
9.76 \\
6.63 \\
15.59 \\
251 \\
14.45\end{array}$ & $\begin{array}{r}6.10 \\
2.60 \\
1.69 \\
1.74 \\
1.64 \\
2.89 \\
4.80 \\
3.60 \\
4.16 \\
6.16 \\
12.70 \\
2.87 \\
13.59\end{array}$ & $\begin{array}{r}5.09 \\
3.34 \\
1.69 \\
1.79 \\
1.61 \\
2.90 \\
4.48 \\
9.38 \\
3.98 \\
4.97 \\
14.01 \\
2.34 \\
13.79\end{array}$ & 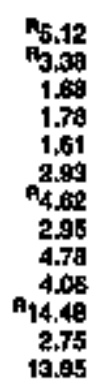 & $\begin{array}{r}5.40 \\
9.70 \\
1.69 \\
1.79 \\
1.68 \\
2.95 \\
25.37 \\
3.09 \\
5.68 \\
5.37 \\
n_{14.60} \\
3.10 \\
13.92\end{array}$ & 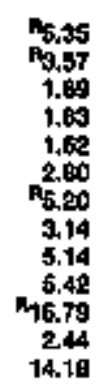 & 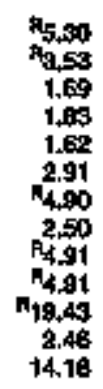 & $\begin{array}{r}5.30 \\
3.95 \\
1.98 \\
1.79 \\
1.99 \\
3.16 \\
4.79 \\
2.99 \\
4.79 \\
4.74 \\
18.94 \\
2.41 \\
14.212\end{array}$ \\
\hline 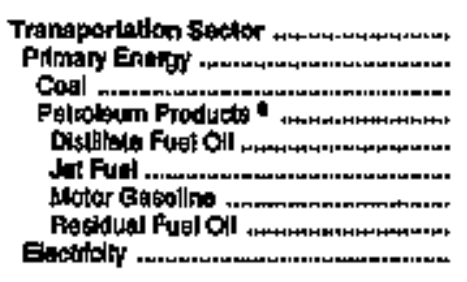 & $\begin{array}{l}2.31 \\
2.31 \\
0.41 \\
2.31 \\
1.31 \\
0.79 \\
2.85 \\
0.38 \\
4.55\end{array}$ & $\begin{array}{r}4,00 \\
4,02 \\
1.28 \\
1,02 \\
2,00 \\
2.05 \\
4,84 \\
1,72 \\
11,72\end{array}$ & $\begin{array}{r}8.81 \\
8.60 \\
15) \\
6.60 \\
7.19 \\
6.38 \\
9.84 \\
3.81 \\
14.71\end{array}$ & $\begin{array}{l}0.28 \\
8.25 \\
(5) \\
8.25 \\
7.50 \\
5.51 \\
0.05 \\
4.36 \\
18.74\end{array}$ & 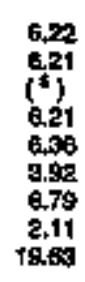 & $\begin{array}{l}6.57 \\
6.56 \\
(5) \\
6.66 \\
9.75 \\
400 \\
7.22 \\
2.64 \\
2.04\end{array}$ & $\begin{array}{l}6.56 \\
6.55 \\
61 \\
6.65 \\
6.55 \\
3.80 \\
7.32 \\
2.22 \\
2.25\end{array}$ & $\begin{array}{l}7.17 \\
7.10 \\
(8) \\
7.16 \\
7.16 \\
4.39 \\
8.01 \\
2.47 \\
22.98\end{array}$ & 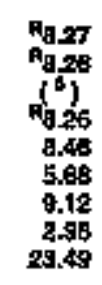 & 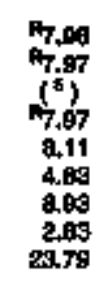 & 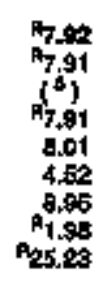 & $\begin{array}{c}\text { sos } \\
8.08 \\
16 \\
8.02 \\
800 \\
4.99 \\
907 \\
1.90 \\
28.09\end{array}$ \\
\hline 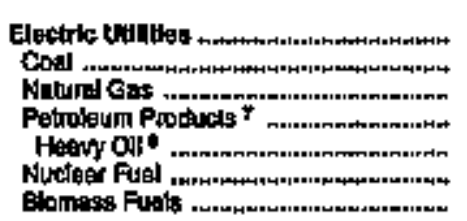 & $\begin{array}{l}0.32 \\
0.31 \\
0,23 \\
0.42 \\
0.41 \\
0.19 \\
0.65\end{array}$ & $\begin{array}{l}0.06 \\
0.82 \\
0.75 \\
200 \\
1.09 \\
0.24 \\
0.92\end{array}$ & $\begin{array}{l}t .76 \\
1.35 \\
2.20 \\
4.94 \\
1.25 \\
0.40 \\
1,74\end{array}$ & $\begin{array}{l}1.65 \\
1.05 \\
3.43 \\
4.36 \\
4.24 \\
0.71 \\
0.79\end{array}$ & $\begin{array}{l}1.55 \\
1.50 \\
2.55 \\
2.46 \\
2.42 \\
0.70 \\
0.32\end{array}$ & $\begin{array}{l}1.54 \\
1,51 \\
2.24 \\
3,04 \\
2.97 \\
0.71 \\
0.93\end{array}$ & $\begin{array}{l}1.45 \\
1.47 \\
2.48 \\
2.49 \\
2.41 \\
0.73 \\
0.87\end{array}$ & $\begin{array}{l}1.49 \\
1.45 \\
2.38 \\
2.96 \\
2.85 \\
0.70 \\
0.69\end{array}$ & $\begin{array}{l}1.96 \\
1.45 \\
2.39 \\
3.41 \\
3.30 \\
0.67 \\
0.52\end{array}$ & $\begin{array}{l}1.37 \\
1.45 \\
2.44 \\
2.69 \\
2.46 \\
0.69 \\
0.59\end{array}$ & $\begin{array}{r}1.34 \\
1.41 \\
2.32 \\
2.58 \\
2.46 \\
0.59 \\
0.56\end{array}$ & $\begin{array}{l}1.35 \\
1.39 \\
2.58 \\
2.45 \\
2.37 \\
0.56 \\
0.53\end{array}$ \\
\hline
\end{tabular}

1 Nominal dolabs,

If in eddillon to lisiod products, includes kerosene.

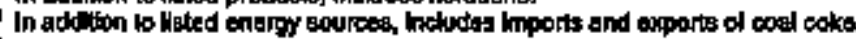

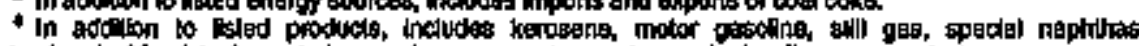

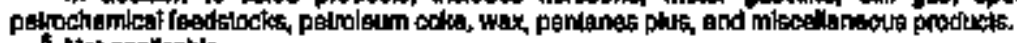

Not applinabla.

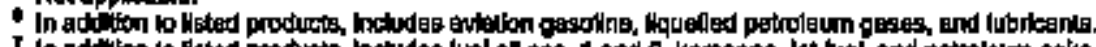

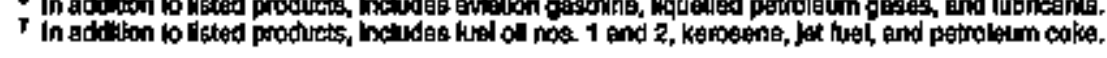

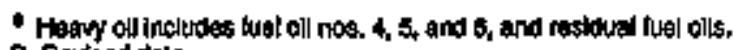

Apherised dala

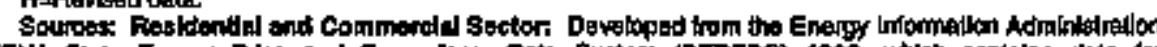

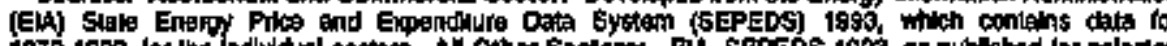

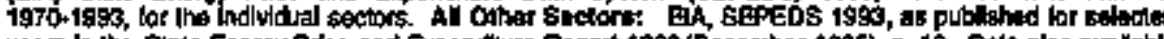

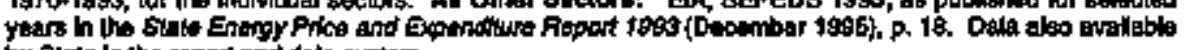
by Stats hi the reporl end data system. 
Totad

600-

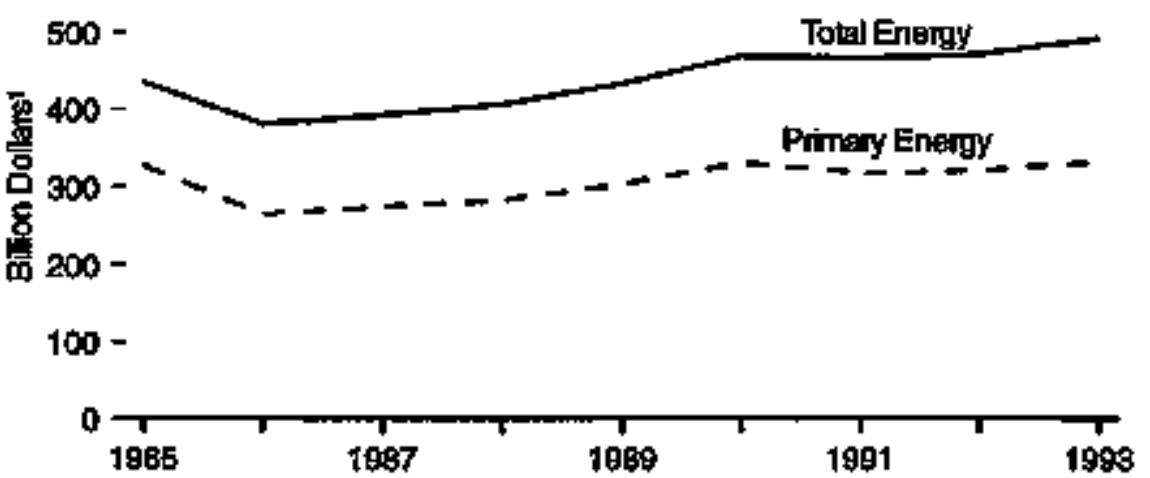

\section{By Selected Petroleum Prodtsot}

$130-$

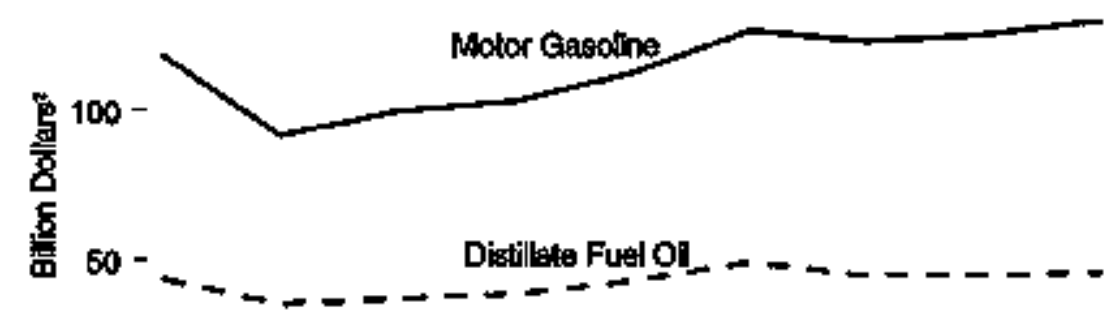

Residual Fu영 Oit

\begin{tabular}{|c|c|c|c|}
\hline 1985 & 1987 & 1809 & 1991 \\
\hline
\end{tabular}

\section{By Fossil Fuel}

$300-$

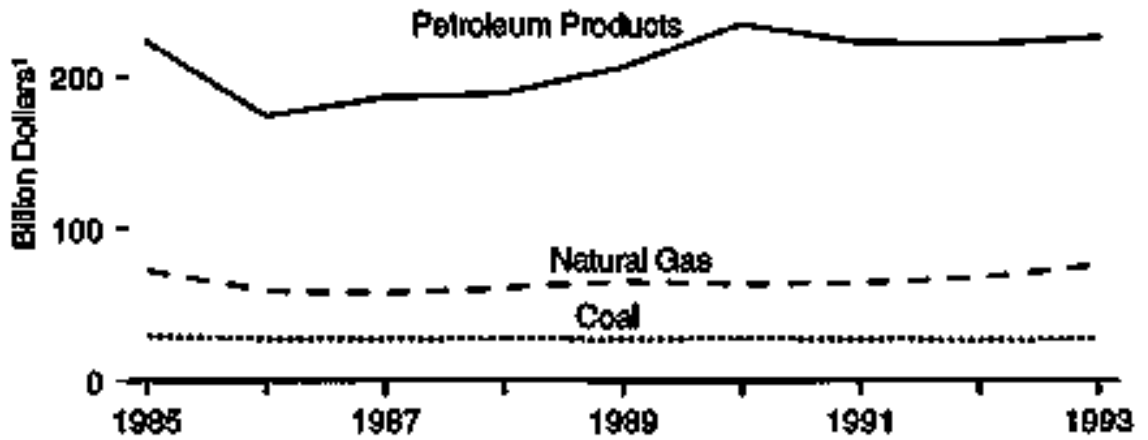

Por Caplta

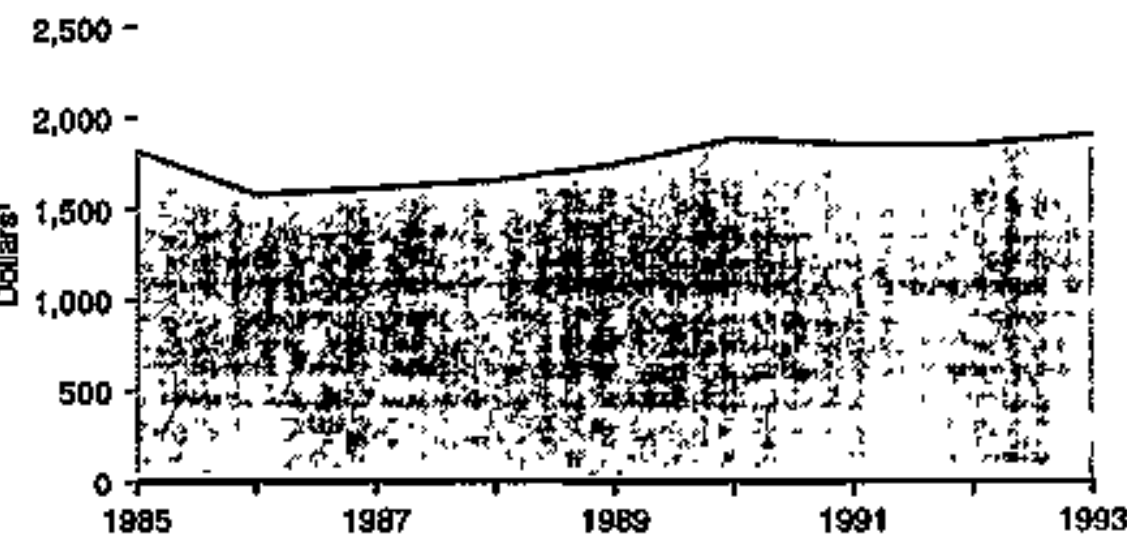

Source; Thatia 3.8

Note: Because verlcal scelos differ, graphe stould not be cempared. 
Table 3.8 Energy Expenditure Estimates, 1970, 1975, 1980, and 1985-1993

(Billon Dollars', Exsept as Noted)

\begin{tabular}{|c|c|c|c|c|c|c|c|c|c|c|c|c|}
\hline Energy souro & 1970 & tors & 190 & 195 & 19:46 & 1997 & 1989 & 1980 & 1990 & 1991 & $1 \% 2$ & 1090 \\
\hline 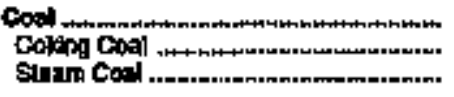 & $\begin{array}{l}4.6 \\
1.2 \\
3.4\end{array}$ & $\begin{array}{r}13.0 \\
3.7 \\
9.4\end{array}$ & $\begin{array}{r}22.6 \\
3.8 \\
16.9\end{array}$ & $\begin{array}{r}29.7 \\
27.7 \\
27.5\end{array}$ & $\begin{aligned} 27.9 \\
1,8 \\
26,1\end{aligned}$ & $\begin{aligned} 27.6 \\
1.7 \\
25.5\end{aligned}$ & $\begin{array}{r}26.4 \\
20 \\
28.4\end{array}$ & $\begin{array}{r}28.1 \\
1.9 \\
268\end{array}$ & $\begin{array}{r}28.4 \\
1,9 \\
25.5\end{array}$ & $\begin{array}{r}27.9 \\
1.7 \\
26.2\end{array}$ & $\begin{array}{r}27.4 \\
1.6 \\
25.6\end{array}$ & $\begin{array}{r}27.9 \\
1.5 \\
26.4\end{array}$ \\
\hline 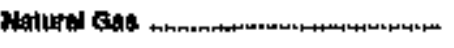 & 20.9 & 20.1 & 51.1 & 72.9 & 69.7 & 56.0 & 61.1 & 6.4 .4 & 64.1 & 64.7 & 66.4 & 76.0 \\
\hline 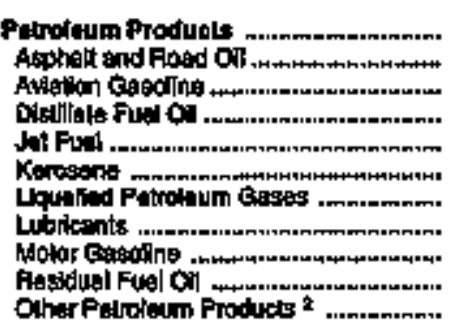 & $\begin{array}{r}46.1 \\
0.7 \\
0.2 \\
6.3 \\
1.4 \\
0.6 \\
2.4 \\
1.6 \\
31.6 \\
2.0 \\
1.2\end{array}$ & $\begin{array}{r}100.9 \\
1.9 \\
0.3 \\
15.7 \\
4.2 \\
0.9 \\
5.9 \\
2.3 \\
50.4 \\
10.4 \\
3.6\end{array}$ & $\begin{array}{r}230.4 \\
3.5 \\
0.6 \\
1.9 .5 \\
19.9 \\
2.3 \\
10.9 \\
6.9 \\
124.4 \\
21.6 \\
15.3\end{array}$ & $\begin{array}{r}23.2 \\
4.9 \\
0.5 \\
49.6 \\
14.7 \\
\$ .9 \\
13.1 \\
5.7 \\
118.0 \\
11.5 \\
9.2\end{array}$ & $\begin{array}{r}174.5 \\
4.7 \\
0.5 \\
9.0 \\
10.5 \\
1.3 \\
12.3 \\
4.9 \\
91.5 \\
7.5 \\
6.3\end{array}$ & $\begin{array}{r}t=8.4 \\
1.0 \\
0.3 \\
37.0 \\
11.4 \\
1.4 \\
12.4 \\
4.4 \\
09.8 \\
6.9 \\
7.9\end{array}$ & $\begin{array}{r}1993 \\
3.0 \\
0.4 \\
3.4 \\
11.3 \\
1.8 \\
123 \\
6.0 \\
102 \\
7.3 \\
8.4\end{array}$ & $\begin{array}{r}1208.7 \\
3.2 \\
0.4 \\
43.5 \\
13.4 \\
1.8 \\
17.8 \\
1.7 \\
112.6 \\
8.4 \\
7.3\end{array}$ & 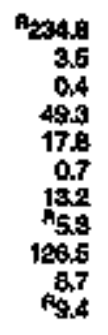 & $\begin{array}{r}r y .3 \\
3.4 \\
0.4 \\
43.1 \\
14.8 \\
0.8 \\
14.4 \\
12.4 \\
129.1 \\
6.8 \\
6.4\end{array}$ & 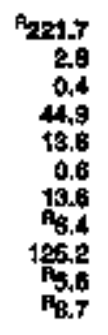 & $\begin{array}{r}226.8 \\
3.3 \\
0.3 \\
45.7 \\
13.0 \\
0.7 \\
73.2 \\
6.4 \\
130.0 \\
5.5 \\
7.7\end{array}$ \\
\hline 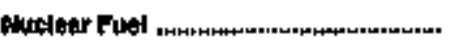 & (8) & 0.4 & 1.2 & 2.9 & 3.1 & 3.5 & 4,1 & 40 & 4.1 & 4.2 & 3.9 & 3.7 \\
\hline 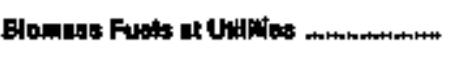 & (8) & (ㅂ) & $(a)$ & (s) & (a) & (s) & (a) & (a) & $|\xi|$ & (s) & $\Leftrightarrow$ & (6) \\
\hline 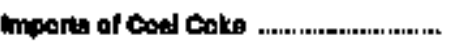 & (s) & 02 & D.t & (的) & [8] & 0.1 & as & as & 0.1 & 0.1 & o.t & 0.1 \\
\hline Exparts of Casi Colde 3 & 0.1 & $\cdot 0.1$ & -0.1 & -0.1 & -0.1 & (s) & -0.1 & -0.1 & 0.1 & -0.1 & (s) & a.t \\
\hline 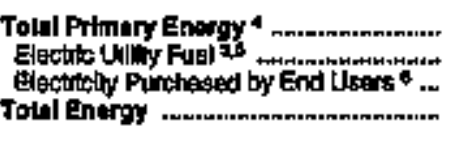 & $\begin{array}{l}6.8 \\
+1.3 \\
29.4 \\
20.8\end{array}$ & $\begin{array}{r}137.8 \\
+16.4 \\
50.7 \\
171.6\end{array}$ & $\begin{array}{c}313.2 \\
37.4 \\
\text { 38.1 } \\
375.6\end{array}$ & $\begin{array}{r}329.9 \\
-42.6 \\
149.2 \\
48.4\end{array}$ & $\begin{array}{r}255,2 \\
355.0 \\
\$ 61,0 \\
9391,2\end{array}$ & $\begin{array}{l}375,5 \\
38.7 \\
164.7 \\
393 ., 5\end{array}$ & $\begin{array}{l}295.0 \\
37.4 \\
162.1 \\
107.6\end{array}$ & 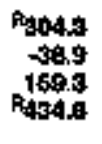 & $\begin{array}{r}\text { Pats } \\
-39.4 \\
179.7 \\
469.8\end{array}$ & $\begin{array}{r}\text { Antg.1 } \\
38,5 \\
184,8 \\
449,4\end{array}$ & $\begin{array}{r}\text { par1.5 } \\
35.8 \\
187.0 \\
4 \times 7.7\end{array}$ & $\begin{array}{r}396.4 \\
39.7 \\
190.6 \\
09.3\end{array}$ \\
\hline 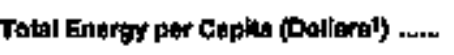 & 406 & $7 \theta 7$ & 1,600 & 1,824 & 1,681 & 1,617 & 1,650 & $A_{1,751}$ & $m, a 09$ & $A_{1,954}$ & $M, 664$ & 1,014 \\
\hline
\end{tabular}

$t$ Nombal dollewio.

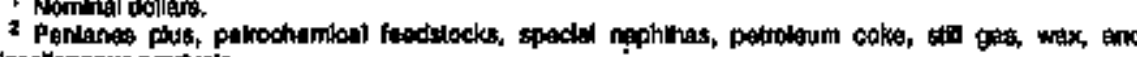

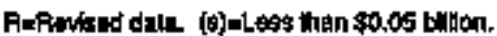

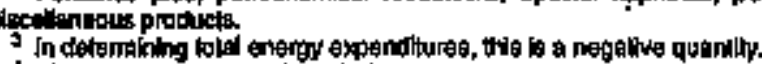

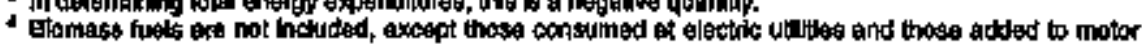

gassing.

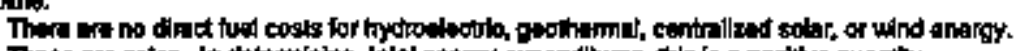

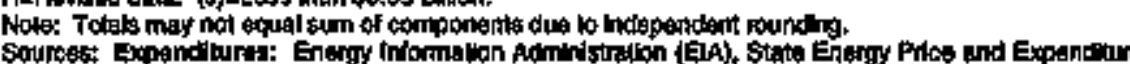

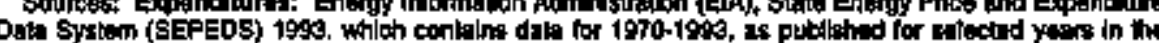

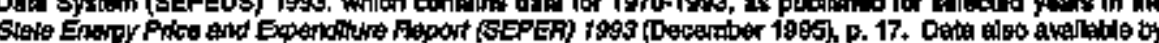

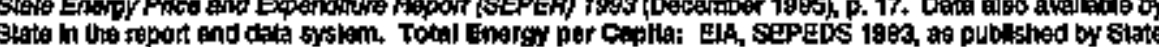

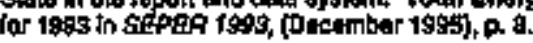


FR5 Shares of U.S. Total Production

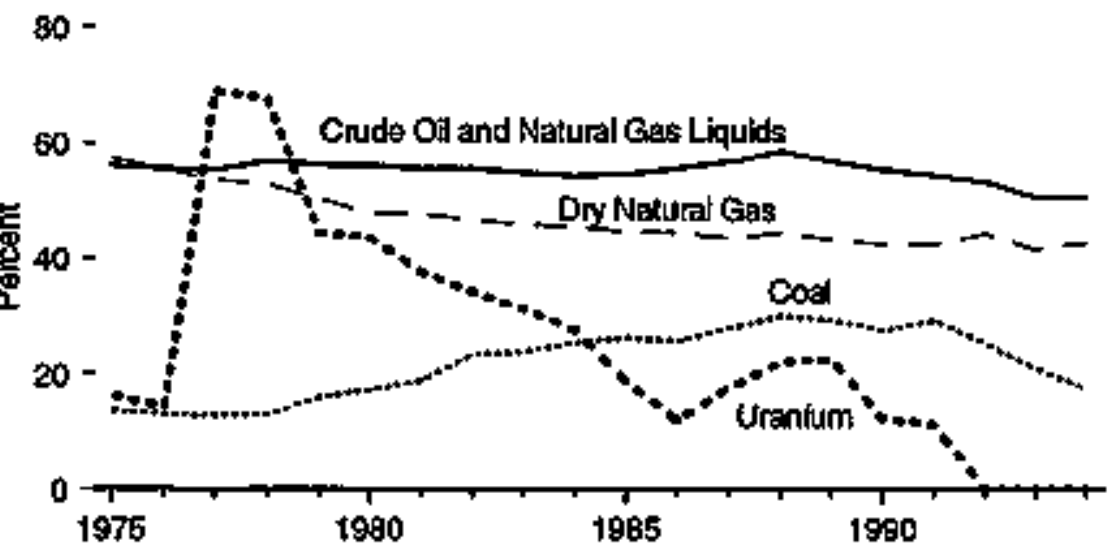

FRs Companies" Net hoome to Stockholders' Equlty

$30-$

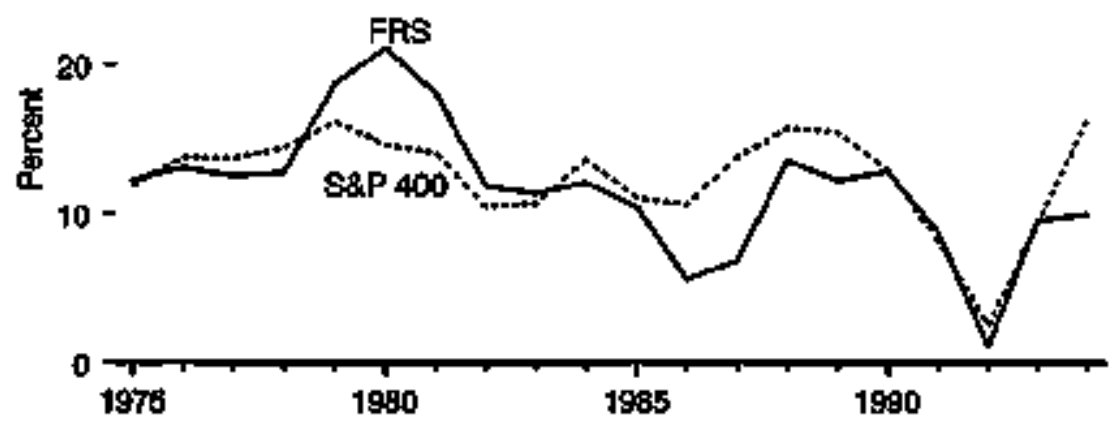

Fas shares of U.8. Refinlng Capaclty and Oulput

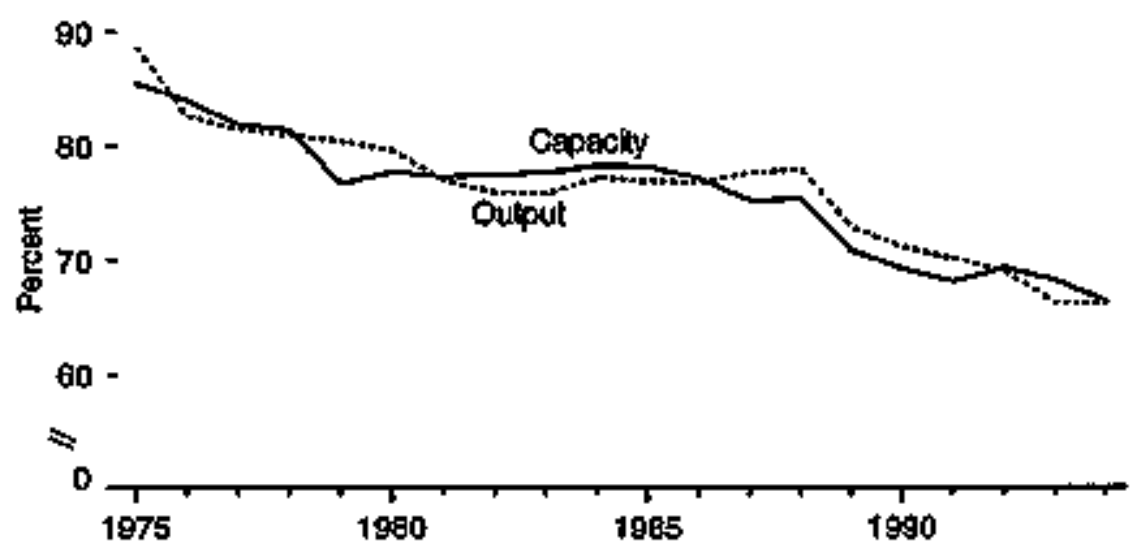

FRS Companlog' Indleators

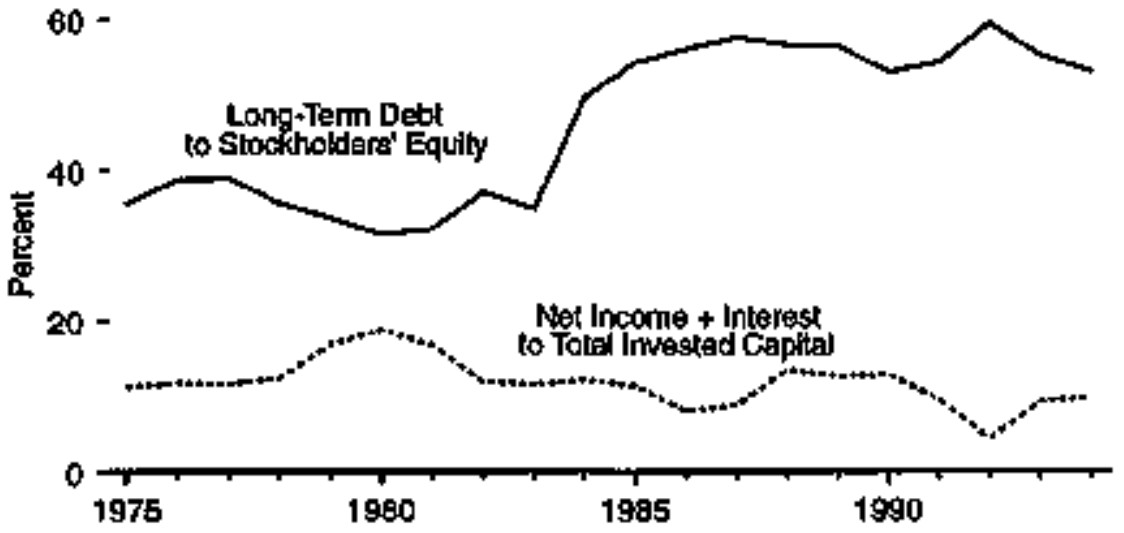


Table 3.9 FRS Companies' Operations, Selected Statistics, 1975-1994

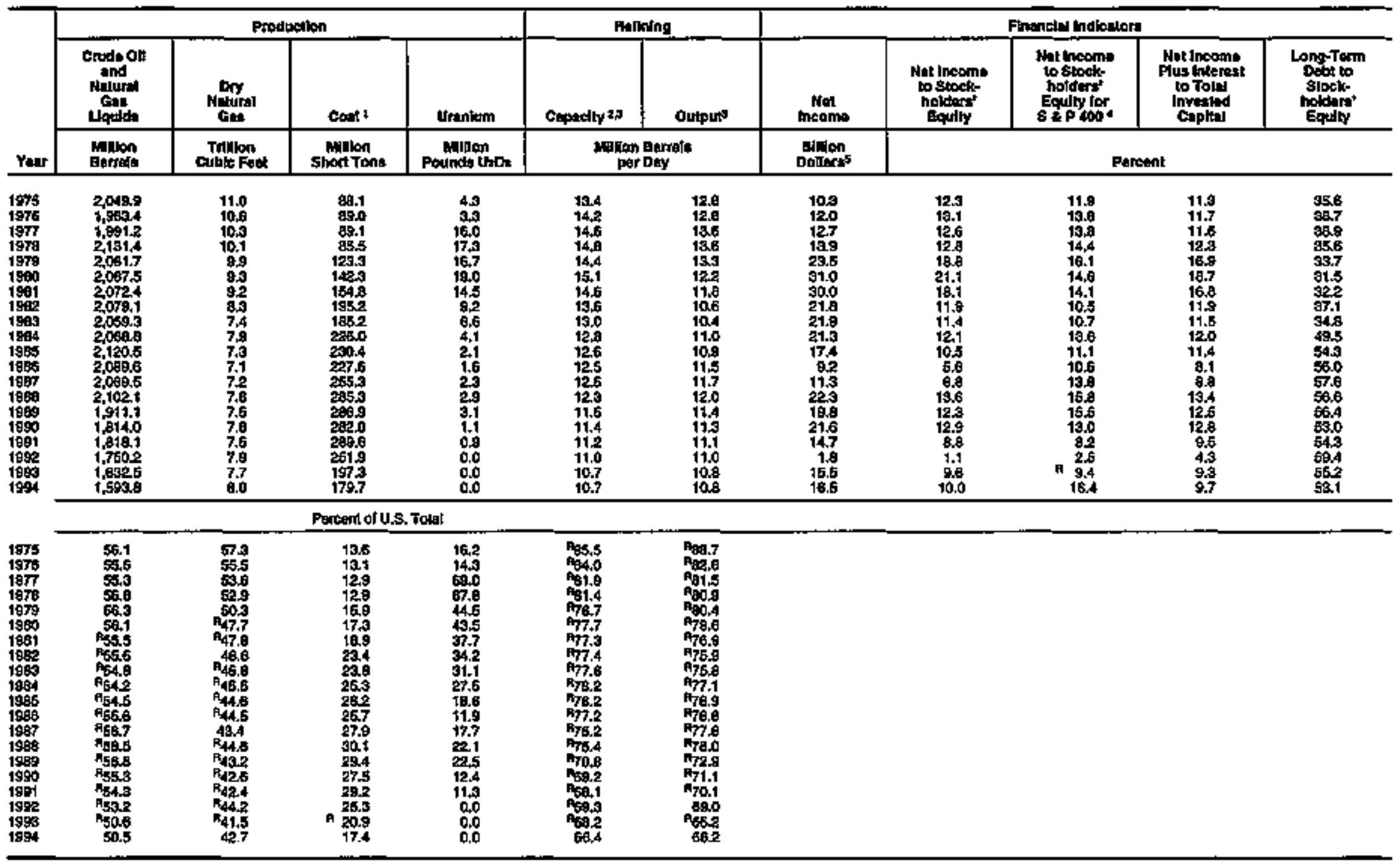

1 Elluminous cosh, cebblumbous cosl, and lorits. Z Oparabio capaciny as oi January 1 of tho lollowing your. hatudes Puant atco and the vingin telents.

Noles: - FRS is the Financted Reporting Systam (see Tabla 3.14). FAS Cnude OH Exd NBL and

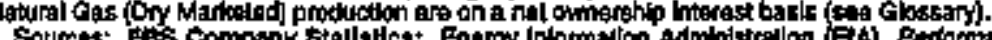

Whe 1 Slandard and Poor' 100 .

Raftertised data

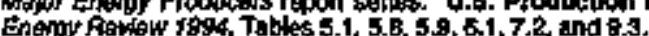




\section{Type of Busingss}

$+30-$

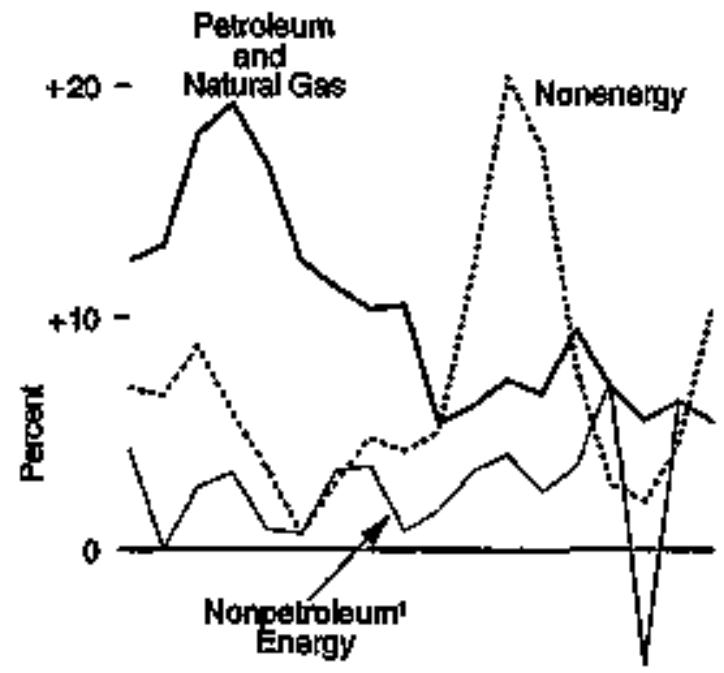

$-10-$

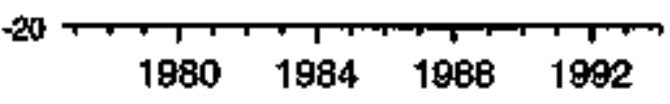

\section{Domostic Petrolown and Natural Gag}

$+30-$

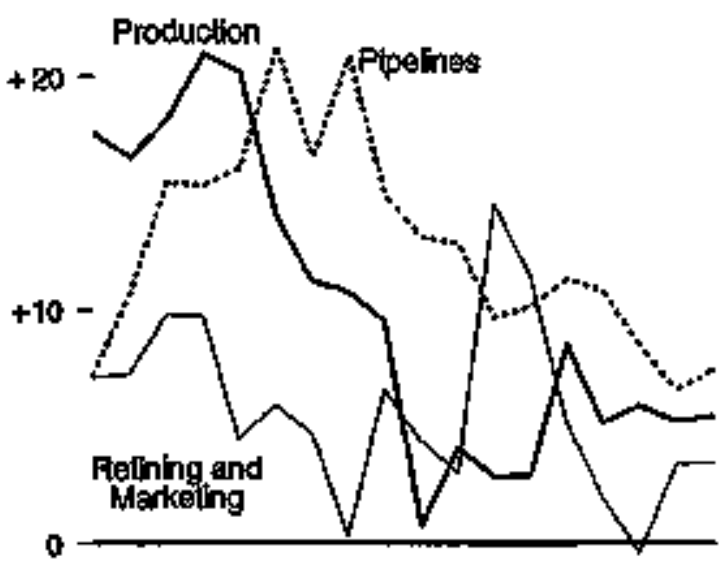

$-10-$

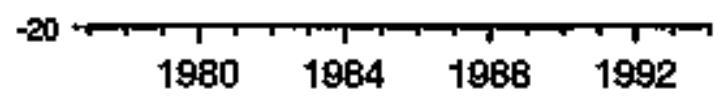

Forelgn Petroteum and Naturet Gas

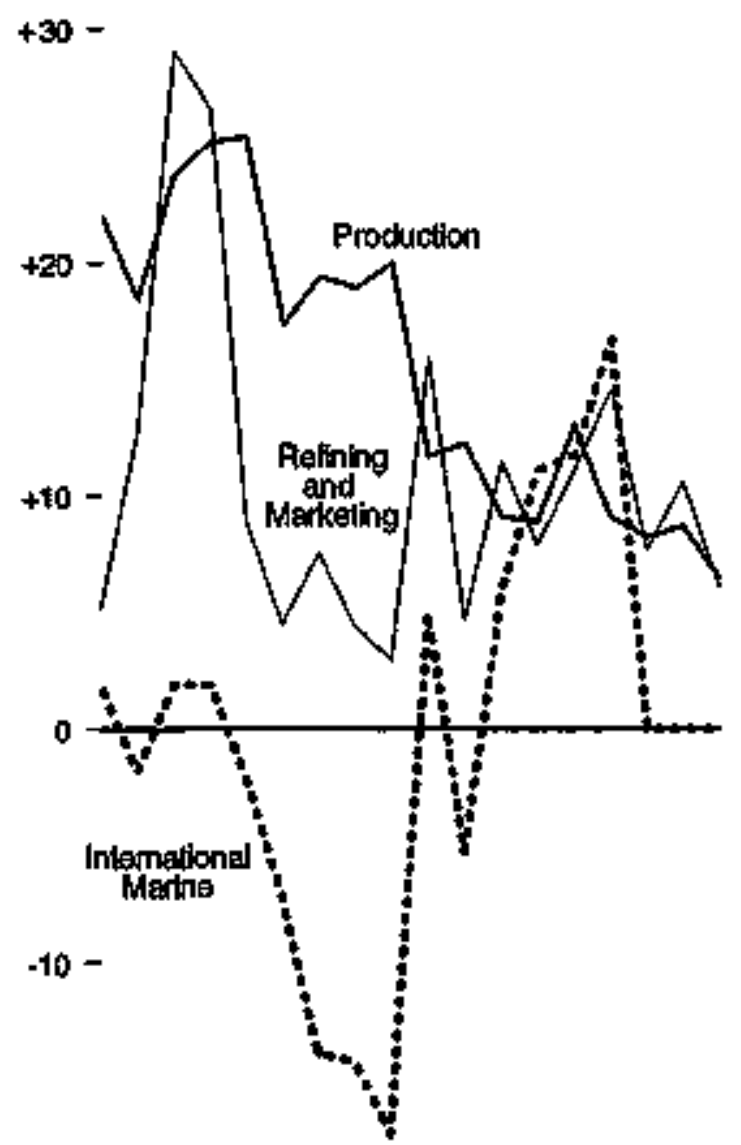

$-20$

$\begin{array}{llll}1980 & 1984 & 1988 & 1992\end{array}$


Table 3.10 FRS Compantes' Net Income, 1975-1994

(Billion Dotlars')

\begin{tabular}{|c|c|c|c|c|c|c|c|c|c|c|c|c|c|}
\hline \multirow[b]{2}{*}{ Your } & \multicolumn{5}{|c|}{ Type of Bushupess } & \multicolumn{4}{|c|}{ 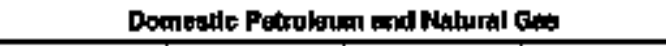 } & \multicolumn{4}{|c|}{ 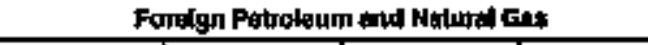 } \\
\hline & $\begin{array}{c}\text { Potroleus } \\
\text { ind } \\
\text { Whiral } \\
\text { Gas }\end{array}$ & Cond & $\begin{array}{l}\text { Nuolonr } \\
\text { nud } \\
\text { other } \\
\text { Enory }\end{array}$ & $\begin{array}{l}\text { Nop } \\
\text { onomy }\end{array}$ & Totel 3 & Producution & $\begin{array}{c}\text { Ronning } \\
\text { and } \\
\text { haikelkng }\end{array}$ & $\begin{array}{c}\text { Fralo } \\
\text { Ragufietad } \\
\text { Pypesines }\end{array}$ & Told 2 & Prodtedion & $\begin{array}{l}\text { Roninkng } \\
\text { and } \\
\text { Mathelng }\end{array}$ & $\begin{array}{c}\text { Intemathond } \\
\text { Miarino }\end{array}$ & Tolal ${ }^{2}$ \\
\hline $\begin{array}{l}1975 \\
1976 \\
1977 \\
1979 \\
1979 \\
19600 \\
1991 \\
19602 \\
1969 \\
1994 \\
1965 \\
1966 \\
1967 \\
19690 \\
1969 \\
1990 \\
19991 \\
19802 \\
1903 \\
1994\end{array}$ & $\begin{array}{r}N A \\
N A \\
13.0 \\
14.7 \\
23.0 \\
29.1 \\
29.5 \\
26.0 \\
240 \\
20.8 \\
24.8 \\
12.9 \\
148 \\
17.5 \\
18.2 \\
23.4 \\
17.7 \\
14.4 \\
16.5 \\
14.4\end{array}$ & $\begin{array}{l}0.4 \\
0.4 \\
0.2 \\
0.1 \\
0.3 \\
0.3 \\
0.4 \\
0.4 \\
0.5 \\
0.8 \\
0.4 \\
0.2 \\
0.4 \\
0.6 \\
0.4 \\
0.3 \\
0.6 \\
0.6 \\
0.4 \\
0.2\end{array}$ & 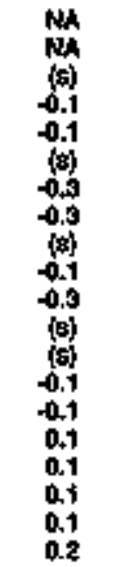 & $\begin{array}{c}M A \\
M A \\
1.7 \\
1.8 \\
28 \\
2.8 \\
1.6 \\
0.6 \\
1.8 \\
2.9 \\
2.5 \\
8.8 \\
7.1 \\
106 \\
8.7 \\
4.3 \\
1.6 \\
1.2 \\
2.7 \\
6.2\end{array}$ & $\begin{array}{r}10.3 \\
12.0 \\
12.7 \\
13.8 \\
23.5 \\
31.0 \\
30.0 \\
27.8 \\
21.0 \\
21.8 \\
17.4 \\
9.2 \\
11.3 \\
22.3 \\
10.8 \\
21.6 \\
14.7 \\
1.8 \\
15.5 \\
16.5\end{array}$ & $\begin{array}{c}M A \\
M A \\
6.4 \\
6.7 \\
9.4 \\
13.8 \\
16.8 \\
14.1 \\
18.9 \\
13.8 \\
12.1 \\
0.9 \\
4.7 \\
3.2 \\
3.1 \\
8.7 \\
5.1 \\
5.8 \\
4.8 \\
4.8\end{array}$ & $\begin{array}{l}M A \\
M A \\
1.5 \\
1.5 \\
2.3 \\
2.5 \\
1.3 \\
1.5 \\
1.8 \\
0.1 \\
2.8 \\
1.8 \\
1.1 \\
5.4 \\
4.5 \\
2.2 \\
0.8 \\
-0.2 \\
1.7 \\
1.8\end{array}$ & $\begin{array}{l}M A \\
N A \\
0.8 \\
12 \\
1.7 \\
1.7 \\
1.8 \\
2.3 \\
20 \\
2.5 \\
2.3 \\
2.6 \\
2.6 \\
20 \\
t .9 \\
21 \\
20 \\
2.1 \\
1.6 \\
1.8\end{array}$ & $\begin{array}{r}M A \\
M A \\
8.6 \\
9.5 \\
13.4 \\
17.0 \\
19.9 \\
18.3 \\
15.0 \\
15.0 \\
16.7 \\
5.9 \\
8.4 \\
10.6 \\
8.5 \\
12.8 \\
7.8 \\
7.5 \\
8.1 \\
8.5\end{array}$ & $\begin{array}{l}\text { NA } \\
N A \\
3.6 \\
3.5 \\
5.4 \\
6.9 \\
8.0 \\
6.1 \\
7.2 \\
7.5 \\
80 \\
4.7 \\
5.4 \\
4.3 \\
4.7 \\
7.4 \\
5.4 \\
4.7 \\
6.2 \\
4.0\end{array}$ & $\begin{array}{l}\text { NA } \\
\text { NA } \\
0.7 \\
1.8 \\
4.3 \\
4.3 \\
1.6 \\
0.8 \\
1.3 \\
0.7 \\
0.5 \\
2.0 \\
1.0 \\
2.4 \\
1.8 \\
2.8 \\
4.1 \\
2.2 \\
3.2 \\
2.0\end{array}$ & $\begin{array}{c}M A \\
M A \\
0.1 \\
-0.1 \\
0.1 \\
0.1 \\
-0.1 \\
-0.5 \\
0.5 \\
-0.4 \\
-0.4 \\
0.1 \\
-0.1 \\
0.1 \\
0.2 \\
0.2 \\
0.9 \\
(B) \\
(8) \\
(6)\end{array}$ & $\begin{array}{r}\text { MA } \\
\text { M.A } \\
4.4 \\
5.2 \\
9.7 \\
11.2 \\
9.6 \\
6.7 \\
9.2 \\
7.9 \\
9.1 \\
7.7 \\
6.4 \\
6.9 \\
6.7 \\
10.5 \\
9.6 \\
6.9 \\
0.4 \\
5.9\end{array}$ \\
\hline
\end{tabular}

1 Momintel tholate

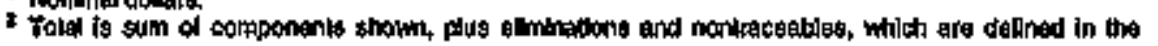

How: Fas is the Finenodd Reporlng System (seo Tablo 3. 14)

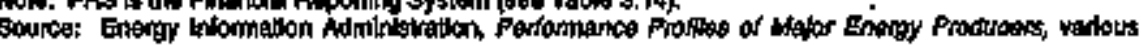

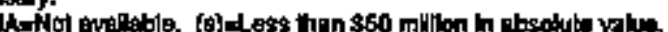




\section{Figure 3.11 FRS Companies' Net Investment in Place, 1975-1994}

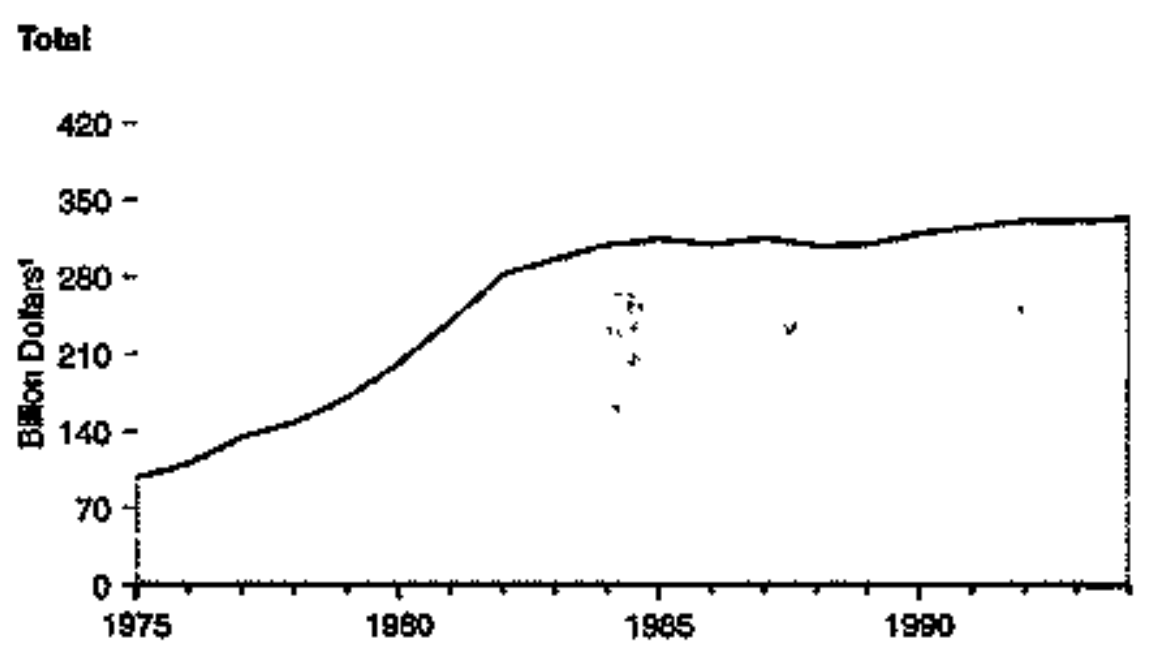

\section{Type of Business by Fuol}

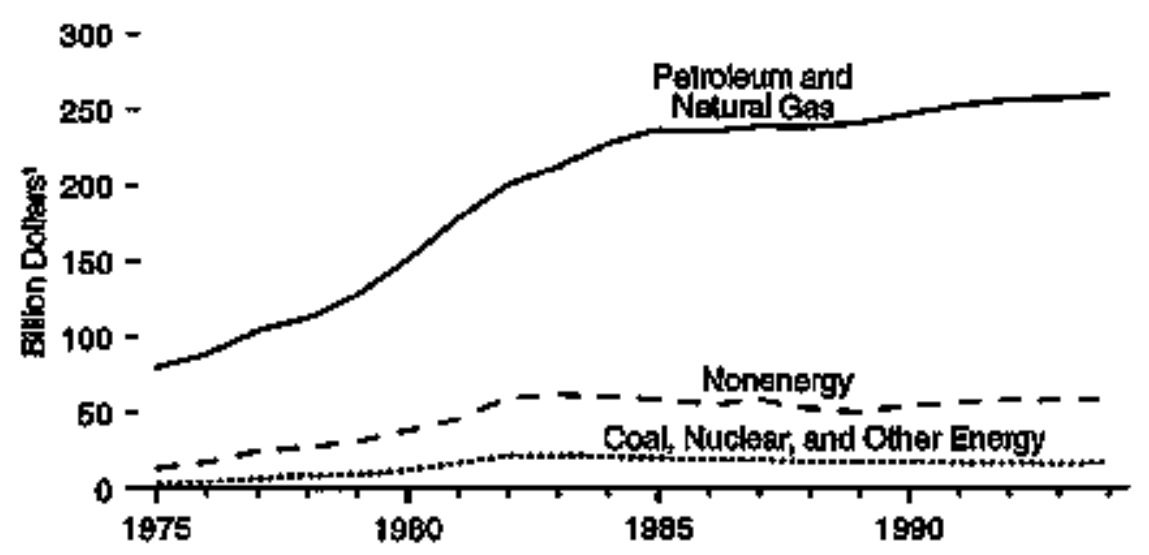

Domestic Pelrokum and Natural Gas

\section{Forolgn Potroleum and Natural Gas}
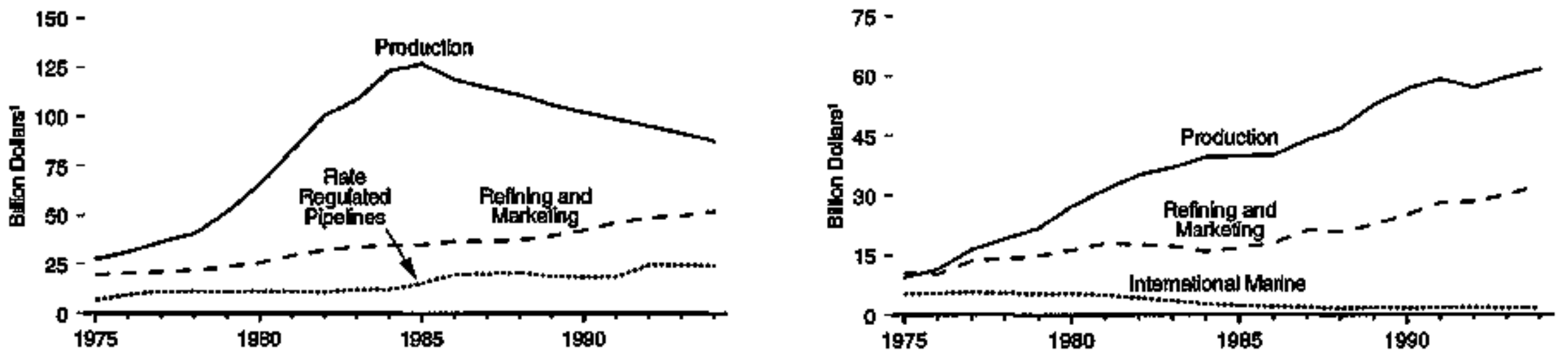

- Nominal collars.

Notes: - FFS Is the Finencial Reponting System (cee Table a.14). * Because vertheat

sceles dither, grephs shoutd nol be compared. Source: Tabie 3.11. 
Table 3.11 FRS Companies' Net Investment in Place, 1975-1994

(Billion Dollars')

\begin{tabular}{|c|c|c|c|c|c|c|c|c|c|c|c|c|c|c|}
\hline \multirow[b]{2}{*}{ Yoar } & \multicolumn{6}{|c|}{ Type of Bualness } & \multicolumn{4}{|c|}{ Domasdo Petroteum and Notural Gas } & \multicolumn{4}{|c|}{ Forolgn Putrohum and bokred Gas } \\
\hline & $\begin{array}{l}\text { Petrolotim } \\
\text { and } \\
\text { Nalural } \\
\text { centio }\end{array}$ & Gфы & $\begin{array}{l}\text { Nucloper } \\
\text { and } \\
\text { Diber } \\
\text { Endrgy }\end{array}$ & Hont & $\begin{array}{c}\text { Non- } \\
\text { trateglodes }\end{array}$ & Totat: & Frophr=tidn & $\begin{array}{l}\text { Fielining } \\
\text { enid } \\
\text { markekting }\end{array}$ & $\begin{array}{c}\text { Rats } \\
\text { Regulpited } \\
\text { Piptibltet }\end{array}$ & Tobal & Prockuction & $\begin{array}{l}\text { Reining } \\
\text { Antd } \\
\text { Merlowing }\end{array}$ & $\begin{array}{c}\text { Internotlonted } \\
\text { Marine }\end{array}$ & Total \\
\hline 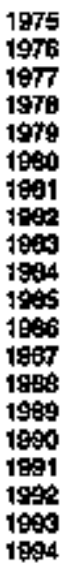 & $\begin{array}{r}78.8 \\
88.9 \\
10.9 \\
1.2 .2 \\
128.3 \\
151.4 \\
178.0 \\
200.7 \\
212.2 \\
227.8 \\
235.8 \\
234.4 \\
238.7 \\
258.4 \\
241.3 \\
248.7 \\
252.6 \\
238.0 \\
25.1 \\
250.4\end{array}$ & $\begin{array}{l}1.6 \\
2.0 \\
2.8 \\
3.3 \\
4.1 \\
5.0 \\
7.2 \\
9.3 \\
9.4 \\
8.2 \\
9.1 \\
8.4 \\
9.6 \\
0.7 \\
9.7 \\
9.2 \\
6.7 \\
6.9 \\
4.9 \\
4.1\end{array}$ & $\begin{array}{l}0.8 \\
1.0 \\
1.9 \\
3.1 \\
3.5 \\
4.0 \\
4.5 \\
5.3 \\
5.1 \\
4.7 \\
3.7 \\
3.3 \\
3.3 \\
3.4 \\
3.1 \\
3.0 \\
2.9 \\
2.8 \\
3.0 \\
3.1\end{array}$ & $\begin{array}{l}19.7 \\
17.6 \\
24.3 \\
27.3 \\
31.9 \\
39.7 \\
45.9 \\
60.3 \\
69.2 \\
60.3 \\
58.9 \\
56.4 \\
58.5 \\
59.1 \\
60.6 \\
55.1 \\
56.3 \\
58.7 \\
58.0 \\
58.5\end{array}$ & $\begin{array}{l}1.0 \\
1.1 \\
1.9 \\
2.1 \\
2.4 \\
3.4 \\
5.2 \\
6.8 \\
7.4 \\
7.4 \\
7.5 \\
7.4 \\
7.3 \\
6.0 \\
8.2 \\
6.6 \\
7.0 \\
0.7 \\
6.8 \\
9.5\end{array}$ & $\begin{array}{r}57.3 \\
111.1 \\
135.2 \\
148.1 \\
185.9 \\
300.6 \\
240.8 \\
292.5 \\
296.3 \\
309.4 \\
315.4 \\
309.9 \\
316.4 \\
309.6 \\
308.9 \\
319.6 \\
325.6 \\
331.5 \\
351.5 \\
334.6\end{array}$ & $\begin{array}{r}27.8 \\
31.4 \\
38.4 \\
40.5 \\
51.9 \\
68.8 \\
83.2 \\
100.7 \\
108.4 \\
123.1 \\
125.8 \\
118.9 \\
114.7 \\
111.1 \\
108.0 \\
102.1 \\
88.6 \\
\$ 5.1 \\
91.4 \\
97.6\end{array}$ & $\begin{array}{l}20.0 \\
20.7 \\
21.1 \\
22.0 \\
2 . .5 \\
25.7 \\
28.2 \\
32.1 \\
33.0 \\
34.3 \\
34.3 \\
36.5 \\
39.6 \\
37.1 \\
39.4 \\
42.5 \\
46.2 \\
40.8 \\
49.8 \\
51.8\end{array}$ & $\begin{array}{r}7.0 \\
9.6 \\
11.2 \\
11.2 \\
11.0 \\
11.1 \\
11.2 \\
10.8 \\
12.4 \\
12.0 \\
15.4 \\
19.8 \\
20.2 \\
20.8 \\
18.7 \\
18.6 \\
18.5 \\
24.7 \\
24.4 \\
24.1\end{array}$ & 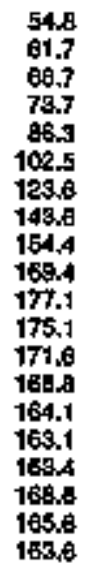 & $\begin{array}{r}8.4 \\
11.4 \\
16.4 \\
19.0 \\
21.5 \\
27.4 \\
31.0 \\
35.2 \\
37.1 \\
39.6 \\
40.0 \\
40.1 \\
44.0 \\
46.8 \\
59.7 \\
56.7 \\
59.2 \\
57.0 \\
59.7 \\
61.5\end{array}$ & $\begin{array}{l}10.3 \\
10.3 \\
13.5 \\
14.1 \\
14.9 \\
18.2 \\
17.9 \\
17.6 \\
17.2 \\
15.9 \\
16.9 \\
18.1 \\
21.2 \\
20.9 \\
22.7 \\
25.2 \\
26.2 \\
20.5 \\
30.1 \\
32.6\end{array}$ & $\begin{array}{l}5.9 \\
5.4 \\
5.9 \\
5.4 \\
5.9 \\
5.3 \\
4.9 \\
4.2 \\
3.8 \\
2.8 \\
2.9 \\
20 \\
1.9 \\
1.7 \\
1.8 \\
1.7 \\
1.8 \\
1.6 \\
1.7 \\
9.7\end{array}$ & $\begin{array}{l}24.9 \\
27.1 \\
35.6 \\
38.5 \\
420 \\
48.9 \\
54.3 \\
57.2 \\
67.9 \\
58.4 \\
59.0 \\
60.3 \\
67.1 \\
68.5 \\
77.2 \\
83.6 \\
89.8 \\
87.4 \\
91.5 \\
95.8\end{array}$ \\
\hline
\end{tabular}

1 Nommal dellars.

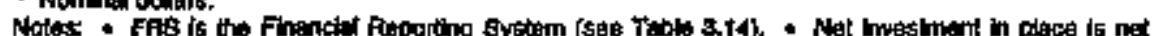

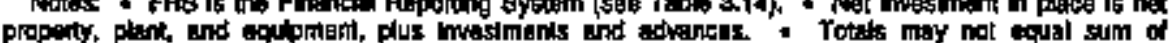

comporitents tus to independenl mulkiling.

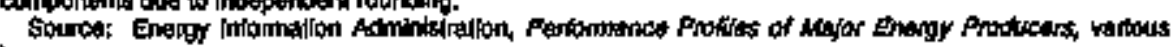


Type of Business, Total

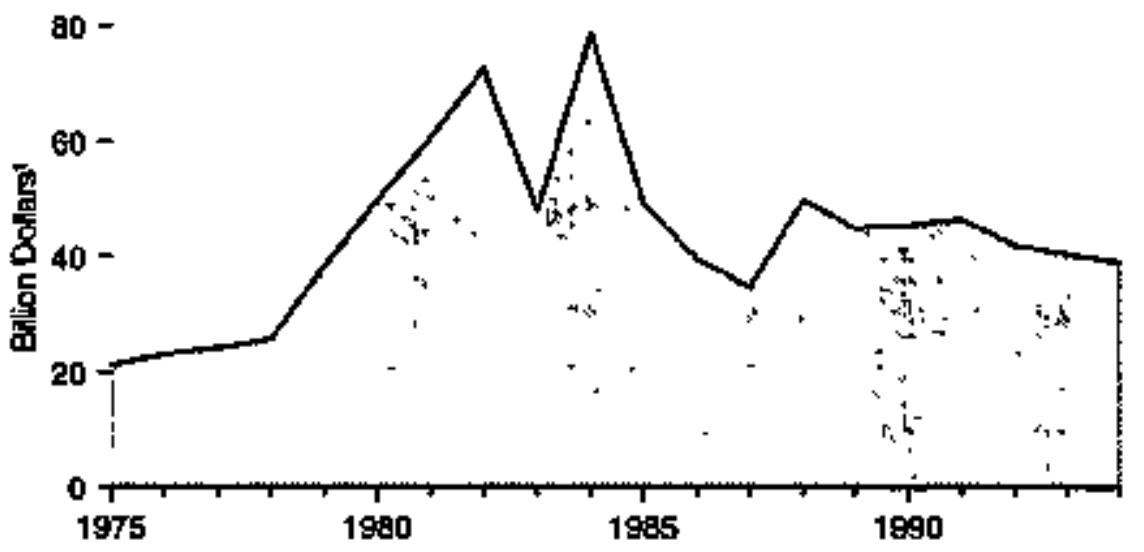

Domestic Petroleum and Fatural Gas

$$
45-
$$

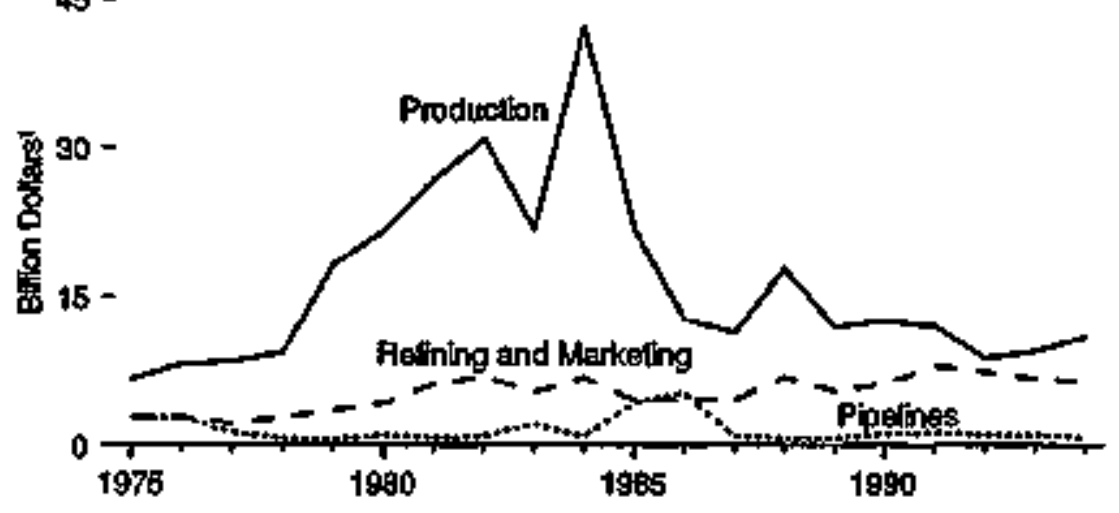

INonhtal donllars.

¿Coal, ntictear, atd othar anergy.

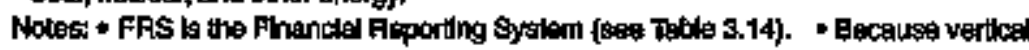

\section{Type of Business by Fued}

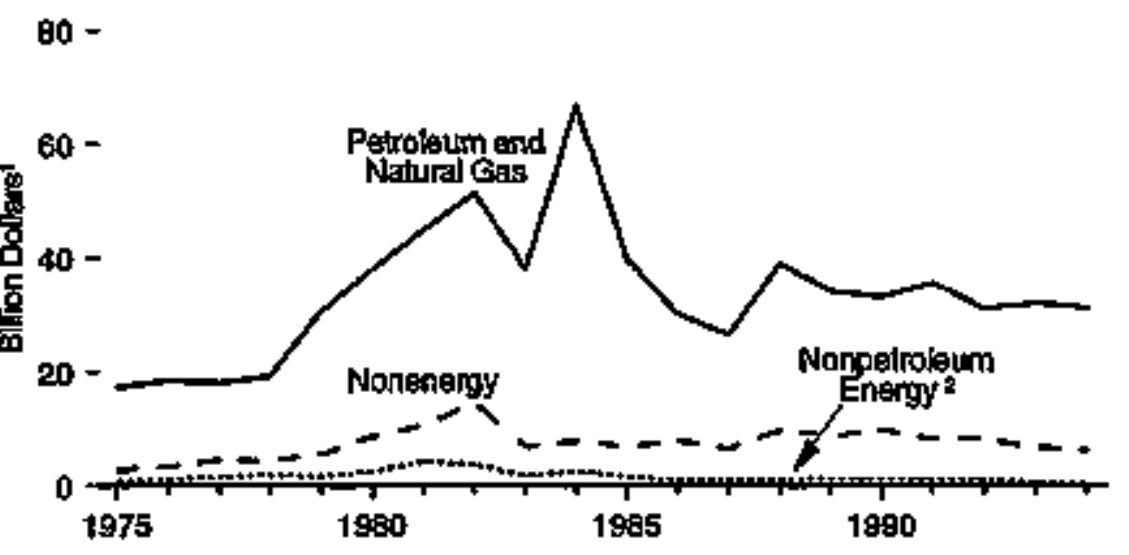

Forelgn Petroleum and Natured Gas

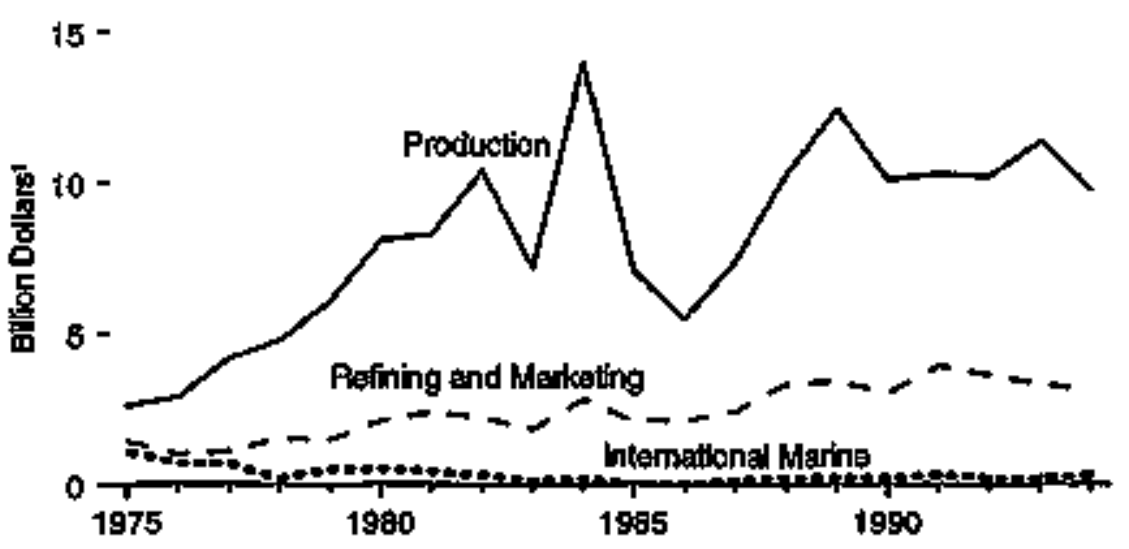

scellas differ, arephis should nol bo comparied. Sourcer, Table 3.12 
Table 3.12 FRS Companies' Additions to Investment in Place, 1975-1994 (Bilion Dollers')

\begin{tabular}{|c|c|c|c|c|c|c|c|c|c|c|c|c|c|}
\hline \multirow[b]{2}{*}{ Yes } & \multicolumn{5}{|c|}{ Tyen of Bundmeat: } & \multicolumn{4}{|c|}{ 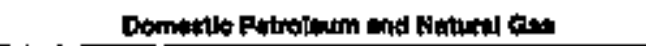 } & \multicolumn{4}{|c|}{ 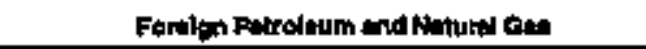 } \\
\hline & 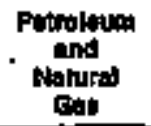 & Cod & $\begin{array}{l}\text { Muctob } \\
\text { ind } \\
\text { othar } \\
\text { Energy }\end{array}$ & Hant & Totrd 7 & Protuation & 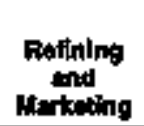 & $\begin{array}{c}\text { Falk } \\
\text { Phoulatwd } \\
\text { Flpallnas }\end{array}$ & Total & Produsetion & 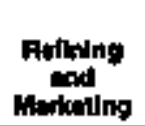 & $\begin{array}{c}\text { Imternational } \\
\text { Merins }\end{array}$ & Totat \\
\hline $\begin{array}{l}1976 \\
1975 \\
1977 \\
1979 \\
1979 \\
1980 \\
1984 \\
1989 \\
19983 \\
1994 \\
1985 \\
1935 \\
1997 \\
1988 \\
1998 \\
1998 \\
1999 \\
1992 \\
1998 \\
1994\end{array}$ & 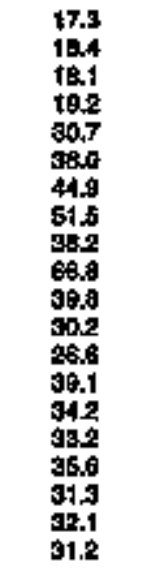 & $\begin{array}{l}0.5 \\
0.5 \\
0.9 \\
1.0 \\
0.8 \\
1.3 \\
2.9 \\
2.1 \\
1.1 \\
1.6 \\
1.6 \\
0.7 \\
0.6 \\
0.6 \\
1.0 \\
0.9 \\
1.0 \\
0.9 \\
0.2 \\
(8.1\end{array}$ & $\begin{array}{l}0.3 \\
0.5 \\
0.5 \\
0.9 \\
0.9 \\
t .2 \\
1.2 \\
t .7 \\
0.3 \\
0.0 \\
0.1 \\
0.2 \\
0.3 \\
0.4 \\
0.3 \\
0.2 \\
0.2 \\
0.2 \\
0.4 \\
0.3\end{array}$ & $\begin{array}{r}2.7 \\
3.9 \\
4.5 \\
4.4 \\
6.7 \\
8.6 \\
10.7 \\
14.6 \\
6.9 \\
7.9 \\
6.6 \\
7.6 \\
6.7 \\
5.7 \\
8.0 \\
8.0 \\
8.9 \\
8.3 \\
6.7 \\
6.3\end{array}$ & $\begin{array}{l}21 . t \\
29.1 \\
24.3 \\
25.6 \\
34.5 \\
50.1 \\
60.0 \\
72.8 \\
48.0 \\
78.7 \\
49.2 \\
39.7 \\
34.8 \\
49.7 \\
45.0 \\
45.5 \\
48.4 \\
42.0 \\
40.4 \\
34.1\end{array}$ & $\begin{array}{r}6.6 \\
8.1 \\
8.5 \\
9.3 \\
18.2 \\
21.6 \\
26.6 \\
50.6 \\
21.6 \\
42.1 \\
21.6 \\
12.7 \\
11.3 \\
17.8 \\
11.9 \\
12.6 \\
12.0 \\
8.8 \\
9.5 \\
10.9\end{array}$ & $\begin{array}{l}2.0 \\
2.9 \\
2.2 \\
2.0 \\
3.5 \\
4.2 \\
6.1 \\
6.9 \\
5.3 \\
6.9 \\
4.5 \\
4.5 \\
4.5 \\
6.9 \\
8.5 \\
6.3 \\
7.9 \\
7.4 \\
6.7 \\
6.3\end{array}$ & $\begin{array}{l}2.8 \\
2.0 \\
1.4 \\
0.0 \\
0.0 \\
1.0 \\
0.0 \\
0.9 \\
2.1 \\
0.8 \\
4.3 \\
5.3 \\
0.8 \\
0.7 \\
0.7 \\
1.1 \\
1.3 \\
1.0 \\
1.0 \\
0.0\end{array}$ & $\begin{array}{l}12.2 \\
13.8 \\
12.1 \\
12.7 \\
22.5 \\
25.9 \\
33.8 \\
38.8 \\
28.2 \\
49.7 \\
30.8 \\
22.5 \\
16.7 \\
25.3 \\
18.2 \\
20.0 \\
21.3 \\
17.3 \\
17.1 \\
16.1\end{array}$ & $\begin{array}{r}2.8 \\
2.8 \\
4.2 \\
4.8 \\
6.1 \\
6.1 \\
0.3 \\
10.4 \\
7.2 \\
14.0 \\
7.1 \\
5.5 \\
7.4 \\
10.3 \\
12.4 \\
10.1 \\
10.3 \\
10.2 \\
11.4 \\
8.0\end{array}$ & $\begin{array}{l}1.4 \\
1.0 \\
1.1 \\
t .5 \\
t .5 \\
2.1 \\
2.4 \\
2.2 \\
1.6 \\
2.6 \\
2.1 \\
2.1 \\
2.4 \\
3.3 \\
3.4 \\
3.0 \\
3.9 \\
3.6 \\
3.3 \\
3.1\end{array}$ & $\begin{array}{l}1.1 \\
0.7 \\
0.7 \\
0.2 \\
0.5 \\
0.5 \\
0.4 \\
0.3 \\
0.1 \\
0.2 \\
091 \\
0.1 \\
0.1 \\
0.2 \\
0.2 \\
0.2 \\
0.3 \\
0.2 \\
0.2 \\
0.3\end{array}$ & $\begin{array}{r}5.1 \\
4.5 \\
6.0 \\
6.6 \\
8.2 \\
11.1 \\
11.1 \\
12.8 \\
9.1 \\
17.1 \\
9.3 \\
7.7 \\
8.9 \\
13.7 \\
16.0 \\
13.2 \\
14.4 \\
14.0 \\
15.0 \\
13.1\end{array}$ \\
\hline
\end{tabular}

\$ tominal doliars.

2 Total $k$ sum of components shoun, phus noniracabtess, which are delined in lhe glossary. Touss may

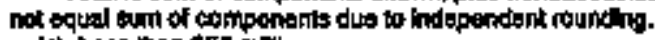

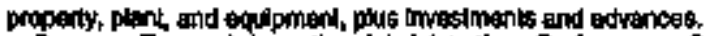

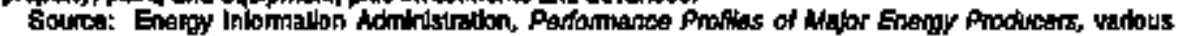
(ל)

henes.

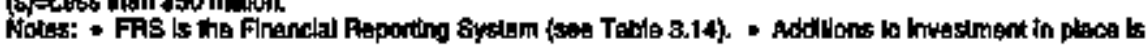




\section{Soveranee Taxes}

B -
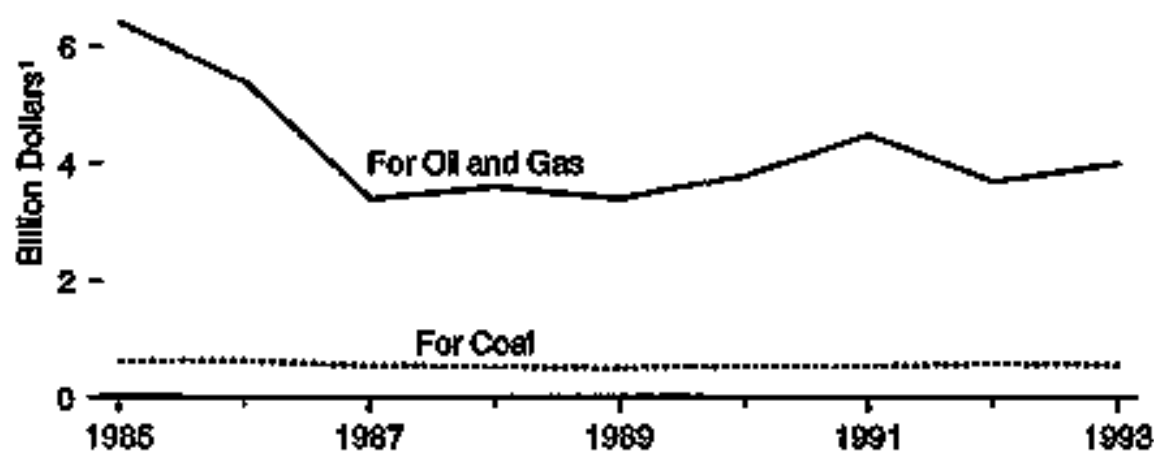

Effective Tax as Bhare of Price

6 -

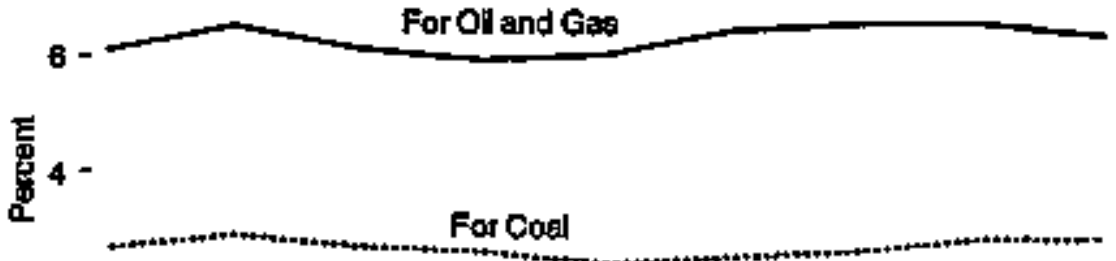

$2-$

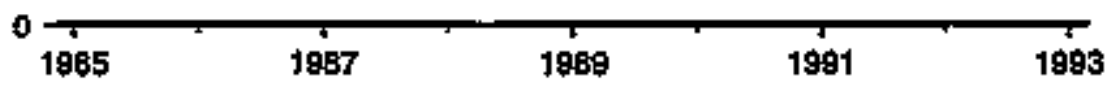

Slate Government Total Tax Fecelpto

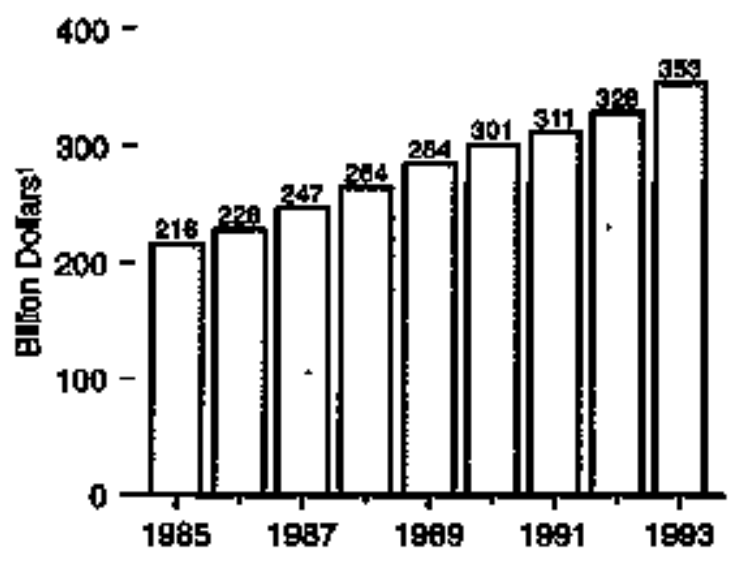

Stato Governmont Energy Sovorance Taxos

8 -

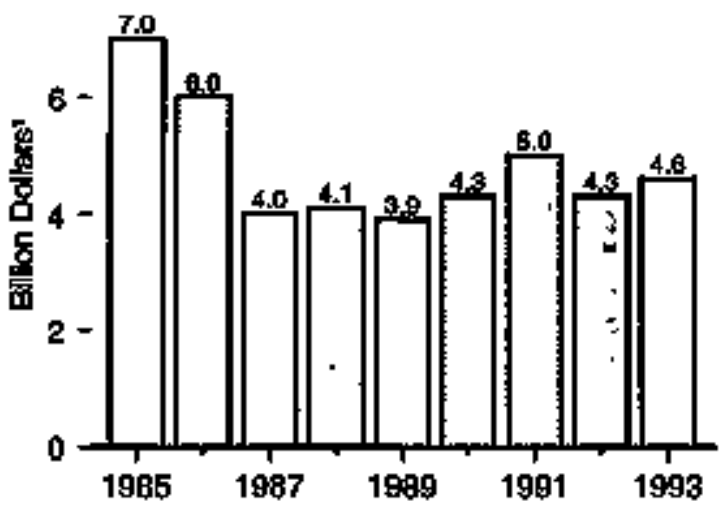

Shate Governmont Energy Severance Taxes as Share of Total State Taxes

4 -

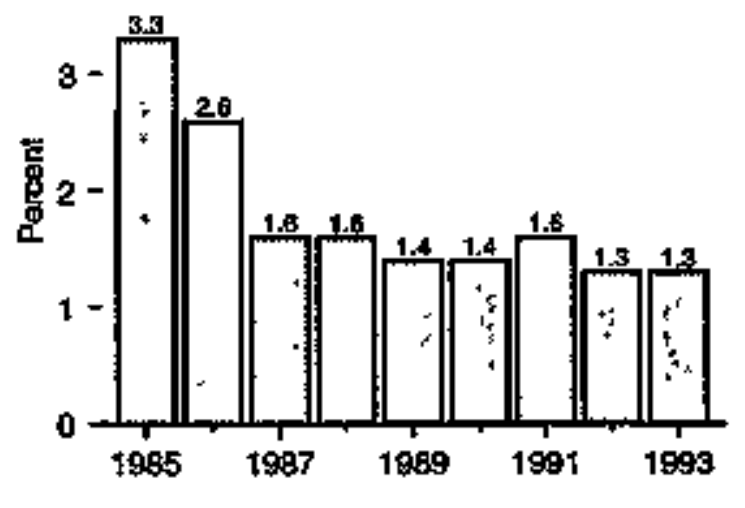

1 Nominal dollers.

Noles: - A severance laxis a tax on the taking and use of nalurol tources imposed at

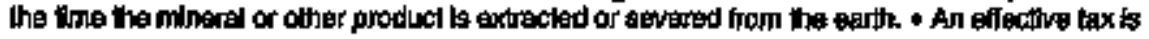

Sourer: Table 3.13. 
Table 3.13 State Government Severance Taxes, 1985-1993

\begin{tabular}{|c|c|c|c|c|c|c|c|c|c|c|c|}
\hline \multirow[b]{3}{*}{ Yagr } & \multicolumn{4}{|c|}{ Fox Oll end Gas } & \multicolumn{4}{|c|}{ For conl } & \multicolumn{3}{|c|}{ Stab Govemment Tax floosipts } \\
\hline & $\begin{array}{c}\text { Sovonnes } \\
\text { Texas }\end{array}$ & $\begin{array}{c}\text { Etfoetiva tox } \\
\text { par Burnal1 }\end{array}$ & $\begin{array}{l}\text { Prico } \\
\text { por taimel }\end{array}$ & $\begin{array}{l}\text { Efrieolho Tax } \\
\text { as shars of } \\
\text { Price }\end{array}$ & $\begin{array}{l}\text { Soverance } \\
\text { Thutes }\end{array}$ & $\begin{array}{c}\text { Effectlye Tax } \\
\text { perton }\end{array}$ & $\begin{array}{l}\text { Polce } \\
\text { por short } \\
\text { Twi }\end{array}$ & $\begin{array}{l}\text { Effecthe Tux } \\
\text { an share of } \\
\text { Prien }\end{array}$ & $\begin{array}{l}\text { Energy } \\
\text { sovertice } \\
\text { Taxes }\end{array}$ & $\begin{array}{l}\text { Totet } \\
\text { somit texes }\end{array}$ & 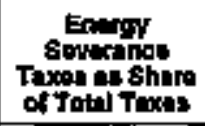 \\
\hline & Brilisen Dollars 2 & \multicolumn{2}{|c|}{ 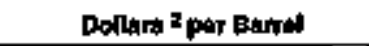 } & Portant & Bdutom Dosllars 2 & \multicolumn{2}{|c|}{ Dellamil I par Fhert Ton } & Pureont & \multicolumn{2}{|c|}{ Aiplent dollers z } & Powtint \\
\hline $\begin{array}{l}1995 \\
1998 \\
1997 \\
7999 \\
1999 \\
1990 \\
1991 \\
1999 \\
1993\end{array}$ & $\begin{array}{l}6.4 \\
\$ .4 \\
3.4 \\
3.6 \\
3.4 \\
3.8 \\
4.5 \\
3.7 \\
4.4\end{array}$ & $\begin{array}{l}1,17 \\
1,00 \\
0.69 \\
0.69 \\
0.66 \\
0.76 \\
0.89 \\
0.76 \\
0.81\end{array}$ & $\begin{array}{l}12.19 \\
15.48 \\
10.84 \\
11.59 \\
11.09 \\
11,69 \\
13.72 \\
11.05 \\
12.77\end{array}$ & $\begin{array}{l}6.1 \\
6.5 \\
8.1 \\
5.9 \\
6.9 \\
6.4 \\
6.5 \\
6.5 \\
0.3\end{array}$ & $\begin{array}{l}0.5 \\
0.5 \\
0.6 \\
0.5 \\
0.5 \\
0.6 \\
0.6 \\
0.6 \\
0.6\end{array}$ & $\begin{array}{l}0.65 \\
0.71 \\
0.65 \\
0.57 \\
0.58 \\
0.55 \\
0.55 \\
0.56 \\
0.57\end{array}$ & $\begin{array}{l}25.41 \\
24.59 \\
29.25 \\
27.40 \\
21.70 \\
21.64 \\
21.31 \\
21.07 \\
20.39\end{array}$ & $\begin{array}{l}27 \\
2.9 \\
27 \\
28 \\
24 \\
2.5 \\
2.6 \\
2.6 \\
2.6\end{array}$ & $\begin{array}{l}7.0 \\
6.0 \\
4.0 \\
4.1 \\
3.9 \\
4.3 \\
5.0 \\
4,3 \\
4.6\end{array}$ & $\begin{array}{l}219,9 \\
228,3 \\
246.5 \\
254,1 \\
264,4 \\
300,7 \\
311.1 \\
327,4 \\
354,3\end{array}$ & $\begin{array}{l}3.3 \\
2.6 \\
1.6 \\
1.6 \\
1.4 \\
1.4 \\
1.6 \\
1.3 \\
1.9\end{array}$ \\
\hline
\end{tabular}

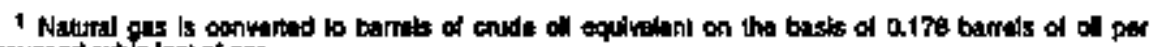
houstand cablo lasl ot gas.

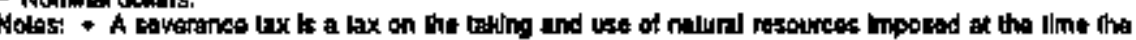

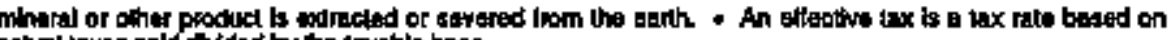

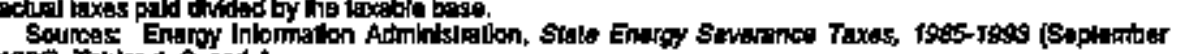
sos), Tatoos 1,3, and 4 . 
Table 3.14 Companies Reporting to the Financial Reporting System, 1975-1994

\begin{tabular}{|c|c|c|c|c|c|c|c|c|c|c|}
\hline Compeny & 1975-1981 & 1982 & treas & 19B5-16 & 1987 & 1969 & 1569-20 & 1591 & 1992.53 & 194 \\
\hline \multirow{19}{*}{ 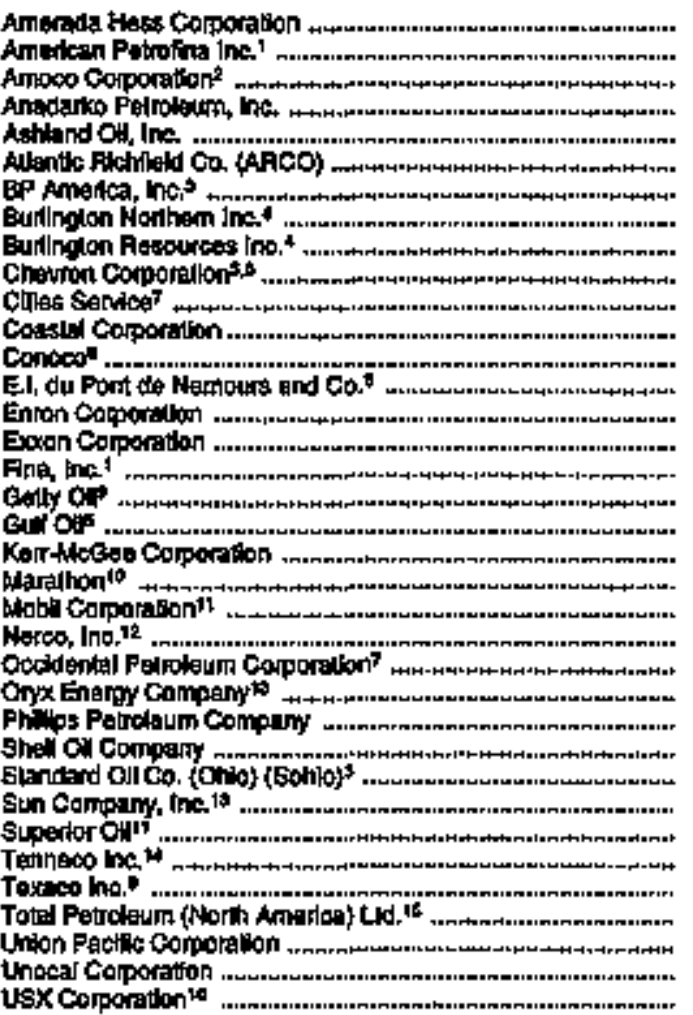 } & $x$ & $x$ & $x$ & $x$ & $x$ & $x$ & $x$ & $x$ & $x$ & $x$ \\
\hline & $\begin{array}{l}\mathbf{x} \\
\mathbf{x}\end{array}$ & $\underset{x}{x}$ & $\begin{array}{l}\mathbf{x} \\
\mathbf{x}\end{array}$ & $\begin{array}{l}x \\
x\end{array}$ & $\begin{array}{l}\mathbf{x} \\
\mathbf{x}\end{array}$ & $\begin{array}{l}x \\
x\end{array}$ & $\begin{array}{l}\mathbf{x} \\
\mathbf{X}\end{array}$ & $x$ & $\underset{x}{x}$ & $\underset{y}{x}$ \\
\hline & $x$ & $x$ & $x$ & $x$ & $x$ & $x$ & $x$ & $x$ & $\begin{array}{l}x \\
x\end{array}$ & $\underset{x}{x}$ \\
\hline & $\hat{x}$ & $\hat{x}$ & $x$ & $x$ & $\hat{x}$ & $\hat{x}$ & $\hat{x}$ & $\hat{x}$ & $\hat{x}$ & $x$ \\
\hline & $x$ & $x$ & $x$ & $x$ & $\hat{x}$ & & & & & \\
\hline & & & & & & $x$ & $x$ & $x$ & $x$ & $x$ \\
\hline & $\underset{x}{x}$ & $\underset{x}{x}$ & $x$ & $x$ & $x$ & $x$ & $x$ & $x$ & $x$ & $x$ \\
\hline & $\begin{array}{l}x \\
x\end{array}$ & $\widehat{x}$ & $x$ & $x$ & $x$ & $x$ & $x$ & $x$ & $x$ & $x$ \\
\hline & & $x$ & $x$ & $x$ & $x$ & $x$ & $x$ & $x$ & $\frac{x}{x}$ & $\underset{x}{x}$ \\
\hline & $x$ & $x$ & $x$ & $x$ & $x$ & $x$ & $x$ & $\begin{array}{l}x \\
x\end{array}$ & $\begin{array}{l}\hat{x} \\
\hat{x}\end{array}$ & $\underset{x}{\ddot{x}}$ \\
\hline & $\begin{array}{l}x \\
x\end{array}$ & $\underset{x}{x}$ & $\underset{x}{x}$ & & & & & & & \\
\hline & $\begin{array}{l}x \\
x\end{array}$ & $x$ & $x$ & $x$ & $x$ & $x$ & $x$ & $x$ & $x$ & $x$ \\
\hline & $x$ & $x$ & $x$ & $x$ & $x$ & $x$ & $x$ & $x$ & $\begin{array}{l}x \\
x\end{array}$ & $x$ \\
\hline & $x$ & $x$ & $x$ & $x$ & $x$ & $\begin{array}{l}x \\
x\end{array}$ & $\underset{x}{x}$ & $\begin{array}{l}x \\
x\end{array}$ & $\begin{array}{l}x \\
x\end{array}$ & $\underset{x}{x}$ \\
\hline & $\begin{array}{l}x \\
x \\
x\end{array}$ & $\begin{array}{l}x \\
x \\
x\end{array}$ & $\begin{array}{l}x \\
x \\
x\end{array}$ & $\begin{array}{l}x \\
x \\
x\end{array}$ & $\begin{array}{l}x \\
x\end{array}$ & $\underset{x}{x}$ & $\begin{array}{l}x \\
x\end{array}$ & $\begin{array}{l}x \\
x\end{array}$ & $\begin{array}{l}x \\
x\end{array}$ & $\begin{array}{l}x \\
x\end{array}$ \\
\hline & $\begin{array}{l}x \\
x\end{array}$ & $\underset{x}{x}$ & $\begin{array}{l}\ddot{x} \\
x\end{array}$ & $x$ & $x$ & $x$ & $x$ & $x$ & $x$ & $x$ \\
\hline & $x$ & $\mathbf{x}$ & $x$ & $x$ & $x$ & $x$ & & & & \\
\hline & $x$ & $x$ & $x$ & $x$ & $x$ & $x$ & $\begin{array}{l}x \\
x\end{array}$ & $\stackrel{x}{x}$ & $x$ & $x$ \\
\hline & $\begin{array}{l}x \\
x\end{array}$ & $\begin{array}{l}x \\
\dot{x} \\
\dot{x}\end{array}$ & $\begin{array}{l}x \\
\dot{x} \\
\dot{x}\end{array}$ & $\begin{array}{l}x \\
x \\
x\end{array}$ & $\begin{array}{l}\mathbf{x} \\
\mathrm{x} \\
\mathrm{x}\end{array}$ & $\begin{array}{l}\mathbf{x} \\
\mathbf{x} \\
\mathbf{x}\end{array}$ & $\begin{array}{l}\mathbf{x} \\
\mathbf{x} \\
\mathbf{x}\end{array}$ & $\begin{array}{l}\mathbf{x} \\
\mathbf{x} \\
\mathbf{x}\end{array}$ & $\begin{array}{l}x \\
x \\
x\end{array}$ & $\begin{array}{l}\underset{x}{x} \\
x\end{array}$ \\
\hline
\end{tabular}

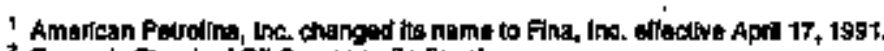

2 Formely Stendard on Compalty (Indlane).

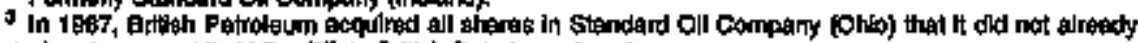

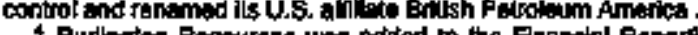

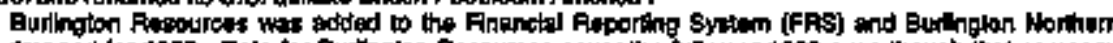

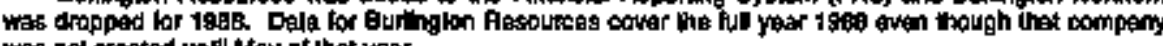
mos not created und May of that year.

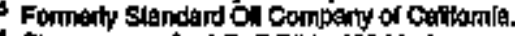

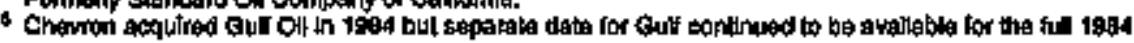
roser.

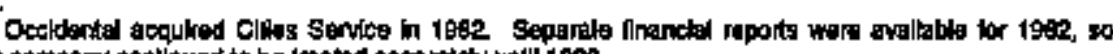

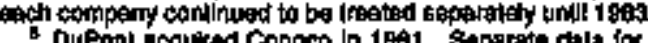

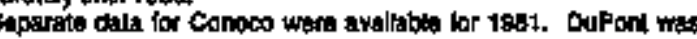

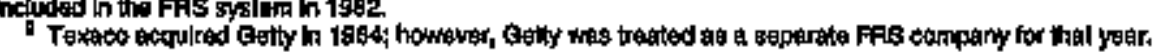

1) U.S. SIsed (nom USX) acqulred harathon in 1982.

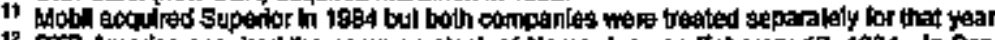

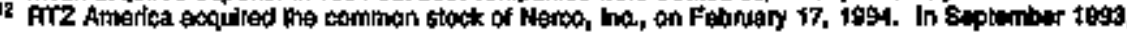

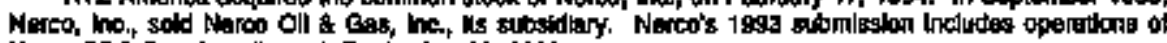

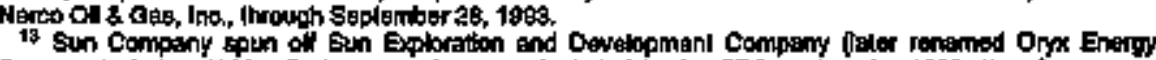

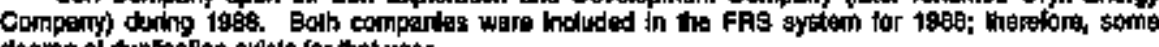

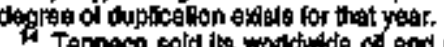

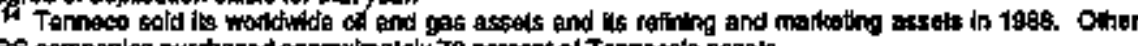

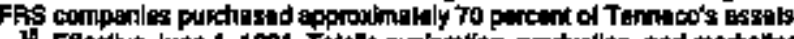

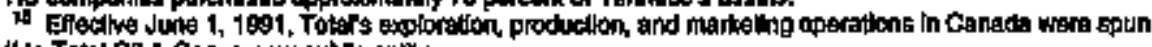

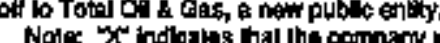

Sow

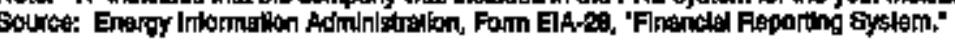




\section{Energy Resources}

\section{Crude Oil and Natural Gas Resources}

The U.S. Department of the Interior's 1987 mean estimates of domestic undiscovered recoverable resources trapped in conventional reservoirs were 49 billion barrels of crude oil (of which 33.3 billion barrels were located onshore and in State jurisdiction waters, with 13.2 billion barrels of the latter loctated in or off Alaska), 399 trillion cubic feet of natural gas, and 8.6 billion barrels of natural gas liquids (4.1). Only the onshore and State waters portion of the 1994 estimates were available in time for publication in this report; the 1994 estimates are 30.3 billion barrels of crude oil (of which 8.4 billion barrels occur in and off Alaska), 259 trillion cubic feet of natural gas, and 7.2 billion barrels of natural gas liquids.

\section{Crude Oil and Natural Gas Proved Reserves}

The combined oil-equivalent proved reserves of crude oil, natural gas, ard natural gas liquids increased every year from 1949 until 1968 (4.10), when, for the first time, production exceeded net additions to proved reserves. Except for the addition of Alaska's North Slope roserves in 1970, proved reserves trended downward, falling to 57 billion barrels oil equivalent in 1994. At the end of 1994, proved reserves were 24 billion barrels of crude ail (including lease condensate) and 172 trillion cubic feet of natural gas (4.2). Through 1994, crude oil cumulative production of 173 billion barrels from 40,001 fields equaled about 88 percent of estimated ultimate recovery, while natural gas cumulative production of 877 trillion cubic feet from 35,724 fields equaled about 84 percent of ultimate recovery.

\section{Coal Reserves}

The Energy Information Administration has estimated that the demonstrated reserve base of coal contained 496 billion short tons at the beginning of 1995 (4.11). Although recoverability rates differ from site to site, about 55 percent of the demonstrated reserve base is es* timated to be recoverable.

\section{Uranium Resources}

At the end of 1995, uranium reserves with forward costs (those yet to be ineurred in production) of no more than $\$ 30$ per pound totaled 290 million pounds of uranium oxide $\left(\mathrm{U}_{3} \mathrm{O}_{8}\right), 40$ percent of which was in Wyoming (4.13). Estimated additional resources and speculative resources in the $\$ 30$-per-pound category in 1995 totaled 2.2 billion pounds and 1.3 billion pounds, respectively.

\section{Exploring for Energy Resources}

Exploration for oil and gas la shaped by market conditions and tochnologival developments. Markel forces significanthy decreased the number of rotary rigs in operation and the number of exploratory wells from highs in 1981 of 3,970 rlgs and 17.5 thousand exploratory wells (4.3 and 4.5) to 723 rigs and 3.5 thousand exploratory wels in 1995. The use of new technologies, such three-dimensional seismis aurveying, multidiscipllnary leams supported by a common and comprehensive computertzed database, and horizonta drilling, has Inoreased the efflelency of energy indusiny operallons. During the $1990^{\prime} s$, the percentage of successtid wells difiled, particularty exploratory wels, generathy incressed (4.4). In 19e5, 44 percent of ofl and gas exploratory wells were successful, compered with 25 percent In 1990 (4.5). The percentage of successjul oil and gas developrent welts rose from 82 percent in 1990 to 85 percent in 1995 (4.6).

Exploration tor uran|um also reflects changes in energy markets. The number of exploratory and development holes titited peaked in 1979 at 104 thousand (4.\$2). As uranium market conditions deterlorated after 1978, the number plunged to fewer than 4 thols. sand per year In the mid-1980's. In \$995, the number of holes ditlled lataled 2.3 thoutsand. 


\section{Crude Oil, 1987 and 1994}

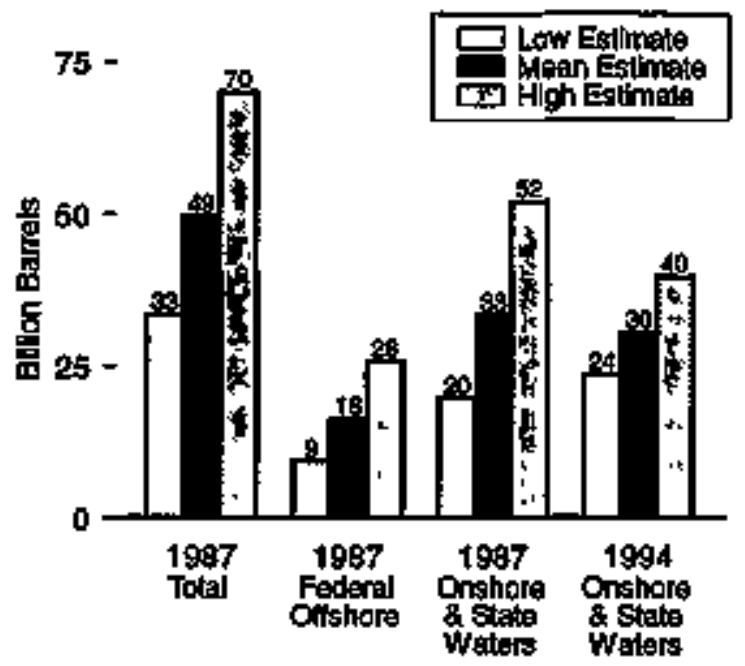

Natural Gess Llquids, 1967 and 1994

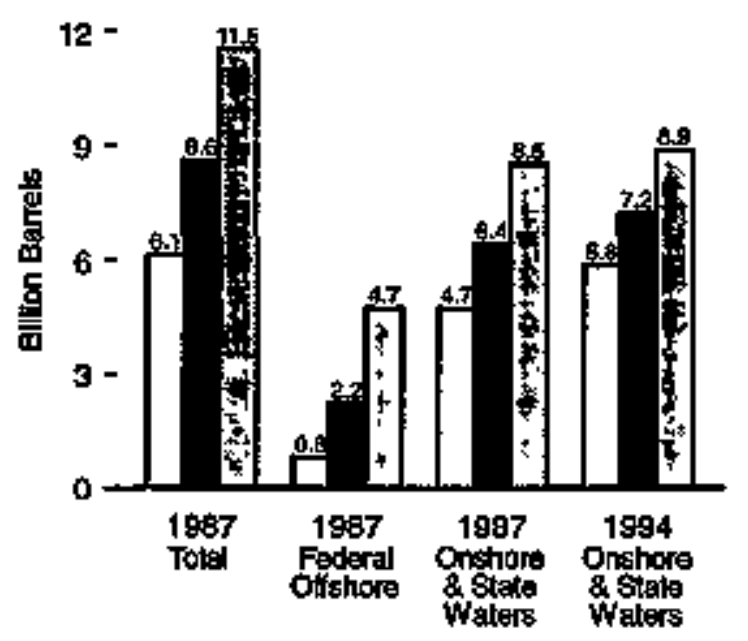

Natural Gas, 1987 and 1994

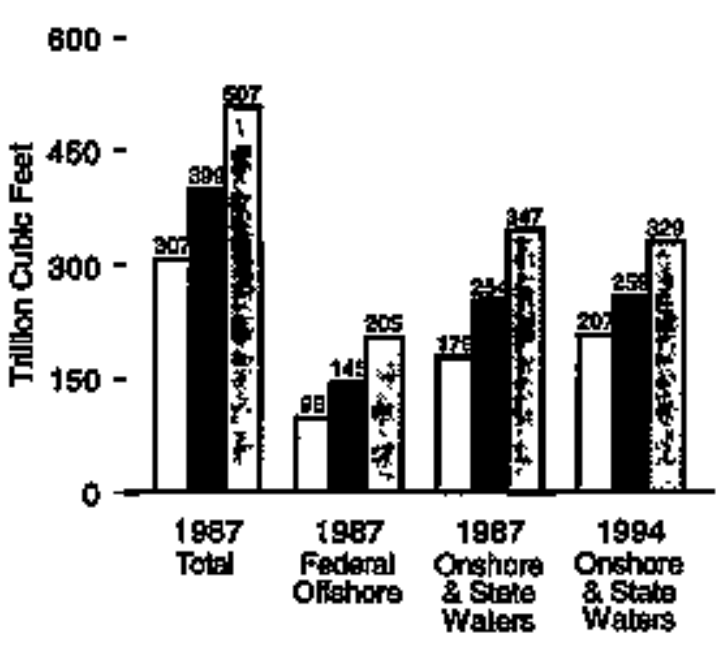

Onshore and State Watets, Motan Estimates, by Reglon, 1994
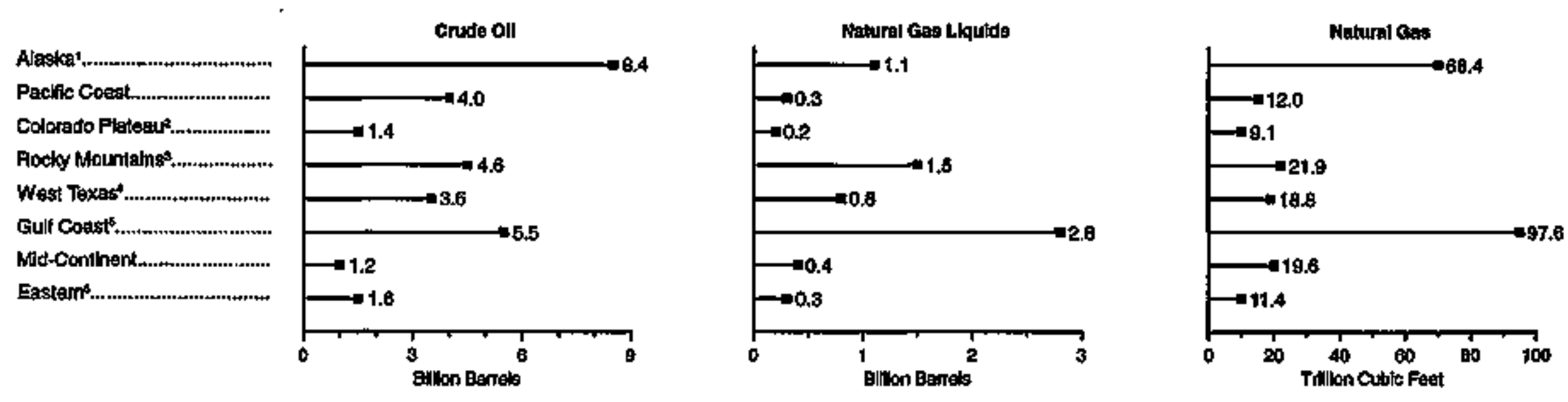

1 Inolutes Avetle Neritonat wichite Relinge.

And Basin and Pange.

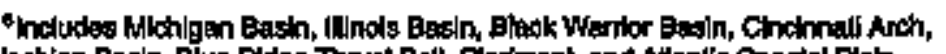

- And Norlhom Graat Plains.

4 And Eastem Now Hexdeo.

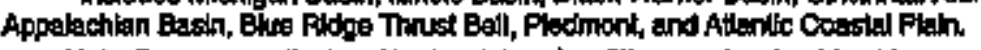

5 Ireiudios êl of Florida.

Note: Becauss verical and horizontal scales difir, graphs shoukd not be compered.

Sorfos: Table 4.1. 
Table 4.1 Undiscovered Recoverable Resource Estimates for Petroleum, 1987 and 1994

\begin{tabular}{|c|c|c|c|c|c|c|c|c|c|}
\hline \multirow[b]{3}{*}{ Reglon } & \multicolumn{3}{|c|}{$\begin{array}{c}\text { Crude Oll } \\
\text { (billion borrels) }\end{array}$} & \multicolumn{3}{|c|}{ 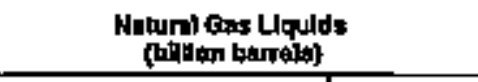 } & \multicolumn{3}{|c|}{ 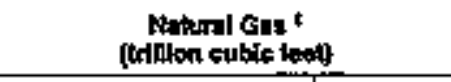 } \\
\hline & \multicolumn{2}{|c|}{ Eotimatod fange 2} & \multirow[b]{2}{*}{ Means } & \multicolumn{2}{|c|}{ Estunated Ringe 2} & \multirow[b]{2}{*}{$\operatorname{logen}{ }^{3}$} & \multicolumn{2}{|c|}{ Eefimatod Range * } & \multirow[b]{2}{*}{ Means } \\
\hline & Low & Hogh & & Low & High & & Low & thangh & \\
\hline & \multicolumn{9}{|c|}{ January t. 1987} \\
\hline 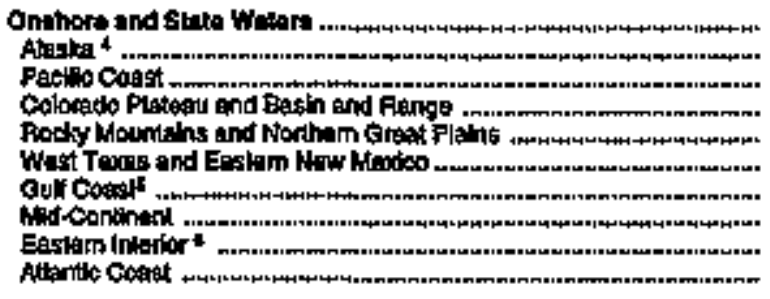 & $\begin{array}{r}10.5 \\
3.5 \\
1.5 \\
0.5 \\
2.7 \\
1.5 \\
2.4 \\
1.2 \\
1.3 \\
0.1\end{array}$ & $\begin{array}{r}51.8 \\
31.3 \\
6.6 \\
3.4 \\
6.9 \\
4.0 \\
6.7 \\
2.7 \\
2.4 \\
0.6\end{array}$ & $\begin{array}{r}30.3 \\
13.2 \\
3.5 \\
1.5 \\
4.5 \\
2.8 \\
4.2 \\
1.9 \\
1.8 \\
0.2\end{array}$ & $\begin{array}{l}4.7 \\
\text { NC } \\
\text { NC } \\
\text { NC } \\
\text { NC } \\
\text { NC } \\
\text { NC } \\
\text { NC } \\
\text { NC } \\
\text { NC }\end{array}$ & 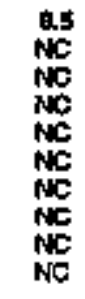 & 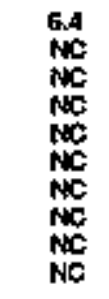 & $\begin{array}{r}178.7 \\
15.5 \\
5.5 \\
9.5 \\
7.0 \\
11.9 \\
51.2 \\
16.2 \\
10.8 \\
(8)\end{array}$ & 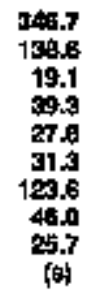 & $\begin{array}{r}2540 \\
47.9 \\
11.0 \\
21.5 \\
15.8 \\
20.1 \\
92.5 \\
28.7 \\
172 \\
147\end{array}$ \\
\hline 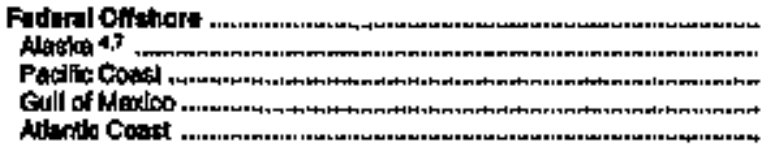 & $\begin{array}{l}9.2 \\
0.8 \\
0.9 \\
4.9 \\
0.1\end{array}$ & $\begin{array}{r}25.8 \\
6.4 \\
8.3 \\
13.6 \\
2.3\end{array}$ & $\begin{array}{r}18.1 \\
3.4 \\
3.4 \\
8.6 \\
0.7\end{array}$ & 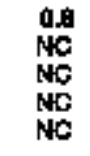 & $\begin{array}{l}4.7 \\
\text { NG } \\
\text { NG } \\
\text { NC } \\
\text { NC }\end{array}$ & $\begin{array}{l}\mathbf{N C} \\
\mathrm{NC} \\
\mathrm{NC} \\
\mathrm{NC}\end{array}$ & $\begin{array}{r}97.9 \\
4.7 \\
3.5 \\
6 \times, 0 \\
\mathbf{6 . 9}\end{array}$ & $\begin{array}{r}204.8 \\
39.4 \\
15.1 \\
136,9 \\
33.7\end{array}$ & $\begin{array}{r}145.1 \\
16.8 \\
8.0 \\
102.0 \\
17.0\end{array}$ \\
\hline \multirow[t]{2}{*}{ 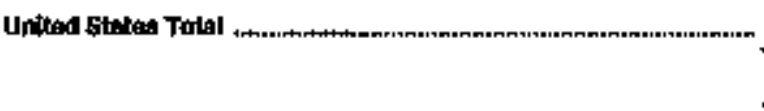 } & 3.2. & 68.0 & 49.4 & 6.1 & $\$ 1.5$ & 6.6 & 300,9 & 507.2 & 389,1 \\
\hline & \multicolumn{9}{|c|}{ Januay $1,+9 \% 4$} \\
\hline 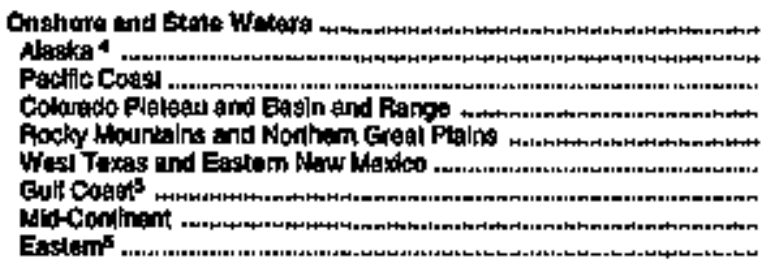 & $\begin{array}{l}23.5 \\
3.2 \\
2.8 \\
0.7 \\
3.1 \\
2.2 \\
2.7 \\
0.0 \\
0.9\end{array}$ & $\begin{array}{r}39.4 \\
15.8 \\
5.9 \\
2.5 \\
6.0 \\
5.9 \\
8.9 \\
1.0 \\
2.5\end{array}$ & $\begin{array}{r}30.3 \\
8.4 \\
4.0 \\
1.4 \\
4.6 \\
8.6 \\
5.8 \\
1.2 \\
1.8\end{array}$ & $\begin{array}{l}5.12 \\
0.4 \\
0.2 \\
0.1 \\
0.0 \\
0.5 \\
1.0 \\
0.8 \\
0.8\end{array}$ & $\begin{array}{r}6.67 \\
2.1 \\
0.4 \\
0.4 \\
2.2 \\
1.0 \\
3.9 \\
0.5 \\
0.4\end{array}$ & $\begin{array}{l}7.2 \\
1.1 \\
0.3 \\
0.2 \\
1.5 \\
0.8 \\
2.8 \\
0.4 \\
0.8\end{array}$ & $\begin{array}{r}207.1 \\
27.9 \\
7.7 \\
5.5 \\
15.2 \\
12.9 \\
70.9 \\
19.6 \\
7.9\end{array}$ & $\begin{array}{r}328.1 \\
128.2 \\
17.7 \\
15.3 \\
31.1 \\
15.8 \\
130.2 \\
27.5 \\
15.8\end{array}$ & $\begin{array}{r}250.7 \\
684 \\
120 \\
9.1 \\
21.9 \\
188 \\
97.6 \\
196 \\
11.4\end{array}$ \\
\hline 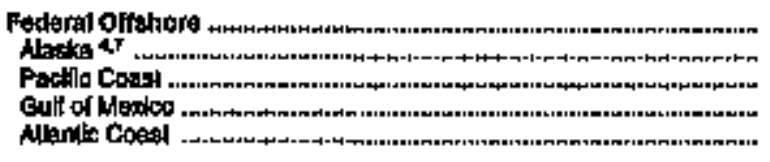 & $\underset{M A}{M A}$ & $\begin{array}{l}\text { NA } \\
\text { NA } \\
N A \\
N A\end{array}$ & $\begin{array}{l}\text { NA } \\
\text { NA } \\
\text { NA } \\
N A \\
\text { (1) }\end{array}$ & $\begin{array}{l}\text { NA } \\
\text { NA } \\
\text { NA } \\
\text { NA } \\
\left({ }^{*}\right)\end{array}$ & 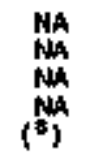 & $\begin{array}{l}\text { NA } \\
\text { NA } \\
N_{A} \\
N_{A} \\
\left.N_{A}^{*}\right)\end{array}$ & 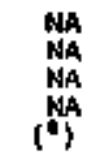 & 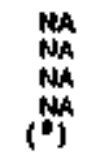 & $\begin{array}{l}\mathrm{MA} \\
\mathrm{MA} \\
\mathrm{MA} \\
\mathrm{OA}\end{array}$ \\
\hline United Sintes Total .m. & $\mathbf{r a}$ & NA & Ma & MA & MA & Na & Ma & HA & $\mathbf{M A}$ \\
\hline
\end{tabular}

1 Sop Note $\mathrm{x}$ al end of section.

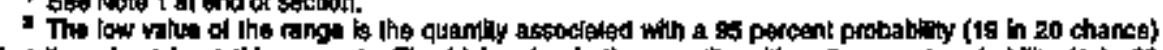

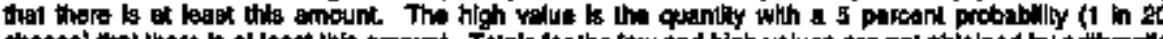

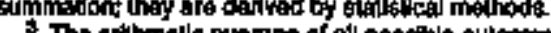

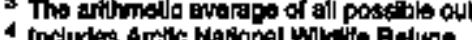

- tincludes Aredc Haxonel Wilatio Aatuge.

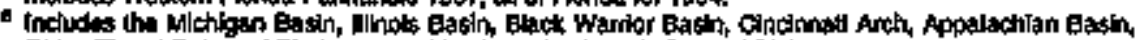

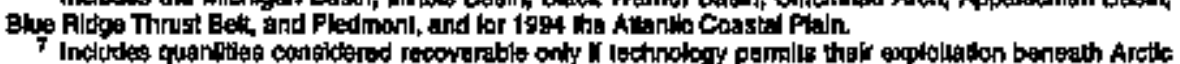

Ce- a conifition nol yed mat.

Peglon (Aulantle Coasi oll-shores not usad in 1984.

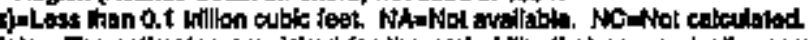

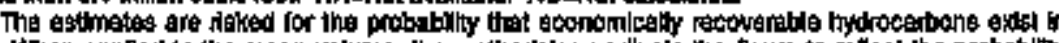

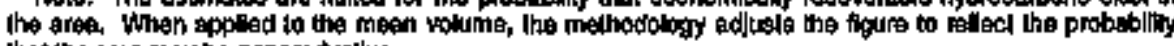

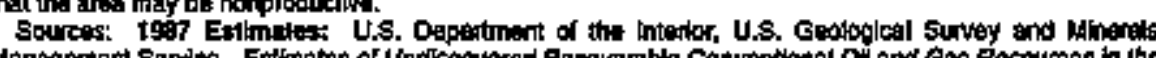

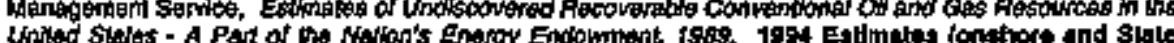

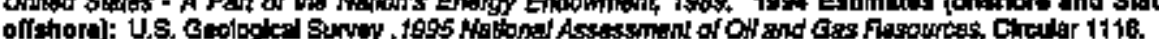




\section{Figure 4.2 Crude Oil and Natural Gas Fieid Counts, Cumulative Production, Proved Reserves, and Ultimate Recovery, End of Year 1977-1994}

\section{Cumulailve Wumber of Fids}

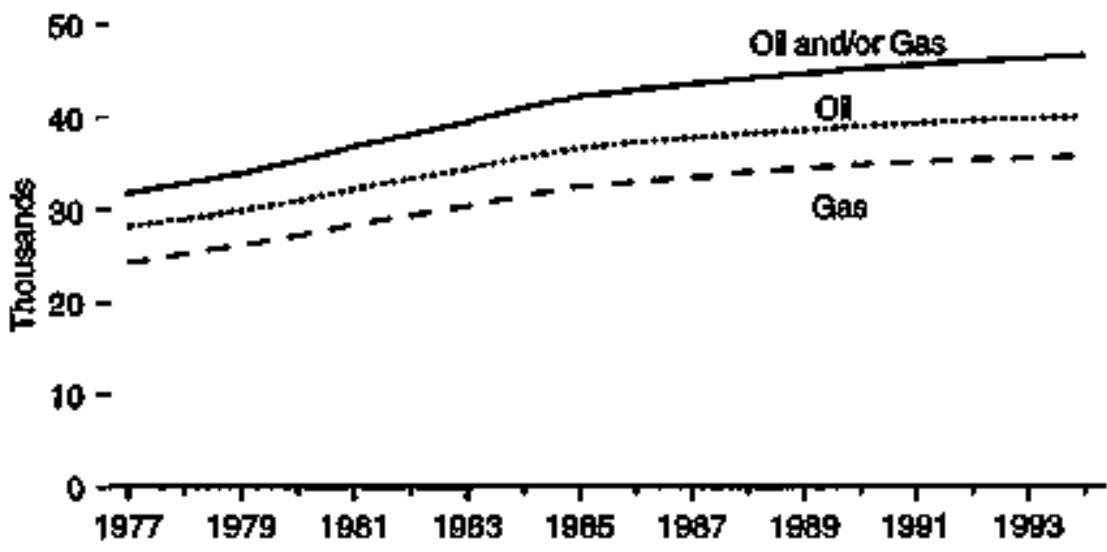

\section{Cruste 에}

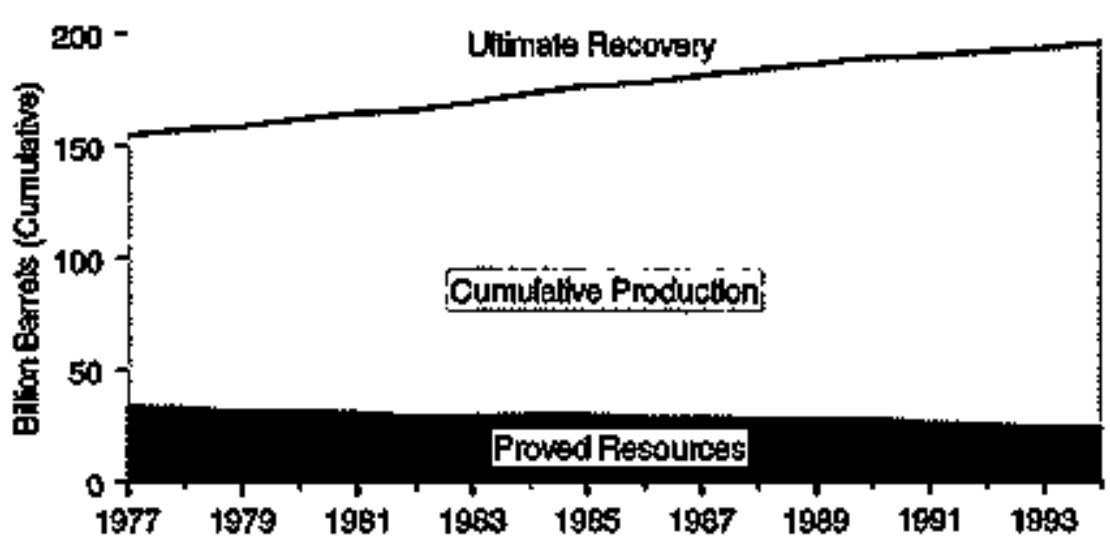

Cumulative Production and Proved Reserves, Indexed to 1977

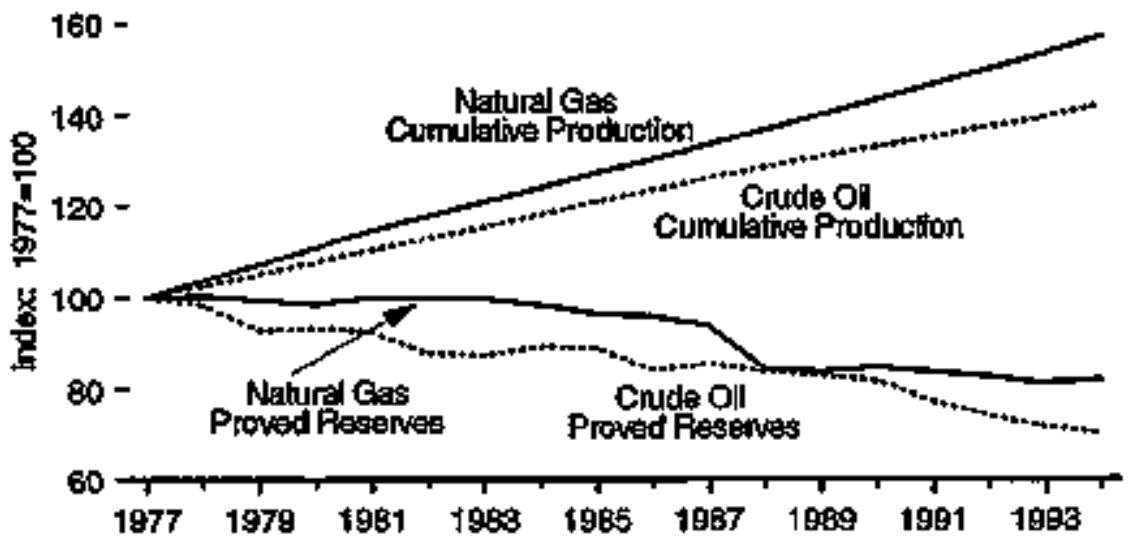

Natural Gas

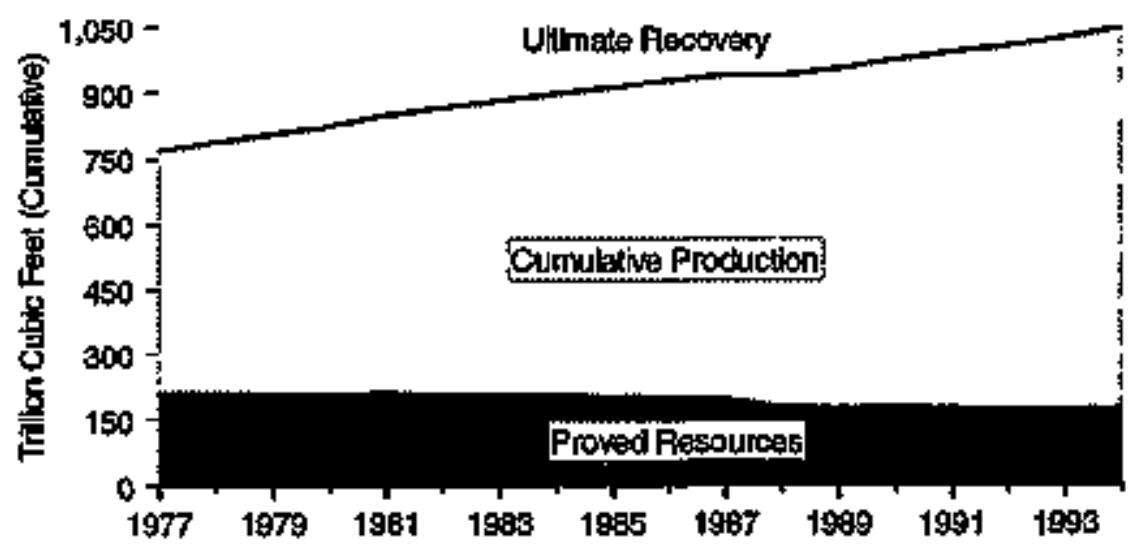

Sorrces: Taten 42. 
Table 4.2 Crude Oll and Natural Gas Fleld Counts, Cumulatlve Production, Proved Reserves, and Uitimate Recovery, End of Year 1977-1994

\begin{tabular}{|c|c|c|c|c|c|c|c|c|c|}
\hline \multirow[b]{2}{*}{ Yur } & \multirow{2}{*}{ 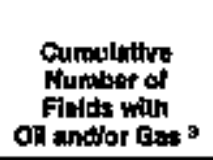 } & \multirow{2}{*}{ 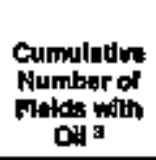 } & \multicolumn{3}{|c|}{$\begin{array}{l}\text { Grude OR } 1 \\
\text { (bitilion barrels) }\end{array}$} & \multirow{2}{*}{$\begin{array}{l}\text { Cumulatus } \\
\text { Nhumber of } \\
\text { Fledds with } \\
\text { Bas? }\end{array}$} & \multicolumn{3}{|c|}{$\begin{array}{c}\text { Mencer Gess } 2 \\
\text { (orlition cublo feet) }\end{array}$} \\
\hline & & & $\begin{array}{l}\text { Cumulatire } \\
\text { Produallon }\end{array}$ & $\begin{array}{l}\text { Prowod } \\
\text { Peserves }\end{array}$ & $\begin{array}{c}\text { Mlimaiks } \\
\text { fecovary }\end{array}$ & & $\begin{array}{l}\text { Cumulative } \\
\text { Produclion }\end{array}$ & $\begin{array}{l}\text { Prevod } \\
\text { Arsenves }\end{array}$ & $\begin{array}{l}\text { Iotimale } \\
\text { Racowory }\end{array}$ \\
\hline $\begin{array}{l}1977 \\
1978 \\
1979 \\
1990 \\
1981 \\
1998 \\
1989 \\
1994 \\
19895 \\
1985 \\
1098 \\
1097 \\
1909 \\
1969 \\
1990 \\
1994 \\
1998 \\
7993 \\
7094\end{array}$ & 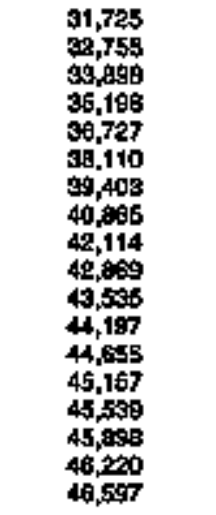 & 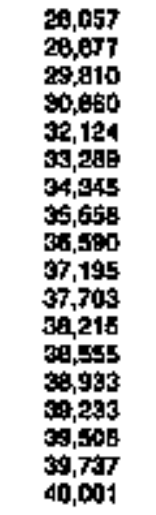 & $\begin{array}{l}121.4 \\
124.6 \\
127.7 \\
130.8 \\
133.9 \\
137.1 \\
140.3 \\
143.5 \\
145.8 \\
150.0 \\
153.0 \\
155.0 \\
158.8 \\
161.5 \\
164.5 \\
1655.8 \\
169.3 \\
172.5\end{array}$ & $\begin{array}{l}39.6 \\
39.1 \\
31.2 \\
31.3 \\
31.0 \\
29.5 \\
29.3 \\
30.0 \\
29.9 \\
29.9 \\
29.7 \\
29.2 \\
27.9 \\
27.6 \\
25.9 \\
25.0 \\
24.1 \\
23.6\end{array}$ & $\begin{array}{l}156.0 \\
157.6 \\
159.9 \\
158.2 \\
185.0 \\
168.6 \\
169.6 \\
173.5 \\
176.7 \\
178.3 \\
181.7 \\
184.2 \\
186.7 \\
189.0 \\
190.1 \\
195.8 \\
193.4 \\
198.2\end{array}$ & 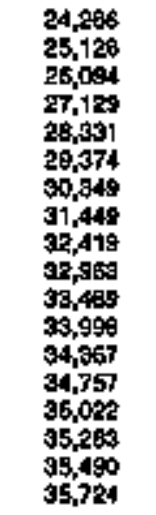 & 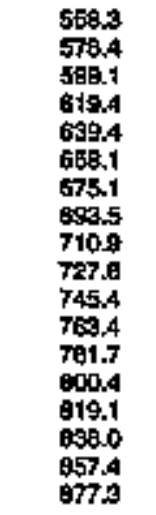 & $\begin{array}{l}200.5 \\
210.1 \\
200.3 \\
200.3 \\
205.4 \\
200.5 \\
200.0 \\
200.0 \\
200.2 \\
201.1 \\
196.4 \\
177.0 \\
175.4 \\
177.6 \\
175.3 \\
179.3 \\
170.5 \\
171.9\end{array}$ & $\begin{array}{r}767.8 \\
780.5 \\
807.4 \\
926.8 \\
849.9 \\
967.4 \\
904.1 \\
699.5 \\
919.1 \\
929.9 \\
941.8 \\
940.4 \\
957.4 \\
979.0 \\
994.4 \\
1,011.3 \\
1,087.9 \\
1,040.2\end{array}$ \\
\hline
\end{tabular}

1 Inctudes learg condensigle.

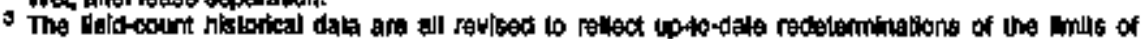

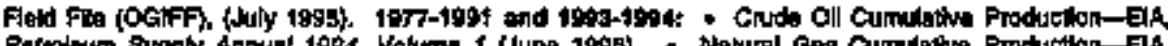

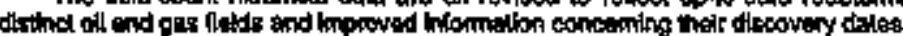

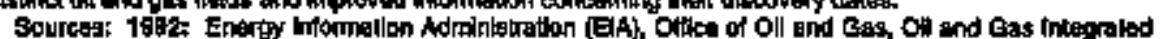

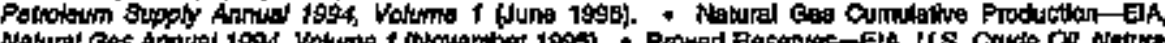
Ges, and

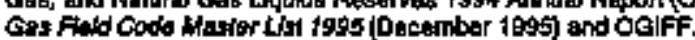


Figure 4.3 Oil and Gas Drilling Activity Measurements

Crews Engaged in Seismic Exploration, 1949-1993

$800-$

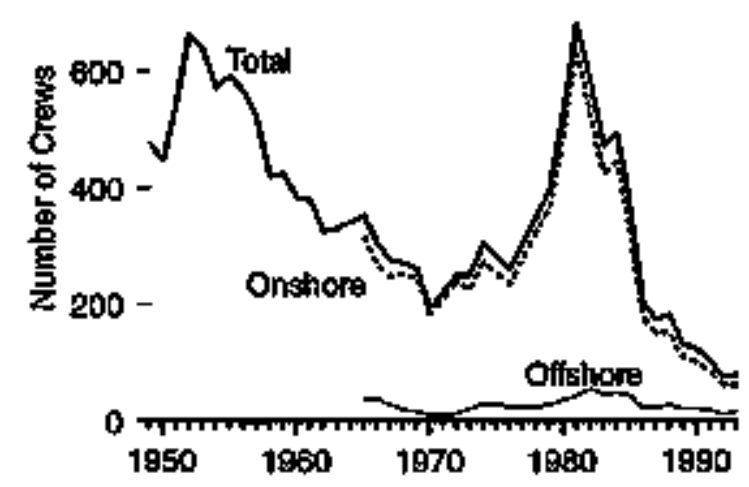

Rotary Figs in Operation by \$1to, 1949-1995

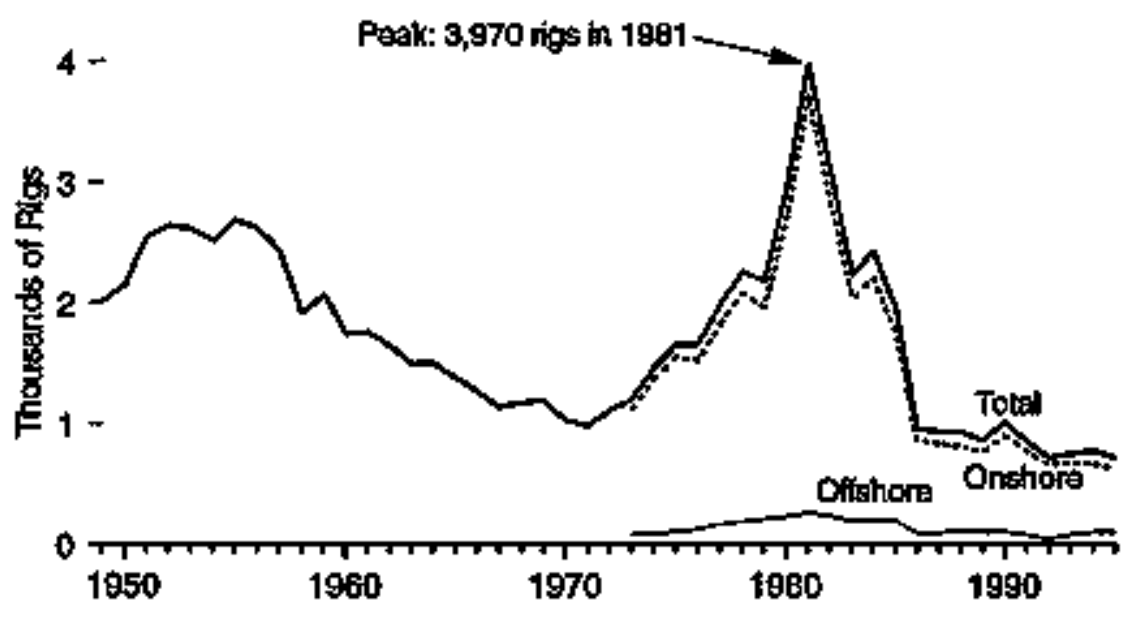

\section{Aetive Woll Servicing Units, 1976-1995}

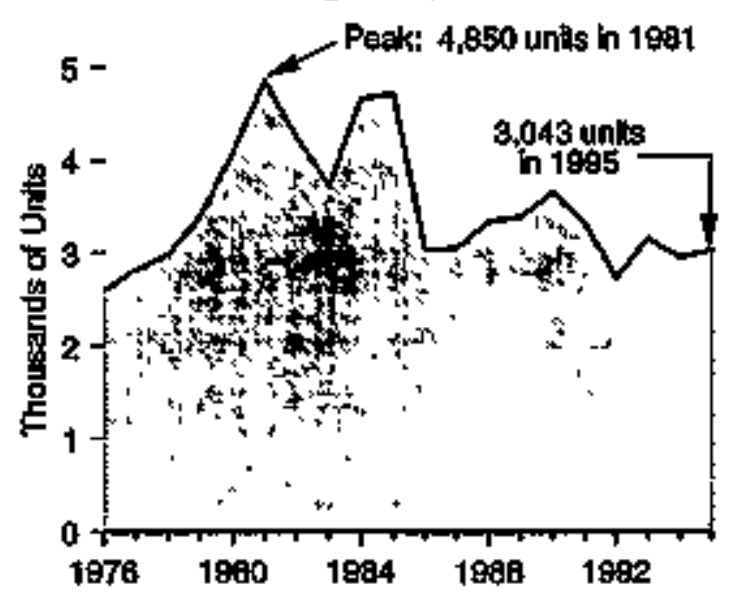

Souree: Tabla 4.3, 
Table 4.3 Oil and Gas Drilling Activity Measurements, 1949-1995

\begin{tabular}{|c|c|c|c|c|c|c|c|c|c|c|c|c|}
\hline \multirow[b]{3}{*}{ Yanr } & \multicolumn{3}{|c|}{ 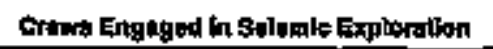 } & \multicolumn{3}{|c|}{ 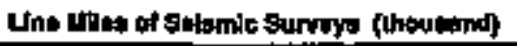 } & \multicolumn{5}{|c|}{ Fottry rlese In Opuntition 1} & \multirow{3}{*}{ 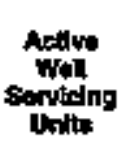 } \\
\hline & \multirow[b]{2}{*}{ Olishore } & \multirow[b]{2}{*}{ Onghare } & \multirow[b]{2}{*}{ Tots } & \multirow[b]{2}{*}{ Otlahore } & \multirow[b]{2}{*}{ Onshorn } & \multirow[b]{2}{*}{ Totnl } & \multicolumn{2}{|c|}{ Brsto } & \multicolumn{2}{|c|}{ By Typo } & \multirow[b]{2}{*}{ Tolve 2} & \\
\hline & & & & & & & Offistere & Onatsore & on & an: & & \\
\hline 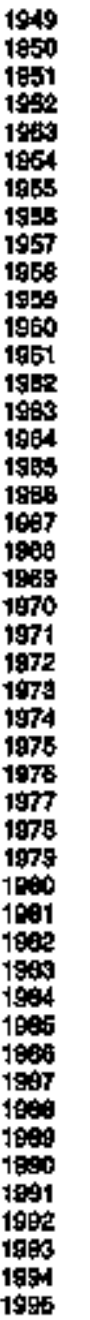 & 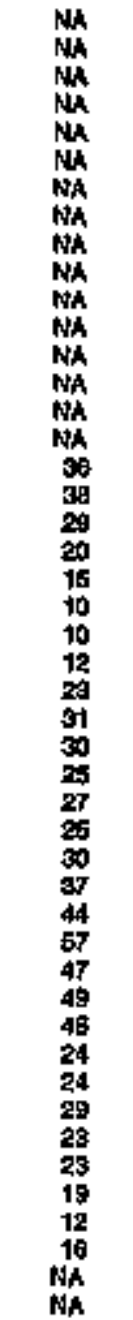 & 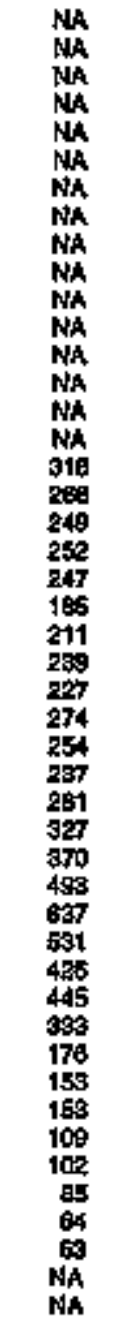 & 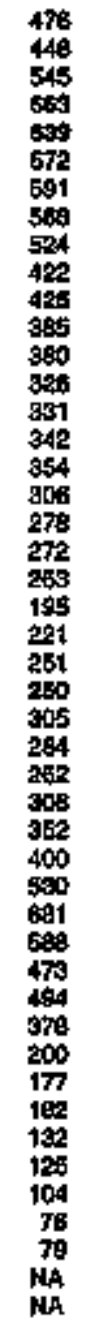 & 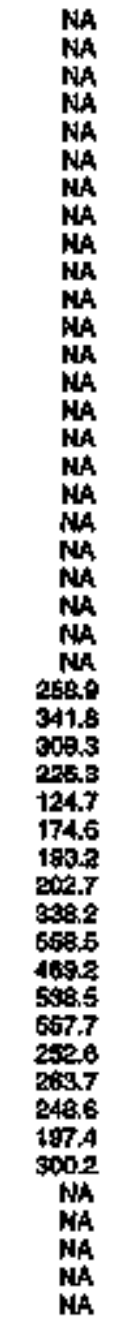 & 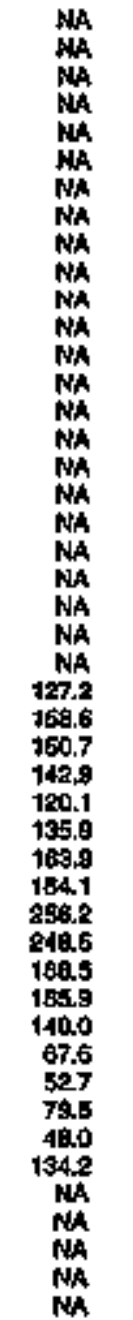 & 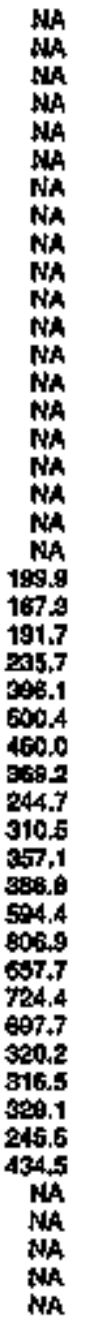 & 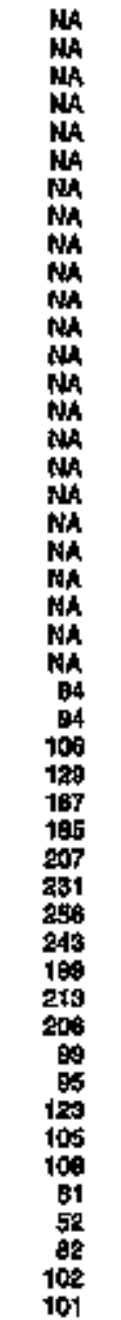 & 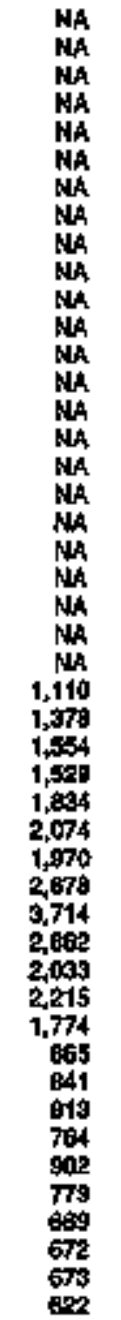 & $\begin{array}{l}\text { NA } \\
N A \\
N A \\
N A \\
N A \\
N A \\
N A \\
N A \\
N A \\
N A \\
N A \\
N A \\
N A \\
N A \\
N A \\
N A \\
N A \\
N A \\
N A \\
N A \\
N A \\
N A \\
N A \\
N A \\
N A \\
N A \\
N A \\
N A \\
N A \\
N A \\
N A \\
N A \\
N A \\
N A \\
N A \\
N A \\
N A \\
N A \\
N A \\
N A \\
B A 4 \\
45 B \\
58 A \\
498 \\
373 \\
373 \\
395 \\
329\end{array}$ & 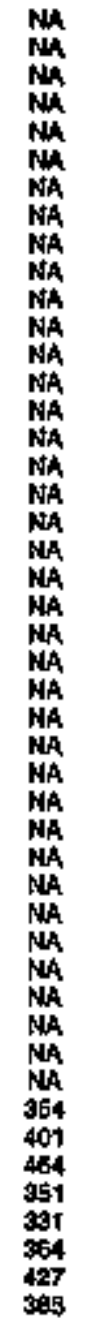 & 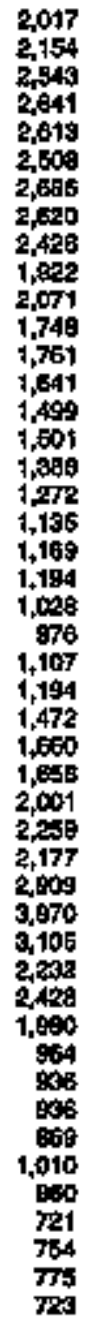 & 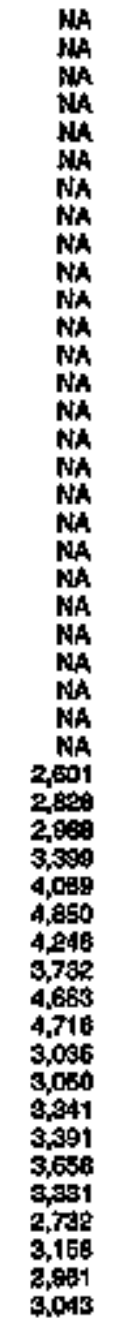 \\
\hline
\end{tabular}

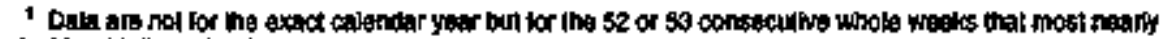

colnclde with the calendar your.

NhaNot watsole

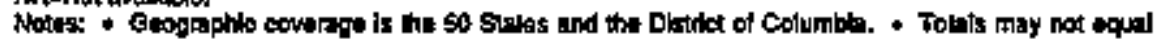

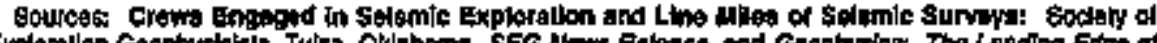

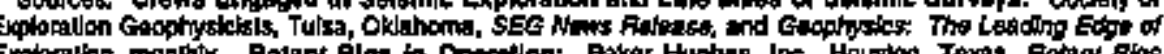

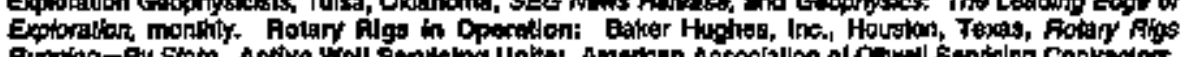

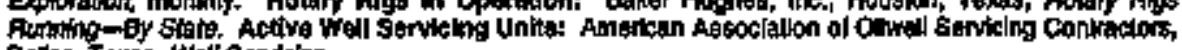
sula tol copriporienis dus to horependent rounding. 


\section{Figure 4.4 Oil and Gas Exploratory and Development Wolls, 1949-1995}

\section{Wells Dritled}

$45-$

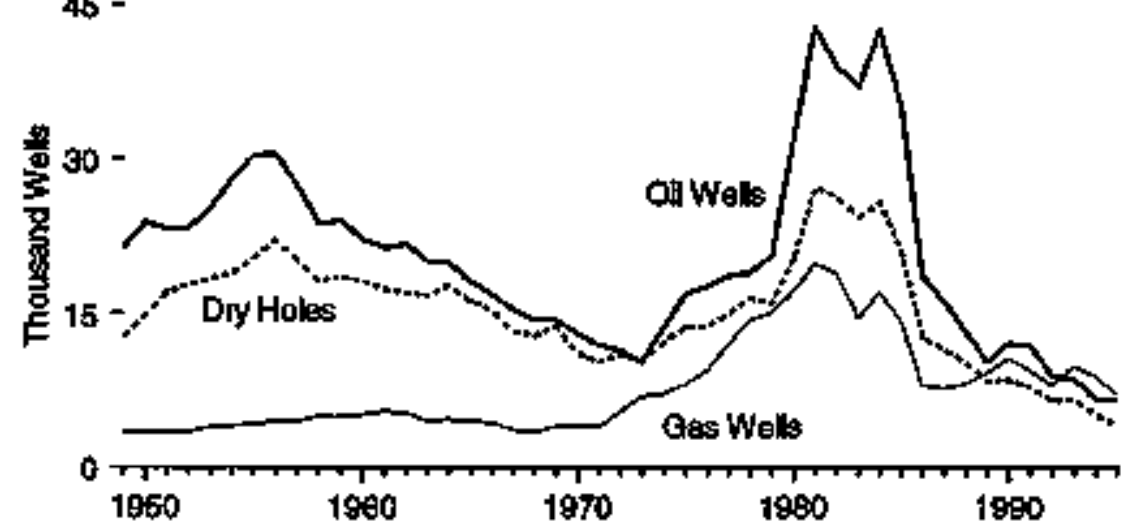

\section{Footage Drilled}

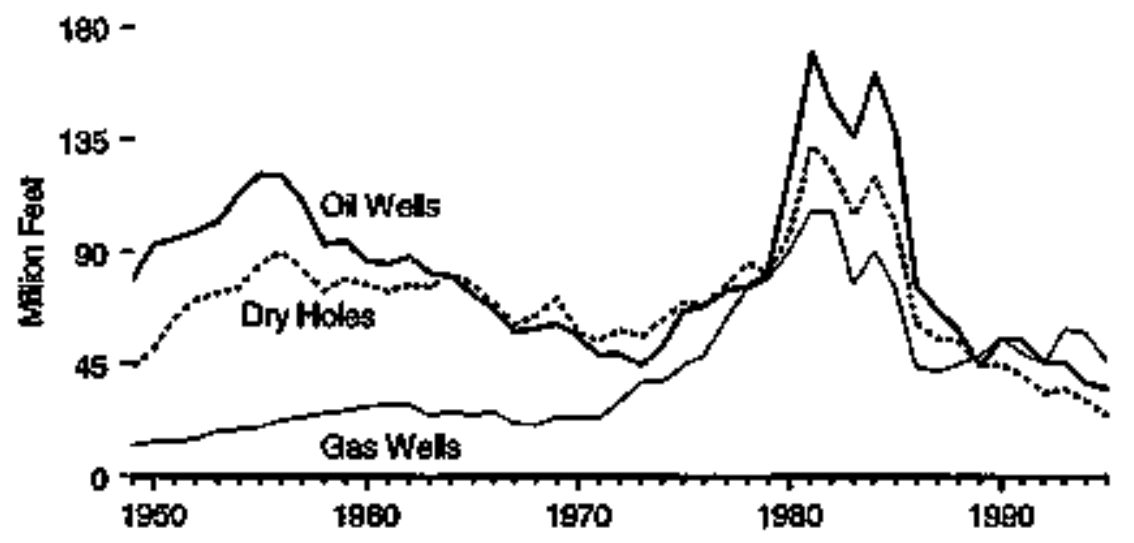

\section{Successful Wobs}

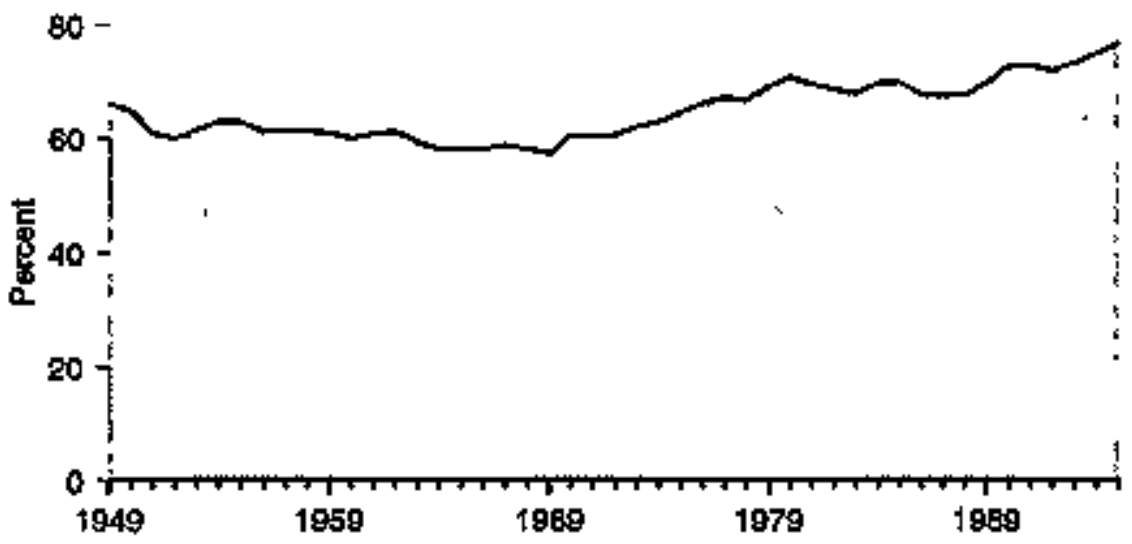

\section{Aperage Deplh}

8-

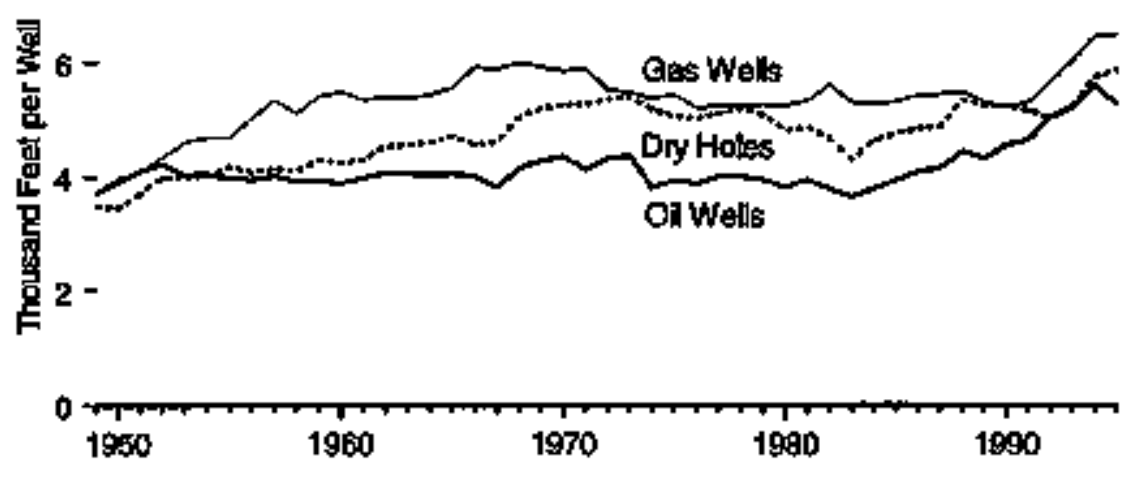

Sounce: Table 4.4. 
Table 4.4 Ofl and Gas Exploratory and Development Wells, 1949-1995

\begin{tabular}{|c|c|c|c|c|c|c|c|c|c|c|c|c|c|}
\hline \multirow[b]{2}{*}{ Vear } & \multicolumn{4}{|c|}{$\begin{array}{l}\text { Wolla Drined } \\
\text { (thiacreandit) }\end{array}$} & \multirow{2}{*}{$\begin{array}{c}\text { Successstul } \\
\text { Woilla } \\
\text { (pereant) }\end{array}$} & \multicolumn{4}{|c|}{$\begin{array}{c}\text { Footopg Drilfed } \\
\text { (midilon feet) }\end{array}$} & \multicolumn{4}{|c|}{ 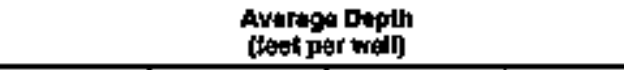 } \\
\hline & 에 & Gas & Dry Holes & Total & & OAl & Gag & by Haka & Tolde & 에 & Gas & Ory Holes & Tota \\
\hline 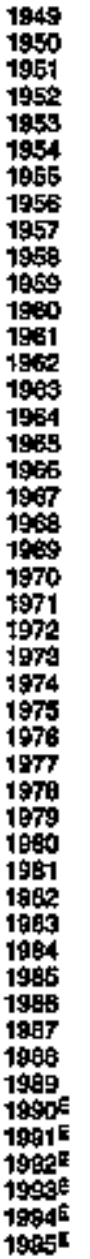 & 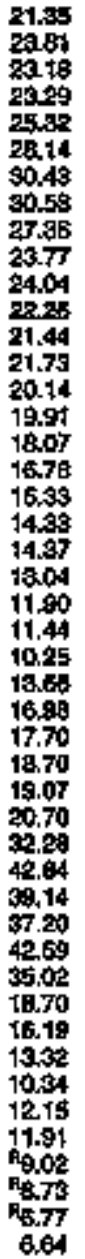 & 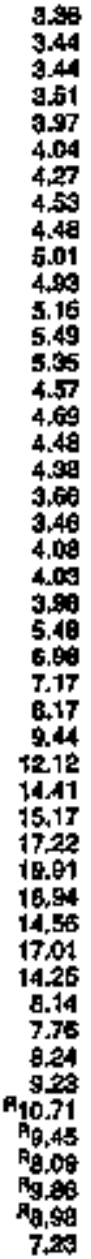 & 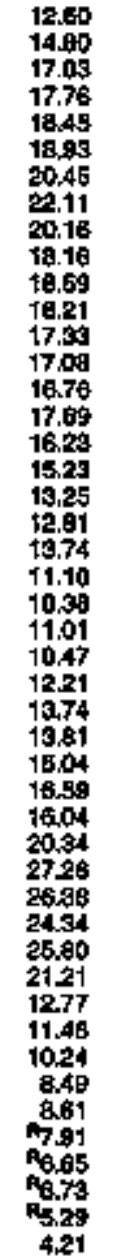 & 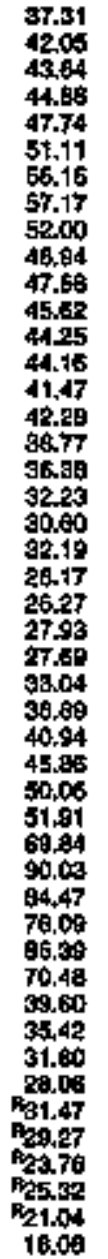 & 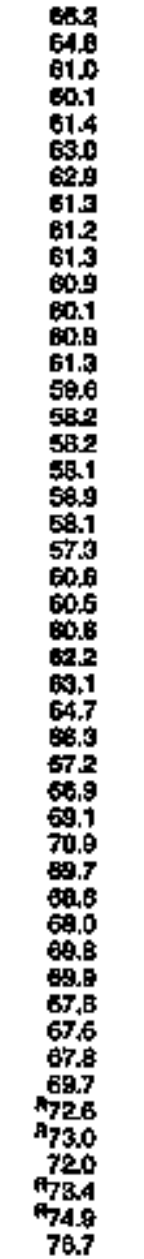 & 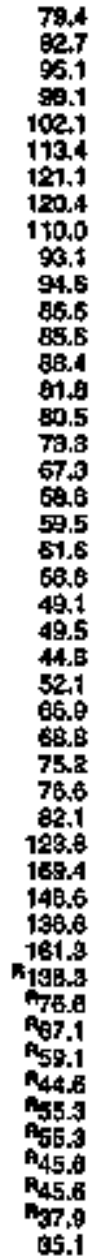 & 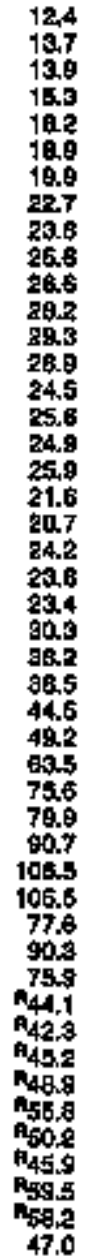 & 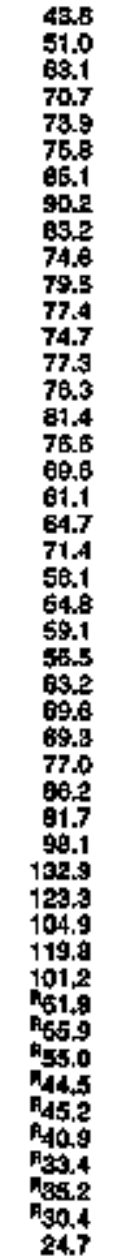 & 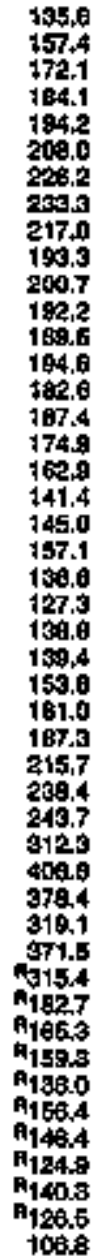 & 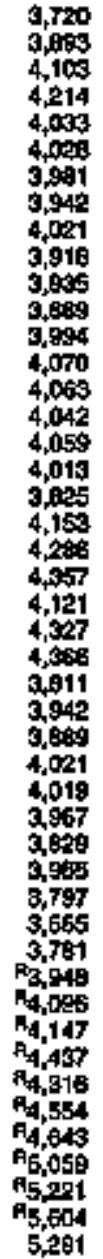 & 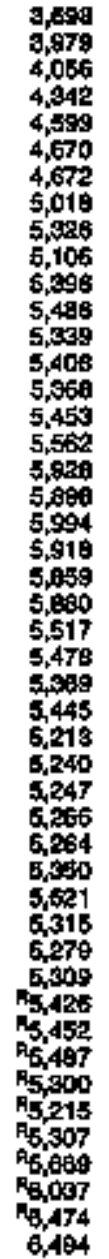 & 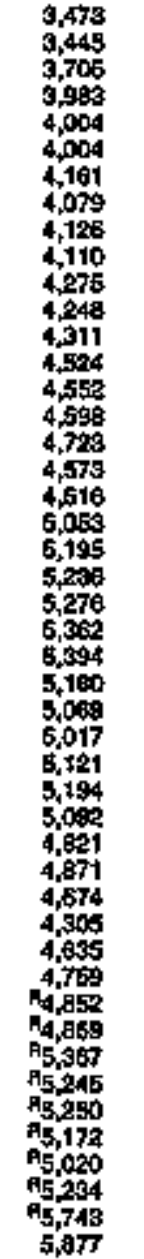 & 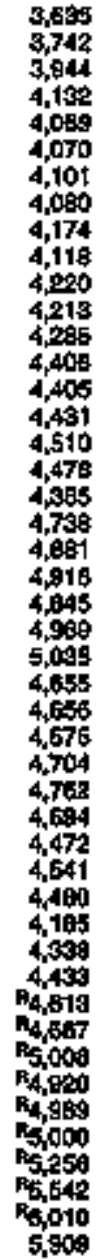 \\
\hline
\end{tabular}

A=Provised fala. E-Estimelta. Sat Noto 2 at and of stolion.

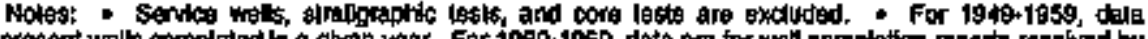

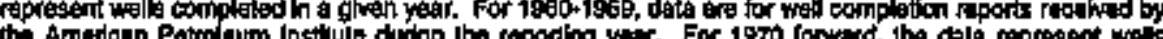

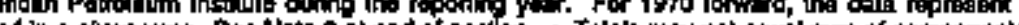

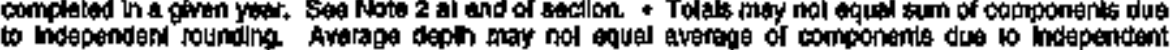

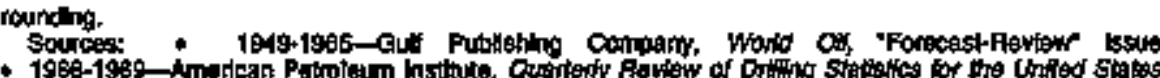

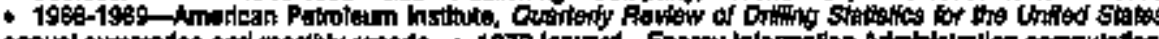

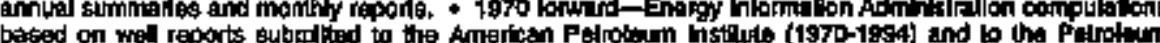

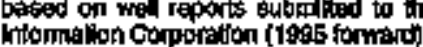




\section{Walls Drilled}

16 -

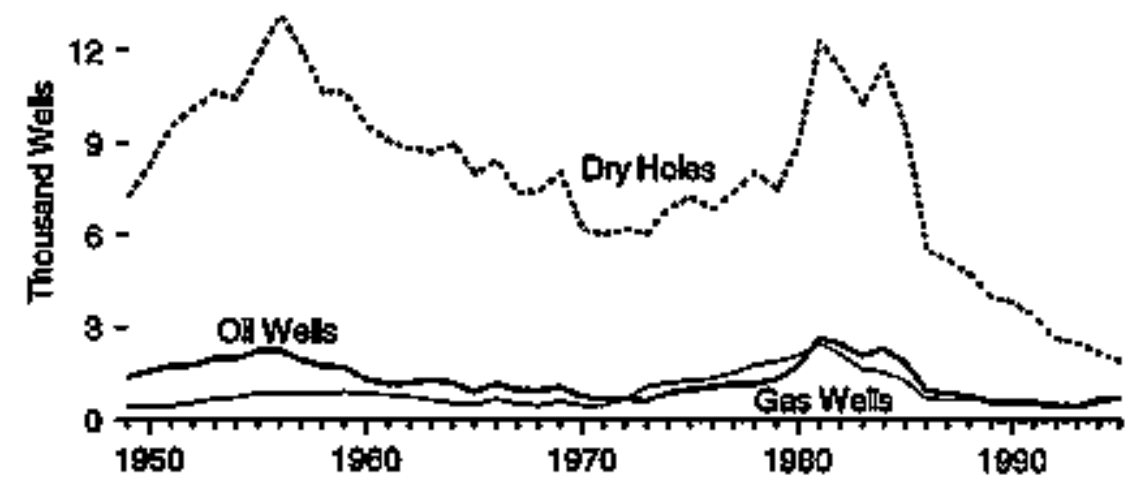

Footage Drilled

60 -

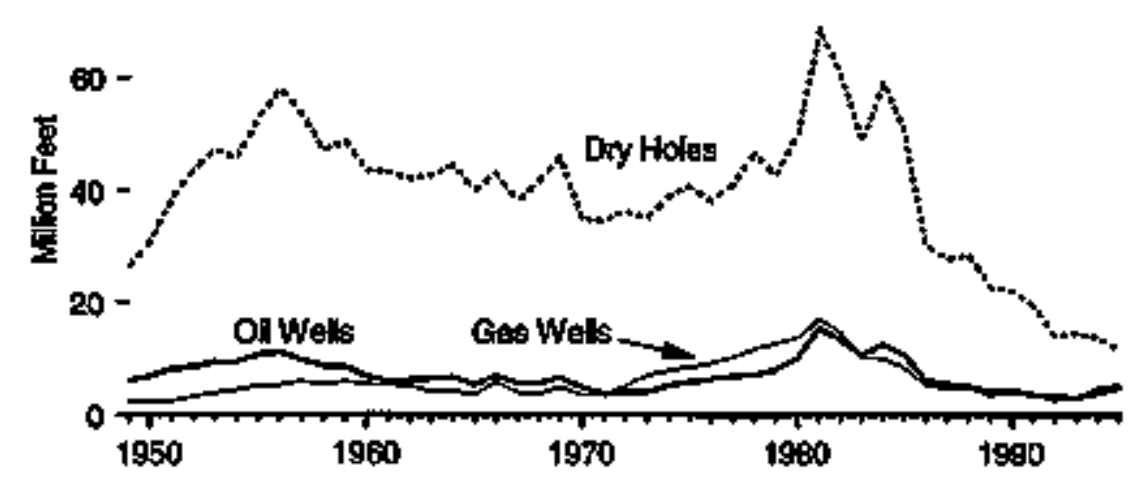

Buccesstul Weds

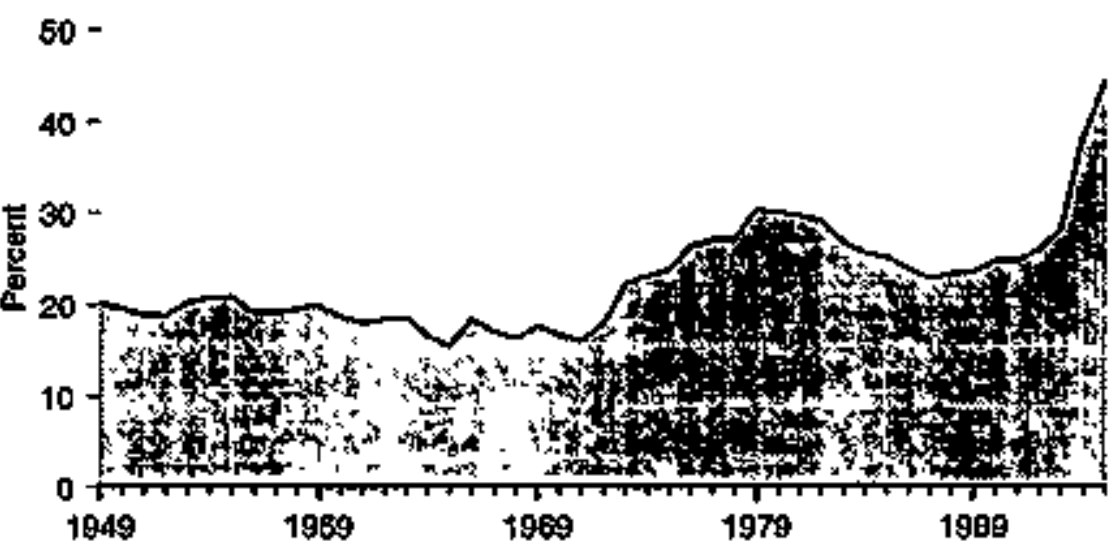

Average Deplh

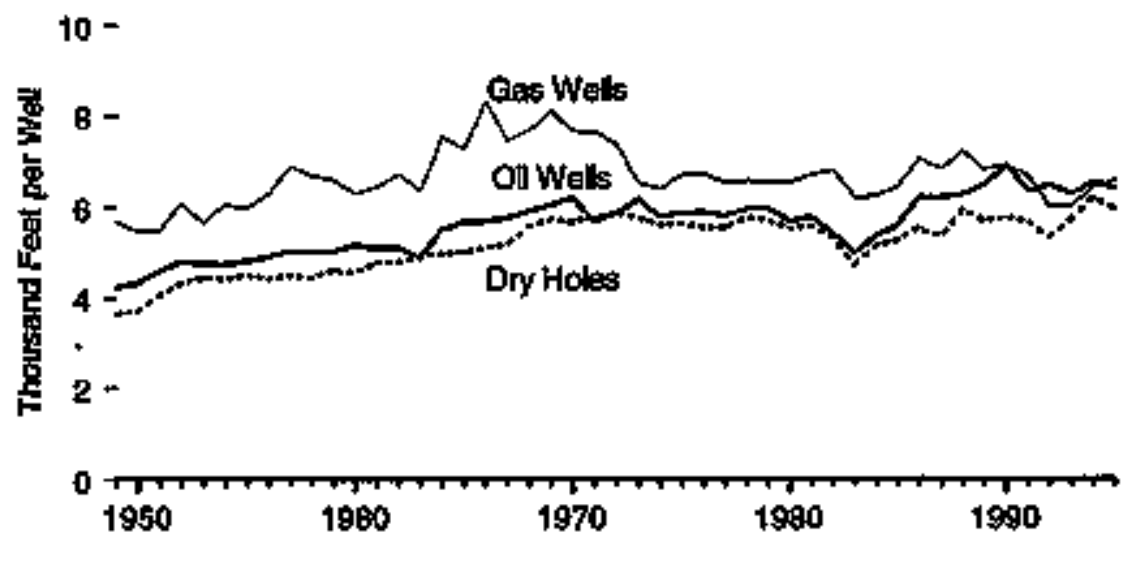

Sourca: Teble 4.5 . 
Table 4.5 Oil and Gas Exploratory Wells, 1949-1995

\begin{tabular}{|c|c|c|c|c|c|c|c|c|c|c|c|c|c|}
\hline \multirow[b]{2}{*}{ Your } & \multicolumn{4}{|c|}{ 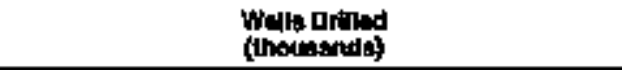 } & \multirow{2}{*}{$\begin{array}{c}\text { Suecesstul } \\
\text { Wello } \\
\text { (percenti) }\end{array}$} & \multicolumn{4}{|c|}{$\begin{array}{l}\text { Fostupe Drilled } \\
\text { (million foel) }\end{array}$} & \multicolumn{4}{|c|}{$\begin{array}{l}\text { Avergo bopth } \\
\text { (Ineal por whil) }\end{array}$} \\
\hline & on & Cos & Dry tolas & Toted & & 에 & C:s & Dry Holes & Total & Off & Ras: & Dn fiotes & Totsl \\
\hline 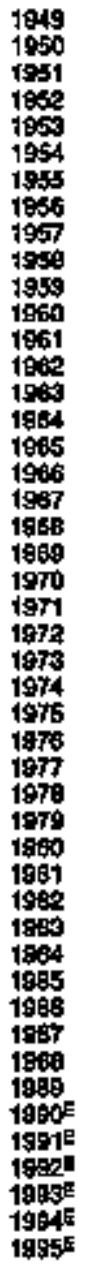 & 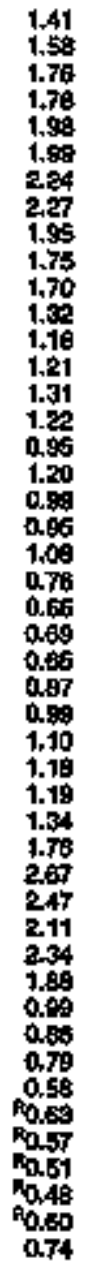 & 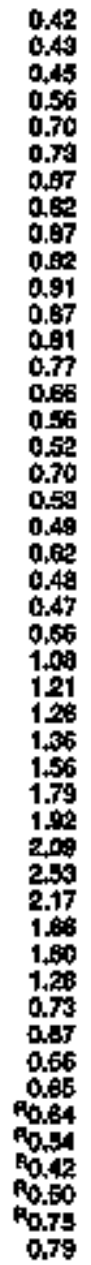 & 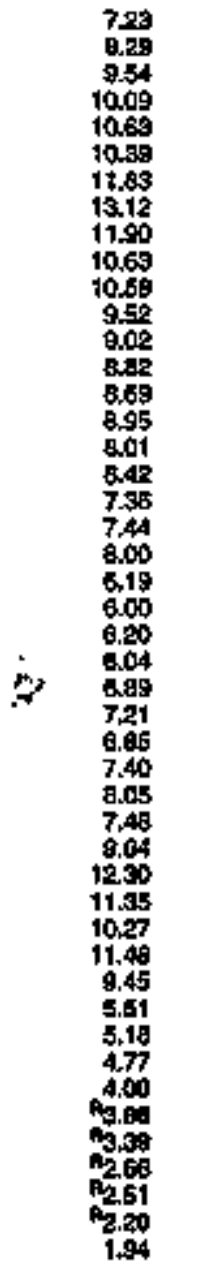 & 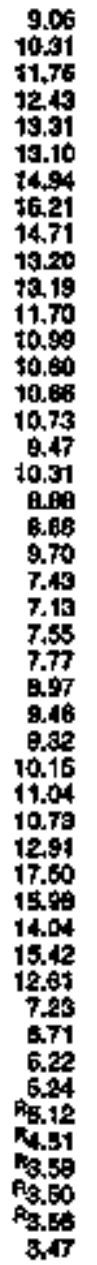 & 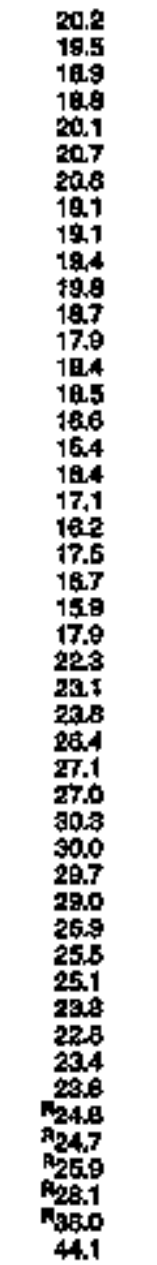 & 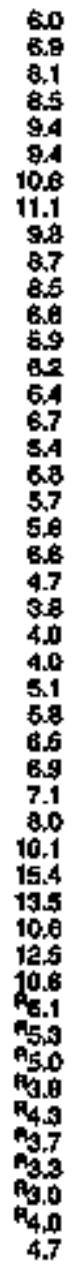 & 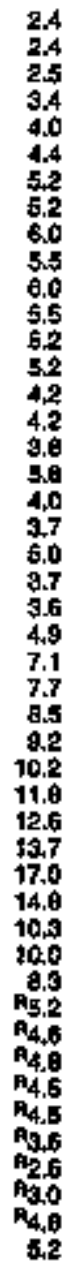 & 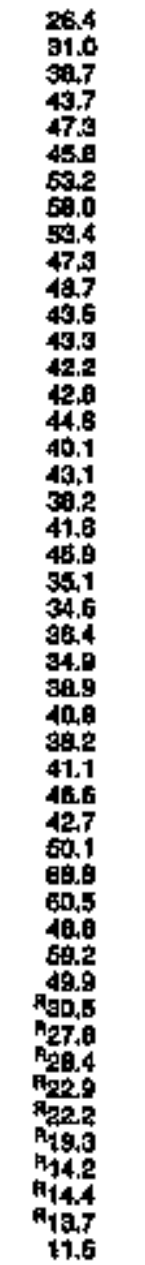 & 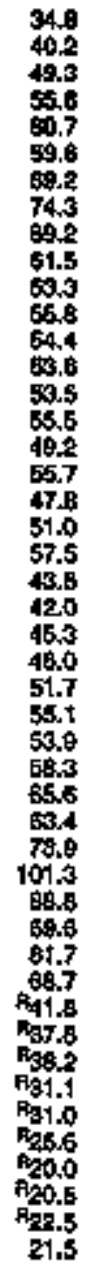 & 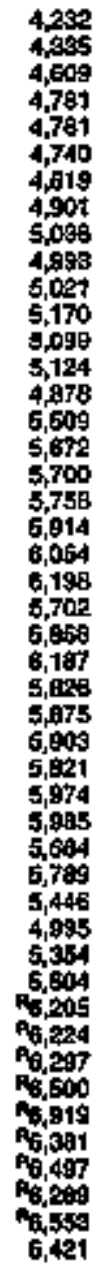 & 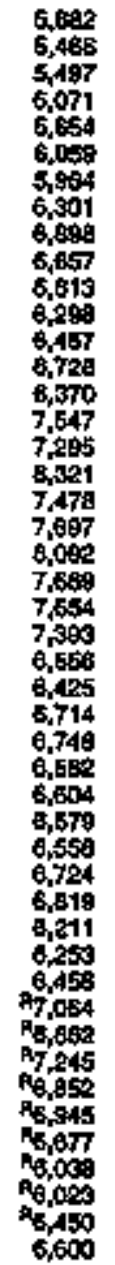 & 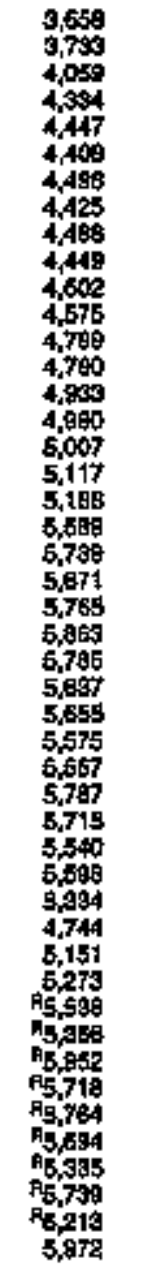 & 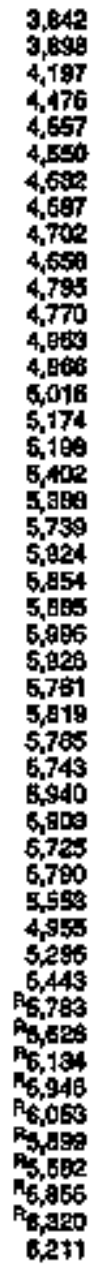 \\
\hline
\end{tabular}

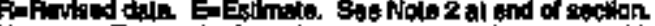

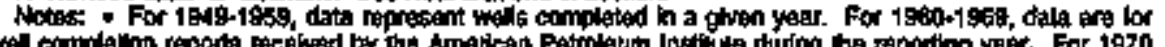

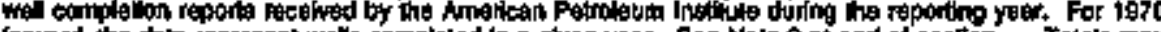

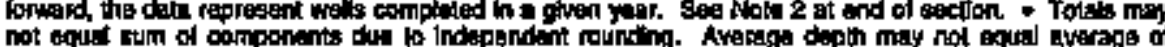
not equat itim of corponents dus lo lnd

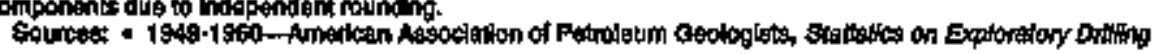

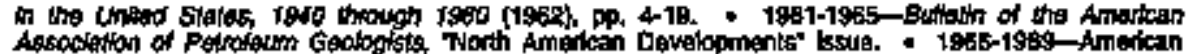

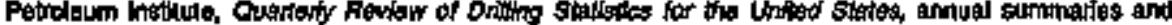

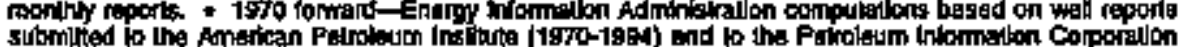
(19:5 tancard). 


\section{Wells Drited}

$45-$

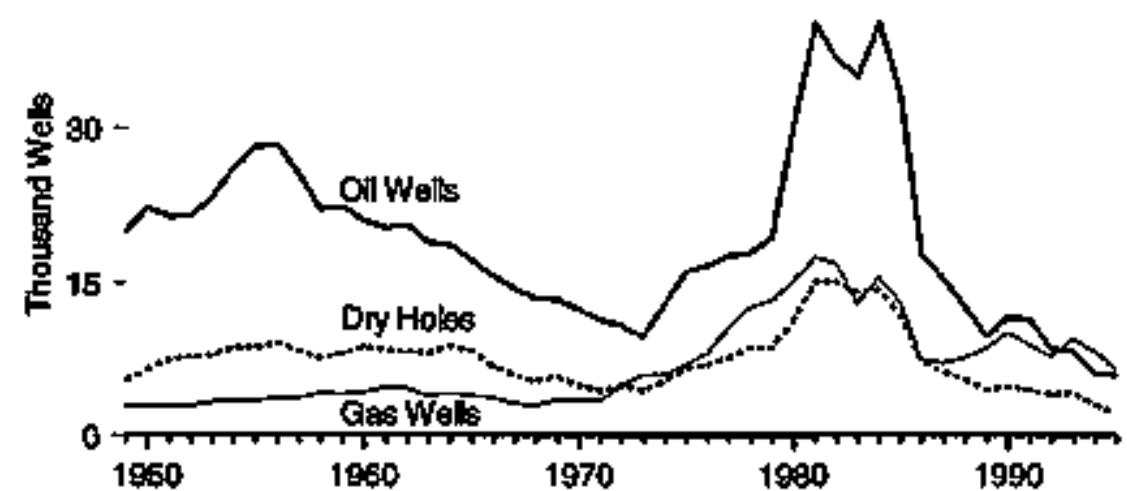

\section{Footage Drlled}

$180-$

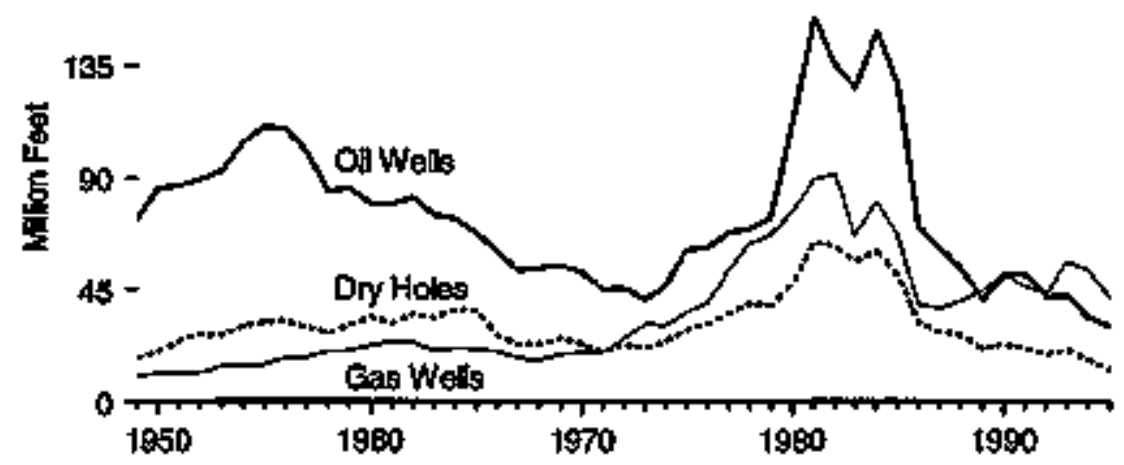

\section{Successful Wolls}

$100-$

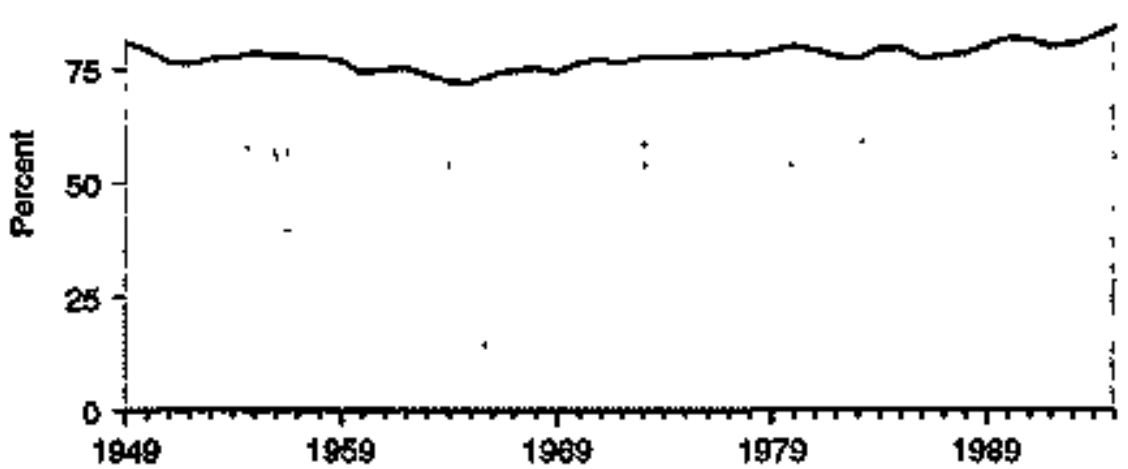

\section{Awarage Depth}

$$
\text { 8- }
$$

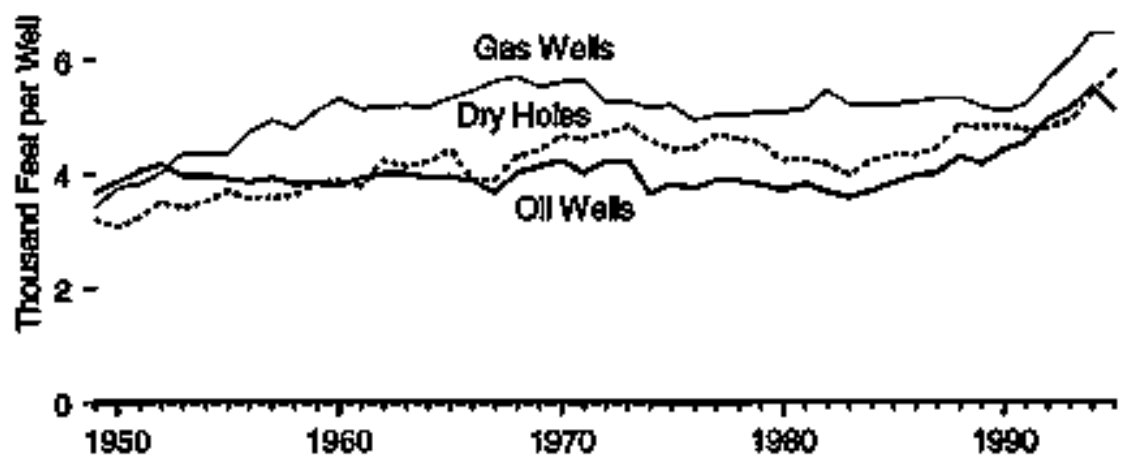

Source; Table 4.6. 
Table 4.6 Oll and Gas Development Wells, 1949-1995

\begin{tabular}{|c|c|c|c|c|c|c|c|c|c|c|c|c|c|}
\hline \multirow[b]{2}{*}{ Yaur } & \multicolumn{4}{|c|}{ 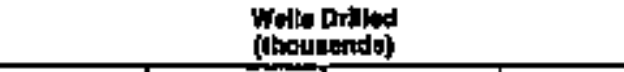 } & \multirow{2}{*}{ 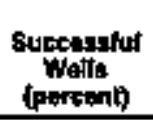 } & \multicolumn{4}{|c|}{$\begin{array}{c}\text { Footigo Ditled } \\
\text { (million feet) }\end{array}$} & \multicolumn{4}{|c|}{ 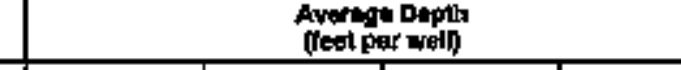 } \\
\hline & of & $\tan$ & Orytholes & Tot & & on & Cist & Dry Hothes & Toral & 䟚 & Gat & Drytholes & Total \\
\hline 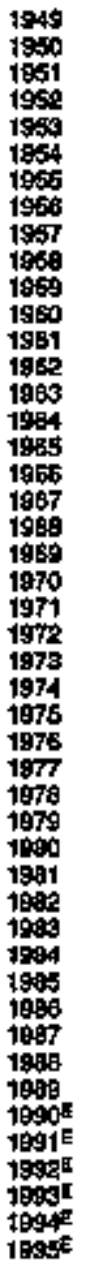 & 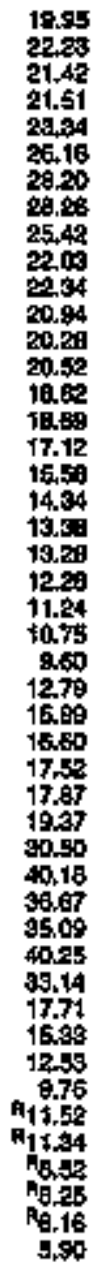 & 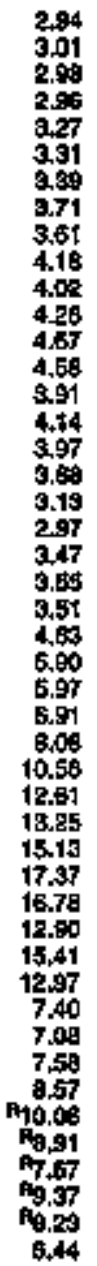 & 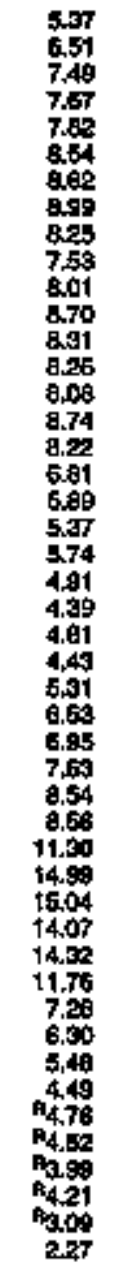 & 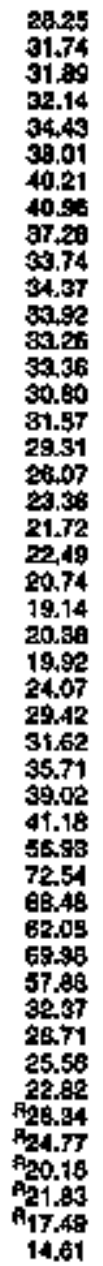 & 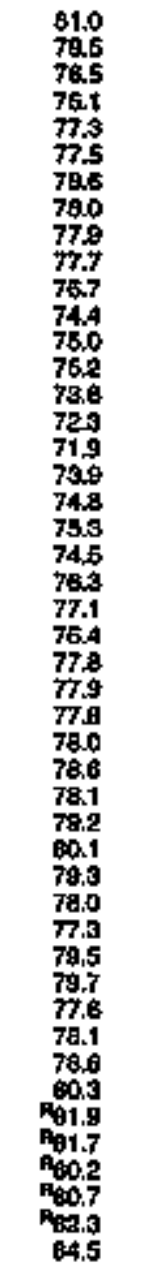 & 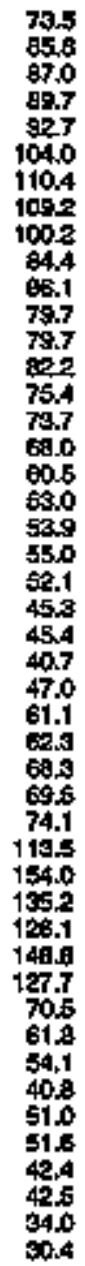 & 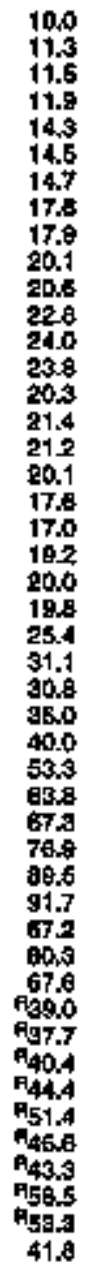 & 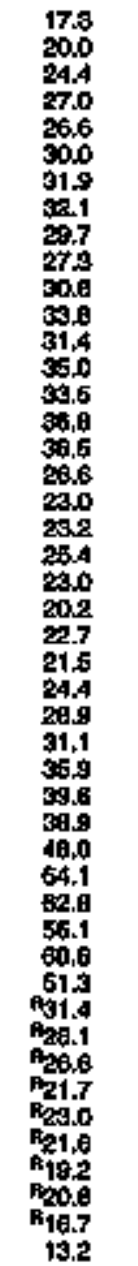 & 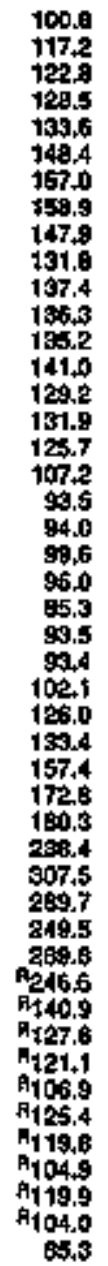 & 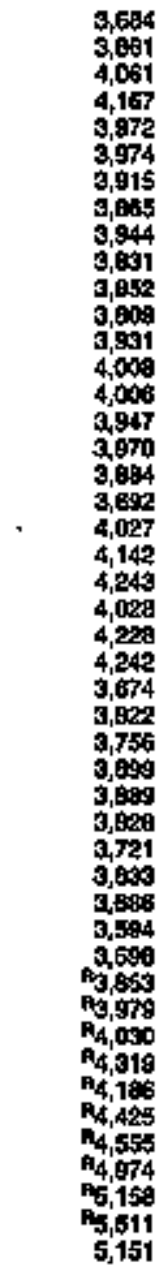 & 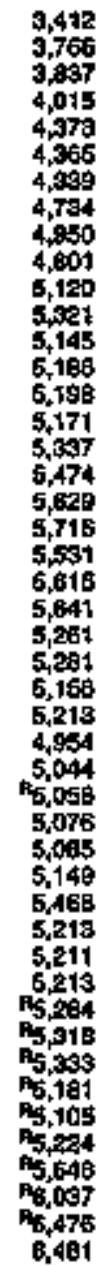 & 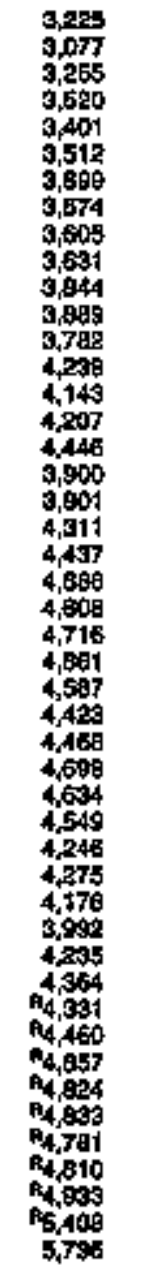 & 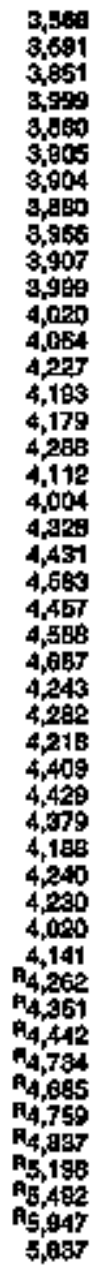 \\
\hline
\end{tabular}

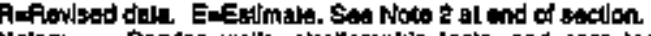

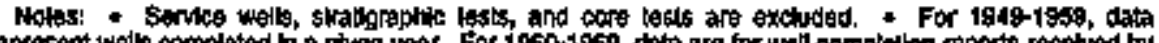

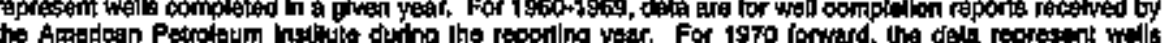

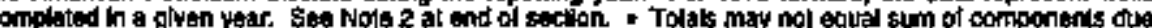
rouniding

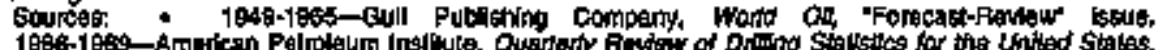

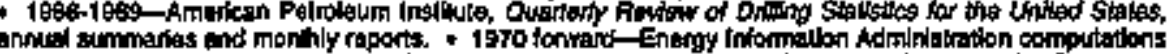

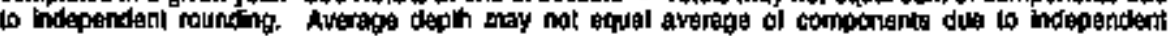

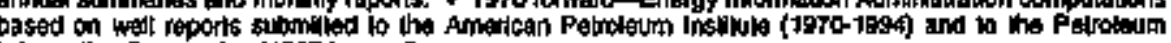

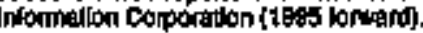




\section{Figure 4.7 Costs of Wells Drilled, 1960-1994}

\section{Costs per Well, All Wells}

$800-$
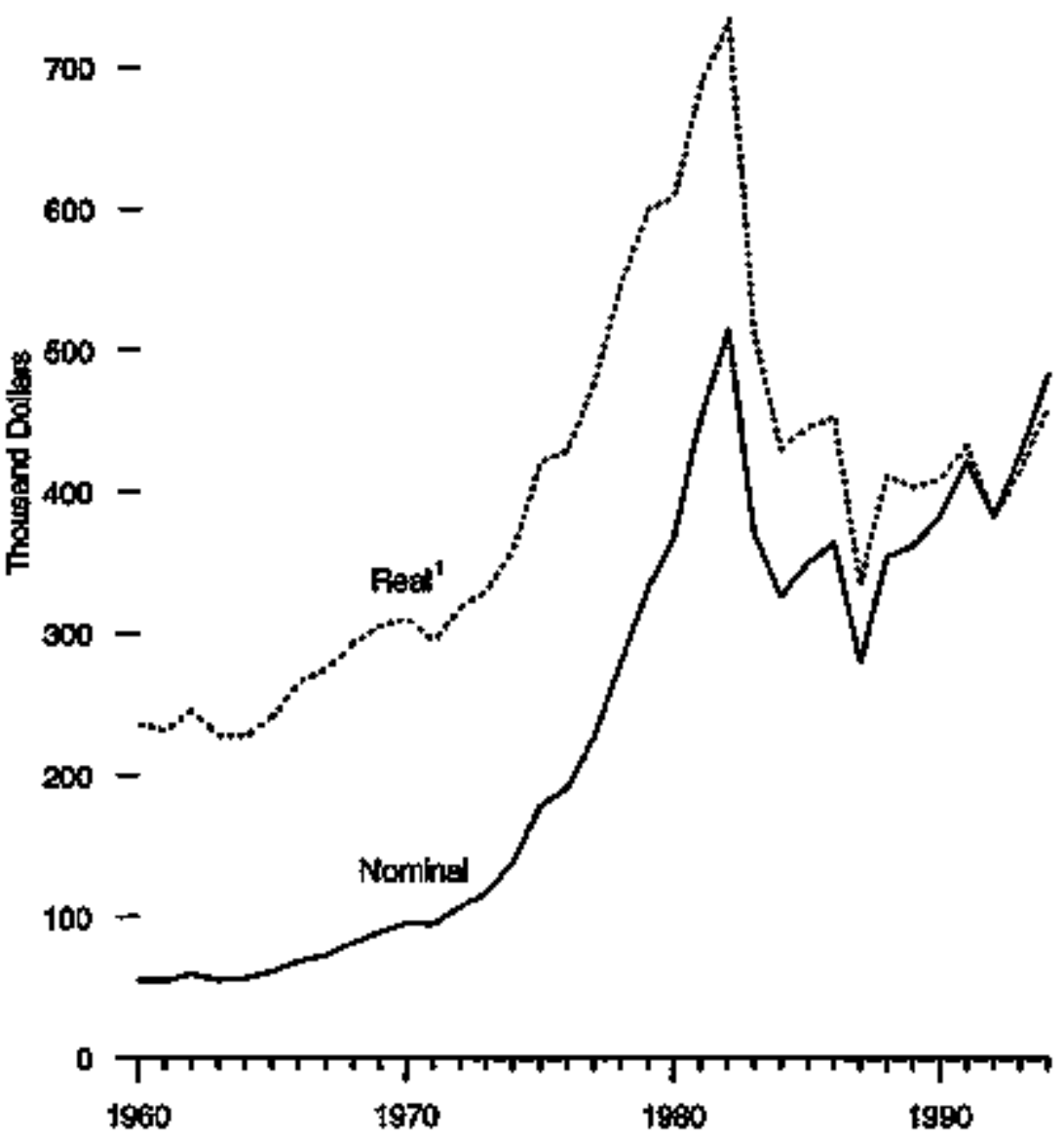

\section{Costs per Foot, All Wells}

$176-$

$150-$

$205-$

$\frac{5}{8}^{100-}$

$75-$
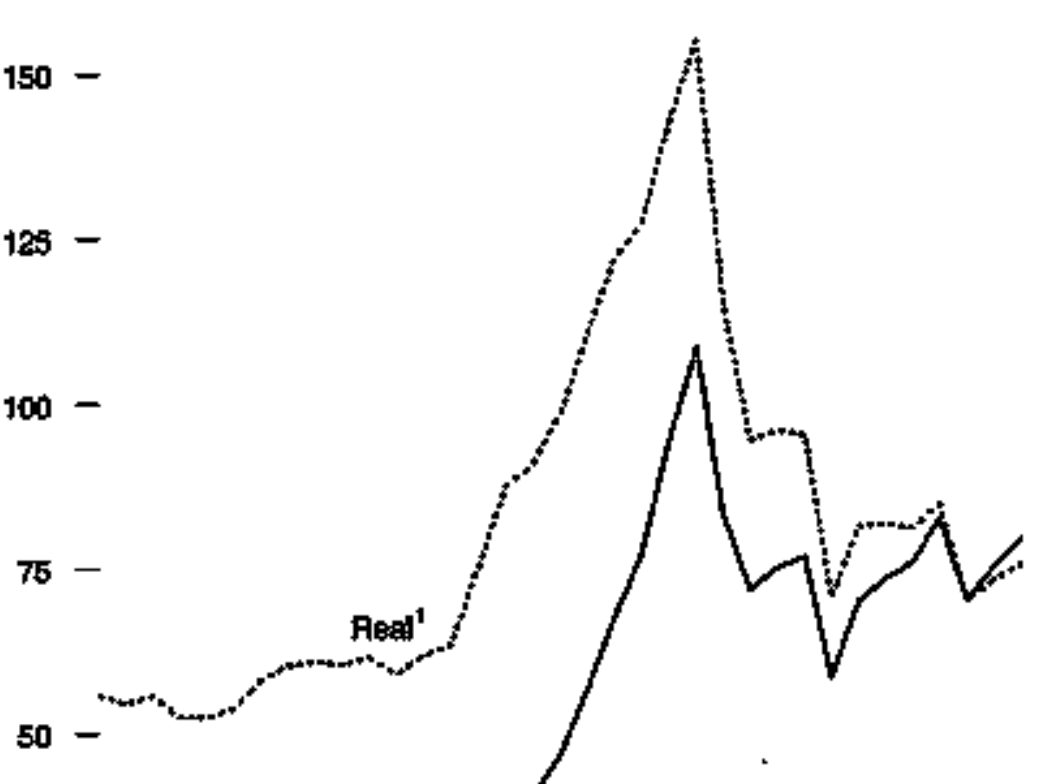
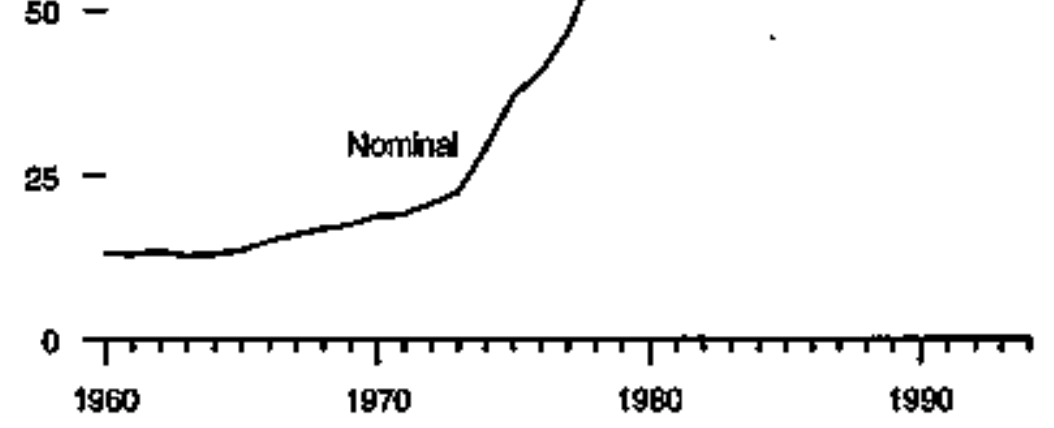

In thahed (1992) dollars, celculated by weind ooss domestic product implicti price dellatort. See Appendix E.

Sotice: Tablo 4.7 
Table 4.7 Costs of Oil and Gas Wells Drilled, 1960-1994

\begin{tabular}{|c|c|c|c|c|c|c|c|c|c|c|}
\hline \multirow[b]{3}{*}{ Your } & \multicolumn{5}{|c|}{$\begin{array}{c}\text { coonte poe Woit } \\
\text { (thousend dottan) }\end{array}$} & \multicolumn{5}{|c|}{$\begin{array}{l}\text { Cotht: par Fotot } \\
\text { (dotinr) }\end{array}$} \\
\hline & \multirow{2}{*}{$\begin{array}{c}\text { 예 } \\
\text { (nomina) }\end{array}$} & \multirow{2}{*}{$\begin{array}{c}\text { Gas } \\
\text { \{nomirnel\} }\end{array}$} & \multirow{2}{*}{$\begin{array}{l}\text { Ory Hotes } \\
\text { (ntomlonall) }\end{array}$} & \multicolumn{2}{|c|}{ All } & \multirow{2}{*}{$\begin{array}{c}\text { 예 } \\
\text { (nominal) }\end{array}$} & \multirow{2}{*}{ (norminal) } & \multirow{2}{*}{$\begin{array}{l}\text { Dry holta } \\
\text { (norntnal) }\end{array}$} & \multicolumn{2}{|c|}{ Al } \\
\hline & & & & (nomlenes) & (ros) & & & & (nonlna) & (resal) \\
\hline 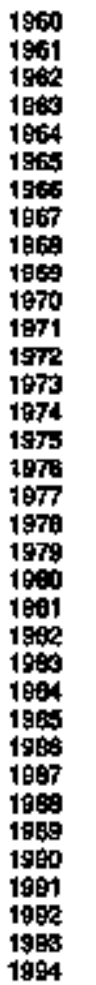 & 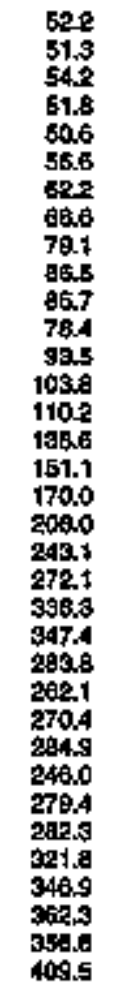 & 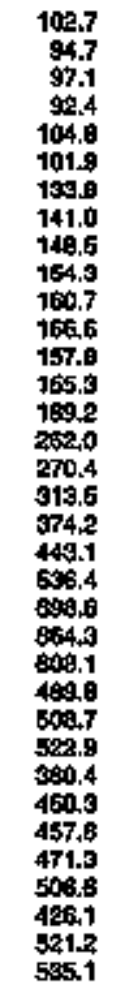 & 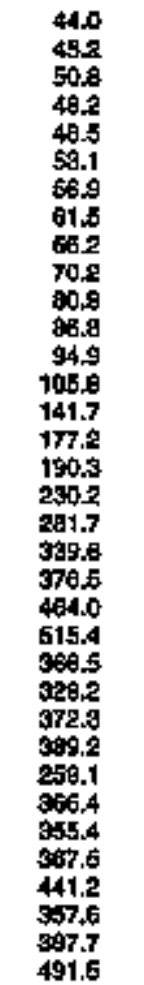 & 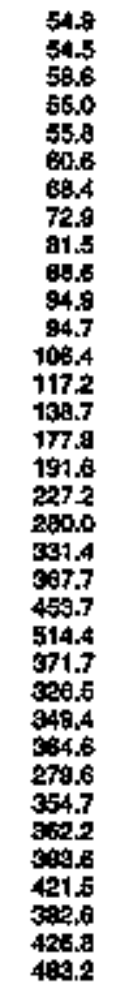 & 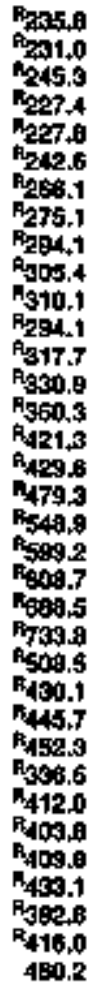 & 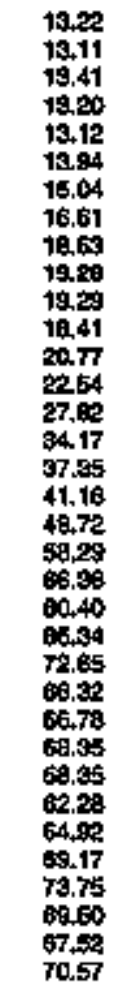 & 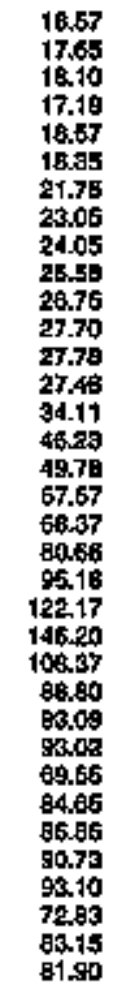 & 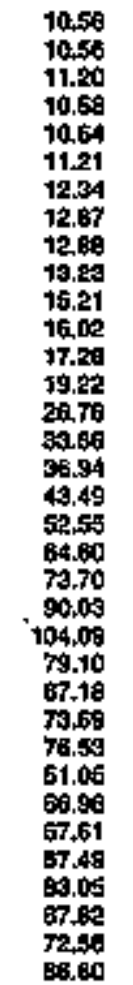 & 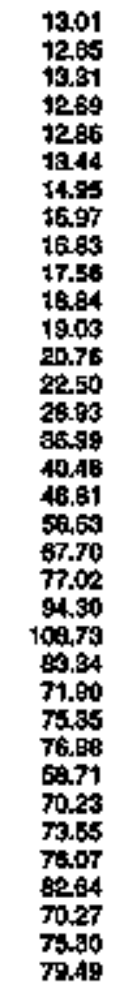 & 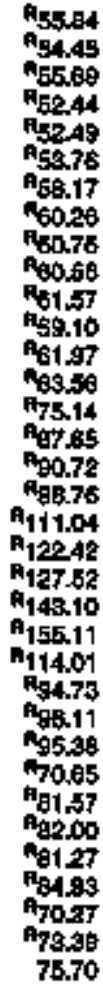 \\
\hline
\end{tabular}

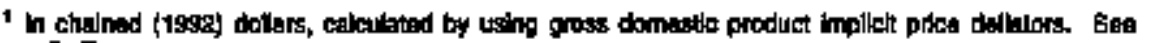
Appandex E.

NoRertsed datal

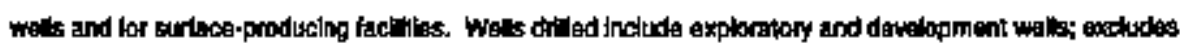

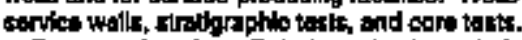

A A

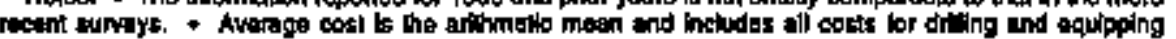


Figure 4.8 U.S. Exploration and Development Expenditures, Gross Additions to Proved Reserves, and Production of Liquid and Gaseous Hydrocarbons by FRS Companies and U.S. Industry

\section{Exploration and Dovelopment Expenditures, 1975-1994}

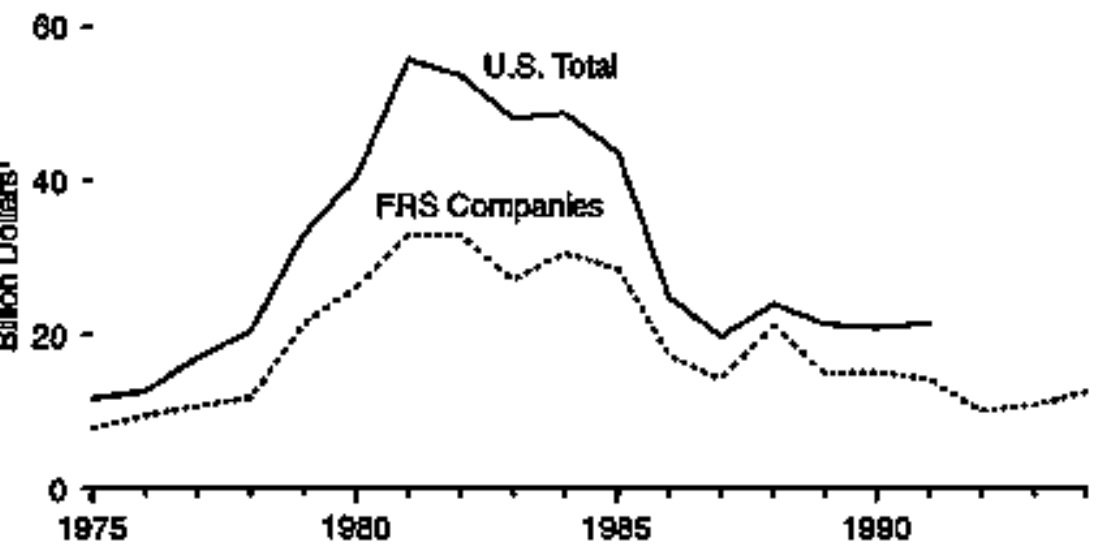

Production, 1975-1994
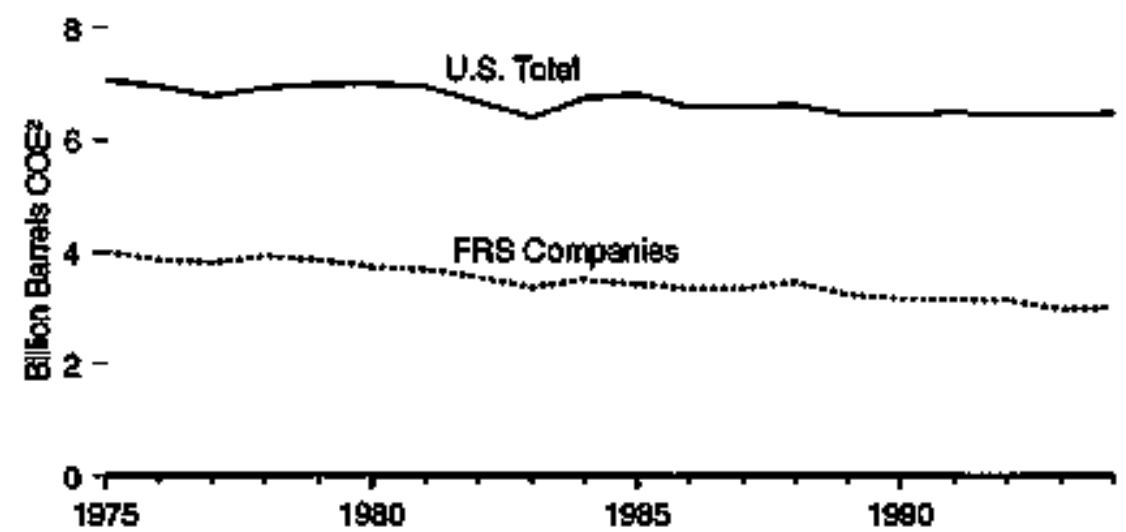

Expenditures per Barrel of Aeperve Additions, 1975-1993

(19-year woighted averago)

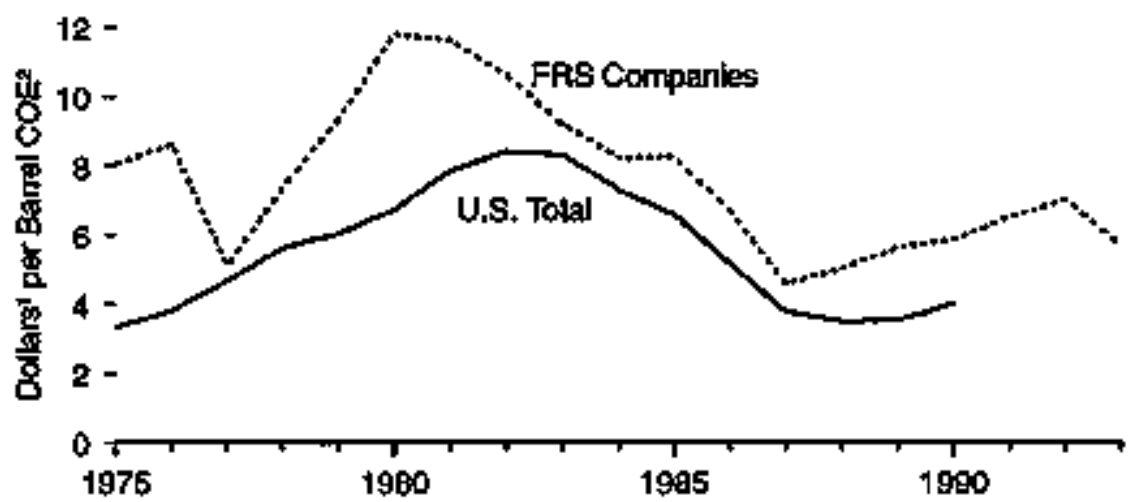

Gross Additions to Proved Reserves, 1975-1994

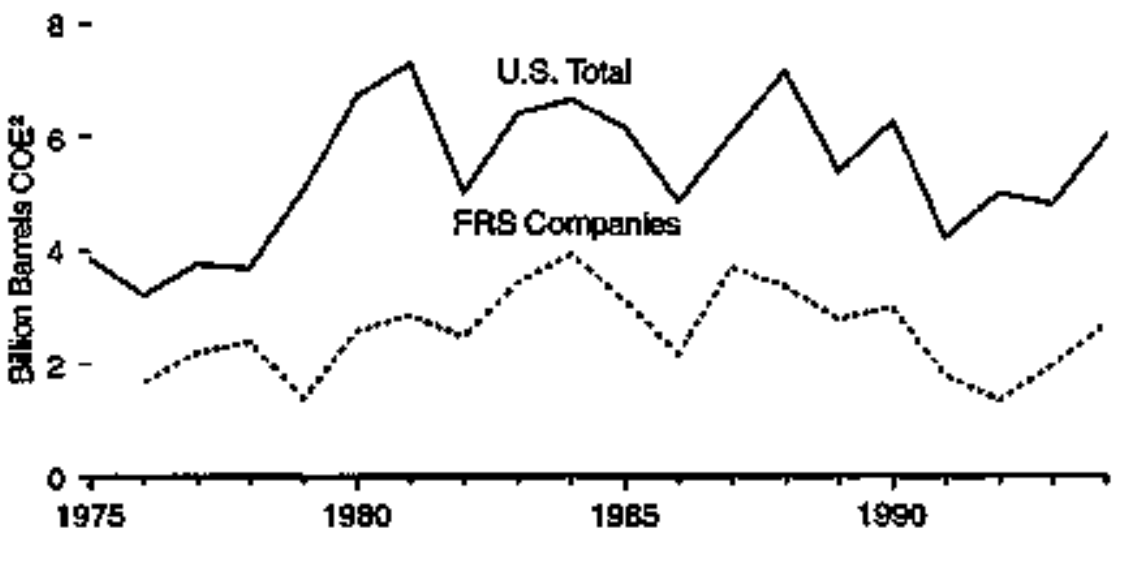

Souturg; Tabile 4.8.

1 Nominal dollars.

R COEEcrude oll equlvalerit.

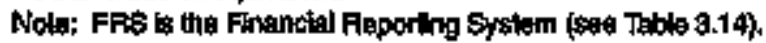


Table 4.8 U.S. Exploration and Development Expenditures, Gross Additions to Proved Reserves, and Production of Liquid and Gaseous Hydrocarbons by FRS Companies and U.S. Industry, 1975-1994

\begin{tabular}{|c|c|c|c|c|c|c|c|c|}
\hline \multirow[b]{2}{*}{ Yeer } & \multicolumn{2}{|c|}{ 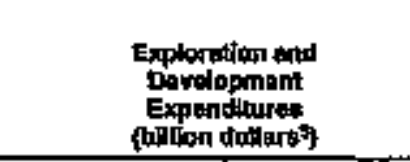 } & \multicolumn{2}{|c|}{ 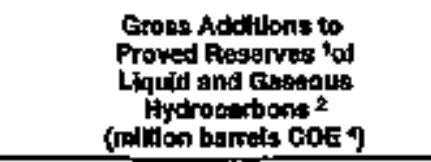 } & \multicolumn{2}{|c|}{ 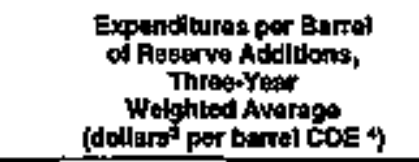 } & \multicolumn{2}{|c|}{ 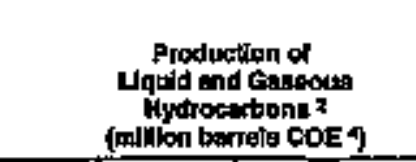 } \\
\hline & $\begin{array}{c}\text { FRS } \\
\text { Camponiog s }\end{array}$ & U.S. & $\begin{array}{c}\text { Fas } \\
\text { Companles ar }\end{array}$ & U.s. & $\underset{\text { Compunies }}{\text { at }}$ & $\begin{array}{l}\text { U.S. } \\
\text { Tobil }\end{array}$ & Comparles" & $\begin{array}{l}\text { U.S. } \\
\text { Total }\end{array}$ \\
\hline $\begin{array}{l}1975 \\
1976 \\
1977 \\
1979 \\
1979 \\
1980 \\
1961 \\
1992 \\
1963 \\
1964 \\
1965 \\
1968 \\
1997 \\
1998 \\
1989 \\
1990 \\
1991 \\
1998 \\
1993 \\
1994\end{array}$ & $\begin{array}{r}7.6 \\
9.5 \\
10.7 \\
11.6 \\
21.3 \\
28.2 \\
39.0 \\
32.9 \\
27.1 \\
30.6 \\
29.5 \\
17.4 \\
14.2 \\
21.2 \\
13.0 \\
76.1 \\
14.2 \\
10.8 \\
10.9 \\
12.6\end{array}$ & $\begin{array}{l}11.7 \\
12.6 \\
17.0 \\
20.4 \\
32.9 \\
40.4 \\
55.7 \\
53.7 \\
45.2 \\
48.7 \\
48.6 \\
24.9 \\
19.6 \\
24.0 \\
21.4 \\
21.0 \\
21.6 \\
\text { NA } \\
\text { NA } \\
\text { NA }\end{array}$ & $\begin{array}{r}\mathrm{NA} \\
1,669 \\
2,200 \\
2,389 \\
1,879 \\
2,590 \\
2,840 \\
2,468 \\
3,427 \\
3,941 \\
3,129 \\
2,179 \\
3,698 \\
3,359 \\
2,798 \\
8,979 \\
1,772 \\
1,392 \\
1,945 \\
2,703\end{array}$ & 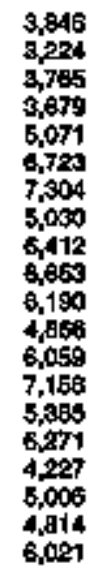 & $\begin{array}{r}8.05 \\
8.04 \\
5.12 \\
7.34 \\
8.34 \\
11.00 \\
11.63 \\
10.02 \\
5.20 \\
8.01 \\
8.27 \\
6.67 \\
4.59 \\
5.05 \\
5.50 \\
5.97 \\
6.52 \\
7.02 \\
7.60 \\
1.64\end{array}$ & 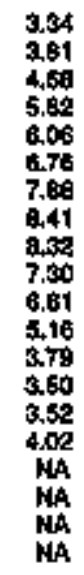 & 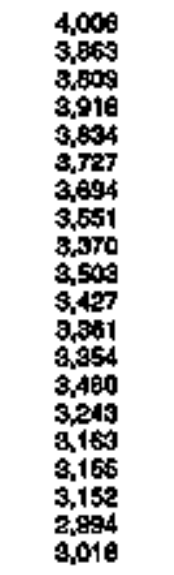 & 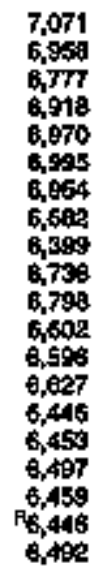 \\
\hline
\end{tabular}

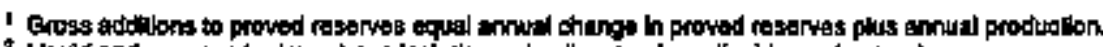

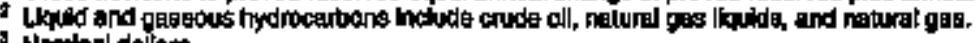

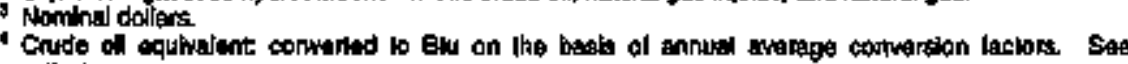
Appendith A.

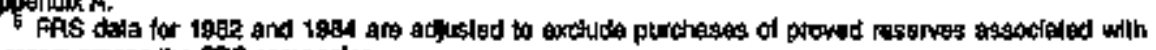
megors amang the FAS companlas.

Beged on net ommistip Lnderesi (see Blossaryh

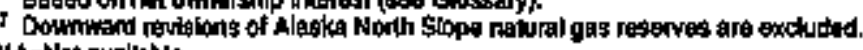

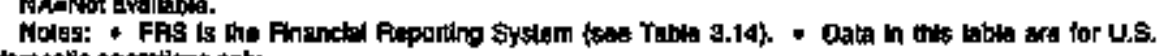

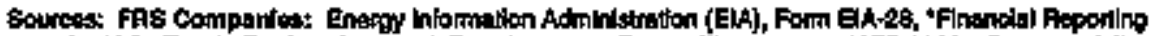

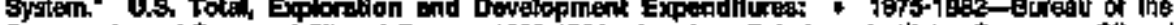

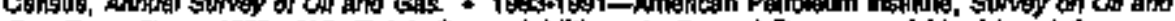

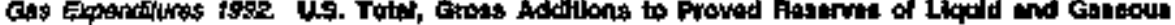

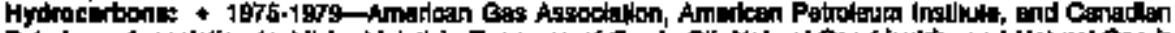

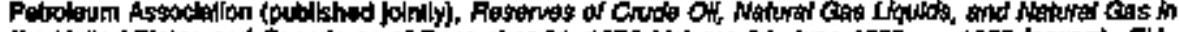

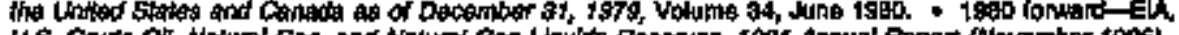

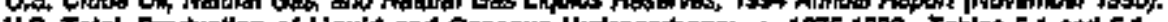

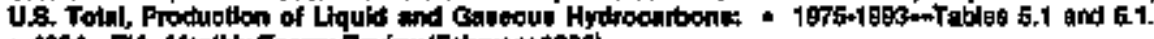

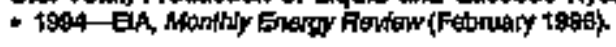




\section{Figure 4.9 FRS Companles' Expenditures for Oil and Gas Exploration and Development by Region}

\section{Total, 1977-1994}

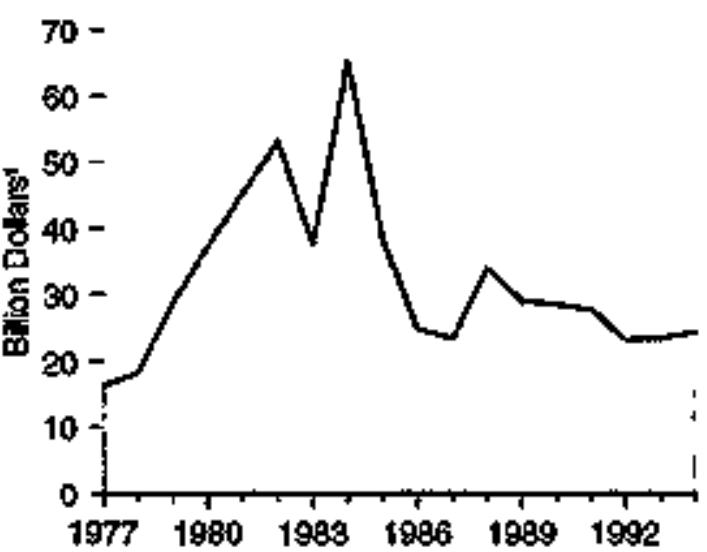

\section{U.S. and Forelgn, 1977-1994}

$70-$

60 -

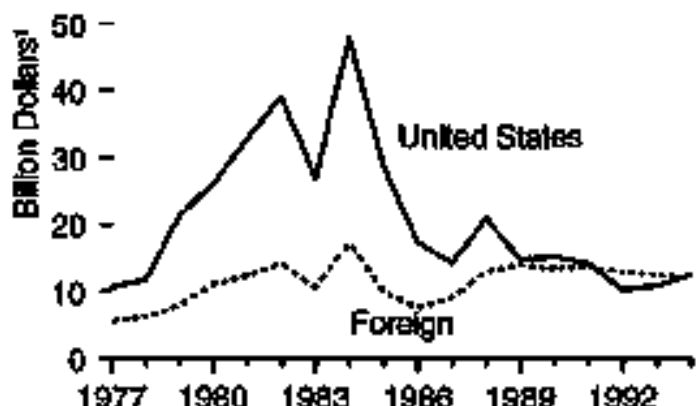

U.S. Onshore and Offshore, t977-1994

$70-$

60 -

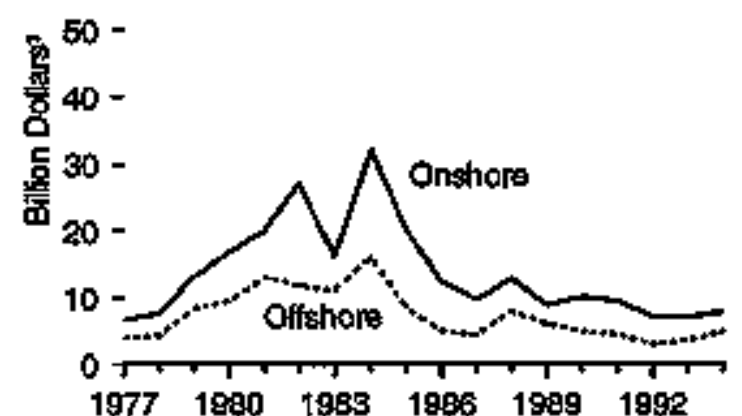

By Region, 1994

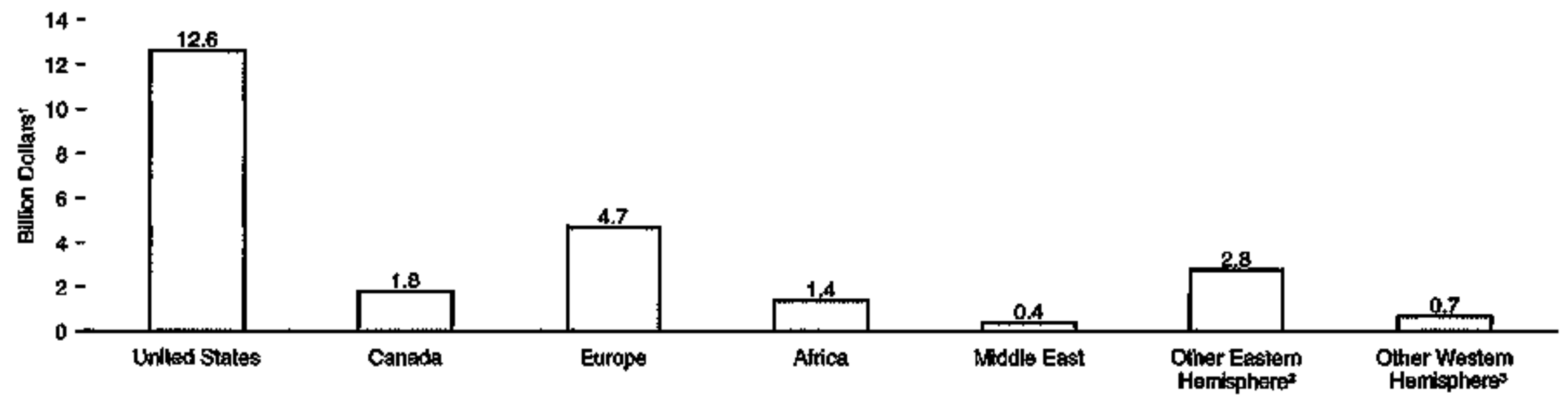

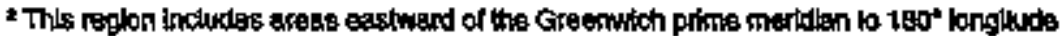

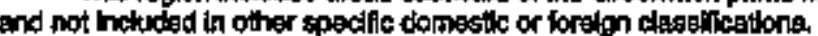

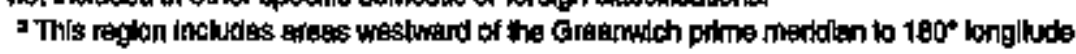

and nol lincludied in other apecinc dorrestle er foreion chassilicaltons.

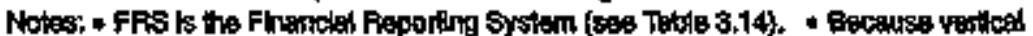
scales difier, graphis shoutd not be compared.

Sounce: Tabla 4.9 . 
Table 4.9 FRS Companies' Expenditures for Oil and Gas Exploration and Development by Region, 1977-1994 (Billion Dollars')

\begin{tabular}{|c|c|c|c|c|c|c|c|c|c|c|c|}
\hline \multirow[b]{2}{*}{ Yas } & \multicolumn{3}{|c|}{ Undted Stutes } & \multicolumn{7}{|c|}{ Forelgn } & \multirow[b]{2}{*}{ Toted } \\
\hline & Onahore & oftutere & Totol & $\operatorname{coshos}$ & Extopos & Airica & $\begin{array}{c}\text { Middto } \\
\text { Eatat }\end{array}$ & 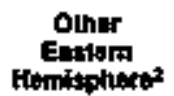 & 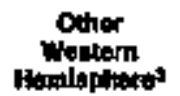 & Total & \\
\hline 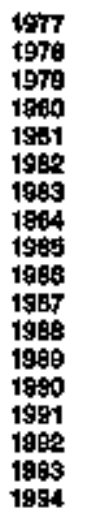 & $\begin{array}{r}6.7 \\
7.5 \\
13.0 \\
10.9 \\
19.9 \\
97.2 \\
10.0 \\
32.1 \\
20.0 \\
12.5 \\
9.7 \\
12.9 \\
9.0 \\
10.2 \\
9.8 \\
7.3 \\
7.2 \\
7.8\end{array}$ & $\begin{array}{r}4.3 \\
4.3 \\
8.3 \\
8.4 \\
13.0 \\
11.9 \\
11.1 \\
16.0 \\
8.5 \\
4.9 \\
4.5 \\
6.1 \\
6.0 \\
4.9 \\
4.6 \\
3.0 \\
3.7 \\
4.9\end{array}$ & $\begin{array}{l}10.7 \\
11.9 \\
21.3 \\
20.2 \\
33.0 \\
39.1 \\
22.1 \\
49.1 \\
29.5 \\
17.4 \\
14.3 \\
21.0 \\
16.0 \\
15.1 \\
14.2 \\
10.3 \\
10.0 \\
12.6\end{array}$ & $\begin{array}{l}1.5 \\
1.8 \\
2.3 \\
0.1 \\
1.8 \\
1.9 \\
1.8 \\
5.4 \\
1.9 \\
1.1 \\
1.9 \\
5.4 \\
6.3 \\
1.8 \\
1.7 \\
1.1 \\
1.8 \\
1.8\end{array}$ & $\begin{array}{l}2.5 \\
2.8 \\
3.0 \\
4.9 \\
5.0 \\
6.3 \\
4.3 \\
5.5 \\
3.7 \\
3.2 \\
3.0 \\
4.3 \\
3.5 \\
6.6 \\
5.8 \\
5.8 \\
5.7 \\
4.7\end{array}$ & $\begin{array}{l}0.7 \\
0.8 \\
0.8 \\
1.4 \\
2.1 \\
2.1 \\
1.7 \\
3.4 \\
1.6 \\
1.1 \\
0.8 \\
0.8 \\
1.0 \\
1.4 \\
1.5 \\
1.4 \\
1.5 \\
1.4\end{array}$ & $\begin{array}{l}0.3 \\
0.3 \\
0.2 \\
0.2 \\
0.3 \\
0.4 \\
0.5 \\
0.5 \\
0.9 \\
0.3 \\
0.4 \\
0.4 \\
0.4 \\
0.6 \\
0.5 \\
0.5 \\
0.7 \\
0.4\end{array}$ & $\begin{array}{l}0.3 \\
0.4 \\
0.5 \\
0.8 \\
1.5 \\
2.4 \\
2.0 \\
2.0 \\
1.3 \\
1.2 \\
2.0 \\
1.4 \\
2.3 \\
2.4 \\
2.4 \\
2.4 \\
2.5 \\
2.0\end{array}$ & $\begin{array}{l}0.4 \\
0.5 \\
0.8 \\
1.0 \\
1.3 \\
1.1 \\
0.6 \\
0.5 \\
0.7 \\
0.6 \\
0.5 \\
0.7 \\
0.6 \\
0.7 \\
0.7 \\
0.6 \\
0.0 \\
0.7\end{array}$ & $\begin{array}{r}5.6 \\
6.4 \\
7.8 \\
11.0 \\
12.4 \\
194.2 \\
10.7 \\
17.3 \\
10.1 \\
7.5 \\
9.2 \\
19.0 \\
14.1 \\
13.6 \\
13.7 \\
12.9 \\
12.5 \\
11.9\end{array}$ & $\begin{array}{l}16.3 \\
18.9 \\
29.1 \\
37.2 \\
45.4 \\
69.4 \\
37.7 \\
65.3 \\
38.8 \\
24.9 \\
29.5 \\
34.1 \\
29.1 \\
28.7 \\
27.8 \\
29.2 \\
23.5 \\
24.5\end{array}$ \\
\hline
\end{tabular}

Nominel dalare.

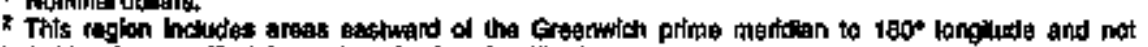

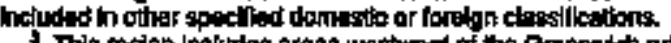

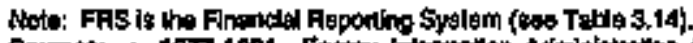

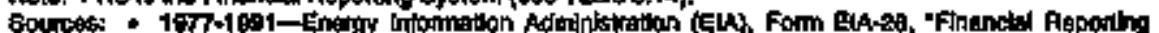

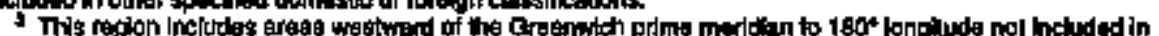

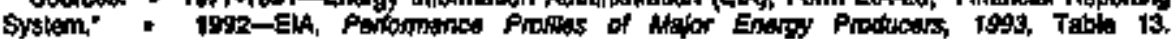

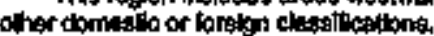




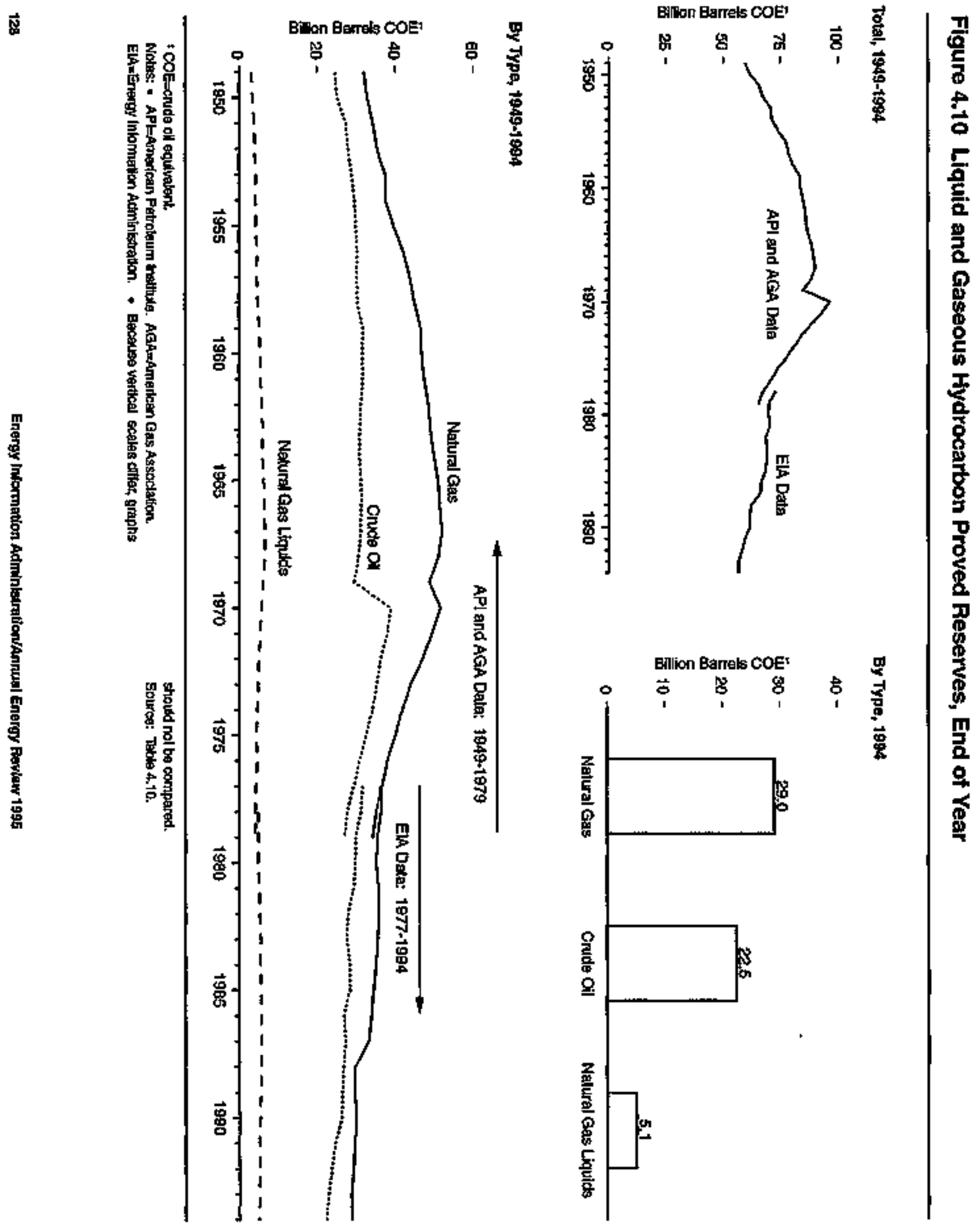


Table 4.10 Liquid and Gaseous Hydrocarbon Proved Reserves, End of Year 1949-1994

\begin{tabular}{|c|c|c|c|c|c|c|}
\hline \multirow[b]{2}{*}{ Yest } & \multirow{2}{*}{$\frac{\text { Grude oll }}{\text { Bdtiton Earrels }}$} & \multicolumn{2}{|c|}{ NAtared Ges } & \multicolumn{2}{|c|}{ 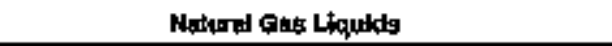 } & \multirow{2}{*}{$\frac{\text { Tokal }}{\text { Batlisn Barrots COE? }}$} \\
\hline & & Trillem Cutek Feet 1 & Bullan asarrets Co: ${ }^{2}$ & anlon Batreds & 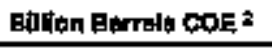 & \\
\hline & \multicolumn{6}{|c|}{ 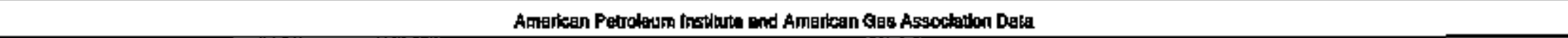 } \\
\hline \multirow[t]{2}{*}{$\begin{array}{l}1949 \\
1950 \\
1951 \\
1962 \\
1963 \\
1954 \\
1966 \\
1958 \\
1957 \\
1969 \\
1999 \\
1960 \\
1981 \\
1986 \\
1989 \\
1964 \\
1965 \\
1958 \\
1957 \\
1968 \\
1969 \\
19670 \\
1971 \\
1972 \\
1973 \\
1974 \\
1975 \\
1976 \\
1977 \\
1978 \\
1979\end{array}$} & 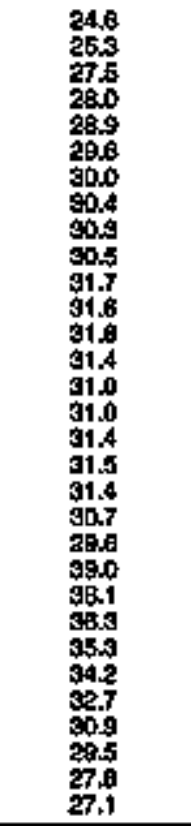 & 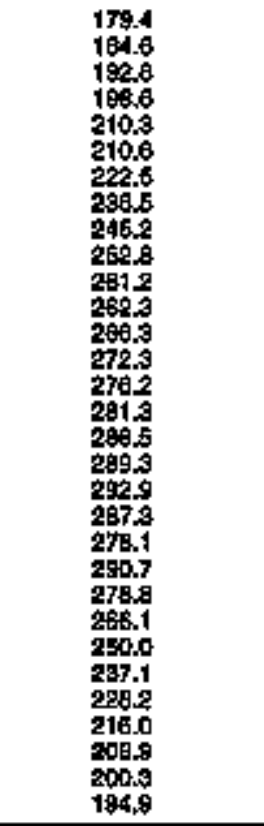 & $\begin{array}{l}32.0 \\
32.9 \\
34.4 \\
35.4 \\
37.5 \\
37.6 \\
39.7 \\
42.2 \\
43.0 \\
441 \\
46.6 \\
48.6 \\
47.6 \\
49.6 \\
49.1 \\
50.0 \\
51.0 \\
51.5 \\
52.1 \\
51.1 \\
49.9 \\
51.7 \\
49.8 \\
47.1 \\
44.0 \\
41.9 \\
40.2 \\
39.0 \\
39.9 \\
35.2 \\
34.3\end{array}$ & $\begin{array}{l}3.7 \\
4.3 \\
4.7 \\
5.0 \\
5.4 \\
5.2 \\
5.4 \\
5.9 \\
5.7 \\
8.2 \\
6.5 \\
8.8 \\
7.0 \\
7.3 \\
7.7 \\
7.7 \\
8.0 \\
8.3 \\
8.6 \\
9.5 \\
8.1 \\
7.7 \\
7.3 \\
5.8 \\
6.5 \\
6.4 \\
6.3 \\
6.4 \\
6.0 \\
5.8 \\
5.7\end{array}$ & $\begin{array}{l}3.1 \\
3.5 \\
3.5 \\
4.1 \\
4.4 \\
4.2 \\
4.4 \\
4.7 \\
4.5 \\
5.0 \\
5.2 \\
5.4 \\
5.6 \\
6.6 \\
8.0 \\
6.1 \\
6.3 \\
6.5 \\
8.7 \\
6.7 \\
6.3 \\
5.9 \\
5.5 \\
5.1 \\
4.9 \\
4.7 \\
4.4 \\
4.7 \\
4.4 \\
4.3 \\
4.1\end{array}$ & 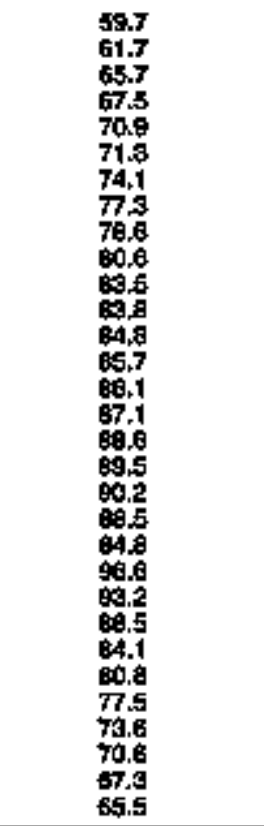 \\
\hline & \multicolumn{6}{|c|}{ 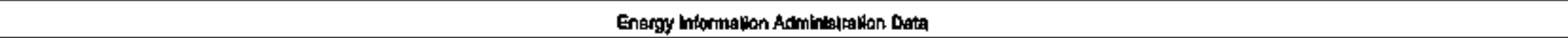 } \\
\hline 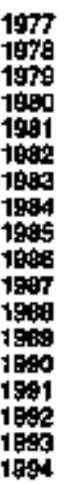 & $\begin{array}{l}31.9 \\
31.4 \\
29.8 \\
29.8 \\
29.4 \\
27.9 \\
27.7 \\
29.4 \\
29.4 \\
23.9 \\
27.8 \\
26.8 \\
26.8 \\
26.9 \\
24.7 \\
23.7 \\
23.0 \\
22.5\end{array}$ & $\begin{array}{l}207.4 \\
200.0 \\
201.0 \\
199.6 \\
201.7 \\
201.6 \\
200.2 \\
197.5 \\
199.4 \\
191.6 \\
197.2 \\
169.0 \\
167.1 \\
169.3 \\
167.1 \\
155.0 \\
152.4 \\
163.8\end{array}$ & $\begin{array}{l}36.5 \\
38.5 \\
35.4 \\
35.2 \\
35.7 \\
35.7 \\
35.8 \\
35.1 \\
34.4 \\
34.0 \\
393 \\
29.8 \\
29.7 \\
30.1 \\
29.7 \\
29.3 \\
28.8 \\
20.0\end{array}$ & $\begin{array}{l}\text { MA } \\
6.9 \\
6.8 \\
6.7 \\
7.1 \\
7.2 \\
7.9 \\
7.6 \\
7.9 \\
6.2 \\
6.1 \\
6.2 \\
7.6 \\
7.6 \\
7.5 \\
7.5 \\
7.2 \\
7.2\end{array}$ & $\begin{array}{l}N A \\
4.9 \\
4.8 \\
4.9 \\
5.2 \\
5.2 \\
5.7 \\
5.5 \\
5.5 \\
5.7 \\
5.6 \\
5.8 \\
5.5 \\
5.4 \\
5.3 \\
5.2 \\
5.1 \\
5.1\end{array}$ & 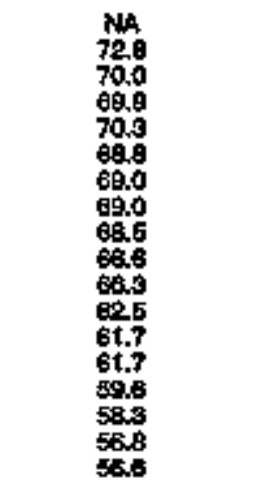 \\
\hline
\end{tabular}

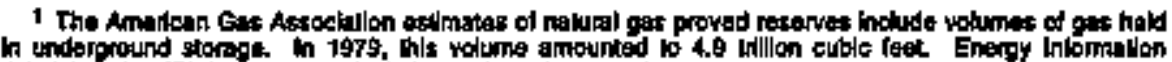

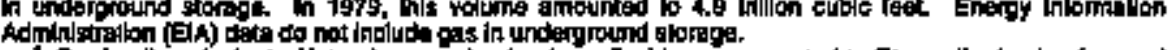

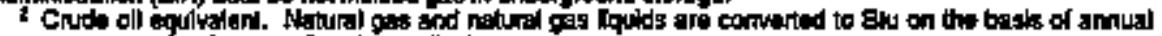

NAlNot avellabl.

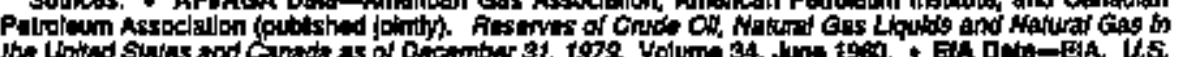

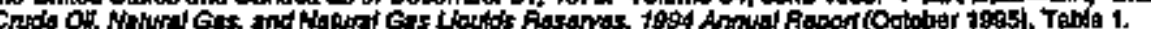




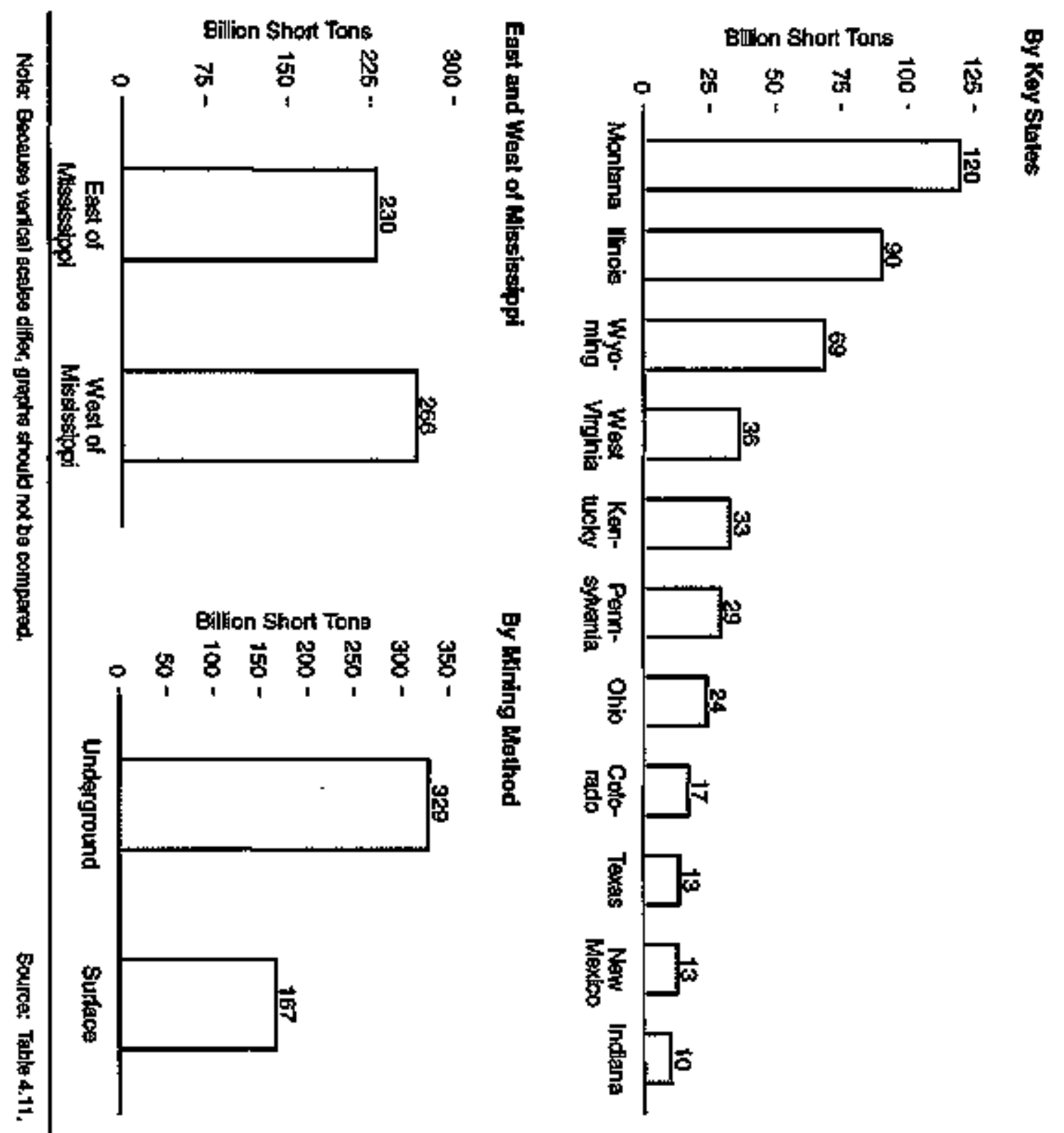

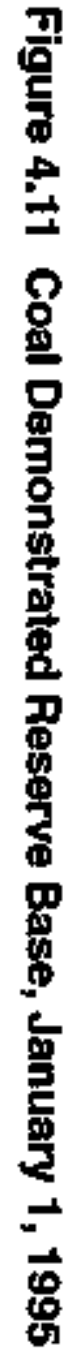

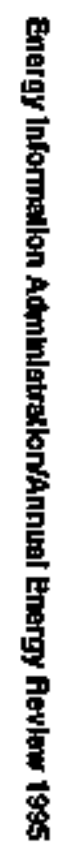

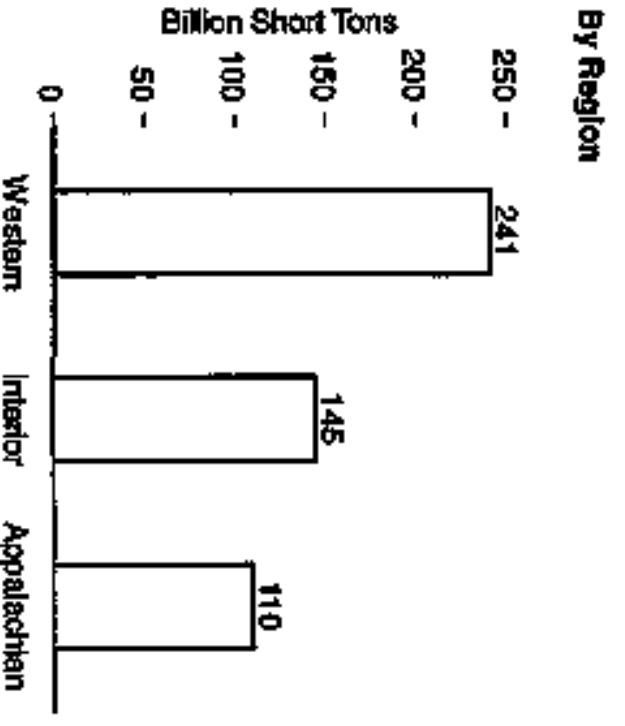


Table 4.11 Coal Demonstrated Reserve Base, January 1, 1995

(Billlon Short Tons)

\begin{tabular}{|c|c|c|c|c|c|c|c|}
\hline \multirow[b]{2}{*}{ Feglon and betere } & \multirow{2}{*}{$\begin{array}{l}\text { Amthraoks } \\
\text { tindargraund } \\
\text { and sutace }\end{array}$} & \multicolumn{2}{|c|}{ Bltumhous Coef 1} & \multirow{2}{*}{$\begin{array}{l}\text { LLignima } \\
\text { Furtaens }\end{array}$} & \multicolumn{3}{|c|}{ Told } \\
\hline & & Underground & strinest & & Underground & surfios & Tollol \\
\hline 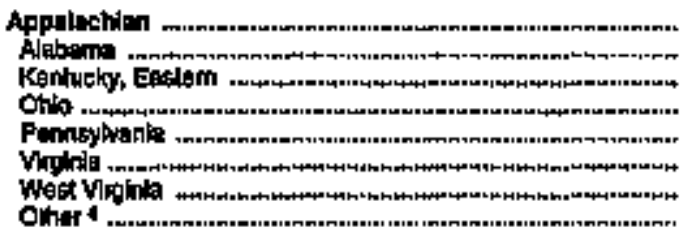 & $\begin{array}{r}7.4 \\
0 \\
0 \\
0 \\
7.2 \\
0.1 \\
0 \\
0\end{array}$ & $\begin{array}{r}76.4 \\
1.4 \\
2.5 \\
17.8 \\
20.6 \\
1.5 \\
31.4 \\
1.2\end{array}$ & $\begin{array}{r}24.0 \\
2.2 \\
10.0 \\
5.9 \\
1.1 \\
0.7 \\
4.6 \\
0.4\end{array}$ & $\begin{array}{r}1.1 \\
1.1 \\
0 \\
0 \\
0 \\
0 \\
0 \\
0\end{array}$ & $\begin{array}{r}00.4 \\
1.4 \\
2.5 \\
17.8 \\
24.4 \\
1.6 \\
31.4 \\
1.2\end{array}$ & $\begin{array}{r}2.2 \\
3.3 \\
10.0 \\
5.9 \\
4.5 \\
0.7 \\
4.6 \\
0.4\end{array}$ & $\begin{array}{r}109.5 \\
4.6 \\
12.5 \\
20.8 \\
28.9 \\
2.3 \\
30.0 \\
1.6\end{array}$ \\
\hline 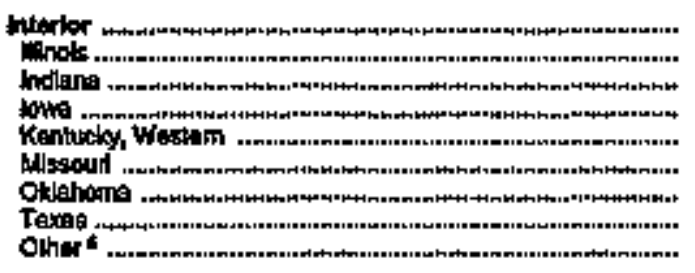 & $\begin{array}{r}0.1 \\
0 \\
0 \\
0 \\
0 \\
0 \\
0 \\
0 \\
0.1\end{array}$ & $\begin{array}{r}105.8 \\
73.8 \\
0.9 \\
1.7 \\
18.4 \\
1.5 \\
1.5 \\
0 \\
0.5\end{array}$ & $\begin{array}{r}27.4 \\
16.2 \\
1.1 \\
0.6 \\
3.7 \\
4.5 \\
0.3 \\
0 \\
1.1\end{array}$ & $\begin{array}{r}13.6 \\
0 \\
0 \\
0 \\
0 \\
0 \\
0 \\
13.1 \\
0.5\end{array}$ & $\begin{array}{r}10039 \\
73.8 \\
8.9 \\
1.7 \\
18.4 \\
1.5 \\
1.2 \\
0 \\
0.4\end{array}$ & $\begin{array}{r}41.0 \\
16.2 \\
1.1 \\
0.5 \\
3.7 \\
4.5 \\
0.3 \\
13.1 \\
1.6\end{array}$ & $\begin{array}{r}144.6 \\
800 \\
10.0 \\
22 \\
20,4 \\
6.0 \\
1.6 \\
13.1 \\
2.0\end{array}$ \\
\hline 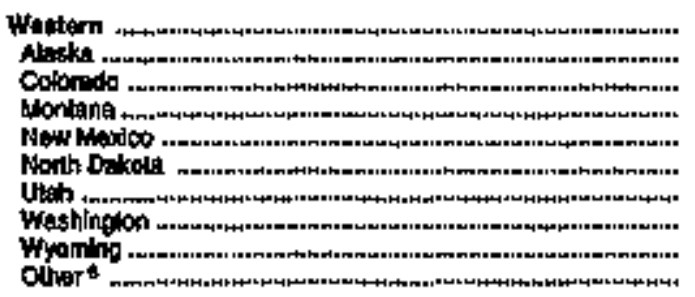 & $\begin{array}{l}\text { (0) } \\
0 \\
0 \\
0 \\
0 \\
0 \\
0 \\
0 \\
0\end{array}$ & $\begin{array}{r}144.3 \\
5.4 \\
1.0 \\
71.0 \\
6.2 \\
0 \\
5.7 \\
1.3 \\
42.5 \\
0.1\end{array}$ & $\begin{array}{r}67.1 \\
0.7 \\
0.6 \\
39.1 \\
6.0 \\
0 \\
0.3 \\
0.1 \\
28,0 \\
0.1\end{array}$ & 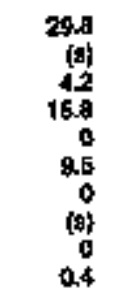 & $\begin{array}{r}14.4 .4 \\
6.4 \\
12.0 \\
71.0 \\
8.2 \\
0 \\
5.7 \\
1.3 \\
42.5 \\
0.1\end{array}$ & $\begin{array}{r}96.9 \\
0.7 \\
4.6 \\
40.6 \\
6.3 \\
9.5 \\
0.3 \\
0.1 \\
26.0 \\
0.5\end{array}$ & $\begin{array}{r}241.2 \\
6.1 \\
18.8 \\
119.8 \\
12.5 \\
8.5 \\
6.0 \\
1.4 \\
6.4 \\
0.8 \\
0.8\end{array}$ \\
\hline 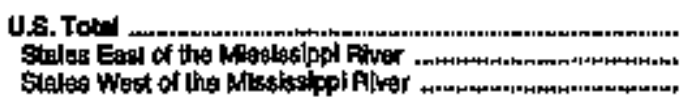 & $\begin{array}{l}7.6 \\
7.4 \\
0.1\end{array}$ & $\begin{array}{l}324.5 \\
1758 \\
148.8\end{array}$ & $\begin{array}{r}118.9 \\
45.8 \\
79.5\end{array}$ & $\begin{array}{r}44.5 \\
13.1 \\
43.4\end{array}$ & $\begin{array}{l}325.8 \\
179.5 \\
149.9\end{array}$ & $\begin{array}{r}167.1 \\
50.3 \\
116.9\end{array}$ & $\begin{array}{l}495,7 \\
209.8 \\
26.9\end{array}$ \\
\hline
\end{tabular}

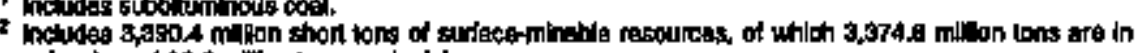

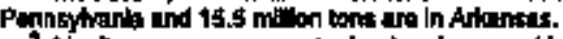

Lonte resources are nol mined und erpround in Une Uniled Statos.

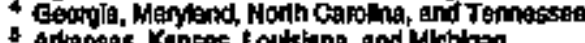

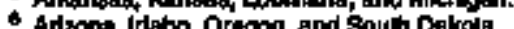

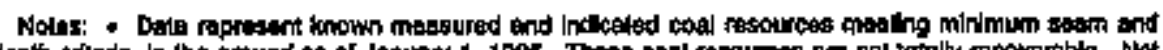

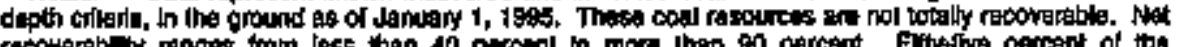

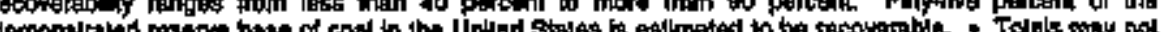

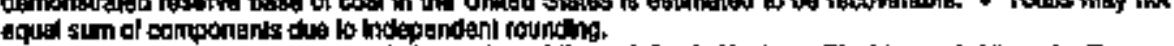

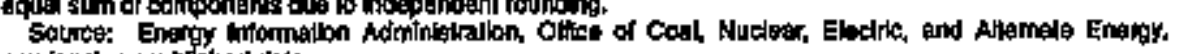

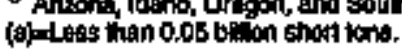

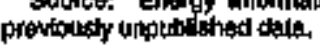




\section{Figure 4.12 Uranium Exploration and Development Drilling, 1949-1995}

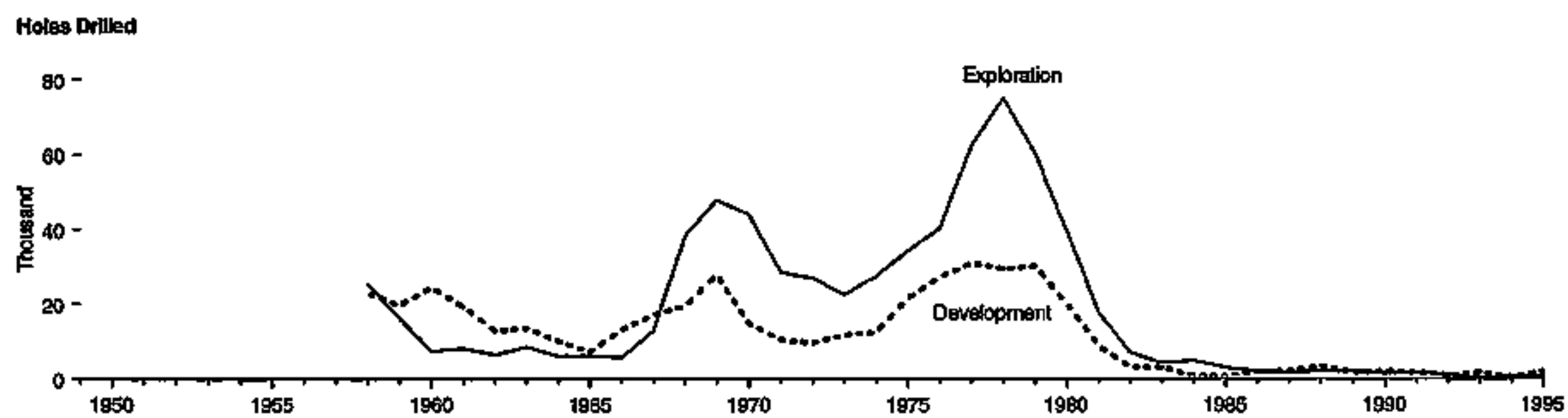

\section{Footage Drlled}

40-

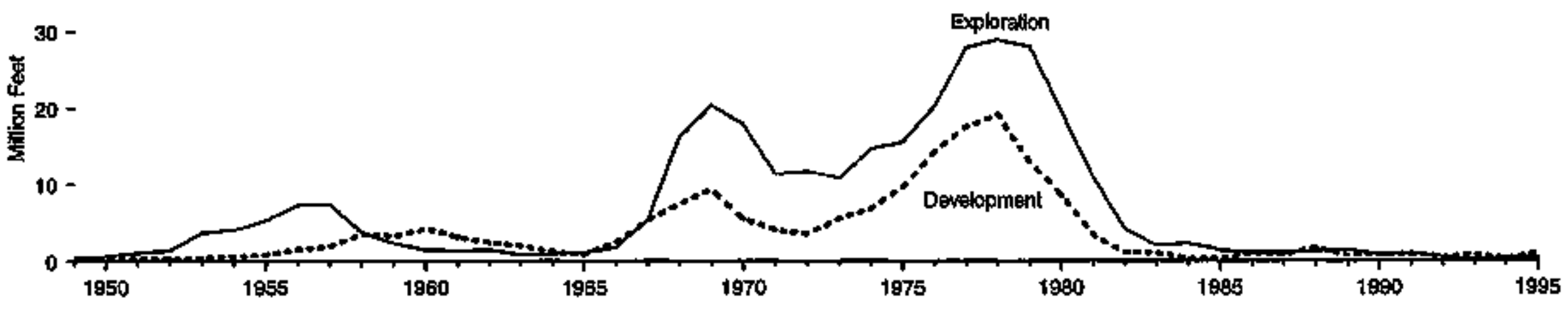

Sevircet Tabde 4.12. 
Table 4.12 Uranium Exploration and Development Drilling, 1949-1995

\begin{tabular}{|c|c|c|c|c|c|c|}
\hline \multirow[b]{2}{*}{ Yar } & \multicolumn{2}{|c|}{ Explorition 1} & \multicolumn{2}{|c|}{ Derrotoponent 2} & \multicolumn{2}{|c|}{ Toknt } \\
\hline & $\begin{array}{l}\text { Holes Drillod } \\
\text { (thouseands) }\end{array}$ & 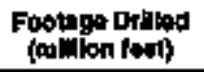 & $\begin{array}{l}\text { Holea Driled } \\
\text { (Itovstinds) }\end{array}$ & $\begin{array}{l}\text { Fooluge Doilued } \\
\text { (mllition foel) }\end{array}$ & $\begin{array}{l}\text { Holpo Dxilled } \\
\text { (thousundn) }\end{array}$ & $\begin{array}{l}\text { Feptege Drinad } \\
\text { (million fent) }\end{array}$ \\
\hline 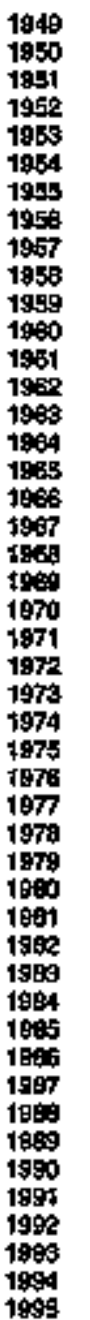 & 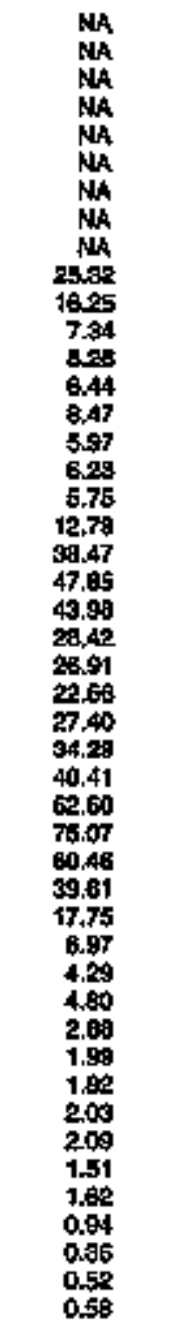 & 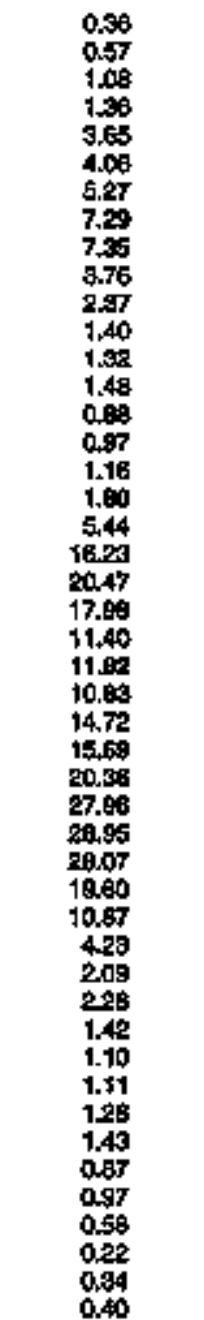 & 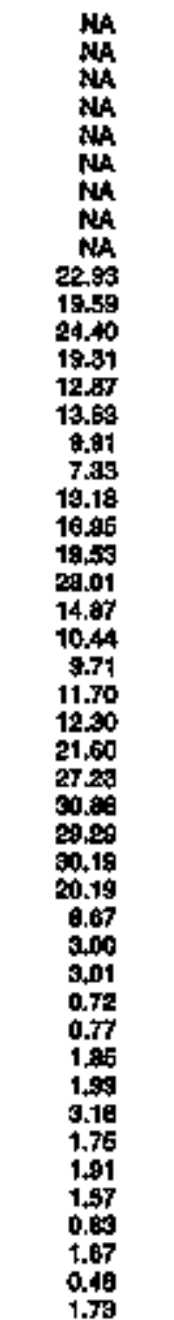 & 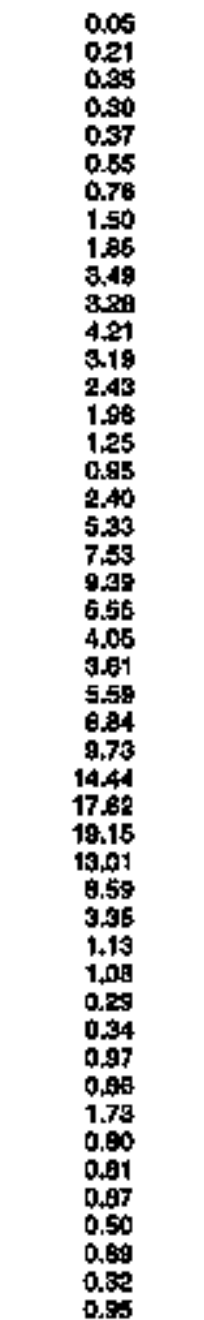 & 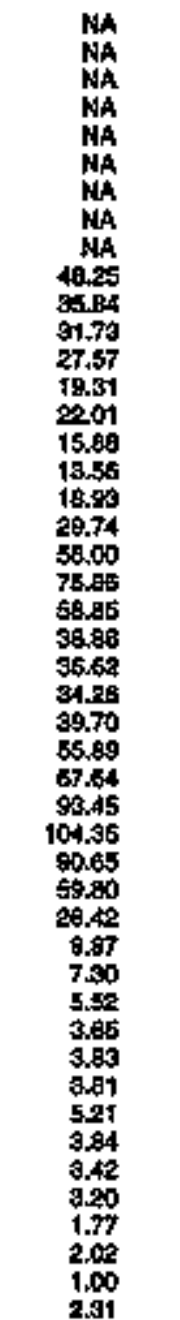 & 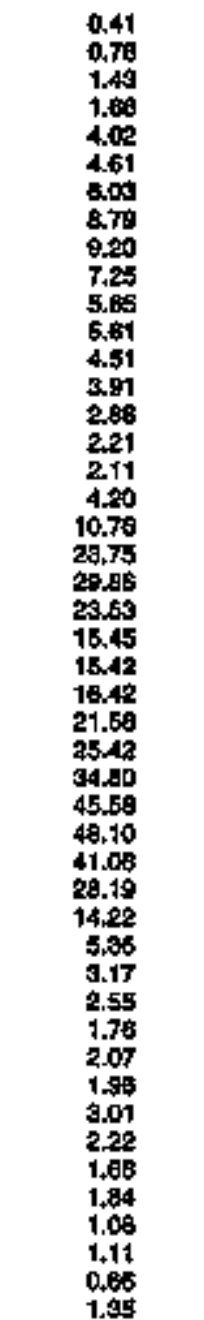 \\
\hline
\end{tabular}

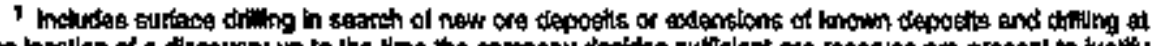

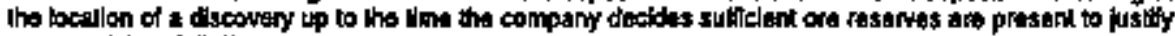

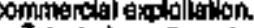

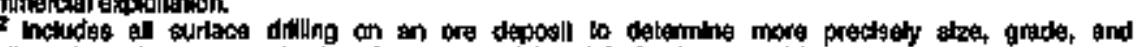

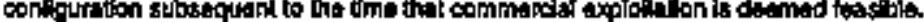

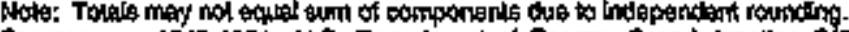

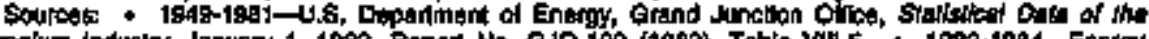

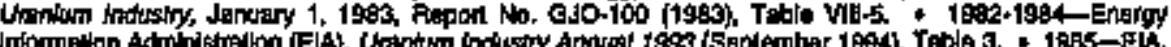

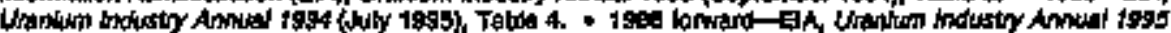
(hay 158), Tats 1. 


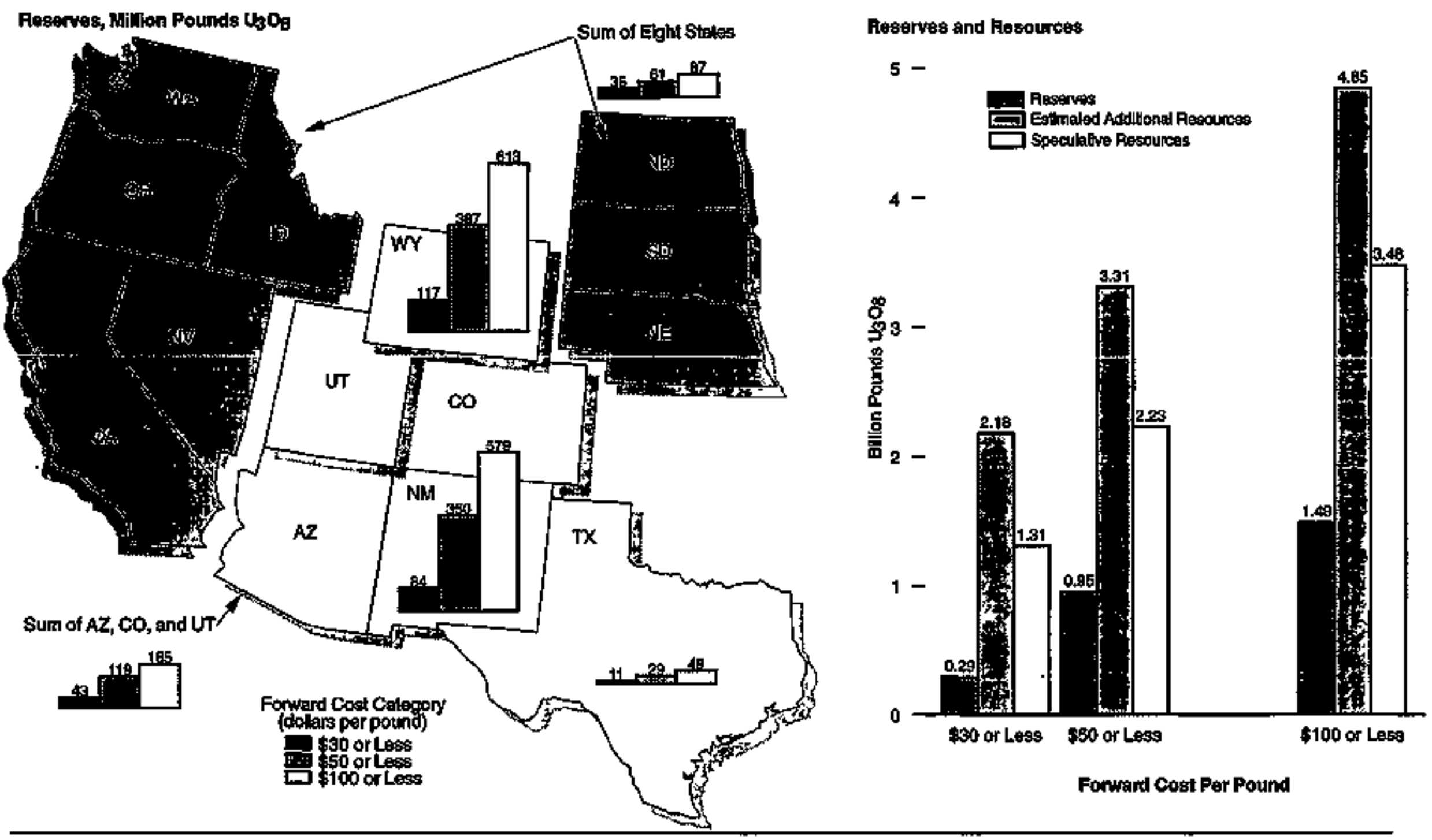


Table 4.13 Uranium Reserves and Resources, December 31, 1995

(Million Pounds $U: \mathrm{S}_{\mathrm{s}}$ )

\begin{tabular}{|c|c|c|c|}
\hline \multirow[b]{2}{*}{ Geacures Catingory and flite } & \multicolumn{3}{|c|}{ Forwurd cosi cotegory (doders per pound) } \\
\hline & $\$ 00$ or L L & \$50 or Lest: & $\$ 900$ or tons: \\
\hline 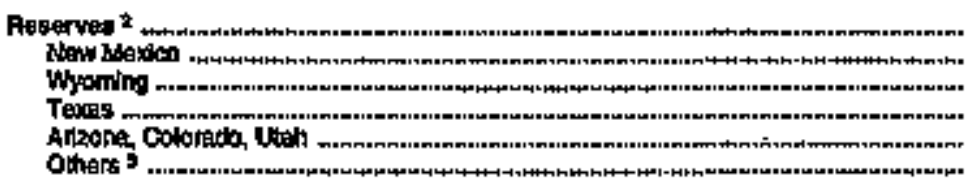 & $\begin{array}{r}200 \\
84 \\
117 \\
11 \\
43 \\
36\end{array}$ & $\begin{array}{r}947 \\
360 \\
387 \\
29 \\
119 \\
61\end{array}$ & $\begin{array}{r}1,480 \\
579 \\
613 \\
49 \\
165 \\
87\end{array}$ \\
\hline \multicolumn{4}{|l|}{ 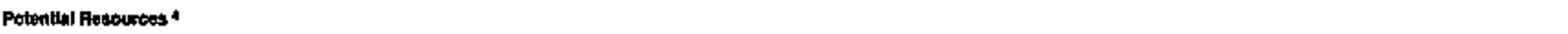 } \\
\hline 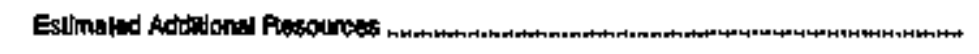 & 2,100 & 3,310 & $4, a 50$ \\
\hline 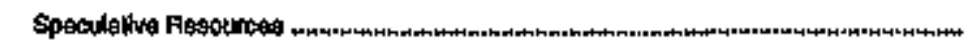 & 1,310 & 2,230 & 3,480 \\
\hline
\end{tabular}

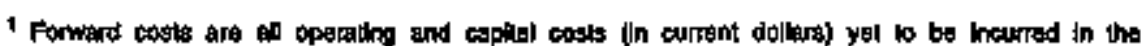

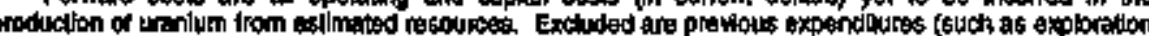

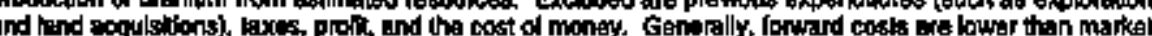

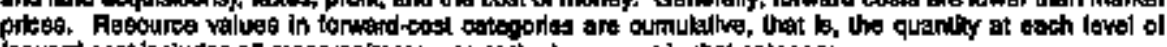

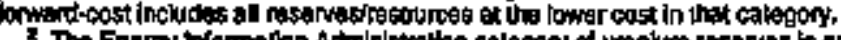

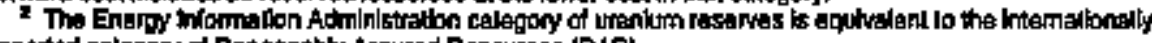
reported calegony of Reasonibby Asaured Resources (RAR).

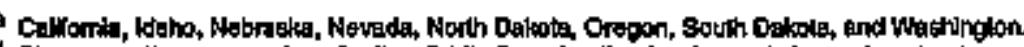

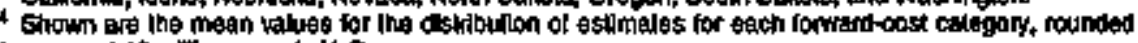

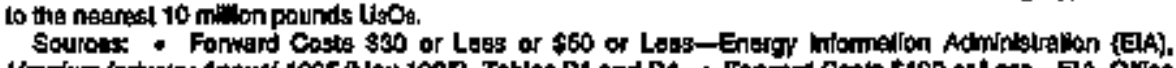

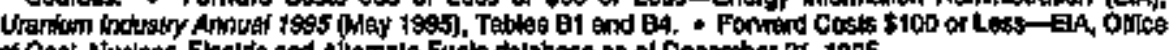

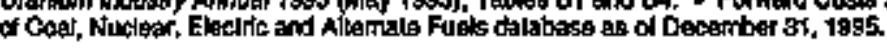




\section{Energy Resources Notes}

1. There are numerous more recent, nongovernment-generated natural gas resource estimates that are larger, in part because (a) they include natural gas from such sourcas as coalbeds and tight sands beyond the conventionally producible reservoirs that were included in the 1987 Department of the Interior estimate, and (b) they reflect larger estimates of ultimate recovery appreciation. For example, the Potential Gas Committee's latest mean estimate, published in 'Potential Supply of Natural Gas in the United States, December 31, 1994," is 1,028 trillion cubic feet. The National Petrolenm Council's one-time, 1992 mean estimate, published in "The Potential for Natural Gas in the United States: Source and Supply," was 1,065 trillion cubic feet.
The onshore and State waters portion of the 1995 Department of the Interior National Oil and Gas Resource assessment is reported in U.S. Geological Survey Circular 1118, 7995 National Assessment of United States Otl and Gas Resources. Minerals Management Service data on the Federal offshore portion were not available in time for publication in this report.

2. For 1970 forward, annual well completions are estimated by the Energy Information Administration (ElA) by using the American Petroleum Institute's drilling data files. For more recent years, these files are not complete, due to delays in the reporting of wells drilled. Based on statistical analysis, EIA employs an adjustment process to impute missing data to show total well completions and footages for current years. 


\section{Petroleum}

\section{Fluctuations in Prices}

After the oil embargo in 1973-1974, the average annual composite re* finer acquisition cost, in real terms, ${ }^{1}$ of a barrel of crude oil rose to $\$ 23.56$ in 1974, double the price in 1973 (5.19).* Successive price bikes in following years brought the real price of crude oil to an alltime high of $\$ 53.47$ per bartel in 1981. In 1982, however, oil prices began trending downward and then plummeted in 1986. The real price per barrel of crade oil fell from $\$ 34.12$ in 1985 to $\$ 18.05$ in 1986. Of the several factors contributing to the unprecedented decline in crude oil prices during 1986, the most important was increased worldwide production, primarily by members of the Organization of Petroleum Exporting Countries (OPEC) seeking to regain market share.

After 1986, crude oil prices fluctuated. In 1990, the Iraqi invasion of Kuwait drove up the real price of a barrel of crude oil to $\$ 23.74$. In 1991 , oil-producing nations' ability to replace Iraqi and Kuwaiti oil. coupled with an economic recession that restrained petroleum demand, caused the real price to decline to $\$ 19.59$ per barrel. The following year, the real price of cride oil declined to $\$ 18.43$ per barrel, despite political unrest in several oil-producing cotntries (most notably Russia) and the oil sates embargo on Irag, as well as attempts by OPEC to bolster crude oil prices. In 1993, due to restrained demand and increased production worldwide, the real price of cride oil fell to $\$ 15.99$. In 1994, the real price of crude oil fell to $\$ 14.85$, the lowest annual average in 21 years. Despite continued growth in worldwide production in 1995 , the real price of crude oil rose 7.9 percent to $\$ 16.03$.

The end-use prices, excluding taxes, of most petroleum products also increased in 1995 (5.20). The average price of all types of motor gasoline rose from 74 cents per gallon in 1994 to 77 cents per gallon in 1995. Aviation gasoline, kerosene-type jet fuel, residual fuel oil, and No. 2 diesel oil ayerage prices, excluding taxes, also increased. In contrast,

${ }^{1}$ Real (anflation-adjusied) prices are expressed in chatined (1992) dollars.

Numbers in parentheses indicate related tebles. Annugi data are the mosi necont avellable; they frequently are prelikningry and may be revised in future publications. Percentages and numbers in text are calculated by using data in the tables. the average prices per gallon, excluding taxes, of kerosene, propane, and No. 2 fuel oil declined in 1995.

\section{Production and Productivity}

During much of the 1950's and 1960's, production capacity exceeded demand to such an extent that such mechanisms as production pro-rationing and import ceilings were implemented to protect domestic production. By the 1970's, however, petroleum demand had increased, the average productivity of wells began to decline, and oil production leveled off (5.2). Increases in Alaskan production at the end of the 1970's and through 1988 partially counteracted declines in Lower-48 production. In 1989, however, even Alaskan production began to decline. In 1995, U.S. crude oil production totaled 6.5 million bartels per day, the lowest level in 41 years.

\section{In 1995, U.S. crude oil production totaled 6.5 million} barrels per day, the lowest level in 11 years.

Of total U.S. production in 1995, 79 percent came from onshore wells and 21 percent from offshore. The 574 thousand producing wells attained an average productivity of 11 barrels per day per well, down 0.9 percent from the 1994 level and significantly below peak productivity of over 18 barrels attained in the early 1970's.

\section{Imports and Exports}

Despite import quotas, net imports of low-priced petroleum increased throughout most of the 1949-to-1973 period, and in 1973 totaled 6.0 miltion barrels per day (5.1). Thereafter, net imports fluctuated, peaking at 8.6 mitlion barrels per day in 1977, then declining to 4.3 million barrels per day in 1985. In 1986, excess world production drove prices down, inhibiting domestic production and boosting demand, and net imports totaled 5.4 million barrels per day. Subsequently, with prices significantly below peak levels, net imports rose to 7.2 million barrels 
per day in 1989 and 1990. In 1991, lower demand for petroleum due to the economic recession contributed to a decline in petroleum imports. In addition, in 1991, the United States exponted a record level of petroleum products, and petroletum net imports declined to 6.6 million barrels per day. Thereafter, economic recovery contribnted to growth in net imports of petroleum, which totaled 7.9 million barrels per day in 1995.

U.S. dependence on petroleum net imports peaked at 46.5 percent of consumption in 1977, then fell in 1985 to 27.3 percent, the lowest level since 1971 (5.7). In 1994, dependence on petroleum net imports reached a 17-year high of $\mathbf{4 5 . 5}$ percent. In 1995, dependence was 44.5 percent. Venezuela, Sandi Arabia, Canada, Moxico, and Nigeria were the primary foreign suppliers of petroleum to the United States.

\section{Consumption of Petroleum Products}

Consumption of petroleum products (petroleum products supplied) increased throughout the 1949-10-1973 period at an average annual rate of 4.7 percent, and, by 1973, consumption of petroleum products totaled 17.3 million barrels per day (5.1). In 1974, however, marked increases in the price of crude oil, coupled with a petroleum supply interruption caused by the oil embargo, resulted in a 3.8-percent decline in petroleum consumption. Although demand recovered during the late 1970's, peaking at 18.9 million barrels per day in 1978, by 1983 it had declined to 15.2 million barrels per day. After 1983, lower crudo oil prices tended to promote consumption, which reached 17.3 million barrels per day in 1989. In 1990 and 1991, however, warm winters and a stagnant economy combined to restrain petroleum consumption, which fel] to 16.7 million barre[s per day in 1991. The subsequent economic recovery contributed to an increase in consumption to 17.7 million barreis per day in both 1994 and 1995.

Consumption of most petroleum products in 1995 remained near 1994 levels (5.11). Consumption of motor gasoline, which consistently accounts for the largest share of all petroleum products, exhibited the largest increase; it rose 2.5 percent to 7.8 million barrels per day. Distillate fuel oil consumption totaled 3.2 million barrels per day, consumption of jet fuel totaled 1.5 million barrels per day, and consumption of liquefied petroleum gases totaled 1.9 million barrels per day in 1995. By contrast, consumption of residual fuel oil fell 17 percent to 0.9 million batrels per day, the lowest level since at least 1949. Demand for residual fuel oil declined because the electric utility and industrial sectors continued to increase their consumption of natural gas (6.6).

\section{The Refining Industry in a Changing Market}

The average daily output from US. refineries trended upward from 1949 throtgh 1978 , when it peaked at 16 miltion barrels per day (5.8). Durting the mext 5 years, output declined, falling to 13 million bartels per day in 1983. As crude oil prices declined in the mid-1980's and the demand for petroleum rose, refinery output began to recover. In 1994 it averaged 16 million barrels per day for the third consecutive year.

The rate of refinery utilization fell below 80 percent in 1980 through 1985 , despite deactivation of refinery capacity $(5.9)$. Thereafter, the utilization rate improved. In 1986, the rate was 83 percent, well above its nadir of 69 percent in 1981. After 1986, strong product demand contributed to even higher utilization rates, which reached a 21-year high of 93 percent in 1994. In 1995, the utilization rate was 92 percent.

\section{Petroietim Stocks and the Strategic Petroleum Reserve}

The U.S. Government establshed the Strategic Petroleum Resenve(SPR) In response to the oil supply dilsnipitions of the early $1970^{\circ} \mathrm{s}$. Intended to

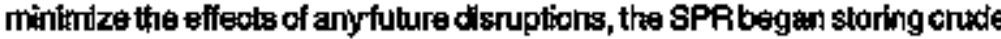
oil in 1977, and by the end of 1929 , it held 590 million barrels $(6,15)$, The first seles of SPR crude ol occurred following the Iraq imwasion of Kuwait in August 1990. In addlion, SPR purcheses were suspended in August 1990 due to concern ahout world cruda ofl sapplies, Purchases resumed In 1992. A1 the end of 1995, the SPs heid 592 million barrels.

One meesire of the SPF'a adequecy is the number of days of petroleum net imports it could prowde in the event of an oll supply kitersuption. Through 1985, that measture of enerry security increased every year, dte to additions to the SPR and a decline in the level of ned impots. In 1986,

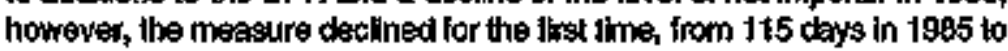
94 days in 1986, In 1984, the measture was 73 days, the lowesi In 12 years. Although SPR stocke in 1995 remalned at the 1994 level, a dacrease in petroleum net imporis caused the meastre to increase to 75 days.

At the end of 1995, SPA slocks, plus 302 million barreks of privately held crude oil stocks, toialed 893 million bairels $(5,14)$. Private stocks of crude of were less than the 340 mallolon-barrel level recorded In 1977 , when flling of the SPR began. A1 609 million barress, ptivate stocks of peiroleum proclucts in 1925 remalned conslderably betow the record level of 964 million barreks recorded in 1977. 


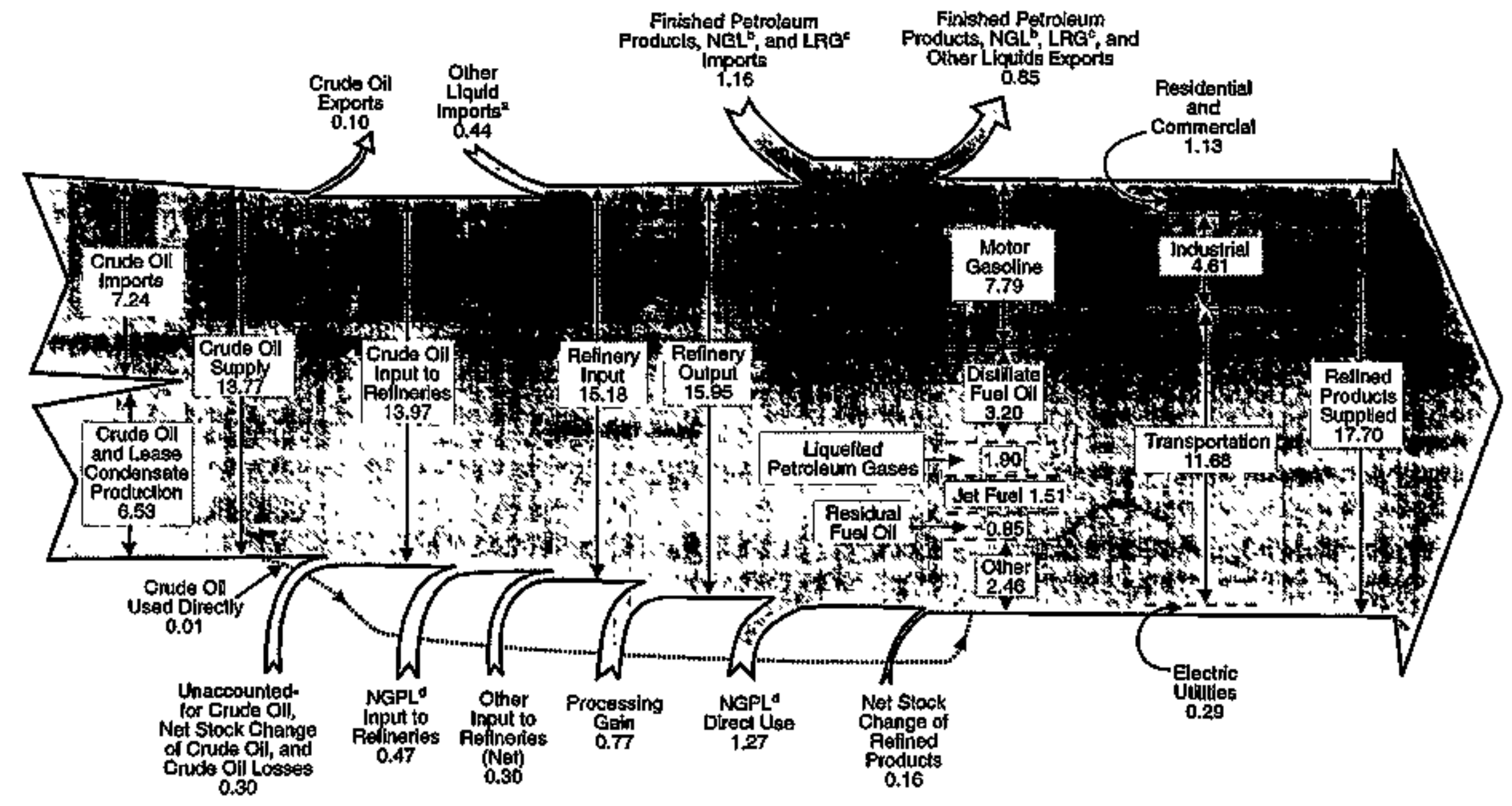

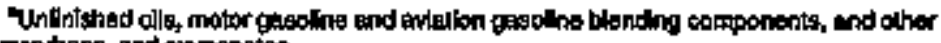
hydrocabons, and oxpenates.

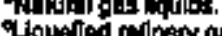

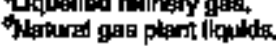

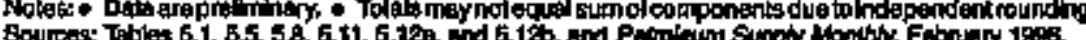
Tablo 3 , 


\section{Figure 5.1 Petroleum Overview}

\section{Overviaw, 1949-1995}

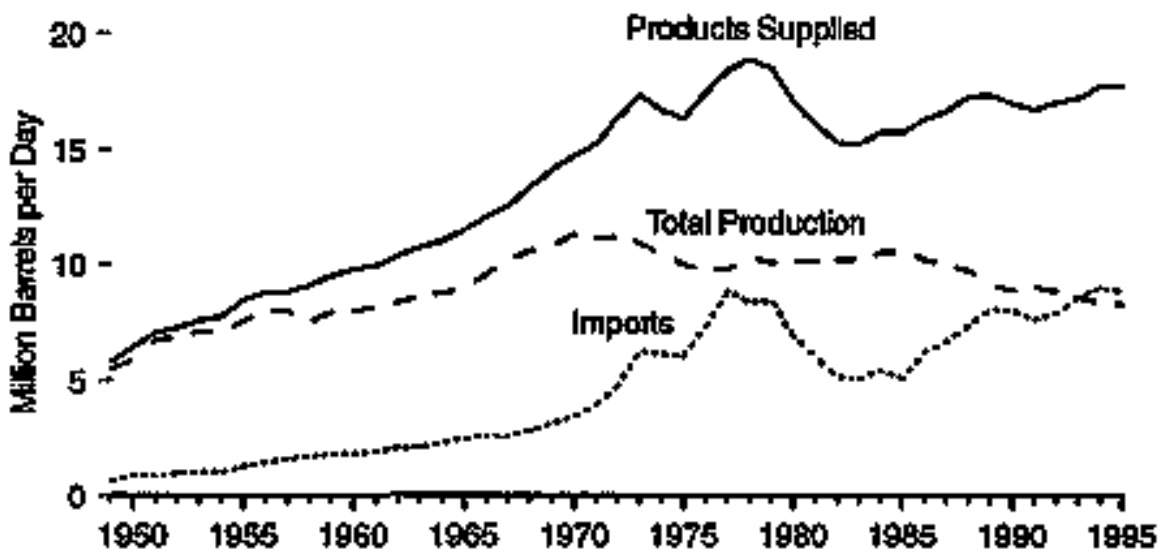

Produotion, 1949-1995

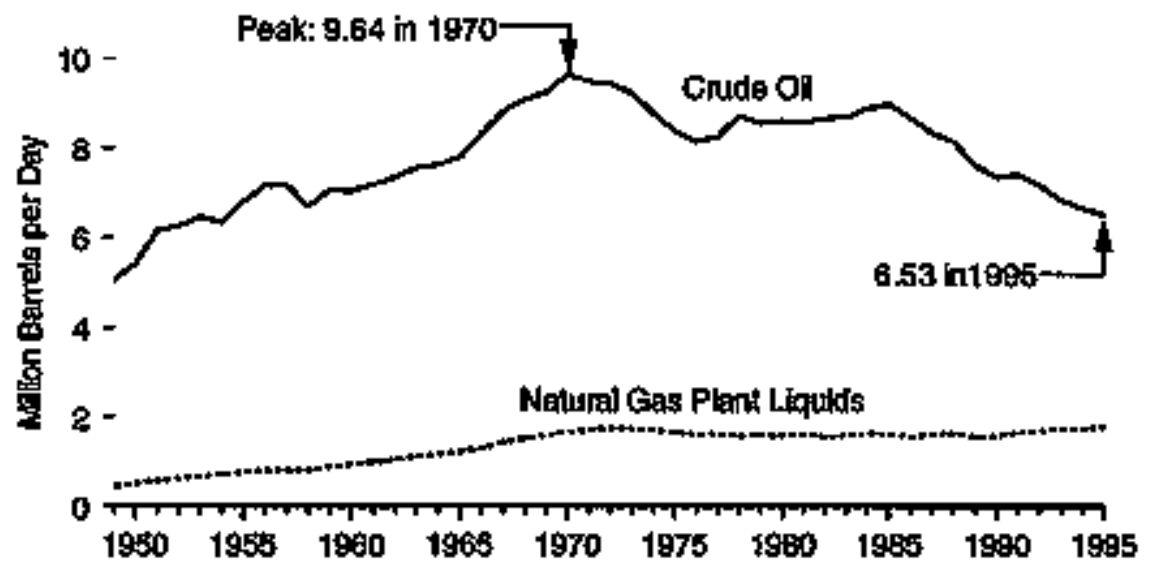

\section{Overvlew, 1995}

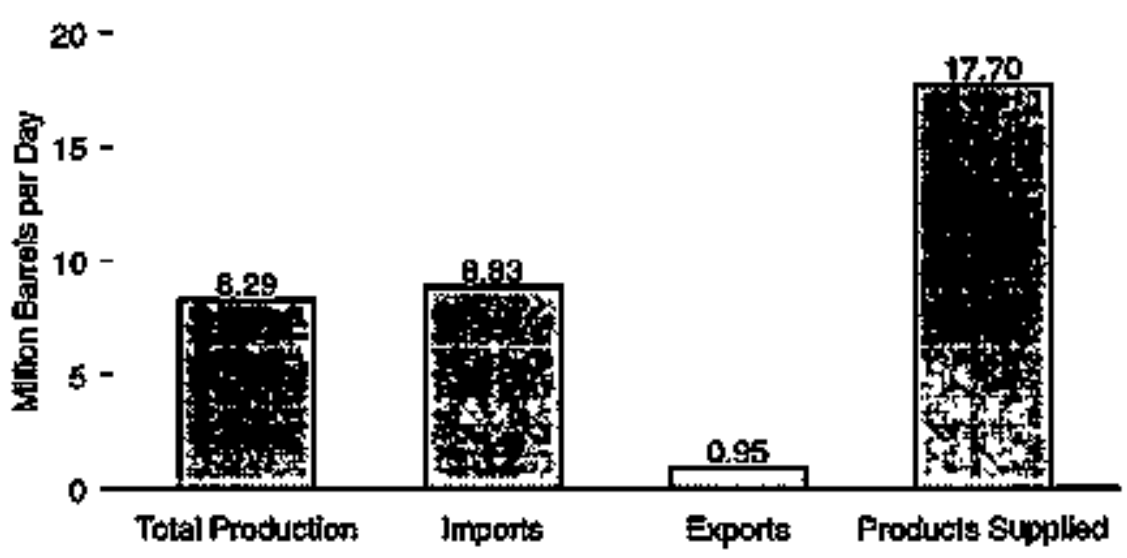

Trade, 1949-19g5

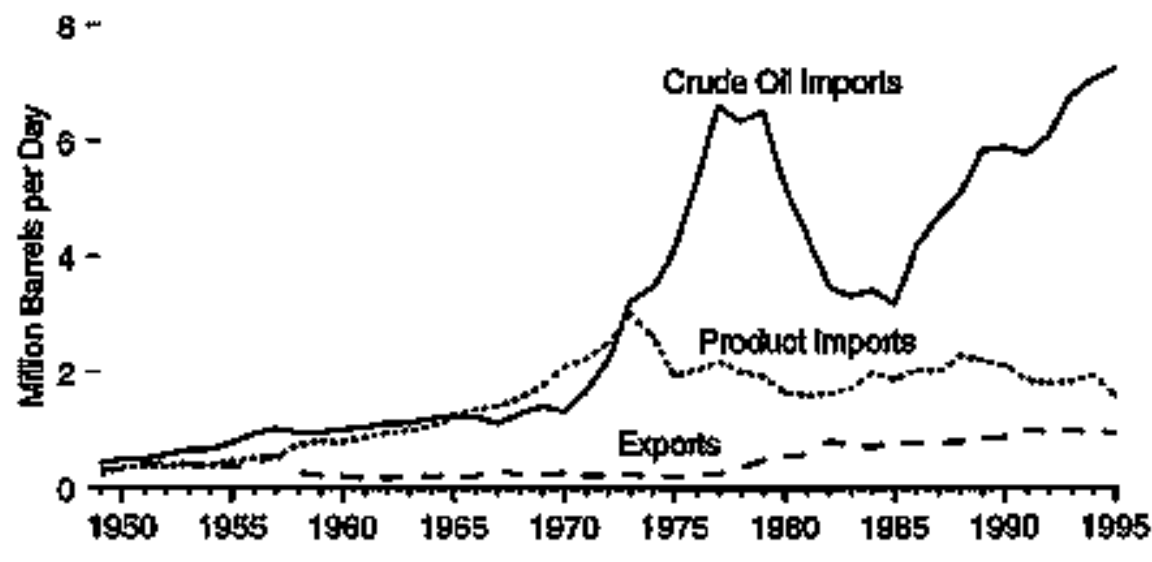

Sounce: Tabte 5.1 
Table 5.1 Petroleum Overview, 1949-1995

(Million Barrels per Day)

\begin{tabular}{|c|c|c|c|c|c|c|c|c|c|c|c|c|}
\hline \multirow[b]{2}{*}{ Yentr } & \multicolumn{3}{|c|}{ Propuctuas } & \multirow[b]{2}{*}{$\begin{array}{l}\text { Oihar } \\
\text { Dowiantle } \\
\text { strpity }\end{array}$} & \multicolumn{5}{|c|}{ Trowlin } & \multirow[b]{2}{*}{$\begin{array}{l}\text { Gude } \\
\text { of } \\
\text { Losins }\end{array}$} & \multirow[b]{2}{*}{$\begin{array}{l}\text { Changes } \\
\text { In } \\
\text { stocke. }\end{array}$} & \multirow[b]{2}{*}{$\begin{array}{l}\text { Petroleum } \\
\text { Producte } \\
\text { Suppled }\end{array}$} \\
\hline & Crode & $\begin{array}{c}\text { Motural Gur } \\
\text { Fink } \\
\text { tiowide }\end{array}$ & 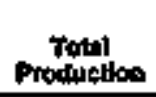 & & 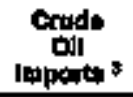 & 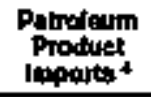 & $\begin{array}{l}\text { Total } \\
\text { imponts: }\end{array}$ & $\begin{array}{l}\text { Tots } \\
\text { Expents }\end{array}$ & $\begin{array}{c}\text { Wht } \\
\text { Inpotts s }\end{array}$ & & & \\
\hline 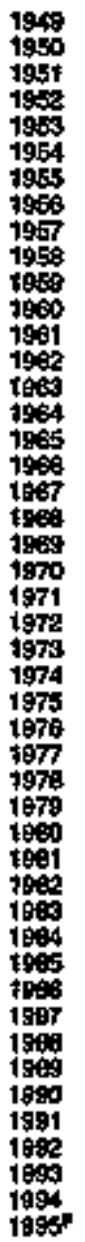 & 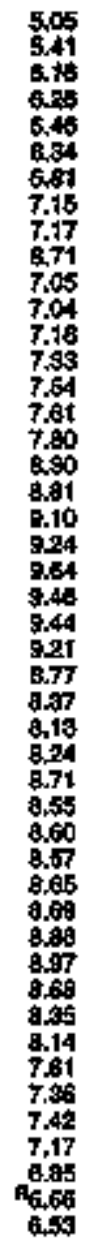 & 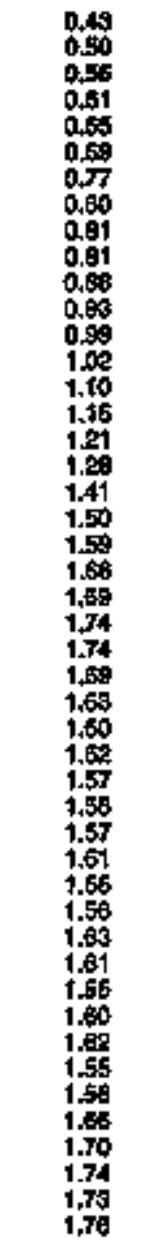 & 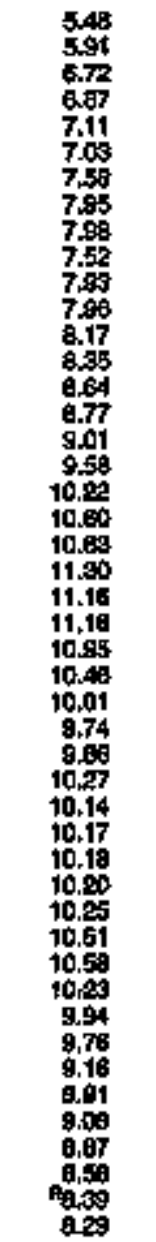 & 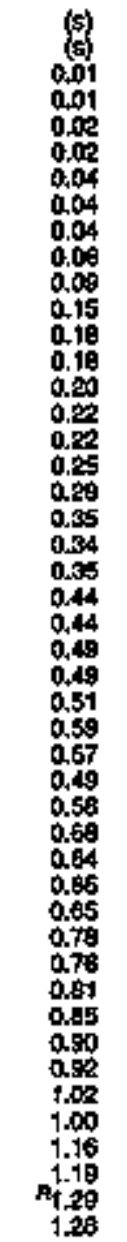 & 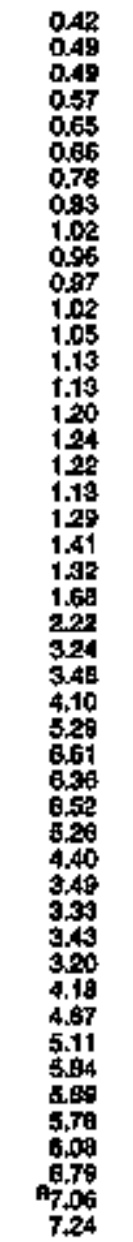 & 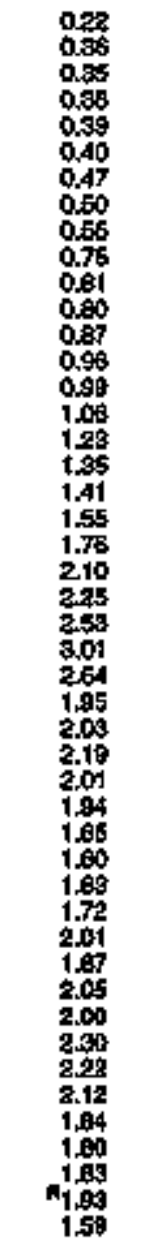 & 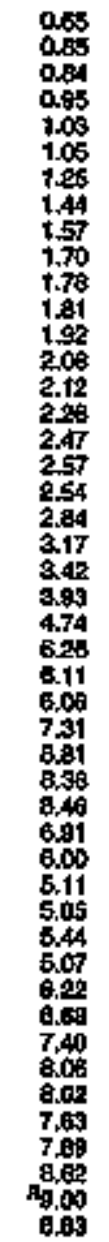 & 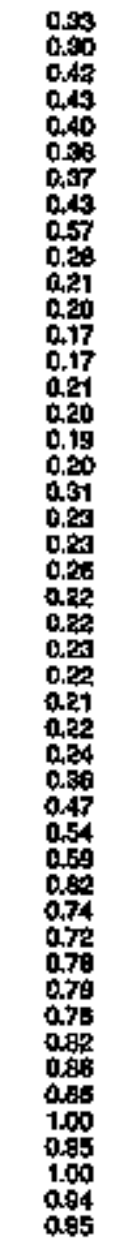 & 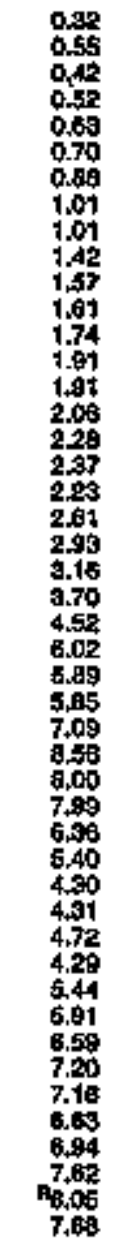 & 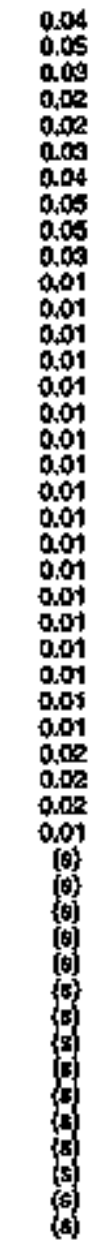 & 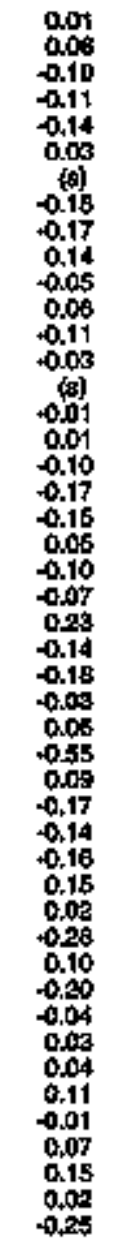 & 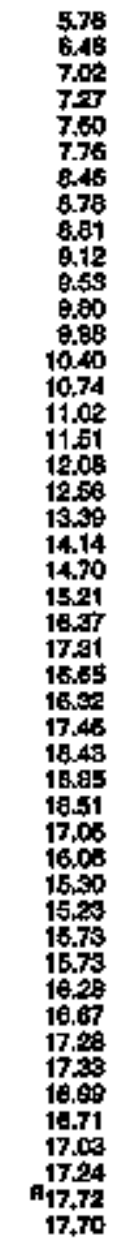 \\
\hline
\end{tabular}

1 Includes lasse condengerta.

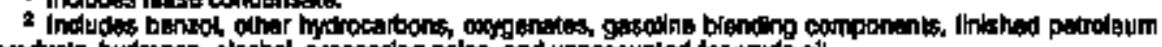

net miludiantal trom stocks or an adtition lo supply.

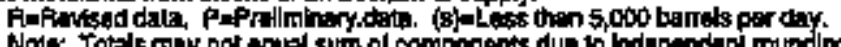

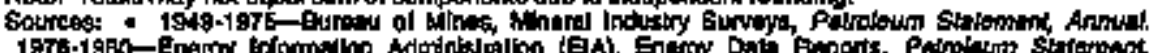

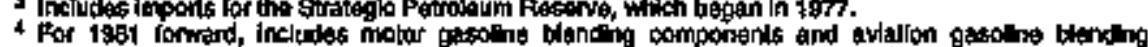

amporinhs.

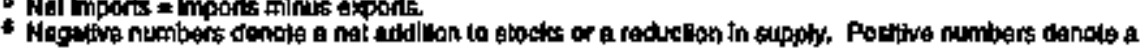

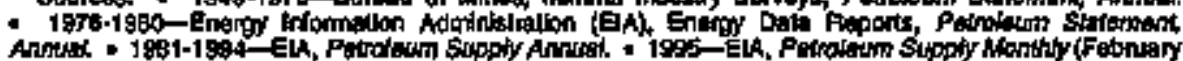
1906]. 


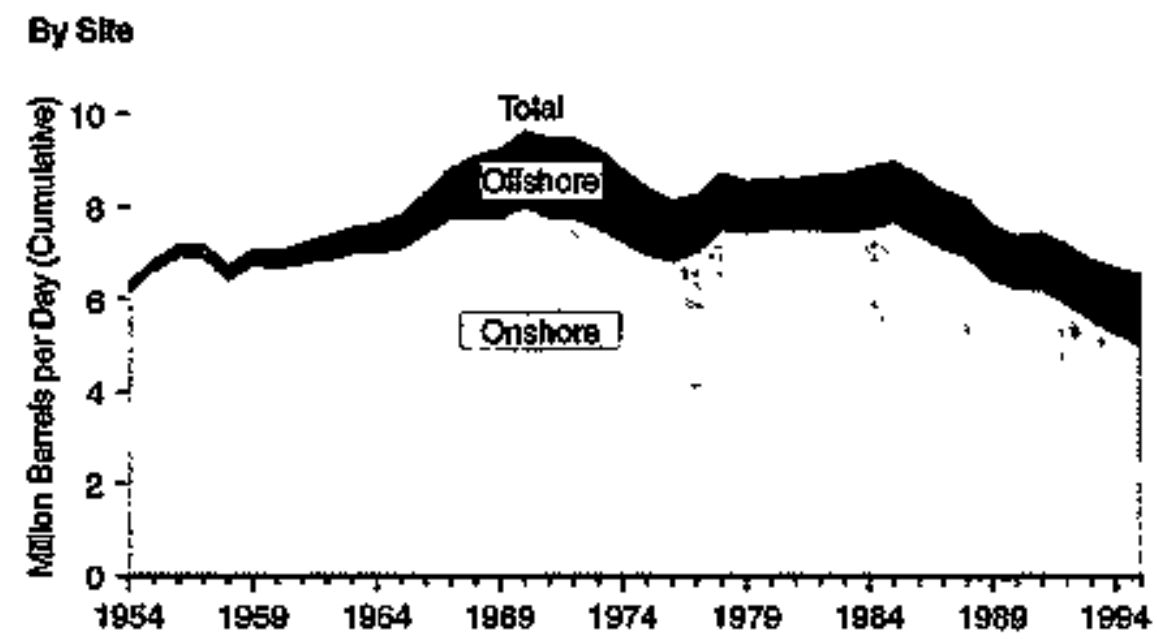

Number of Producing Oll Wells

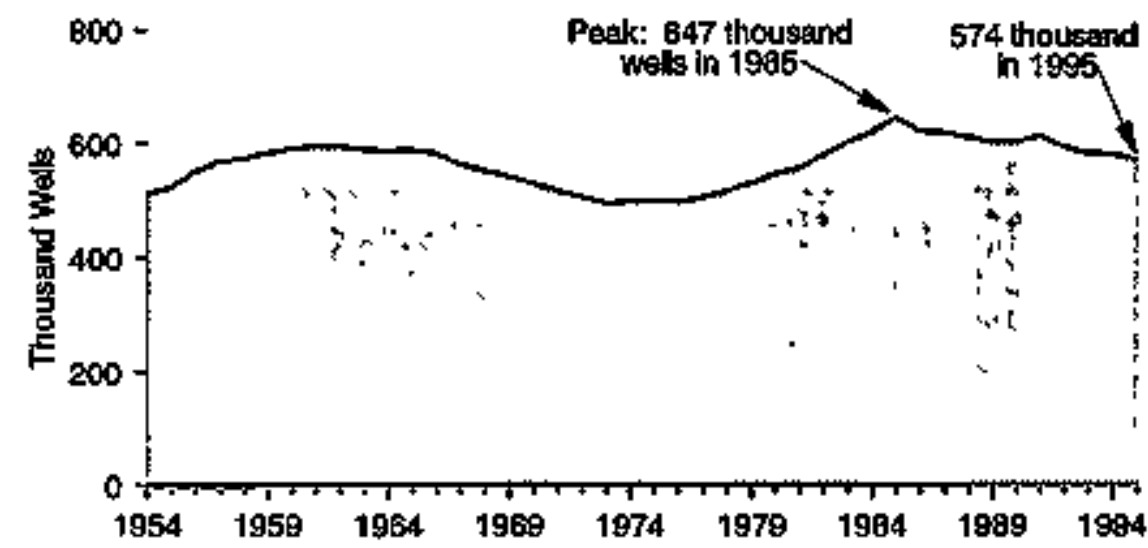

By Ceographic Localtion

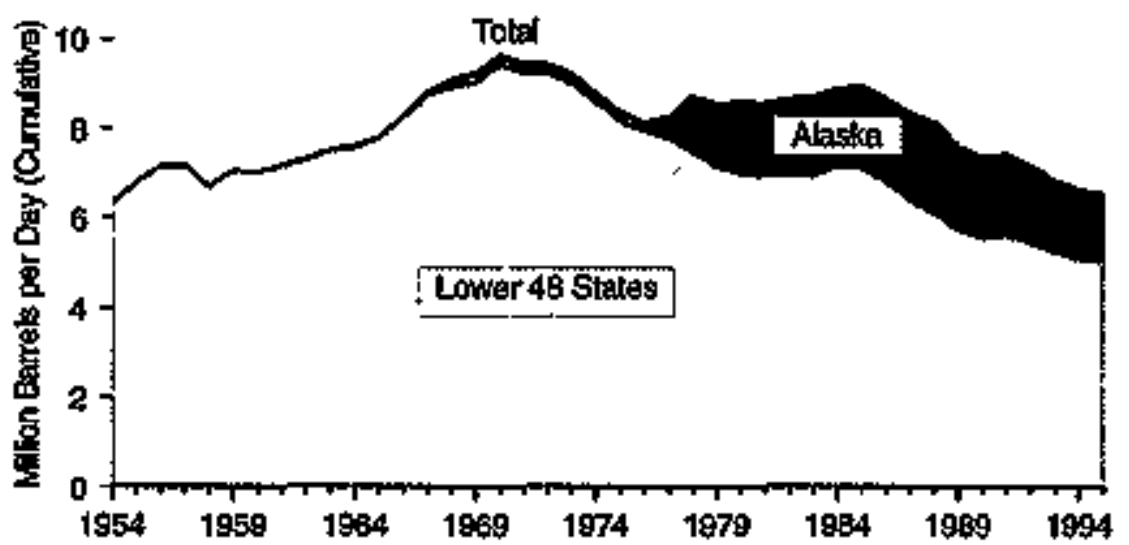

Average Productivity

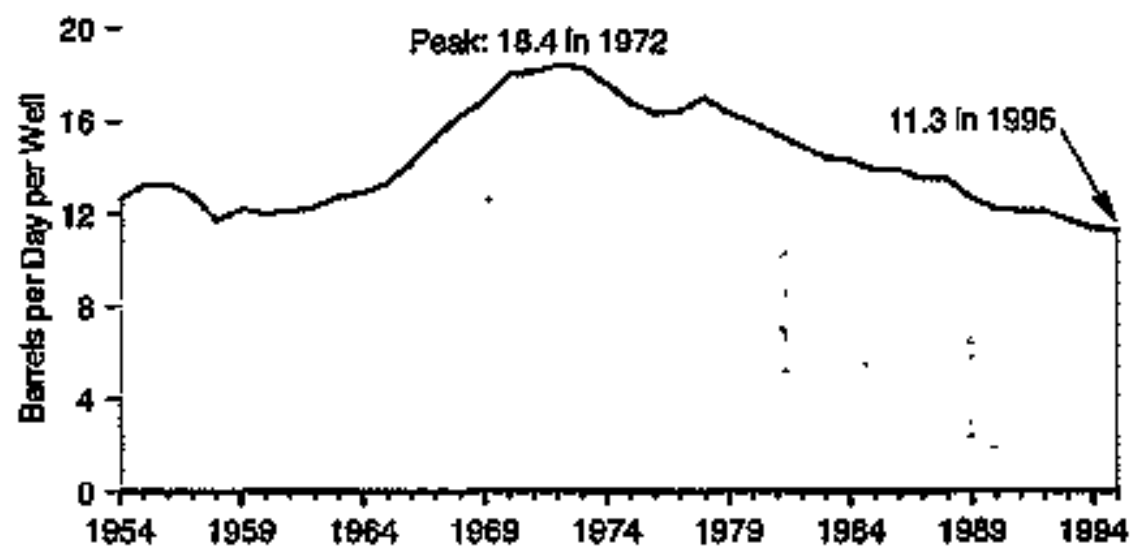

Source: Table Bs. 
Table 5.2 Crude Oll and Lease Condensate Production and Oil Well Productivity, 1954-1995 (Thousand Barrels per Day, Except as Noted)

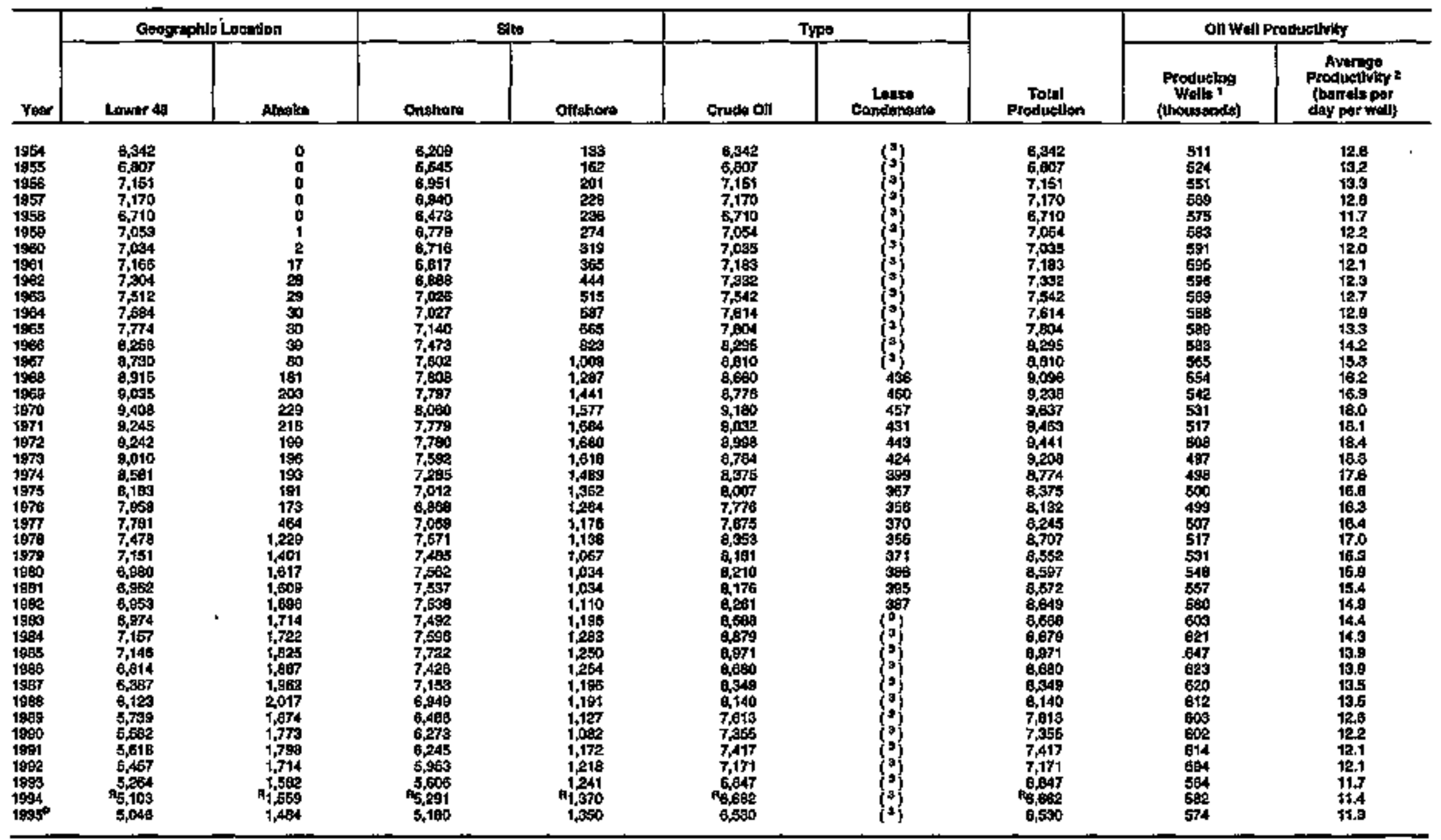

As of December 31.

2 For 1954-1976, average producthty is besed on the awaraga number of produding walls. For 1977

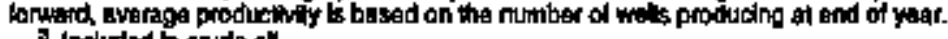

Inceluded in erude on.

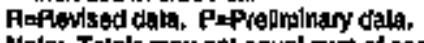

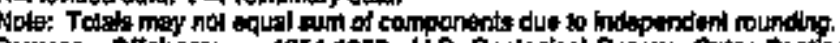

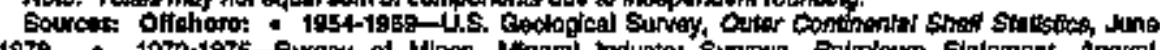

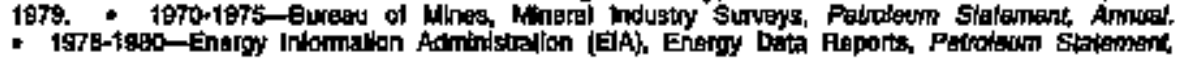

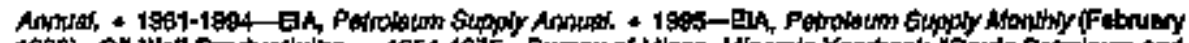

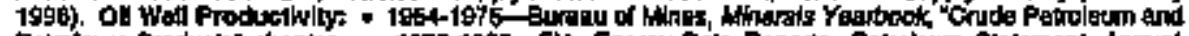

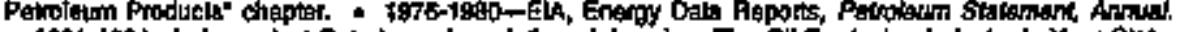

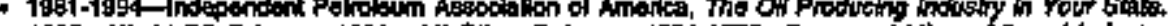

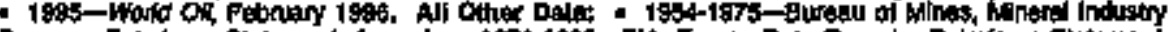

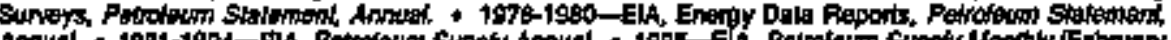

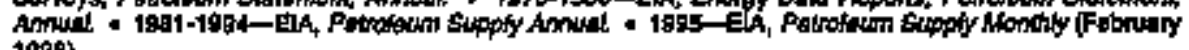
1998). 


\section{Figure 5.3 Petroleum Imports by Type}

\section{Totel, 1949-1995}

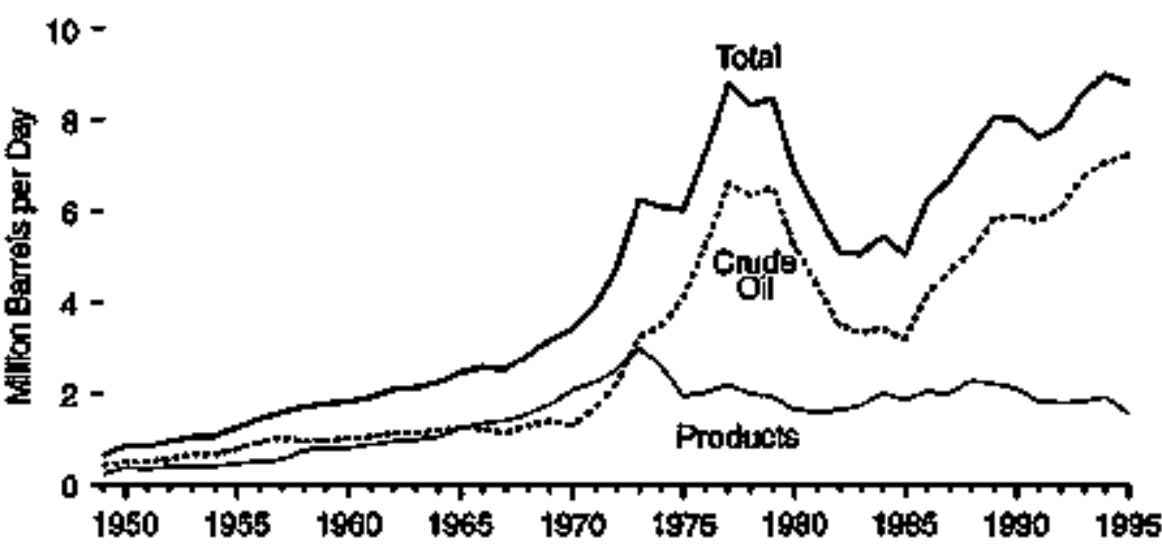

\section{By Product, 1895}

$500-$

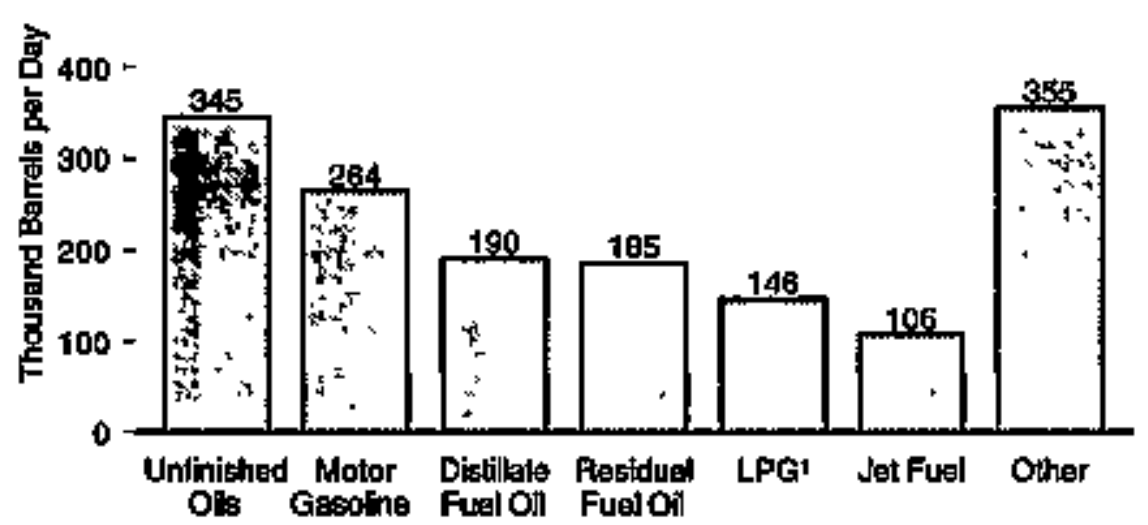

\section{By Selected Product, 1949-1995}

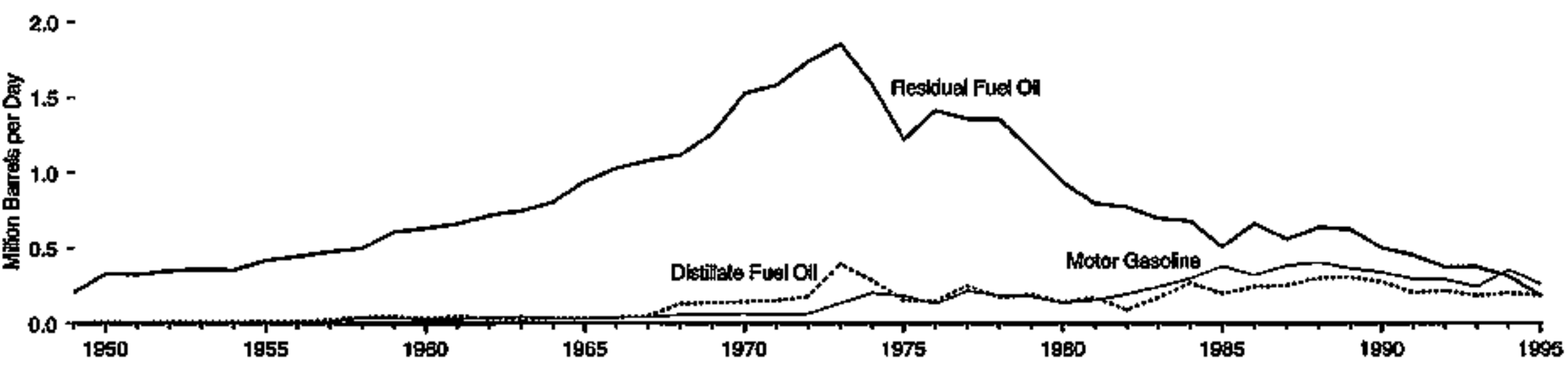

' Uqueled perroterm geses.

Source: Tabte 5.3.

Nole: Becalse vertical ecetes dilier, oraphe should nol be compared, 
Table 5.3 Petroleum Imports by Type, 1949-1995 (Thousand Barrets per Day)

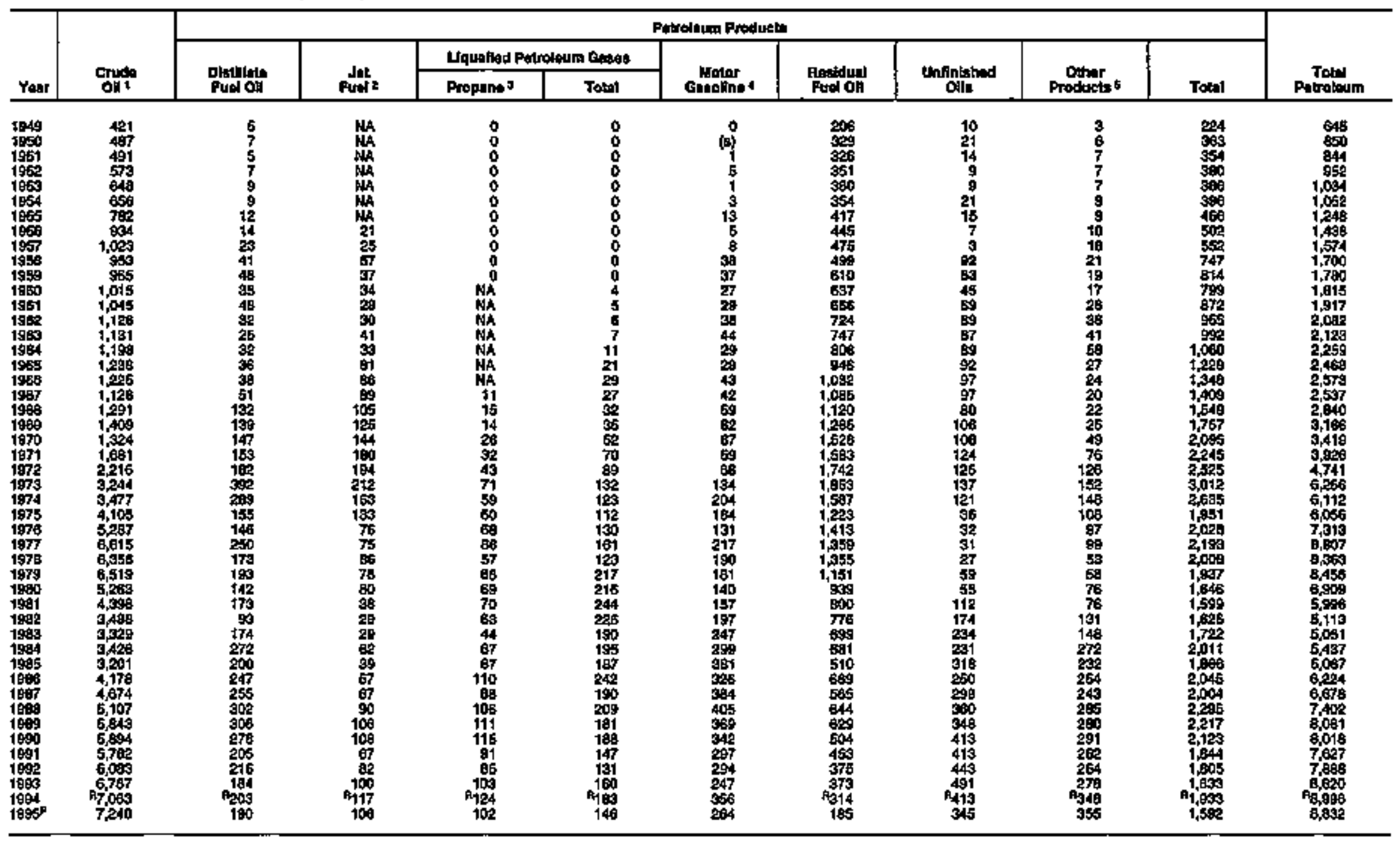

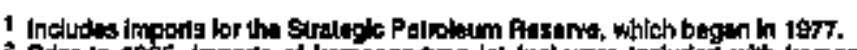

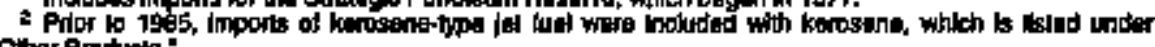
Ohivi Products.

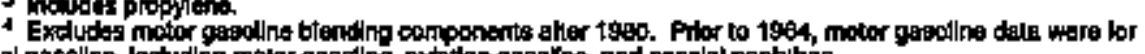

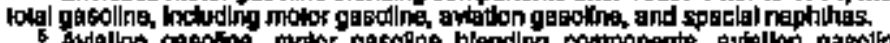

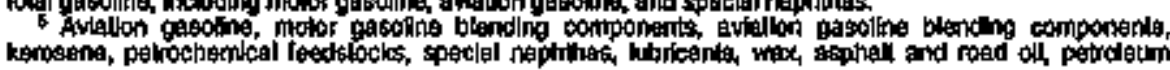

ooke, pankanes pess, and miactlantous products.

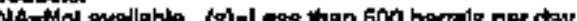

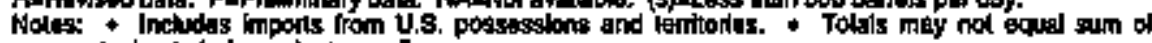
ompanents du lo independont roundits.

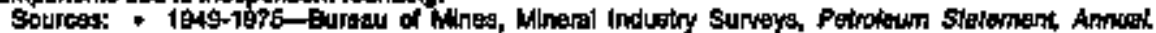
- 1976-1990-EngrTy hrom

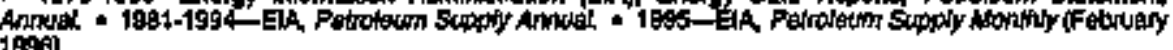




\section{Tobal, OPEC, and Non-OPEC, 1860-1995}

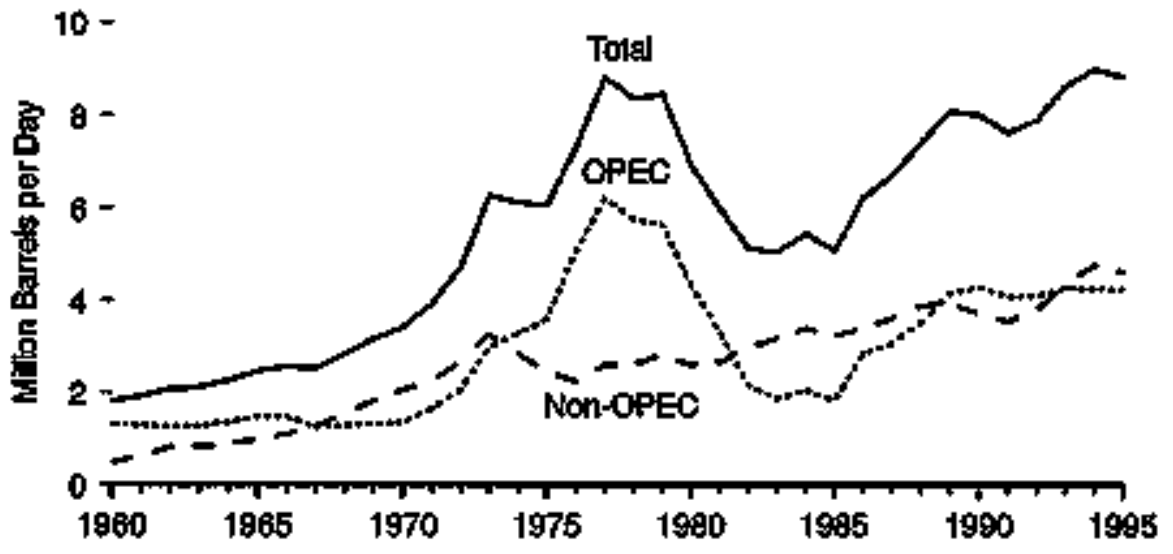

selected OPEC Coumtries, 1960-1995

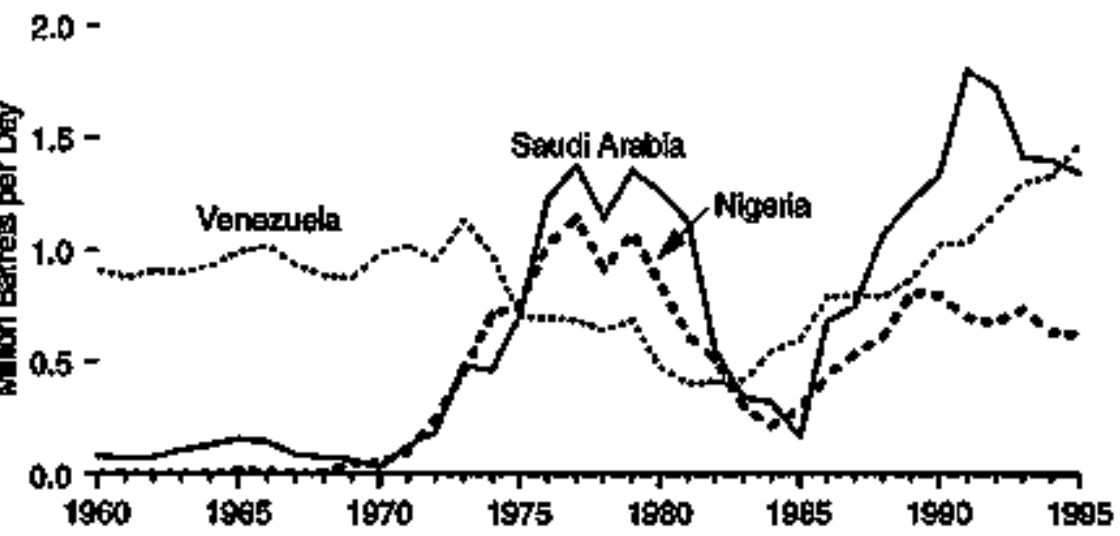

Top Countrles, tsgs

$$
2.0-
$$

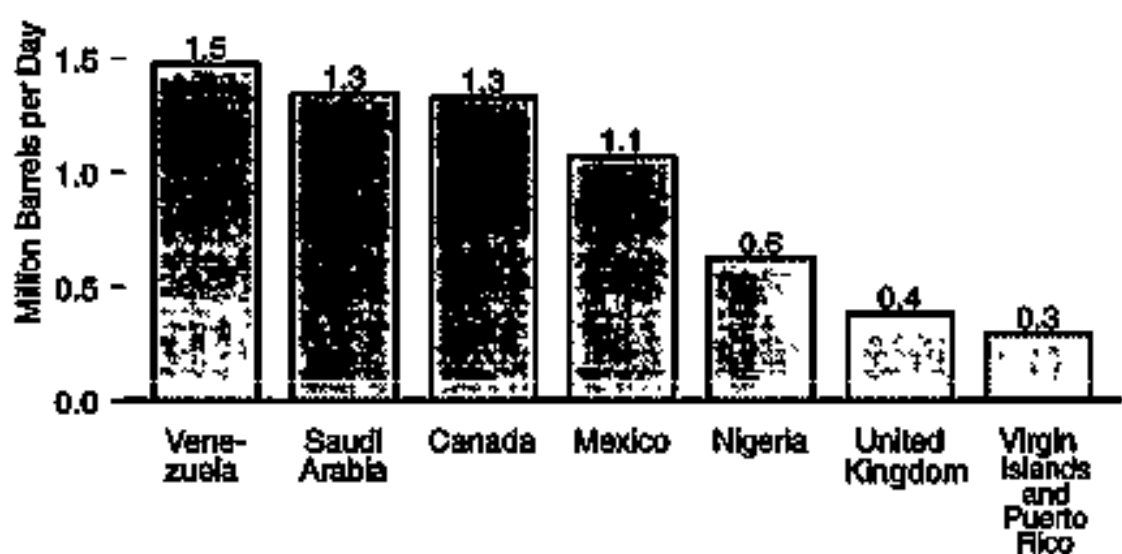

\section{Solocted Non-OPEC Countries, 1960-1995}

$$
2.0 \text { - }
$$

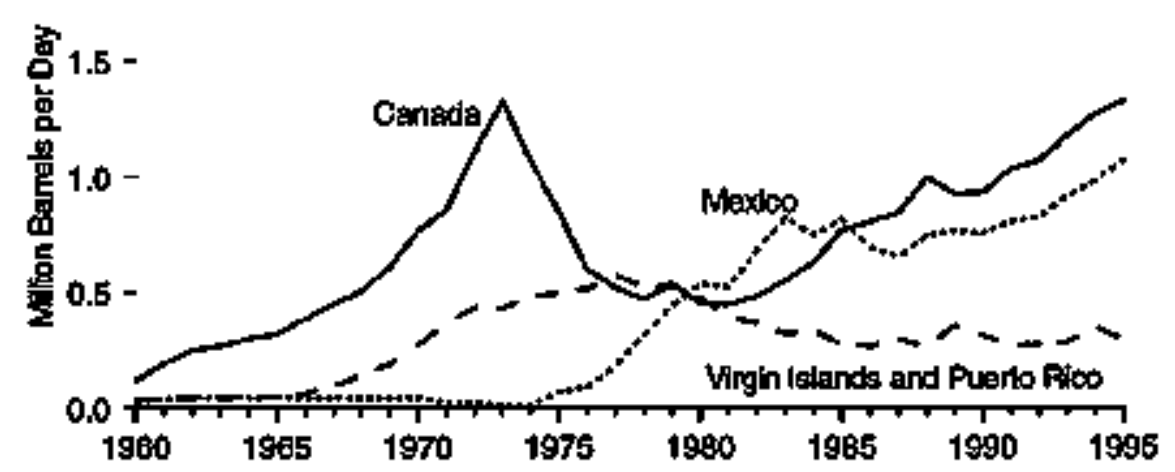

Nola: Becaute vertical scalos dlier, graphe thoutd nol be compared.

Source: Table 6.4. 
Table 5.4 Petroleum Imports by Country of Origin, 1960-1995

\begin{tabular}{|c|c|c|c|c|c|c|c|c|c|c|c|c|c|c|}
\hline \multirow[b]{3}{*}{ Yaur } & \multicolumn{6}{|c|}{ OPEC 1 } & \multicolumn{5}{|c|}{ Nan-OPEC } & \multirow[b]{2}{*}{$\begin{array}{c}\text { Total } \\
\text { imports }\end{array}$} & \multirow{2}{*}{$\begin{array}{l}\text { Imports from } \\
\text { Arob opes } \\
\text { of Share of } \\
\text { Tolal timports }\end{array}$} & \multirow{2}{*}{$\begin{array}{l}\text { Importe from } \\
\text { OPFe } \\
\text { ne Share of } \\
\text { Tot:inl Imports }\end{array}$} \\
\hline & Nigeria & $\begin{array}{l}\text { Sald } \\
\text { Arablo }\end{array}$ & Vonosunelo & Other: & Towal $\mathbf{3}$ & Arebs & Canada & Moxkos & $\begin{array}{c}\text { Uniliot } \\
\text { Ningdom }\end{array}$ & $\begin{array}{c}\text { Virgin } \\
\text { Mtands and } \\
\text { Puncto Rike }\end{array}$ & Other & & & \\
\hline & \multicolumn{12}{|c|}{ Thoustand Batrels por Dey } & \multicolumn{2}{|c|}{ Porceont } \\
\hline 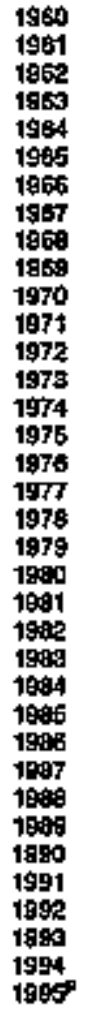 & 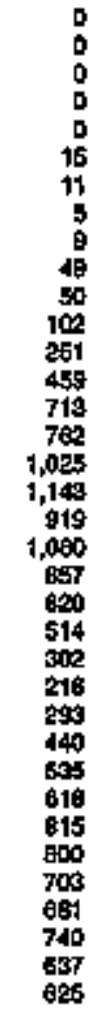 & 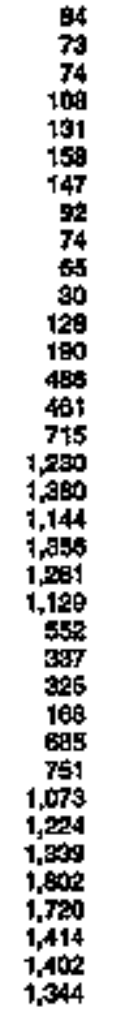 & 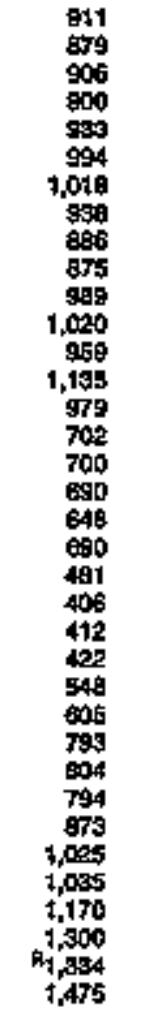 & 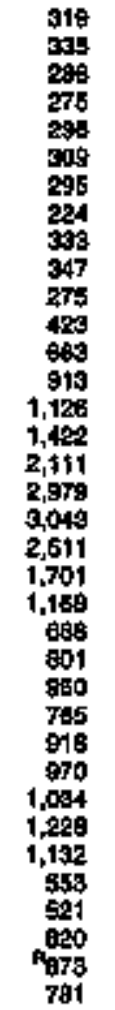 & 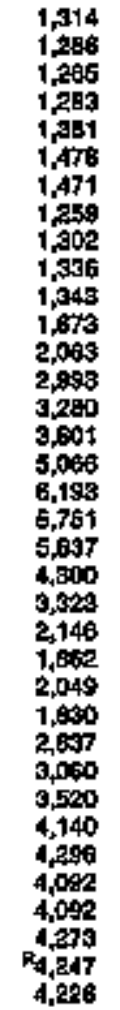 & 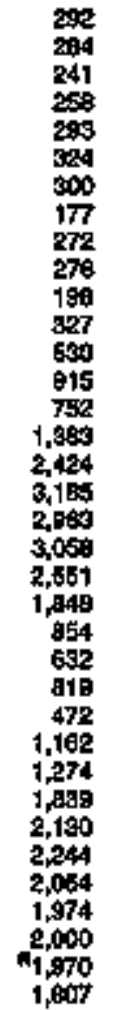 & 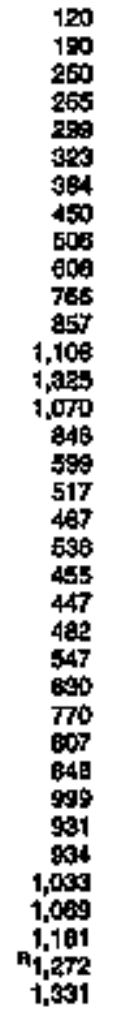 & 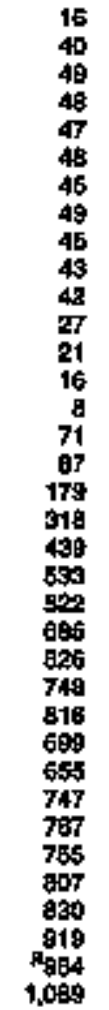 & 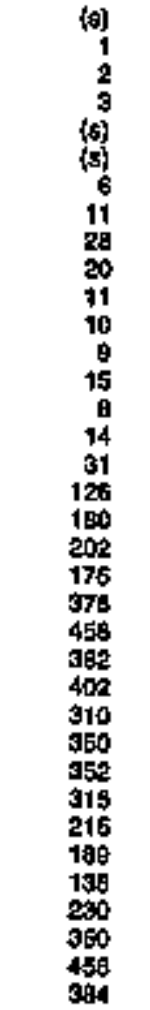 & 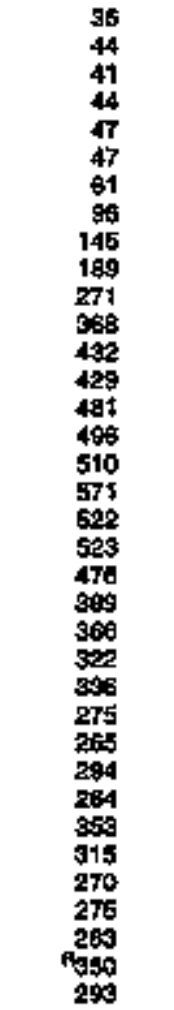 & 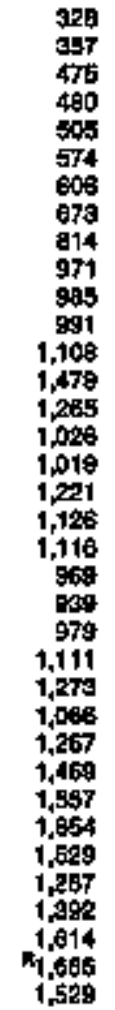 & 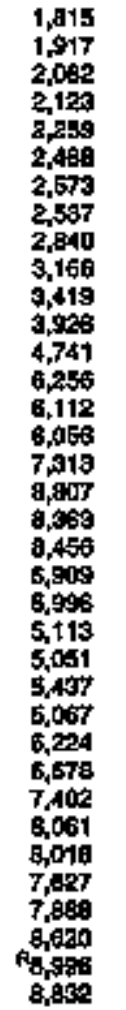 & 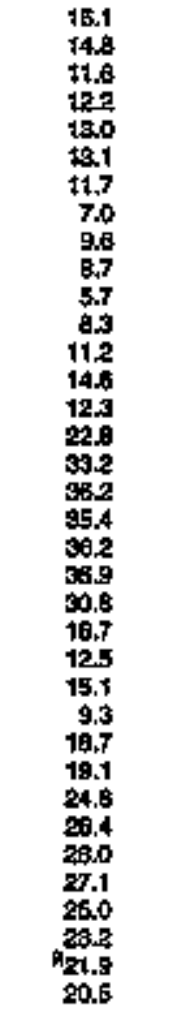 & 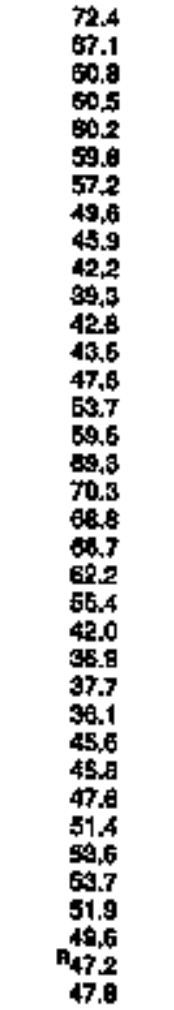 \\
\hline
\end{tabular}

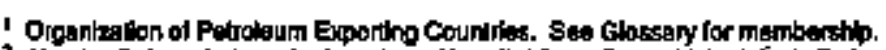

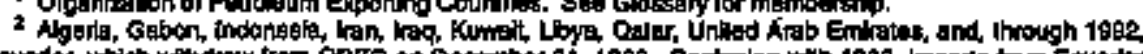

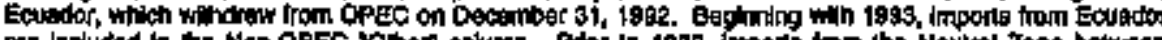

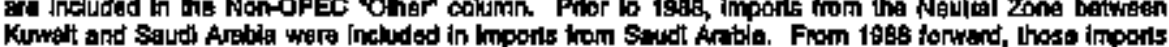

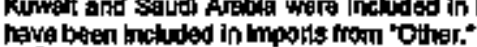

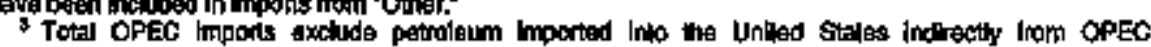

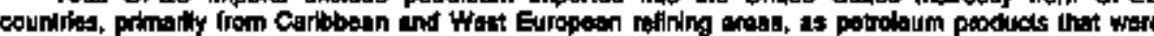

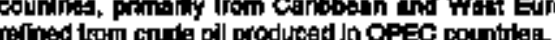

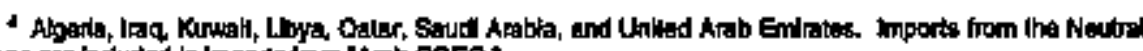
Zono are inoluted in impons tom "AFBb OPEC."

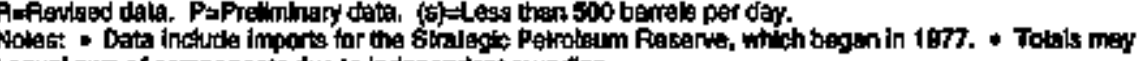

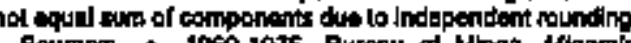

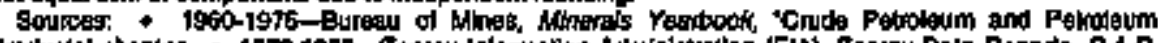

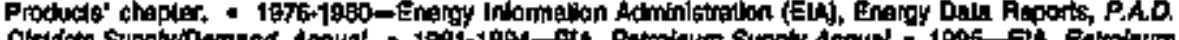

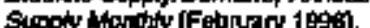




\section{Figure 5.5 Petroleum Exports by Type}

Total, 1949-1995

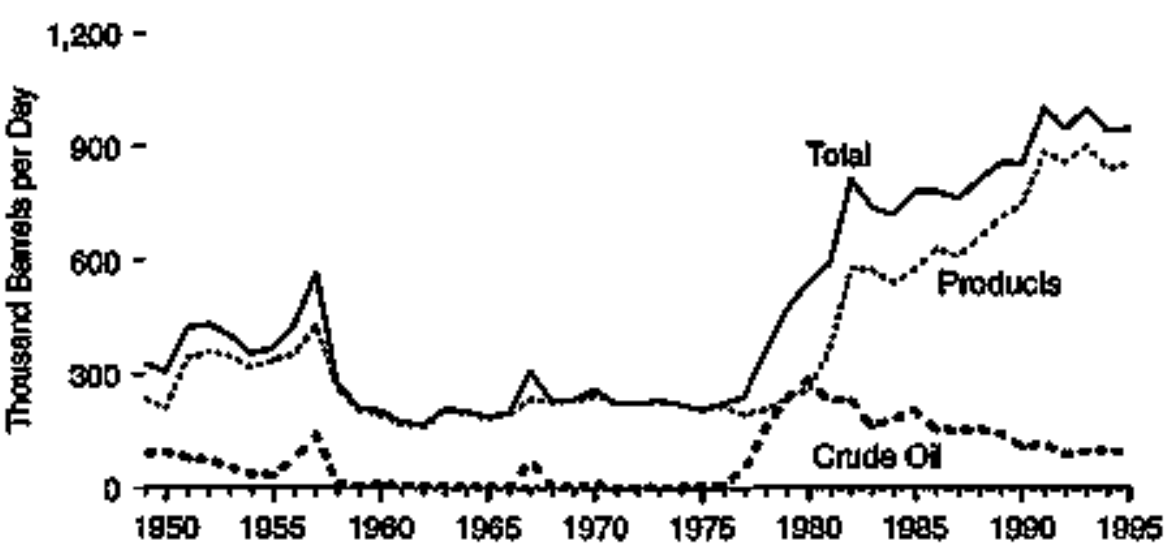

\section{By Product, t\$gs}

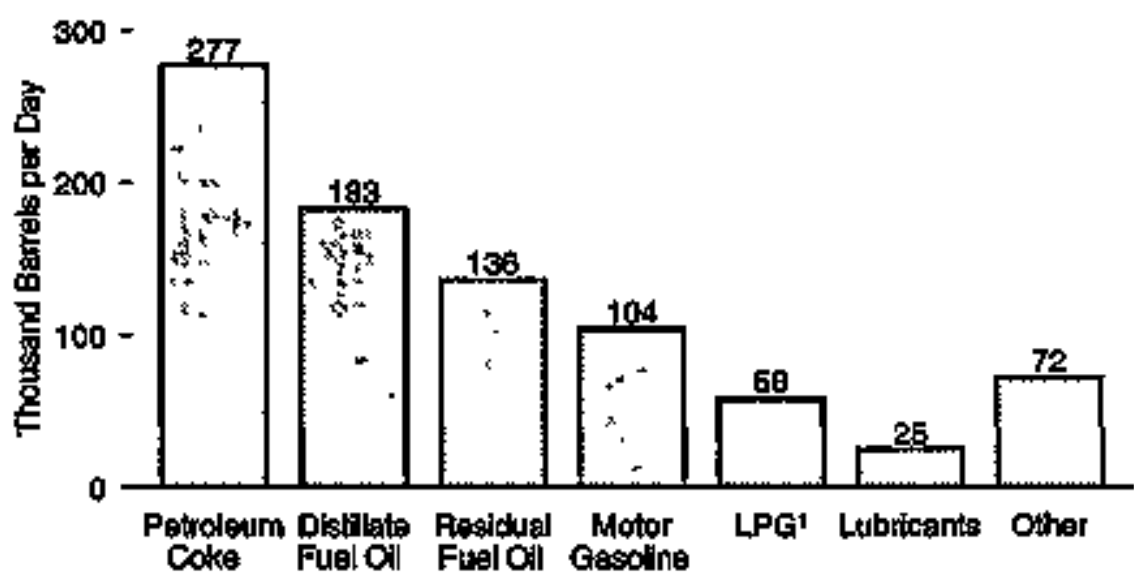

By Selected Products, 1949-1995

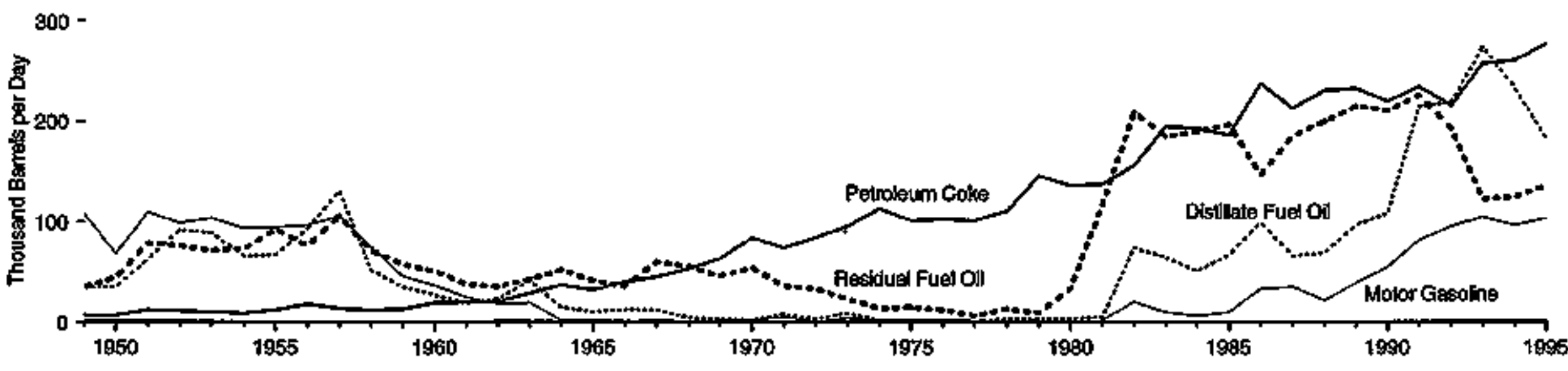

Source: Table 5.5.

Note: Because vertital sceless Gifer, graphs should not be compared. 
Table 5.5 Petroleum Exports by Type, 1949-1995

(Thousand Earrels per Day)

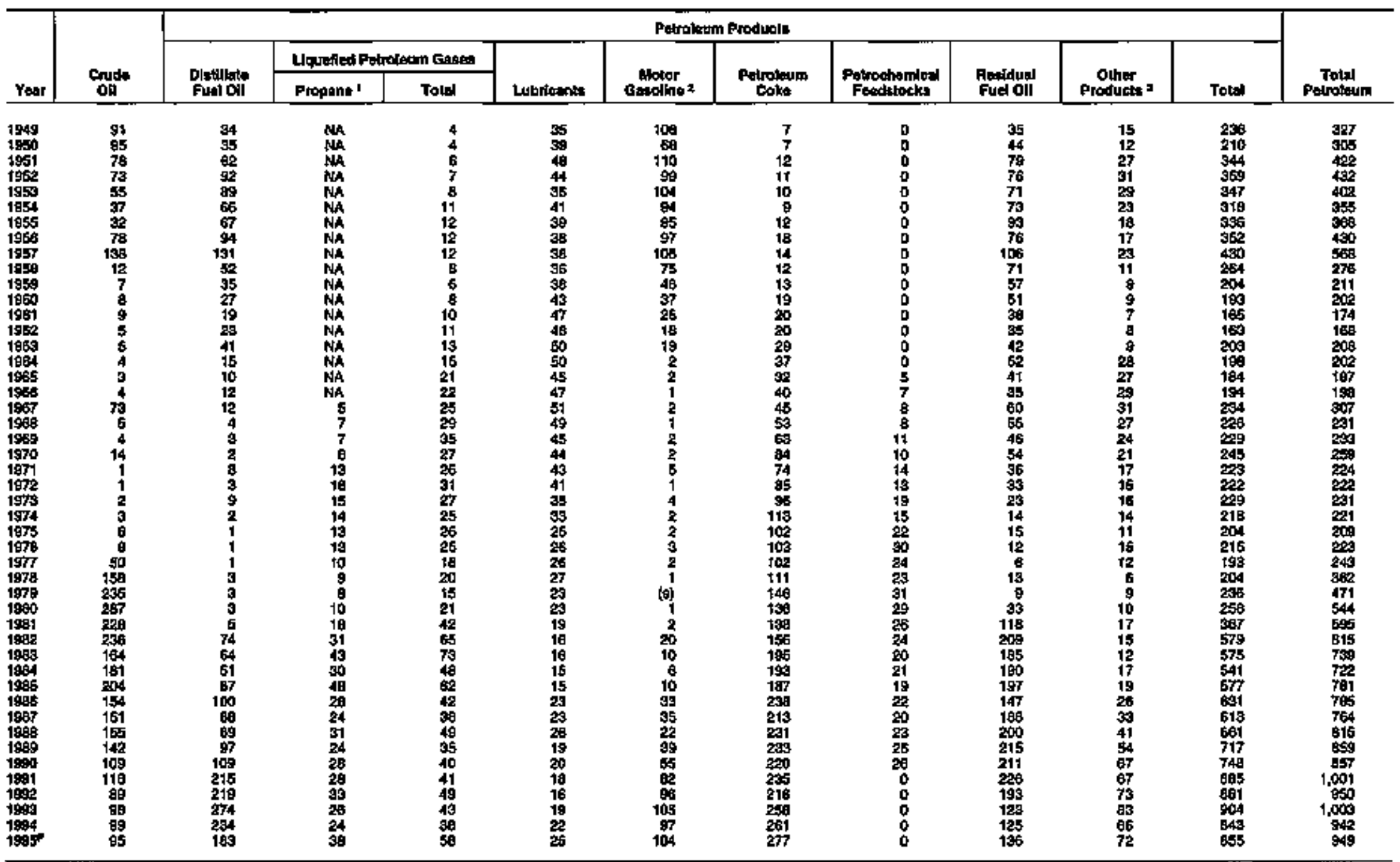

Inctudes propyeng.

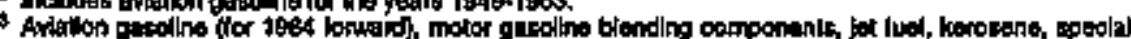

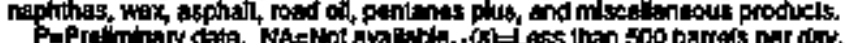

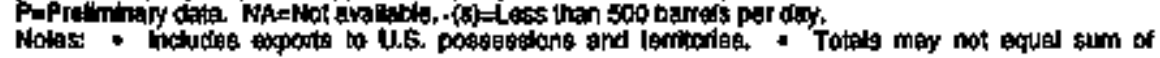

components ove to independen rounding

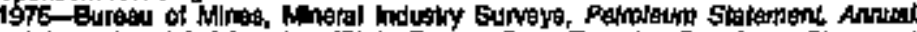

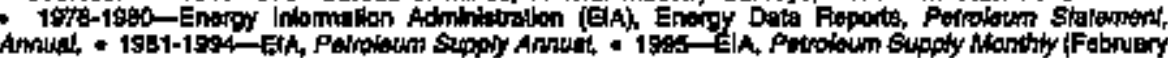
1986]. 


\section{Totel Exports and Exports to Canade and Mexitoo, 19\%0-1995}

$1,200-$

展
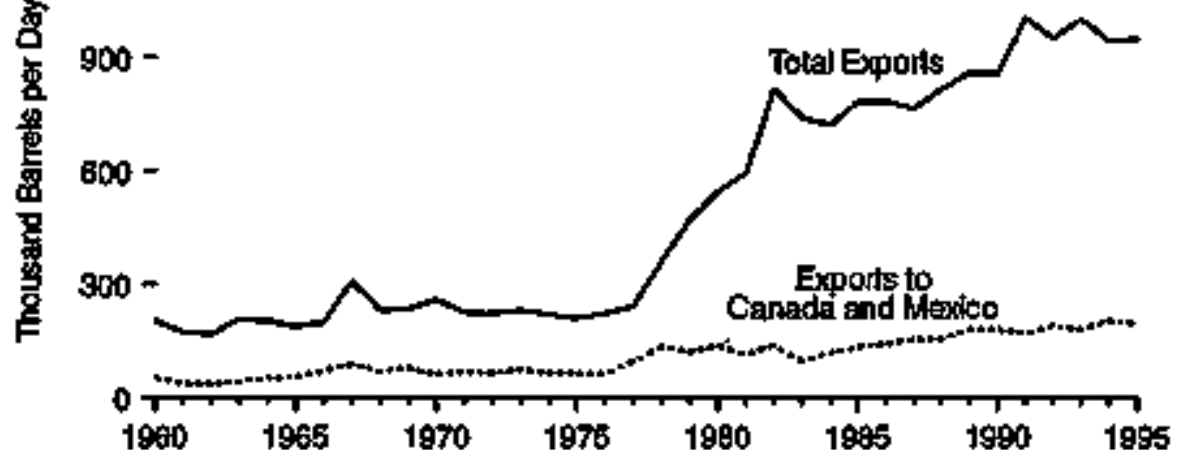

By Selected Countries, 1998

$150-$

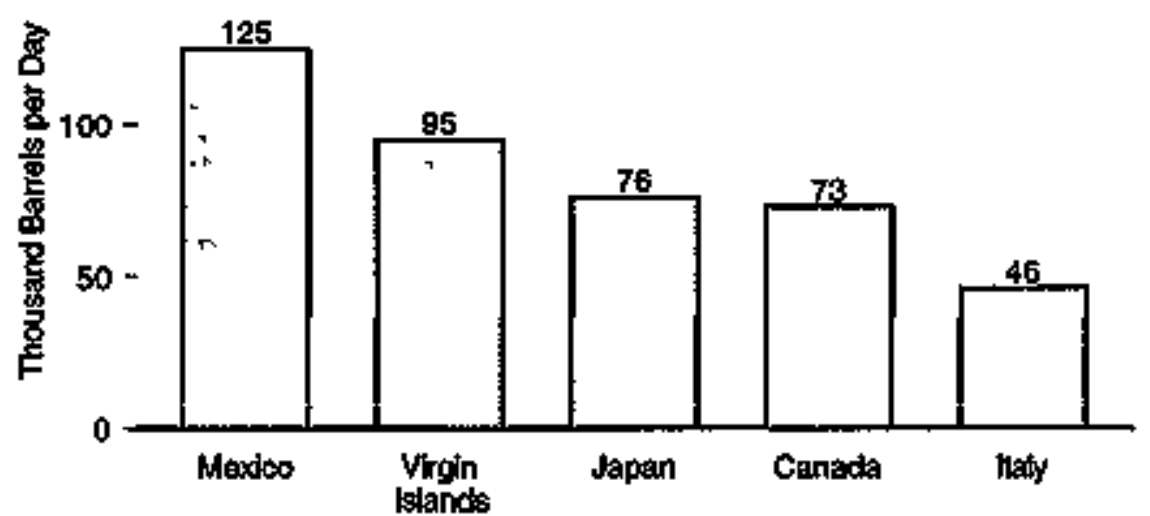

By Selsoted Countries, 1960-1995

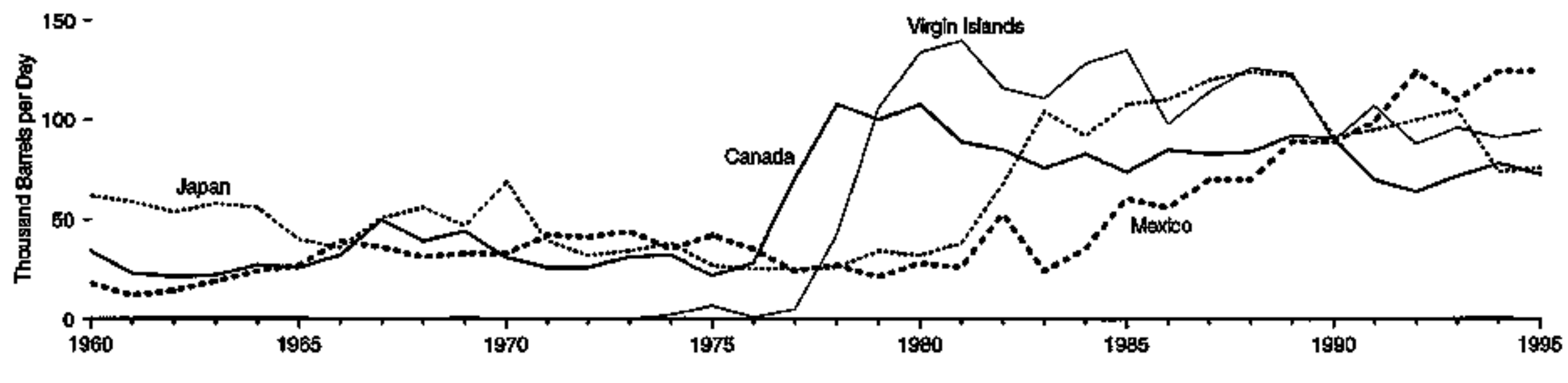

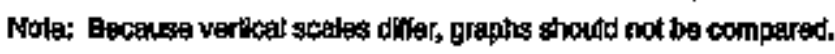

Sources Table 5.6. 
Table 5.6 Petroleum Exports by Country of Destination, 1960-1995

(Thousand Barrels per Day)

\begin{tabular}{|c|c|c|c|c|c|c|c|c|c|c|c|c|c|}
\hline Vurr & Cmadi & Moxkleo & Jepan & Walhettandl & Balstur ' & $\| t=y$ & $\begin{array}{c}\text { Unitod } \\
\text { Kingtom }\end{array}$ & Frange & Brarll & $\begin{array}{c}\text { Pursti } \\
\text { froo }\end{array}$ & $\begin{array}{c}\text { Virsign } \\
\text { lsinnde }\end{array}$ & Olher & Told머 \\
\hline 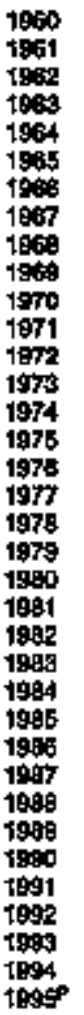 & 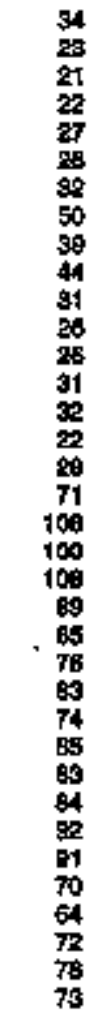 & $\begin{array}{c}18 \\
12 \\
14 \\
19 \\
24 \\
27 \\
38 \\
38 \\
31 \\
33 \\
33 \\
48 \\
41 \\
14 \\
75 \\
42 \\
35 \\
24 \\
27 \\
21 \\
28 \\
28 \\
53 \\
24 \\
35 \\
61 \\
56 \\
70 \\
70 \\
89 \\
99 \\
59 \\
124 \\
110 \\
124 \\
125\end{array}$ & 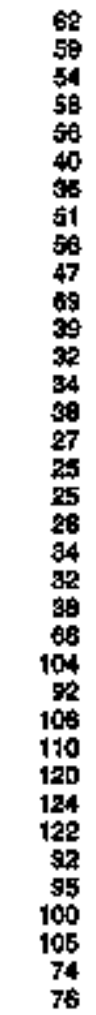 & $\begin{array}{r}6 \\
4 \\
5 \\
19 \\
9 \\
10 \\
9 \\
13 \\
10 \\
9 \\
15 \\
11 \\
12 \\
18 \\
17 \\
23 \\
28 \\
17 \\
18 \\
28 \\
28 \\
40 \\
85 \\
49 \\
37 \\
44 \\
58 \\
38 \\
28 \\
39 \\
59 \\
72 \\
62 \\
46 \\
30 \\
919\end{array}$ & $\begin{array}{r}3 \\
4 \\
3 \\
9 \\
4 \\
3 \\
3 \\
6 \\
4 \\
4 \\
5 \\
7 \\
13 \\
19 \\
19 \\
8 \\
12 \\
16 \\
15 \\
19 \\
20 \\
12 \\
17 \\
22 \\
21 \\
29 \\
30 \\
17 \\
25 \\
22 \\
20 \\
22 \\
22 \\
21 \\
26 \\
21\end{array}$ & 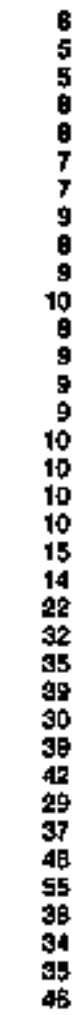 & $\begin{array}{r}12 \\
10 \\
10 \\
11 \\
11 \\
10 \\
12 \\
12 \\
12 \\
14 \\
14 \\
12 \\
12 \\
9 \\
10 \\
9 \\
6 \\
7 \\
13 \\
9 \\
7 \\
7 \\
7 \\
5 \\
14 \\
8 \\
14 \\
14 \\
8 \\
6 \\
6 \\
9 \\
91 \\
13 \\
13 \\
12 \\
10 \\
10 \\
14\end{array}$ & $\begin{array}{r}4 \\
3 \\
4 \\
4 \\
3 \\
4 \\
3 \\
4 \\
4 \\
5 \\
5 \\
3 \\
44 \\
6 \\
5 \\
9 \\
9 \\
13 \\
11 \\
15 \\
24 \\
23 \\
18 \\
11 \\
11 \\
12 \\
12 \\
11 \\
17 \\
27 \\
9 \\
81 \\
11 \\
11\end{array}$ & $\begin{array}{l}4 \\
4 \\
5 \\
4 \\
4 \\
3 \\
4 \\
6 \\
6 \\
7 \\
7 \\
9 \\
9 \\
8 \\
8 \\
5 \\
7 \\
8 \\
8 \\
7 \\
4 \\
5 \\
6 \\
2 \\
5 \\
3 \\
3 \\
2 \\
3 \\
5 \\
2 \\
13 \\
20 \\
16 \\
13 \\
16\end{array}$ & $\begin{array}{r}1 \\
1 \\
1 \\
1 \\
1 \\
1 \\
3 \\
7 \\
8 \\
2 \\
1 \\
3 \\
3 \\
3 \\
4 \\
5 \\
21 \\
5 \\
44 \\
64 \\
85 \\
84 \\
96 \\
33 \\
24 \\
28 \\
14 \\
28 \\
24 \\
18 \\
11 \\
10 \\
7 \\
12 \\
12 \\
28\end{array}$ & 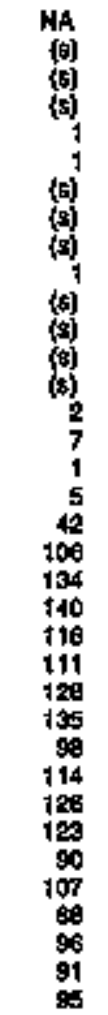 & $\begin{array}{c}52 \\
48 \\
50 \\
59 \\
55 \\
54 \\
49 \\
65 \\
65 \\
59 \\
71 \\
67 \\
59 \\
50 \\
59 \\
44 \\
49 \\
44 \\
47 \\
57 \\
79 \\
124 \\
210 \\
251 \\
299 \\
249 \\
273 \\
295 \\
288 \\
294 \\
399 \\
419 \\
416 \\
474 \\
435 \\
412\end{array}$ & 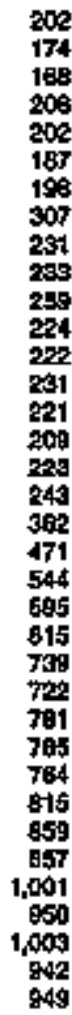 \\
\hline
\end{tabular}

1 Inctutho Luxemboum.

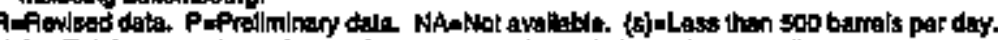

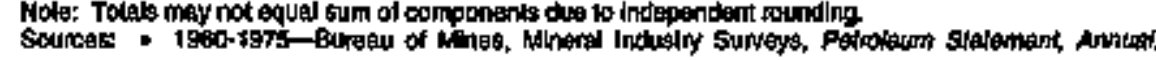

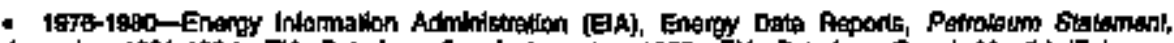

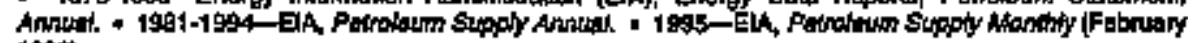
1006 , 


\section{Total, OPEC, and Mon-OPEC}

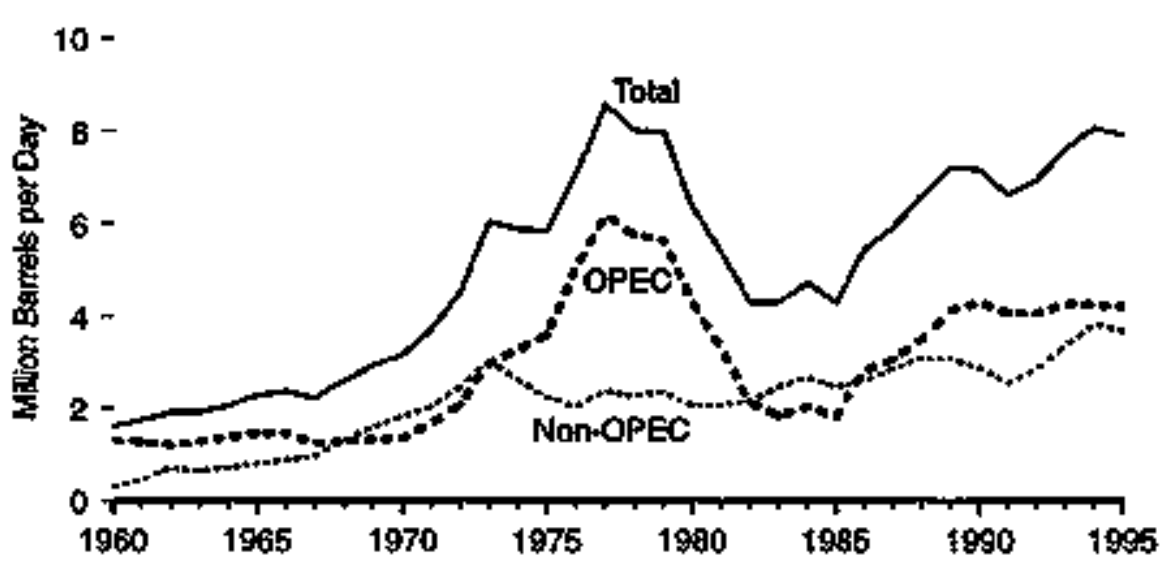

Share of Consumption

$100-$

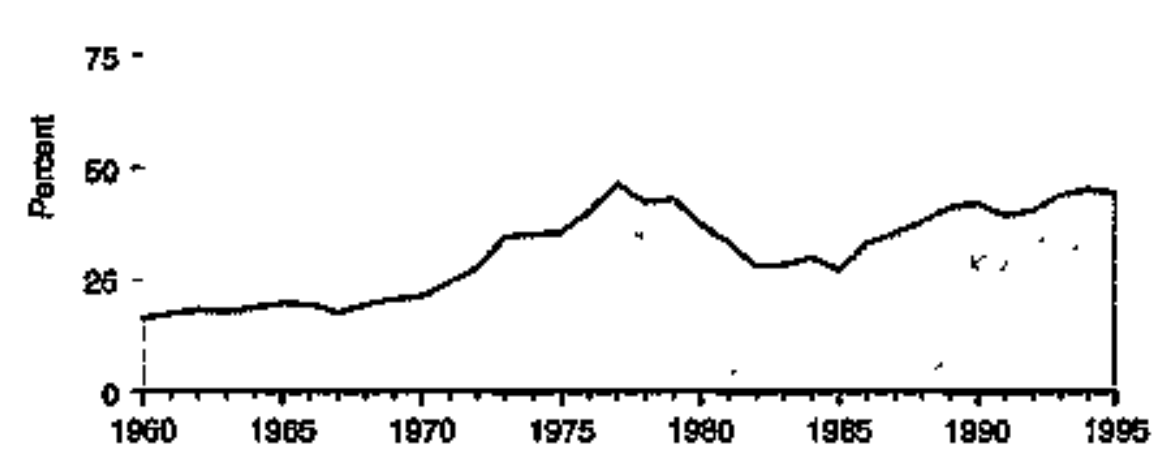

Note: Bectuse vertcal scalos offiar, graphe should nol be compared.

\section{By Selected Country}

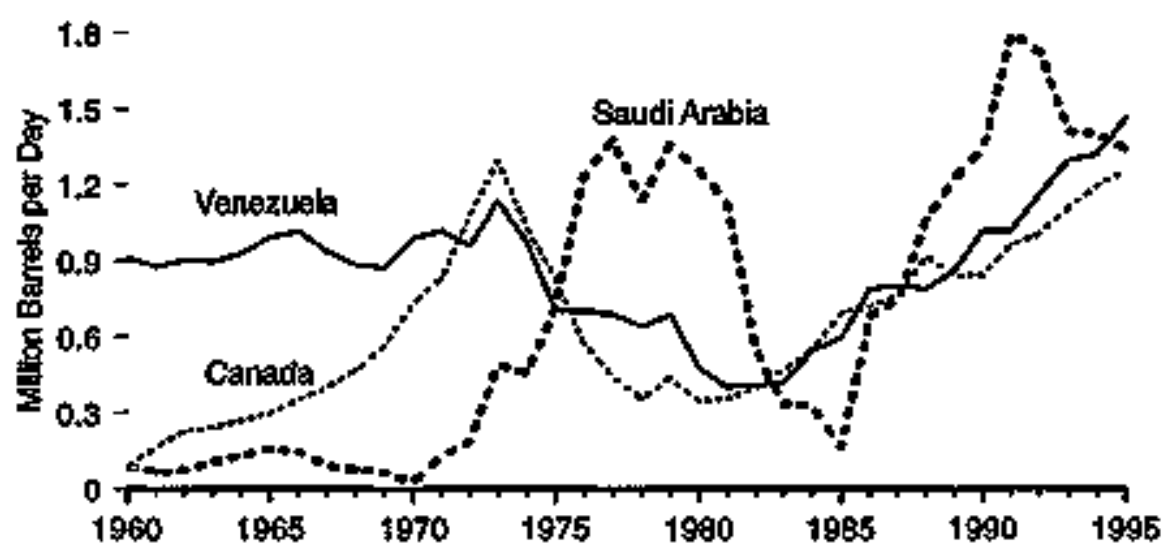

Nel linports from OPEC

$100-$

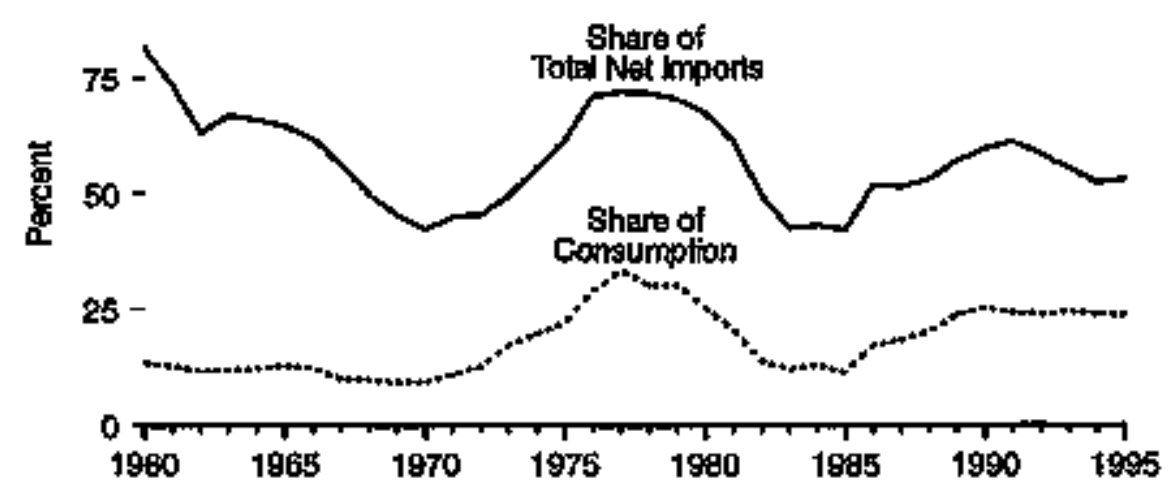

Source: 5.7 . 
Table 5.7 Petroleum Net Imports by Country of Origin, 1960-1995

\begin{tabular}{|c|c|c|c|c|c|c|c|c|c|c|c|c|c|c|c|}
\hline \multirow[b]{3}{*}{ Year } & \multicolumn{6}{|c|}{ OPECI } & \multicolumn{5}{|c|}{ Non-OPeC } & \multirow[b]{2}{*}{$\begin{array}{c}\text { Toled } \\
\text { Nex } \\
\text { mports }\end{array}$} & \multirow[b]{2}{*}{ 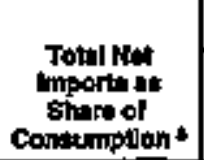 } & \multicolumn{2}{|c|}{ Net Imports trom teret } \\
\hline & Nogorfa & $\begin{array}{l}\text { Saudi } \\
\text { Arable }\end{array}$ & Veneruala & Oather 2 & Folnls & $\begin{array}{l}\text { Arab } \\
\text { OPEC. }\end{array}$ & Canuda & Mexdos & $\begin{array}{l}\text { Untiad } \\
\text { Ningdom }\end{array}$ & 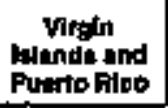 & OAhrr & & & 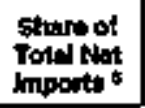 & Connurepilon? \\
\hline & \multicolumn{12}{|c|}{ Thoustind teamele par Day } & \multicolumn{3}{|c|}{ Percant } \\
\hline 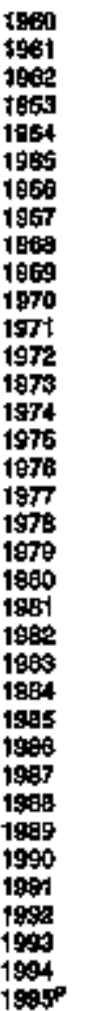 & 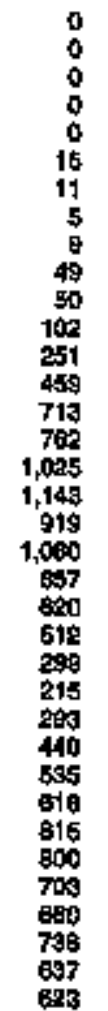 & 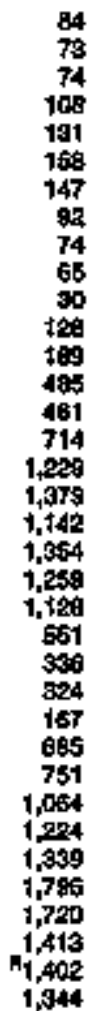 & 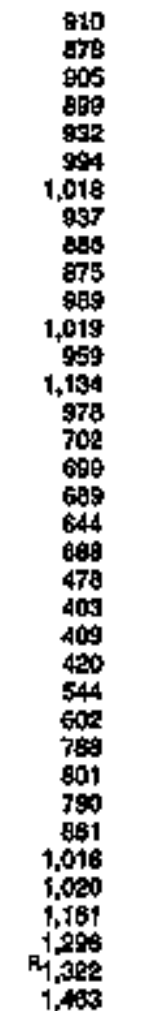 & 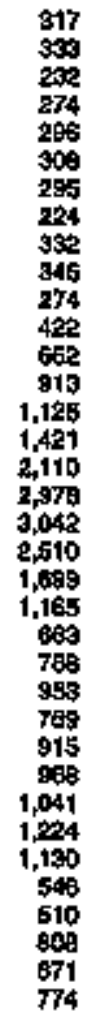 & 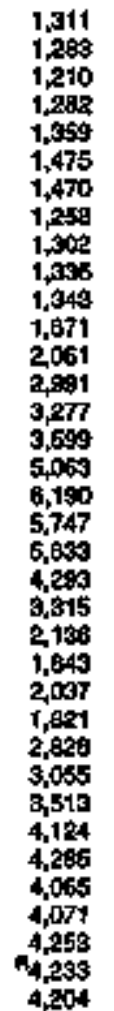 & 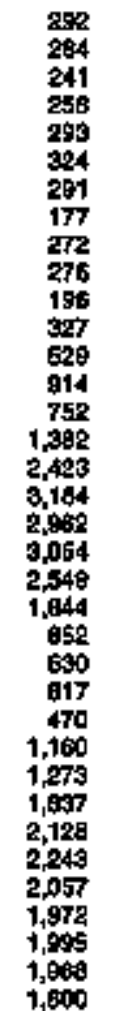 & 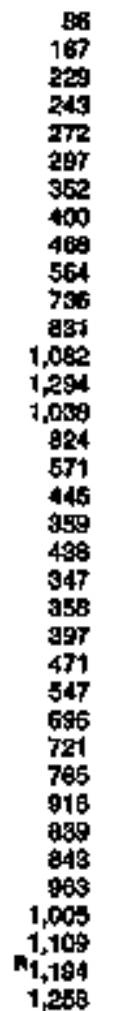 & 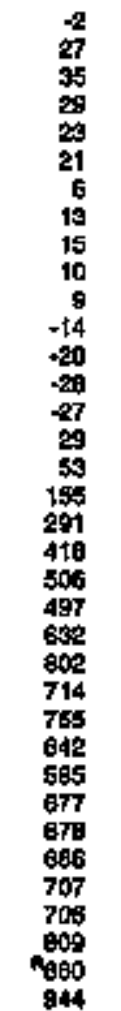 & $\begin{array}{r}-12 \\
-50 \\
46 \\
-7 \\
-5 \\
-11 \\
45 \\
-51 \\
13 \\
7 \\
-1 \\
1 \\
-1 \\
191 \\
1 \\
7 \\
24 \\
117 \\
173 \\
198 \\
169 \\
370 \\
442 \\
374 \\
386 \\
295 \\
342 \\
346 \\
305 \\
208 \\
170 \\
125 \\
219 \\
340 \\
448 \\
370\end{array}$ & 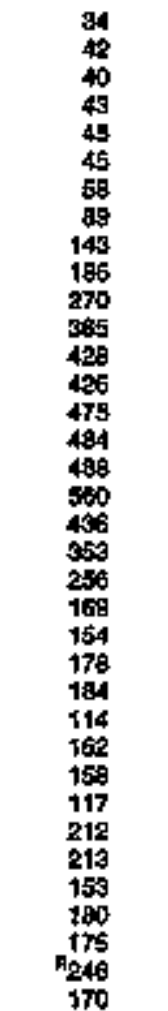 & 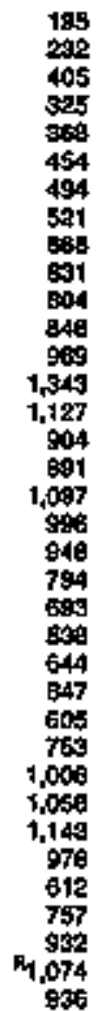 & 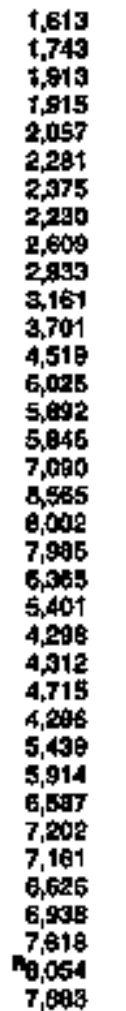 & $\begin{array}{l}16.5 \\
17.5 \\
19.4 \\
17.8 \\
19.7 \\
19.8 \\
19.7 \\
17.8 \\
19.5 \\
20.4 \\
21.5 \\
24.3 \\
37.6 \\
34.8 \\
35.4 \\
35.5 \\
40.5 \\
46.5 \\
42.5 \\
43.1 \\
37.3 \\
35.8 \\
29.1 \\
29.3 \\
30.0 \\
27.5 \\
33.4 \\
35.5 \\
38.1 \\
44.6 \\
42.2 \\
39.5 \\
40.7 \\
44.2 \\
445.5 \\
44.5\end{array}$ & $\begin{array}{r}81.3 \\
73.6 \\
65.3 \\
57.0 \\
68.1 \\
64.7 \\
51.9 \\
56.4 \\
49.9 \\
45.5 \\
12.5 \\
45.2 \\
45.6 \\
48.5 \\
55.8 \\
61.6 \\
71.4 \\
72.3 \\
71.8 \\
70.5 \\
67.5 \\
61.4 \\
49.7 \\
42.7 \\
41.2 \\
42.5 \\
62.0 \\
51.7 \\
53.3 \\
57.3 \\
59.9 \\
61.3 \\
59.7 \\
56.8 \\
052.6 \\
59.3\end{array}$ & $\begin{array}{r}13.4 \\
12.9 \\
17.6 \\
17.8 \\
12.3 \\
12.8 \\
12.2 \\
10.0 \\
0.7 \\
9.5 \\
8.1 \\
11.0 \\
12.6 \\
17.3 \\
15.7 \\
22.1 \\
28.0 \\
33.6 \\
30.5 \\
30.4 \\
25.2 \\
20.6 \\
14.0 \\
12.1 \\
13.0 \\
11.6 \\
17.4 \\
19.3 \\
20.3 \\
28.6 \\
25.2 \\
24.3 \\
23.9 \\
24.7 \\
129.9 \\
29.7\end{array}$ \\
\hline
\end{tabular}

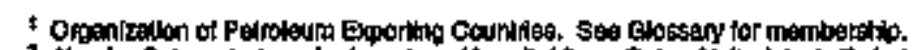

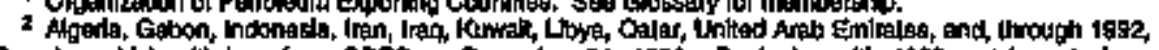
Eoundor, which withdraw from OPEC on Decamber 31 , 1902 Beginhing with 199s, not Imports from

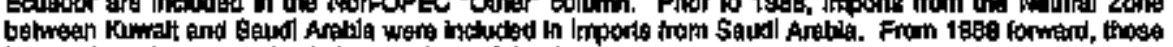

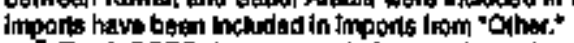

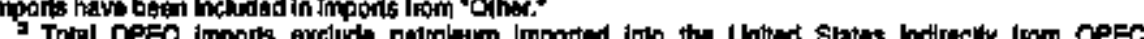

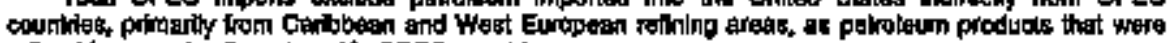

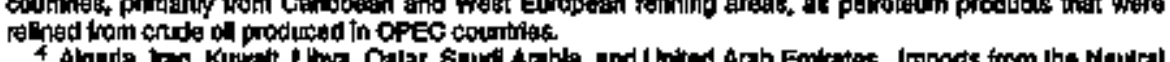

Antrates. Imports frem ths Newreal

OPEC."

(Eonsumolloni.

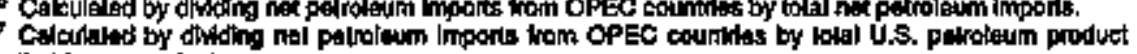
supplod (consoumption).

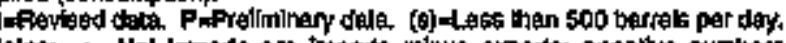

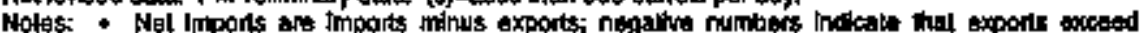

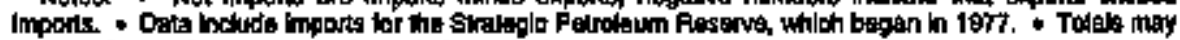
not equal wuat of oomponanis due lo independent rounding.

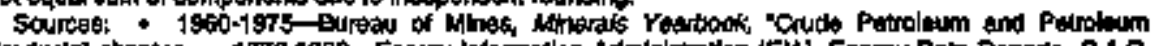
Plstus suapter, - 1976-1980Suppoty Morillisy (February 1996). 


\section{Input}

$15-$

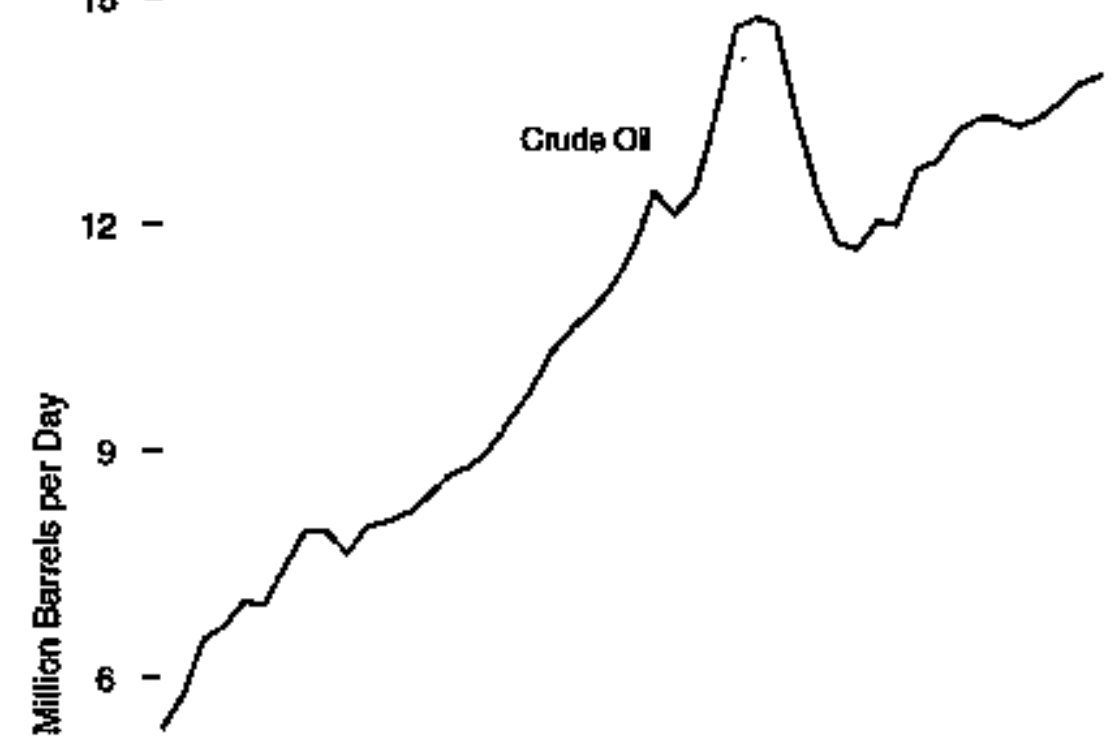

$3-$

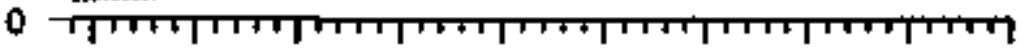
$\begin{array}{llllllllll}1950 & 1965 & 1960 & 1965 & 1970 & 1975 & 1980 & 1985 & 1990 & 1995\end{array}$

\section{Output of Selected Products}

$15-$

$12-$

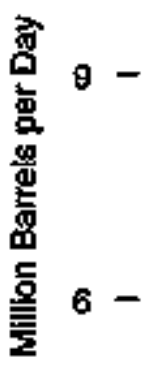

3

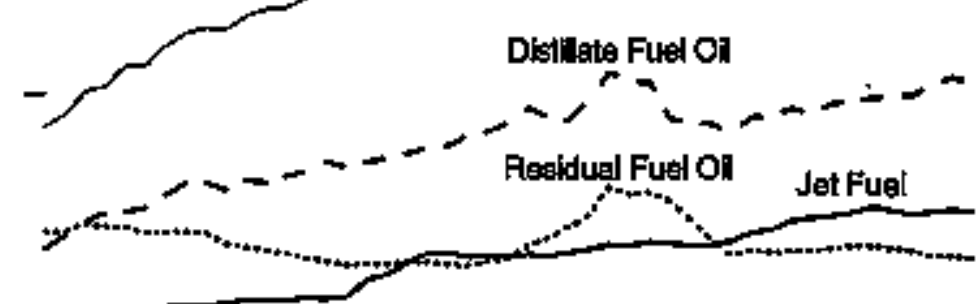

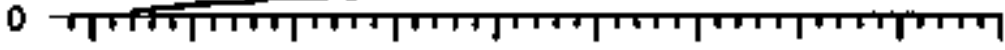
$\begin{array}{llllllllll}1950 & 1955 & 1960 & 1965 & 1970 & 1975 & 1980 & 1985 & 1990 & 1995\end{array}$ 
Table 5.8 Refinery Input and Output, 1949-1995

(Mition Barrels per Day)

\begin{tabular}{|c|c|c|c|c|c|c|c|c|c|c|c|c|}
\hline \multirow[b]{2}{*}{ Yar } & \multicolumn{4}{|c|}{ inpet } & \multicolumn{7}{|c|}{ Oulpus } & \multirow[b]{2}{*}{$\begin{array}{c}\text { Processalpo } \\
\text { Galn }\end{array}$} \\
\hline & Crudo & $\begin{array}{l}\text { Nahufat Ges } \\
\text { Plant Lquuldo }\end{array}$ & $\begin{array}{l}\text { Other } \\
\text { Liquide } 1\end{array}$ & $\begin{array}{l}\text { Told } \\
\text { Inputt }\end{array}$ & $\begin{array}{c}\text { Hokor } \\
\text { Gespolite }\end{array}$ & $\begin{array}{l}\text { Jet } \\
\text { Futed } 2\end{array}$ & $\begin{array}{l}\text { Diastlitale } \\
\text { Fial di }\end{array}$ & $\begin{array}{l}\text { Atalduel } \\
\text { Fuet oll }\end{array}$ & $\begin{array}{l}\text { Ulqueltiod } \\
\text { Pobroloum } \\
\text { Einges }\end{array}$ & $\begin{array}{l}\text { Olher } \\
\text { Productes? }\end{array}$ & $\begin{array}{l}\text { Tokal } \\
\text { Ounpux }\end{array}$ & \\
\hline 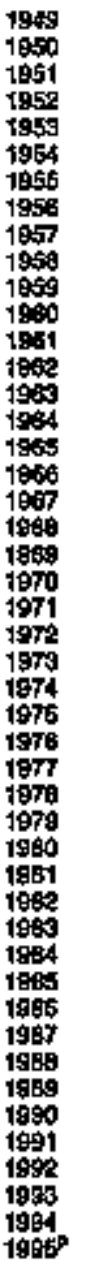 & 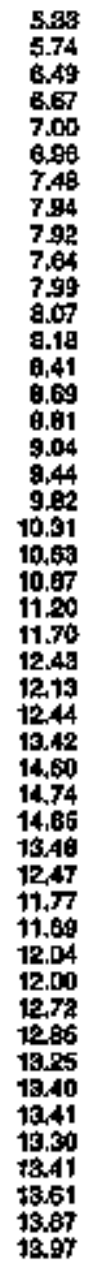 & $\begin{array}{l}0.20 \\
0.26 \\
0.27 \\
0.29 \\
0.30 \\
0.32 \\
0.34 \\
0.37 \\
0.41 \\
0.37 \\
0.42 \\
0.45 \\
0.48 \\
0.50 \\
0.52 \\
0.50 \\
0.62 \\
0.65 \\
0.67 \\
0.71 \\
0.72 \\
0.76 \\
0.70 \\
0.80 \\
0.82 \\
0.75 \\
0.71 \\
0.70 \\
0.67 \\
0.64 \\
0.51 \\
0.40 \\
0.59 \\
0.50 \\
0.46 \\
0.50 \\
0.51 \\
0.48 \\
0.47 \\
0.51 \\
0.60 \\
0.77 \\
0.47 \\
0.47 \\
0.49 \\
0.47 \\
0.47\end{array}$ & $\begin{array}{l}0.03 \\
0.02 \\
0.03 \\
0.01 \\
191 \\
0.02 \\
0.03 \\
0.01 \\
191 \\
0.00 \\
0.07 \\
0.06 \\
0.06 \\
0.08 \\
0.09 \\
0.07 \\
0.09 \\
0.09 \\
0.09 \\
0.08 \\
0.11 \\
0.12 \\
0.14 \\
0.17 \\
0.15 \\
0.14 \\
0.07 \\
0.06 \\
0.07 \\
0.09 \\
0.08 \\
0.08 \\
0.49 \\
0.57 \\
0.50 \\
0.50 \\
0.68 \\
0.71 \\
0.67 \\
0,61 \\
0.01 \\
0.71 \\
0.77 \\
0.75 \\
0.96 \\
0.09 \\
0.74\end{array}$ & 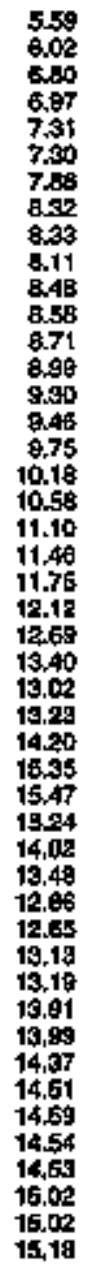 & $\begin{array}{l}2.57 \\
2.74 \\
3.04 \\
3.12 \\
3.39 \\
3.93 \\
3.85 \\
3.82 \\
3.89 \\
3.87 \\
4.04 \\
4.13 \\
4.15 \\
4.30 \\
4.39 \\
4.37 \\
4.51 \\
4.77 \\
4.94 \\
5.90 \\
5.47 \\
5.70 \\
5.97 \\
6.29 \\
6.59 \\
6.35 \\
6.52 \\
6.84 \\
7.03 \\
7.17 \\
8.44 \\
6.49 \\
6.40 \\
6.34 \\
8.34 \\
6.45 \\
6.42 \\
6.76 \\
6.84 \\
6.96 \\
6.96 \\
6.96 \\
6.98 \\
7.06 \\
7.30 \\
7.18 \\
7.43\end{array}$ & 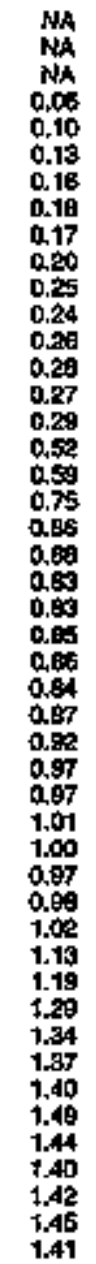 & 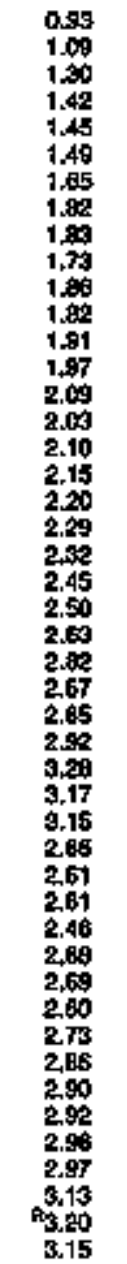 & 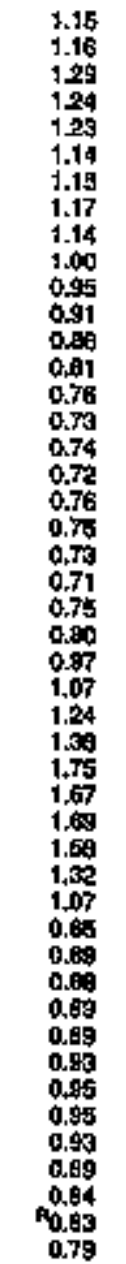 & 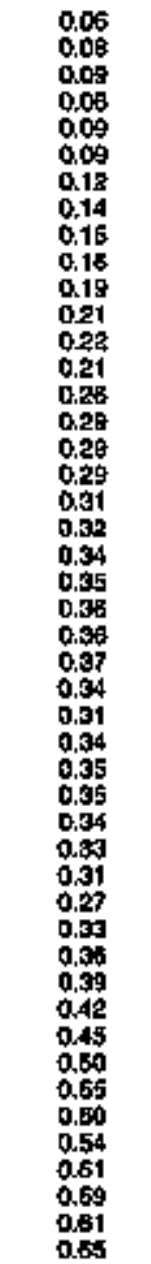 & 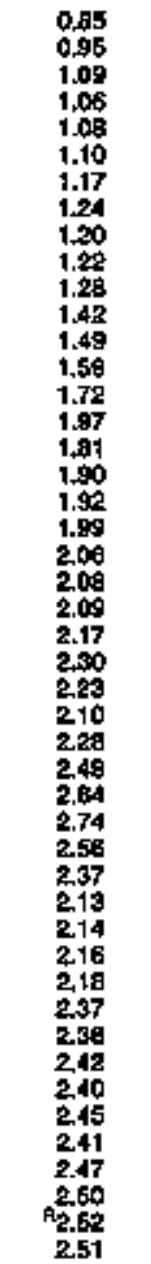 & 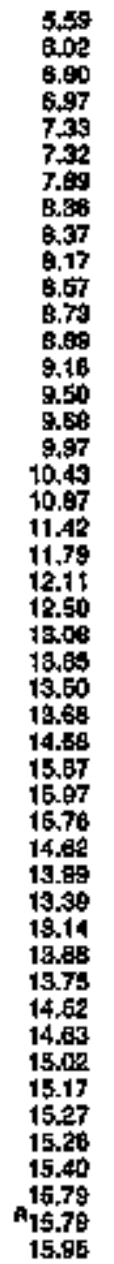 & 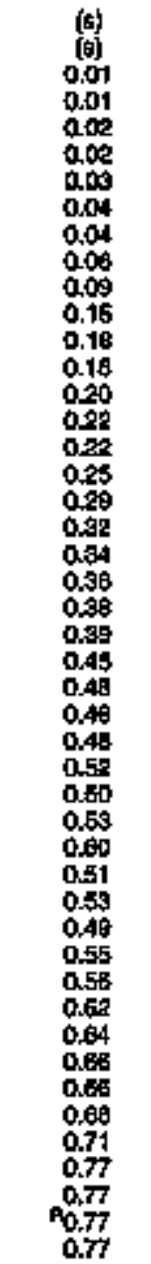 \\
\hline
\end{tabular}

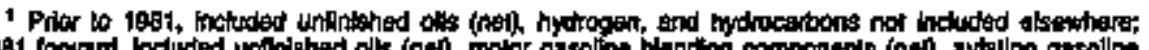

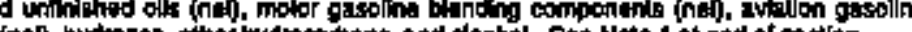

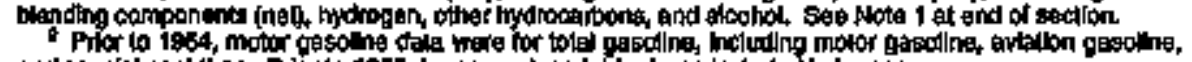

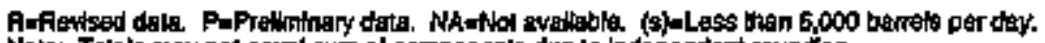

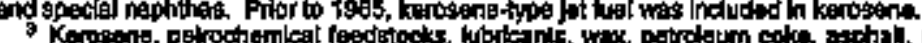

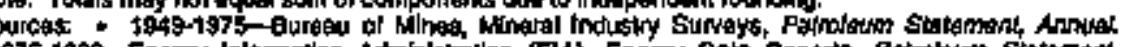

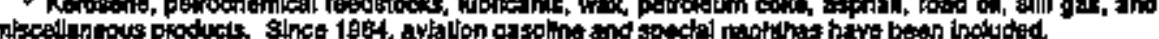

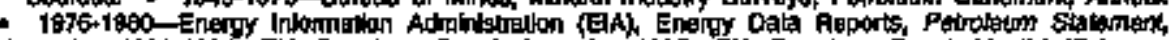

Anntopit. 


\section{Number of Opecable Fiolinedes}

$400 *$

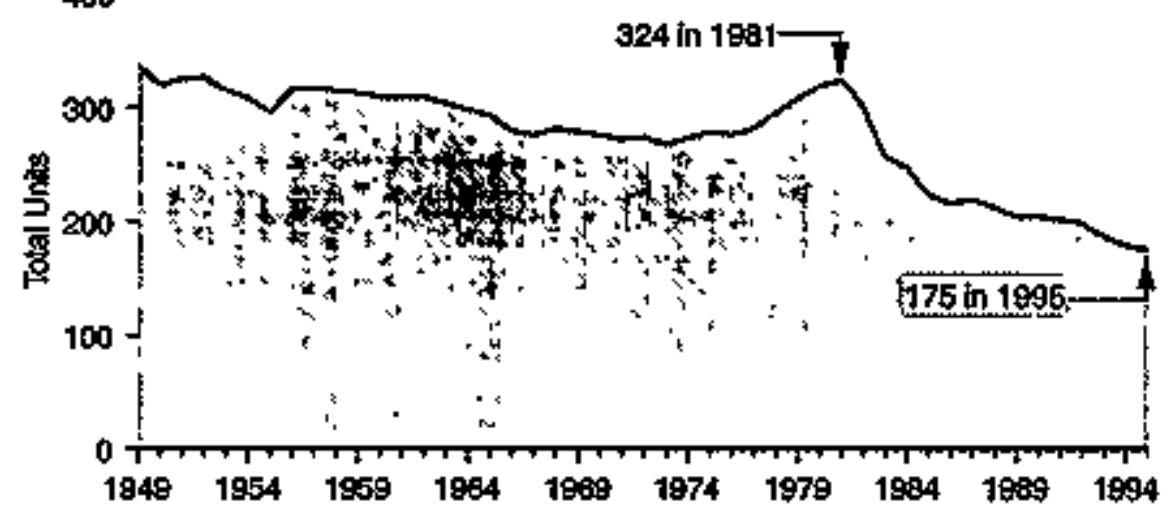

\section{Utilization}

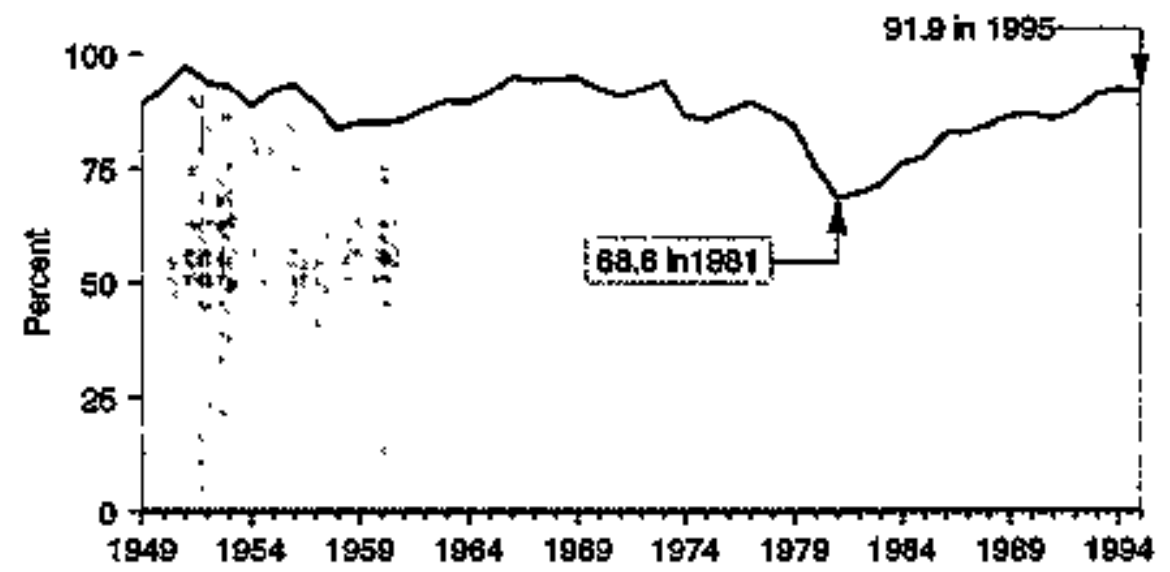

\section{Unused Capactly}

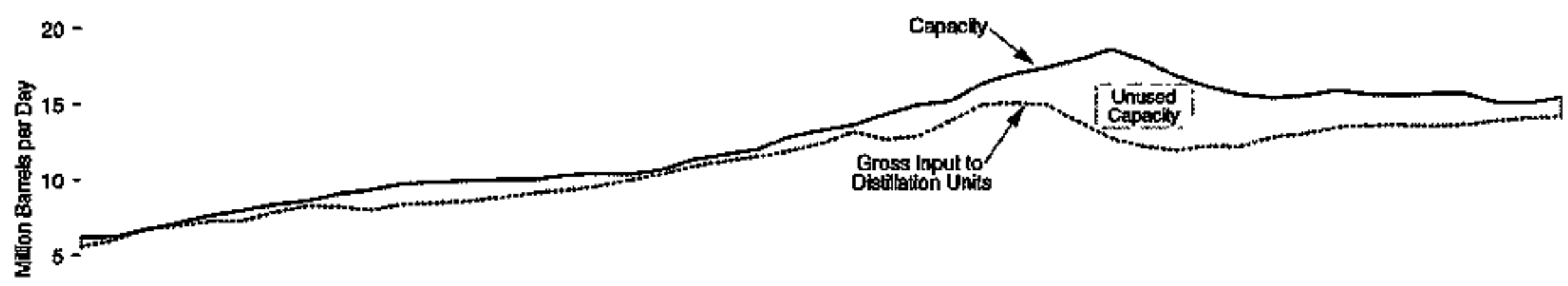

\begin{tabular}{|c|c|c|c|c|c|c|c|c|c|}
\hline 1949 & 1954 & 1969 & 1064 & 1969 & 1974 & 1979 & 1984 & 1989 & 1994 \\
\hline
\end{tabular}

Source: Tabre 6.9. 
Table 5.9 Refinery Capacity and Utilization, 1949-1995

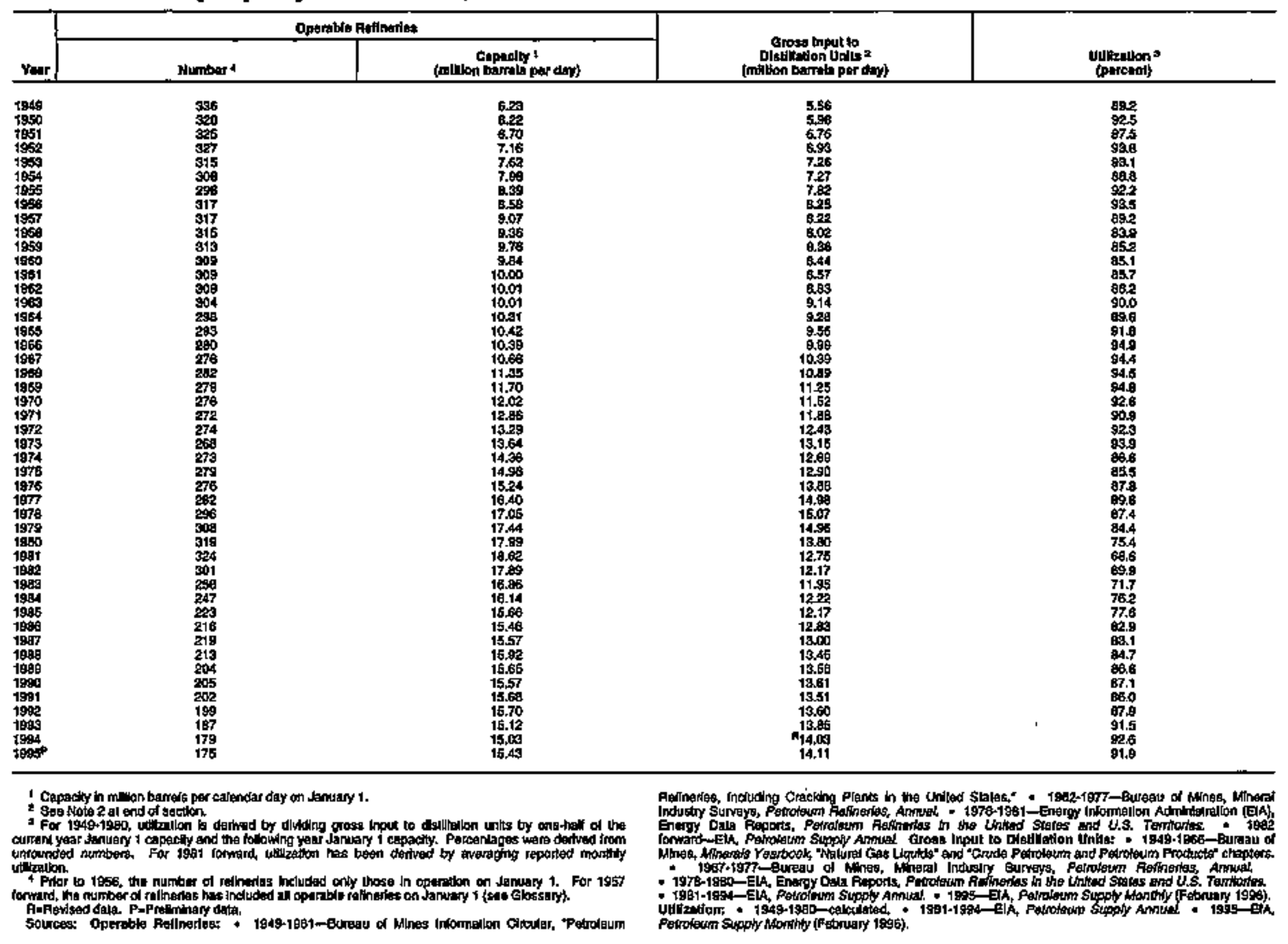




\section{Figure 5.10 Natural Gas Plant Llquids Production}

\section{Total, 1949-1985}

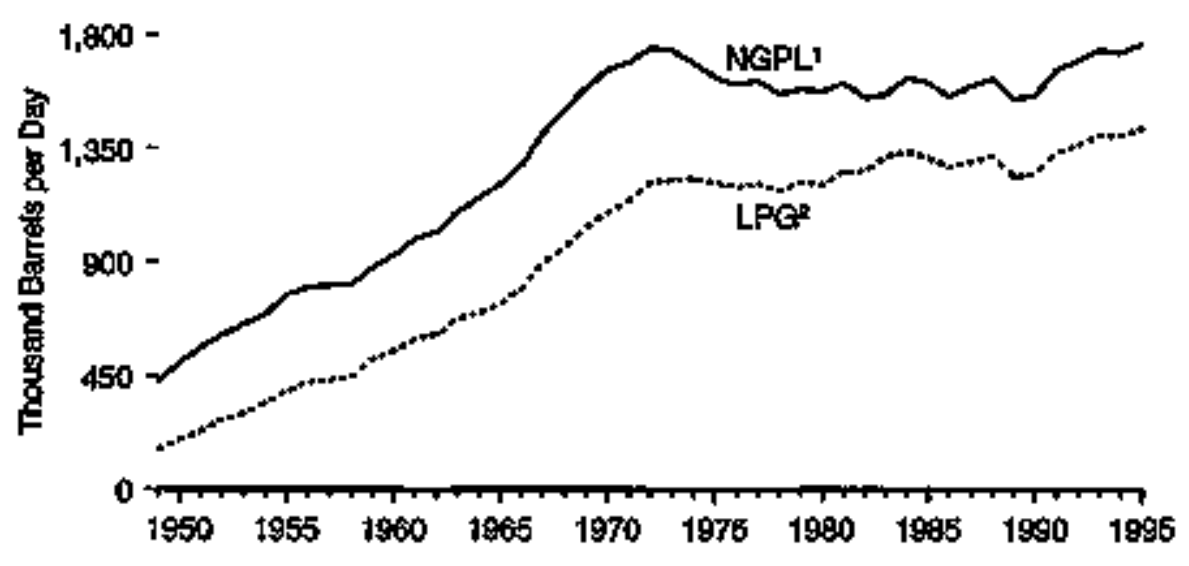

By Product, 1995

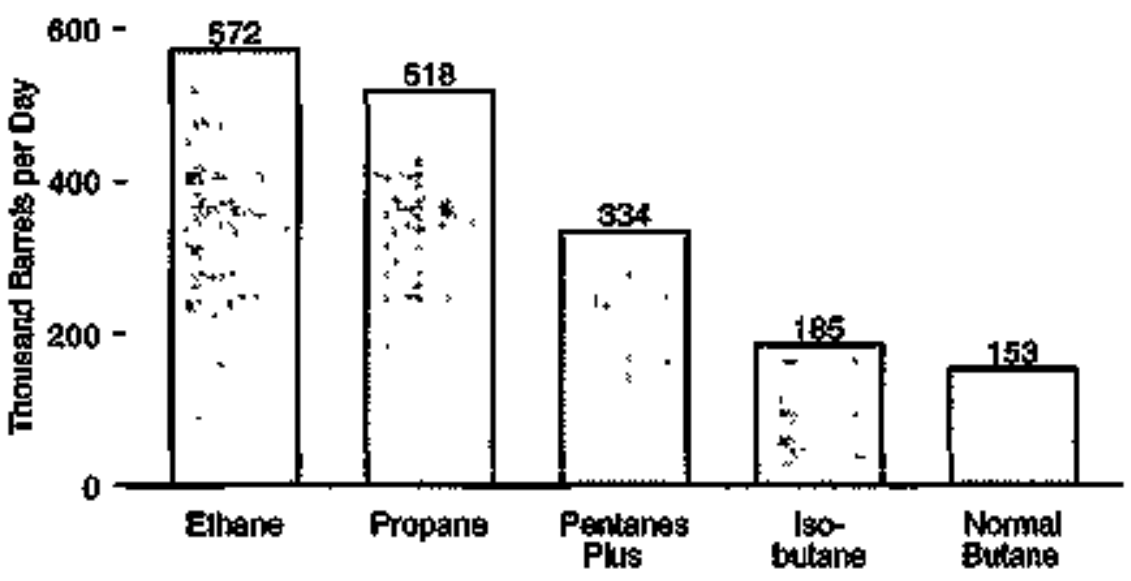

\section{By Solected Produet, 1949-1995}

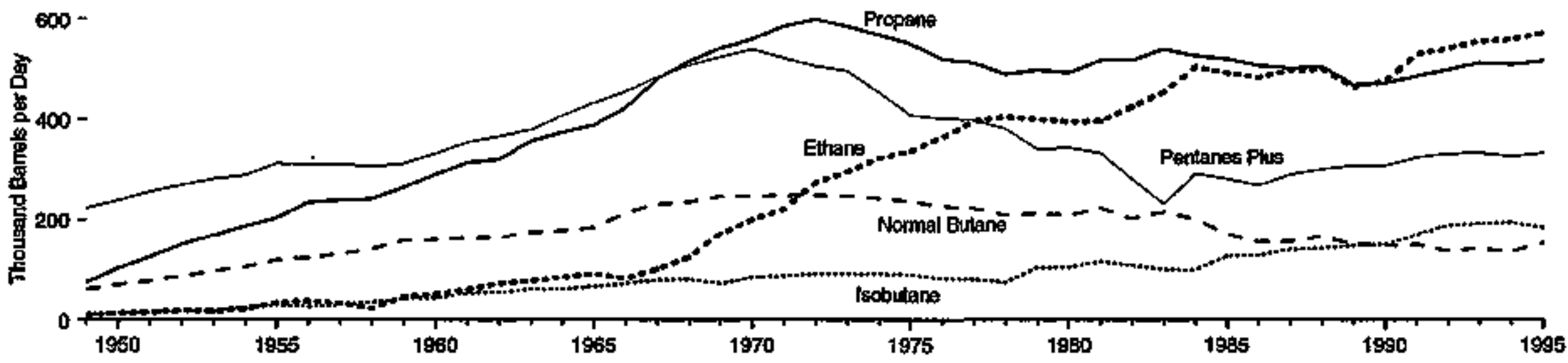

1 Natureal gas planl laulds s Lqueled peroteum oases.

Source: Trable 5.10 .

Note: Eecrause verttcal sceles dififer, eraphs should nol be compared. 
Table 5.10 Natural Gas Plant Liquids Production, 1949-1995

(Thousand Barrels per Day)

\begin{tabular}{|c|c|c|c|c|c|c|c|c|}
\hline \multirow[b]{2}{*}{ Ye: } & \multicolumn{5}{|c|}{ Llapedted Petroloung Ongeq } & \multirow[b]{2}{*}{ Peptanges } & \multirow{2}{*}{$\begin{array}{l}\text { Fintippod } \\
\text { Potroloum } \\
\text { Produots } 4\end{array}$} & \multirow[b]{2}{*}{ Tow } \\
\hline & Elhato 1 & Propente 27 & $\begin{array}{l}\text { Homial } \\
\text { Butunis }\end{array}$ & teobutine & Total & & & \\
\hline 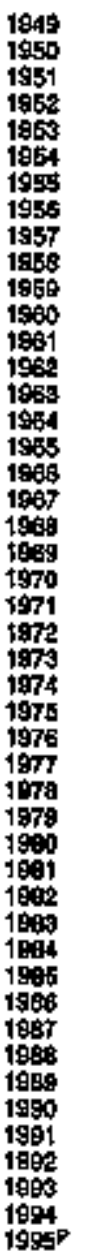 & 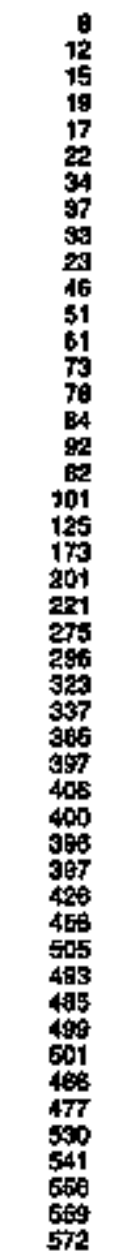 & 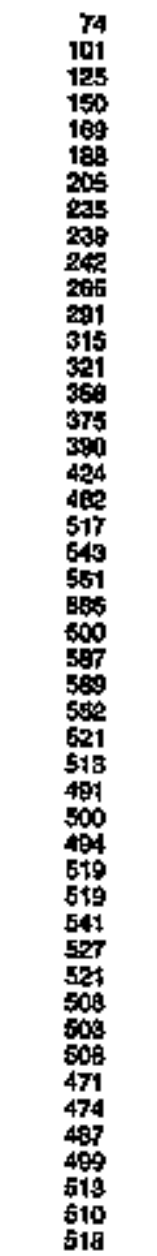 & 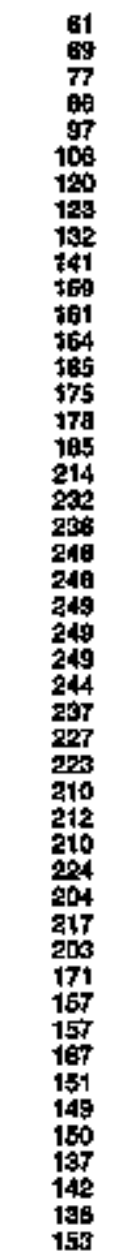 & 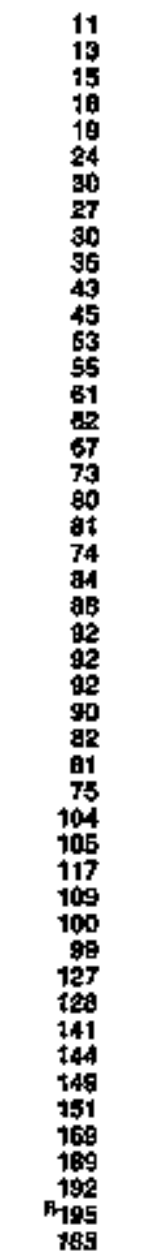 & 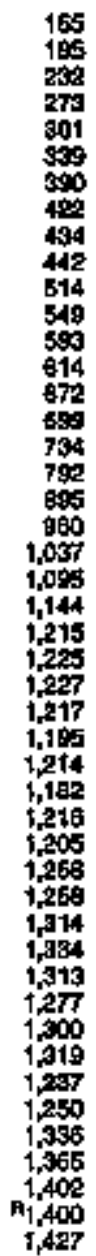 & 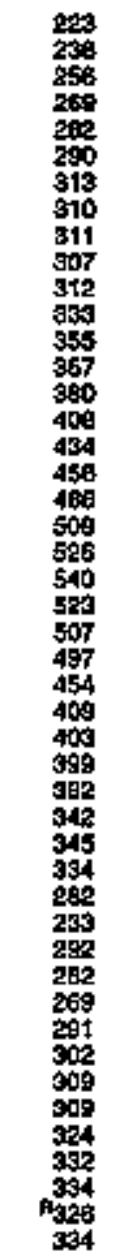 & 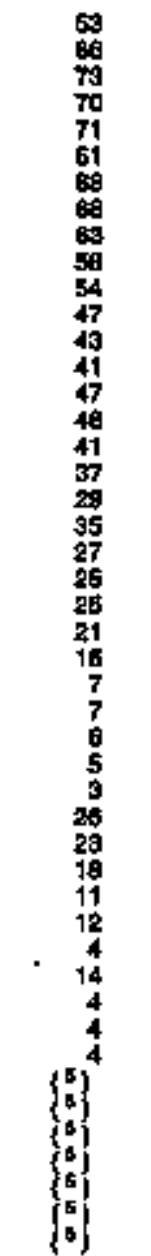 & 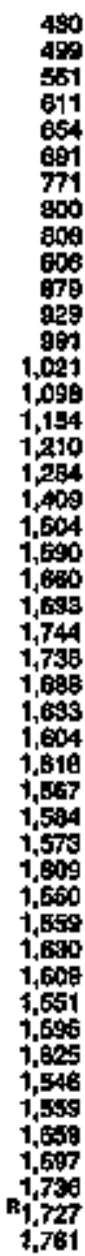 \\
\hline
\end{tabular}

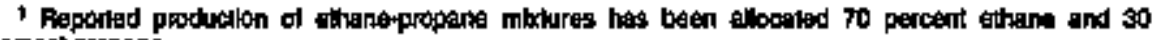

Derent propant.

pencent propart.

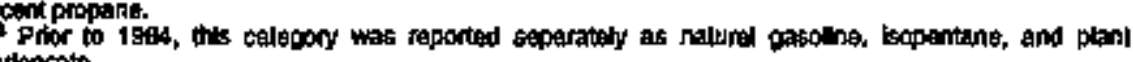
cortangett.

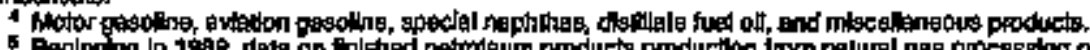

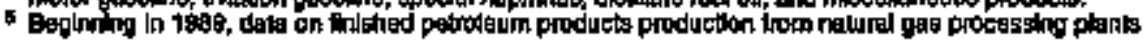

wera no longer avallable.

red data. Pupreiminany data.

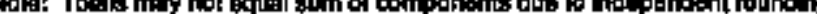

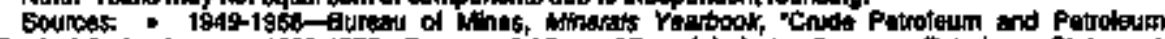

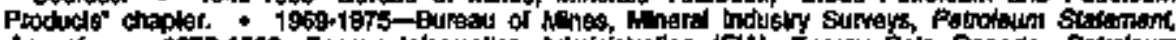

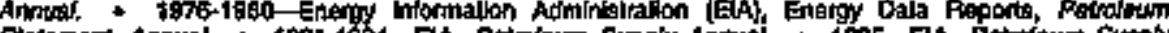

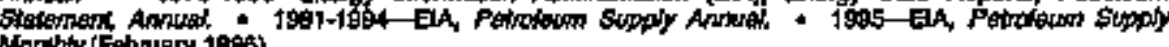
Nordohy (Febuary 1906). 


\section{Figure 5.11 Petroleum Products Supplied by Type}

\section{By Selected Product, 1949-1985}

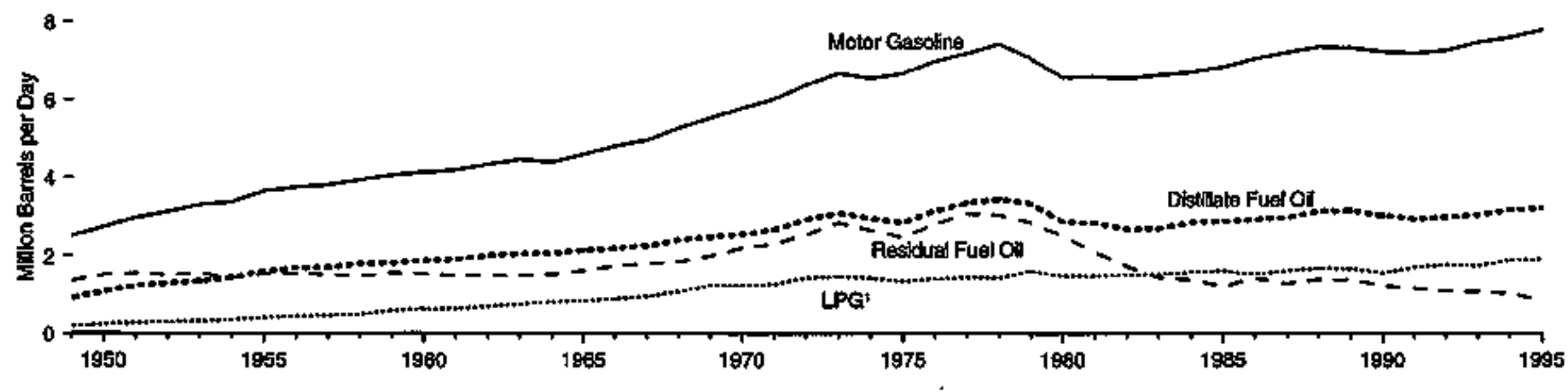

\section{By Product, 1995}

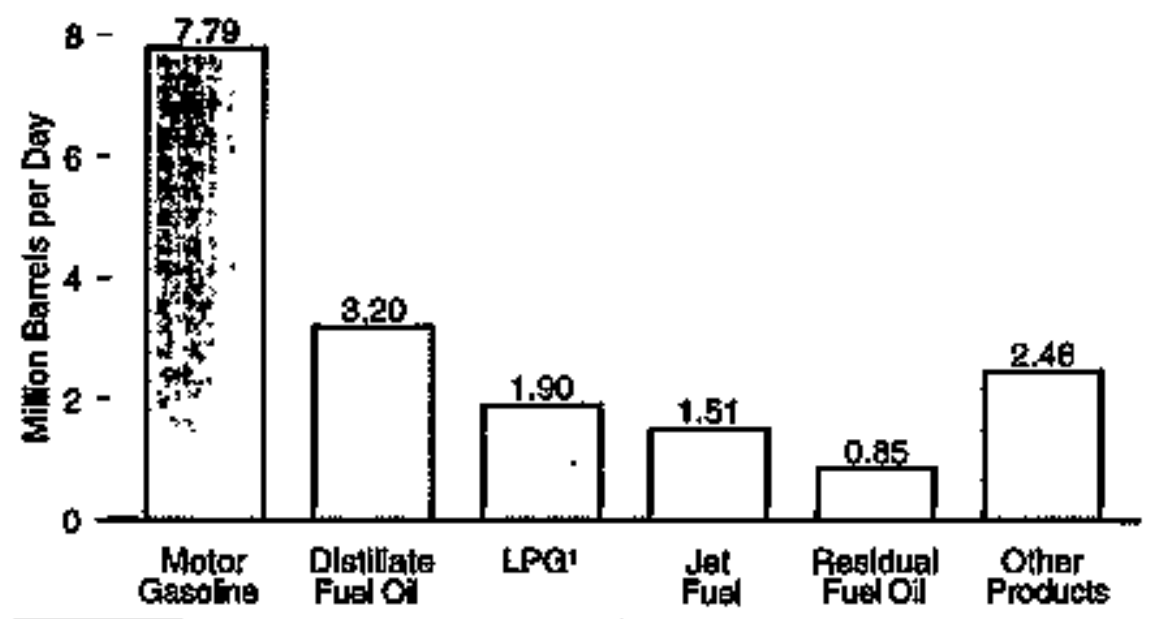

Motor Gasoline's Share of Totel Petroleum Products Supplied, 1949-1995

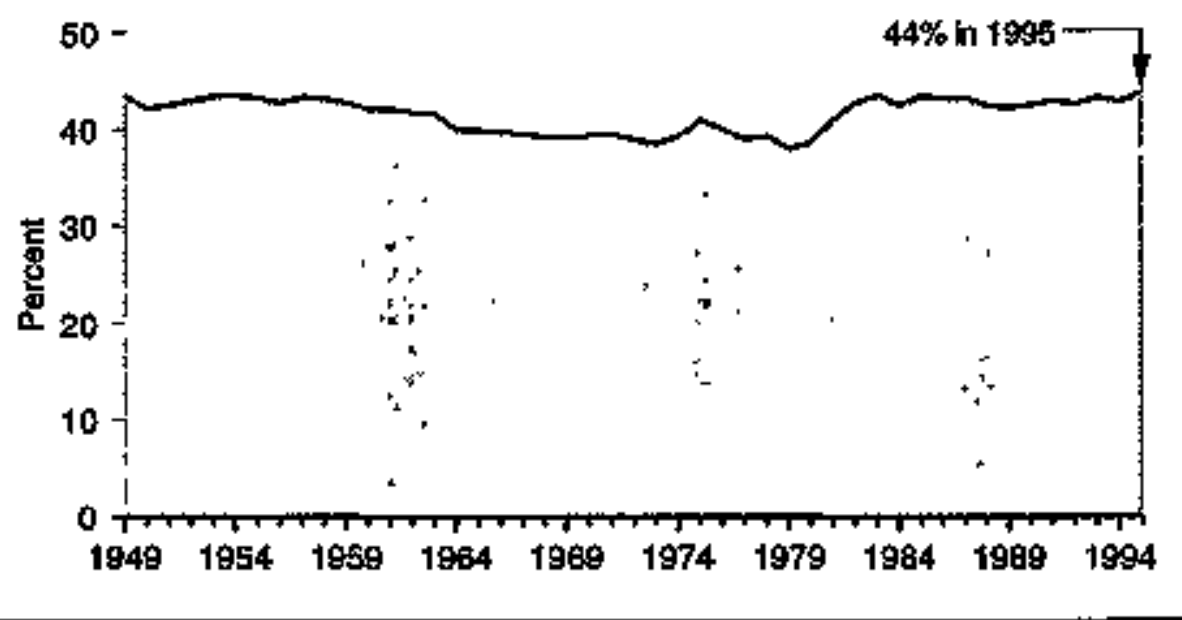

Source: Table 5.11. 
Table 5.11 Petroleum Products Supplied by Type, 1949-1995

(Milion Barrels ger Day)

\begin{tabular}{|c|c|c|c|c|c|c|c|c|c|}
\hline \multirow[b]{2}{*}{ Year } & \multirow{2}{*}{$\begin{array}{c}\text { Molor } \\
\text { otgodine } 1\end{array}$} & \multirow[b]{2}{*}{ Jol Fuel } & \multirow{2}{*}{$\begin{array}{l}\text { Olntilyen } \\
\text { Futel of }\end{array}$} & \multirow{2}{*}{$\begin{array}{l}\text { Pooldtul| } \\
\text { Futl of }\end{array}$} & \multicolumn{2}{|c|}{ Uquotiod Petroliam Geses } & \multirow{2}{*}{$\begin{array}{l}\text { Other } \\
\text { prophrta? }\end{array}$} & \multirow{2}{*}{$\begin{array}{c}\text { Tolal } \\
\text { Proptints:s }\end{array}$} & \multirow{2}{*}{$\begin{array}{l}\text { Percentago } \\
\text { Chunges from } \\
\text { Prewloul Yeart }\end{array}$} \\
\hline & & & & & Preppanto 2 & Tolpl & & & \\
\hline 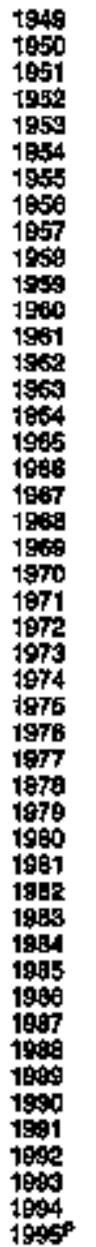 & 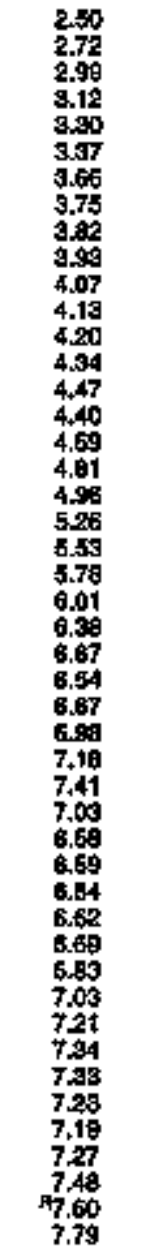 & 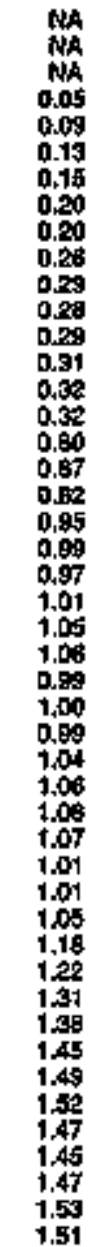 & 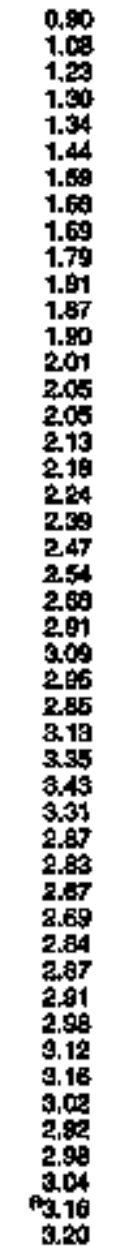 & 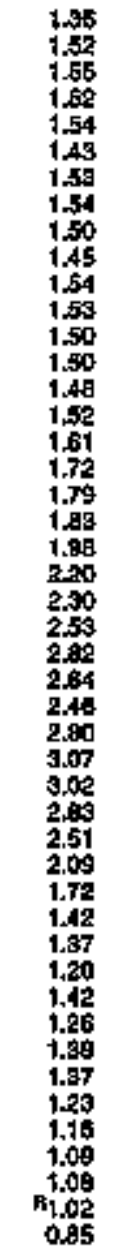 & 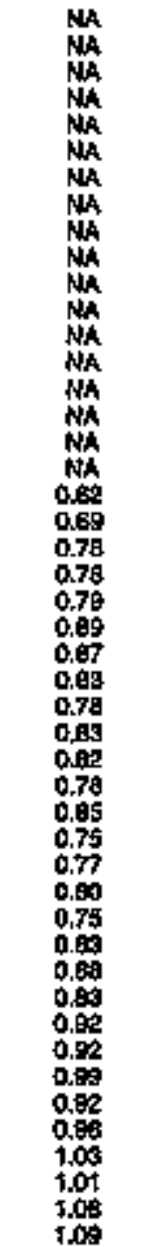 & 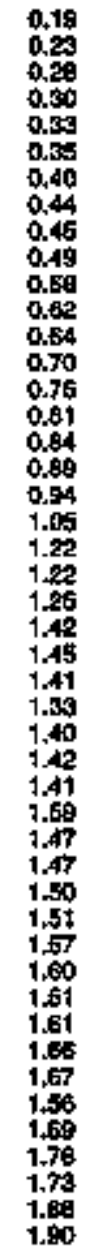 & 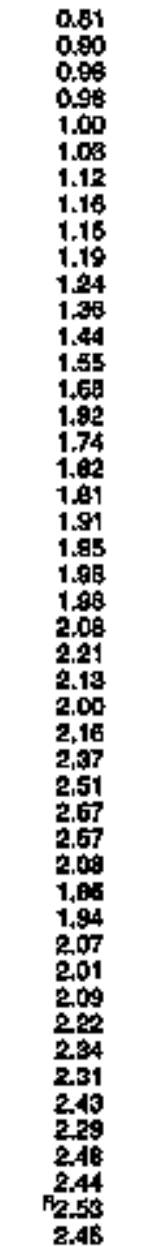 & 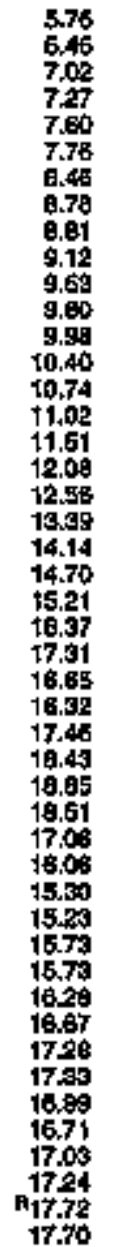 & 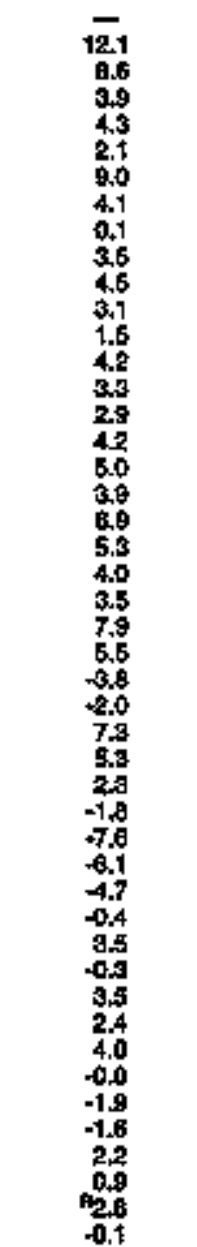 \\
\hline
\end{tabular}

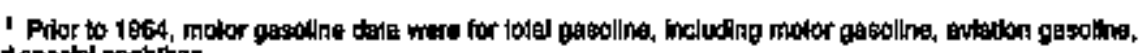
and apoctai naph hhas.

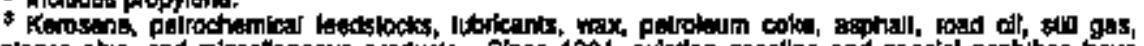

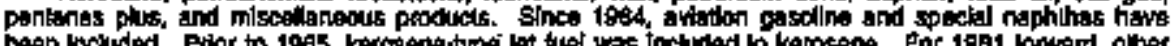

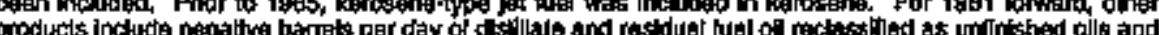

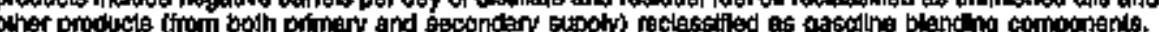

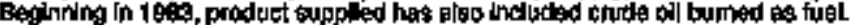

1 Percent change from prwilous yagr cakespted from daka pilor to rounding

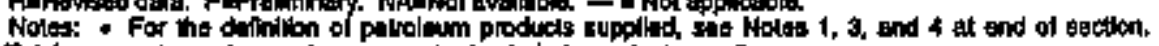

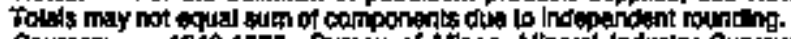

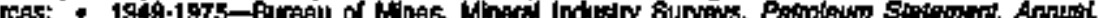

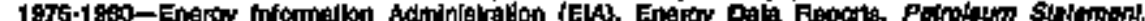

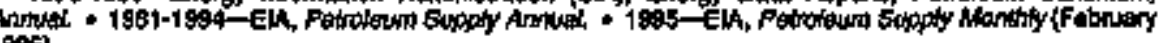
1900 ]. 


\section{By Sector, 1949-1995}

12 -

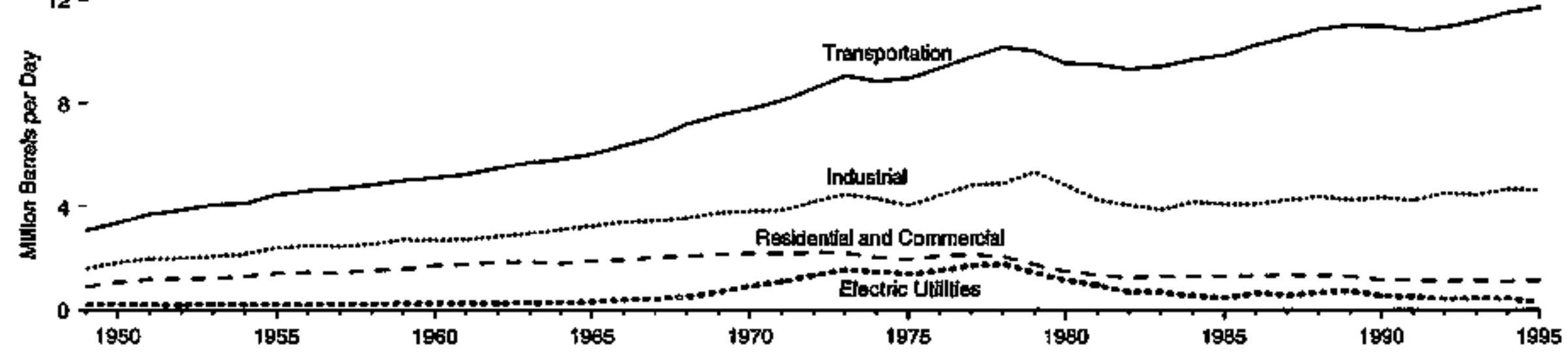

\section{By Sector, 1995}

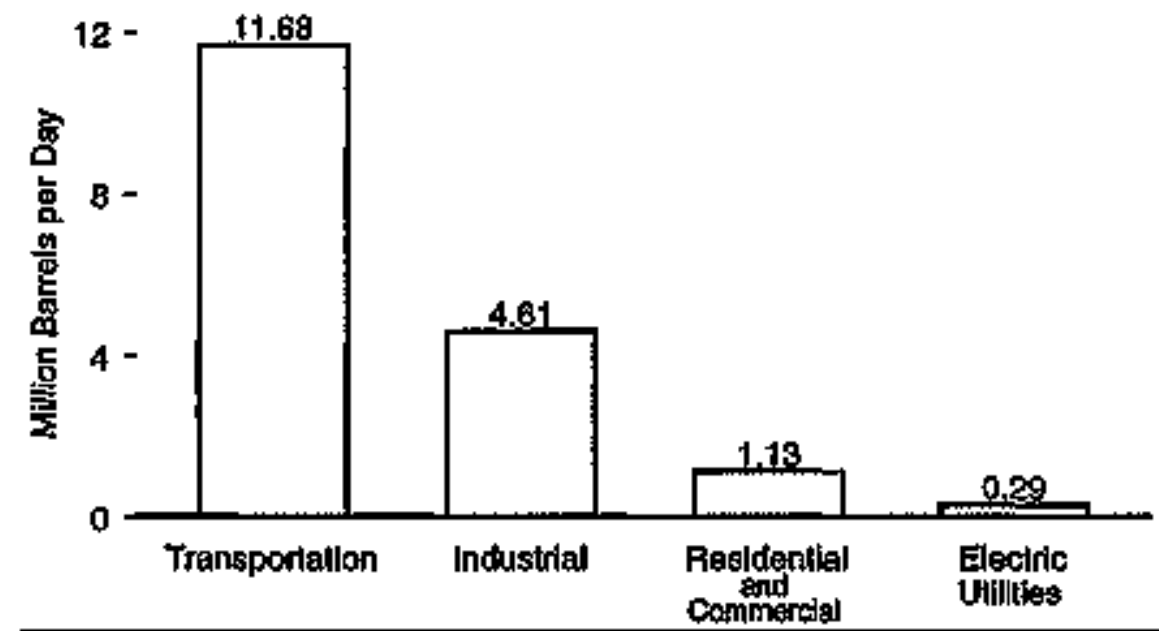

\section{Shares by Sector, 1949 and 1995}

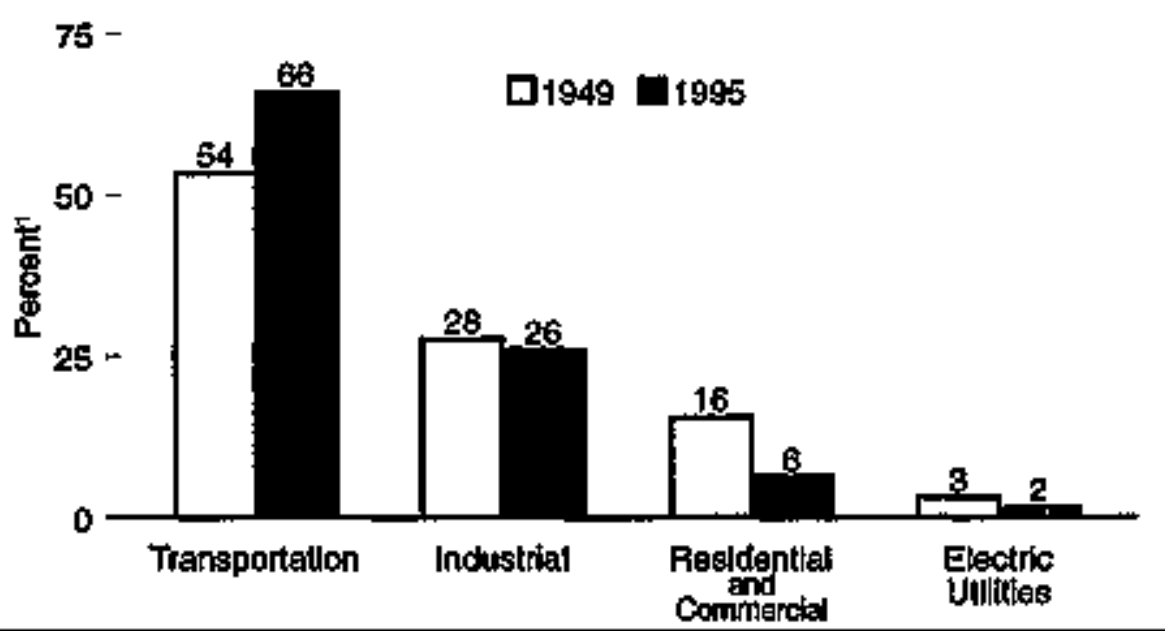

, Totals may not equal sam of components dwe io hdependent roundling. Note: Ste related Flgure 5.t2p.

Sources: Tablos 5.12a and 5.12b. 
Figure 5.12b Petroleum Products Supplied by Product by Sector, 1949-1995

Fesidenlial and Commencial Sector, Selected Products

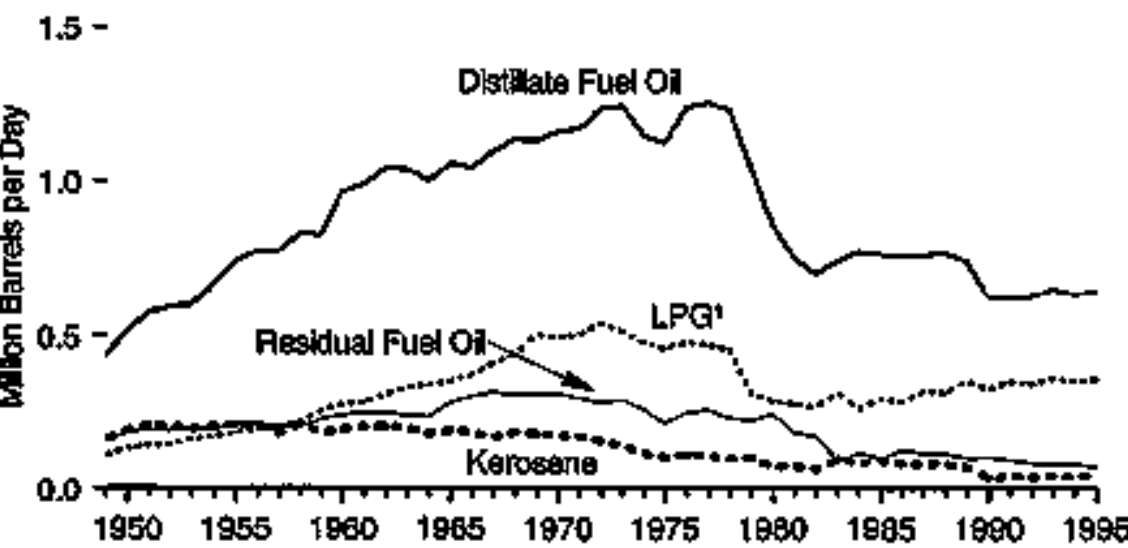

Transportallon Sector, Selected Products

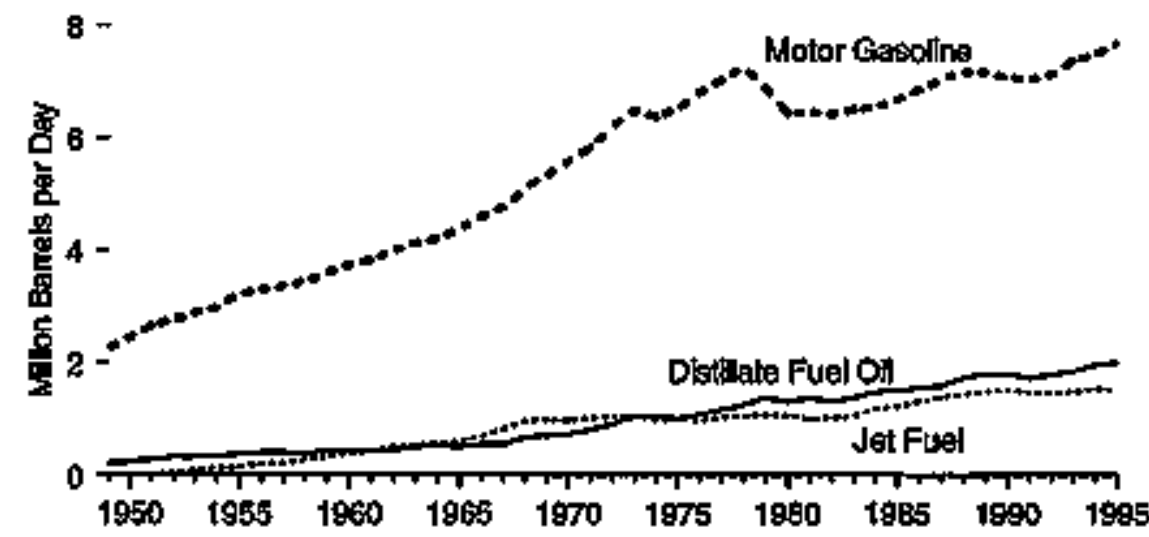

1 Lqueifod pelroleum gaseo.

2 Pritar is 1980, besed on oll used is stean plants. Since 1980, heavy oll includes huel oll nos, 4, 5, and 6 , and resictual tued on.

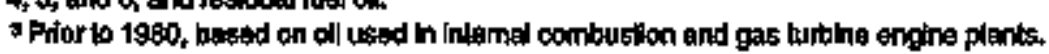

\section{Industral Sector, Solacted Products}

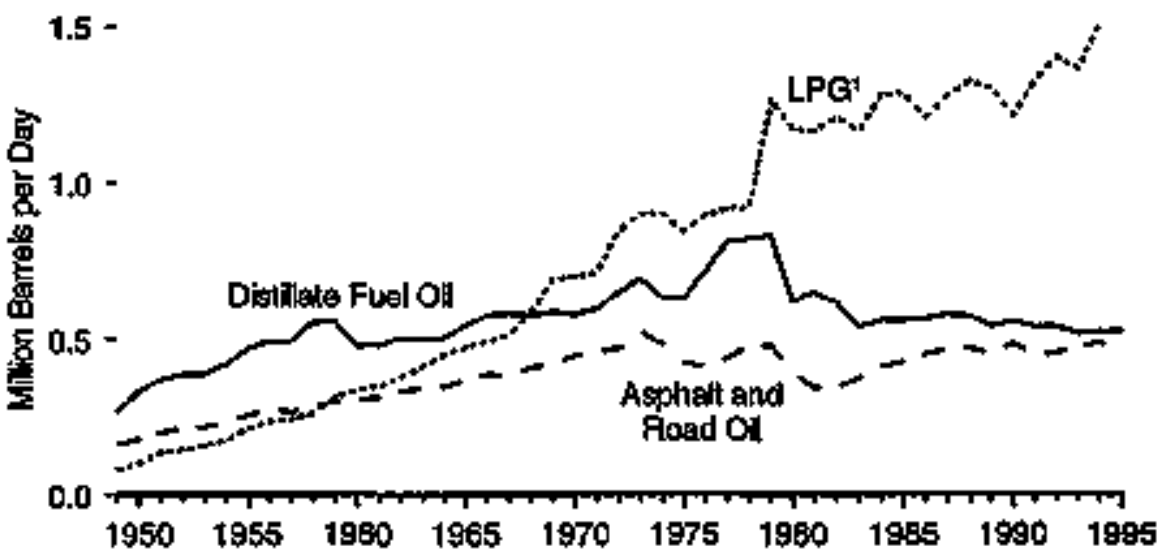

\section{Electric Utillies, Selected Products}
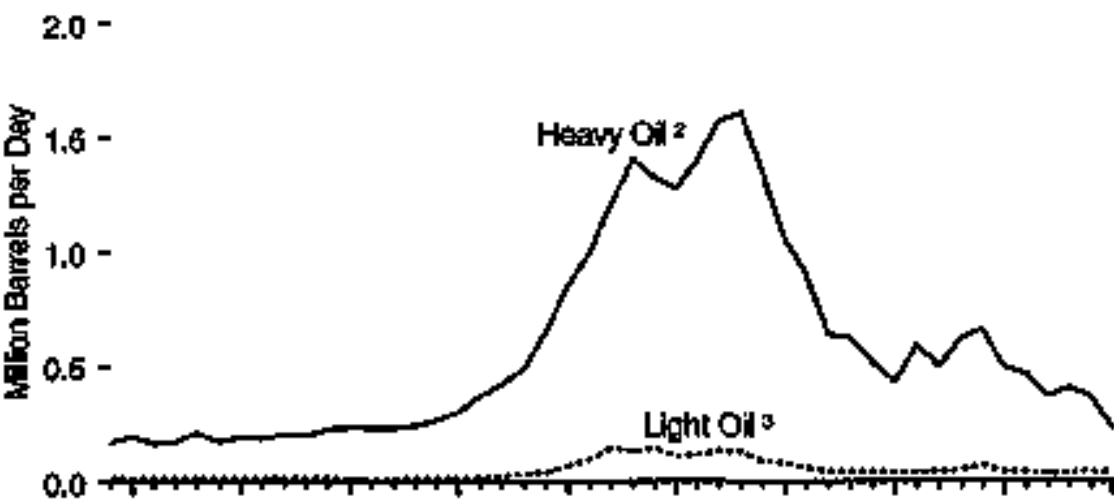

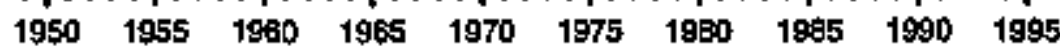

Since 1980, listin oll inctudos twel nos. 1 and 2 , herosene, and tel wel.

Notes: * See retaled Figure 5.12a. * Because verticel scales differ, graphs shoult not be cimpared.

Bourees: Tables 5.12a and 5.12b. 
Table 5.12a Petroleum Products Supplied to the Residential and Commercial Sector and the Industrial Sector, 1949-1995

(Million Barrels per Day)

\begin{tabular}{|c|c|c|c|c|c|c|c|c|c|c|c|c|c|c|c|}
\hline \multirow[b]{2}{*}{ Votor } & \multicolumn{6}{|c|}{ Aealdenitit and cormancrelal } & \multicolumn{9}{|c|}{ Indsotsial } \\
\hline & $\begin{array}{l}\text { Obintlate } \\
\text { Fual } \\
\text { of }\end{array}$ & Kertipento & 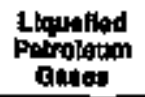 & $\begin{array}{l}\text { nover } \\
\text { arooling }\end{array}$ & $\begin{array}{l}\text { Realdual } \\
\text { Tyol } \\
\text { of }\end{array}$ & Tㅇt헤 & $\begin{array}{l}\text { Auphat } \\
\text { int } \\
\text { Rotal on }\end{array}$ & $\begin{array}{l}\text { Cyabdato } \\
\text { Fuel } \\
\text { On }\end{array}$ & Kordingente & 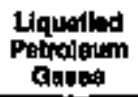 & Lubricapate & Motox & $\begin{array}{l}\text { Reotdual } \\
\text { Fuel } \\
\text { oll }\end{array}$ & Other: & Total \\
\hline 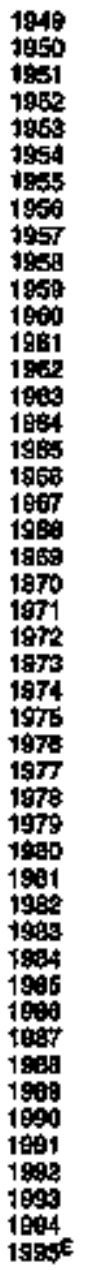 & 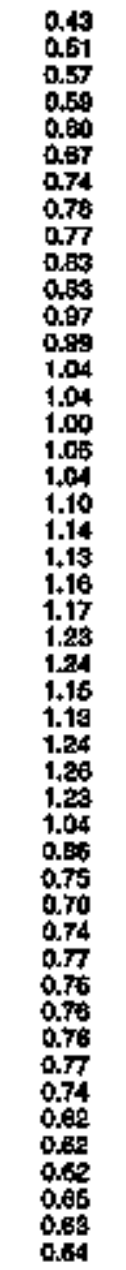 & 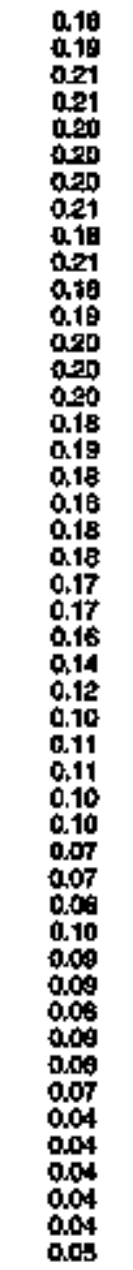 & 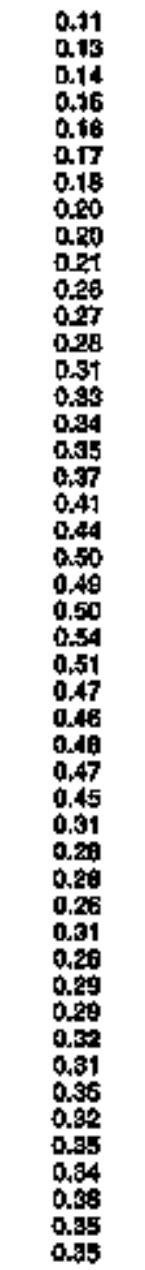 & 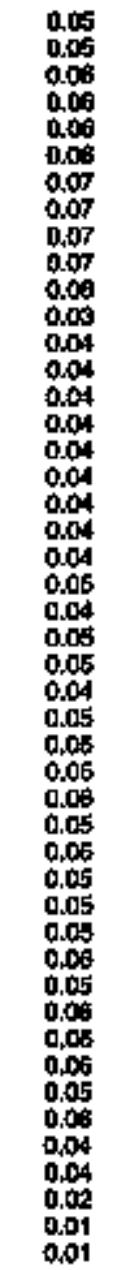 & 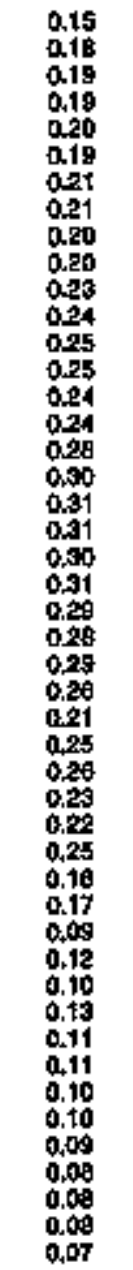 & 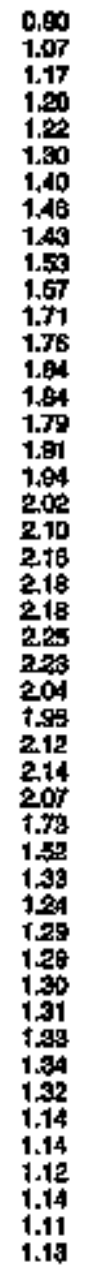 & $\begin{array}{l}0.18 \\
0.18 \\
0.20 \\
0.21 \\
0.23 \\
0.23 \\
0.25 \\
0.27 \\
0.26 \\
0.28 \\
0.30 \\
0.30 \\
0.31 \\
0.33 \\
0.34 \\
0.35 \\
0.37 \\
0.69 \\
0.38 \\
0.41 \\
0.42 \\
0.45 \\
0.48 \\
0.47 \\
0.52 \\
0.49 \\
0.42 \\
0.41 \\
0.44 \\
0.49 \\
0.46 \\
0.49 \\
0.34 \\
0.34 \\
0.37 \\
0.41 \\
0.49 \\
0.45 \\
0.47 \\
0.47 \\
0.45 \\
0.49 \\
0.44 \\
0.45 \\
0.47 \\
0.49 \\
0.49\end{array}$ & 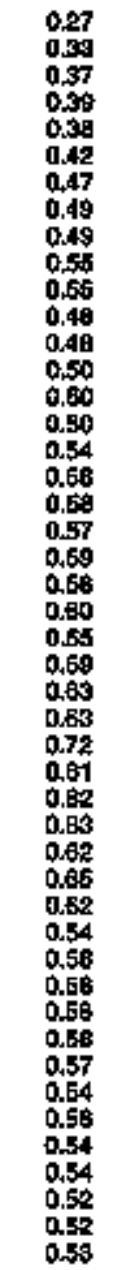 & $\begin{array}{l}0.12 \\
0.13 \\
0.13 \\
0.19 \\
0.12 \\
0.12 \\
0.12 \\
0.11 \\
0.10 \\
0.00 \\
0.00 \\
0.09 \\
0.06 \\
0.07 \\
0.07 \\
0.09 \\
0.00 \\
0.09 \\
0.11 \\
0.10 \\
0.10 \\
0.00 \\
0.08 \\
0.00 \\
0.09 \\
0.08 \\
0.05 \\
0.06 \\
0.07 \\
0.09 \\
0.09 \\
0.09 \\
0.05 \\
0.07 \\
0.09 \\
0.03 \\
0.02 \\
0.02 \\
0.01 \\
0.01 \\
0.01 \\
0.01 \\
0.01 \\
0.9 \\
0.05 \\
0.04 \\
0.01\end{array}$ & 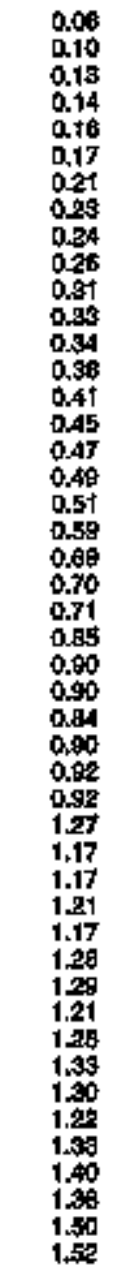 & $\begin{array}{l}0.04 \\
0.04 \\
0.05 \\
0.04 \\
0.04 \\
0.04 \\
0.05 \\
0.05 \\
0.05 \\
0.04 \\
0.05 \\
0.05 \\
0.05 \\
0.05 \\
0.05 \\
0.08 \\
0.08 \\
0.08 \\
0.00 \\
0.07 \\
0.07 \\
0.07 \\
0.07 \\
0.07 \\
0.09 \\
0.08 \\
0.07 \\
0.07 \\
0.06 \\
0.09 \\
0.09 \\
0.08 \\
0.08 \\
0.07 \\
0.08 \\
0.08 \\
0.07 \\
0.07 \\
0.08 \\
0.08 \\
0.08 \\
0.08 \\
0.08 \\
0.08 \\
0.08 \\
0.00 \\
0.00\end{array}$ & $\begin{array}{l}0.12 \\
0.13 \\
0.14 \\
0.15 \\
0.18 \\
0.16 \\
0.17 \\
0.19 \\
0.19 \\
0.19 \\
0.49 \\
0.20 \\
0.19 \\
0.19 \\
0.19 \\
0.19 \\
0.19 \\
0.17 \\
0.16 \\
0.13 \\
0.15 \\
0.15 \\
0.14 \\
0.19 \\
0.13 \\
0.12 \\
0.12 \\
0.17 \\
0.10 \\
0.09 \\
0.08 \\
0.08 \\
0.08 \\
0.07 \\
0.05 \\
0.08 \\
0.11 \\
0.11 \\
0.11 \\
0.10 \\
0.10 \\
0.10 \\
0.10 \\
0.10 \\
0.09 \\
0.10 \\
0.10\end{array}$ & 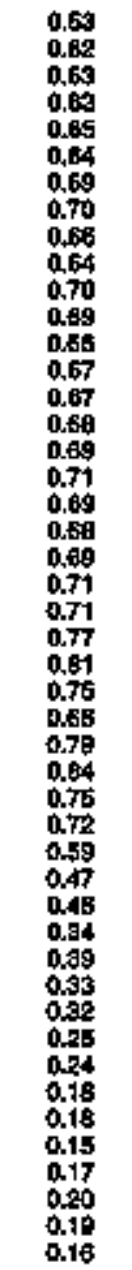 & 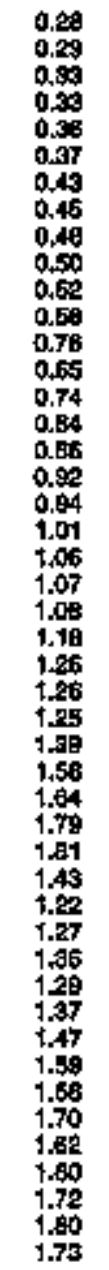 & 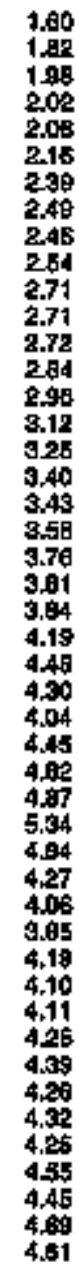 \\
\hline
\end{tabular}

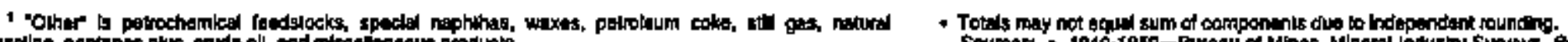

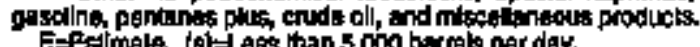

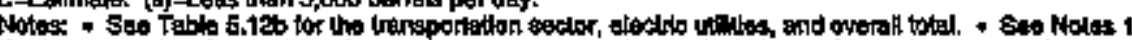

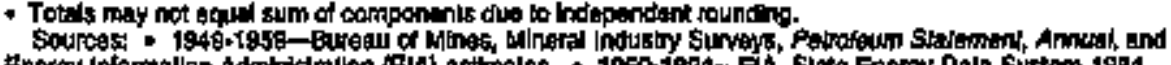
and 3 at end of seston for comments on the caleulation of products supplad.

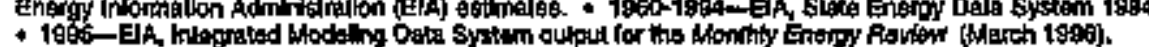


Table 5.12b Petroleum Products Supplied to the Transportatlon Sector, Electrlc Utilitles, and Total, 1949-1995 (Malison Bartels per Day)

\begin{tabular}{|c|c|c|c|c|c|c|c|c|c|c|c|c|c|}
\hline \multirow[b]{2}{*}{ Yoar } & \multicolumn{8}{|c|}{ Trensportetion } & \multicolumn{4}{|c|}{ Electric Udillues } & \multirow[b]{2}{*}{ Tolal } \\
\hline & $\begin{array}{l}\text { Avfation } \\
\text { Basoinn }\end{array}$ & 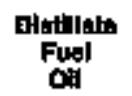 & Jut & $\begin{array}{l}\text { Llapintiod } \\
\text { Potroleum } \\
\text { Gateis }\end{array}$ & Lubricamts & $\begin{array}{l}\text { Motor } \\
\text { Getsoline }\end{array}$ & $\begin{array}{c}\text { Feelltival } \\
\text { Fuel } \\
\text { Óll }\end{array}$ & Total & Heary & 내유: & $\begin{array}{l}\text { Petroleum } \\
\text { coks }\end{array}$ & Total & \\
\hline 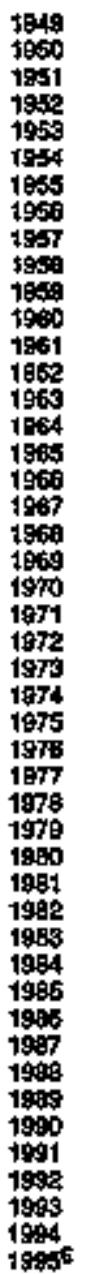 & $\begin{array}{l}0.09 \\
0.11 \\
0.19 \\
0.17 \\
0.19 \\
0.19 \\
0.19 \\
0.20 \\
0.20 \\
0.22 \\
0.21 \\
0.16 \\
0.16 \\
0.14 \\
0.14 \\
0.13 \\
0.12 \\
0.11 \\
0.09 \\
0.06 \\
0.07 \\
0.05 \\
0.09 \\
0.06 \\
0.05 \\
0.04 \\
0.04 \\
0.04 \\
0.04 \\
0.04 \\
0.04 \\
0.09 \\
0.03 \\
0.09 \\
0.09 \\
0.02 \\
0.03 \\
0.03 \\
0.02 \\
0.08 \\
0.03 \\
0.02 \\
0.02 \\
0.08 \\
0.02 \\
0.02 \\
0.02\end{array}$ & $\begin{array}{l}0.19 \\
0.23 \\
0.77 \\
0.31 \\
0.34 \\
0.34 \\
0.37 \\
0.40 \\
0.41 \\
0.39 \\
0.41 \\
0.42 \\
0.42 \\
0.45 \\
0.50 \\
0.58 \\
0.51 \\
0.55 \\
0.54 \\
0.65 \\
0.70 \\
0.74 \\
0.90 \\
0.91 \\
1.05 \\
1.04 \\
1.00 \\
1.07 \\
1.17 \\
1.26 \\
1.37 \\
1.31 \\
1.36 \\
1.31 \\
1.37 \\
1.47 \\
1.51 \\
1.55 \\
1.59 \\
1.73 \\
1.81 \\
1.690 \\
1.73 \\
1.79 \\
1.64 \\
4.98 \\
1.89\end{array}$ & $\begin{array}{l}0.00 \\
0.00 \\
0.00 \\
0.05 \\
0.09 \\
0.13 \\
0.15 \\
0.20 \\
0.20 \\
0.27 \\
0.93 \\
0.97 \\
0.42 \\
0.49 \\
0.52 \\
0.08 \\
0.00 \\
0.67 \\
0.02 \\
0.95 \\
0.99 \\
0.97 \\
1.01 \\
1.02 \\
1.04 \\
0.94 \\
0.90 \\
0.08 \\
1.02 \\
1.04 \\
1.07 \\
1.06 \\
1.91 \\
1.01 \\
1.05 \\
1.10 \\
1.22 \\
1.91 \\
1.35 \\
1.45 \\
1.49 \\
1.52 \\
1.47 \\
1.45 \\
1.47 \\
1.58 \\
1.51\end{array}$ & 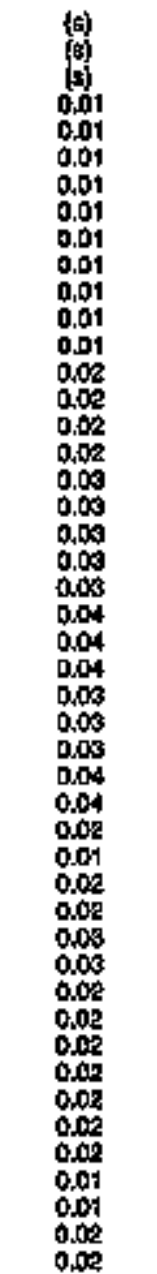 & $\begin{array}{l}0.05 \\
0.06 \\
0.07 \\
0.06 \\
0.07 \\
0.08 \\
0.07 \\
0.07 \\
0.07 \\
0.06 \\
0.07 \\
0.07 \\
0.07 \\
0.07 \\
0.07 \\
0.07 \\
0.07 \\
0.07 \\
0.06 \\
0.07 \\
0.07 \\
0.07 \\
0.07 \\
0.07 \\
0.07 \\
0.07 \\
0.07 \\
0.07 \\
0.07 \\
0.09 \\
0.09 \\
0.09 \\
0.07 \\
0.07 \\
0.07 \\
0.00 \\
0.07 \\
0.07 \\
0.09 \\
0.09 \\
0.009 \\
0.09 \\
0.07 \\
0.07 \\
0.07 \\
0.08 \\
0.08\end{array}$ & 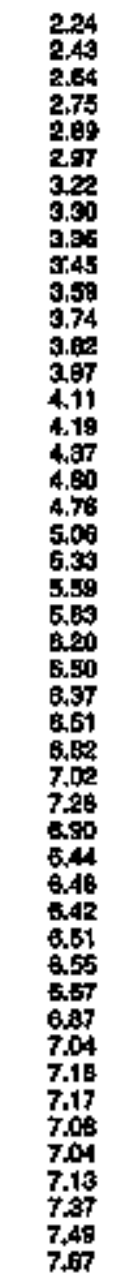 & $\begin{array}{l}0.50 \\
0.52 \\
0.56 \\
0.50 \\
0.49 \\
0.45 \\
0.44 \\
0.44 \\
0.44 \\
0.41 \\
0.39 \\
0.37 \\
0.35 \\
0.34 \\
0.33 \\
0.34 \\
0.34 \\
0.34 \\
0.35 \\
0.35 \\
0.33 \\
0.33 \\
0.31 \\
0.28 \\
0.32 \\
0.30 \\
0.31 \\
0.35 \\
0.40 \\
0.43 \\
0.64 \\
0.31 \\
0.53 \\
0.44 \\
0.36 \\
0.35 \\
0.34 \\
0.39 \\
0.39 \\
0.40 \\
0.43 \\
0.45 \\
0.45 \\
0.47 \\
0.40 \\
0.39 \\
0.39\end{array}$ & 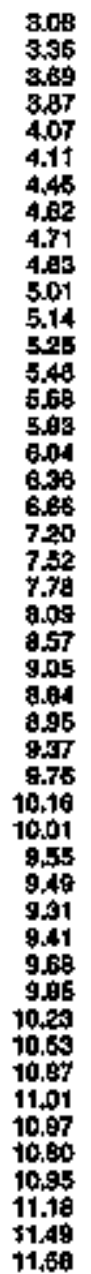 & 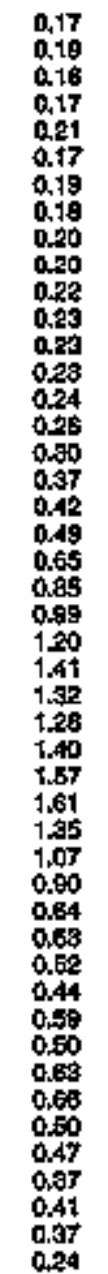 & $\begin{array}{l}0.01 \\
0.01 \\
0.01 \\
0.01 \\
0.02 \\
0.01 \\
0.01 \\
0.01 \\
0.02 \\
0.02 \\
0.02 \\
0.01 \\
0.01 \\
0.01 \\
0.01 \\
0.01 \\
0.01 \\
0.02 \\
0.02 \\
0.09 \\
0.04 \\
0.07 \\
0.09 \\
0.15 \\
0.13 \\
0.15 \\
0.11 \\
0.11 \\
0.13 \\
0.13 \\
0.08 \\
0.06 \\
0.06 \\
0.04 \\
0.09 \\
0.04 \\
0.04 \\
0.04 \\
0.04 \\
0.04 \\
0.07 \\
0.04 \\
0.04 \\
0.03 \\
0.04 \\
0.04 \\
0.04\end{array}$ & 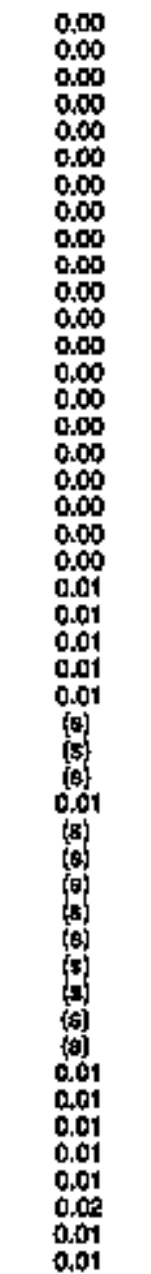 & 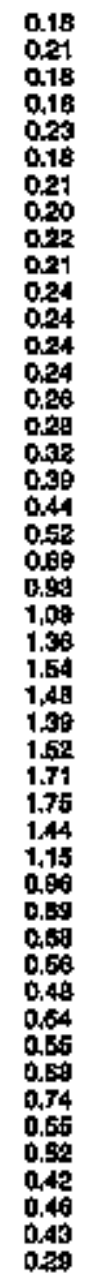 & 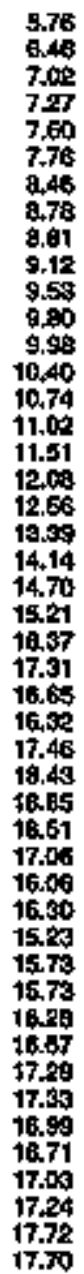 \\
\hline
\end{tabular}

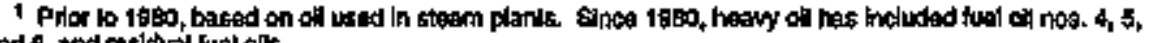
and 6 , and restedect wal ants,

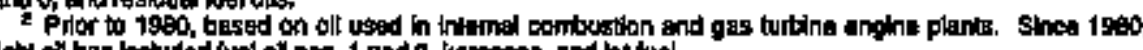
llght oil har hectuded ivel oll nos. 1 and 2, kerosent, und jat tual.

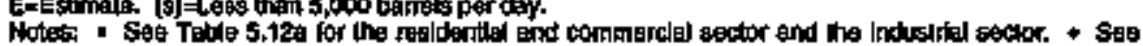

Notes 1 and 3 al end of gectien lor comments on the calculation of products suppiliad.

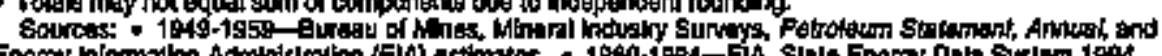

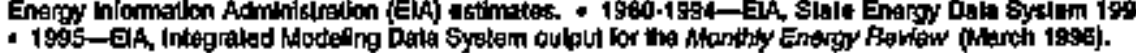




\section{Total by Fuel}

$4.0-$
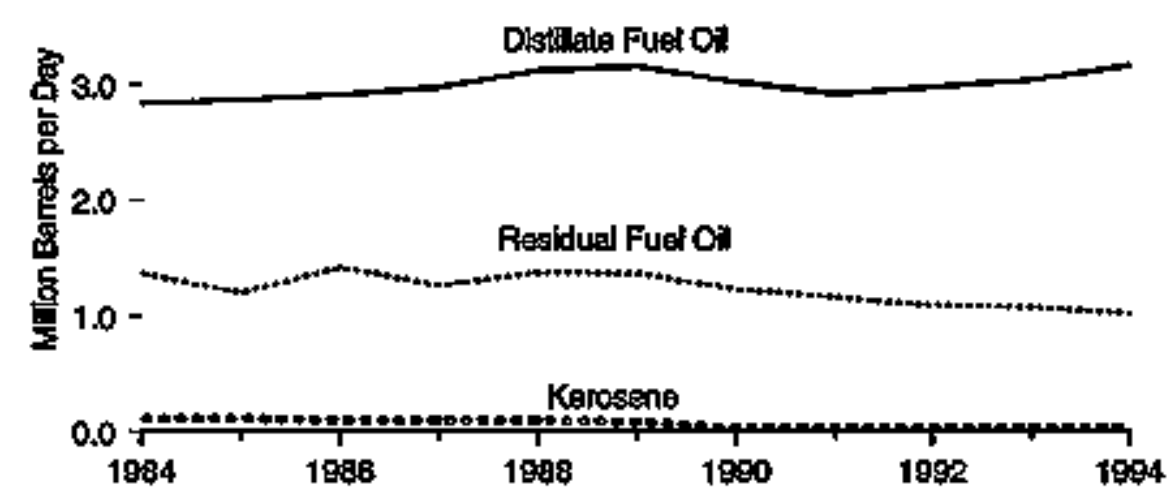

\section{Festatual Fual, Major End Usess}

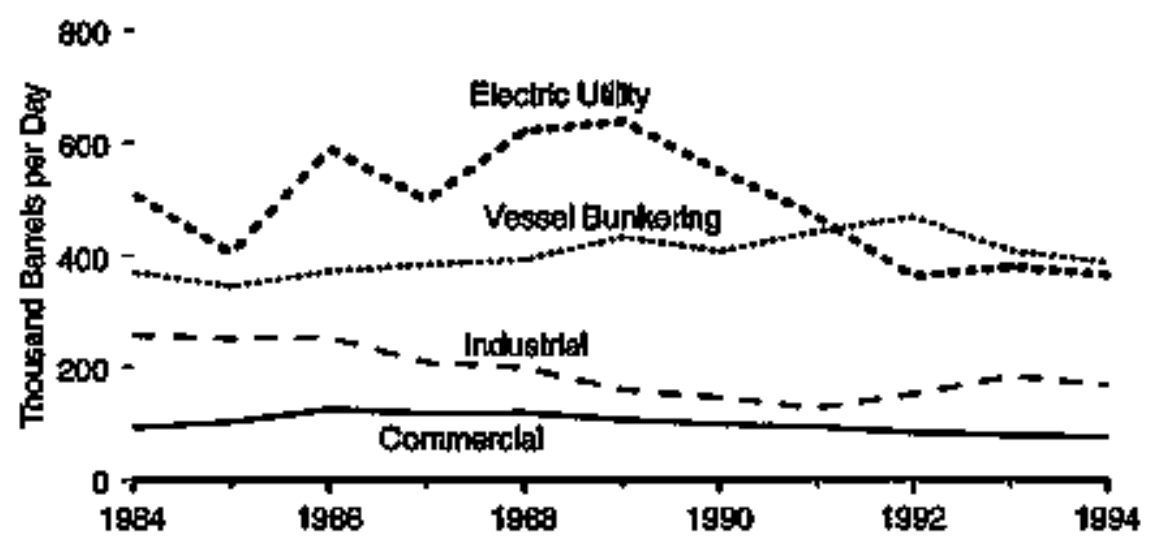

Distillate Fued Oll, Major End Uses

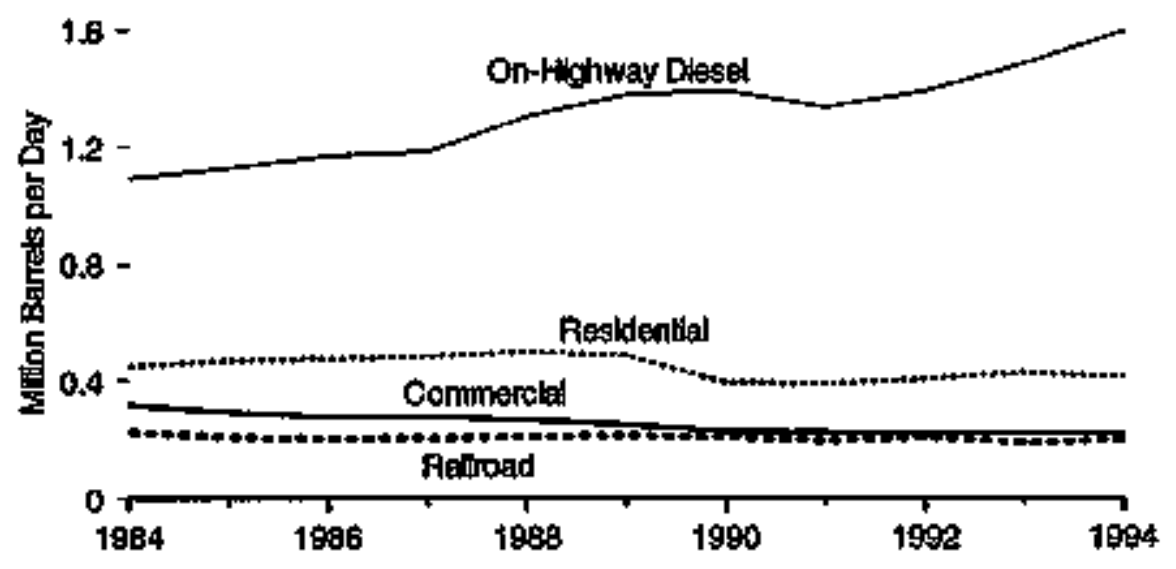

\section{Kerosene, Major End Uses}

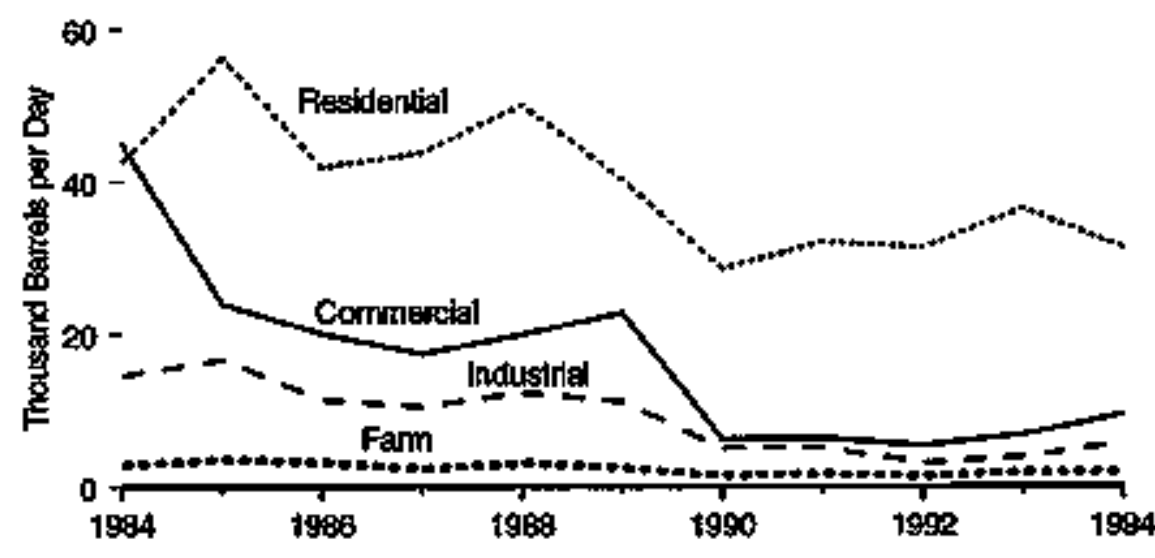

Sourca: Table 5.13. 
Table 5.13 Fuel Oll and Kerosene Adjusted Sales, 1984-1994

(Thousand Barrels per Day)

\begin{tabular}{|c|c|c|c|c|c|c|c|c|c|c|c|c|c|}
\hline Year & Reslditenthol & Comprnercted & Inchustital & Ori & Farm & $\begin{array}{l}\text { Eecurle } \\
\text { 1yiliny }\end{array}$ & Pallinatod & $\begin{array}{c}\text { Vostal } \\
\text { Bunkering }\end{array}$ & $\begin{array}{c}\text { On- } \\
\text { Hogloway } \\
\text { Diased }\end{array}$ & Mathy & $\begin{array}{c}\text { Ofi- } \\
\text { Highmyy } \\
\text { Oitesel }\end{array}$ & All & Totel \\
\hline & \multicolumn{13}{|c|}{ Dletiliato Fuel OA } \\
\hline \multirow[t]{2}{*}{$\begin{array}{l}1984 \\
1995 \\
19985 \\
1998 \\
1988 \\
1999 \\
1990 \\
1991 \\
19998 \\
1998 \\
1994\end{array}$} & $\begin{array}{l}450 \\
471 \\
478 \\
484 \\
488 \\
489 \\
383 \\
391 \\
407 \\
429 \\
413 \\
\end{array}$ & $\begin{array}{l}319 \\
294 \\
290 \\
279 \\
2799 \\
258 \\
228 \\
228 \\
218 \\
218 \\
219\end{array}$ & $\begin{array}{l}150 \\
160 \\
175 \\
190 \\
170 \\
167 \\
160 \\
150 \\
145 \\
128 \\
130\end{array}$ & $\begin{array}{l}59 \\
57 \\
49 \\
59 \\
57 \\
55 \\
85 \\
59 \\
51 \\
50 \\
46 \\
\end{array}$ & $\begin{array}{l}100 \\
216 \\
220 \\
211 \\
220 \\
209 \\
215 \\
214 \\
229 \\
211 \\
209\end{array}$ & $\begin{array}{l}45 \\
34 \\
40 \\
42 \\
62 \\
70 \\
49 \\
39 \\
31 \\
38 \\
49\end{array}$ & $\begin{array}{l}225 \\
209 \\
202 \\
206 \\
212 \\
213 \\
209 \\
197 \\
210 \\
180 \\
200 \\
\end{array}$ & $\begin{array}{l}110 \\
124 \\
138 \\
145 \\
150 \\
154 \\
143 \\
141 \\
145 \\
133 \\
138 \\
\end{array}$ & $\begin{array}{l}1,098 \\
1,127 \\
1,169 \\
1,185 \\
1,304 \\
1,378 \\
1,393 \\
1,339 \\
1,394 \\
1,489 \\
1,594\end{array}$ & $\begin{array}{l}45 \\
50 \\
50 \\
58 \\
64 \\
61 \\
51 \\
54 \\
48 \\
31 \\
34 \\
\end{array}$ & $\begin{array}{l}109 \\
105 \\
111 \\
113 \\
119 \\
107 \\
116 \\
110 \\
119 \\
127 \\
130 \\
\end{array}$ & 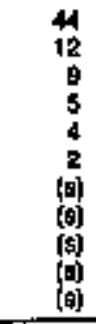 & $\begin{array}{l}2,946 \\
2,668 \\
2,914 \\
2,976 \\
3,122 \\
3,167 \\
3,091 \\
2,921 \\
2,997 \\
3,041 \\
3,162\end{array}$ \\
\hline & \multicolumn{13}{|c|}{ Fesiourd fued } \\
\hline \multirow[t]{2}{*}{$\begin{array}{l}1904 \\
1985 \\
1986 \\
1997 \\
1998 \\
1998 \\
1990 \\
1991 \\
1998 \\
1989 \\
19984 \\
1994\end{array}$} & $\begin{array}{l}= \\
= \\
= \\
= \\
= \\
=\end{array}$ & $\begin{array}{r}92 \\
109 \\
128 \\
118 \\
119 \\
109 \\
109 \\
93 \\
94 \\
79 \\
76 \\
\end{array}$ & $\begin{array}{l}250 \\
258 \\
254 \\
200 \\
200 \\
160 \\
145 \\
126 \\
152 \\
184 \\
169 \\
\end{array}$ & $\begin{array}{l}76 \\
71 \\
51 \\
42 \\
34 \\
22 \\
21 \\
20 \\
19 \\
21 \\
17 \\
\end{array}$ & $\begin{array}{l}= \\
= \\
= \\
= \\
= \\
=\end{array}$ & $\begin{array}{l}609 \\
409 \\
590 \\
499 \\
625 \\
659 \\
590 \\
499 \\
364 \\
981 \\
386 \\
351\end{array}$ & 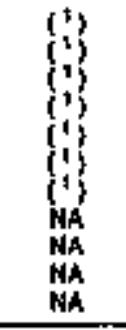 & $\begin{array}{l}370 \\
346 \\
371 \\
393 \\
392 \\
438 \\
408 \\
443 \\
470 \\
409 \\
388\end{array}$ & $\begin{array}{l}\bar{z} \\
\bar{z} \\
\bar{z} \\
\bar{z} \\
\bar{z}\end{array}$ & $\begin{array}{r}14 \\
13 \\
12 \\
\mathbf{1 2} \\
9 \\
9 \\
7 \\
5 \\
9 \\
7 \\
6 \\
4 \\
\end{array}$ & $\begin{array}{l}= \\
= \\
= \\
= \\
= \\
=\end{array}$ & $\begin{array}{r}50 \\
15 \\
15 \\
3 \\
4 \\
2 \\
0 \\
2 \\
1 \\
1 \\
69 \\
00 \\
\end{array}$ & $\begin{array}{l}1,369 \\
1,002 \\
1,418 \\
1,264 \\
1,379 \\
1,370 \\
1,229 \\
1,159 \\
1,097 \\
1,060 \\
1,021 \\
\end{array}$ \\
\hline & \multicolumn{13}{|c|}{ Kemosene } \\
\hline $\begin{array}{l}1994 \\
1509 \\
1906 \\
1997 \\
1999 \\
1998 \\
1990 \\
1991 \\
1998 \\
1090 \\
1694\end{array}$ & $\begin{array}{l}42 \\
58 \\
42 \\
44 \\
50 \\
40 \\
29 \\
32 \\
31 \\
37 \\
31\end{array}$ & $\begin{array}{l}45 \\
24 \\
20 \\
57 \\
20 \\
20 \\
6 \\
6 \\
5 \\
7 \\
0\end{array}$ & $\begin{array}{r}14 \\
17 \\
11 \\
10 \\
12 \\
11 \\
6 \\
5 \\
3 \\
4 \\
6\end{array}$ & $\begin{array}{l}= \\
= \\
= \\
= \\
=\end{array}$ & $\begin{array}{l}3 \\
\mathbf{a} \\
3 \\
2 \\
3 \\
2 \\
1 \\
2 \\
1 \\
2 \\
2\end{array}$ & $\begin{array}{l}\bar{z} \\
= \\
\bar{z} \\
\bar{z} \\
\bar{z}\end{array}$ & $\begin{array}{l}= \\
= \\
= \\
= \\
= \\
=\end{array}$ & $\begin{array}{l}= \\
= \\
= \\
= \\
= \\
=\end{array}$ & $\begin{array}{l}= \\
= \\
= \\
= \\
= \\
=\end{array}$ & $\begin{array}{l}= \\
= \\
= \\
= \\
= \\
=\end{array}$ & $\begin{array}{l}= \\
= \\
= \\
= \\
= \\
=\end{array}$ & $\begin{array}{r}11 \\
14 \\
22 \\
21 \\
11 \\
8 \\
1 \\
1 \\
(5) \\
1 \\
1\end{array}$ & $\begin{array}{r}115 \\
114 \\
99 \\
90 \\
96 \\
94 \\
43 \\
40 \\
42 \\
60 \\
49\end{array}$ \\
\hline
\end{tabular}

1 Includad ho "All Other:"

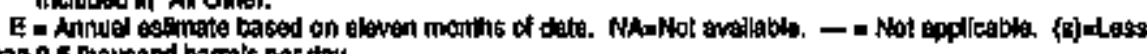
has 0.5 drousand barrols per thy.

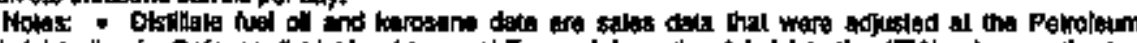

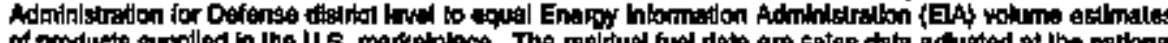

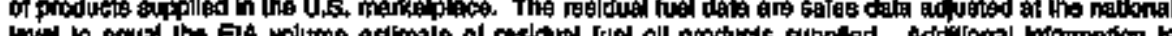
men to componants twe to indispendent rounding.

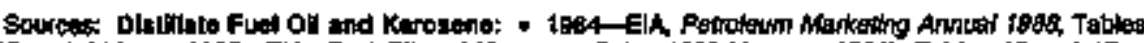

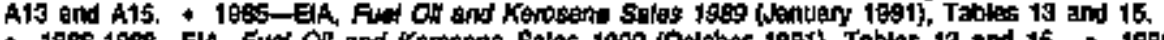

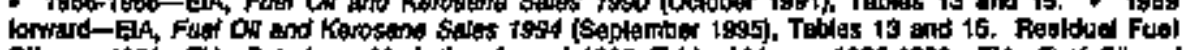

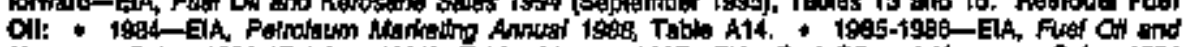

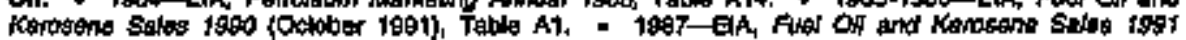

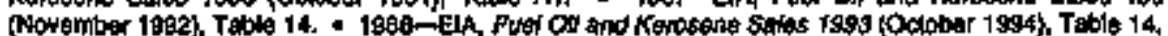

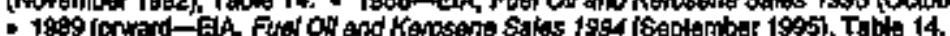


Total, Produets, and Crude On1,1949-1996

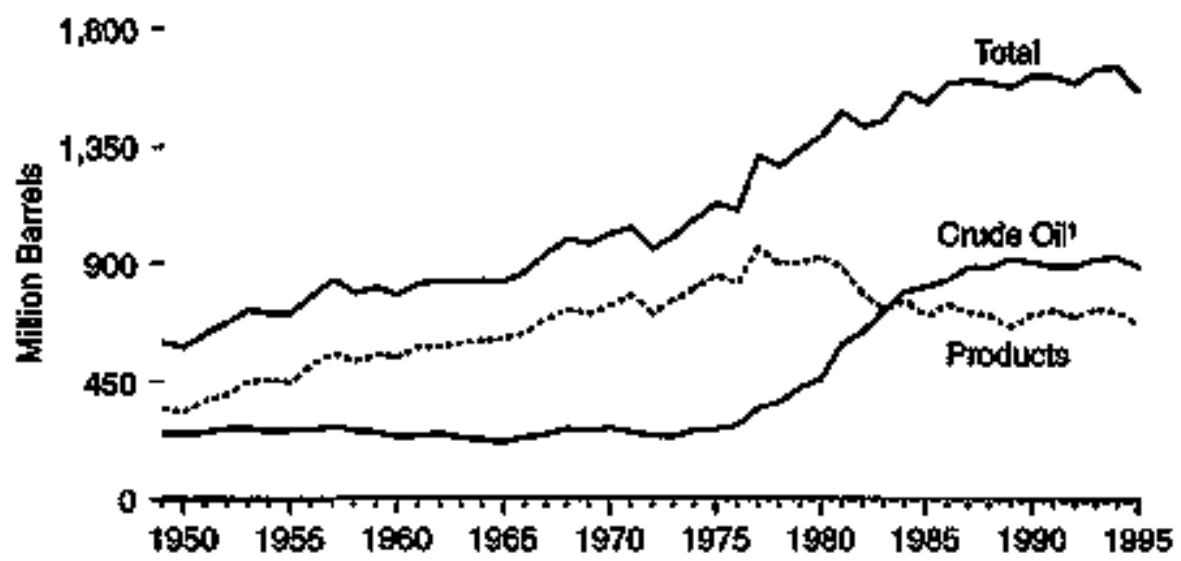

By Type, 1995

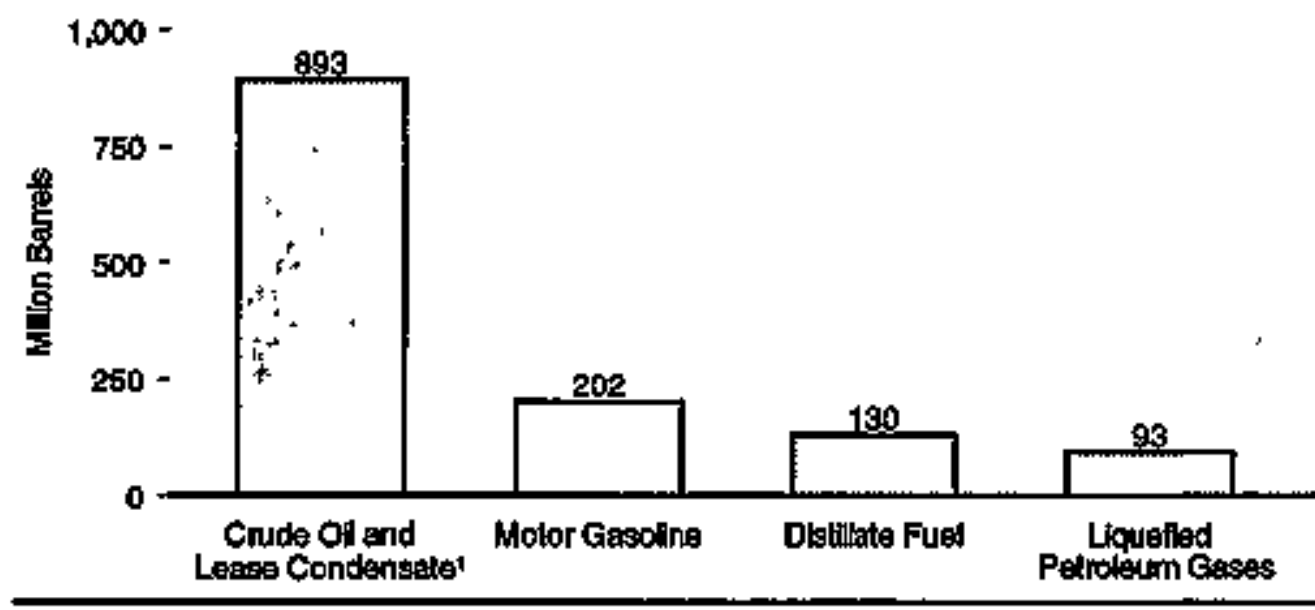

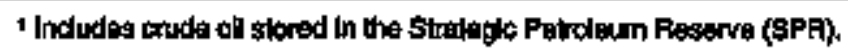

2 See Foure B.15 for additanal Strategle Pelkutotsm Reserve hformalton.
SPR, Non-SPR, end Total Stocks, 1949-1895

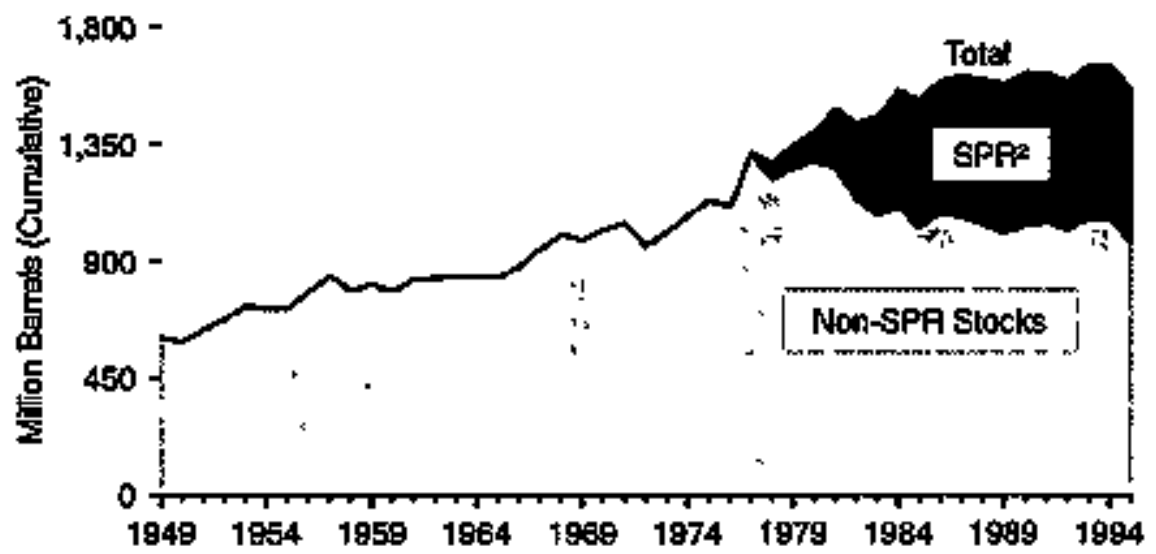


Table 5.14 Petroleum Primary Stocks by Typo, End of Year 1949-1995

(Million Barrels)

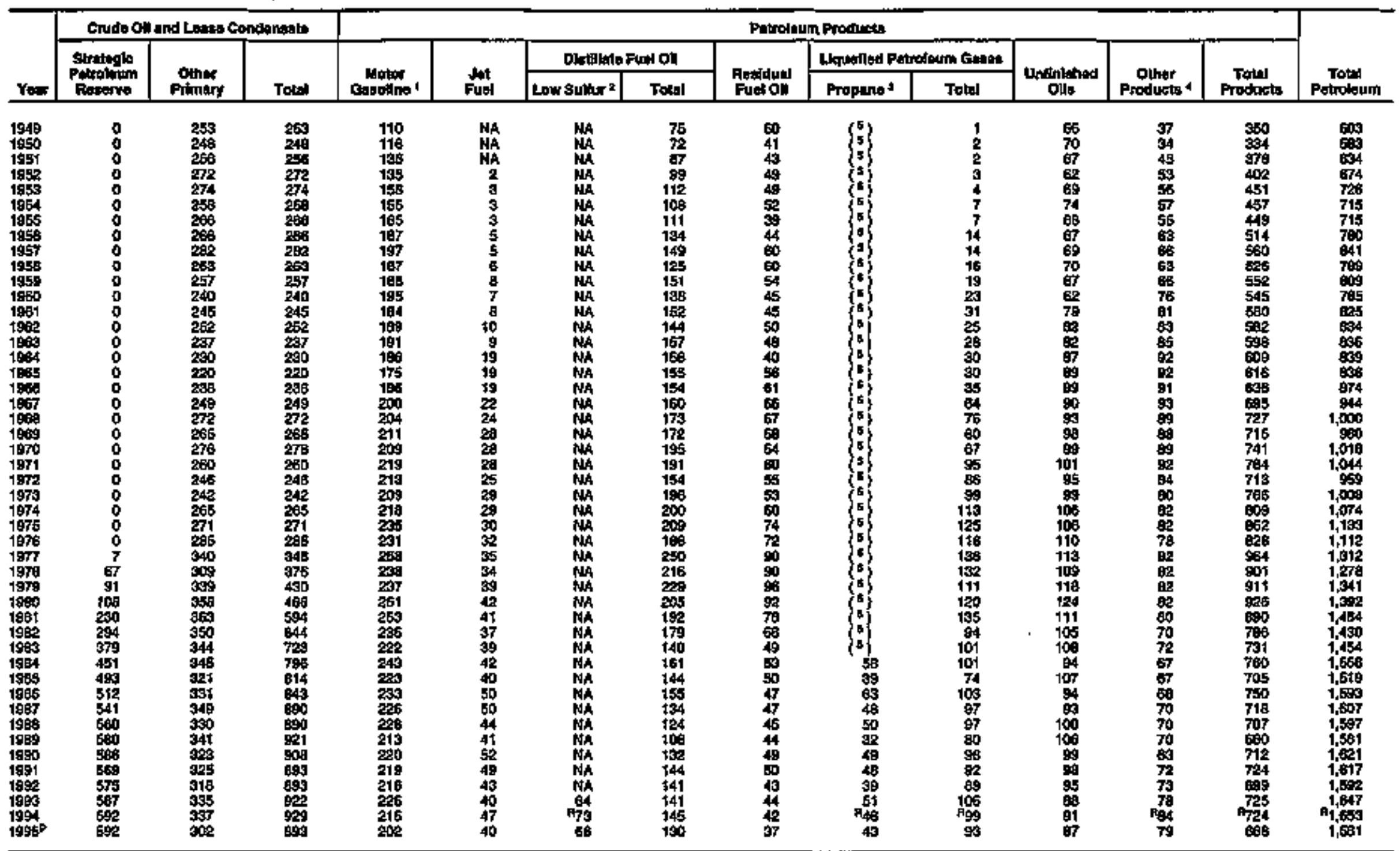

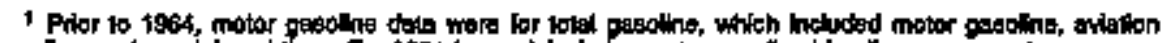

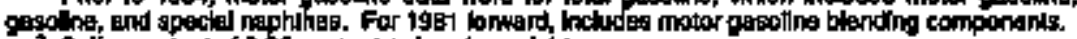

3 sulur coniunl of obs pereent or less by midis.

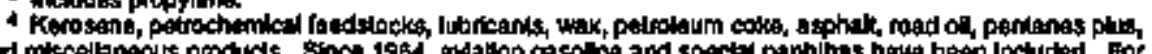

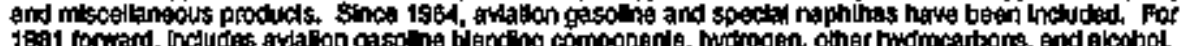

6 Induded In liaua fed potroleum gases lolal.

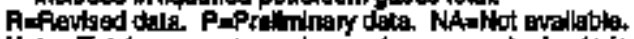

Hois: Totols may not equal sum od components dus to [independint counding.

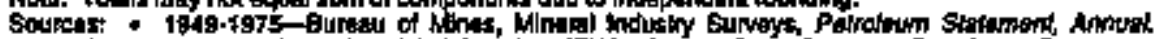

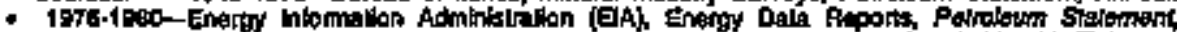

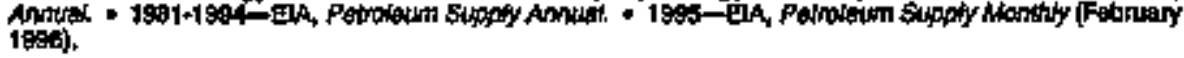




\section{End-of-Year Stocks in SPA}

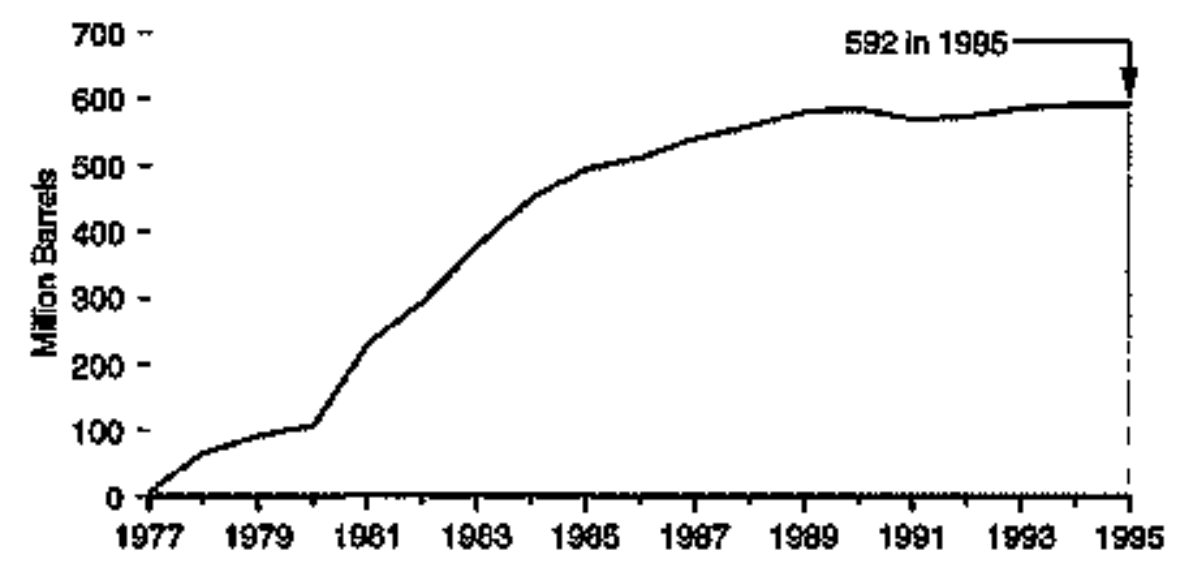

Days of Net Petroleum Imports Stored in SPR'

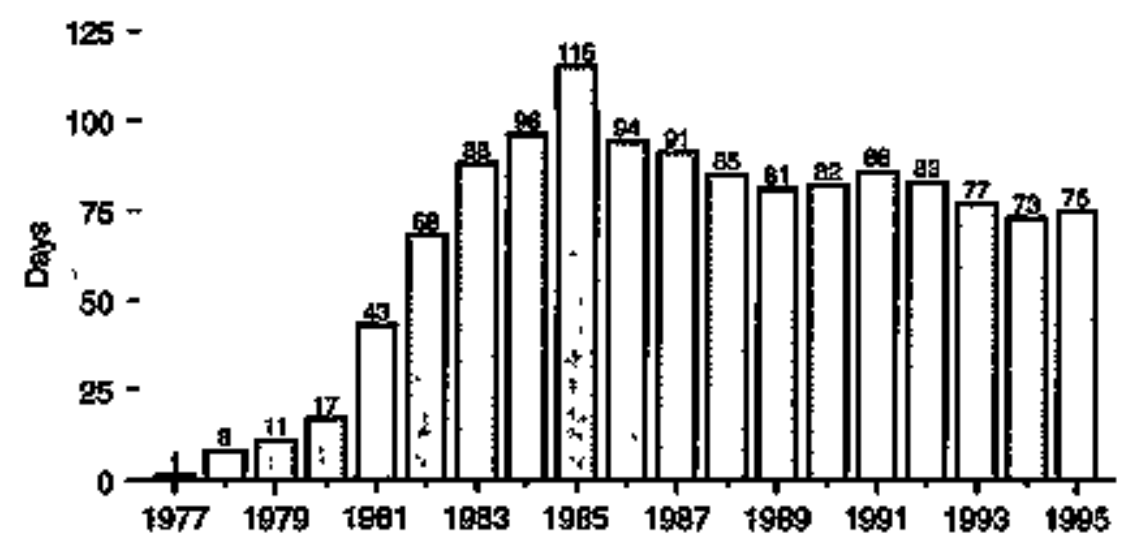

Crude Oil timports for SPR

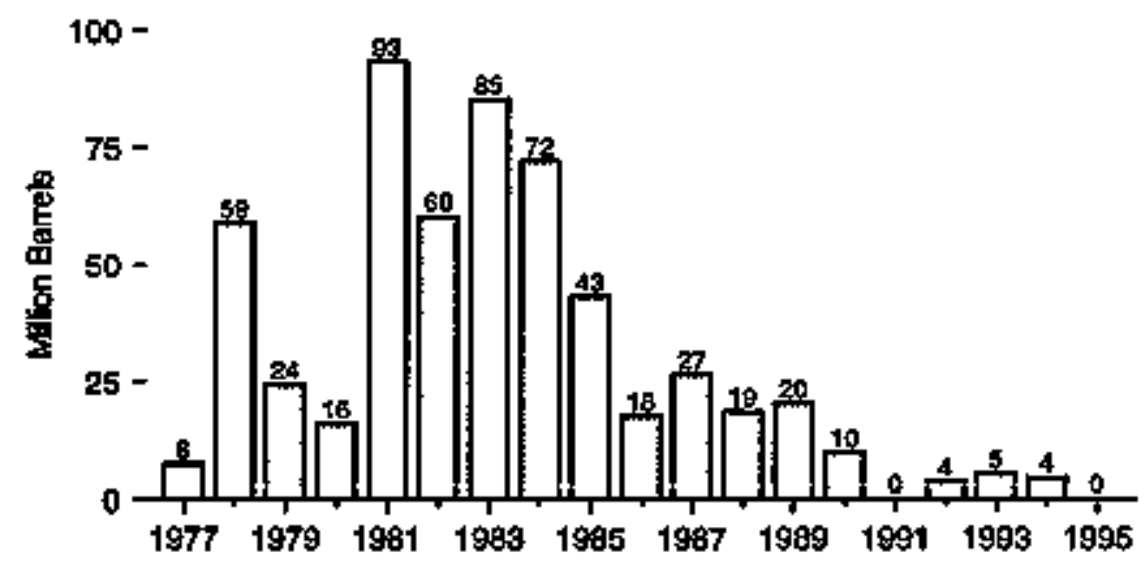

SPR as Share of Domestis Stocks

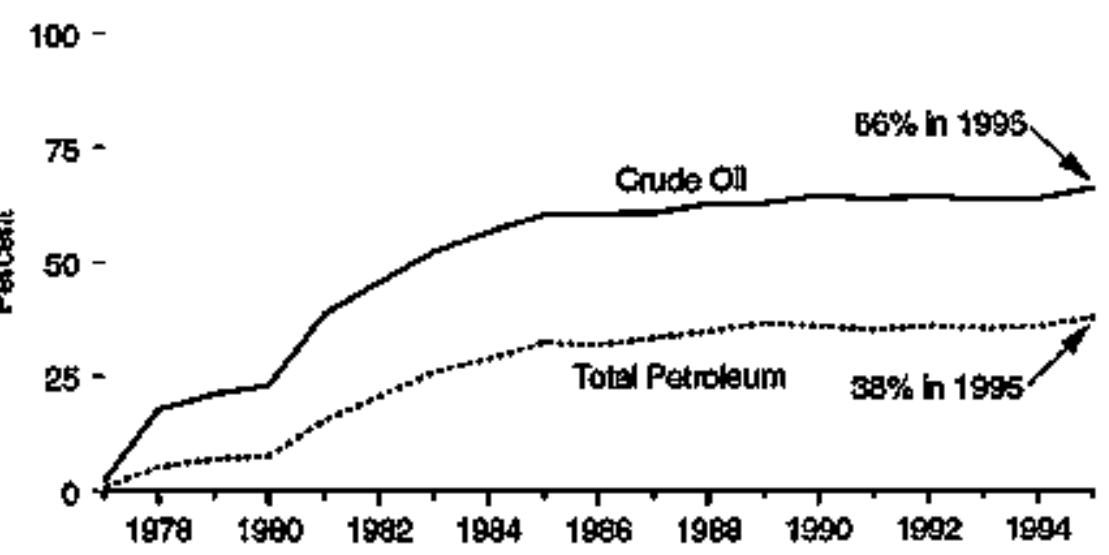

- Because vertlcal sceles differ, graphs should not be compared. Spurve: Tabt 5.15.

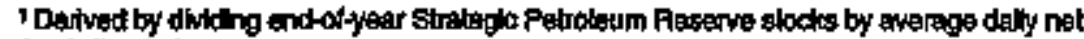
imports of all potioloum. 
Table 5.15 Strategic Petroleum Reserve, 1977-1995

(Million Barrels, Excopt as Noted)

\begin{tabular}{|c|c|c|c|c|c|c|c|}
\hline \multirow[b]{2}{*}{ Yayr } & \multirow[b]{2}{*}{$\begin{array}{l}\text { Grudo on } \\
\text { Imports }\end{array}$} & \multirow[b]{2}{*}{ 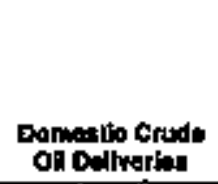 } & \multirow[b]{2}{*}{$\begin{array}{l}\text { Domatitc Cruts } \\
\text { Dil Sties }\end{array}$} & \multicolumn{3}{|c|}{ End-at-Your stoteks } & \multirow[b]{2}{*}{$\begin{array}{l}\text { Dave of the } \\
\text { Petroluum } \\
\text { Imports a }\end{array}$} \\
\hline & & & & Ouaniky 1 & 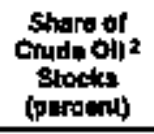 & 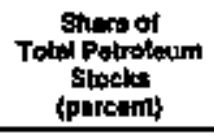 & \\
\hline 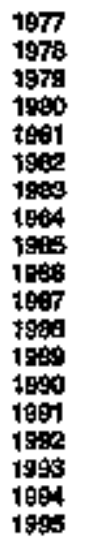 & 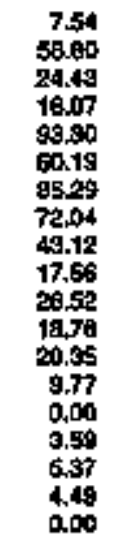 & $\begin{array}{r}40.37 \\
0.00 \\
(15) \\
1.30 \\
20.79 \\
0.79 \\
0.42 \\
0.05 \\
0.17 \\
1.21 \\
2.69 \\
0.01 \\
0.00 \\
0.00 \\
0.00 \\
2.60 \\
6.06 \\
0.11 \\
0.00\end{array}$ & $\begin{array}{l}0.00 \\
0.00 \\
0,00 \\
0.00 \\
0.00 \\
0,00 \\
0.00 \\
0.00 \\
0,00 \\
0.00 \\
0.00 \\
0.00 \\
0.00 \\
3.01 \\
17.28 \\
0.00 \\
0.00 \\
0.00 \\
0,00\end{array}$ & 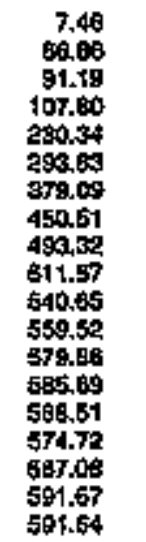 & $\begin{array}{r}2.1 \\
17.0 \\
21.2 \\
29.1 \\
38.6 \\
45.7 \\
52.4 \\
58.6 \\
50.6 \\
50.7 \\
60.6 \\
52.9 \\
62.9 \\
84.5 \\
63.7 \\
64.4 \\
63.6 \\
63.7 \\
65.8\end{array}$ & $\begin{array}{r}0.6 \\
5.2 \\
6.8 \\
7.7 \\
16.6 \\
20.5 \\
25.1 \\
28.9 \\
32.5 \\
32.1 \\
38.6 \\
35.0 \\
39.7 \\
38.1 \\
35.2 \\
\$ 3.1 \\
35.6 \\
35.8 \\
37.8\end{array}$ & $\begin{array}{r}1 \\
9 \\
11 \\
17 \\
49 \\
68 \\
69 \\
96 \\
115 \\
94 \\
91 \\
95 \\
91 \\
82 \\
85 \\
93 \\
97 \\
73 \\
75\end{array}$ \\
\hline
\end{tabular}

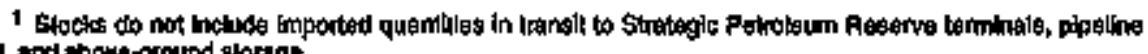
In, and athowe-pround storags.

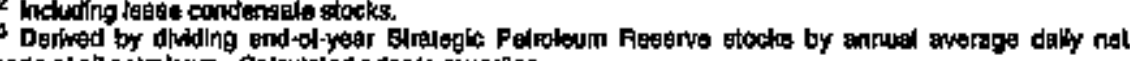

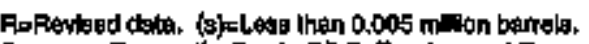

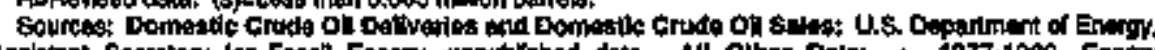

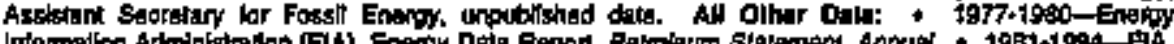

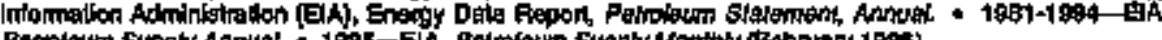

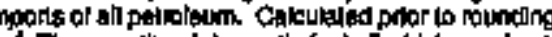

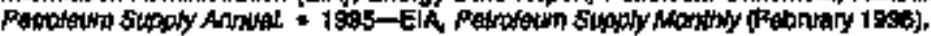

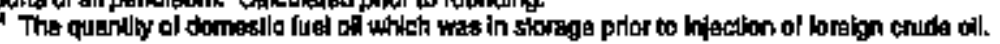




\section{Figure 5.16 Crude Oil Domestic First Purchase Prices}

\section{U.S. Average Reali and Nombnal Prlees, 1949-198s}

$50 *$

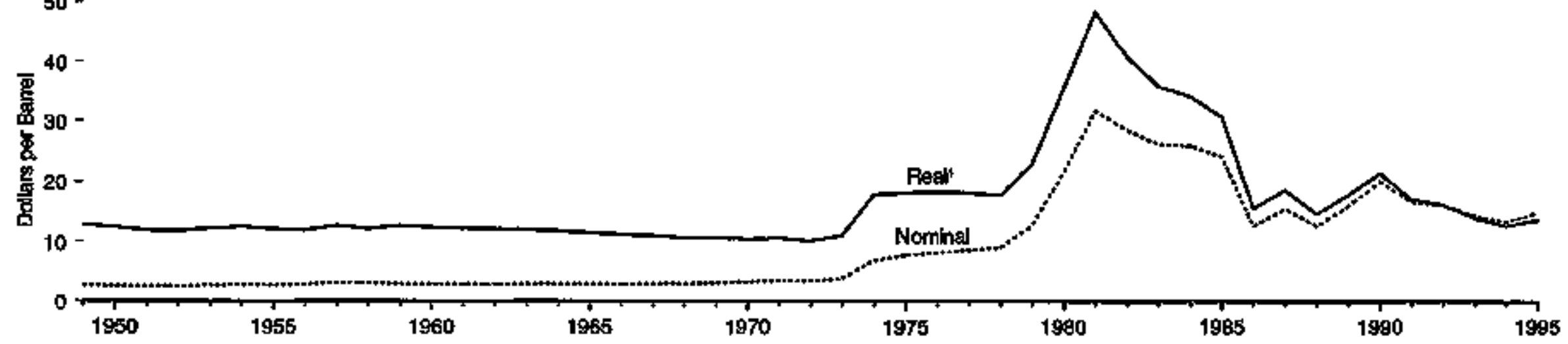

Alaska North Slope, Caliornla, and TexaG, 1977-1998
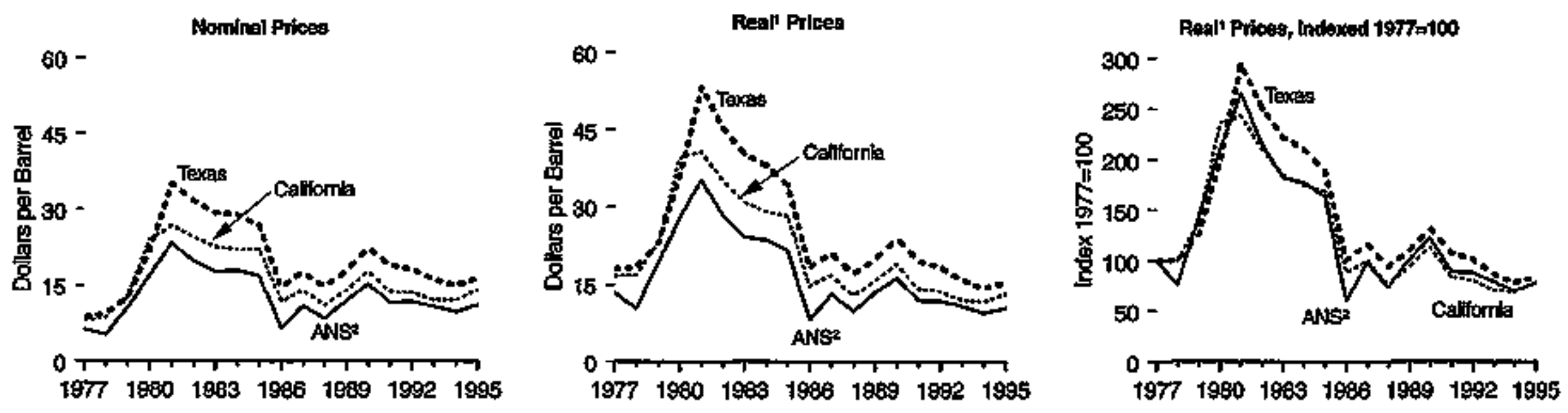

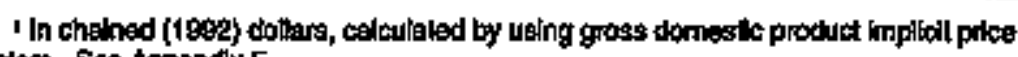
detteions. See Appendlx E.

Alaska North Slope.

Nolet Becense vertical scales differ, graphs should not be compared.

Source: Tatbilo 5.18. 
Table 5.16 Crude Ofl Domestic First Purchase Prices, 1949-1995

(Dollars per Barrel)

\begin{tabular}{|c|c|c|c|c|c|c|c|c|}
\hline \multirow[b]{2}{*}{ Yeat } & \multicolumn{2}{|c|}{ Alnska North Silapa } & \multicolumn{2}{|c|}{ caltionita } & \multicolumn{2}{|c|}{ Taxas } & \multicolumn{2}{|c|}{ U.t. Avwnge } \\
\hline & Nominhol & Renl 1 & Nominal & Real 1 & Mominal & Ragil 1 & Nominal & Rem 1 \\
\hline 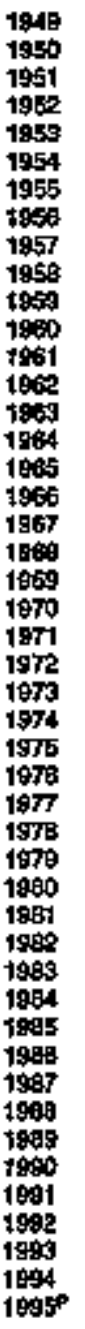 & 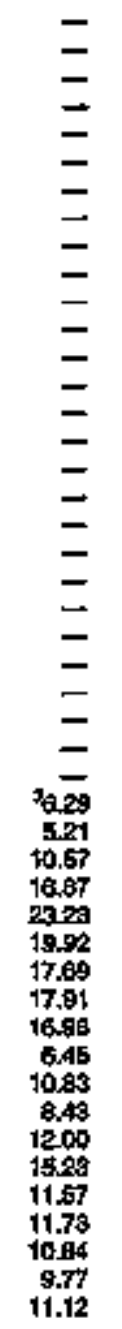 & 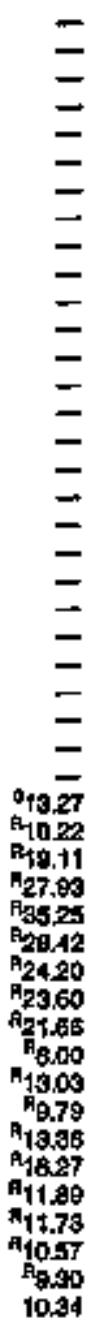 & 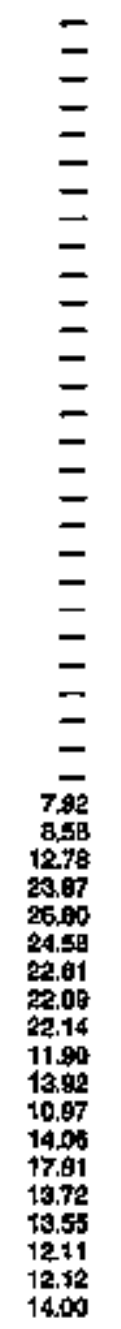 & 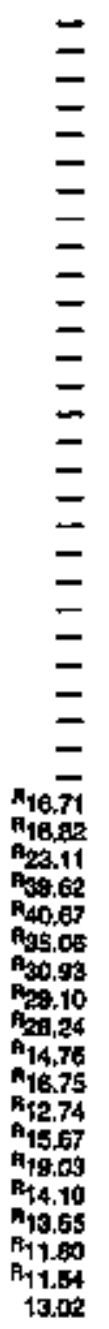 & $\begin{array}{r}= \\
= \\
= \\
= \\
= \\
= \\
= \\
= \\
= \\
= \\
= \\
= \\
= \\
= \\
= \\
= \\
= \\
= \\
0.58 \\
9.25 \\
12.89 \\
21.64 \\
35,06 \\
31.77 \\
29.35 \\
23.87 \\
25.90 \\
14.79 \\
17.55 \\
14.71 \\
17.01 \\
22.57 \\
10.04 \\
58.38 \\
16.19 \\
14.89 \\
16.39\end{array}$ & 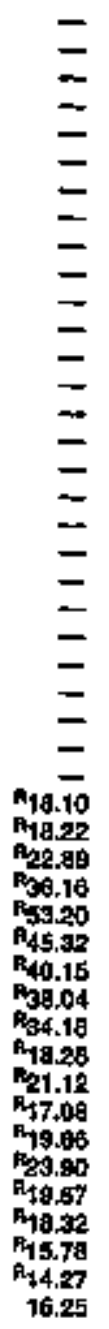 & 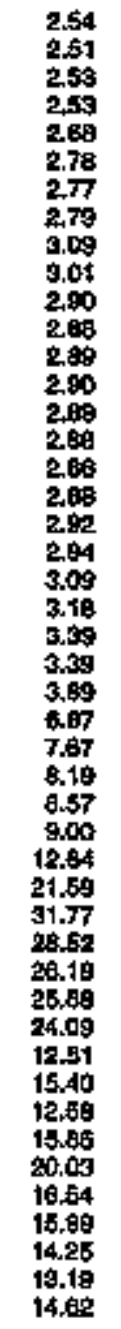 & 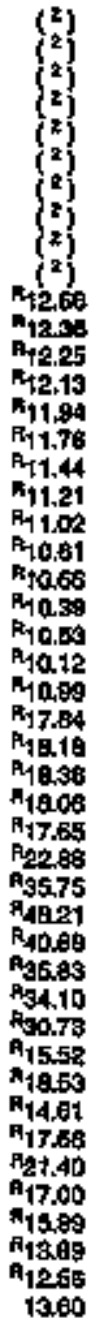 \\
\hline
\end{tabular}

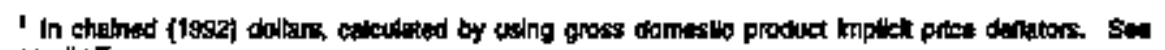
Appendx

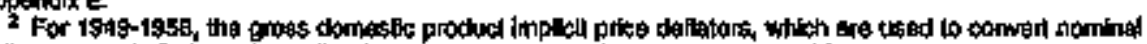

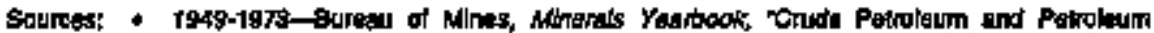

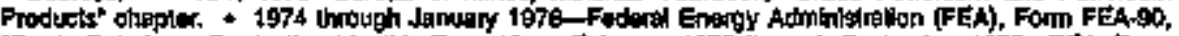

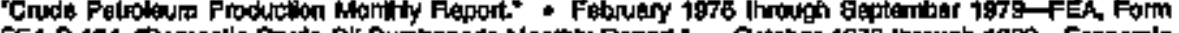

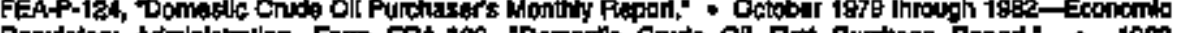

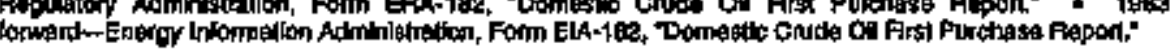

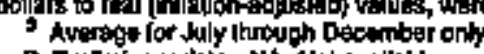

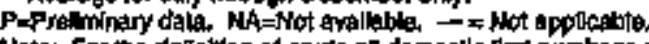

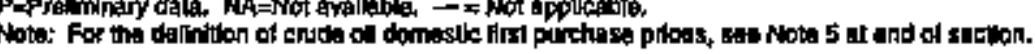


Total, 1973r-1995

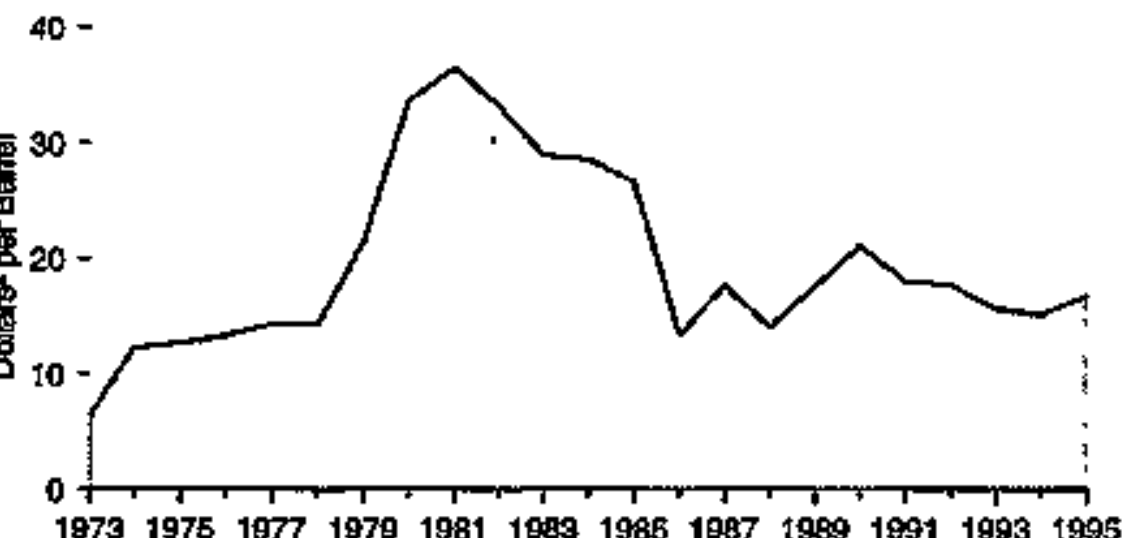

By Selected OPEC Coundry, 1973'-t995

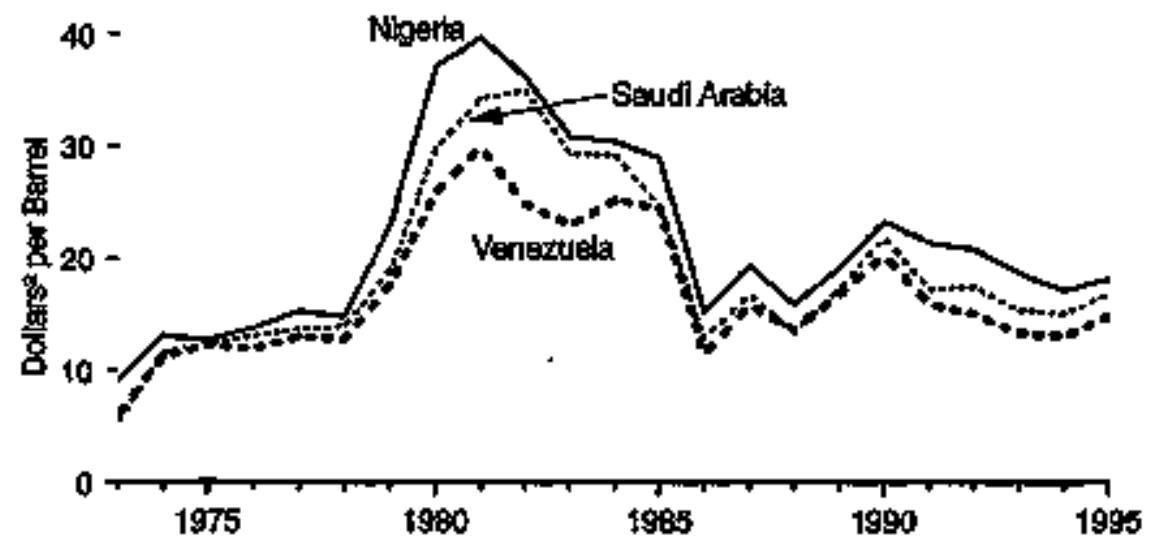

Ey Selected Country, 1995

$25-$

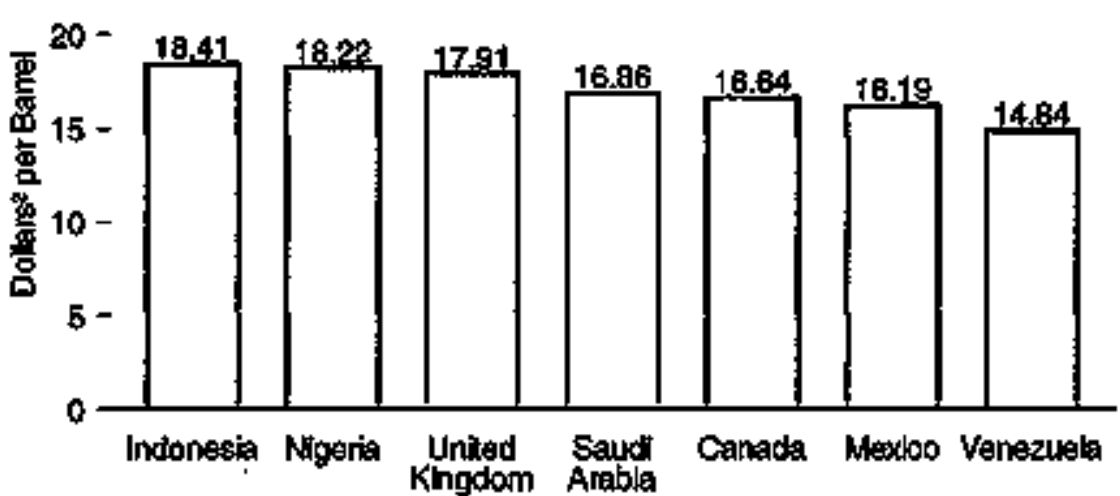

By Selected Non-OPEC Country, 1973'-1995

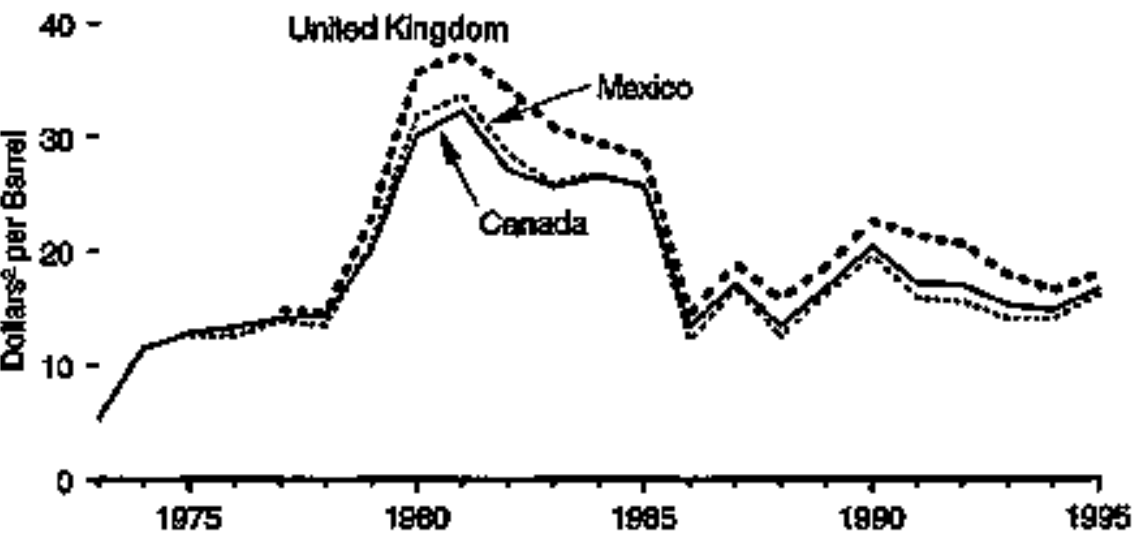

Note: Because verical aceles ditter, grapts should nad be compared. Source: Table 5.17. 
Table 5.17 Landed Costs of Crude Oil Imports From Selected Countries, 1973-1995

(Dollars' per Bartel)

\begin{tabular}{|c|c|c|c|c|c|c|c|c|c|c|c|c|c|}
\hline \multirow[b]{2}{*}{ Year } & \multicolumn{8}{|c|}{ OPEC ${ }^{2}$} & \multicolumn{4}{|c|}{ Non-DPEC } & \multirow[b]{2}{*}{ Tothal } \\
\hline & Algerila & Indonesin & Nhgerta & $\begin{array}{l}\text { Sotudi } \\
\text { Aroble }\end{array}$ & Vonelarielo & Other ${ }^{2}$ & Total A & $\begin{array}{c}\text { Arab } \\
\text { OPEC: }\end{array}$ & Canudg & Hoxileo & $\begin{array}{c}\text { Uilted } \\
\text { Khightom }\end{array}$ & Other & \\
\hline 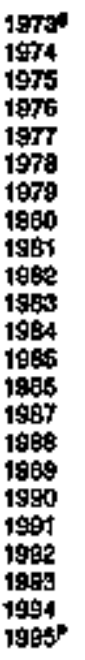 & $\begin{array}{r}1.99 \\
13.97 \\
12.80 \\
13.90 \\
19.24 \\
14.93 \\
21.88 \\
37.92 \\
40.46 \\
36.35 \\
31.26 \\
29.06 \\
27.51 \\
14.82 \\
17.97 \\
W \\
19.13 \\
W \\
W \\
W \\
17.34 \\
W \\
W\end{array}$ & 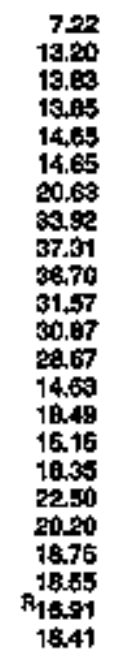 & 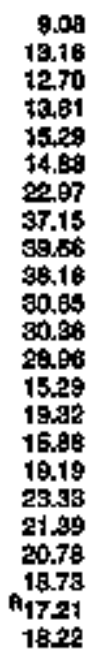 & 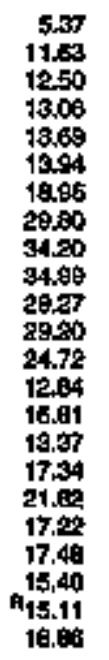 & 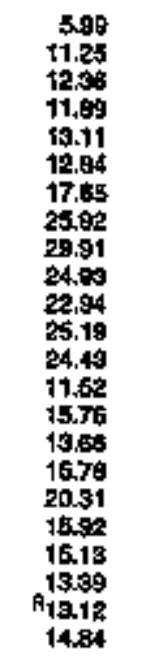 & 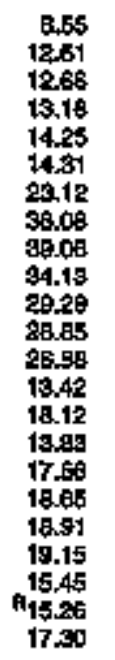 & 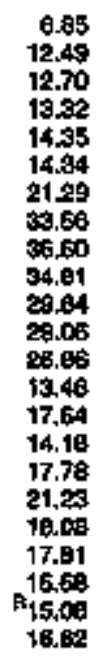 & 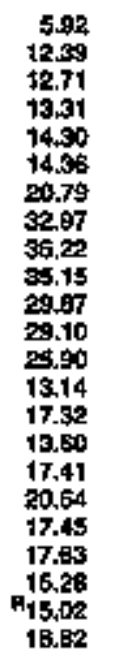 & 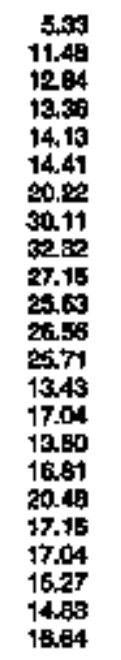 & 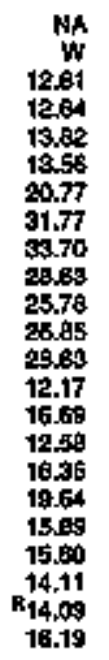 & 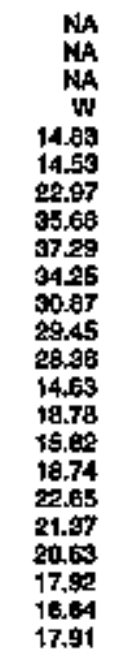 & 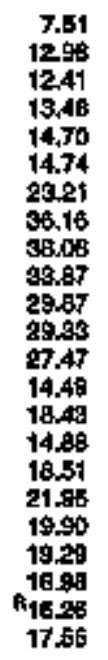 & 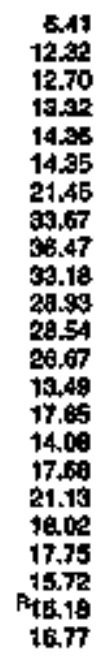 \\
\hline
\end{tabular}

2 Nanhal dollars.

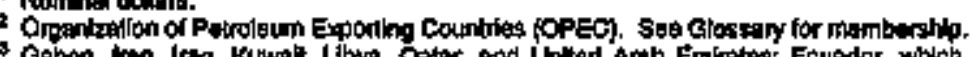

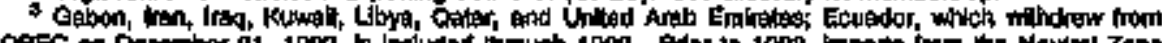

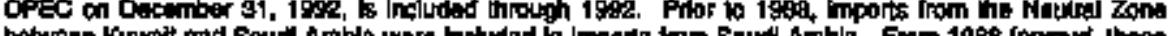

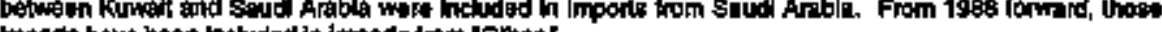

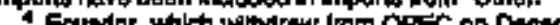

Oetember 31, 1992, is incturitod thpung 1992. Total OPEC

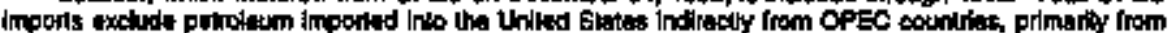

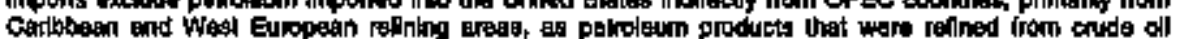
Propuced in OPEC counutrets.

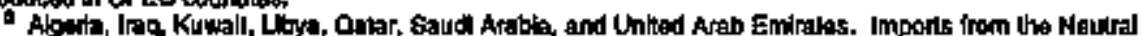

- Easas on Oclober, Novesmber, and Oecember date orly.

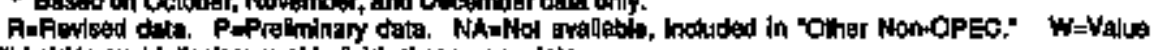

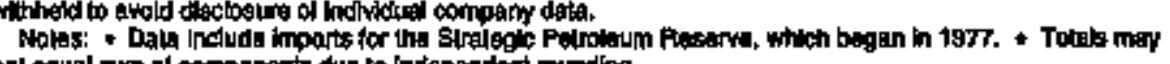

not equal sum of components dut to independent rounding.

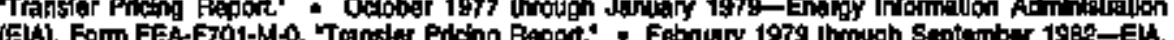

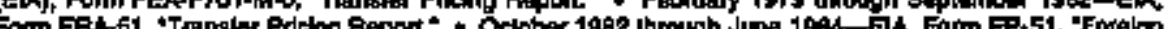

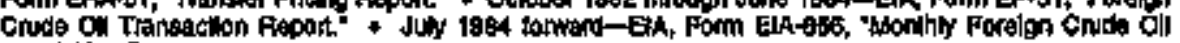
Aequitsition Aepart: 


\section{Figure 5.18 Value of Crude Oll Imports From Selected Countries}

\section{Total, 1975-1995}

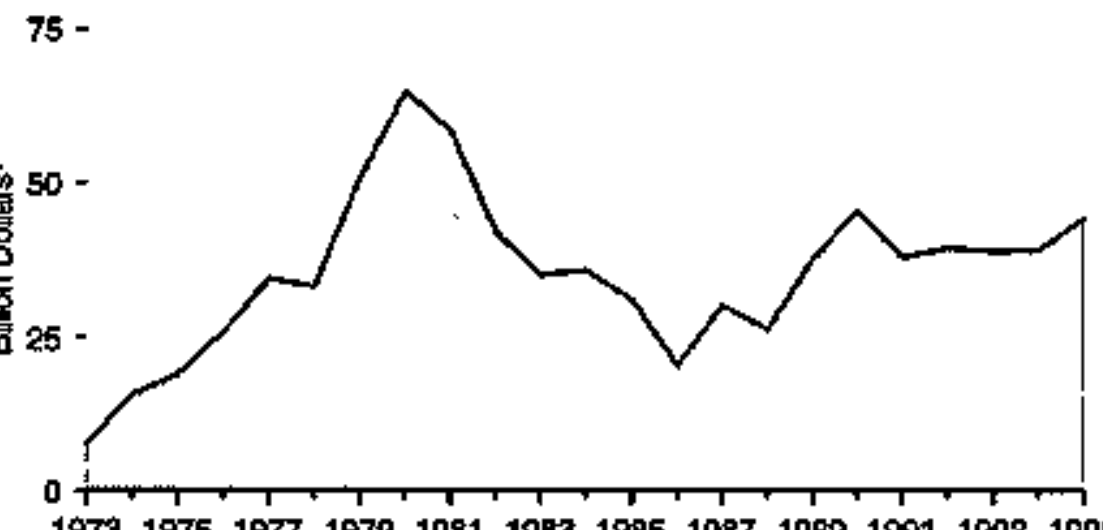

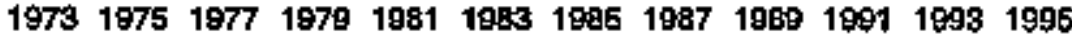

By Selected OPEC Country, 1973-1995

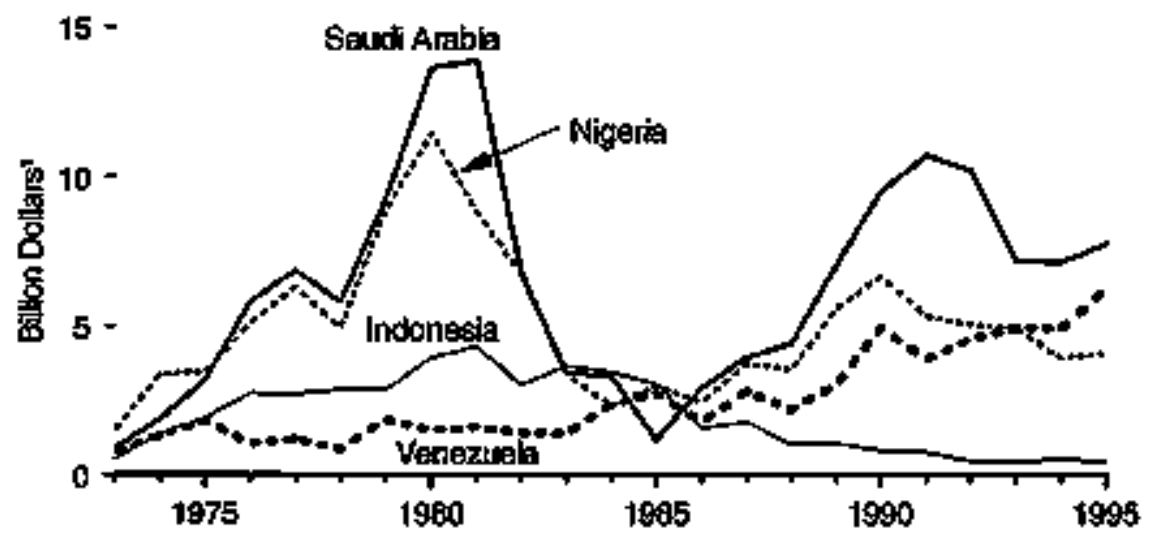

By Selected Country, 1995

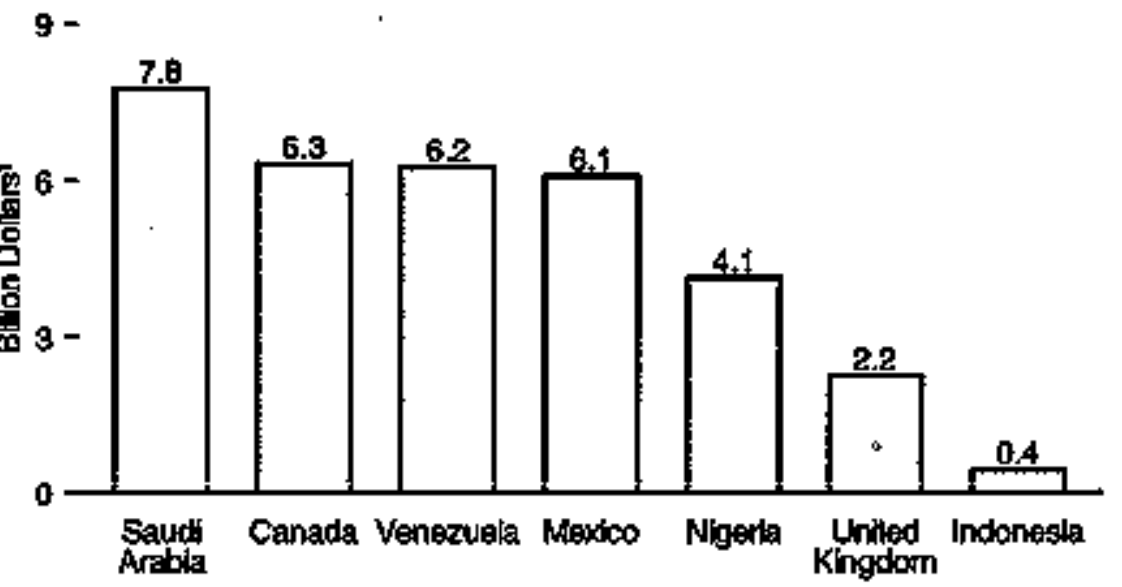

By Soleeted Non-OFEC Country, 1973-1998

9-

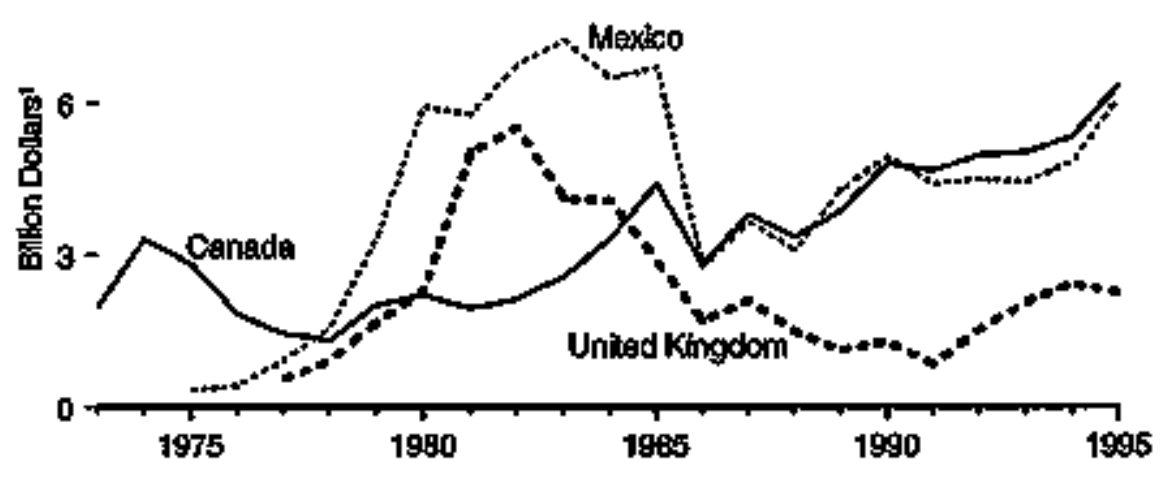

Sourcer Table 5.16

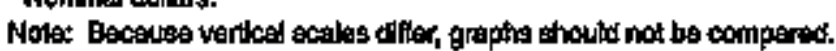


Table 5.18 Value of Crude Oil Imports From Selected Countries, 1973-1995 (Billion Dolfars')

\begin{tabular}{|c|c|c|c|c|c|c|c|c|c|c|c|c|c|}
\hline \multirow[b]{2}{*}{ Yaur } & \multicolumn{8}{|c|}{ OPEC 2} & \multicolumn{4}{|c|}{ Nor-OPEC } & \multirow[b]{2}{*}{ Totent } \\
\hline & Algeria & indonestia & Mgeria & $\begin{array}{l}\text { Sauci } \\
\text { Anbl }\end{array}$ & Venezuala & Other ${ }^{3}$ & Total 4 & APEC: & Canuds & Mexico & $\underset{\text { Kinglod }}{\text { Unilom }}$ & Other & \\
\hline 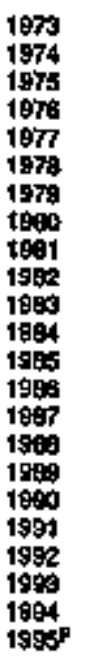 & $\begin{array}{l}0.4 \\
0.9 \\
1.2 \\
2.1 \\
3.0 \\
3.5 \\
4.9 \\
6.3 \\
3.9 \\
1.2 \\
2.0 \\
2.1 \\
0.9 \\
0.4 \\
0.7 \\
w \\
0.4 \\
w \\
w \\
w \\
0.2 \\
w \\
w\end{array}$ & $\begin{array}{l}0.5 \\
1.4 \\
1.9 \\
2.7 \\
2.7 \\
2.9 \\
2.9 \\
3.9 \\
4.3 \\
3.0 \\
3.8 \\
3.4 \\
3.1 \\
1.8 \\
1.8 \\
1.0 \\
1.1 \\
0.0 \\
0.9 \\
0.5 \\
0.4 \\
0.8 \\
0.4\end{array}$ & $\begin{array}{r}1.5 \\
3.3 \\
3.5 \\
6.1 \\
6.3 \\
4.9 \\
9.0 \\
11.4 \\
8.9 \\
6.7 \\
3.4 \\
2.3 \\
3.0 \\
2.4 \\
3.7 \\
3.5 \\
55.5 \\
6.7 \\
5.3 \\
5.1 \\
4.9 \\
3.9 \\
4.1\end{array}$ & $\begin{array}{r}0.9 \\
1.9 \\
8.8 \\
5.8 \\
6.9 \\
5.8 \\
5.3 \\
13.8 \\
18.9 \\
6.8 \\
3.4 \\
3.3 \\
1.2 \\
2.9 \\
3.9 \\
4.4 \\
7.1 \\
9.5 \\
10.7 \\
10.2 \\
7.2 \\
7.2 \\
7.8\end{array}$ & $\begin{array}{l}0.8 \\
1.9 \\
1.6 \\
1.0 \\
1.2 \\
0.6 \\
1.9 \\
1.5 \\
1.6 \\
1.4 \\
1.4 \\
2.3 \\
2.7 \\
1.8 \\
2.8 \\
2.2 \\
3.0 \\
4.9 \\
3.0 \\
4.6 \\
4.9 \\
1.9 \\
6.0\end{array}$ & $\begin{array}{r}1.2 \\
2.9 \\
3.4 \\
5.4 \\
9.6 \\
6.3 \\
12.0 \\
11.2 \\
6.7 \\
2.9 \\
2.1 \\
2.6 \\
2.1 \\
1.3 \\
2.4 \\
2.5 \\
4.8 \\
4.8 \\
1.2 \\
1.5 \\
2.9 \\
2.9 \\
0.9 \\
2.8\end{array}$ & $\begin{array}{r}5.8 \\
11.6 \\
14.9 \\
20.9 \\
29.6 \\
27.1 \\
39.7 \\
47.5 \\
39.0 \\
22.0 \\
18.1 \\
16.1 \\
12.9 \\
10.4 \\
15.5 \\
140 \\
21.9 \\
27.2 \\
22.3 \\
27.2 \\
20.7 \\
910.7 \\
21.7\end{array}$ & $\begin{array}{r}1.8 \\
3.2 \\
5.2 \\
15.8 \\
16.4 \\
15.4 \\
22.8 \\
30.2 \\
23.4 \\
9.4 \\
5.8 \\
6.7 \\
2.8 \\
4.1 \\
6.1 \\
7.0 \\
11.4 \\
14.0 \\
11.2 \\
10.7 \\
9.3 \\
A 0.0 \\
0.2\end{array}$ & $\begin{array}{c}1.9 \\
3.3 \\
28 \\
1.8 \\
1.4 \\
1.3 \\
40 \\
2.2 \\
4.9 \\
2.1 \\
2.8 \\
3.3 \\
4.4 \\
2.8 \\
3.8 \\
3.4 \\
2.8 \\
4.8 \\
4.7 \\
5.0 \\
5.0 \\
95.3 \\
0.3\end{array}$ & $\begin{array}{l}\mu k \\
w \\
0.3 \\
0.4 \\
0.9 \\
1.6 \\
3.3 \\
6.9 \\
5.6 \\
6.7 \\
7.2 \\
6.5 \\
6.7 \\
2.8 \\
3.7 \\
3.1 \\
4.3 \\
4.9 \\
4.4 \\
4.5 \\
4.4 \\
4.0 \\
5.1\end{array}$ & $\begin{array}{l}N A \\
N A \\
N A \\
W \\
0.6 \\
0.9 \\
1.7 \\
2.3 \\
5.0 \\
5.5 \\
4.1 \\
1.1 \\
2.9 \\
1.7 \\
2.1 \\
1.5 \\
1.1 \\
1.3 \\
0.6 \\
1.5 \\
2.0 \\
2.4 \\
2.2\end{array}$ & $\begin{array}{l}0.4 \\
0.7 \\
1.0 \\
1.3 \\
2.2 \\
2.4 \\
4.2 \\
6.9 \\
6.5 \\
5.8 \\
4.9 \\
6.9 \\
4.3 \\
2.9 \\
5.1 \\
4.4 \\
6.5 \\
7.2 \\
5.6 \\
6.3 \\
6.0 \\
6.9 \\
6.1\end{array}$ & 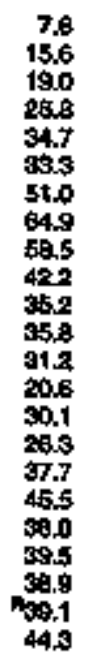 \\
\hline
\end{tabular}

Nominal dollare.

2 Opgentalion of Patroleum Exponting Countrios. Ste Glassary tor membetshtp.

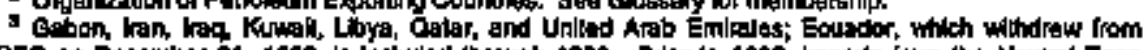

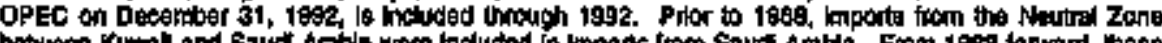

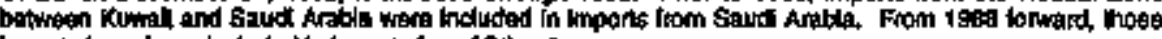

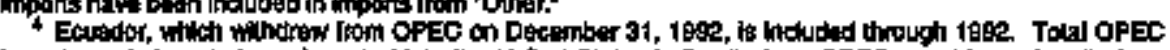

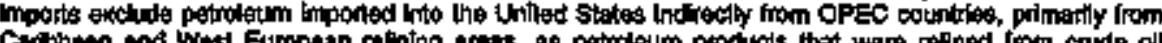

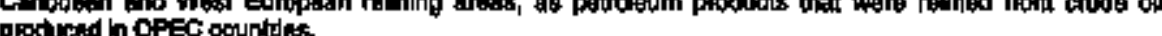

Zore gre Instudad in hiports from "Arab OPEC:

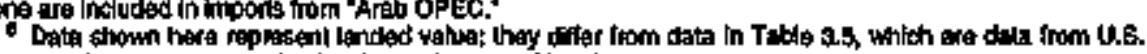

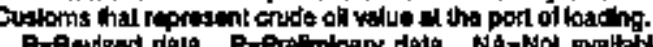

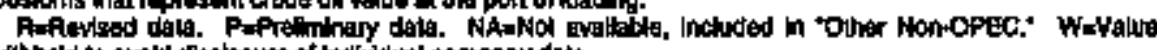

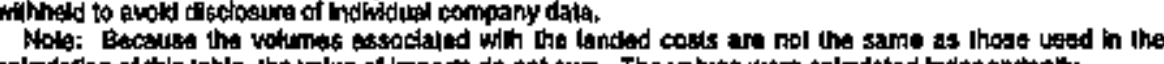

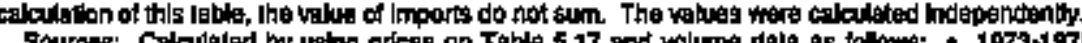

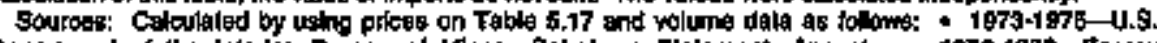

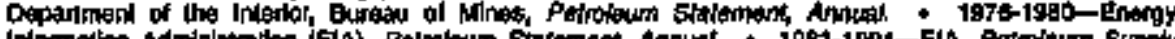

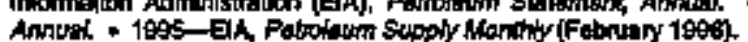




\section{Summany}

$\underbrace{40-0-}$

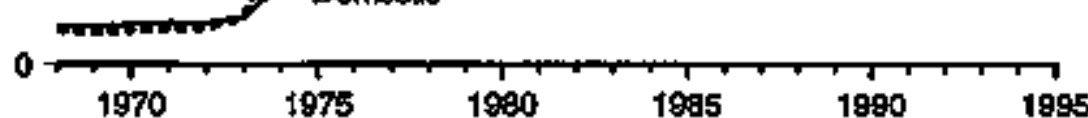

\section{Domealc Costa}

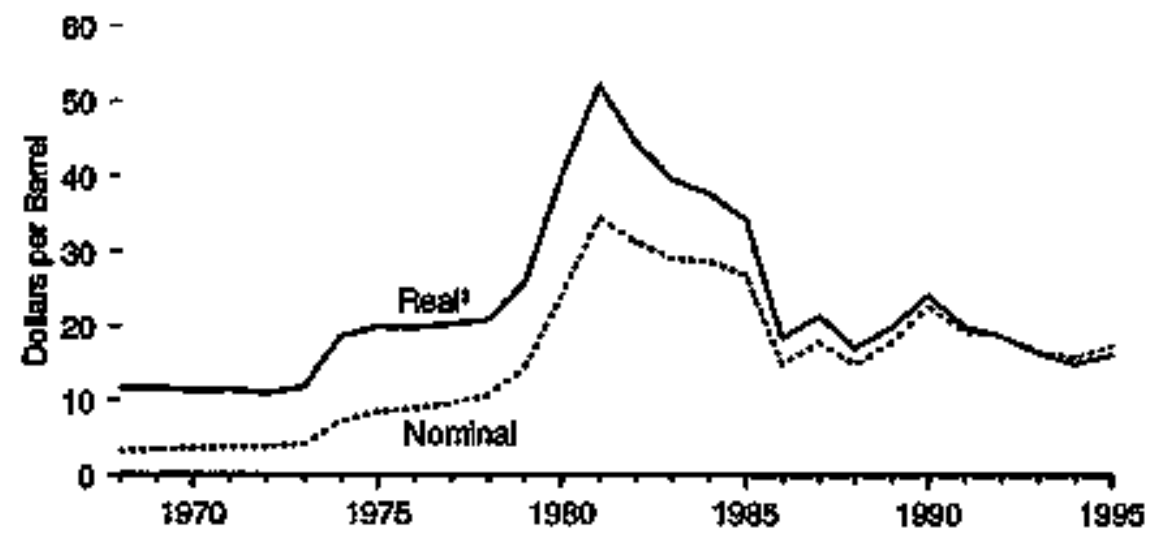

In chalned (1992) dollars, calculated by using goss dornestc product impl|ckt price deitators, Seo Appendik E.

\section{Composits Coats}

60 -

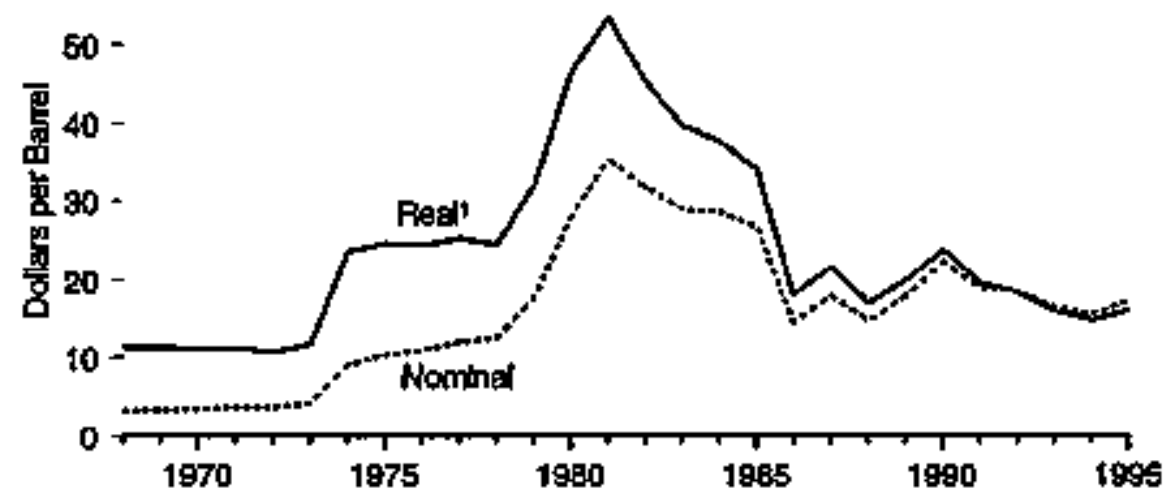

\section{Imported Costs}

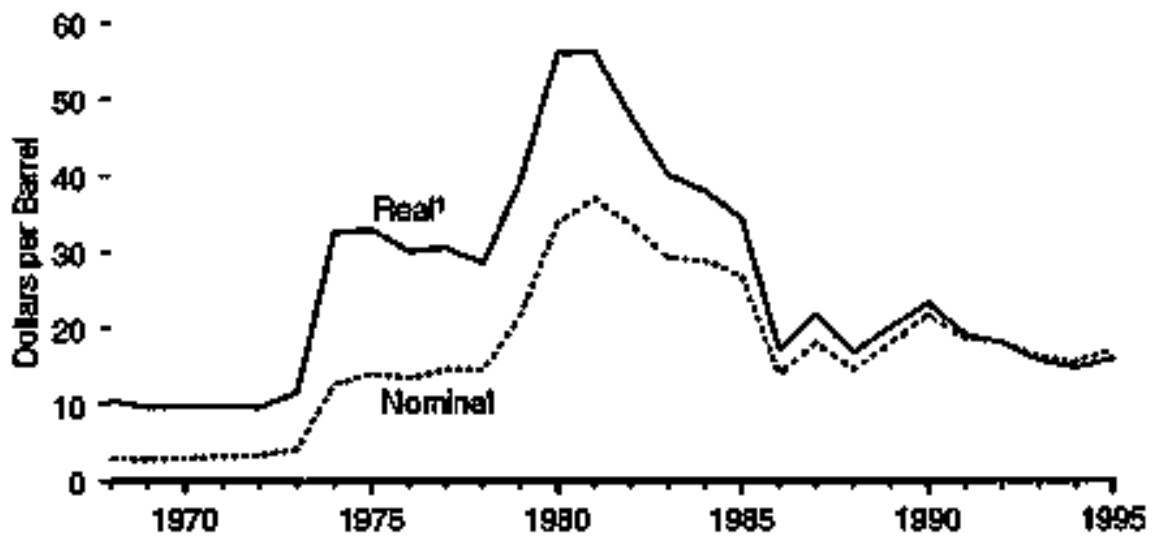

Nove: Because vericat scales alfier, graphe should not be comparad Source: Table S.19. 
Table 5.19 Crude OAl Refiner Acquisition Costs, 1968-1995

(Dollars per Barrel)

\begin{tabular}{|c|c|c|c|c|c|c|}
\hline \multirow[b]{2}{*}{ Yots } & \multicolumn{2}{|c|}{ Dorresilo } & \multicolumn{2}{|c|}{ importad } & \multicolumn{2}{|c|}{ Compest to } \\
\hline & Alominet & Aned 1 & Homininal & Rotal 1 & Mominal & Find \\
\hline 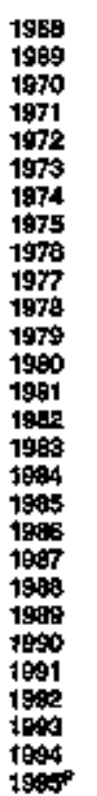 & 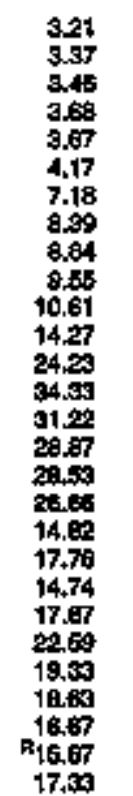 & 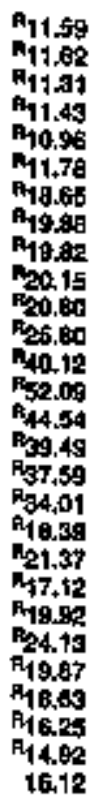 & 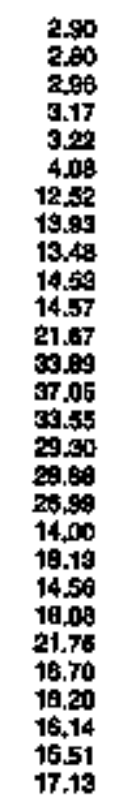 & 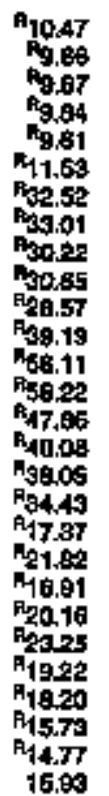 & 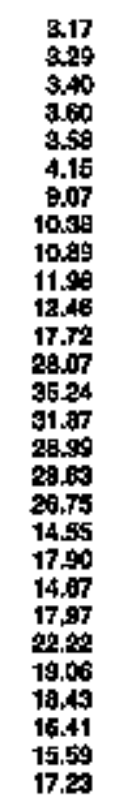 & 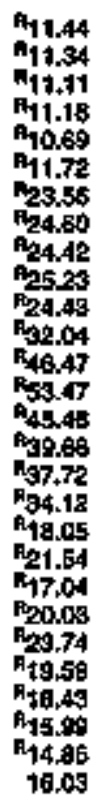 \\
\hline
\end{tabular}

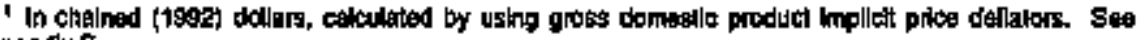
Appendix $\mathrm{E}_{\text {, }}$

Refiutsed dala. Prefeltminary dats.

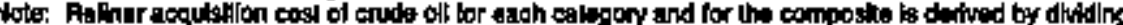

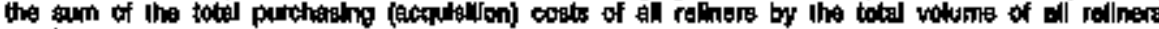
pupdrasest.

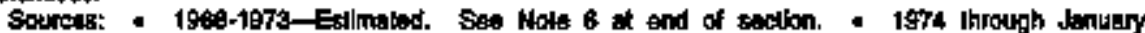

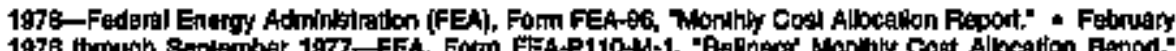

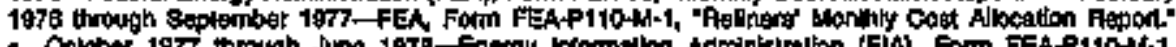

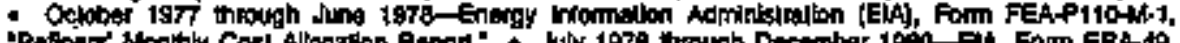

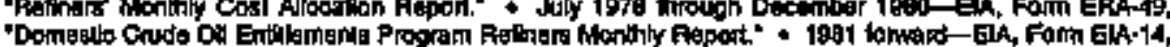

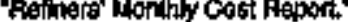




\section{To Resellers}

$125-$
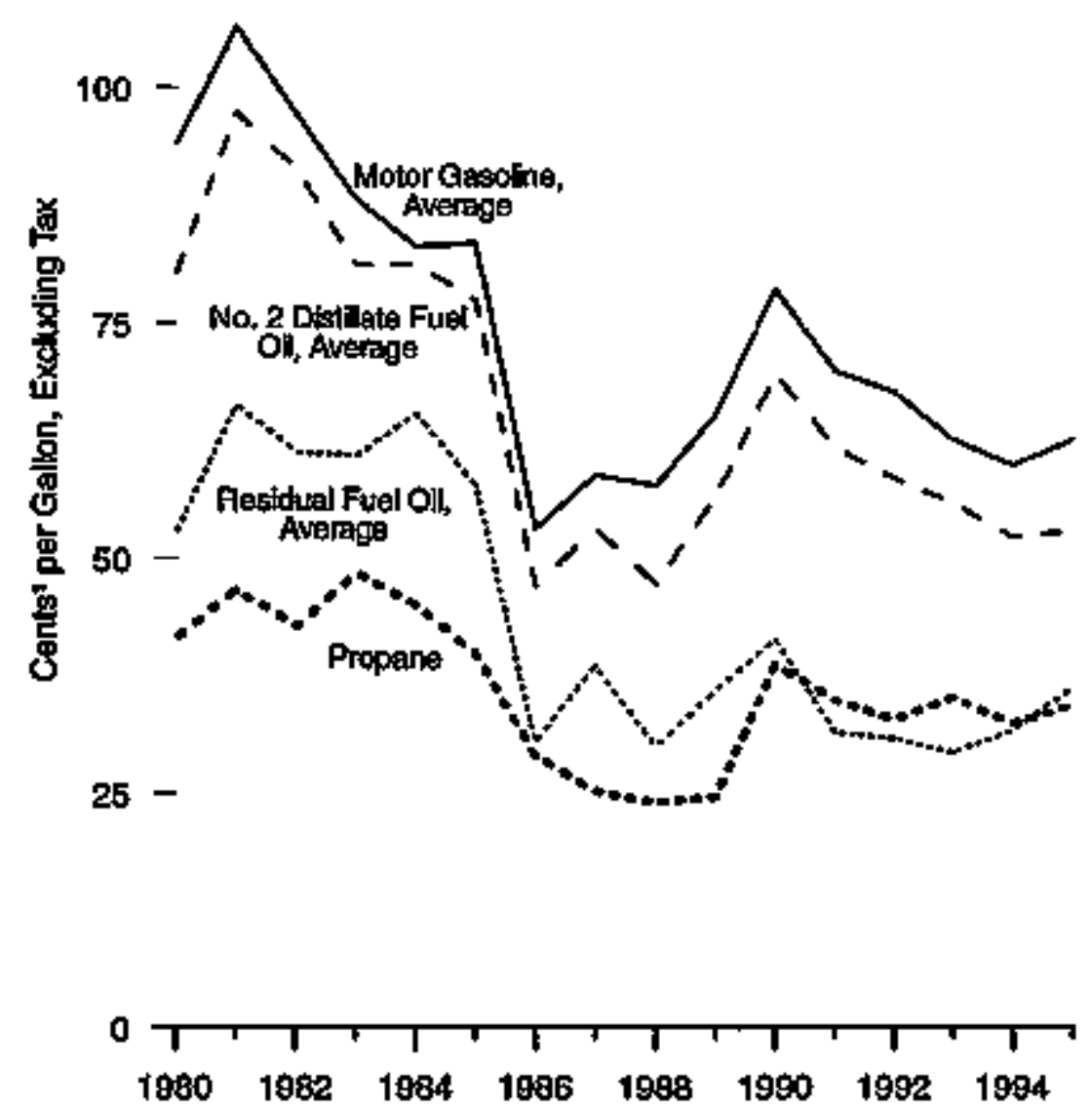

\section{To End Users}

$125-$
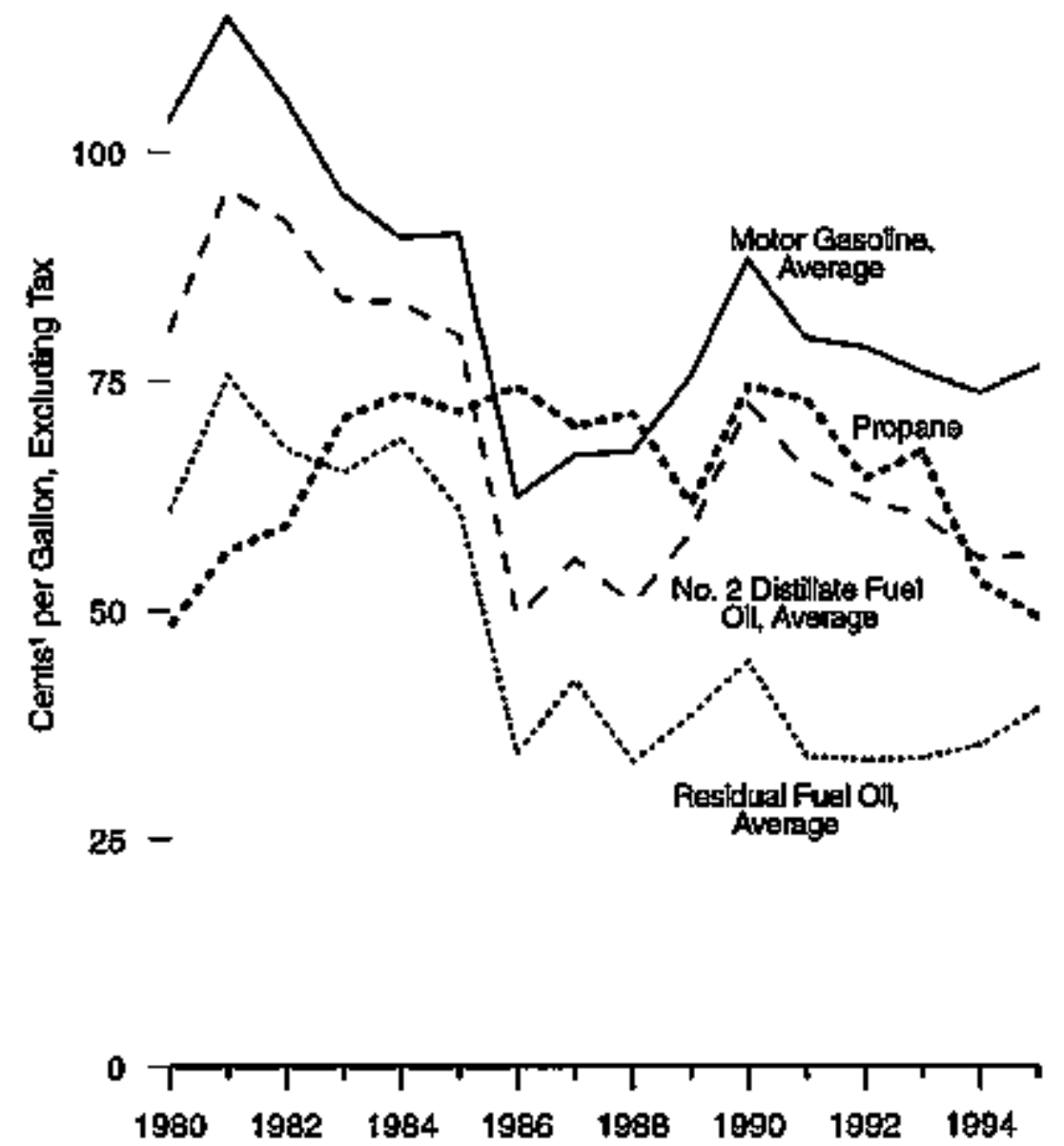
Table 5.20 Refiner Sales Prices and Refiner Margins of Selected Petroleum Products, 1980-1995 (Cents' per Gallon, Excluding Taxes)

\begin{tabular}{|c|c|c|c|c|c|c|c|c|c|c|c|c|c|c|c|c|}
\hline Product & 1990 & 1961 & 1962 & 1060 & 1964 & 1985 & 19:15 & 1967 & 1090 & 1989 & 1960 & 1901 & 1982 & 1983 & 1994 & $5905 \mathrm{P}$ \\
\hline 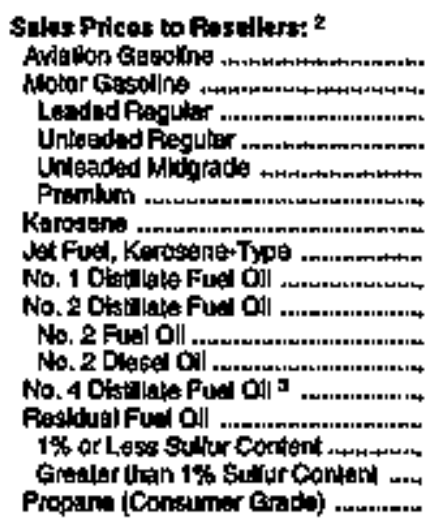 & $\begin{array}{l}112.8 \\
94.4 \\
\text { NA } \\
\text { NA } \\
\text { NA } \\
\text { NA } \\
08.4 \\
98.8 \\
68.0 \\
80.8 \\
80.3 \\
80.1 \\
67.0 \\
58.8 \\
60.8 \\
47.9 \\
41.5\end{array}$ & $\begin{array}{r}125.0 \\
105.4 \\
N A \\
N A \\
N A \\
\text { MA } \\
109.8 \\
101.2 \\
107.1 \\
97.4 \\
97.8 \\
97.2 \\
70.3 \\
69.3 \\
74.6 \\
62.2 \\
16.8\end{array}$ & $\begin{array}{r}102.8 \\
97.3 \\
N A \\
N A \\
N A 4 \\
N A \\
101.9 \\
96.3 \\
109.8 \\
91.4 \\
91.4 \\
91.4 \\
79.7 \\
69.2 \\
69.6 \\
57.2 \\
127\end{array}$ & 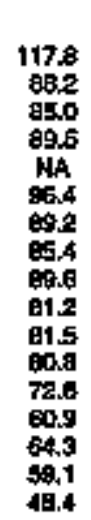 & $\begin{array}{l}116.5 \\
83.2 \\
79.5 \\
84.2 \\
104 \\
91.5 \\
01.6 \\
60.0 \\
60.2 \\
61.3 \\
80.1 \\
60.3 \\
70.7 \\
6.4 \\
69.6 \\
\$ 9.9 \\
45.0\end{array}$ & $\begin{array}{r}713.0 \\
8.5 \\
78.3 \\
64.3 \\
14 . \\
92.2 \\
97.4 \\
79.4 \\
90.3 \\
7 \pi .4 \\
77.6 \\
77.2 \\
67.2 \\
57.7 \\
81.0 \\
58.0 \\
39.8\end{array}$ & $\begin{array}{l}91.2 \\
59.1 \\
50.1 \\
59.2 \\
14 . \\
51.0 \\
80.6 \\
49.6 \\
57.9 \\
47.0 \\
49.6 \\
45.2 \\
40.9 \\
30.5 \\
32.8 \\
30.9 \\
29.0\end{array}$ & $\begin{array}{l}66.9 \\
58.9 \\
58.5 \\
58.9 \\
\mathrm{NA} \\
67.1 \\
59.2 \\
59.8 \\
69.9 \\
59.1 \\
59.7 \\
59.4 \\
46.2 \\
39.5 \\
41.2 \\
30.2 \\
2.2\end{array}$ & $\begin{array}{l}85.0 \\
57.7 \\
54.8 \\
64.8 \\
14 . \\
67.2 \\
54.5 \\
49.5 \\
54.8 \\
47.3 \\
47.3 \\
47.3 \\
42.5 \\
30.0 \\
30.5 \\
27.1 \\
24.0\end{array}$ & $\begin{array}{l}85.0 \\
65.4 \\
64.1 \\
61.8 \\
68.0 \\
74.9 \\
68.5 \\
58.3 \\
65.8 \\
5.0 \\
58.5 \\
58.7 \\
48.0 \\
340 \\
40.7 \\
39.1 \\
24.7\end{array}$ & $\begin{array}{r}106.3 \\
79.6 \\
75.4 \\
76.8 \\
87.4 \\
87.4 \\
63.9 \\
77.3 \\
83.8 \\
69.5 \\
69.7 \\
68.4 \\
59.0 \\
44.3 \\
47.2 \\
\$ 7.2 \\
39.8\end{array}$ & $\begin{array}{l}100.1 \\
69.9 \\
65.7 \\
67.8 \\
73.3 \\
79.8 \\
74.8 \\
65.0 \\
73.0 \\
61.8 \\
62.9 \\
61.5 \\
556 \\
31.4 \\
39.4 \\
29.2 \\
34.9\end{array}$ & $\begin{array}{l}99.1 \\
67.7 \\
68.3 \\
64.5 \\
70.8 \\
77.4 \\
63.2 \\
60.5 \\
65.2 \\
50.5 \\
57.9 \\
59.1 \\
49.5 \\
30.8 \\
35.1 \\
28.5 \\
32.8\end{array}$ & $\begin{array}{l}96.5 \\
62.6 \\
N A \\
59.3 \\
66.0 \\
72.2 \\
60.4 \\
57.7 \\
69.5 \\
55.9 \\
54.4 \\
57.0 \\
48.3 \\
29.3 \\
39.7 \\
25.4 \\
35.1\end{array}$ & 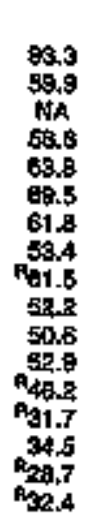 & $\begin{array}{l}97.5 \\
62.6 \\
19 A \\
69.3 \\
67.0 \\
72.2 \\
58.0 \\
50.9 \\
62.5 \\
50.0 \\
51.1 \\
59.9 \\
46.3 \\
56.2 \\
39.4 \\
39.1 \\
34.4\end{array}$ \\
\hline 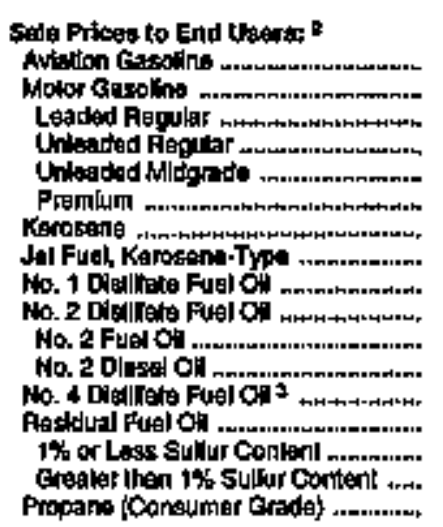 & 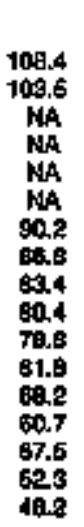 & 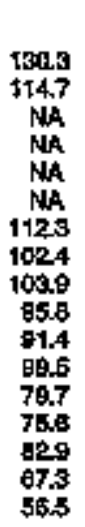 & $\begin{array}{c}181.2 \\
108.0 \\
104 \\
M 4 \\
108.9 \\
98.3 \\
102.3 \\
92.5 \\
90.5 \\
94.2 \\
76.0 \\
67.6 \\
74.7 \\
61.1 \\
59.2\end{array}$ & $\begin{array}{r}128.5 \\
66.4 \\
90.0 \\
97.0 \\
N A \\
105.7 \\
65.1 \\
87.8 \\
96.2 \\
83.9 \\
84.5 \\
82.8 \\
76.5 \\
65.1 \\
69.5 \\
64.1 \\
70.9\end{array}$ & $\begin{array}{r}123.4 \\
0.7 \\
64.8 \\
91.5 \\
104 \\
101.5 \\
103.6 \\
84.2 \\
92.7 \\
63.7 \\
98.8 \\
82.3 \\
79.6 \\
68.7 \\
72.0 \\
65.0 \\
73.7\end{array}$ & $\begin{array}{c}120.1 \\
91.2 \\
84.2 \\
91.7 \\
N A \\
102.3 \\
108.0 \\
78.8 \\
88.0 \\
70.9 \\
84.8 \\
78.9 \\
77.3 \\
61.0 \\
64.4 \\
58.2 \\
71.7\end{array}$ & 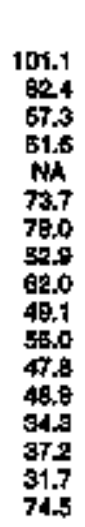 & $\begin{array}{l}50.7 \\
58.9 \\
61.6 \\
65.0 \\
N A \\
78.4 \\
77.0 \\
54.9 \\
60.4 \\
56.4 \\
56.1 \\
55.1 \\
55.3 \\
42.3 \\
44.7 \\
39.6 \\
70.1\end{array}$ & $\begin{array}{l}68.1 \\
67.3 \\
61.9 \\
64.1 \\
N .4 \\
70.6 \\
73.8 \\
51.3 \\
58.4 \\
60.7 \\
54.4 \\
50.0 \\
46.1 \\
33.4 \\
37.2 \\
30.0 \\
71.4\end{array}$ & $\begin{array}{l}99.5 \\
76.6 \\
71.0 \\
71,4 \\
79.2 \\
60.7 \\
70.9 \\
50.2 \\
60.1 \\
59.6 \\
59.7 \\
64.5 \\
51.2 \\
39.6 \\
43.6 \\
34.4 \\
61.6\end{array}$ & $\begin{array}{r}112.0 \\
28.3 \\
83.1 \\
94.9 \\
98.1 \\
98.6 \\
92.3 \\
76.5 \\
61.9 \\
72.6 \\
79.4 \\
72.5 \\
62.2 \\
14.4 \\
50.5 \\
10.0 \\
74.5\end{array}$ & $\begin{array}{r}104.7 \\
70.7 \\
71.5 \\
78.1 \\
04.3 \\
60.7 \\
69.0 \\
65.2 \\
74.0 \\
65.0 \\
58.5 \\
64.0 \\
59.0 \\
34.0 \\
40.2 \\
30.6 \\
79.0\end{array}$ & $\begin{array}{r}102.7 \\
72.7 \\
78.6 \\
74.0 \\
92.7 \\
91.4 \\
78.8 \\
61.0 \\
68.6 \\
62.0 \\
62.7 \\
61.9 \\
62.6 \\
39.6 \\
38.9 \\
31.2 \\
64.3\end{array}$ & $\begin{array}{l}98.0 \\
75.6 \\
N A \\
71.2 \\
80.5 \\
89.6 \\
75.4 \\
58.0 \\
68.6 \\
602 \\
80.2 \\
60.3 \\
50.1 \\
38.7 \\
39.7 \\
30.3 \\
67.3\end{array}$ & 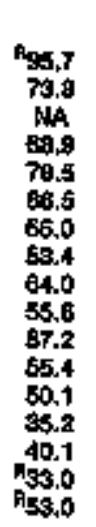 & $\begin{array}{c}100.5 \\
78.5 \\
N A \\
71.7 \\
80.8 \\
89.0 \\
58.9 \\
54.0 \\
62.0 \\
580 \\
58.0 \\
680 \\
50.5 \\
38.1 \\
48.4 \\
37.7 \\
48.2\end{array}$ \\
\hline 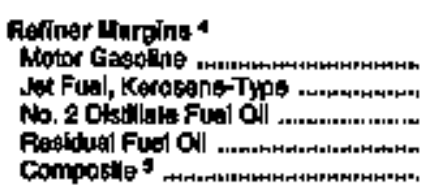 & $\begin{array}{r}27.3 \\
20.0 \\
13.4 \\
-14.0 \\
22.4\end{array}$ & $\begin{array}{r}22.5 \\
17.3 \\
18.5 \\
-17.6 \\
18.4\end{array}$ & $\begin{array}{r}21.4 \\
19.4 \\
15.5 \\
-14.7 \\
19.4\end{array}$ & $\begin{array}{l}19.2 \\
16.4 \\
12.2 \\
8.1 \\
16.0\end{array}$ & $\begin{array}{l}15.1 \\
14,9 \\
13.1 \\
2.8 \\
19.7\end{array}$ & $\begin{array}{r}19.8 \\
15.0 \\
19.8 \\
6.0 \\
17.0\end{array}$ & $\begin{array}{l}19,4 \\
14,9 \\
12,4 \\
-4.1 \\
18,0\end{array}$ & $\begin{array}{l}10.8 \\
11.2 \\
10.4 \\
-4.1 \\
13.8\end{array}$ & $\begin{array}{l}22.8 \\
14.6 \\
12.4 \\
8.0 \\
18.7\end{array}$ & $\begin{array}{r}22.8 \\
15.8 \\
13.8 \\
6.8 \\
10.8\end{array}$ & $\begin{array}{r}26.7 \\
24.4 \\
13.6 \\
-11.6 \\
22.1\end{array}$ & $\begin{array}{r}24.5 \\
19.6 \\
16.4 \\
-14.0 \\
20.7\end{array}$ & $\begin{array}{r}29.8 \\
16.5 \\
14.6 \\
-13.2 \\
19.8\end{array}$ & $\begin{array}{c}23.5 \\
18,6 \\
18.9 \\
-9.8 \\
19,0\end{array}$ & $\begin{array}{r}22.8 \\
16.8 \\
15.1 \\
1.6 .4 \\
\mathrm{~F}_{10.8}\end{array}$ & $\begin{array}{l}21,6 \\
12,9 \\
12.0 \\
4,8 \\
19.1\end{array}$ \\
\hline
\end{tabular}

Nomlnel doulari.

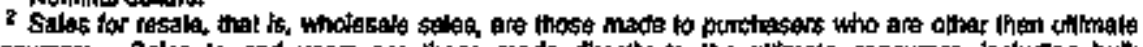

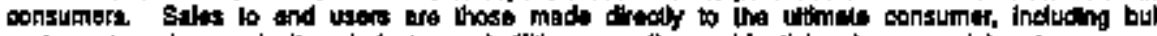

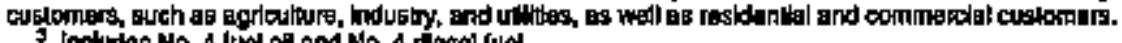

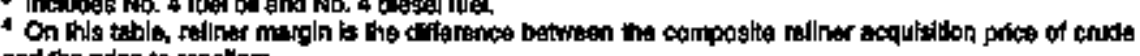

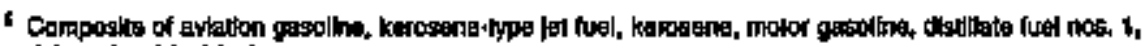
2, End 4, end resoldeal ferel

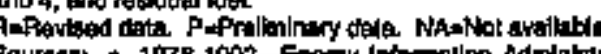

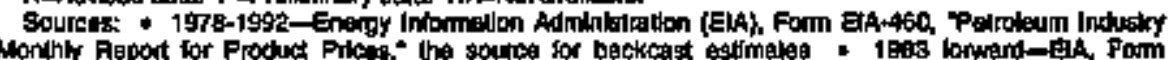

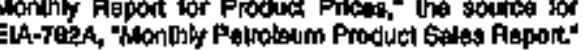
oll and the pries to resellis? 


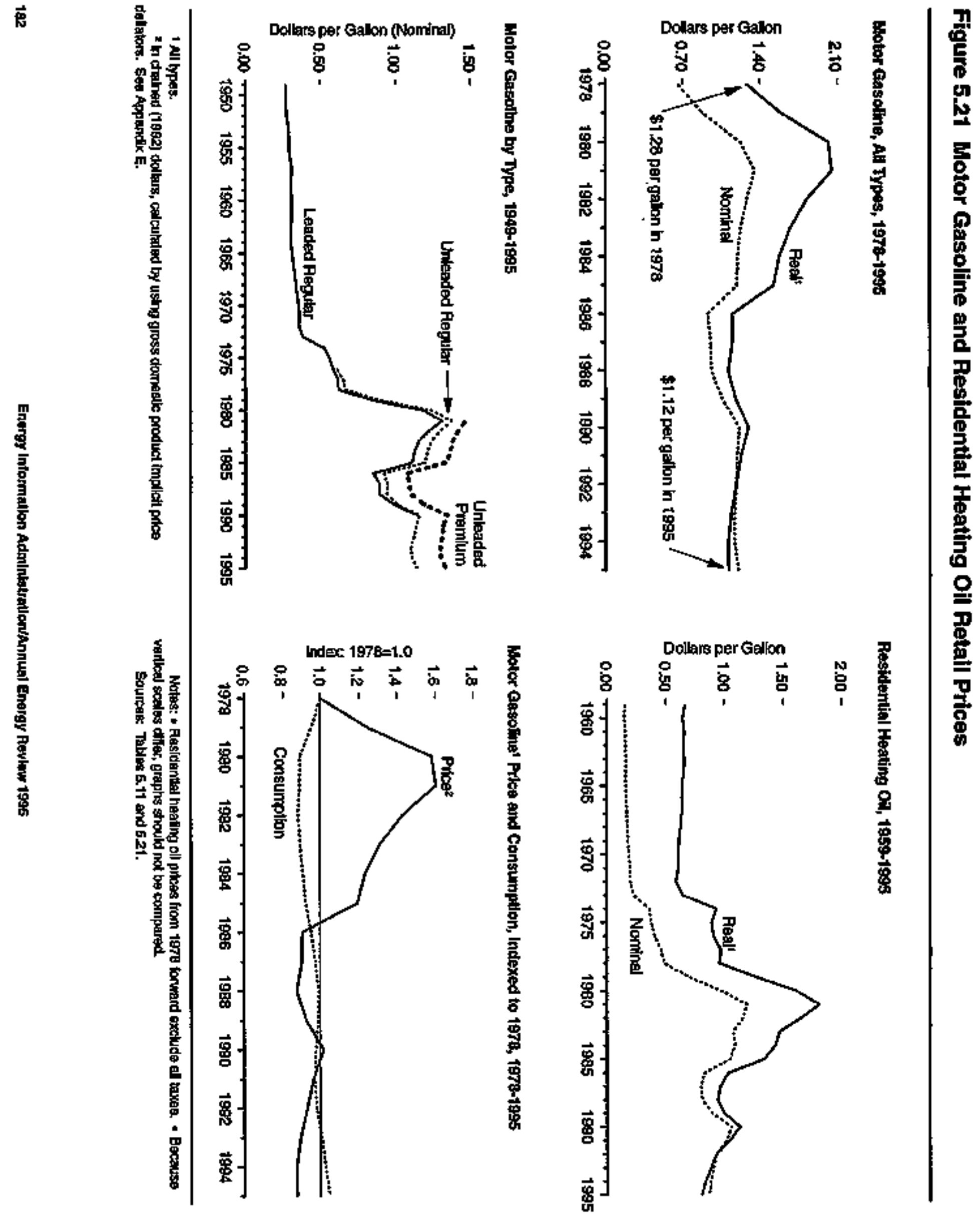


Table 5.21 Motor Gasoline and Residential Heating Oll Retail Prices, 1949-1995

(Cents per Gallon)

\begin{tabular}{|c|c|c|c|c|c|c|c|c|c|c|}
\hline \multirow[b]{3}{*}{ Your } & \multicolumn{8}{|c|}{ 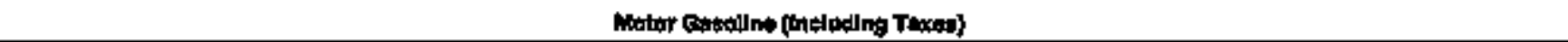 } & \multirow{2}{*}{\multicolumn{2}{|c|}{ Acshtential Hating on : }} \\
\hline & \multicolumn{2}{|c|}{ Legded Pegular ' } & \multicolumn{2}{|c|}{ Vriteroted Rogrolar } & \multicolumn{2}{|c|}{ Unteated Profrilur } & \multicolumn{2}{|c|}{ All Types } & & \\
\hline & Mominat & Resal $^{3}$ & Nominal & Atonl ${ }^{3}$ & Noralnat & Ptoal $\left.\right|^{\mathrm{s}}$ & Nomhed & Ranls & Homind & Rises ${ }^{2}$ \\
\hline 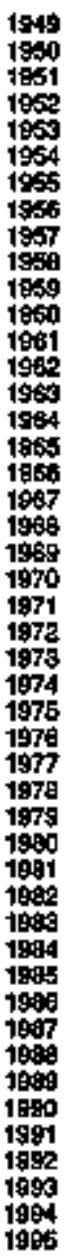 & 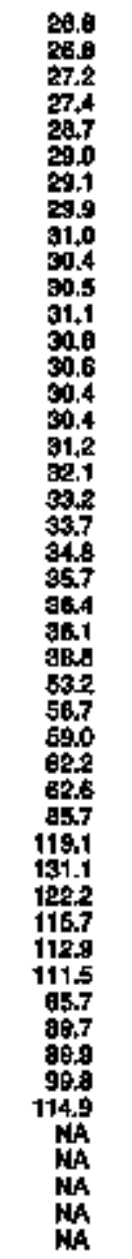 & 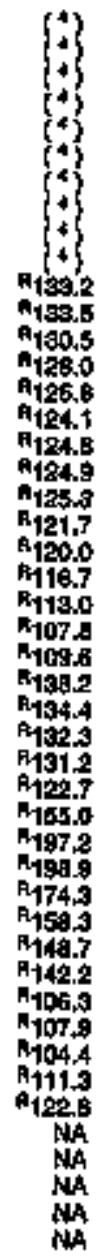 & 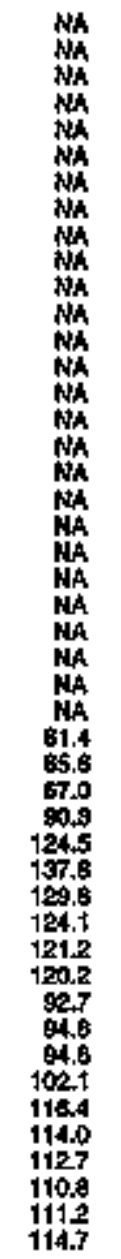 & 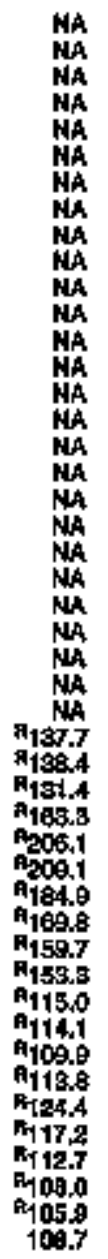 & 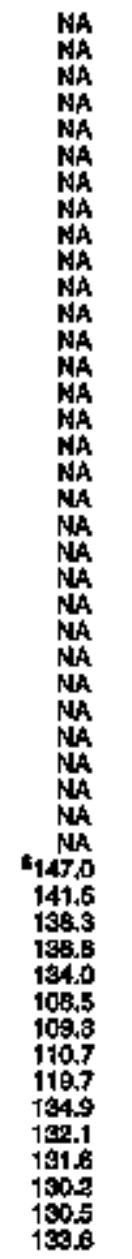 & 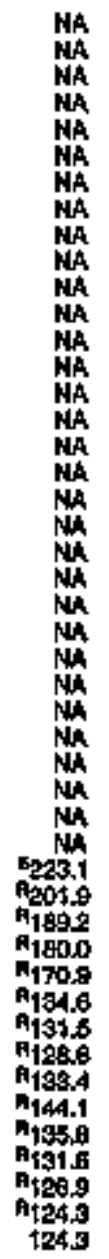 & 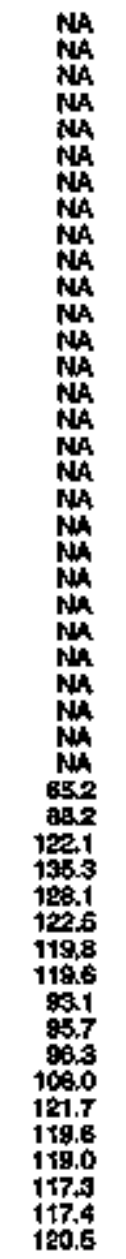 & 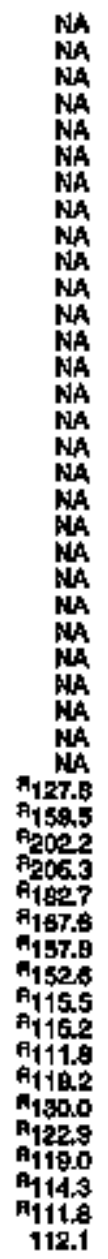 & 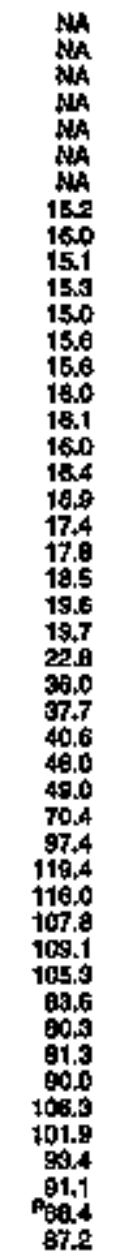 & 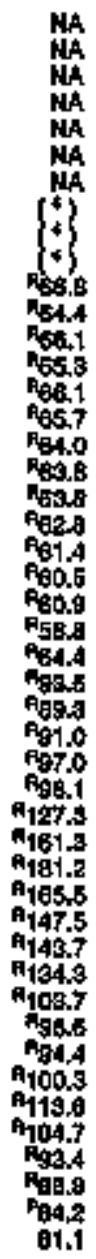 \\
\hline
\end{tabular}

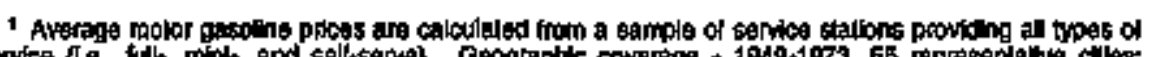

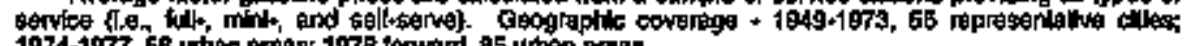

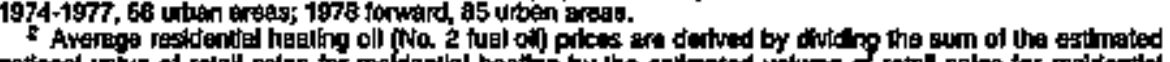

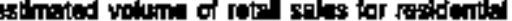

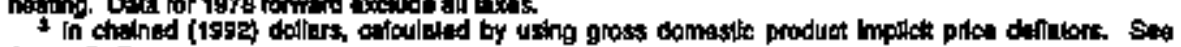
Appentex E.

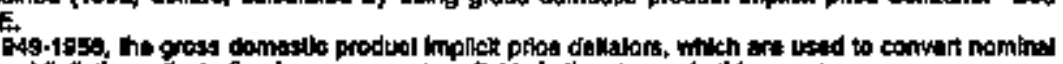

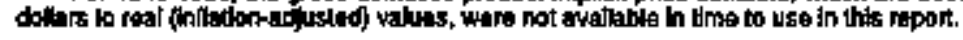

I Based on Sepiember through December data onty.

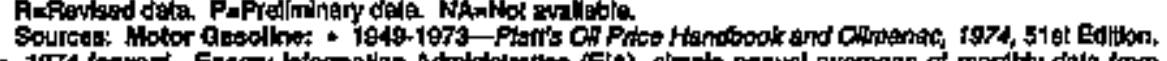

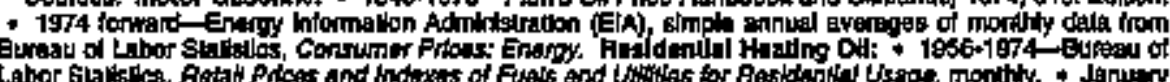

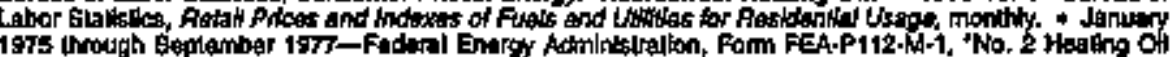

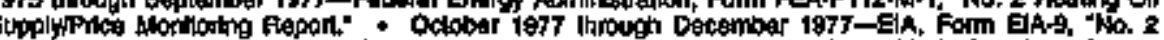

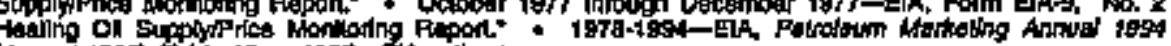

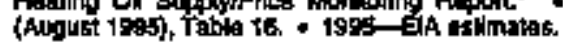




\section{Petroleum Notes}

1. Accurate calculation of the quantity of petroleum products supplied to the domestic market is complicated by the recycling of products at the refinery, the renaming of products involved in a transfer, and the receipt of products from outside the primary supply system. Beginning in 1981, a single adjustment (always a negative quantity) is made to total product supplied to correct this accounting problem. The calculation of this adjustment, called "reclassified," involves only unfinished oils and gasoline blending components. It is the sum of their net changes in primary stocks (net withdrawals is a plus quantity, net additions is a minus quantity) plus imports minus net input to refineries.

2. The methods for deriving Gross Input to Distillation Units (GIDU) in thits report are as follows: 1949-1966, GIDU is estimated by sum. ming annual crude oil runs to stills, net unfinished oil rertns at refineries, and shipments of aatural gasoline and plant condensale from natural gas processing plants to refineries. 1967-1973, GIDU is estimated by summing annual crude oil runs to stills, net unfinished oil reruns, and refinery input of natural gasoline and plant condensate. 1974-1980, GIDU is published annual data. 1981 forward, GIDU is the sum of reported monthly data.

3. Total petroleum products supplied is the sum of the product supplied for each petroleum product, crude oil, unfinished oils, and gasoline blending components. For each of these, except crude oil, product supplied is calculated by adding refinery production, natural gas plant fiquids production, new supply of other liquids, imports, and stock withdrawals, and subtracting stock additions, refinery inputs, and exports. Crude oil product supplied is the sum of crude oil burned on leases and at pipeline pump stations as reported on Form EIA-813, "Monthly Crudo Oil Report." Prior to 1983, crude oil burned on leases and at pipeline pump stations was reported as either distillate or residual fuel oil and was included as product supplied for these products. Petroleum products sapplied is an approximation of petroleum consumption and is synonymous with the term "Petrolenm Consumption" in Section 1. Sector data for petroleum products used in more than one sector are derived from surveys of sales to ultimate consumers by refiners, marketers, distributors, and dealers and from receipts at electric utilities.

4. Beginning in January 1981, several Energy Information Administration survey forms and calculation methodologies were changed to reflect new developments in refinery and blending plant practices and to improve data integrity. Those changes affect production and product supplied statistics for motor gasoline, distillate fuel oil, and residual fuel oil, and stocks of motor gasoline. On the basis of those changes, motor gasoline production during the last half of 1980 would have averaged 289,000 barrels per day higher than that which was published on the old basis. Distillate and residual fuel oil production and product supplied for all of 1980 would have averaged, respectively, 105,000 and 54,000 barrels per day higher than the numbers that were published.

5. The Crude Oil Domestic First Purchase Prices were derived as follows: 1949-1973, weighted average domestic first purchase values as reported by State agencies and calculated by the Bureau of Mines; 1974 and 1975, weighted averages of a sample survey of major first purchasers' purchases; 1976 forwand, weighted averages of all first purchasers" purchases.

6. The Refiner Acquisition Cost of Crude Oil was estimated for 19681973. The cast of domestic crude oil was derived by adding estimated transportation costs to the reported average domestie first purchase value. The cost of imported crude oils was derived by adding an estimated ocean transport cost based on the published "Average Freight Rate Assessment" to the average "Free Alongside Ship" value published by the U.S. Bureau of the Census. The composite cost was derived by weighting domestic costs and imported costs on the basis of quantities produced and imported. 


\section{Natural Gas}

\section{Prices}

Through the early 1970 's, natural gas prices were relatively stable. Therenfter, the natural gas market underwent a period of price fluctuations bronght on by deregulation and industry restructoring. The annual average wollhead price, in real terms,' trended downward from a 1983 peak of $\$ 3.54$ per thonsand cubic feet to a 19-yoar low of $\$ 1.48$ per thousand cubic feet in 1995 (6.8).* Lower costs of producing and transporting natural gas benefited consumers. In 1995, the average price, in real terms, paid by residential consumers was down 32 pereent from the 1983 price (6.9). Corresponding prices paid by the commercial, indastrial, and electric utilities sectors were down 39 percent, 57 percent, and 62 percent, respectively.

\section{Sectoral Patterns of Demand}

Throughout the 1950's and 1960's, the market for natural gas expanded as low prices encouraged demand. Of the many factors affecting hatrral gas markets during those decades, FederaI and State regulatory commissions wert the most inflnential. Below-market rates for certain eategories of natural gas, coupled with strong demand, ultimately resulted in regional shortages daring the second half of the $1970^{\circ}$ s.

In 1972, total consumption of natural gas reached an all-time high of 22 trillion cubic feet $(6.6)$. Thereafter, uncertainties about supply and rising energy prices began to erode demand. By the 1980's, lower demand resulted in a short-term surplus of deliverable gas and gas well shut-ins in many producing areas. In 1986, natural gas consumption totaled 16 trillion cubic feet, the lowest annual total since 1965.

Weakened demand spanned all end-use sectors but was most severe in the industrial and electric utiltity sectors, where, particularly during the

'Real (inflation-edjosted) prices are expuessed in chained (1992) dollars. Prites arte nomi. nal unless spocifically noted as real.

Wumbers in parentheses indicate related fables. Anirugl dafa are the most recent availabte; they frequently are pretininary and may be revised in futume pubtications. Percentages and numbers in lext are calculated by uoing data in the fabies. early and mid-1980's, the option of fuel switching proved to be most viable. Lower consumption by the industrial sector accounted for over half of the 5.9-trillion-cubic-foot reduction from 1972 through 1986, and lower use at electric utilities accounted for close to one-fourth.

After the 1986 low point, natural gas consumption trended upward, reaching 22 trillion cubic feet in 1995 (6.6). All sectors except the residential consumed more natural gas in 1995 than they had in 1994. Industrial consumption of natural gas rose to 9.8 trillion cubic fet, a 4.4-percent increase, and electric utility consumption rose to 3.2 trillion cubic feet, up 6.7 percent. Consumption in the commercial sector rose to 3.1 trillion cubic feet, a 6.9-percent increase, in 1995. Transportation consumption of natural gas edged up to 0.7 trillion cubic feet. Residential consumption totaled 4.8 trillion cubic feet, slightly lower than consumption in 1994.

\section{Meetiting Peak Demand}

Seasonal, end even dally, fluctuations in natural gas demand are met by withdrawels from storages when demand is high and by injections into atorage when demand is low compared with avaitable gas flow in tranemisaion Ines. Net withdrawals from storage can provide more than half of some companles' peak winter deliveries. During the 1994-1996 heating season (October through March), net withdrawals from storage supplied 13 percent of total nalural gas constumed.

Natural gas in slorage at the end of the yoar genersily increased throughout the pertiod of the 1970's, when local sharlages resulted In curtailments to some corsumers (6.7). Underground storage of working gas (1kat in excess of the base gas reeded to maintain optimum reservoir pressure) equaled 7.1 percent of anntzal consumption in 1969 and 10 pereent in 1995 (6.1 and 6.7). At the end of 1995, working gas in storage was 2.2 triallon cublc feet and base gas was 4.3 trillion cubic leel.

Energy InIormallon Adrmingtratlon. Monthy Enarcy Rewiour March 1998,

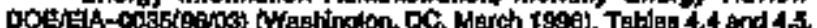




\section{Natural Gas Delivered for the Account of Others}

During the 1980's, regulatory and legislative changes allowed consumers to purchase natural gas directly from prodncers and to arrange for pipeline and distribution companies to deliver it to them for a fee. Federal Energy Regulatory Commission Order 636 (implemented No. vember 1,1993 ) extended that trend toward a more efficient market by requiring interstate pipeline companies to unbandle (separate) their sales and transportation services. In 1994, natural gas delivered for the account of others to industrial, electric utility, and commercial customers reached 8.8 trillion cubic feet (6.5). Such deliveries accounted for 75 percent of total deliveries to industrial customers, 75 percent of total deliveries to electric utilities, and 21 percent of total deliveries to commercial customers.

\section{Natural Gas Production and Productivity}

In 1995, gross withdrawals of natural gas from wells totaled 24 trillion cubic feet, np for the ninth consecutive year (6.2). Texas, Louisians, and Oklahoma, the largest producers of natural gas, accounted for 59 percent of the U.S. total int 1995 (6.4). Most withorawals came from onshore wells and State offshore wells, but 4.9 trillion cubic fet were Federal offshore withdrawals. The 24 trillion cubic feet of gross withdrawals in 1995 yielded 20 trillion cubic feet of matketed production (6.2).

The U.S. total of natural gas gross well withdrawals includes a small but rapidly growing amount of methane produced from coalbeds. In 1994 , gross withdrawals of coalbed methane totaled about 851 billton cubic feet, an amount equal to 5 percent of U.S. total dry production. ${ }^{3}$ However, the rats of increase in coalbed methane reserves slowed after 1992, when Federal tax incentives for new coalbed methane wells expired. In 1994, coalbed methane reserves declined for the first time since data collection began in 1988 . U.S. total reserves in coalbed

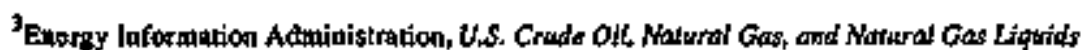
Reserves I994 Awwol Report, DOE/EJA-0216(94) (Woshington, DC October 1995), p. 34 methane fields accounted for 6 percent of U.S. natural gas totaI reserves in 1994, about the same share as in 1993.

About 294 thousand gas wells were in operation during 1995 (6.4). Withdrawals from those wells accounted for almost three-fourths of atl gross withdrawals, while oil wells supplied the remainder. After peaking at 435 thousand cubic feet per day in 1971 (6.4), average gas well productivity trended downward; from 1985 through 1993, productivity remained below 165 thousand cubic feet per day. In 1995 , gas well productivity averaged 164 thousand cubic feet per day.

\section{Imports and Exports}

U.S. natural gas trade was limited to the border countries of Mexico and Canada until shipping natural gas in liquefied form emerged as an alternative to pipelines. In 1969, the first shipments of liquefied natural gas (LNG) from Alaska were sent to Japan, and U.S. imports from Algeria began the following year (6.3). In 1995, U.S. net imports of natural gas by all routes totaled 2.6 trillion cubic feet, up 4.5 percent from 1994 net imports and the equivalent of 12 percent of domestic consumption.

Historically, Canada has been the major supplier of U.S. nataral gas imports, with Algeria and Mexico supplying smaller amounts. The remarkable growth in U.S. net imports of natural gas from the 1986 leve] of 689 billion cubjc feet (a 17-year low at the time) to 2,6 tritlion cubic feet in 1995 was dure almost entirely to bigher levels of imports from Canada. In 1995, Canada supplied net imports of $\mathbf{2 . 7}$ trillion eubic feet. Importing Canadian natural gas was facilitated by the completion of the Iroquois transportation system in January 1992.

From 1970 through 1990 and again in 1993 through 1995, Japan was the primary purchaser of U.S. natural gas. In 1995, Japan purchased 67 billion cubic feet of U.S. natural gas. 


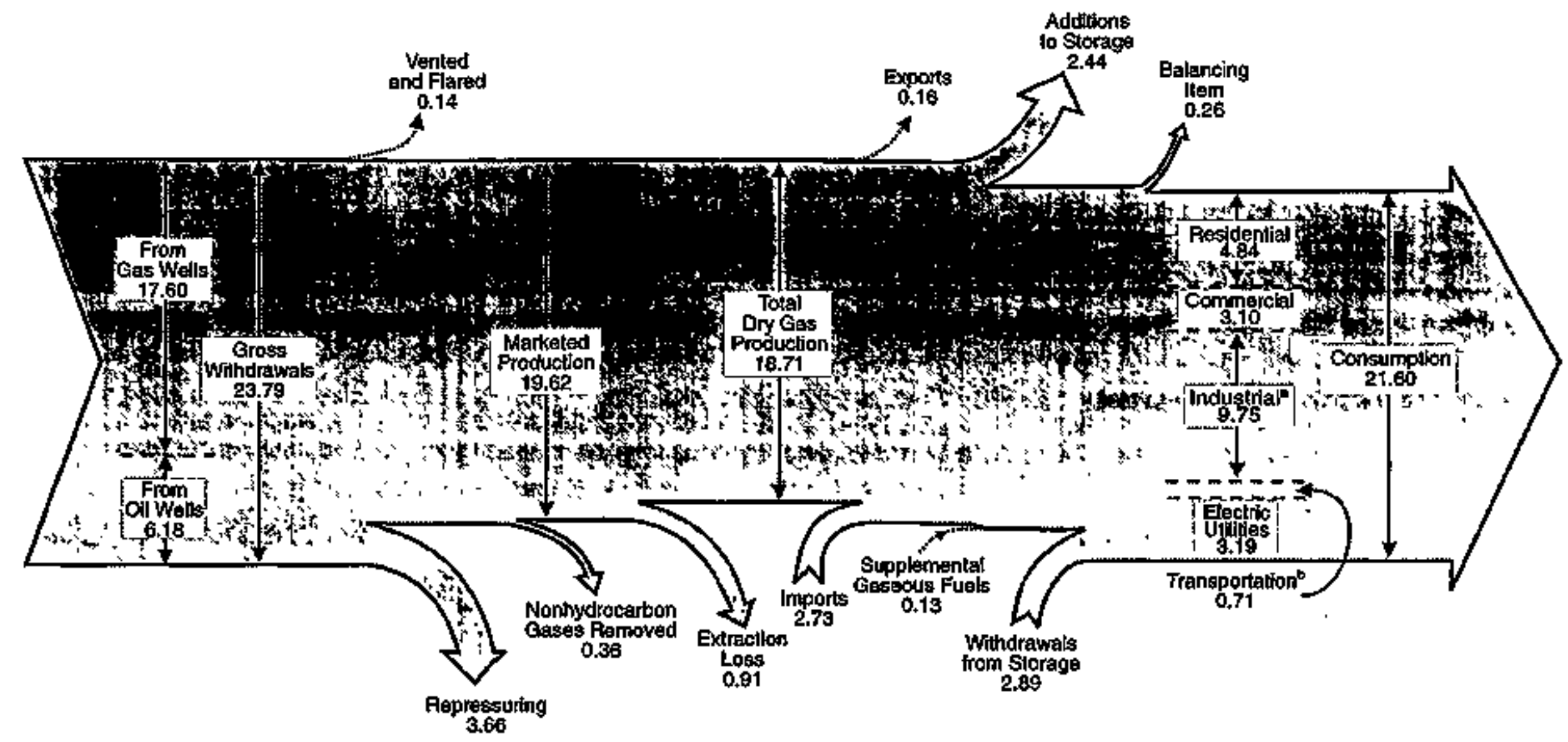

tinchudes bease and ptent will

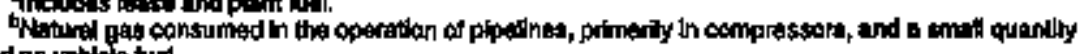
used as vothen tued.

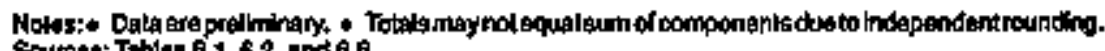
Soutsen: Tables 6.1, 6.2, and 6.0 . 


\section{Overview, 1949-1095}

$25-$

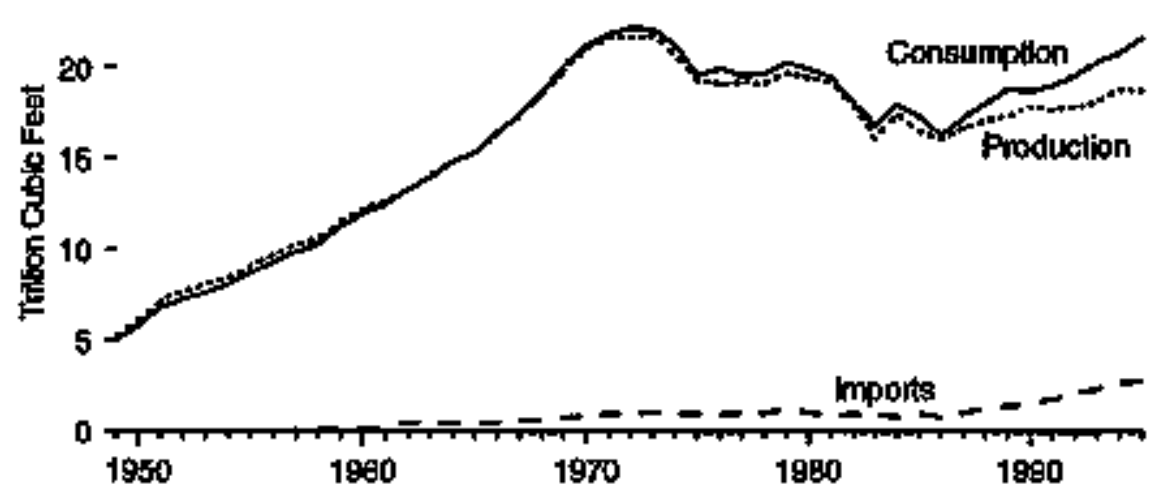

Overview, 1995

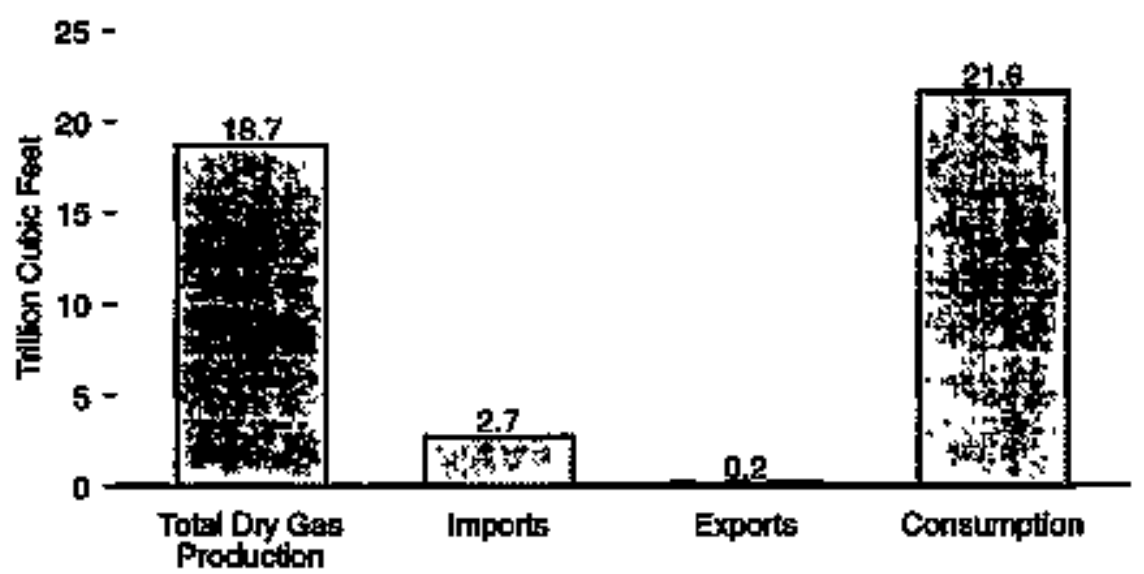

\section{Storage Additions and Withdrawals', 1949-1995}

$$
4 \text { - }
$$

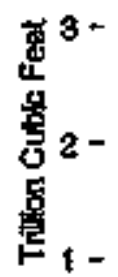
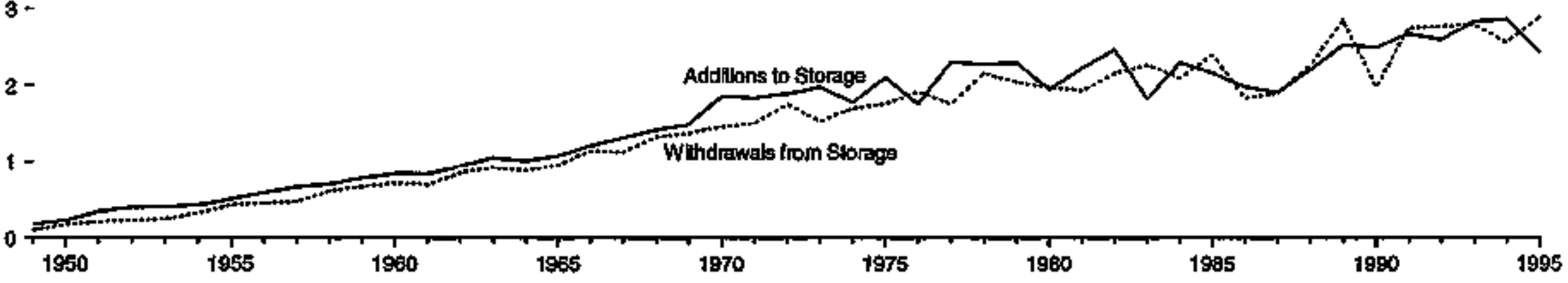

\footnotetext{
1 Beginning with 1980, hotudes lowelied natureal gas stored in abowe-gound tankts. Sourex: Tabls 6.1 .
} 
Table 6.1 Natural Gas Overview, 1949-1995

(Trillion Cublo Feet)

\begin{tabular}{|c|c|c|c|c|c|c|c|c|}
\hline Year & $\begin{array}{c}\text { Tota } \\
\text { boy cis } \\
\text { Producllon }\end{array}$ & $\begin{array}{c}\text { Sugplemmits } \\
\text { gupous } \\
\text { funts }\end{array}$ & Imports & Export: & $\begin{array}{l}\text { Whindraw sts } \\
\text { trom } \\
\text { storago } 1\end{array}$ & $\begin{array}{l}\text { Adsplons } \\
\text { to } \\
\text { stonge? }\end{array}$ & $\begin{array}{c}\text { Bsidungins } \\
\text { them }{ }^{2}\end{array}$ & Contumpition \\
\hline 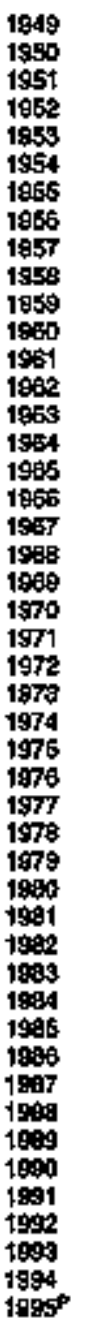 & 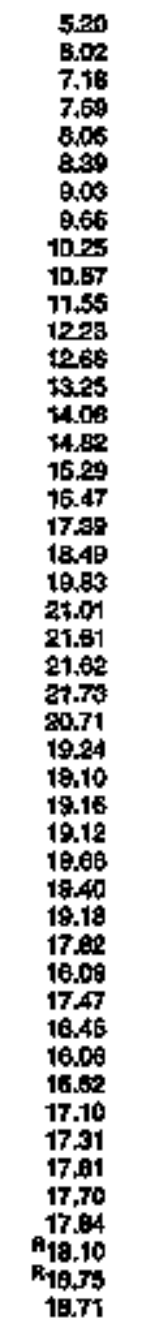 & 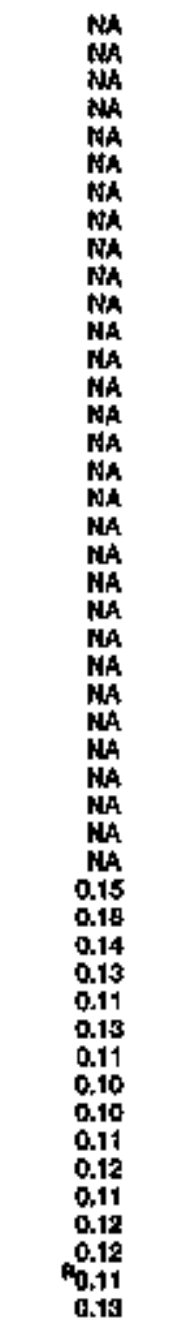 & 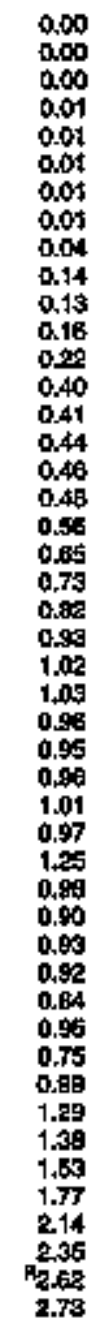 & 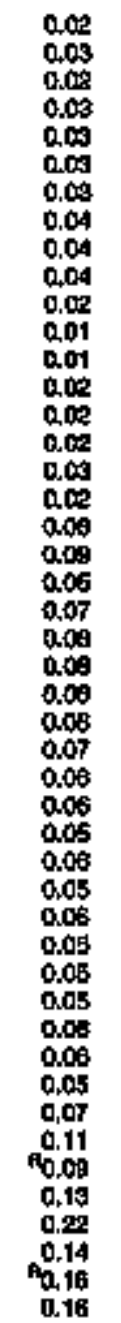 & 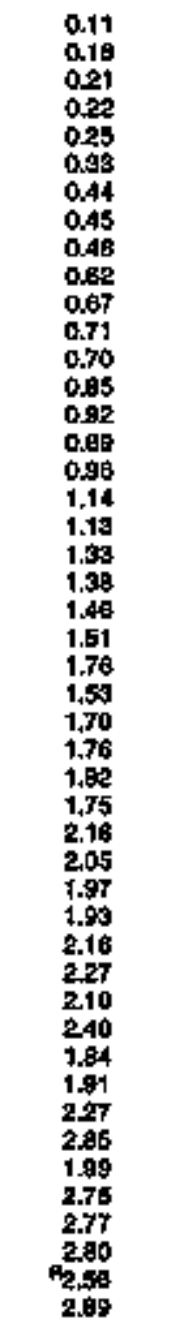 & 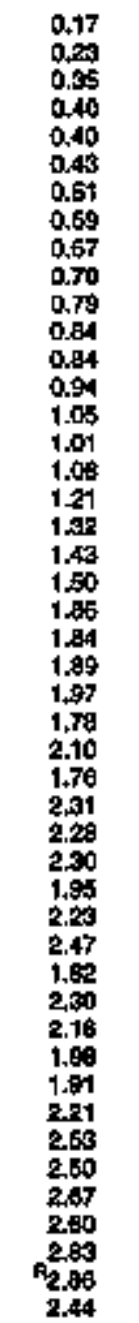 & 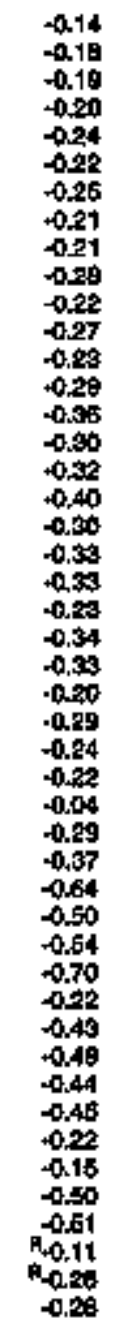 & 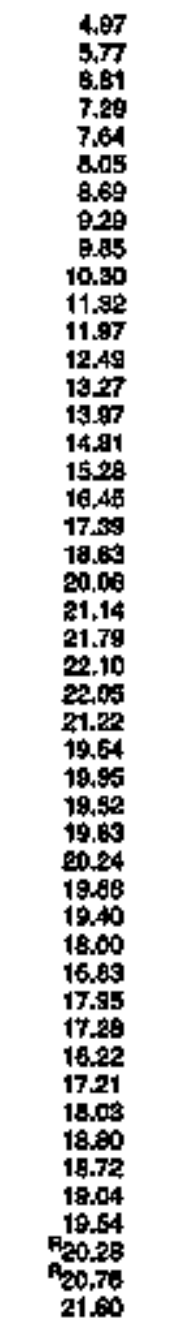 \\
\hline
\end{tabular}

I Baploning with 1960, inchudas linuated natural ges stored k abowa graund banks.

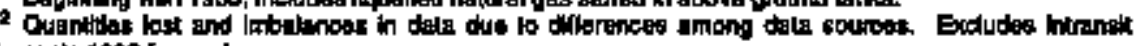
Htomensks 1860 Lorward

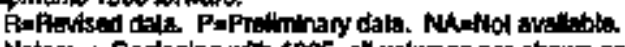

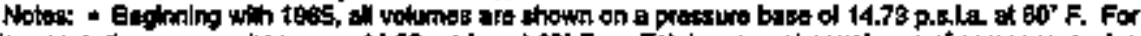

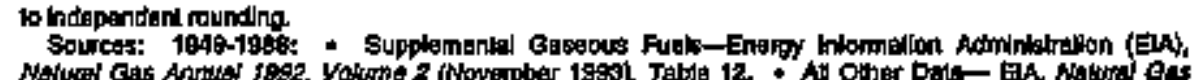

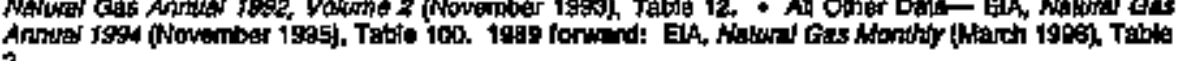

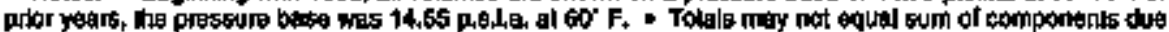




\section{Figure 6.2 Natural Gas Productlon, 1949-1995}

Gross Withdrawsls by Wall Type

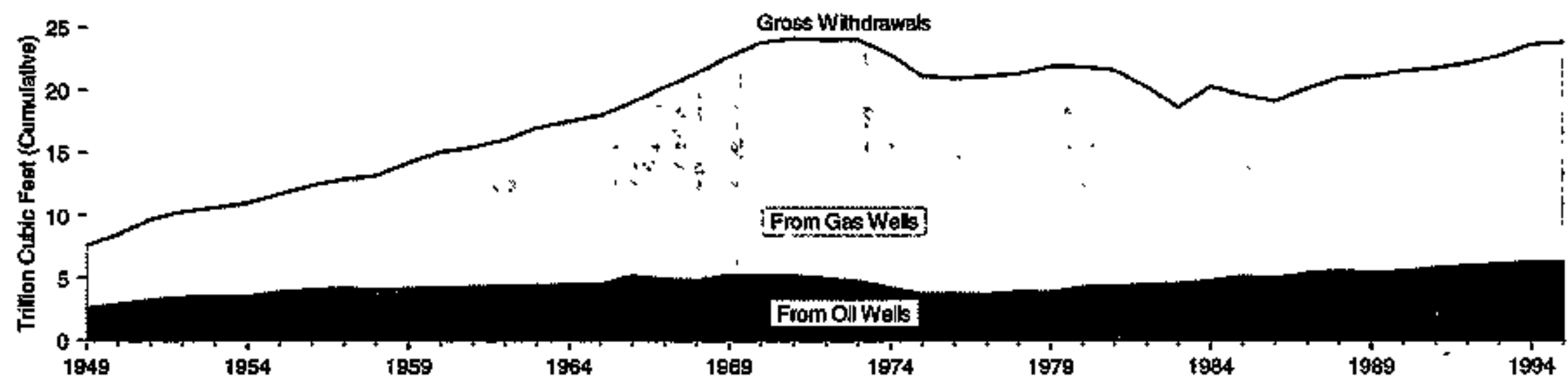

\section{Nalural Gas Prodiction by Phase}

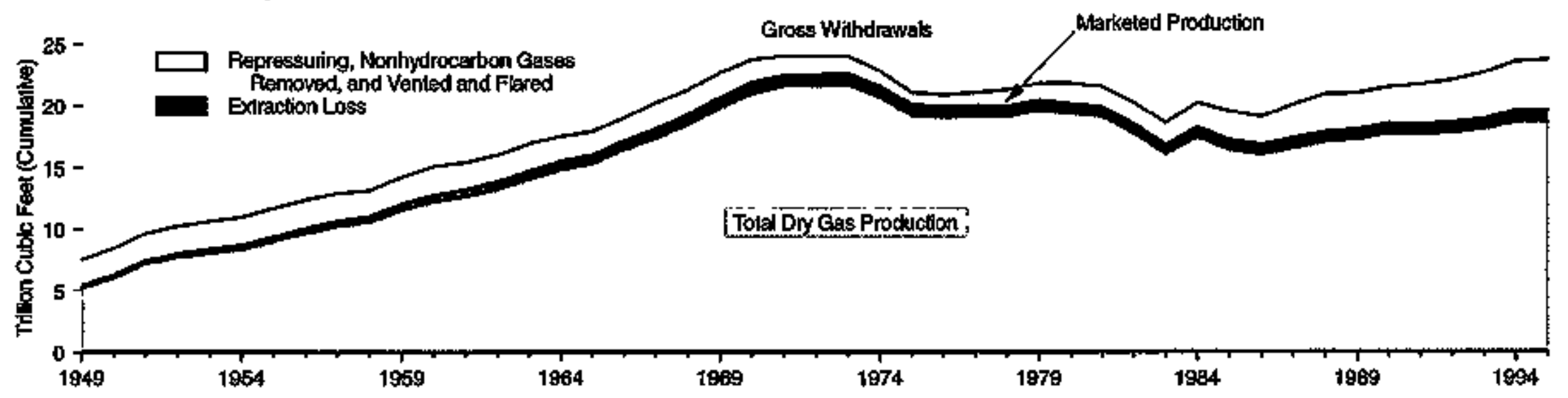

Sourci: Table 6.2. 
Table 6.2 Natural Gas Production, 1949-1995

(Trillion Cubic Feet)

\begin{tabular}{|c|c|c|c|c|c|c|c|c|c|}
\hline \multirow[b]{2}{*}{ Year } & \multicolumn{3}{|c|}{ Gross Wiluntrawaks } & \multirow[b]{2}{*}{ Fepratopurting } & \multirow[b]{2}{*}{$\begin{array}{l}\text { Norilhy irocabon } \\
\text { Gases fimoved }\end{array}$} & \multirow[b]{2}{*}{$\begin{array}{c}\text { Vonlod } \\
\text { and Fiared }\end{array}$} & \multirow[b]{2}{*}{$\begin{array}{l}\text { Matiselod } \\
\text { Production }\end{array}$} & \multirow[b]{2}{*}{$\begin{array}{l}\text { Extraction } \\
\text { Lost } 1\end{array}$} & \multirow{2}{*}{$\begin{array}{c}\text { Told } \\
\text { Dry pies } \\
\text { Produation. }\end{array}$} \\
\hline & $\begin{array}{c}\text { From } \\
\text { aes wite }\end{array}$ & $\begin{array}{l}\text { From } \\
\text { oll Weils }\end{array}$ & Total & & & & & & \\
\hline 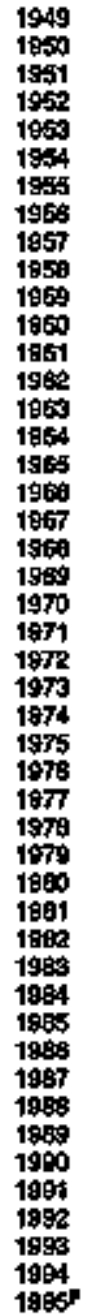 & 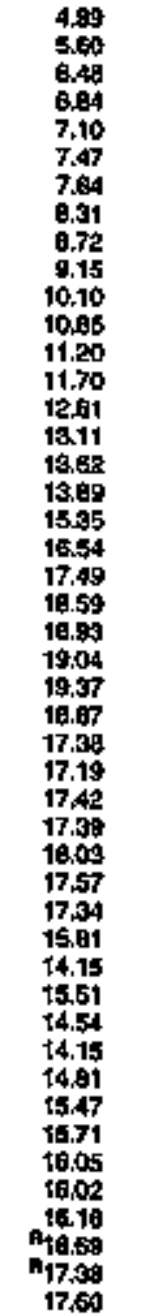 & 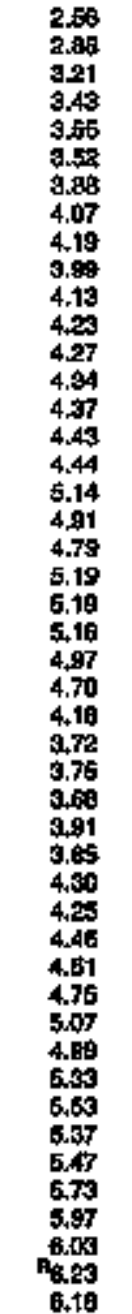 & 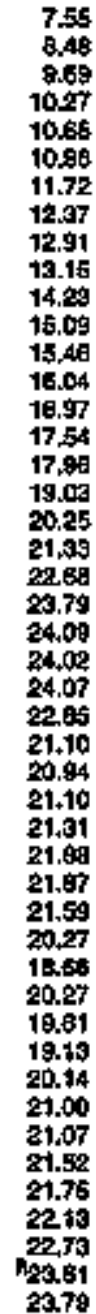 & 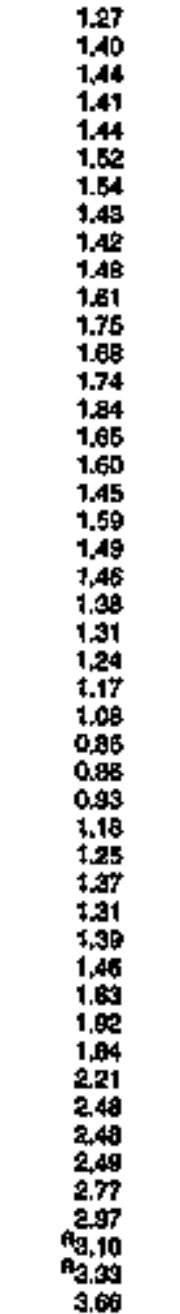 & $\begin{array}{l}\text { NA } \\
\text { NA } \\
\text { NA } \\
\text { NA } \\
\text { NA } \\
\text { NA } \\
\text { NA } \\
\text { MA } \\
\text { MA } \\
\text { MA } \\
\text { MA } \\
\text { MA } \\
\text { NA } \\
\text { NA } \\
\text { MA } \\
\text { NA } \\
\text { MA } \\
\text { MA } \\
\text { NA } \\
\text { NA } \\
\text { MA } \\
\text { MA } \\
\text { MA } \\
\text { NA } \\
\text { MA } \\
\text { MA } \\
\text { MA } \\
\text { NA } \\
\text { MA } \\
\text { MA } \\
\text { MA } \\
0.20 \\
0.22 \\
0.21 \\
0.24 \\
0.22 \\
0.33 \\
0.34 \\
0.38 \\
0.46 \\
0.28 \\
0.28 \\
0.28 \\
0.28 \\
0.41 \\
0.41 \\
0.36\end{array}$ & 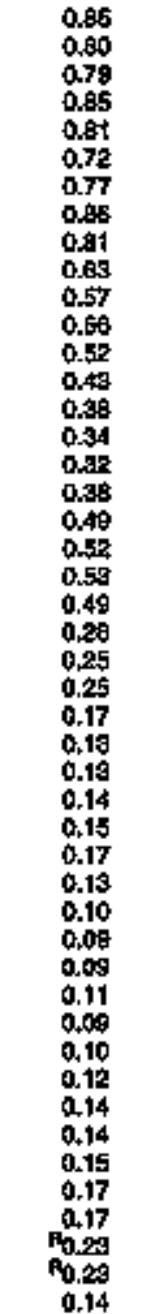 & 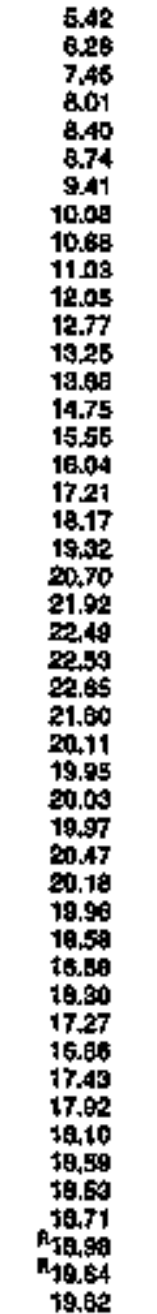 & 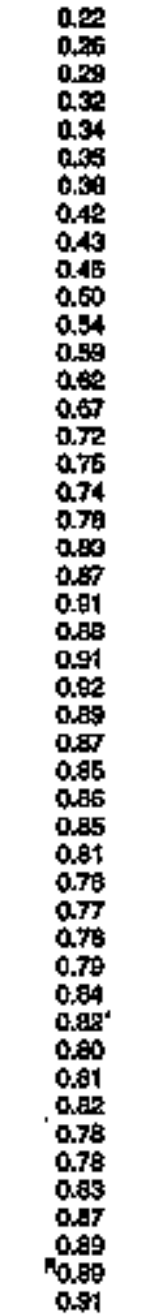 & 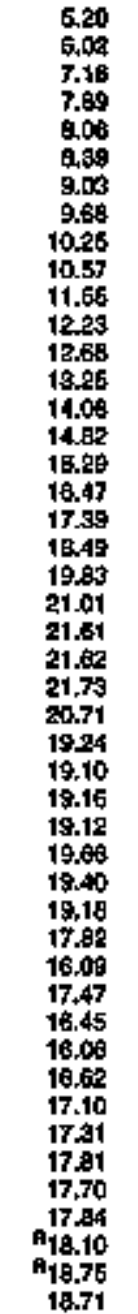 \\
\hline
\end{tabular}

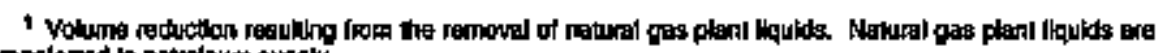
manstarted to petooloum suody.

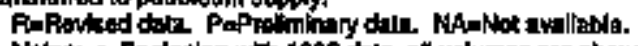

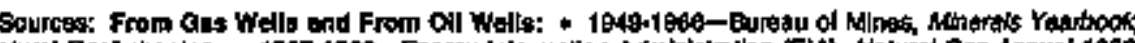

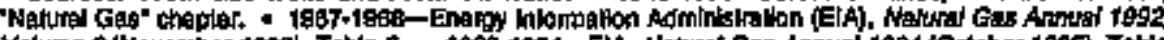

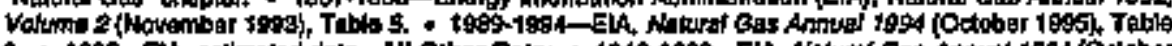

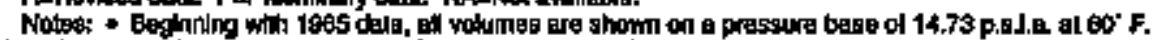

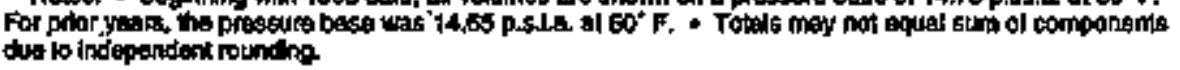

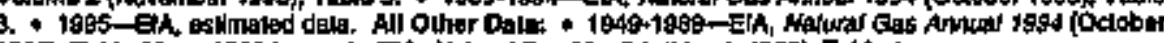

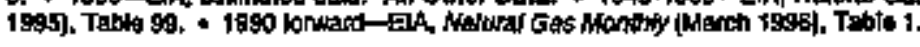




\section{Figure 6.3 Natural Gas Imports, Exports, and Net imports}

\section{Trade Ovarview, 1949-199s}

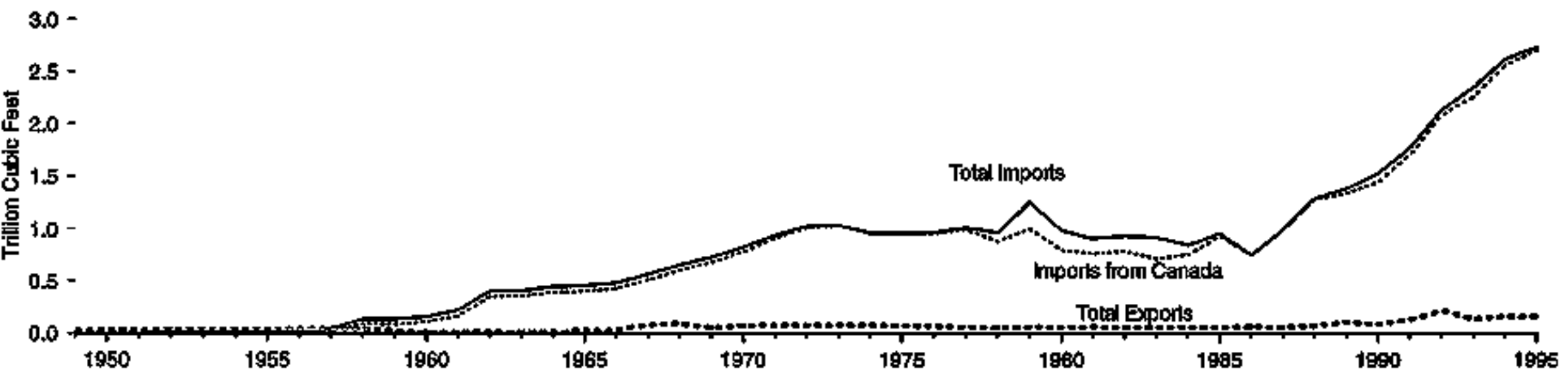

Trade, 1996

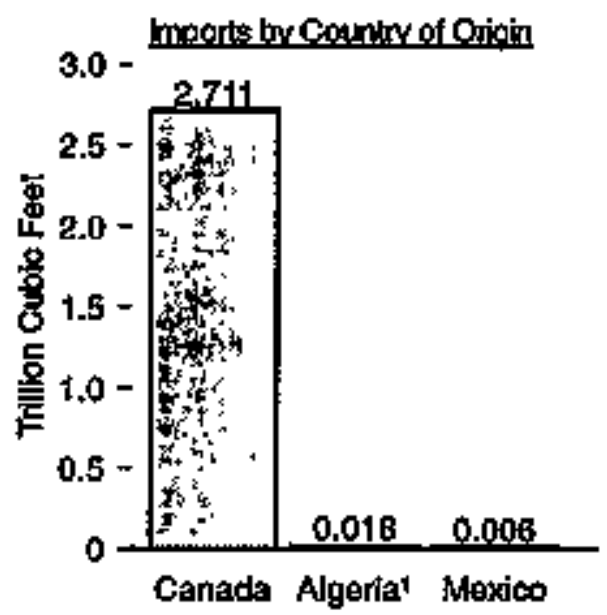

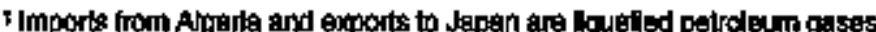

Net Imports as share of Consumptlon, 1958-1995

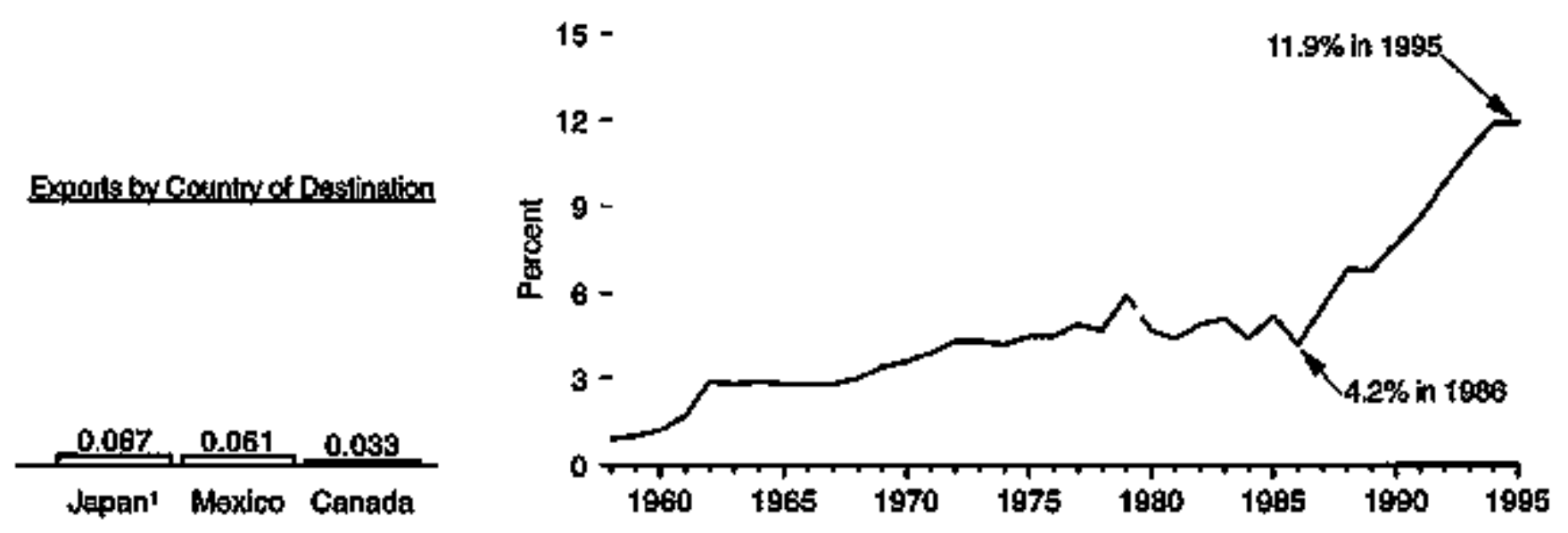

Sounce: Table BS 
Table 6.3 Natural Gas Imports, Exports, and Net Imports, 1949-1995

(Billion Cubic Feet, Except as Noted)

\begin{tabular}{|c|c|c|c|c|c|c|c|c|c|c|c|}
\hline \multirow[b]{2}{*}{ Yanr } & \multicolumn{5}{|c|}{ Imperts by corniry ol Orlgin } & \multicolumn{4}{|c|}{ 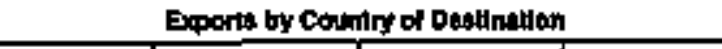 } & \multicolumn{2}{|c|}{ Not imporis: 1} \\
\hline & Cinnumata & Moxdos & Afgontia ${ }^{2}$ & Indion & Total & Catede & Alexidoo & $\operatorname{tapan}{ }^{2}$ & Totel & Total & $\begin{array}{c}\text { Percent of } \\
\text { us. } \\
\text { Cantumption }\end{array}$ \\
\hline 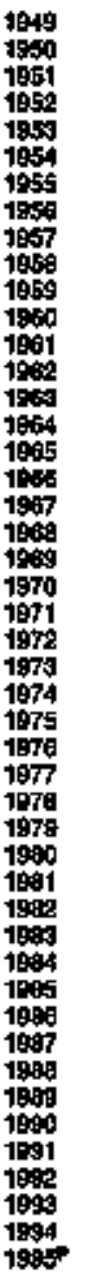 & 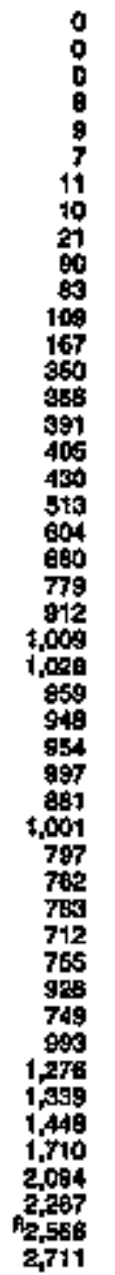 & 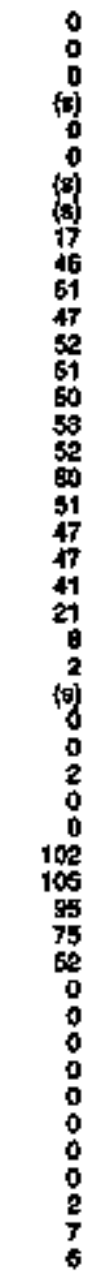 & $\begin{array}{r}0 \\
0 \\
0 \\
0 \\
0 \\
0 \\
0 \\
0 \\
0 \\
0 \\
0 \\
0 \\
0 \\
0 \\
0 \\
0 \\
0 \\
0 \\
0 \\
0 \\
0 \\
0 \\
0 \\
1 \\
1 \\
0 \\
3 \\
0 \\
5 \\
10 \\
11 \\
84 \\
050 \\
090 \\
37 \\
56 \\
131 \\
36 \\
24 \\
0 \\
0 \\
17 \\
42 \\
64 \\
04 \\
49 \\
00 \\
51 \\
10\end{array}$ & $\begin{array}{l}0 \\
0 \\
0 \\
0 \\
0 \\
0 \\
0 \\
0 \\
0 \\
0 \\
0 \\
0 \\
0 \\
0 \\
0 \\
0 \\
0 \\
0 \\
0 \\
0 \\
0 \\
0 \\
0 \\
0 \\
0 \\
0 \\
0 \\
0 \\
0 \\
0 \\
0 \\
0 \\
0 \\
0 \\
0 \\
0 \\
0 \\
2 \\
0 \\
0 \\
0 \\
0 \\
0 \\
0 \\
0 \\
0 \\
0\end{array}$ & 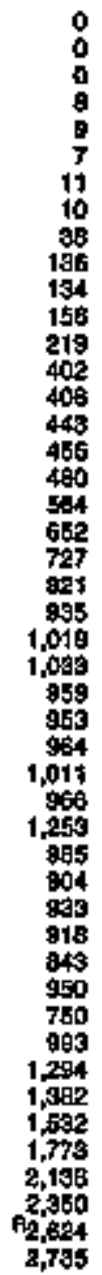 & 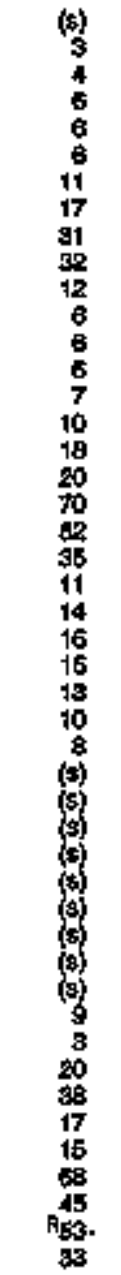 & 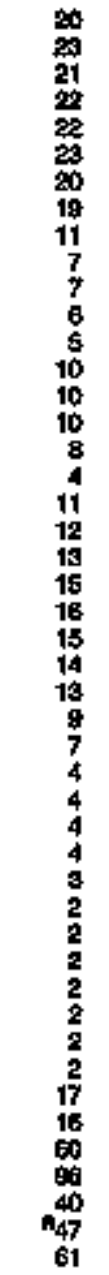 & $\begin{array}{l}0 \\
0 \\
0 \\
0 \\
0 \\
0 \\
0 \\
0 \\
0 \\
0 \\
0 \\
0 \\
0 \\
0 \\
0 \\
0 \\
0 \\
0 \\
0 \\
0 \\
3 \\
44 \\
50 \\
48 \\
48 \\
50 \\
53 \\
50 \\
50 \\
48 \\
51 \\
45 \\
58 \\
50 \\
58 \\
55 \\
55 \\
50 \\
19 \\
58 \\
51 \\
55 \\
54 \\
58 \\
56 \\
63 \\
67\end{array}$ & 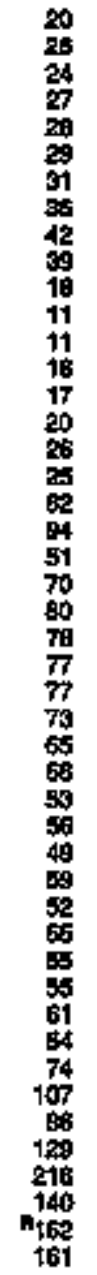 & 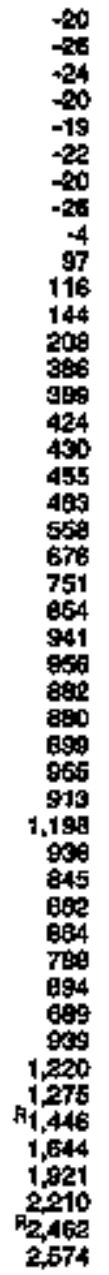 & 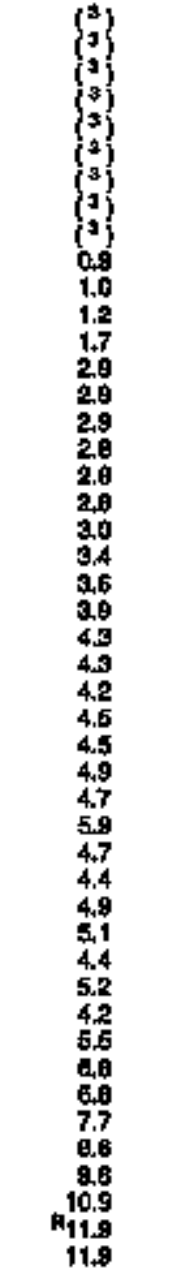 \\
\hline
\end{tabular}



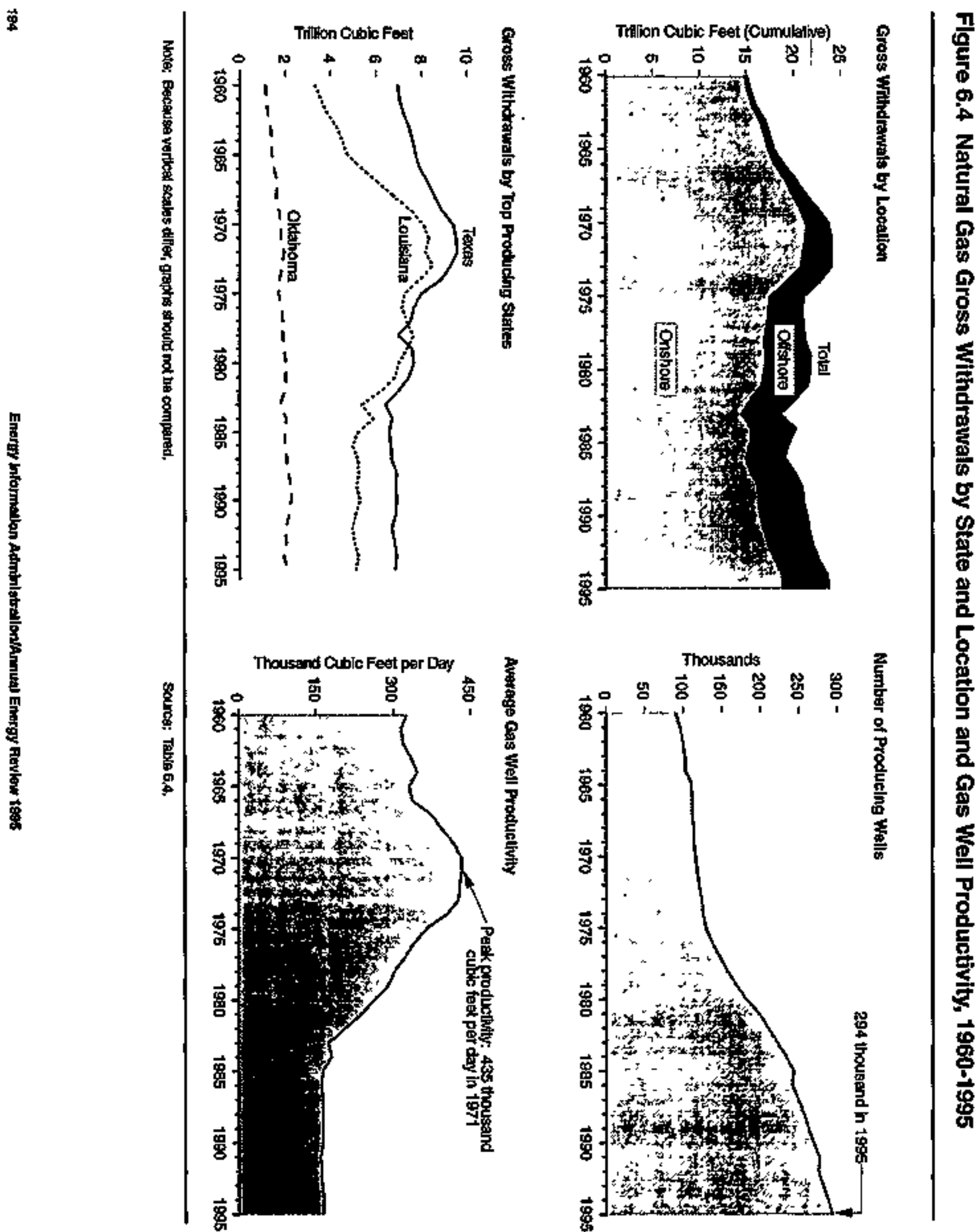
Table 6.4 Natural Gas Gross Withdrawals by State and Location and Gas Well Productivity, 1960-1995

(Trition Cubic Feet, Except as Noted)

\begin{tabular}{|c|c|c|c|c|c|c|c|c|c|c|}
\hline \multirow[b]{2}{*}{ Your } & \multicolumn{4}{|c|}{ state } & \multicolumn{2}{|c|}{ Loceation } & \multirow[b]{2}{*}{ 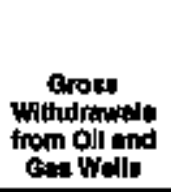 } & \multicolumn{3}{|c|}{ Gus: Woll ' Produetting } \\
\hline & Touas & Loulitima & Oldahoran & Othar & On:shor: 2 & Cttahorea & & 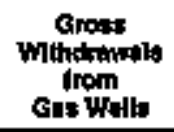 & $\begin{array}{l}\text { Thousinds } \\
\text { of } \\
\text { Propducing } \\
\text { wall }\end{array}$ & 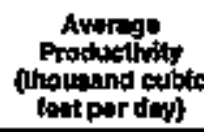 \\
\hline 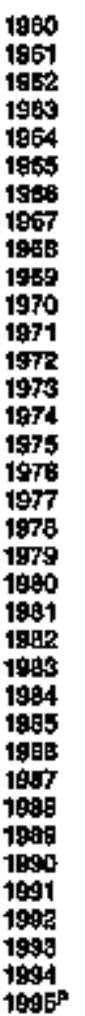 & 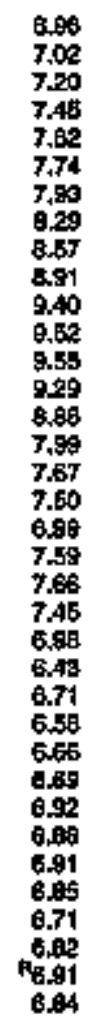 & 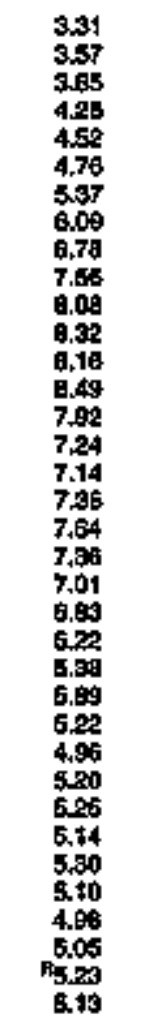 & 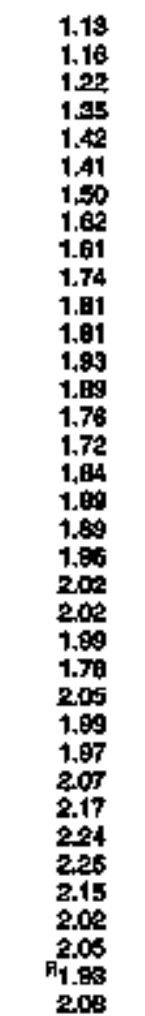 & 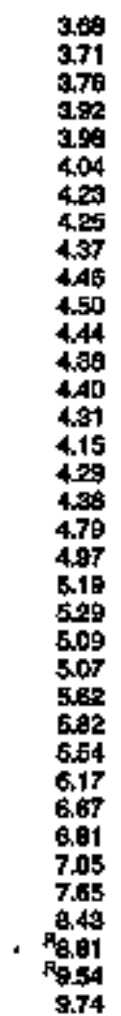 & 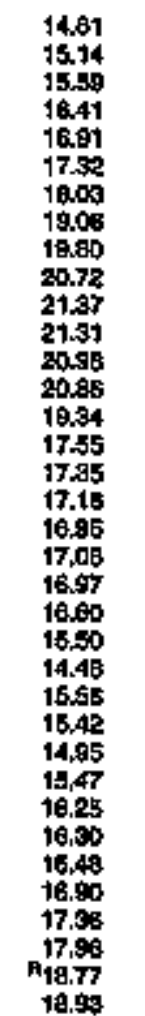 & 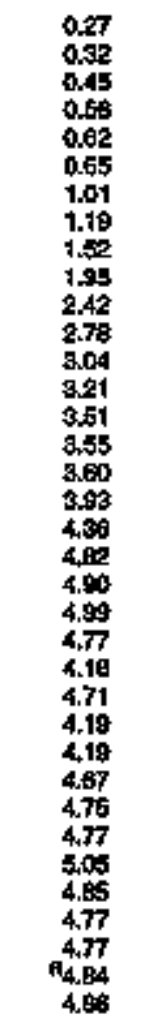 & 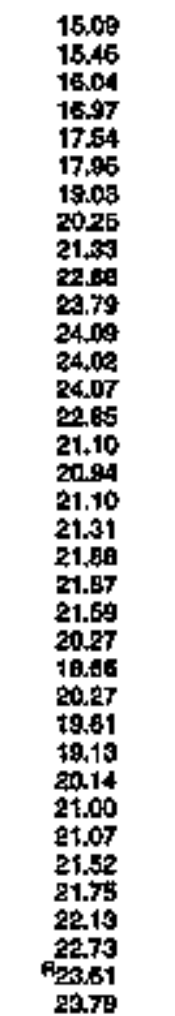 & 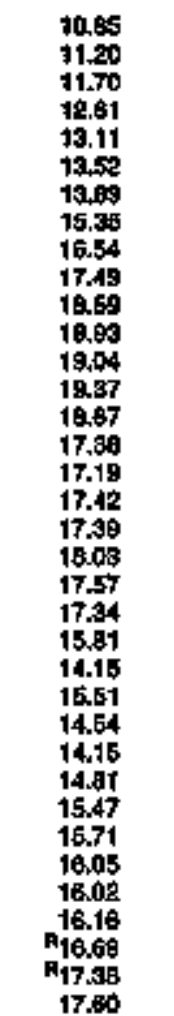 & 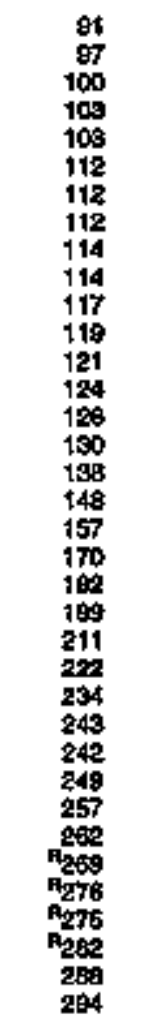 & 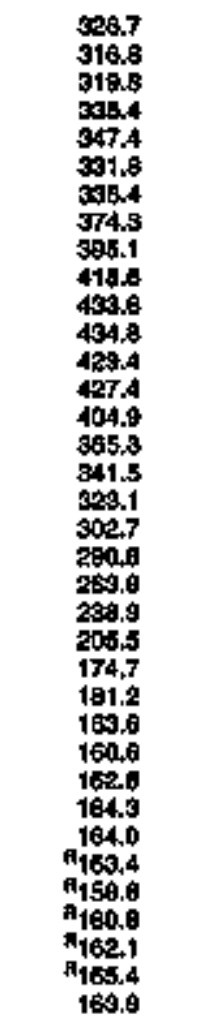 \\
\hline
\end{tabular}

Sas Glossary.

incterdes Slate oflshore gross withirimels.

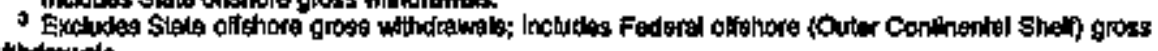
whidrateds.

As of Decantar 31 .

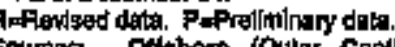

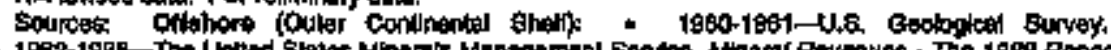

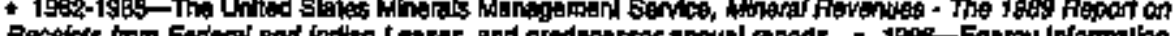

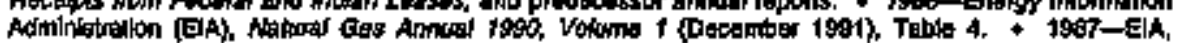

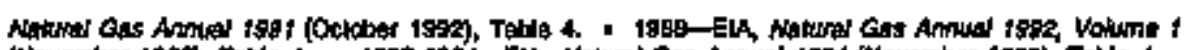

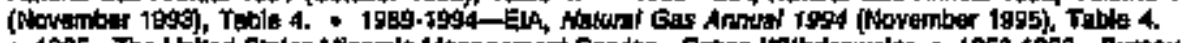

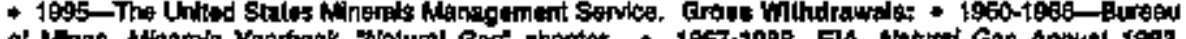

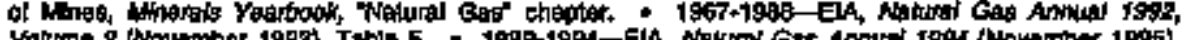

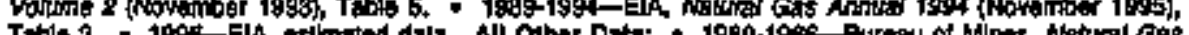

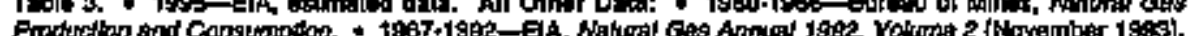

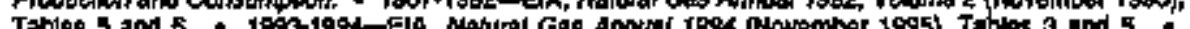

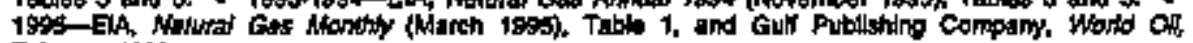
Fetruary 1000. 


\section{Transaclion Paths for Natural Gas Purchases}

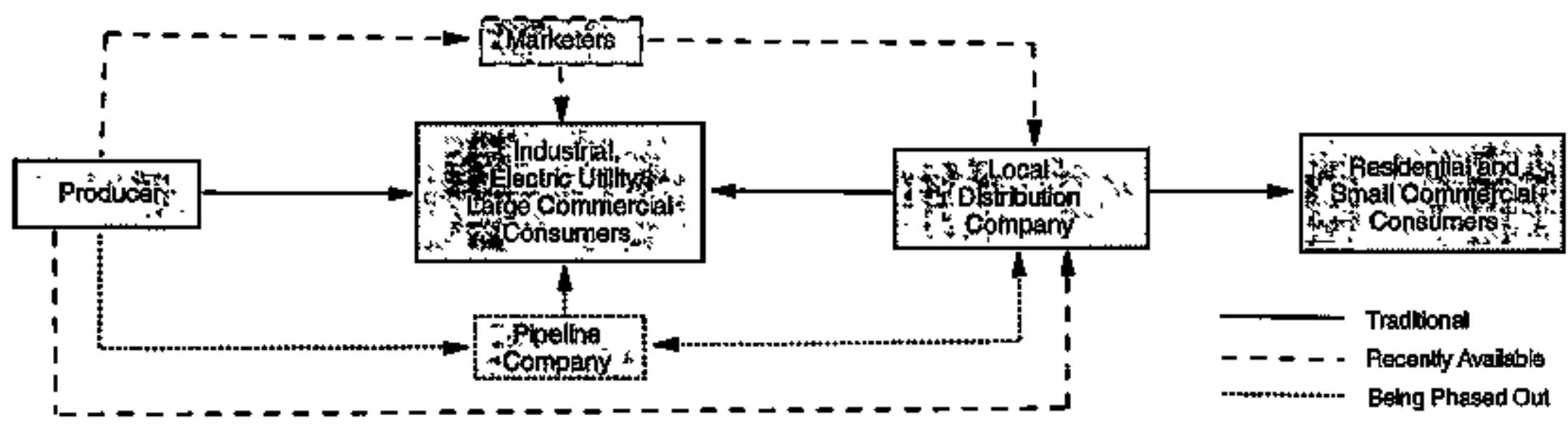

Natural Gas Delivered for the Account of Others, 1986-1994

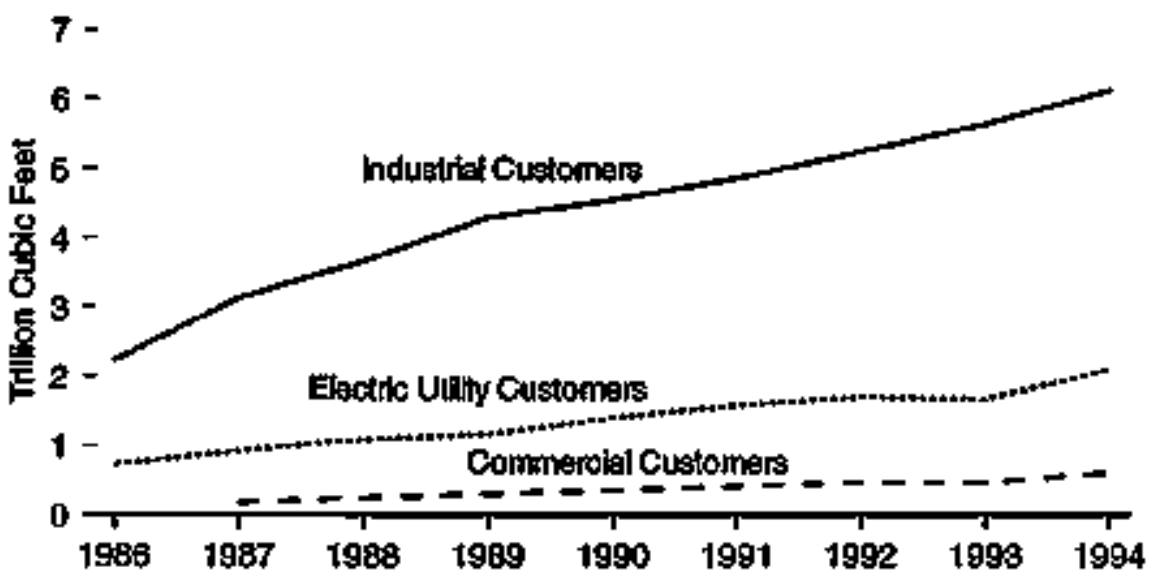

Account of Others share of Total Dellwerles to Sector, 1986-1994

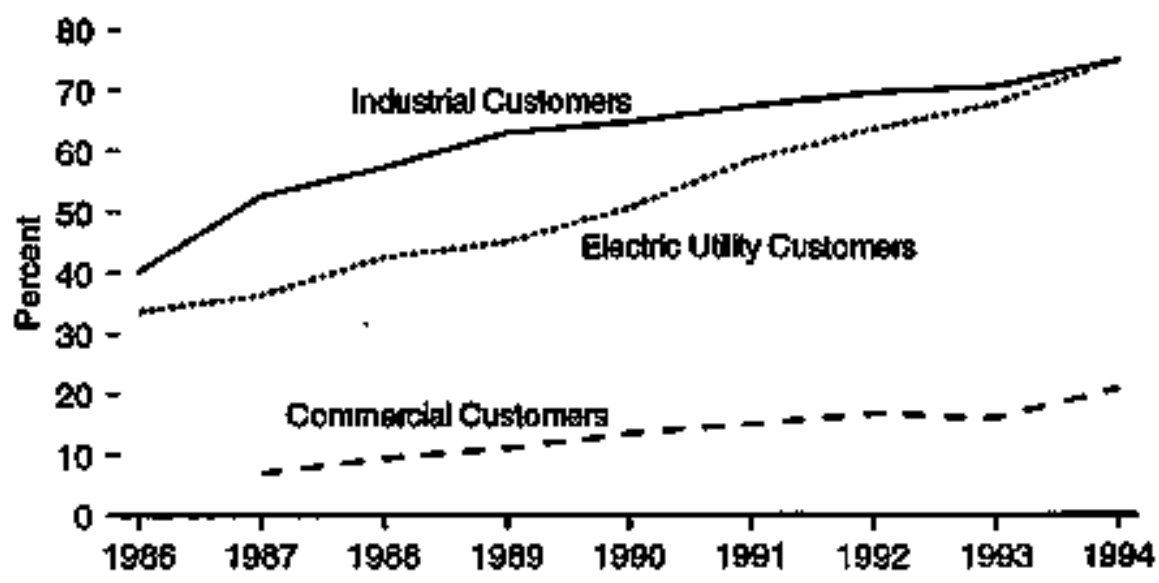

Sounce: Tatio 6.5. 
Table 6.5 Natural Gas Delivered for the Account of Others, 1986-1994

\begin{tabular}{|c|c|c|c|c|c|c|c|c|c|}
\hline \multirow[b]{3}{*}{ Year } & \multicolumn{3}{|c|}{ Commrrabl Customers } & \multicolumn{3}{|c|}{ inthegtrital Cutetomera } & \multicolumn{3}{|c|}{ Elnetrie trillotes, } \\
\hline & $\begin{array}{l}\text { Doflupred } \\
\text { for the } \\
\text { Adocoum } \\
\text { of Others }\end{array}$ & $\begin{array}{c}\text { Toln1 } \\
\text { Dollueries } 2\end{array}$ & $\begin{array}{l}\text { Ascount } \\
\text { of Olher: } \\
\text { strece of } \\
\text { Total }\end{array}$ & $\begin{array}{l}\text { Dedwered } \\
\text { loc iht: } \\
\text { Aceotint } \\
\text { of Chiturt }\end{array}$ & $\begin{array}{l}\text { Tolal } \\
\text { Deploriteg }\end{array}$ & $\begin{array}{l}\text { Arcount } \\
\text { of Others } \\
\text { Strare of } \\
\text { Total }\end{array}$ & $\begin{array}{l}\text { Delhrored } \\
\text { for the } \\
\text { Acoount } \\
\text { of Othere }\end{array}$ & $\begin{array}{l}\text { Total } \\
\text { Datreflac }\end{array}$ & $\begin{array}{l}\text { Account } \\
\text { of Others } \\
\text { sthere of } \\
\text { Toted ? }\end{array}$ \\
\hline & \multicolumn{2}{|c|}{ Ballon Cuble Foet } & Percent & \multicolumn{2}{|c|}{ Ballion Cublo fand } & Peraent & \multicolumn{2}{|c|}{ Bdllon Cublo Feet } & Percent \\
\hline $\begin{array}{l}1998 \\
1997 \\
1988 \\
1989 \\
1990 \\
1991 \\
1992 \\
1993 \\
1984\end{array}$ & $\begin{array}{l}\text { NA } \\
167 \\
347 \\
296 \\
359 \\
490 \\
471 \\
471 \\
400 \\
699\end{array}$ & $\begin{array}{r}2,318 \\
2,490 \\
2,670 \\
2,718 \\
2,623 \\
2,729 \\
2,609 \\
0,660 \\
2,695\end{array}$ & $\begin{array}{c}N A \\
7 \\
9 \\
17 \\
13 \\
15 \\
17 \\
16 \\
21\end{array}$ & $\begin{array}{r}2,240 \\
3,129 \\
3,693 \\
4,296 \\
4,545 \\
4,664 \\
4,249 \\
5,249 \\
75,645 \\
6,124\end{array}$ & 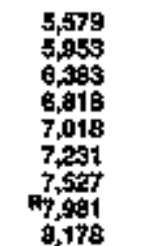 & $\begin{array}{l}40 \\
53 \\
57 \\
68 \\
65 \\
97 \\
70 \\
79 \\
75\end{array}$ & $\begin{array}{r}721 \\
914 \\
1,076 \\
1,152 \\
1,390 \\
1,560 \\
1,697 \\
1,658 \\
2,092\end{array}$ & 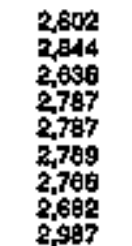 & $\begin{array}{l}34 \\
35 \\
43 \\
45 \\
51 \\
59 \\
64 \\
68 \\
76\end{array}$ \\
\hline
\end{tabular}

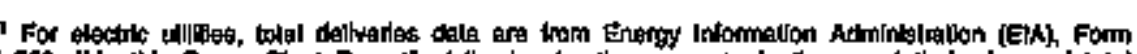

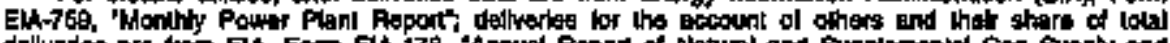

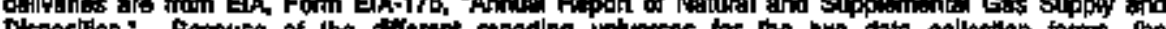

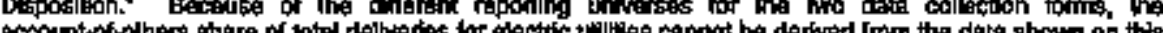

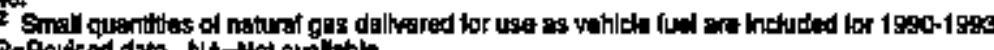

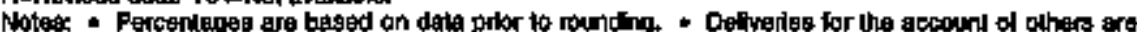

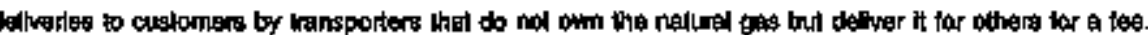

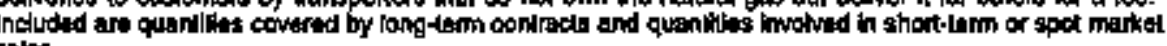

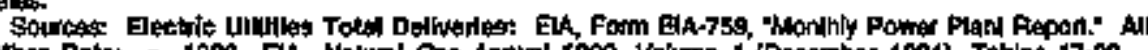

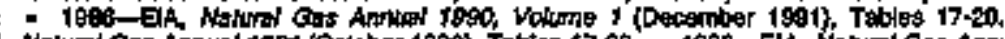

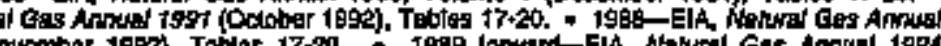
(Nowember 1995), Teten 15-1日 


\section{Figure 6.6 Natural Gas Consumption by Sector}

\section{By Sector, 1940-1995}

12 -

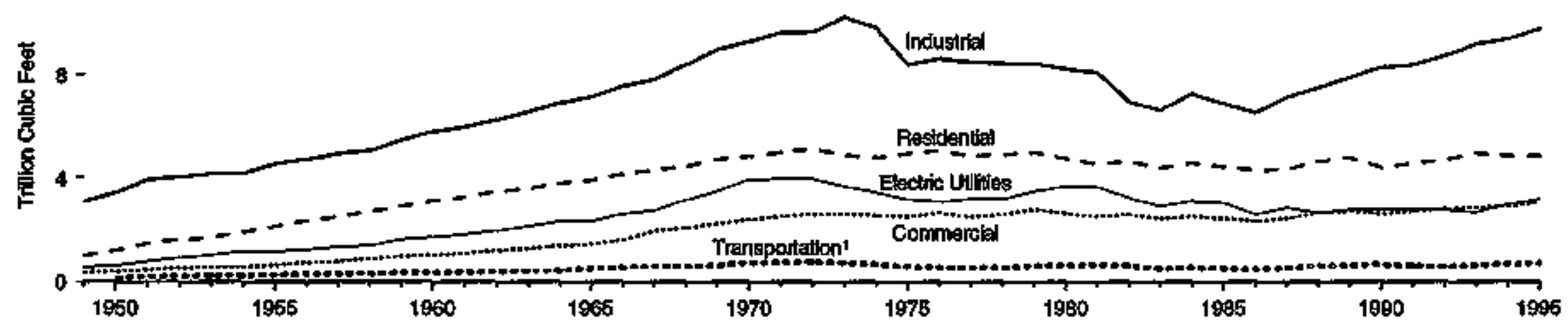

By Sector, 1995

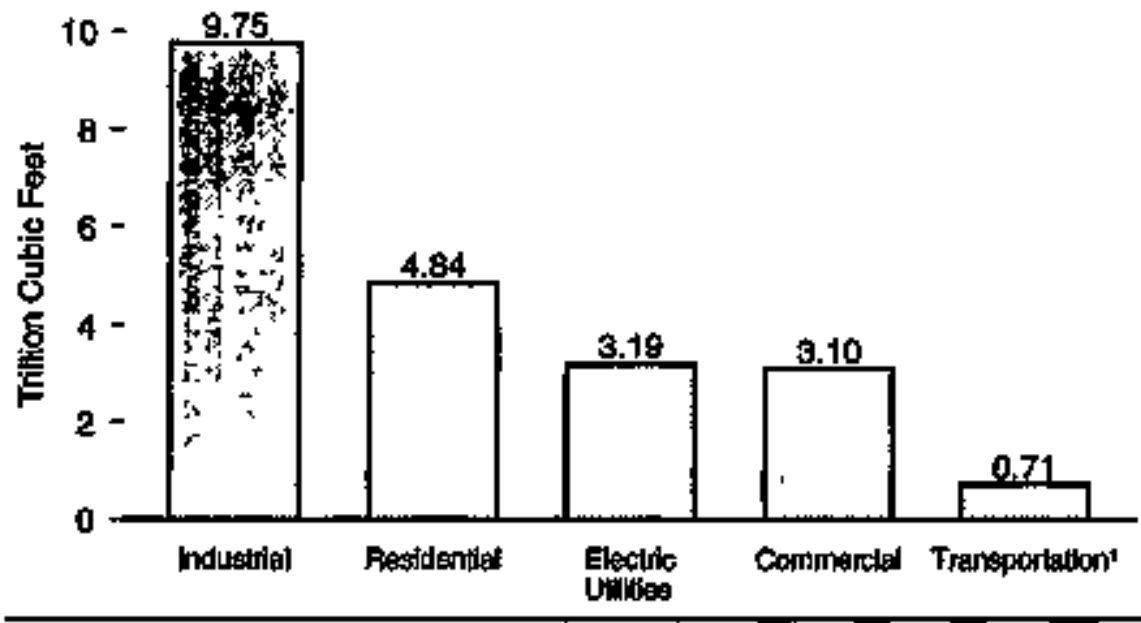

1 Pipeling hel and weticte hell.

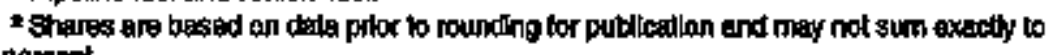
100 percent.
Shares ${ }^{2}$ by Sector, 1950 and 1995

$$
100-
$$

$$
75 \%
$$

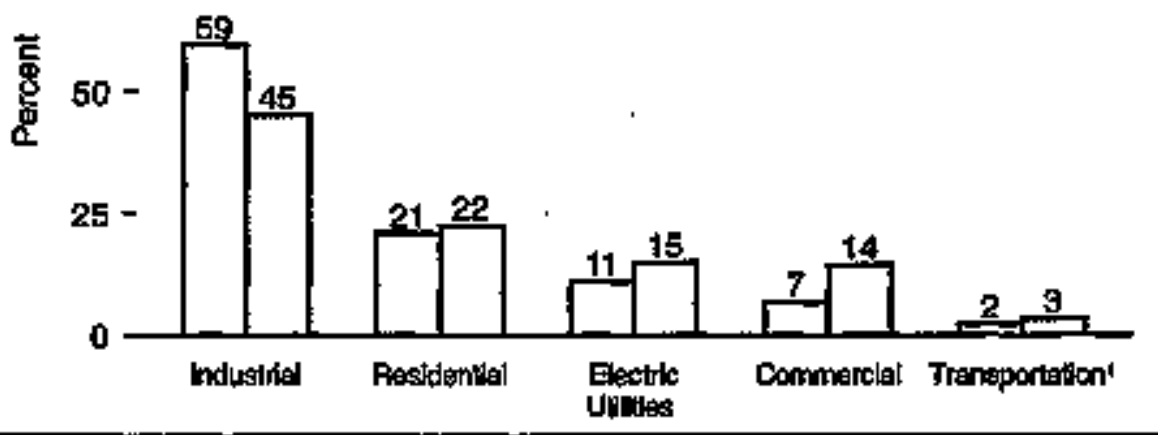

Note: Because vallical scales diter, graphs should not be compared. Sources: Table 6.6 . 
Table 6.6 Natural Gas Consumption by Sector, 1949-1995

(Trillion Cubic Feet)

\begin{tabular}{|c|c|c|c|c|c|c|c|c|c|c|}
\hline \multirow[b]{2}{*}{ Yeer } & \multirow[b]{2}{*}{ 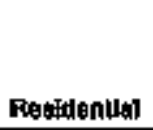 } & \multirow[b]{2}{*}{ Comnertall 1} & \multicolumn{3}{|c|}{ Inxinastatal } & \multicolumn{3}{|c|}{ Trtungpactiolion } & \multirow[b]{2}{*}{$\begin{array}{l}\text { Electric } \\
\text { Utitios }\end{array}$} & \multirow[b]{2}{*}{ Tolte } \\
\hline & & & $\begin{array}{l}\text { Lease and } \\
\text { Ptant Fat }\end{array}$ & Other & Total & Pipeline & $\begin{array}{l}\text { Vethelo } \\
\text { Ftel }\end{array}$ & Totall & & \\
\hline 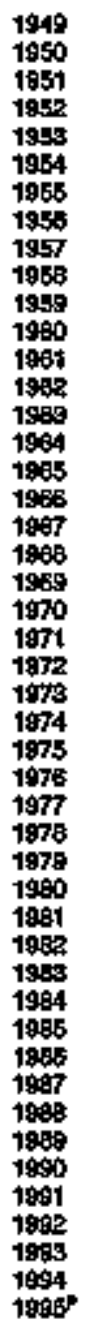 & 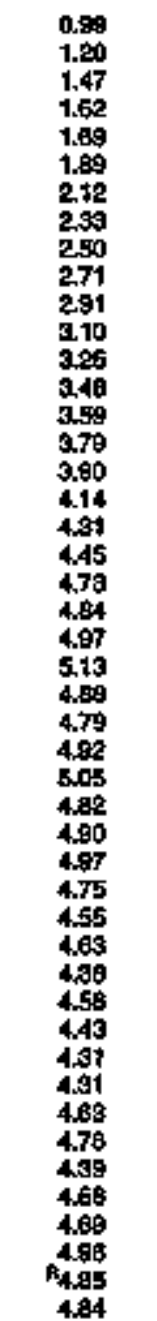 & 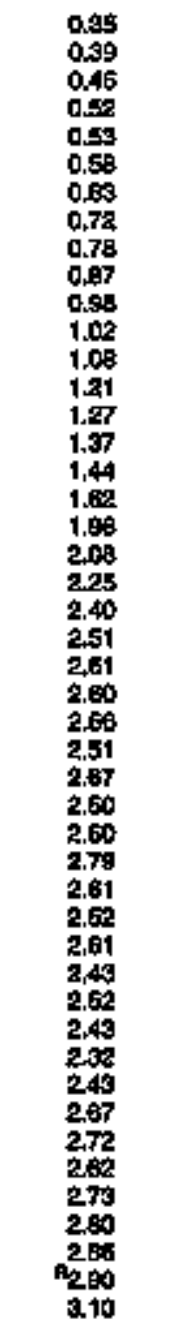 & 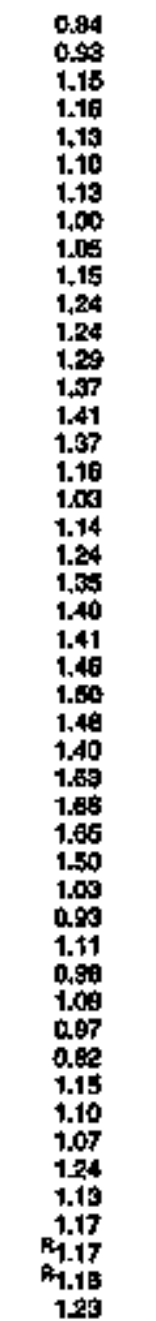 & 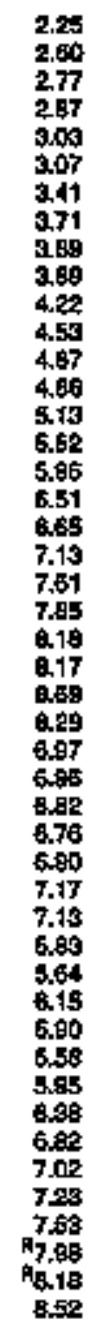 & 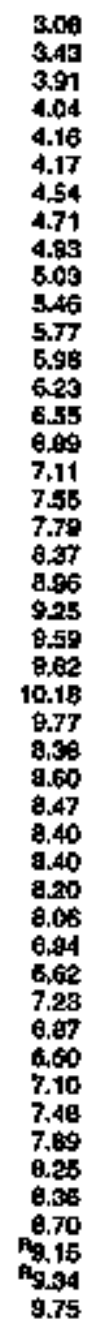 & 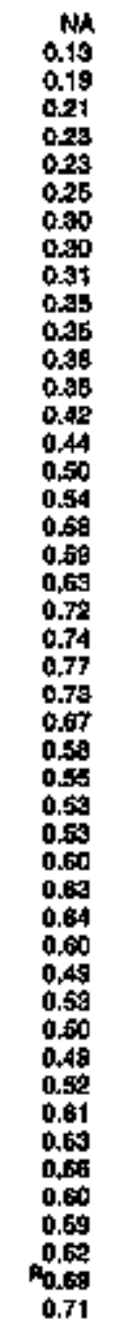 & $\begin{array}{l}\text { NA } \\
N A \\
N A \\
N A \\
N A \\
N A \\
N A \\
N A \\
N A \\
N A \\
N A \\
N A \\
N A \\
N A \\
N A \\
N A \\
N A \\
N A \\
N A \\
N A \\
N A \\
N A \\
N A \\
N A \\
N A \\
N A \\
N A \\
N A \\
N A \\
N A \\
N A \\
N A \\
N A \\
N A \\
N A \\
N A \\
N A \\
N A \\
N A \\
N A \\
69 \\
6 S \\
N= \\
69 \\
69 \\
(S)\end{array}$ & 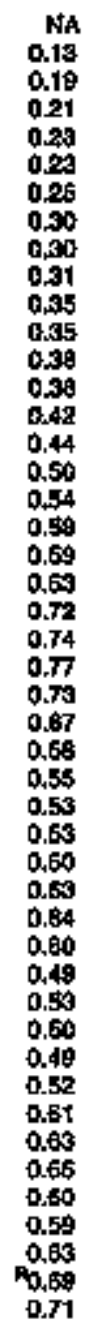 & 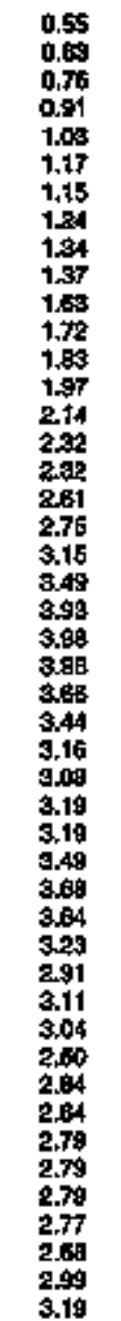 & 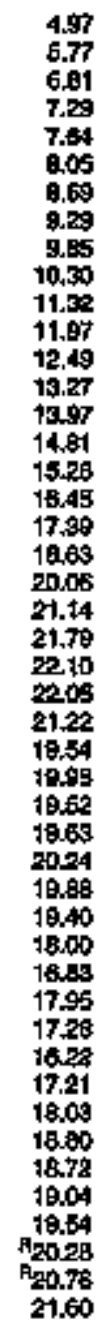 \\
\hline
\end{tabular}




\section{Figure 6.7 Natural Gas in Underground Storage, End of Year 1954-1995}

Tolal

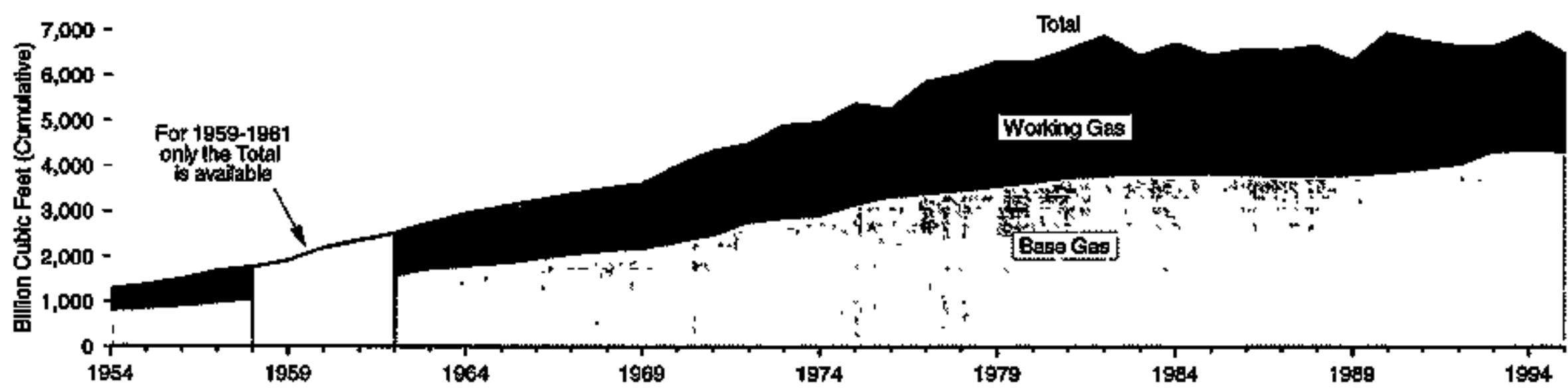

Base Gas and Working Gas

$5,000-$

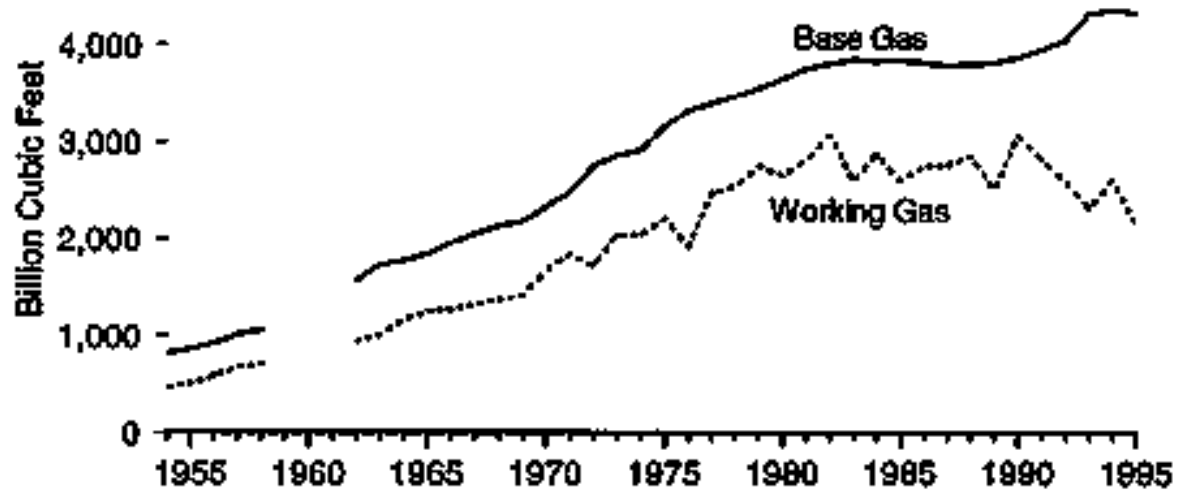

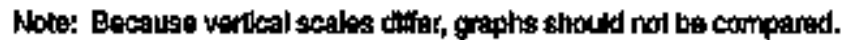

\section{End-of-Year Storage at a Share of Total Consumption}

50 -

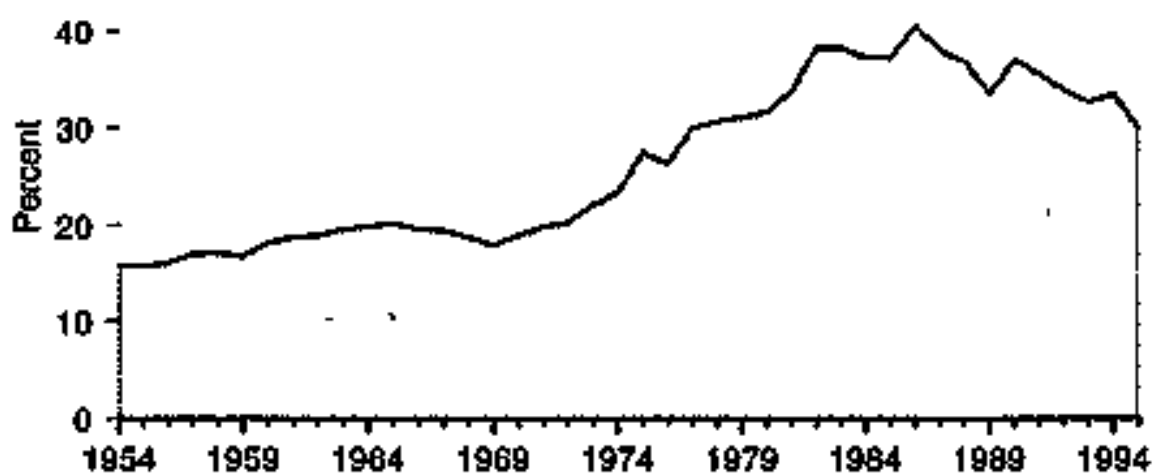

Sounces: Tables 6.6 and 6.7 . 
Table 6.7 Natural Gas in Underground Storage, End of Year 1954-1995

(Billion Cubio Feet)

\begin{tabular}{|c|c|c|c|}
\hline$r=r$ & Barte Gan 1 & Worktng Gas. & Totaly 1 \\
\hline 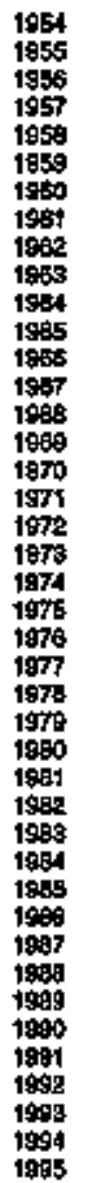 & 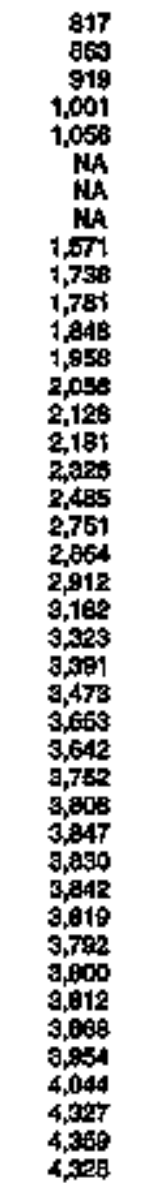 & 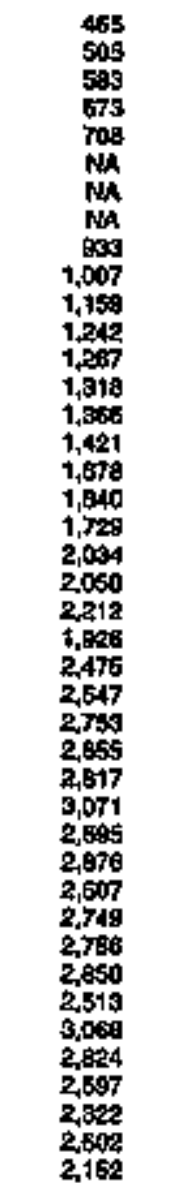 & 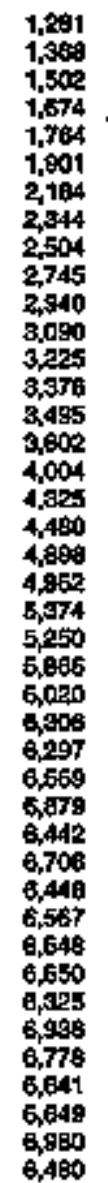 \\
\hline
\end{tabular}

1 motudes nathe pos.

NA=Nat ovallable.

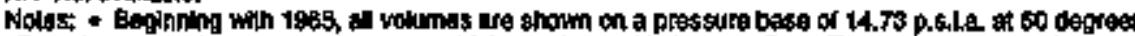

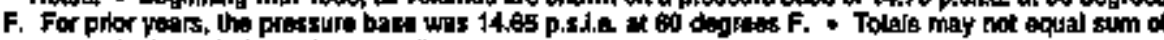

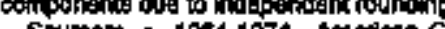

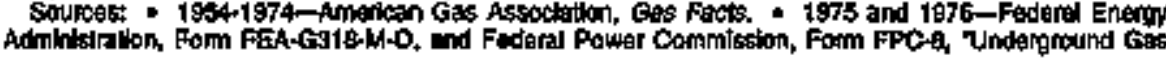

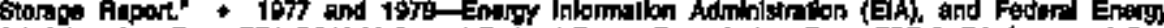

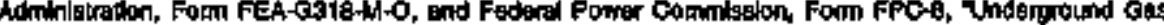
cor

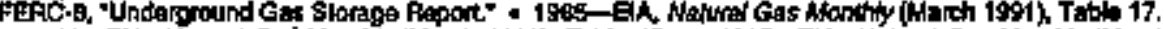

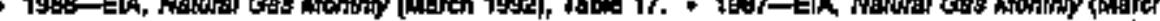

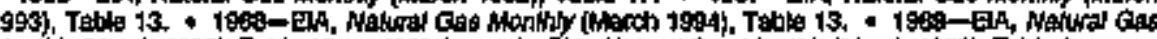

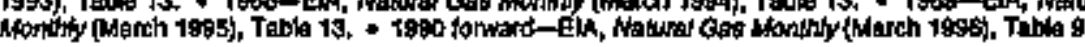




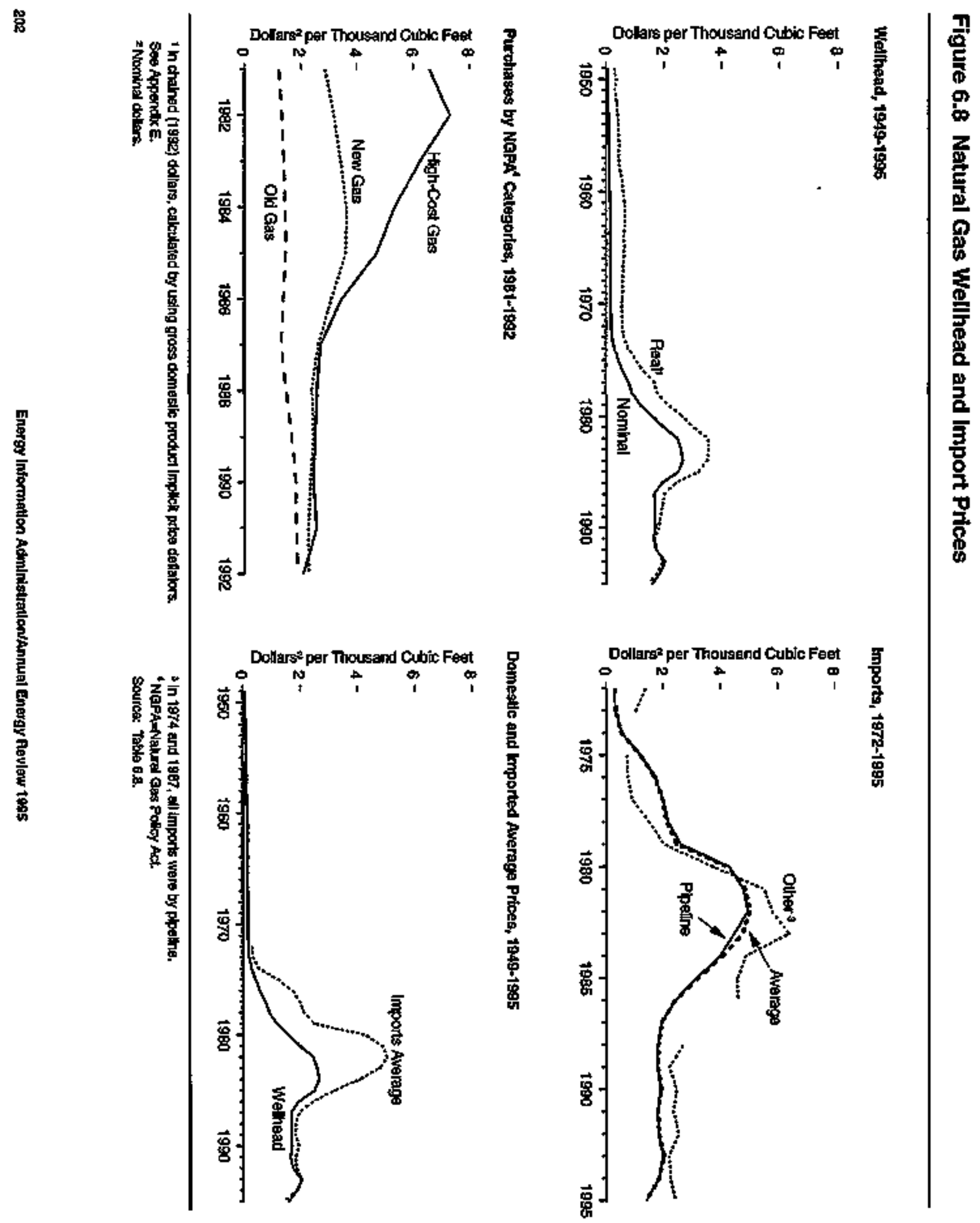


Table 6.8 Natural Gas Wellhead and Import Prices, 1949-1995 (Dollars per Thousand Cubic Feet)

\begin{tabular}{|c|c|c|c|c|c|c|c|c|}
\hline \multirow[b]{3}{*}{ Year } & & & \multicolumn{3}{|c|}{ 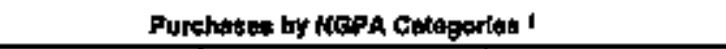 } & \multicolumn{3}{|c|}{ mporte } \\
\hline & \multicolumn{2}{|c|}{ Wellhead ${ }^{2}$} & \multirow{2}{*}{ Old Ga: } & \multirow{2}{*}{ 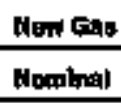 } & \multirow{2}{*}{ 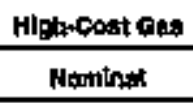 } & \multirow{2}{*}{$\begin{array}{l}\text { Pipolina } \\
\text { Alomitren }\end{array}$} & \multirow{2}{*}{$\begin{array}{c}\text { Othar * } \\
\text { Nóninital }\end{array}$} & \multirow{2}{*}{ Averape } \\
\hline & Momines & Fital 4 & & & & & & \\
\hline 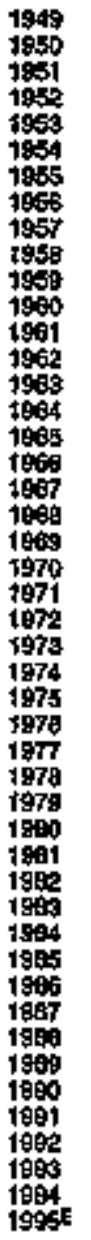 & 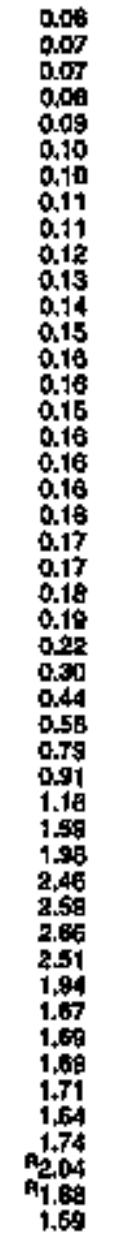 & 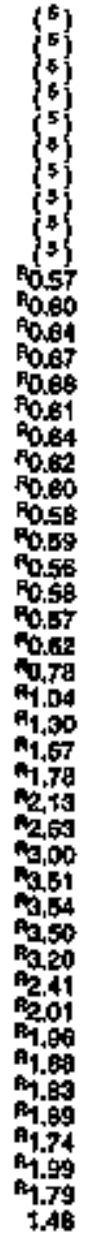 & $\begin{array}{l}\bar{z} \\
= \\
= \\
= \\
= \\
= \\
= \\
= \\
= \\
= \\
= \\
= \\
= \\
= \\
= \\
= \\
= \\
= \\
\bar{z} \\
1.29 \\
1.34 \\
1.45 \\
1.47 \\
1.39 \\
1.49 \\
1.69 \\
1.94 \\
1.91 \\
= \\
=\end{array}$ & 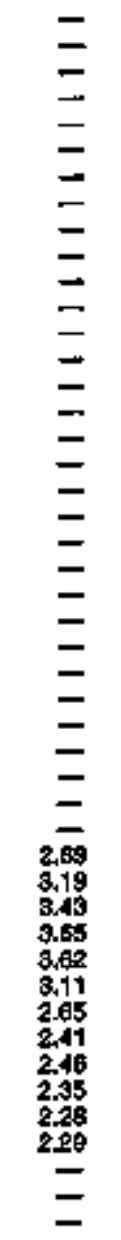 & $\begin{array}{l}= \\
= \\
= \\
= \\
= \\
= \\
= \\
= \\
= \\
= \\
= \\
= \\
= \\
= \\
= \\
= \\
= \\
= \\
= \\
6.58 \\
7.31 \\
625 \\
4.71 \\
3.48 \\
272 \\
2.61 \\
2.58 \\
2.65 \\
2.40 \\
= \\
=\end{array}$ & 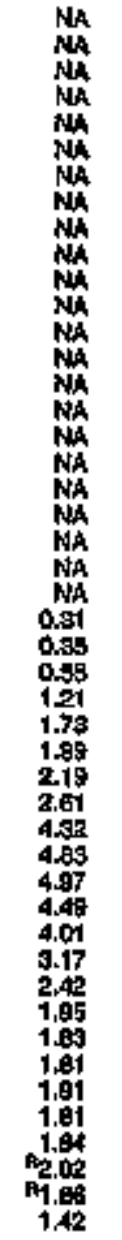 & 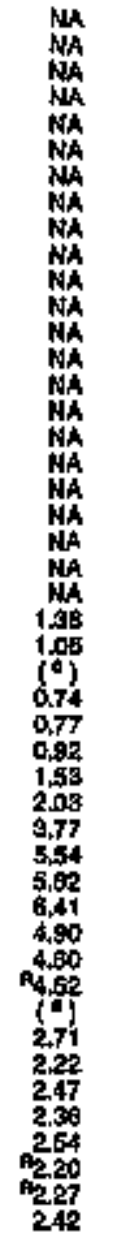 & 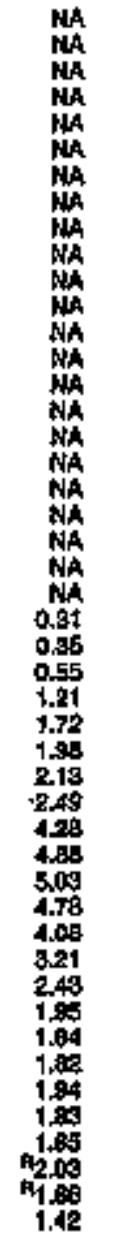 \\
\hline
\end{tabular}

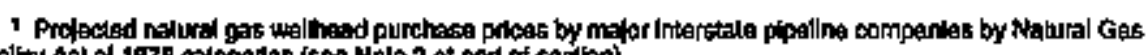

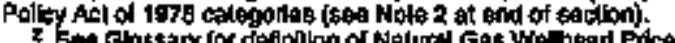

Primer

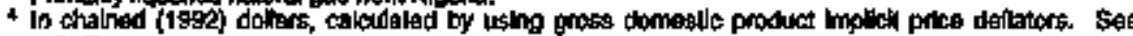

Appencix E.

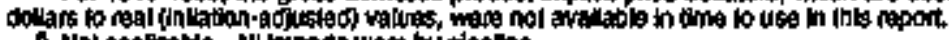

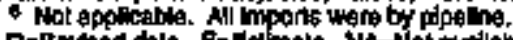

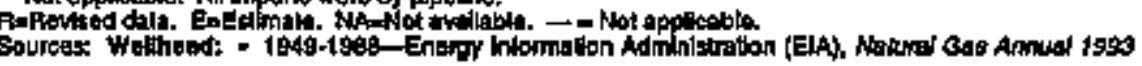

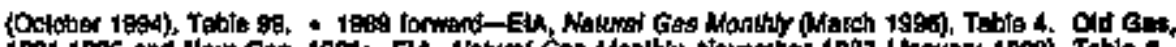

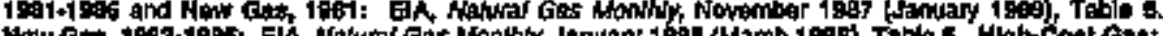

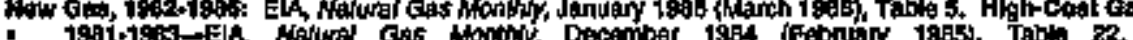
- rast 1006 -

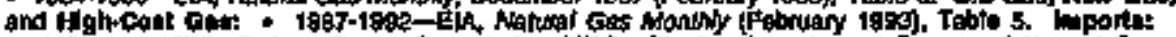

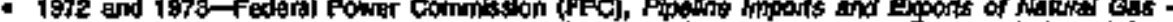

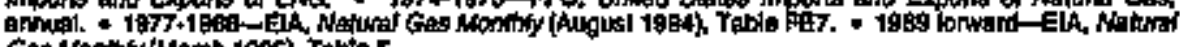
Gas Msonthyt (NAarth 1996), Tabte 5 . 


\section{Prices, 1895}

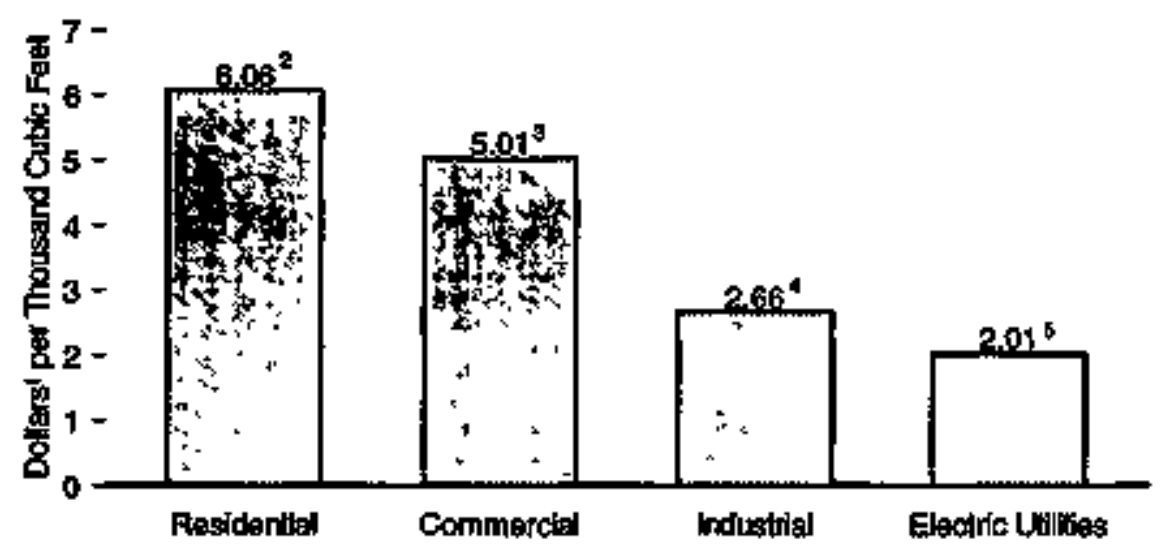

\section{Prices indexed, 1867-1995}

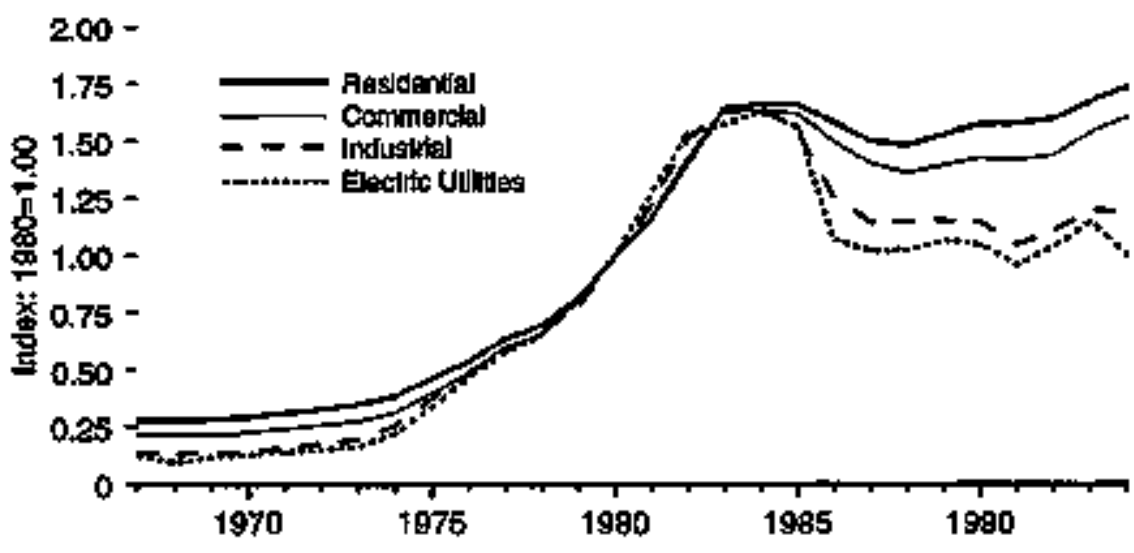

\section{Prices, 1967-1995}
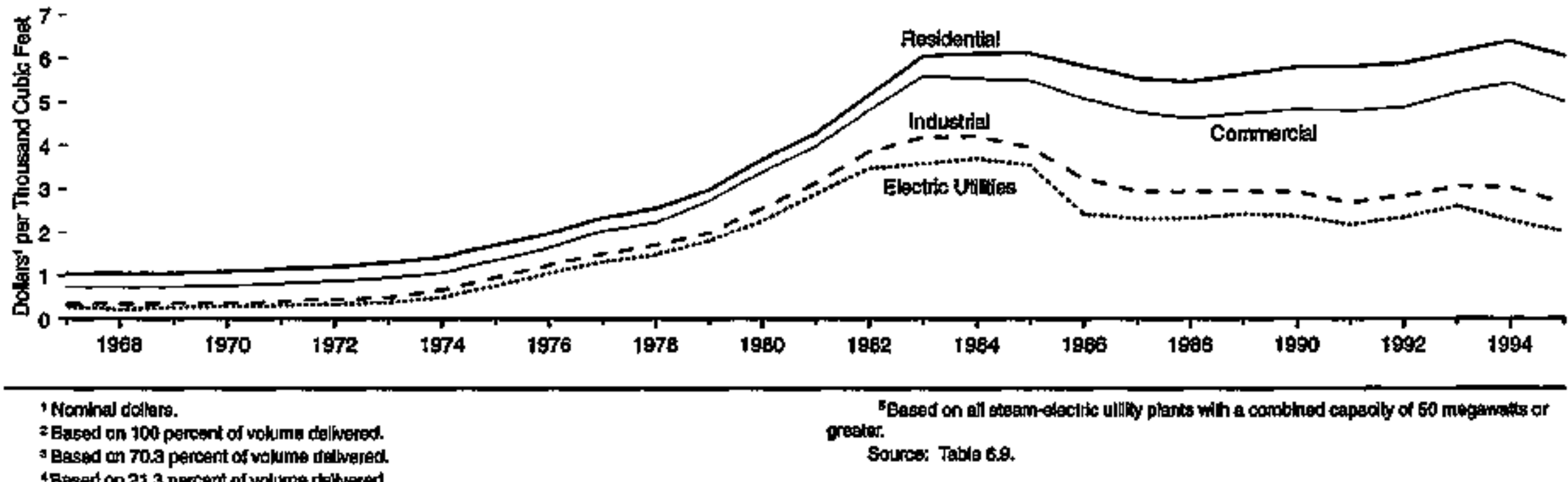

Induskiflel

Commenclal

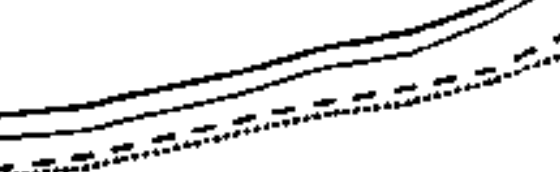

Election vilities
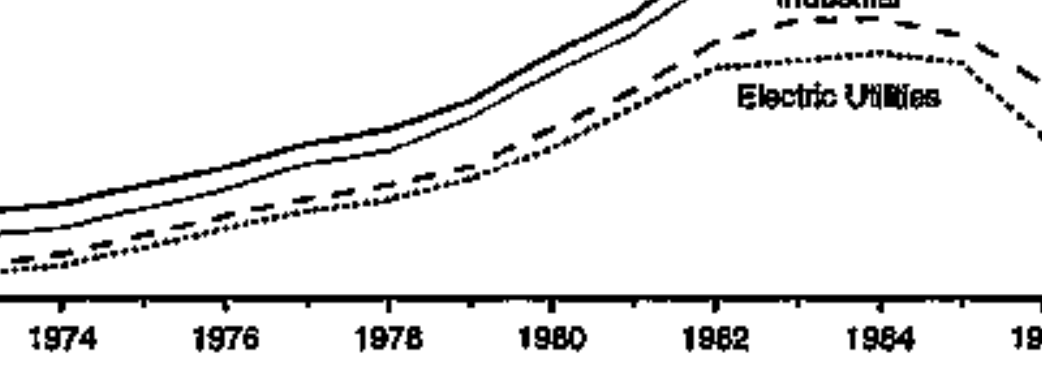

$1978 \quad 1980$

$1989 \quad 1984$

1968

1898

1092

1994

Nominal dollers.

Besed on 70 a percent of volume iflatwered.

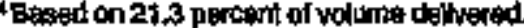

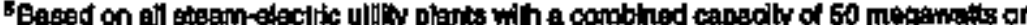
prestor.

Source: Table 6.9. 
Table 6.9 Natural Gas Prices by Sector, 1967-1995

(Price: Dollars' per Thousand Cubic Feet; Share of Total Volume Delivered: Percentage)

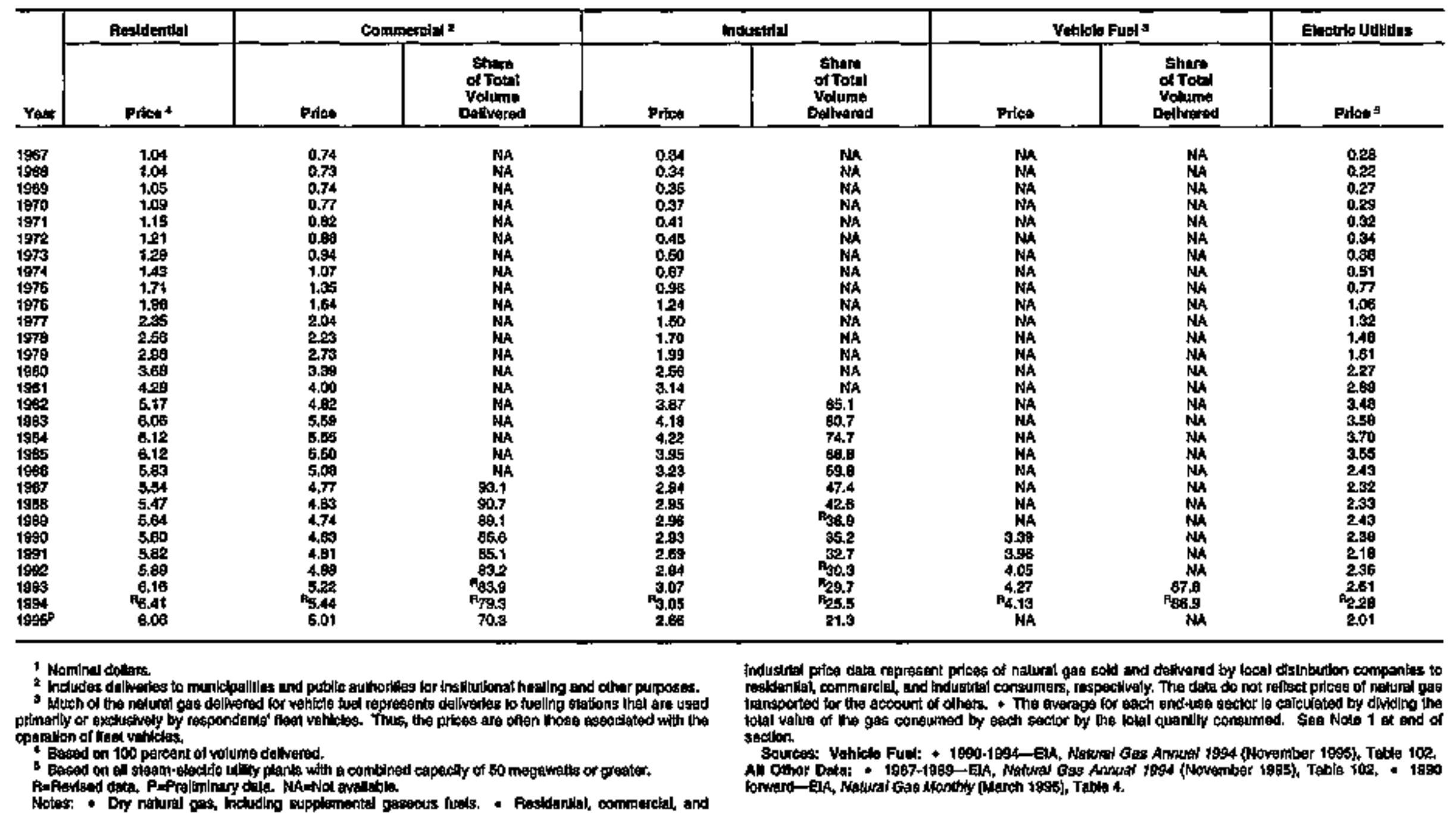




\section{Natural Gas Notes}

1. Natural gas consumption statistics are compiled from surveys of natural gas production, transmission, and distribution companies and electric utility companies. Consumption by sector from these surveys is compiled on a national and individual State basis and then balanced with national and individual State supply data. Included in the data are the following: Commercial Sector-consumption by nonmapufacturing establishments, by municipalities for institutional heating and lighting, and those engaged in agriculture, forestry, and nishing; Electric Utility Sector-constmption by electric utilities for the generation of electric power; Industrial Sector-consumption by establishments engaged primarily in processing unfinished materials into another form of product (includes mining, petroleum Jefining, manufacturing, and natural gas industry use for lease and plant fuel); Residential Sector-consumption by ptivate households for space heating, cooking. and other household uses; Transportation Sector-natural gas transmission (pipeline) fuel.

\section{Natural Gas Prices by Natural Gas Policy Act of 1978 (NGPA)}

Categories: Old Gas: Includes natural gas dedicated to interstate commerce and natural gas purchased under existing interstate or rollover contracts (NGPA Sections 104, 105, and 106). New Gas: Includes new natural gas and certain natural gas produced from the Outer Continental Shelf, stripper wel] gas, and other new gas categories (NGPA Sections 102, 103, 108, and 109). High-Cost Gas: Includes natural gas from deep wells and low permeability (tight) reservoirs and unregulated gas (NGPA Section 107). 


\section{Changing Patterns of Coal Production}

In 1995, estimated production of all types of coal totaled 1,030 million short tons, the second highest total ever (7.1)** The 1995 total was 3.8 million short tons below the 1994 record level of 1,034 million short tons.

Of all coal production, bituminons and subbituminous coal accounted for by far the largest share (91 percent) in 1995 (7.2). Lignite and anthracite accounted for the remainder of coal prodnced. Anthracite, which is mined in northeastern Pennsylvania and is known for its superior burning qualities, accounts for a diminishing share of total coal production. In 1949, arthracite accounted for 8.9 percent of the total; by 1995 , its share had shrunk to 0.4 percerit.

More coil is mined east of the Mississippi than in the West, but the West's share of total production incressed almost every year after 1965 (7.2). That year, prodaction of western coal was 27 million short tons, 5.2 percent of the total. By 1995, western production bad increased by a factor of 18 , to 488 million short tons ( 47 percent of the total). The growth in western coal production was due in part to environmental concerns that led to increased demand for low-sulfur coal, which is concentrated in the West. In addition, surface mining, with its bigher average productivity, is much more prevalent in the West.

Production of coke, which is generally made from bituminous coal, trended downward during the 1949-to-1995 period, particularly after 1981. In 1995, coke production totaled 24 million short tons (7.7). The decline in coke production was due to a decline in the use of coke by the U.S. iron and steel industry, the principal consumer of coke.

\section{Domestic Markets: Changes in Coal End Use}

Electric utilities are the dominant consumers of coal (7.3). Their consamption grew from 84 million short tons, a 17-percent share, in 1949,

Numbers in panentheses incticale related tables. Anmual clata are the most recent

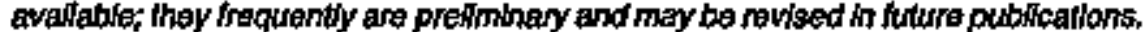
Percenlages and numbers in led are calculstod by using dats in the tables. to 829 million short tons, an 88-percent share, in 1995. By contrast, consumption by all other economic sectors in 1995 was lower than it had been in 1949. The most dramatic declines occurred in the transportation sector, where railroads switched to petroleum, and in the residential and commercial sector. In 1949, those two sectors accounted for 187 million short tons, 39 percent of total coal consuniption. By 1995, their consumption totaled 5.8 million short tons, less than 1 percent of U.S. coal consumption.

Consumption by the industrial sector, including coke plants, trended downward after the mid-1960's. From 205 million short tons in 1966, industrial consumption fell to about 112 million short tons in 1986 and 1987. In 1988, growth in manufacturing activity was accomptnied by a modest increase in industrial constimption, which rose to 718 million short tons. In 1989, indnstrial consumption fell to 117 million short tons, and, through 1995, slow growth in the economy restrained industrial dernand for coal. In 1995, industrial consumption totaled 106 million short tons, down 1.0 percent from the 1994 lovel.

\section{Coal Mining Productivity}

The average productivly of all types of mhes in the United States increased each year trom 1948 io 1969, when II reached 2.4 short tons per miner hour (7.6). Productivily during the 1970's and early 1020 's was fower, due primarily to the coal industry's compliance with the Fedoral coal Mitne Health and Salety Act of 1969, as well as to emvironmentes and other lectors.

The growing trapertance of surface casl mining, where productivily is generally higher than for underground mining and the closing of non-productive mines, led to increases in average productlvity durIng the 1980's and 1990's. In 1994, average producthity in all types of mirres (excluding anthracite) reached an ell-time high of 5.0 short tons per miner hour. That year, producllwity of underground mines (excluding anthractite) was 3.2 short tons per miner hour and producthity of surtace mines (exckiding anthracite) was 7.8 short tons por miner hour. 


\section{Foreign Markets}

Since World War II, coal has been the United States' major energy ex. port (1.4). Throughout most of the 1960's and 1970's, U.S. exports of coal increased, peaking at 113 million short tons in 1981 (7.4). Increased shipments to Canada, Japan, and European markets contributed to the growth. The level of U.S. coal exports fluctuated throughout the $1980^{\circ}$ 's, falling as low as 78 million short tons in 1983 but attaining 95 million short tous in 1988 . That year, difficulties experienced by competing countries (particularly China, Australia, and Poland) allowed the United States to recapture some export markets, and thereafter coal exports rose each year through 1991, when coal exports totaled 109 million short tons. In 1992, coal exports fell to 103 millton short tous and in 1993, the continuing weakness of the European economy and ongoing subsidies for domestic European coal caused exports to fall dramatically to 75 million short tons. In 1994 , coal exports fell to 71 milition short tons, the lowest level in 15 years. In 1995, however, coal exports to almost all countries increased and the U.S. total rose to 89 millton short tons, up 24 percent from the 1994 level. Japan, Canada, and Itaiy remained the three largest foreign purchasers of U.S. coal.

\section{Prices}

In 1995, the avertige real price' of bituminous coal and tignite at the minemouth fell to $\$ 17.67$ per short ton, down for the sixteenth year in a row (7.8). The 1995 price was less then half of the peak roal price of $\$ 45.57$ per short ton recorded in 1975 . The average real price of anthracite of $\$ 33.95$ per short ton was also well below the 1975 peak of $\$ 76.45$ per short ton. The decline in coal prices was the result of gains

'Real (inflation-adjosied) prices are expressed in chained (I992) dotlars. in productivity, the expanded use of longwall mining in underground mines, and the increased use of less-expensive western coal.

From 1961 on, electric utilities were the primary consumers of coal (7.3). Throughout the $1960^{\prime} \mathrm{s}$, the average real price of coal delivered to electric utilities declined (7.8). However, when prices of other fossil fuels rose rapidly after 1973, coal prices at electric utilities also increased, from $\$ 25.45$ per short ton in 1973 to $\$ 40.16$ per short ton the following year. (Despite that increase, coal remained the least expensive fossil fuel, on a Btu basis.) The price of coal at olectric utilities gradually rose after 1974 , peaking at $\$ 49.80$ per short ton in 1982 , and then declined each year through 1995 , by which time the price had fallen to $\$ 25.20$ per short ton.

\section{Stocks}

Although there is littie seasonal variation in demand, production of coal can vary considerably due to such factors as coal miners' strikes and bad weather. To compensate for possible supply interruptions, coal producers and distributors, as well as such major consumers as electric utilities and coke plants, generally maintain large stockpiles. For example, wildcat strikes in 1989 resulted in year-end stocks of 175 mitlion short tons, the lowest level since 1978 (7.5). Similarly, in 1993, a series of strikes by the United Mine Workers of America led to lower levels of coal production and stocks were drawn down to compensate. At yeat end, coal stocks totaled 146 million short tons. In 1994, a major stock bulld-up by electric utilities brought year-end stocks to 169 million short tons, and, in 1995, year-end stocks remained at that level.

In 1995, electric utilities held three-fourths of the coal, and coal producers and distributors held most of the remainder. Stocks at coke plants and other industrial sites were relatively small. 


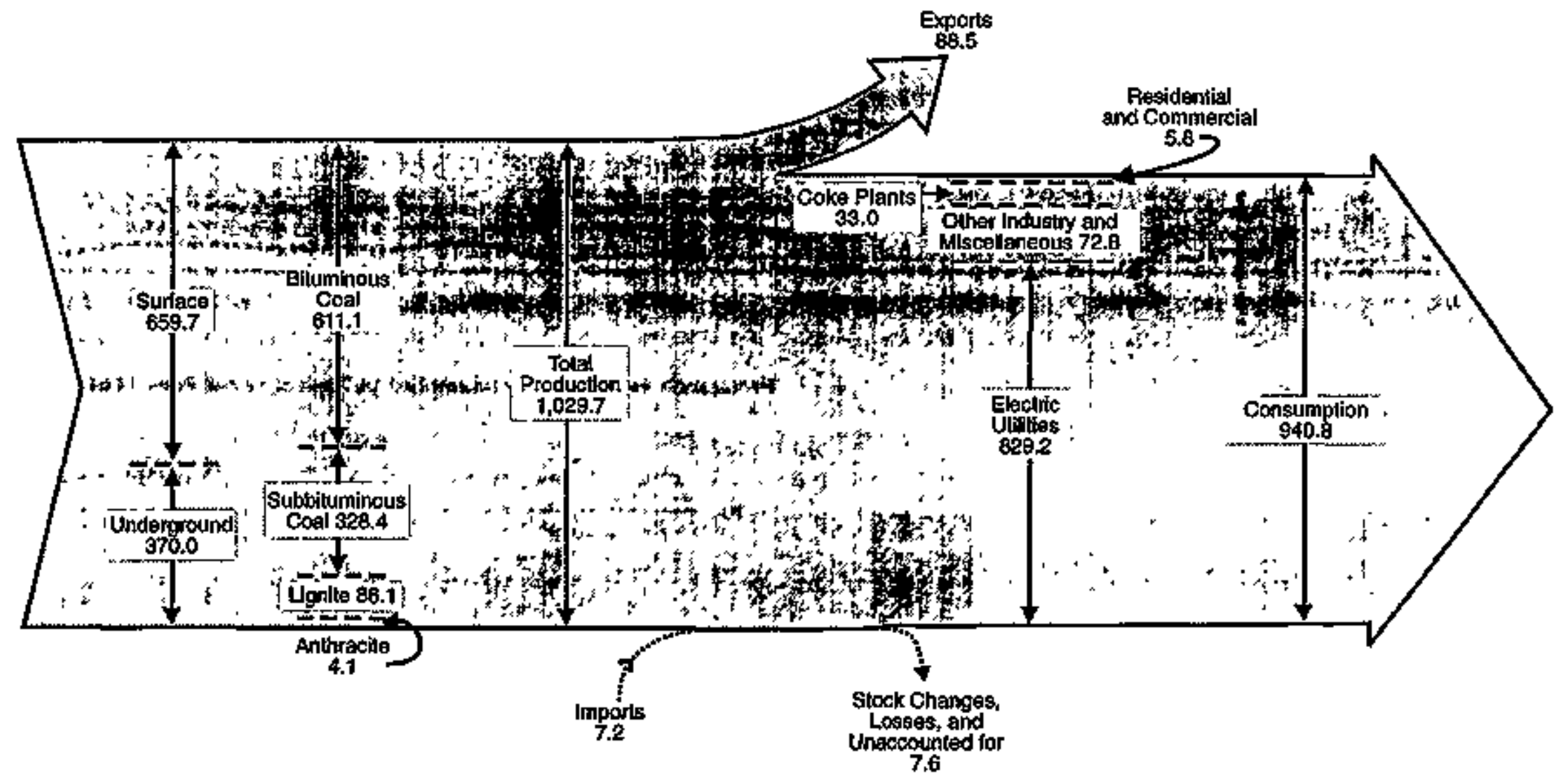




\section{Flgure 7.1 Coal Overview}

\section{Overview, t949-1995}

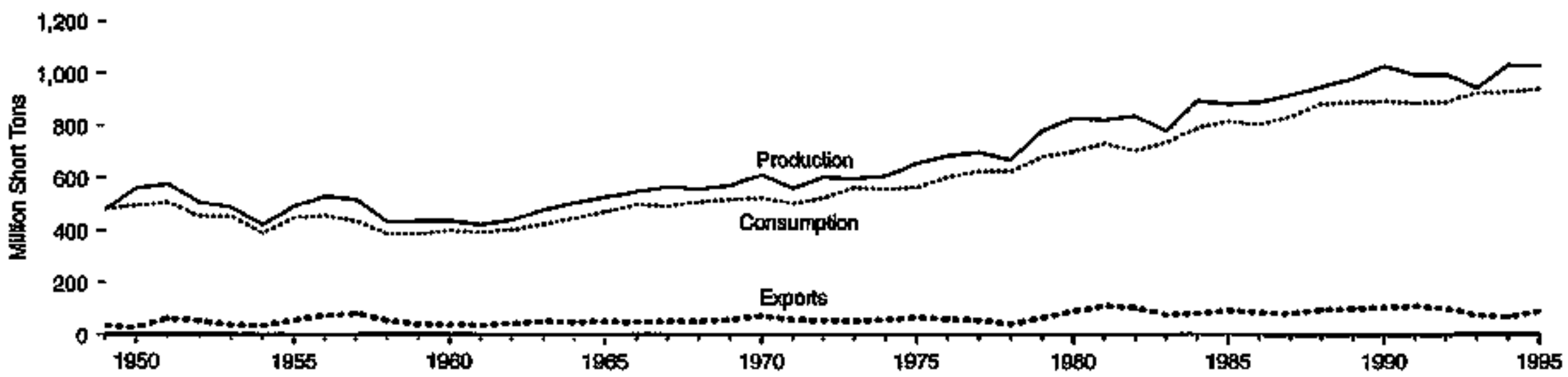

\section{Overvlew, 1995}

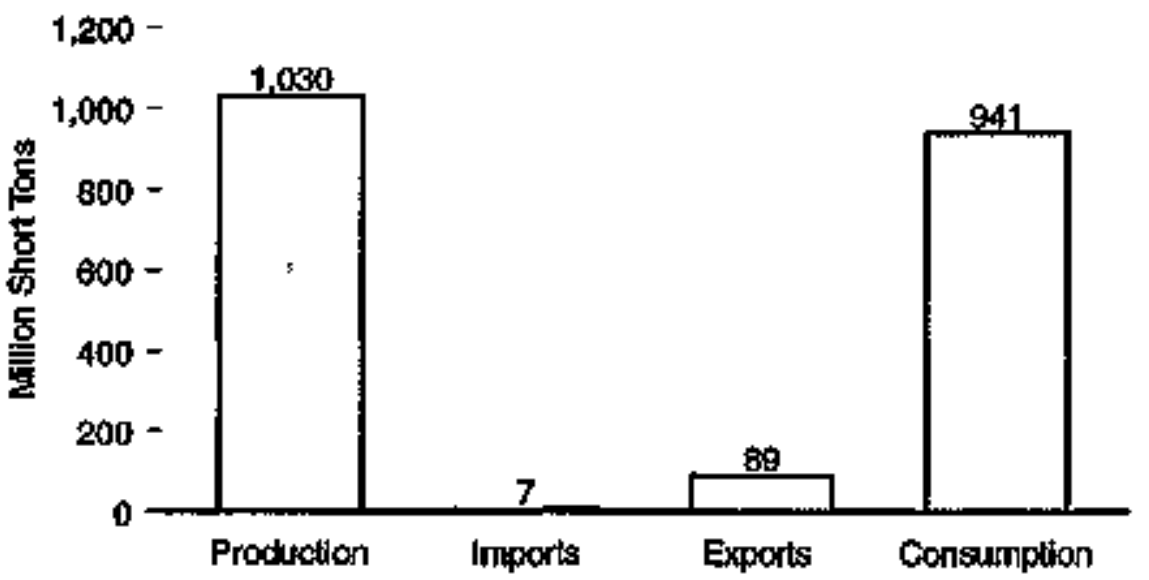

Production as Share of Consumption by Type of Fossil Fuel, 1949-1995

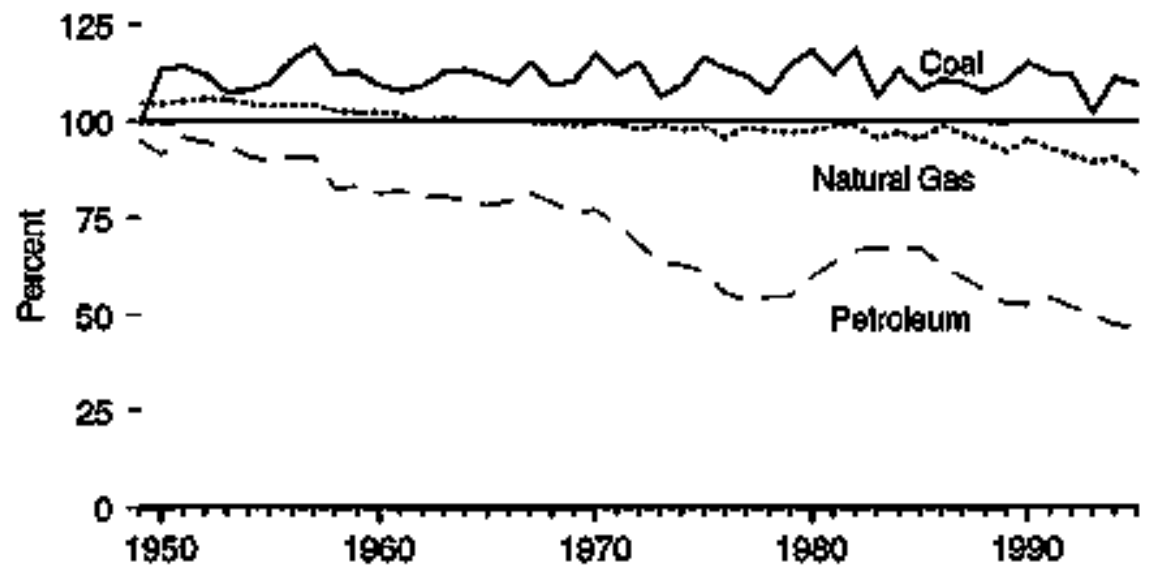

Sources: Tables 5.1, 6.1, and 7.1. 
Table 7.1 Coal Overview, 1949-1995

(Million Short Tons)

\begin{tabular}{|c|c|c|c|c|c|}
\hline Yar & Production & Importa & Exponts & $\begin{array}{l}\text { Slook } \\
\text { Changes, Losson, and } \\
\text { Unnicoounded for i }\end{array}$ & Contumpingtun \\
\hline 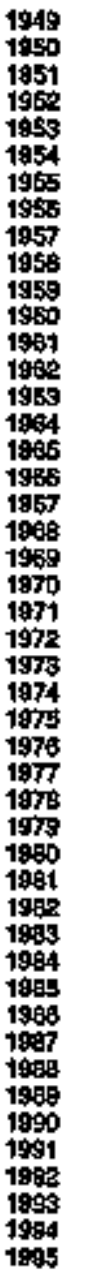 & 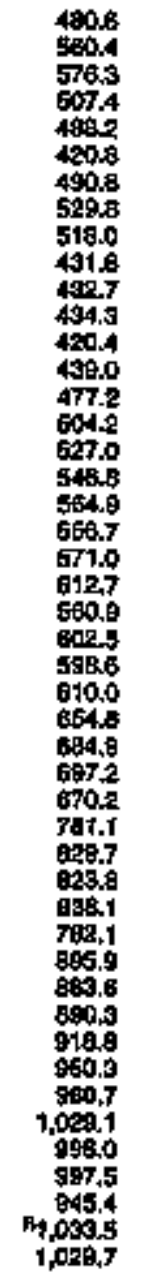 & $\begin{array}{l}0.3 \\
0.4 \\
0.3 \\
0.3 \\
0.3 \\
0.2 \\
0.3 \\
0.4 \\
0.4 \\
0.3 \\
0.4 \\
0.3 \\
0.2 \\
0.2 \\
0.3 \\
0.3 \\
0.2 \\
0.2 \\
0.2 \\
0.2 \\
0.1 \\
(5 .) \\
0.4 \\
(3) \\
0.1 \\
2.1 \\
0.9 \\
1.2 \\
1.6 \\
3.0 \\
2.1 \\
1.2 \\
1.0 \\
0.7 \\
1.3 \\
1.3 \\
2.0 \\
2.2 \\
1.7 \\
2.1 \\
2.3 \\
2.7 \\
3.4 \\
3.0 \\
7.3 \\
7.6 \\
7.2\end{array}$ & 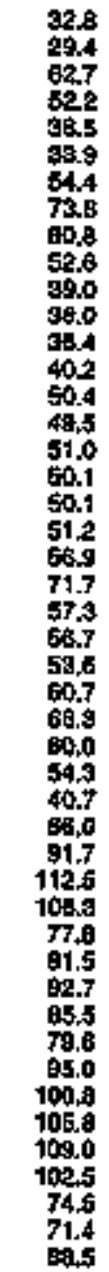 & 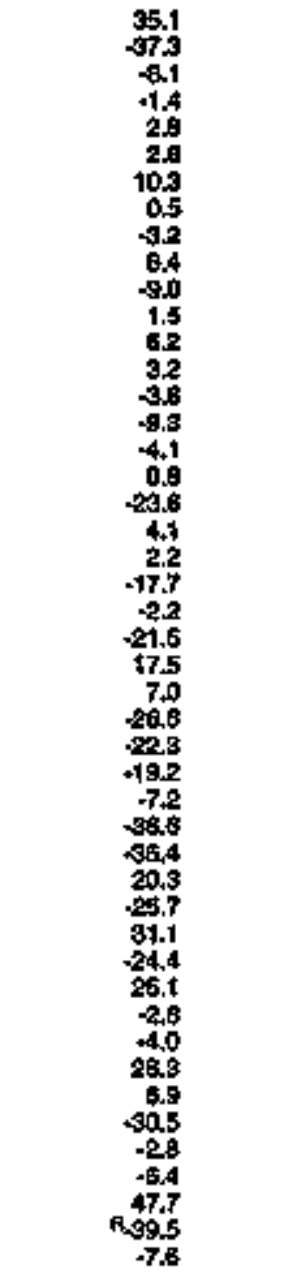 & 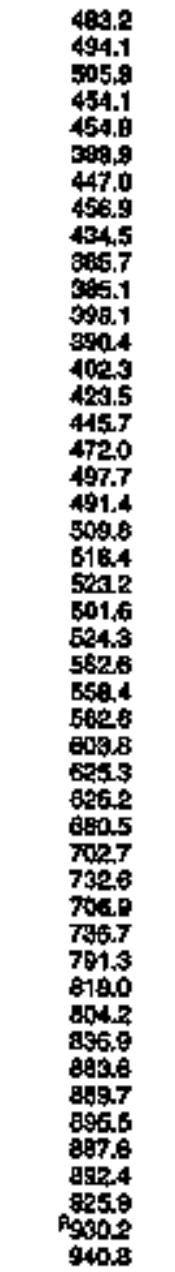 \\
\hline
\end{tabular}

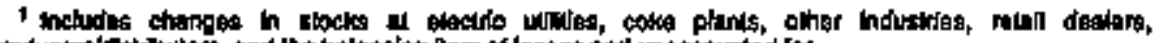

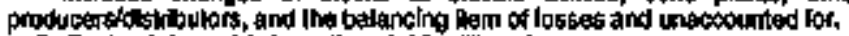

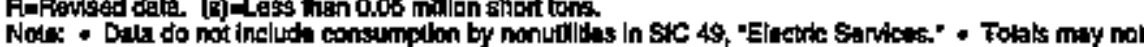

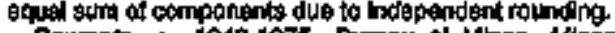

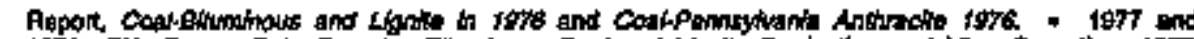

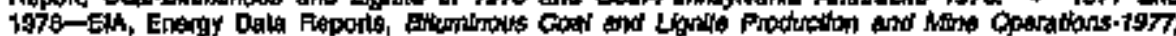

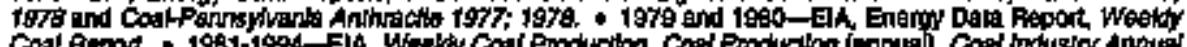

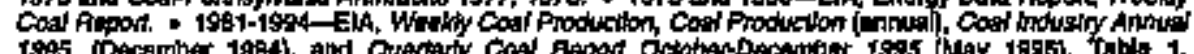

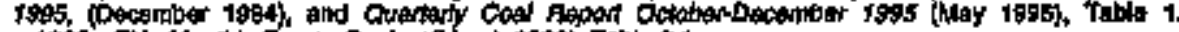

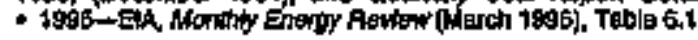




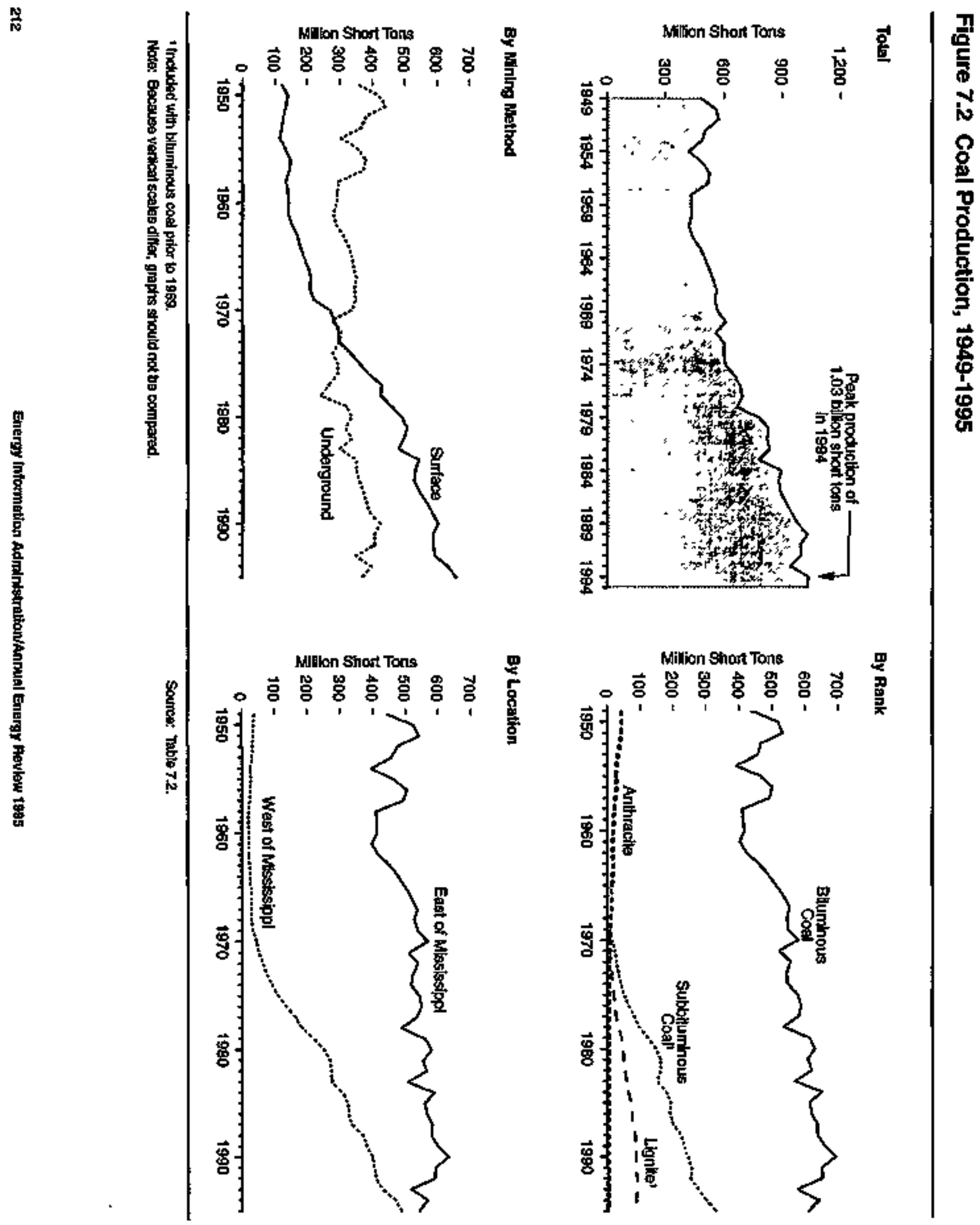


Table 7.2 Coal Production, 1949-1995

(Million Short Tons)

\begin{tabular}{|c|c|c|c|c|c|c|c|c|c|}
\hline \multirow[b]{2}{*}{ Yarr } & \multicolumn{4}{|c|}{ Rattok } & \multicolumn{2}{|c|}{ Mining Mathod } & \multicolumn{2}{|c|}{ Lachitos } & \multirow[b]{2}{*}{ Totnl } \\
\hline & $\begin{array}{c}\text { Bthuminos: } \\
\text { Co:til }\end{array}$ & $\begin{array}{c}\text { Subbliuninou: } \\
\text { Cow }\end{array}$ & 타 에 & Anthratitin & Bithlororound & Stuferes & 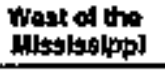 & 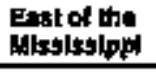 & \\
\hline 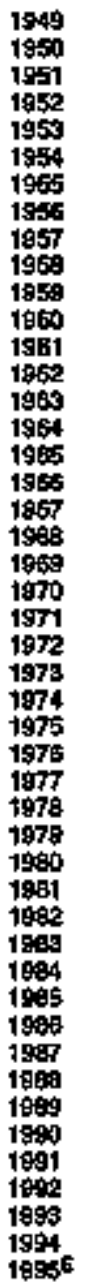 & 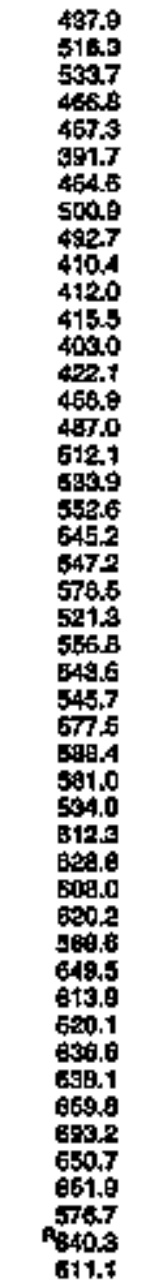 & 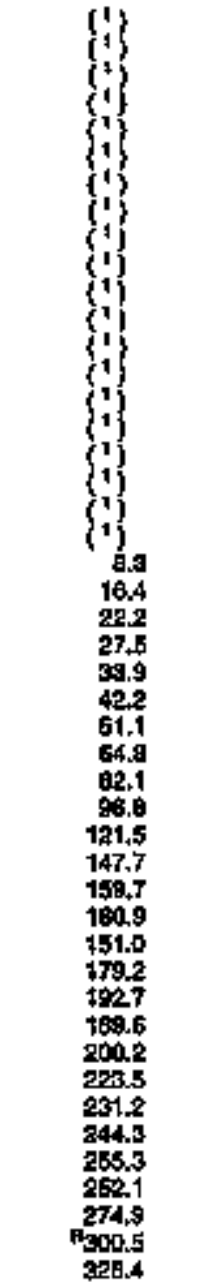 & 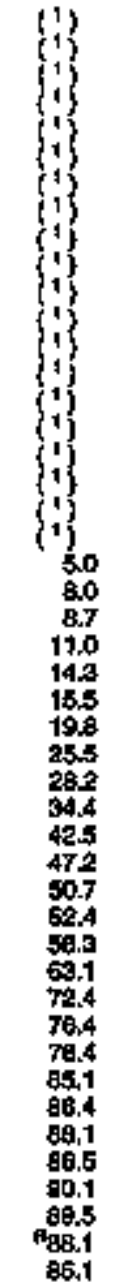 & 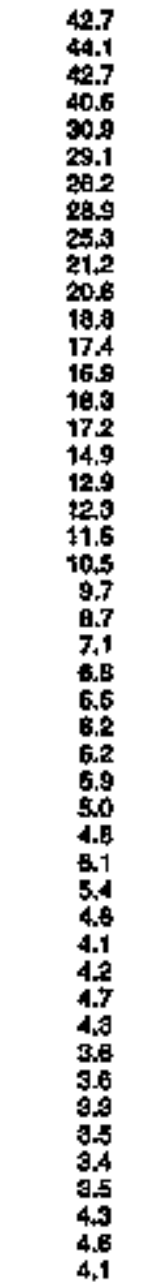 & 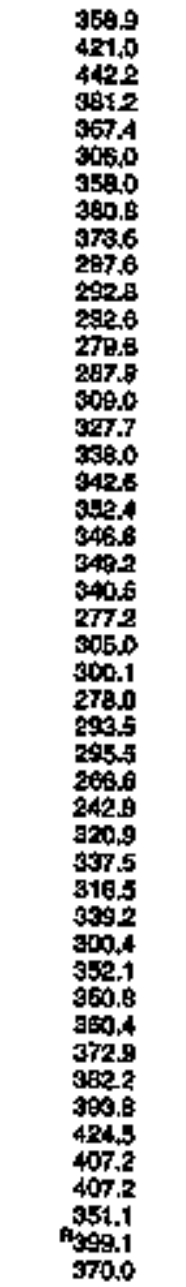 & 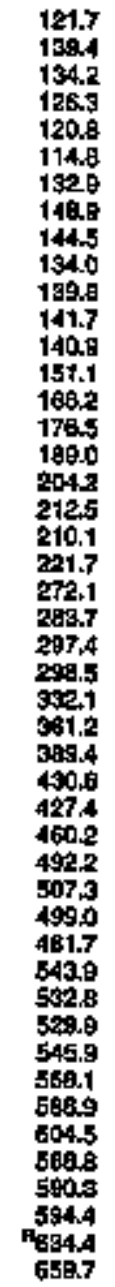 & 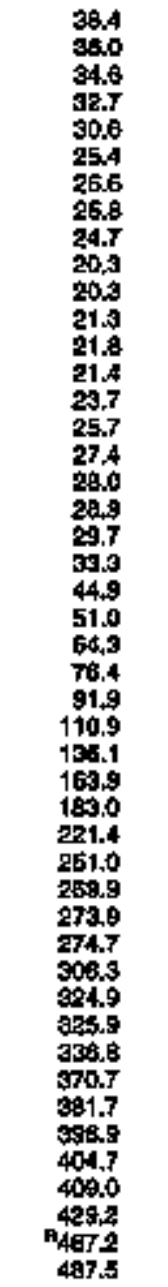 & 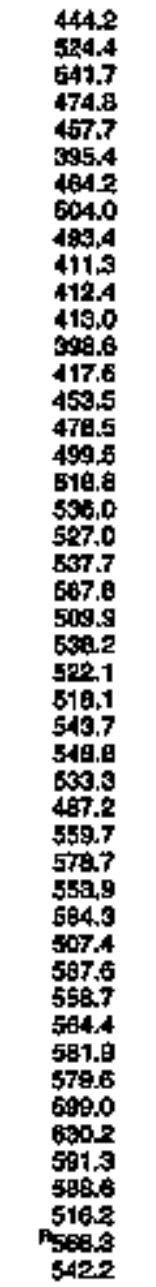 & 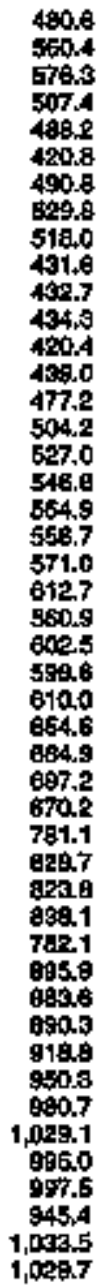 \\
\hline
\end{tabular}




\section{Figure 7.3 Coal Consumption by Sector}

\section{By Sector, 1949-1995}

$900-$

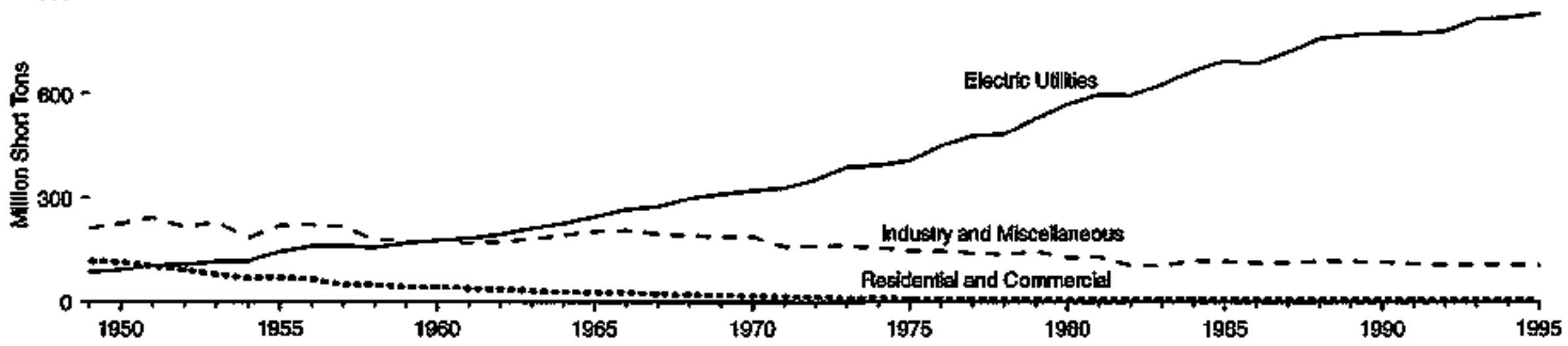

\section{By sector, 1995}

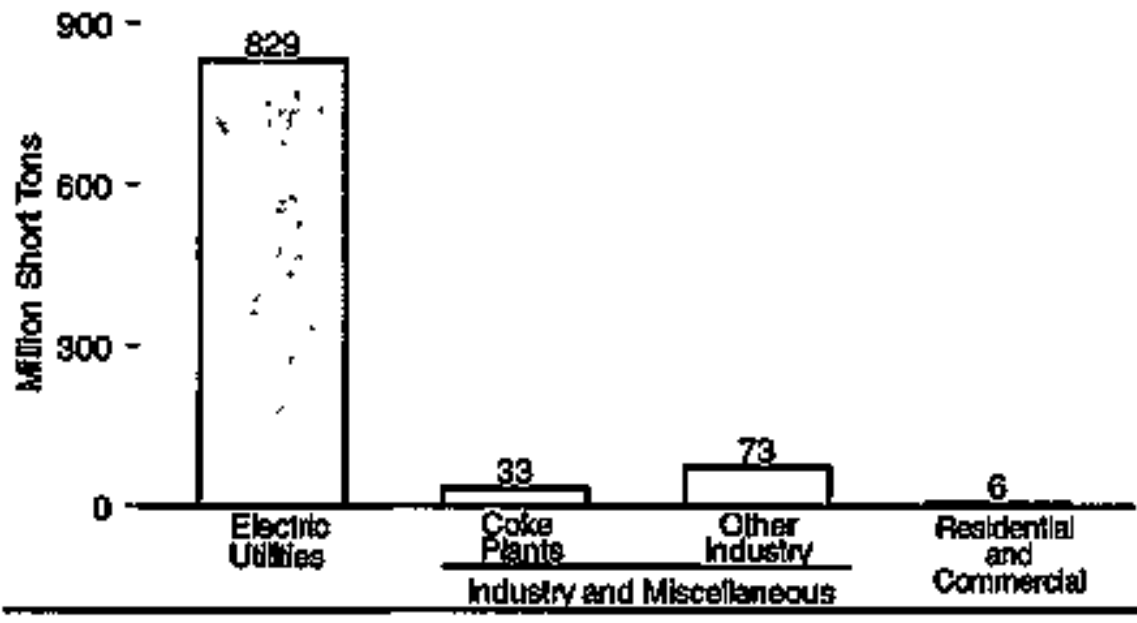

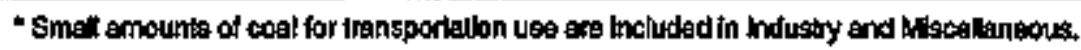

Shares by Sector, 1949 and 1995

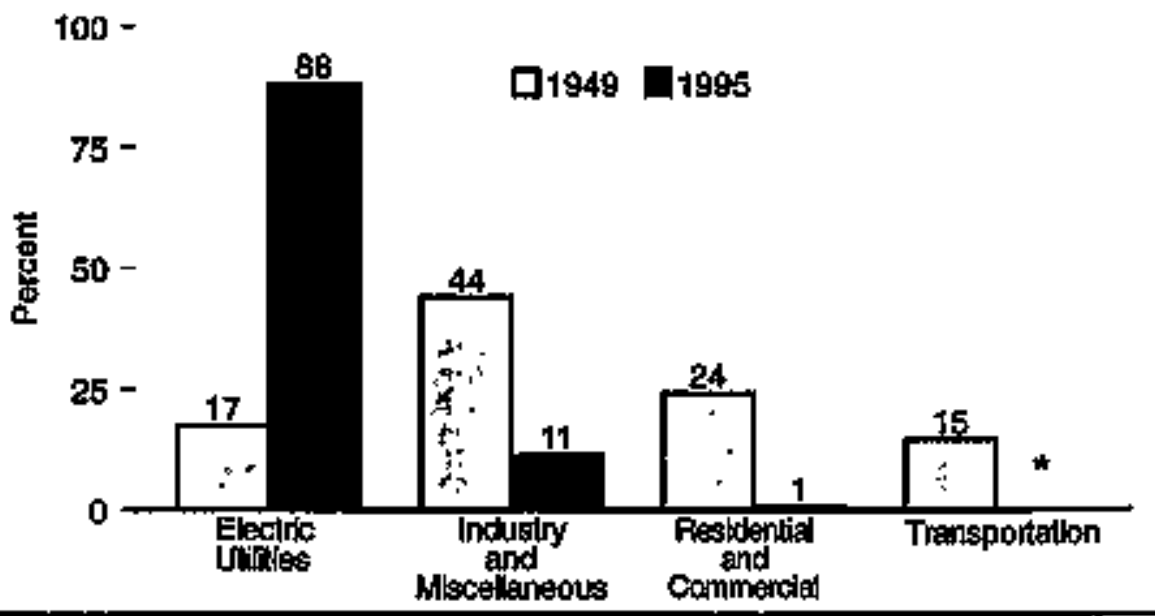

Sourcert Tato 7.3. 
Table 7.3 Coal Consumption by Sector, 1949-1995 (Milion Short Tons)

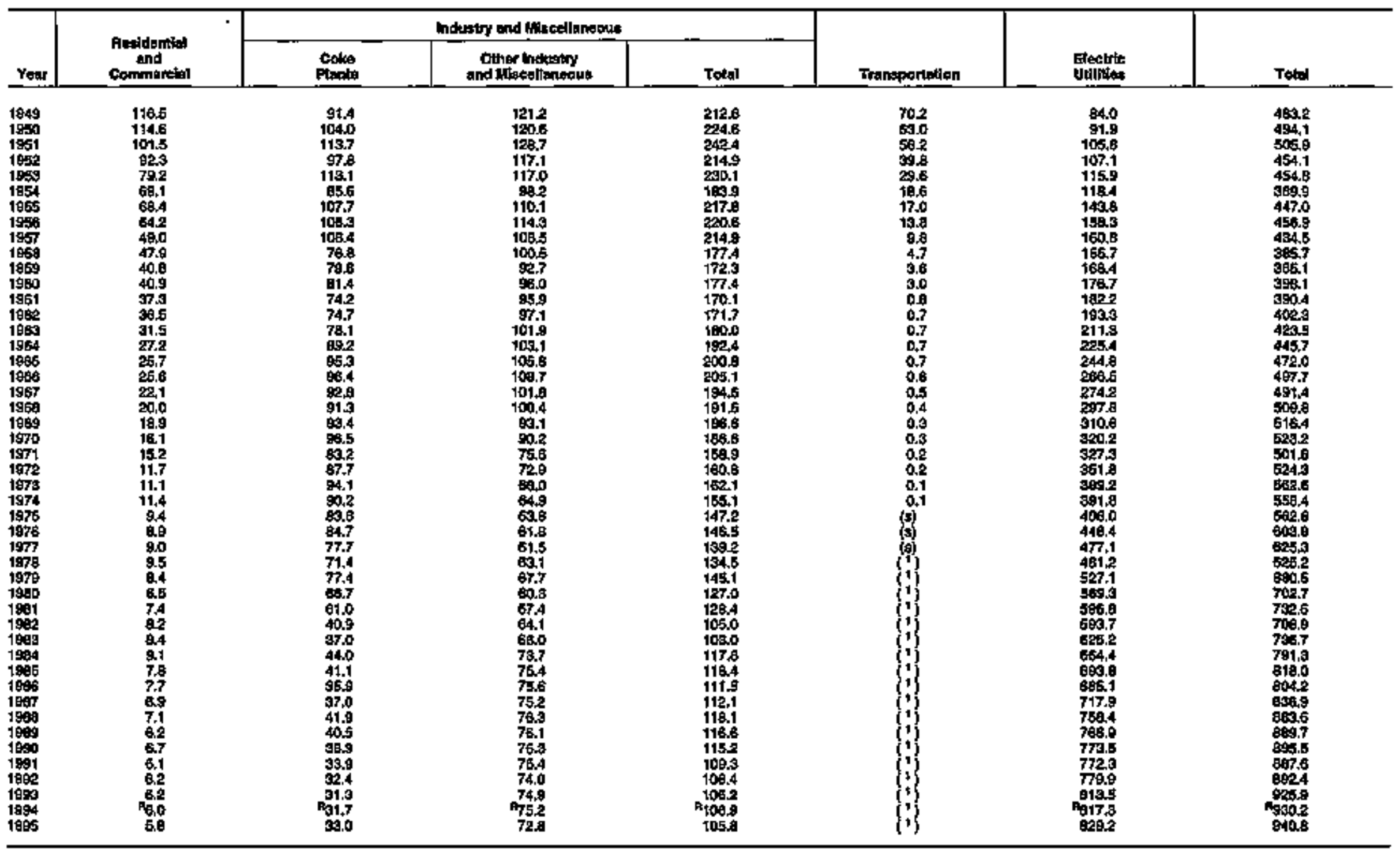

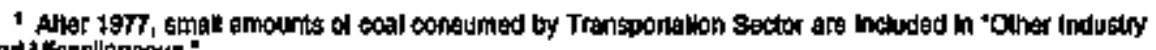

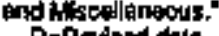

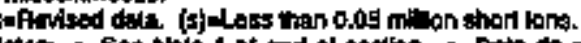

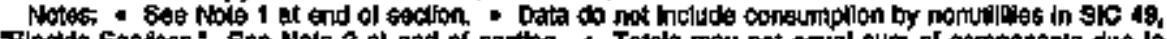

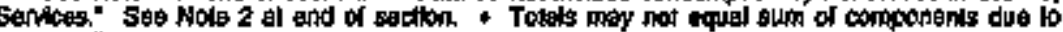

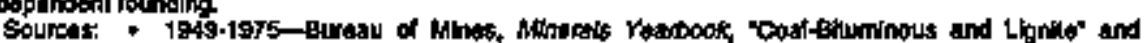

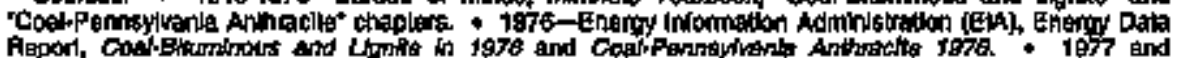

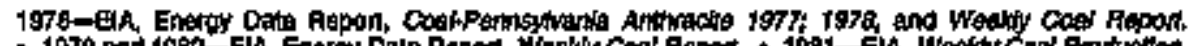

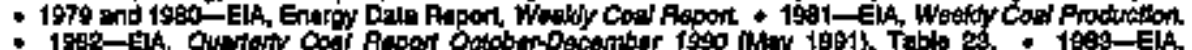

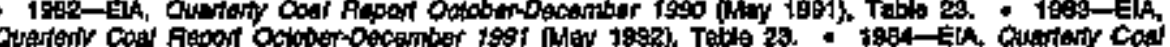

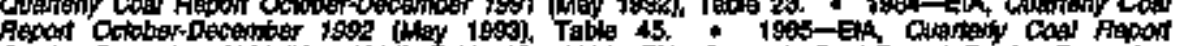

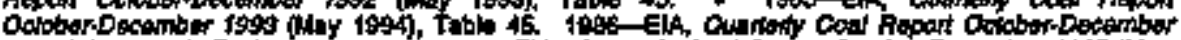

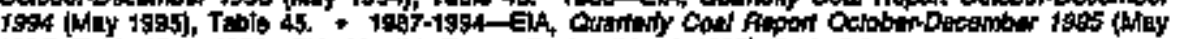

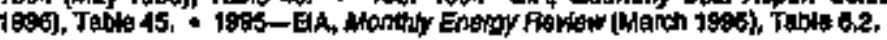




\section{Tolal and Europe, t980-1895}

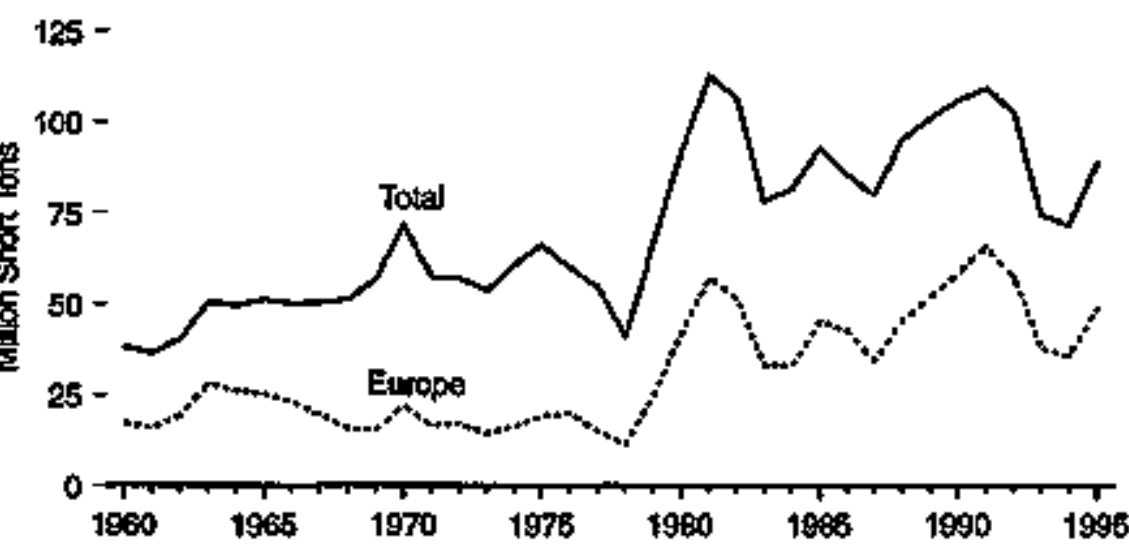

By Selected Country, 1998

18 -

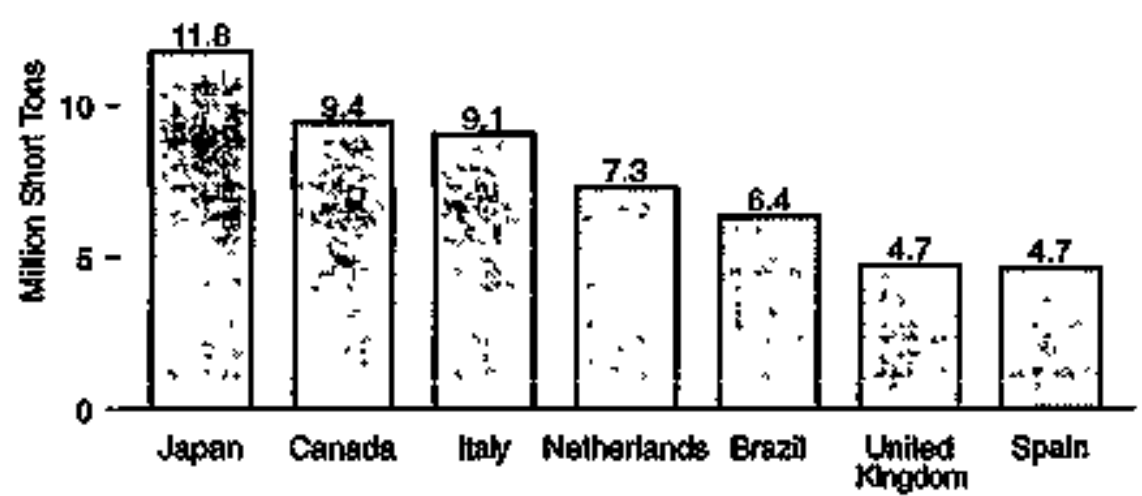

By Selected Country, 1980-1996

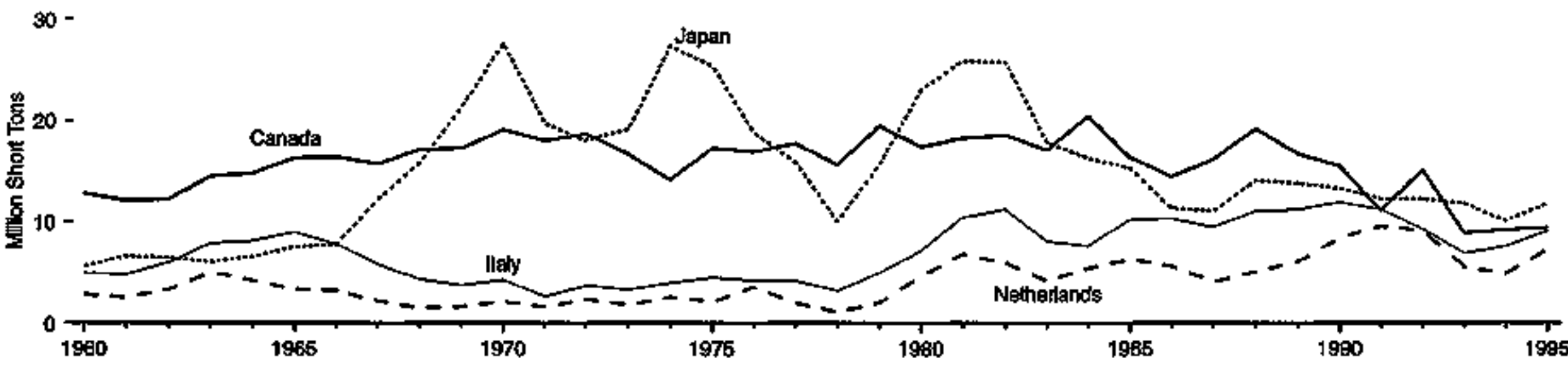


Table 7.4 Coal Exports by Country of Destination, 1960-1995 (Milion Short Tons)

\begin{tabular}{|c|c|c|c|c|c|c|c|c|c|c|c|c|c|c|c|}
\hline \multirow[b]{2}{*}{ Year } & \multirow[b]{2}{*}{ Cantata } & \multirow[b]{2}{*}{ Eraz: } & \multicolumn{10}{|c|}{ Etrape } & \multirow[b]{2}{*}{ 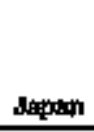 } & \multirow[b]{2}{*}{ Other } & \multirow[b]{2}{*}{ Totad } \\
\hline & & & $\begin{array}{c}\text { Befgium } \\
\text { Lutembourg }\end{array}$ & Deipmatk & Franses & cermany 1 & Paty & Weihertande & Spaln & $\begin{array}{l}\text { Untred } \\
\text { kingtingt }\end{array}$ & other & Toftel & & & \\
\hline 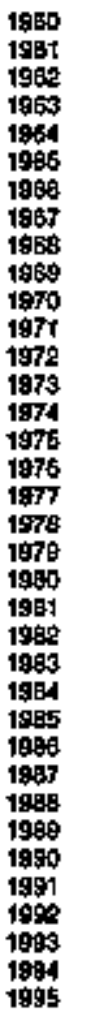 & 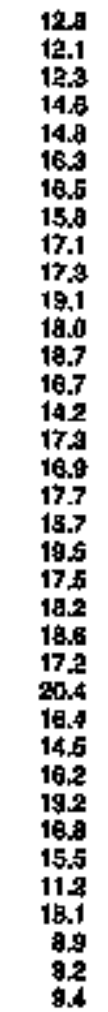 & $\begin{array}{l}1.1 \\
1.0 \\
1.3 \\
1.2 \\
1.1 \\
19.7 \\
1.7 \\
1.7 \\
1.8 \\
1.6 \\
2.0 \\
1.9 \\
1.9 \\
1.8 \\
1.3 \\
2.9 \\
2.2 \\
2.3 \\
1.5 \\
2.8 \\
3.3 \\
2.7 \\
3.1 \\
3.8 \\
4.7 \\
5.9 \\
5.3 \\
6.8 \\
5.3 \\
5.7 \\
6.9 \\
7.1 \\
6.4 \\
5.2 \\
5.5 \\
6.4\end{array}$ & $\begin{array}{l}1.1 \\
1.0 \\
1.3 \\
2.7 \\
2.3 \\
2.2 \\
1.9 \\
1.4 \\
1.1 \\
0.9 \\
1.9 \\
0.6 \\
1.1 \\
1.2 \\
1.1 \\
0.6 \\
2.2 \\
1.5 \\
1.1 \\
3.2 \\
4.6 \\
4.3 \\
4.9 \\
2.5 \\
3.5 \\
4.4 \\
4.4 \\
4.6 \\
6.5 \\
7.1 \\
8.5 \\
7.5 \\
7.2 \\
5.2 \\
4.9 \\
4.5\end{array}$ & 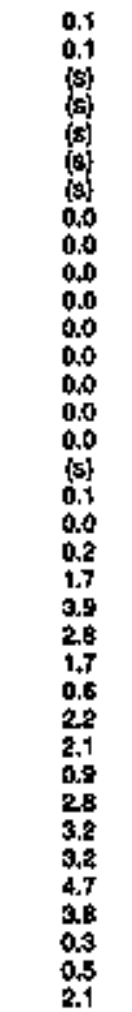 & $\begin{array}{l}0.9 \\
0.7 \\
0.9 \\
2.7 \\
2.2 \\
2.1 \\
1.6 \\
2.1 \\
1.5 \\
2.3 \\
3.6 \\
3.2 \\
1.7 \\
2.0 \\
2.7 \\
3.6 \\
3.5 \\
2.1 \\
1.7 \\
3.9 \\
7.8 \\
9.7 \\
9.0 \\
4.2 \\
3.0 \\
4.5 \\
5.4 \\
2.8 \\
4.3 \\
6.5 \\
6.9 \\
9.5 \\
6.1 \\
4.0 \\
2.9 \\
3.7\end{array}$ & $\begin{array}{l}4.6 \\
4.3 \\
5.1 \\
5.6 \\
6.8 \\
4.7 \\
4.9 \\
4.7 \\
3.8 \\
3.6 \\
4.0 \\
2.9 \\
2.4 \\
1.6 \\
1.5 \\
2.0 \\
1.0 \\
0.9 \\
0.5 \\
2.8 \\
2.5 \\
4.3 \\
2.3 \\
1.5 \\
0.9 \\
1.7 \\
0.8 \\
0.5 \\
0.7 \\
0.7 \\
1.1 \\
1.7 \\
1.0 \\
0.5 \\
0.3 \\
20\end{array}$ & $\begin{array}{r}4.9 \\
4.8 \\
6.0 \\
7.5 \\
8.1 \\
9.0 \\
7.8 \\
5.8 \\
4.3 \\
3.7 \\
4.3 \\
2.7 \\
3.7 \\
9.3 \\
9.9 \\
4.6 \\
4.2 \\
4.1 \\
8.9 \\
5.0 \\
7.1 \\
10.5 \\
11.3 \\
8.1 \\
7.6 \\
10.3 \\
10.4 \\
9.5 \\
11.1 \\
11.2 \\
11.9 \\
11.3 \\
9.3 \\
6.9 \\
7.5 \\
9.1\end{array}$ & $\begin{array}{l}2.9 \\
2.8 \\
3.3 \\
5.0 \\
4.2 \\
3.4 \\
3.2 \\
2.2 \\
1.5 \\
1.6 \\
2.1 \\
1.6 \\
2.3 \\
1.9 \\
2.6 \\
2.1 \\
3.5 \\
2.0 \\
1.1 \\
2.0 \\
4.7 \\
6.0 \\
6.9 \\
4.2 \\
5.5 \\
6.3 \\
5.6 \\
4.1 \\
5.1 \\
6.1 \\
9.4 \\
9.6 \\
9.1 \\
5.6 \\
4.9 \\
7.3\end{array}$ & $\begin{array}{l}0.3 \\
0.2 \\
0.9 \\
1.5 \\
1.4 \\
1.4 \\
1.2 \\
1.0 \\
1.5 \\
1.8 \\
3.2 \\
2.8 \\
2.1 \\
2.2 \\
2.0 \\
2.7 \\
2.5 \\
1.6 \\
0.8 \\
1.4 \\
3.4 \\
6.4 \\
5.6 \\
3.3 \\
2.3 \\
3.5 \\
2.6 \\
2.5 \\
2.5 \\
3.3 \\
3.5 \\
4.7 \\
4.5 \\
4.4 \\
4.1 \\
1.7\end{array}$ & 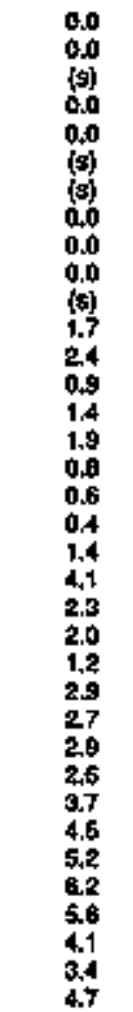 & $\begin{array}{r}2.4 \\
2.4 \\
1.8 \\
2.4 \\
2.8 \\
2.3 \\
2.5 \\
2.4 \\
1.9 \\
1.3 \\
1.8 \\
4.4 \\
5.1 \\
1.3 \\
0.9 \\
1.6 \\
2.1 \\
2.4 \\
2.2 \\
4.4 \\
6.0 \\
8.8 \\
7.6 \\
5.4 \\
5.3 \\
10.3 \\
8.4 \\
6.8 \\
8.5 \\
8.6 \\
9.5 \\
10.4 \\
8.5 \\
6.9 \\
7.3 \\
10.7\end{array}$ & 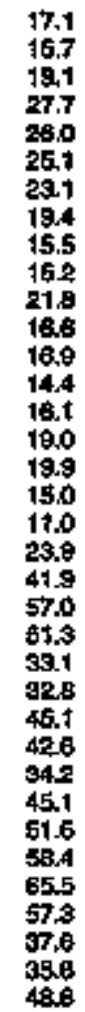 & 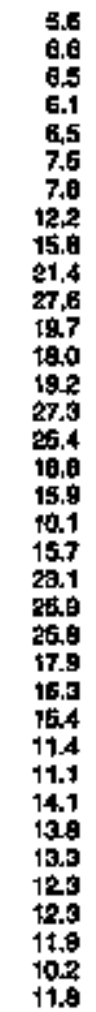 & $\begin{array}{c}1.3 \\
1.0 \\
1.0 \\
0.8 \\
1.1 \\
0.9 \\
1.0 \\
1.0 \\
0.9 \\
1.0 \\
1.2 \\
1.1 \\
1.2 \\
1.6 \\
1.6 \\
2.6 \\
2.1 \\
3.5 \\
2.6 \\
4.1 \\
6.0 \\
6.7 \\
7.5 \\
6.1 \\
7.2 \\
9.0 \\
\$ 1.4 \\
12.3 \\
11.3 \\
12.0 \\
12.7 \\
13.0 \\
11.4 \\
11.0 \\
10.7 \\
12.4\end{array}$ & $\begin{array}{r}39.0 \\
30.4 \\
40.2 \\
50.4 \\
49.8 \\
51.0 \\
50.1 \\
50.1 \\
51.2 \\
50.9 \\
71.7 \\
57.3 \\
56.7 \\
50.5 \\
60.7 \\
66.3 \\
80.0 \\
54.3 \\
49.7 \\
65.0 \\
91.7 \\
112.5 \\
105.3 \\
77.8 \\
81.5 \\
82.7 \\
85.5 \\
70.5 \\
86.0 \\
100.8 \\
105.8 \\
109.0 \\
102 . \\
71.5 \\
71.4 \\
88.5\end{array}$ \\
\hline
\end{tabular}

1 Through 1990, the dala for Gemaeny are for the tormar Wast Gemany on't. Baghning wilh 1891, the

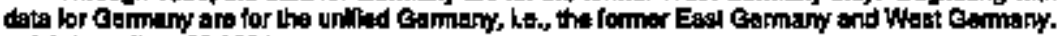
(jolesese then 50,000 lons.

Bourcass - 1950-1980-U.S. Deparment of Commars, Oureau of the Concus. U.S. Exponts by

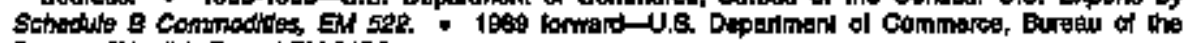

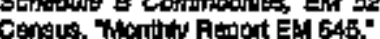


Total and Eloctric Utillity Stocks, 1949-1995

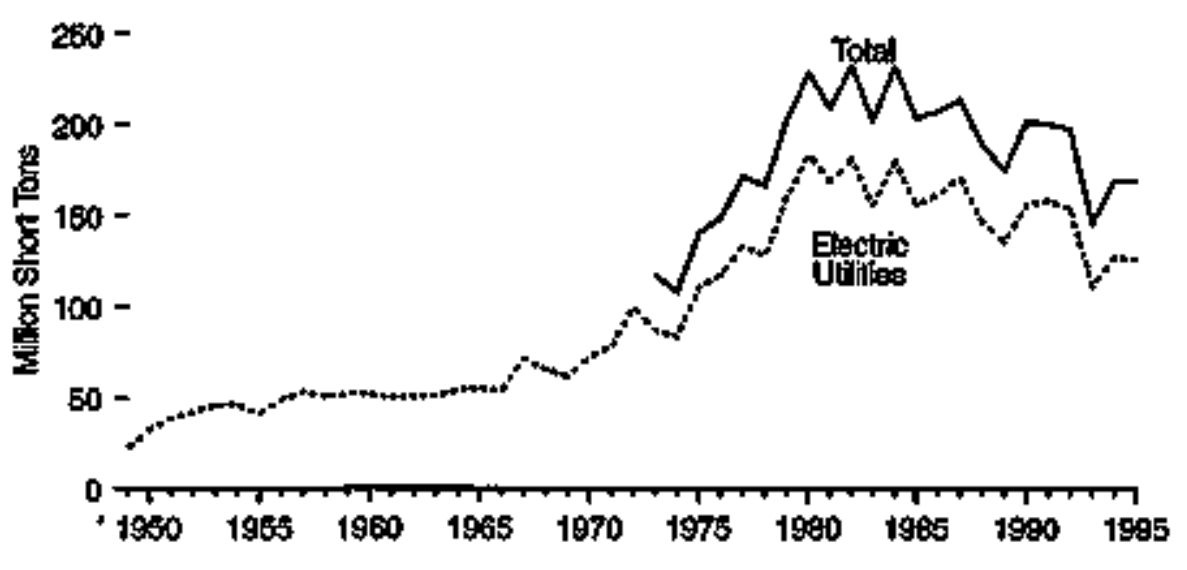

\section{By Holding Entity, 1995}

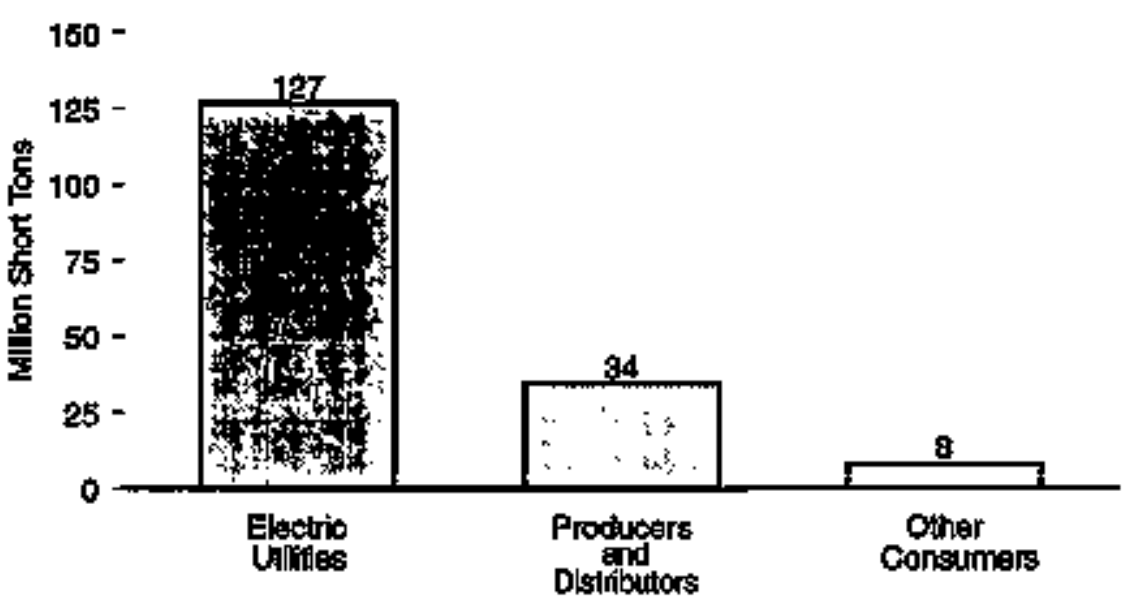

\section{By Holding Ently, 1949-1996}

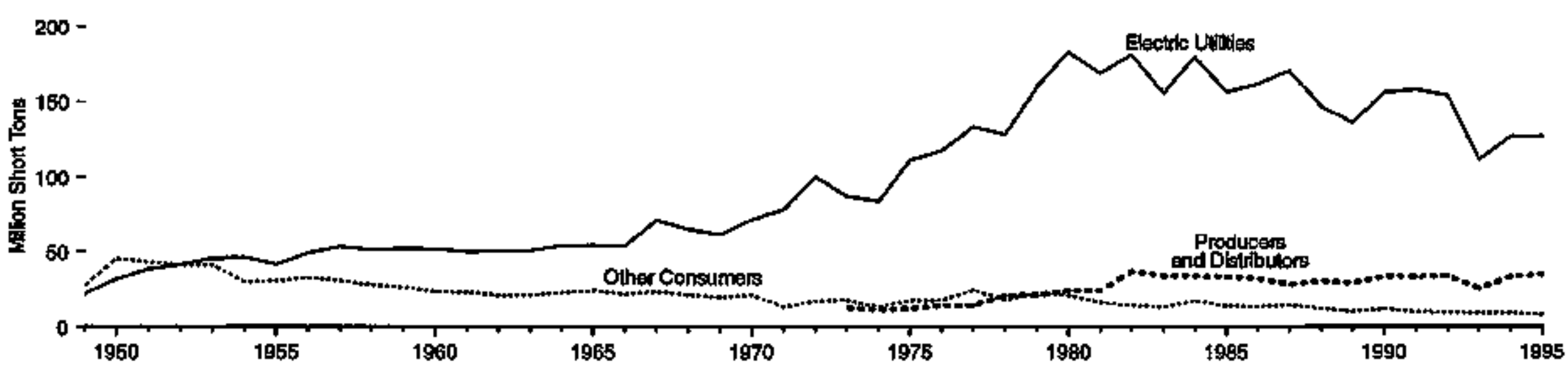

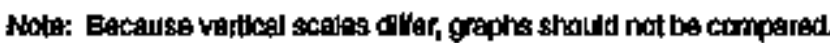

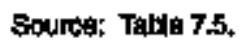


Table 7.5 Coal Stocks, End of Year 1949-1995

(Milion Short Tons)

\begin{tabular}{|c|c|c|c|c|c|c|c|}
\hline \multirow[b]{2}{*}{ Year } & \multicolumn{5}{|c|}{ conewimar } & \multirow[b]{2}{*}{$\begin{array}{c}\text { Producers } \\
\text { and } \\
\text { Dtetribulocs }\end{array}$} & \multirow[b]{2}{*}{ Total } \\
\hline & 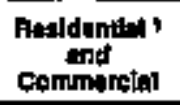 & Poks & Anduotry & 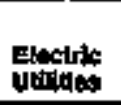 & Tolnel & & \\
\hline 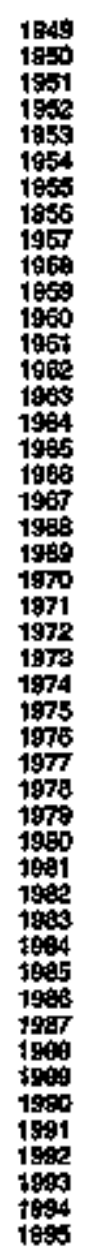 & 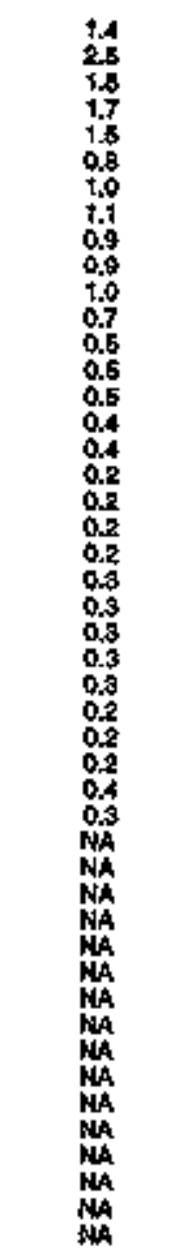 & 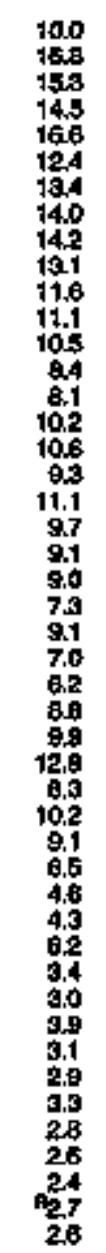 & 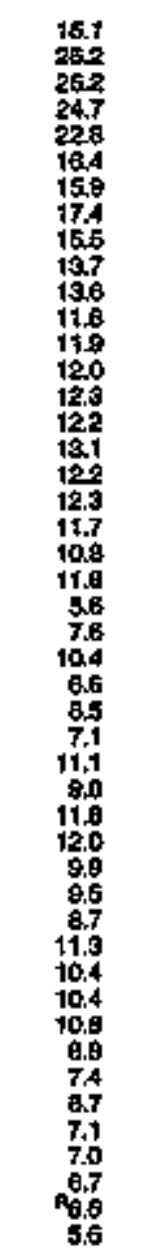 & 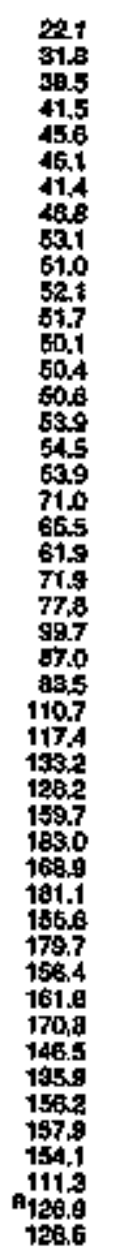 & 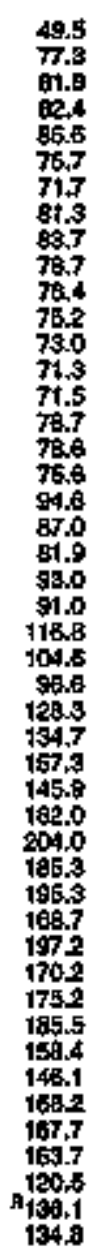 & 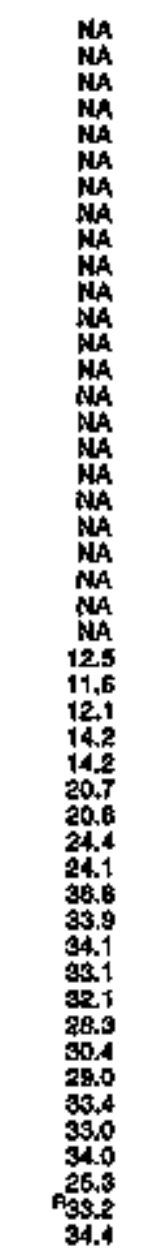 & 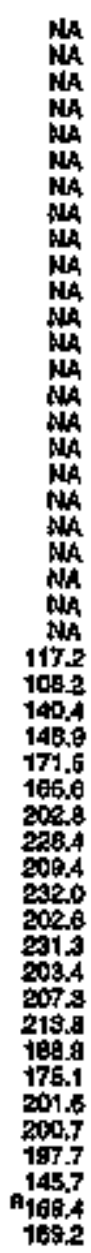 \\
\hline
\end{tabular}

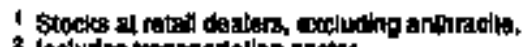

2 Includiss wansportalion stector.

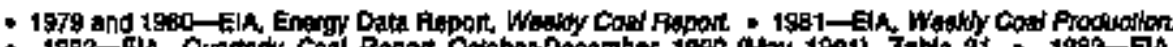

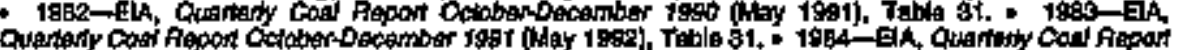

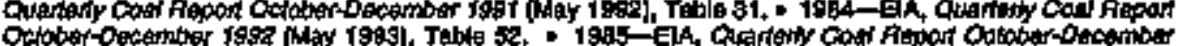

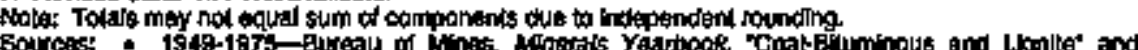

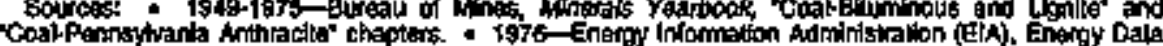

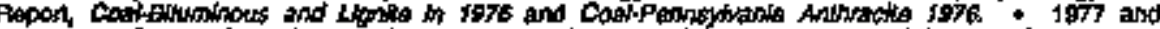
1973 -

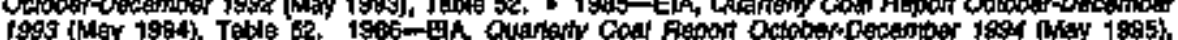

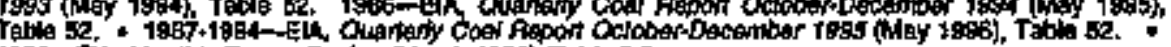

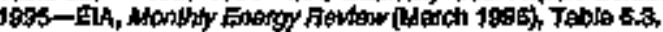


BAtturtinous Coal and Llgnits Mines, by Type

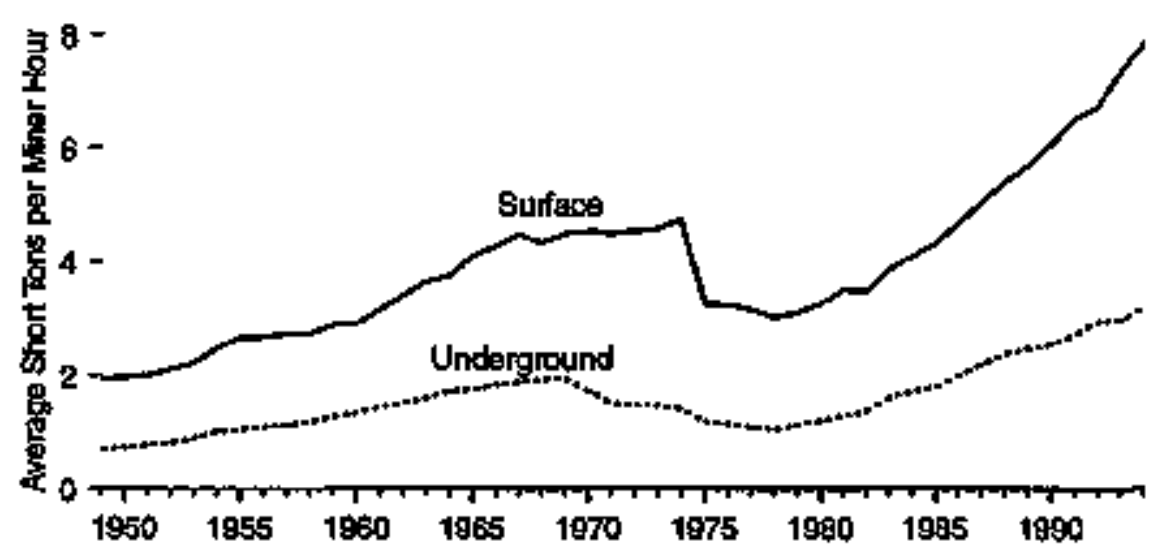

All Mines, Average

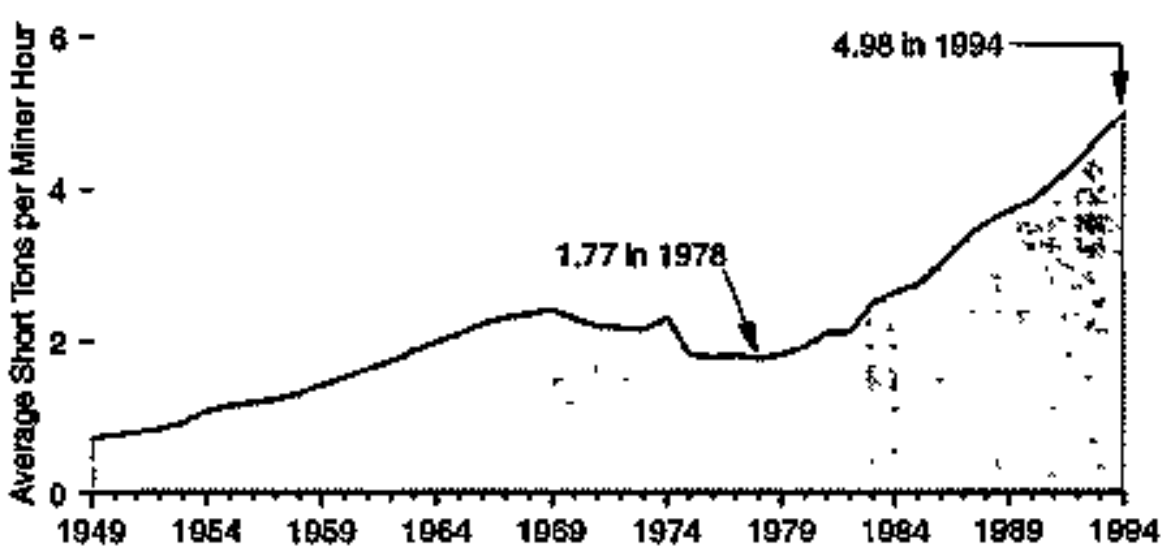

\section{All Mines, by Coel Type}

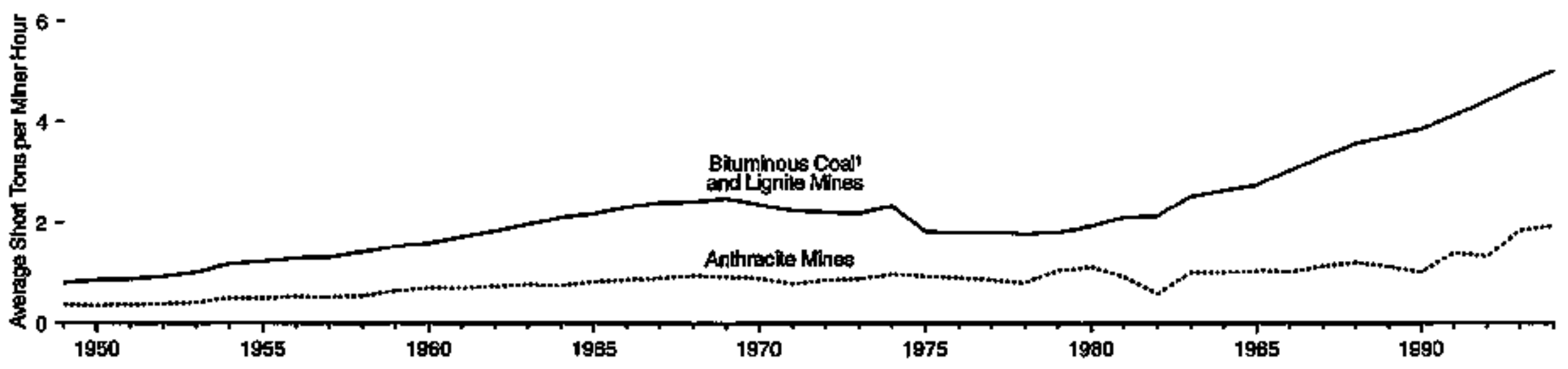

1 matudes subbhuminous cod.

Bource: Tablo 7.6.

Nitis; Becense vertical scales differ, opaphs should not be compend. 
Table 7.6 Coal Mining Productivity, 1949-1994

(Short Tons per MAiner Hour ")

\begin{tabular}{|c|c|c|c|c|c|}
\hline \multirow[b]{2}{*}{ Yerr } & \multicolumn{3}{|c|}{ 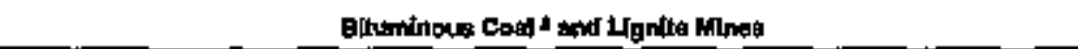 } & \multirow[b]{2}{*}{ Ambroche Mlnes } & \multirow[b]{2}{*}{ All Whe: } \\
\hline & Undarground & Surfice & Avange & & \\
\hline 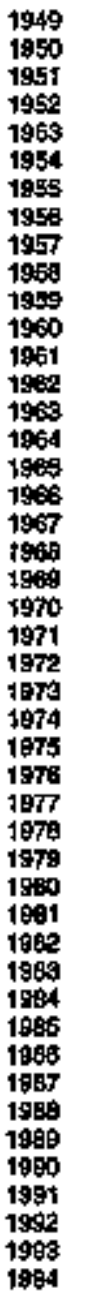 & $\begin{array}{l}0.68 \\
0.72 \\
0.76 \\
0.80 \\
0.88 \\
1,00 \\
1.04 \\
1.09 \\
1.11 \\
1.17 \\
1.28 \\
1.33 \\
1.49 \\
1.50 \\
1.60 \\
1.72 \\
1.75 \\
1.89 \\
1.69 \\
1.99 \\
1.95 \\
1.72 \\
1.50 \\
1.49 \\
1.48 \\
1.41 \\
7.19 \\
1.14 \\
1.09 \\
1.04 \\
1.13 \\
1.21 \\
1.29 \\
1.37 \\
1.69 \\
1.72 \\
1.70 \\
2.00 \\
2.21 \\
2.38 \\
2.46 \\
2.54 \\
2.70 \\
2.05 \\
2.97 \\
3.20\end{array}$ & 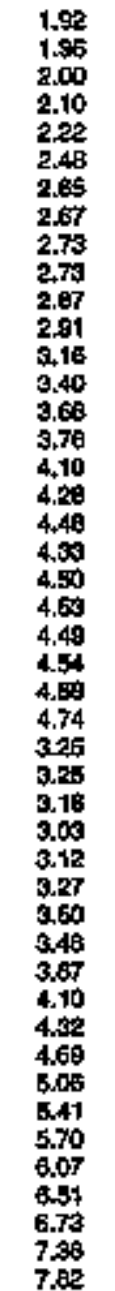 & 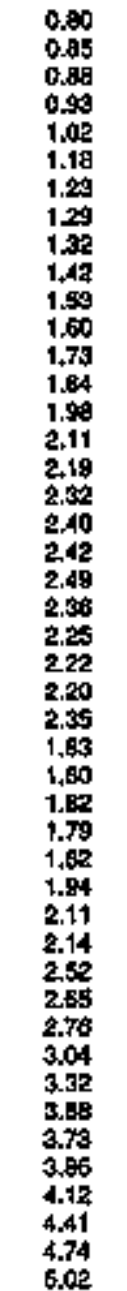 & 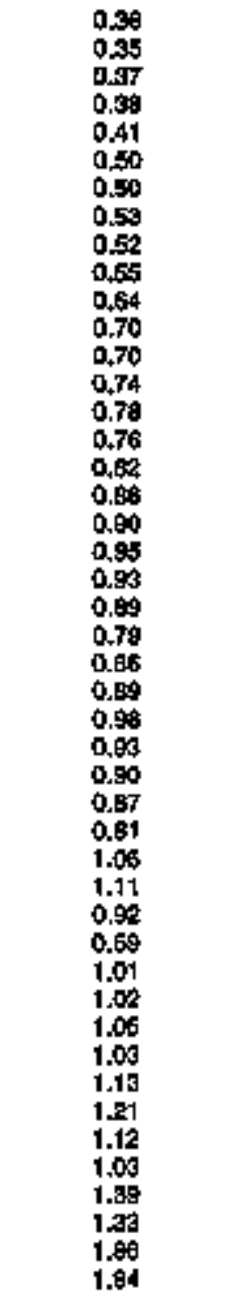 & 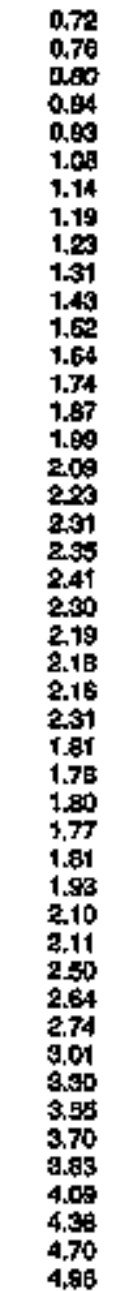 \\
\hline
\end{tabular}

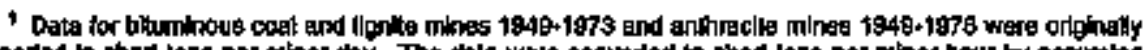

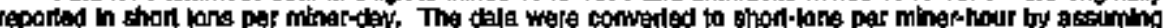

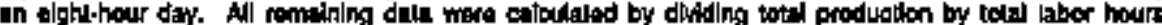

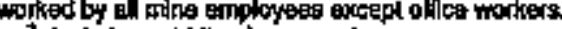

2 inchules subtiluminous coal.

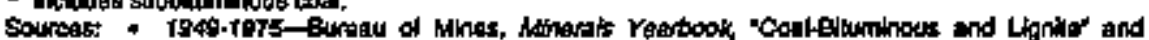

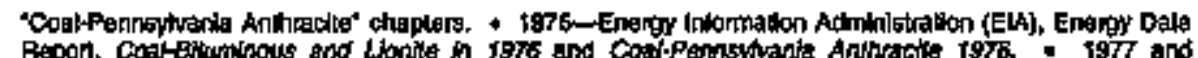

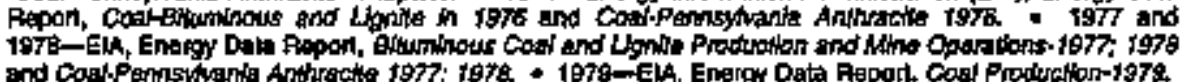

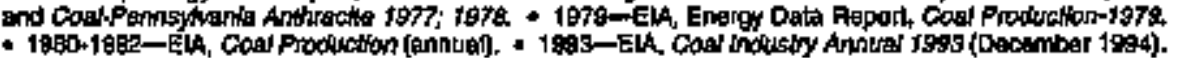

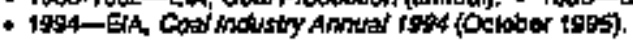


Figure 7.7 Coke Overview, 1949-1995

\section{Production and Consumption}
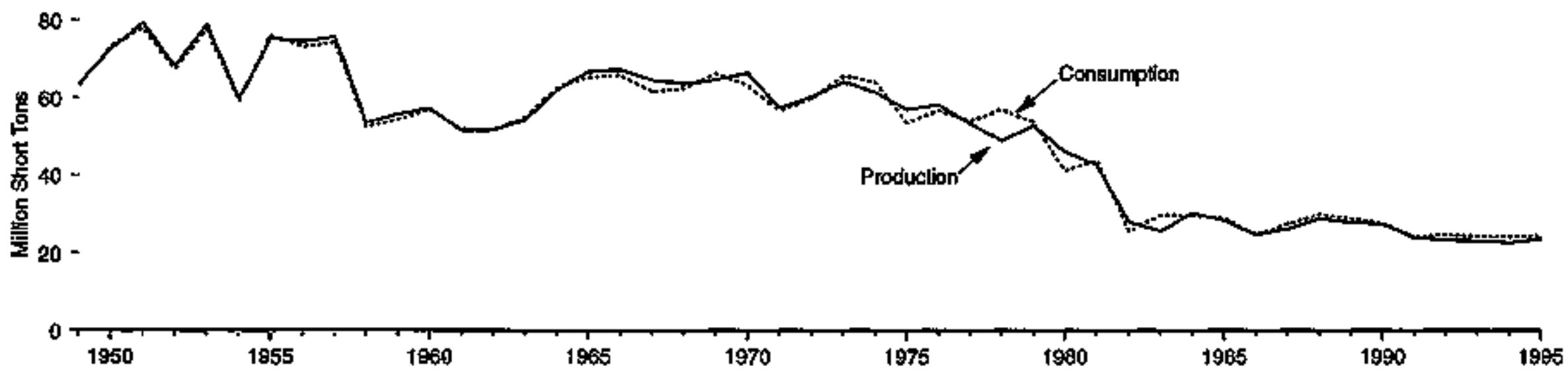

\section{Iimports and Exponts}

6-

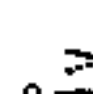
19

Note: Because verfical sceles dither, grephs ahould nol be compered.

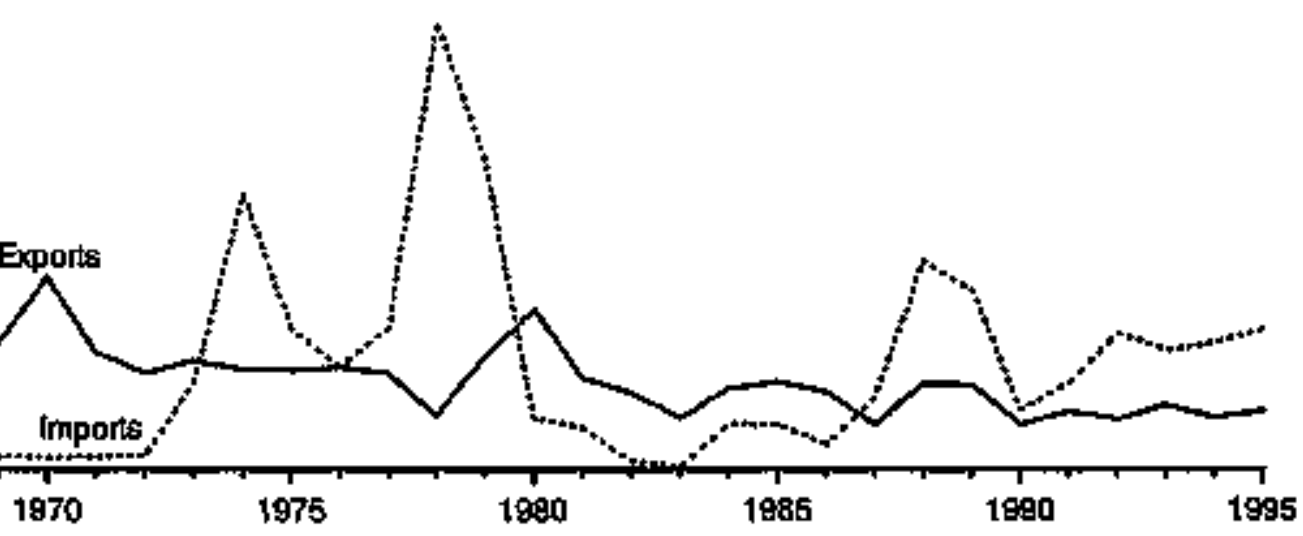


Table 7.7 Coke Overview, 1949-1995

(Million Shout Tons)

\begin{tabular}{|c|c|c|c|c|c|}
\hline Yoar & Production & inporte & Exporis & Slock Change I & Consumption 2 \\
\hline 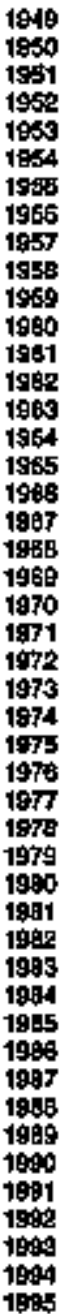 & 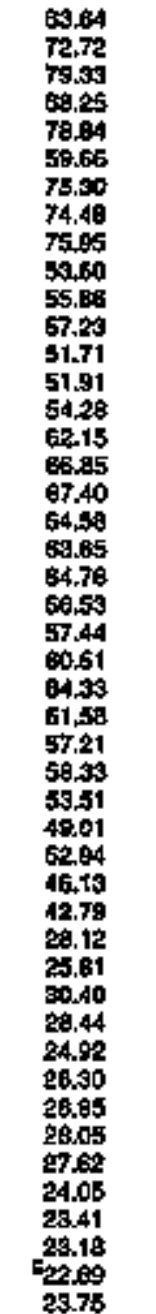 & 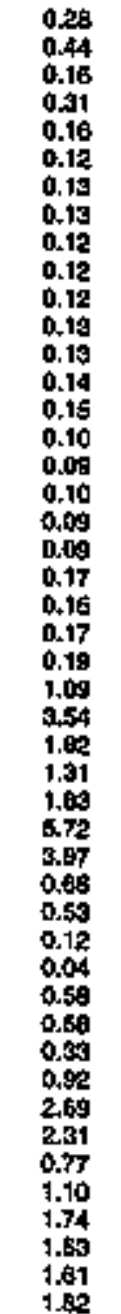 & 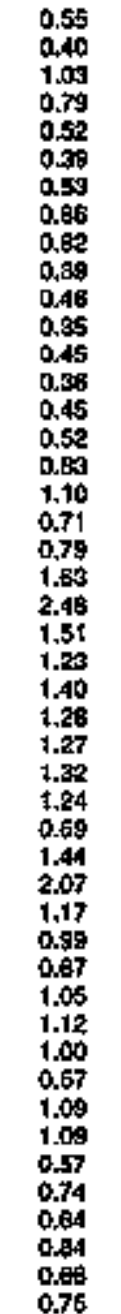 & 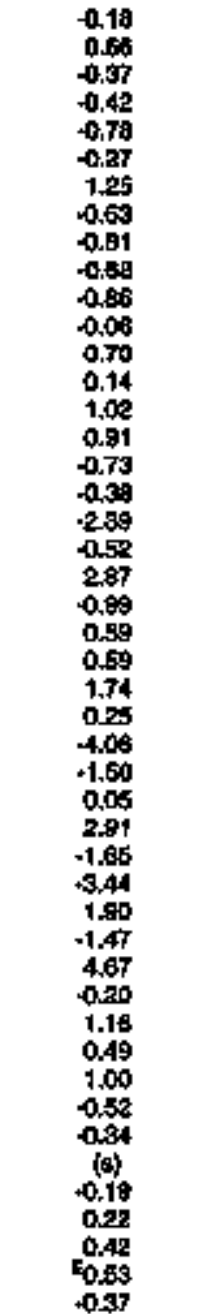 & 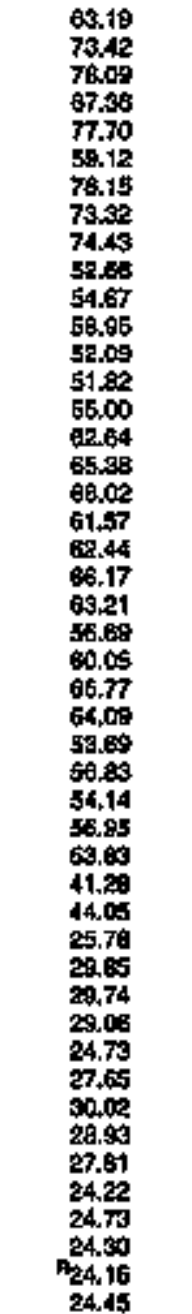 \\
\hline
\end{tabular}

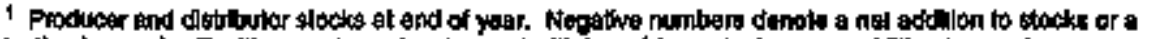

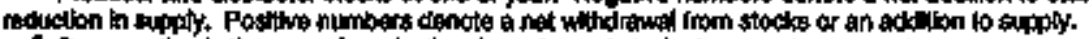

1 Consumpilon is tha Eum of production, impoits, and stock change minuls wports.

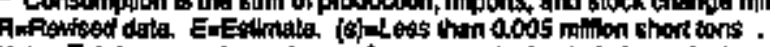

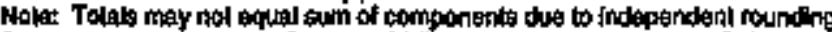

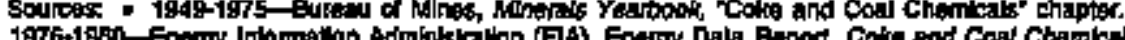

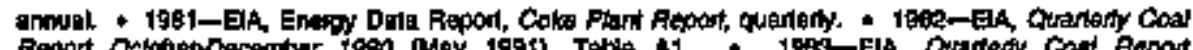

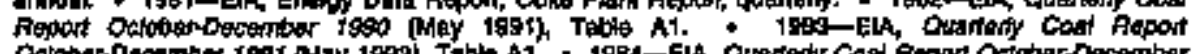

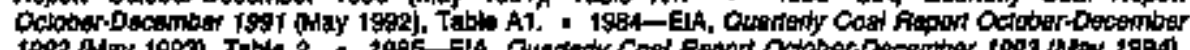

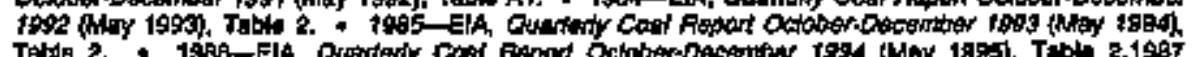

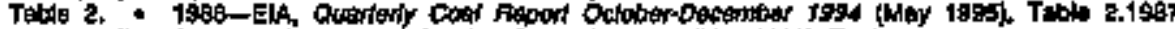

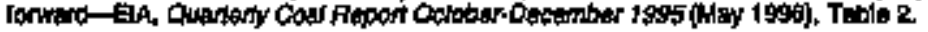




\section{Figure 7.8 Coal Prices, 1959-1995}

\section{Noninal}

$60-$

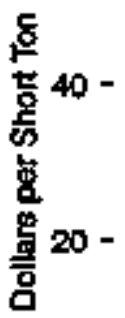

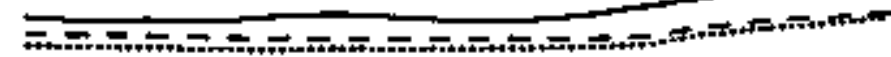

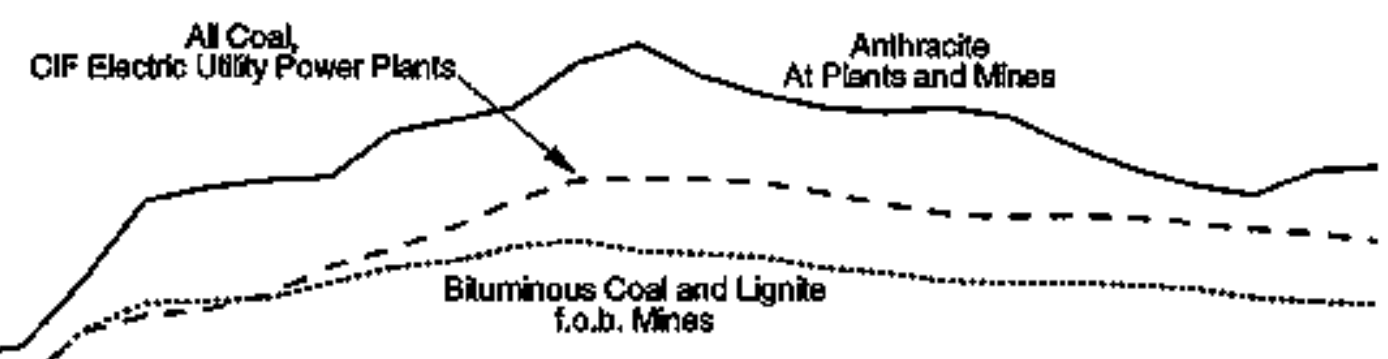

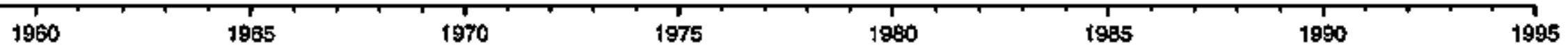

Real'
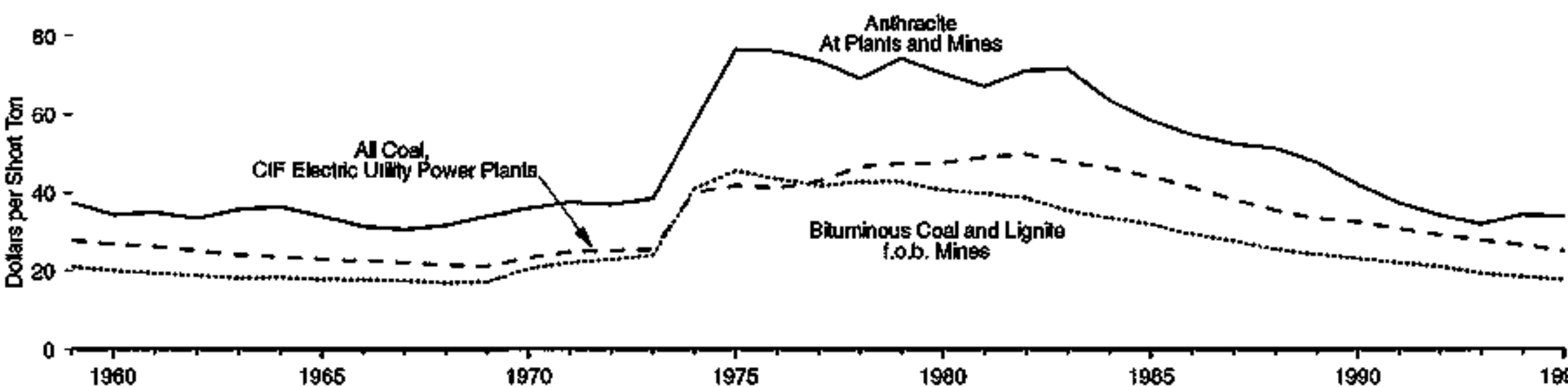

1965

1970

1975

1980

1985

1990

1905

'In chadned (1982) dollars, caiculabed by using gross domestic product implical prico defalors. Ses Apperndx $E$.

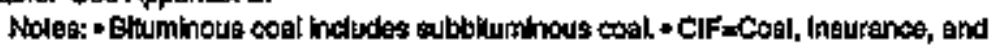

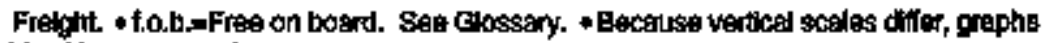
should not be compared Sorice: Table 7.8 . 
Table 7.8 Coal Prices, 1949-1995

(Dollars per Short Ton)

\begin{tabular}{|c|c|c|c|c|c|c|}
\hline \multirow[b]{3}{*}{ Year } & \multicolumn{2}{|c|}{ Ohtuminous Coal I and Ligntas } & \multicolumn{2}{|c|}{ Anihreolis: } & \multicolumn{2}{|c|}{ An Con } \\
\hline & \multicolumn{2}{|c|}{ 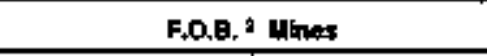 } & \multicolumn{2}{|c|}{ Al Pinats and Mines:3 } & \multicolumn{2}{|c|}{ ClF a Electide Uilathy Power Pianta } \\
\hline & Nominal & Peged 5 & Nomtrity & Extol & Nomplnal & F日e영 \\
\hline 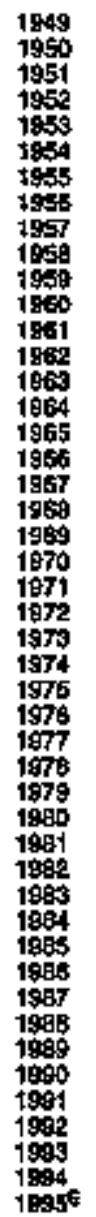 & 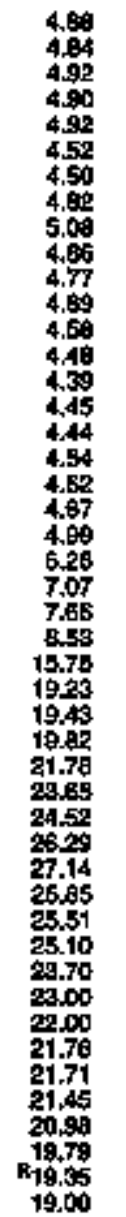 & 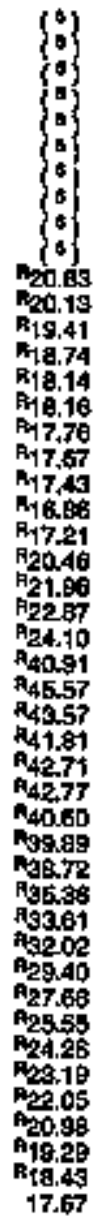 & 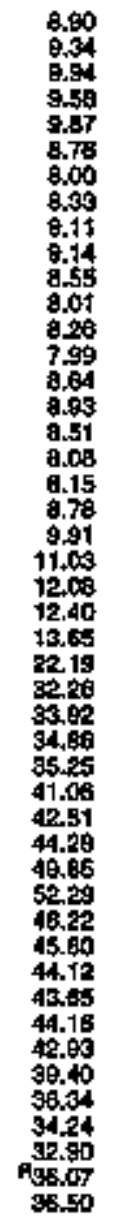 & 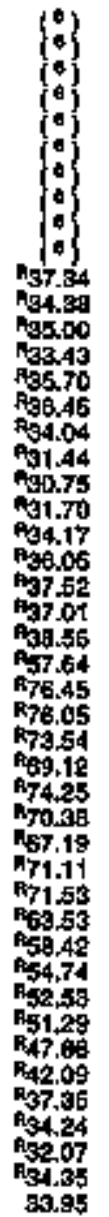 & 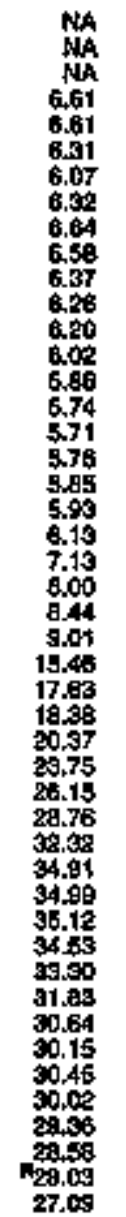 & 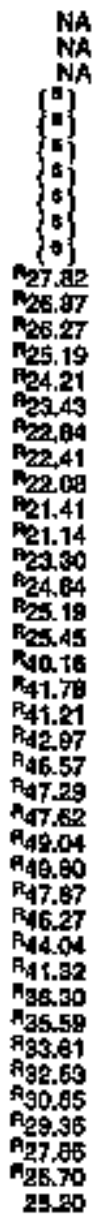 \\
\hline
\end{tabular}

I Inciudes Edtabimuminouts coal.

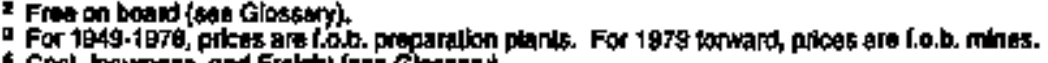

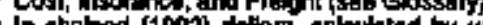

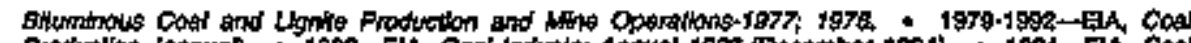

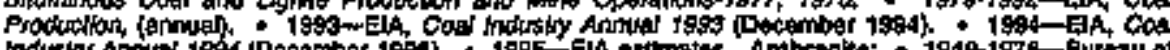

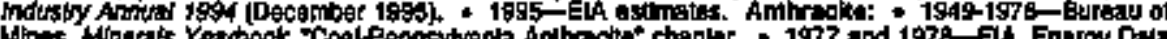

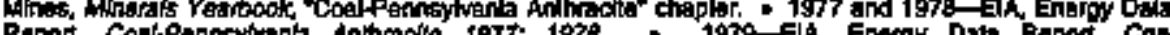
Ropar Prover

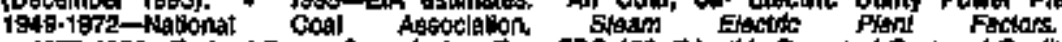

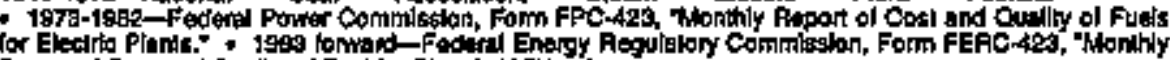
Appendlx E.

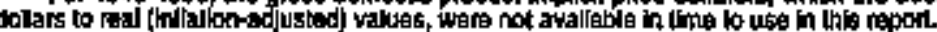

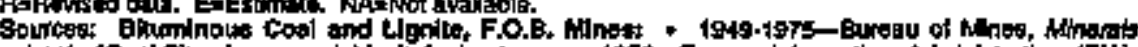

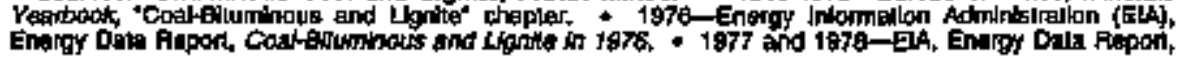

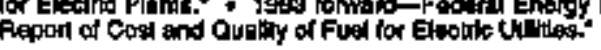




\section{Coal Notes}

1. Data in this report on the consumption of bituminous coal (including subbituminous coal), lignite, and anthracite are generated primarily from consumption data reported in surveys. Included are data reported by all electric utility companies and coke plant companies. Data on coal consumption by all industrial and manufacturing establishments and by the residential and commercial sector are based on distribution data obtained quarterly from coal companles. Included in each sector's data are the following: Electric Utility Sector-consumption by privately and publicly owned establishments engaged in the generation and/or distribution of electric power primarily for sale or resale; Industrial and Miscellaneous Sector-consumption at manufacturing plants, large commercial establishments, coking plants, and by agriculture, mining (other than coal mining), and construction industries; Transportation Sector-sales to railroads and vessel bunker fuel; Residential and Commercial Sector-retail dealer sales to households and smakl commercial establisbments.

2. Consumption data for 1995 exclude Energy Information Administration estimates of 4 million short tons per quarter that are consumed by independent power producers to generate electricity and by cogeneration plants not included in the other industrabl, coke, and commercial sectors. Those estimates, in thousand short tons, are as follows: 1989,$219 ; 1990,400 ; 1991,1,500 ; 1992,2,500 ; 1993,3,086$; and $1994,3,785$. 


\section{Electricity}

\section{The Electric Power Industry}

Electric utilities are the primary source of electricity in the United States; however, after the Public Utility Regulatory Policies Act of 1978 was passed, nonutility power producers supplied an ever-increasing amount of electricity. Nonutility power producers Dwn electric generating capacity but, unlike electric utilities, lack a designated service area. Cogenerators, small power producers, and independent power producers are all classified as nonutility power producers. In 1994, electric utilities purchased 209 billion kłlowatthours of nonutility electricity generation (8.1).* By comparison, electric utilities' net generation in 1994 totaled 2,911 billion kilowathours.

\section{Net Summer Capability}

Net summer capability, a common measure of generating capacity, is defined as the steady hourly output that generating equipment is expected to supply to the system load, exclusive of auxiliary power, as demonstrated by testing at the time of summer peak demand. AJthough data on net summer capability at electric utilities have been collected only since 1985, the Energy Information Administration has estimated values for prior years (8.8). Estimates and collected data indicate that net summer capability during the 1949-to-1995 period increased at an average annual tate of 5.4 percent, reaching $705 \mathrm{mil}-$ lion kilowatts.

At electric utilities, conventional steam plants fueled by fossil fuels, wood, and waste were responsible for most of the growth. In 1995, they accounted for close to two-thirds of electric utility total net summer capability. Nuclear-powered plants accounted for 14 percent of the total in 1995. Conventional and pumped storage hydroelectric facilities also accounted for 14 percent. Internal combustion and gas turbine plants, as well as plants powered by emerging sources of energy, such as geothermal, accounted for the remainder.

Numbers in parentheses hidicate retated tables. Annugl data are the most recent avellable; they frequenty are prelininary and may be revised in future pubilications. Percentages and numbers in lext are calculated by using data in the tables.
At nonutility power producers, net summer capability in 1994 increased 12 percent from the 1993 level to 62 million kilowats, 8.1 percent of the electric power industry total (8.2).

\section{Electricity Generation}

Net generation of electricity by electric utilities in 1995 totaled 3.0 tritlion kilowatthours, us 2.9 percent from the 1994 level (8.3). Coal continued to fuel most of the generation and accounted for 1.7 trillion kjlowatthours. Natural gas accounted for 307 billion kilowatthours. Despite continuing low petroleum prices, petroleum-fired generation in 1995 fell to 61 billion kilowatthours. In contrast, nuclear-based generation rose 5.2 percent to 673 billion kilowatthours, an all-time high. Conventional hydroelectric generation totaled 296 billion kilowatthours, up 20 percent from generation in 1994. Hydroelectric pumped storage generation, however, was a negative 3 billion kilowatthours, because the energy used for pumping exceeded energy generated. Geothermal and other renewable energy sources accounted for 6 billion kilowatthours.

Nonutilities' gross generation totaled 355 billion kilowathours in 1994, up 9.1 percent from the 1993 leve] (8.12). Over half of that total was sold to electric utilities (8.1 and 8.12). In 1994, by far the largest shate of nonutility power gross generation came from manufacturers (8.13). The transportation, public utilities, and mining industries also generated signiffcant amounts of electric power. The West South Central and Pacific Census Divisions led the Natton in nonutility power gross generation.

\section{Energy Consumption}

During the 1949-to-1995 period, consumption of coal at electric utilities grew at a faster rate than did consumption of nataral gas and petroleum (8.5). On a Btu basis, coal accounted for 67 percent of total fossil fuel consumption in 1949 and 81 percent of the total in 1995. Seventeen quadrillion Bta of coal were consumed by electric utilities in 1995. 
Electric utility consumption of both petroleum and natural gas increased during much of the period, but growth in the use of both fuels began to slow during the 1970's. Ditring the first half of the 1980's, consumption actually decreased.

Changes in the consumption of petroleum and natural gas at electric utilities from 1986 through 1988 illustrated the utilities' fael-switching capabilities and their use of them to respond to fluchuations in fuel prices. After 1988, however, electric utility consumption of petroleum fell from 1.7 quadrillion Btu in 1989 to 0.7 quadrillion Btu in 1995. Electric utility consumption of clean-burning natural gas, on the other hand, remained near the 1988 level for 4 years and then increased in 1994 and again in 1995 to 3.3 quadrillion Bta, as electric utilities sought to comply with environmental regulations.

But whereas electric utilities rely most heavily on coal as an energy input, 51 percent of the nonutilities' 1994 gross generation came from natural gas and 24 percent came from renewable energy sources (8.12).

\section{Sales of Electricity to Consumers}

During the 1949-to-1995 period, electricity sales increased at an average ammual rate of 5.5 percent (8.6). Annalal sales declined only two times, in 1974 and 1982. In 1974, the decline in sales spanned all sectors, whereas in 1982, lower sales to the industrial sector alone acconnted for the decline.

Historically (from 1949 through 1990), sales of electricity to the industrial sector exceedexd sales to other sectors. In 1991, 1993, and 1995, however, sales to the residential sector accounted for the largest share. In 1995, sales to the residential sector rose 3.5 percent to the record level of 1,043 billion kilowatthours, while sales to the industrial sector rose 0.3 percent to 1,011 billion kilowatthours. Sales to the commercial sector of 853 billion kilowatthours were 4.0 percent above the 1994 level.

\section{Retall Prices of Electricity}

The weighted average real price' of electricity to all sectors in 1995 was 6.4 cents per kilowatthour, 17 percent below the price in 1960 (8.11). However, the apparent stability in electricity prices masked

\footnotetext{
'Rosl (inflation+afjiusted) prites are expressed in chained (1992) dollass.
}

fluctuations that occurred throughout the period and variations in prices paid by consumers in different end-use sectors. And, because conversion losses account for roughly two-thitds of the energy input for electricity generation, electricity remained by far the most expensive source of energy on a Btu basis. The average real price of electricity sold to the residential sector, where prices have usually been the highest, was 7.8 cents per kilowatthour in 1995, down 2.5 percent from the price in 1994. The commercial sector price of 7.2 cents per kilowatthour in 1995 was down 1.4 percent. Industrial customers continued to pay prices that cormpared favorably with prices in other sectors. In 1995, the real price of electricity sold to industrial users was 4.4 cents per kilowatthour, down 4.3 percent from the price in 1994 .

\section{Demand-Side Managoment at Electric Utitities}

The planning, inptementation, and moniloring of electric utithy activities designed to enpourage customers to modisy their partems of electricity usage, including the timing and levet of electricily chemand, is ceiled dermant-side muanagernenk (DSh). Febates to cussiomers who insta energy-etficient applances and reduced rates for non-peakload use of efectricty are examples of DSM programs.

DSM has both economic and envionmental benefits. The economis benelit to customers lias in its abbity to provide the same leved of energy services at a tower cost. DSM is most advantageous when electrio utilites can use it to ellminate the need for costly new capacily. The environmental benefit of DSM occurs when in lowers fossil fued use. Becalese electrictly generation relles heavily on the burning of fossil Hels, it is responsible for emissions of cartan cloxide, sulfur tloxide and ritrogen oxides. To the extent that DSW reduces fossll huet consumption, cortribules to improving the quality of the environment.

In 1994, eleciric utintes spent \$2.7 billion on DSM programs, \$28 milion less than in 1993 (8.7). The aclual peakload reduction, however, in creesed from 23,069 megawatts in 19931026,001 megewalts in 1094 , and the ensrgy savings attributable to DSM programs rose from 45 billion kilowrelthours in 1998 to 52 billion killowatthours in 1994. 


\section{Diagram 5. Electricity Flow, 1994}

(Quadrillion Btu)
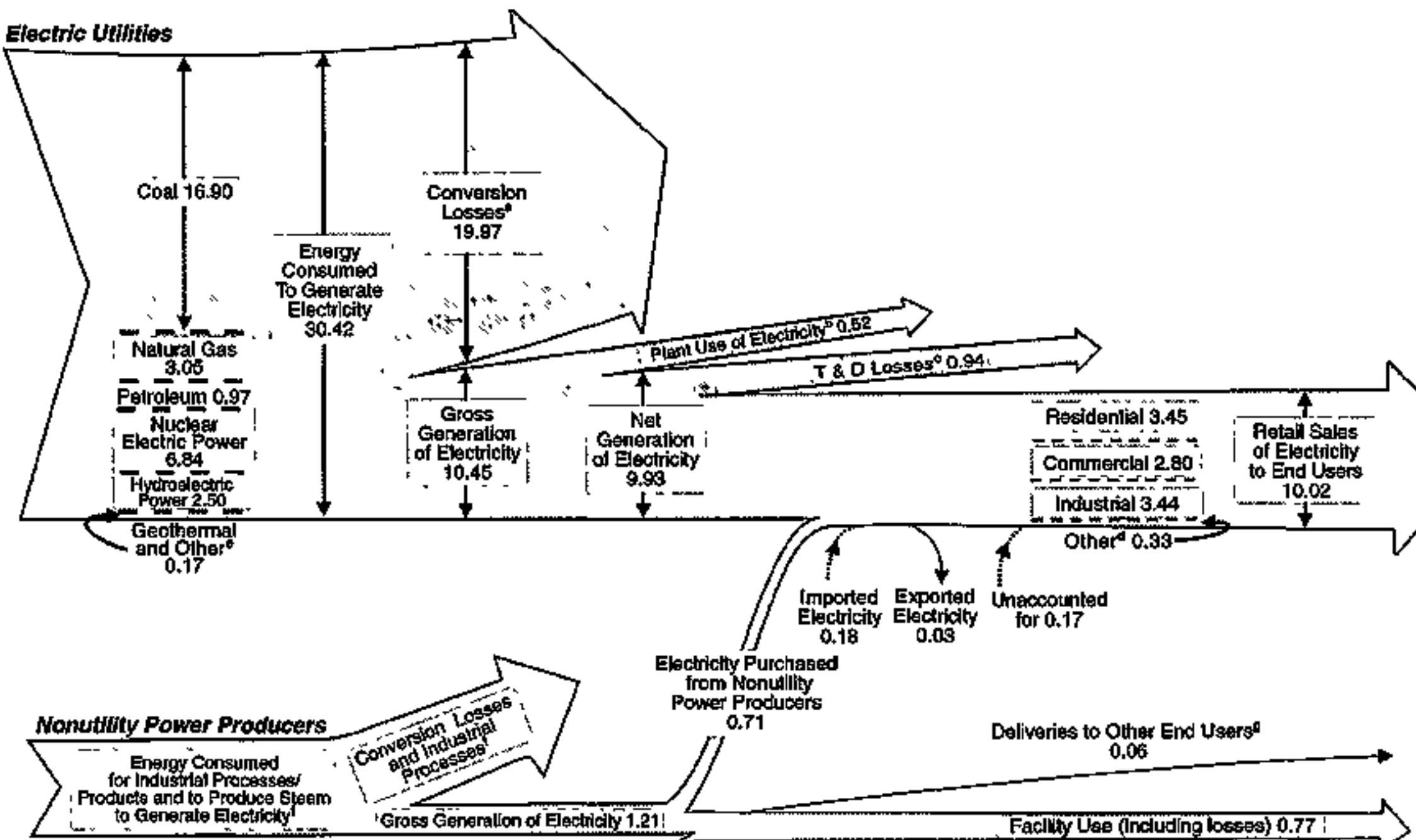

from Nonullity

Power Producers

0.71

Deliveries to Other End Users?

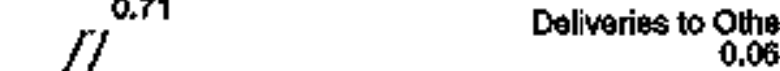

$$
0.06
$$

Facllity Uoe (including losses) 0.77

Receipts from

Other Producerst" 0.92

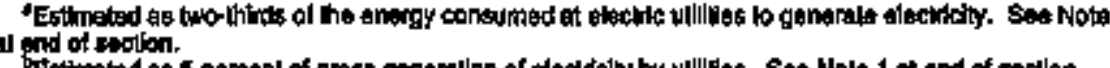

Alstutulion. Ses Table 10s.

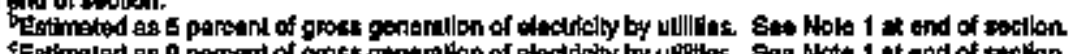

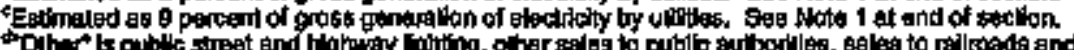

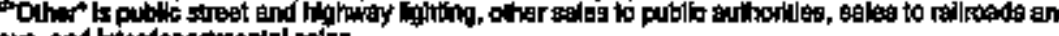

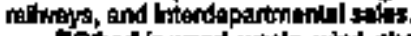

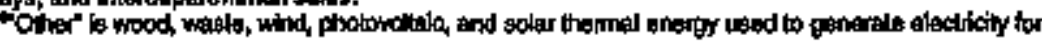

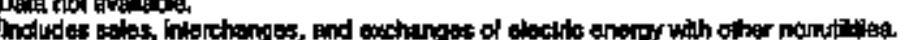

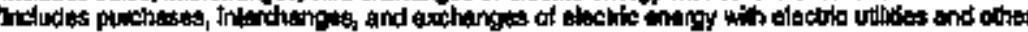
nonvintes

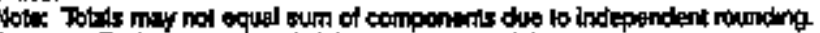

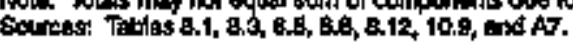




\section{Flgure 8.1 Electricity Overview}

\section{Net Ceneralion by Eleotric Utilitios the Retall 8ales, 1949-1995}

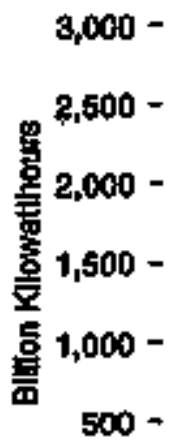

, 000

$3.00-$

$500-$

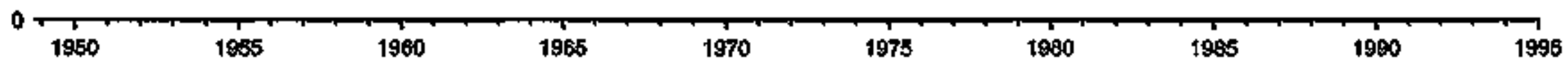

Intemational Electriclty Tracte, 1649-1995

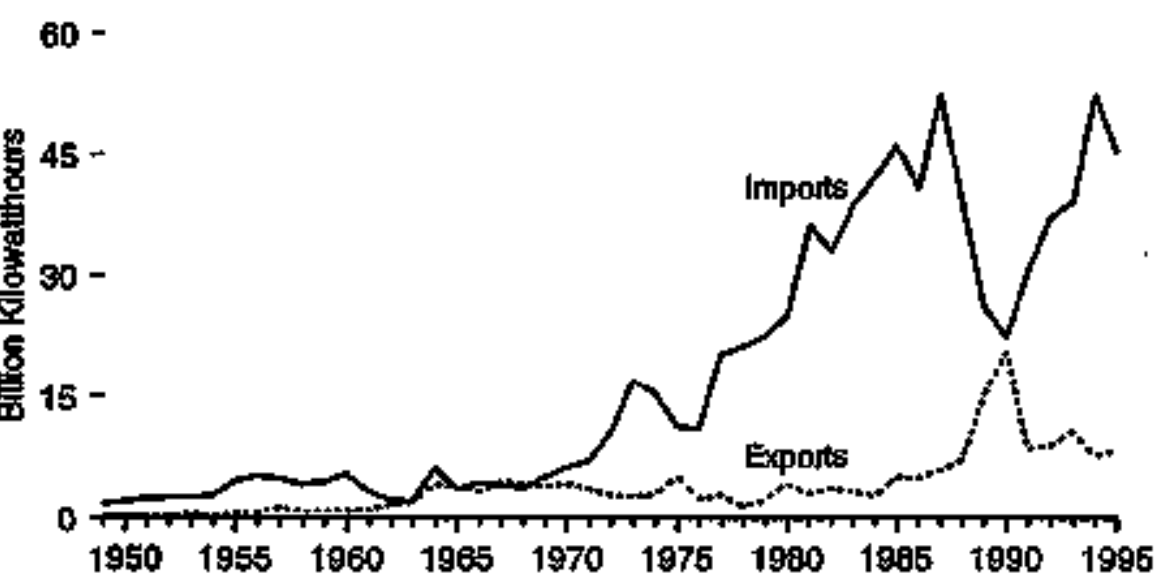

Puroha6es by Electrio Utillities from Nonutility Power Producers, 1978-1994

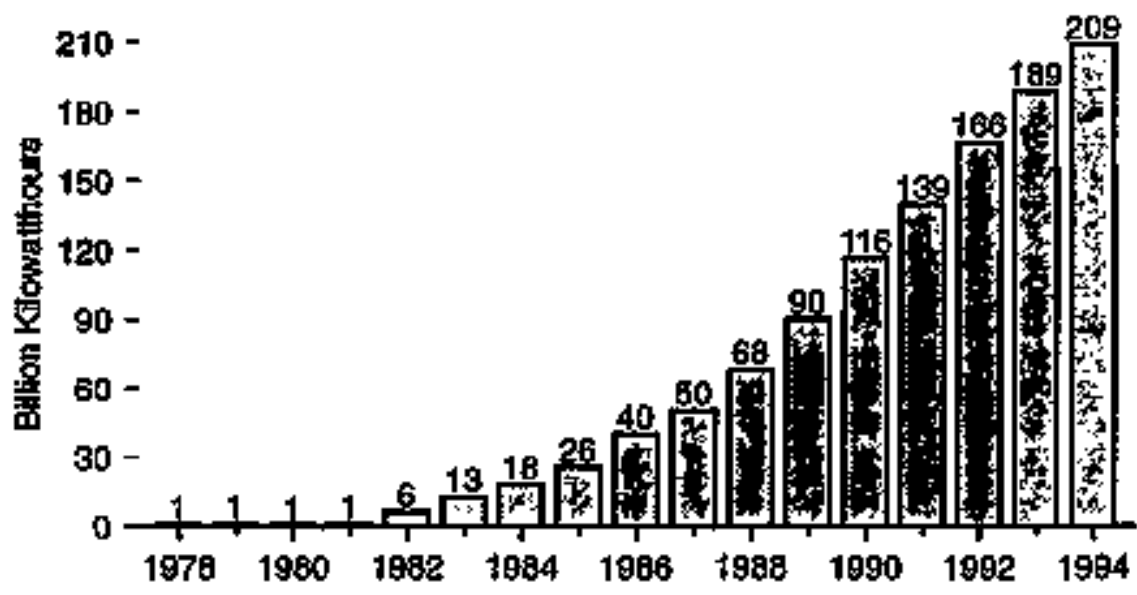

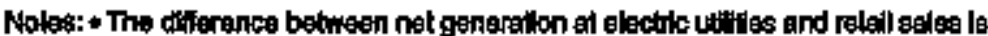
pucheses by electic utilites from nonulitly power producers and imports minus exports,

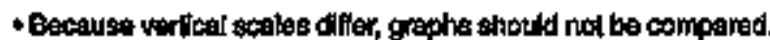
Source: Tabio 8.1 
Table 8.1 Electricity Overview, 1949-1995

(Bibion Kilowatthours)

\begin{tabular}{|c|c|c|c|c|c|c|}
\hline Your & 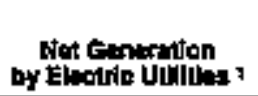 & 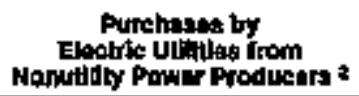 & Imports 0 & Expons? & $\begin{array}{l}\text { Lostint und } \\
\text { Unageounted far }\end{array}$ & Raloll Sultes \\
\hline 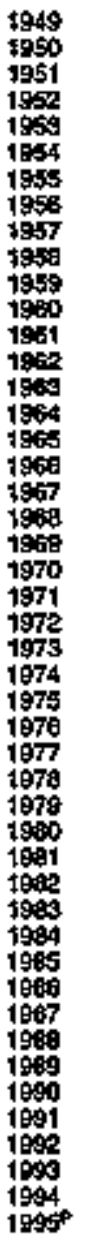 & 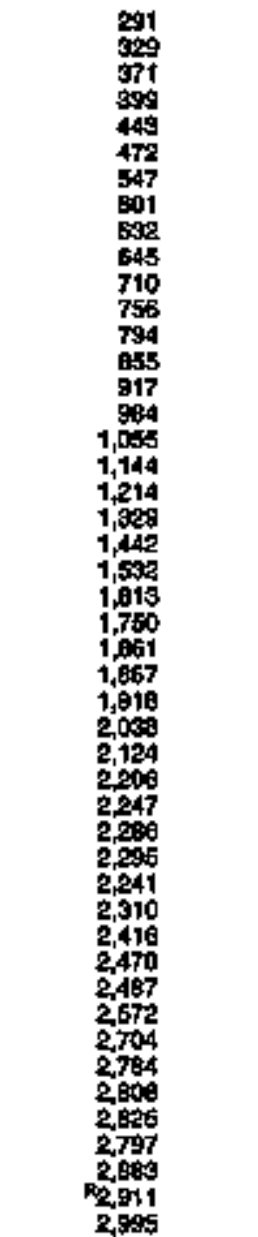 & 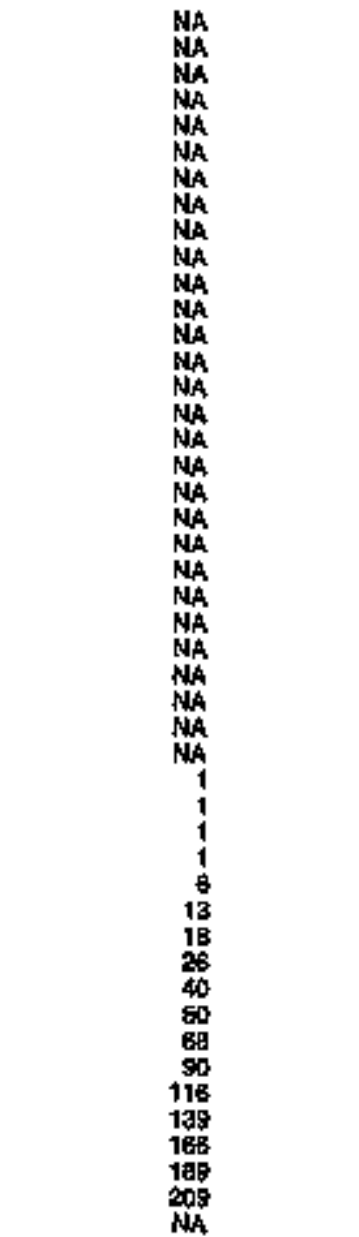 & 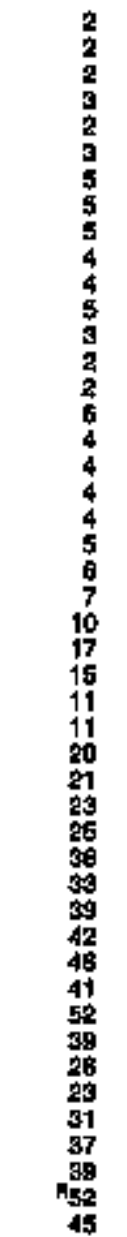 & 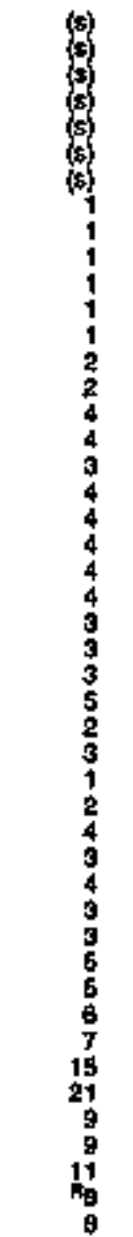 & 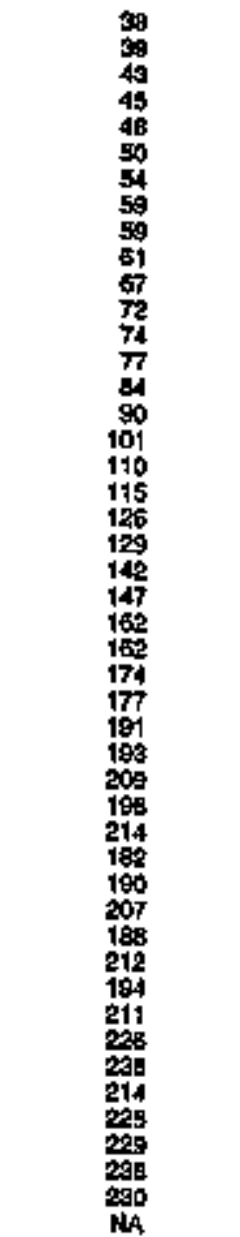 & 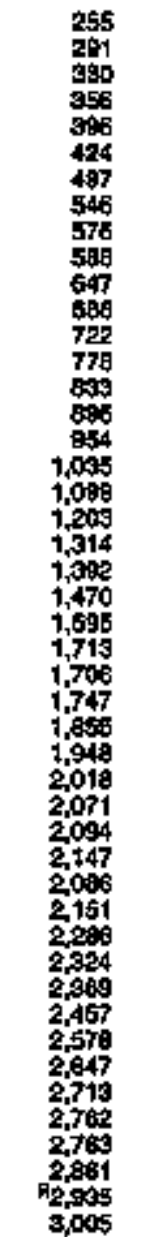 \\
\hline
\end{tabular}

I sog Note 2 at end ol seckan.

2 SaO Cilosseny.

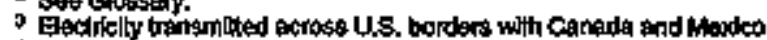

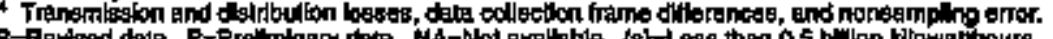

R=Aextsed dai

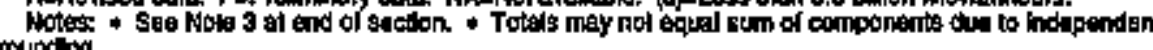
monting.

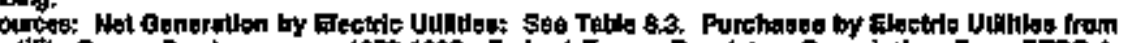

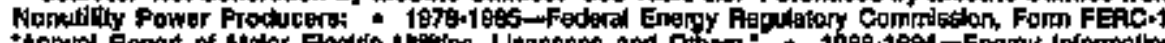

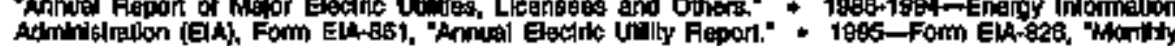

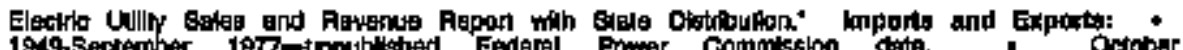

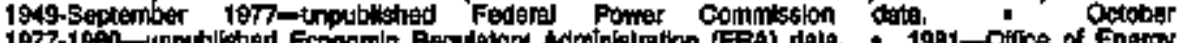

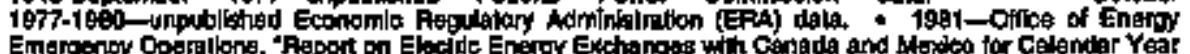

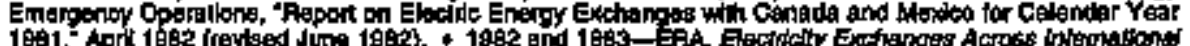

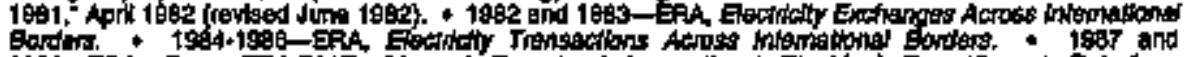

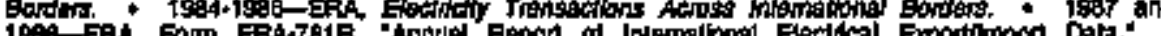

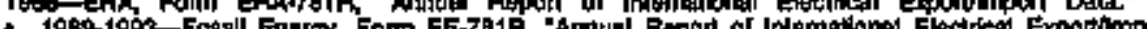
1.

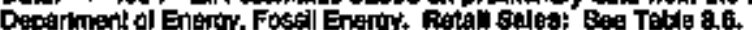


Net Generallon Shares by Source of Power

(Percent of Total)

\section{Net Generalion}

4-

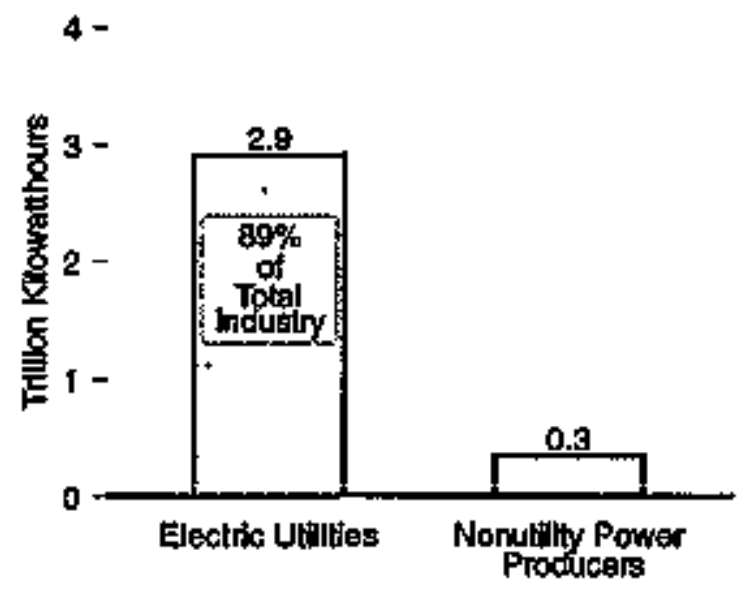

Net sumaner Capabilty

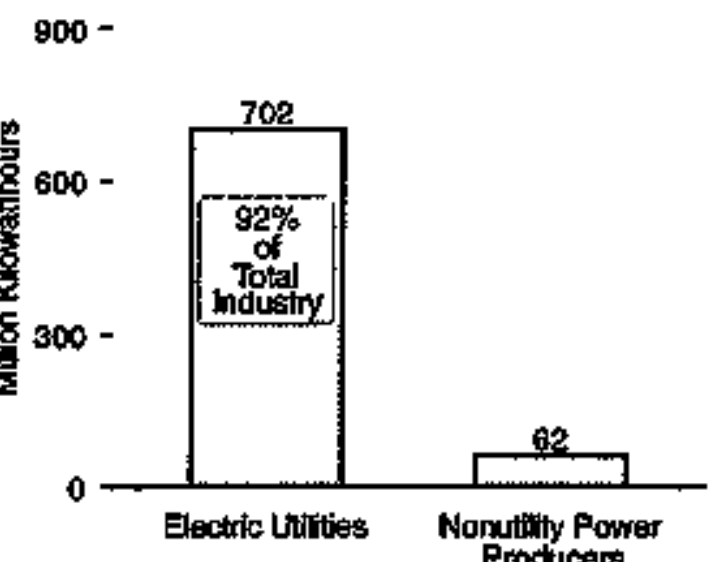

1 Oher is polkoletum, geothermol enorgy, wood, waste, solar, and wind.

1 sheres do not atd exacty to 100 percerd due or munding of comportents.

- "Oher is pelroleum, hydroeloctric pover, geothemal ensph' wind, solar, nuchear,

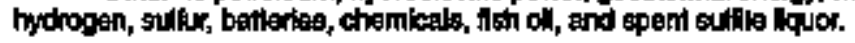
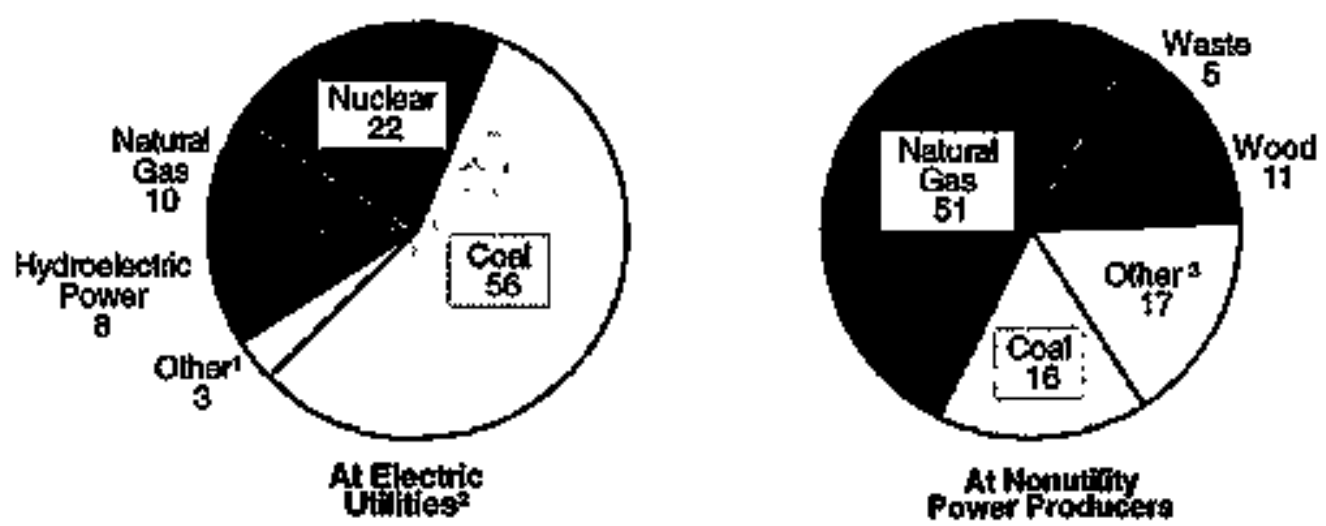

Nol Summer Capablity Shares by Type of Capacty (Percent of Tolal)
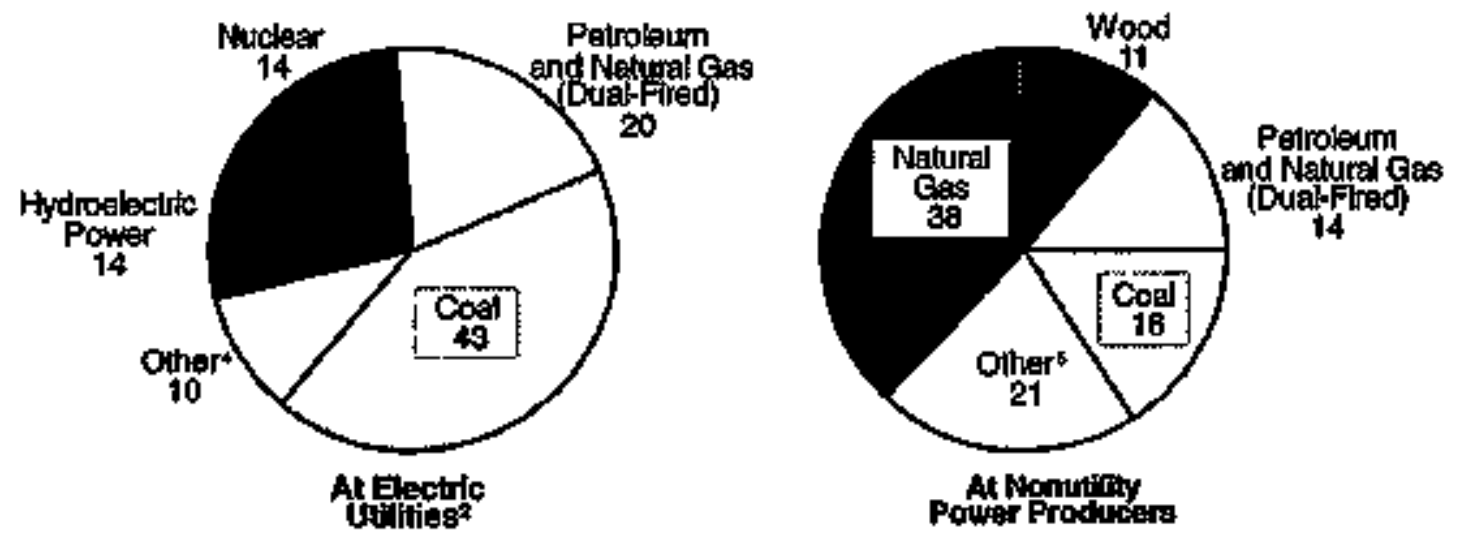
Table 8.2 Electric Power Industry Net Generation and Net Summer Capability, 1992-1994

\begin{tabular}{|c|c|c|c|c|c|c|c|c|c|}
\hline \multirow[b]{2}{*}{ knm } & \multicolumn{3}{|c|}{ Electito Uinitites } & \multicolumn{3}{|c|}{ Nonullity Pomer Producers } & \multicolumn{3}{|c|}{ Tot:al } \\
\hline & 1902 & 1998 & 1994 & 1992 & 1093 & 1594 & 1992 & 1503 & 1904 \\
\hline 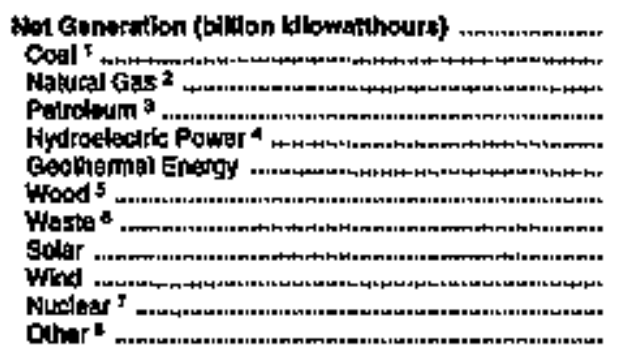 & 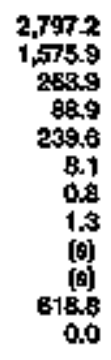 & 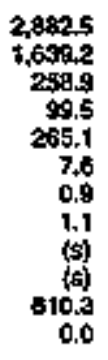 & $\begin{array}{r}2,910.7 \\
1,035.5 \\
2991.7 \\
91.0 \\
243.7 \\
6.9 \\
0.3 \\
1.2 \\
6.9 \\
6.9 \\
640.4 \\
0.0\end{array}$ & $\begin{array}{r}290.1 \\
4.2 \\
154.4 \\
10.5 \\
9.4 \\
8.9 \\
34.3 \\
16.5 \\
0.7 \\
2.8 \\
0.1 \\
3.4\end{array}$ & $\begin{array}{r}314.4 \\
50.9 \\
169.5 \\
12.8 \\
\$ 1.4 \\
9.5 \\
35.9 \\
17.4 \\
0.9 \\
3.0 \\
0.5 \\
3.1\end{array}$ & $\begin{array}{r}348, t \\
5.4 .2 \\
174.8 \\
14.6 \\
13.4 \\
9.8 \\
37.0 \\
17.0 \\
0.8 \\
3.4 \\
0.8 \\
15.5\end{array}$ & $\begin{array}{r}3.003 .4 \\
1,021.4 \\
418.3 \\
99.4 \\
248.9 \\
16.4 \\
35.6 \\
17.8 \\
0.7 \\
2.0 \\
618.8 \\
3.4\end{array}$ & $\begin{array}{r}3,198.9 \\
1,690.0 \\
428.4 \\
112.4 \\
278.5 \\
17.0 \\
38.8 \\
18.5 \\
0.9 \\
3.0 \\
610.4 \\
3.1\end{array}$ & $\begin{array}{r}3,259.8 \\
1,691.7 \\
465.9 \\
705.9 \\
256.8 \\
16.8 \\
37.6 \\
18.1 \\
0.8 \\
3.4 \\
640.5 \\
16.5\end{array}$ \\
\hline 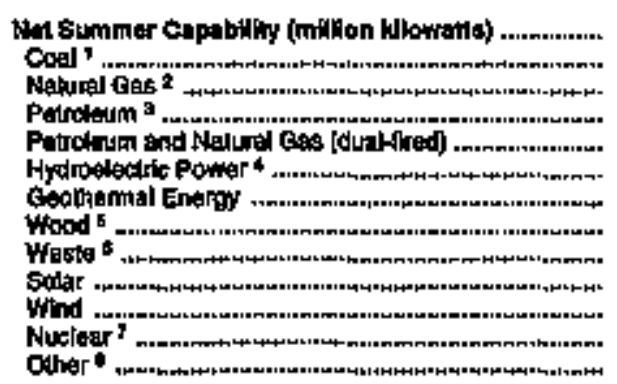 & $\begin{array}{r}698.1 \\
300.5 \\
15.7 \\
50.5 \\
133.6 \\
90.4 \\
1.7 \\
0.2 \\
0.2 \\
157 \\
0.0 \\
00.0 \\
0.0\end{array}$ & $\begin{array}{r}700.0 \\
300.8 \\
16.6 \\
49.3 \\
137.2 \\
95.9 \\
1.7 \\
0.2 \\
0.2 \\
167 \\
185 \\
96.0 \\
0.0\end{array}$ & $\begin{array}{r}760.2 \\
301.4 \\
19.4 \\
15.9 \\
139.4 \\
06.0 \\
1.7 \\
0.3 \\
0.3 \\
157 \\
(8) \\
09.1 \\
0.0\end{array}$ & $\begin{array}{r}61.6 \\
7.9 \\
18.7 \\
1.8 \\
7.5 \\
2.6 \\
1.8 \\
6.4 \\
2.8 \\
0.0 \\
1.9 \\
181 \\
0.6\end{array}$ & $\begin{array}{r}88.0 \\
0.1 \\
20.3 \\
1.9 \\
7.6 \\
2.6 \\
1.2 \\
6.7 \\
2.9 \\
0.3 \\
1.8 \\
19 . \\
0.5\end{array}$ & $\begin{array}{r}61.0 \\
0.7 \\
23.2 \\
0.1 \\
8.5 \\
3.3 \\
1.3 \\
7.0 \\
2.0 \\
0.3 \\
1.7 \\
0.0 \\
1.6\end{array}$ & 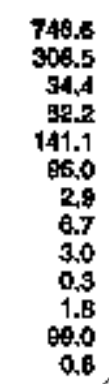 & $\begin{array}{r}768.0 \\
308.0 \\
35.6 \\
50.2 \\
144.7 \\
96.6 \\
3.0 \\
6.9 \\
3.2 \\
0.8 \\
1.8 \\
99.1 \\
0.5\end{array}$ & $\begin{array}{r}704.0 \\
310.0 \\
42.7 \\
48.0 \\
147.0 \\
98.3 \\
3.0 \\
7.3 \\
3.2 \\
0.3 \\
1.7 \\
90.1 \\
1.6\end{array}$ \\
\hline
\end{tabular}

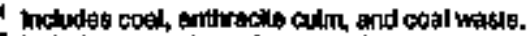

hetudes naturil gas, berlane, Glhana, propane, waste hasl, and wasle gases.

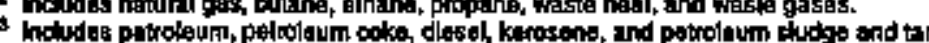

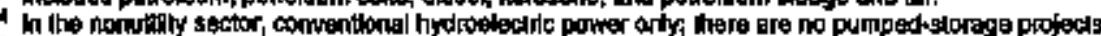

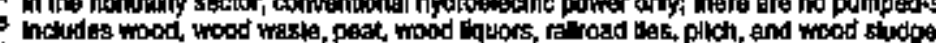

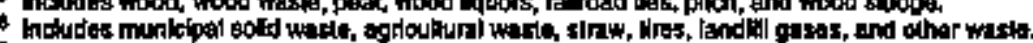

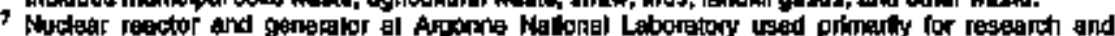

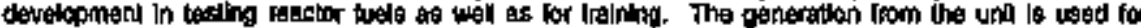

intermat consimpton.

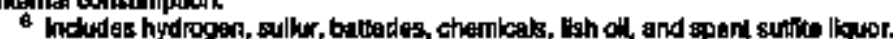

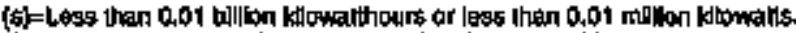

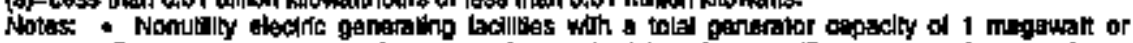
groaler. 108. Tolals may nol equel gum of components thle ba Independenl rounding.

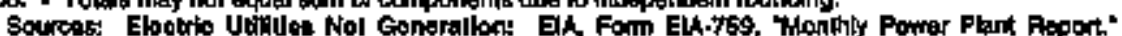

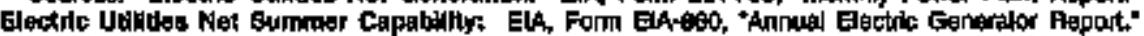

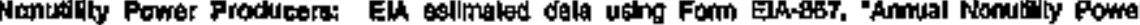
Producer Faport." 


\section{Total, 1949-1985}

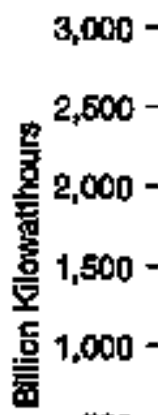

$500-$

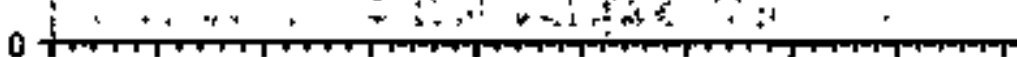

$\begin{array}{llllllllll}1949 & 1954 & 1959 & 1964 & 1969 & 1974 & 1979 & 1984 & 1989 & 1994\end{array}$

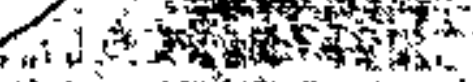

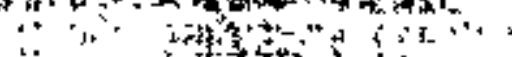

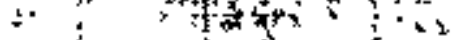

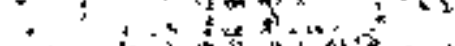

\subsection{9 trition kiowatihours}

in 1995

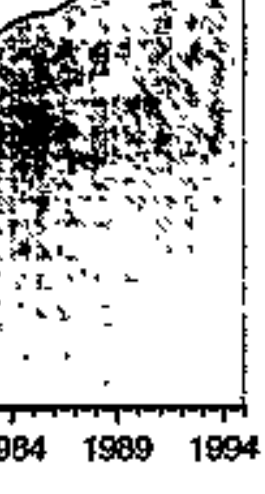

By Major Energy Source, 1995

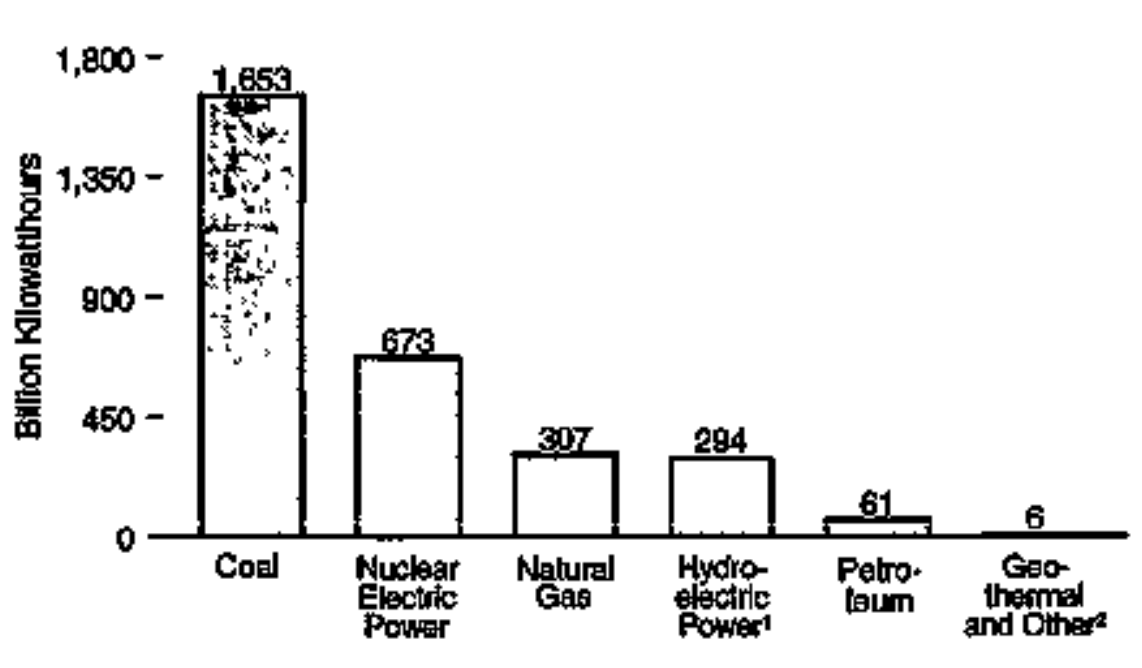

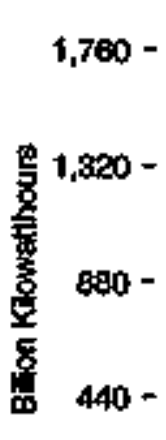

\section{Total, 1949-1995}

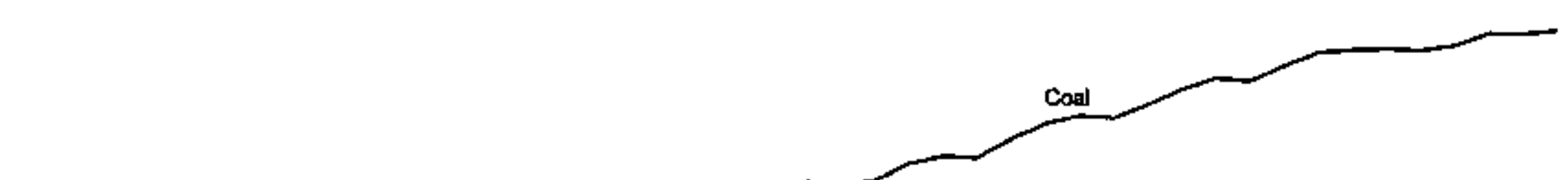

-

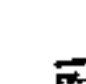

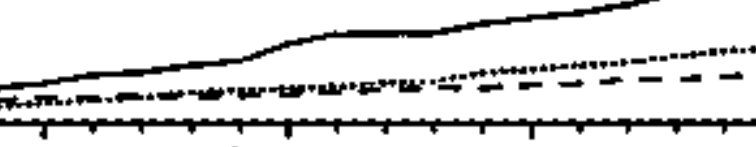

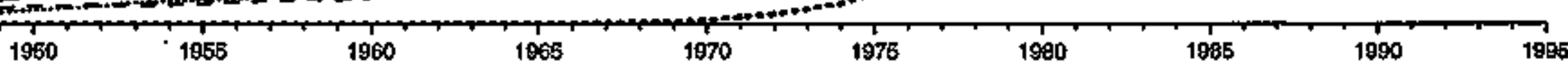

1 Comantiontol and pumpertstarige hydroelectric power.

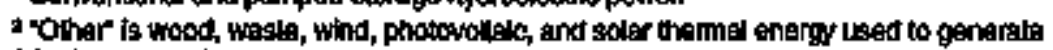

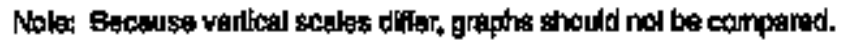
electrictly tor distribution. 
Table 8.3 Electric Utility Net Generation of Electricity by Energy Source, 1949-1995 (Billion Kilowatthours)

\begin{tabular}{|c|c|c|c|c|c|c|c|c|c|c|}
\hline \multirow[b]{2}{*}{ Yeser } & \multicolumn{4}{|c|}{ Foasll Fuals } & \multirow[b]{2}{*}{$\begin{array}{l}\text { Phuctear } \\
\text { Gectio } \\
\text { Powner }\end{array}$} & \multirow[b]{2}{*}{ 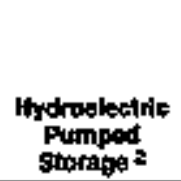 } & \multicolumn{3}{|c|}{ Rantrwablo Enary } & \multirow[b]{2}{*}{ Tats } \\
\hline & $C 0 \$ 1$ & $\begin{array}{l}\text { Nalumel } \\
\text { Clos }\end{array}$ & Peinoleum I & Total & & & $\begin{array}{l}\text { Convenulatal } \\
\text { Hydrotetelrio } \\
\text { Ponere? }\end{array}$ & $\begin{array}{l}\text { Geothermal } \\
\text { Energy } \\
\text { and } \\
\text { oiner }\end{array}$ & Total & \\
\hline 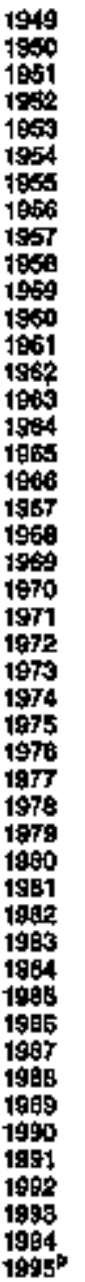 & 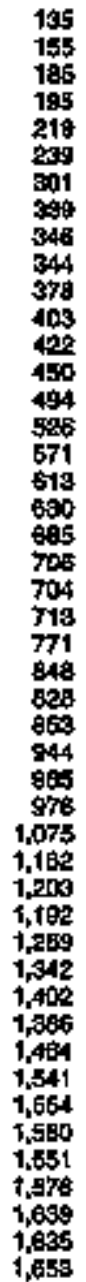 & 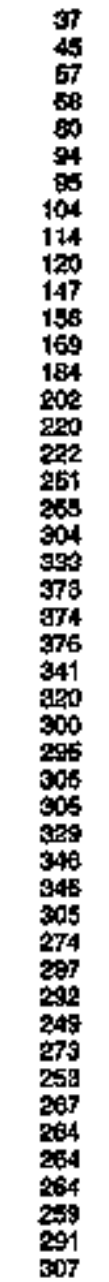 & $\begin{array}{r}29 \\
34 \\
29 \\
30 \\
98 \\
39 \\
37 \\
36 \\
40 \\
40 \\
47 \\
40 \\
49 \\
49 \\
52 \\
57 \\
65 \\
79 \\
69 \\
104 \\
199 \\
584 \\
280 \\
274 \\
314 \\
301 \\
209 \\
320 \\
359 \\
365 \\
304 \\
246 \\
208 \\
147 \\
144 \\
120 \\
100 \\
197 \\
119 \\
149 \\
158 \\
117 \\
111 \\
899 \\
100 \\
81 \\
61\end{array}$ & 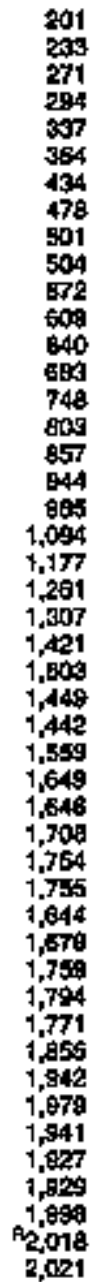 & 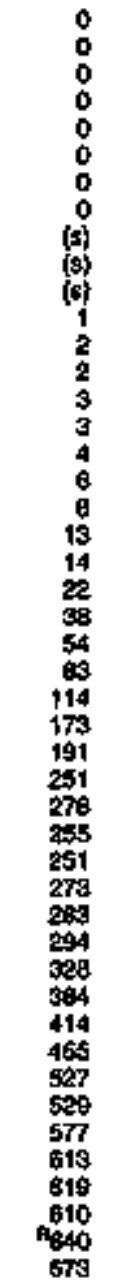 & 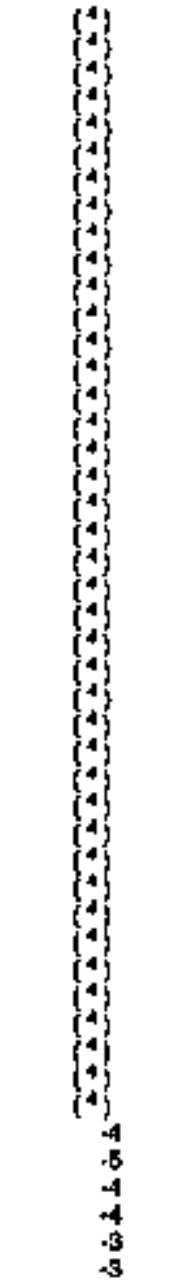 & 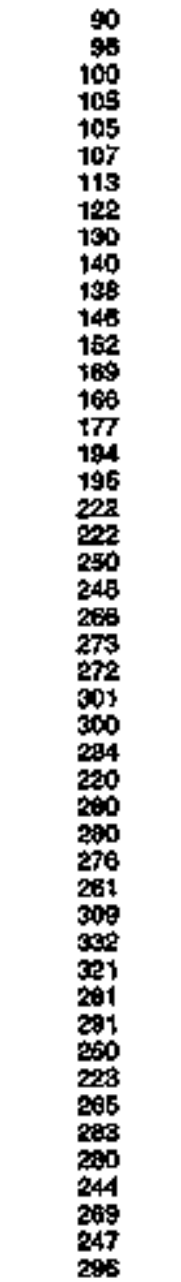 & 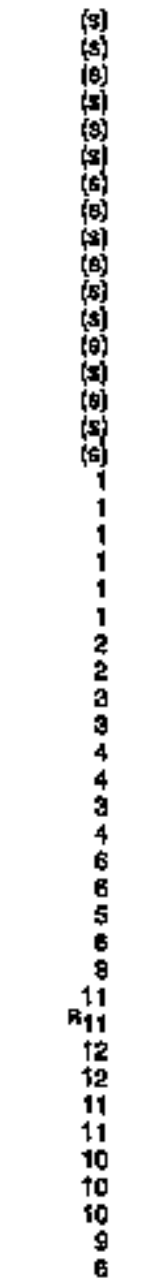 & 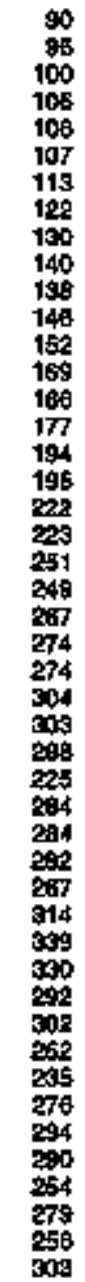 & 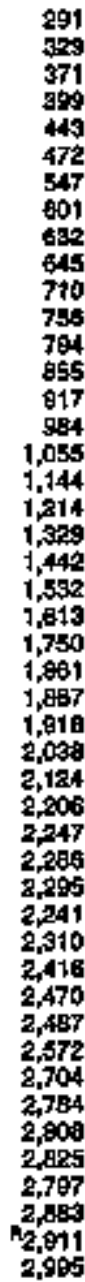 \\
\hline
\end{tabular}

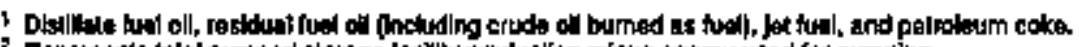

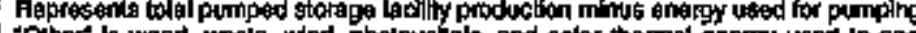

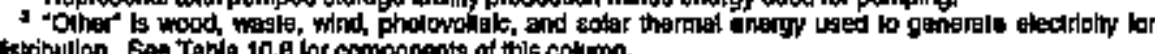

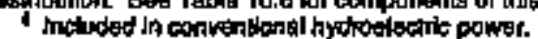

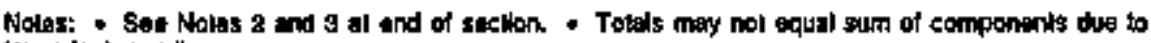
ingendend founding.

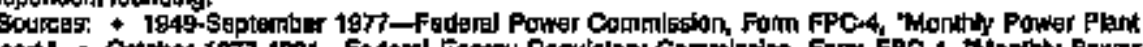

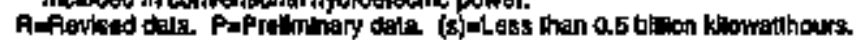




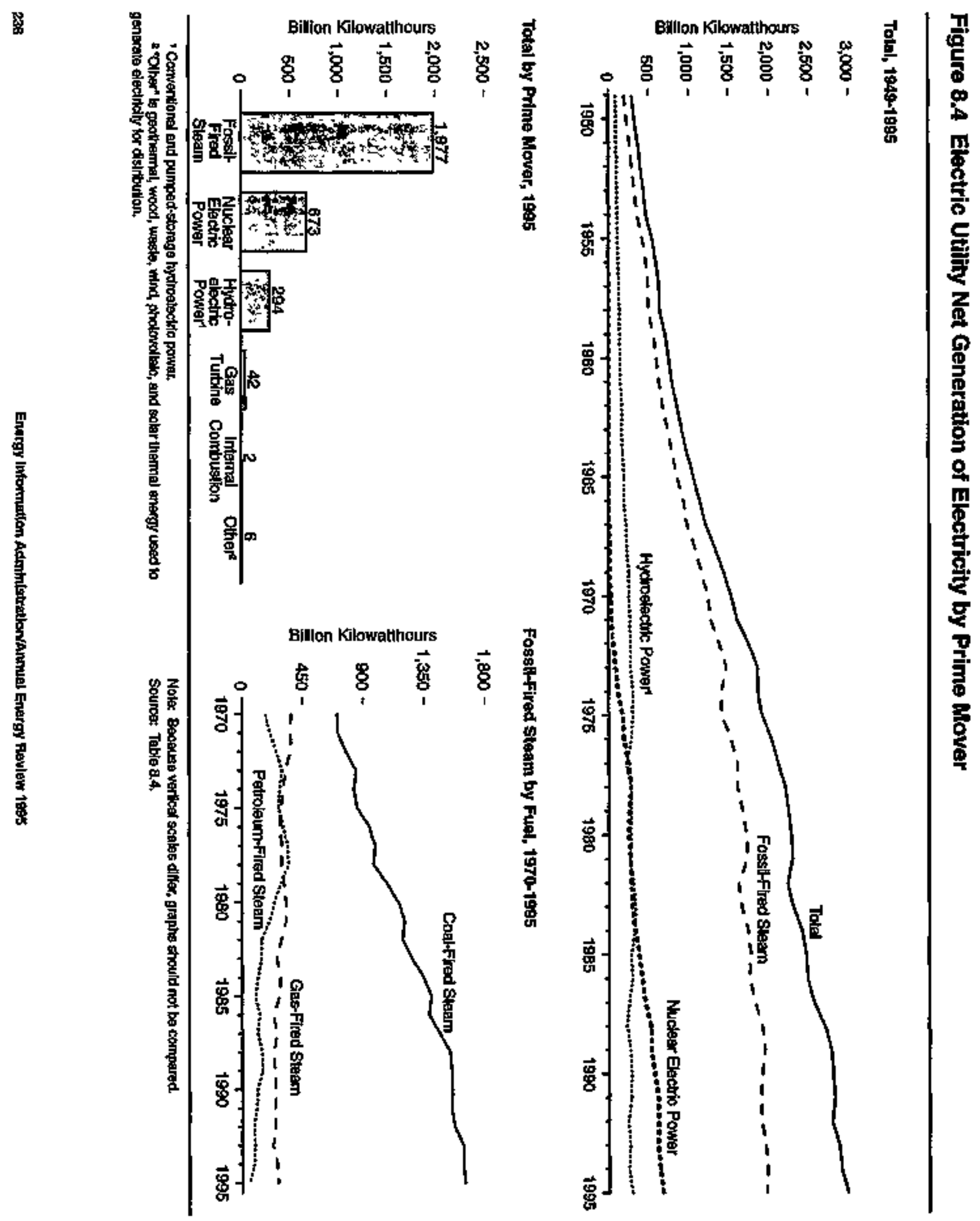


Table 8.4 Electric Utility Net Generation of Electricity by Prime Mover, 1949-1995

(Bition Kilowatthours)

\begin{tabular}{|c|c|c|c|c|c|c|c|c|c|c|c|c|}
\hline \multirow[b]{2}{*}{ Year } & \multicolumn{4}{|c|}{ Fowsinfind Blum } & \multirow[b]{2}{*}{$\begin{array}{l}\text { nombrimal } \\
\text { Combustion }\end{array}$} & \multirow[b]{2}{*}{$\begin{array}{c}\text { chom } \\
\text { Turbine }\end{array}$} & \multirow{2}{*}{$\begin{array}{l}\text { Nuclear } \\
\text { Ellacirto } \\
\text { Powwer } \\
\end{array}$} & \multicolumn{3}{|c|}{ Hydroelectilo Powar } & \multirow[b]{2}{*}{ Oihar ' } & \multirow[b]{2}{*}{ Total } \\
\hline & Conl-Firtd & Potroleumfried & Gas-fitsed & Tokit & & & & Conwentions: & $\begin{array}{l}\text { Pumped } \\
\text { storige }\end{array}$ & Toter & & \\
\hline 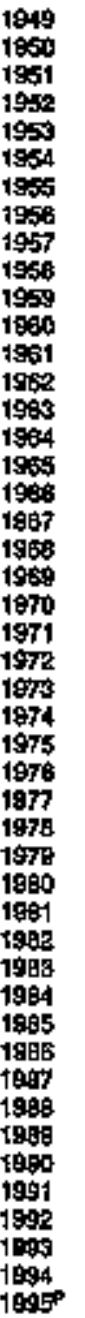 & 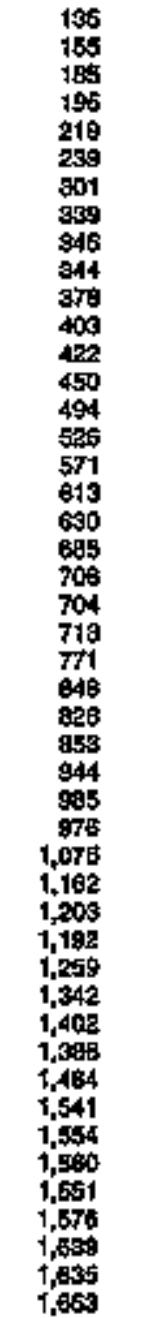 & $\begin{array}{l}N A \\
N A \\
N A \\
N A \\
N A \\
N A \\
N A \\
N A \\
N A \\
N A \\
N A \\
N A \\
N A \\
N A \\
N A \\
N A \\
N A \\
N A \\
N A \\
N A \\
N A \\
174 \\
206 \\
250 \\
290 \\
279 \\
279 \\
300 \\
339 \\
345 \\
290 \\
230 \\
202 \\
144 \\
141 \\
117 \\
97 \\
139 \\
115 \\
144 \\
151 \\
113 \\
109 \\
95 \\
956 \\
98 \\
B 6\end{array}$ & 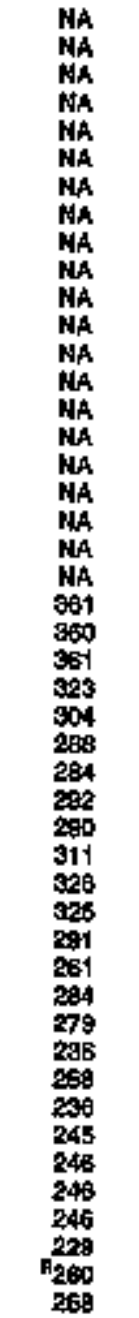 & 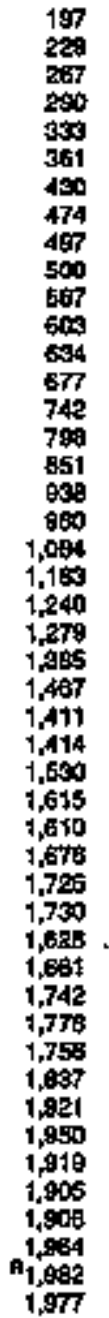 & $\begin{array}{r}3 \\
4 \\
4 \\
4 \\
4 \\
4 \\
4 \\
4 \\
4 \\
4 \\
4 \\
4 \\
5 \\
5 \\
5 \\
5 \\
5 \\
5 \\
5 \\
9 \\
14 \\
6 \\
5 \\
7 \\
7 \\
6 \\
6 \\
5 \\
5 \\
5 \\
4 \\
4 \\
3 \\
2 \\
2 \\
2 \\
2 \\
2 \\
2 \\
2 \\
2 \\
2 \\
2 \\
2 \\
0 \\
2 \\
2\end{array}$ & 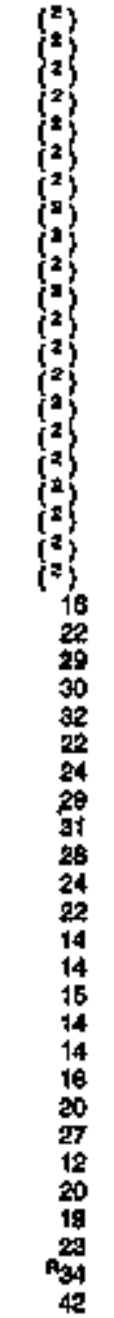 & 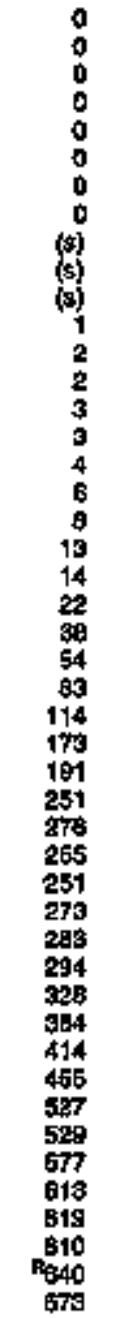 & 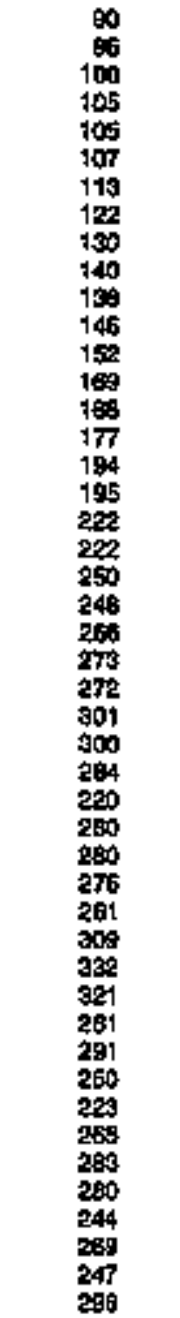 & 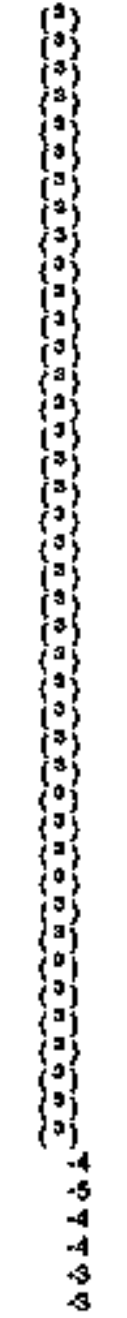 & 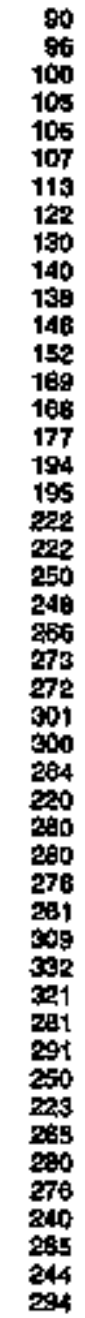 & 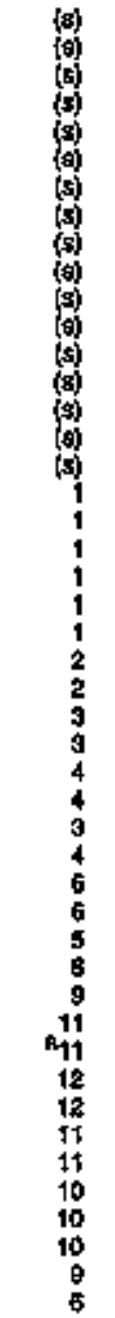 & 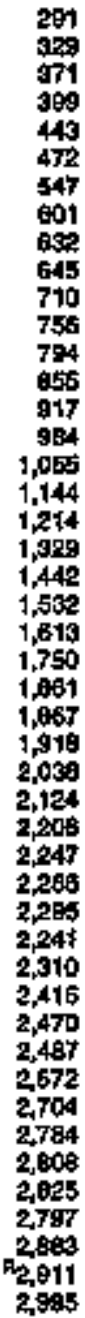 \\
\hline
\end{tabular}

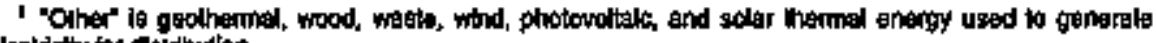

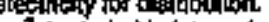

2 Inctuded In inuem: combuston.

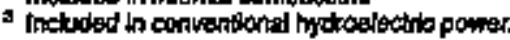

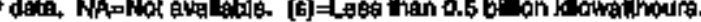

independenal roundind.

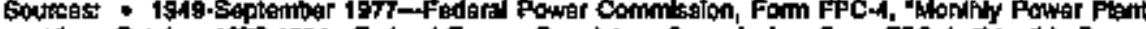

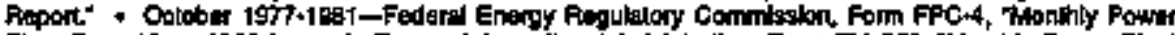

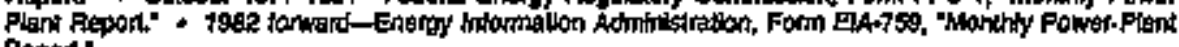
Notes: - Sae kloks 2 and 3 al and of section. Tokds may not equal sum ol componants due bo 


\section{Figure 8.5 Electric Utility Consumption of Fossll Fuels To Generate Electricity}

Total, 1949-1933

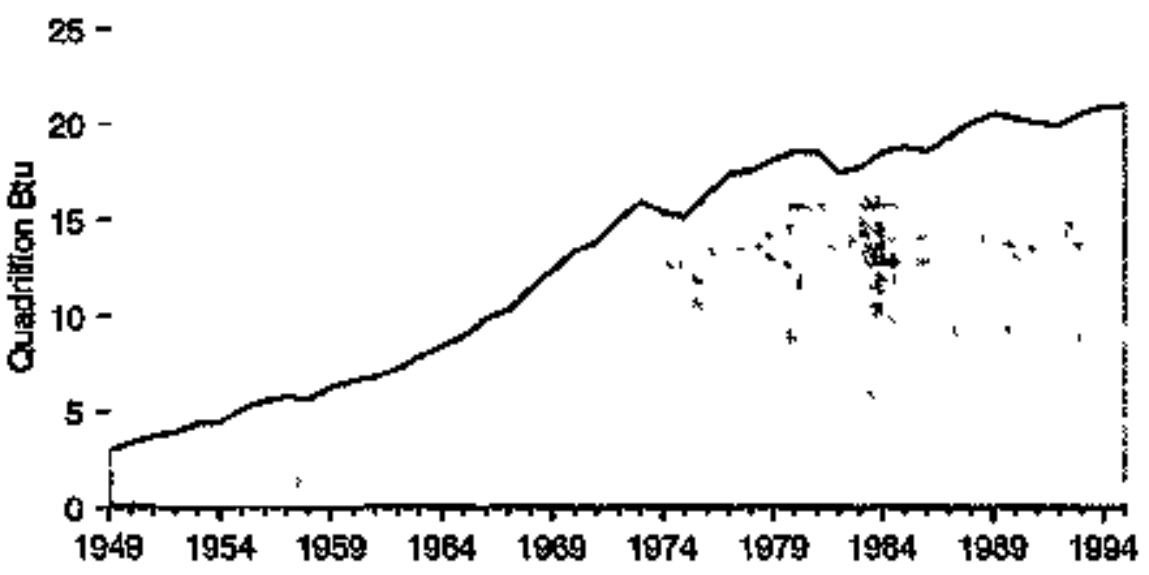

\section{By Energy Source, 1995}

$20-$

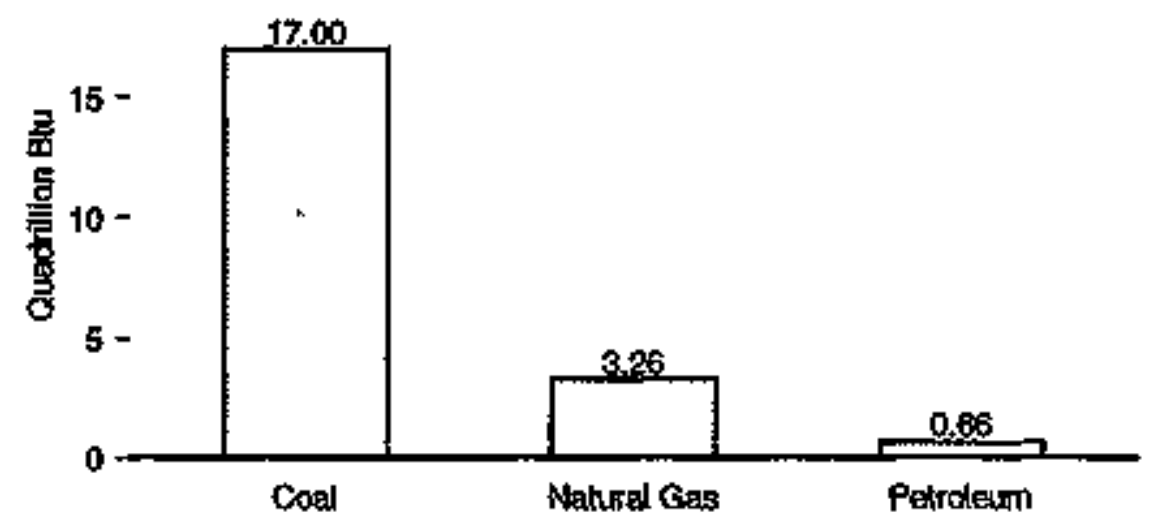

\section{By Energy Soures, 1949-19s5}

$20-$

离 ${ }^{15}$ -

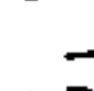
꾼. 1950

Nele: Because verilcat scales effier, graphe should not be compered.

Sources: Tatolo 0.5 
Table 8.5 Electric Utility Consumption of Fossil Fuels To Generate Electricity, 1949-1995

\begin{tabular}{|c|c|c|c|c|c|c|c|c|}
\hline \multirow[b]{2}{*}{ Yestr } & \multicolumn{3}{|c|}{ con } & \multicolumn{2}{|c|}{ Dotures tex } & \multicolumn{2}{|c|}{ Putrotoun 1} & \multirow{2}{*}{ Total } \\
\hline & Whitan Strort Tons & Duparifion Btu & & anion outic Feet & Qundfillion Ehu & Mullon Barrels & Dutedifition Elo & \\
\hline 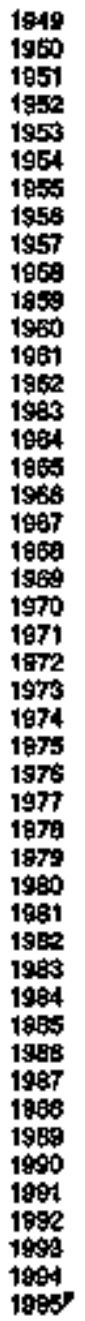 & 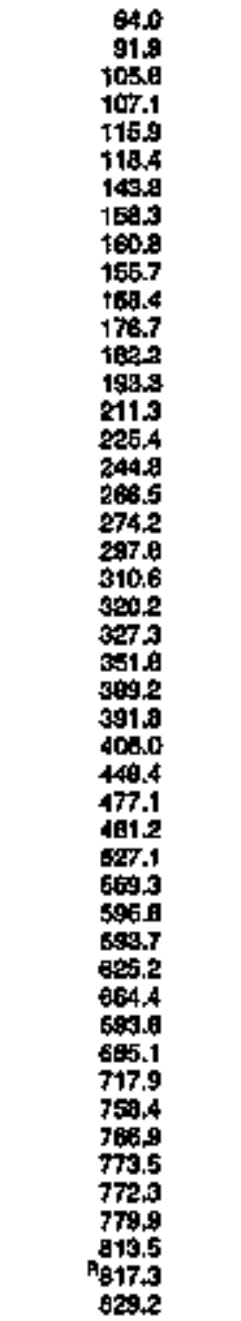 & 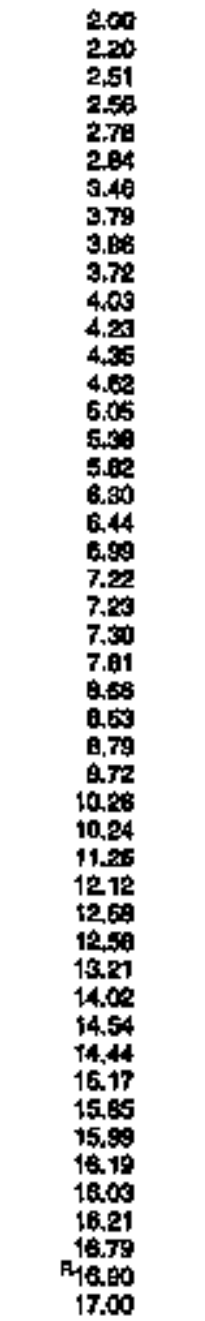 & - & 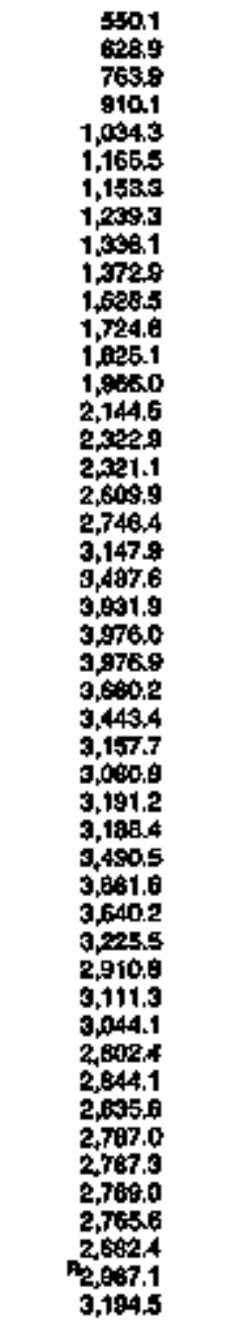 & $\begin{array}{l}0.67 \\
0.85 \\
0.79 \\
0.94 \\
1.07 \\
1.21 \\
1.19 \\
1.29 \\
1.39 \\
1.49 \\
1.69 \\
1.79 \\
1.49 \\
2.09 \\
2.21 \\
2.10 \\
2.40 \\
2.70 \\
2.89 \\
3.25 \\
3.50 \\
4.05 \\
4.10 \\
4.08 \\
3.76 \\
3.62 \\
3.24 \\
3.15 \\
3.26 \\
3.30 \\
3.51 \\
3.81 \\
3.77 \\
3.34 \\
3.30 \\
3.22 \\
3.46 \\
2.69 \\
2.94 \\
2.71 \\
2.67 \\
2.60 \\
2.86 \\
2.63 \\
2.74 \\
3.06 \\
3.26\end{array}$ & 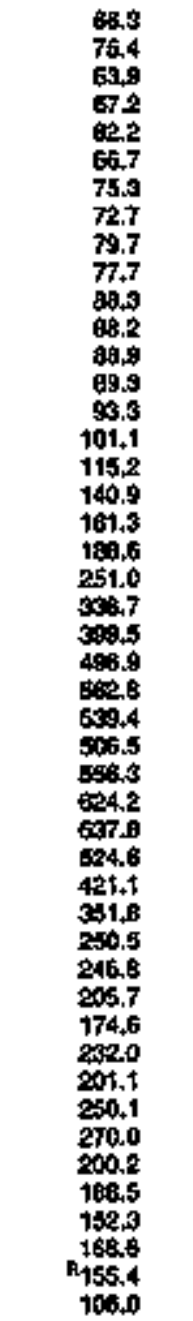 & 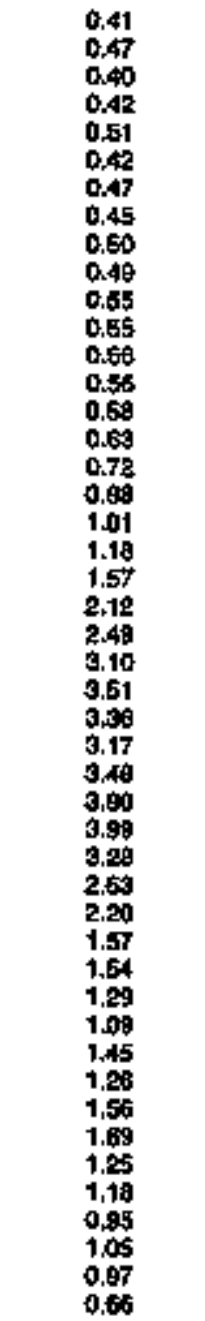 & 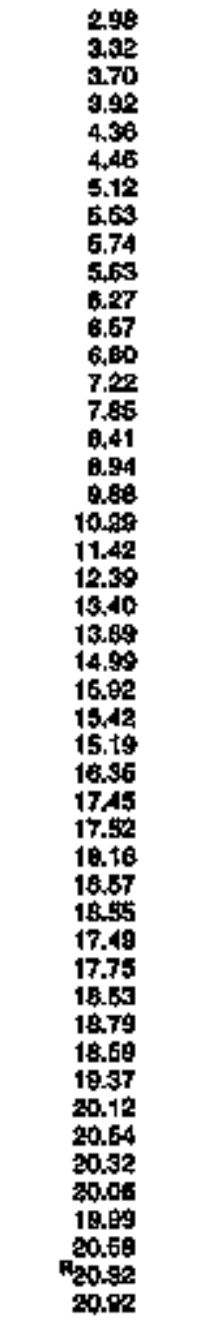 \\
\hline
\end{tabular}

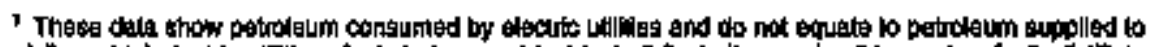

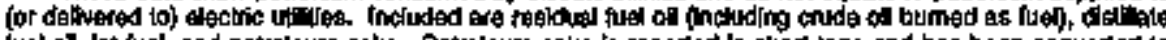
barres at a rate of 6 barrets per short lon.

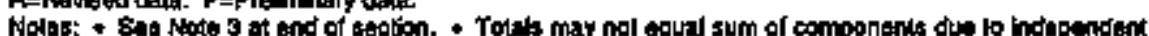

rounding.

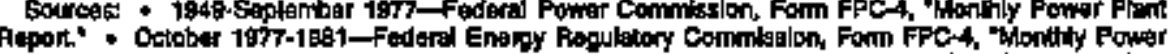

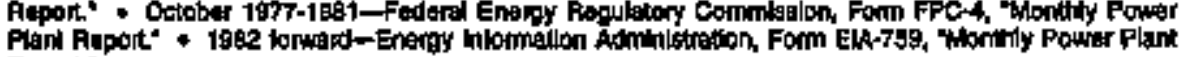
Repont:" 


\section{Figure 8.6 Electric Utility Retail Sales of Electricity}

\section{Total, 1949-1295}

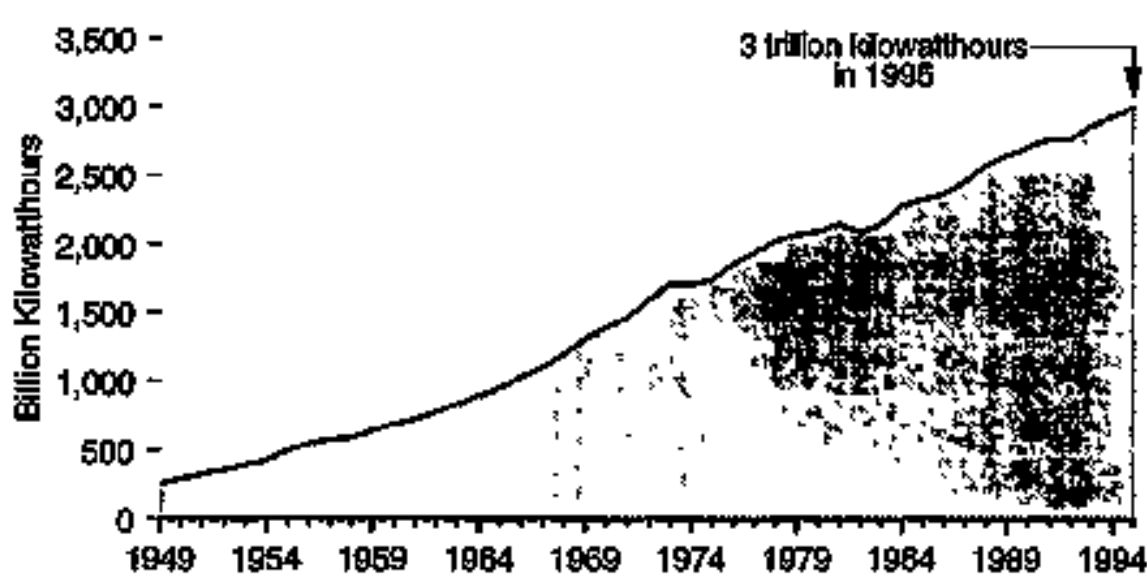

\section{By EndUse Sector, 1949-1985}

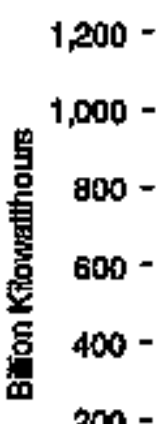

$200-$

\section{By End-Use Sector, 1995}

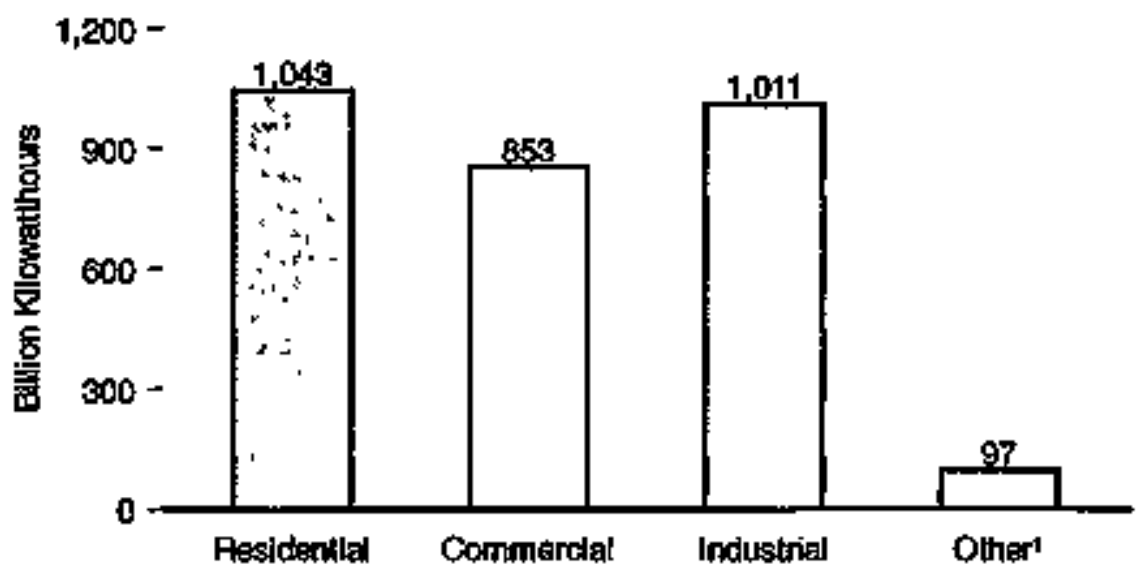

\section{0}

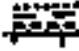

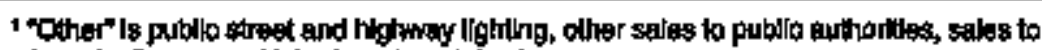

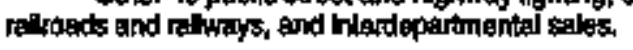

Note: Beowise vertiogl scates dilier, graphs should nol be cornpared. Source: Tatin 68 .

Other!.

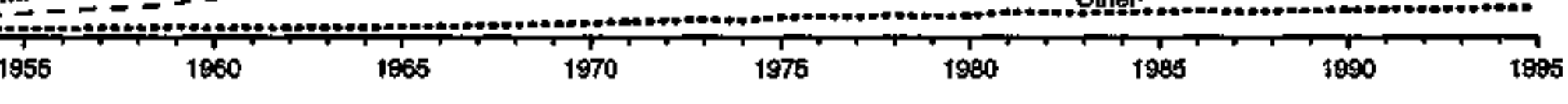


Table 8.6 Electric Utllty Retail Sales of Electricity by End-Use Sector, 1949-1995 (Billion Kilowathours)

\begin{tabular}{|c|c|c|c|c|c|}
\hline Yaar & Rosibtentited & Coarmardint: & Industrial & odon' 1 & Total \\
\hline 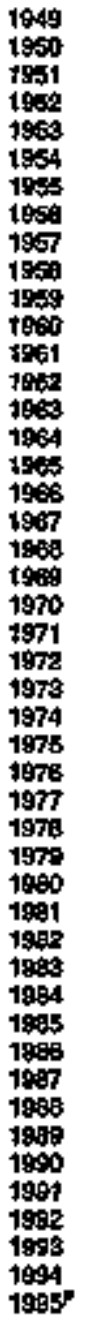 & 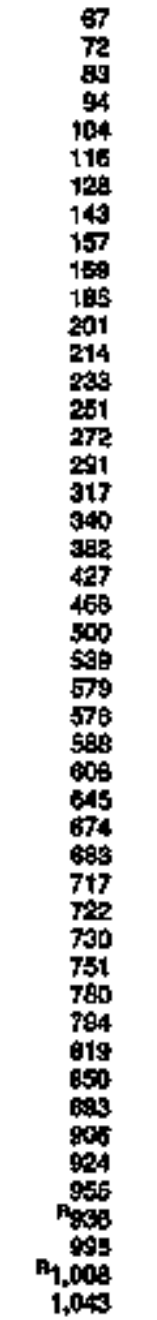 & 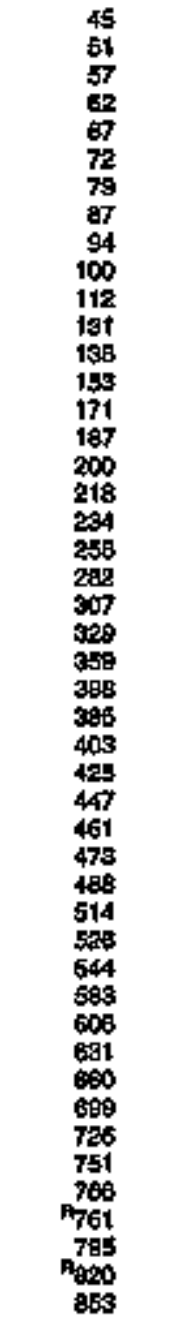 & 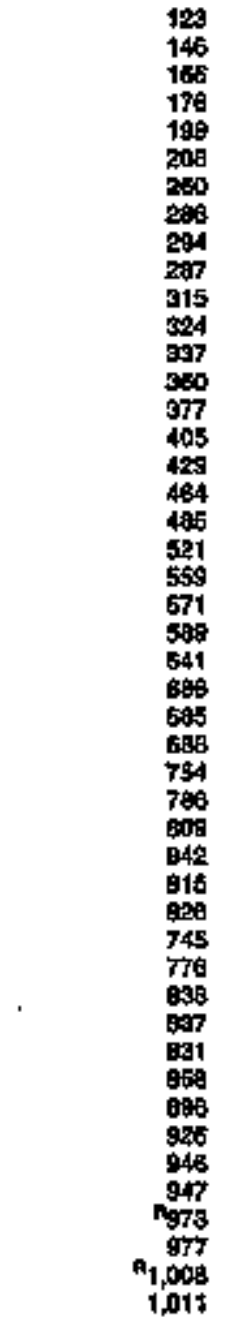 & 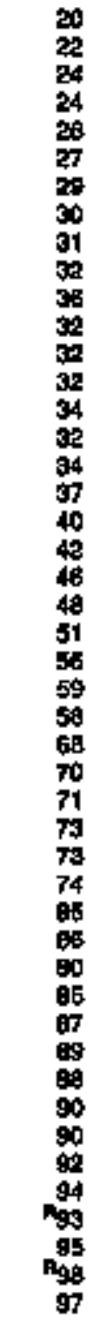 & 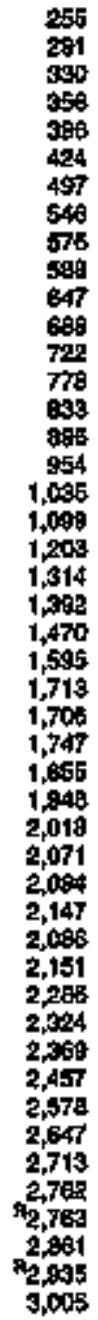 \\
\hline
\end{tabular}

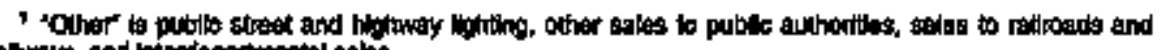
rathryss, and intentiparmantal sales.

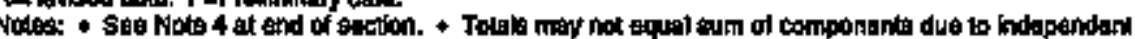
muinoting.

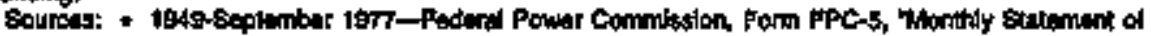

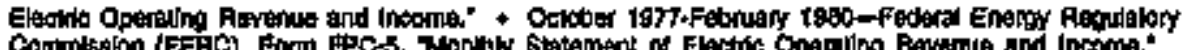

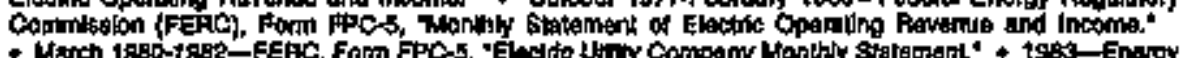

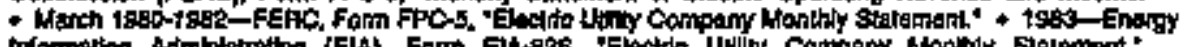

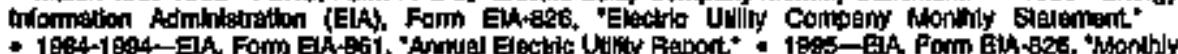

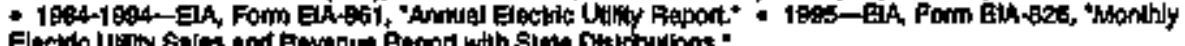


Actual Pealdoad Reductions, Total of AD Programts, 1989-1994

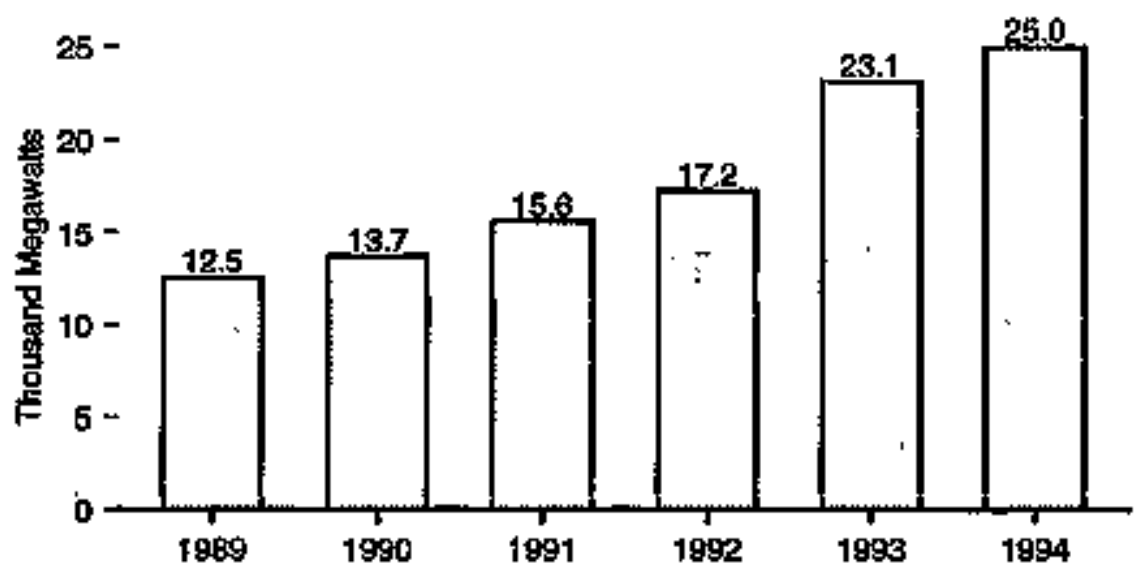

\section{Energy Savinge, 1890-1994}

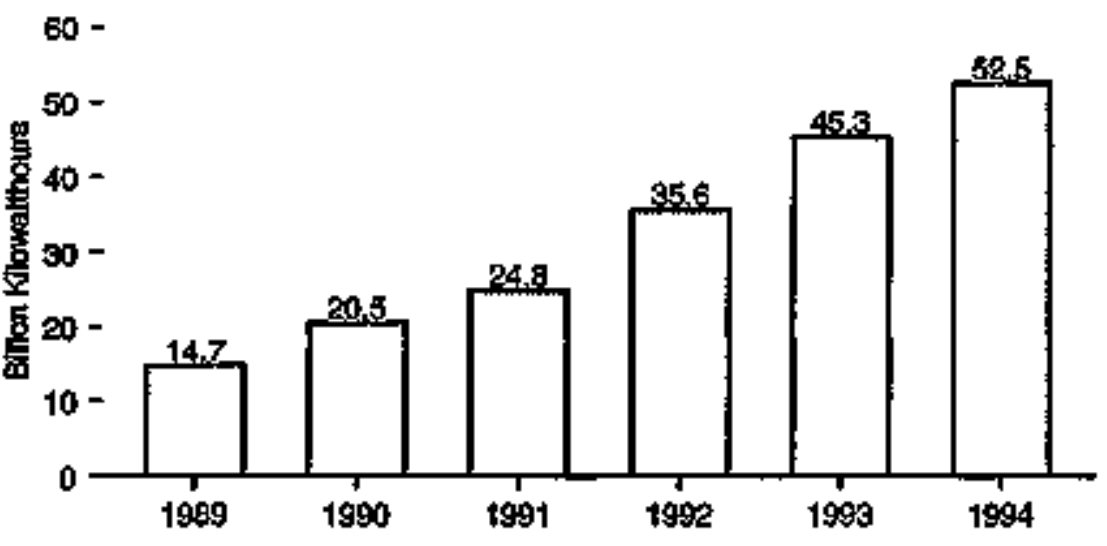

Aolual Peakdoad Reductlons by Program, 1994

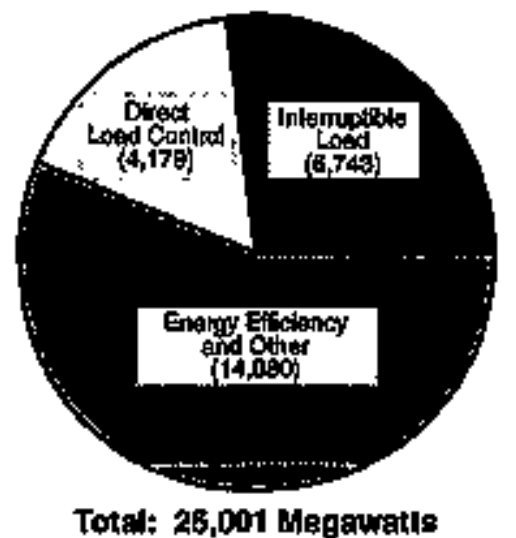

Total: 28,001 Megawatle
Costs, $1909-1994$

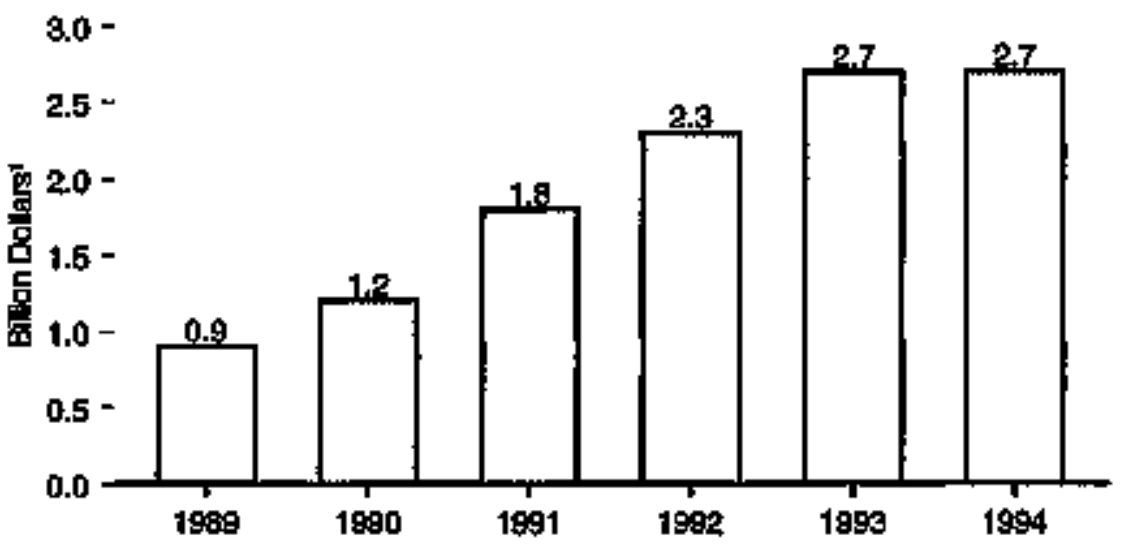

Nominal dotiars.

Sourca: Table 0.7 
Table 8.7 Electric Utlity Demand-Side Management Programs: Peakload Reductions, Energy Savings, and Costs, 1989-1994

\begin{tabular}{|c|c|c|c|c|c|c|}
\hline \multirow[b]{2}{*}{ Your } & \multicolumn{4}{|c|}{ 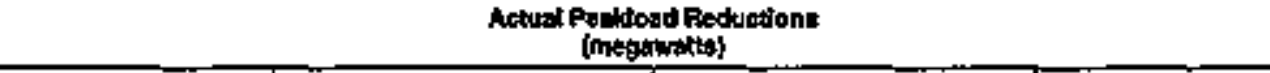 } & \multirow{2}{*}{ 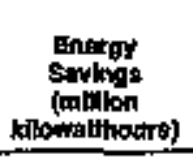 } & \multirow[b]{2}{*}{$\begin{array}{l}\text { Coots } \\
\text { (uhotsinnd } \\
\text { dollars o) }\end{array}$} \\
\hline & 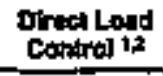 & Inlerrupitoto & $\begin{array}{c}\text { Enargy Etidenay + } \\
\text { and Other : }\end{array}$ & Tots & & \\
\hline $\begin{array}{l}1969 \\
1990 \\
1991 \\
1992 \\
1909 \\
1994\end{array}$ & $\begin{array}{r}\text { NA } \\
3,092 \\
5,093 \\
3,779 \\
3,855 \\
4,179\end{array}$ & $\begin{array}{r}\text { KA } \\
4,219 \\
3,674 \\
3,679 \\
6,608 \\
6,743\end{array}$ & 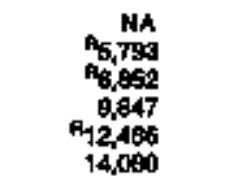 & $\begin{array}{r}12,150 \\
A_{13,704} \\
n_{15,619} \\
17,204 \\
A^{15,069} \\
25,001\end{array}$ & 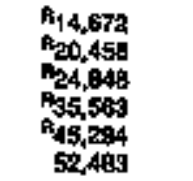 & 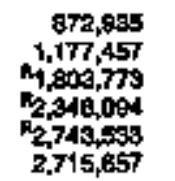 \\
\hline
\end{tabular}

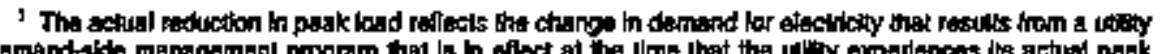

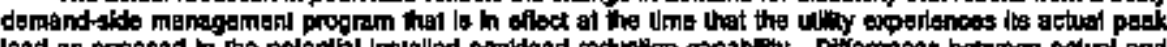

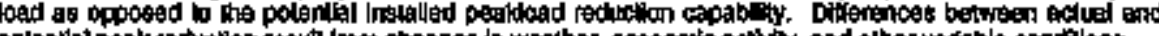

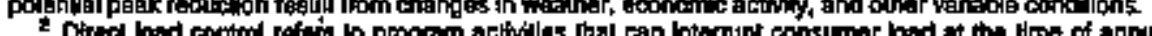

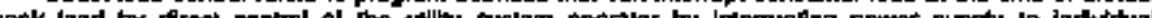

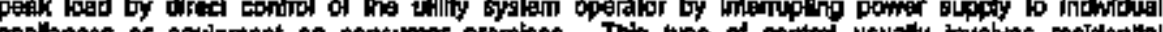

congumars.

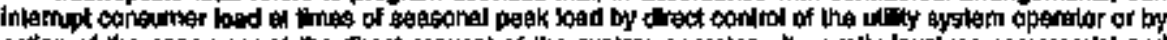

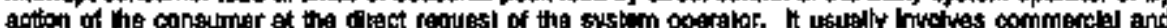
lndill

t En (n)

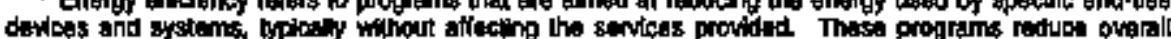

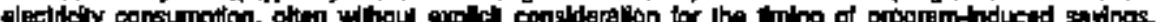

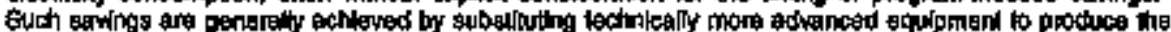

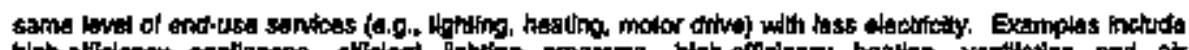

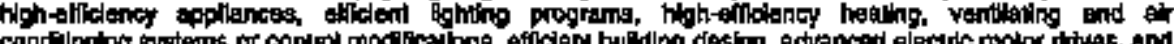

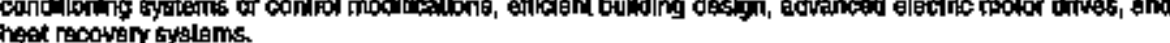
s recovery sysilams.

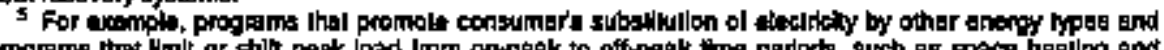

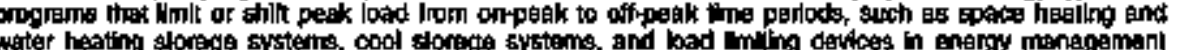
syatems.

Nominel dollors

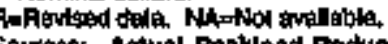

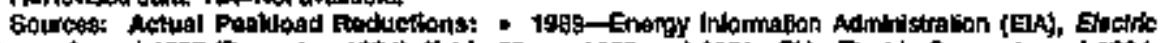

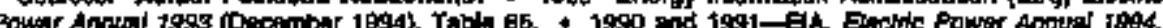

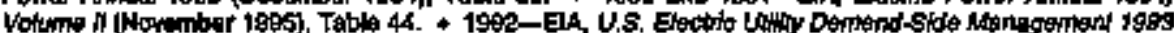

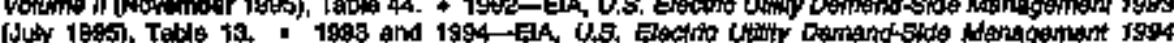

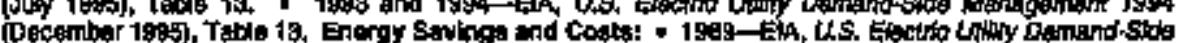

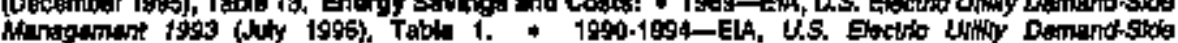

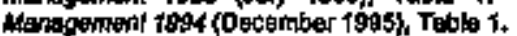




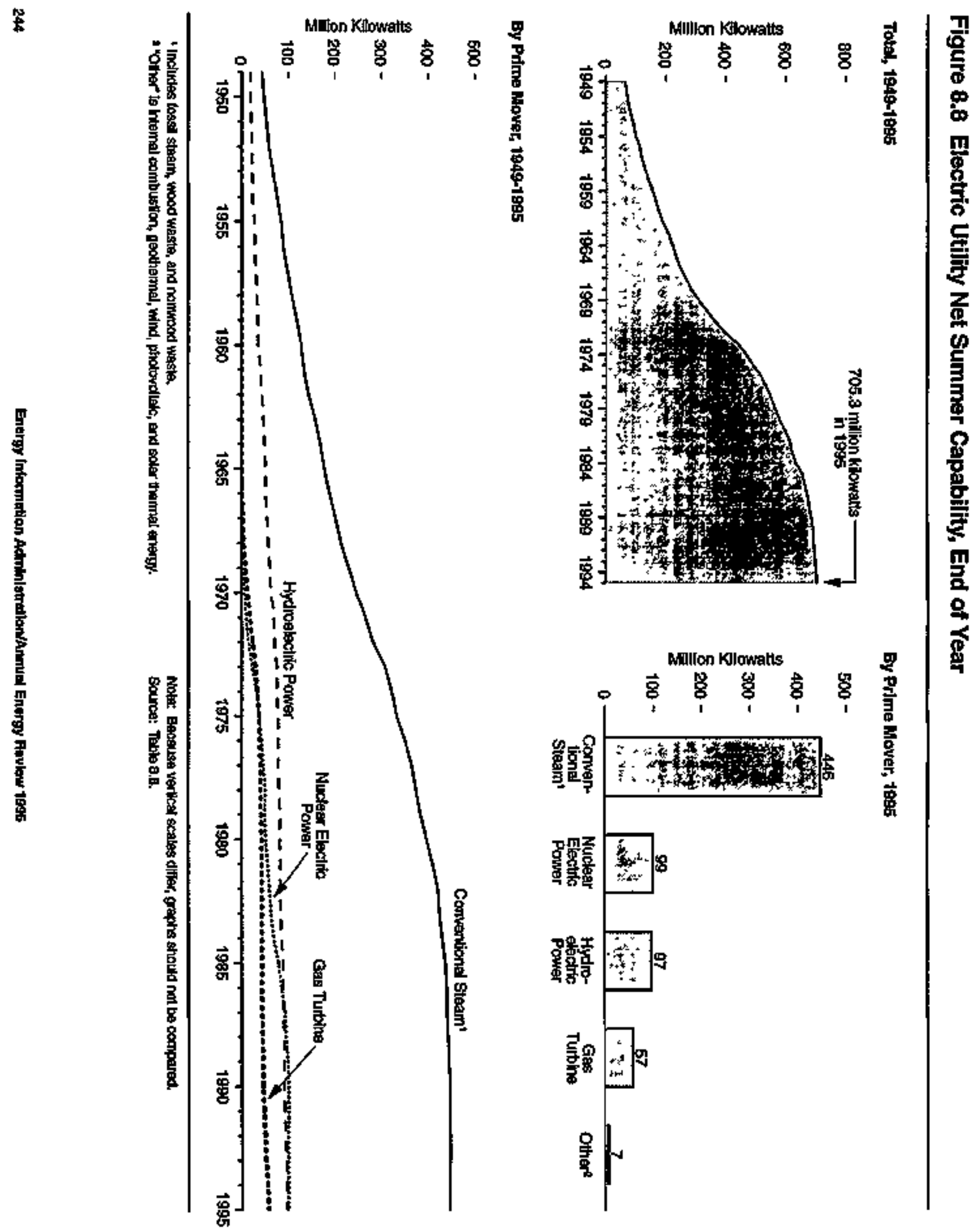


Table 8.8 Electric Utility Net Summer Capability, End of Year 1949-1995

(Milion Kilowatts)

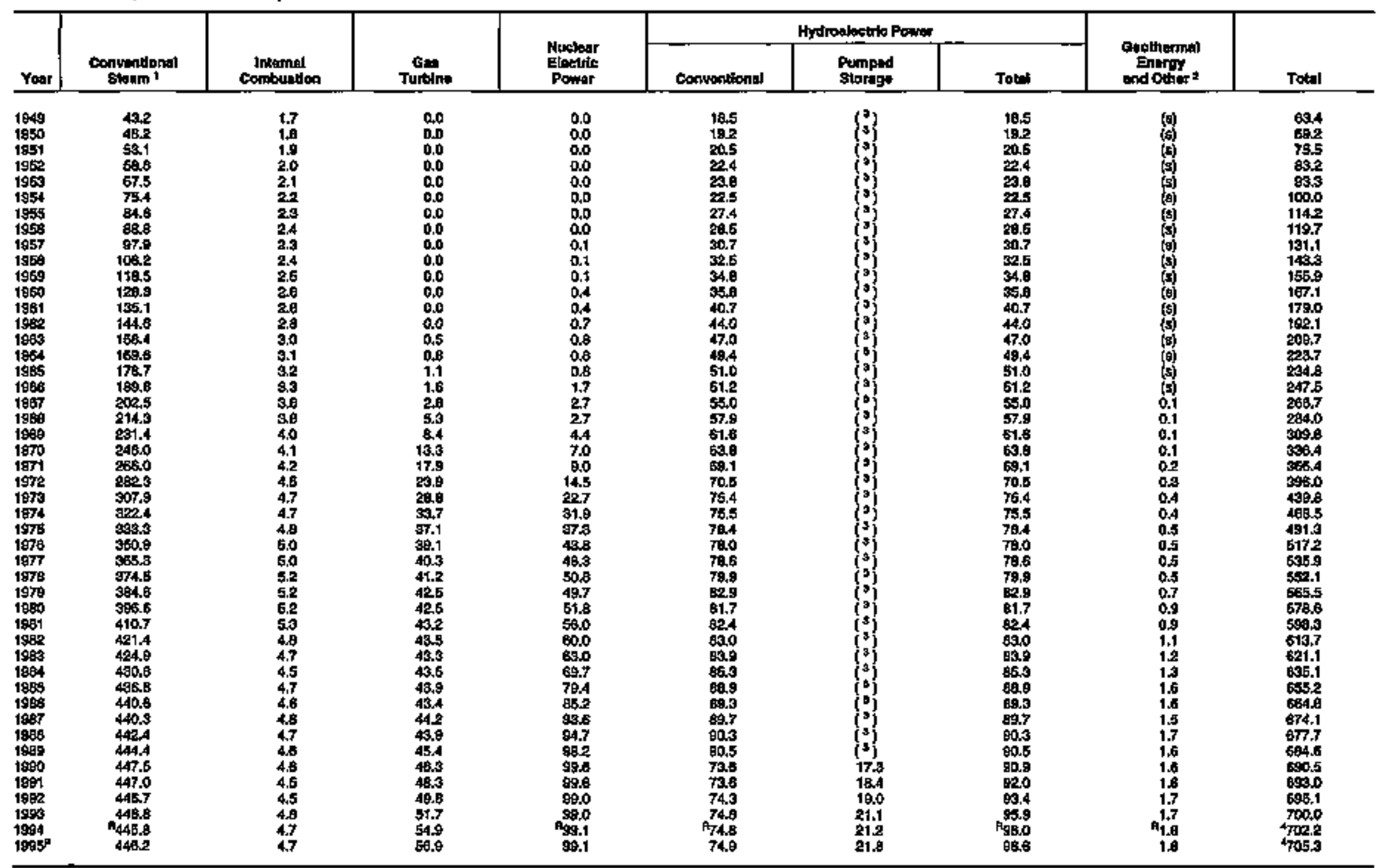

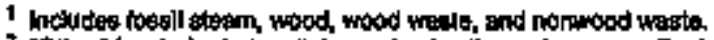

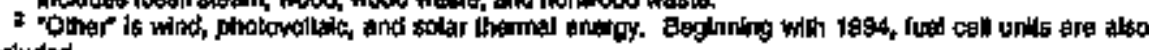

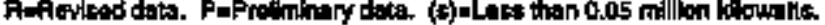

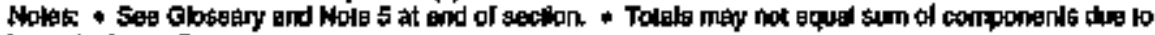
includid.

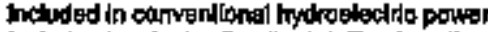

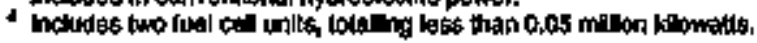
ndependend rounding.

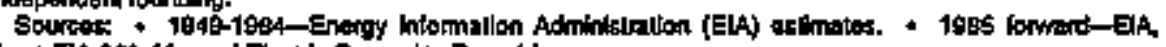
Fom ElA 650 , 'Anulual Electic Oenerator Report' 
In the ContIguous United States, 1966-1994

$900-$

Esummer EWinter

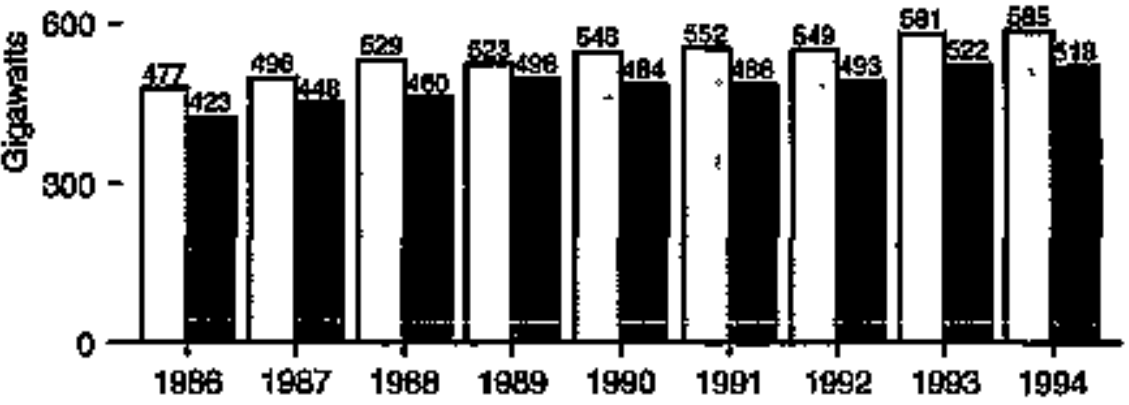

North American Electric feliabillty Council Map for the United States

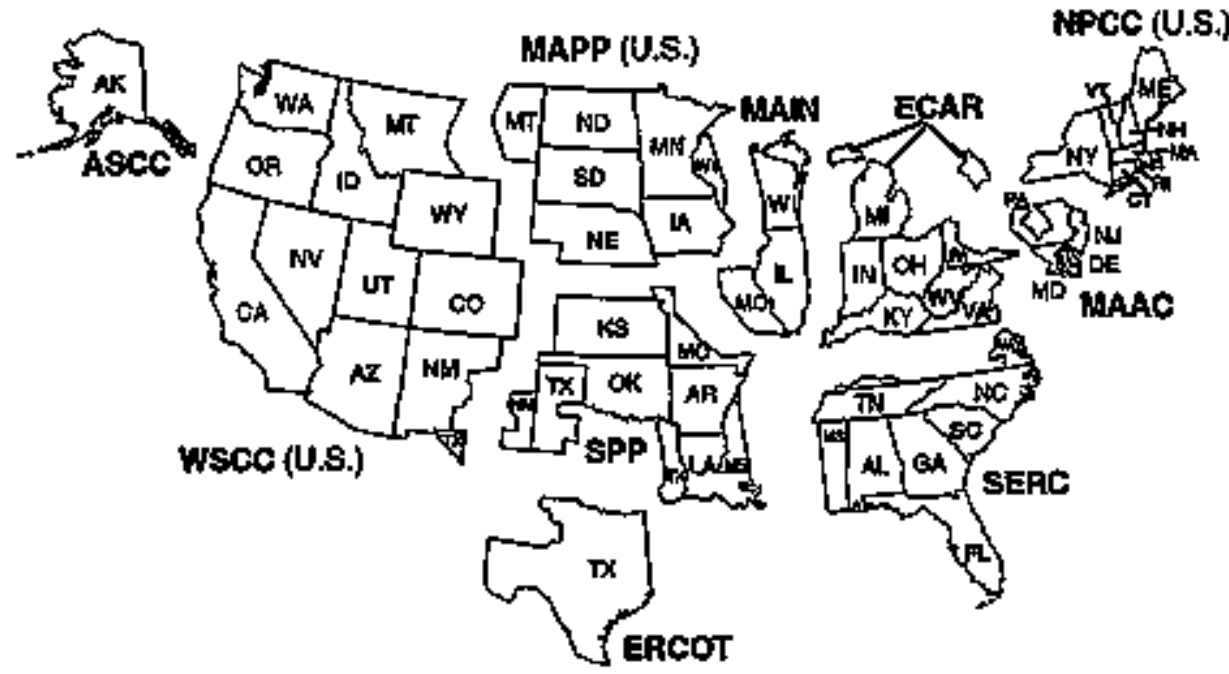

BY NERC Rogtions, 1994

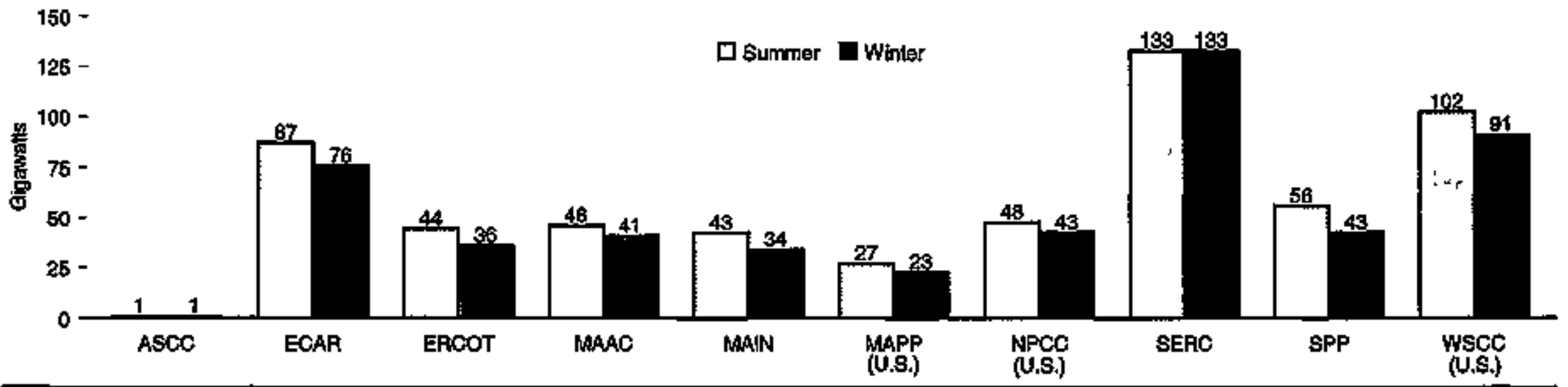

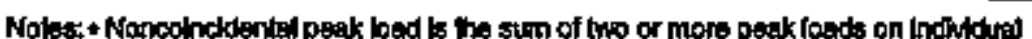

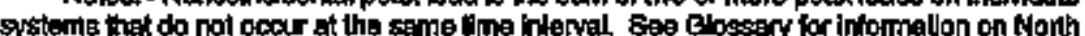

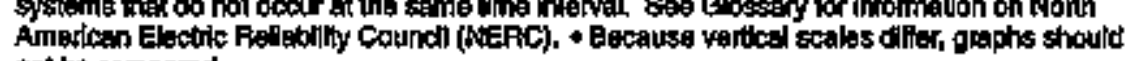
Source: Table $\mathrm{B} .9$. not bie compered. 
Table 8.9 Electric Utllity Noncoincidental Peak Load by Region, 1986-1994

(Megawatts)

\begin{tabular}{|c|c|c|c|c|c|c|c|c|c|c|c|}
\hline \multirow[b]{2}{*}{ Yatar } & \multicolumn{9}{|c|}{ North Amertean Electe Rallabilly Counoll Fegions : } & \multirow[b]{2}{*}{$\begin{array}{c}\text { Conluguals } \\
\text { Unifed } \\
\text { Sisies }\end{array}$} & \multirow[b]{2}{*}{$\begin{array}{l}\text { AscC } \\
\text { (Alasko) }\end{array}$} \\
\hline & ECAA & EACOT & MALC & MAIN & $\begin{array}{l}\text { MAPP } \\
\text { (U.8.) } \\
\end{array}$ & $\begin{array}{l}\text { MPcC } \\
\text { \{us.j }\end{array}$ & SEAC & spp & $\begin{array}{l}\text { wsec } \\
\text { fuss.j }\end{array}$ & & \\
\hline & \multicolumn{11}{|c|}{ Summar } \\
\hline \multirow[t]{2}{*}{$\begin{array}{l}1986 \\
1989 \\
19969 \\
1969 \\
1990 \\
1991 \\
1998 \\
1999 \\
1994\end{array}$} & $\begin{array}{l}69,600 \\
72,581 \\
79,149 \\
76,412 \\
79,259 \\
67,549 \\
78,660 \\
65,930 \\
87,185\end{array}$ & $\begin{array}{l}39,306 \\
39,339 \\
10,849 \\
10,409 \\
42,757 \\
41,870 \\
42,810 \\
44,255 \\
44,168\end{array}$ & $\begin{array}{l}37,564 \\
10,526 \\
43,510 \\
41,614 \\
42,619 \\
45,997 \\
43,469 \\
16,494 \\
46,019\end{array}$ & $\begin{array}{l}35,943 \\
37,446 \\
41,496 \\
39,460 \\
40,740 \\
41,589 \\
38,819 \\
41,960 \\
42,689\end{array}$ & $\begin{array}{l}27,099 \\
23,164 \\
24,969 \\
23,537 \\
24,984 \\
25,488 \\
22,838 \\
24,985 \\
27,000\end{array}$ & $\begin{array}{l}39,028 \\
42,651 \\
45,245 \\
46,031 \\
44,110 \\
45,594 \\
43,659 \\
46,706 \\
47,591\end{array}$ & $\begin{array}{l}706,570 \\
108,798 \\
115,168 \\
117,061 \\
121,149 \\
124,688 \\
129,296 \\
136,101 \\
102,584\end{array}$ & $\begin{array}{l}47,163 \\
47,723 \\
49,3568 \\
49,499 \\
52,541 \\
51,685 \\
51,324 \\
57,106 \\
56,045\end{array}$ & $\begin{array}{r}81,767 \\
82,987 \\
90,551 \\
90,667 \\
97,369 \\
92,096 \\
90,206 \\
97,909 \\
102,212\end{array}$ & 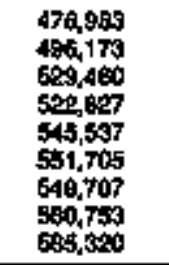 & $\begin{array}{l}\left(\begin{array}{l}7 \\
2\end{array}\right) \\
(2) \\
455 \\
469 \\
477 \\
504 \\
511 \\
524\end{array}$ \\
\hline & \multicolumn{11}{|c|}{ Winter } \\
\hline $\begin{array}{l}1966 \\
1987 \\
1969 \\
1989 \\
1990 \\
1991 \\
1982 \\
1998 \\
1994\end{array}$ & $\begin{array}{l}64,681 \\
68,118 \\
67,771 \\
73,080 \\
67,097 \\
71,189 \\
72,985 \\
81,846 \\
75,698\end{array}$ & $\begin{array}{l}28,730 \\
31,399 \\
34,521 \\
38,369 \\
35,816 \\
35,448 \\
35,059 \\
35,497 \\
36,180\end{array}$ & $\begin{array}{l}32,807 \\
55,776 \\
36,3603 \\
38,181 \\
38,651 \\
37,969 \\
97,915 \\
41,408 \\
40,663\end{array}$ & $\begin{array}{l}28,038 \\
30,608 \\
30,631 \\
35,770 \\
34,461 \\
33,420 \\
31,299 \\
34,968 \\
33,899\end{array}$ & $\begin{array}{l}19,650 \\
19,335 \\
20,152 \\
20,699 \\
21,115 \\
21,432 \\
21,655 \\
21,955 \\
20,0033\end{array}$ & $\begin{array}{l}37,978 \\
41,002 \\
12,951 \\
42,589 \\
40,545 \\
41,780 \\
11,125 \\
12,069 \\
42,547\end{array}$ & $\begin{array}{l}101,649 \\
10,476 \\
108,649 \\
121,895 \\
117,231 \\
119,675 \\
121,250 \\
192,695 \\
132,691\end{array}$ & $\begin{array}{l}33,877 \\
34,472 \\
35,649 \\
42,269 \\
38,949 \\
38,769 \\
39,912 \\
41,644 \\
42,605\end{array}$ & $\begin{array}{l}76,171 \\
81,182 \\
62,937 \\
84,768 \\
94,258 \\
85,097 \\
81,698 \\
89,911 \\
91,067\end{array}$ & $\begin{array}{l}492,857 \\
449,265 \\
459,734 \\
485,717 \\
484,014 \\
486,481 \\
492,590 \\
521,730 \\
518,263\end{array}$ & 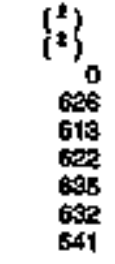 \\
\hline
\end{tabular}

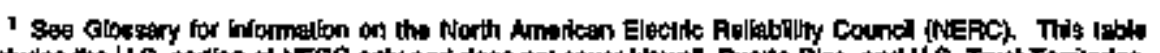

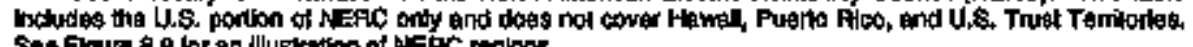
Sas Flgura a.9 lor an illustration of WEFC roglons.

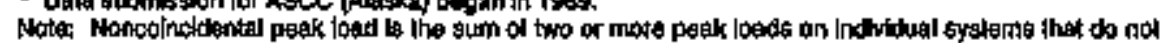

coour at the same time hitenval.

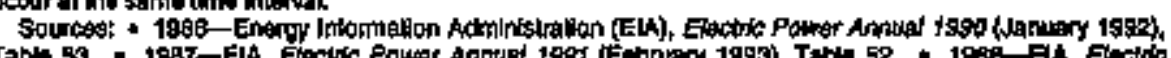

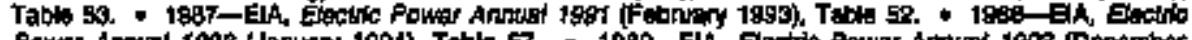

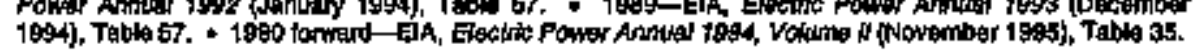




\section{Figure 8.10 Electric Utility Stocks of Coal and Petroleum, End of Year}

\section{Co:d end Petroleum, 1949-1995}

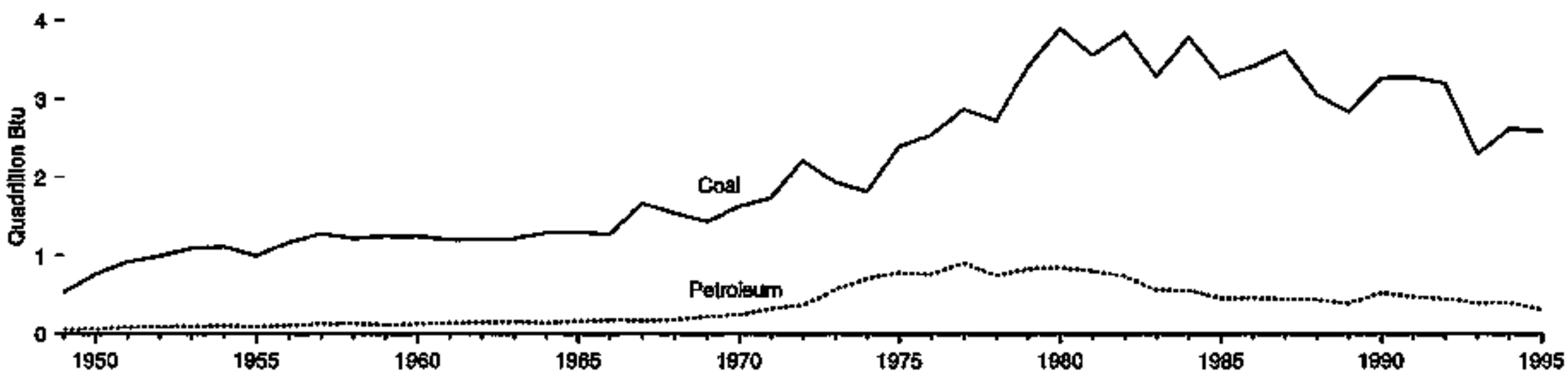

\section{Conl, 1995}

$150-$

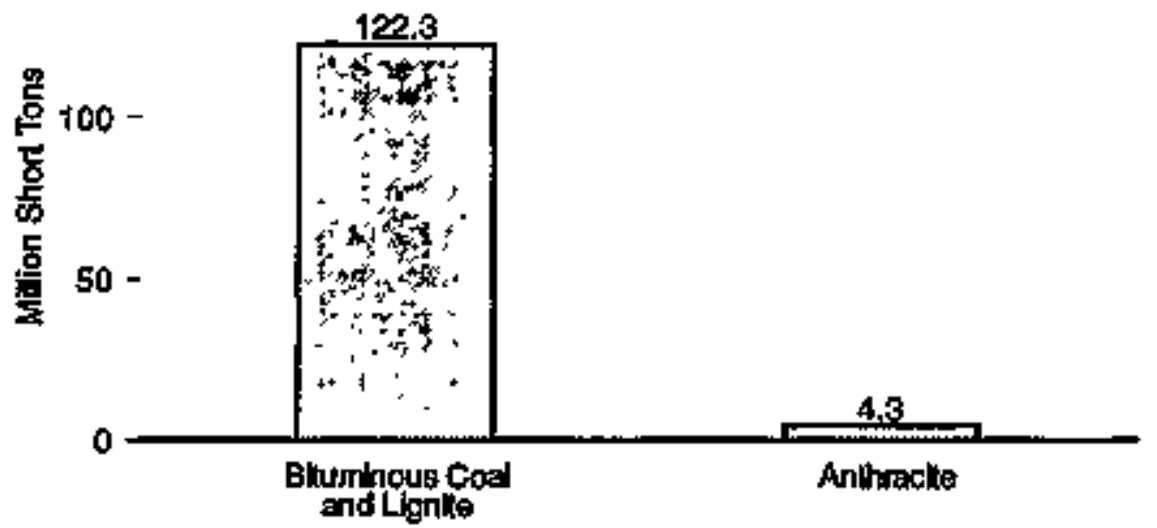

Petroleum, 1996

60-

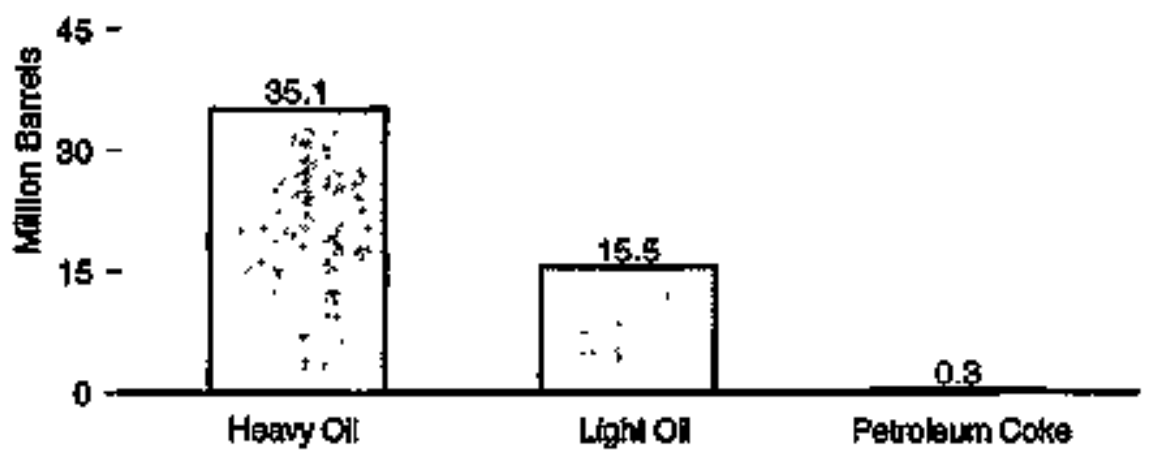

Soturce: Tablo B,10. 
Table 8.10 Electric Utility Stocks of Coal and Petroleum, End of Year 1949-1995

\begin{tabular}{|c|c|c|c|c|c|c|c|c|c|c|}
\hline \multirow[b]{3}{*}{ Your } & \multicolumn{4}{|c|}{ Cpol } & \multicolumn{6}{|c|}{ Pulrolfirum } \\
\hline & \multirow{2}{*}{\multicolumn{2}{|c|}{$\begin{array}{l}\text { Bhtuminour } \\
\text { Cootz } \\
\text { Bnd Wralle }\end{array}$}} & \multicolumn{2}{|c|}{ Total } & Hoany & Light & $\begin{array}{l}\text { Total } \\
\text { Llquilds }\end{array}$ & $\begin{array}{l}\text { Petroloum } \\
\text { Colst: }\end{array}$ & \multicolumn{2}{|c|}{ Total } \\
\hline & & & $\begin{array}{l}\text { Millon } \\
\text { shopt trons: }\end{array}$ & $\begin{array}{c}\text { Trifuton } \\
\text { Etiu }\end{array}$ & \multicolumn{4}{|c|}{ Whllkon Barteds } & $\begin{array}{l}\text { Mition } \\
\text { Banress }\end{array}$ & $\begin{array}{c}\text { Trillon } \\
\text { Elat }\end{array}$ \\
\hline 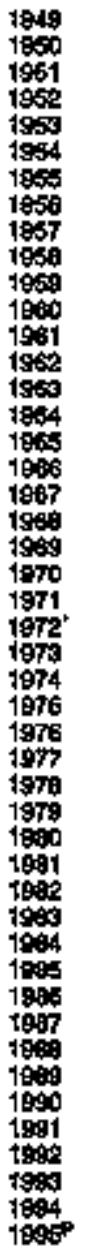 & $\begin{array}{l}4.3 \\
4.7 \\
5.1 \\
5.6 \\
5.9 \\
6.4 \\
3.2 \\
2.8 \\
2.5 \\
2.2 \\
2.0 \\
1.8 \\
1.5 \\
1.4 \\
1.3 \\
1.3 \\
1.4 \\
1.0 \\
1.3 \\
1.3 \\
1.3 \\
1.1 \\
1.1 \\
0.6 \\
1.1 \\
0.9 \\
1.0 \\
1.0 \\
2.3 \\
2.2 \\
3.3 \\
4.7 \\
5.5 \\
6.1 \\
8.5 \\
8.7 \\
7.2 \\
7.1 \\
6.9 \\
6.6 \\
6.4 \\
6.5 \\
8.5 \\
6.2 \\
5.8 \\
4.9 \\
4.3\end{array}$ & 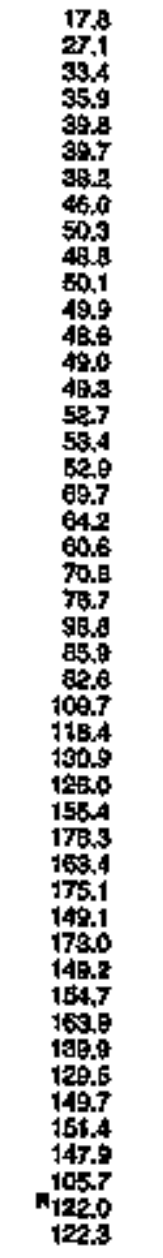 & 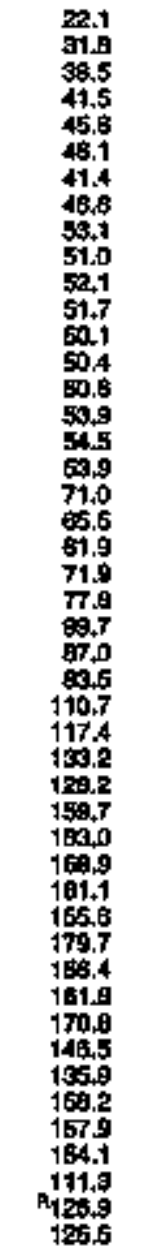 & 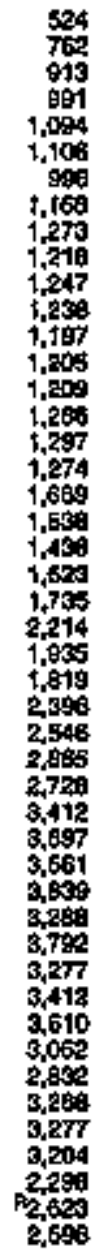 & 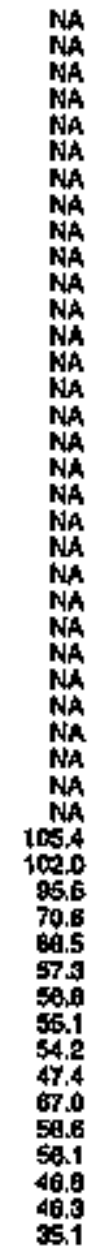 & 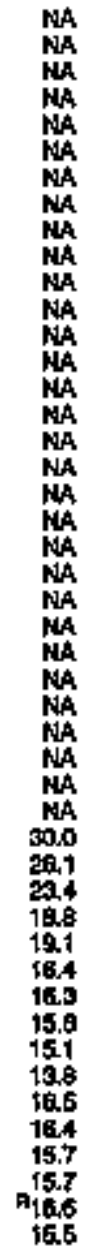 & 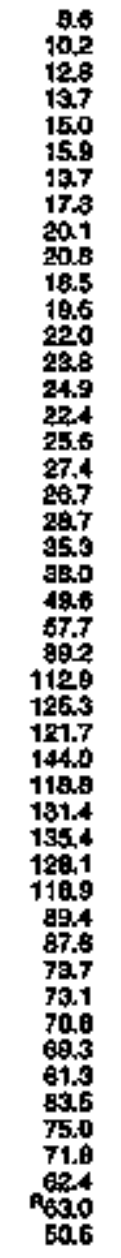 & 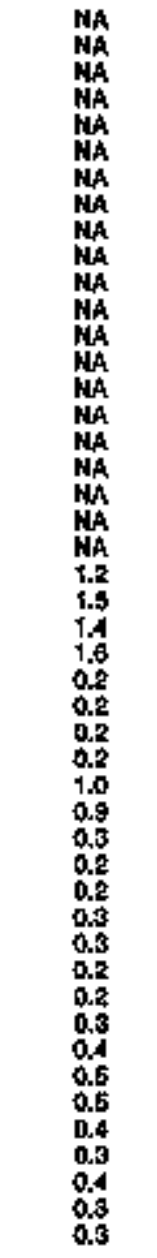 & 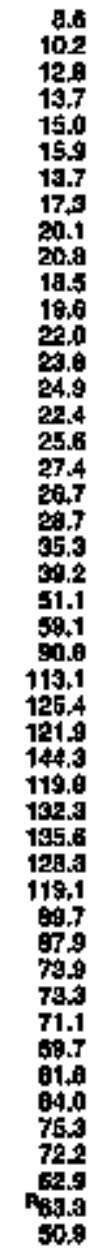 & 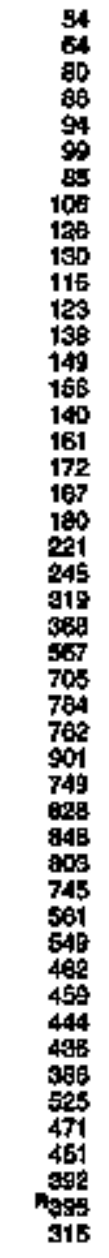 \\
\hline
\end{tabular}

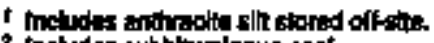

2 includes gubthtuminotus cont

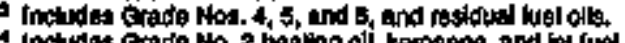

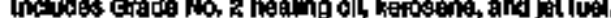

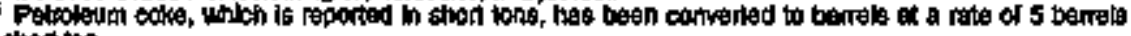

per short ton

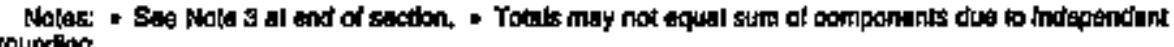

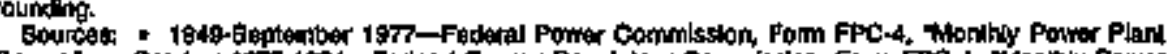

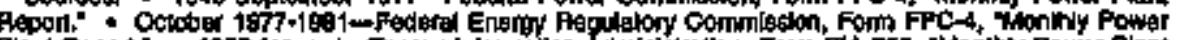

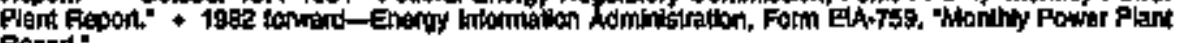
Repport" 


\section{Nominal Prices}

9 -

$8-$

$7-$

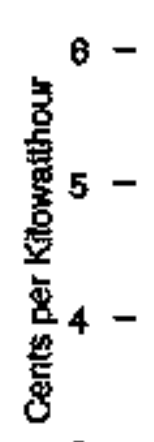

$3-$

2

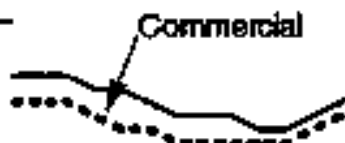

Total

Mdusinat

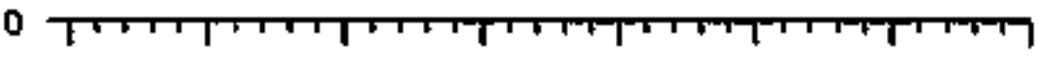

$\begin{array}{llllllll}1960 & 1965 & 1970 & 1975 & 1980 & 1985 & 1990 & 1995\end{array}$

1 In chaihed (1999) dollars, calculaled by using grase domestic prodict tampilail price delators. Ses Appendix E.

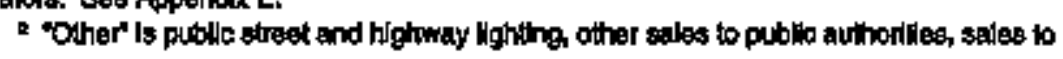

\section{Real' Prices}

$12-$

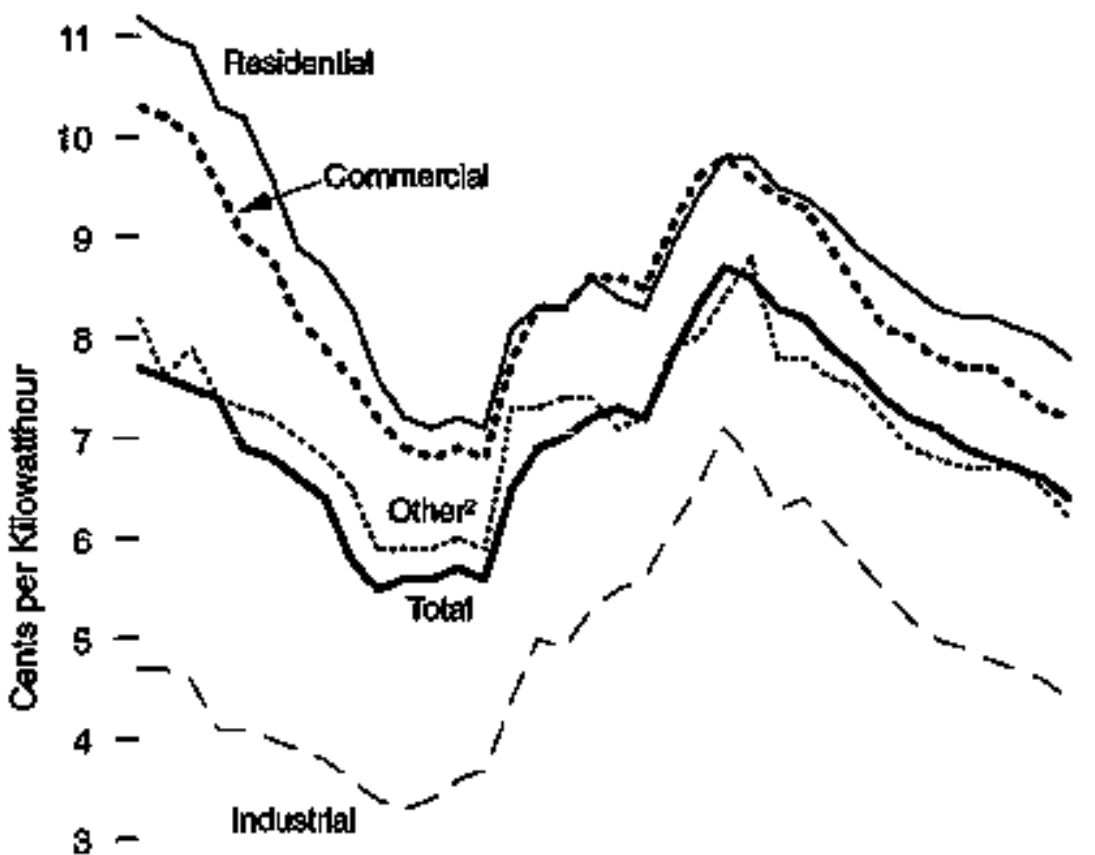

$2-$

$1-$

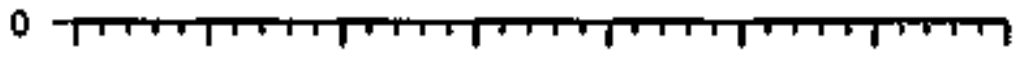

$\begin{array}{llllllll}1960 & 1965 & 1970 & 1975 & 1980 & 1985 & 1990 & 1995\end{array}$


Table 8.11 Retail Prices of Electricity Sold by Electric Utilities, 1960-1995

(Cents per Kilowatthour)

\begin{tabular}{|c|c|c|c|c|c|c|c|c|c|c|}
\hline \multirow[b]{2}{*}{ Yaas: } & \multicolumn{2}{|c|}{ Rugikiondet } & \multicolumn{2}{|c|}{ Commercks } & \multicolumn{2}{|c|}{ industion } & \multicolumn{2}{|c|}{ Other 1} & \multicolumn{2}{|c|}{ Total } \\
\hline & Norn'nal & Ftasl 2 & Nominnl & $\operatorname{Ran} 12$ & Naminst & Fent 2 & Mom'nn: & $\operatorname{Ran} 2$ & Noninal & Feal $z$ \\
\hline 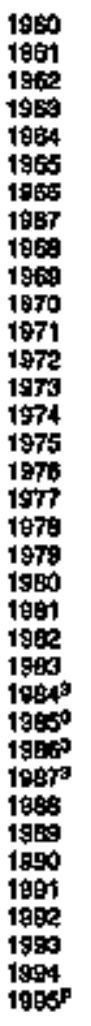 & $\begin{array}{l}2.6 \\
2.6 \\
2.6 \\
2.5 \\
2.5 \\
2.4 \\
2.3 \\
2.3 \\
2.3 \\
2.2 \\
2.2 \\
2.3 \\
2.4 \\
2.5 \\
3.1 \\
3.5 \\
3.7 \\
4.1 \\
4.3 \\
4.6 \\
5.4 \\
6.2 \\
6.9 \\
7.2 \\
7.2 \\
7.4 \\
7.4 \\
7.4 \\
7.5 \\
7.6 \\
7.6 \\
6.0 \\
6.2 \\
6.3 \\
8.4 \\
6.4\end{array}$ & 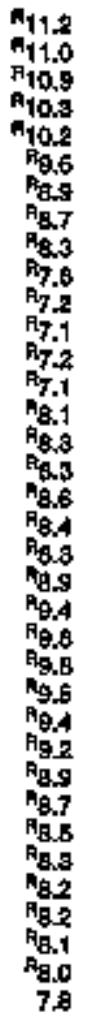 & $\begin{array}{r}2.4 \\
2.4 \\
2.4 \\
2.3 \\
2.2 \\
2.2 \\
2.1 \\
2.1 \\
2.1 \\
2.1 \\
2.1 \\
2.2 \\
1.3 \\
2.4 \\
3.0 \\
3.5 \\
3.7 \\
4.1 \\
4.4 \\
4.7 \\
5.5 \\
6.3 \\
6.9 \\
7.6 \\
7.1 \\
7.3 \\
7.2 \\
7.1 \\
7.0 \\
7.2 \\
7.3 \\
7.6 \\
7.7 \\
7.7 \\
97.7 \\
7.7\end{array}$ & 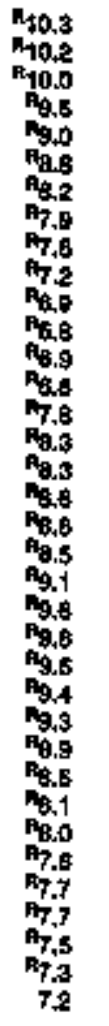 & $\begin{array}{l}1.1 \\
1.1 \\
1.4 \\
1.0 \\
1.0 \\
1.0 \\
7.0 \\
1.0 \\
1.0 \\
1.0 \\
7.0 \\
1.1 \\
1.2 \\
7.3 \\
1.7 \\
2.1 \\
2.2 \\
2.5 \\
2.8 \\
3.1 \\
3.7 \\
4.8 \\
5.0 \\
5.0 \\
4.8 \\
5.0 \\
4.9 \\
4.8 \\
4.7 \\
4.7 \\
4.7 \\
4.8 \\
4.8 \\
4.8 \\
8.9 \\
4.7\end{array}$ & 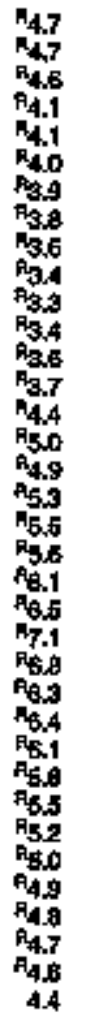 & $\begin{array}{l}1.9 \\
1.0 \\
1.9 \\
1.9 \\
1.9 \\
1.9 \\
1.9 \\
1.9 \\
1.9 \\
1.7 \\
1.8 \\
1.9 \\
2.0 \\
2.1 \\
2.9 \\
3.1 \\
0.3 \\
3.5 \\
3.8 \\
4.9 \\
4.8 \\
5.3 \\
5.9 \\
6.4 \\
5.9 \\
6.1 \\
6.1 \\
6.2 \\
6.2 \\
6.2 \\
5.4 \\
8.5 \\
6.7 \\
6.9 \\
8.8 \\
6.7\end{array}$ & 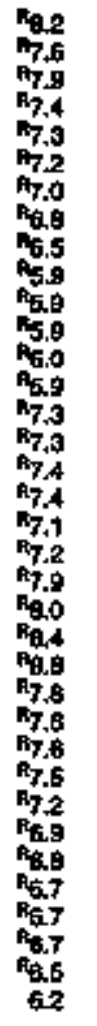 & $\begin{array}{l}1.8 \\
1.5 \\
1.8 \\
1.8 \\
1.7 \\
1.7 \\
1.7 \\
1.7 \\
1.5 \\
1.5 \\
1.7 \\
1.8 \\
1.9 \\
2.0 \\
2.5 \\
2.9 \\
3.1 \\
3.4 \\
3.7 \\
4.9 \\
4.7 \\
5.5 \\
4.1 \\
6.9 \\
6.3 \\
6.4 \\
6.4 \\
6.4 \\
6.4 \\
6.5 \\
6.5 \\
6.7 \\
6.8 \\
6.9 \\
6.5 \\
6.9\end{array}$ & 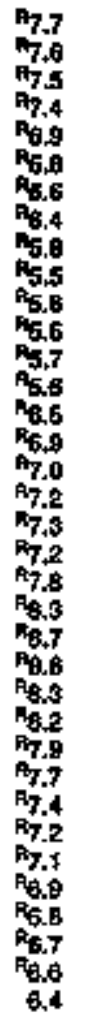 \\
\hline
\end{tabular}

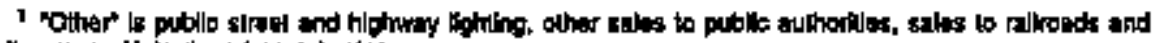

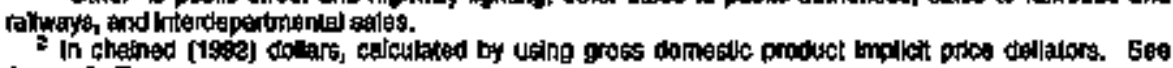
Apopindix E

pginchix E.

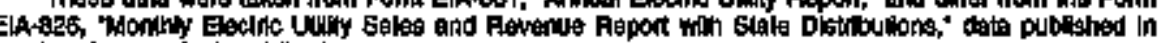
pravious kasusts of wis pubtleation.

RimRerksed data. Papteininary data.

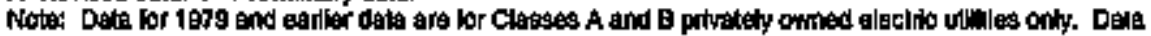

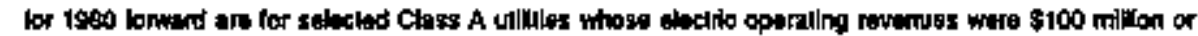
move durkey the provious year.

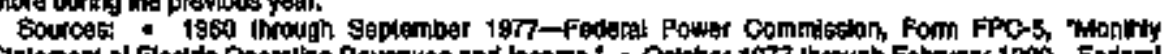

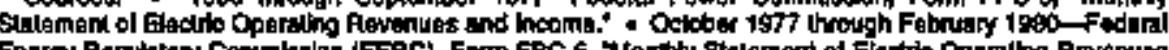

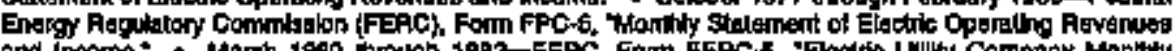

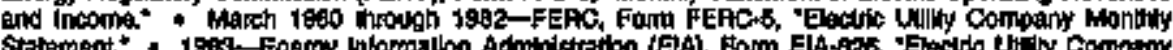

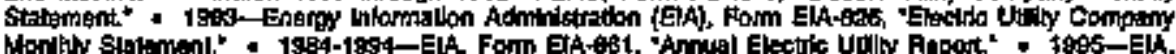

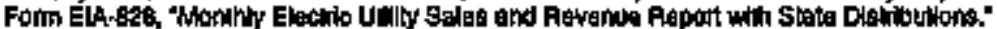


Supply and Disposition, 1694

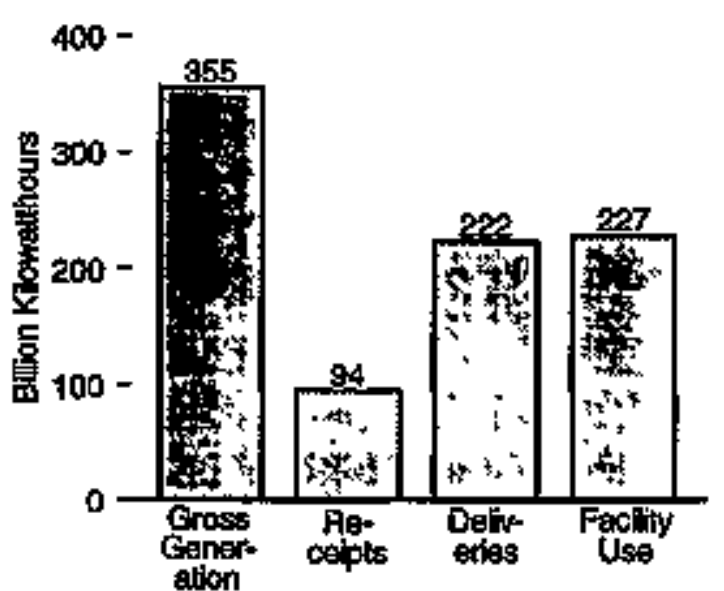

\section{Gross Generation, 1968-1984}

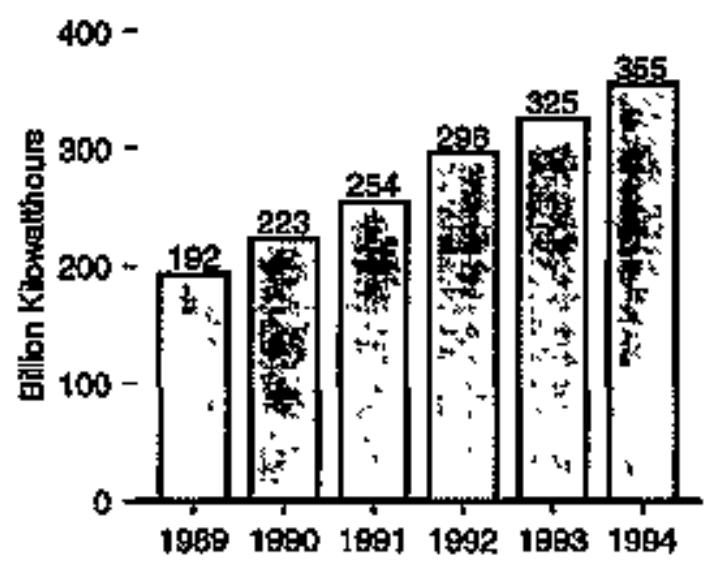

\section{Instailied Nameplato Capacity, 1989-1994}

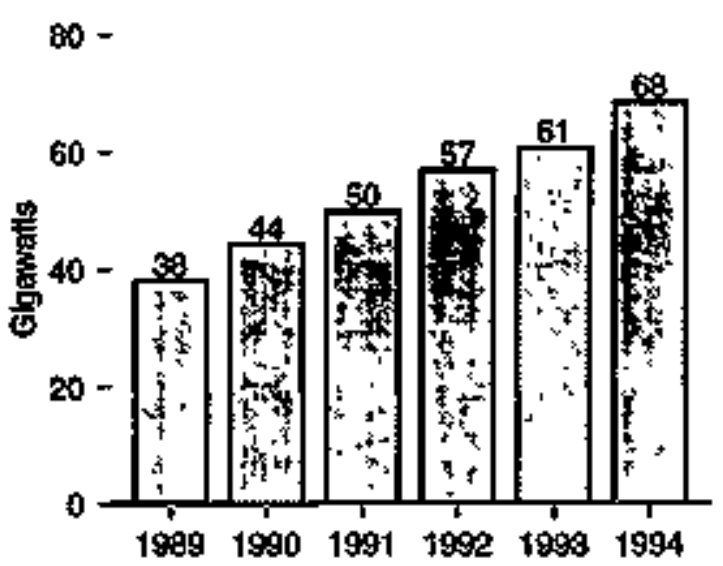

Gross Generation by Major Sources, 1989-1984

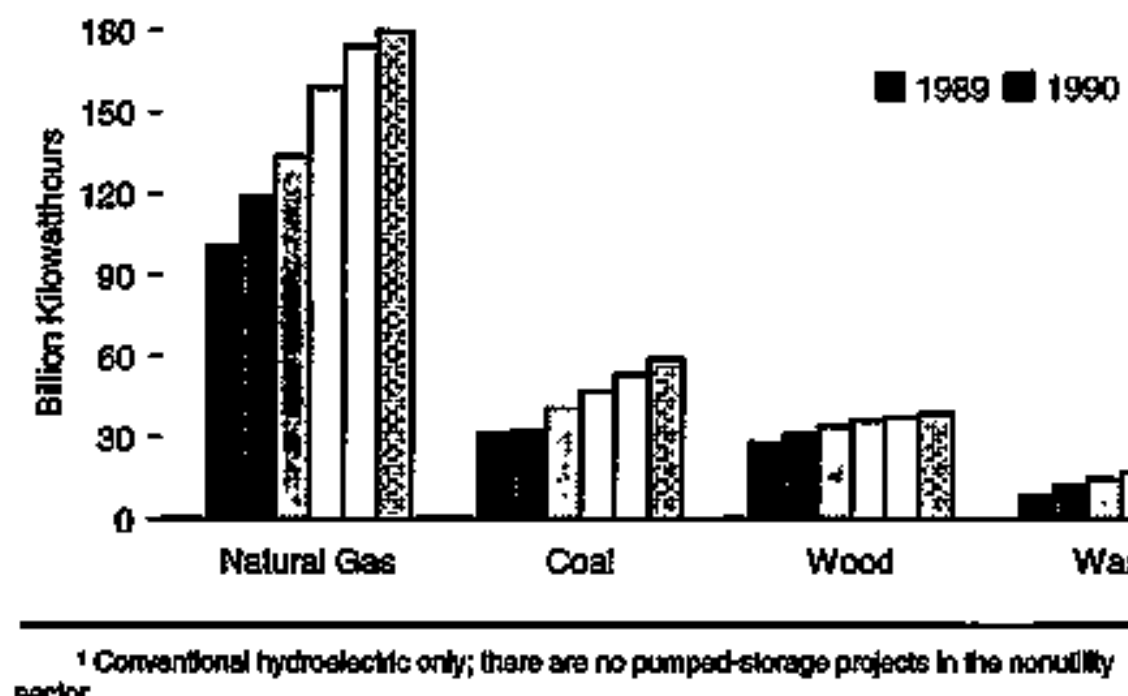
Bector.

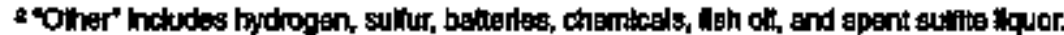

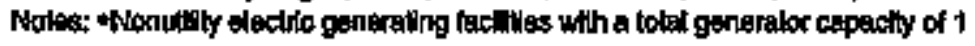

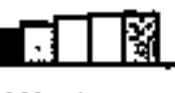

Waste
Petrodeum

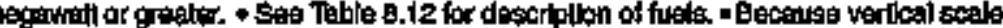

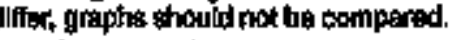

Souree: Tablet 8.12 . 
Table 8.12 Nonutility Power Overvlew, 1989-1994

\begin{tabular}{|c|c|c|c|c|c|c|}
\hline Item & 1980 & 1000 & 19 & 1992 & 1993 & 1954 \\
\hline 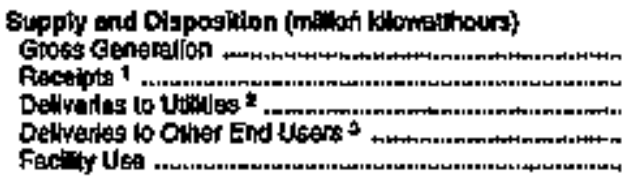 & $\begin{array}{r}182.327 \\
63,249 \\
N A \\
152,354\end{array}$ & $\begin{array}{r}222,721 \\
70,154 \\
\text { NA } \\
\text { NA } \\
159,946\end{array}$ & 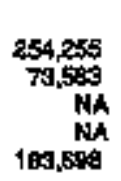 & $\begin{array}{r}285,001 \\
83,421 \\
\text { NKK } \\
\text { Now, } \\
201\end{array}$ & $\begin{array}{r}325,226 \\
85,323 \\
107,468 \\
15,509 \\
207,514\end{array}$ & $\begin{array}{r}354,925 \\
94,168 \\
204,688 \\
77,626 \\
228,777\end{array}$ \\
\hline 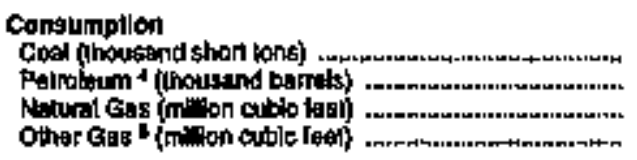 & $\begin{array}{l}\text { NA } \\
\text { NA } \\
\text { NA } \\
\text { NA }\end{array}$ & $\begin{array}{l}\text { NA } \\
\text { NA } \\
\text { NA }\end{array}$ & $\begin{array}{l}\text { NA } \\
\text { NA } \\
\text { NA }\end{array}$ & $\begin{array}{l}\text { NA } \\
\text { NA } \\
\text { NA } \\
\text { NA }\end{array}$ & $\begin{array}{r}18,343 \\
38,788 \\
2,013,768 \\
1,676,166\end{array}$ & $\begin{array}{r}52,281 \\
40,460 \\
2,149,248 \\
1,586,185\end{array}$ \\
\hline 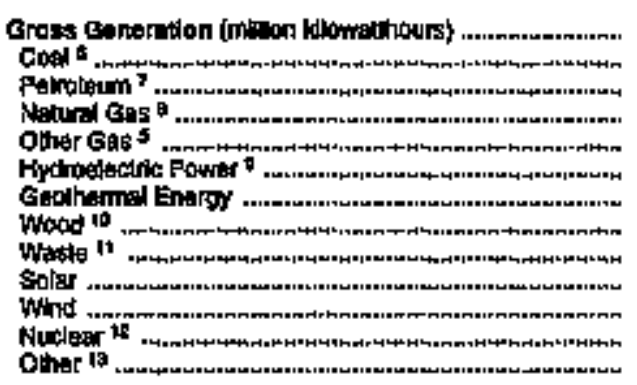 & $\begin{array}{r}182,327 \\
31,700 \\
5,572 \\
100,813 \\
1,504 \\
7,504 \\
5,091 \\
28,051 \\
9,015 \\
1,189 \\
1,877 \\
49 \\
1,763\end{array}$ & 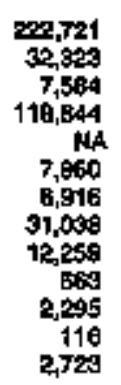 & 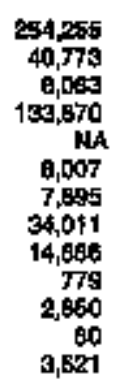 & 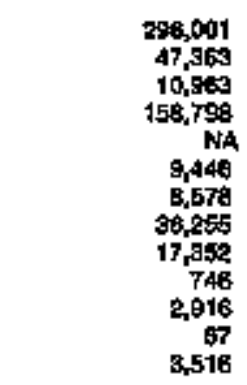 & $\begin{array}{r}325,225 \\
53,757 \\
13,354 \\
174,280 \\
\text { NA } \\
11,511 \\
9,749 \\
37,421 \\
18,025 \\
8997 \\
3,069 \\
78 \\
3,181\end{array}$ & $\begin{array}{r}354,025 \\
59,035 \\
15,059 \\
179,735 \\
12,490 \\
10,227 \\
10,128 \\
39.695 \\
19,797 \\
802 \\
3,492 \\
54 \\
3,507\end{array}$ \\
\hline 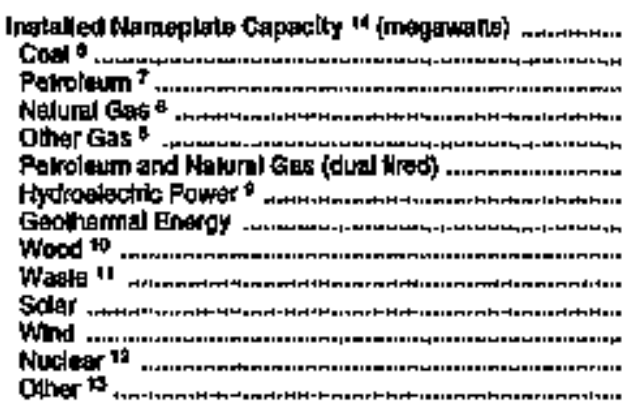 & $\begin{array}{r}37,094 \\
8,284 \\
1,030 \\
14,349 \\
N 44 \\
4,641 \\
1,049 \\
856 \\
5,321 \\
1,675 \\
200 \\
1,376 \\
200 \\
184\end{array}$ & $\begin{array}{r}4,352 \\
5,769 \\
946 \\
17,003 \\
\mathrm{NA} \\
5,279 \\
5,991 \\
1,043 \\
5,054 \\
2,392 \\
390 \\
1,441 \\
200 \\
106\end{array}$ & 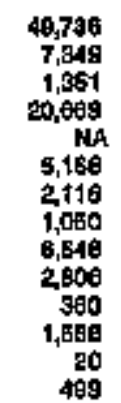 & 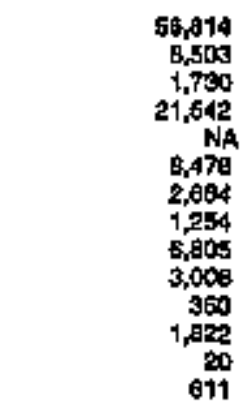 & 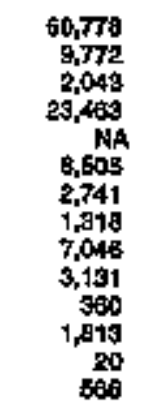 & $\begin{array}{r}68,461 \\
10,372 \\
2,262 \\
26,029 \\
1,190 \\
9,850 \\
9,394 \\
1,305 \\
7,416 \\
0,150 \\
354 \\
1,737 \\
0 \\
597\end{array}$ \\
\hline
\end{tabular}

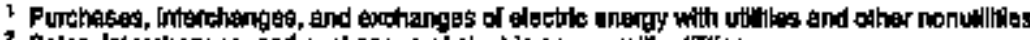

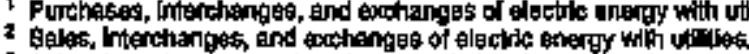

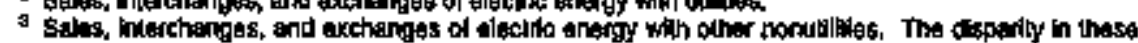

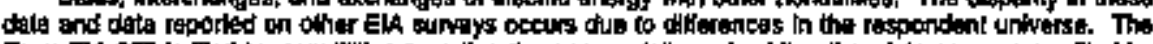

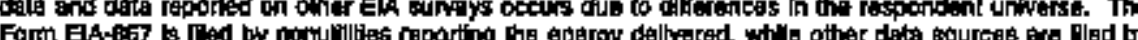
Frection

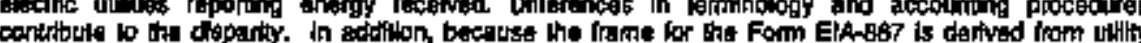

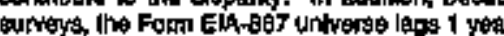

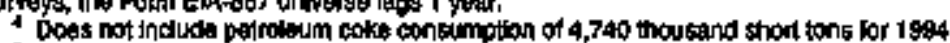

8 Bitane then prosing, and other pase

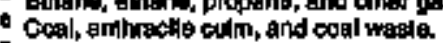

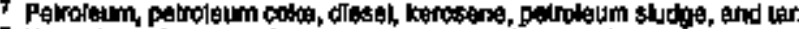

- Halural gas, bulano, whane, propant, wasto heat, and wasle gases.

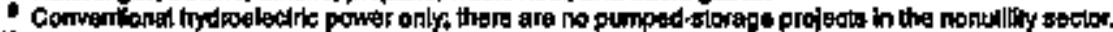

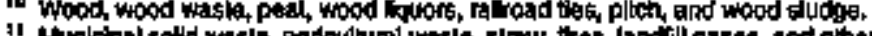

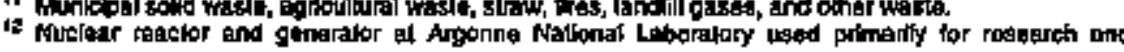

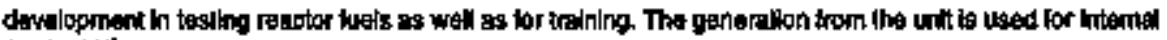

congrampithon,

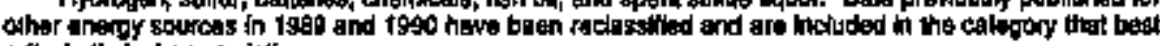
reflects ineir theracteristics.

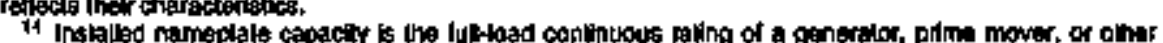

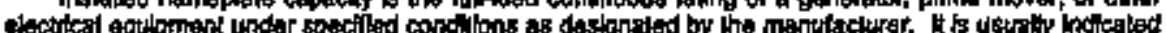

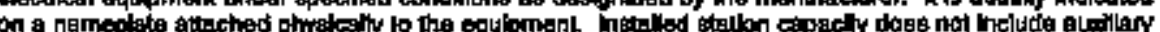
or bouse unds.

NA Nitot ava:

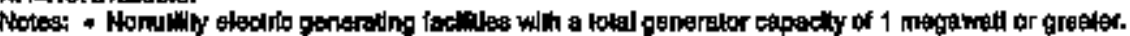

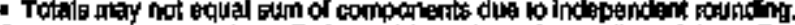

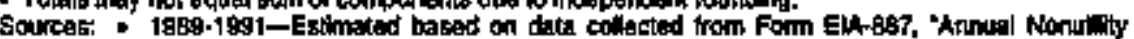

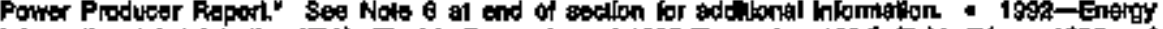

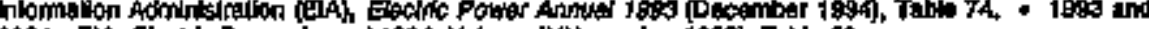

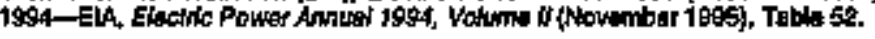




\section{By Producing Energy Group}

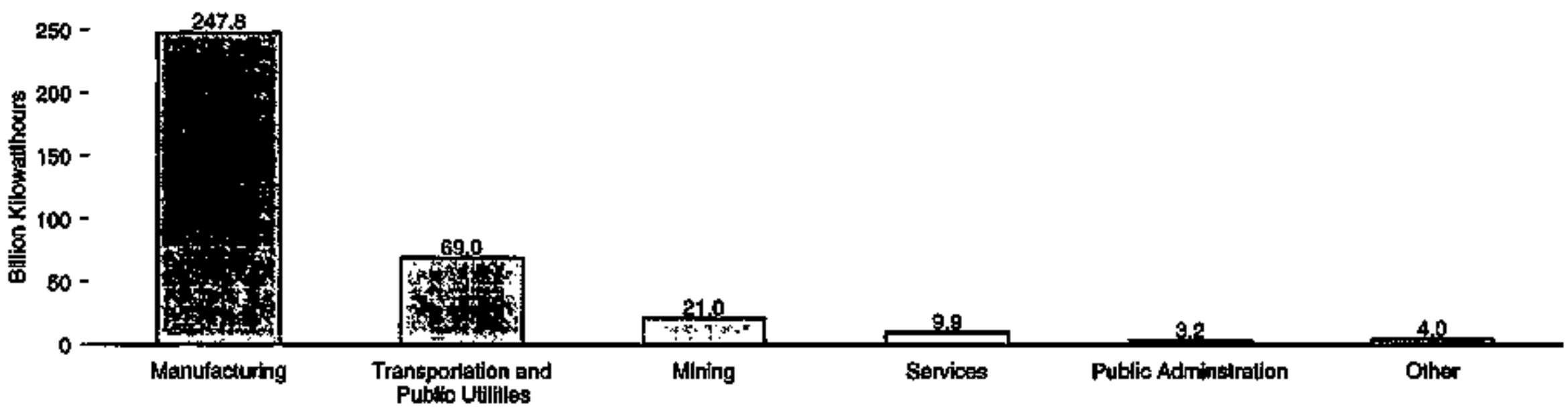

\section{By Census Divlsions}

$100-$

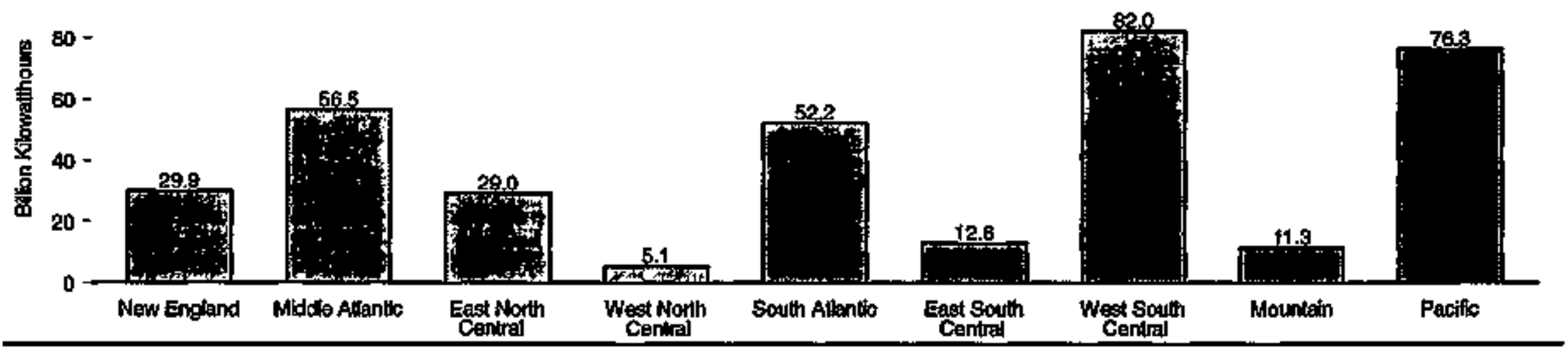

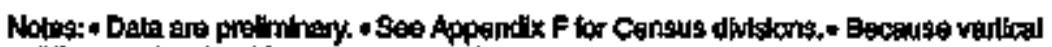
Soumt: Table Q,13. scales tififar, graphs shoutd not bo compared 
Table 8.13 Nonutility Power Gross Generation, 1994

(Mition Kilowatthours)

\begin{tabular}{|c|c|c|c|c|c|c|c|}
\hline Dwilokaragslon & Menufienturthe & 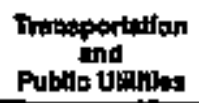 & Strviles: & Mnnimg & $\begin{array}{c}\text { Publlc } \\
\text { Adimintatustion }\end{array}$ & $\begin{array}{l}\text { Othor } \\
\text { Indisstry } \\
\text { Eroupe }\end{array}$ & Towal \\
\hline & \multicolumn{7}{|c|}{ Cansus DWotons } \\
\hline 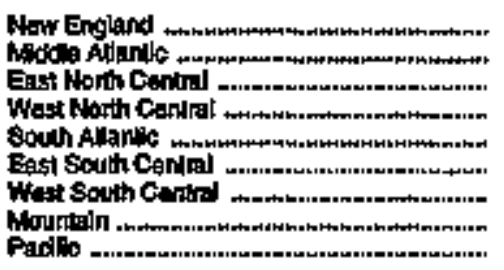 & $\begin{array}{r}13,641 \\
37,490 \\
2,4009 \\
3,150 \\
14,152 \\
12,470 \\
79,974 \\
5,006 \\
31,050\end{array}$ & $\begin{array}{r}15,743 \\
12,009 \\
2,415 \\
434 \\
10,142 \\
81 \\
2,013 \\
3,173 \\
22,971\end{array}$ & 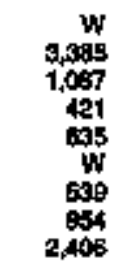 & $\begin{array}{r}\bar{w} \\
w \\
w \\
w \\
148 \\
464 \\
553 \\
17,757\end{array}$ & $\begin{array}{l}\overline{1,452} \\
w \\
w \\
w \\
w \\
w\end{array}$ & 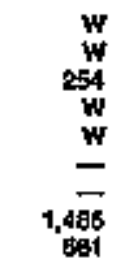 & $\begin{array}{r}79,925 \\
56,497 \\
26,090 \\
5,077 \\
52,152 \\
12,765 \\
81,969 \\
11,273 \\
76,271\end{array}$ \\
\hline \multirow[t]{2}{*}{ 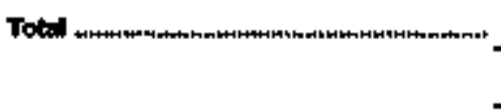 } & 247,038 & 60,9992 & 9,900 & 21,024 & $\mathbf{3 , 1 7 2}$ & 4,011 & 354,025 \\
\hline & \multicolumn{7}{|c|}{ Woth Amordean Electrio Rallabilly Counell Roglons ' } \\
\hline 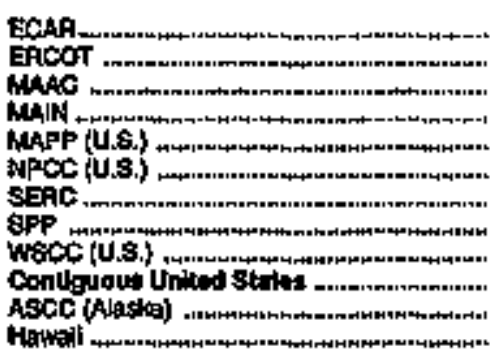 & $\begin{array}{r}24,512 \\
46,600 \\
15,602 \\
7,014 \\
2,901 \\
34,349 \\
47,270 \\
32,050 \\
32,3896 \\
243,960 \\
490 \\
3,376\end{array}$ & $\begin{array}{r}3,498 \\
989 \\
7,690 \\
470 \\
418 \\
20,126 \\
8,442 \\
1,499 \\
25,484 \\
69,323 \\
4 \\
655\end{array}$ & $\begin{array}{r}1,219 \\
405 \\
1,409 \\
440 \\
270 \\
2,392 \\
174 \\
144 \\
9,309 \\
9,845 \\
55 \\
0\end{array}$ & $\begin{array}{r}0 \\
292 \\
718 \\
318 \\
1,055 \\
0 \\
153 \\
100 \\
17,898 \\
20,491 \\
5 \% 9 \\
0\end{array}$ & $\begin{array}{r}15 \\
0 \\
422 \\
10 \\
17 \\
1,044 \\
132 \\
0 \\
1,397 \\
2,995 \\
177 \\
0\end{array}$ & $\begin{array}{r}48 \\
0 \\
1,103 \\
205 \\
0 \\
647 \\
139 \\
0 \\
1,989 \\
3,902 \\
19 \\
97\end{array}$ & 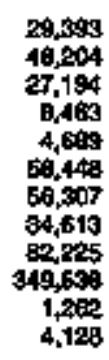 \\
\hline 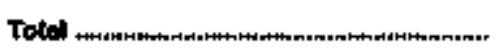 & 247,6360 & 69992 & 9,906 & 21,024 & 3,172 & 4,011 & 354,95 \\
\hline
\end{tabular}

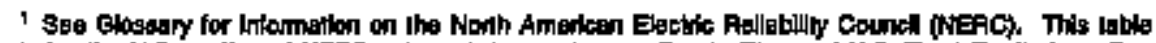

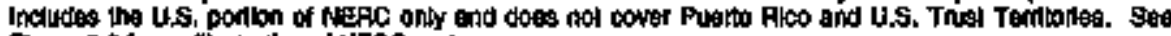

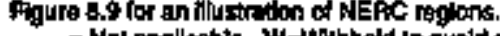

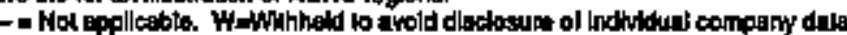

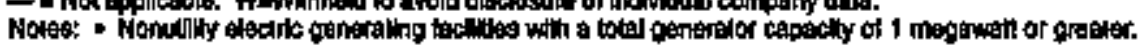

- Dala are based on lechllag' conoumpiton. - Totak may not equal oum of components dus to

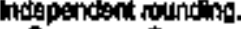

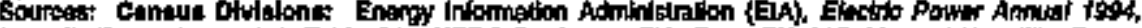

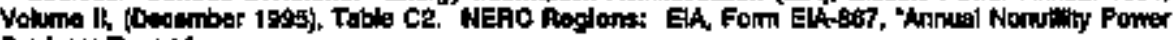
Producer Report." 


\section{Electrlcity Notes}

1. Electrical system energy losses are estimated as the difference between total energy input at electric utilities and the total energy content of electricity sold to end-use consumers. Most of these losses occur at steam-electric power plants (conventional and nuclear) in the conversion of heat energy into mechanical energy to tum electric generators. This loss is a thermodynamically necessary feature of the steam-electric cycle. Part of the energy input-to-output losses is a rosuit of imputing fossil energy equivalent inpets for hydroelectric and other energy sources, since there is no gentrally accepted practice for measuring these thermal conversion rates. In addition to conversion losses, other losses include power plant use of electricity, transmission and distribution $\alpha$ electricity from power plants to end-use consumers (also called "line-losses"), and unaccounted-for electricity. Total losses are allocated to the end-use sectors in proportion to each sector's share of total electricity sales. Overall, approximately 67 percent of total energy input is lost in conversion; of electricity generated, approximately 5 percent is lost in plant use and 9 percent is lost in transmission and distribution. Calculated electrical energy systern losses may be less than actual losses, because primary consumption does not include the energy equivalent of utility purchases of electricity from non-electric utilities and from Canada and Mexico, although they are included in electricity sales.

2. Data on the geweration of electricity in the United States represent net generation, which is gross output of electricity (measured at the generator terminals) minus power plant use. Nuclear electricity generation data identified by individual countries in Section I1 are gross output of electricity.

3. Prior to 1985 , electric utility supply and distribution statistics included data reported by institutions (such as universities) and military facilities that generated electricity primasily for their own use. Beginning in 1985, electricity statistics exclude data for these facilities and include data only for those organizations that generate electricity primarily for public use. In 1989, data for nonutility power producers (cogenerators, small power producers, and independent power producers) are provided.

4. Data on the sales of electric utility electricity represent gross output of electricity (menstured at the genterator teminals) minus powser plant use and transinission and distribution losses. Included in each end-use sector are the following: Conmercial Sector-sales of electricity to businesses that generally require less than 1,000 kilowatts of service; Industrial Sector-sales of electricity to businesses that generally require more than 1,000 kilowatts of service; Residential Sector-sales of electricity to residences for household perposes; "Other" Sector-sales of electricity for publie street and highway lighting, to public authorities, railways, and railroads, and interdepartmental sales.

5. Net summer capabilities were first collected on Form EIA-860, "Annual Electric Generator Report" for 1984. Units not assigned a net summer capability rating by the utility were given an estimated rating by use of a statistical relationship between installed nameplate capacity and net summer capability for each prime mover. To estimate net summer capability for the years 1949 through 1984, two methods were used. For each prime mover except nuclear and "other," net summer capability estimates were calculated in two steps. First, the unit capacity values reported on Form EIA-860 and the unit start dates contained in the 1984 Generating Unit Reference File (GURF) were used to compute preliminary aggregate estimates of annual net summer capability atnd installed nameplate capacity. These preliminary estimates were abtained by aggtegating unit capacity values for all units in service during a given year. Next, the ratio of the preliminary capability to nameplate estimate was computed for each year and multiplied by the previously published installed nameplate capacity values to produce the final estimates of net summer capability. The net summer capability data for nuclear and "other" units were used directly from the 1984 GURF for all years. Historical aggregates were then developed by using the unit start dates on the GURF.

Historical capacity has also been modified to estimate capability based upon the operable definition. This was accomplished by assuming that nonnuclear generatiog units became operable between 1 and $A$ months prior to their commercial operation dates, depending upon the prime mover and time period. The actual operable dates for nuclear units were used. It should be noted that net summer capabilities are not currently collected for nonutilities.

6. Year-to-year changes in data from the Form EIA-867, "Annual Nonutility Power Plant Report," can result from correcting misteported data and modifying the frame to account for new or retired facilities, anong other improyements. Data for 1989, 1990, and 1991 were collected for facilities of 5 megawatts or more. In 1992, the threshold was lowered to include facilities with capacities of 1 megawatt or more. Estimates of the 1-to-5-megawatt range for prior years were derived from hissorical data. The estimation did not include retirements that occurred prior to 1992 and included only the capacity of facilities that came on line before 1992 . 


\section{Status of Nuclear Generating Units}

At the end of 1995, there were 109 licensed operable nuclear generating units and one unit (Watts Bar 1) licensed for startup in the United States (9.1).* Most of the licensed units were located east of the Mississippi River. In addition to the licensed units, six units possessed construction permits; however, construction for all six units had been halted or canceled.

The nurnber of units in all stages of planning, construction, and operation in 1995 was 116, well below the total of 226 in 1974. After 1974, many planned units were canceled; after 1977 , no orders for new units were alusounced.

The Thuee Mile Island accident in 1979 greatly increased concems about the safety of nuclear power plants. The regulatory reaction to those conconks contributed to the decline in the number of planned nuclear units. Longer leadtimes for licensing and construction, coupled with higher i1nancing expenses, increased the cast of nuclear power plants. In addition, growth in electricity demand was slower than expected. The uncertain economic enviroument diminished electric utilities' willingness to commission new plants. For muclear power to remain a viable option in the United States, significant changes will be required.

\section{Contributions to Electricity Net Generation}

Nuclear electric power's contribution to electricity net generation in the United States increased almost every year from the late 1950's through 1995 (9.2). Nuclear electric power production in 1995 totaled 673 billion kilowatthours, up 5.2 percent from the 1994 level. The nuclear portion of domestic electricity net generation rose from 22,0 percent is 1994 to 22.5 percent in 1995 , and the capacity factor' rose from. 74 percent in 1994 to 78 percent in 1995.

'Tho peinal generation in a glven time period divided by the maximesu possible generation in that time period.

- Wumbers in parentheses indicte related fables. Annual data dre the most recent avallable; they hequently are prelinthary and may be revised in future pubilications. Percentages and numbers in lext are coliculated by using data in the tables.

\section{The Uraniem industry}

From 1949 through 1967, the Atomic Energy Commission (AEC) was the major purchaser of uranium. The $A E C^{\prime} s$ demand for uranium for military purposes wes strong during the 1950 s and domestic production, spumed by AEC incentives, grew from $0, A$ million pounds of uranium oxdde $\left(\mathrm{U}_{3} \mathrm{O}_{6}\right.$ ) in 1949 to 35 million pounds in 1960 (9.3). As the $\mathrm{AEC}$ began to accurmulate stockpiles, its purchases.deolined and U.8. production fell to 21 million pounds in 1965. From 1966 through 1976, prodiction fluctuased between 21 and 27 rililion pourdis. Subsequerthy, ofders for now nuclear plants led to strong growth, and production peaked at 44 million pounds in 1980 .

However, plant cancelations and postponements during the late 1970's ted to a decline in profected demand and, coupled with foreign compefullon and buildups of inventoties at electric vitilites, caused the second major dectine in domestic urantum production, which toil to 11 milition pounds in 1985. Many domesttc urantum-producing faclitios closed permanently. In the early 1990's, low uranium prices, excess world supply, and continuing low expeclations for luture urantum damand brought domedtic urantum production to a 40year low of 3.1 million pousds in 1993. In 1995, however, uranium production rose to 6.0 milion pounds, partly as a resuk of higher uranium prices and the need among electitic ullitites and luel suppiters to bolster inventorles.

Histofically, domestio producers have faced compelition from low-cost urantum Impofis. From 1949 through 1960, net imporls actually exceeded domestic productlon (9.3). In 1966, the AEC effectively suspended imports by curtailing enriolment services tor loxelign uranium intended for use in domesalc facilities, and nouranium was imported from 1967 throsgh 1974. With the graduat removal of the AEC restrictions curing the 1977 -to-1983 pertod, foreign uranium delveties to the United Stales began to increase. In 1900 ihrough 1995, nex importa of $U_{3} D_{0}$ once again exceeded domestic producllon. For example, in 1995, net imports tofated an estimated 32 million pounds, compared with demestic production of 6.0 million poinds. The prive of purchesed Imporls averaged $\$ 10.20$ per poind of $\mathrm{U}_{3} \mathrm{O}_{\mathrm{B}}$ and the price of purctased domestic uranium averaged $\$ 11.11$ per pound of $\mathrm{U}_{3} \mathrm{O}_{\mathrm{O}}$. 
Figure 9.1 Nuclear Generating Units, December 31, 1995

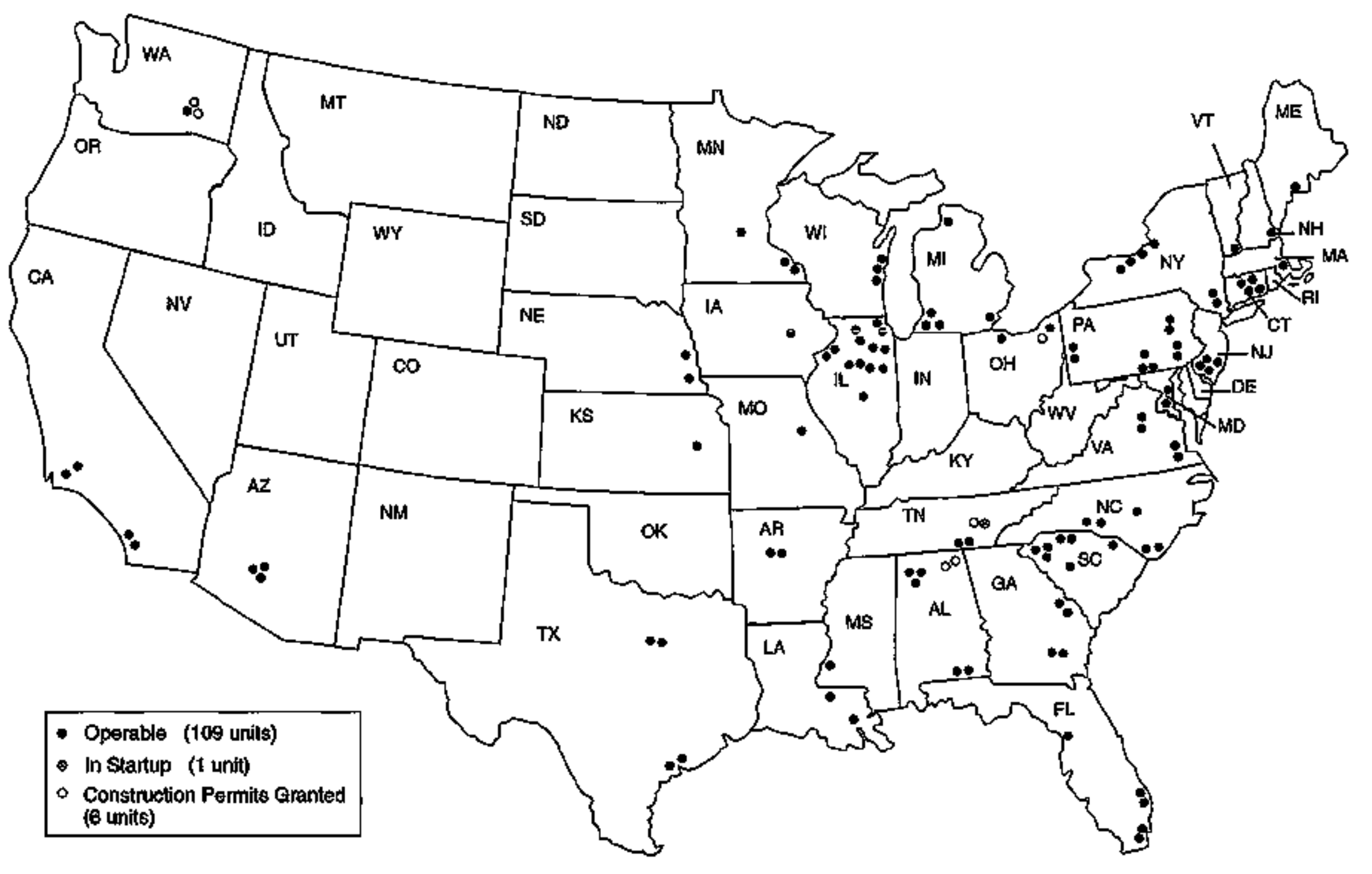

Note: Dua to spaca limilallons, bymbots do nol reprosent aciugl locationg. 
Table 9.1 Nuclear Generating Units, End of Year 1973-1995

\begin{tabular}{|c|c|c|c|c|c|c|c|c|}
\hline \multirow[b]{3}{*}{ Yaar } & \multicolumn{2}{|c|}{ Licensed tor Opention } & \multicolumn{2}{|c|}{ consinuetion Perming } & \multirow[b]{2}{*}{ On Order } & \multirow{2}{*}{ Anrounoed } & \multirow[b]{2}{*}{ Totat } & \multirow{2}{*}{$\begin{array}{c}\text { Total } \\
\text { onation } \\
\text { cipueditys }\end{array}$} \\
\hline & Openuble' & In Slartup? & Gramed & Ponding & & & & \\
\hline & \multicolumn{7}{|c|}{ Humber of unts } & Miton Kitematls \\
\hline 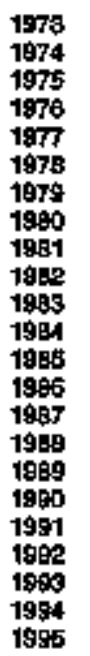 & 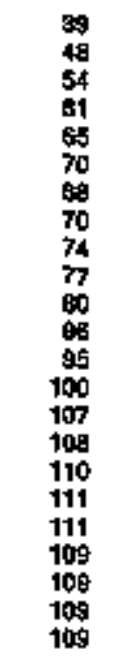 & $\begin{array}{l}2 \\
5 \\
2 \\
1 \\
2 \\
0 \\
0 \\
1 \\
0 \\
2 \\
3 \\
6 \\
3 \\
7 \\
4 \\
3 \\
1 \\
0 \\
0 \\
0 \\
0 \\
0 \\
1\end{array}$ & $\begin{array}{l}87 \\
62 \\
68 \\
71 \\
78 \\
78 \\
90 \\
90 \\
98 \\
76 \\
60 \\
58 \\
38 \\
30 \\
19 \\
14 \\
19 \\
10 \\
8 \\
8 \\
8 \\
8 \\
7 \\
7 \\
6\end{array}$ & $\begin{array}{c}52 \\
75 \\
69 \\
69 \\
68 \\
48 \\
92 \\
24 \\
12 \\
11 \\
3 \\
0 \\
0 \\
0 \\
0 \\
0 \\
0 \\
0 \\
0 \\
0 \\
0 \\
0 \\
0 \\
0 \\
0\end{array}$ & $\begin{array}{l}49 \\
40 \\
14 \\
16 \\
15 \\
13 \\
5 \\
3 \\
3 \\
3 \\
2 \\
2 \\
2 \\
2 \\
2 \\
2 \\
2 \\
2 \\
0 \\
0 \\
0 \\
0 \\
0 \\
0 \\
0 \\
0 \\
0\end{array}$ & $\begin{array}{l}9 \\
0 \\
0 \\
5 \\
2 \\
2 \\
0 \\
0 \\
0 \\
0 \\
0 \\
0 \\
0 \\
0 \\
0 \\
0 \\
0 \\
0 \\
0 \\
0 \\
0 \\
0 \\
0 \\
0 \\
0\end{array}$ & $\begin{array}{l}200 \\
226 \\
213 \\
214 \\
209 \\
105 \\
185 \\
156 \\
169 \\
144 \\
130 \\
132 \\
130 \\
126 \\
1127 \\
129 \\
1121 \\
119 \\
119 \\
117 \\
116 \\
116 \\
116\end{array}$ & $\begin{array}{l}150 \\
283 \\
2272 \\
211 \\
209 \\
201 \\
191 \\
180 \\
162 \\
157 \\
134 \\
129 \\
123 \\
121 \\
119 \\
119 \\
1116 \\
1119 \\
111 \\
111 \\
111 \\
170 \\
110 \\
110\end{array}$ \\
\hline
\end{tabular}

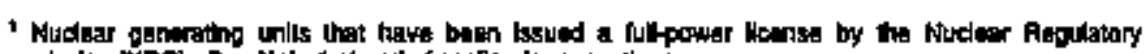

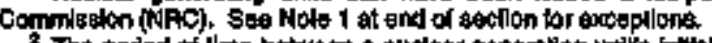

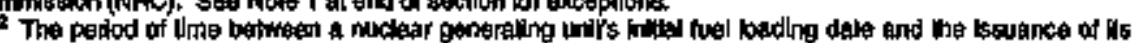

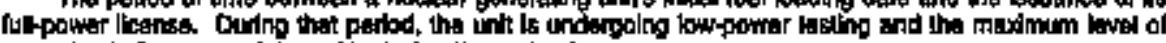
cptrallon is 6 percent of the unt's doosign thermal rating.

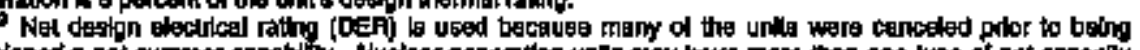

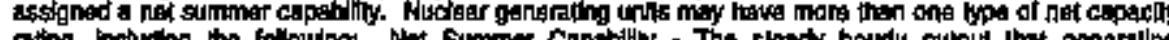

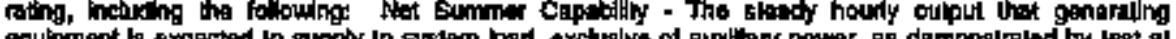

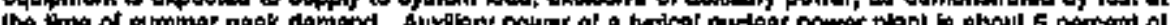

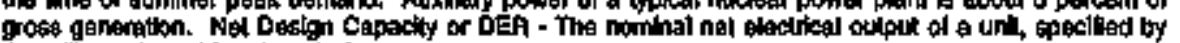
the unthly and usad for ptank dasign.

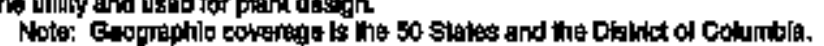

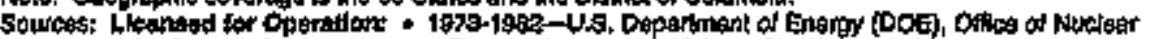

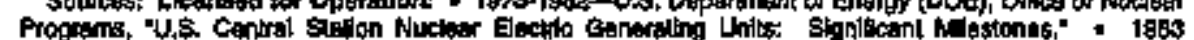

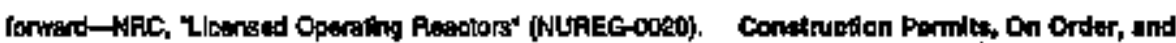

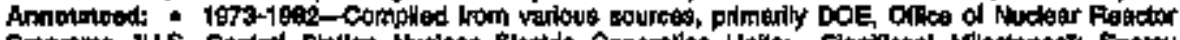

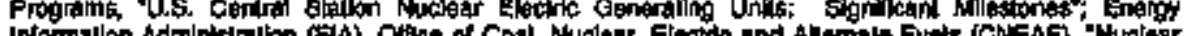
Gog

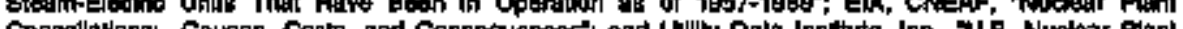
Gancent

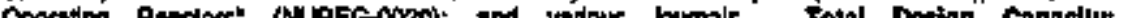
- to7s-

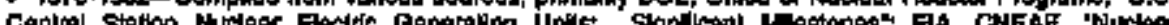
Conm E Copto fortem

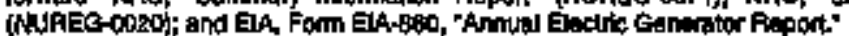


Figure 9.2 Nuclear Power Plant Operations

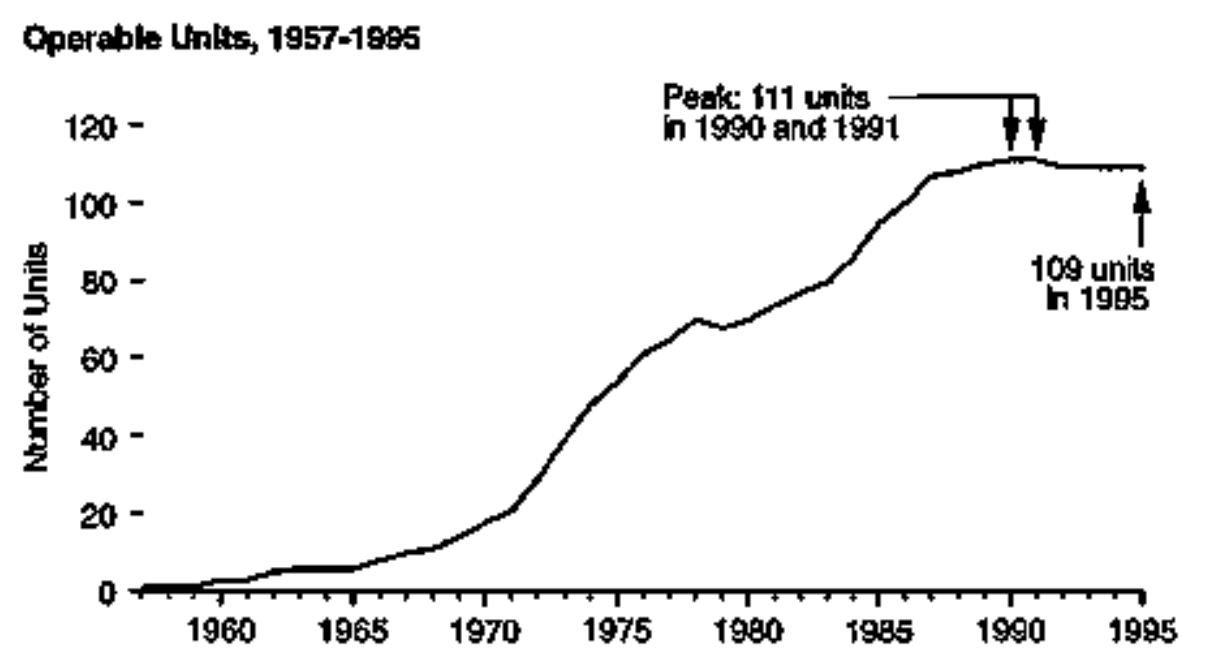

Nuclear and Totel Net Generalion of Electrictiy, te57-1995

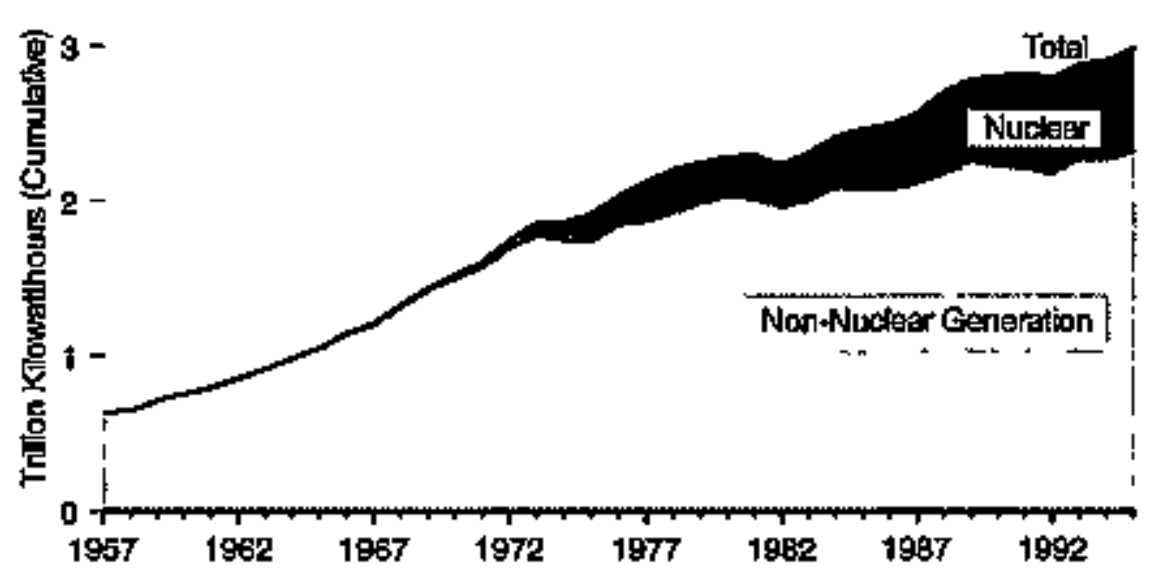

Nuclear Portion of Domesllc

Electriclty Not Generation, 1984-1985

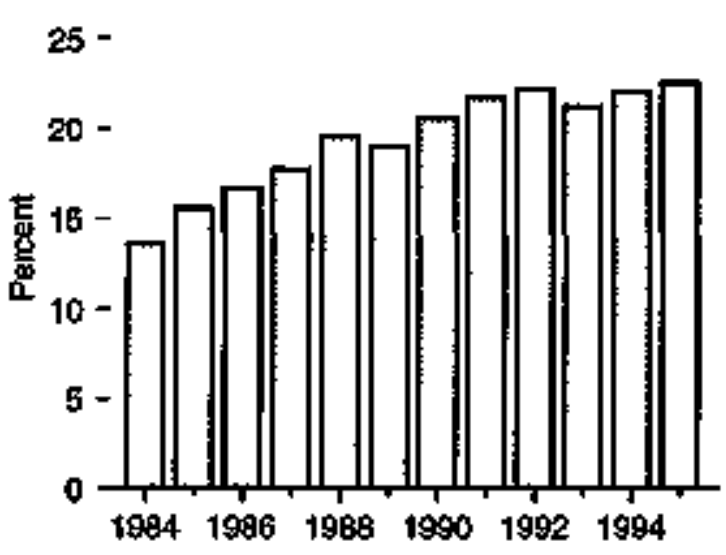

Nelt Summer Capab'thy

of Operable Units, 1457-1995

$120-$

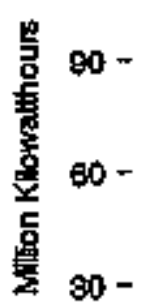

$30-$

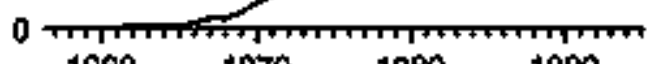

Capacly Factor, 1973-1995

$100=$

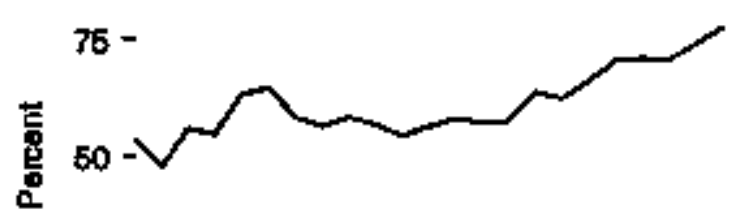

$25-$

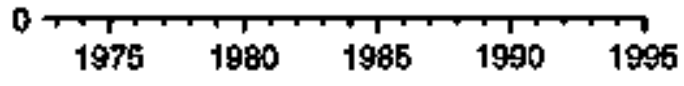

Sources: Tobles 0.3 and 9,2 
Table 9.2 Nuclear Power Plant Operations, 1957-1995

\begin{tabular}{|c|c|c|c|c|c|}
\hline & Opersable thiths 1.2 & $\begin{array}{l}\text { Nuckent Electritidty } \\
\text { Wht Gindrallont }\end{array}$ & 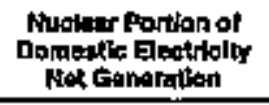 & 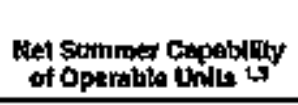 & Capacty Facto: ${ }^{3}$ \\
\hline Yoar & Mumber & Blylon Khowratthours & Percent & Hallon KGitonats & Percent \\
\hline 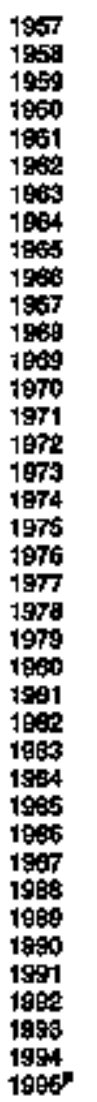 & 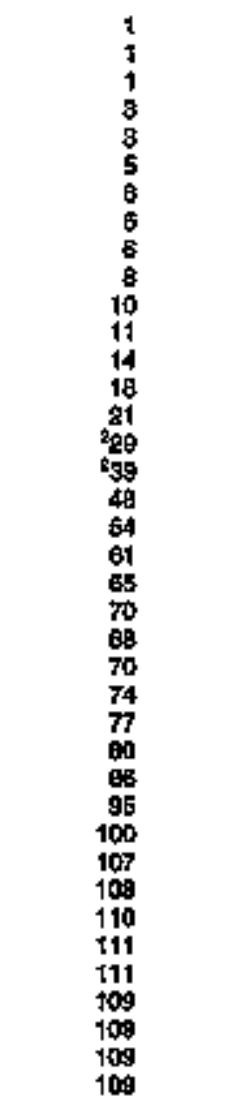 & 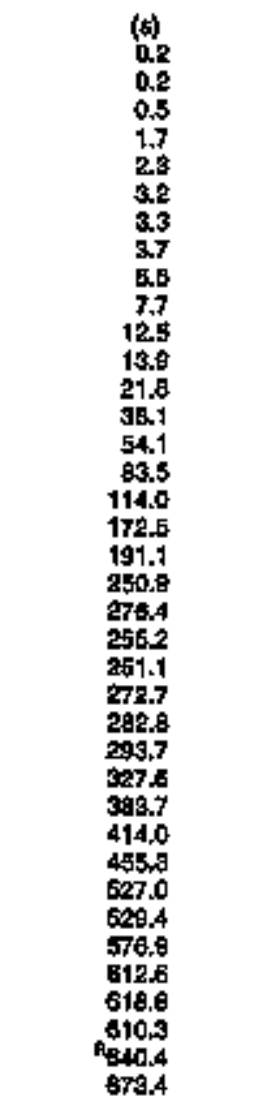 & 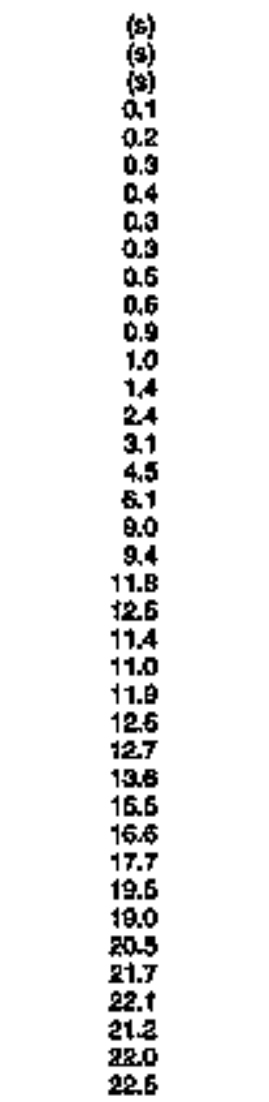 & 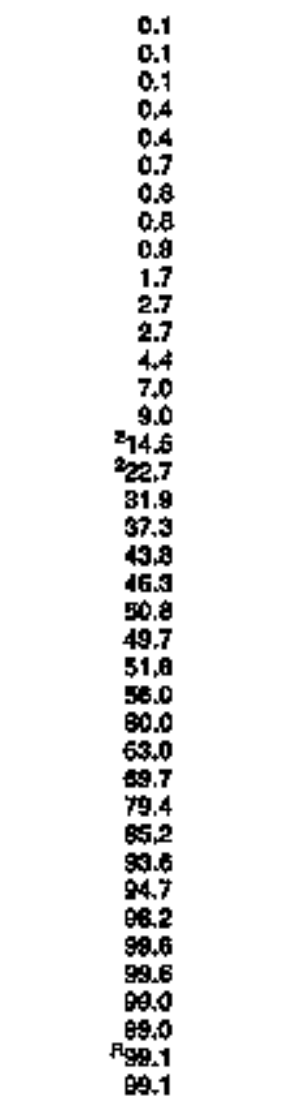 & 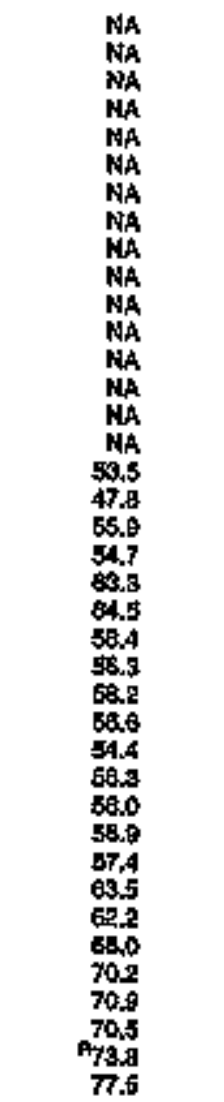 \\
\hline
\end{tabular}

A A mod ol year.

5ép Hols 2 at ind of section.

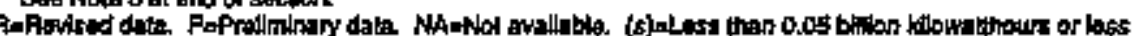
Haen 0.05 percent.

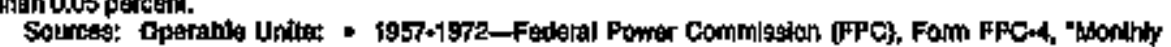

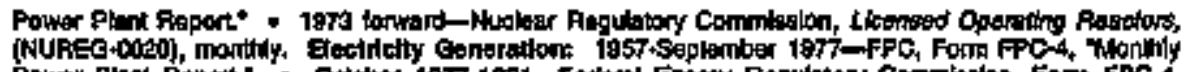

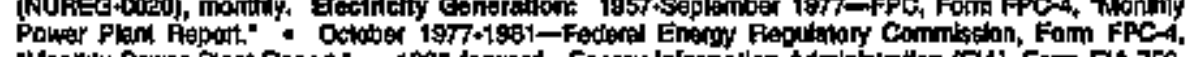

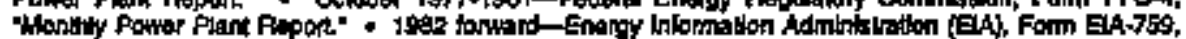

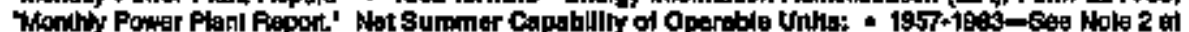

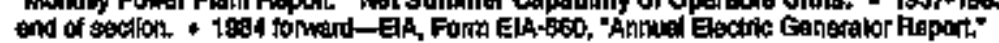




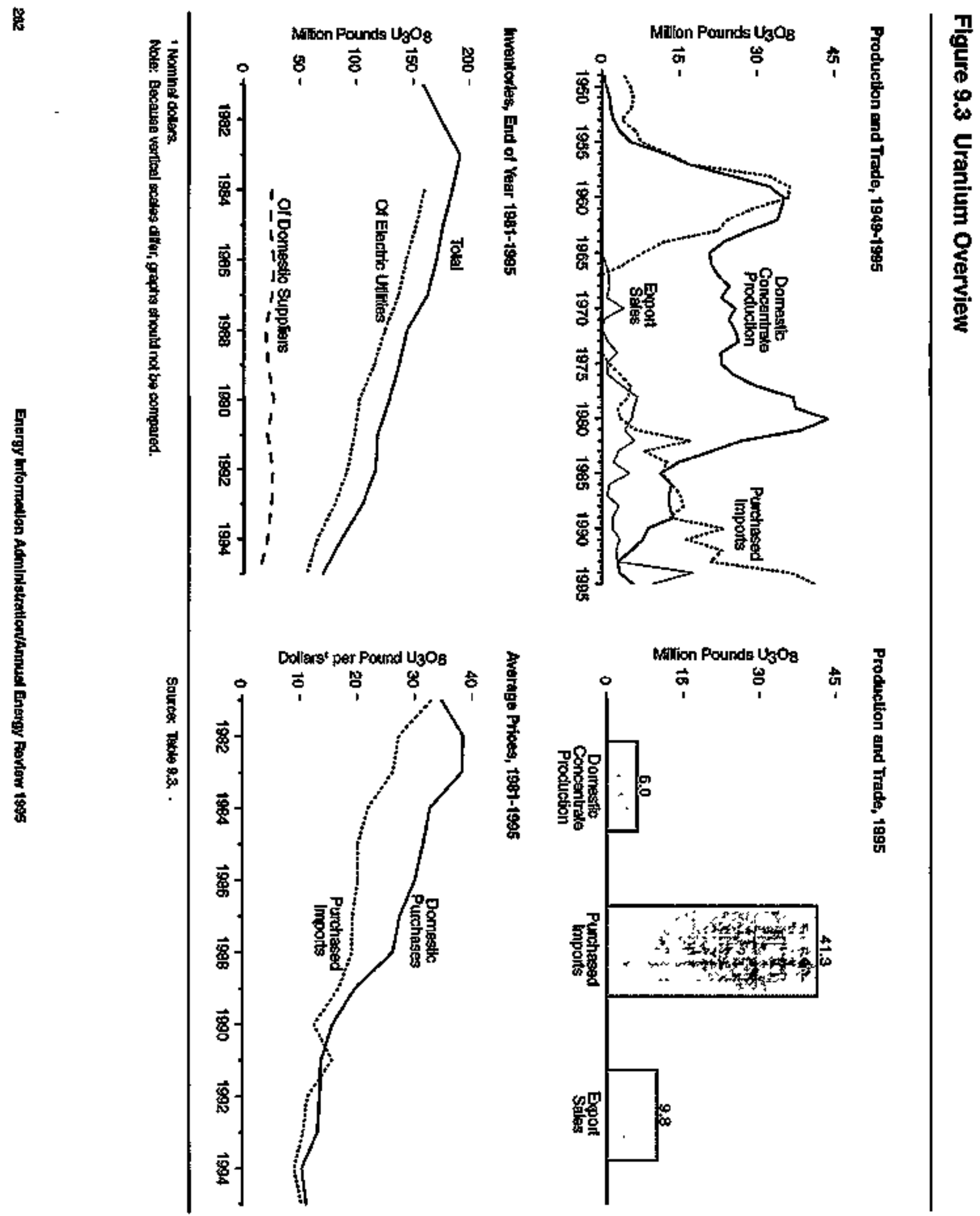


Table 9.3 Uranium Overview, 1949-1995

\begin{tabular}{|c|c|c|c|c|c|c|c|c|c|c|}
\hline \multirow[b]{3}{*}{ Yatr } & \multirow[b]{2}{*}{$\begin{array}{l}\text { Comasilo } \\
\text { Congemints } \\
\text { Production }\end{array}$} & \multirow[b]{2}{*}{$\begin{array}{l}\text { Purctuated } \\
\text { Importa }\end{array}$} & \multirow[b]{2}{*}{$\begin{array}{l}\text { Export" } \\
\text { Slleat }\end{array}$} & \multirow{2}{*}{ 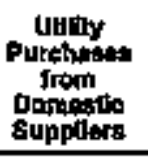 } & \multirow[b]{2}{*}{ 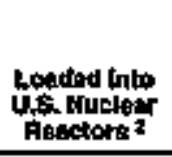 } & \multicolumn{3}{|c|}{ Inventorie: } & \multicolumn{2}{|c|}{ Averege Prics. } \\
\hline & & & & & & $\begin{array}{c}\text { of } \\
\text { Oxpnuslo } \\
\text { Suppitere }\end{array}$ & $\begin{array}{c}\text { on } \\
\text { Cincirio } \\
\text { Uillides }\end{array}$ & Total & $\begin{array}{l}\text { of } \\
\text { Purchased } \\
\text { imports }\end{array}$ & $\begin{array}{c}\text { of } \\
\text { Domiatio } \\
\text { Purohtestes }\end{array}$ \\
\hline & \multicolumn{8}{|c|}{ 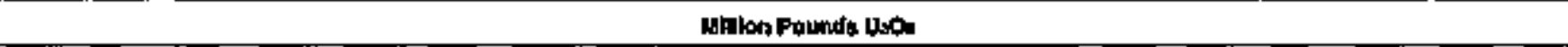 } & \multicolumn{2}{|c|}{ U.S. boltarts pes Pound Urot } \\
\hline 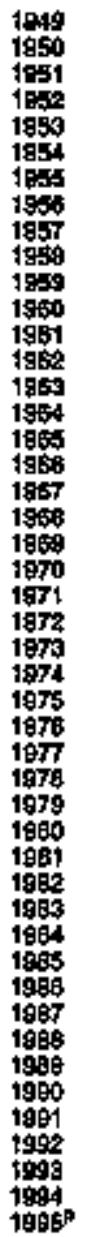 & 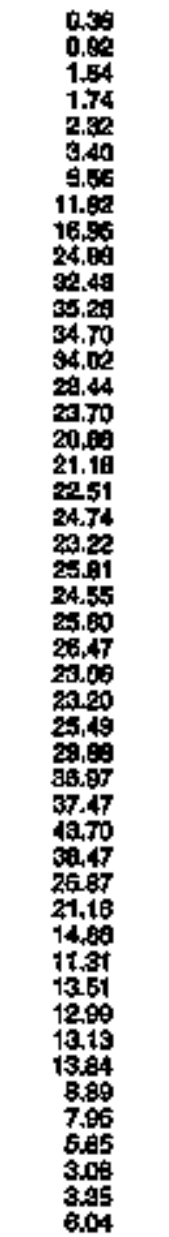 & 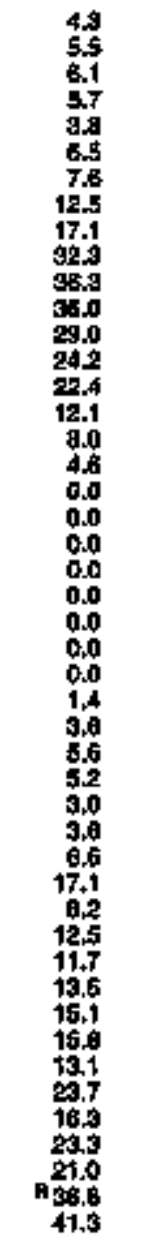 & 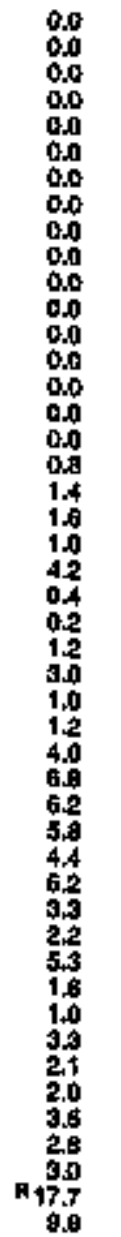 & 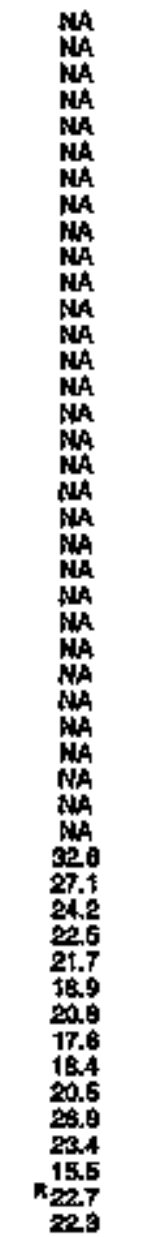 & 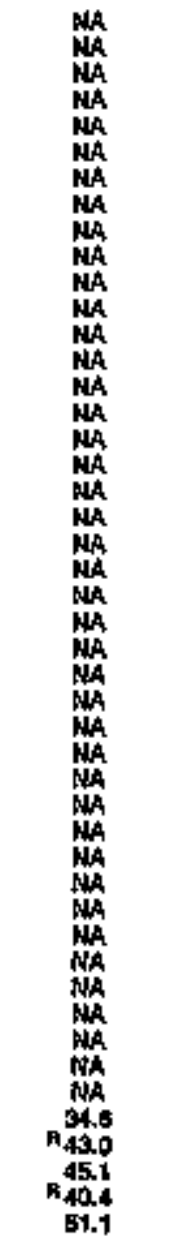 & 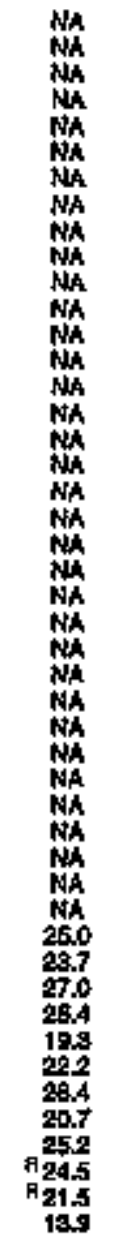 & 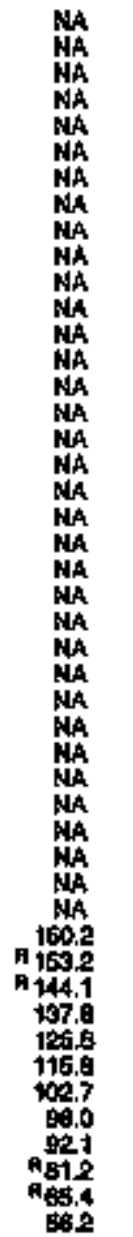 & 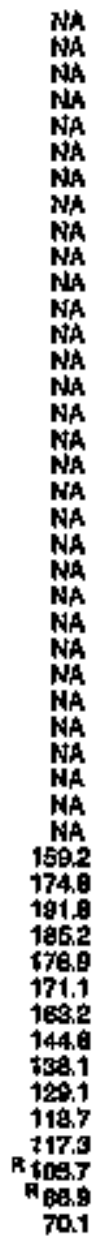 & 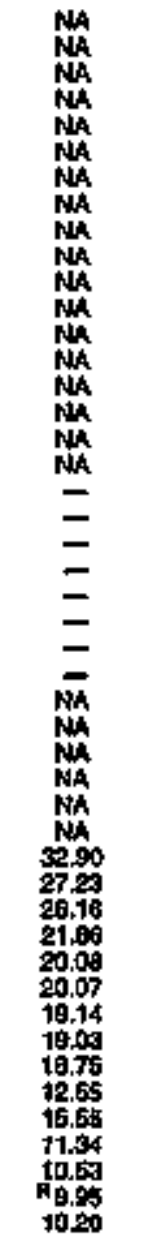 & 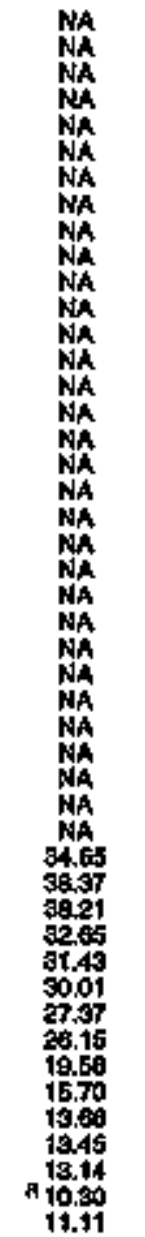 \\
\hline
\end{tabular}

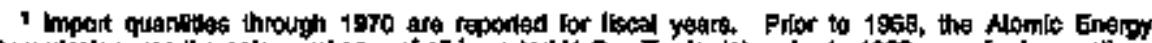

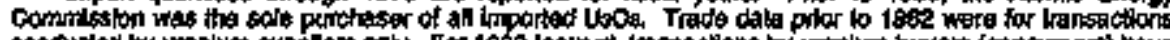

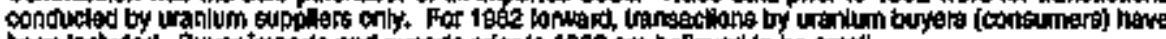

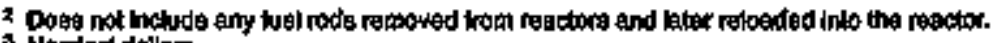

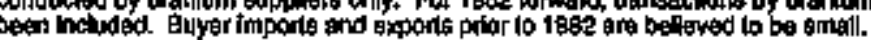




\section{Nuclear Energy Notes}

1. Nine units have been retired and therefore removed from the operable category. Those units are: Peach Bottom 1 ( $40 \mathrm{MW}$ ) and Indian Point $1(265 \mathrm{MW})$, both retired in 1974; Humboldt Bay ( $65 \mathrm{MW}$ ), officially retired in 1976; Drescen 1 (200 MW), retired in October 1979; LaCrosse (51 MW), retired in May 1987; Fort Saint Vtain (217 MW), retired in October 1989; Yarkee Rowe 1 (185 MW), retired in February 1992; San Onofre 1 (436 MW), retired in December 1992; and Trojan $(1,104 \mathrm{MW})$, retired in January 1993.

In addition, several units have been excluded from the operable cate. gory that normally would have been included (and, in one case-Hanford-N-a unit was included that normaliy would have been excluded). Detailed information on those exceptions can be found in Energy Information Administration, Monthly Energy Review April 1996, DOE/EIA-0035(96/04) (Washington, DC, April 1996), p. 107.

2. Prior to 1973, the number of operable trits inciuded units that were in commercial operation by December 31 of the stated year. Units decommissioned or inoperative for extended periods were generally included. Also included were two DOE-operated plants that supply electricity to the commercial grid. A third DOE plant, which does not distribute electricity to the grid, was excluded. For 1973 forward, the number of units includes units issued full-power or operating licenses and genterally does not include units in long-term shutdown status.

3. Net summer capabilities were first collected on Form EIA-860, "Anpual Electric Generator Report," for 1984, Units not assigned a net summer capability rating by the utility were given an estimated rating by use of a statistical relationship between installed nameplate capacity and net summer capability for each prime mover. To estimate net summer capability for $1949+1984$, two methods were used. For each prime mover except nuclear and "other," net summer capability estimates were calculated in two steps. First, the unit capacity values reported on Form EIA-860 and the unit start dates contained in the 1984 Generating Unit Reference File (GURF) were used to compute preliminary aggregate estimates of annual net summer capability and installed nameplate capacity. These proliminary estimates were obtained by aggregating unit capacity values for all units in service during a given year. Next, the ratio of the preliminary capability to nameplate estimate was computed for each year and multiplied by the previously published installed nameplate capacity values to produce the final estimates of net summer capability. The net sumner capability data for nuclear and "other" units were used directly from the 1984 GURF for all years. Historical asgregates were then developed by use of the unit start dates on the GURF.

Historical capacity has also been modified to estimate capability based upon the operable definition. This was accomplished by assuming that nonnuclear generating units became operable between 1 and 4 months prior to their commercial operation dates, depending upon the prime mover and time period. The actual operable dates for nuclear units were used.

4. Table 9.3 Sources: * 1949-1966: U.S. Department of Energy, Grand Junction Office, Statistical Data of the Uranium Industry, Re. port No. GJO-100, annual. - 1967-1995: Domestic Concentrate Production: 1976-1984-Energy Information Administration, Uranium Industry Annual 1992 (UIA 1992) (October 1993), Table 17, 1985-1995-UIA 1995 (May 1996), Table 5. Purchased Imports and Export Sales: 1967-1984-UIA 1992 (Oetober 1993), Table 30; 1985-1995-UIA I995 (May 1996), Table H2. Utility Purchases From Domestic Suppliers: 1981-1984-UIA 1992 (October 1993) Table ES1; 1985-1995-UIA I995 (May 1996), Table 14. Loaded Into U.S. Nuclear Reactors: 1991-UIA I992 (October 1993), p. 61; 1992-UIA 1993 (September 1994), o. 45; 1993-UIA J994 (July 1995), p. 37; 1994 and 1995-UIA 1995 (May 1996), Table 27. Inventories: 1981-1983-UlA J992 (October 1993), Table ESI 1984-UIA 1985 (December 1986), Table 47; 1985-UIA 1986 (October 1987), Tables 45 and $47 ; 1986$-UIA 1987 (October 1988), Tables 45 and $47 ; 1987$-UIA I988 (September 1989). Table 47; 1988-UIA 1989 (September 1990), Table 48; 1989-UIA 1990 (September 1991), Table 44; 1990-UlA I99J (October 1992), Table 40; 1991-UIA 1992 (November 1993), Table 40; 1992-UIA I993 (September 1994), Tables 39 and 40; 1993-UlA J994 (July 1995), Table 39; 1994 and 1995-UIA 1995 (May 1996), Table 31. Average Price: 1981-1984-UIA I992 (October 1993), Table ES1; 1985-1995-UIA 1995 (May 1996), Tables 14 and 28. 


\section{Renewable Energy}

\section{Renewable Energy Consumption}

In 1995 , the United States consumed an estimated 6.9 quadrillion Bto of renewable energy (10. 1a).* Conventional hydroelectric power and biofuels accounted for the largest shates (50 percent and 43 percent, respectively). Geothermal, solar, and wind energy accounted for tho remainder.

Over the 6-year period of 1990 through 1995 (the only years for which data are available), renewable energy consumption rose 12 percent. Among the five major renewable energy sources, wind energy showed the greatest percentage increase ( 71 percent).

The types and amounts of renewable energy consumed varied by sector (10.1b). Electric utilities and the industrial sector (the primary source of nonutitity electric power) were the biggest consumers throughout the 1990-through-1995 period.

Conventional Hydroelectric Power. Almost all of the 3.5 quadrillion Btu of conventional hydroelectric power generation in 1995 occurred at electric utilities (10.1a and 10.1b). The industrial sector, which includes nonutility power producers (cogenerators, independent power producers, and small power producers), accounted for only 153 tríllion Btu.

Blotuels. Biofuels are fuelwood, wood byproducts, waste wood, municipal solid waste, manufacturing process waste, and alcohol fuels. In 1995, biofuel consumption totaled an estimated 2.9 quadrillion Btu, most of which (2.4 quadrillion Btr) was wood energy (10.2). Some industries, such as the paper and lumber industries, have ready access to wood and wood byproducts, and those rely heavily on wood as an energy saurce. Consumption of municipal solid waste and other wastes

"Numbars in parentheses indicats related tables. Annual defa are the most recent avaltable; they fraquently are prollminary and may be rewised in future publicalions. Percentages and numbers in text are calculated by using dota in the tables. totaled 486 trillion $B(t)$ in 1995 , and consumption of alcohol fuels (ethanol) totaled 105 trillion Btu.

Geothermal Energy. The thitd biggest source of renewable energy in 1995 was geothermal energy, which can be used directly, for purposes such as space heating, or converted to electricity. In 1960, The Geysers in California became the first U.S. power plant to generate electricity from geothermal steam. In 1995, geothermal energy consumption reached 362 trillion Btu (10.1a), 118 trillion Btu at electric utikities and 244 trillion Btu by the industrial sector (which includes nonutilities) (10.1b).

Solar Energy. Of the 74 trillion Btu of solar energy supplied in 1995 , most (64 trijlion Bui) was used in the residential and commercial sector $(10.1 \mathrm{~b})$. The industrial sector accounted for 10 trillion Bth and electric utilities accounted for less than 0.5 trillion Btu.

Because it is difficult to measure solar energy use directly, producer shipments of equipment are used as an indicator. Shipments of lowtemperature collectors, used primarily for heating swimming pools, totaled 6.8 million square feet in 1994 (10.4). Shipments of mediumtemperature collectors, used for pool heating and domestic hot water, peaked at 12 million square feet in 1983 and 1984 but, following the expiration of the Federal energy tax credit in 1985, totaled only 0.8 million square feet in 1994. Shipments of high-temperature collectors, used for electricity generation, reached 5.2 million square feet in 1990 but fell to near zero in 1991 through 1994, when Luz Intemational Ltd, ceased operating. In 1994, shipinents of photovoltaic cells and modules, which have a wide variety of applications, rose for the tenth consecutive year, to 26 thousand peak kilowatts (10.6).

Wind Energy. An estimated 41 trillion Btu of wind energy was consumed in 1995, virtually all in the industrial sector (which juclades nonutilities) (10.1b). Very small amounts (less than 0.5 trillion Btu) were consumed at electric utilities. 


\section{Flgure 10.1 Renewable Energy Consumption Estimates}

\section{As Share' of Total Entergy, 1995}

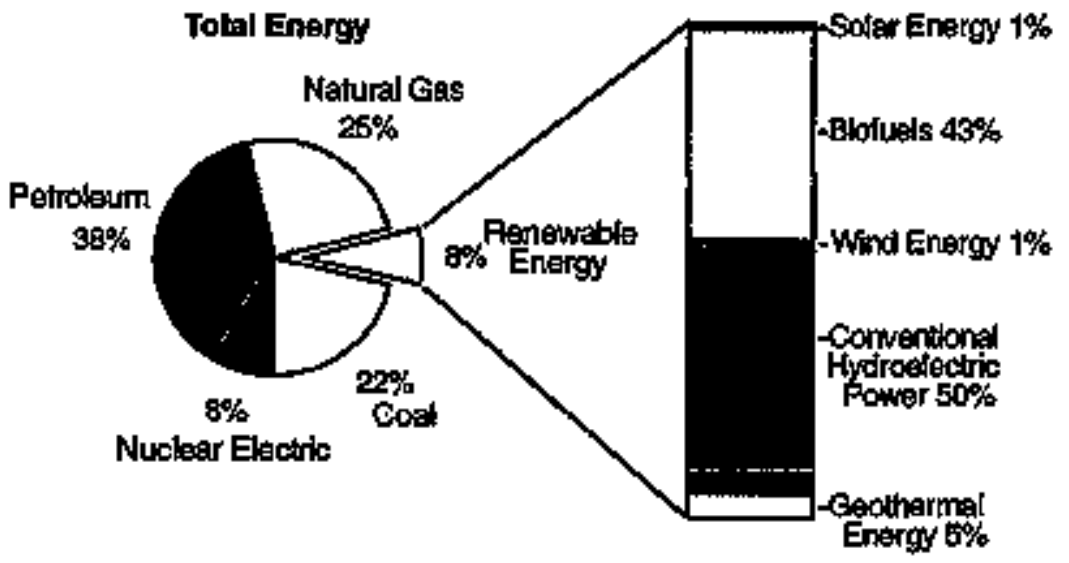

Tokad, 1990-1995

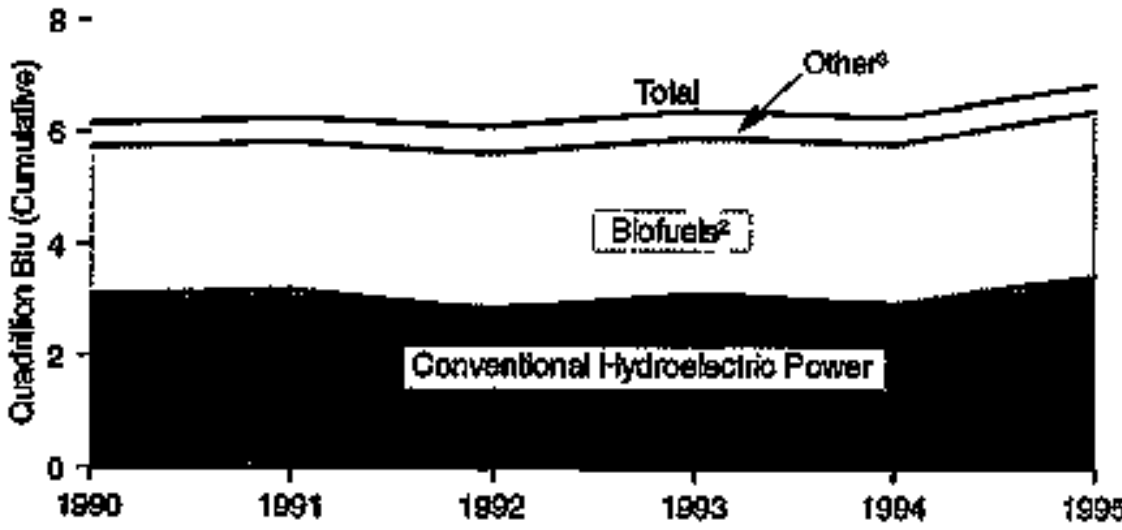

By Sources, 1995

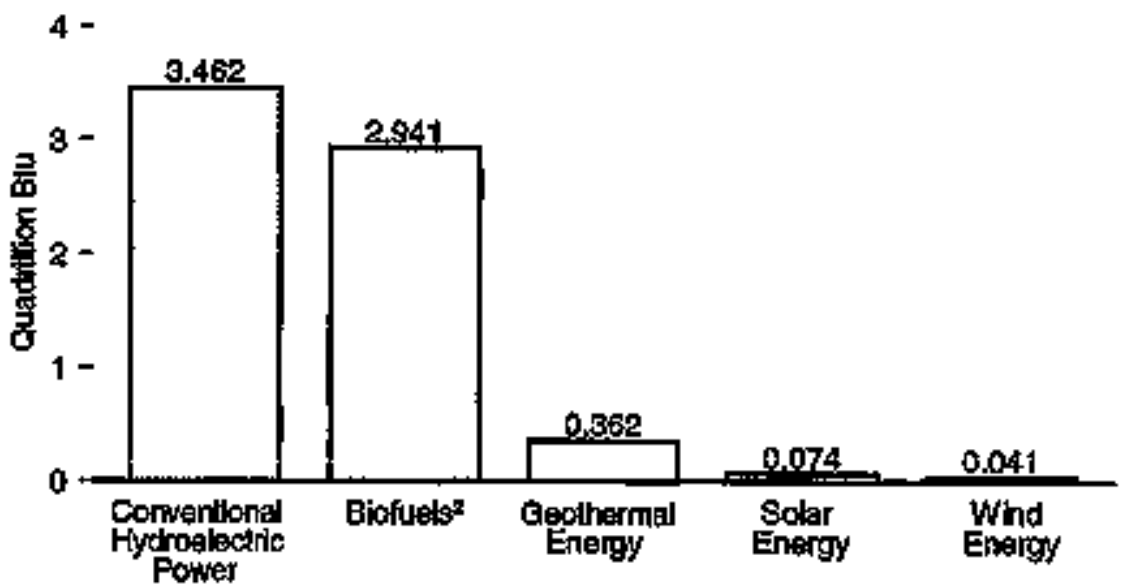

By Sector, 1995

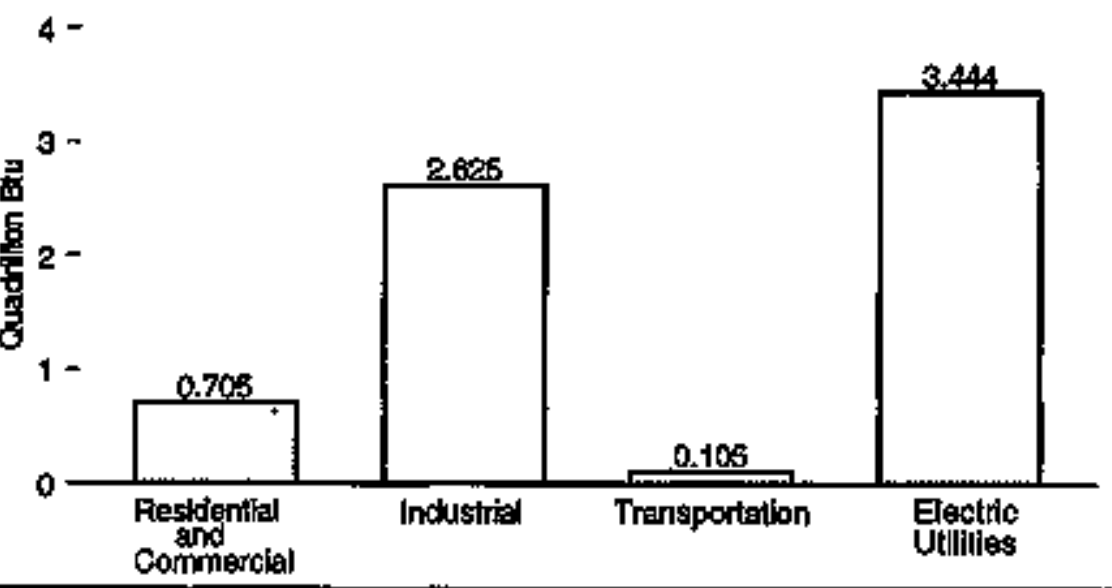

T Geothotmad, bolkr, and wind energy.

Note: Because vertical scelas difier, Graphs should not be compared. Sources: Tables 1,3, 10.1a, and 10.tb.

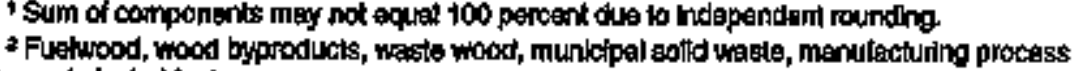
wasile, and alcothol fuets 
Table 10.1a Renewable Energy Consumption by Source, 1990-1995

(Quadrillion Btu)

\begin{tabular}{|c|c|c|c|c|c|c|}
\hline Yoar & Blokutals" & $\begin{array}{c}\text { Geothermil } \\
\text { Entrgy }\end{array}$ & 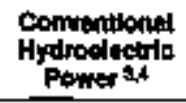 & $\begin{array}{c}\text { Solur } \\
\text { Energy }\end{array}$ & $\begin{array}{l}\text { Whind } \\
\text { Energye }\end{array}$ & Total \\
\hline $\begin{array}{l}1900 \\
1991 \\
1908 \\
1993 \\
1984 \\
10098\end{array}$ & 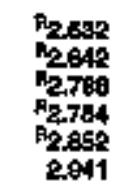 & 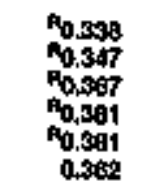 & $\begin{array}{l}R_{3.102} \\
R_{3.161} \\
R_{2.652} \\
R_{3.130} \\
R_{2.50} \\
3.180\end{array}$ & 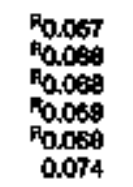 & $\begin{array}{c}70.024 \\
70.007 \\
70.030 \\
0.031 \\
0.038 \\
0.041\end{array}$ & 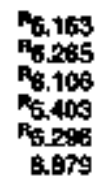 \\
\hline
\end{tabular}

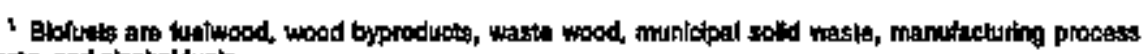
whte and aleohol wets.

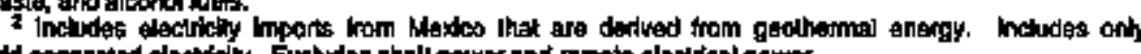

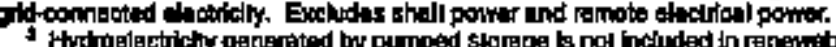

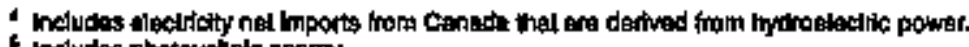
* ineludes photonoling anersy.

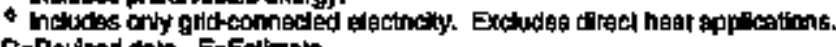

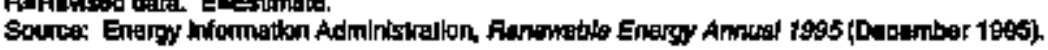

Table 10.1b Renewable Energy Consumption by Sector, 1990-1995

(Quadrillion Btu)

\begin{tabular}{|c|c|c|c|c|c|c|c|c|c|c|c|c|c|c|c|c|}
\hline \multirow[b]{2}{*}{ Your } & \multicolumn{3}{|c|}{ 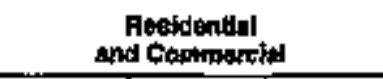 } & \multicolumn{6}{|c|}{ Intustertal 1} & \multirow{2}{*}{$\begin{array}{l}\text { Trung. } \\
\text { partation }\end{array}$} & \multicolumn{5}{|c|}{ 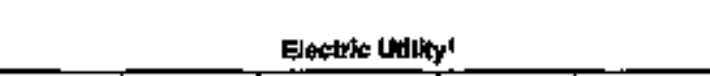 } & \multirow[b]{2}{*}{ Toutal } \\
\hline & eforugb & Solar ${ }^{2}$ & Total & Elpiosio & thorim & 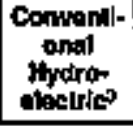 & Solner & Whad & Total & & Bloryeds: & Oeo- & $\begin{array}{l}\text { Convemtional } \\
\text { Hydro- } \\
\text { elocintic } 28\end{array}$ & $\begin{array}{l}\text { solur } \\
\text { and } \\
\text { wind }\end{array}$ & Total & \\
\hline $\begin{array}{l}1900 \\
1991 \\
1998 \\
1998 \\
1994 \\
1985 F\end{array}$ & $\begin{array}{l}0.581 \\
0.013 \\
0.645 \\
A_{0.02} \\
0.682 \\
0.641\end{array}$ & $\begin{array}{l}0.060 \\
0.000 \\
0.060 \\
0.050 \\
0.000 \\
0.064\end{array}$ & $\begin{array}{r}0.641 \\
0.673 \\
0.705 \\
70.852 \\
F_{0.642} \\
0.705\end{array}$ & $\begin{array}{l}R_{1.048} \\
R_{1.949} \\
R_{2.042} \\
R_{2.004} \\
R_{2.162} \\
3.170\end{array}$ & $\begin{array}{r}F_{0.146} \\
F_{0.162} \\
F_{0.179} \\
F_{0.204} \\
F_{0.212} \\
0.244\end{array}$ & 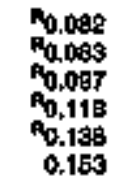 & $\begin{array}{l}0.007 \\
P_{0.008} \\
P_{0.000} \\
P_{0.009} \\
P_{0.000} \\
0.010\end{array}$ & $\begin{array}{l}P_{0.024} \\
m_{0.027} \\
P_{0.030} \\
P_{0.031} \\
P_{0.060} \\
0.041\end{array}$ & $\begin{array}{l}A_{2.206} \\
R_{2.223} \\
A_{7.357} \\
A_{2.448} \\
R_{2.543} \\
2.625\end{array}$ & $\begin{array}{r}0.089 \\
0.085 \\
0.079 \\
0.098 \\
0.009 \\
0.105\end{array}$ & $\begin{array}{l}0.021 \\
0.021 \\
0.022 \\
0.020 \\
0.020 \\
0.017\end{array}$ & $\begin{array}{l}0.192 \\
0.185 \\
0.188 \\
0.177 \\
0.170 \\
0.1118\end{array}$ & 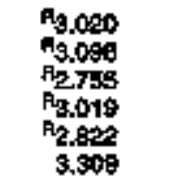 & $\begin{array}{l}(6) \\
(6) \\
(6) \\
(8) \\
(8)\end{array}$ & 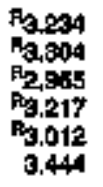 & 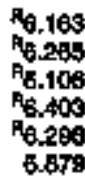 \\
\hline
\end{tabular}

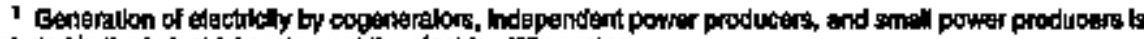

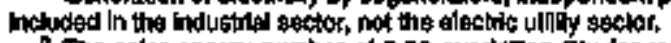

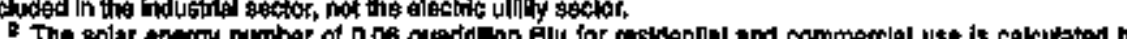

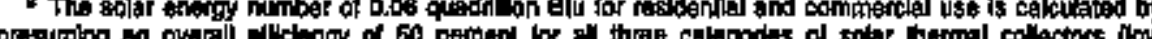

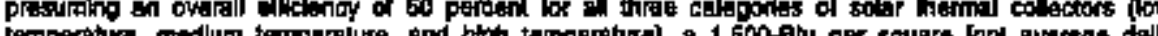

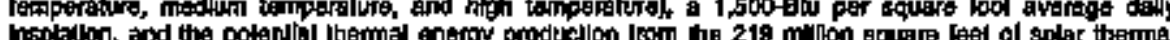

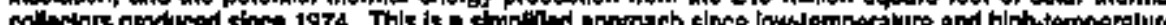

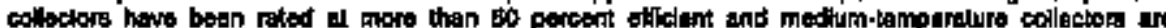

genarally less than 50 percent elikeloni.

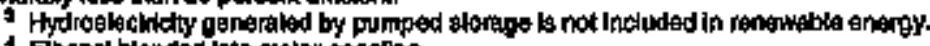

5

thel ars detvod fiom geothermel entigy.

.

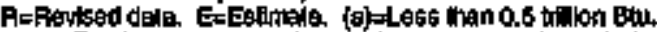

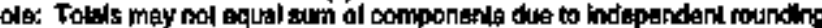

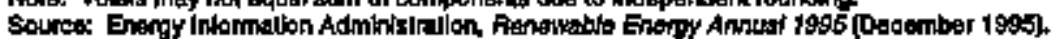


Etotuel Total, 1987-1984, 1987, and 1989-19951

4 -

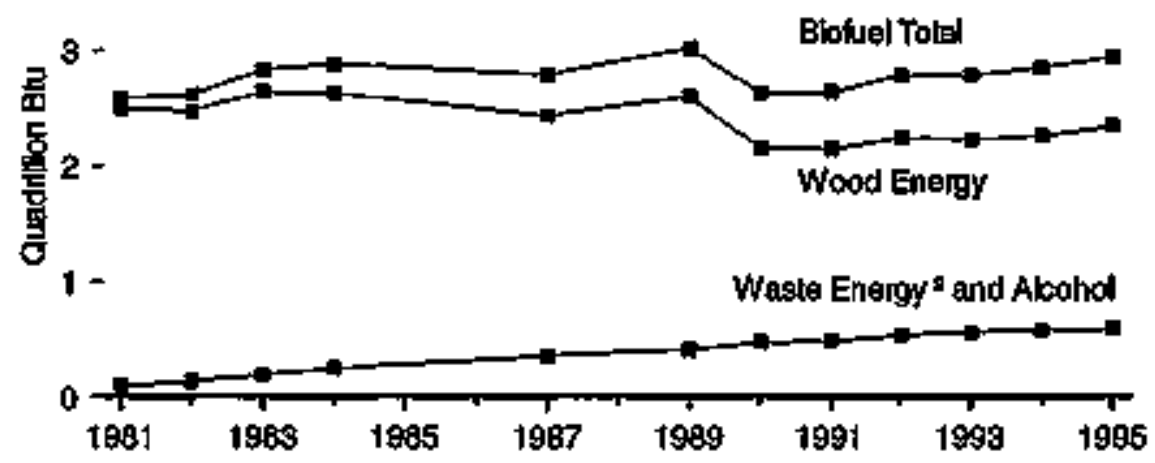

Wood Energy by Sector, 1995

$20-$

룸․ $^{1.5-}$

$0.5-$

0.0

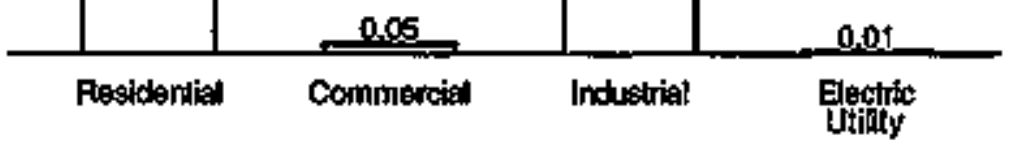

t No deta aro avalleble for 1985, 1986, and 1998.

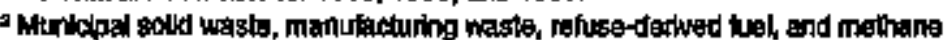
recorared brom landials.
Wood Energy by Census Region, 1996

$$
2.0-
$$

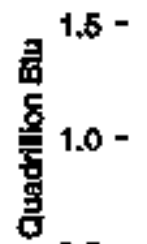

0.5 -

0.0

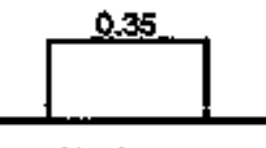

Northeasi

Waste Entorgy and Noohol Futs by Census fieglon, togs

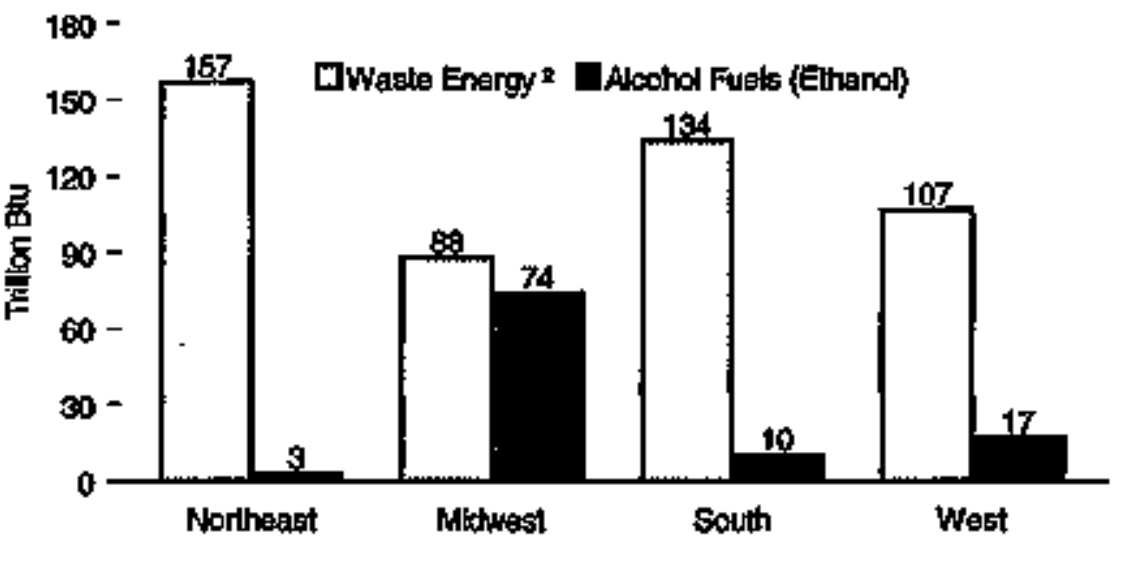

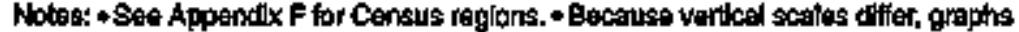
Should not be compared

Bource: Table 102. 
Table 10.2 Wood and Waste Energy and Alcohol Fuels Consumption by Sector and Census Region, Selected Years, 1981-1995

(Trillion Bitu)

\begin{tabular}{|c|c|c|c|c|c|c|c|c|c|c|c|c|}
\hline Energy Stcurtese & 1981 & 1982 & 1983 & 1994 & 1997 & 1809 & 1090 & 1901 & 1992 & 1993 & 1904 & 1986 \\
\hline Mood Enerigy , & 2,495 & $2,47 a$ & 2,640 & 2,639 & 2,487 & 2,604 & 2,155 & 12,151 & 2,249 & $n_{2,223}$ & 2,296 & 2,350 \\
\hline 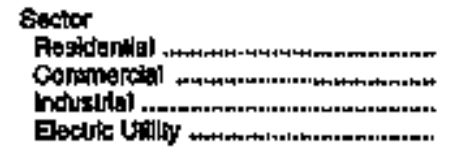 & $\begin{array}{r}860 \\
21 \\
1,802 \\
3\end{array}$ & $\begin{array}{r}997 \\
22 \\
1.516 \\
2\end{array}$ & $\begin{array}{r}006 \\
220 \\
1,090 \\
3\end{array}$ & $\begin{array}{r}929 \\
22 \\
1,879 \\
9\end{array}$ & $\frac{852}{1576}$ & 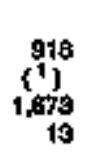 & $\frac{587}{1,562}$ & $\underset{10}{613}$ & 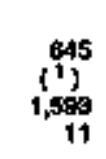 & $\begin{array}{r}549 \\
5,54 \\
11\end{array}$ & $\begin{array}{r}5 \$ 7 \\
1,675 \\
\$ 1\end{array}$ & $\begin{array}{r}596 \\
45 \\
1,688 \\
11\end{array}$ \\
\hline 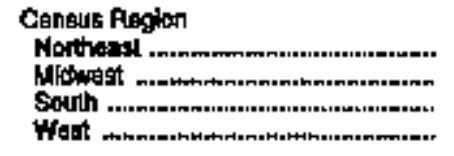 & $\begin{array}{r}396 \\
335 \\
r, 349 \\
416\end{array}$ & $\begin{array}{r}368 \\
343 \\
1,392 \\
305\end{array}$ & $\begin{array}{r}300 \\
320 \\
1,506 \\
411\end{array}$ & $\begin{array}{r}349 \\
341 \\
1,499 \\
461\end{array}$ & $\begin{array}{r}350 \\
474 \\
1,147 \\
487\end{array}$ & $\begin{array}{r}436 \\
650 \\
1,181 \\
469\end{array}$ & $\begin{array}{r}268 \\
300 \\
1,064 \\
506\end{array}$ & $\begin{array}{r}294 \\
290 \\
12167 \\
1.469\end{array}$ & $\begin{array}{r}284 \\
286 \\
1.244 \\
466\end{array}$ & $\begin{array}{r}\mathrm{R}_{2 m} \\
\mathrm{R}_{202} \\
\mathrm{H}_{204}\end{array}$ & 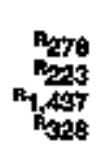 & $\begin{array}{r}354 \\
277 \\
1.075 \\
644\end{array}$ \\
\hline Wath tinarg ${ }^{2}$ & Bs & 124 & 格 & 2009 & 269 & 344 & 395 & 425 & $P_{465}$ & 46 & $R_{\text {eq⿴囗十⺝木 }}$ & 406 \\
\hline 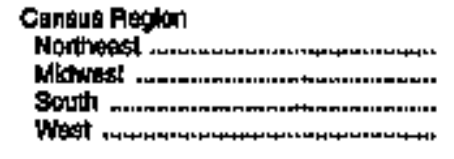 & $\underset{37}{15}$ & $\begin{array}{l}20 \\
13 \\
50 \\
36\end{array}$ & $\begin{array}{l}30 \\
17 \\
518 \\
48\end{array}$ & $\begin{array}{l}39 \\
21 \\
57 \\
91\end{array}$ & $\begin{array}{r}60 \\
47 \\
709\end{array}$ & $\begin{array}{r}84 \\
64 \\
145 \\
51\end{array}$ & $\begin{array}{r}119 \\
89 \\
114 \\
73\end{array}$ & $\begin{array}{r}\boldsymbol{N}_{133} \\
\mathrm{r}_{\mathrm{gB}} \\
\mathrm{A}_{109} \\
87\end{array}$ & $\begin{array}{r}148 \\
84 \\
128 \\
100\end{array}$ & $\begin{array}{r}151 \\
85 \\
130 \\
108\end{array}$ & $\begin{array}{r}157 \\
R_{135} \\
107\end{array}$ & $\begin{array}{r}157 \\
134 \\
107\end{array}$ \\
\hline Alcohol Fude (Ethanol) …................. & 7 & 10 & 35 & 4 & 69 & 71 & 42 & 65 & 70 & 66 & $\mathbf{P}_{96}$ & 105 \\
\hline 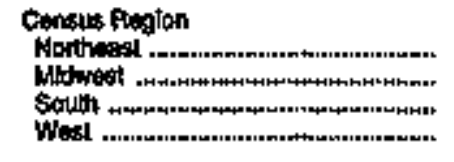 & $\begin{array}{r}\text { 何 } \\
1 \\
1 \\
2\end{array}$ & $\begin{array}{r}(8) \\
11 \\
4 \\
4\end{array}$ & 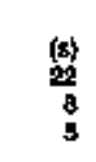 & $\begin{array}{r}(8) \\
25 \\
13 \\
5\end{array}$ & $\begin{array}{r}(5) \\
30 \\
20 \\
4\end{array}$ & $\begin{array}{r}(8) \\
38 \\
26 \\
7\end{array}$ & $\begin{array}{l}\text { (s) } \\
\mu_{j 5}^{5} \\
\mu_{17} \\
\mu_{10}\end{array}$ & $\begin{array}{l}(s) \\
f_{45}^{(s)} \\
n_{11} \\
n_{9}\end{array}$ & $\begin{array}{l}\text { (58 } \\
65 \\
13 \\
10\end{array}$ & $\begin{array}{l}\text { (s) } \\
61 \\
15 \\
11\end{array}$ & $\begin{array}{r}(8) \\
16 \\
12\end{array}$ & $\begin{array}{l}3 \\
74 \\
10 \\
17\end{array}$ \\
\hline Blolutel Tollal & 2,590 & 2,617 & 2,692 & $2,6: 94$ & 2,794 & 3,010 & 2,0312 & 72,642 & "2,798 & $A_{2,704}$ & $R_{2,1892}$ & 2,941 \\
\hline
\end{tabular}

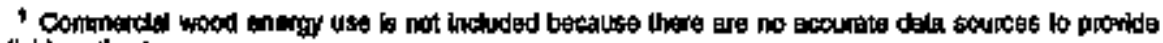
realabia esthmales.

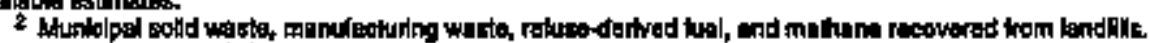
R=Rertsed date. (t) =Loss then 0.5 tilliton Btu.

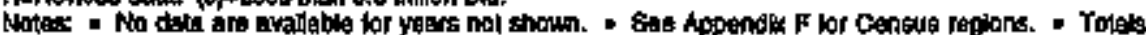

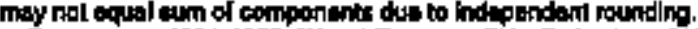

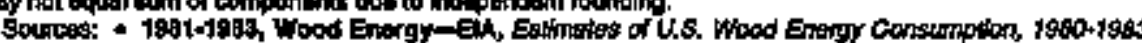

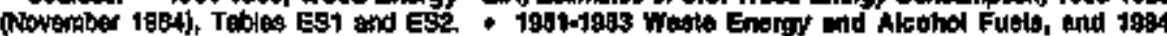

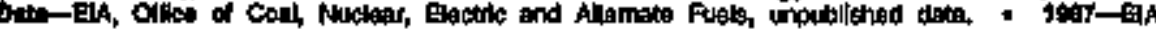

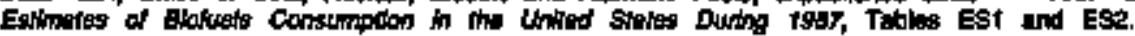

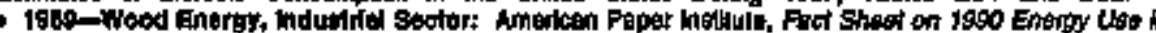

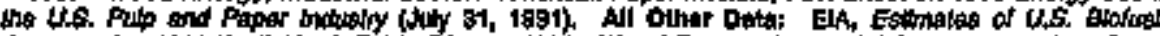

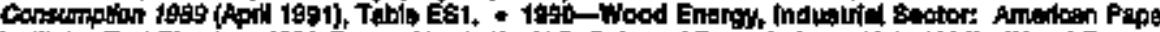

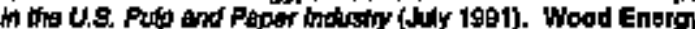

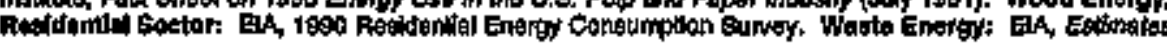

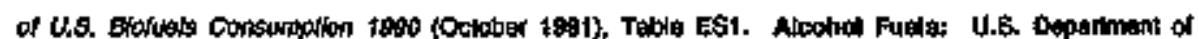

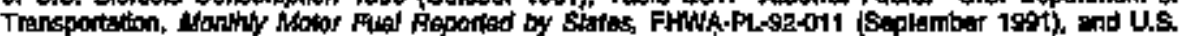

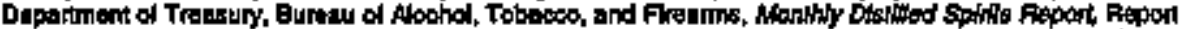

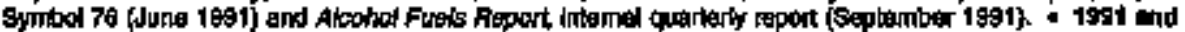

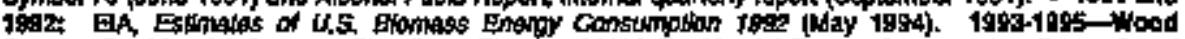

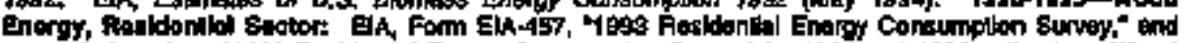

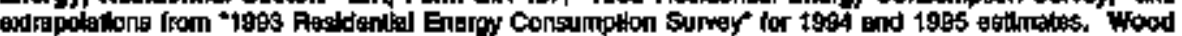

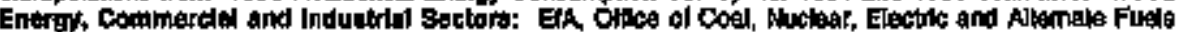

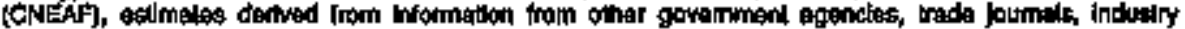
(

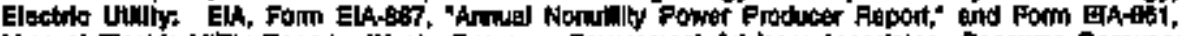

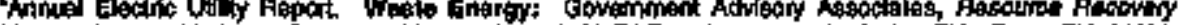

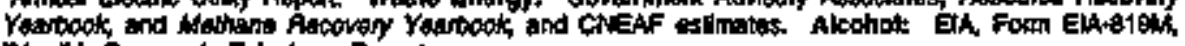
Wonthly Ongrinate Tolephone Repon. 


\section{Figure 10.3 Households That Burn Wood, Selected Years, 1980-1993}

\section{Number of Households}
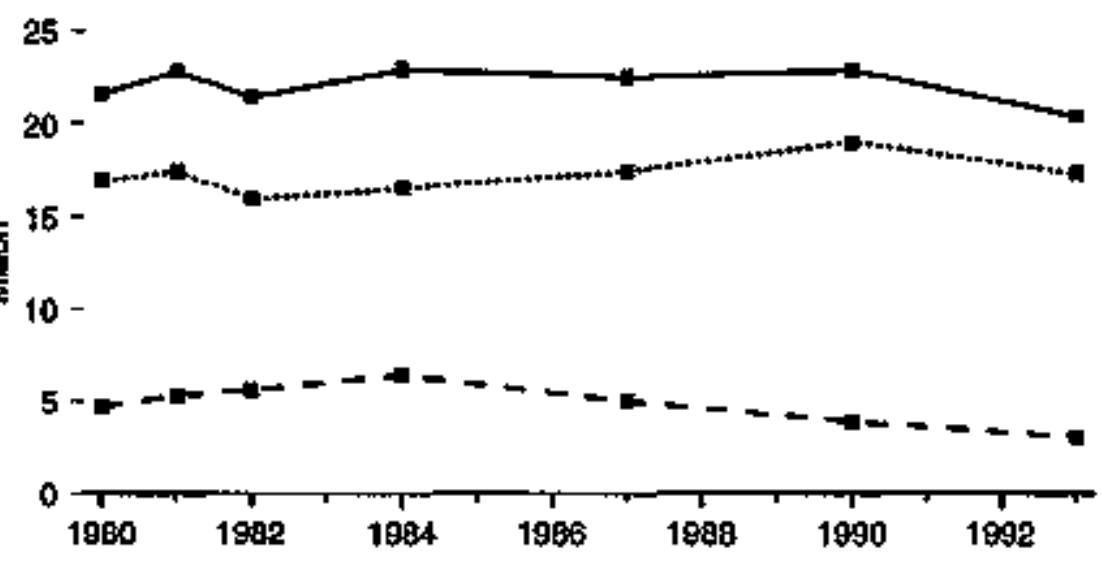

Wood Energy Constumed

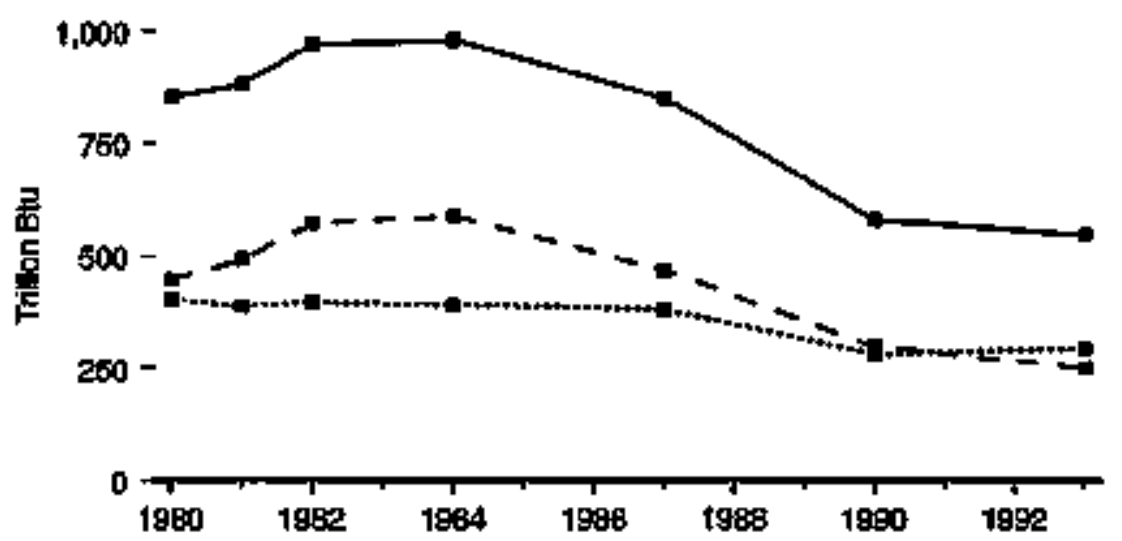

\section{Share of All Households}

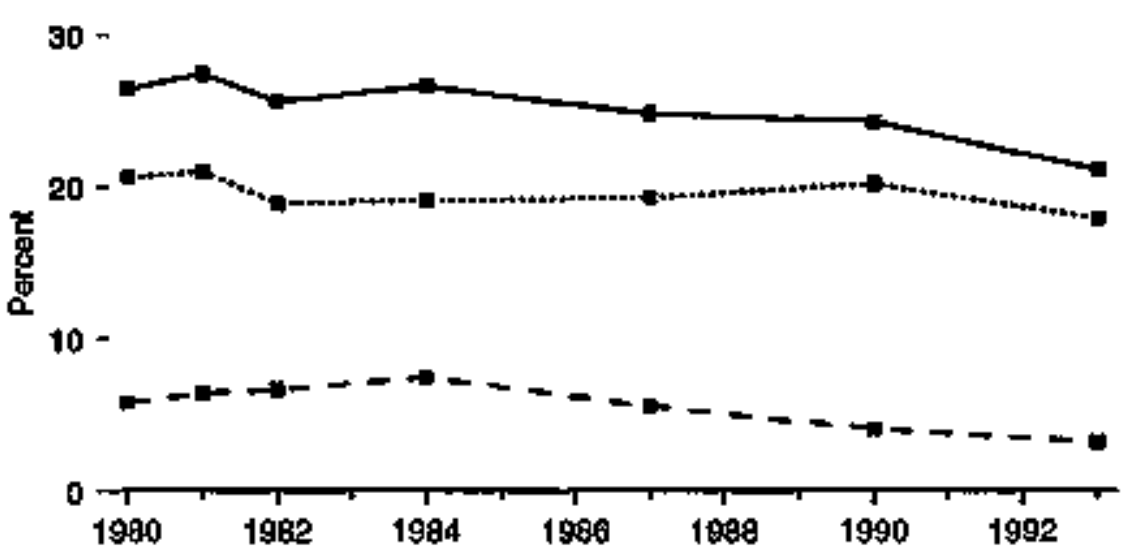

Avorage Bumed par Household (Mman)

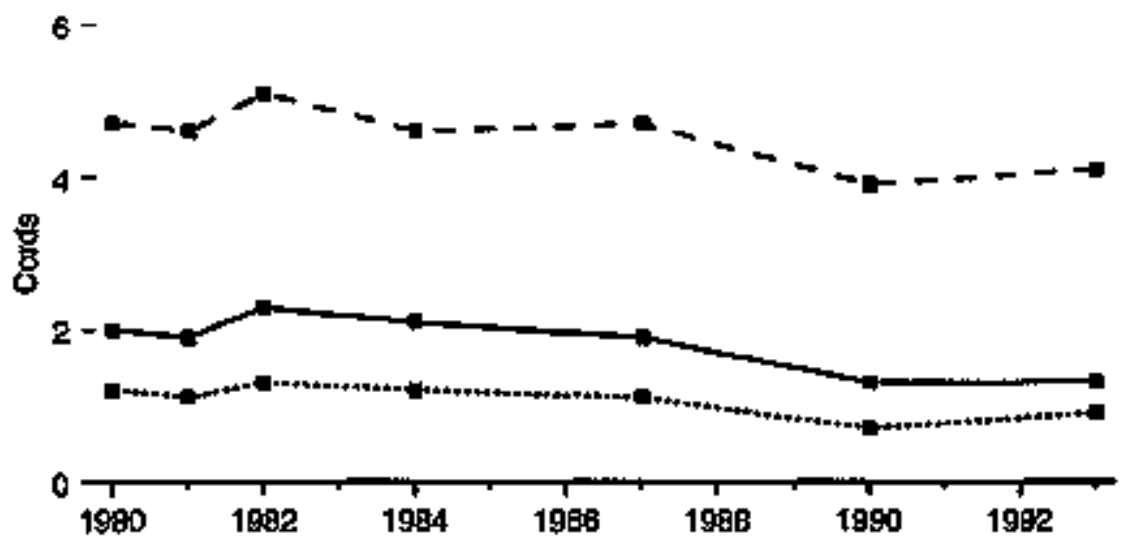

Note: No dale ere avalablo tor 1969, teg5, 1986, 1988, 1899, 1991, and 1989

Sptrace: Jable 10.s

Households That Bum Wood

Households That Bum Wood as Main Heating Fuel

...-... Households That Bum Wood as Sacondary Heating Fual and for Olher Furposes 
Table 10.3 Households That Burn Wood, Selected Years, 1980-1993

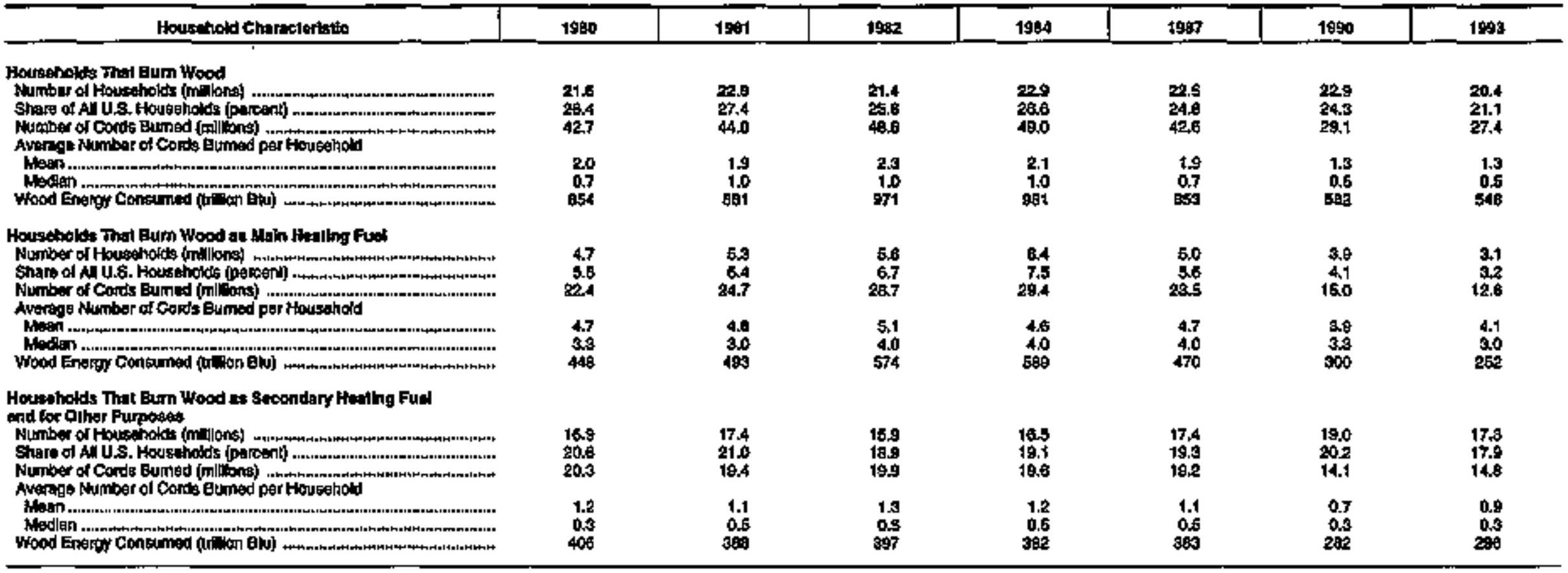

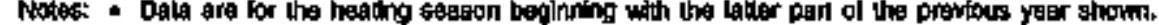

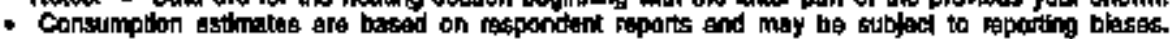

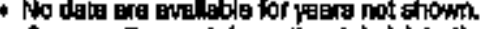

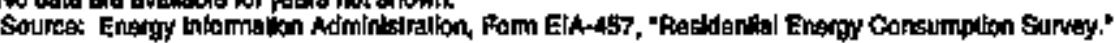




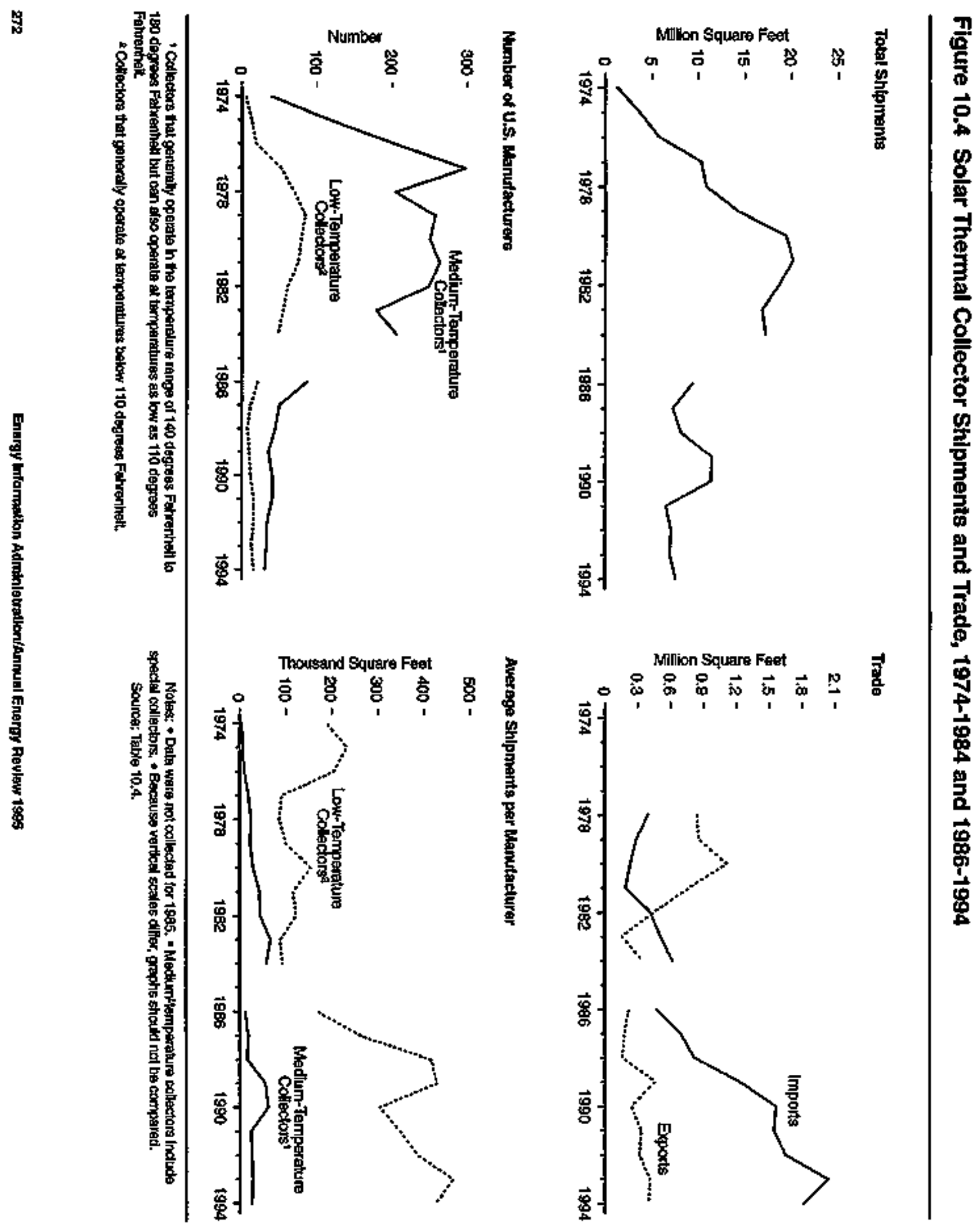


Table 10.4 Solar Thermal Collector Shipments by Type and Trade, 1974-1984 and 1986-1994

\begin{tabular}{|c|c|c|c|c|c|c|c|c|c|c|}
\hline \multirow[b]{3}{*}{ Yanr } & \multicolumn{3}{|c|}{ Lom-Tenperaturs Collootore 1} & \multicolumn{3}{|c|}{ Aoduri-Temparature Colleckors 2} & \multirow{3}{*}{$\begin{array}{l}\text { Hilgh-Temporalure } \\
\text { Coillector }{ }^{3} \\
\text { Shlymerdis } \\
\text { (mition } \\
\text { oquare lest) }\end{array}$} & & \multirow[b]{2}{*}{ Imports } & \multirow[b]{2}{*}{ Exports } \\
\hline & \multirow{2}{*}{$\begin{array}{l}\text { Number } \\
\text { of U.S. } \\
\text { Menulucturers }\end{array}$} & \multirow{2}{*}{$\begin{array}{l}\text { Cunmity } \\
\text { shipped } \\
\text { (milion } \\
\text { equerofos) }\end{array}$} & \multirow{2}{*}{ 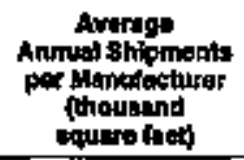 } & \multirow{2}{*}{$\begin{array}{c}\text { Almber } \\
\text { of U.S. } \\
\text { Menulaburers }\end{array}$} & \multirow{2}{*}{$\begin{array}{l}\text { Qusinty } \\
\text { Shipped } \\
\text { (milition } \\
\text { square foet) }\end{array}$} & \multirow{2}{*}{ 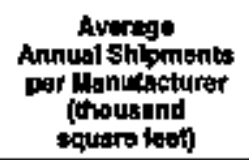 } & & $\begin{array}{c}\text { Total } \\
\text { stinparents }\end{array}$ & & \\
\hline & & & & & & & & \multicolumn{3}{|c|}{ Thounand square Feol } \\
\hline 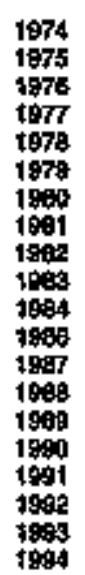 & $\begin{array}{c}B \\
11 \\
19 \\
62 \\
69 \\
84 \\
79 \\
75 \\
61 \\
66 \\
48 \\
28 \\
12 \\
8 \\
10 \\
12 \\
16 \\
16 \\
18 \\
16\end{array}$ & 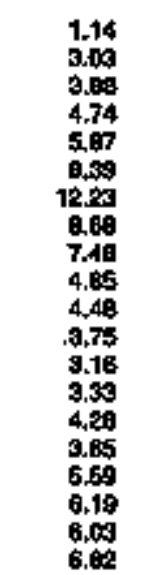 & 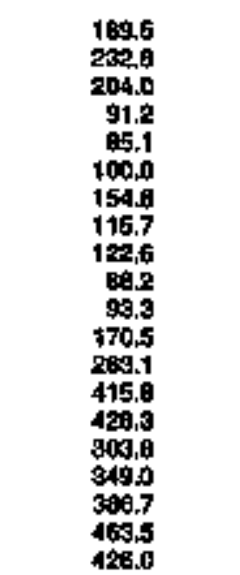 & $\begin{array}{c}39 \\
119 \\
2003 \\
297 \\
204 \\
207 \\
250 \\
280 \\
249 \\
179 \\
208 \\
07 \\
50 \\
45 \\
35 \\
41 \\
41 \\
34 \\
33 \\
31\end{array}$ & $\begin{array}{r}0.14 \\
0.72 \\
1.99 \\
5.57 \\
4.99 \\
5.86 \\
7.17 \\
11.46 \\
11.15 \\
11.98 \\
11.94 \\
1.11 \\
0.95 \\
0.78 \\
1.99 \\
2.53 \\
0.98 \\
0.90 \\
0.95 \\
0.05\end{array}$ & $\begin{array}{r}3.5 \\
6,1 \\
9.5 \\
18.8 \\
24.5 \\
22.6 \\
28.7 \\
43.6 \\
44.9 \\
68.9 \\
59.0 \\
12.6 \\
19.1 \\
16.2 \\
55.3 \\
61.6 \\
24.1 \\
26.4 \\
28.2 \\
28.0\end{array}$ & 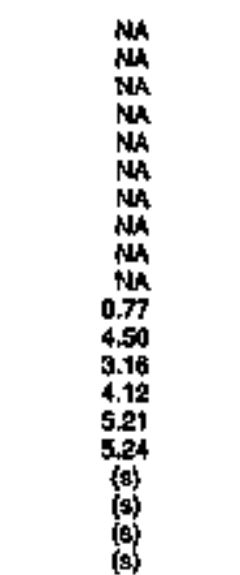 & 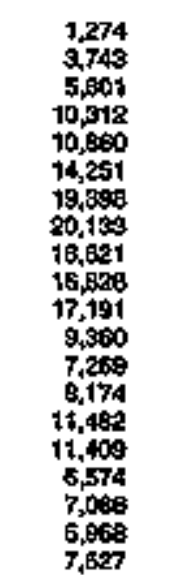 & $\begin{array}{l}\mathrm{NA} \\
\mathrm{NA} \\
\mathrm{NA} \\
\mathrm{MA} \\
396 \\
290 \\
395 \\
196 \\
410 \\
511 \\
621 \\
470 \\
691 \\
814 \\
1,230 \\
1,562 \\
1,543 \\
1,050 \\
20099 \\
1,815\end{array}$ & $\begin{array}{r}\mathrm{NA} \\
\mathrm{NA} \\
\mathrm{NA} \\
\mathrm{NA} \\
840 \\
855 \\
1,115 \\
771 \\
455 \\
159 \\
346 \\
824 \\
162 \\
158 \\
461 \\
245 \\
352 \\
318 \\
411 \\
405\end{array}$ \\
\hline
\end{tabular}

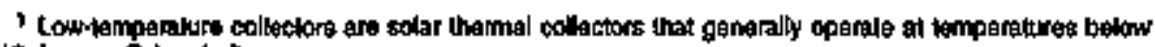

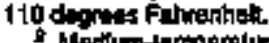

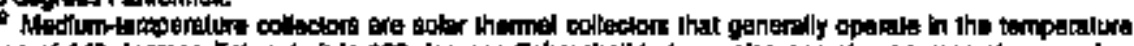

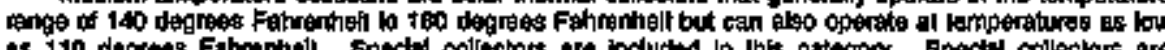

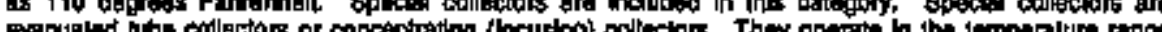

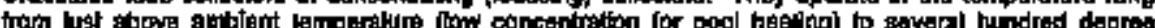

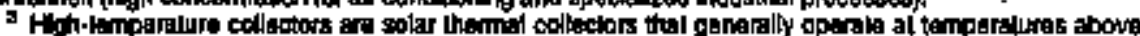
160 dogreos Fathonthelt.

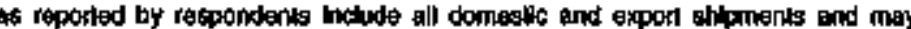

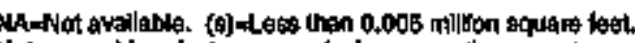

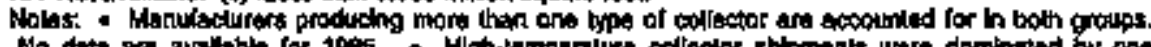
oeliector sh'mants were dominoted by one

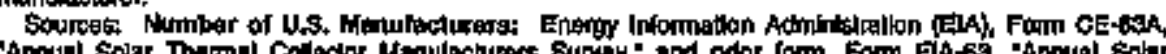

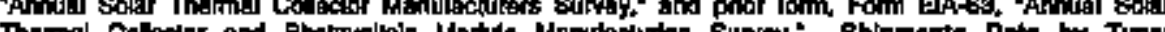
- 1974-1975-Fond Phor - 1977and toto-

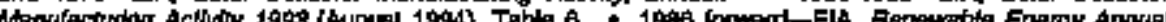
1985 (December 1985), Thabs 12 and t3. 


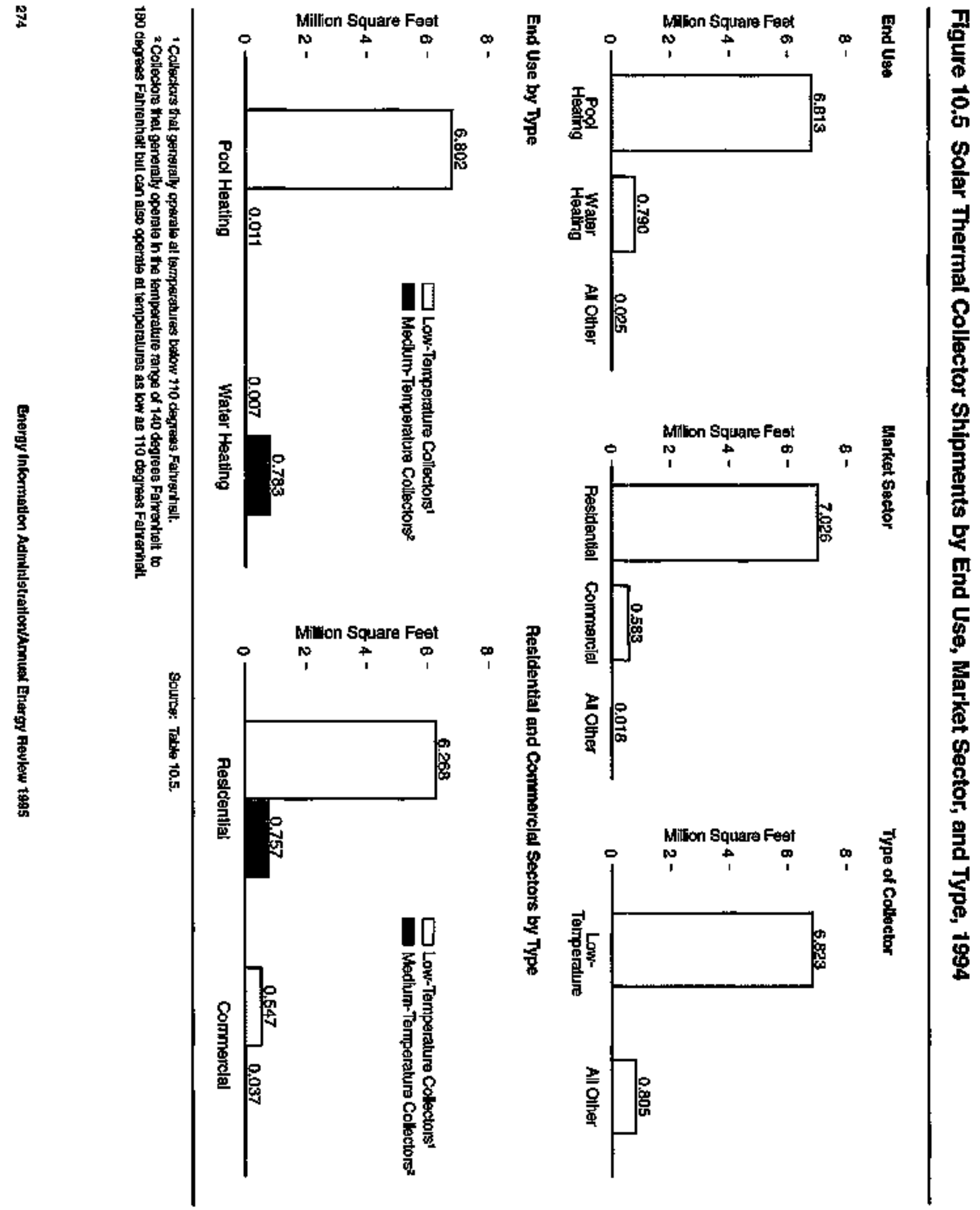


Table 10.5 Solar Thermal Collector Shipments by End Use, Market Sector, and Type, 1994

(Thousand Square Feet)

\begin{tabular}{|c|c|c|c|c|}
\hline End Us: & 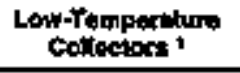 & 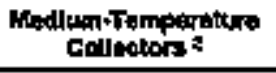 & 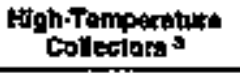 & Totre \\
\hline 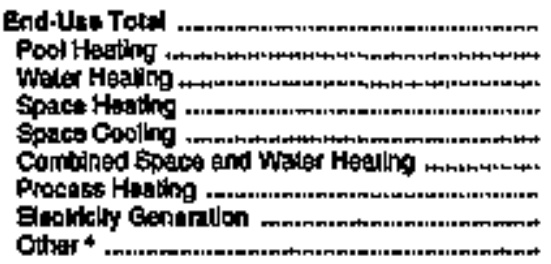 & $\begin{array}{r}6,023 \\
6,802 \\
7 \\
14 \\
0 \\
0 \\
0 \\
0 \\
0\end{array}$ & $\begin{array}{r}603 \\
11 \\
793 \\
5 \\
0 \\
4 \\
0 \\
0 \\
0\end{array}$ & $\begin{array}{l}2 \\
0 \\
0 \\
0 \\
0 \\
0 \\
0 \\
2 \\
0\end{array}$ & $\begin{array}{r}7,697 \\
6,813 \\
790 \\
19 \\
0 \\
4 \\
0 \\
2 \\
0\end{array}$ \\
\hline 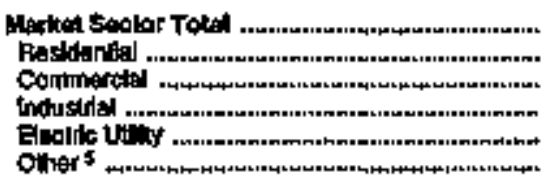 & 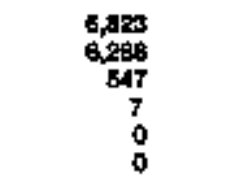 & $\begin{array}{r}\infty 08 \\
757 \\
37 \\
6 \\
1 \\
0\end{array}$ & $\begin{array}{l}2 \\
0 \\
0 \\
1 \\
1 \\
0\end{array}$ & $\begin{array}{r}7,627 \\
7,029 \\
\text { sas } \\
16 \\
2 \\
0\end{array}$ \\
\hline
\end{tabular}

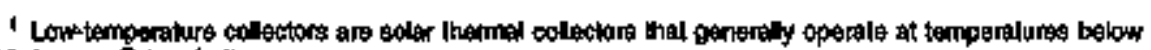

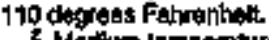

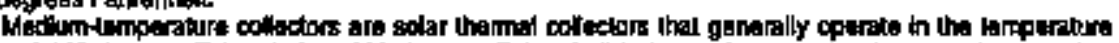

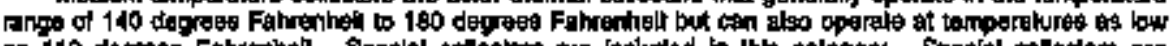

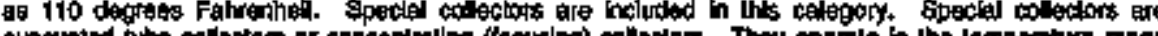

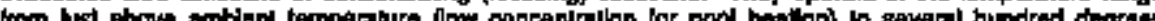

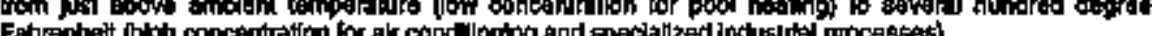

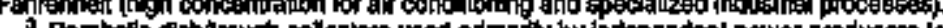

vemperaluras above 180 degrege Fahrenheth.

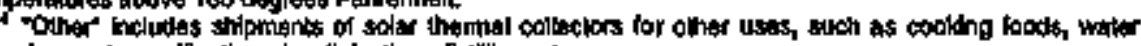

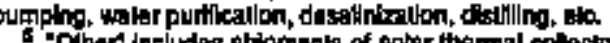

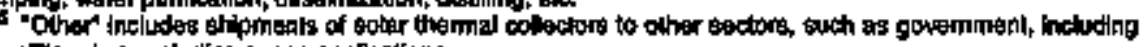

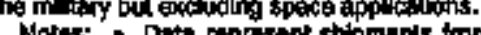

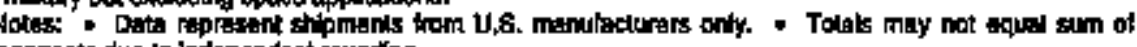
int rounding.

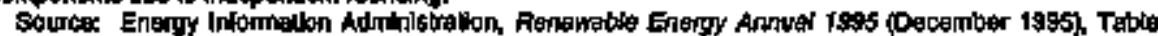


Number of U.S. Companies Peporting Shipments, 1992-1994

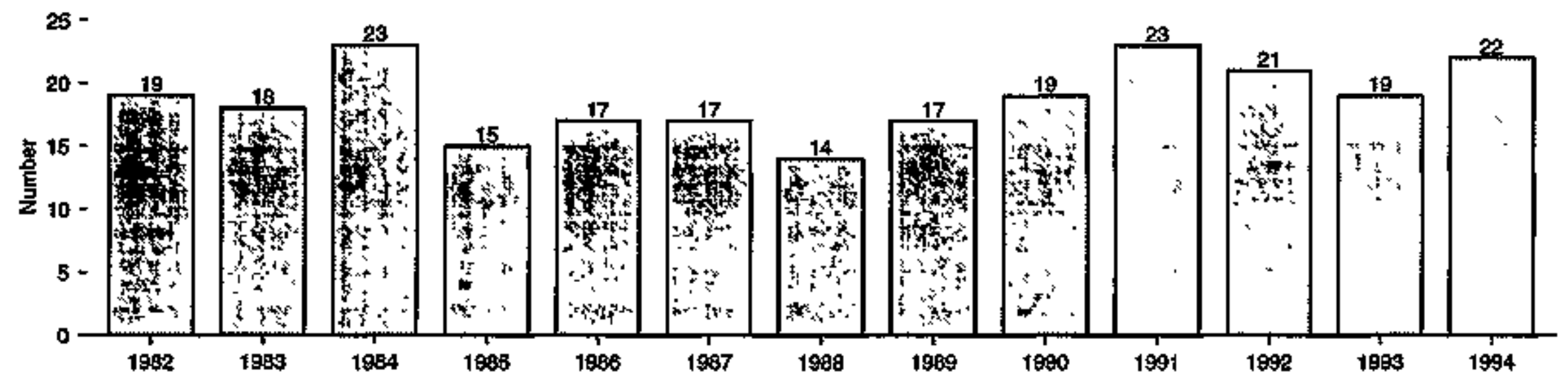

Totel Shipmonts, 1982-1994

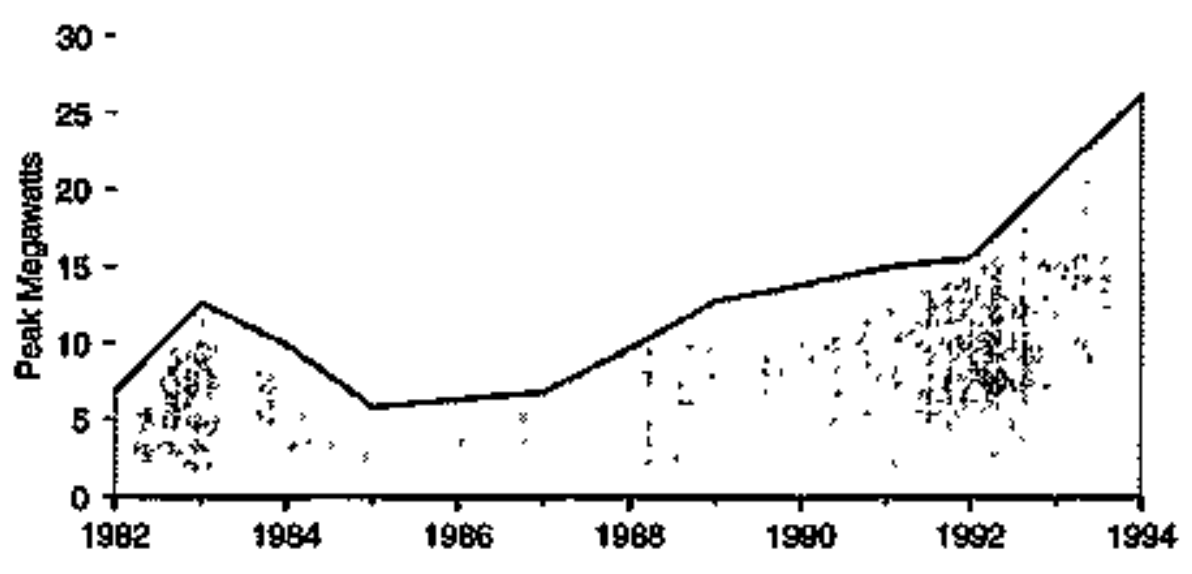

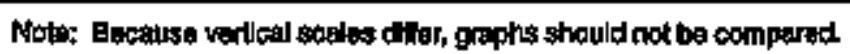

Trade, 1999-1994

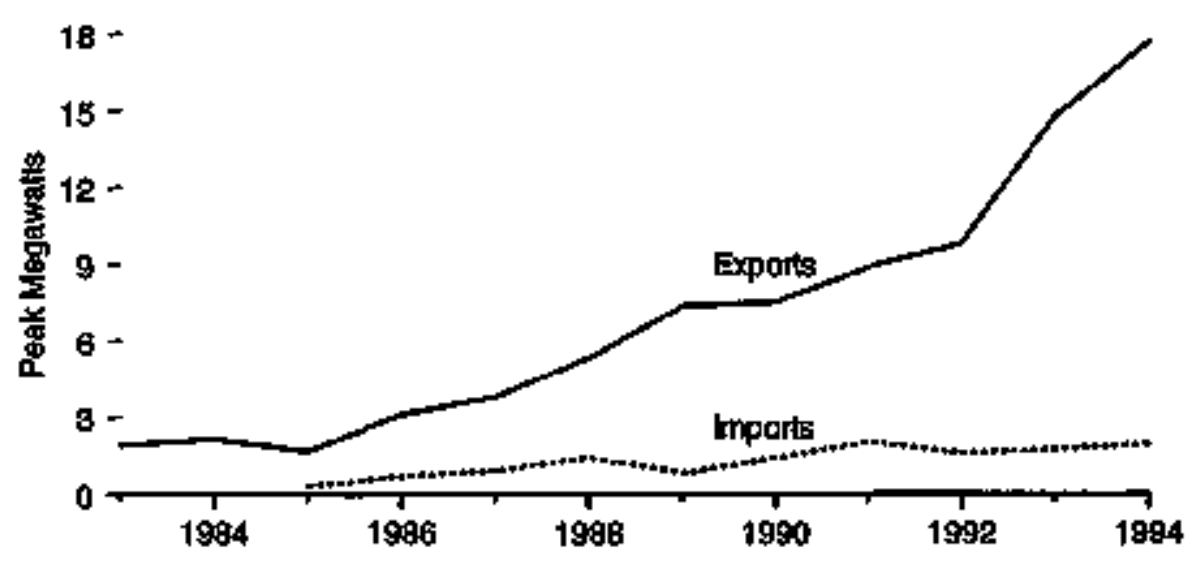

Solureat: Thble 10,6 
Table 10.6 Photovoltaic Cell and Module Shlpments and Trade, 1982-1994

\begin{tabular}{|c|c|c|c|c|}
\hline \multirow[b]{2}{*}{ Yatr } & \multirow{2}{*}{ 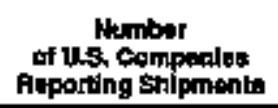 } & Toled shipmente 1 & inport: & Exporty \\
\hline & & \multicolumn{3}{|c|}{ Patk Ktowatis } \\
\hline 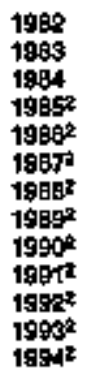 & $\begin{array}{l}19 \\
19 \\
29 \\
16 \\
17 \\
17 \\
14 \\
17 \\
919 \\
23 \\
21 \\
19 \\
22\end{array}$ & 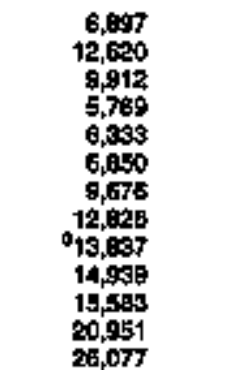 & 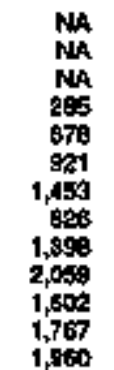 & $\begin{array}{r}\mathrm{NA} \\
1,90 \mathrm{AB} \\
2,158 \\
1,670 \\
3,108 \\
9,691 \\
9,358 \\
7,303 \\
7,544 \\
9,905 \\
9,628 \\
14,014 \\
17,714\end{array}$ \\
\hline
\end{tabular}

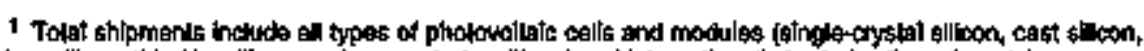

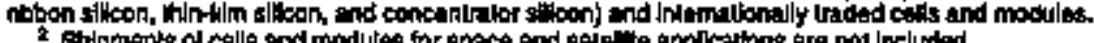

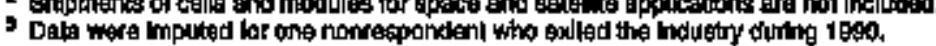

NADAlot entalame.

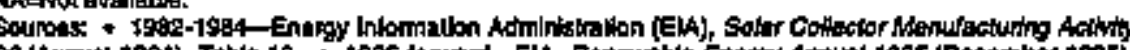

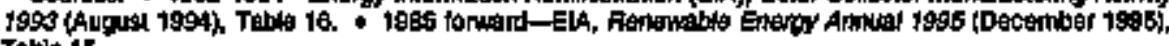
Table 15. 


\section{By End Use}

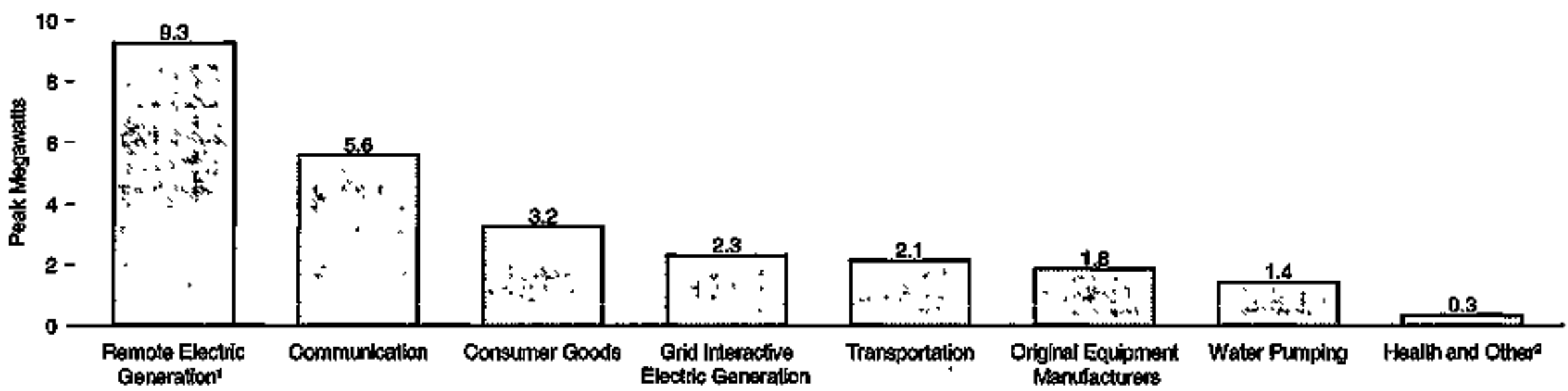

\section{By Market Soctor}

$$
10 \text { - }
$$

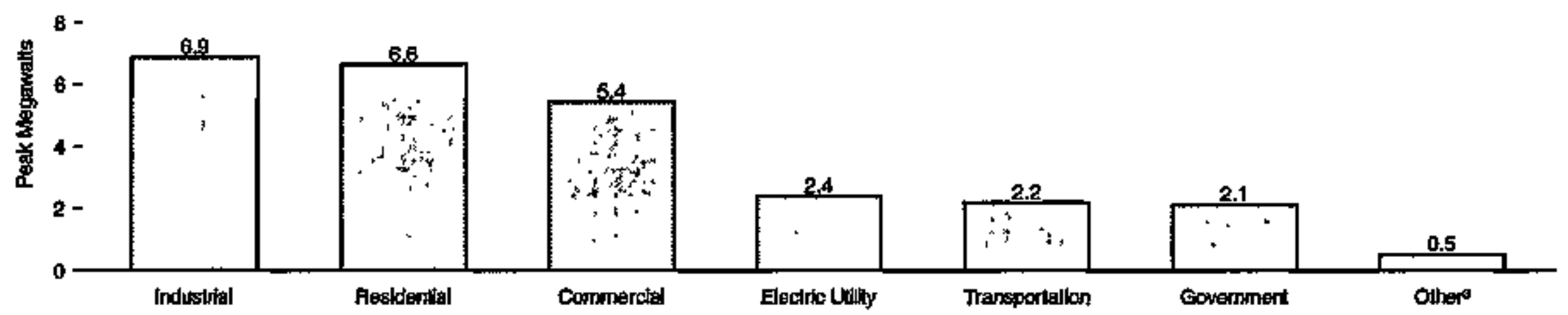

I Units deslgned for hastallations that are not gnternteractive.

'Stipments to lorelgn govermments end for speclaily purposea.

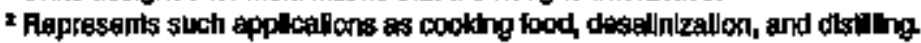
Eounce: Table 10.7. 
Table 10.7 Photovoltalc Cell and Module Shipments by End Use, 1989-1994

\begin{tabular}{|c|c|c|c|c|c|c|c|c|c|c|c|c|}
\hline \multirow[b]{2}{*}{ Ens Use } & \multicolumn{6}{|c|}{$\begin{array}{l}\text { Amount Shtpped } \\
\text { (pentik lallowidts) }\end{array}$} & \multicolumn{6}{|c|}{ Percent of Total } \\
\hline & 1089 & 1090 & 1991 & 1992 & 1993 & 1994 & 1869 & to90 & 1691 & 1092 & 1993 & to94 \\
\hline 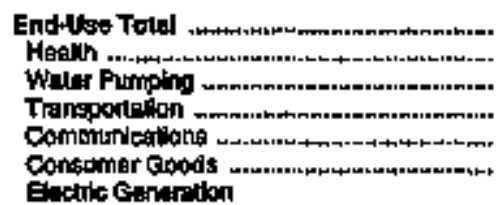 & $\begin{array}{r}12,625 \\
5 \\
711 \\
7,190 \\
2,590 \\
2,789\end{array}$ & $\begin{array}{r}13,097 \\
5 \\
1,014 \\
1,069 \\
4,340 \\
2,454\end{array}$ & $\begin{array}{r}14,999 \\
61 \\
729 \\
1,503 \\
3,558 \\
3,012 \\
0,312\end{array}$ & $\begin{array}{r}15,503 \\
67 \\
609 \\
1,602 \\
3,717 \\
2,565\end{array}$ & $\begin{array}{r}20,951 \\
674 \\
2,294 \\
4,288 \\
3,045 \\
945\end{array}$ & $\begin{array}{r}26,077 \\
79 \\
1,410 \\
2,128 \\
5,570 \\
3,789\end{array}$ & $\begin{array}{r}100.0 \\
(5) \\
5.8 \\
0.3 \\
20.3 \\
21.7\end{array}$ & $\begin{array}{r}100.0 \\
(8) \\
7.3 \\
7.7 \\
31.4 \\
10.4\end{array}$ & $\begin{array}{r}190.0 \\
0.4 \\
4.9 \\
10.2 \\
23.7 \\
28.4\end{array}$ & $\begin{array}{r}100.0 \\
0.4 \\
5.2 \\
10.3 \\
23.9 \\
16.5\end{array}$ & $\begin{array}{r}100.0 \\
8.2 \\
10.5 \\
20.2 \\
18.4 \\
4.5\end{array}$ & $\begin{array}{r}100.0 \\
0.3 \\
5.4 \\
8.2 \\
21.4 \\
12.4\end{array}$ \\
\hline 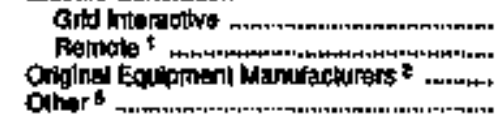 & $\begin{array}{r}1,251 \\
2,680 \\
1,595 \\
69\end{array}$ & $\begin{array}{r}469 \\
3,097 \\
1,119 \\
240\end{array}$ & $\begin{array}{r}656 \\
9,594 \\
1,315 \\
113\end{array}$ & $\begin{array}{r}1,207 \\
4,295 \\
008 \\
630\end{array}$ & $\begin{array}{r}1,096 \\
5,761 \\
2,0083 \\
74\end{array}$ & $\begin{array}{r}2,206 \\
9,253 \\
1,249 \\
254\end{array}$ & $\begin{array}{r}9.8 \\
20.4 \\
12.4 \\
0.5\end{array}$ & $\begin{array}{r}3.4 \\
22.4 \\
0.1 \\
1.7\end{array}$ & $\begin{array}{r}5.7 \\
24.4 \\
8.1 \\
0.1\end{array}$ & $\begin{array}{r}7.9 \\
27.2 \\
5.3 \\
3.4\end{array}$ & $\begin{array}{r}5.2 \\
27.5 \\
9.7 \\
0.4\end{array}$ & $\begin{array}{r}8.8 \\
25,5 \\
7,1 \\
1.0\end{array}$ \\
\hline 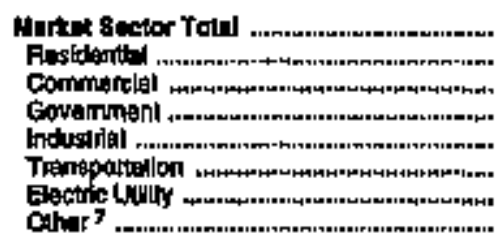 & $\begin{array}{r}12,825 \\
1,439 \\
3,050 \\
1,077 \\
3,993 \\
1,195 \\
785 \\
551\end{array}$ & $\begin{array}{r}13,937 \\
1,701 \\
6,096 \\
1,000 \\
2,817 \\
974 \\
898 \\
192\end{array}$ & $\begin{array}{r}14,939 \\
3,684 \\
9,945 \\
815 \\
3,947 \\
1,555 \\
1,275 \\
377\end{array}$ & $\begin{array}{r}15,593 \\
4,154 \\
2,366 \\
1,083 \\
4,270 \\
1,073 \\
1,353 \\
477\end{array}$ & $\begin{array}{r}20,951 \\
6,237 \\
1,115 \\
1,305 \\
5,350 \\
2,684 \\
1,509 \\
858\end{array}$ & $\begin{array}{r}28,07 \\
5,635 \\
5,429 \\
2.114 \\
8,855 \\
2,174 \\
2.354 \\
510\end{array}$ & $\begin{array}{r}100.0 \\
71.2 \\
39.0 \\
6.4 \\
31.1 \\
0.6 \\
6.1 \\
4.3\end{array}$ & $\begin{array}{r}100,0 \\
12.3 \\
14,0 \\
7.2 \\
20.4 \\
7.0 \\
6,0 \\
3.1\end{array}$ & $\begin{array}{r}100.0 \\
24.3 \\
2.4 \\
5.5 \\
28.4 \\
10.4 \\
8.3 \\
2.5\end{array}$ & $\begin{array}{r}100.0 \\
28.7 \\
15.3 \\
6.8 \\
27.6 \\
10.7 \\
10.0 \\
3.0\end{array}$ & $\begin{array}{r}100.0 \\
25.0 \\
19.6 \\
6.3 \\
25.5 \\
12.2 \\
7.2 \\
4.1\end{array}$ & $\begin{array}{r}100.0 \\
25.4 \\
20.0 \\
8.1 \\
28.2 \\
8.0 \\
8.1 \\
2.0\end{array}$ \\
\hline
\end{tabular}

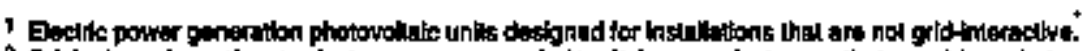

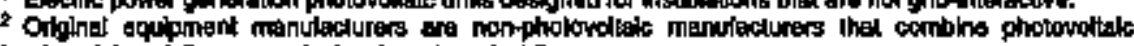

(s)-l.ese than c.0s percent.

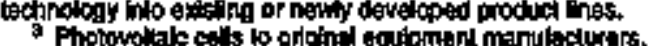

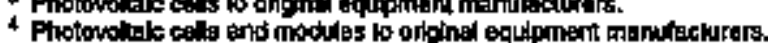

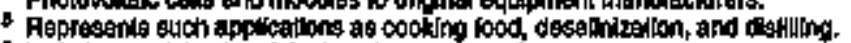

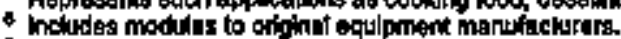

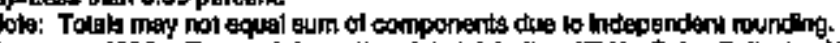

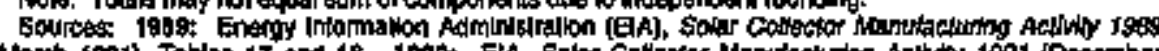

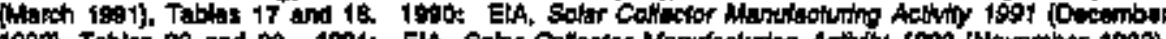

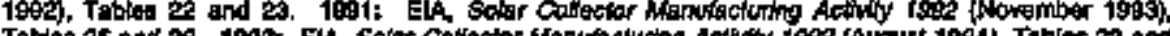

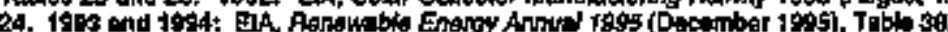

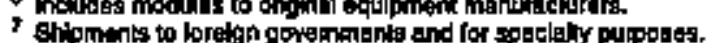




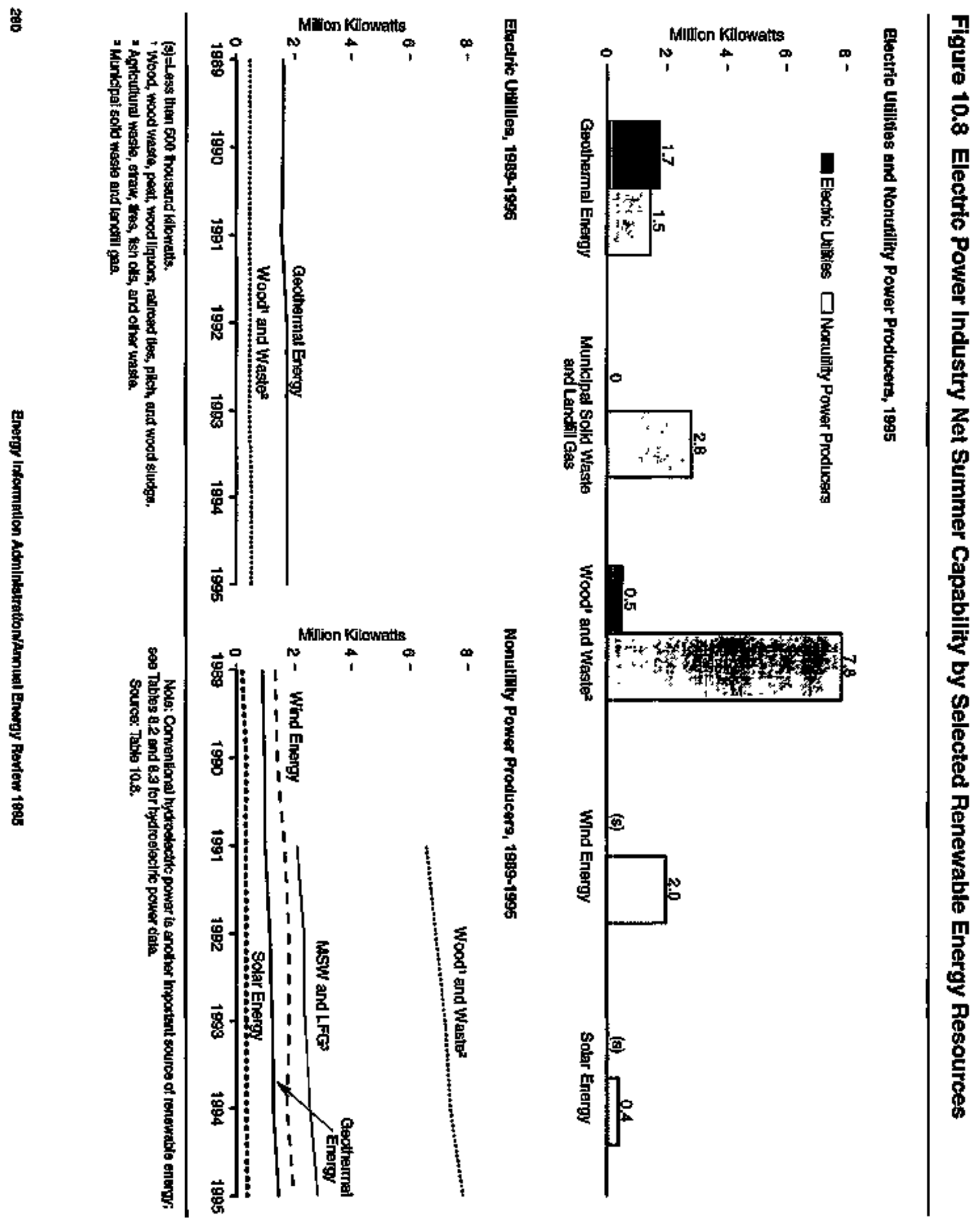


Table 10.8 Electric Power Industry Net Summer Capability by Selected Renewable Energy Resources, 1949-1995 (Thousand Kilowatts)

\begin{tabular}{|c|c|c|c|c|c|c|c|c|c|c|}
\hline \multirow[b]{2}{*}{ Your } & \multicolumn{2}{|c|}{ Comiheratul Enterty } & \multicolumn{2}{|c|}{ 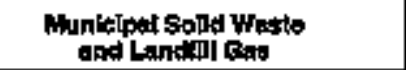 } & \multicolumn{2}{|c|}{ Wood" ind Wasto" } & \multicolumn{2}{|c|}{ Wind Emurgy } & \multicolumn{2}{|c|}{ Folur Energy } \\
\hline & Ofoctive & 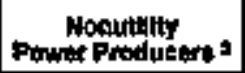 & 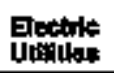 & 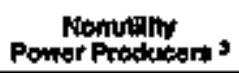 & 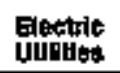 & 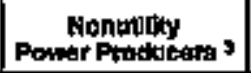 & $\begin{array}{l}\text { Pectite } \\
\text { Uhtilites }\end{array}$ & $\begin{array}{c}\text { Morutisty } \\
\text { Perwef Producers? }\end{array}$ & $\begin{array}{l}\text { Electioce } \\
\text { Ithitas }\end{array}$ & 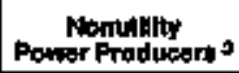 \\
\hline 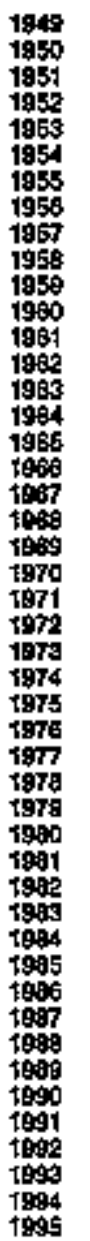 & 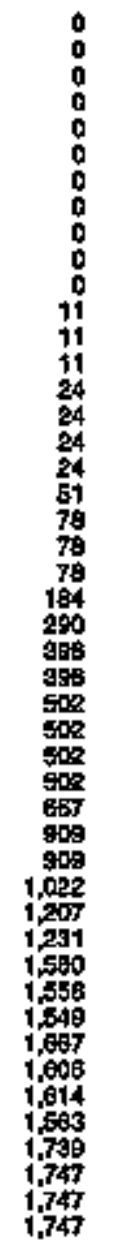 & MA & $\begin{array}{l}0 \\
0 \\
0 \\
0 \\
0 \\
0 \\
0 \\
0 \\
0 \\
0 \\
0 \\
0 \\
0 \\
0 \\
0 \\
0 \\
0 \\
0 \\
0 \\
0 \\
0 \\
0 \\
0 \\
0 \\
0 \\
0 \\
0 \\
0 \\
0 \\
0 \\
0 \\
0 \\
0 \\
0 \\
0 \\
0 \\
0 \\
0 \\
0 \\
0 \\
0 \\
0 \\
0 \\
0 \\
0 \\
0 \\
0\end{array}$ & 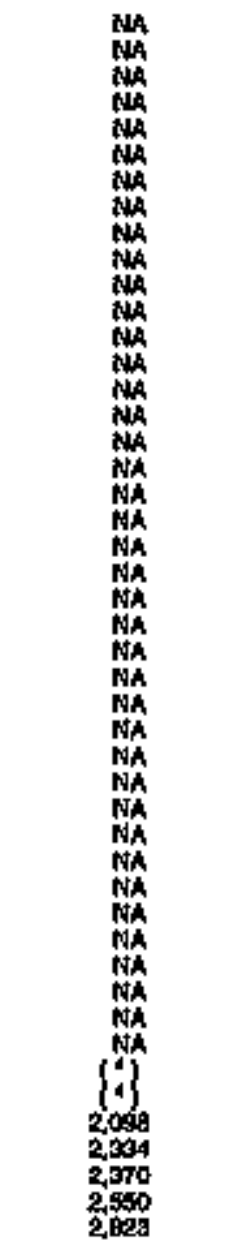 & $\begin{array}{l}13 \\
13 \\
13 \\
37 \\
37 \\
37 \\
37 \\
37 \\
64 \\
64 \\
64 \\
64 \\
64 \\
64 \\
64 \\
64 \\
64 \\
72 \\
72 \\
72 \\
72 \\
72 \\
72 \\
77 \\
77 \\
77 \\
77 \\
77 \\
77 \\
77 \\
73 \\
73\end{array}$ & 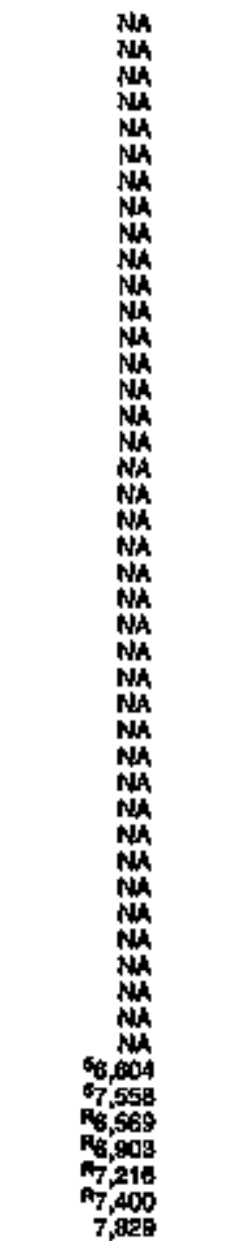 & 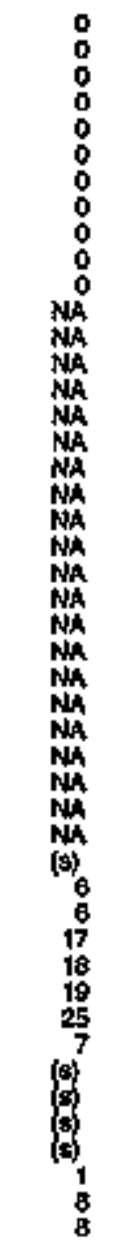 & 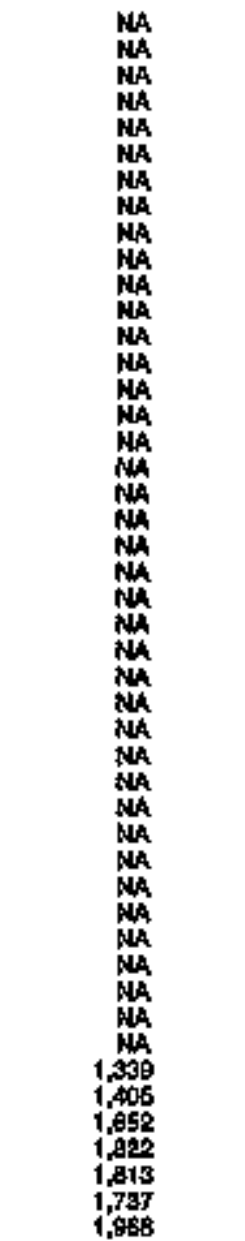 & $\begin{array}{l}0 \\
0 \\
0 \\
0 \\
0 \\
0 \\
0 \\
0 \\
0 \\
0 \\
0 \\
0 \\
0 \\
0 \\
0 \\
0 \\
0 \\
0 \\
0 \\
0 \\
0 \\
0 \\
0 \\
0 \\
0 \\
0 \\
0 \\
0 \\
0 \\
0 \\
0 \\
0 \\
0 \\
0 \\
0 \\
0 \\
0 \\
0 \\
0 \\
0 \\
0 \\
3 \\
3 \\
3 \\
4 \\
4 \\
4\end{array}$ & 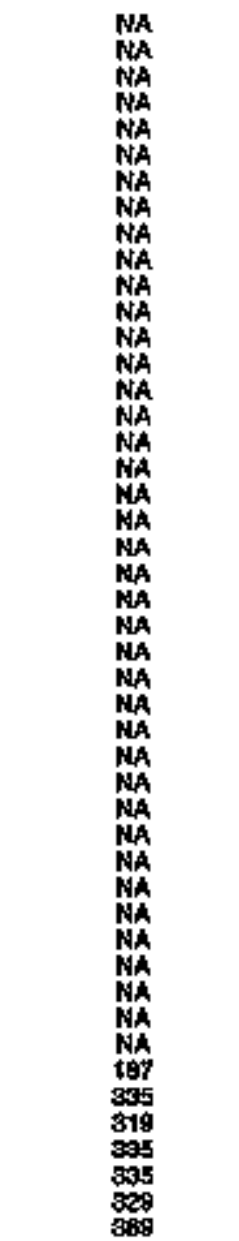 \\
\hline
\end{tabular}

I Wood, wood waste, peet, wood Bquors, rall rosad Wes, phth, and mood studpo.

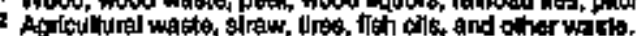

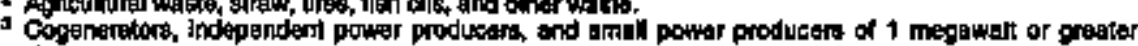

equeclatided in wood and wagta."

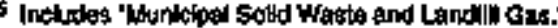

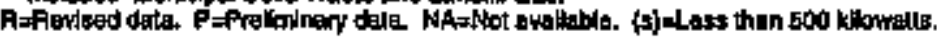

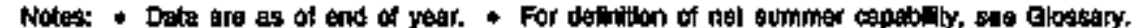

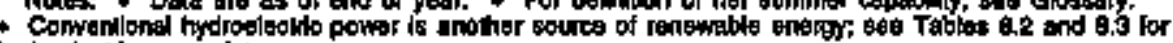

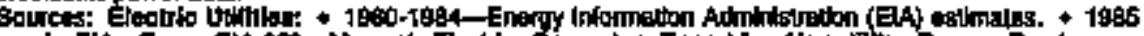

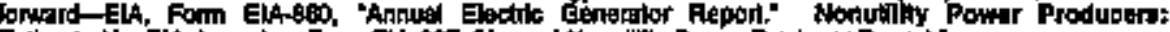

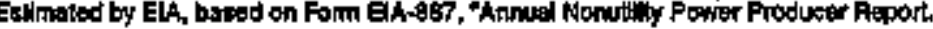


Electric Utibties and Monulitity Power Producers, 1995

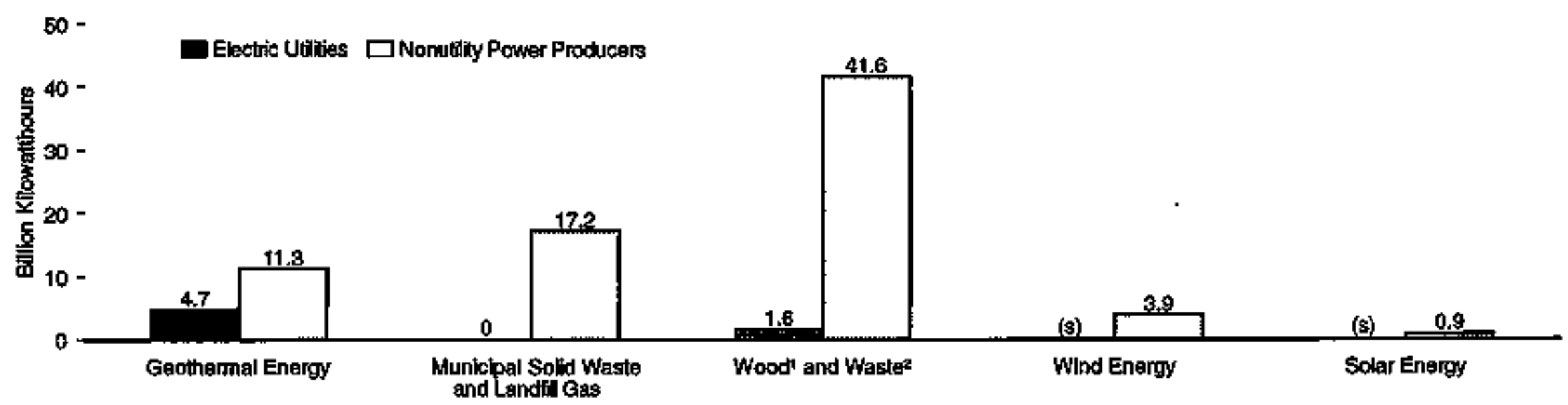

\section{Eleotric Utioties, 1999-1995}

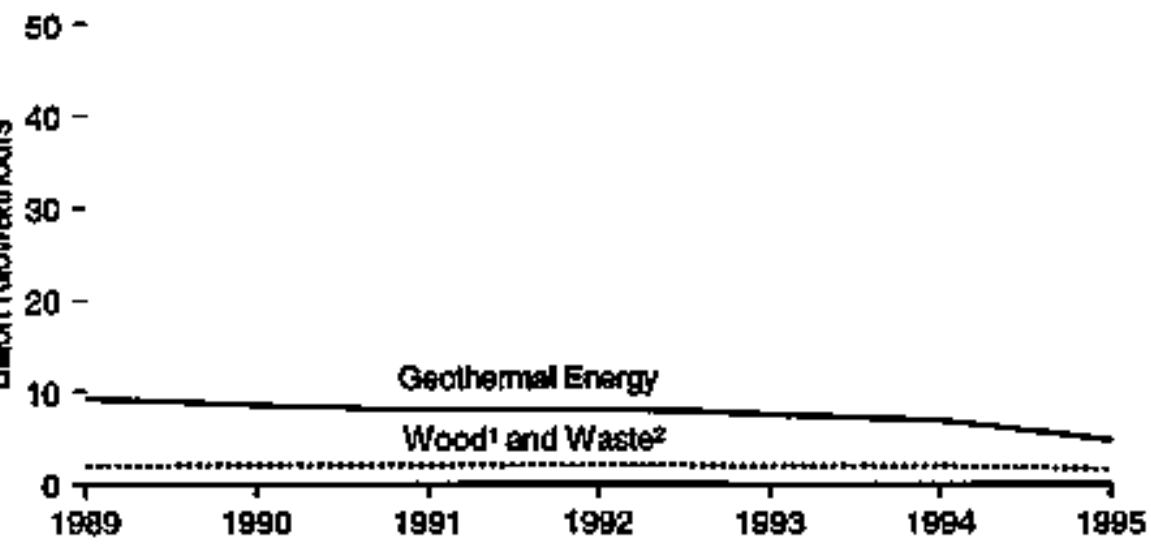

(8) =Less than $600 \mathrm{mil}$ lon klowathours.

1 Wopd, wood wasts, pasi, wood liquors, falliroed lies, phich, and wood alludge.

2 Agricultural waste, straw, ties, itsh olls, and other wasle.

$\checkmark$ Murdelpel solid wasie and tenditi gas.
Nonutiltiy Power Preducers, 1989-1995

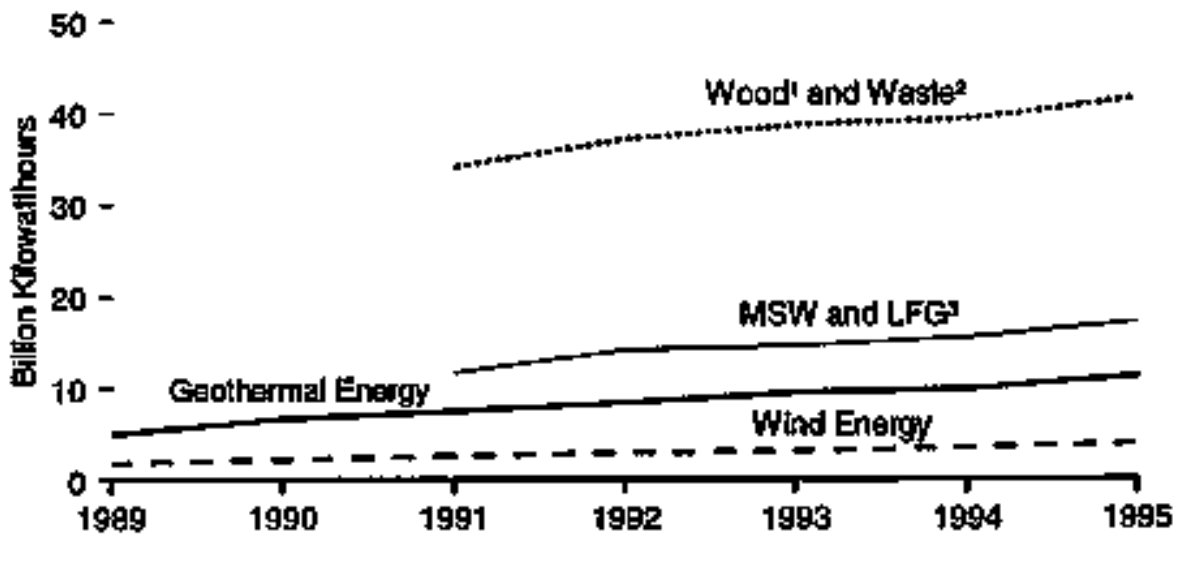

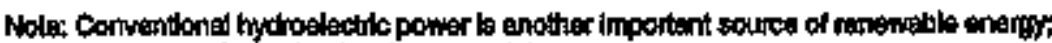

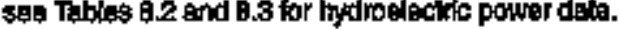

Solnot Toble 10.8. 
Table 10.9 Electric Power Industry Net Generation by Selected Renewable Energy Resources, 1949-1995 (Million Killowatthours)

\begin{tabular}{|c|c|c|c|c|c|c|c|c|c|c|}
\hline \multirow[b]{2}{*}{ Year } & \multicolumn{2}{|c|}{ Goothatmal Energy } & \multicolumn{2}{|c|}{ 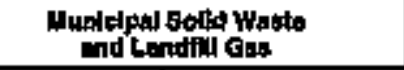 } & \multicolumn{2}{|c|}{ Wood' and Wortote } & \multicolumn{2}{|c|}{ Whot Enorgy } & \multicolumn{2}{|c|}{ Solur Enorgy } \\
\hline & $\begin{array}{l}\text { Elostitc } \\
\text { Thalition }\end{array}$ & $\begin{array}{l}\text { Nonktithy } \\
\text { Power Prothecers, }\end{array}$ & $\begin{array}{l}\text { Elactith } \\
\text { vollutes }\end{array}$ & $\begin{array}{l}\text { Montulinly } \\
\text { Power Producers, }\end{array}$ & $\begin{array}{l}\text { Elontite } \\
\text { Lididas. }\end{array}$ & 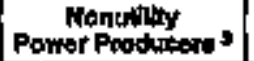 & 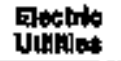 & 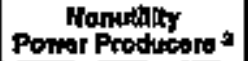 & $\begin{array}{l}\text { Elotinte } \\
\text { Udpites }\end{array}$ & $\begin{array}{c}\text { Nontutinty } \\
\text { Pomiar Produstre }\end{array}$ \\
\hline
\end{tabular}

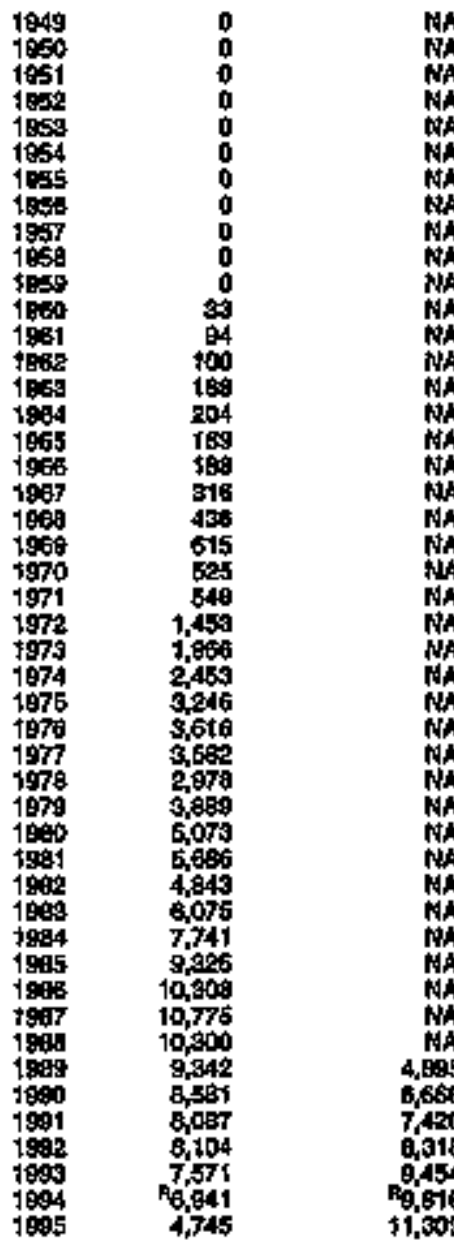

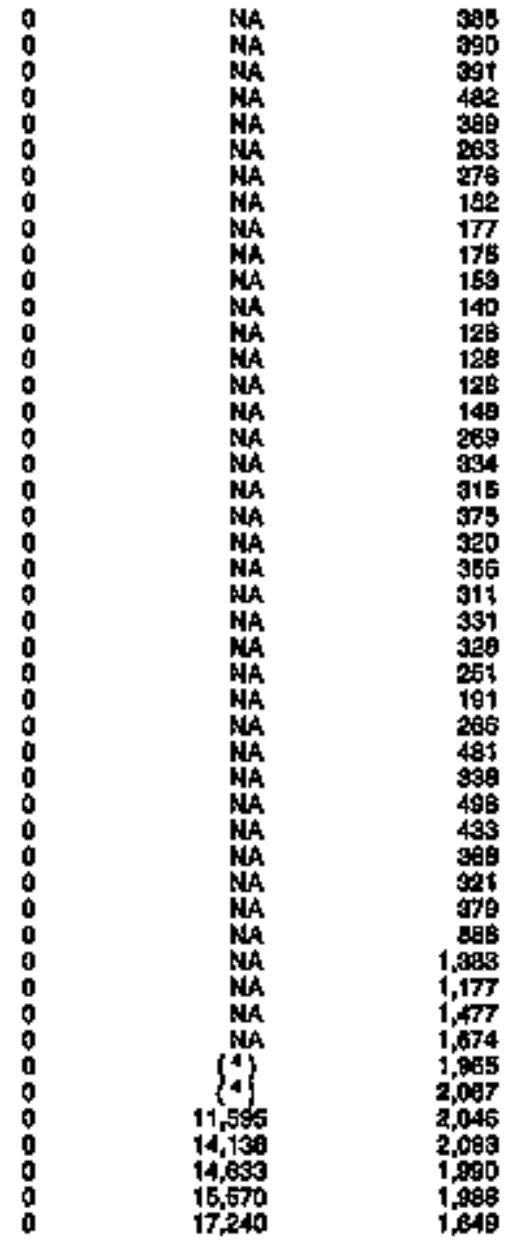

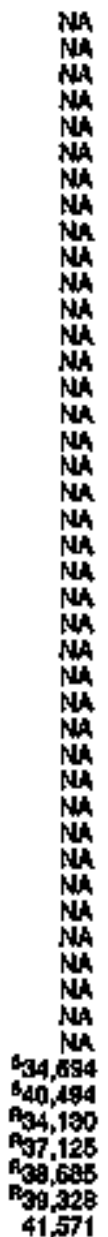

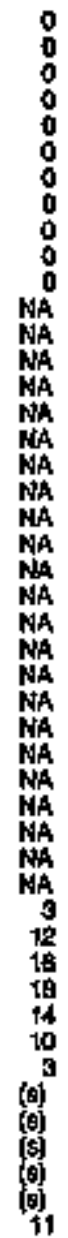

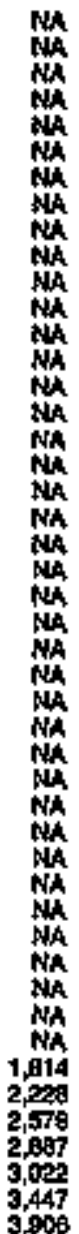

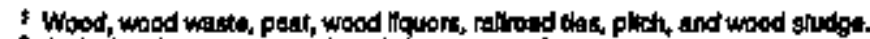

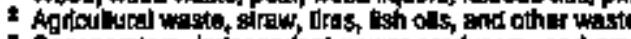

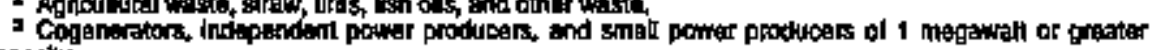
capacty.

4 Inctuded in "Wood and Warte"

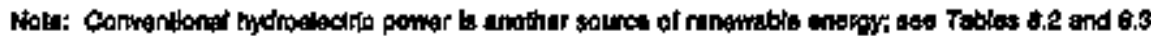

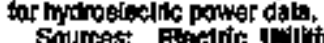

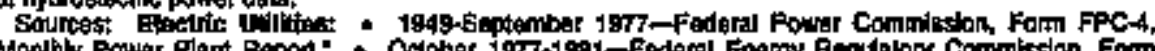

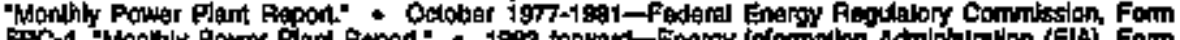

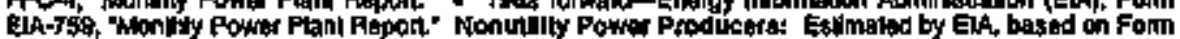

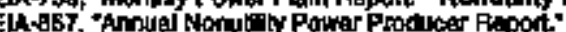


\begin{tabular}{|} 
\\
\\
\\
\\
\\
\\
\\
\\
\end{tabular} 


\section{International Energy}

\section{World Leaders in Energy Production}

Worldwide energy production of 355 guadrillion Btu in 1994 was 51 quadrillion Btu greater than in 1985 (11.1).* The relative contributions of the four leading energy producers changed markedly over the 10-year period.

In 1985, the United States was the leading producer of energy and U.S. production of 65 quadrilfion Btu accounted for 21.3 percent of the wortd total. The former U.S.S.R., the second leading producer, accounted for 63 quadrillion Btn, a 20.7 percent share. In 1986, the former U.S.S.R.'s production surpassed U.S. production for the first time and remained higher than U.S. production through 1989. In 1990, however, former U.S.S.R. production of 69 quadrillion Btu was lower than U.S. production of 71 quadrillion Bto.

As of December 31, 1991, the U.S.S.R. ceased to exist as a political entity. Three of the U.S.S.R.'s constituent republics (Russia, Ukraine, and Kazakstan) together produced 47 quadrillion Btu of energy in 1994. That year the United States produced 71 quadrillion But.

Energy production in Ching, the third largest producer of energy in 1985, increased throughout the 10-year pertod. In 1985, China produced 24 quadrillion Btu of energy, much of which was coal. By 1994, Chinese production had reached 34 quadrillion Btu.

At 8.6 quadrillion Btu, Saudj Arabia was the sixth largest producer of energy in 1985. That year marked a low point in Saudi Arabian production, brought on by a cutback in petroleum production intended to allow Saudt Arabia to regain control of world oil markets. During the remainder of the 10-yeat period, however, Sandi Arabiant energy prom duction exhibited the greatest growth, in absolute terms. By 1994, it had risen to 20 quadrillion Btu, making Saudi Arabia the fourth largest producer of energy.

"Numbers in parenilheses indicate related labjes. Annual data are the most necent avalable; they frequently are prellminany and may be rewised in future publteations. Percentages and numbers in text are calculaled by using data in the tables.

\section{Crude Oil Production in 1995}

World production of crude oil totaled 62.23 million battels per day in 1995, up 2.2 percent from the 1994 level (11.5). The most noticeable production increases occurred in Venezvela and the United Kingdon. Small production declines occurred in the United States, where production fell from 6.66 milion bartels per day in 1994 to 6.53 million barrels per day in 1995, and in Mexico, where production declined from 2.69 mitlion barrels per day to 2.62 million barrels per day. In Saudi Arabia, the largest producer of crude oil in 1995, production rose slightly to 8.23 million bartels per day. Crude oil production by all members of the Organization of Petroleum Exporting Countries combined rose to 26.48 million barrels per day and accounted for 43 percent of the world total in 1995.

\section{Natural Gas Production in 1994}

World production of dry natural gas totaled 77 trillion cubic feet (11.11) and, on a Btu basis, equaled 22 percent of world energy production in 1994 (11.2). Natural gas production in 1994 was 1.1 percent above the 1993 level (11.11). Russia was the major producer of natural gas in 1994 and accounted for 21 tillion cubic feet, a 28-percent share of the world total. The United States was the second largest producer and accounted for 19 trillion cubic feet, a 24-percent share.

\section{Coal Production in 1994}

World production of coal totaled 5.0 billion short tons (11.15) and, on a Btu basis, equaled 25 percent of world onergy production in 1994 (11.2). That level of coal production was 1.8 percent above the 1993 level (11.15). China, the leading producer, accounted for 1.4 billion short tons in 1994. Coal production in the United States, the second leading producer, tataled 1.0 billion short tons, a record level. Germany and India each accounted for 295 million short tons, and Russia accounted for 294 million short tons. 


\section{Installed Capacity and Electricity Generation}

As of January 1, 1994, world electricity installed capacity at all sites (including nonutility power producers) totaled 2.8 billion kilowatts (11.18). Most of the capacity (66 percent) was fossil fuel-fired. Hydroelectric generating capacity accounted for 21 percent and nuclear electric generating capacity accounted for 12 percent. Renewable sources, such as biofuels and geothermal, solar, and wind energy, accounted for less than 1 percent of the world total.

In real terms, the 1994 average price of onde oil was the second lowest in 21 years.

World fossil fuel-fired net generation totaled 7.6 trillion kilowatthours in 1993 (11.17). The United States, with 2.4 trillion kilowatthours, was by far the largest producer of fossil fuel-fired net generation. China's net generation totaled 645 billion kilowathours and Russia's totaled 623 billion kilowatthours. World hydruelectric power net generation in 1994 totaled 2.3 trillion kilowatthours, down slightly from the 1993 level (11.19). Canada, the United States, Brazil, Russia, and China were the world leaders in hydroelectric power net generation and together accounted for 50 percent of the world total. In 1995, nuclear-based electricity gross generation totaled 2.3 trillion kilowatthours $(11.20)$. The U.S. share of the world total was 31 percent. France accounted for 17 percent and Japan for 13 percent of the world total.

\section{Fluctuations in Petroleum Prices and Demand}

In 1973, the expanding post-World War II petroleum market reached 57 million barrels per day $(11,9)$. At that point, oil-producing nations became able, for the first time, to exploit the relative inelasticity of petroleura demand in the short term by raising prices substantially. In response, petroleum consumption dipped for 2 years before resuming its climb to 65 million barrels per day in 1979.

A steep price hike in 1979 and 1980, combined with the longer-term effects of fuel switching and increased efficiency, began to curb consumption, even as the higher prices stimulated new sources of production. World petroleum consumption had fallen to 59 million barrels per day in 1983 when lowered demand and excess production began to erote the price of oil (11.9). In 1986, the price of crude oil plonged 46 percent to $\$ 14.55$ per barrel $(5.19)$. Prices stayed low in the second half of the 1980's and petroleum consumption reached 66 million barrels per day, a record level at the time, in 1989.

Following Iraq's invasion of Knwait in August 1990, the average price of crude oll rose to $\$ 22.22$ per barrel, the highest in 5 years (5.19), and year-to-year growth in world petroleum consumption of only 0.2 percent was the lowest in those years (11.9). In 1991, following the resolntion of the war in the Persian Gulf, the average price of crude oil fell to $\$ 19.06$ per barrel. World consumption of petroleum rose 0.8 percent to 67 million barrels per day. In 1992 through 1994, the average price of crude oil fell further, reaching $\$ 15.59$ per barrel. In rea! terms, the 1994 price was the lowest in 21 years. Reflecting the price decline, world consumption of petroleum rose to 68 million barrels per day.

From 1960 through 1994, the United States consumed more petroleum by far than any other country (11.9). In 1994, U.S. consumption accounted for $\mathbf{4 2}$ percent of the $\mathbf{4 2}$ million barrels per day consumed by the Organization for Economic Cooperation and Development (OECD) countries. Japan consumed 5.7 million barrels per day. Of the non-OECD countries, Russia and China were the biggest consumers, accounting for 3.3 million barrels per day and 3.2 mitlion barrels per day, respectively.

\section{Petroleum Stocks in OECD Countrles}

Following ithe oll supply discuptions in the mld-1970's, petroteum stooks held by members of the Organization for Economic Cooperation and Development (OECD) trended upward (11.10). If 1973, OECD petrobeum stecks todated 2,6 bllion barrets. Al the end of 1994, slocks were 3.7 billion barrels. Throughout the 22-year period, the United Stales held the largest shire of total OECD stocks. U.S. petroleum stocks in 1973 totaled 1.0 bilion bafrets, a 39-percent share. In 1994, U.S. petroteum stacks of 1,7 ballion bents equaled a 44-percenh ghare. Jepen more then doubled its petroleum atocks over the semne perlod, from 300 million barrels in 1979 to 645 m'llion barrets in 1994. 


\section{Dry Natural Gas Consumption in 1994}

Although naturaf gas can be transported across borders in pipelines and some natural gas is shipped as liguefied natural gas, in general, natural gas tends to be consumed closer to its site of production than does petroleum. Not surptisingly, the two top producers of dry natural gas in 1994 were aiso the top consumers (11.11 and 11.13). U.S. consumption of dry natural gas totaled 21 trillion cubic feet, equal to 111 percent of its production. Russia consumed 15 trillion cubic feet, an amount equal to 70 percent of its production of dry natural gas. Ukraine, the third largest consumer of natural gas, consumed 3.1 trilliton cubic feet and Germany consumed 3.0 trillion cubic feet.

\section{Coal Consumption in 1994}

World coal consumption in 1994 totaled 5.0 billion short tons, up slightly from the level of consumption in 1993 (11.16). China, the United States, and Germany, three of the world's leading producers of coa! (11.15), were the leading consumers. China consumed 1.4 billion short tons, the United States consumed 930 mitlion short tons, and Germany consumed 316 million short tons of coal in 1994.

\section{Energy Reserves}

As of January 1,1995 , world crude oil reserves were estimated to equal about 999 billion barrels (11.3).' Almost two-thirds of the reserves

tolt and Gas Jownal dats. were located in the Middle East, especially in Saudi Arabia, where about 40 percent of the region's reserves were estimated to be. Iraq, the United Arab Emirates, Kuwait, and Iran each were estimated to have more crude otl reserves than entire regions in the rest of the world. Outside of the Middle East, three countries were estimated to have very large reserves: the former U.S.S.R., 57 billion barrels; Venezuela, 65 billion barrels; and Mexico, 51 billion barrels. The United States, at 23 billion barrels, ranked eleventh in the world in amount of crude oil reserves.

The distribution of the world's 5.0 quadrillion cubic feet of natural gas reserves was different from the distribution of crude oil reserves (11.3). Former U.S.S.R. reserves of 2.0 quadrillion cubic feet made the Eastern Europe and former U.S.S.R, region first in the world in amount of natural gas reserves. The Middle East was estimated to have reserves of 1.6 quadrillion cubic feet, primarily in Iran, as well as in Qatar, the United Arab Emirates, Saudi Arabia, and Irag. The United States, at 164 trillion cubic feet, ranked sixth in the world in amount of natural gas reserves.

As of the end of 1993, recoverable reserves of coal were estiniated to be 1.1 trillion short tons (11.14), ${ }^{2}$ The three countries with the most plentiful coal reserves were the United States, with 268 billion short tons ${ }^{3}$; the former U.S.S.R., with 265 billion short tons; and China, with 126 billion short tons.

2Word Energy Councll dola, with the exceplton or U.S. data, which are extimated by we Energy Information Admiaistration. Doxa for the former U.S.S.R. and Chine are as of December 31, 1993, the mast recent poriod for which tboy are avoiluble.

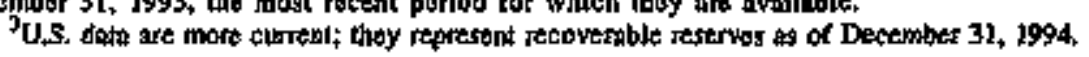




\section{Figure 11.1 World Primary Energy Production}

\section{World and Leading Producers, 1985-1894}

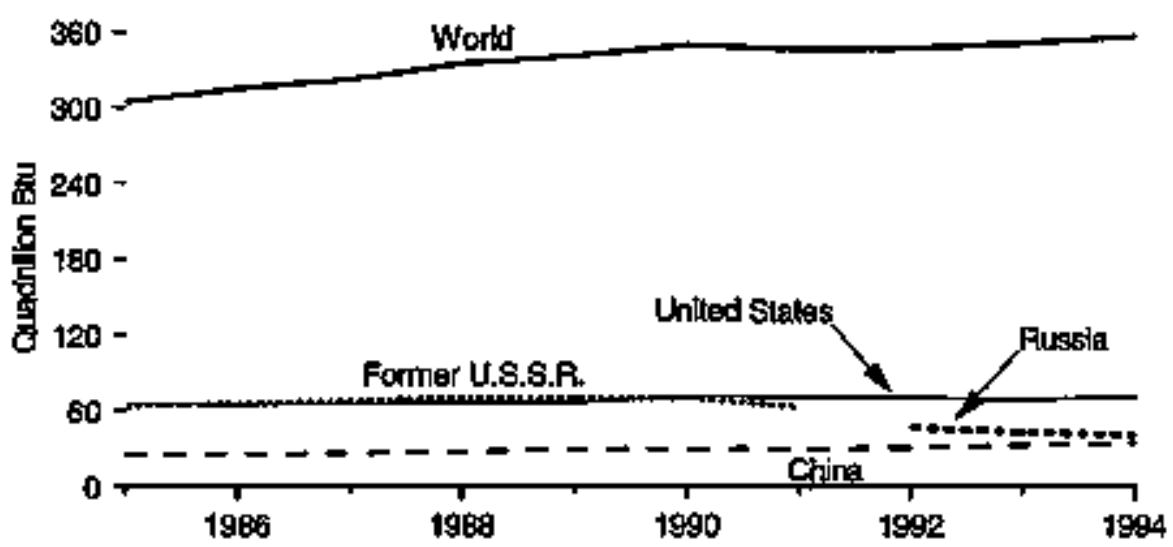

\section{Wotd Areas, 1985-1994}

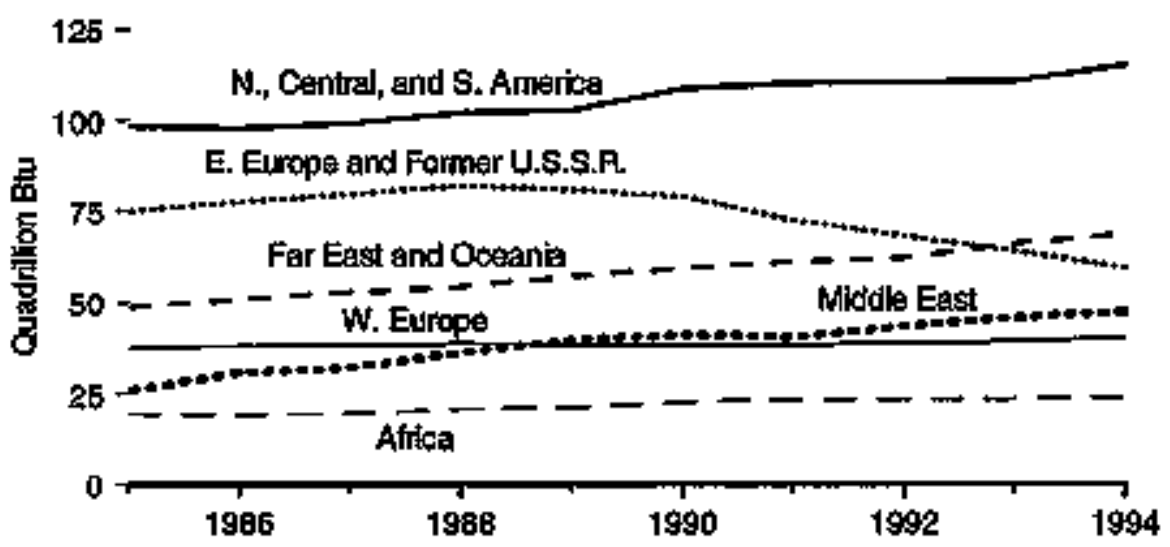

Top Producing Countries, 1994

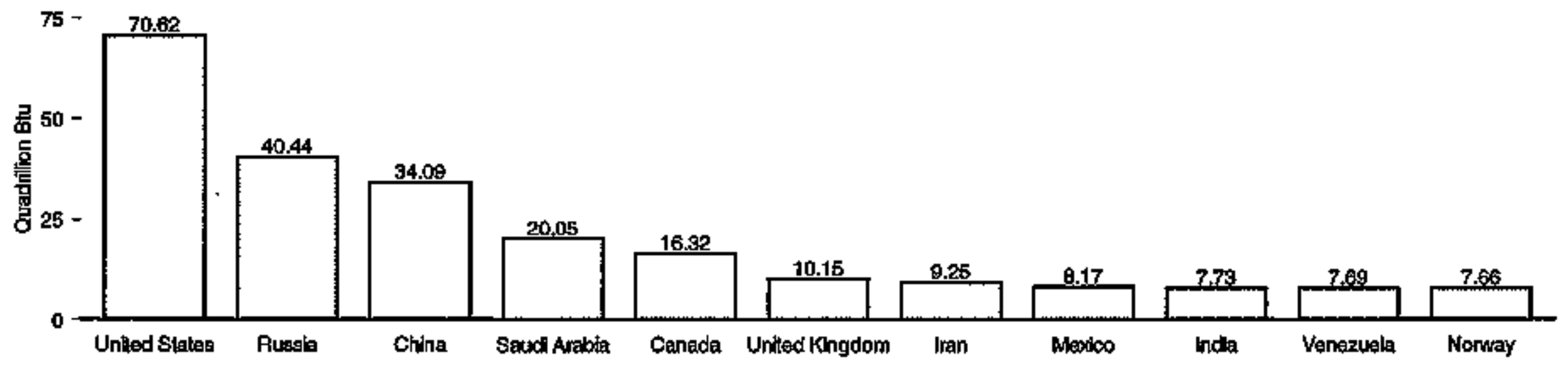


Table 11.1 World Prtmary Energy Production, 1985-1994

(Quedrillion B(u)

\begin{tabular}{|c|c|c|c|c|c|c|c|c|c|c|}
\hline Foglan and cauntry & 1965 & 1966 & 1067 & 1989 & 19909 & 1090 & 1994 & 1598 & 1998 & $1094^{\circ}$ \\
\hline 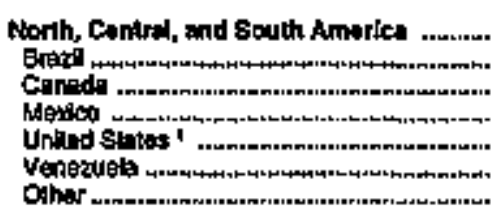 & 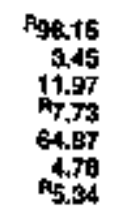 & 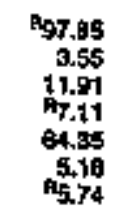 & 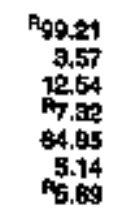 & $\begin{array}{r}A_{102.16} \\
3.67 \\
13.41 \\
7.97 \\
76.10 \\
5.55 \\
6.05\end{array}$ & 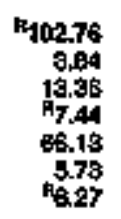 & 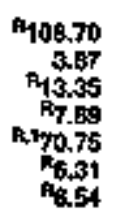 & 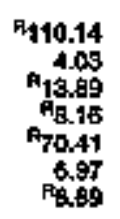 & 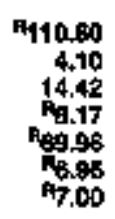 & 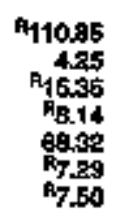 & $\begin{array}{r}116.13 \\
4.40 \\
16.32 \\
8.17 \\
70.62 \\
7.65 \\
7.92\end{array}$ \\
\hline 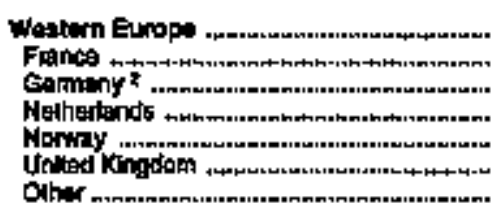 & 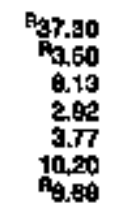 & 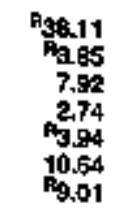 & 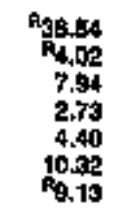 & 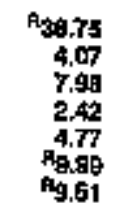 & 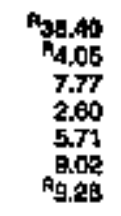 & 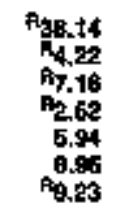 & 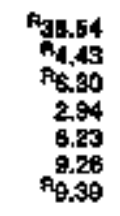 & 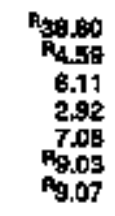 & 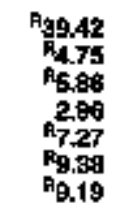 & $\begin{array}{r}\$ 0.27 \\
4.76 \\
6.69 \\
2.90 \\
7.98 \\
10.15 \\
9.22\end{array}$ \\
\hline 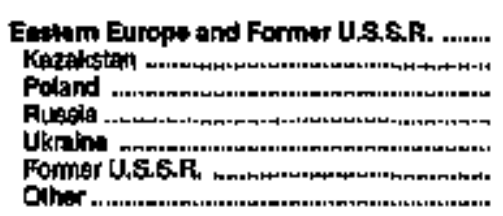 & 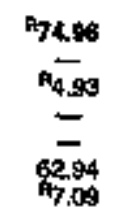 & 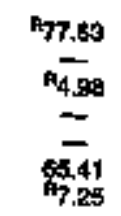 & 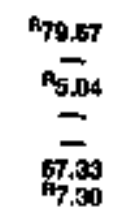 & 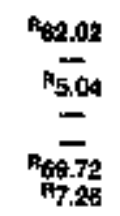 & 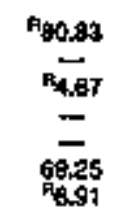 & $\frac{n_{3.09}}{\bar{n}}$ & 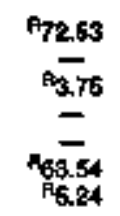 & 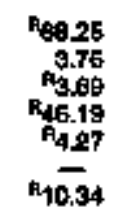 & $\begin{array}{l}R_{04.16} \\
R_{3.43} \\
R_{3.71} \\
R_{12.59} \\
R_{4.12} \\
R_{10.30}\end{array}$ & $\begin{array}{r}59.67 \\
2.57 \\
3.78 \\
40.44 \\
3.64 \\
\frac{9.27}{9.27}\end{array}$ \\
\hline 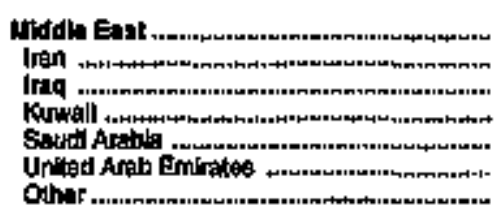 & $\begin{array}{r}23.77 \\
5.59 \\
3.09 \\
2.44 \\
1.34 \\
3.29 \\
2.72\end{array}$ & $\begin{array}{r}30.75 \\
\$ .06 \\
3.65 \\
3.39 \\
12.04 \\
3.99 \\
2.95\end{array}$ & $\begin{array}{r}32.21 \\
5.67 \\
4.69 \\
3.77 \\
10.74 \\
4.21 \\
3.14\end{array}$ & $\begin{array}{r}3.12 \\
5.71 \\
5.97 \\
3.68 \\
H_{12.85} \\
4.22 \\
3.74\end{array}$ & $\begin{array}{r}3.72 \\
7.02 \\
6.47 \\
4.32 \\
12.87 \\
4.98 \\
k .12\end{array}$ & 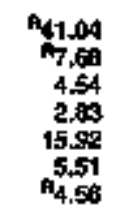 & 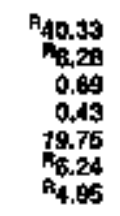 & 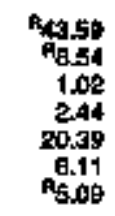 & 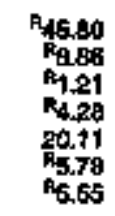 & $\begin{array}{r}47.39 \\
8.25 \\
1.33 \\
4.75 \\
20.05 \\
6.09 \\
6.97\end{array}$ \\
\hline 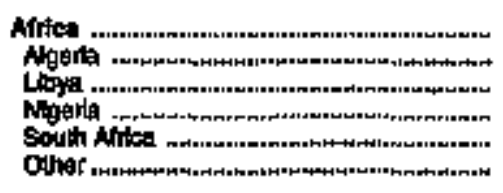 & $\begin{array}{r}19.27 \\
3.77 \\
2.46 \\
3.30 \\
5.01 \\
4.69\end{array}$ & 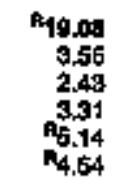 & $\begin{array}{r}19.45 \\
4.01 \\
2.29 \\
3.06 \\
8.11 \\
4.99\end{array}$ & $\begin{array}{r}40.57 \\
4.07 \\
273 \\
3.39 \\
P_{0.91} .31 \\
5.16\end{array}$ & $\begin{array}{r}r_{21.41} \\
4.29 \\
2.70 \\
3.89 \\
n_{5.17} \\
\text { Fi.37 }\end{array}$ & 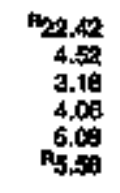 & 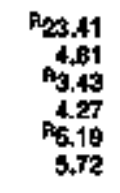 & $\begin{array}{r}4.50 \\
4.92 \\
3.34 \\
4.40 \\
9_{5.08} \\
5.06\end{array}$ & $\begin{array}{l}R_{20,46} \\
R_{4,45} \\
P_{3.17} \\
P_{4.49} \\
P_{6.35} \\
r_{5.87}\end{array}$ & $\begin{array}{r}24.05 \\
4.54 \\
3.21 \\
4.58 \\
6.77 \\
9.95\end{array}$ \\
\hline 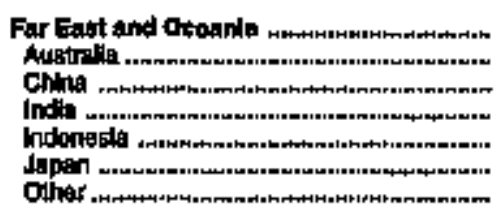 & $\begin{array}{r}R_{49.69} \\
\beta_{4.67} \\
R_{24.25} \\
\beta_{5.26} \\
r_{4.26} \\
2.99 \\
7.07\end{array}$ & 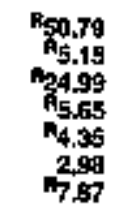 & 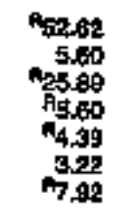 & 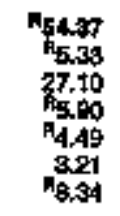 & 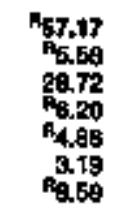 & 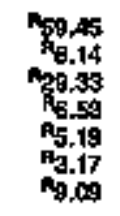 & 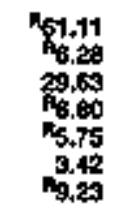 & 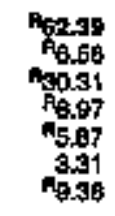 & $\begin{array}{r}R_{66.19} \\
R_{0.59} \\
R_{32.28} \\
R_{7.46} \\
R_{9.24} \\
R_{3.72} \\
R_{9.00}\end{array}$ & $\begin{array}{r}6.98 \\
6.76 \\
34.09 \\
7.73 \\
6.57 \\
3.68 \\
10.15\end{array}$ \\
\hline 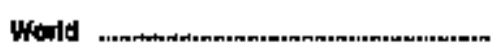 & P304.16 & M1421 & M321.71 & P393.99 & A34020 & 1349.69 & $A_{346.00}$ & ra7.15 & $n_{349,67}$ & 355,40 \\
\hline
\end{tabular}

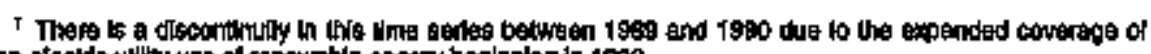

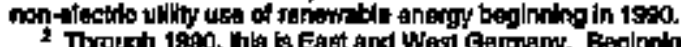

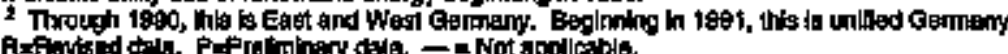

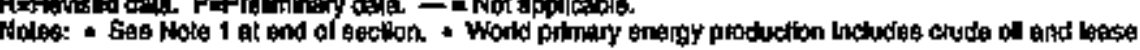

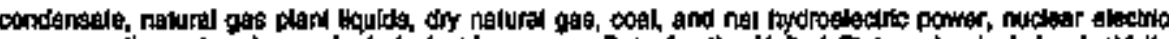

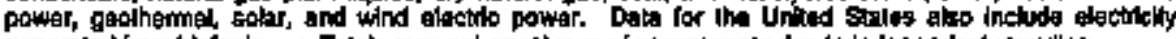

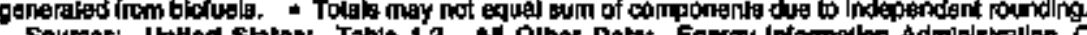

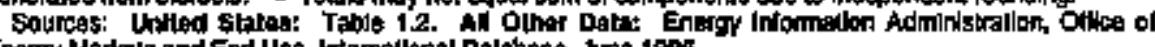

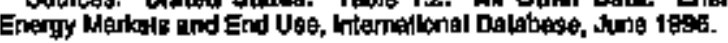




\section{FIgure 11.2 World Primary Energy Production by Source}

\section{Tolal and Crude OA and NGPL, 1973-19g4}

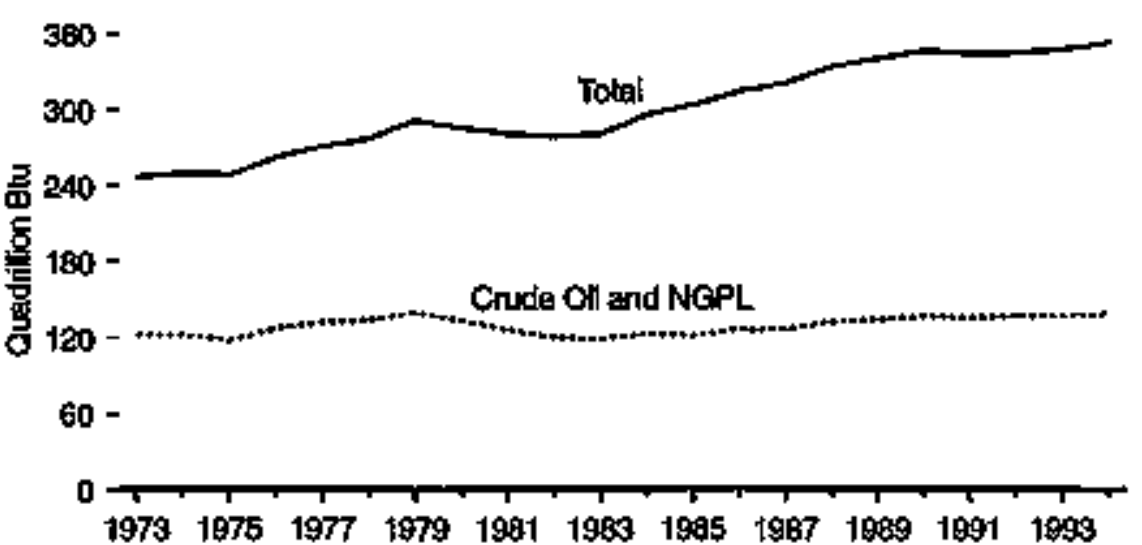

By Source, 1994

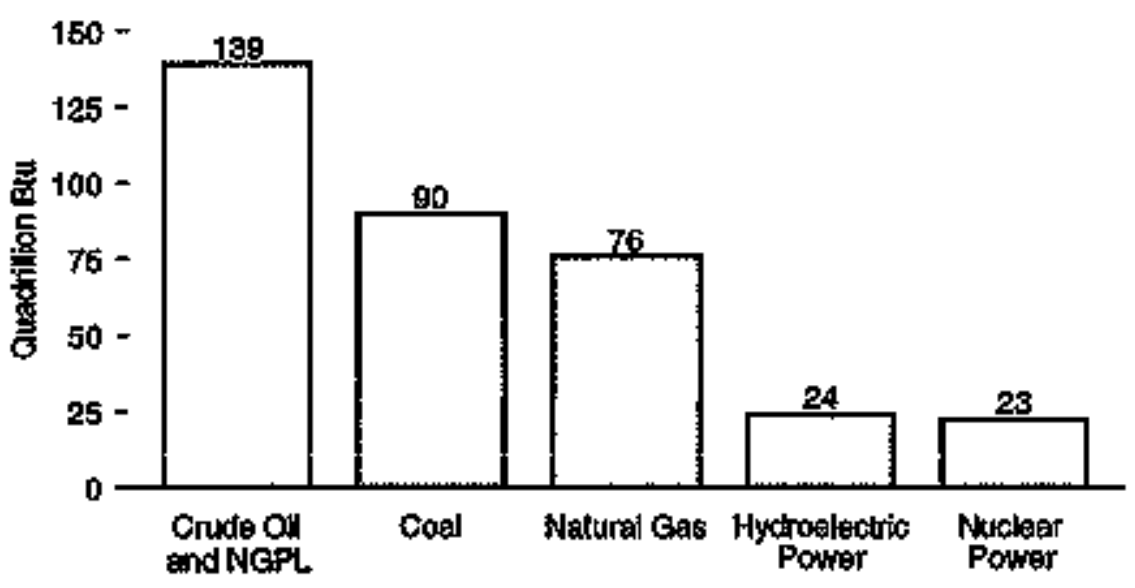

By Source, 1973-1994

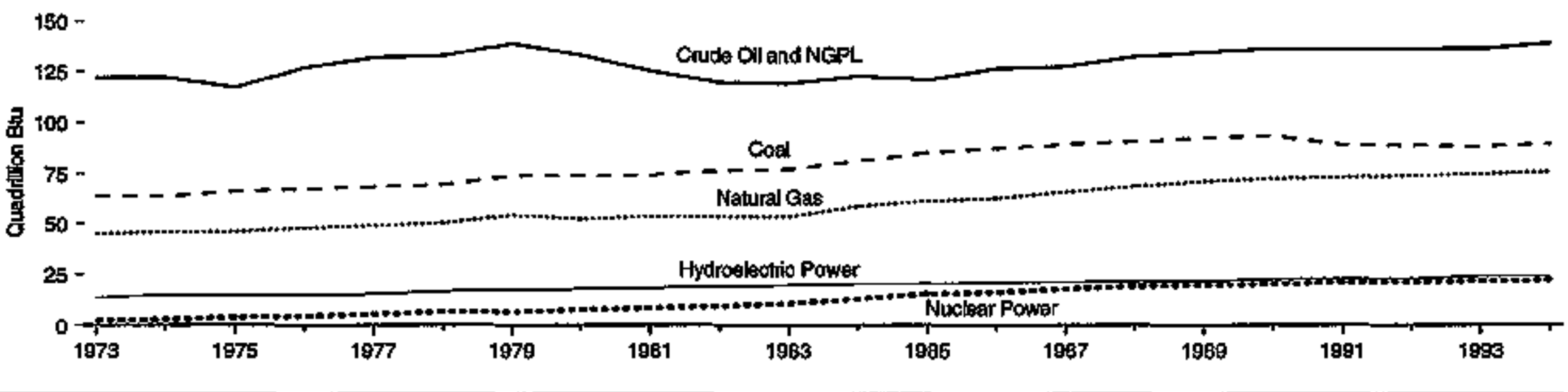

Noles: * Crude ol includes lease condensale. * NGPL is nowural gas plant liquitis. Source: Thable 11.2.

- Because verilcal scelles diter, graphs ahould not be compared. 
Table 112 World Primary Energy Production by Source, 1973-1994

(Quadrillion Btu)

\begin{tabular}{|c|c|c|c|c|c|c|c|c|}
\hline Varr & Cool & $\begin{array}{l}\text { Mawural } \\
\text { Bial }\end{array}$ & Crude Ollx & $\begin{array}{l}\text { Whatut tias } \\
\text { Plank Liquits }\end{array}$ & $\begin{array}{l}\text { Nuclan } \\
\text { Power }\end{array}$ & $\begin{array}{l}\text { Hydtoniatintic } \\
\text { Pownr? }\end{array}$ & 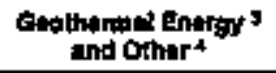 & Totals \\
\hline 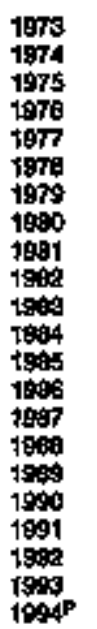 & 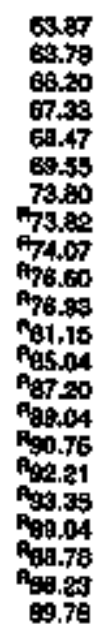 & 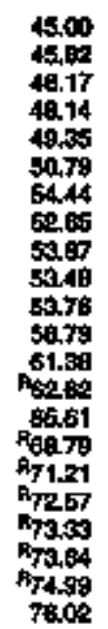 & 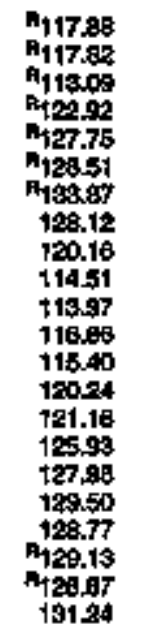 & 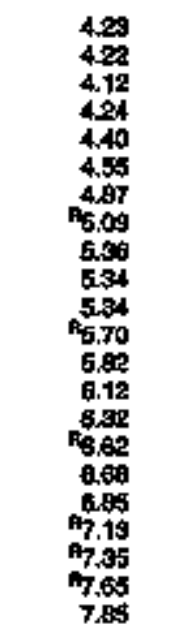 & 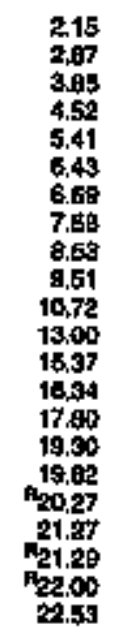 & 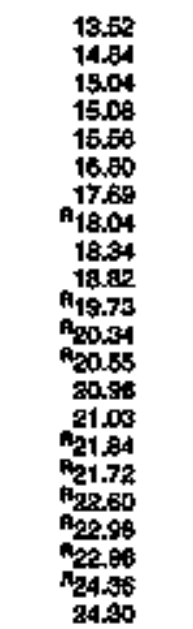 & 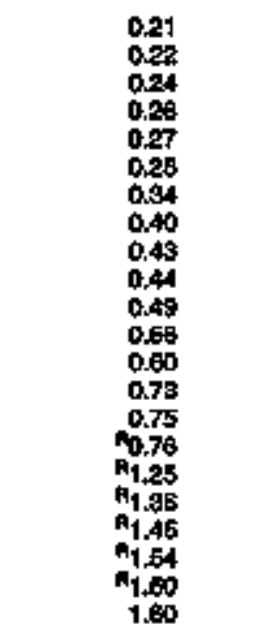 & 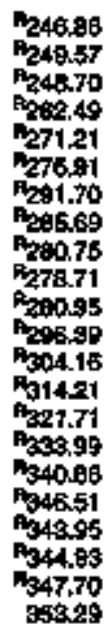 \\
\hline
\end{tabular}

1 Orypoduciton.

2 Inchudes lease vondancers.

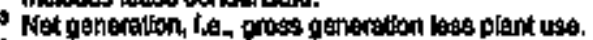

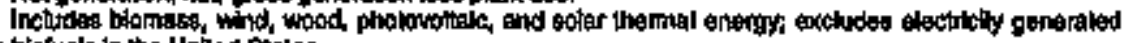

tron biofuah is the United stales.

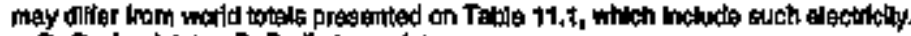

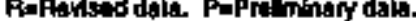

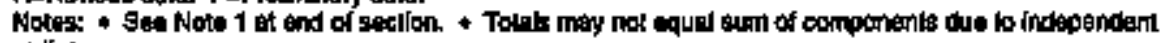
rounding

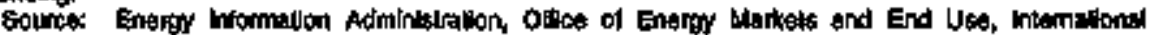
Dakabase, Jus 1 \%ge. 

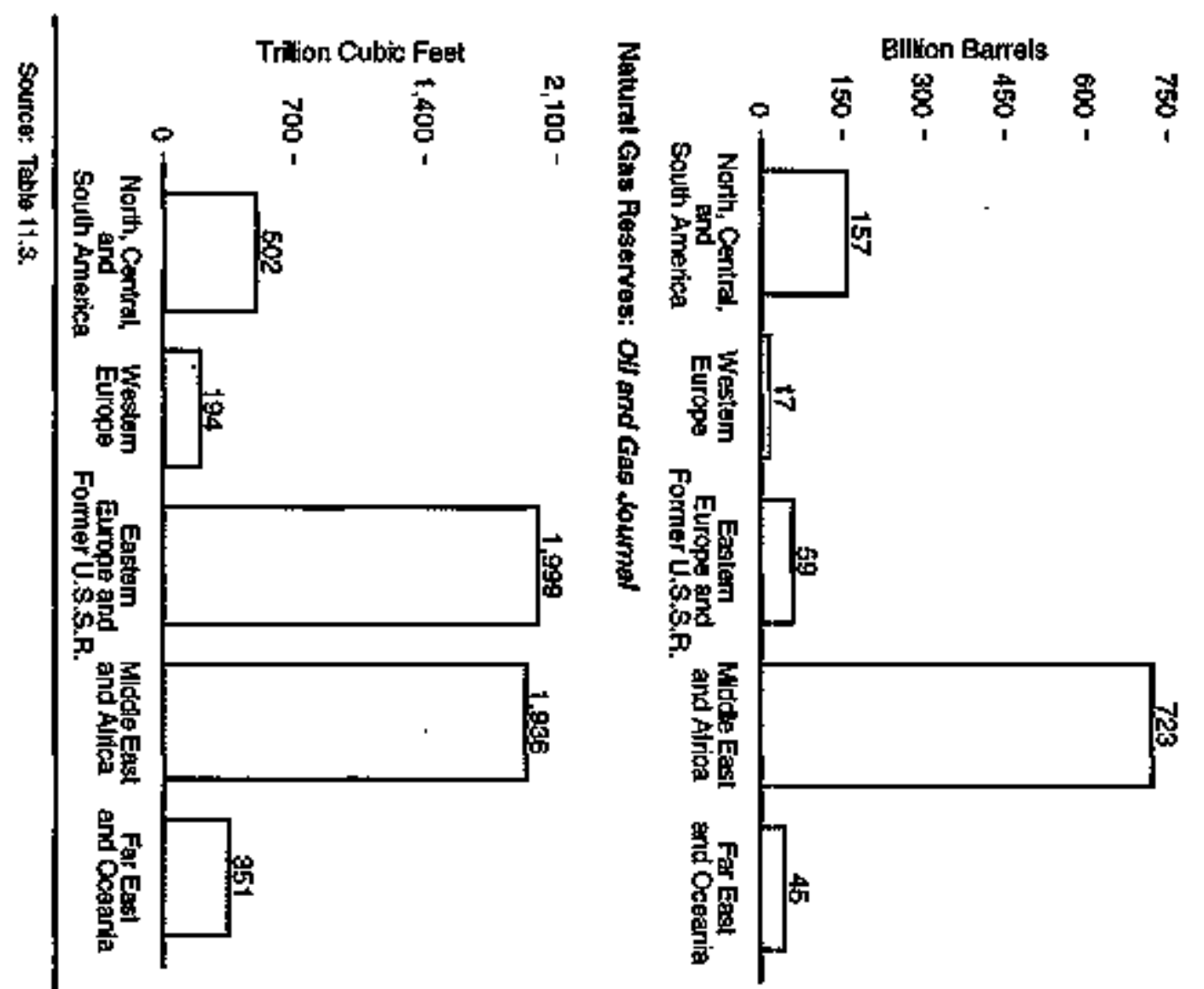

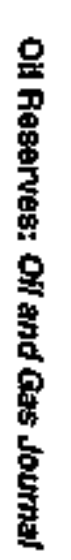

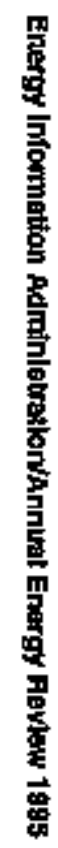
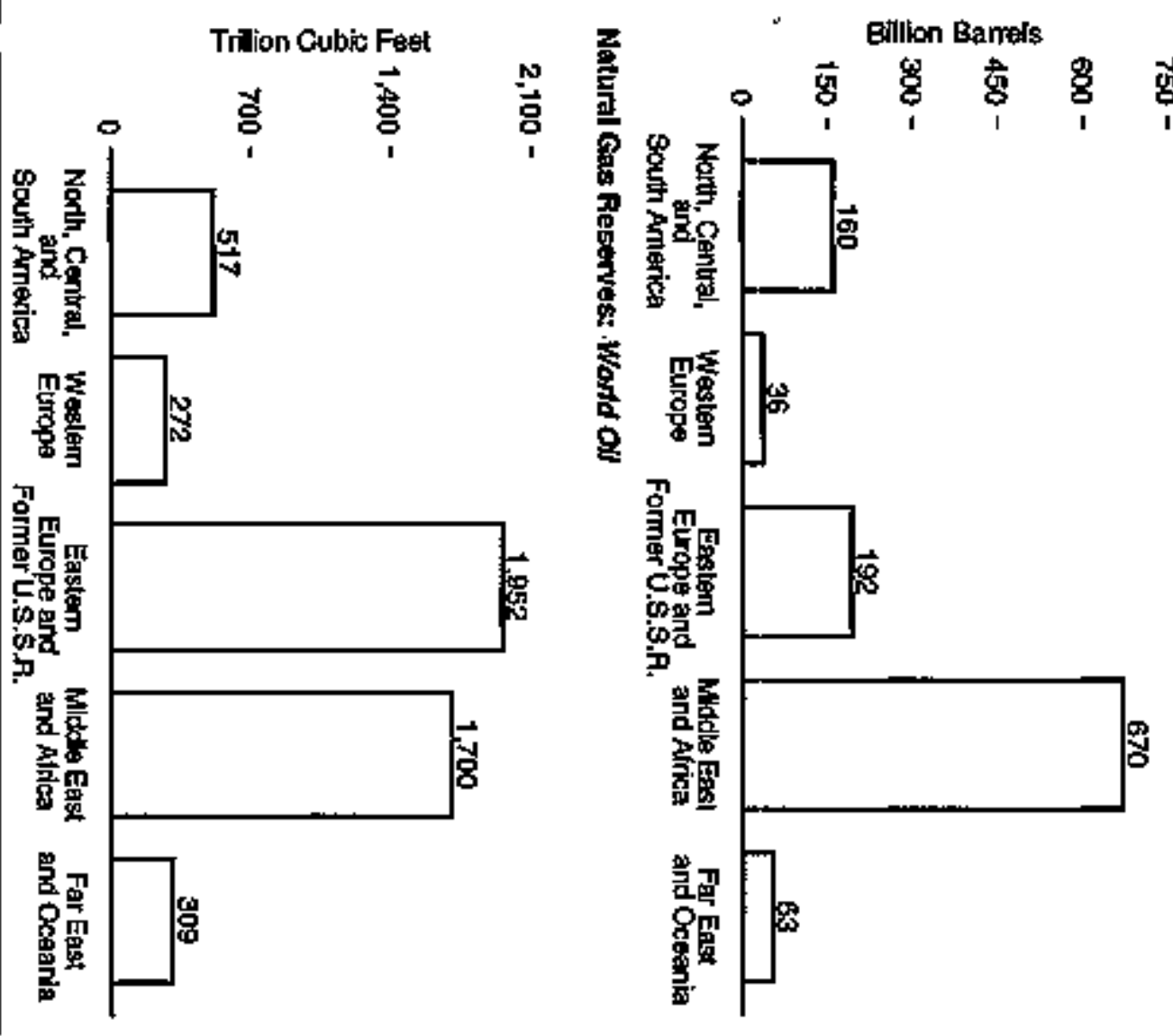

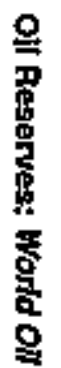


Table 11.3 World Crucie Otl and Natural Gas Reserves, January 1, 1995

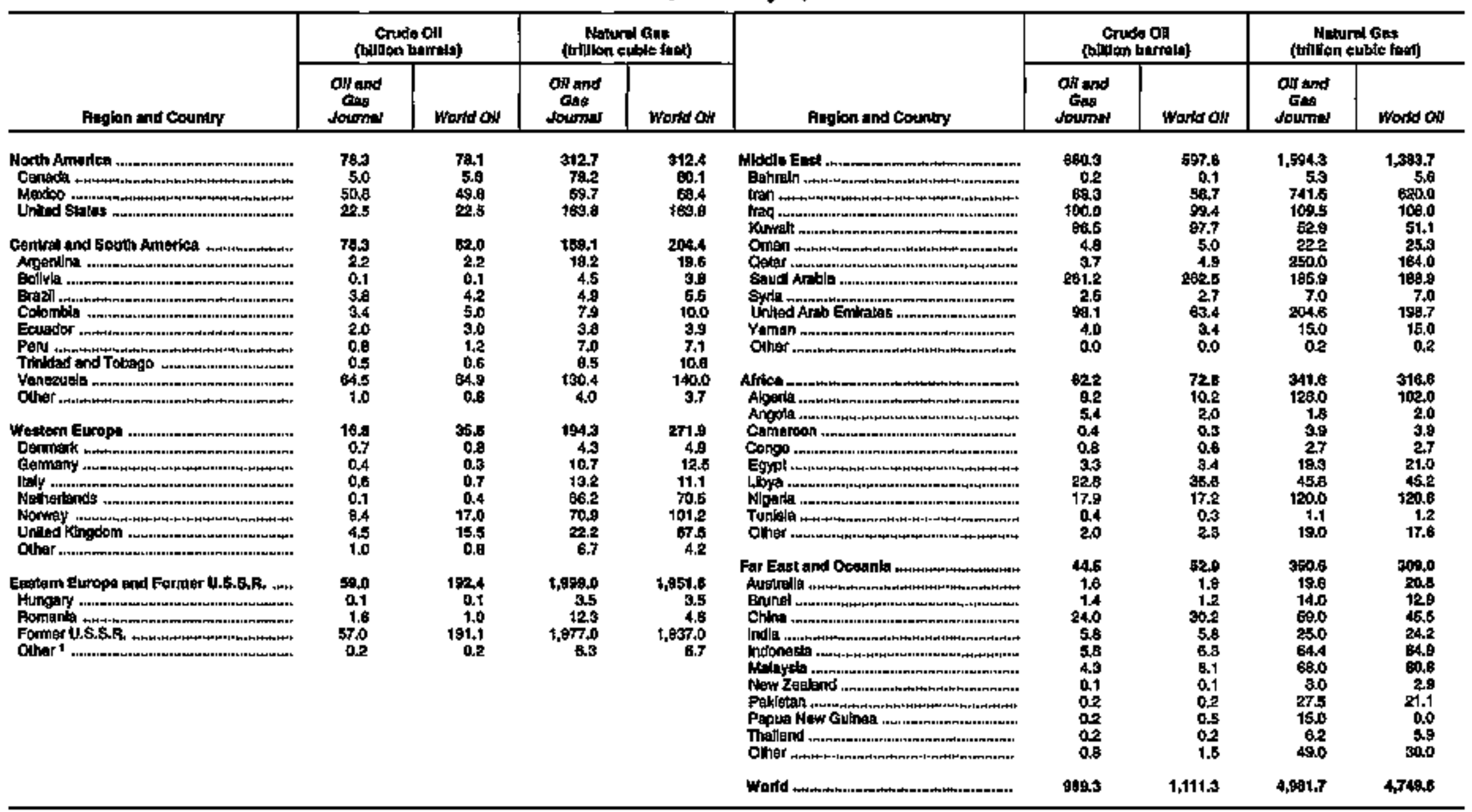

' Atbentar, Bulgada, kmar Gechostovalda, and Potand.

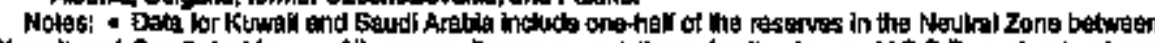

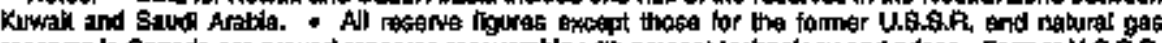

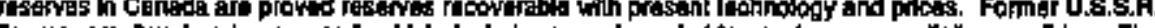

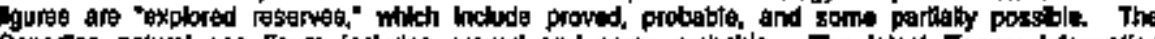

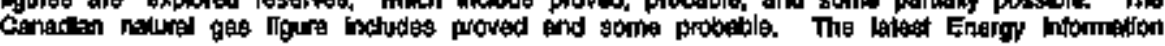

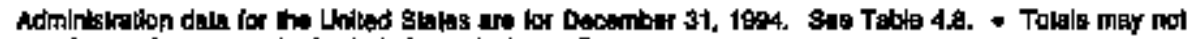

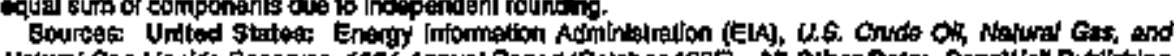

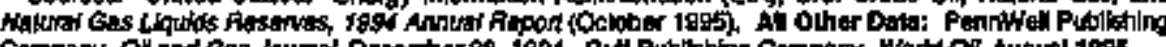

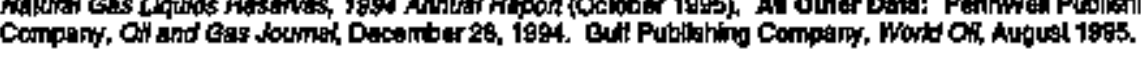




\section{Figure 11.4 World Rotary Rigs in Operation}

\section{Wortd Tolal, 1982-1994}

$6-$

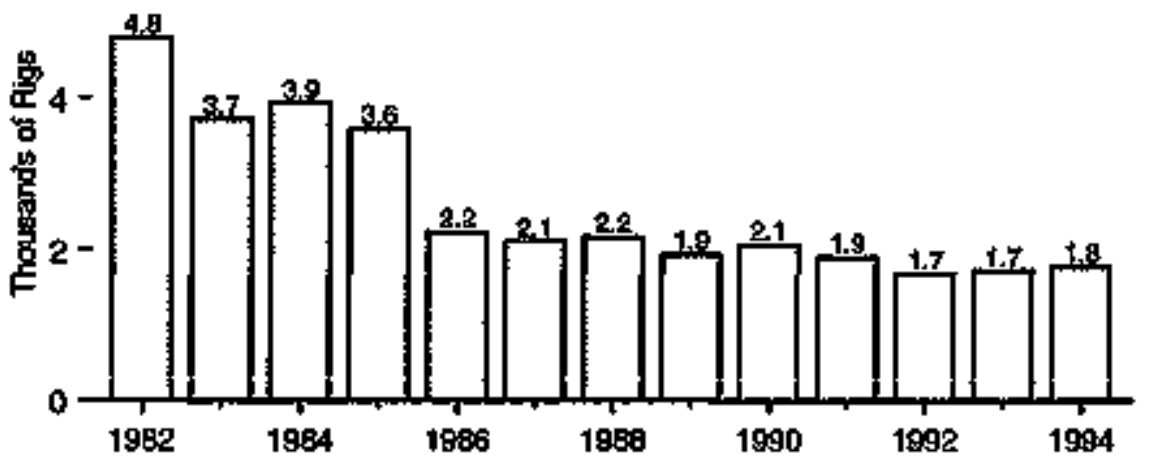

World Areas, 1982-1994

$$
5 \text { - }
$$

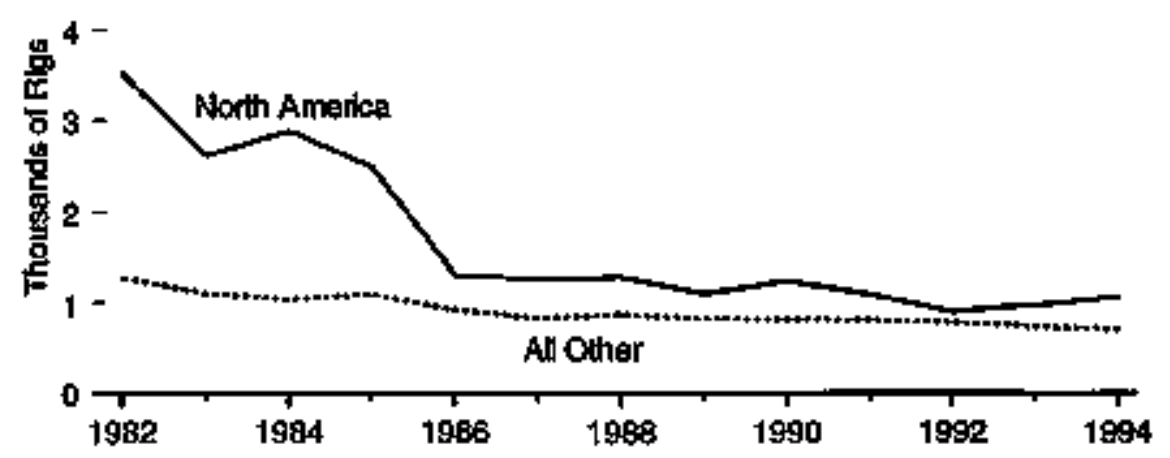

\section{Selocted Coundries, 1904}

$1,000=$

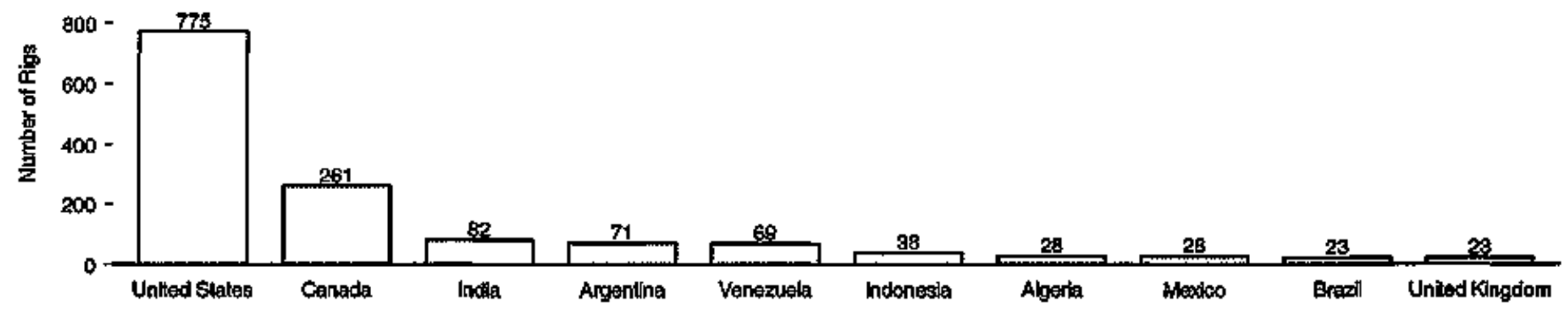

Noler Beceuse vertical seceles differ, graphs should nol be companed.

Sourd: Tabte 1 1 .4. 
Table 11.4 World Rotary Rigs in Operation, 1982-1994

\begin{tabular}{|c|c|c|c|c|c|c|c|c|c|c|c|c|c|}
\hline Feglion and country & $10: 2$ & 1806 & JPA4 & 1995 & 1986 & 1997 & 19B8 & 1088 & 1900 & 190 & $\operatorname{tin} 2$ & 1004 & 1904 \\
\hline 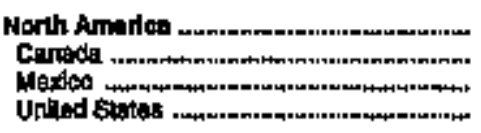 & $\begin{array}{r}3,805 \\
199 \\
200 \\
3,105\end{array}$ & $\begin{array}{r}2620 \\
201 \\
197 \\
2,232\end{array}$ & $\begin{array}{r}2,603 \\
259 \\
196 \\
2,496\end{array}$ & $\begin{array}{r}2,457 \\
\$ 11 \\
196 \\
1,960\end{array}$ & $\begin{array}{l}1,705 \\
178 \\
169 \\
964\end{array}$ & $\begin{array}{l}1,2=0 \\
181 \\
149 \\
\$ 38\end{array}$ & $\begin{array}{l}1,207 \\
190 \\
155 \\
960\end{array}$ & $\begin{array}{r}1,102 \\
130 \\
103 \\
\mathrm{Bg}\end{array}$ & $\begin{array}{r}1,2009 \\
138 \\
90 \\
1,010\end{array}$ & $\begin{array}{r}1,050 \\
121 \\
109 \\
9 \leq 0\end{array}$ & $\begin{array}{r}697 \\
85 \\
60 \\
721\end{array}$ & $\begin{array}{r}074 \\
n_{184} \\
35 \\
754\end{array}$ & $\begin{array}{r}1,058 \\
281 \\
29 \\
75\end{array}$ \\
\hline 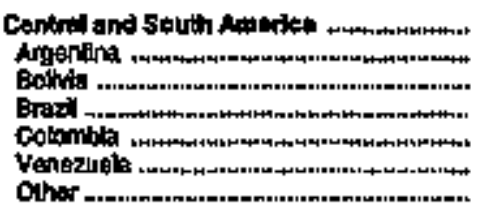 & $\begin{array}{r}300 \\
67 \\
11 \\
94 \\
23 \\
69 \\
695\end{array}$ & $\begin{array}{r}254 \\
73 \\
8 \\
89 \\
19 \\
41 \\
n_{41}^{4}\end{array}$ & $\begin{array}{r}243 \\
92 \\
8 \\
70 \\
16 \\
30 \\
39\end{array}$ & $\begin{array}{r}247 \\
81 \\
5 \\
78 \\
21 \\
30 \\
30\end{array}$ & $\begin{array}{r}209 \\
47 \\
4 \\
77 \\
17 \\
29 \\
894\end{array}$ & $\begin{array}{r}195 \\
51 \\
8 \\
60 \\
14 \\
14 \\
18 \\
035\end{array}$ & $\begin{array}{r}t 60 \\
69 \\
5 \\
59 \\
19 \\
19 \\
\mathrm{R}_{29}^{25}\end{array}$ & $\begin{array}{r}159 \\
35 \\
6 \\
28 \\
15 \\
28 \\
28\end{array}$ & 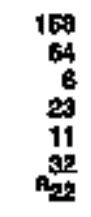 & $\begin{array}{r}167 \\
60 \\
10 \\
21 \\
9 \\
45\end{array}$ & $\begin{array}{r}170 \\
49 \\
18 \\
26 \\
12 \\
50 \\
717\end{array}$ & $\begin{array}{r}167 \\
42 \\
11 \\
25 \\
18 \\
58 \\
\mathrm{P}_{18}\end{array}$ & $\begin{array}{r}296 \\
71 \\
10 \\
29 \\
15 \\
69 \\
19\end{array}$ \\
\hline 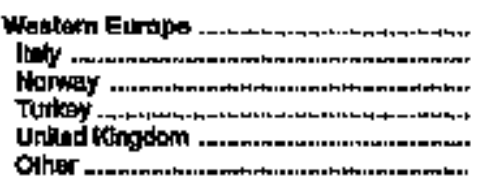 & $\begin{array}{r}271 \\
38 \\
13 \\
34 \\
58 \\
59\end{array}$ & $\begin{array}{r}211 \\
26 \\
10 \\
26 \\
42 \\
4107\end{array}$ & $\begin{array}{r}205 \\
25 \\
10 \\
24 \\
60 \\
0107\end{array}$ & $\begin{array}{r}256 \\
40 \\
13 \\
25 \\
00 \\
0117\end{array}$ & $\begin{array}{r}211 \\
3 \\
12 \\
27 \\
49 \\
090\end{array}$ & $\begin{array}{r}181 \\
28 \\
12 \\
26 \\
44 \\
173\end{array}$ & $\begin{array}{r}190 \\
24 \\
16 \\
21 \\
97 \\
773\end{array}$ & $\begin{array}{r}167 \\
22 \\
12 \\
20 \\
48 \\
967\end{array}$ & $\begin{array}{r}162 \\
21 \\
12 \\
17 \\
49 \\
04\end{array}$ & $\begin{array}{r}142 \\
25 \\
76 \\
19 \\
39 \\
39\end{array}$ & $\begin{array}{r}112 \\
23 \\
15 \\
15 \\
38 \\
93\end{array}$ & $\begin{array}{r}\mathbf{R}_{99} \\
14 \\
13 \\
16 \\
24 \\
\mathrm{~m}_{22}\end{array}$ & $\begin{array}{l}3 \\
11 \\
14 \\
16 \\
29 \\
19\end{array}$ \\
\hline 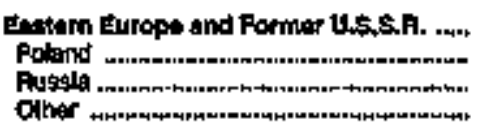 & $\begin{array}{l}\text { NA } \\
\text { NAA } \\
\text { NA }\end{array}$ & $\begin{array}{l}\text { NA } \\
\text { NA }\end{array}$ & $\begin{array}{l}\text { NA } \\
\text { NA } \\
\text { NAA } \\
\text { NA }\end{array}$ & ing & $\begin{array}{l}\text { WA } \\
\text { MA }\end{array}$ & $\begin{array}{l}\text { NA } \\
\text { NA } \\
\text { NA } \\
\text { NA }\end{array}$ & $\begin{array}{l}\text { MA } \\
\text { MA } \\
\text { MA } \\
\text { MA }\end{array}$ & $\begin{array}{l}\text { NA } \\
\text { NA } \\
\text { NA } \\
\text { NA }\end{array}$ & $\begin{array}{l}\text { NA } \\
\text { MA } \\
\text { NA } \\
\text { NA }\end{array}$ & $\begin{array}{l}28 \\
28 \\
24 \\
14\end{array}$ & $\begin{array}{l}21 \\
18 \\
18 \\
N_{3}^{A}\end{array}$ & $\begin{array}{l}24 \\
18 \\
\mathrm{NA} \\
\mathrm{H}\end{array}$ & $\begin{array}{r}24 \\
18 \\
\text { NA } \\
6\end{array}$ \\
\hline 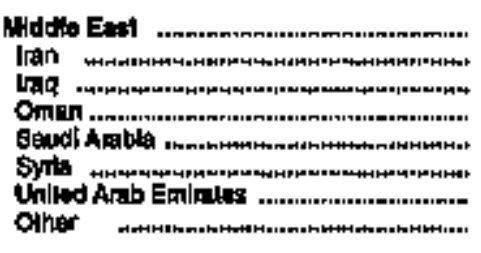 & $\begin{array}{r}130 \\
3 \\
11 \\
12 \\
29 \\
15 \\
150 \\
250\end{array}$ & $\begin{array}{r}142 \\
19 \\
29 \\
11 \\
26 \\
15 \\
45 \\
48 \\
189\end{array}$ & $\begin{array}{r}139 \\
20 \\
19 \\
12 \\
16 \\
23 \\
38 \\
39 \\
\mathrm{f}_{10}\end{array}$ & $\begin{array}{r}139 \\
20 \\
29 \\
13 \\
11 \\
26 \\
25 \\
215\end{array}$ & $\begin{array}{r}118 \\
18 \\
21 \\
13 \\
6 \\
27 \\
16 \\
19\end{array}$ & $\begin{array}{r}90 \\
10 \\
10 \\
10 \\
5 \\
22 \\
11 \\
114\end{array}$ & $\begin{array}{r}102 \\
18 \\
29 \\
9 \\
4 \\
24 \\
10 \\
n_{14}^{10}\end{array}$ & $\begin{array}{r}116 \\
20 \\
26 \\
13 \\
6 \\
24 \\
6 \\
613\end{array}$ & $\begin{array}{r}\mathbf{t} 09 \\
19 \\
128 \\
17 \\
10 \\
17 \\
12 \\
12\end{array}$ & $\begin{array}{r}12 \\
21 \\
N A \\
14 \\
10 \\
14 \\
16 \\
11\end{array}$ & $\begin{array}{r}129 \\
99 \\
1 / 4 \\
12 \\
22 \\
17 \\
18 \\
120\end{array}$ & $\begin{array}{r}135 \\
45 \\
14 \\
16 \\
21 \\
15 \\
18 \\
18\end{array}$ & $\begin{array}{r}102 \\
21 \\
N / 4 \\
16 \\
17 \\
12 \\
17 \\
10\end{array}$ \\
\hline 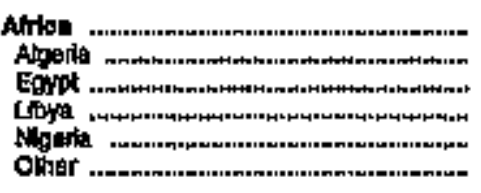 & $\begin{array}{l}242 \\
31 \\
39 \\
31 \\
37 \\
07\end{array}$ & $\begin{array}{r}181 \\
64 \\
35 \\
34 \\
17 \\
51\end{array}$ & $\begin{array}{r}140 \\
27 \\
36 \\
26 \\
11 \\
40\end{array}$ & $\begin{array}{r}155 \\
35 \\
37 \\
30 \\
10 \\
43\end{array}$ & $\begin{array}{r}130 \\
41 \\
30 \\
20 \\
10 \\
26\end{array}$ & $\begin{array}{r}113 \\
40 \\
23 \\
12 \\
11 \\
27\end{array}$ & $\begin{array}{r}\$ 12 \\
32 \\
21 \\
16 \\
13 \\
30\end{array}$ & $\begin{array}{r}101 \\
24 \\
18 \\
17 \\
14 \\
28\end{array}$ & $\begin{array}{r}107 \\
35 \\
18 \\
15 \\
19 \\
24\end{array}$ & $\begin{array}{r}106 \\
31 \\
17 \\
15 \\
21 \\
22\end{array}$ & $\begin{array}{l}94 \\
30 \\
16 \\
16 \\
16 \\
17\end{array}$ & $\begin{array}{l}6 \\
29 \\
18 \\
15 \\
10 \\
10\end{array}$ & $\begin{array}{r}78 \\
29 \\
14 \\
13 \\
7 \\
16\end{array}$ \\
\hline 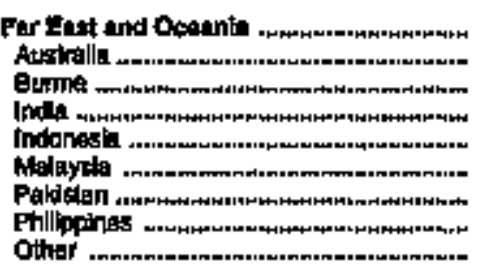 & $\begin{array}{r}311 \\
33 \\
30 \\
50 \\
182 \\
53 \\
17 \\
14 \\
806\end{array}$ & $\begin{array}{r}309 \\
25 \\
36 \\
58 \\
89 \\
10 \\
17 \\
5 \\
863\end{array}$ & $\begin{array}{r}295 \\
34 \\
39 \\
77 \\
69 \\
9 \\
17 \\
3 \\
300\end{array}$ & $\begin{array}{r}298 \\
31 \\
39 \\
62 \\
80 \\
8 \\
18 \\
2 \\
204\end{array}$ & $\begin{array}{r}254 \\
15 \\
33 \\
70 \\
62 \\
6 \\
17 \\
1 \\
1 \\
1018\end{array}$ & 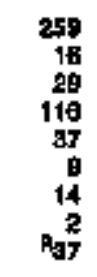 & $\begin{array}{r}267 \\
19 \\
26 \\
131 \\
44 \\
9 \\
+3 \\
4 \\
14\end{array}$ & $\begin{array}{r}296 \\
14 \\
23 \\
135 \\
45 \\
12 \\
13 \\
7 \\
7\end{array}$ & $\begin{array}{r}204 \\
14 \\
19 \\
197 \\
52 \\
19 \\
11 \\
6 \\
492\end{array}$ & $\begin{array}{r}279 \\
12 \\
22 \\
130 \\
37 \\
13 \\
10 \\
5 \\
5 \\
422\end{array}$ & $\begin{array}{r}254 \\
10 \\
18 \\
124 \\
50 \\
10 \\
11 \\
7 \\
724\end{array}$ & $\begin{array}{r}A_{240} \\
11 \\
n_{15} \\
n_{105} \\
a_{40} \\
10 \\
8 \\
\mathbf{s} \\
A_{41}\end{array}$ & $\begin{array}{r}214 \\
10 \\
10 \\
02 \\
98 \\
10 \\
10 \\
10 \\
10 \\
12\end{array}$ \\
\hline 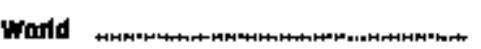 & 4,790 & $3,77 t$ & 3,924 & 3,604 & $2,2,16$ & 2,098 & 2,168 & 1,024 & 2,007 & 1,896 & 1,576 & $n_{1,712}$ & $1, \pi 1$ \\
\hline
\end{tabular}

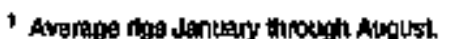

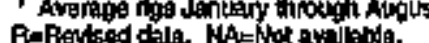

Source: Baker Hughes, ho., Houston, Texar. 


\section{World and OPEC, 1960-1995}

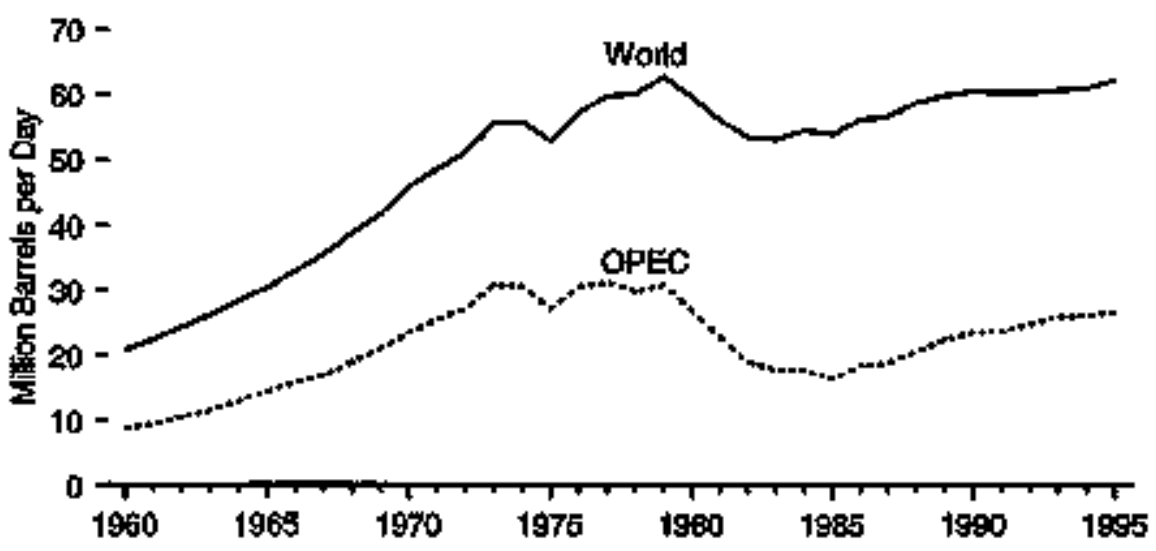

Leading Produters, 1960-1998

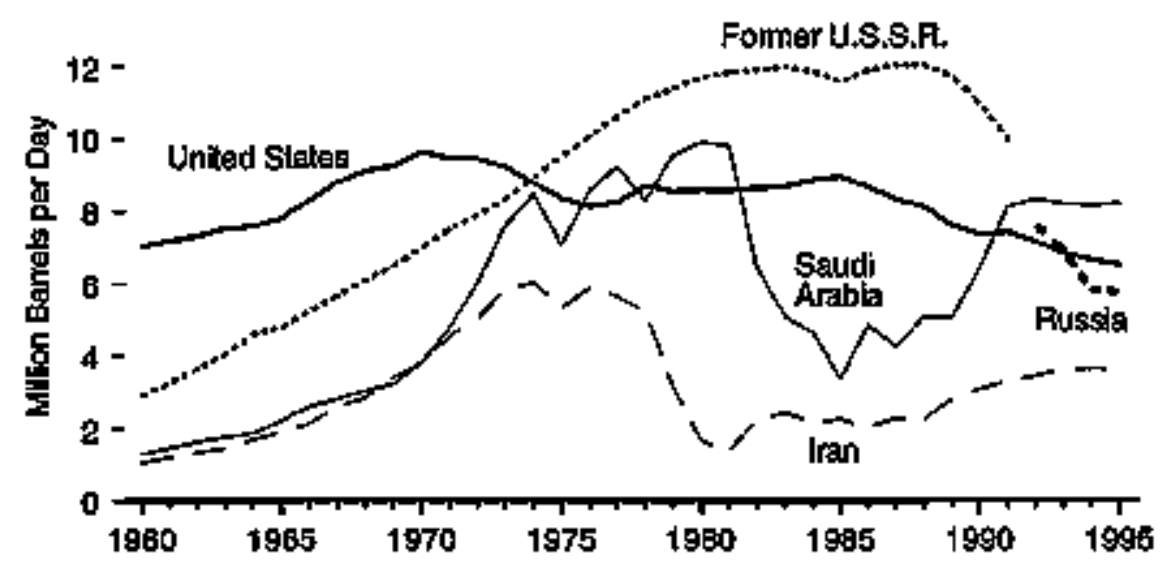

Selected Produoing Counuries, 1905

$12-$

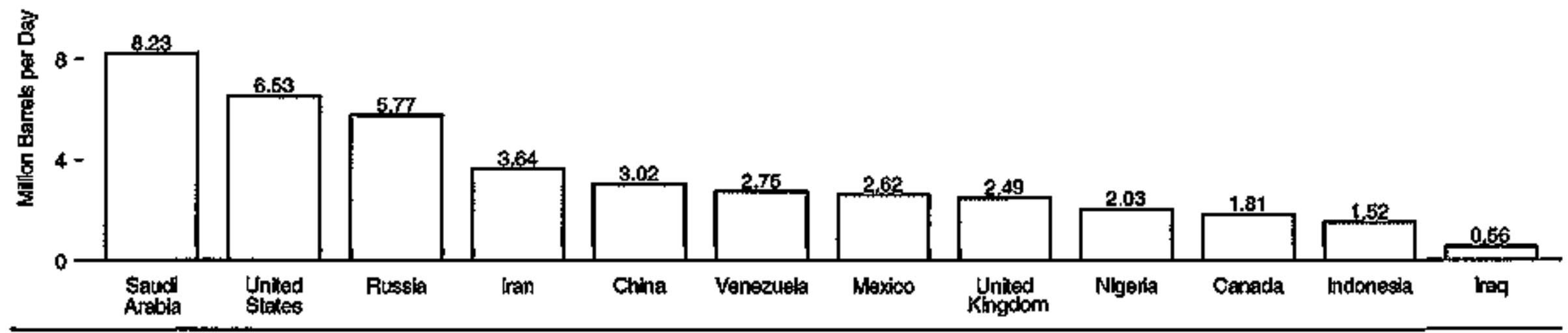

Note: Because vorical sceles offer, graphs should not ba companed.

Sourcer Tabla 11.5 
Table 11.5 World Crude Oil Production, 1960-1995

(Million Bartels per Day)

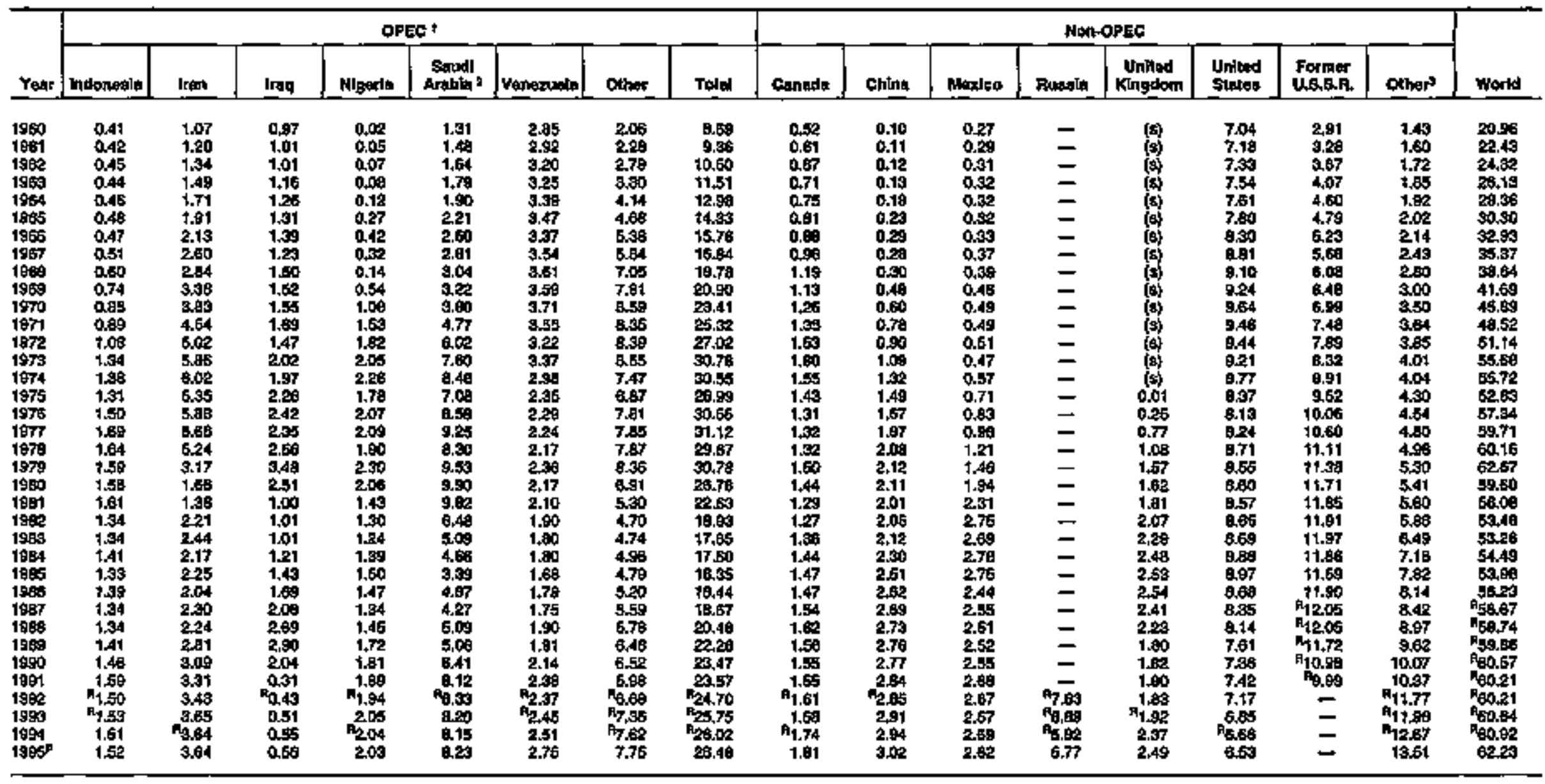

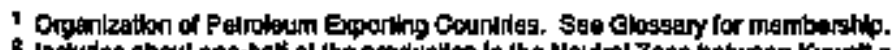

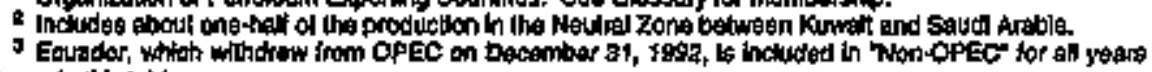
shown in thls lible.

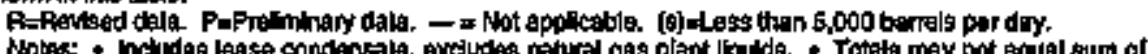

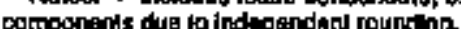

Sources: China: - 10601972 -

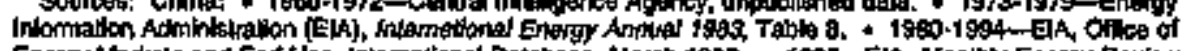

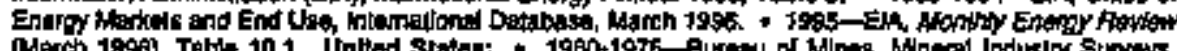

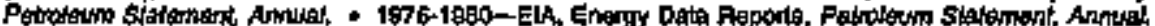

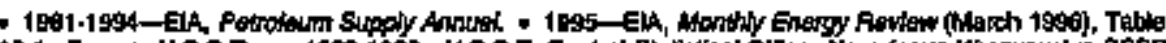

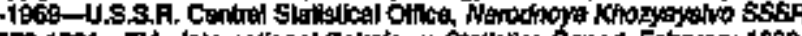

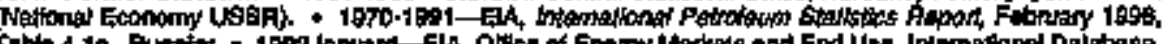

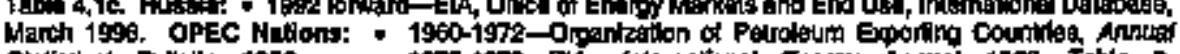

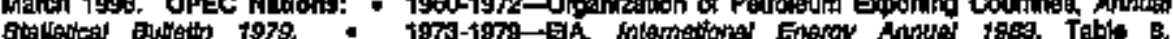

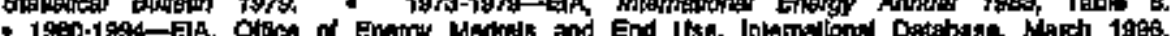

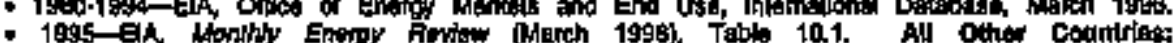

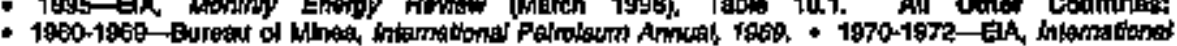

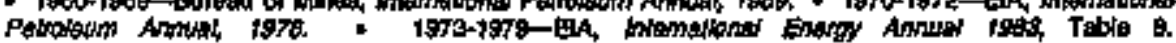

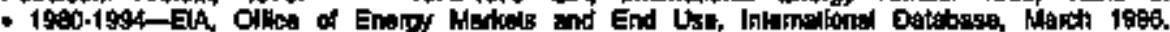

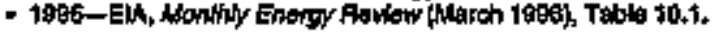




\section{Cruble Olt and NGPL Production, 1973-1894}

70 -

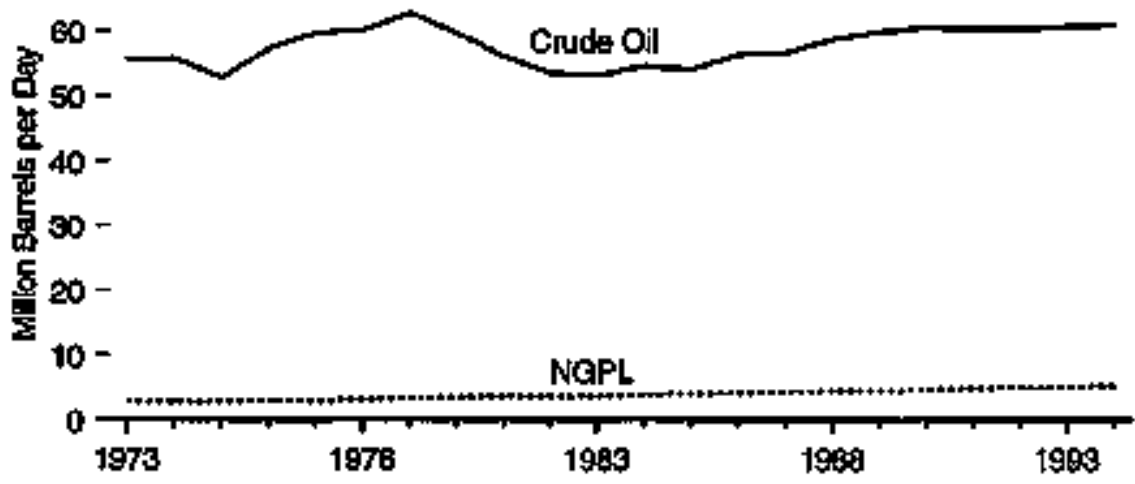

World and OPEC NGPL Production, 1973-1994

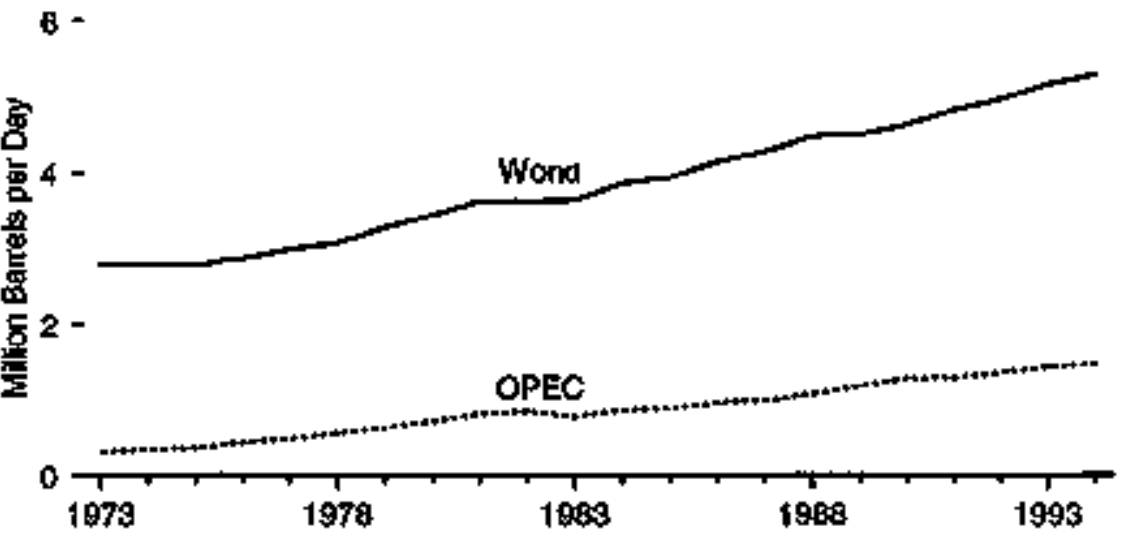

Top MGPL Producing Cotuntries, 1994

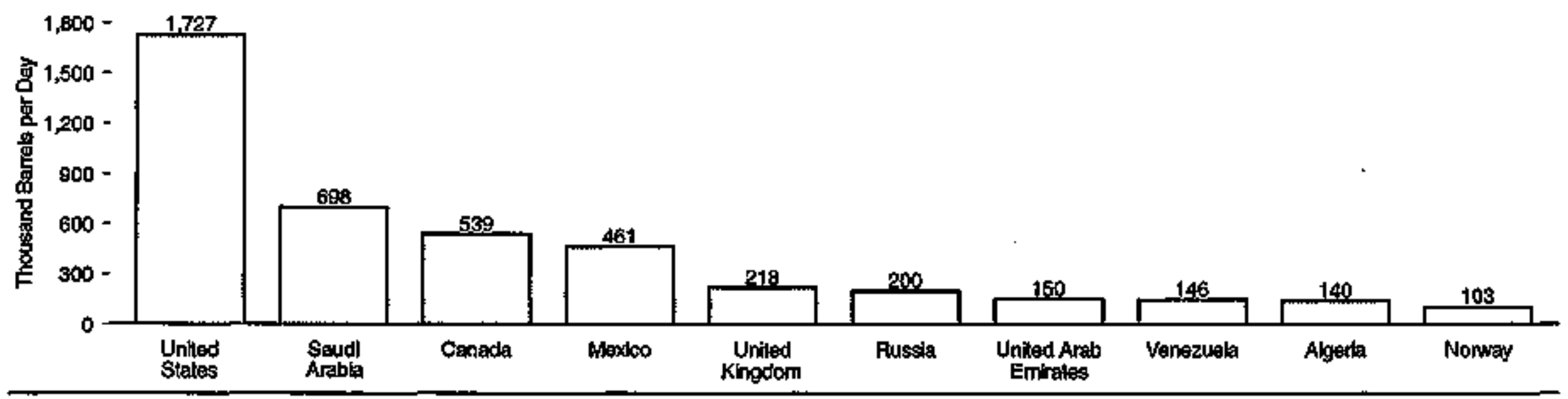

Noter Because vertical sceles ditter, fraphs should not be compared.

Souress; Taldes 11.5 and 11.8. 
Table 11.6 World Natural Gas Plant Liqutds Production, 1973-1994

(Thousand Barrels per Day)

\begin{tabular}{|c|c|c|c|c|c|c|c|c|c|c|c|c|c|c|c|c|c|c|}
\hline \multirow[b]{2}{*}{ Your } & \multicolumn{8}{|c|}{ opec' } & \multicolumn{9}{|c|}{ Hon-OPEC } & \multirow[b]{2}{*}{ Worlt } \\
\hline & Algerla & Indonesla & Kunalt 2 & $\begin{array}{c}\text { Saud } \\
\text { Arabla } 2\end{array}$ & $\begin{array}{c}\text { Unlted } \\
\text { Arte } \\
\text { Emiratus }\end{array}$ & Venveruats & Owher & Toled & Gannda & Kasuksiun & Moxiteo & Homsy & Rossla & $\begin{array}{c}\text { Unhad } \\
\text { Kingdom }\end{array}$ & $\begin{array}{l}\text { Uniled } \\
\text { Sidieg }\end{array}$ & $\begin{array}{l}\text { Pormer } \\
\text { US.s.R. }\end{array}$ & Dthers & \\
\hline 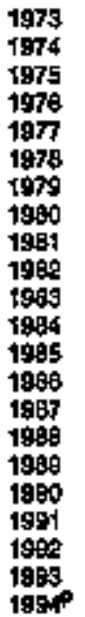 & $\begin{array}{l}9 \\
12 \\
20 \\
24 \\
19 \\
25 \\
30 \\
38 \\
19 \\
69 \\
56 \\
105 \\
120 \\
120 \\
140 \\
120 \\
130 \\
130 \\
140 \\
140 \\
145 \\
110\end{array}$ & $\begin{array}{l}181 \\
191 \\
181 \\
10 \\
10 \\
90 \\
40 \\
70 \\
95 \\
90 \\
94 \\
75 \\
44 \\
90 \\
30 \\
90 \\
72 \\
77 \\
76 \\
75 \\
78 \\
80\end{array}$ & $\begin{array}{c}60 \\
50 \\
50 \\
50 \\
55 \\
75 \\
95 \\
95 \\
60 \\
40 \\
55 \\
67 \\
54 \\
75 \\
59 \\
100 \\
105 \\
65 \\
0 \\
34 \\
53 \\
50\end{array}$ & $\begin{array}{r}90 \\
190 \\
140 \\
185 \\
215 \\
250 \\
303 \\
360 \\
493 \\
490 \\
390 \\
955 \\
975 \\
385 \\
410 \\
495 \\
503 \\
620 \\
690 \\
743 \\
704 \\
6818\end{array}$ & 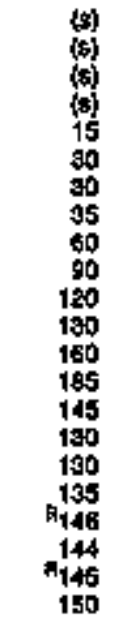 & $\begin{array}{r}99 \\
64 \\
78 \\
77 \\
78 \\
61 \\
69 \\
60 \\
55 \\
60 \\
77 \\
57 \\
69 \\
97 \\
94 \\
99 \\
109 \\
114 \\
117 \\
113 \\
0143 \\
146\end{array}$ & 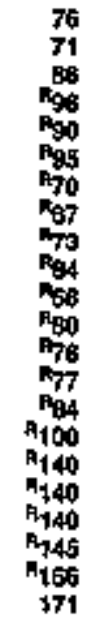 & 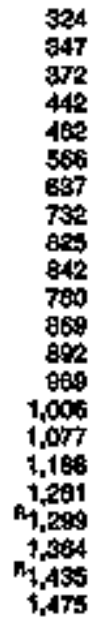 & $\begin{array}{l}314 \\
314 \\
309 \\
289 \\
290 \\
291 \\
331 \\
331 \\
330 \\
318 \\
306 \\
338 \\
397 \\
320 \\
367 \\
331 \\
410 \\
426 \\
431 \\
460 \\
1506 \\
539\end{array}$ & $\begin{array}{l}= \\
= \\
= \\
= \\
= \\
= \\
= \\
= \\
= \\
= \\
= \\
00\end{array}$ & $\begin{array}{r}75 \\
800 \\
800 \\
95 \\
195 \\
115 \\
150 \\
193 \\
341 \\
255 \\
265 \\
257 \\
271 \\
352 \\
338 \\
370 \\
384 \\
428 \\
157 \\
454 \\
459 \\
461\end{array}$ & $\begin{array}{c}{[6]} \\
69] \\
5 \\
20 \\
20 \\
95 \\
40 \\
40 \\
31 \\
33 \\
39 \\
36 \\
41 \\
53 \\
55 \\
75 \\
74 \\
78 \\
94 \\
45 \\
100 \\
109\end{array}$ & $\begin{array}{l}= \\
= \\
= \\
= \\
= \\
= \\
= \\
= \\
= \\
= \\
\bar{z} \\
200 \\
200\end{array}$ & $\begin{array}{r}5 \\
5 \\
15 \\
16 \\
90 \\
40 \\
45 \\
45 \\
50 \\
78 \\
117 \\
138 \\
145 \\
158 \\
168 \\
159 \\
140 \\
108 \\
141 \\
160 \\
169 \\
218\end{array}$ & 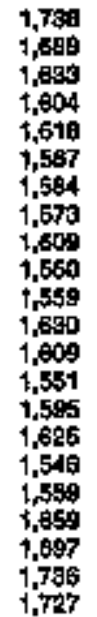 & $\begin{array}{l}170 \\
150 \\
205 \\
220 \\
235 \\
255 \\
270 \\
265 \\
300 \\
375 \\
390 \\
340 \\
360 \\
410 \\
430 \\
460 \\
425 \\
425 \\
420 \\
= \\
=\end{array}$ & 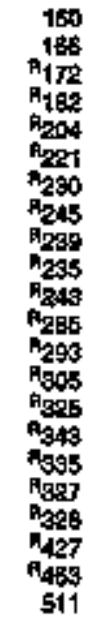 & 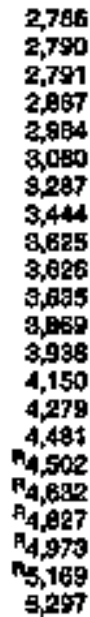 \\
\hline
\end{tabular}

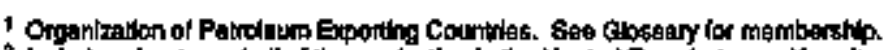

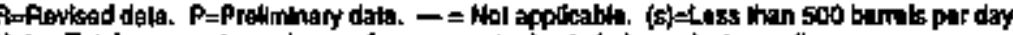

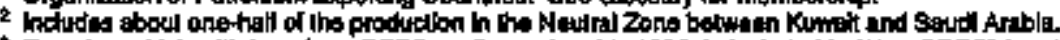

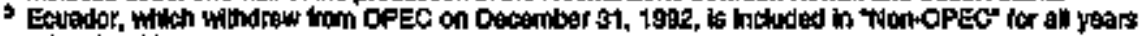

Now: Totals may nol equal sum of componemis duo ko indepondend coundlng

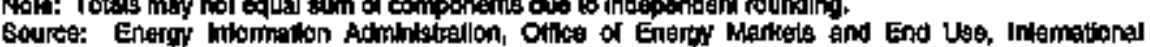
showm in hils labie. Databese, Jina 1905 . 


\section{Selected Types, 1970-1996}

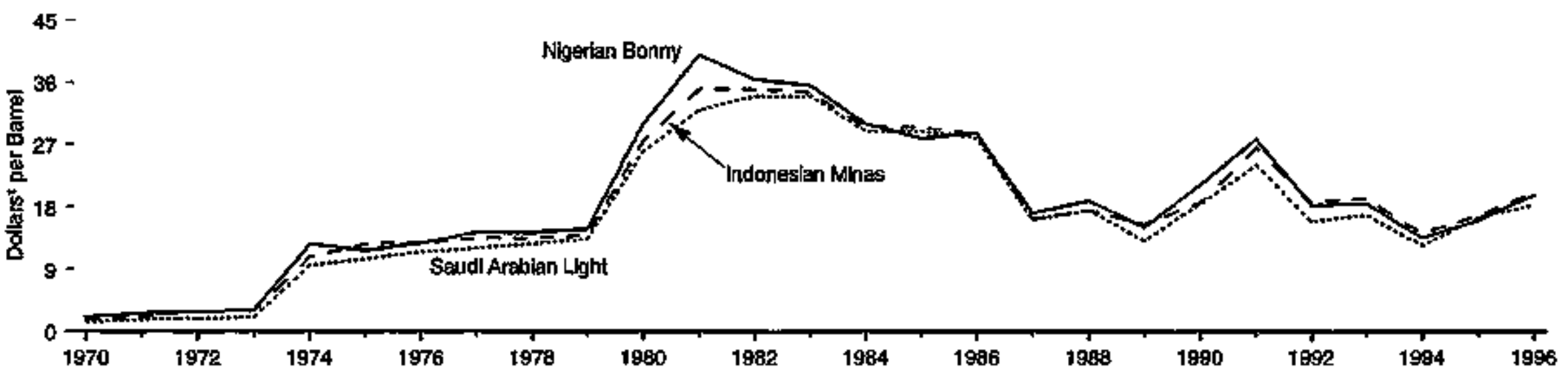

\section{Selocted Types, 1996}

25 -

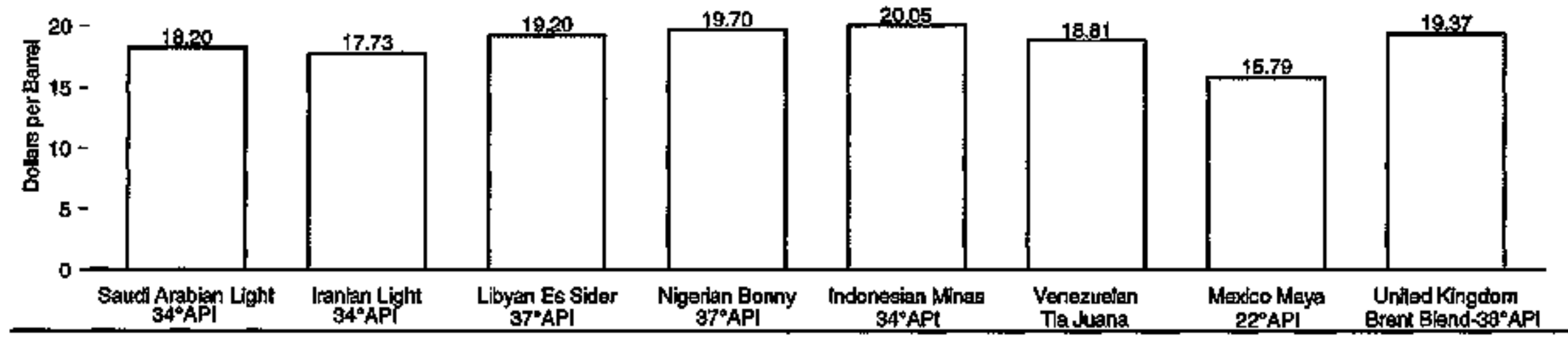

1 Nombrial dallars.

Noteg: * Plices are as of the first Fituday in January, excepi in 1987, when potcos are as of

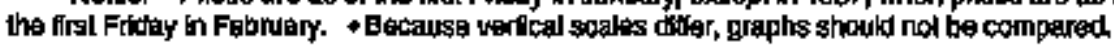


Table 11.7 World Crude Oll Prices by Selected Type, 1970-1996

(Dollars' per Barrel)

\begin{tabular}{|c|c|c|c|c|c|c|c|c|}
\hline Yasr & $\begin{array}{l}\text { Sindil Arabian } \\
\text { Ltgh-3r AFt }\end{array}$ & $\begin{array}{c}\text { kerplan } \\
\text { Ught-34'AFA }\end{array}$ & $\begin{array}{l}\text { Ltoyan } 2 \\
\text { Es Sider } 4 \text { r APS }\end{array}$ & $\begin{array}{c}\text { Gloattant } \\
\text { Donny-3r API }\end{array}$ & 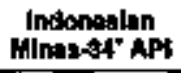 & 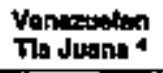 & 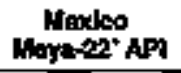 & $\begin{array}{l}\text { Uniled Krydom } \\
\text { Brent Bilend } 36^{\circ} \text { API }\end{array}$ \\
\hline 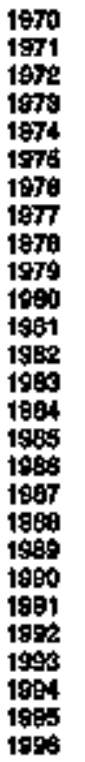 & 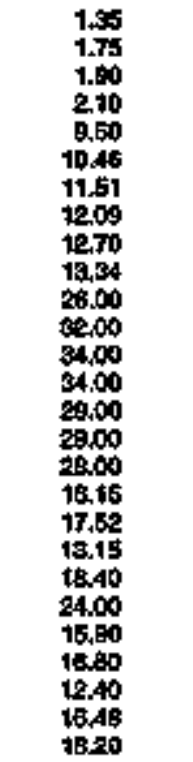 & $\begin{array}{r}1.36 \\
1.76 \\
1.91 \\
2.11 \\
10.65 \\
10.67 \\
11.62 \\
12.91 \\
12.91 \\
13.45 \\
490.37 \\
37.90 \\
34.20 \\
31.20 \\
28.00 \\
29.00 \\
28.05 \\
16.14 \\
15.55 \\
12.75 \\
10.20 \\
23.65 \\
15.55 \\
16.70 \\
12.40 \\
16.09 \\
17.73\end{array}$ & $\begin{array}{r}2.00 \\
2.00 \\
2.80 \\
3.10 \\
14.30 \\
11.90 \\
12.21 \\
19.74 \\
13.80 \\
14.52 \\
34.50 \\
40.78 \\
36.50 \\
35.10 \\
30.15 \\
30.15 \\
30.15 \\
16.95 \\
18.52 \\
15.40 \\
30.40 \\
28.90 \\
17.20 \\
17.55 \\
12.55 \\
16.00 \\
15.20\end{array}$ & $\begin{array}{r}2.10 \\
2.65 \\
2.80 \\
3.10 \\
12.60 \\
11.80 \\
12.84 \\
14.33 \\
14.33 \\
14.80 \\
29.97 \\
40.00 \\
36.50 \\
95.50 \\
30.00 \\
28.00 \\
28.65 \\
17.18 \\
18.92 \\
15.05 \\
21.80 \\
27.80 \\
18.20 \\
18.50 \\
19.00 \\
16.10 \\
18.70\end{array}$ & 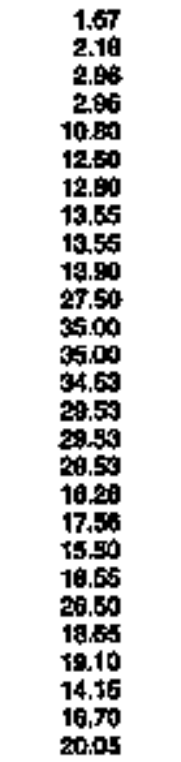 & $\begin{array}{c}2.05 \\
2.45 \\
2.45 \\
2.60 \\
9.30 \\
11.00 \\
11.12 \\
12.72 \\
12.02 \\
13.38 \\
25.20 \\
32.09 \\
32.89 \\
32.89 \\
27.98 \\
27.89 \\
27.10 \\
15.10 \\
17.82 \\
12.27 \\
24.09 \\
29.02 \\
19.07 \\
17.97 \\
12.97 \\
17.10 \\
18.01\end{array}$ & 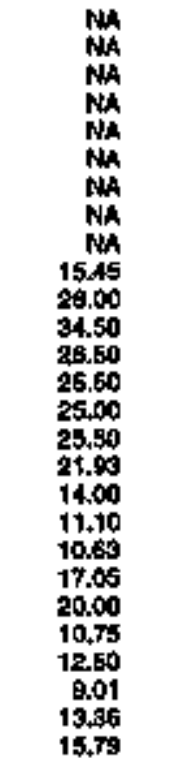 & 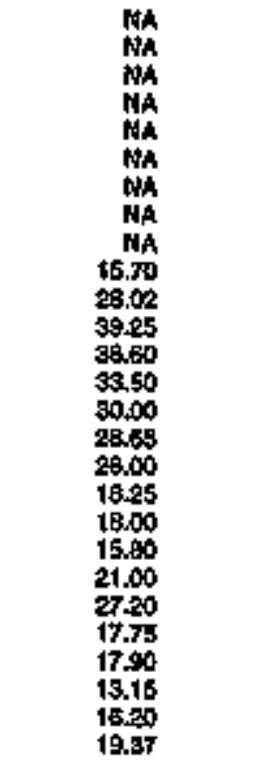 \\
\hline
\end{tabular}

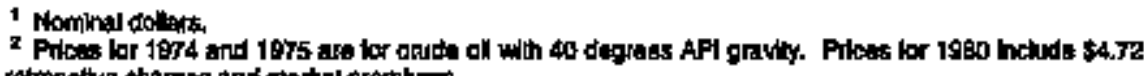

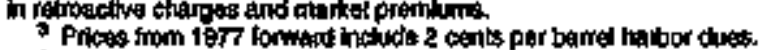

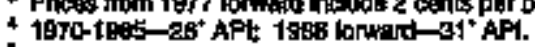

MA=Not gratlabie.

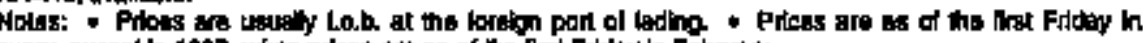

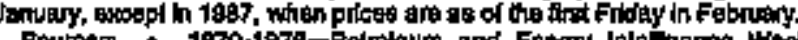

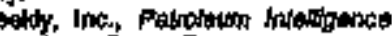

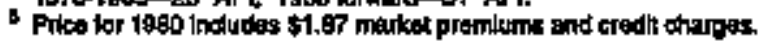

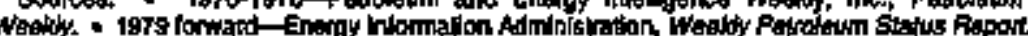




\section{Figure 11.8 World Crude Oil Reflning Capacity}

\section{Wortd and OECD, 1970-1994}

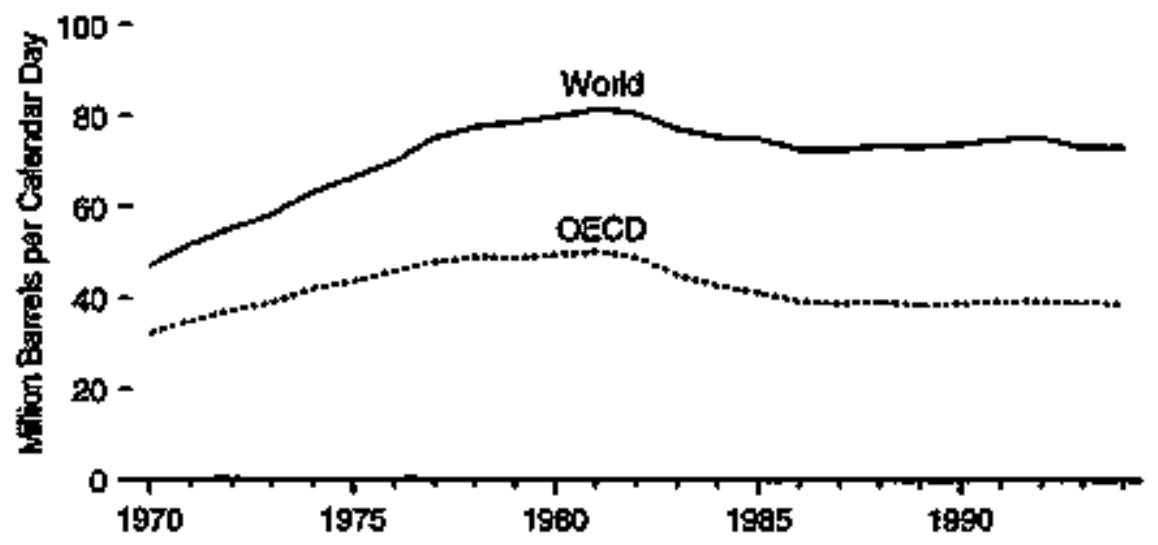

Capacity In Leoding Countries, 1970-1994

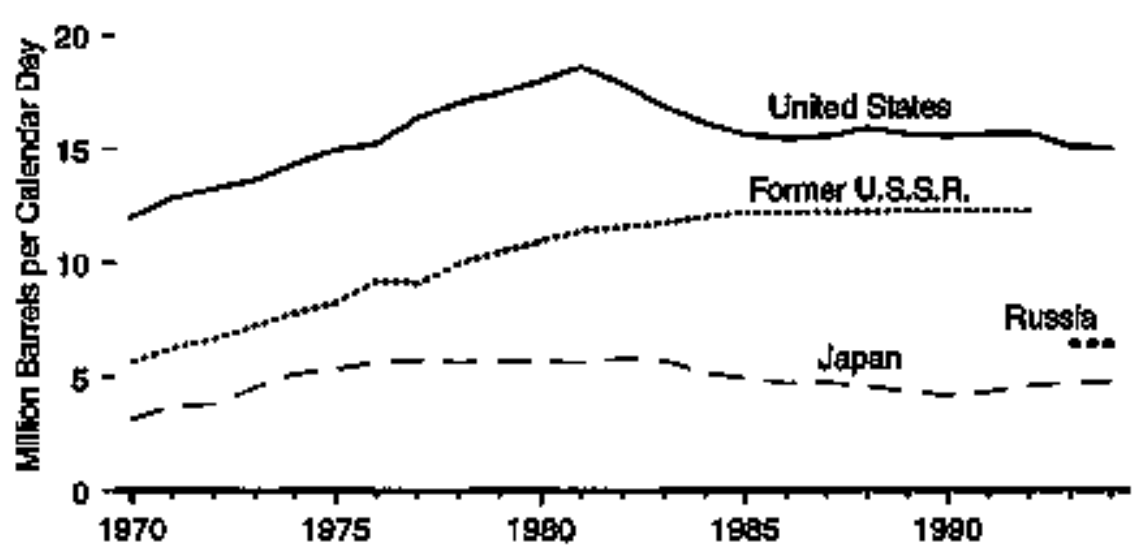

OECD Cruxde ON Refining Capapity by Country, 1994

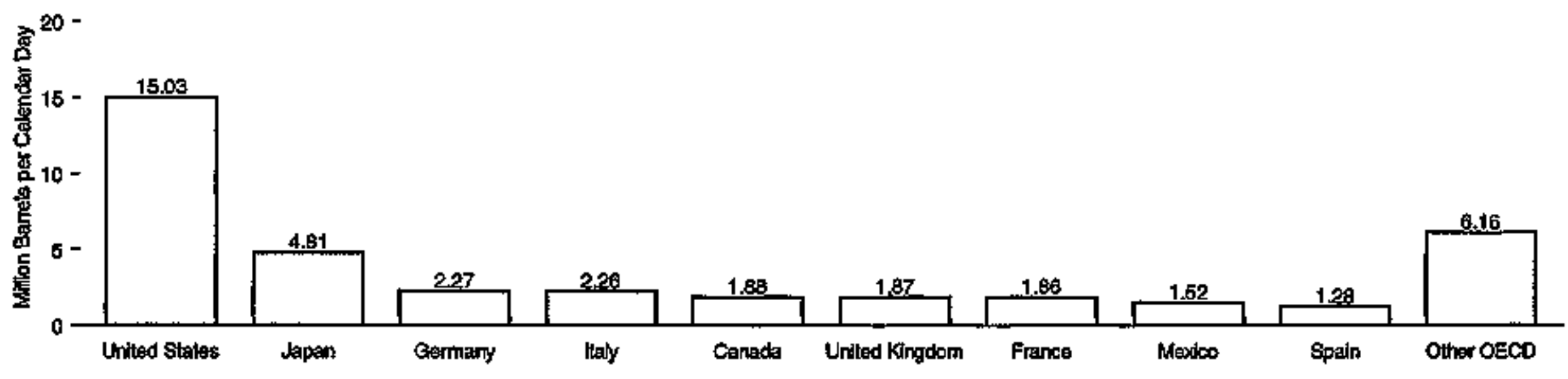

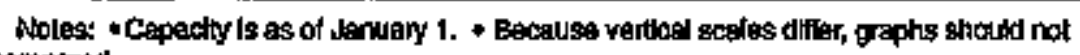
Sotneg: Tainia 11.8. be compered. 
Table 11.8 World Crude Oil Refining Capacity, 1970-1994 (Million Barrels par Calendar Day)

\begin{tabular}{|c|c|c|c|c|c|c|c|c|c|c|c|c|c|c|c|c|c|c|c|}
\hline \multirow[b]{2}{*}{ Yas! } & \multicolumn{11}{|c|}{ QECD' } & \multicolumn{7}{|c|}{ Wan-OECS } & \multirow[b]{2}{*}{ World } \\
\hline & Cunudn & Frances & Gormuny & indy & Japh & Aloxicos & Spatin & $\begin{array}{c}\text { Unitrect } \\
\text { Klagdom }\end{array}$ & $\begin{array}{l}\text { United } \\
\text { Slitas }\end{array}$ & Other & Tolal & Bradl & Chlna & Runele & $\begin{array}{l}\text { Sundi } \\
\text { Ancill }\end{array}$ & Uleraine & $\begin{array}{l}\text { Formle } \\
\text { Us.s.R. }\end{array}$ & Olwer & \\
\hline $\begin{array}{l}1970 \\
1971 \\
1977 \\
1973 \\
1974 \\
1976 \\
1975 \\
1977 \\
1979 \\
1979 \\
1980 \\
1981 \\
1998 \\
1989 \\
1984 \\
1985 \\
1985 \\
1997 \\
1986 \\
1989 \\
1990 \\
1999 \\
1998 \\
1998 \\
1994\end{array}$ & 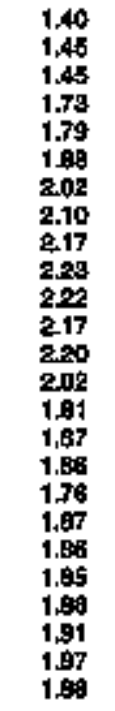 & $\begin{array}{l}2.38 \\
2.53 \\
2.69 \\
296 \\
3.14 \\
3.34 \\
3.39 \\
3.58 \\
3.16 \\
3.47 \\
3.40 \\
3.34 \\
3.29 \\
2.87 \\
2.67 \\
2.39 \\
1.95 \\
1.83 \\
1.94 \\
2.88 \\
1.89 \\
1.82 \\
1.82 \\
1.85 \\
1.86\end{array}$ & $\begin{array}{l}2.36 \\
2.54 \\
2.56 \\
2.70 \\
2.83 \\
2.99 \\
3.10 \\
3.09 \\
3.09 \\
8.10 \\
2.09 \\
2002 \\
2.94 \\
2.47 \\
2.39 \\
2.17 \\
1.93 \\
1.72 \\
1.45 \\
1.59 \\
1.51 \\
2.07 \\
2.08 \\
2.29 \\
2.27\end{array}$ & $\begin{array}{l}2.96 \\
3.24 \\
3.80 \\
3.59 \\
3.69 \\
3.95 \\
4.09 \\
4.26 \\
4.23 \\
4.20 \\
4.13 \\
4.09 \\
4.00 \\
3.28 \\
3.05 \\
3.90 \\
2.74 \\
2.86 \\
2.56 \\
2.45 \\
2.60 \\
2.39 \\
2.39 \\
2.42 \\
2.26\end{array}$ & $\begin{array}{l}3.14 \\
3.70 \\
3.62 \\
4.63 \\
5.15 \\
6.35 \\
5.69 \\
5.78 \\
6.67 \\
5.66 \\
5.71 \\
5.66 \\
5.91 \\
5.79 \\
5.17 \\
4.97 \\
4.72 \\
4.70 \\
4.57 \\
4.36 \\
4.20 \\
4.58 \\
4.61 \\
4.74 \\
4.81\end{array}$ & $\begin{array}{l}0.50 \\
0.57 \\
0.59 \\
0.03 \\
0.63 \\
0.76 \\
0.76 \\
0.94 \\
5.39 \\
1.24 \\
1.39 \\
1.39 \\
1.47 \\
1.29 \\
1.27 \\
1.27 \\
1.37 \\
1.36 \\
1.35 \\
1.35 \\
1.54 \\
1.66 \\
1.57 \\
1.52 \\
1.54\end{array}$ & $\begin{array}{l}0.89 \\
0.95 \\
0.67 \\
1.03 \\
1.18 \\
1.17 \\
1.32 \\
1.28 \\
1.27 \\
1.43 \\
+.46 \\
7.46 \\
1.58 \\
1.52 \\
1.49 \\
1.46 \\
1.37 \\
1.31 \\
1.31 \\
1.28 \\
1.29 \\
1.32 \\
1.39 \\
1.30 \\
1.28\end{array}$ & $\begin{array}{l}2.30 \\
2.39 \\
2.09 \\
2.47 \\
2.76 \\
2.76 \\
2.89 \\
3.01 \\
2.01 \\
2.63 \\
2.69 \\
2.69 \\
2.49 \\
2.26 \\
2.09 \\
2.01 \\
1.79 \\
1.79 \\
1.80 \\
1.80 \\
1.83 \\
1.67 \\
1.86 \\
1.84 \\
1.87\end{array}$ & 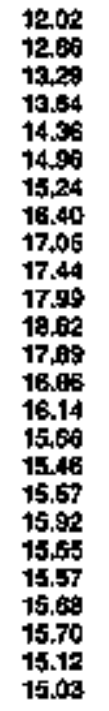 & 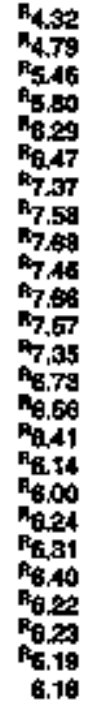 & 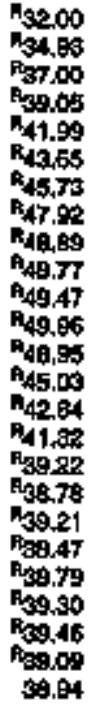 & $\begin{array}{l}0.50 \\
0.51 \\
0.56 \\
0.72 \\
0.79 \\
0.96 \\
0.99 \\
1.92 \\
1.16 \\
1.21 \\
1.21 \\
1.40 \\
1.41 \\
1.29 \\
1.30 \\
1.41 \\
1.31 \\
1.34 \\
1.41 \\
1.41 \\
1.40 \\
1.41 \\
1.41 \\
1.40 \\
1.26\end{array}$ & $\begin{array}{l}0.30 \\
0.42 \\
0.48 \\
0.80 \\
0.80 \\
0.85 \\
1.91 \\
1.40 \\
1.46 \\
1.50 \\
1.80 \\
1.91 \\
1.91 \\
2.00 \\
2.05 \\
2.15 \\
215 \\
2.20 \\
2.20 \\
2.20 \\
2.20 \\
2.20 \\
2.20 \\
2.20 \\
2.20\end{array}$ & $\begin{array}{l}= \\
= \\
= \\
= \\
= \\
= \\
= \\
= \\
= \\
= \\
= \\
= \\
= \\
= \\
5.46 \\
8.46\end{array}$ & $\begin{array}{l}0.98 \\
0.81 \\
0.51 \\
0.43 \\
0.43 \\
0.61 \\
0.54 \\
0.40 \\
0.59 \\
0.49 \\
0.49 \\
0.49 \\
0.49 \\
0.71 \\
0.86 \\
0.64 \\
1.12 \\
1.13 \\
1.98 \\
1.38 \\
1.49 \\
1.09 \\
1.86 \\
1.88 \\
1.61\end{array}$ & $\begin{array}{l}\bar{z} \\
= \\
= \\
= \\
= \\
= \\
= \\
= \\
= \\
= \\
= \\
\bar{z} \\
1.24\end{array}$ & 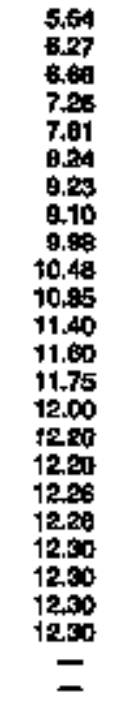 & 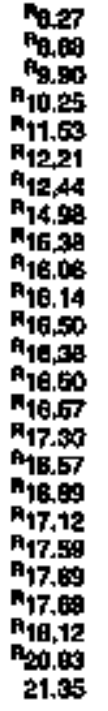 & 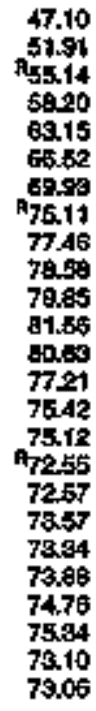 \\
\hline
\end{tabular}

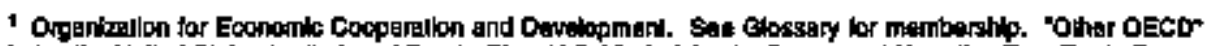

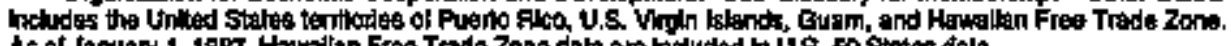

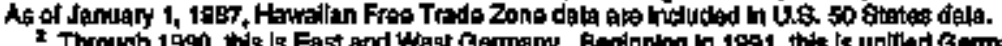

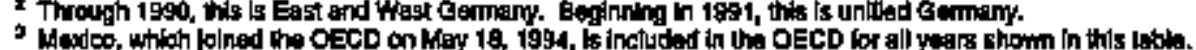

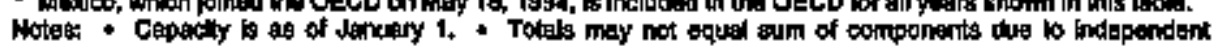

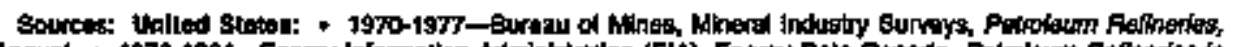

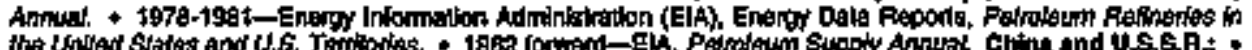

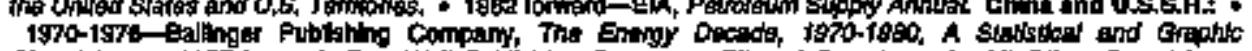

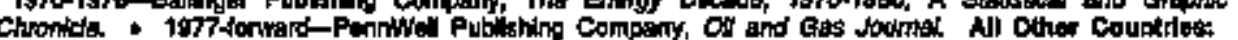
motiniting.

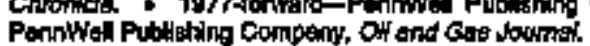




\section{Wortd and OECD, t960-1994}

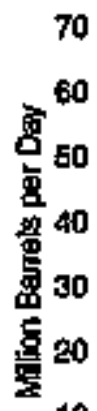

10 -

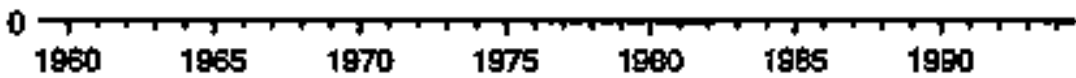

\section{Leading Consumers, 1960-1994}

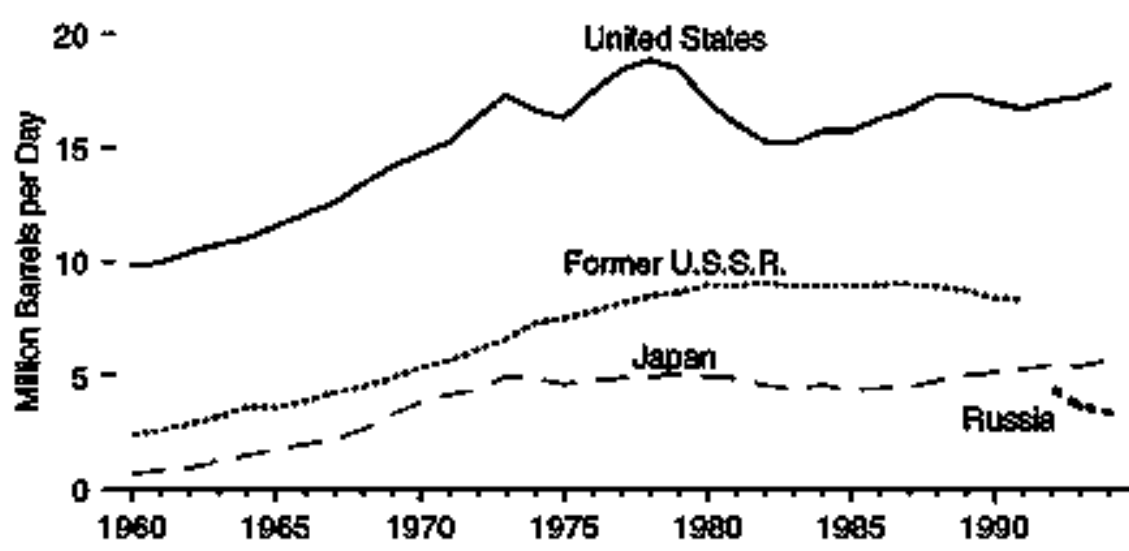

\section{OECD Constumers, 1994}

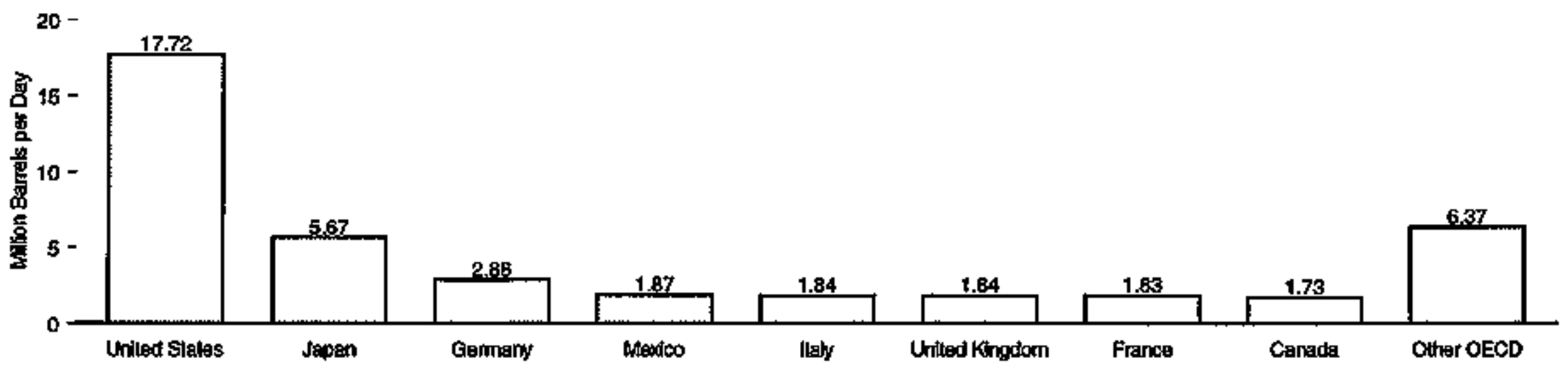

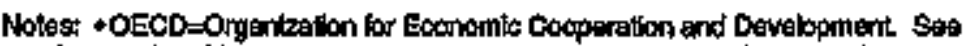
Sourcax Talble 11. 9. Glossary for membership. -Beceuse vertical scales fitier, graphs should not be compared. 
Table 11.9 World Petroleum Consumption, 1960-1994

(Million Barrels per Day)

\begin{tabular}{|c|c|c|c|c|c|c|c|c|c|c|c|c|c|c|c|c|c|}
\hline \multirow[b]{2}{*}{ Yaap } & \multicolumn{10}{|c|}{ OECD1 } & \multicolumn{6}{|c|}{ MAn-OECD } & \multirow[b]{2}{*}{ Workd } \\
\hline & Compdis & Frances & Gorniminga & thaty & Jippen & Mexteo & $\begin{array}{l}\text { Uniked } \\
\text { Kloggtom }\end{array}$ & $\begin{array}{l}\text { Inltod } \\
\text { states }\end{array}$ & Other & Totot & Ara:d & Chino & indla & Rusaldo & $\begin{array}{l}\text { South } \\
\text { Kores }\end{array}$ & $\begin{array}{l}\text { Fommor } \\
\text { US.S.F, }\end{array}$ & \\
\hline 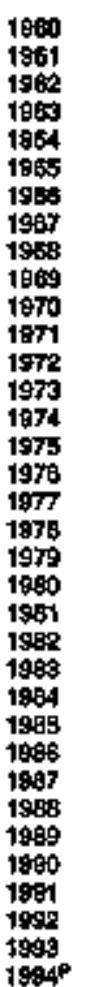 & $\begin{array}{l}0.94 \\
0.97 \\
6.02 \\
0.09 \\
1.05 \\
1.14 \\
1.91 \\
1.25 \\
1.34 \\
1.48 \\
1.60 \\
1.56 \\
1.68 \\
1.73 \\
1.79 \\
1.79 \\
1.82 \\
1.85 \\
1.90 \\
1.97 \\
1.87 \\
1.77 \\
1.58 \\
1.46 \\
1.47 \\
1.50 \\
1.51 \\
1.55 \\
1.69 \\
1.73 \\
1.69 \\
1.68 \\
1.64 \\
1.69 \\
1.73\end{array}$ & 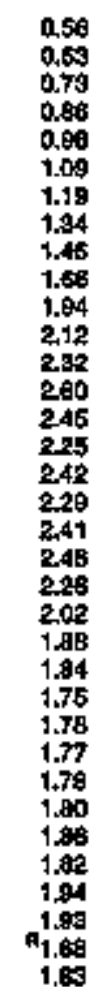 & 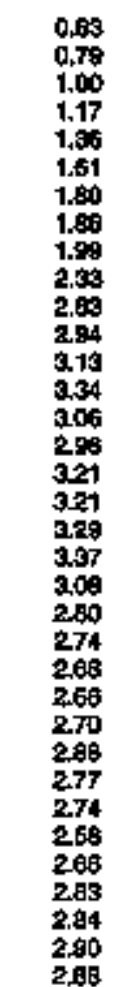 & $\begin{array}{l}0.44 \\
0.54 \\
0.67 \\
0.77 \\
0.90 \\
0.98 \\
1.08 \\
1.19 \\
1.10 \\
1.69 \\
1.74 \\
1.98 \\
1.95 \\
2.07 \\
2.00 \\
1.66 \\
1.97 \\
1.90 \\
1.95 \\
2.04 \\
1.06 \\
1.67 \\
1.79 \\
1.76 \\
1.65 \\
1.72 \\
1.74 \\
1.86 \\
1.64 \\
1.93 \\
1.87 \\
1.86 \\
1.94 \\
1.85 \\
1.84\end{array}$ & 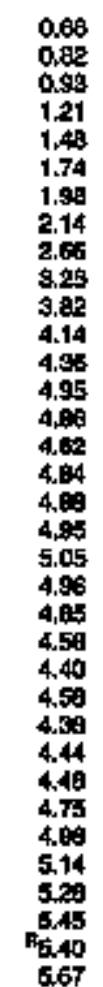 & $\begin{array}{l}0.90 \\
0.29 \\
0.50 \\
0.91 \\
0.33 \\
0.34 \\
0.39 \\
0.39 \\
0.41 \\
0.45 \\
0.50 \\
0.59 \\
0.59 \\
0.57 \\
0.71 \\
0.75 \\
0.89 \\
0.89 \\
0.99 \\
1.10 \\
1.27 \\
1.40 \\
1.48 \\
1.35 \\
1.46 \\
1.47 \\
1.49 \\
1.62 \\
1.55 \\
1.65 \\
1.79 \\
1.80 \\
1.69 \\
1.84 \\
1.87\end{array}$ & $\begin{array}{l}0.94 \\
1.04 \\
1.12 \\
1.27 \\
1.36 \\
1.49 \\
1.59 \\
1.64 \\
1.62 \\
1.98 \\
2.10 \\
2.14 \\
2.29 \\
2.34 \\
2.21 \\
1.91 \\
1.89 \\
1.91 \\
1.94 \\
1.97 \\
1.73 \\
1.59 \\
1.59 \\
1.60 \\
1.65 \\
1.53 \\
1.65 \\
1.60 \\
1.70 \\
1.74 \\
1.76 \\
1.80 \\
1.60 \\
1.89 \\
1.84\end{array}$ & 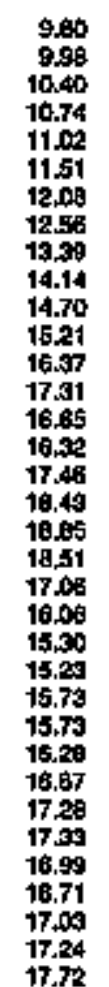 & 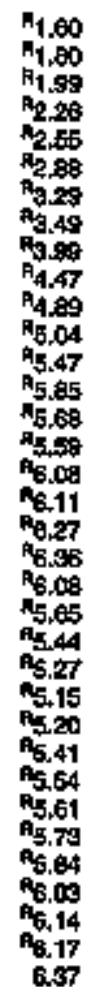 & 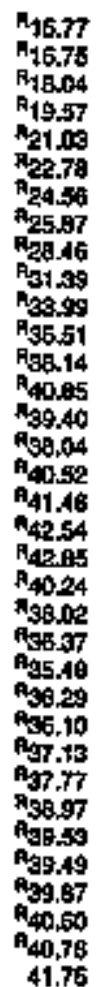 & 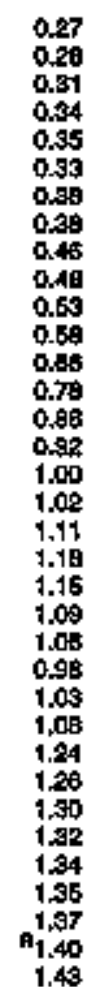 & 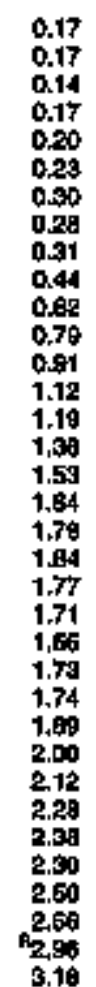 & $\begin{array}{l}0.18 \\
0.17 \\
0.18 \\
0.21 \\
0.22 \\
0.25 \\
0.28 \\
0.28 \\
0.34 \\
0.34 \\
0.40 \\
0.42 \\
0.45 \\
0.49 \\
0.47 \\
0.50 \\
0.51 \\
0.55 \\
0.62 \\
0.58 \\
0.64 \\
0.73 \\
0.74 \\
0.77 \\
0.02 \\
0.90 \\
0.95 \\
0.96 \\
1.08 \\
1.15 \\
1.17 \\
1.19 \\
1.28 \\
1.31 \\
1.34\end{array}$ & 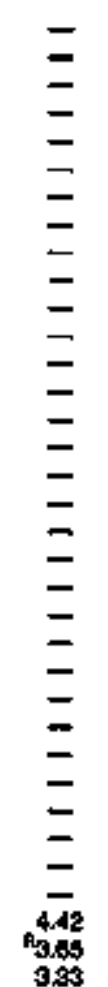 & $\begin{array}{l}0.01 \\
0.02 \\
0.02 \\
0.03 \\
0.02 \\
0.03 \\
0.04 \\
0.07 \\
0.10 \\
0.15 \\
0.20 \\
0.23 \\
0.23 \\
0.28 \\
0.29 \\
0.35 \\
0.38 \\
0.42 \\
0.46 \\
0.53 \\
0.64 \\
0.54 \\
0.58 \\
0.68 \\
0.59 \\
0.57 \\
0.61 \\
0.04 \\
0.75 \\
0.84 \\
1.08 \\
1.20 \\
1.46 \\
1.65 \\
1.70\end{array}$ & 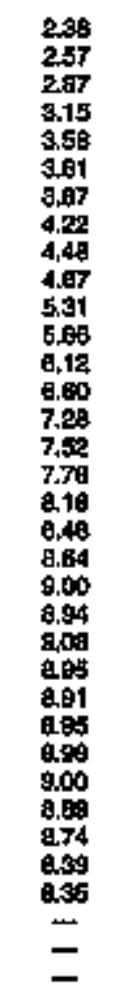 & 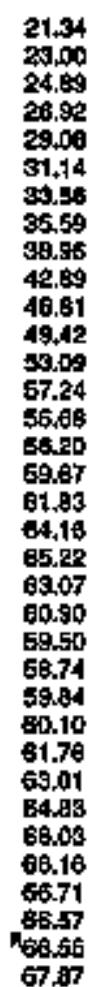 \\
\hline
\end{tabular}

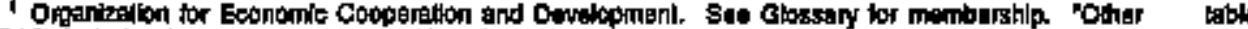

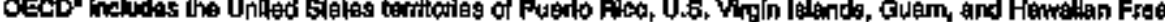

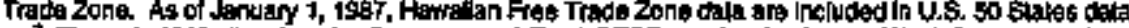

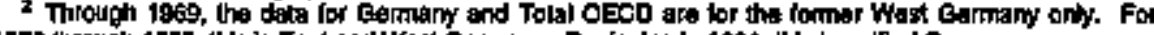

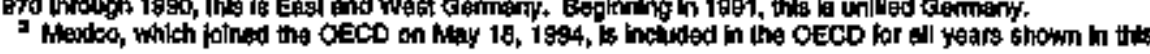

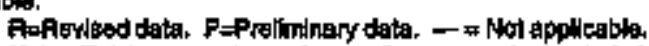

Nolat Tadals mey nol ecured oum or componenis due to independafl rounding.

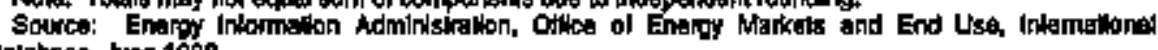
Delabsse, June 1996. 
Total, 1973-1994

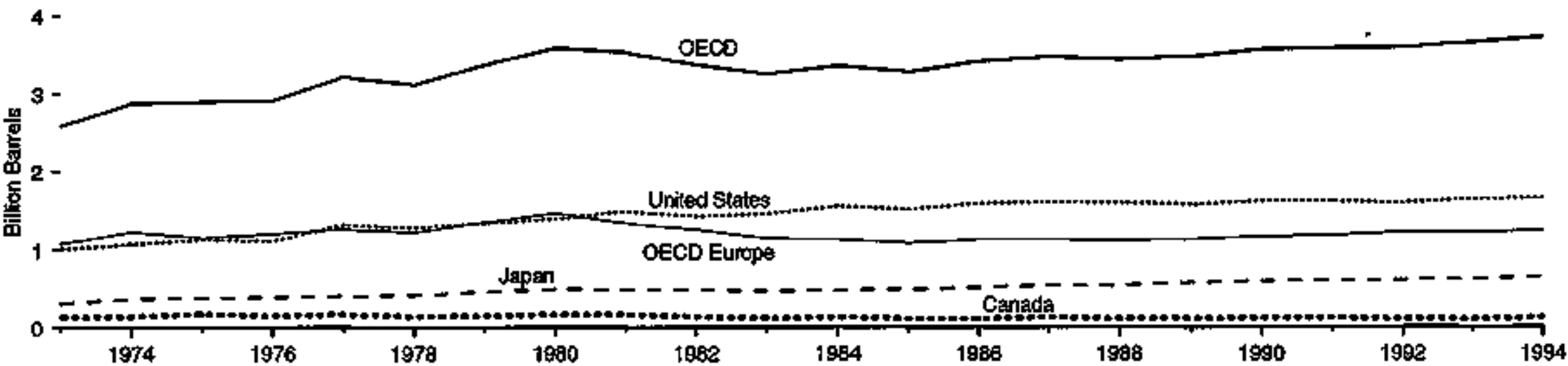

\section{By Country, 1894}

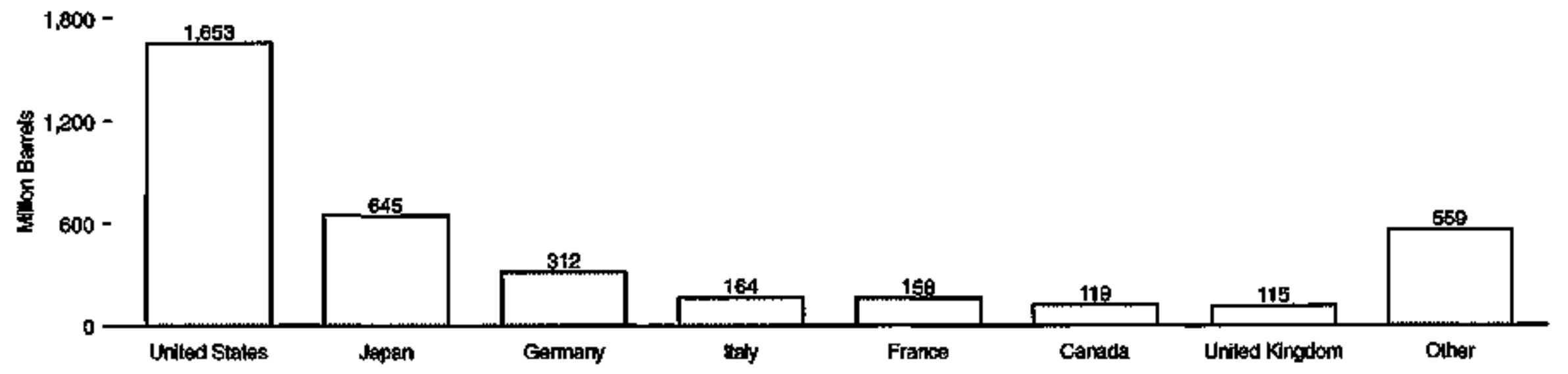

Note: QECO-Organizalien for Economic Cooperation and Developmeni, See Gloserary

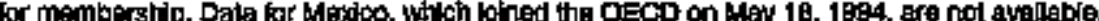

Source: Table 11,10 
Table 11.10 Petroleum Stocks in OECD Countries, End of Year 1973-1994

(Million Barrels)

\begin{tabular}{|c|c|c|c|c|c|c|c|c|c|c|c|}
\hline Year & Frantes & Germinty & thaly & $\begin{array}{c}\text { Uniled } \\
\text { Khrodom }\end{array}$ & $\begin{array}{l}\text { OHhar } \\
\text { OECOO2 } \\
\text { Extrope }\end{array}$ & $\begin{array}{l}\text { OECO } \\
\text { Eumpos }\end{array}$ & Canged & Japun & $\begin{array}{l}\text { Uniked } \\
\text { Stektes: }\end{array}$ & $\begin{array}{l}\text { Opher } \\
\text { oferos }\end{array}$ & OREs \\
\hline 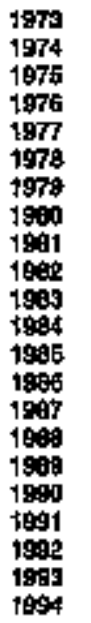 & $\begin{array}{l}201 \\
249 \\
225 \\
294 \\
249 \\
207 \\
220 \\
245 \\
214 \\
199 \\
153 \\
158 \\
199 \\
127 \\
127 \\
140 \\
139 \\
140 \\
153 \\
146 \\
158 \\
158\end{array}$ & $\begin{array}{l}181 \\
213 \\
197 \\
208 \\
225 \\
238 \\
272 \\
319 \\
295 \\
272 \\
249 \\
299 \\
293 \\
259 \\
259 \\
206 \\
271 \\
265 \\
298 \\
910 \\
9309 \\
312\end{array}$ & $\begin{array}{l}159 \\
767 \\
149 \\
143 \\
181 \\
154 \\
159 \\
170 \\
167 \\
179 \\
149 \\
169 \\
197 \\
153 \\
169 \\
195 \\
194 \\
172 \\
160 \\
174 \\
1769 \\
164\end{array}$ & $\begin{array}{l}158 \\
191 \\
165 \\
155 \\
148 \\
158 \\
169 \\
168 \\
143 \\
125 \\
118 \\
112 \\
120 \\
124 \\
121 \\
112 \\
118 \\
112 \\
110 \\
119 \\
119 \\
116\end{array}$ & $\begin{array}{r}390 \\
437 \\
434 \\
455 \\
495 \\
469 \\
523 \\
564 \\
516 \\
499 \\
473 \\
465 \\
440 \\
475 \\
454 \\
446 \\
442 \\
474 \\
461 \\
476 \\
7475 \\
490\end{array}$ & 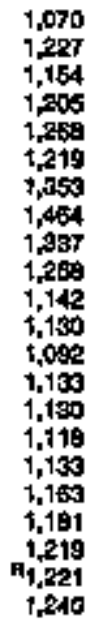 & $\begin{array}{r}140 \\
145 \\
174 \\
159 \\
167 \\
144 \\
150 \\
164 \\
161 \\
198 \\
121 \\
129 \\
113 \\
111 \\
125 \\
118 \\
114 \\
121 \\
119 \\
107 \\
1905 \\
179\end{array}$ & $\begin{array}{c}303 \\
370 \\
375 \\
300 \\
409 \\
413 \\
460 \\
495 \\
498 \\
464 \\
470 \\
479 \\
494 \\
509 \\
640 \\
558 \\
577 \\
590 \\
606 \\
503 \\
618 \\
645\end{array}$ & $\begin{array}{l}1,000 \\
1,074 \\
1,138 \\
1,118 \\
1,312 \\
1,278 \\
1,341 \\
1,398 \\
1,404 \\
1,480 \\
1,454 \\
1,656 \\
1,519 \\
1,598 \\
1,607 \\
1,597 \\
1,501 \\
1,621 \\
1,617 \\
1,598 \\
1,847 \\
1,850\end{array}$ & $\begin{array}{l}57 \\
64 \\
67 \\
69 \\
68 \\
68 \\
75 \\
72 \\
67 \\
68 \\
68 \\
69 \\
66 \\
72 \\
71 \\
71 \\
71 \\
79 \\
65 \\
67 \\
69 \\
69\end{array}$ & 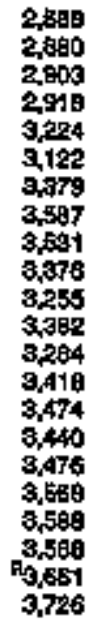 \\
\hline
\end{tabular}

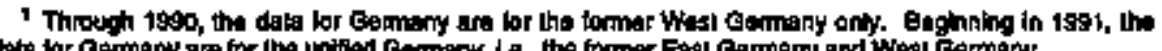

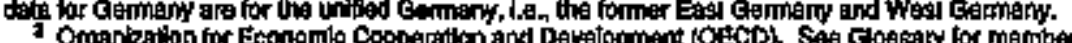

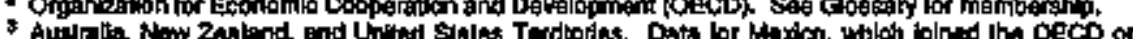
May 18, 1994, ere not avalable.
Rapientsed dala.

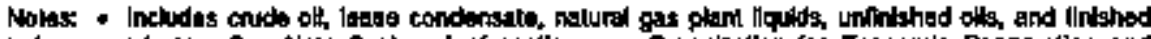

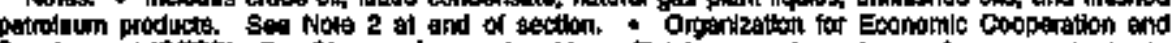

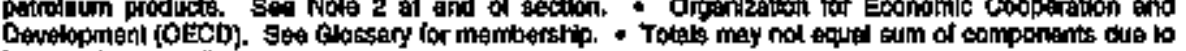
indepontion munton

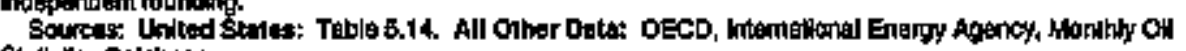


\&
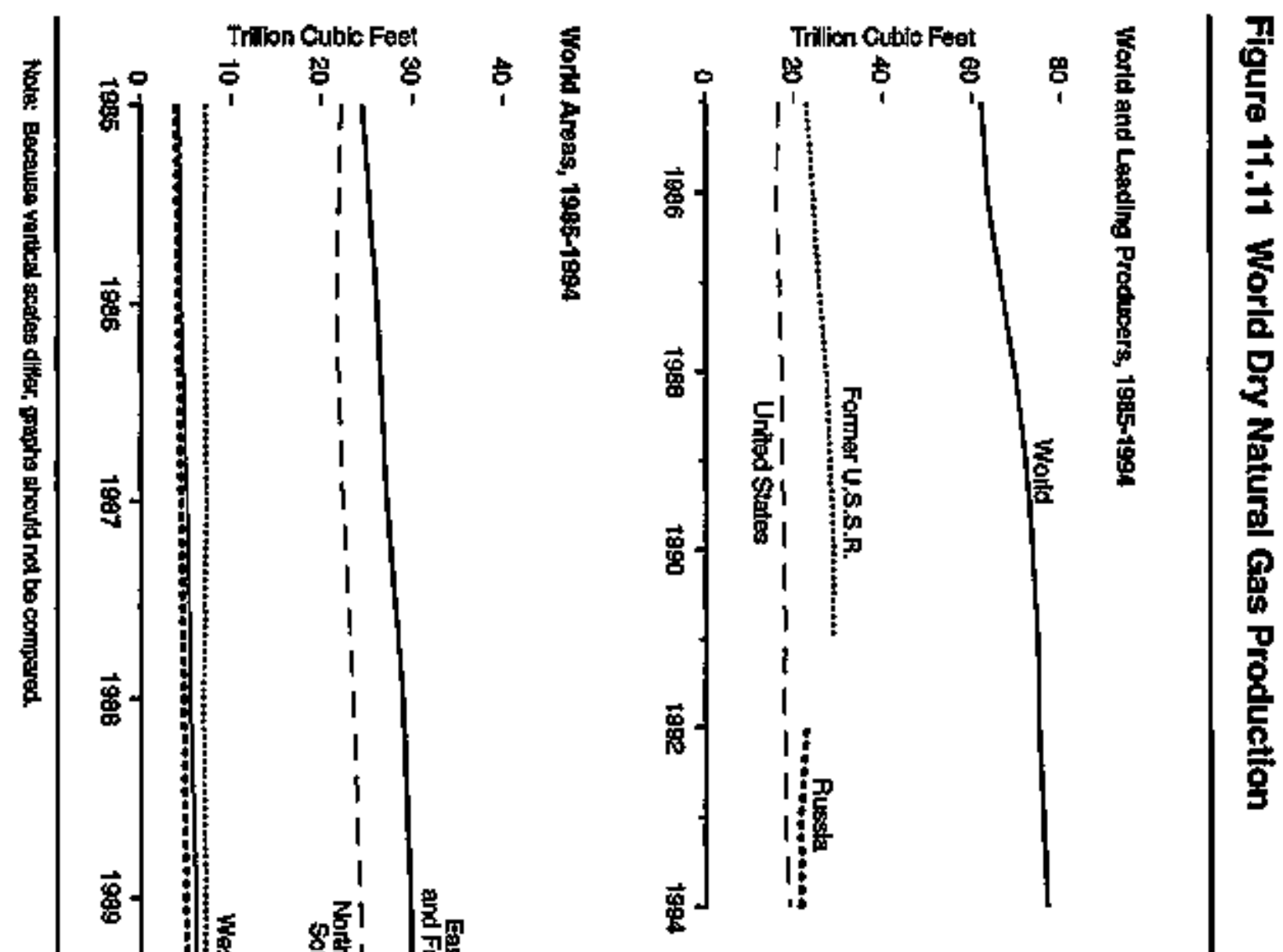

告

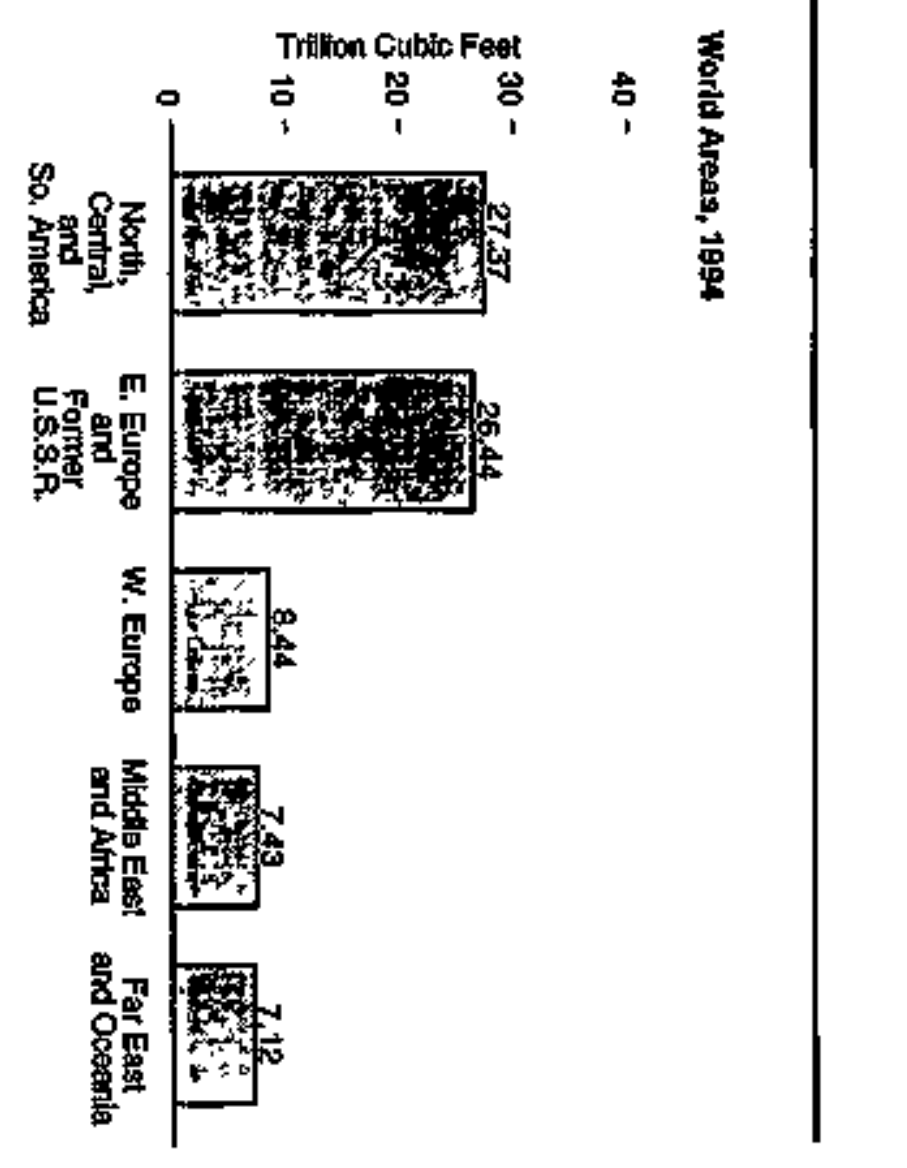


Table 11.11 World Dry Natural Gas Production, 1985-1994

(Trillion Cubic Feet)

\begin{tabular}{|c|c|c|c|c|c|c|c|c|c|c|}
\hline Aoglon tund Coontry & 1065 & to:0 & 1968 & 1989 & 1069 & 1990 & $199 t$ & $\$ 692$ & 1900 & 19040 \\
\hline 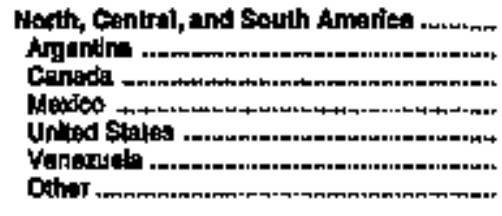 & $\begin{array}{r}22.21 \\
0.50 \\
3.04 \\
0.95 \\
16.45 \\
0.62 \\
0.65\end{array}$ & $\begin{array}{r}21.62 \\
0.55 \\
2.88 \\
0.98 \\
1608 \\
0.67 \\
0.58\end{array}$ & $\begin{array}{r}22.39 \\
0.50 \\
3.10 \\
0.80 \\
16.52 \\
0.58 \\
0.56\end{array}$ & $\begin{array}{r}23.47 \\
0.58 \\
3.57 \\
0.62 \\
17,02 \\
0.68 \\
0.69\end{array}$ & $\begin{array}{r}24.16 \\
0.72 \\
3.60 \\
0.93 \\
17.31 \\
0.77 \\
0.64\end{array}$ & $\begin{array}{r}26.62 \\
0.69 \\
R_{3.85} \\
0.94 \\
17.91 \\
\mathbf{R}_{0.76} \\
\mathbf{R}_{0.62}\end{array}$ & 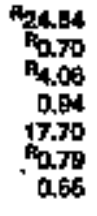 & $\begin{array}{r}P_{25.42} \\
\text { P.71 } \\
P_{4.52} \\
0.92 \\
17.04 \\
0.76 \\
0.06\end{array}$ & 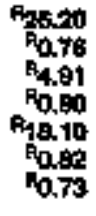 & $\begin{array}{r}2+.37 \\
0.78 \\
5.27 \\
0.91 \\
19.73 \\
0.88 \\
0.78\end{array}$ \\
\hline 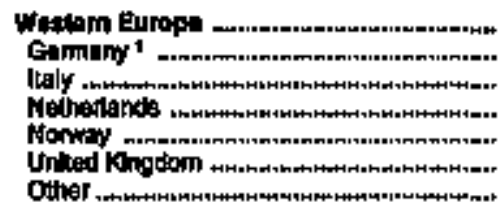 & $\begin{array}{l}7.22 \\
0.77 \\
0.50 \\
3.01 \\
0.94 \\
1.59 \\
0.45\end{array}$ & $\begin{array}{l}7.07 \\
0.71 \\
0.58 \\
2.76 \\
0.0 \% \\
1.60 \\
0.45\end{array}$ & $\begin{array}{l}7.38 \\
0.79 \\
0.50 \\
2.77 \\
1.06 \\
1.69 \\
0.44\end{array}$ & $\begin{array}{l}6.91 \\
0.74 \\
0.59 \\
2.45 \\
1.05 \\
1.62 \\
0.46\end{array}$ & $\begin{array}{l}7.18 \\
0.71 \\
0.60 \\
2.67 \\
1.08 \\
1.58 \\
0.51\end{array}$ & $\begin{array}{r}7.19 \\
\mathbf{p}_{0.66} \\
0.61 \\
2.69 \\
0.06 \\
1.76 \\
0.50\end{array}$ & $\begin{array}{r}7.63 \\
0.87 \\
0.67 \\
3.04 \\
0.97 \\
2.01 \\
0.53\end{array}$ & $\begin{array}{r}7.89 \\
0.68 \\
0.04 \\
3.05 \\
1.04 \\
1.93 \\
0.54\end{array}$ & $\begin{array}{r}0.32 \\
0.60 \\
0.60 \\
3.11 \\
0.97 \\
2.31 \\
0.56\end{array}$ & $\begin{array}{l}9.44 \\
0.71 \\
0.73 \\
2.95 \\
1.04 \\
2.47 \\
0.54\end{array}$ \\
\hline 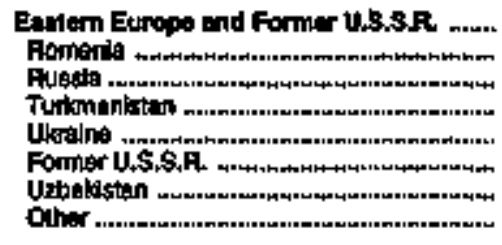 & $\begin{array}{r}24.80 \\
1.27 \\
= \\
22.71 \\
0.53\end{array}$ & $\frac{1.34}{=}$ & $\begin{array}{r}27.14 \\
1.32 \\
= \\
= \\
\overline{0.35} \\
\overline{0.45}\end{array}$ & $\begin{array}{r}29.96 \\
\bar{z} \\
\bar{z} \\
\overline{0.19} \\
\overline{0.17}\end{array}$ & $\begin{array}{r}29.70 \\
1.13 \\
\overline{=} \\
29.11 \\
0.48\end{array}$ & $\begin{array}{c}1.13 \\
1.00 \\
\overline{-} \\
29.70 \\
0.55\end{array}$ & $\begin{array}{c}29.65 \\
0.88 \\
- \\
\frac{-}{20.62} \\
0.35\end{array}$ & $\begin{array}{r}A_{28.08} \\
0.78 \\
2.62 \\
A_{2.12} \\
0.74 \\
-1.51 \\
P_{0.91}\end{array}$ & 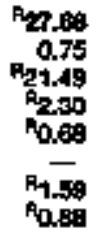 & $\begin{array}{r}20.44 \\
0.60 \\
21.43 \\
1.26 \\
0.65 \\
\frac{1.67}{0.76}\end{array}$ \\
\hline 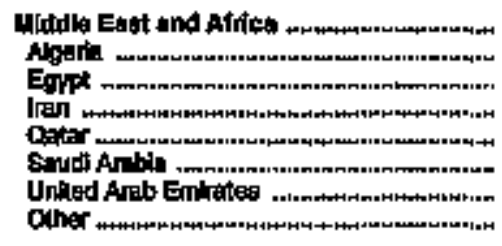 & $\begin{array}{r}4.24 \\
1.38 \\
0.16 \\
0.80 \\
0,19 \\
0.72 \\
0.49 \\
0.71\end{array}$ & $\begin{array}{l}4.51 \\
1.39 \\
0.20 \\
0.54 \\
0.18 \\
0.65 \\
0.54 \\
0.04\end{array}$ & $\begin{array}{r}5.13 \\
1.52 \\
0.02 \\
0.50 \\
0.20 \\
0.80 \\
0.00 \\
n_{1,00}\end{array}$ & $\begin{array}{l}5.55 \\
1.69 \\
0.24 \\
0.71 \\
0.21 \\
1.00 \\
0.60 \\
P 1.07\end{array}$ & $\begin{array}{r}6.09 \\
1.71 \\
0.27 \\
0.79 \\
0.22 \\
1.05 \\
0.21 \\
11.24\end{array}$ & $\begin{array}{l}0.17 \\
1,79 \\
0.29 \\
0.94 \\
0.28 \\
1.09 \\
0.78 \\
1.13\end{array}$ & $\begin{array}{l}6.58 \\
1.53 \\
0.82 \\
0.08 \\
0.83 \\
1.13 \\
0.02 \\
0.06\end{array}$ & $\begin{array}{r}\text { P9.91 } \\
1.97 \\
0.05 \\
0.86 \\
0.40 \\
1.20 \\
1.02 \\
01.08\end{array}$ & $\begin{array}{l}m .24 \\
m_{1.94} \\
0.40 \\
m 0.00 \\
0.40 \\
1.27 \\
m 0.04 \\
m .30\end{array}$ & $\begin{array}{l}7,49 \\
1.78 \\
0.42 \\
1,12 \\
0.48 \\
1,38 \\
0,45 \\
1,35\end{array}$ \\
\hline 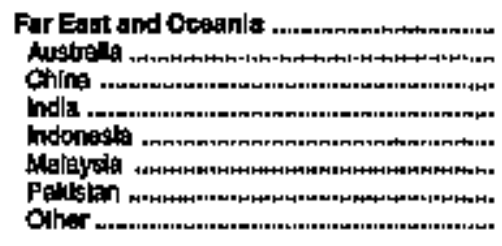 & $\begin{array}{l}4.00 \\
0.46 \\
0.46 \\
0.14 \\
1.23 \\
0.44 \\
0.37 \\
0.53\end{array}$ & $\begin{array}{l}4.21 \\
0.52 \\
0.49 \\
0.19 \\
1.18 \\
0.63 \\
0.39 \\
0.93\end{array}$ & $\begin{array}{l}4.60 \\
0.59 \\
0.49 \\
0.28 \\
5.29 \\
0.56 \\
0.42 \\
0.58\end{array}$ & $\begin{array}{l}4.76 \\
0.66 \\
0.49 \\
0.31 \\
1.34 \\
0.69 \\
0.44 \\
1.05\end{array}$ & $\begin{array}{l}4.99 \\
0.37 \\
0.51 \\
0.32 \\
1.42 \\
0.61 \\
0.47 \\
1.08\end{array}$ & $\begin{array}{l}5.44 \\
0.72 \\
0.51 \\
0.40 \\
1.50 \\
0.65 \\
0.48 \\
1.15\end{array}$ & $\begin{array}{l}5.76 \\
0.76 \\
0.53 \\
0.45 \\
1.72 \\
0.76 \\
0.63 \\
\text { F..05 }\end{array}$ & $\begin{array}{r}0.07 \\
0.82 \\
0.00 \\
0.48 \\
1.79 \\
0.00 \\
0.55 \\
1.10\end{array}$ & $\begin{array}{r}P_{6.66} \\
0.68 \\
0.56 \\
R_{0.56} \\
n_{5.97} \\
0.89 \\
0.56 \\
A_{1.16}\end{array}$ & $\begin{array}{l}7.12 \\
0.93 \\
0.09 \\
0.09 \\
2.24 \\
0.92 \\
0.63 \\
1.23\end{array}$ \\
\hline 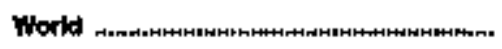 & 82.17 & 69,45 & 66,41 & 69.66 & 72.00 & A7.s.S6 & $A 74.61$ & ค7497 & $\mathrm{F}_{76,00}$ & 76.60 \\
\hline
\end{tabular}

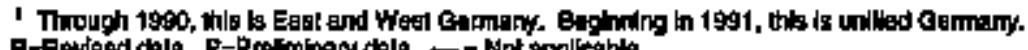

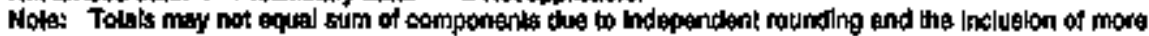

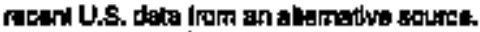

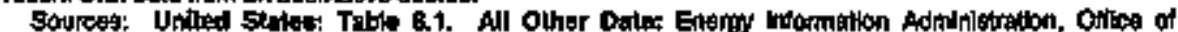

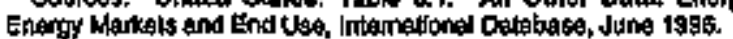


Figure 11.12 Worid Dry Natural Gas Supply and Disposition, 1993

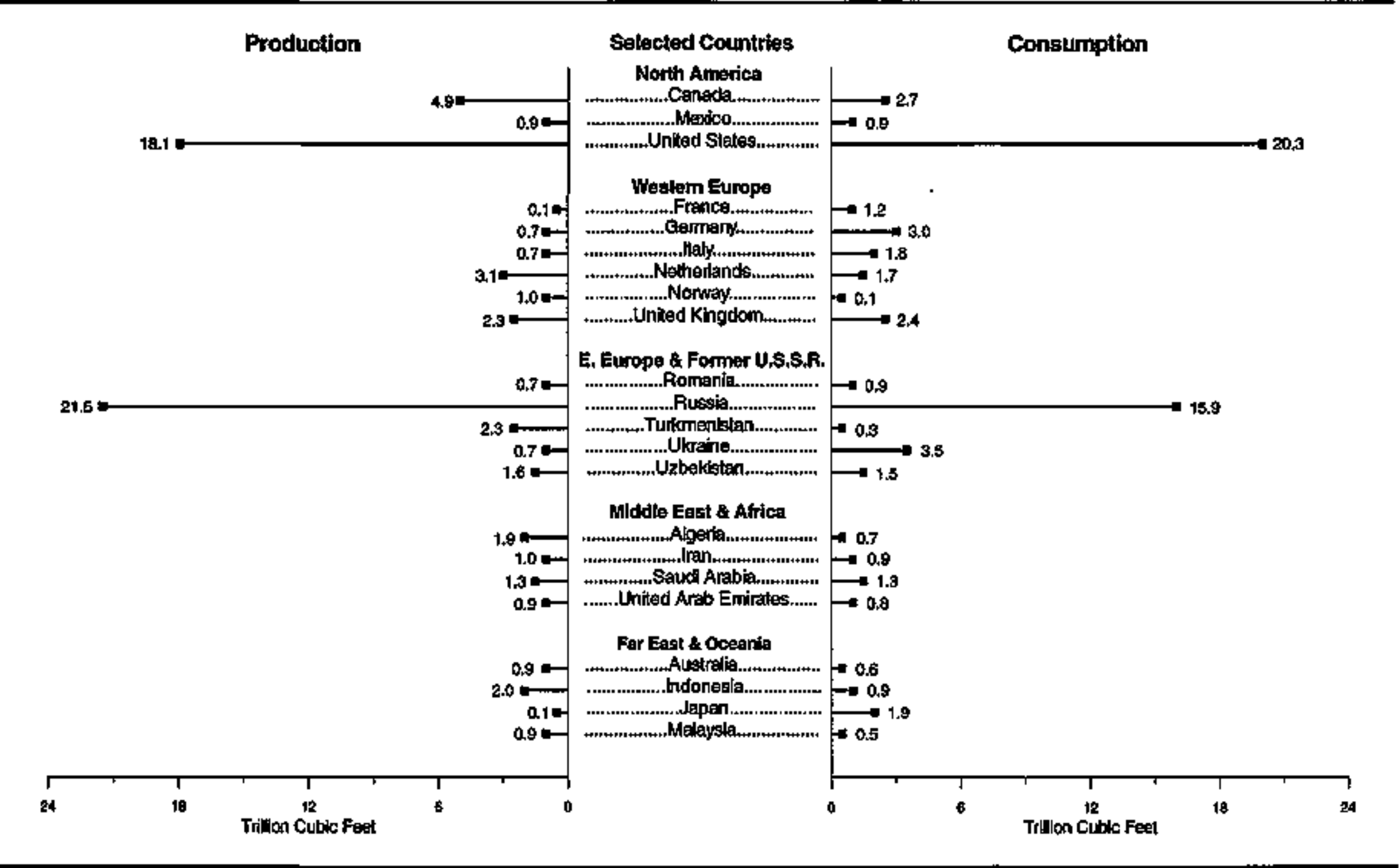

Source: Table 11.12. 
Table 11.12 World Dry Natural Gas Supply and Disposition, 1993 (Billon Cubic Feet)

\begin{tabular}{|c|c|c|c|c|}
\hline \multirow[b]{2}{*}{ Aloglos and Country } & \multicolumn{2}{|c|}{ Sugphy } & \multicolumn{2}{|c|}{ Doppostlon } \\
\hline & $\begin{array}{l}\text { Dry Nahunal } \\
\text { Bas Productlon }\end{array}$ & Imports 1 & Export: 1 & $\begin{array}{l}\text { Apparent } \\
\text { Copedinpilon } 2\end{array}$ \\
\hline 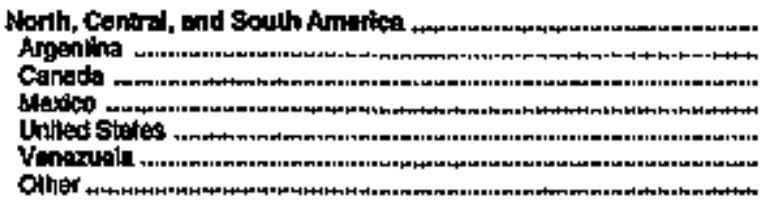 & $\begin{array}{r}25,206 \\
760 \\
4,910 \\
899 \\
18,096 \\
\text { art } \\
726\end{array}$ & $\begin{array}{r}2,492 \\
73 \\
29 \\
40 \\
2,350 \\
0 \\
0\end{array}$ & $\begin{array}{r}2,41 \\
0 \\
2,2028 \\
2 \\
140 \\
0 \\
73\end{array}$ & $\begin{array}{r}28,200 \\
839 \\
2719 \\
936 \\
20,279 \\
815 \\
658\end{array}$ \\
\hline 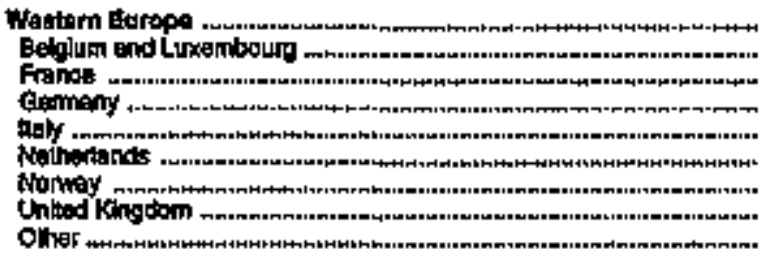 & $\begin{array}{r}1,351 \\
60) \\
115 \\
679 \\
698 \\
0,112 \\
097 \\
2,313 \\
448\end{array}$ & $\begin{array}{r}6,170 \\
416 \\
1,047 \\
2,790 \\
1,135 \\
197 \\
0 \\
149 \\
697\end{array}$ & $\begin{array}{r}2,594 \\
0 \\
20 \\
65 \\
1 \\
1,552 \\
877 \\
22 \\
67\end{array}$ & $\begin{array}{r}11,995 \\
416 \\
1,172 \\
2,042 \\
\$, 601 \\
\$, 695 \\
90 \\
2,410 \\
1,270\end{array}$ \\
\hline 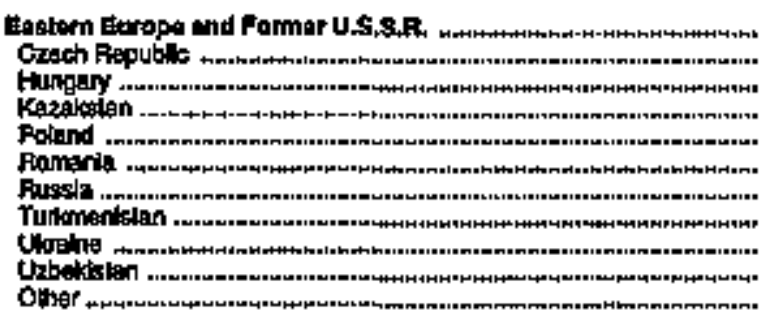 & $\begin{array}{r}27,604 \\
8 \\
199 \\
237 \\
175 \\
746 \\
21,499 \\
2,309 \\
678 \\
1,561 \\
200\end{array}$ & $\begin{array}{r}6,060 \\
249 \\
197 \\
2,51 \\
209 \\
150 \\
370 \\
0 \\
2,806 \\
208 \\
1,612\end{array}$ & $\begin{array}{r}8,149 \\
(s) \\
0 \\
0 \\
0 \\
0 \\
5,969 \\
1,967 \\
7 \\
256 \\
(9)\end{array}$ & $\begin{array}{r}25,644 \\
267 \\
376 \\
487 \\
398 \\
900 \\
15,910 \\
395 \\
3,607 \\
1,541 \\
1,870\end{array}$ \\
\hline 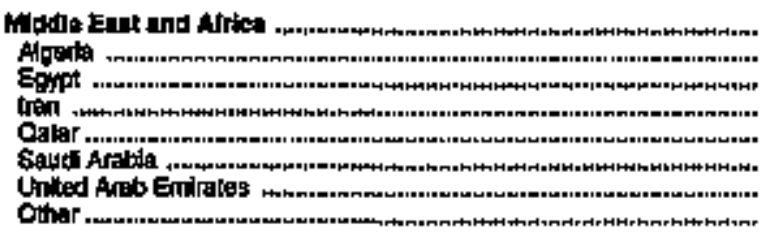 & $\begin{array}{r}7,237 \\
1,902 \\
399 \\
958 \\
1,277 \\
1,208 \\
1,209 \\
1,298\end{array}$ & $\begin{array}{r}40 \\
0 \\
0 \\
0 \\
0 \\
0\end{array}$ & $\begin{array}{r}1,460 \\
1,247 \\
0 \\
18 \\
0 \\
0 \\
139 \\
57\end{array}$ & $\begin{array}{r}5,816 \\
695 \\
399 \\
938 \\
477 \\
1,260 \\
700 \\
1,200\end{array}$ \\
\hline 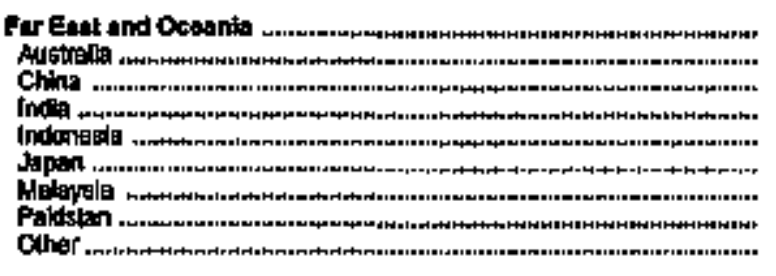 & $\begin{array}{r}6,551 \\
904 \\
558 \\
582 \\
1,973 \\
77 \\
960 \\
583 \\
1,084\end{array}$ & $\begin{array}{r}2,272 \\
0 \\
0 \\
0 \\
0 \\
1,873 \\
0 \\
0 \\
340\end{array}$ & $\begin{array}{r}2,049 \\
234 \\
0 \\
0 \\
1,129 \\
0 \\
120 \\
0 \\
284\end{array}$ & $\begin{array}{r}\mathbf{9} 720 \\
630 \\
550 \\
530 \\
850 \\
1.949 \\
460 \\
560 \\
1,160\end{array}$ \\
\hline 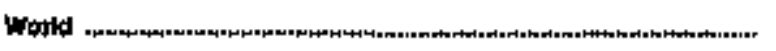 & 75,995 & 10,694 & 16,660 & 76,315 \\
\hline
\end{tabular}

I Inctudas liquallad nabural gas,

chaves stouts changes.

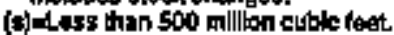

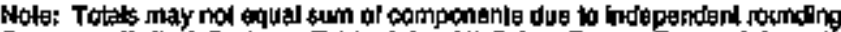

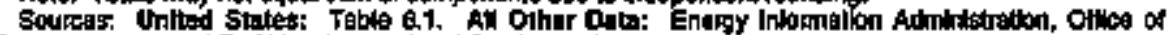

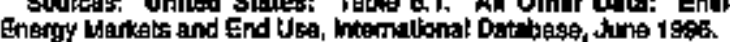




\section{Figure 11.13 Workd Dry Natural Gas Consumption}

\section{Wortd and Leading Consumers, 1980-1994}

20 -

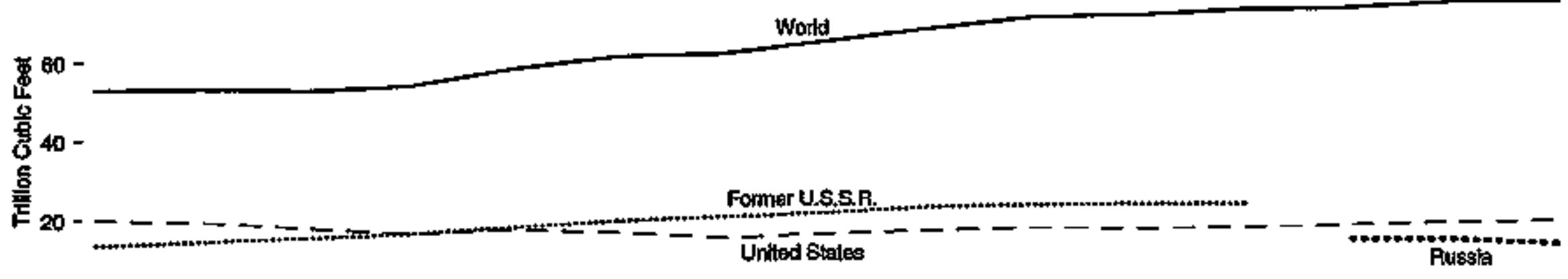

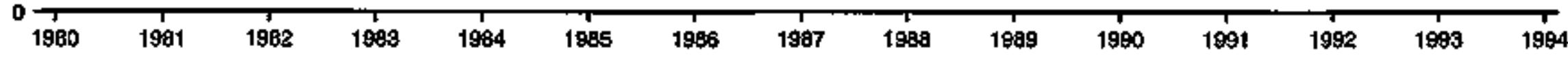

\section{Top Consuming Countries, 1994}

эอ -

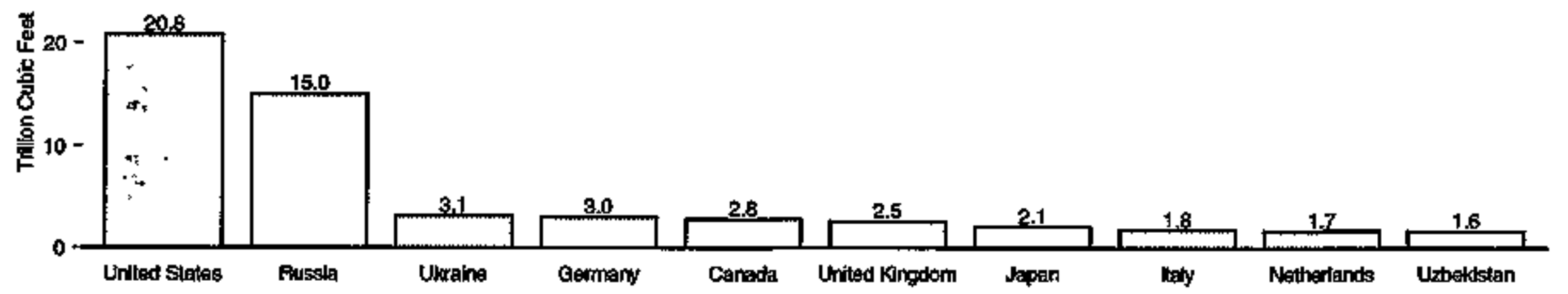

Note: Because vertical scalos difier, graphs should not be companded.

Source: Table t1.13. 
Table 11.13 World Dry Natural Gas Consumption, 1980-1994

(Bîlition Cubic Feet)

\begin{tabular}{|c|c|c|c|c|c|c|c|c|c|c|c|c|c|c|c|c|c|}
\hline Ver & Conato & France & Germany' & laby & Itan & Japan & Manicos & $\begin{array}{l}\text { Nether- } \\
\text { Ianthe }\end{array}$ & Fues: & $\begin{array}{l}\text { Spodd } \\
\text { Arnbio }\end{array}$ & UkTating & Kingodon & $\begin{array}{l}\text { United } \\
\text { Stelose }\end{array}$ & $\begin{array}{l}\text { Forme. } \\
\text { USTE. }\end{array}$ & $\begin{array}{l}\text { Uebole } \\
\text { latim }\end{array}$ & Oiner & Wark \\
\hline $\begin{array}{l}1980 \\
1991 \\
1998 \\
1998 \\
1984 \\
1895 \\
1985 \\
1989 \\
1988 \\
1998 \\
1990 \\
1991 \\
1998 \\
1999 \\
1994\end{array}$ & 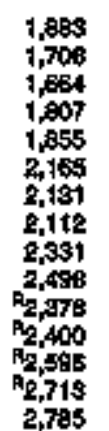 & $\begin{array}{r}1,006 \\
896 \\
919 \\
1,049 \\
1,009 \\
1,420 \\
1,127 \\
1,067 \\
981 \\
891 \\
1,072 \\
1,149 \\
1,139 \\
1,172 \\
1,206\end{array}$ & 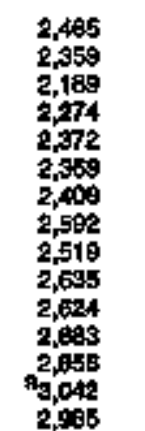 & $\begin{array}{r}973 \\
983 \\
989 \\
1,009 \\
1,171 \\
1,150 \\
1,298 \\
1,371 \\
1,460 \\
1,579 \\
1,672 \\
1,779 \\
1,757 \\
1,001 \\
1,777\end{array}$ & $\begin{array}{l}232 \\
155 \\
200 \\
310 \\
476 \\
600 \\
586 \\
585 \\
706 \\
794 \\
897 \\
811 \\
883 \\
\$ 38 \\
1,128\end{array}$ & 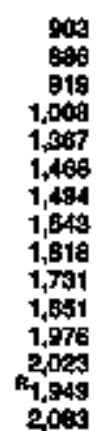 & 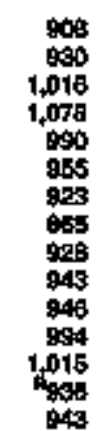 & 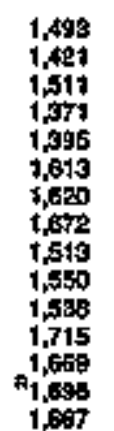 & $\begin{array}{r}= \\
= \\
= \\
= \\
= \\
= \\
= \\
\overline{1} \\
15,967 \\
14,948\end{array}$ & $\begin{array}{l}517 \\
400 \\
201 \\
200 \\
253 \\
716 \\
890 \\
940 \\
1,029 \\
1,050 \\
1,077 \\
1,190 \\
1,001 \\
1,058 \\
1,339\end{array}$ & $\begin{array}{l}= \\
= \\
= \\
= \\
= \\
= \\
= \\
0.000 \\
0,000\end{array}$ & $\begin{array}{l}1,702 \\
1,671 \\
1,570 \\
1,774 \\
1,900 \\
1,691 \\
2,090 \\
2,070 \\
1,972 \\
1,951 \\
2,059 \\
2,218 \\
2,127 \\
2,440 \\
2,647\end{array}$ & $\begin{array}{c}19,877 \\
19,404 \\
18,001 \\
15,855 \\
17,061 \\
17,291 \\
15,211 \\
17,211 \\
18,000 \\
18,601 \\
18,716 \\
19,065 \\
18,544 \\
920,279 \\
20,765\end{array}$ & $\begin{array}{c}13,309 \\
14,440 \\
15,502 \\
15,802 \\
19,512 \\
20,302 \\
21,502 \\
20,450 \\
24,002 \\
24,529 \\
24,501 \\
25,014 \\
= \\
=\end{array}$ & $\begin{array}{l}= \\
= \\
= \\
= \\
= \\
= \\
= \\
A_{1}, 359 \\
1,564\end{array}$ & 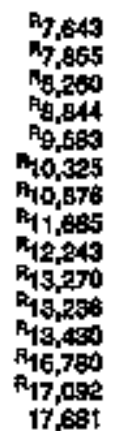 & 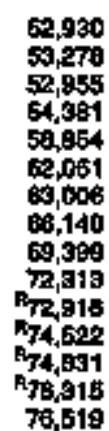 \\
\hline
\end{tabular}

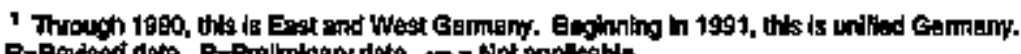

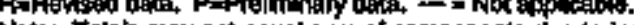

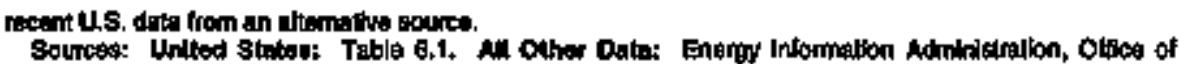

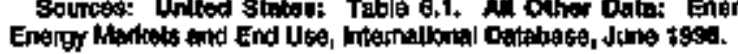




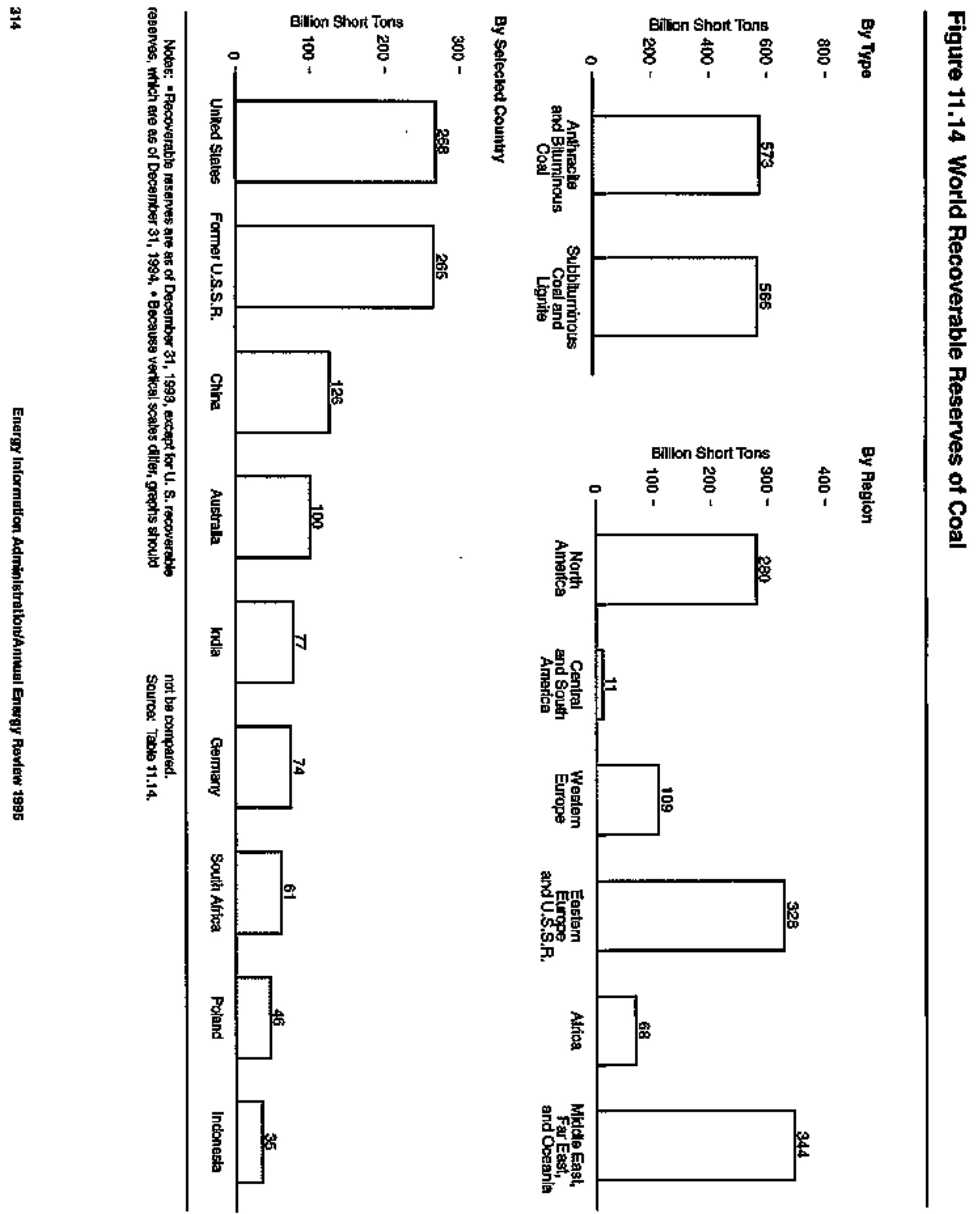


Table 11.14 World Recoverable Reserves of Coal

(Million Short Tons)

\begin{tabular}{|c|c|c|c|}
\hline Ragion and Couniny & Antipractio ind Gitiminous Coel & Subblatumineug Coal and Ltynthe & Totol \\
\hline 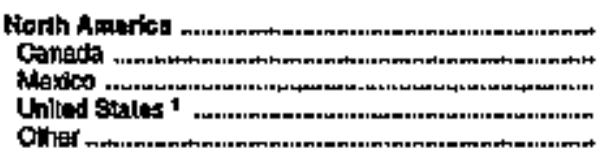 & $\begin{array}{r}124,091 \\
4,970 \\
948 \\
116,173 \\
0\end{array}$ & $\begin{array}{r}158,411 \\
4,535 \\
3097 \\
150,298 \\
200\end{array}$ & $\begin{array}{r}279,502 \\
8,505 \\
1,395 \\
289,400 \\
200\end{array}$ \\
\hline 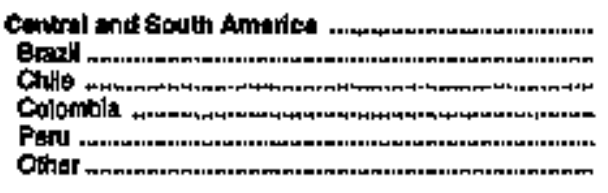 & $\begin{array}{r}6,277 \\
0 \\
34 \\
4,674 \\
1,059 \\
464\end{array}$ & $\begin{array}{l}5,018 \\
3,138 \\
7,259 \\
3 \% 9 \\
110 \\
170\end{array}$ & $\begin{array}{r}11,200 \\
3,160 \\
1,302 \\
5,005 \\
1,1 \mathrm{Bg} \\
691\end{array}$ \\
\hline 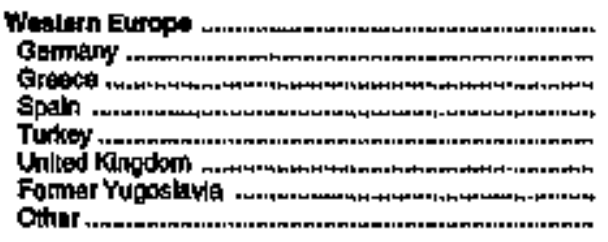 & $\begin{array}{r}30,544 \\
20,465 \\
0 \\
937 \\
179 \\
2,205 \\
70 \\
698\end{array}$ & $\begin{array}{r}78,291 \\
47,730 \\
3,907 \\
681 \\
7,701 \\
551 \\
18,152 \\
178\end{array}$ & $\begin{array}{r}108,625 \\
74,180 \\
8,307 \\
1,598 \\
7,679 \\
2,750 \\
18,228 \\
877\end{array}$ \\
\hline 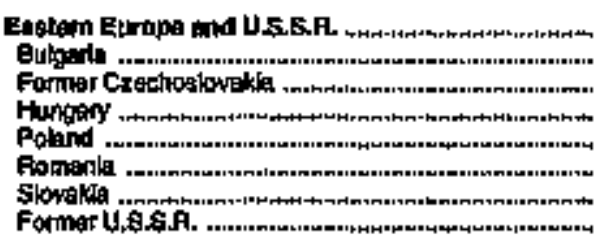 & $\begin{array}{r}149,200 \\
14 \\
1,810 \\
857 \\
32,077 \\
1 \\
0 \\
114,040\end{array}$ & $\begin{array}{r}176,230 \\
3,274 \\
3,665 \\
1,250 \\
14,350 \\
3,438 \\
251 \\
150,122\end{array}$ & $\begin{array}{r}329,491 \\
2,899 \\
5,668 \\
4,917 \\
46,407 \\
3,407 \\
261 \\
264,760\end{array}$ \\
\hline 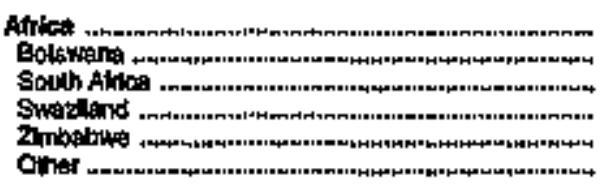 & $\begin{array}{r}66,596 \\
3,056 \\
60,994 \\
128 \\
609 \\
796\end{array}$ & $\begin{array}{r}1,397 \\
0 \\
0 \\
1,101 \\
0 \\
0 \\
209\end{array}$ & $\begin{array}{r}67,967 \\
3,659 \\
60,594 \\
1,299 \\
809 \\
1,091\end{array}$ \\
\hline 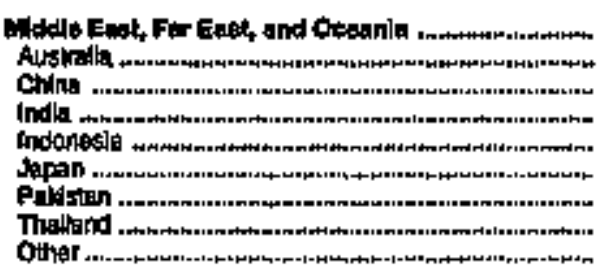 & $\begin{array}{r}196,690 \\
49,979 \\
60,564 \\
76,009 \\
1,080 \\
085 \\
0 \\
0 \\
1,132\end{array}$ & $\begin{array}{r}146,941 \\
50,265 \\
57,651 \\
2,004 \\
34,200 \\
10 \\
009 \\
1,701 \\
718\end{array}$ & $\begin{array}{r}349,671 \\
100,240 \\
126,215 \\
77,109 \\
35,343 \\
905 \\
909 \\
1,10 \% \\
1,650\end{array}$ \\
\hline 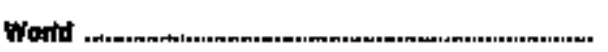 & $678,2 \pi$ & $5 A 3,27$ & $1,139,651$ \\
\hline
\end{tabular}

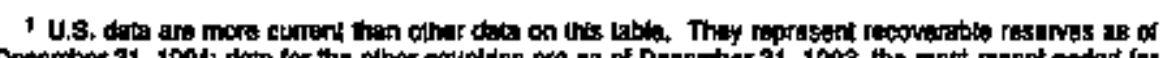

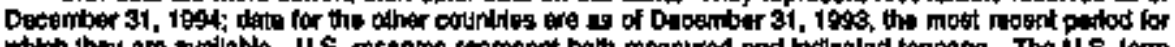

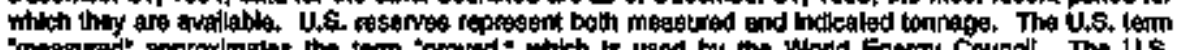

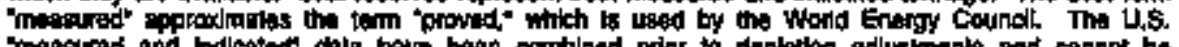

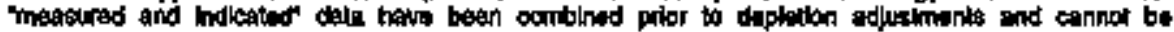
menptured as "meesured elona:"

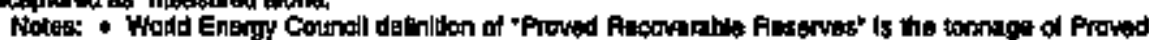

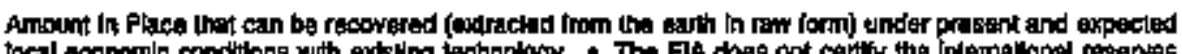

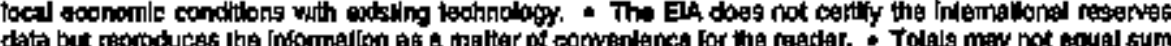

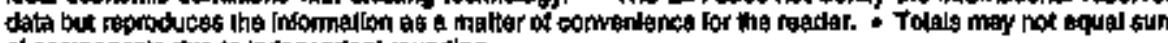

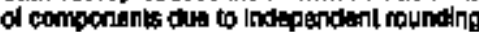

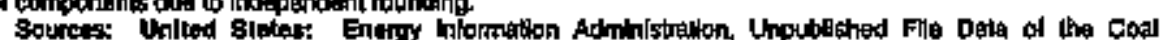

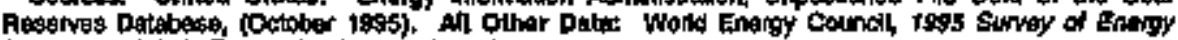

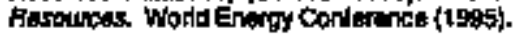




\section{Figure 11.t5 World Coal Production}

\section{Work and Leading Producere, 1995-1994}

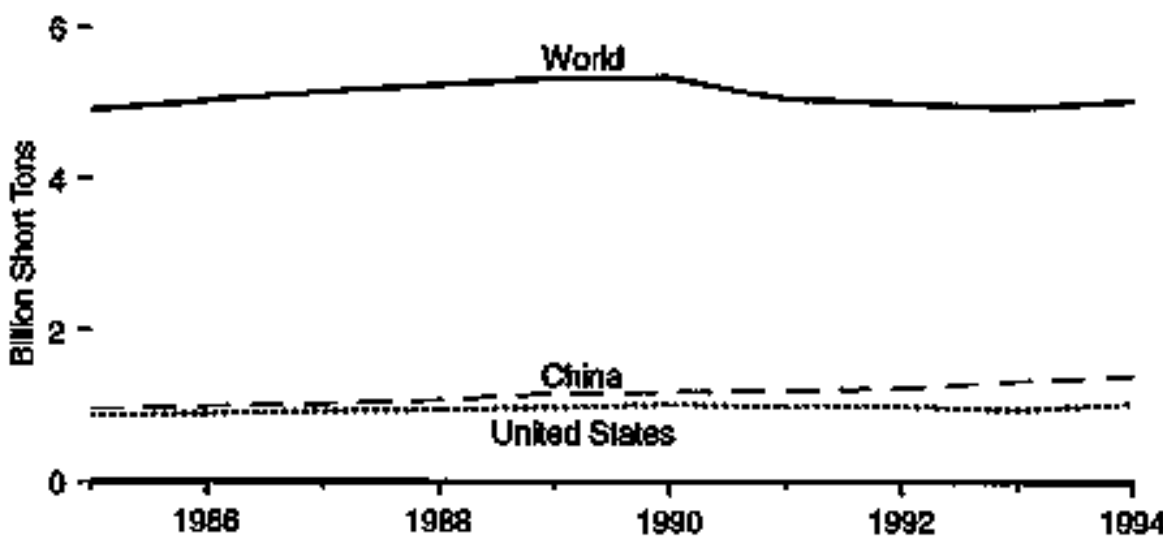

\section{World Areas, 1985-1964}

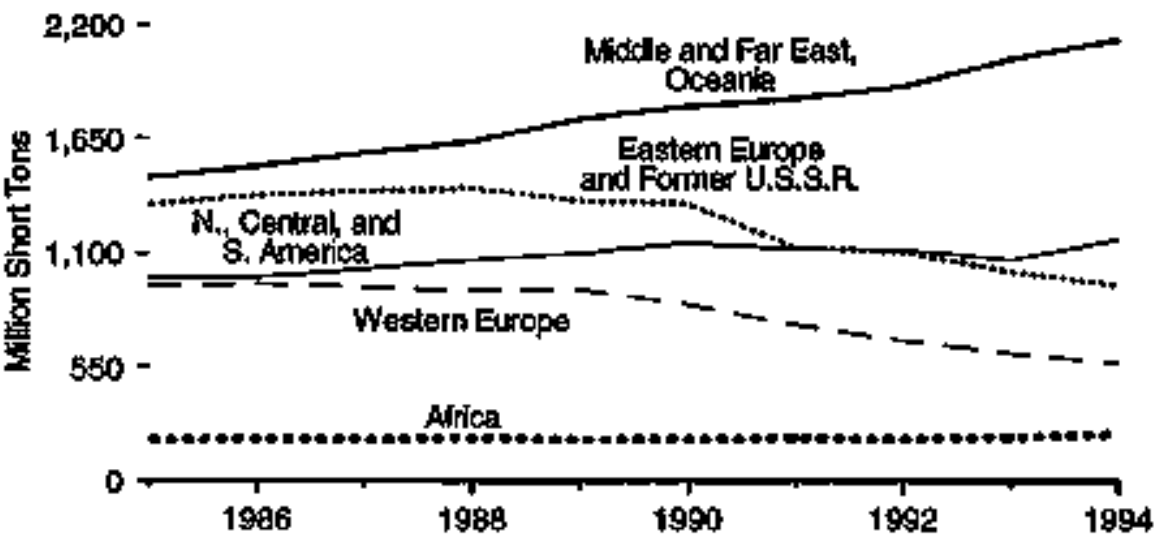

Top Producing Countrles, t994

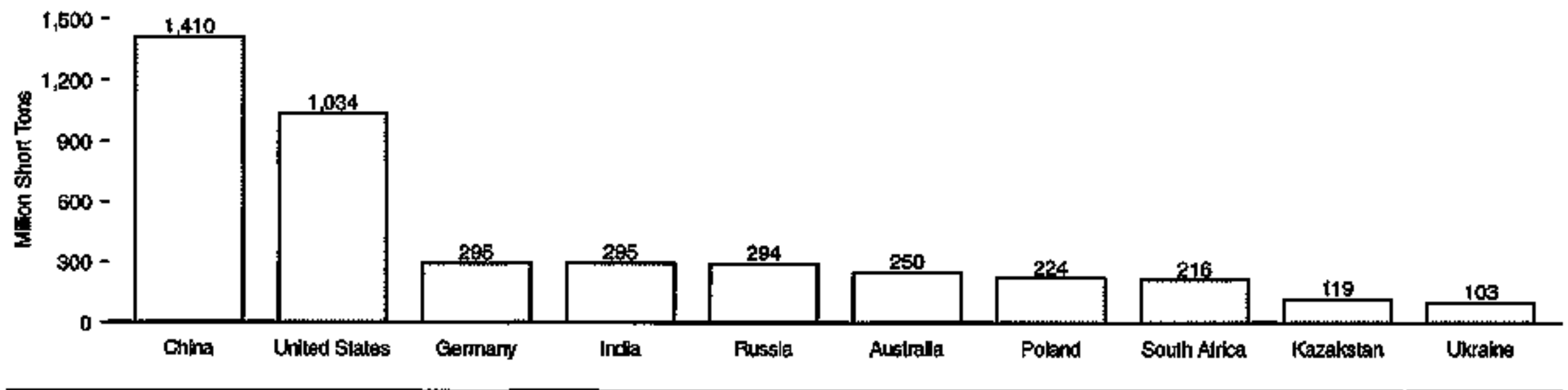


Table 11.15 World Coal Production, 1985-1994

(Million Short Tons)

\begin{tabular}{|c|c|c|c|c|c|c|c|c|c|c|}
\hline Rogien apd County & 1905 & 1906 & 1807 & 1869 & 1000 & 1900 & 1091 & 1002 & 10003 & $1094^{\circ}$ \\
\hline 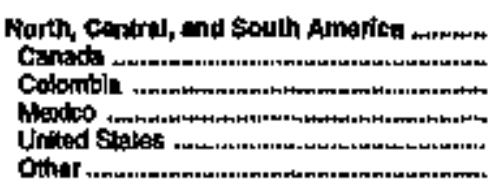 & 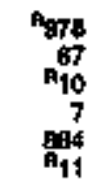 & 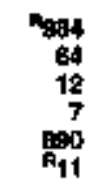 & $\begin{array}{r}1,021 \\
67 \\
16 \\
9 \\
919 \\
910\end{array}$ & $\begin{array}{r}F_{1,065} \\
78 \\
17 \\
8 \\
950 \\
950\end{array}$ & $\begin{array}{r}01,100 \\
79 \\
21 \\
8 \\
89 \\
913\end{array}$ & $\begin{array}{r}1,145 \\
75 \\
25 \\
5 \\
1,029 \\
\text { h-10 }\end{array}$ & 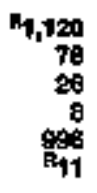 & 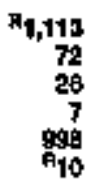 & $\begin{array}{r}R_{1,018} \\
76 \\
26 \\
7 \\
945 \\
\mathrm{R}_{11}\end{array}$ & $\begin{array}{r}1,103 \\
60 \\
28 \\
10 \\
1,008 \\
11\end{array}$ \\
\hline 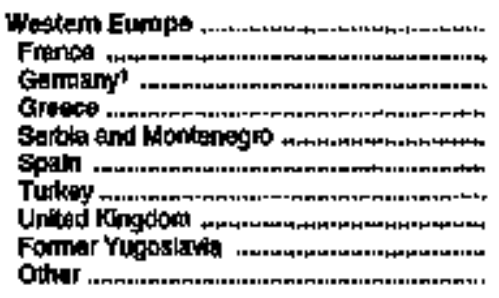 & 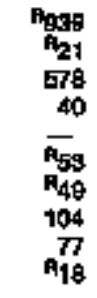 & 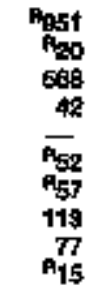 & 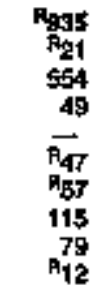 & 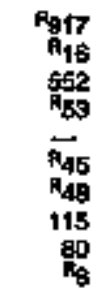 & 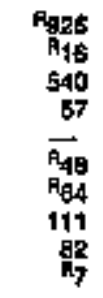 & 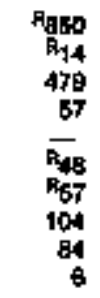 & 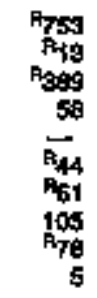 & $\begin{array}{l}P_{676} \\
A_{12} \\
340 \\
64 \\
47 \\
P_{44} \\
57 \\
94 \\
\frac{97}{115}\end{array}$ & 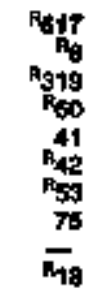 & $\begin{array}{r}570 \\
7 \\
285 \\
68 \\
41 \\
40 \\
60 \\
8 \\
12\end{array}$ \\
\hline 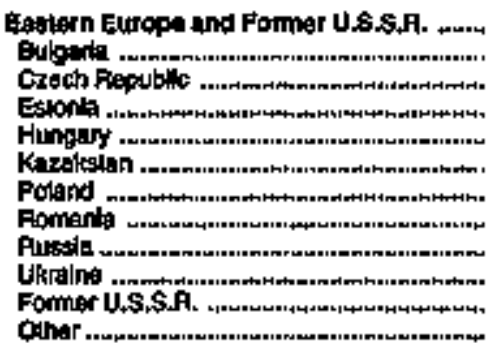 & 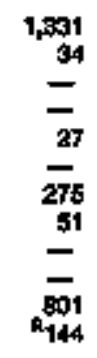 & 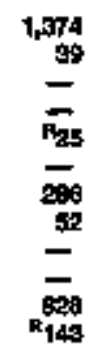 & $\frac{1}{\frac{4}{439}}$ & $\begin{array}{l}1,411 \\
38 \\
\frac{-}{28} \\
\frac{294}{65} \\
= \\
\overline{901}\end{array}$ & 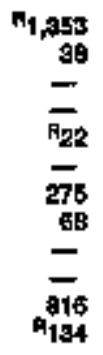 & 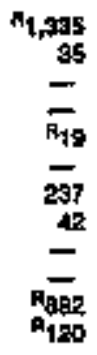 & $\begin{array}{l}n_{1,129} \\
\frac{-}{19} \\
\frac{231}{36} \\
\frac{-}{702} \\
F_{111}\end{array}$ & 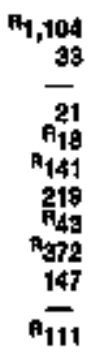 & 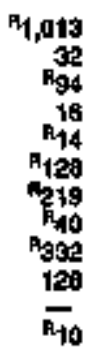 & $\begin{array}{r}291 \\
32 \\
09 \\
16 \\
13 \\
119 \\
224 \\
41 \\
294 \\
103 \\
-9\end{array}$ \\
\hline 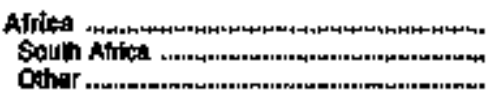 & $\begin{array}{r}197 \\
191 \\
6\end{array}$ & $\begin{array}{r}202 \\
195 \\
7\end{array}$ & $\begin{array}{r}203 \\
195 \\
8\end{array}$ & $\frac{2000}{8}$ & $\begin{array}{r}m_{202} \\
194 \\
8\end{array}$ & $\begin{array}{l}201 \\
193 \\
88 \\
88\end{array}$ & $\begin{array}{l}P_{295} \\
F_{180} \\
9\end{array}$ & $\begin{aligned} P_{201} \\
f_{192} \\
0\end{aligned}$ & $\begin{array}{l}2000 \\
201 \\
\mathrm{Fag}_{\mathrm{g}}\end{array}$ & $\begin{array}{r}225 \\
216 \\
9\end{array}$ \\
\hline 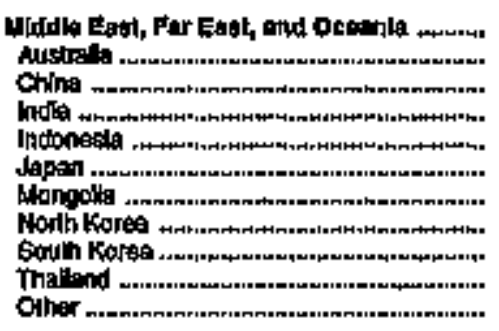 & 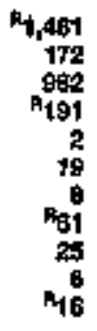 & 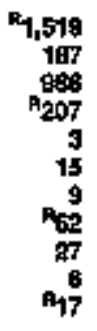 & 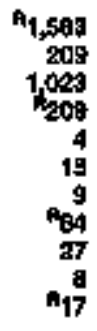 & 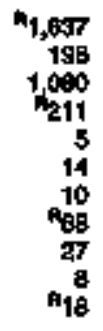 & $\begin{array}{r}1,747 \\
216 \\
1,162 \\
R_{220} \\
9 \\
13 \\
10 \\
771 \\
23 \\
10 \\
914\end{array}$ & $\begin{array}{r}M_{1,005} \\
2088 \\
1,190 \\
4235 \\
12 \\
11 \\
10 \\
10 \\
74 \\
19 \\
14 \\
R_{15}\end{array}$ & 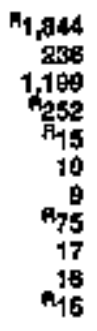 & 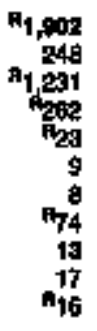 & 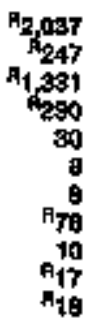 & $\begin{array}{r}2,122 \\
2,400 \\
1,410 \\
795 \\
720 \\
9 \\
6 \\
79 \\
79 \\
6 \\
19 \\
10\end{array}$ \\
\hline 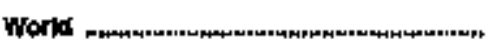 & $A_{\mathbf{4}, \text { an: }}$ & $A_{5,029}$ & $A_{5,139}$ & $R_{5,2800}$ & $4,5,4$ & $A_{3,3}, 7$ & $R_{5,032}$ & 4,56 & $A_{4,943}$ & 5,027 \\
\hline
\end{tabular}

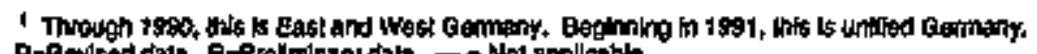

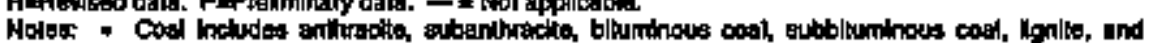

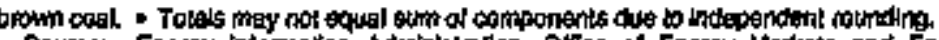

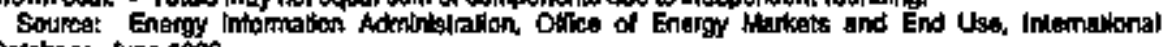
Database Juno 5998 


\section{Figure 11.16 World Coal Consumption}

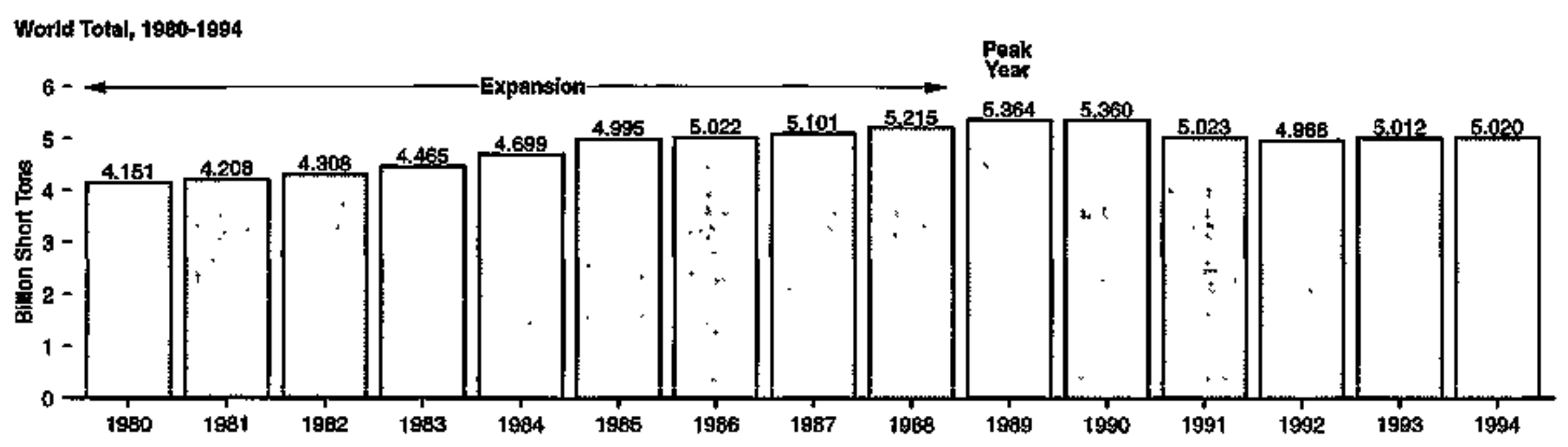

Top Consuming Countrios, 1994

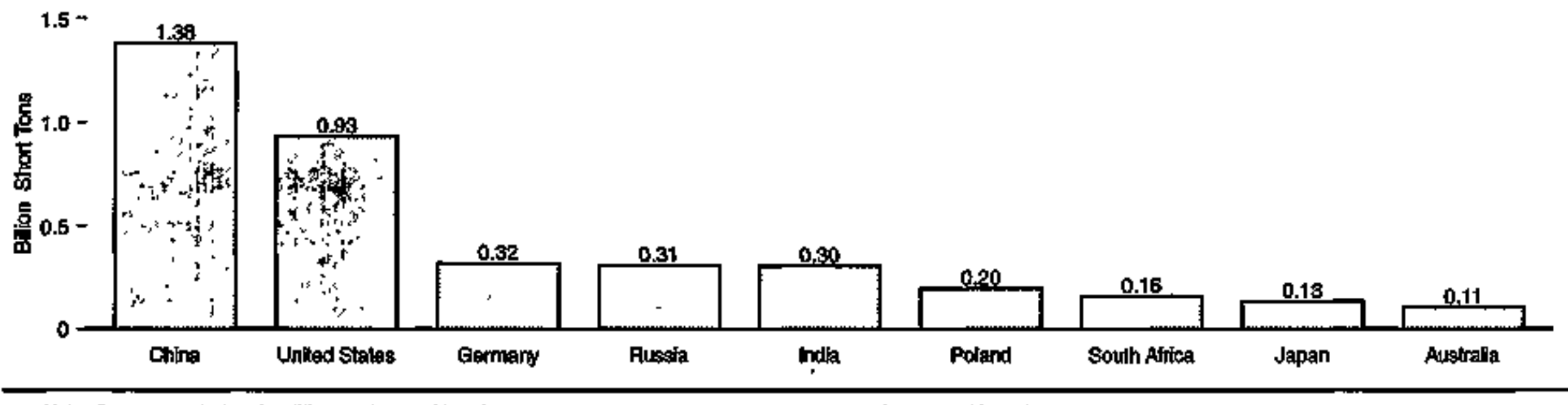

Noted Because ventcal sceles difier, graphs ahould not be compared.

Sourcox Table 11.t6. 
Table 11.16 World Coal Consumption, 1980-1994

(Million Short Tons)

\begin{tabular}{|c|c|c|c|c|c|c|c|c|c|c|c|c|c|c|c|c|c|}
\hline Yanr & Auginat a & Chind & $\begin{array}{l}\text { Crach } \\
\text { Repubtito }\end{array}$ & Cemany' & hadio & Japan & $\begin{array}{c}\text { Karak- } \\
\text { atan }\end{array}$ & $\begin{array}{l}\text { Nonth } \\
\text { Kortat }\end{array}$ & Polung & fursalo & $\begin{array}{l}\text { Saunh } \\
\text { Atritca }\end{array}$ & Uloraine & $\begin{array}{c}\text { Untitad } \\
\text { Angtom }\end{array}$ & $\begin{array}{l}\text { Unined } \\
\text { stries }\end{array}$ & $\begin{array}{l}\text { Formur } \\
\text { USSSR. }\end{array}$ & Olher & Work \\
\hline 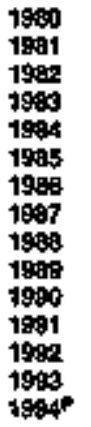 & $\begin{array}{l}74 \\
75 \\
85 \\
78 \\
80 \\
88 \\
85 \\
93 \\
96 \\
104 \\
118 \\
113 \\
111 \\
101 \\
105\end{array}$ & 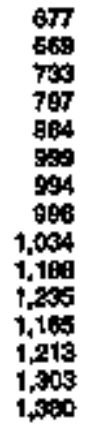 & $\begin{array}{l}\bar{z} \\
= \\
= \\
\bar{z} \\
\bar{z} \\
\bar{z} \\
= \\
\bar{z} \\
88\end{array}$ & $\begin{array}{l}535 \\
544 \\
548 \\
549 \\
562 \\
585 \\
576 \\
686 \\
561 \\
551 \\
480 \\
402 \\
959 \\
340 \\
346\end{array}$ & $\begin{array}{l}130 \\
139 \\
147 \\
165 \\
180 \\
194 \\
200 \\
206 \\
212 \\
224 \\
243 \\
242 \\
286 \\
296 \\
903\end{array}$ & $\begin{array}{c}98 \\
106 \\
109 \\
100 \\
113 \\
119 \\
109 \\
111 \\
123 \\
123 \\
128 \\
190 \\
195 \\
125 \\
133\end{array}$ & $\begin{array}{l}= \\
= \\
= \\
= \\
= \\
= \\
= \\
\overline{9} \\
94\end{array}$ & $\begin{array}{l}53 \\
59 \\
54 \\
58 \\
62 \\
64 \\
\mathbf{B 5} \\
67 \\
71 \\
74 \\
76 \\
76 \\
78 \\
60 \\
01\end{array}$ & $\begin{array}{l}221 \\
200 \\
2009 \\
213 \\
227 \\
239 \\
247 \\
260 \\
254 \\
242 \\
2092 \\
202 \\
192 \\
194 \\
195\end{array}$ & $\begin{array}{l}= \\
= \\
= \\
= \\
= \\
= \\
= \\
= \\
305\end{array}$ & $\begin{array}{l}105 \\
117 \\
123 \\
127 \\
137 \\
142 \\
145 \\
148 \\
153 \\
143 \\
138 \\
148 \\
199 \\
144 \\
156\end{array}$ & $\begin{array}{l}= \\
= \\
= \\
= \\
= \\
= \\
= \\
153 \\
132\end{array}$ & $\begin{array}{r}130 \\
130 \\
122 \\
128 \\
89 \\
116 \\
128 \\
129 \\
129 \\
128 \\
116 \\
118 \\
111 \\
97 \\
71\end{array}$ & $\begin{array}{l}703 \\
735 \\
707 \\
797 \\
791 \\
918 \\
804 \\
907 \\
894 \\
895 \\
996 \\
998 \\
898 \\
928 \\
990\end{array}$ & $\begin{array}{l}751 \\
755 \\
773 \\
773 \\
799 \\
777 \\
801 \\
804 \\
815 \\
777 \\
848 \\
673 \\
= \\
=\end{array}$ & $\begin{array}{l}670 \\
607 \\
707 \\
760 \\
605 \\
657 \\
665 \\
606 \\
690 \\
980 \\
978 \\
609 \\
684 \\
746 \\
760\end{array}$ & 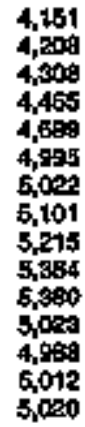 \\
\hline
\end{tabular}

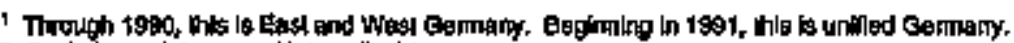

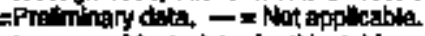

Napra

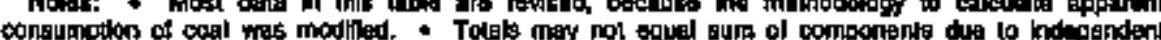

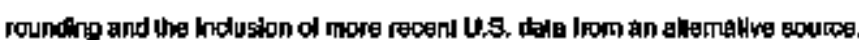

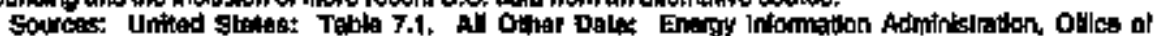

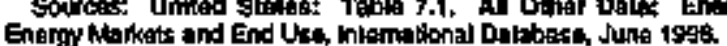


Net Generatlon by Type

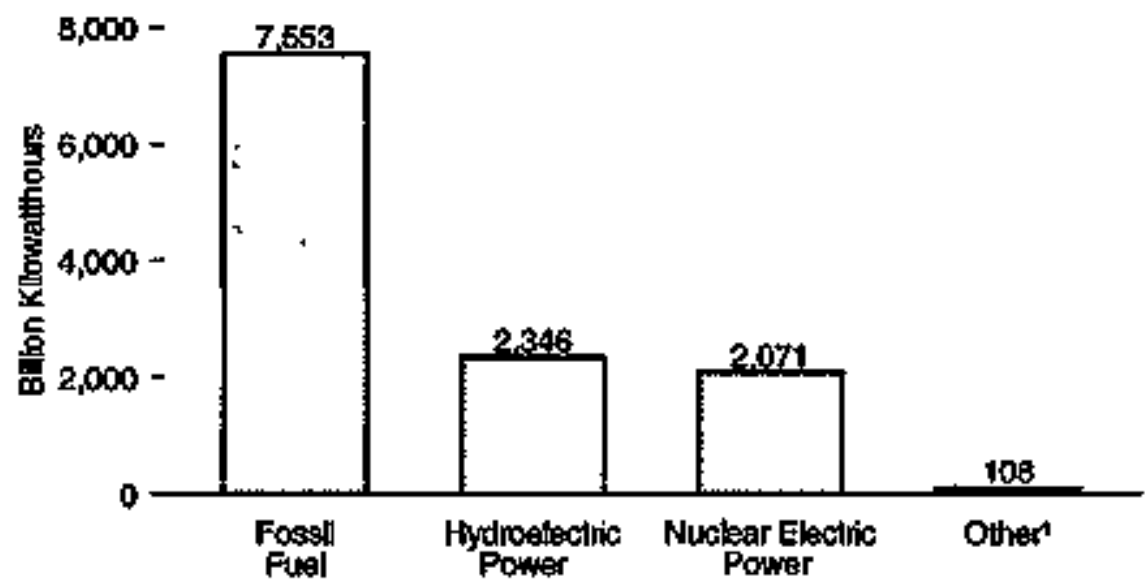

Net Ceneration in Leading Countrles

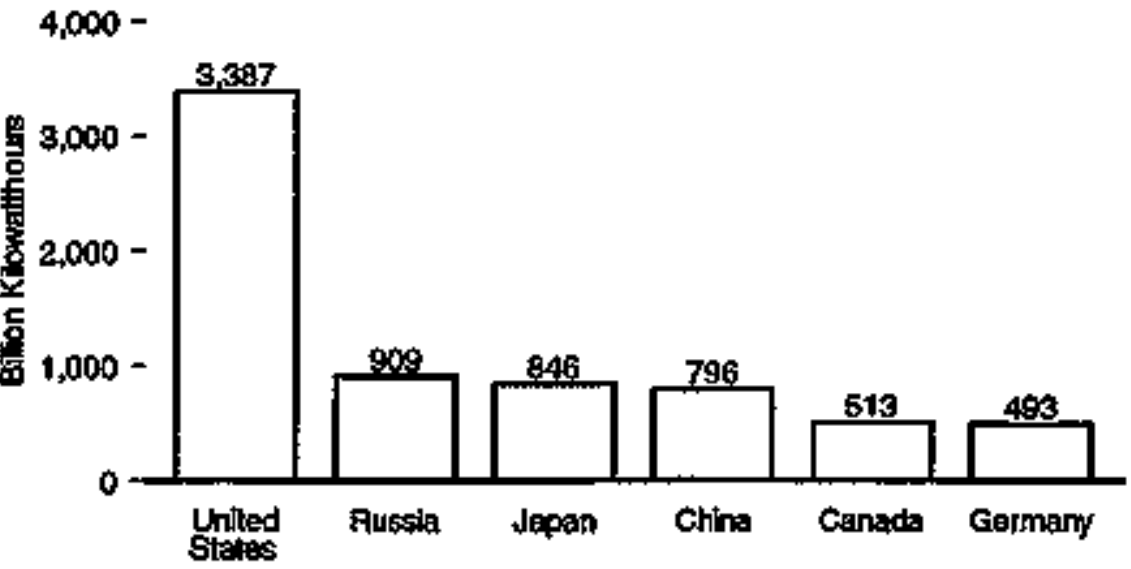

I Geothemel, blomass, whod, pholowoltalc, and soter themat generation.

Notes: - Data include both electilc ututly and non wectric ullity sources.
Net Generatton by Type by Reglon

(Percent of Regional Total)
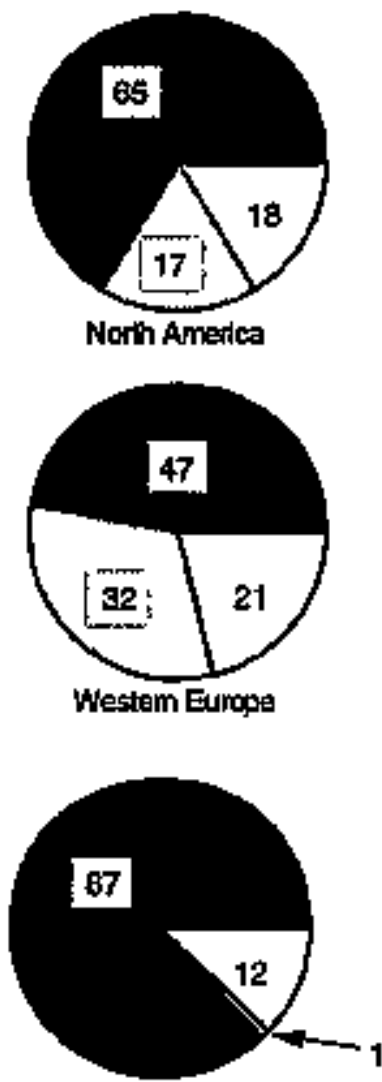

Mintiles Eastind Atrico
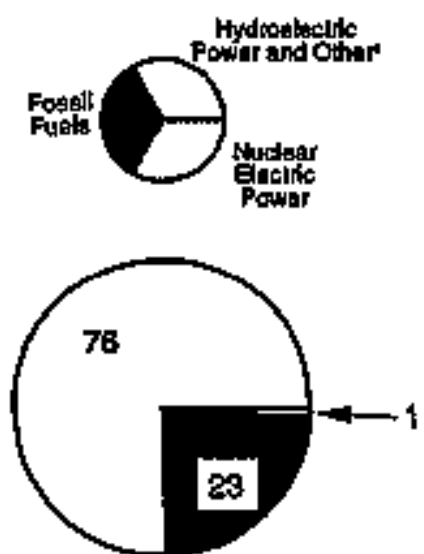

Central and South Amprica

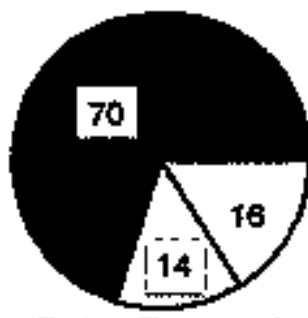

Easkem Eurcpe and Former U.S.S.P.

71

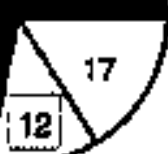

Far East and Ocoank

- Beceves vertical scales ditfer, graphs should not be compared. Sources Tabla 11.17. 
Tabłe 11.17 World Net Generation of Electriclty by Type, 1993

(Bilion Kilowatthoure)

\begin{tabular}{|c|c|c|c|c|c|}
\hline Feglon and country & $\begin{array}{l}\text { Fosspht } \\
\text { Futel }\end{array}$ & $\begin{array}{l}\text { Nutedar } \\
\text { Eleatrila } \\
\text { Powwer }\end{array}$ & $\begin{array}{l}\text { Hydro- } \\
\text { flectic } \\
\text { Powite }\end{array}$ & Oathe; 1 & Total \\
\hline 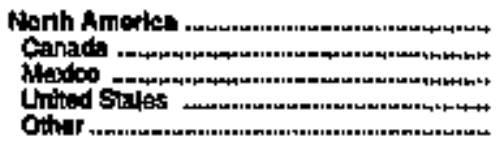 & $\begin{array}{r}2,515.0 \\
109.6 \\
97.5 \\
2,413.2 \\
0.8\end{array}$ & $\begin{array}{r}703.7 \\
08.6 \\
4.7 \\
610.4 \\
6.0\end{array}$ & $\begin{array}{r}534.3 \\
320.3 \\
26.0 \\
287.9 \\
0.0\end{array}$ & $\begin{array}{r}89.4 \\
6.4 \\
5.8 \\
75.8 \\
0.0\end{array}$ & $\begin{array}{r}4,034.4 \\
512.6 \\
103.8 \\
0,397.2 \\
0.8\end{array}$ \\
\hline 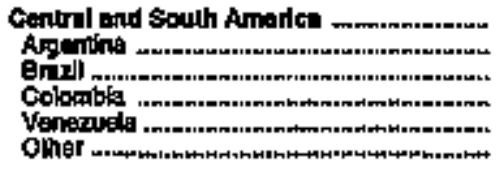 & $\begin{array}{r}129.9 \\
29.3 \\
6.3 \\
11.6 \\
2.5 \\
59.3\end{array}$ & $\begin{array}{l}7.7 \\
7.3 \\
(s) \\
0.0 \\
0.0 \\
0.01\end{array}$ & $\begin{array}{r}420.4 \\
23.9 \\
232.4 \\
27.7 \\
47.0 \\
69.4\end{array}$ & $\begin{array}{l}7.9 \\
0.0 \\
7.0 \\
0.0 \\
0.0 \\
0.9\end{array}$ & $\begin{array}{r}565.9 \\
60.5 \\
248.1 \\
39.5 \\
69.5 \\
148.5\end{array}$ \\
\hline 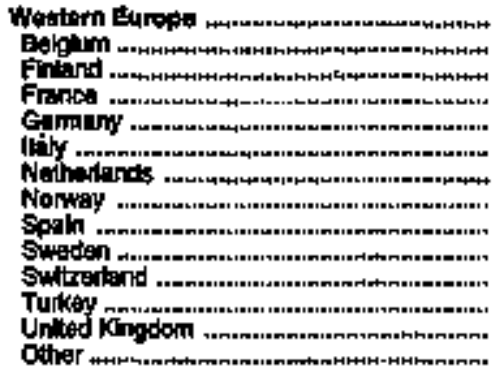 & 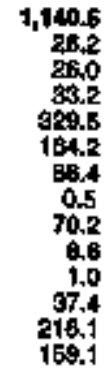 & $\begin{array}{r}77.4 \\
9.5 \\
10.9 \\
950.2 \\
145.9 \\
0.0 \\
3.9 \\
0.0 \\
5.7 \\
58.7 \\
0.2 \\
0.0 \\
01.0 \\
3.8\end{array}$ & $\begin{array}{r}490.6 \\
(5) \\
69.5 \\
63.1 \\
17.5 \\
41.0 \\
1(5) \\
117.6 \\
24.1 \\
7.9 \\
3.4 \\
30.4 \\
4.2 \\
74.6\end{array}$ & 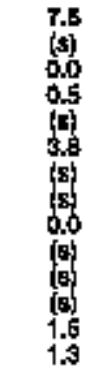 & $\begin{array}{r}2,424.4 \\
60.0 \\
59.4 \\
447.1 \\
493.0 \\
205.0 \\
72.4 \\
118.3 \\
149.0 \\
141.2 \\
58.6 \\
71.1 \\
302.8 \\
230.6\end{array}$ \\
\hline 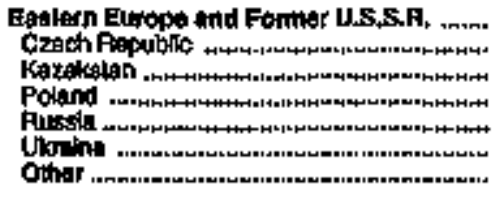 & $\begin{array}{r}1,202.5 \\
120 \\
63.6 \\
122.5 \\
602.6 \\
134.6 \\
218.2\end{array}$ & $\begin{array}{r}246.0 \\
12.5 \\
68.5 \\
0.0 \\
118.2 \\
70.2 \\
49.6\end{array}$ & $\begin{array}{r}26.7 .7 \\
1.6 \\
7.6 \\
3.5 \\
173.4 \\
11.1 \\
6.5\end{array}$ & $\begin{array}{l}\text { by } \\
0.0 \\
0.0 \\
0.0 \\
15 \\
0.0 \\
0.0\end{array}$ & $\begin{array}{r}1716.3 \\
56.1 \\
73.6 \\
126.0 \\
908.2 \\
216.2 \\
334.3\end{array}$ \\
\hline 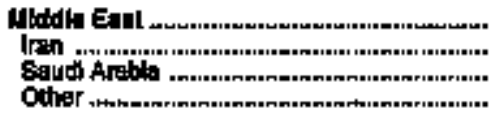 & $\begin{array}{r}232.5 \\
57.5 \\
59.5 \\
116.7\end{array}$ & $\begin{array}{l}0.0 \\
0.0 \\
0.0 \\
0.0\end{array}$ & $\begin{array}{r}19.5 \\
10.9 \\
0.0 \\
7.6\end{array}$ & $\begin{array}{l}0 . \\
0.0 \\
0.1\end{array}$ & $\begin{array}{r}251.1 \\
69.2 \\
09.6 \\
t 23.3\end{array}$ \\
\hline 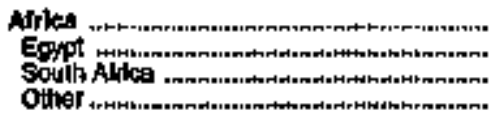 & $\begin{array}{r}258.7 \\
38.6 \\
145.6 \\
71.6\end{array}$ & $\begin{array}{l}7.3 \\
0.0 \\
7.3 \\
0.0\end{array}$ & $\begin{array}{r}49.7 \\
8.4 \\
41.1\end{array}$ & $\begin{array}{l}10.0 \\
0.0 \\
0\end{array}$ & $\begin{array}{r}311.0 \\
45.0 \\
162.8 \\
113.0\end{array}$ \\
\hline 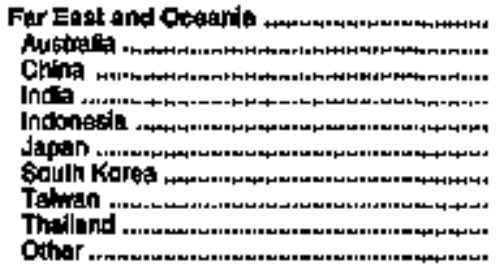 & $\begin{array}{r}1,978.6 \\
134.4 \\
694.6 \\
265.3 \\
40.0 \\
913.6 \\
75.5 \\
70.4 \\
50.6 \\
172.1\end{array}$ & 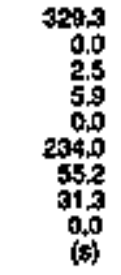 & $\begin{array}{r}456.9 \\
16.0 \\
149.2 \\
70.0 \\
12.0 \\
96.8 \\
5.8 \\
6.8 \\
2.7 \\
86.6\end{array}$ & $\begin{array}{l}10.9 \\
0.0 \\
0.0 \\
601 \\
1.0 \\
1.7 \\
0.0 \\
0.0 \\
0.0 \\
0.1\end{array}$ & $\begin{array}{r}2775.7 \\
154.3 \\
79.2 \\
3 \% .2 \\
50.0 \\
646.3 \\
186.7 \\
108.3 \\
60.5 \\
27.2\end{array}$ \\
\hline 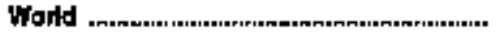 & $7,552.8$ & $2,071.4$ & $2,345.5$ & 109.1 & $12,077.7$ \\
\hline
\end{tabular}

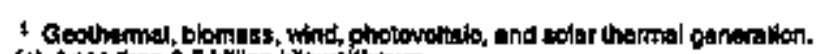

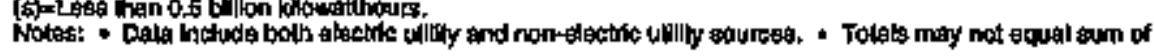

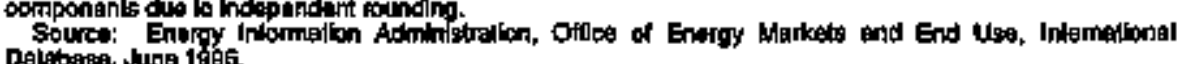
Energy Intormatlon Adminlsiration/Annual Enargy Review 1895 
By Type

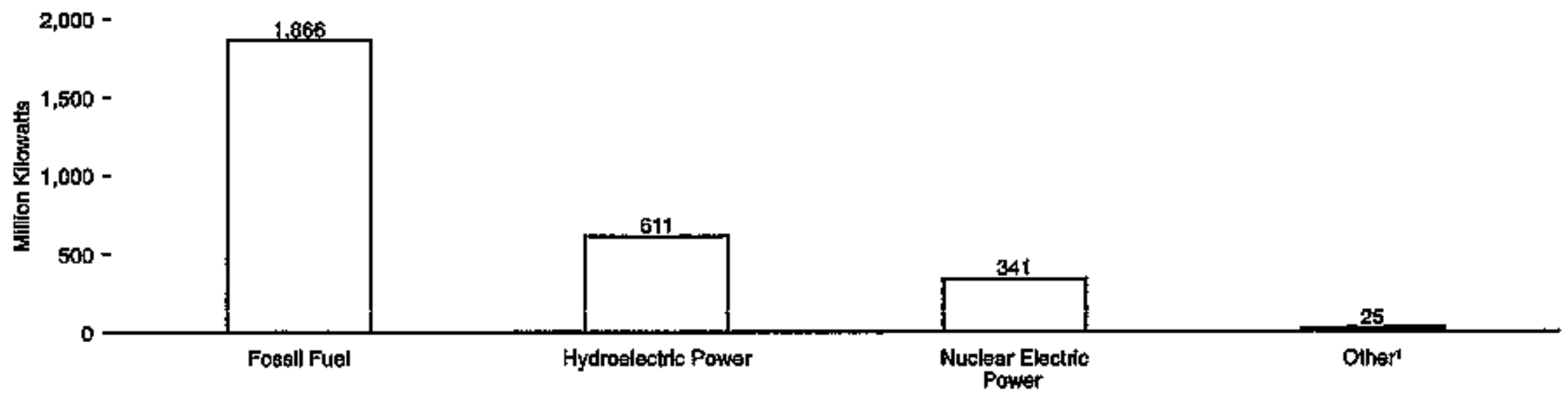

Comparison of Installed Capacity and Net Qonwation Strams' by Typo

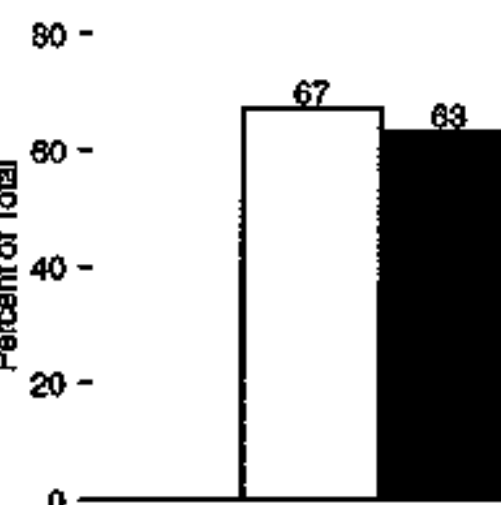

Fossil Fuels

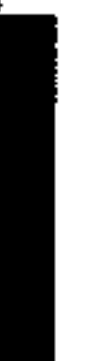

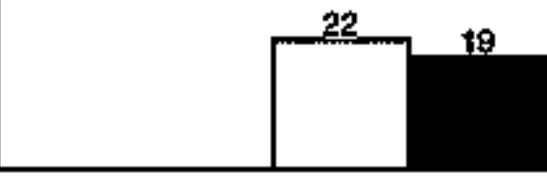

Hyotrolectric Power

Insialled Capacity, Lanuary 1, 1994

Net Generalion, 1993

\footnotetext{
1Geohernal, tlomass, wind, photovdlate, and solar themms sources.
}

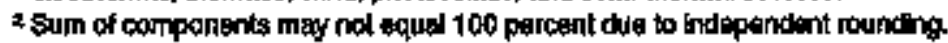


Table 11.18 World Electrical Installed Capacity by Type, January 1, 1994 (Million Kilowatts)

\begin{tabular}{|c|c|c|c|c|c|}
\hline Fegton and Codiniry & $\begin{array}{l}\text { Foosid } \\
\text { Funt }\end{array}$ & $\begin{array}{l}\text { Nuolagr } \\
\text { Evetilic } \\
\text { Power }\end{array}$ & $\begin{array}{l}\text { Fyctros } \\
\text { eteckito } \\
\text { Pentef }\end{array}$ & Oiher $\mathbf{z}^{\mathrm{Z}}$ & Total \\
\hline 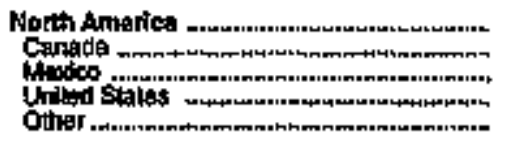 & $\begin{array}{r}59.0 \\
33.0 \\
38.8 \\
541.6 \\
0.7\end{array}$ & $\begin{array}{r}115.2 \\
15.6 \\
0.7 \\
990.0 \\
0.0\end{array}$ & $\begin{array}{r}14.5 \\
61.2 \\
0.2 \\
77.4 \\
0.0\end{array}$ & $\begin{array}{r}16.4 \\
1.8 \\
0.7 \\
15.6 \\
(s)\end{array}$ & $\begin{array}{r}57.4 \\
100.7 \\
20.3 \\
73.5 \\
0.7\end{array}$ \\
\hline 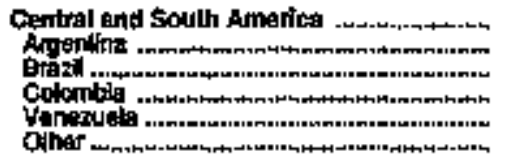 & $\begin{array}{r}43.4 \\
10.0 \\
2.1 \\
2.6 \\
8.1 \\
20.6\end{array}$ & $\begin{array}{l}17 \\
1.0 \\
0.7 \\
0.0 \\
0.0 \\
0.0\end{array}$ & $\begin{array}{r}10.3 \\
7.0 \\
1.95 \\
7.7 \\
10.7 \\
10.3\end{array}$ & $\begin{array}{l}4.8 \\
0.0 \\
4.7 \\
0.0 \\
0.0 \\
0.09\end{array}$ & $\begin{array}{r}142.3 \\
18.0 \\
18.0 \\
10.4 \\
18.8 \\
339.1\end{array}$ \\
\hline 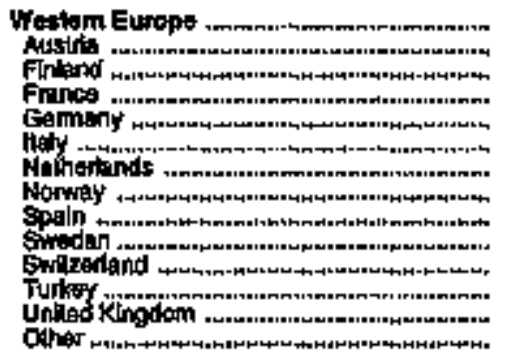 & $\begin{array}{r}316.1 \\
5.1 \\
9.0 \\
23.5 \\
82.8 \\
43.3 \\
18.9 \\
19.4 \\
20.4 \\
8.6 \\
0.8 \\
10.6 \\
50.3 \\
44.2\end{array}$ & $\begin{array}{r}120.0 \\
0.0 \\
2.4 \\
50.0 \\
2.7 \\
0.0 \\
0.5 \\
0.0 \\
7.0 \\
10.0 \\
3.0 \\
0.0 \\
11.9 \\
8.1\end{array}$ & $\begin{array}{r}140.5 \\
11.2 \\
2.7 \\
20.8 \\
3.0 \\
12.8 \\
1,8.0 \\
26.0 \\
11.6 \\
18.0 \\
10.0 \\
6.7 \\
1.4 \\
15.8\end{array}$ & 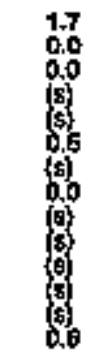 & $\begin{array}{r}564.1 \\
17.3 \\
14.1 \\
108.4 \\
108.4 \\
6.6 .6 \\
17.6 \\
26.3 \\
39.0 \\
3.4 .8 \\
12.9 \\
20.3 \\
65.7 \\
69.7\end{array}$ \\
\hline 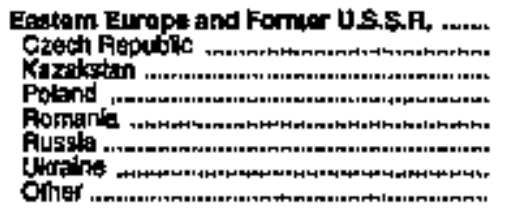 & $\begin{array}{r}319.0 \\
11.1 \\
12.4 \\
77.1 \\
16.4 \\
148.7 \\
30.7 \\
8.6\end{array}$ & $\begin{array}{r}45.4 \\
1.8 \\
6.01 \\
0.0 \\
0.0 \\
21.2 \\
12.8 \\
8.1\end{array}$ & $\begin{array}{r}0.1 \\
1.4 \\
2.5 \\
2.0 \\
5.9 \\
43.4 \\
4.7 \\
22.2\end{array}$ & $\begin{array}{l}(8) \\
0.00 \\
0,0 \\
601 \\
0.0 \\
\text { is }\end{array}$ & $\begin{array}{r}441.5 \\
14.2 \\
18.3 \\
29.2 \\
22.3 \\
213.4 \\
94.3 \\
01.8\end{array}$ \\
\hline 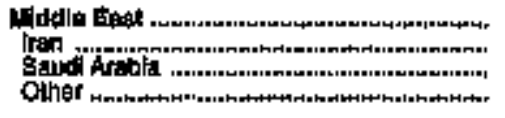 & $\begin{array}{l}70.1 \\
19.9 \\
19.4 \\
3 . .8\end{array}$ & $\begin{array}{l}0.0 \\
0.0 \\
0.0 \\
0.0\end{array}$ & $\begin{array}{l}40 \\
2.0 \\
0.1 \\
2.1\end{array}$ & $\begin{array}{l}\text { (0) } \\
00 \\
00\end{array}$ & $\begin{array}{l}74.2 \\
20.0 \\
194 \\
34.8\end{array}$ \\
\hline 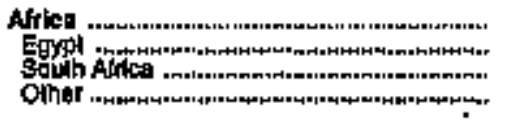 & $\begin{array}{r}56.1 \\
9.0 \\
24.0 \\
20.1\end{array}$ & $\begin{array}{l}1.9 \\
0.9 \\
0.0\end{array}$ & $\begin{array}{r}10.0 \\
2.8 \\
0.8 \\
16.7\end{array}$ & $\begin{array}{l}\text { (a) } \\
00 \\
\text { (6) }\end{array}$ & $\begin{array}{l}7.2 \\
11.8 \\
25.6 \\
39.9\end{array}$ \\
\hline 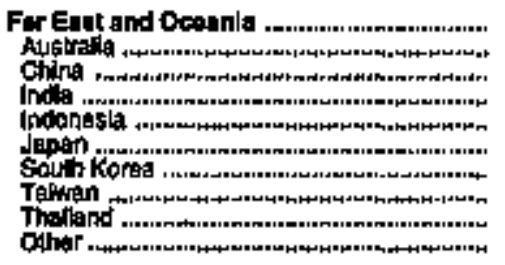 & $\begin{array}{r}465 \\
29.7 \\
137.1 \\
62.3 \\
12.5 \\
134.4 \\
20.4 \\
13.9 \\
114 \\
14.2\end{array}$ & $\begin{array}{r}54.7 \\
0.0 \\
1.2 \\
2.1 \\
0.0 \\
30.6 \\
7.6 \\
6.1 \\
0.0 \\
(5)\end{array}$ & $\begin{array}{r}12.4 .8 \\
6.9 \\
44.8 \\
15.6 \\
3.3 \\
21.0 \\
2.5 \\
2.6 \\
2.5 \\
21.7\end{array}$ & $\begin{array}{l}1.7 \\
60.0 \\
0.0 \\
80 \\
60 \\
0.0 \\
0.0 \\
1.2\end{array}$ & $\begin{array}{r}046.7 \\
35.7 \\
182.9 \\
84.0 \\
15.9 \\
194.0 \\
90.5 \\
21.7 \\
13.9 \\
072\end{array}$ \\
\hline 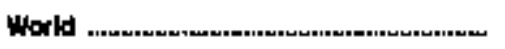 & $1,858,4$ & 3414 & S10.7 & 24.7 & $2, \mathbf{8} 4 \mathbf{4}, 2$ \\
\hline
\end{tabular}

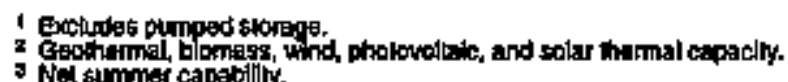

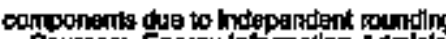

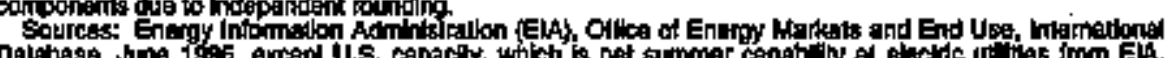
Not summer caperility

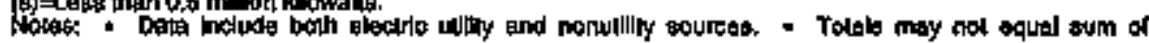




\section{Figure 11.19 World Hydroelectric Power Net Generation}

\section{World and Leading Producers, 1985-1994}

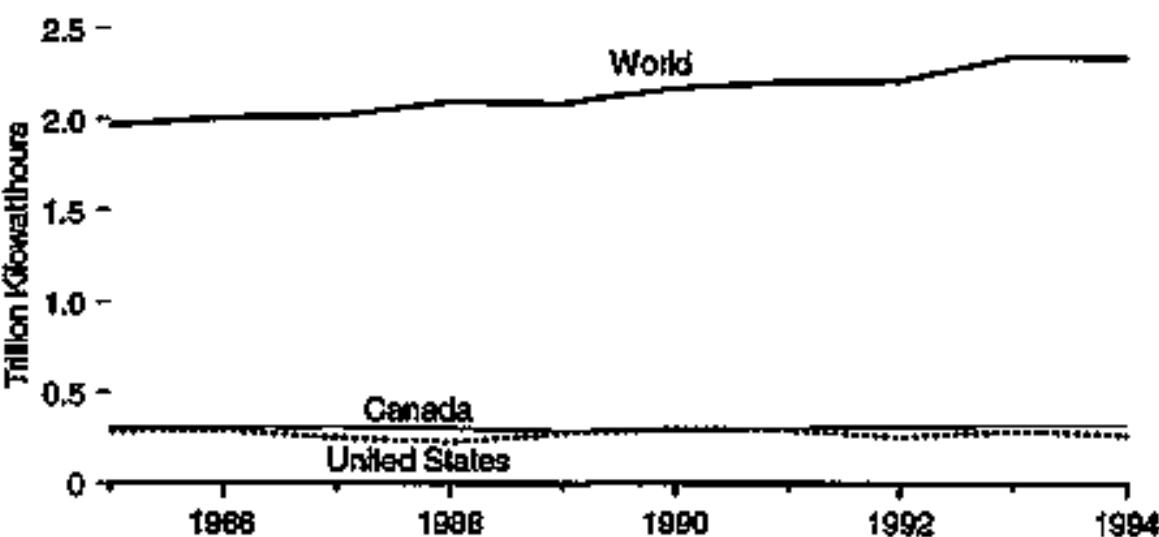

Word Areas, t985-1994

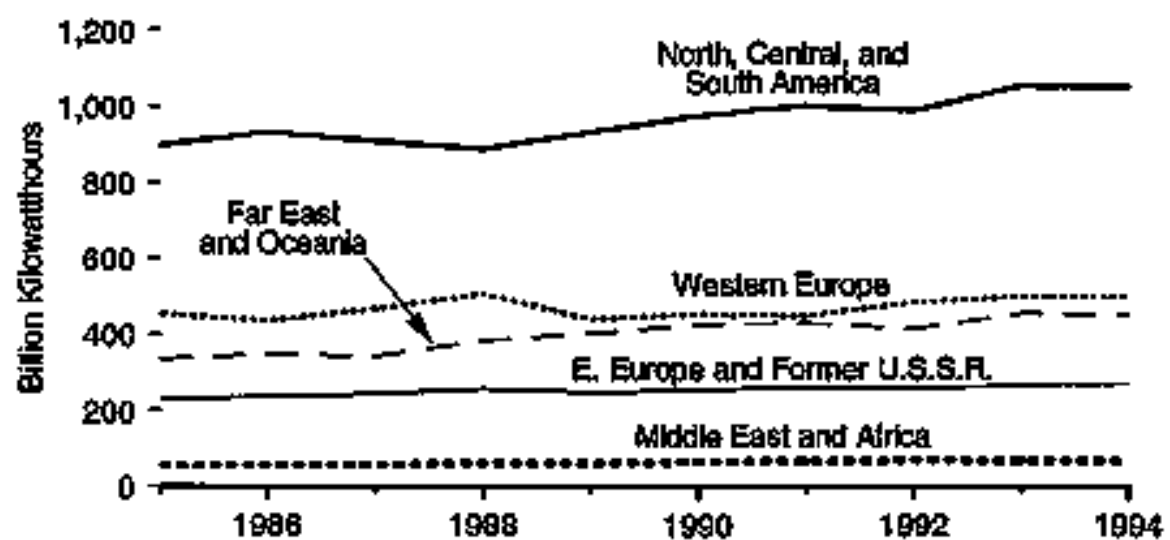

Top Generating Counlries, 1994

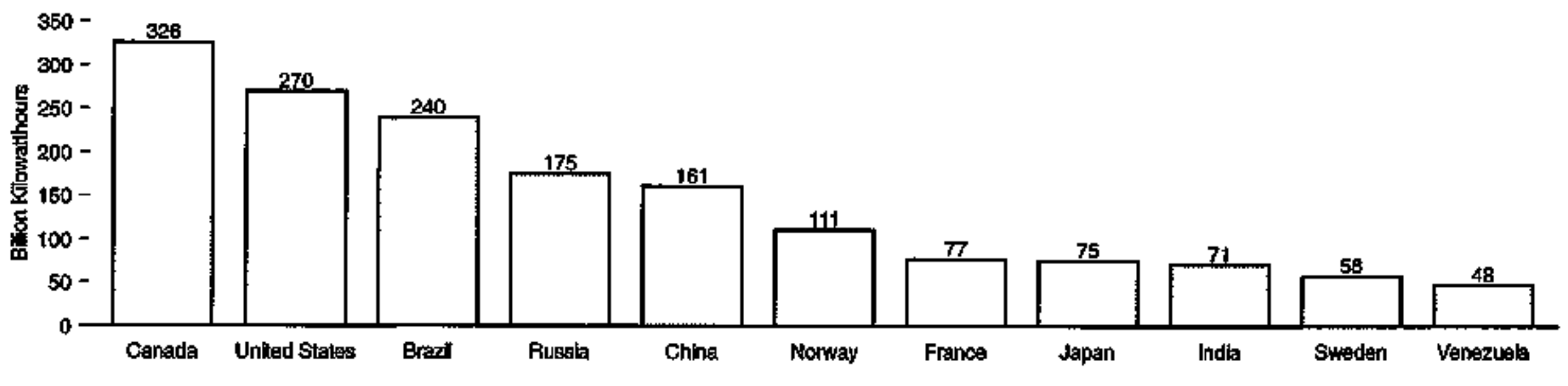


Table 11.19 World Hydroelectric Power Net Generation, 1985-1994

(Billion Kilowathours)

\begin{tabular}{|c|c|c|c|c|c|c|c|c|c|c|}
\hline Flegton und Country & 1985 & $19 B 8$ & 1987 & $15 \mathrm{Han}$ & 1590 & 100 & 1901 & 192 & 1993 & 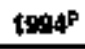 \\
\hline 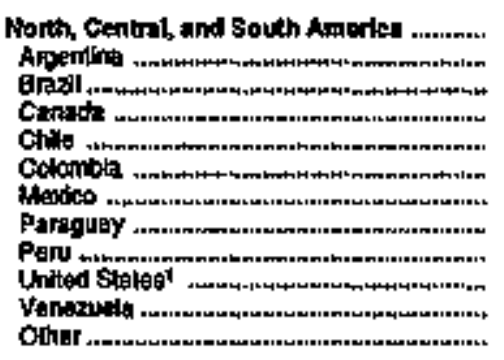 & $\begin{array}{r}607 \\
20 \\
177 \\
301 \\
10 \\
22 \\
25 \\
4 \\
99 \\
294 \\
22 \\
22\end{array}$ & $\begin{array}{r}901 \\
21 \\
161 \\
300 \\
11 \\
25 \\
20 \\
12 \\
10 \\
294 \\
25 \\
254\end{array}$ & $\begin{array}{r}907 \\
22 \\
184 \\
313 \\
12 \\
21 \\
18 \\
18 \\
11 \\
250 \\
31 \\
\mathrm{~A}_{24}\end{array}$ & $\begin{array}{r}697 \\
18 \\
197 \\
305 \\
11 \\
24 \\
21 \\
20 \\
10 \\
220 \\
34 \\
924\end{array}$ & $\begin{array}{r}R_{932} \\
13 \\
203 \\
299 \\
10 \\
26 \\
24 \\
24 \\
10 \\
R_{276} \\
34 \\
R_{24}\end{array}$ & 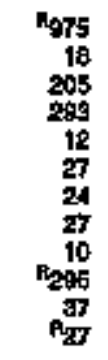 & $\begin{array}{r}1,007 \\
16 \\
218 \\
304 \\
13 \\
27 \\
27 \\
29 \\
11 \\
728 \\
44 \\
26\end{array}$ & 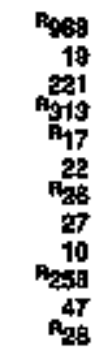 & 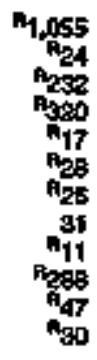 & $\begin{array}{r}1,059 \\
25 \\
240 \\
328 \\
10 \\
29 \\
20 \\
86 \\
12 \\
270 \\
49 \\
31\end{array}$ \\
\hline 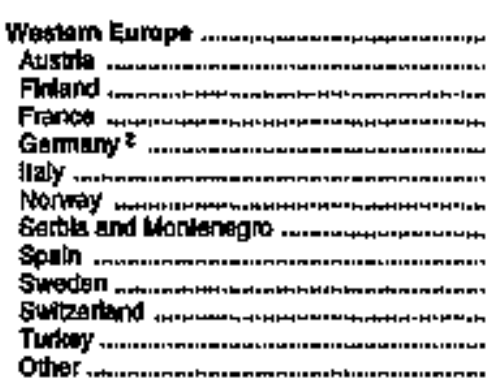 & $\begin{array}{r}453 \\
50 \\
12 \\
60 \\
17 \\
41 \\
101 \\
\frac{31}{71} \\
70 \\
37 \\
12 \\
847\end{array}$ & 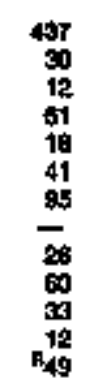 & $\begin{array}{r}467 \\
25 \\
14 \\
69 \\
20 \\
39 \\
102 \\
\frac{102}{27} \\
71 \\
34 \\
18 \\
447\end{array}$ & 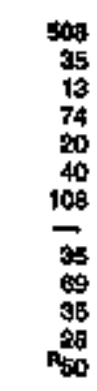 & $\begin{array}{r}40 \\
35 \\
13 \\
46 \\
18 \\
34 \\
117 \\
\frac{19}{19} \\
71 \\
29 \\
18 \\
\mathrm{R}_{41}\end{array}$ & $\begin{array}{r}453 \\
31 \\
11 \\
59 \\
17 \\
31 \\
120 \\
\frac{31}{25} \\
72 \\
30 \\
29 \\
\mathbf{P}_{41}^{20}\end{array}$ & $\begin{array}{r}480 \\
31 \\
14 \\
58 \\
15 \\
42 \\
109 \\
\frac{27}{27} \\
763 \\
32 \\
92 \\
941\end{array}$ & $\begin{array}{r}\mathrm{A}_{404} \\
34 \\
15 \\
67 \\
17 \\
42 \\
416 \\
116 \\
11 \\
19 \\
74 \\
39 \\
36 \\
030\end{array}$ & 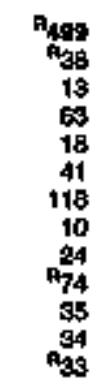 & $\begin{array}{r}490 \\
35 \\
12 \\
77 \\
19 \\
44 \\
111 \\
71 \\
87 \\
50 \\
39 \\
30 \\
30\end{array}$ \\
\hline 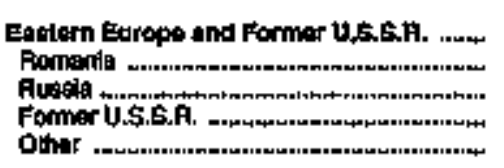 & $\frac{291}{12}$ & $\frac{11}{2+13}$ & $\frac{244}{217}$ & $\frac{13}{13}$ & $\frac{12}{248}$ & $\frac{11}{251}$ & $\frac{259}{14}$ & $\begin{array}{l}A_{258} \\
12 \\
n_{171} \\
A_{73}\end{array}$ & $\begin{array}{r}13 \\
175 \\
17 \\
\operatorname{Ag}_{91}\end{array}$ & $\frac{269}{175}$ \\
\hline 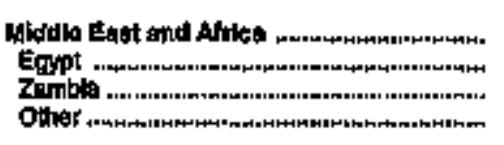 & $\begin{array}{r}60 \\
a \\
10 \\
38\end{array}$ & $\begin{array}{r}8 \\
10 \\
10 \\
R_{40}\end{array}$ & 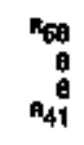 & $\begin{array}{r}R_{69} \\
8 \\
m_{46}^{9}\end{array}$ & $\begin{array}{r}\mathbf{P}_{6} \\
8 \\
7 \\
\mathbf{7}\end{array}$ & $\begin{array}{r}60 \\
10 \\
8 \\
P_{40}^{6}\end{array}$ & $\begin{array}{r}F_{67} \\
\mathrm{E}_{\mathrm{S}} \\
\mathrm{F}_{51}^{6}\end{array}$ & $\begin{array}{r}{ }_{70} \\
\mathbf{6}_{\mathrm{g}} \\
\mathrm{g}\end{array}$ & $\begin{array}{r}68 \\
F_{g} \\
8 \\
\omega_{52}\end{array}$ & $\begin{array}{r}58 \\
8 \\
6 \\
52\end{array}$ \\
\hline 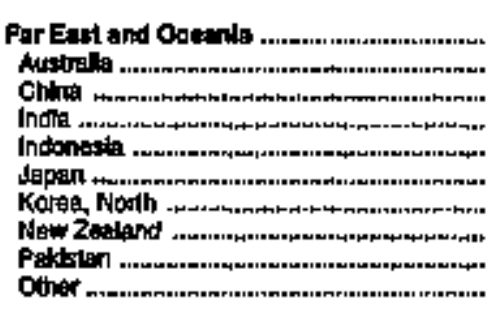 & 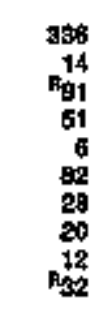 & $\begin{array}{r}n_{1019} \\
14 \\
04 \\
53 \\
7 \\
00 \\
29 \\
22 \\
14 \\
n_{36}\end{array}$ & 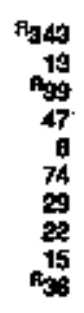 & $\begin{array}{r}364 \\
13 \\
108 \\
77 \\
6 \\
90 \\
31 \\
20 \\
17 \\
n 36\end{array}$ & $\begin{array}{r}104 \\
14 \\
117 \\
62 \\
8 \\
91 \\
31 \\
22 \\
17 \\
\mathrm{P}_{42}\end{array}$ & $\begin{array}{r}F_{465} \\
14 \\
125 \\
71 \\
10 \\
88 \\
31 \\
29 \\
17 \\
\mathbf{n}_{46}\end{array}$ & $\begin{array}{r}1431 \\
18 \\
124 \\
72 \\
10 \\
97 \\
31 \\
23 \\
18 \\
14\end{array}$ & 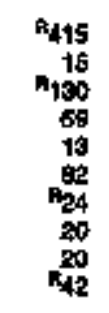 & 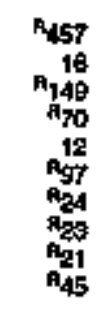 & $\begin{array}{r}452 \\
16 \\
161 \\
71 \\
16 \\
75 \\
24 \\
28 \\
21 \\
15\end{array}$ \\
\hline Ward & $F_{1,872}$ & 2,012 & 2,019 & Fanges & n,os: & $\mathbf{F}_{2,173}$ & $\mathrm{~F}_{2,209}$ & $\mathbf{n}_{2,212}$ & $\mathrm{f}_{2,349}$ & $\mathbf{2 , 3 4 0}$ \\
\hline
\end{tabular}

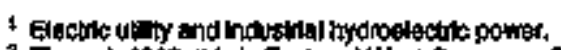

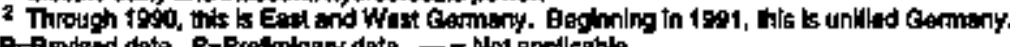

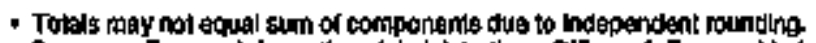

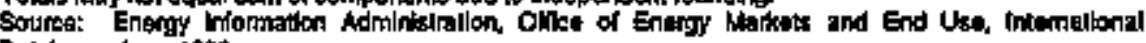

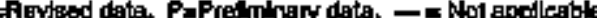
Dotabage, Jung 


\section{Figure 11.20 World Nuclear Electricity Gross Generation}

\section{By fiegion, 1995}

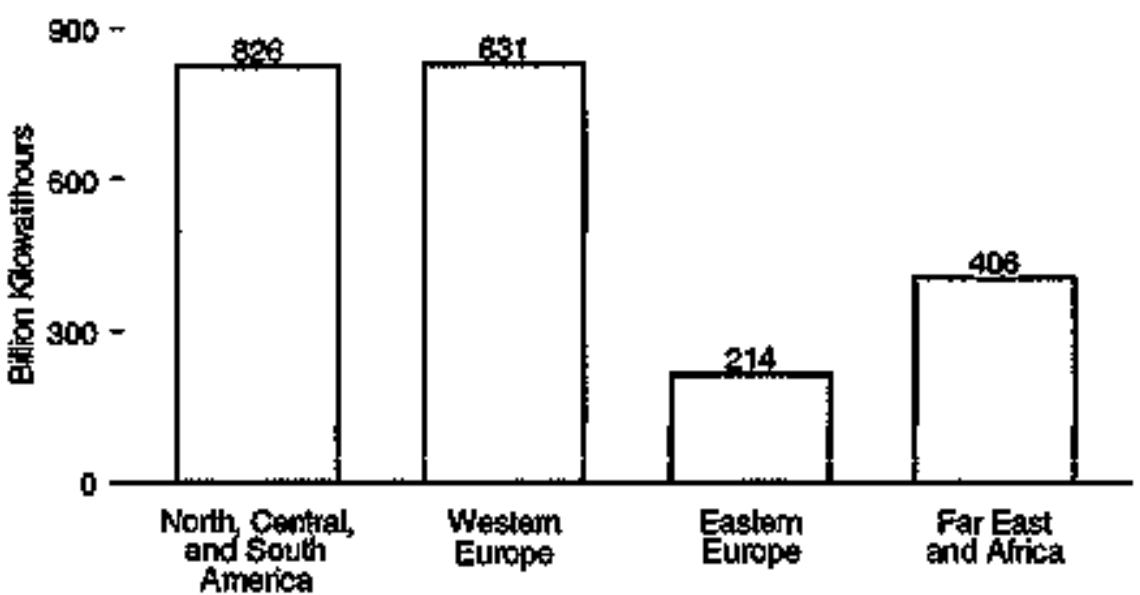

By Major Producers, 1982-1995

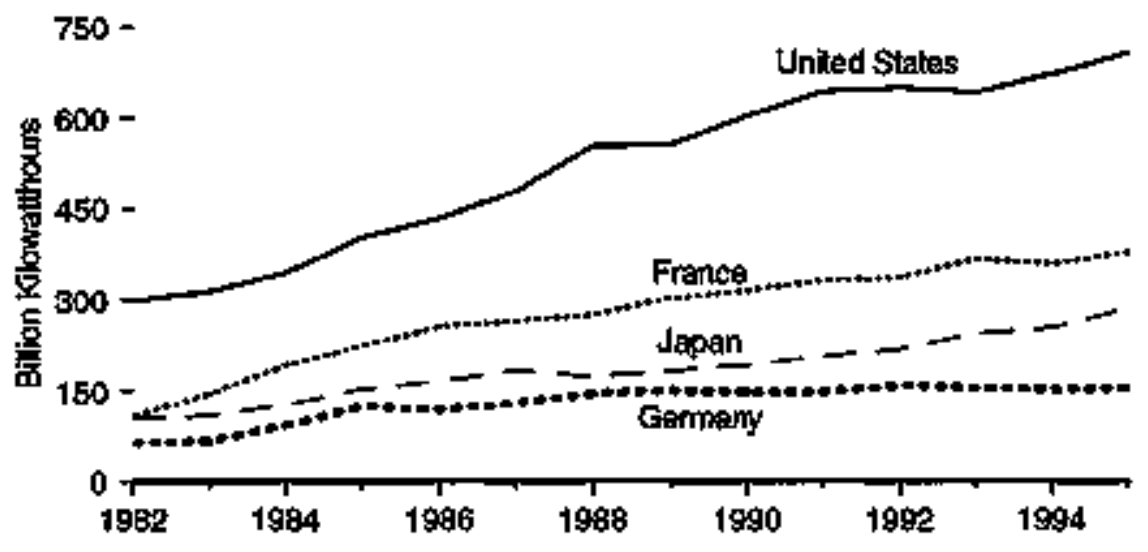

\section{By Country, 1995}

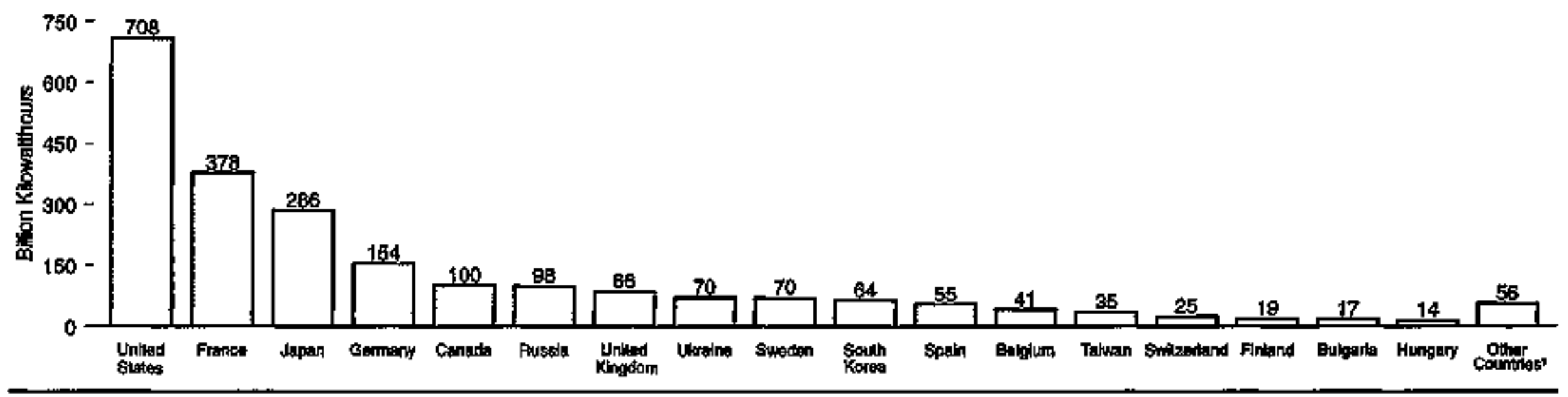

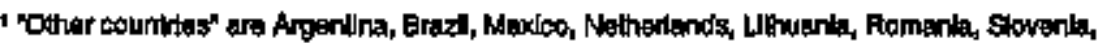
Indlig, Paktslant, and Soulh Africa.

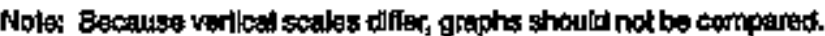
Sourcex: Table 11.20. 
Table 11.20 World Nuclear Electrictty Gross Generation, 1982-1995

(Belion Kilowatthours)

\begin{tabular}{|c|c|c|c|c|c|c|c|c|c|c|c|c|c|c|}
\hline $\begin{array}{c}\text { Reglon } \\
\text { And counthy }\end{array}$ & 19.82 & 19943 & 1084 & 1865 & 1995 & $18 B 7$ & 1089 & 1990 & 1900 & 1981 & 1892 & 1009 & 1904 & 1995 \\
\hline 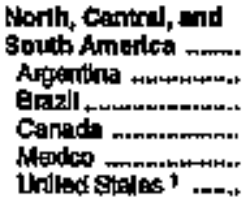 & $\begin{array}{r}34.1 \\
1.9 \\
0.1 \\
42.8 \\
28.6\end{array}$ & $\begin{array}{r}370.2 \\
0.4 \\
0.2 \\
53.0 \\
313.6\end{array}$ & $\begin{array}{r}404.1 \\
4.5 \\
2.1 \\
63.8 \\
- \\
343.8\end{array}$ & $\begin{array}{r}474.8 \\
5.8 \\
3.4 \\
629 \\
-7 \\
4027\end{array}$ & $\begin{array}{r}514.6 \\
5.7 \\
0.1 \\
74.6 \\
\overrightarrow{434.1}\end{array}$ & $\begin{array}{r}669.3 \\
5.2 \\
1.0 \\
00.6 \\
4 \overrightarrow{4} \\
478.5\end{array}$ & $\begin{array}{r}645.2 \\
5.1 \\
0.3 \\
65.6 \\
5 \overline{54.1}\end{array}$ & $\begin{array}{r}64.9 \\
5.0 \\
1,5 \\
09.2 \\
5 \overline{5} .0\end{array}$ & $\begin{array}{r}990.7 \\
7.4 \\
2.0 \\
79.8 \\
\overrightarrow{603.4}\end{array}$ & $\begin{array}{r}742.8 \\
7.7 \\
1.4 \\
68.1 \\
4.2 \\
645,0\end{array}$ & $\begin{array}{r}744.0 \\
7.1 \\
1.8 \\
91.9 \\
3.9 \\
650.0\end{array}$ & $\begin{array}{r}762.7 \\
7.7 \\
0.4 \\
97.8 \\
4.9 \\
642.0\end{array}$ & $\begin{array}{r}705.6 \\
62 \\
0.0 \\
110.7 \\
42 \\
672.4\end{array}$ & $\begin{array}{r}625.6 \\
7.1 \\
2.5 \\
100.4 \\
7.8 \\
707.7\end{array}$ \\
\hline 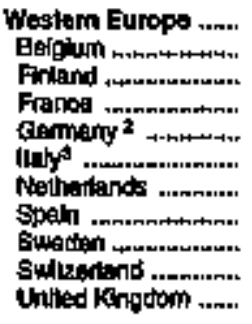 & $\begin{array}{r}121.8 \\
15.6 \\
16.5 \\
108.9 \\
63.4 \\
6.9 \\
3.9 \\
6.8 \\
30.6 \\
15.0 \\
44.1\end{array}$ & $\begin{array}{r}377.2 \\
24.1 \\
17.4 \\
144.2 \\
65.6 \\
5.8 \\
3.6 \\
10.7 \\
10.4 \\
15.5 \\
49.6\end{array}$ & $\begin{array}{r}495.4 \\
27.7 \\
18.5 \\
191.2 \\
82.6 \\
6.9 \\
3.9 \\
23.1 \\
51.3 \\
18.3 \\
54.1\end{array}$ & $\begin{array}{r}5828 \\
34.6 \\
18.8 \\
224.0 \\
125.8 \\
7.0 \\
39 \\
28.0 \\
58.6 \\
224 \\
59.7\end{array}$ & $\begin{array}{r}43.6 \\
39.6 \\
10.6 \\
264.9 \\
118.9 \\
6.7 \\
4.2 \\
37.6 \\
59.9 \\
27.5 \\
69.2\end{array}$ & $\begin{array}{r}849.3 \\
41.9 \\
19.4 \\
265.5 \\
130.2 \\
0.2 \\
3.8 \\
41.3 \\
6.2 \\
29.0 \\
58.2\end{array}$ & $\begin{array}{r}6.5 .1 \\
43.1 \\
19.3 \\
274.6 \\
145.2 \\
0.0 \\
3.7 \\
50.4 \\
69.4 \\
22.7 \\
59.4\end{array}$ & $\begin{array}{r}732.5 \\
41.2 \\
19.8 \\
302.5 \\
149.5 \\
0.0 \\
4.0 \\
68.1 \\
65.5 \\
22.8 \\
71.8\end{array}$ & $\begin{array}{r}739.9 \\
48.7 \\
18.9 \\
314.1 \\
147.7 \\
0.0 \\
3.4 \\
54.3 \\
68.2 \\
238.8 \\
68.1\end{array}$ & $\begin{array}{r}70.7 \\
42.9 \\
19.2 \\
331.4 \\
147.3 \\
0.0 \\
3.3 \\
65.6 \\
70.6 \\
22.9 \\
70.4\end{array}$ & $\begin{array}{r}793.5 \\
43.5 \\
19.0 \\
337.6 \\
158.8 \\
0.0 \\
36.8 \\
56.8 \\
63.5 \\
23.4 \\
78.5\end{array}$ & $\begin{array}{r}617.0 \\
41.9 \\
10.0 \\
368.7 \\
153.5 \\
0.0 \\
3.9 \\
58.1 \\
64.4 \\
20.3 \\
90.4\end{array}$ & $\begin{array}{r}8+5.6 \\
10.6 \\
19.1 \\
359.1 \\
751.1 \\
0.0 \\
4.0 \\
65.1 \\
72.8 \\
24.1 \\
89.6\end{array}$ & $\begin{array}{r}130.9 \\
41.4 \\
19.9 \\
37.8 \\
154.5 \\
0.0 \\
4.0 \\
54.5 \\
69.9 \\
24.8 \\
6.5\end{array}$ \\
\hline 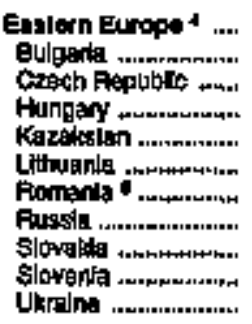 & $\begin{array}{l}\text { NA } \\
\text { NA } \\
\bar{Z} \\
\overline{N A} \\
\bar{E} \\
\text { NA } \\
\text { NA } \\
\text { NA }\end{array}$ & $\begin{array}{l}\text { MA } \\
\text { NA } \\
\bar{A} \\
\overline{N A} \\
\overline{N A} \\
\text { NA }\end{array}$ & 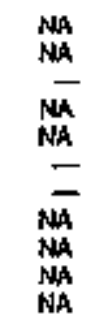 & $\frac{M}{M A M}$ & $\begin{array}{l}\text { MA } \\
\text { MA } \\
\text { NA } \\
\text { MA } \\
\text { MA } \\
\text { MA } \\
\text { NA } \\
\text { NA }\end{array}$ & $\begin{array}{l}N A \\
N A \\
N A \\
N A \\
N A \\
N A \\
N A \\
N A \\
N A \\
N A\end{array}$ & $\begin{array}{l}\text { NA } \\
\text { NA } \\
\text { NAA } \\
\text { MAA } \\
\text { MA } \\
\text { MAA } \\
\text { MAA }\end{array}$ & $\begin{array}{l}\text { NA } \\
\text { NA } \\
N A \\
N A \\
N A \\
N A \\
N A \\
N A \\
N A\end{array}$ & $\begin{array}{l}\text { MA } \\
\text { MA } \\
\text { NAA } \\
\text { NA } \\
\text { NA } \\
\text { NA } \\
\text { NA } \\
\text { NA }\end{array}$ & $\begin{array}{l}\text { NA } \\
\text { NA } \\
\text { NA } \\
\text { NA } \\
\text { NA } \\
\text { NA } \\
\text { NA } \\
\text { NA } \\
\text { NA } \\
\text { NA }\end{array}$ & $\begin{array}{r}271.5 \\
12.2 \\
12.9 \\
130 \\
0.5 \\
16.4 \\
129.6 \\
11.7 \\
14.0 \\
74.6\end{array}$ & $\begin{array}{r}263.0 \\
14.0 \\
13.2 \\
13.0 \\
0.4 \\
12.9 \\
190.4 \\
11.6 \\
4.0 \\
72.7\end{array}$ & 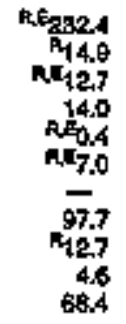 & $\begin{array}{c}214.4 \\
17.2 \\
\mathrm{NA} \\
14.0 \\
\mathrm{NA} \\
9.7 \\
0.0 \\
96.3 \\
\mathrm{NA} \\
4.9 \\
70.4\end{array}$ \\
\hline 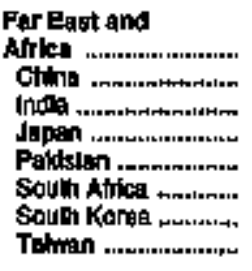 & $\begin{array}{r}120.8 \\
\overline{2.2} \\
10.5 \\
0.1 \\
\frac{1}{3.8} \\
13.1\end{array}$ & $\begin{array}{r}140.1 \\
\overline{2.0} \\
109.1 \\
0.2 \\
\overline{0.0} \\
10.5\end{array}$ & $\begin{array}{r}17.9 \\
4.1 \\
127.2 \\
0.3 \\
\overline{11.9} \\
24.3\end{array}$ & $\begin{array}{r}207.9 \\
\overline{4.6} \\
152.0 \\
0.3 \\
6.9 \\
16.5 \\
28.7\end{array}$ & $\begin{array}{r}23.29 \\
\overline{6.1} \\
18 . .8 \\
0.5 \\
6.3 \\
25.1 \\
26.9\end{array}$ & $\begin{array}{r}268.1 \\
6.6 \\
1628 \\
0.3 \\
6.6 \\
37.6 \\
39.1\end{array}$ & $\begin{array}{r}258.5 \\
\overline{8.1} \\
179.6 \\
0.2 \\
11.1 \\
38.7 \\
29.9\end{array}$ & $\begin{array}{r}273.2 \\
\overline{4.0} \\
188.7 \\
0.1 \\
11.7 \\
17.4 \\
20.3\end{array}$ & $\begin{array}{r}293.2 \\
-6.3 \\
191.9 \\
0.4 \\
2.9 \\
62,8 \\
0,5\end{array}$ & $\begin{array}{r}3+3.0 \\
5.4 \\
205.8 \\
0.4 \\
9.7 \\
69.3 \\
35.3\end{array}$ & $\begin{array}{r}35.1 \\
-6.3 \\
218.0 \\
0.6 \\
9.9 \\
50.4 \\
39.6\end{array}$ & $\begin{array}{r}554.0 \\
2.6 \\
6.2 \\
243.5 \\
0.4 \\
7.7 \\
6.1 \\
3.14\end{array}$ & 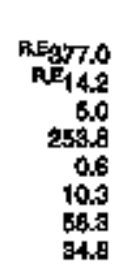 & $\begin{array}{r}405.9 \\
\text { NA } \\
8.0 \\
28.0 \\
0.5 \\
0.5 \\
t 1.8 \\
64.0 \\
35.3\end{array}$ \\
\hline Workd ? & 7as.5 & 698.5 & $1,061,5$ & 1,$266 ;, 4$ & $1,376.9$ & $1,460,6$ & $1,692.8$ & $1,654.2$ & $1,722,6$ & $1,926,2$ & $2,124,6$ & $2,505.6$ & $n_{2,220,4}$ & 2,275.0 \\
\hline
\end{tabular}

2 Theo Note 3 al end of section,

Covars Atarch through Decertiber onty.

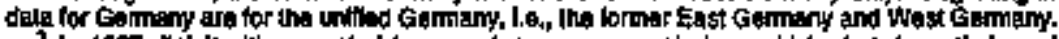

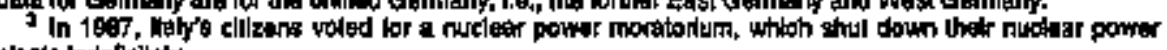
phamis indelinilety.

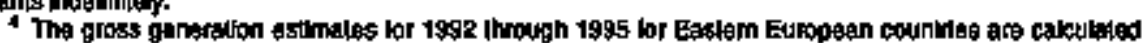

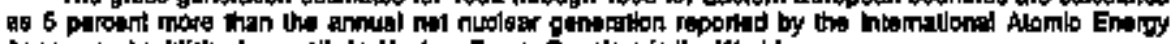

- Covars kares Ihrough Decerrber only.

projected to begin in 1986.

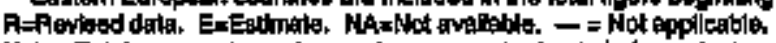

Nole: Tobals may not equal stum of compandents due to ladependenk nounding.

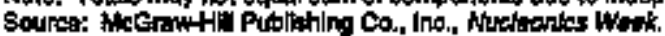




\section{International Energy Notes}

1. World primary energy production comprises cnude oil (including lease condensate), natural gas plant liquidis, dry natural gas, coal, net electricity from hydroelectric power and nuclear electric power, and net electricity generated for distribution from geothermal, wind, and solar thermal energy. Crude oil prodnetion is measured at the wellhead and includes lease condensate. Natural gas plant liquids are products obtained from processing natural gas at natural gas processing plants, including natural gas plants, cycling plants, and fractionators. Dry natural gas production is that amount of natural gas produced that is available to be marketed and consumed as a gas. Production of coal (anthracite, subanthracite, lignite, bituminous coal, subbituminous coal, and brown coal) is the sum of sales, mine consumption, issues to miners, and issues to coking, briquetting, and other ancillary plants at mises. Coal production data include quantities extracted from surface and undergrosnd workings and normally exclude wastes removed at mines or associated preparation plants. The data on production of electricity from hydrolectric power, nuclear electric power, and electricity generated for distribution from geothermal, wind, and solar thermal energy include data on both electric utility and industrial production reported on a net basis, thus excluding electricity that is generally used by the electric power plant for its own operating purposes or electricity losses in the transformers that ane considered integral parts of the station.

2. Petroleum stocks reported by the Organization for Economic Cooperation and Development (OECD) include those held at (or in) the following locations or facilities: leases, refineries, natural gas processing plants, bulk terminals, tanks associated with pipelines, barges, intercoastal tankers, ocean tankers in port, inland ship bunkers, major final consumers, and the strategic storage reserve. For an individual country, stocks include those held for the account of that couritry but located in another country. U.S. stocks include those held in the 50 States and the District of Columbia. "Other OECD" includes stocks held in Puerto Rtco and the Virgin Istands. The OECD definition of petroleum stocks excludes petroleum in pipelines, rail tank cars, tank tricks, oceangoing ship burkers, service stations, retail stores, and tankers at sea. An exception is U.S. stocks, which include petroleum in pipolines.

3. Data on the generation of electricity in the United States represent net generation, which is gross output of electricity (medsured at the generator terminals) minus power plant use. Nuclear electricity generation data identified by individual countries in Table 11.20 are gross output of electricity. 


\section{Environmental Indicators}

\section{Emissions of Greenhouse Gases}

Greenhouse gases--carbon dioxide, methane, nitrous oxide, carbon monoxide, and other gases-are those which block infrared radiation from Earth to space and reradiate the captured heat to the atmosphere. This warming effect, known as the greenhouse effect, keeps Earth's climate hospitable to plant, animal, and human life. But some scientists believe that anthropogenic (human-caused) additions to greenhouse gases will raise global average temperatures and produce deleterious changes in the global climate.

Carbon dloxide. Anthropogenic emissions of carbon dioxide, which accounts for the largest share by far of all anthropogenic emissions of greenhouse gases, rose to 5.2 billion metric tons of gas in 1994, up from 4.7 billion metric tons in 1985 (12.1)." Energy-related carbon dioxide emissions-those produced by the burning of fossil fuelstotaled 1.4 billion metric tons of carbon in 1994 (12.2). (There is one metric ton of carbon in every 3.667 metric tons of carbon dioxide gas.) Consumption of petroleum, particularly motor gasoline, by the transportation sector and coal burning at electric utilitites were the biggest sources of carbon dioxide emissions in 1994 (12.3).

Methane. Einergy-related activities also accounted for a big share of methane enissions (7.4 million metric tons of methane) in 1993 (12.4). But landfills enitted 10 million metric tons and agricultural sources (such as digestive processes in ruminant animals and the anaerobic decomposition of organic materials in animal waste and rice paddies) emitted 8.7 million metric tons of methane in 1993.

Nitrous oxtde. Emissions of nitrous oxjde, which, molecule for molecule, has a warming potential greater than that of either carbon dioxide or methane, rose to 0.5 million metric tons of gas in 1993 (12.1).

Criteria polfutants. The Clean Air Act of 1970 requires that air quality standards be established for pollutants that harm public health. Some criteria pollutants, such as carbon monoxide, nittogen oxides,

Wumbers in parentheses indicate rolated tables. Annual data are the most recent avaliable; they irequently are prefininary and may be revised in future publications. Percentages and numbers in text are calculated by using deta in the tables. and nonmethane volatile organic compounds (VOC's), also influence atmospheric concentrations of greenhouse gases. In 1993, carton monoxide and nonmethane VOC emissions were higher than in the previous year but lower thi.. in 1985 (12.1). Emissions of nitrogen oxides were fairly stable over the 9-year period.

\section{Emissions and Environmental Equipment at Electric Utllities}

In general, changes in electric utility consumption of fossil furels are accompanied by concomitant changes in the emission of carbon dioxide. In 1985 (the first year of the Energy Informatton Administration's electric utility emissions data series), consumption of fossil fuek to generate electricity totaled 19 quadrillion Btu (8.5). Emissions of carbon dioxide from fossil-fueled steam-electric generating units totaled 1.7 billion short tons (12.5). In 1994, consumption of fossil fusls to generate electricity rose to 21 quadrillion Btw, 11 percent higher then in 1985 (8.5), and carbon dioxide emissions from fassil-fueled steam-electric generating units were 13 percent higher than in 1985 (12.5).

\section{Some scientists believe that anthropogenic (human-caused) additions to greenhouse gases will produce deleterious changes in the global climate.}

By contrast, emissions of sulfur dioxide were actually lower in 1994 than they were in 1985. As is true of carbon dioxide emissions, most emissions of sulfur dioxide were attributable to coal combustion. However, such sulfur dioxide emissions can be controlled through the use of coal with a lower sulfur content and the use of scrubbers. From 1985 through 1994, the amount of coal-fired capacity equipped with scrubbers increased 42 percent to 81 million kilowatts (12.6). Although the amount of electrictty generated by burning coal at electric utilities rose 17 percent during the 1985 -ton1994 period (8.3), coal-related sulfur dioxide emissions declined 15 percent (12.5). 


\section{Carbon Dloxide, 1985-1994}

6 -

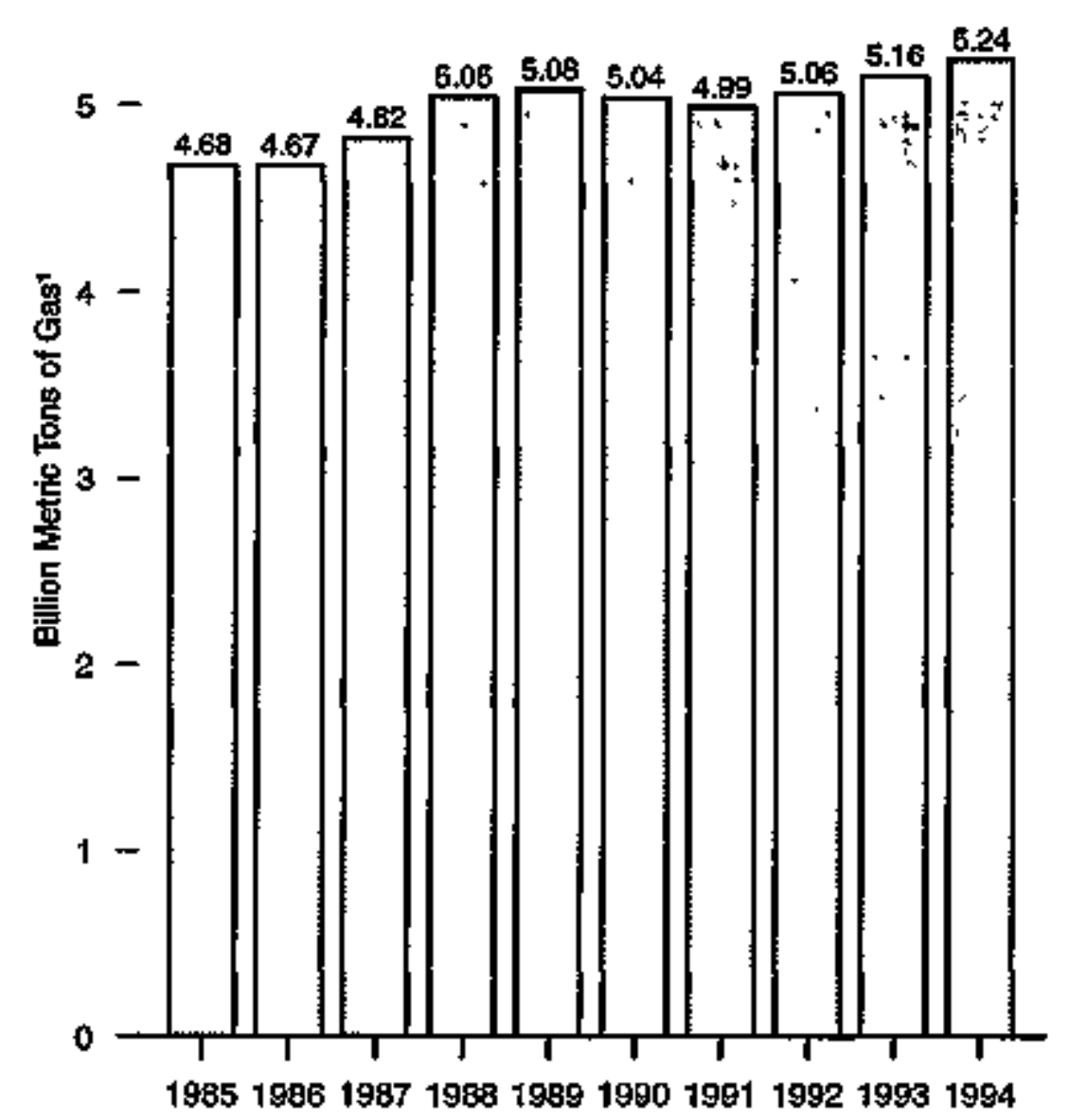

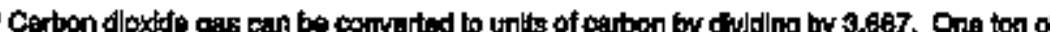
caitogn = 3.667 long of certori diloxdde ges.
Other Gremhouse Gases, 1985-1993

$110-$

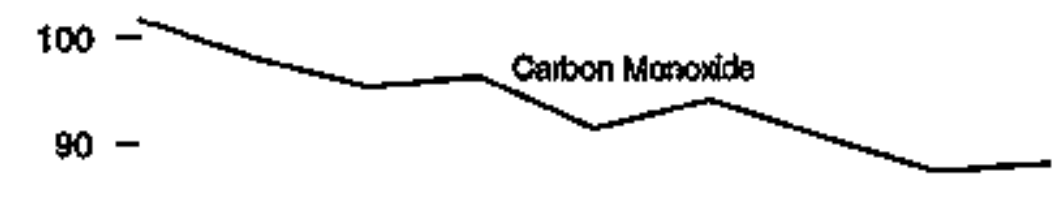

$80-$

量 $70-$

害 $60-$

窟

$50-$

올 $40-$

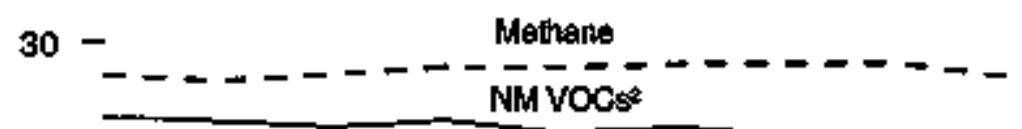

(1) Nitrogen Oxddes

$10-$

Nhrous Oxide

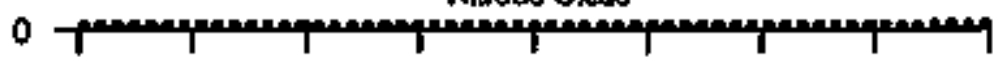
$\begin{array}{lllllllll}1985 & 1986 & 1987 & 1988 & 1989 & 1990 & 1991 & 1992 & 1993\end{array}$ 
Table 12.1 Estimated Emissions of Greenhouse Gases by Gas, 1985-1994 (Milion Metric Tons of Gas)

\begin{tabular}{|c|c|c|c|c|c|c|c|c|c|c|}
\hline an: & 1805 & 1966 & 1997 & 1988 & 1009 & 1590 & 1091 & 1992 & 1998 & 1804 \\
\hline 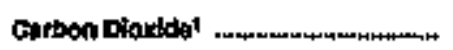 & $P_{4,677,5}$ & $F_{4,574.0}$ & $1,8=0,6$ & $5,046,1$ & $R_{5,080,7}$ & $P_{5,0055.5}$ & Fa,AsBi & $n_{5,052,8}$ & 月5,756,0 & 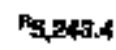 \\
\hline 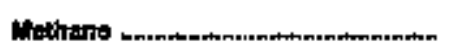 & $\cos s$ & $\mathrm{R}_{20.3}$ & $\mathbf{P}_{27.0}$ & Rer.8 & R27.5 & $M_{27.9}$ & $\mathrm{P} 27.8$ & $\mathrm{R}_{20.0}$ & $n_{20.0}$ & NA \\
\hline 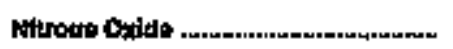 & 0.4 & 0.4 & 0.4 & 0.4 & 0.4 & 0.4 & 0.4 & 0.4 & An.5 & MA \\
\hline 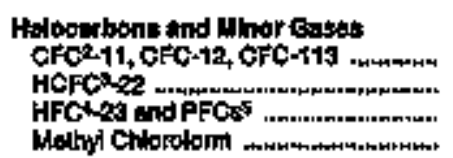 & 0.9 & $0_{0.3}^{0.3}$ & $(*)_{0.3}^{0.3}$ & $\begin{array}{c}0.3 \\
0.1 \\
0.3\end{array}$ & $\langle 0,0.3$ & $\begin{array}{r}0.7 \\
0.1 \\
0.3\end{array}$ & 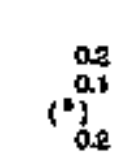 & $i_{0.2}^{0.1}$ & $\overbrace{0,2}^{+0,2}$ & $\begin{array}{l}\text { P.1 } \\
\text { Po.1 } \\
(\stackrel{0}{0.1})\end{array}$ \\
\hline 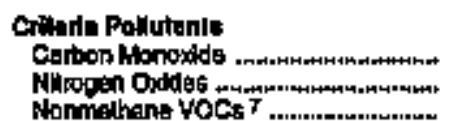 & $\begin{array}{r}A_{101.0} \\
H_{20.7} \\
n_{28.0}\end{array}$ & $\begin{array}{l}R_{93,0} \\
20,3 \\
m_{2,5}\end{array}$ & $\begin{array}{l}\mathrm{F}_{95,3} \\
\mathrm{~F}_{20,3} \\
\mathrm{f}_{2,1.1}\end{array}$ & 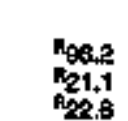 & $\begin{array}{l}R_{91.4} \\
R_{21.1} \\
R_{21.5}\end{array}$ & $\begin{array}{l}f_{94.1} \\
a_{21,0} \\
n_{22,0}\end{array}$ & $\begin{array}{l}\mathrm{P}_{90.6} \\
\mathrm{P}_{206} \\
\mathrm{~A}_{2 \div, 3}\end{array}$ & $\begin{array}{l}\log _{87.4} \\
n_{20.8}\end{array}$ & $\begin{array}{l}n_{60,1} \\
n_{21,2} \\
f_{21.1}\end{array}$ & MA \\
\hline
\end{tabular}

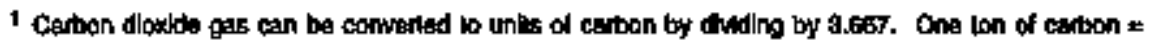
3.s67 Lons of cartion dloxdin gas.

2 Chivouluorocartionts.

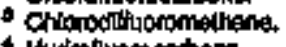

4 itipontuomecabiona.

Particuosoarbons.

and 5.4 thousand mabla lons in 1984

Voleulls ongenio oompoundis.

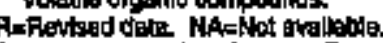

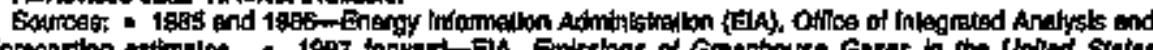

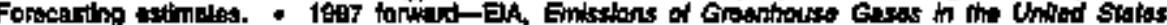

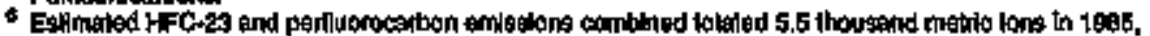

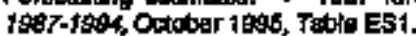




\section{Figure 12.2 Carbon Dioxide Emissions From Fossil Energy Consumption by Sector, 1980-1994}

\section{End-Use Tolel}

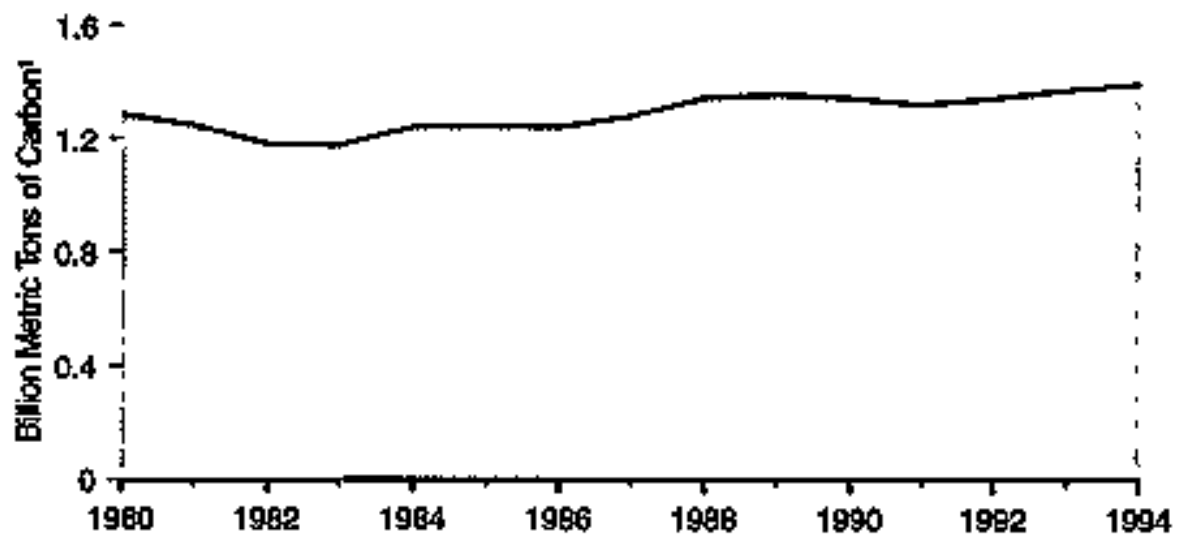

Eloctric Utllity Net Genaration of Electrioity and Carbon Dloxide Em|sosions

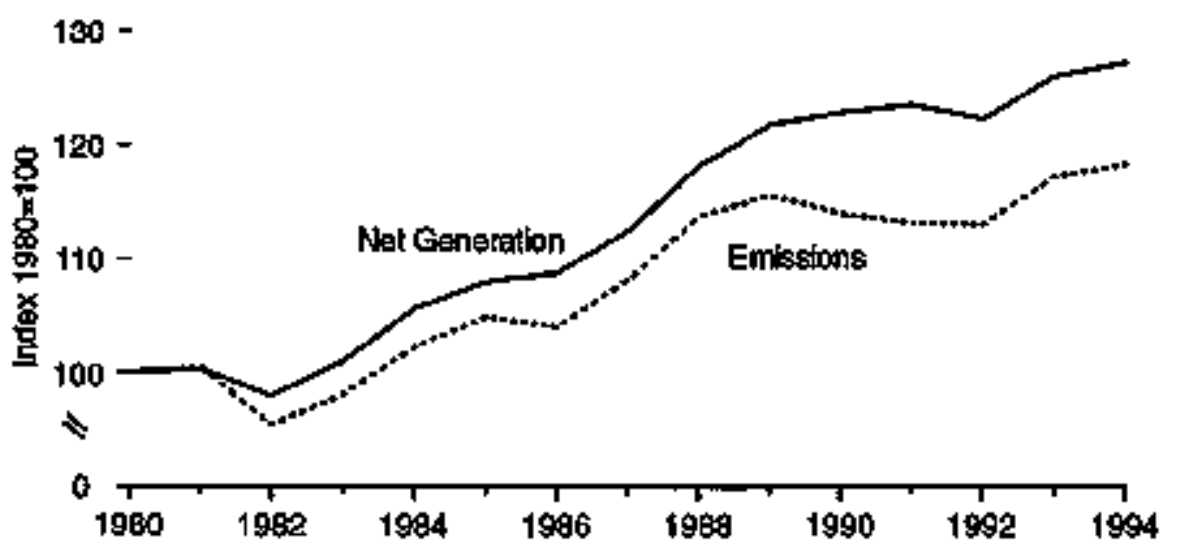

By End-Use Seclor

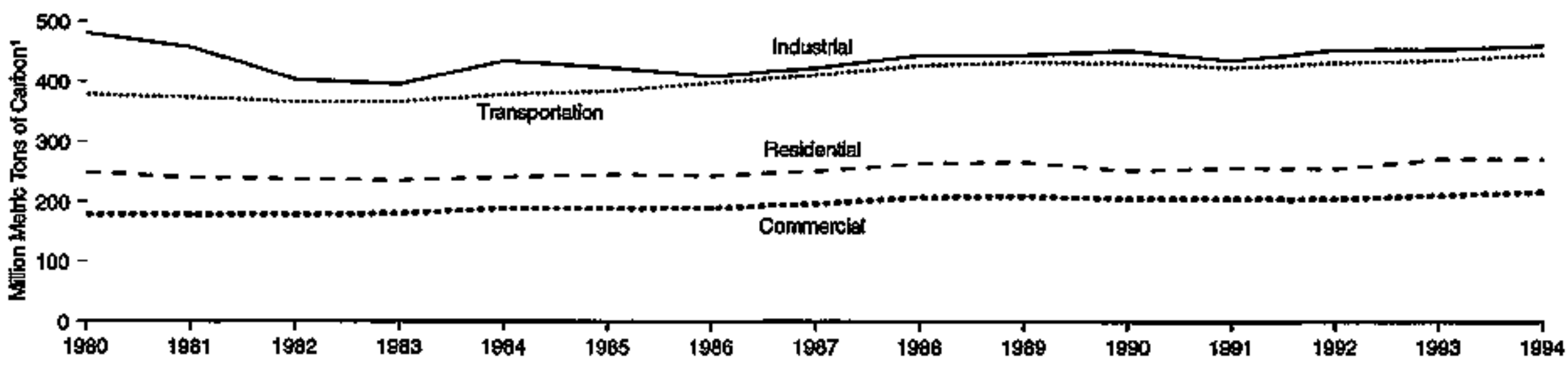

1 Tens of carton cen be converted to tons of caiben doddde ges by muliphying by a,667, One kon of cartion $=9.667$ tors of carbon dloxkde gas.

Sources: Tabliss $8 . t$ and 12.2. 
Table 12.2 Carbon Dioxide Emissions From Fossil Energy Consumption by Sector, 1980-1994 (Million Metric Tons of Carbon')

\begin{tabular}{|c|c|c|c|c|c|c|}
\hline Year & Ronitalsud & Commerctal & Industrial & Thensportalion & $\begin{array}{c}\text { Entilluse } \\
\text { Tolat }\end{array}$ & $\begin{array}{l}\text { Electtke } \\
\text { Dinlibe? }\end{array}$ \\
\hline $\begin{array}{l}1980 \\
1981 \\
1989 \\
19989 \\
1984 \\
1985 \\
1988 \\
1987 \\
1988 \\
1999 \\
1995 \\
1991 \\
1995 \\
1998 \\
1994\end{array}$ & 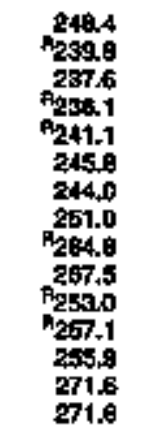 & $\begin{array}{r}17.3 \\
178.3 \\
178.5 \\
100.0 \\
189.8 \\
189.5 \\
190.4 \\
197.2 \\
207.6 \\
210.0 \\
205.7 \\
206.4 \\
2055.5 \\
212.1 \\
218.9\end{array}$ & 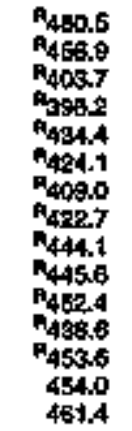 & 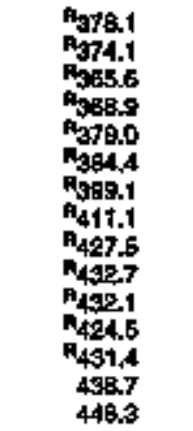 & 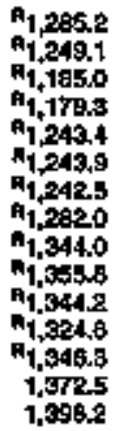 & $\begin{array}{l}418.3 \\
420.8 \\
398.5 \\
410.4 \\
427.9 \\
498.9 \\
438.4 \\
452.6 \\
476.9 \\
469.5 \\
478.9 \\
473.5 \\
472.5 \\
40.6 \\
494.9\end{array}$ \\
\hline
\end{tabular}

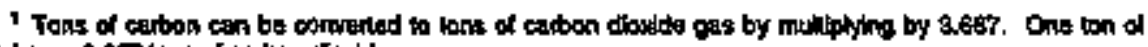

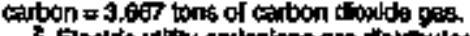

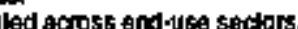

components due to kndepandent reundug

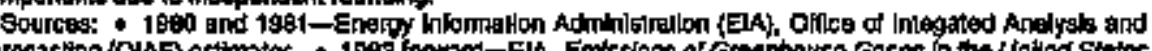

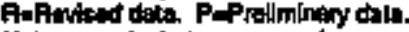

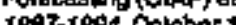

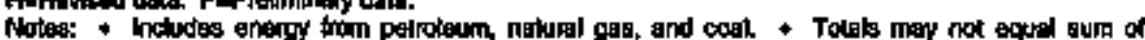



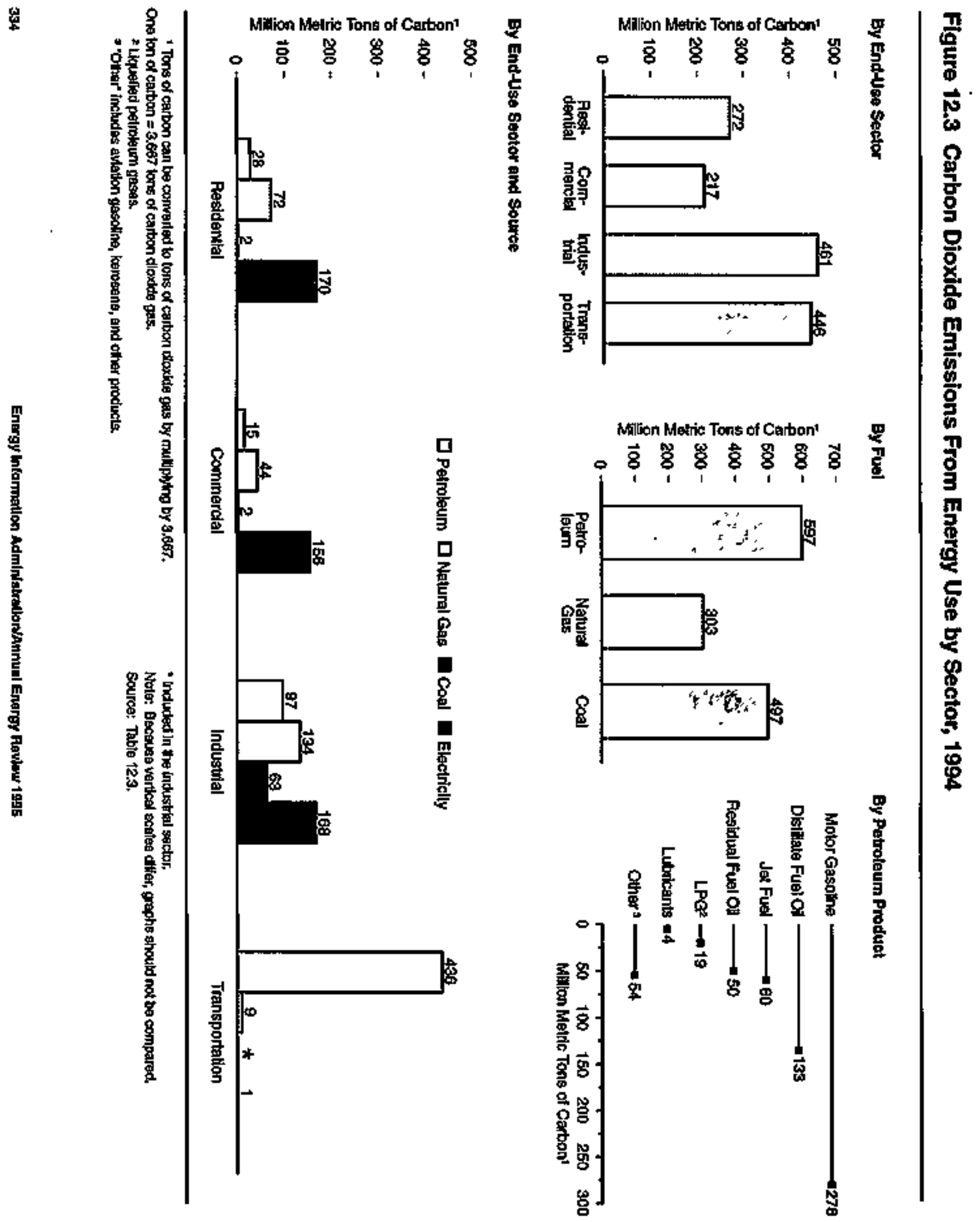
Table 12.3 Carbon Dioxide Emissions From Energy Use by Sector, 1994

(Million Matric Tons of Carbon')

\begin{tabular}{|c|c|c|c|c|c|c|c|}
\hline Enargy Soukce & 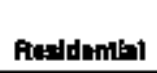 & Comnerelal & 1nduaturat & Transportalon & Tondul & $\begin{array}{l}\text { Elactik } \\
\text { eviltitea } z\end{array}$ & Totel \\
\hline 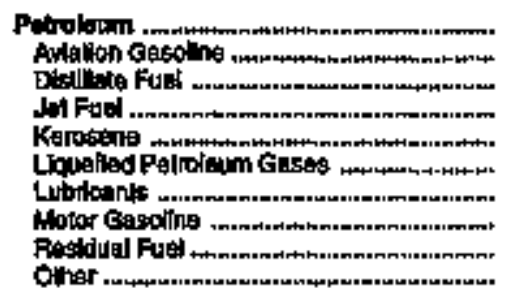 & $\begin{array}{l}\frac{27.6}{18.5} \\
\frac{1}{7.5} \\
\frac{7.4}{=} \\
=\end{array}$ & $\begin{array}{l}\frac{16.4}{8.5} \\
\frac{0.3}{1.3} \\
\frac{0.3}{0.8} \\
\frac{3.6}{-}\end{array}$ & $\begin{array}{l}98.9 \\
\frac{7}{22.3} \\
\overline{0.3} \\
3.9 \\
1.3 \\
3.5 \\
6.9 \\
50.4\end{array}$ & $\begin{array}{r}436.2 \\
0.7 \\
60.3 \\
00.4 \\
\frac{0.4}{1.7} \\
273.5 \\
19.2 \\
-\end{array}$ & $\begin{array}{r}676.1 \\
0.7 \\
130.9 \\
50.4 \\
2.0 \\
18.8 \\
3.5 \\
27.8 \\
35.8 \\
50.4\end{array}$ & 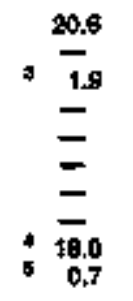 & $\begin{array}{r}696.8 \\
0.7 \\
18.8 \\
60.4 \\
2.0 \\
18.8 \\
3.5 \\
27.8 \\
49.8 \\
51.1\end{array}$ \\
\hline 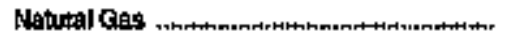 & 72.1 & 43.8 & 133.5 & 0.4 & 268.7 & 44.0 & 302.6 \\
\hline 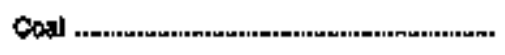 & 1.5 & 2.2 & ges: & (i) & 6B.4 & 460.4 & ASGS: \\
\hline Electitily & 170.4 & 155.7 & 168.2 & 0.7 & 484.8 & - & $\hookrightarrow$ \\
\hline 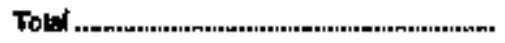 & 271.6 & 216.9 & $\$ 1.4$ & 446.3 & $1,398.2$ & 494.8 & $1,398.2$ \\
\hline
\end{tabular}

1 Tons of carbon can be convartad to tons of carben thoxide gas by mulliplying by 3.567. One ton of

coston a 3.667 kins of caston dilodds gas.

\$ Petroloum coke.

- includod in the indusidat encior.

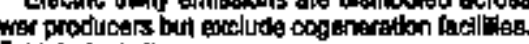

$\rightarrow-N o t$ in the indt

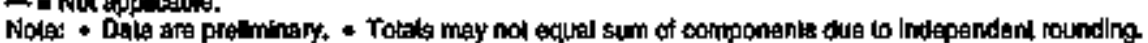

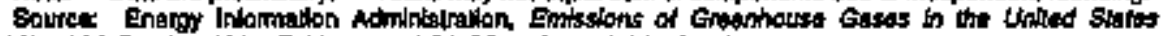

4 Hestry tual on. 1867-1994, Oeloter 1995, Tablas 4 and C1-C5 and unpubstshed esilnores. 

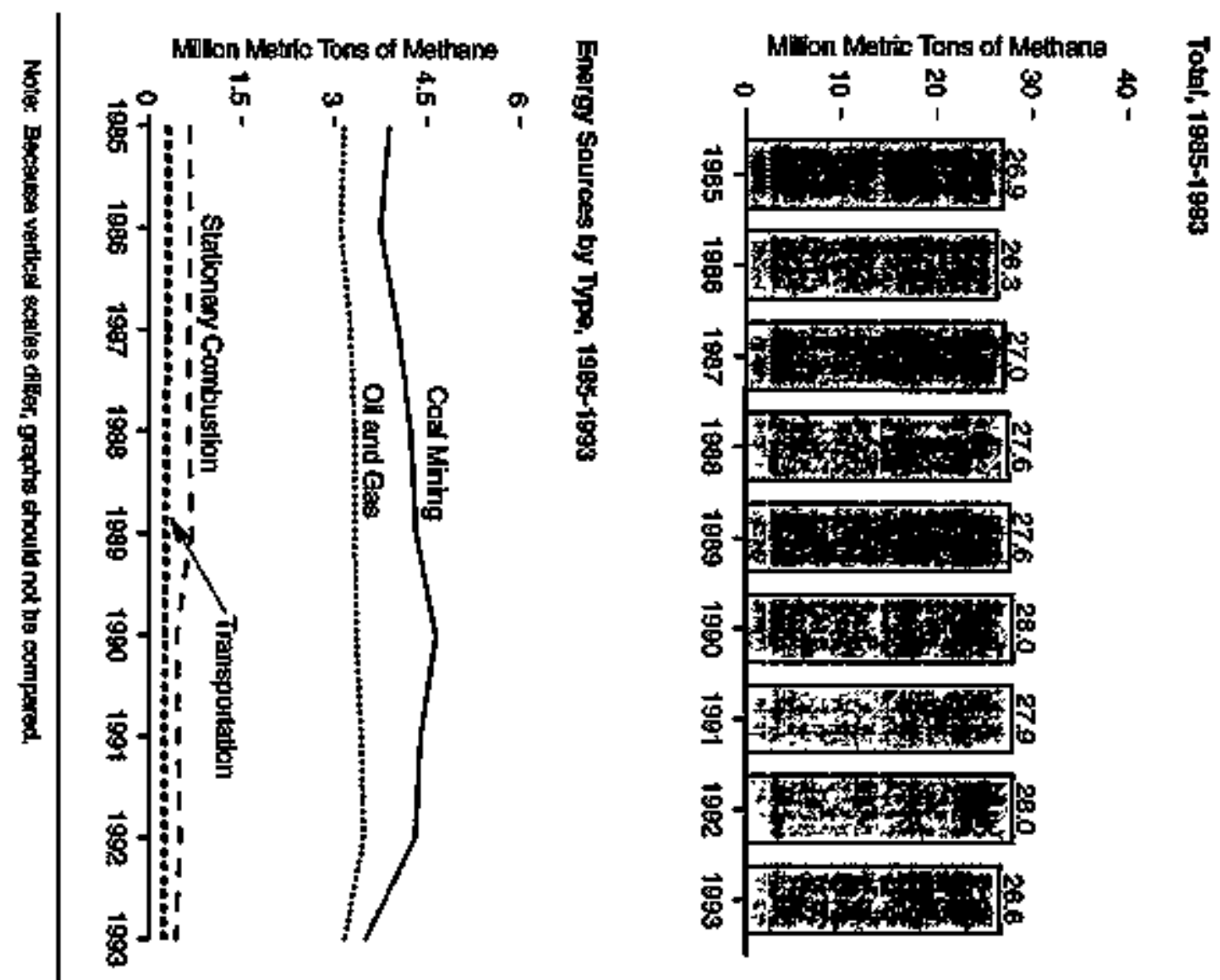

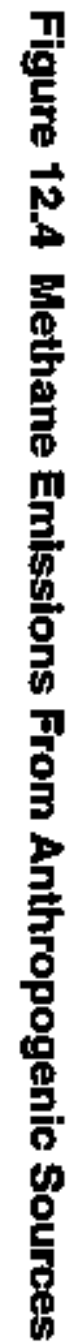
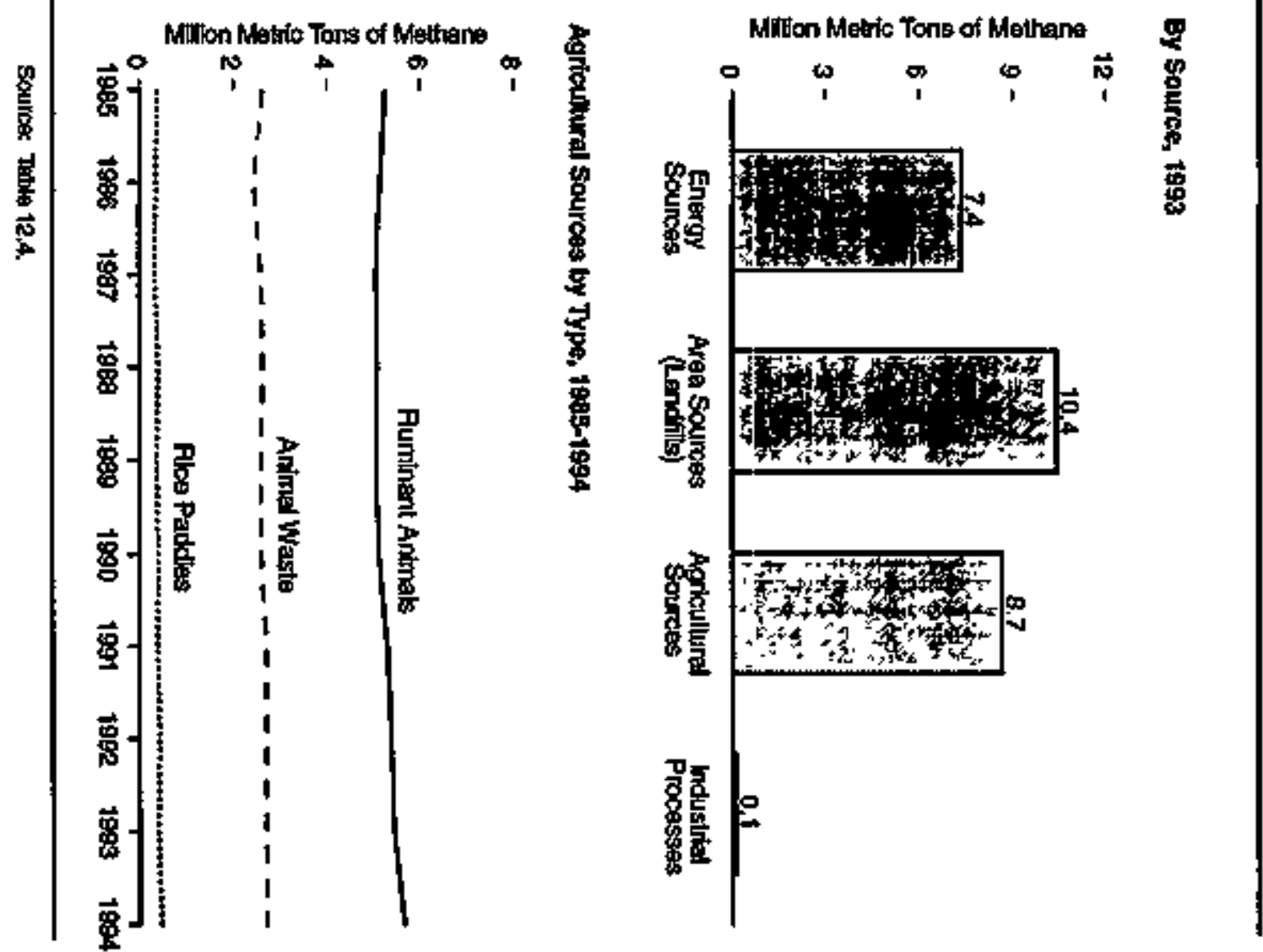
Table 12.4 Methane Emlssions From Anthropogenlc Sources, 1985-1994

(Milion Metric Tons of Methane)

\begin{tabular}{|c|c|c|c|c|c|c|c|c|c|c|c|c|c|}
\hline \multirow[b]{2}{*}{ Yaur? } & \multicolumn{5}{|c|}{ Enwgy Soureas } & \multirow{2}{*}{$\begin{array}{l}\text { Arov } \\
\text { Souros } \\
\text { Landillis }\end{array}$} & \multicolumn{5}{|c|}{ Agriculiural Sourost } & \multirow[b]{2}{*}{$\begin{array}{l}\text { Indugtrital } \\
\text { Procoustes }\end{array}$} & \multirow[b]{2}{*}{ Total } \\
\hline & $\begin{array}{c}\text { 메 } \\
\text { and ans }\end{array}$ & $\begin{array}{c}\text { Coal } \\
\text { Malning }\end{array}$ & Trensportakion & $\begin{array}{l}\text { Stoptionary } \\
\text { Comburtion }\end{array}$ & Total & & $\begin{array}{c}\text { Ruplinent } \\
\text { Anlandele }\end{array}$ & $\begin{array}{l}\text { Anlend } \\
\text { Wable }\end{array}$ & $\begin{array}{l}\text { Fales } \\
\text { Puddks }\end{array}$ & $\begin{array}{c}\text { Crop Festotus } \\
\text { Buming }\end{array}$ & Totel & & \\
\hline $\begin{array}{l}1985 \\
1985 \\
1987 \\
1909 \\
1969 \\
1980 \\
1991 \\
1899 \\
1893 \\
1994\end{array}$ & 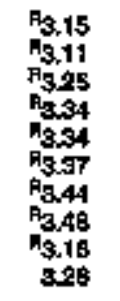 & 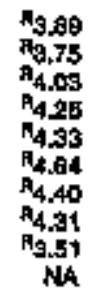 & $\begin{array}{c}0.32 \\
0.34 \\
0.50 \\
0.39 \\
0.28 \\
0.37 \\
0.35 \\
0.25 \\
0.24 \\
\text { NA }\end{array}$ & $\begin{array}{l}0.66 \\
0.68 \\
0.55 \\
0.46 \\
0.69 \\
0.46 \\
0.49 \\
0.51 \\
0.44 \\
0.45\end{array}$ & 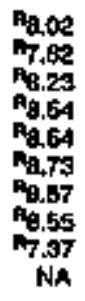 & $\begin{array}{r}A_{10.31} \\
A_{10.34} \\
A_{10.53} \\
A_{10.84} \\
n_{10.65} \\
A_{10.91} \\
A_{10.72} \\
A_{10.80} \\
A_{10.43} \\
\mathrm{NA}\end{array}$ & 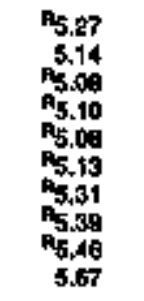 & 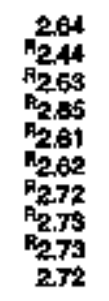 & $\begin{array}{l}0.36 \\
0.34 \\
0.33 \\
0.41 \\
0.38 \\
0.40 \\
0.35 \\
0.44 \\
\mathbf{R} \\
0.40 \\
0.46\end{array}$ & $\begin{array}{l}0.14 \\
0.13 \\
0.12 \\
0.10 \\
0.12 \\
0.13 \\
0.12 \\
0.14 \\
0.11 \\
0.15\end{array}$ & 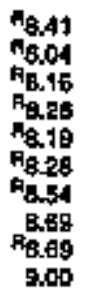 & $\begin{array}{l}0.11 \\
0.10 \\
0.11 \\
0.12 \\
0.12 \\
0.12 \\
0.11 \\
0.12 \\
\mathbb{R} 0.12 \\
0.12\end{array}$ & 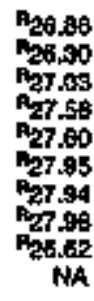 \\
\hline
\end{tabular}

Pefletiond data.

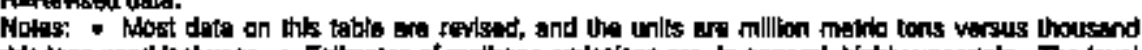

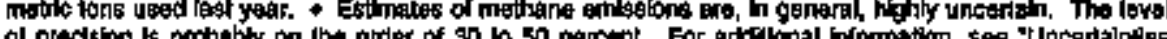

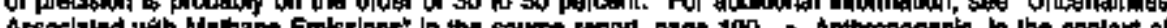

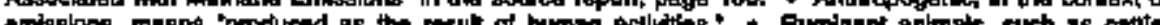

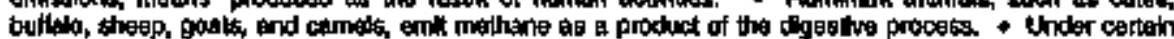

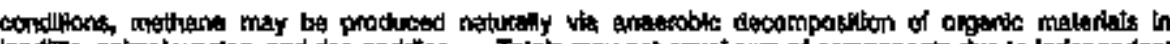

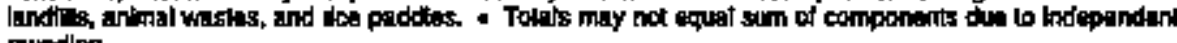

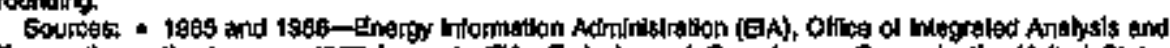

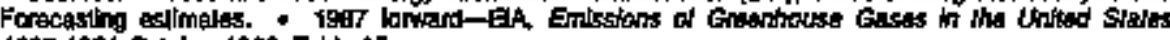

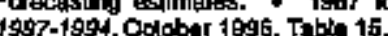




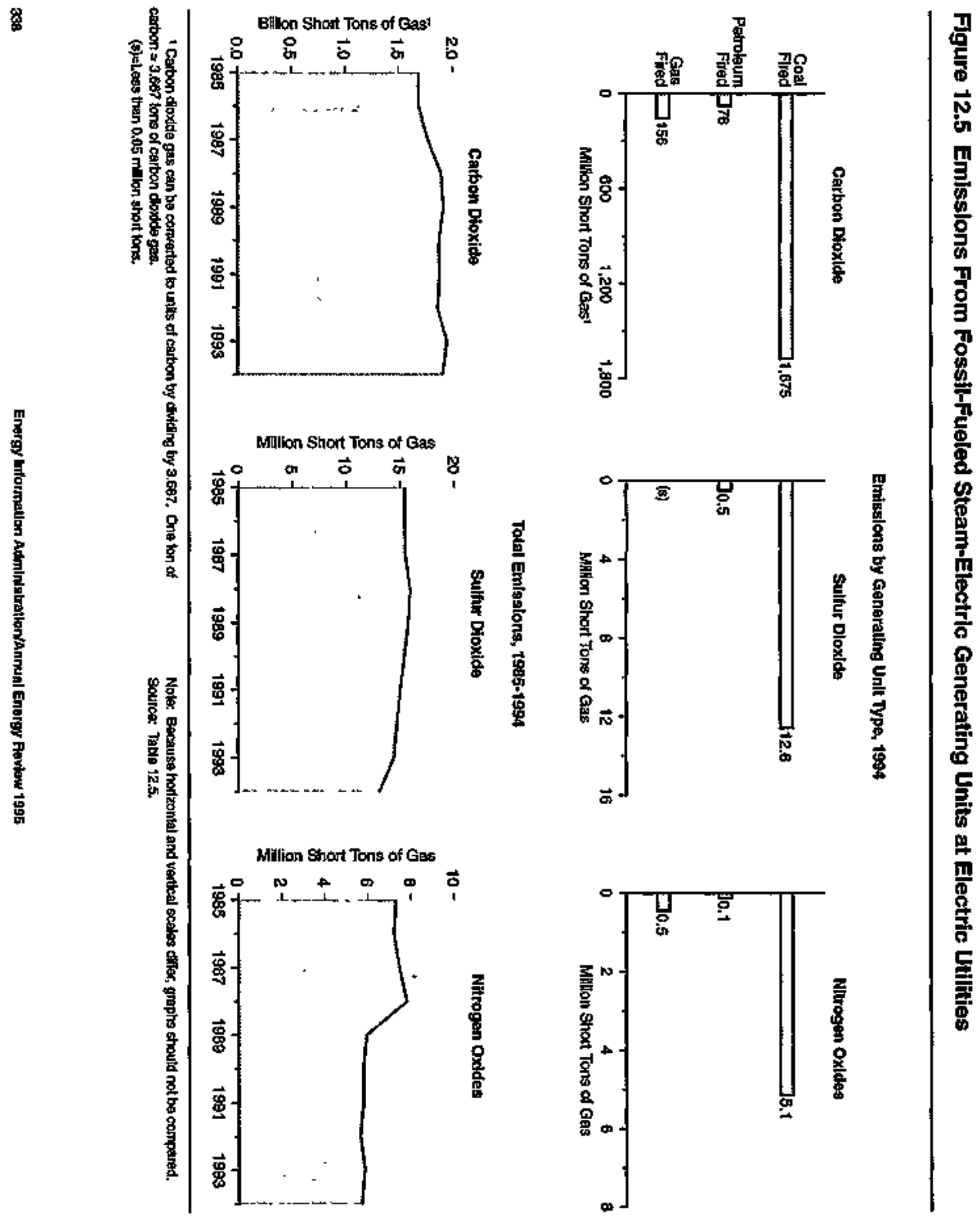


Table 12.5 Emissions From Fossil-Fueled Steam-Electric Generating Unlts at Electrlc Utijities, 1985-1994

(Thousand Short Tons of Gas)

\begin{tabular}{|c|c|c|c|c|c|c|c|c|c|c|c|c|}
\hline \multirow[b]{2}{*}{ Year } & \multicolumn{3}{|c|}{ Cobl Fhod } & \multicolumn{3}{|c|}{ Polnoloum Fred } & \multicolumn{3}{|c|}{ cras Firted } & \multicolumn{3}{|c|}{ Total 3} \\
\hline & $\begin{array}{l}\text { Corbon } \\
\text { Dipddde? }\end{array}$ & $\begin{array}{l}\text { Sulfur } \\
\text { Dloxdde }\end{array}$ & $\begin{array}{l}\text { Nilirogen } \\
\text { Oddes }\end{array}$ & $\begin{array}{l}\text { Carbon } \\
\text { Dloxdde }\end{array}$ & $\begin{array}{l}\text { sulfur } \\
\text { Dloxdd }\end{array}$ & $\begin{array}{l}\text { Minoges } \\
\text { Oxides }\end{array}$ & $\begin{array}{l}\text { Carbon } \\
\text { Dloddg }\end{array}$ & $\begin{array}{l}\text { Sullur } \\
\text { DIoxdde }\end{array}$ & $\begin{array}{c}\text { Nitrogen } \\
\text { Oxkles }\end{array}$ & $\begin{array}{l}\text { Curbon } \\
\text { Dlaxide }\end{array}$ & $\begin{array}{l}\text { Sullur } \\
\text { Dodexkle }\end{array}$ & $\begin{array}{l}\text { Niltragen } \\
\text { oiddes }\end{array}$ \\
\hline $\begin{array}{l}1985 \\
1985 \\
1967 \\
1988 \\
1989 \\
1990 \\
1991 \\
1998 \\
1993 \\
1994\end{array}$ & 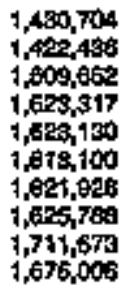 & 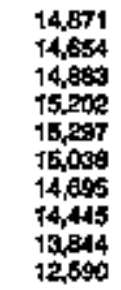 & $\begin{array}{l}6,439 \\
6,590 \\
6,313 \\
6,069 \\
7,045 \\
7,076 \\
7,079 \\
7,719 \\
5,289 \\
5,749\end{array}$ & 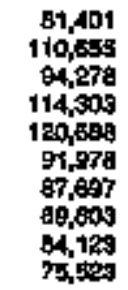 & $\begin{array}{l}502 \\
762 \\
600 \\
710 \\
7 \in 0 \\
629 \\
607 \\
501 \\
589 \\
510\end{array}$ & $\begin{array}{l}165 \\
200 \\
219 \\
272 \\
204 \\
219 \\
209 \\
167 \\
138 \\
118\end{array}$ & 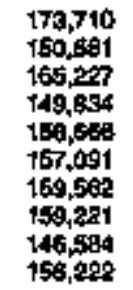 & $\begin{array}{l}1 \\
1 \\
1 \\
1 \\
1 \\
1 \\
1 \\
1 \\
1 \\
1\end{array}$ & $\begin{array}{l}668 \\
672 \\
629 \\
590 \\
605 \\
588 \\
600 \\
907 \\
424 \\
450\end{array}$ & 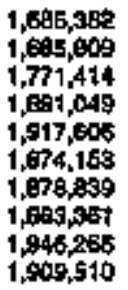 & $\begin{array}{l}15,426 \\
15,419 \\
15,615 \\
15,828 \\
15,750 \\
15,489 \\
15,012 \\
14,690 \\
14,438 \\
13,104\end{array}$ & $\begin{array}{l}7,283 \\
7,217 \\
7,464 \\
7,6028 \\
5,958 \\
5,801 \\
5,8011 \\
5,671 \\
3,852 \\
5,719\end{array}$ \\
\hline
\end{tabular}

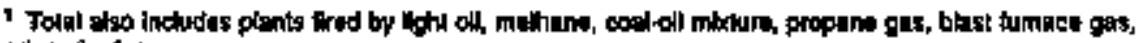
moxid ind retuse.

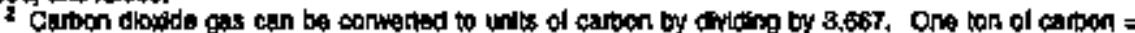

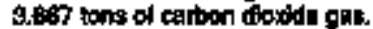

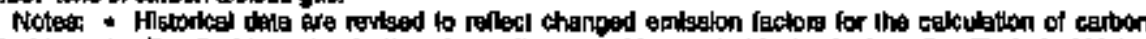

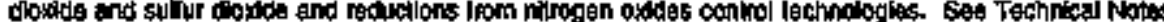

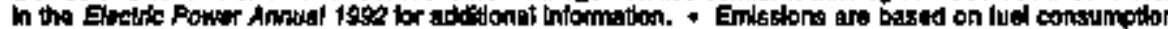

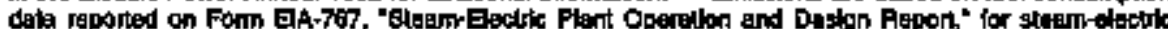

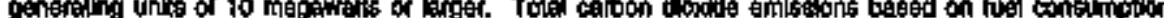

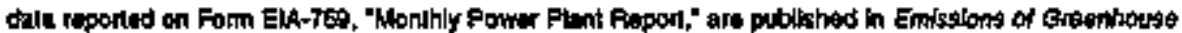

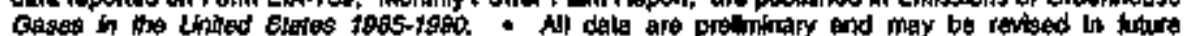

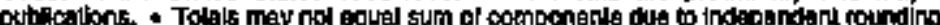

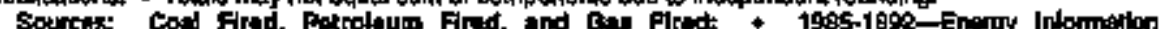

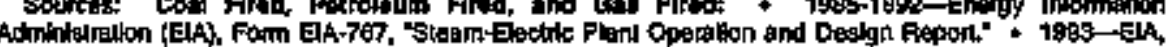

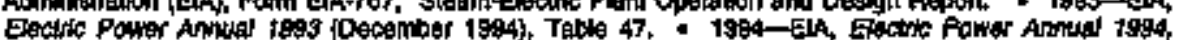

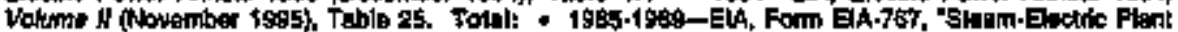

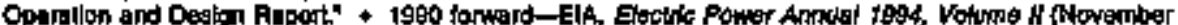
19es, Table 22 


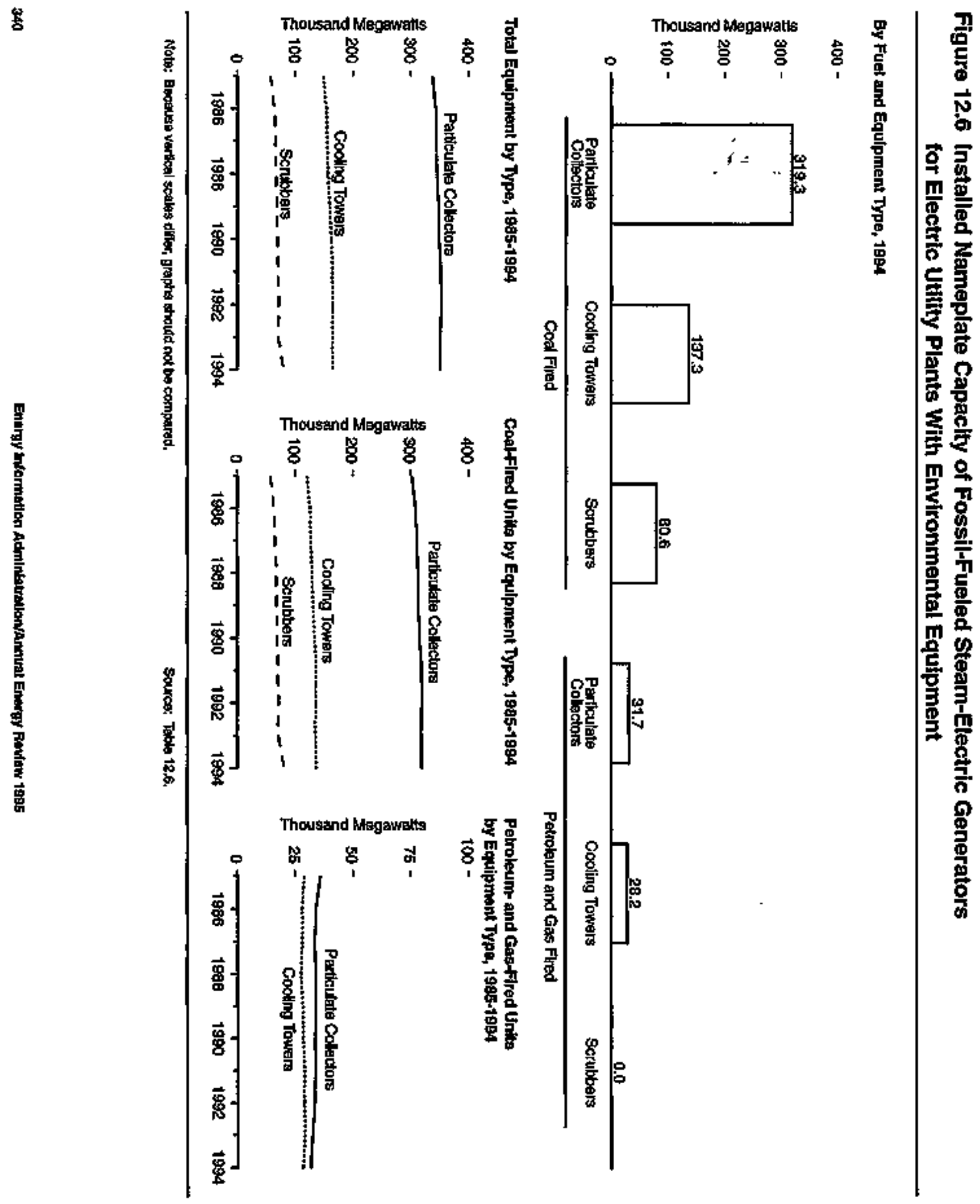


Table 12.6 Installed Nameplate Capacity of Fossil-Fueled Steam-Electric Generators for Electric Utility Plants With Environmental Equipment, 1985-1994

(Megawatts)

\begin{tabular}{|c|c|c|c|c|c|c|c|c|c|c|c|c|}
\hline \multirow[b]{2}{*}{ Your } & \multicolumn{4}{|c|}{ Cosl Fired } & \multicolumn{4}{|c|}{ Petroleum and bas Fined } & \multicolumn{4}{|c|}{ Total } \\
\hline & $\begin{array}{l}\text { Purtieulate } \\
\text { Colkolars }\end{array}$ & $\begin{array}{l}\text { Cooring } \\
\text { Tonwhe }\end{array}$ & serubbers: & Tokn" & $\begin{array}{l}\text { Portitulats } \\
\text { Colleotors }\end{array}$ & $\begin{array}{l}\text { Cotiling } \\
\text { Towise }\end{array}$ & Sorvibuera & Toted 1 & $\begin{array}{l}\text { Parlicutice } \\
\text { eslleclora }\end{array}$ & cooling & Serubbart & Foidal 1 \\
\hline 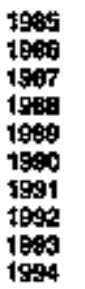 & $\begin{array}{l}302,056 \\
300,566 \\
311,043 \\
31,047 \\
31,768 \\
313,709 \\
315,691 \\
319,127 \\
320,016 \\
319,690 \\
319,309\end{array}$ & $\begin{array}{l}120,591 \\
126,731 \\
127,875 \\
199,988 \\
131,697 \\
134,199 \\
138,770 \\
138,942 \\
198,029 \\
197,268\end{array}$ & 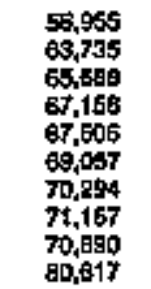 & $\begin{array}{l}304,706 \\
311,217 \\
312,805 \\
313,618 \\
315,540 \\
317,5,220 \\
319,189 \\
320,070 \\
318,490 \\
319,600\end{array}$ & 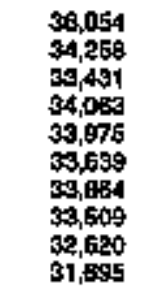 & $\begin{array}{l}28,995 \\
27,919 \\
27,912 \\
27,434 \\
29,396 \\
28,359 \\
29,067 \\
29,784 \\
28,920 \\
28,188\end{array}$ & $\begin{array}{r}65 \\
65 \\
65 \\
65 \\
65 \\
65 \\
265 \\
195 \\
0 \\
0\end{array}$ & $\begin{array}{l}62,371 \\
69,618 \\
59,793 \\
55,567 \\
69,736 \\
59,778 \\
59,773 \\
69,118 \\
59,595 \\
5,128\end{array}$ & $\begin{array}{l}339,110 \\
342,655 \\
344,474 \\
345,839 \\
347,655 \\
349,319 \\
352,980 \\
393,565 \\
351,451 \\
351,004\end{array}$ & $\begin{array}{l}149,498 \\
154,650 \\
195,795 \\
158,600 \\
160,097 \\
162,557 \\
105,937 \\
165,303 \\
169,951 \\
165,452\end{array}$ & $\begin{array}{l}57,020 \\
63,900 \\
65,750 \\
67,201 \\
67,624 \\
59,122 \\
70,554 \\
71,961 \\
70,990 \\
80,517\end{array}$ & $\begin{array}{l}387,078 \\
370,635 \\
371,168 \\
372,158 \\
376,267 \\
976,694 \\
970,963 \\
979,164 \\
977,473 \\
376,723\end{array}$ \\
\hline
\end{tabular}

1 Components are nol addilye because some generators are inctuded in more than one malegary.

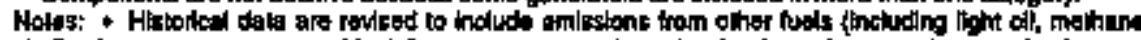

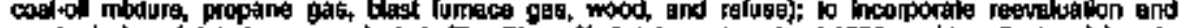
resulom

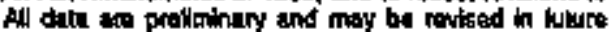

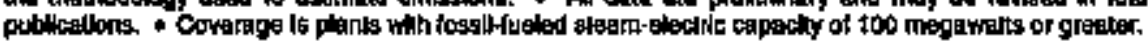

Sourcas: Cosal Fired and Poiralaum and Gas Firedt - 1985-1993-Enatgy Information Admintsilration

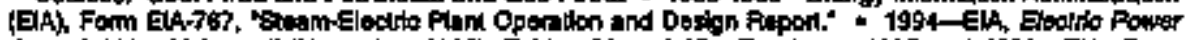

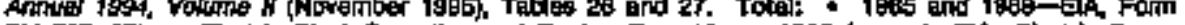

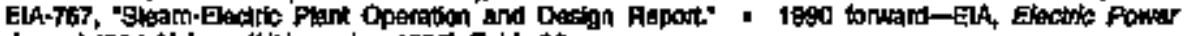

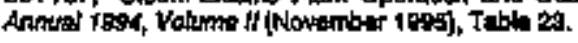





\section{Thermal Conversion Factors}

\section{Using Thermal Conversion Factors}

The thermal conversion factors presented in the following seven tables can be used to estimate the heat content in British thermal units (Btu) of a given amount of energy measured in physical units, such as barrels or cubic feet. For example, 10 barrels of asphalt has a heat content of approximately 66.36 million Btu (10 barrels x 6.636 million $\mathrm{Btu} / \mathrm{barrel}=66.36$ million Btu).

In general, the annual therrial conversion factors presented in Tables A2 through A7 are computed from Final annual data. However, if the current year's final data are not available in time for publication, thermal conversion factors for the current year are computed from the best available data and are labeled "preliminary." The source of each factor is described in the section entitled "Thermal Conversion Factor Source Documentation," which follows Table A7 in this appendix.

Thermal conversion factors for hydrocarbon mixes are weighted averages of the thermal conversion factors for each hydrocarbon included in the mix. For example, in calculating the thermal conversion factor for a $60-40$ butane-propane mixture, the thermal conversion factor for butane is wigithed 1.5 times more heavily than the thermal conversion factor for propane.

More information about British thermal units (the standardized unit of measure for energy) can be found in Appendix D, "Energy Units in Perspective," and in the Glossary.
Table A1. Approximate Heat Content of Petroleum Proclucts (Millon Elu per Barnel)

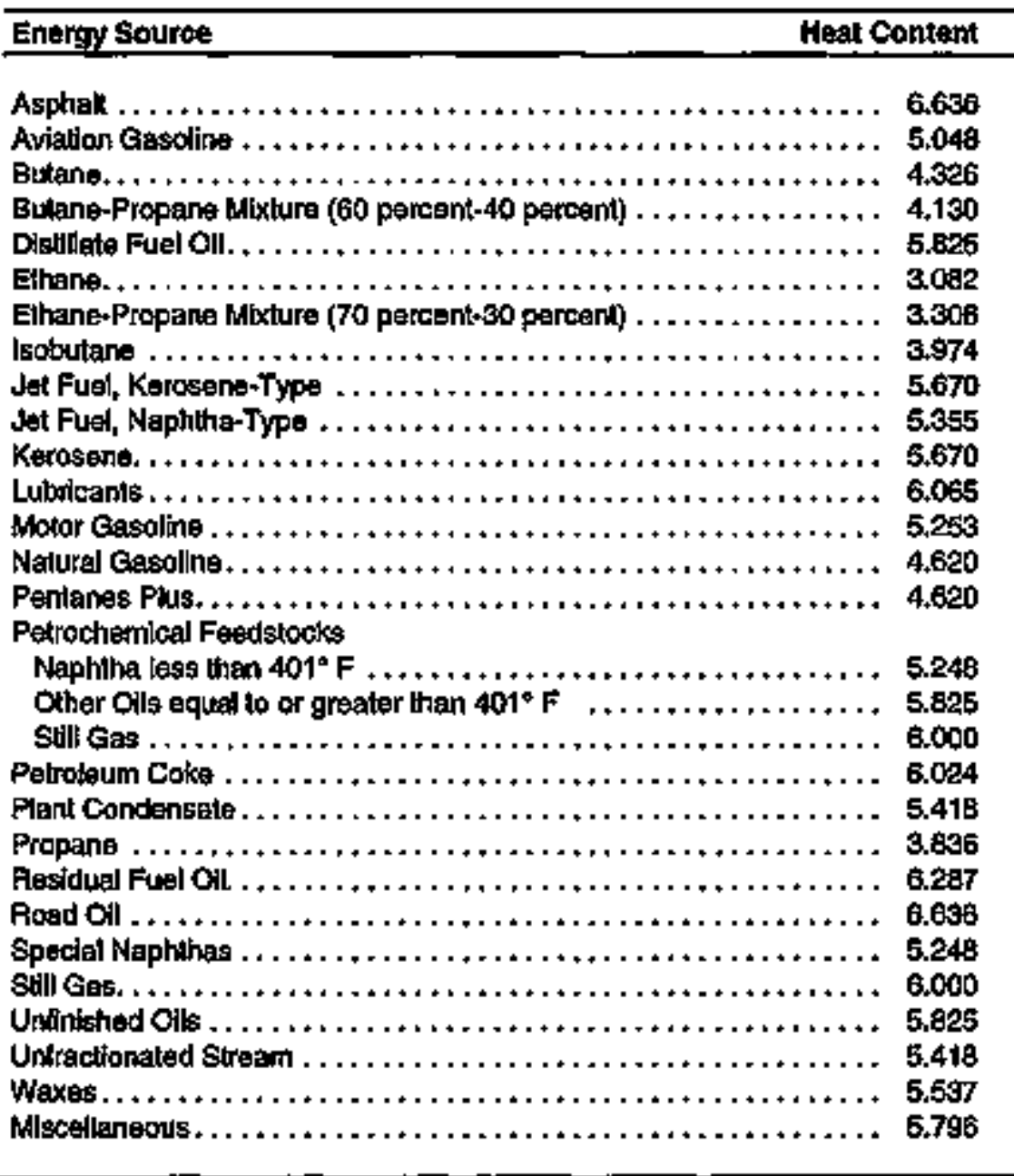

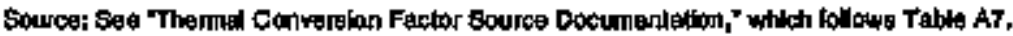


Table A2. Approximate Heat Content of Crude Oil, Crude Oil and Products, and Natural Gas Plant Liquids, 1949-1995 (Milition Btu per Barrel)

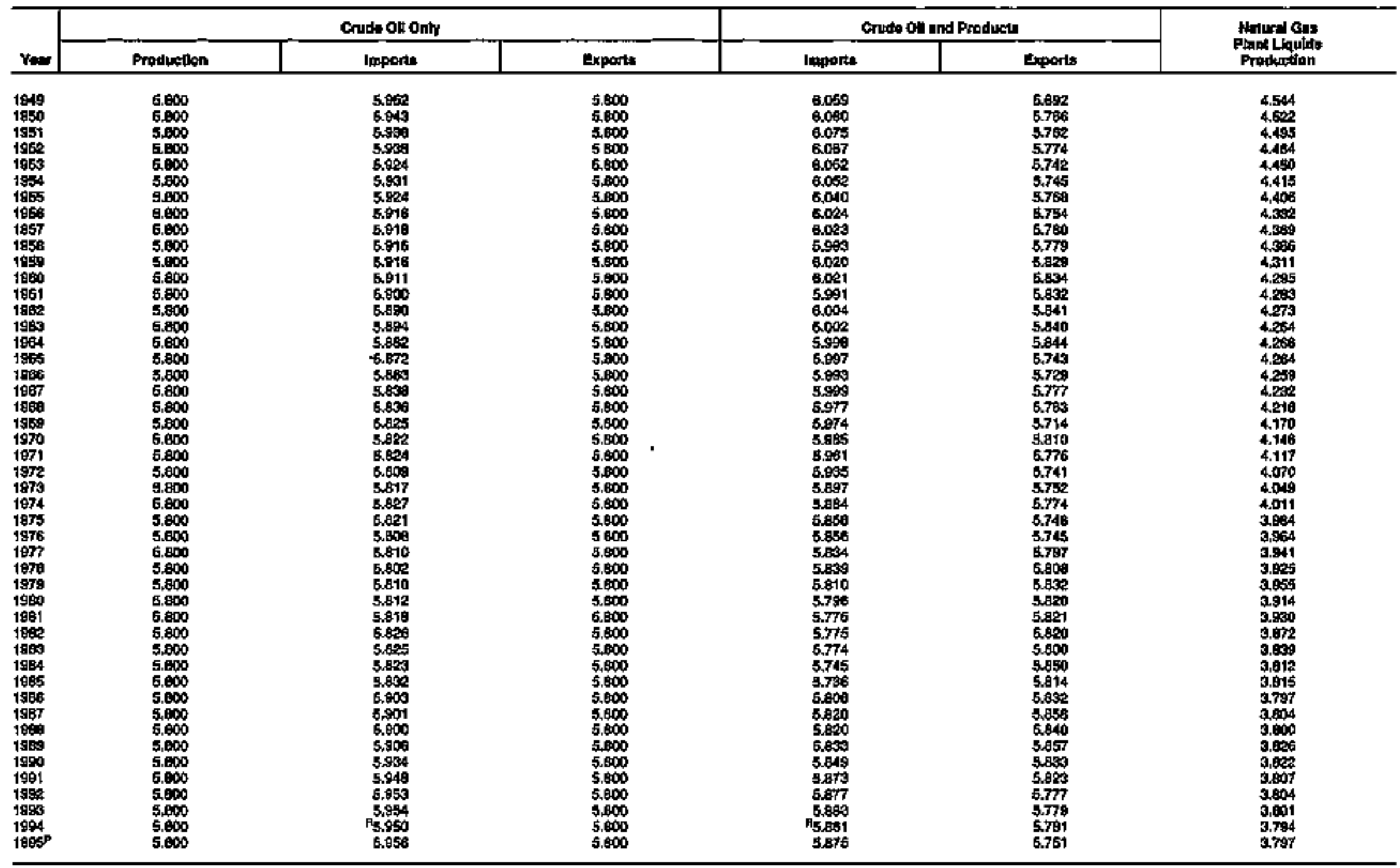


Table A3. Approximate Heat Content of Petroleum Product Weighted Averages, 1949-1995 (Million Btu per Barrel)

\begin{tabular}{|c|c|c|c|c|c|c|c|}
\hline \multirow[b]{2}{*}{ Year } & \multicolumn{5}{|c|}{ Consumption } & \multirow[b]{2}{*}{ imports: } & \multirow[b]{2}{*}{ Export: } \\
\hline & $\begin{array}{l}\text { Residenulal } \\
\text { and Commerciad }\end{array}$ & Mndusirita & Transporteldan & $\begin{array}{l}\text { Eyeretrk } \\
\text { Utilates }\end{array}$ & Tolal & & \\
\hline 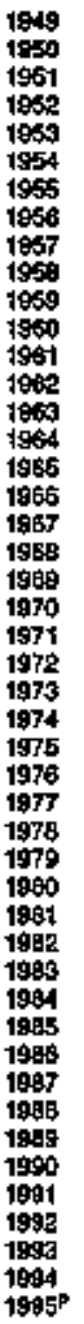 & 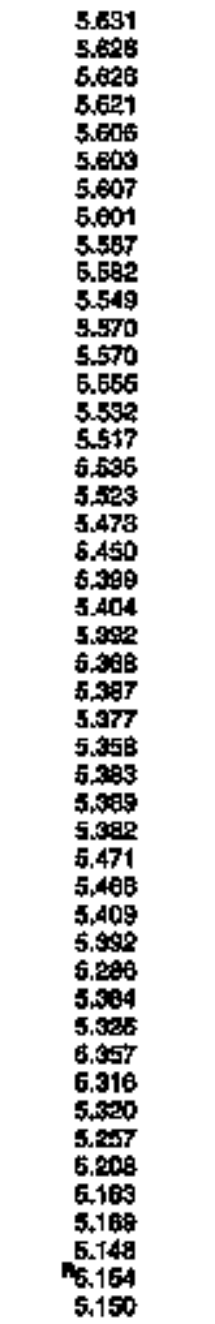 & 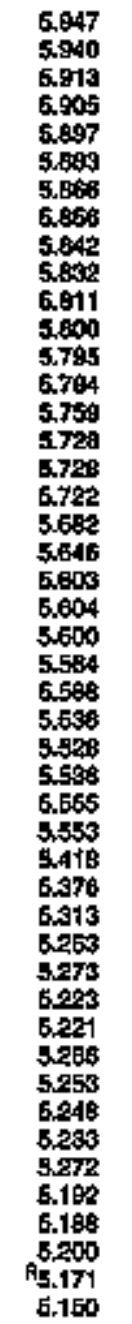 & 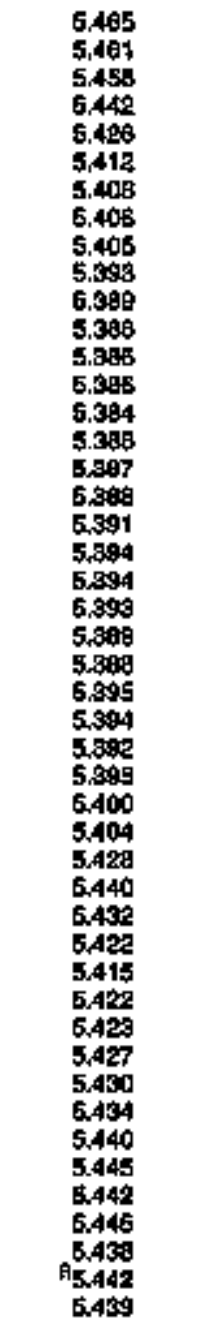 & 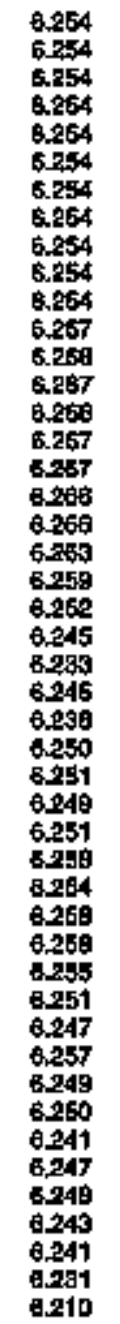 & 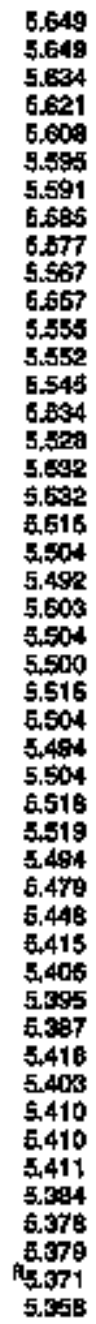 & 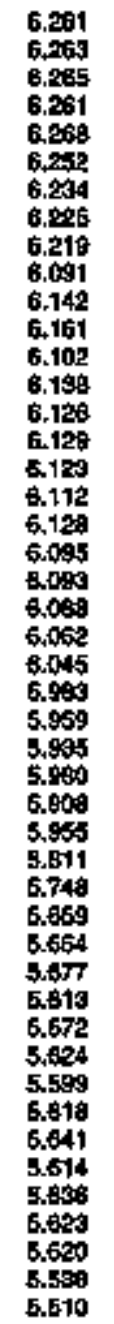 & 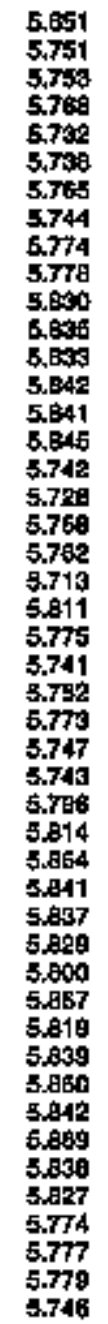 \\
\hline
\end{tabular}

A-Rievied dale PoPrealininary dele.

Nole; Wotghted awaragas of the prodints included in siech category aro calouleled by using has content

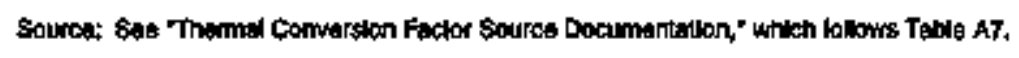
relues chom in Tabla A1. 
Table A4. Approximate Heat Content of Natural Gas, 1949-1995 (Btu per Cubic Foot)

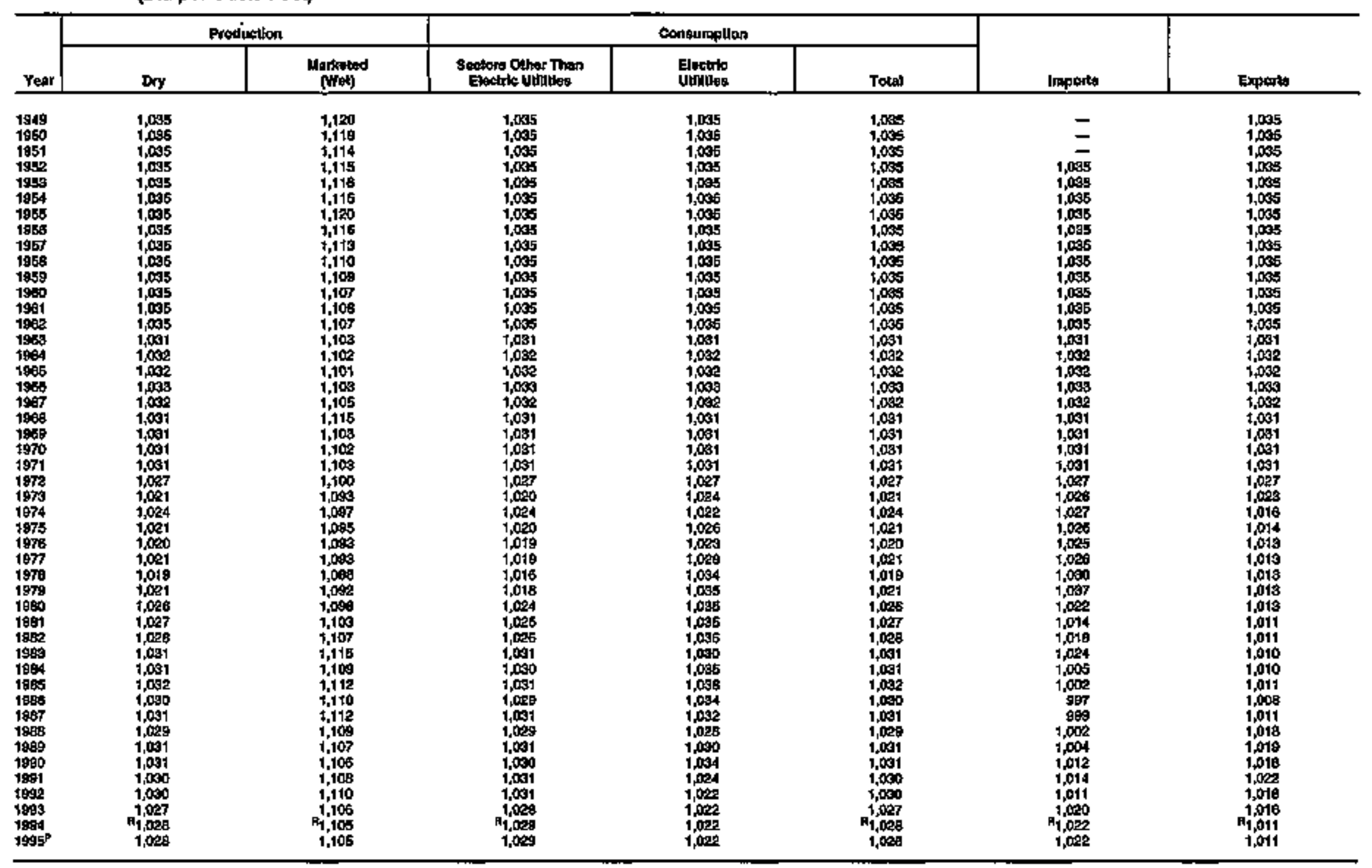


Table A5. Approximate Heat Content of Coal and Coal Coke, 1949-1995 (Million Btu per Short Ton)

\begin{tabular}{|c|c|c|c|c|c|c|c|c|c|}
\hline \multirow[b]{3}{*}{ Your } & \multicolumn{8}{|c|}{ Con } & \multirow{3}{*}{$\begin{array}{l}\text { Cool Cokt } \\
\text { Inports } \\
\text { Exports }\end{array}$} \\
\hline & \multirow[b]{2}{*}{ Produation } & \multicolumn{5}{|c|}{ Consumplkon } & \multirow[b]{2}{*}{ Imports } & \multirow[b]{2}{*}{ Export: } & \\
\hline & & $\begin{array}{l}\text { fiesidentiol } \\
\text { and } \\
\text { Commerolal }\end{array}$ & $\begin{array}{l}\text { Coke } \\
\text { Piants }\end{array}$ & $\begin{array}{l}\text { Othar } \\
\text { Induntrios: }\end{array}$ & $\begin{array}{l}\text { Electriks } \\
\text { Uitihlos }\end{array}$ & Total & & & \\
\hline 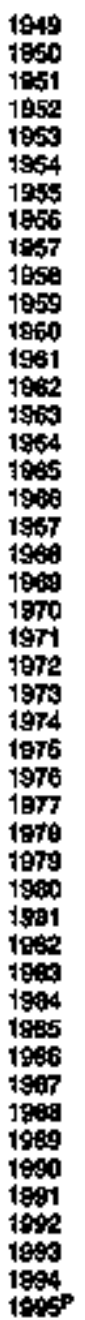 & 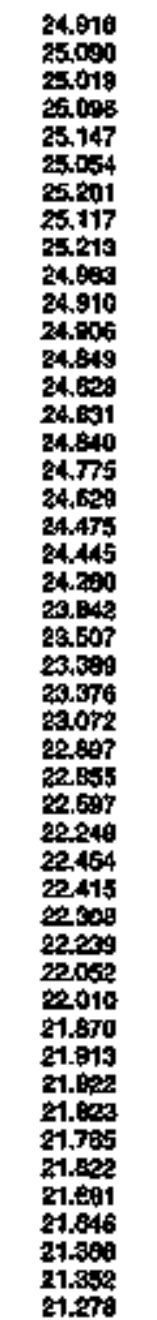 & 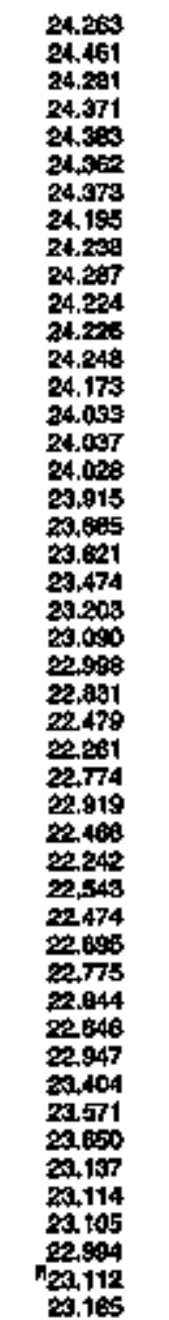 & 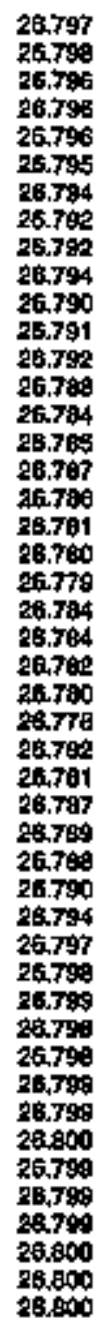 & 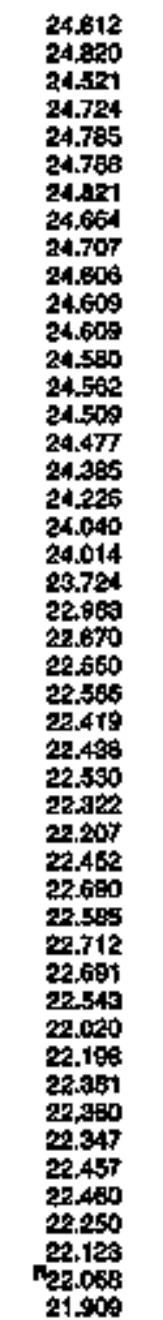 & 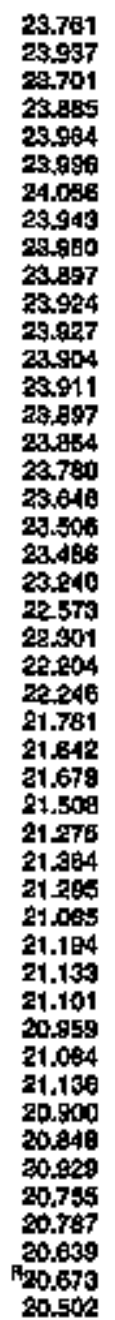 & 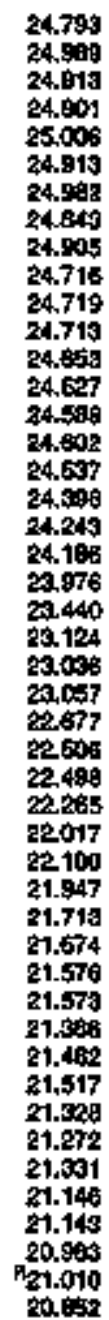 & $\begin{array}{l}25.000 \\
25.000 \\
25.054 \\
25.040 \\
25.048 \\
25.012 \\
25.000 \\
25.000 \\
25.001 \\
25.005 \\
25.003 \\
25.000 \\
25.002 \\
25.013 \\
25.007 \\
23.000 \\
25.000 \\
25.000 \\
25.000 \\
25.000 \\
25.000 \\
25.000 \\
25.000 \\
25.000 \\
25.000 \\
25.000 \\
25.000 \\
25.000 \\
25.000 \\
25.000 \\
25.000 \\
25.000 \\
25,000 \\
25.000 \\
25.000 \\
25.000 \\
25.000 \\
25.000 \\
25.000 \\
25,000 \\
25.000 \\
25.000 \\
25,000 \\
25.000 \\
25.000 \\
25.000 \\
25.000\end{array}$ & 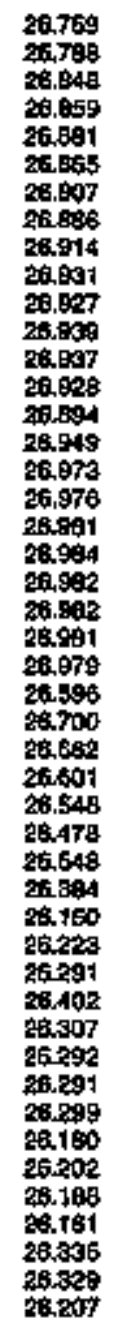 & 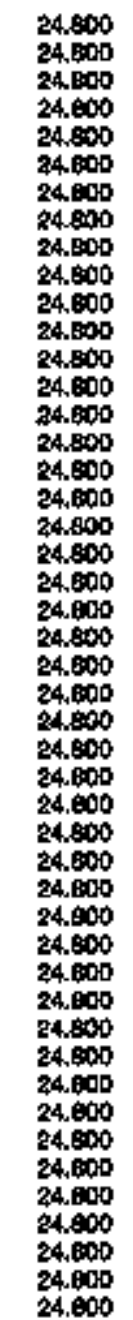 \\
\hline
\end{tabular}

1 Inotudes trankponalon.

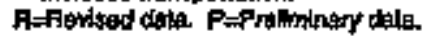

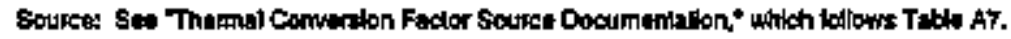


Table A6. Approximate Heat Content of Coal by Type, 1949-1995 (Million Btw per Short Ton)

\begin{tabular}{|c|c|c|c|c|c|c|c|c|c|c|c|c|c|}
\hline \multirow[b]{3}{*}{ Yeur } & \multicolumn{8}{|c|}{ 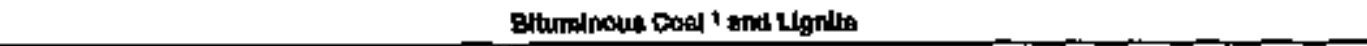 } & \multicolumn{5}{|c|}{ Andhraclis: } \\
\hline & \multirow[b]{2}{*}{ Production } & \multicolumn{5}{|c|}{ Conisumplon } & \multirow[b]{2}{*}{ Imports } & \multirow[b]{2}{*}{ Exports } & \multirow[b]{2}{*}{ Protitetion } & \multicolumn{3}{|c|}{ Consunnption } & \multirow[b]{2}{*}{$\begin{array}{l}\text { Intparts } \\
\text { End } \\
\text { Export. }\end{array}$} \\
\hline & & $\begin{array}{l}\text { Rosidendid } \\
\text { and } \\
\text { Conmmerclial }\end{array}$ & $\begin{array}{l}\text { colke } \\
\text { Planal }\end{array}$ & $\begin{array}{c}\text { Otwer } \\
\text { industry }\end{array}$ & 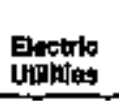 & Told & & & & $\begin{array}{c}\text { Sectors Other } \\
\text { Then Electrit } \\
\text { Ullillese }\end{array}$ & $\begin{array}{l}\text { Elecults } \\
\text { Utitipas }\end{array}$ & Totat & \\
\hline 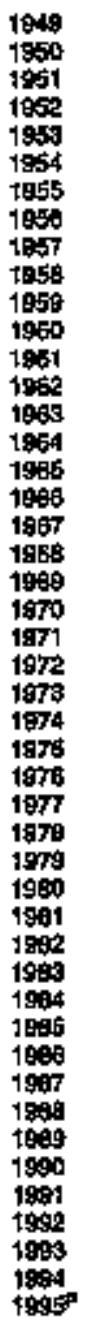 & 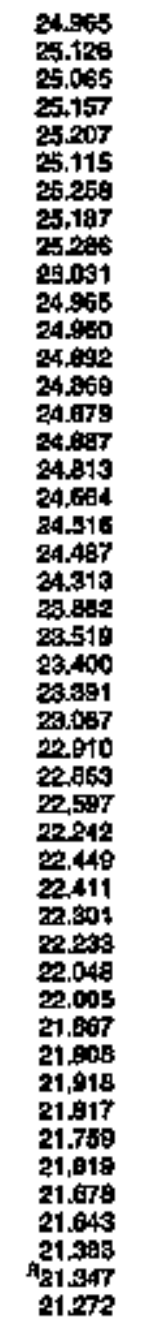 & 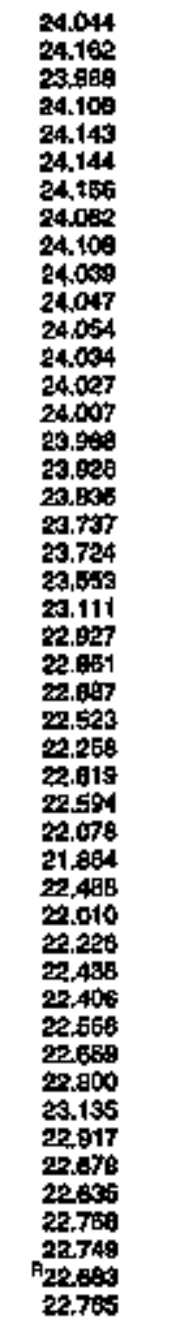 & 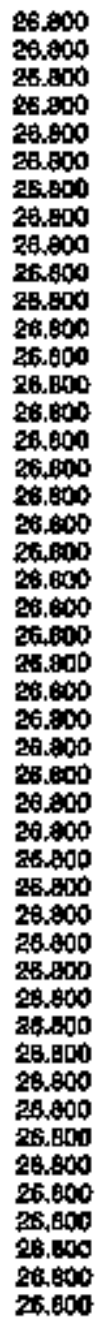 & 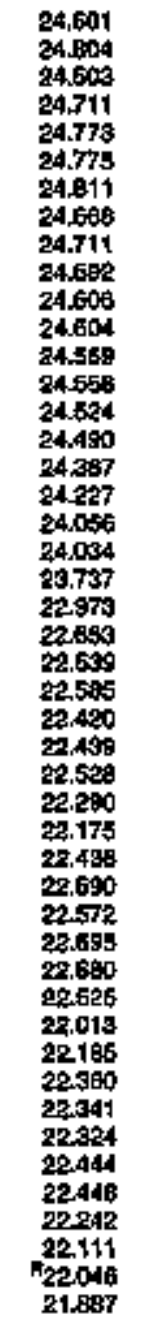 & 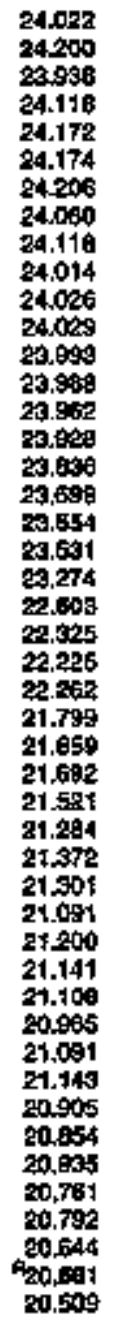 & 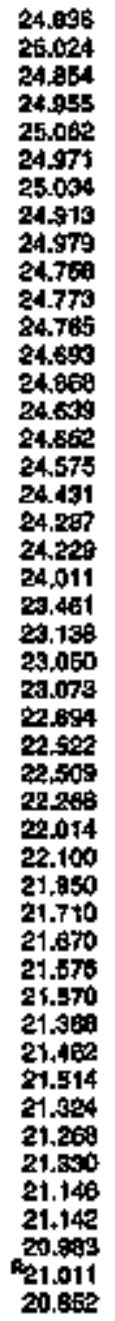 & $\begin{array}{l}25.000 \\
25.000 \\
25.000 \\
25.000 \\
25.000 \\
25.000 \\
25.000 \\
25.000 \\
25.000 \\
25.000 \\
25.000 \\
25.000 \\
25.000 \\
25.000 \\
25.000 \\
25.000 \\
25.000 \\
25.000 \\
25.000 \\
25.000 \\
25.000 \\
25.000 \\
25.000 \\
25.000 \\
25.000 \\
25.000 \\
25.000 \\
25.000 \\
25.000 \\
25.000 \\
25.000 \\
25.000 \\
25.000 \\
25.000 \\
25,000 \\
25.000 \\
25.000 \\
25.000 \\
25.000 \\
26.000 \\
25.000 \\
25.0000 \\
25.000 \\
25.000 \\
25.000 \\
25.000 \\
25.000\end{array}$ & 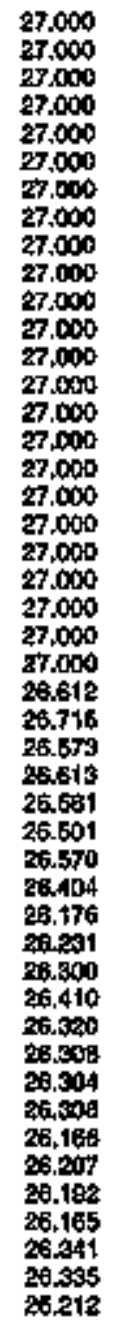 & 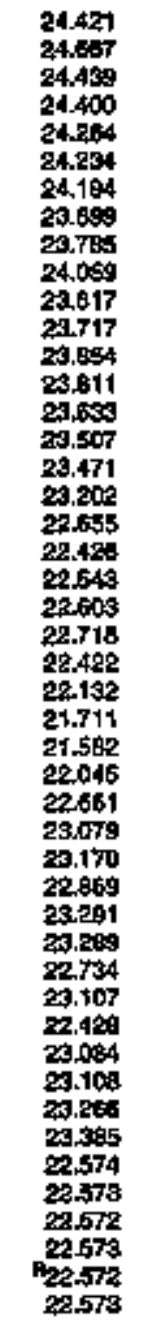 & 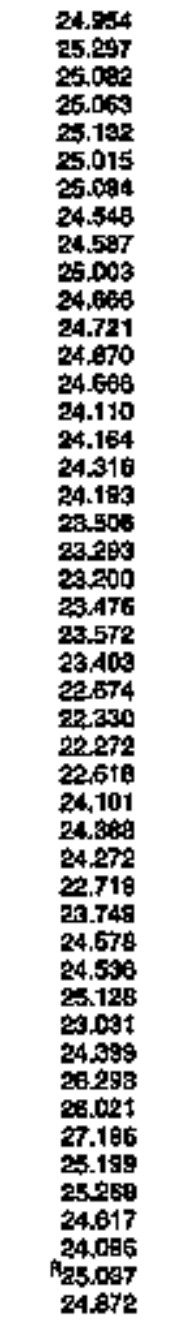 & 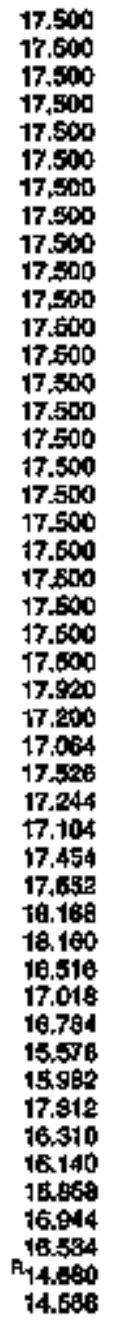 & 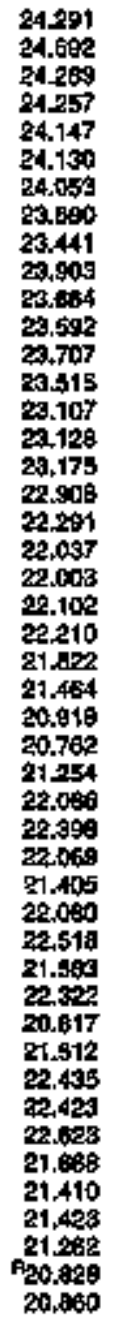 & 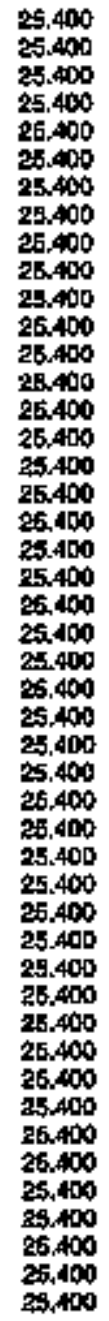 \\
\hline
\end{tabular}

indutes sutbiliurinaus coll.

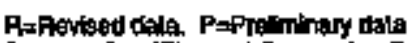


Table A7. Approximate Heat Rates for Electricity, 1949-1995

(Btu per Klowatthour)

\begin{tabular}{|c|c|c|c|c|}
\hline \multirow[b]{2}{*}{ Year } & \multicolumn{3}{|c|}{ Electriclty Eeneration } & \multirow[b]{2}{*}{$\begin{array}{l}\text { Eloctilelyy } \\
\text { Connamption }\end{array}$} \\
\hline & 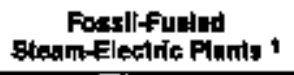 & $\begin{array}{l}\text { Nucloar } \\
\text { Stanm-Eleotric Pinnts }\end{array}$ & $\begin{array}{c}\text { Beotramaleinergy } \\
\text { Pignis }\end{array}$ & \\
\hline 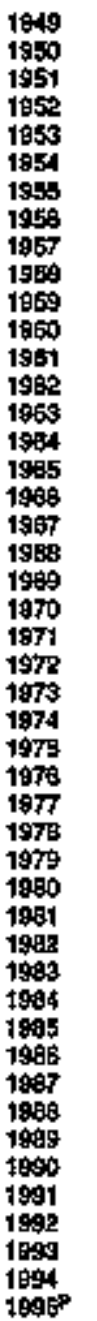 & 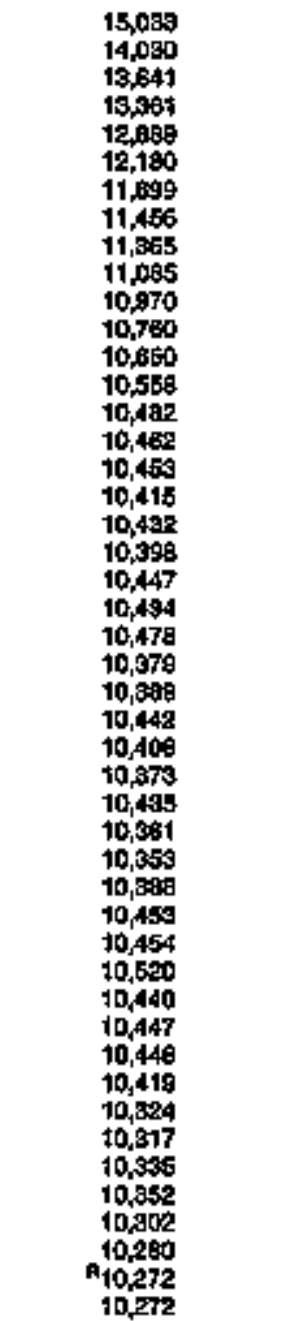 & 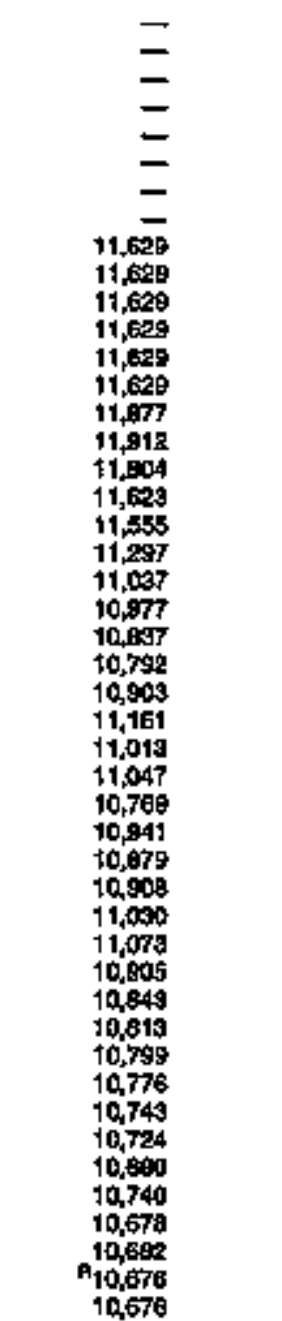 & 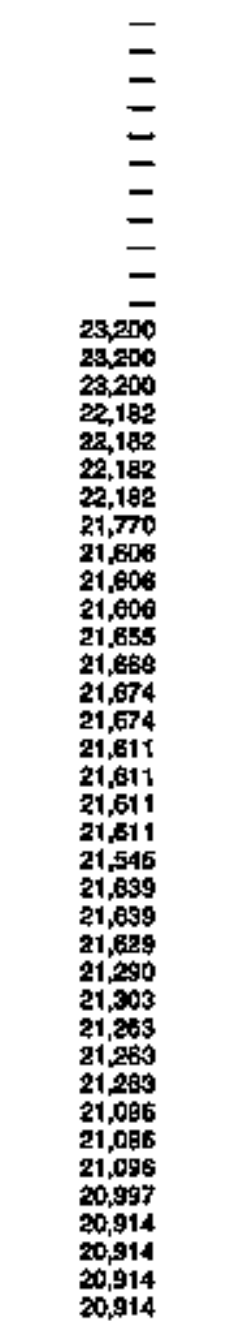 & $\begin{array}{l}3,412 \\
3,412 \\
3,412 \\
3,412 \\
3,412 \\
3,412 \\
3,412 \\
3,412 \\
3,412 \\
3,412 \\
3,412 \\
3,412 \\
3,412 \\
3,412 \\
3,412 \\
3,412 \\
3,412 \\
3,412 \\
3,412 \\
3,412 \\
3,412 \\
3,412 \\
3,412 \\
3,412 \\
3,412 \\
3,412 \\
3,412 \\
3,412 \\
3,412 \\
3,412 \\
3,412 \\
3,412 \\
3,412 \\
3,412 \\
3,412 \\
3,412 \\
3,412 \\
3,412 \\
3,412 \\
3,412 \\
3,412 \\
3,412 \\
3,412 \\
3,412 \\
3,412 \\
3,412 \\
3,412 \\
\end{array}$ \\
\hline
\end{tabular}

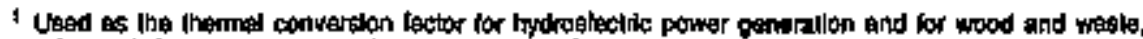

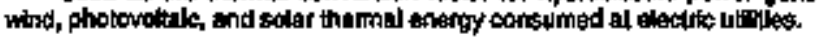

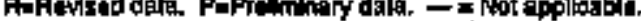

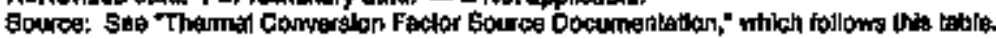




\section{Thermal Conversion Factor Source Documentation}

\section{Approximate Heat Content of Petroleum and Natural Gas Plant Liquits}

Asphalt The Energy Information Administration (EIA) adopted the thermal conversion factor of 6.636 million British thermal units (Btu) per barrel as estimated by the Bureau of Mines and first published in the Petroleum Statement, Annual, 1956.

Aviation Gasoline. EIA adopted the thermal conversion factor of 5.048 million Btu per bartel as adopted by the Bureau of Mines from the Texas Eastern Transmission Corporation publication Competition and Growth in Anterican Energy Markets 1947-1985, a 1968 release of historical and projected statistics.

Butane. EIA adopted the Burcall of Mines thermal conversion factor of 4.326 miltion Btu per barrel as publisbed in the California Oil World and Petroleum Industry, First Issue, April 1942.

Butane-Propane Mixtare. ELA adopted the Bureau of Mines calculation of 4.130 million Btu por barrel based on an assumed mixture of 60 percent butane and 40 percent propane. See Butane and Propane.

Crude Oll, Exports. Assumed by EIA to be 5.800 million Btu per barrel or equal to the thermal couversion factor for crude oil produced in the United States. See Crude Oil and Lease Condensate, Production.

Crude Oil, Imports. Caiculated annually by EIA by weighting the thermal conversion factor of each type of cnude oil imported by the quantity imported. Thermal conversion factors for each type were calculated on a foreign country basis, by determining the average American Petroleum Institute (APD) gravity of crude imported from each foreign country from Form ERA-60 in 1977 and converting average API gravity to average Btu content by using National Bureau of Standards, Miscellaneous Publication No. 97, Thermal Properties of Petroleum Products, 1933.

Crude OtI and Lease Condensate, Production. EIA adopted the thermal conversion factor of 5.800 million Btu per batrel as reported in a Bureau of Mines internal momorandum, "Bureau of Mines Standard Average Heating Values of Various Fuols, Adopted January 3, 1950."
Crude Oil and Petroleum Products, Exports. Calculated annually by ELA as the average of the thermal conversion factors for each petroleam product exported and crude oil exported weighted by the quantity of each petroleum product and crude oil exported. See Petroleum Products, Exports and Crude Oil, Exports.

Crude Ofl and Petroleum Products, Imports. Calculated annually by EIA as the average of the thermal conversion factors for each petroleum product and each crude oil imported weighted by the quantity of each petroleum product and each type of cnude oil imported. Ses Crude Oil, Imports and Petroleum Products, Imports.

Distillate Fuel Oll. EIA adopted the Bureau of Mines thermal conversion factor of 5.825 million Btu per barrel as reported in a Bureau of Mines internal memorandum, "Bureau of Mines Standard Average Heating Values of Various Fuels, Adopted January 3, 1950."

Ethame. EIA adopted the Bureau of Mines thermal conversion factor of 3.082 million Btu per barrel as published in the Caljornia Oil World and Petroleum Industry, First Issue, April 1942.

Ethane-Propane Mixture. EIA calculation of 3.308 million Btu per barrel based on an assumed mixture of 70 percent ethans and 30 percent propane. See Ethane and Propane.

Isobutane. EIA adopted the Bureau of Mines thermal conversion factor of 3.974 million Btu per barrel as pubttshed in the Califomia Oil World and Petroleum Industry, First Issue, Aprit 1942.

Jet Fuel, Kerosene Type. ELA adopted the Bureau of Mines thermal conversion factor of 5.670 million Btu per barrel for "Jet Fuel, Commercial" as published by the Texas Eastern Transmission Corporation in the report Competition and Growth in Anterican Energy Markets 1947-1985, a 1968 release of historical and projected statistics.

Jet Fuel, Naphtha Type. EIA adopted the Bureau of Mines therral conversion factor of 5.355 million Btu per barrel for "Jet Fuel, Military" as published by the Texas Eastem Transmission Corporation in the report Competition and Growth in American Energy Markets J947.1985, a 1968 release of historical and projected statistics.

Kerosene. EIA adopted the Burean of Mines thermal conversion factor of $\mathbf{5 . 6 7 0}$ million Btu per barrel as reported in a Bureau of Mines 
internal memorandum, "Bureau of Mines Standard Average Heating Values of Various Fuels, Adopted January 3, 1950."

Lulricants. ElA adopted the thermal conversion factor of 6.065 million Btu per barrel as estimated by the Bureau of Mines and first published in the Petrolewm Statement, Annual, 1956.

Miscellameous Products. EIA adopted the thermal conversion factor of 5.796 million Btu per barrel as estimated by the Bureav of Mines and first published in the Petroleam Statement, Annual, 1956.

Motor Gasoline. ELA adopted the Bureau of Mines thermal conversion factor of 5.253 million Btu per barrel for "Gasoline, Motor Fuel" as published by the Texas Eastern Transmission Corporation in the report Competition and Growth in American Energy Markets 1947-1985, a 1968 release of historical and projected statistics.

Natural Gas Plant Liquids, Production. Calculated annually by EIA as the average of the thermal conversion factors of each natural gas plant liquid produced, weighted by the quantity of each natural gas plant liquid produced.

Natural Gasoline. ELA adopted the thermal conversion factor of 4.620 mitllion Btu per barrel as estimated by the Bureau of Mines and first published in the Petroleum Statement, Annual, 1956.

Pentanes Pius. ELA assumed the thermal conversion factor to be 4.620 million Btu or equal to that for natural gasoline. See Natural Gasoline.

Petrochemical Feedstocks, Naphtha less than $401^{\circ} \mathrm{F}$. Assumed by EIA to be 5.248 million Btu per batrel, equal to the thermal conversion factor for special naphtha. See Special Naphthas.

Petrochemical Feedstocks, Other Olis equal to or greater than $401^{\circ} \mathrm{F}$. Assumed by EIA to be 5.825 million Btu per barrel, equal to the thermal conversion factor for distillate fuel oil. See Distillate Fuel Ofl.

Petrochemical Feedstocks, Still Gas. Assumed by EIA to be 6.000 million Btu per barrel, equal to the thermal conversion factor for still gas. See Still Gas.

Petroleum Coke. EIA adopted the thermal conversion factor of 6.024 million Btu per barrel as reported in Btu per short ton in the
Bureau of Mines internal memorandum, "Bureau of Mines Standard Average Heating Values of Various Fuels, Adopted January 3, 1950." The Bureau of Mines calculated this factor by dividing 30,120,000 Btu per short ton, as given in the referenced Bureau of Mines internal memorandum, by 5.0 barrels per short ton, as given in the Bureau of Mines Form 6-1300-M and successor EIA forms.

Petroleum Products, Total Consumption. Calculated annually by EIA as the average of the thermal conversion factors for all petroleum products consumed, weighted by the guantity of each petroleum product consumed.

Petroleum Products, Consumption by Electric Utillties. Calculated annually by EIA as the average of the thermal conversion factors for all petroleum products consumed at electric utilities, weighted by the quantity of each petroleum product consumed at electric utilities. The quantity of petroleum products consumed is estimated in the State Energy Data System as documented in EIA's State Energy Dava Report.

Petroleum Products, Consumption by Industrial Users. Calculated annually by EIA as the average of the thermal conversion factors for all petroleum products consumed in the industrial sector, weighted by the estimated quantity of each petroleum product consumed in the industrial sector. The quantity of petroleum products consumed is estimated in the State Energy Data System as documented in EIA's State Energy Data Report.

Petroleum Products, Consumption by Residential and Commercial Users. Calculated arnually by EIA as the average of the thermat conversion factors for all petroleum products consumed by the residential and commercial sector, weighted by the estimated quantity of each petroleum product consumed in the restdential and commercial sector. The quantity of petroleum products consumed is estimated in the State Energy Data System as doctumented in ELA's State Energy Data Report.

Petroleum Prodnets, Consumption by Transportation Users. Calculated annuatly by EIA as the average of the thermal conversion factors for all petrojeum products consumed in the transportation sector, weighted by the estimated quantity of each petroleum product consumed in the transportation sector. The quantity of petroleum products consumed is estimated in the State Energy Data System as documented in EIA's State Energy Data Report. 
Petrolenm Products, Exports. Calculated annually by EIA as the average of the thermal conversion factors for each petroletsm product. weighted by the quantity of each petroleum product exported.

Petroleum Products, Imports. Cakulated annually by EIA as the average of the thermal conversion factors for each petroleum product imported, weighted by the quantity of each petroleum product imported.

Plant Condensate. Estimated to be 5.418 million Btu per barrel by EIA from data provided by McClanahan Consultants, Inc., Houston, Texas.

Propane. EXA adopted the Bureau of Mines thermal conversion factor of 3.836 million Btu per barrel as published in the California Oil World and Petrolewn Industry, First Issue, Ajmil 1942.

Residual Fuel Oil. ElA acopted the thermal conversion factor of 6.287 million Btu per barrel as reported in the Bureau of Mines internal memorandum, "Bureau of Mines Standard Average Heating Values of Various Fuels, Adopted January 3, 1950."

Road Oil. EIA adopted the Bureau of Mines thermal conversion factor of 6.636 million Btu per barrel, which was assumed to be equal to that of asphalt (see Asphalt) and was first published by the Bureau of Mines in the Petrolewm Statement, Annual, 1970.

Special Naphthas. EIA adopted the Burean of Mines thermal conversion factor of 5.248 million Btu per barrel, which was assumed to be equal to that of the total gasoline (aviation and motor) factor and was first published in the Petroleum Statement, Annual, 1970 .

Still Gas. EIA adopted the Bureau of Mines estimated thermal conversion factor of 6.000 million Btu per barrel, fjrst published in the Petroleum Statement, Annual, 1970.

Unfinished Oil. EIA assumed the thermal conversion factor to be 5.825 million Btu per barrel or equal to that for distillate fuel oil (see Distfllate Fuel Ori) and first published it in EIA's Annual Report to Congress, Volume $3,1977$.

Unfractionated Stream. EIA assumed the thermal conversion factor to be 5.418 miltion Btu per barrel or equal to that for plant condensate (see Plant Condensate) and first published it in EIA's Annual Report to Congress, Volume 2 , $198 \mathrm{X}$.
Wax. EIA adopted the thermal conversion factor of 5.537 million Btu per barrel as estimated by the Bureau of Mines and first published in the Petroleum Statement, Annual, 1956.

\section{Approximate Heat Content of Natural Gas}

Natural Gas, Total Consumption. - 1949-1962: EIA adopted the thermal conversion factor of 1,035 Btu per cubic foot as estimated by the Bureat of Mines and first published in the Petroleum Statement. Annual, 1956. - 1963.1979: EIA adopted the themal conversion factor calculated annually by the American Gas Association (AGA) and published in Gas Facts, an AGA annual publication. * 19801992: Calculated annually by EIA by dividing the totol heat content of natural gas consumed by the total quantity of natural gas consumed. The heat content and quantity consumed are from Form EIA-176. Published sources are: - 1980-1989: EHA, Natural Gas Annual J992, Volume 2, Table 15. *1990-1992: EIA, Natural Gas Annual J992, Volune 2, Tabie 16. - 1993: 1992 value used as an estimate.

Natural Gas, Exports. - 1949-1972: Assumed by EIA to be equal to the thermal conversion factor for the consumption of dry natural gas. See Natural Gas, Total Consumption. - 1973 forward: Calculated annually by EIA by dividing the heat content of exported natural gas by the quantity of natural gas exported, both reported on Form FPC-14.

Natural Gas, Imports. - 1949-1972: Assumed by EIA to be equal to the therrnal conversion factor for the consumption of dry natural gas. See Natural Gas, Total Consumption. 1973 forward: Calculated annually by EIA by dividing the heat content of imported natural gas by the quantity of natural gas imported, both reported on Form FPC-14.

Natural Gas, Production (Dry). Assumed by EIA to be equal to the thermal conversion factor for the consumption of dry natural gas. See Natural Gas, Total Consumption.

Natural Gas, Production (Wet). Calculated annually by ELA by adding the heat content of natural gas, dry production, and the total heat content of natural gas plant liquids prodtction and dividing this sum by the total quantity of marketed (wet) natural gas production. 


\section{Approximate Heat Content of Coal and Coal Coke}

Anthracite, Total Consumption. Calculated annually by ELA by dividing the sum of the heat content of anthracite consumed by electric utilities and all other sectors combined by the total quantity of anthracite consnmed.

Anthracite, Consumption by Electric Utilities. 1949-1972: Assumed by EIA that all anthracite consumed at electric utilities was recovered from culm banks and river dredging and estimated to have an average heat content of 17.500 million Btu per short ton. 1973 forward: Calculated anuually by EIA by dividing the heat content of anthracite receipts at electric utilities by the quantity of anthracite received at slectric utilities, as reported on Form FERC-423 and predecessor forms.

Anthracite, Consumption by Sectors Other Than Electric Utilities. Calculated annually by EIA by dividing the heat content of anthracite production less the heat content of the anthracite consumed at electric utilities, net exports, and shipments to U.S. Armed Forces overseas by the quantity of anthracite consumed by sectors other than electric utilities, less the quantity of anthracite stock changes, losses, and "unaccounted for,"

Anthracite, Imports and Exports. EIA assumed the anthracite imports and exports to be freshly mined anthractte having an estimated heat content of 25.400 million Btu per short ton.

Anthracite, Production. Calculated annually by EIA by dividing the sum of the heat content of freshly mined anthracite (estimated to have an average heat content of $\mathbf{2 5 . 4 0 0}$ million Btu per sbort ton) and the heat content of anthracite recovered from culm banks and river dredging (estimated to bave an average heat content of 17.500 million Btu per short ton) by the tatal quantity of anthracite produced.

Bituminous Coal and Lignite, Total Consumption. Calculated annually by ELA by dividing the sum of the heat content of bituminous coal and lignite consumed by electric utilities, coal coke plants, other industrial plants, and by the residential and commercial sector and the transportation sector by the sum of their respective tonnages.

Bituminous Coal and Lignite, Consumption by Coke Plants. Estjmated by EIA to be 26.800 million Btu per short ton based on input-output analysis of coal carbonization.
Bituminous Coal and Lignite, Consumption by Electric Utilities. - 1949-1972: EIA adopted the average thermal conversion factor of the Bureau of Mines, which used the National Coal Association average thermal conversion factor for electric utilities calculated from Form FPC-1 and published in Stean Electric Plant Factors, a National Coal Association annual report. 1973 forward: Calculated annually by EIA by dividing the total heat content of bituminous coal and lignite received at electric utilities by the total quantity received at electric utilities. Heat contents and receipts are from Form FERC. 423 and predecessor forms.

Bitnminous Coal and Lignite, Consumption by Other Industrial Users. - 1949-1973: Calculated annually by EIA through regression analysis measuring the difference between the average $B t u$ value of coal consumed by other industrial users and that of coal consumed at electric utilities in the 1974-1983 period. 1974 forward: Calculated annually by EIA by assuming that the bituminous coal and lignite delivered to other industria] users from each coalnproducing area (reported on Form ELA.6 and predecessor Bureau of Mines Form 61419-Q) contained a heat value equal to that of bituminous coal and lignite recoived at electric utilities from each of the same coal-producing areas (reported on Form FERC-423). The average Btu value of coal by coat-producing area was applied to the volume of deliveries to other industrial users from each coal-producing area, and the sum total of the heat content was divided by the total volume of deliveries. Coal-producing areas ate the Bureau of Mines coal-producing districts for 1974 through 1989 and coal-producing States for 1990 forward.

Bjtuminous Coal and Lignite, Consumption by Residential and Commercial Users. - 1949-1973: Calculated annually by EIA through regression analysis masuring the difference between the average Btu value of coal consumed by residental and commercial users and that of coal consumed by electric utillties in the 1974-1983 period. 11974 forward: Calculated annually by EIA by assuming that the bituminous coal and lignite delivered to residential and commercial users from each coal-producing area (reported on Form EIA-6 and predecessor Bureau of Mines Form 6-1419-Q) contained a heat value equal to that of bituminous coal and lignite received at electric utilities from each of the same coal-producing areas (reported on Form FERC-423). The average Btu value of coal by coal-producing area was applied to the volume of deliveries to residential and commercial users from each coal-producing area, and the sum total of the heat value was divided by the total volume of deliveries. Coal-producing areas are the Burean 
of Mines coal-producing districts for 1974 through 1989 and coal-producing States for 1990 forward.

Bituminous Coal and Lignite, Consurnption by Transportation Ulsers. Assumed by EIA to be equal to the Btu conversion factor for Bituminous Coal and Lignite, Consumption by Other Industrial Users.

Bituminous Coal and Lignite, Exports. • 1949-1972: Assumed by ElA to be all metallurgical coal and to have an average thermal content of 27.000 million Btu per short ton. 1973 forward: Calculated annually by EitA by dividing the sum of the heat content of exported metallurgical coal (estimated to average 27.000 million Btu per short ton) and the heat content of exported steam coal (estimated to have an average thermal content of 25.000 million Btu per short ton) by the total quantity of bituminous coal and lignite exported.

Bituminous Coal and LJgnite, Imports. BIA estimated the average thermal conversion factor to be 25.000 miltion Btu per short ton.

Bituminous Coal and Lignite, Production. Calculated anrually by EIA by dividing the sum of the heat content of bitmininous coal and lignite consumption, net exports, stock changes, and unaccounted for by the sum of their respective tonnates. Consumers' stock changes by sectors were assumed to have the same conversion factor as that for the consumption sector. Producers' stock changes and unaccounted for were assumed to have the same conversion factor as that for consumption by all users.

Coal, Total Consumption. Calculated annually by EIA by dividing the sum of the heat content of bituminous corl and lignite and anthraeite consumption by the sum of their respective tonnages.

Coal, Consumption by Electric Utilities. Calculated annually by EIA by dividing the sum of the heat content of bituminous coal and lignite and anthracite received at electric utilities by the sum of their respective tonnages recejved.

Coal, Consumption by Sectors Other Than Electric Utilities. Calculated annually by EIA by dividing the sum of the heat content of bituminous coal and lignite and anthracite consumed by sectors other than electric utilities by the sum of their respective tonnages.

Coal, Exports. Calculated annually by EIA by dividing the sum of the heat content of bituminous coal and lignite and anthracite exported by the sum of their respective tonnages.
Coal, Imports. Calculated annually by EIA by dividing the sum of the heat content of bituminous coal and lignite and anthracite imported by the sum of their respective tonnages.

Coal, Production. Calculated annually by EIA by dividing the sum of the total heat content of bituminous coal and lignite and anthracite produced by the sum of their respective tonnages.

Coal Coke, Imports and Exports. EIA adopted the Bureau of Mines estimate of 24.800 million Btu per short ton.

\section{Approximate Heat Rates for Electricity}

Fossil-Fueled Stenm-Electric Plant Generation. There is no generally accepted practice for measuring the thermal conversion rates for power plants that generate electricity from hydroelectric, wood and waste, wind, photovoltaic, or solar thermal energy sources. Therefore, EIA used data from Form EIA-767, "Steam-Electric Power Operation and Design Report," to caiculate a rate factor that is equal to the prevailing annuak average heat rate factor for fossil-fueled steamuelectric power plants in the United Stats. By using that factor, it is possible to evaluate fossil fuel requirements for replacing those sources during periods of interruption, such as droughts. The heat content of a kilowatthour of electricity produced, regardless of the generation process, is 3,412 Btu. - 1949-1955: The weighted annual average heat rate for fossil-fueled steam-electric power plants in the United States, as published by EIA in Thermal-Electric Plant Construction Cost and Annual Production Expenses-1981 and Steam-Electric Plant Construction Cost and Annual Production Expenses-1978. • 19561991: The weighted annual average heat rate for fossil-fueled steam-electric power plants in the United States, as published in EIA, Electric Plant Cost and Power Production Expenses 1991, Table 9. * 1992 forward: Unpublished factors calculated on the basis of data from Form EIA-676, "Steam-Electric Plant Operation and Design Report."

Geothermal Energy Pant Generation. . 1960-1981: Calculated annually by ElA by wetghting the aninual average heat rates of operating geothermal units by the installed nameplate capacities as reported on Form FPC-12, "Power System Statement." - 1982 forward: Estimated annually by EIA on the basis of an informal survey of relevant plants. 
Nuclear Steam-Electric Plant Generation. - 1957-1991: Calculated annually by EIA by dividing the total heat content consumed in nuclear generating units by the total (net) electricity generated by nuclear generating units. The heat content and electricity generation are reported on Form FERC-1, "Annual Report of Major Electric Utilities, Licensees, and Others," Form EIA-412, "Annual Report of Public Electric Utilities," and predecessor forms. The factors, beginning with 1982 data, are published in the following EIA reports-1982: Historical
Plant Cost and Anmual Production Expenses for Selected Electric Plants 1982, page 215. 1983-1991: Electric Plant Cost and Power Production Expenses 1991, Table 13. 1992 forward: Calculated annually by EIA by dividing the total heat content of the steam leaving the nuclear generating units to generate electricity by the total (net) electricity gencrated by nuclear generating units. The heat content and electricity generation data are reported in Nuclear Regulatory Commission, $L i$ censed Operating Reactors-Status Summary Report. 


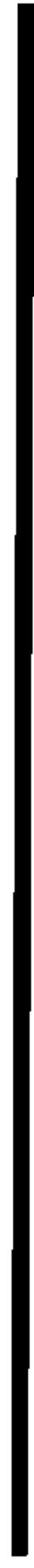




\section{Appendix $\mathrm{B}$}

\section{Metric and Other Physical Conversion Factors}

Data presented in the Annual Energy Review and in other Energy Information Administration publications are expressed predominately in units that historically have been used in the United States, such as British thermal units, barrels, cubje feet, and short tons. However, because U.S. commerce involves other nations, most of which use metric units of measure, the U.S. Government is committed to the transition to the metric system, as stated in the Metric Conversion Act of 1975 (Public Law 94-168), amended by the Omnibus Trade and Competitiveness Aat of 1988 (Public Law 100-418), and Executive Order 12770 of July 25,1991 .

The metric conversion factors presented in Table Bl can be used to calculate the metric-unit equivalents of values expressed in U.S. customary units. For example, 500 short tons is the equivalent of 453.6 metric tons (500 short tons $\times 0.9071847$ metric tons/short ton $=453.6$ metric tons).

In the metric system of weights and measures, the names of multiples and subdivisions of any unit may be derived by combining the name of the unit with prefixes, such as deka, hecto, and kilo, meaning, respectively, 10,100,1,000, and deci, centi, and milli, meaning, respectively, one-tenth, one-hundredth, and one-thousandth. Common metric prefixes can be found in Table B2.

The conversion factors presented in Table B3 can be used to calculate equivalents in various physical units commonly used in energy analyses. For example, 10 barrels is the equivalent of 420 U.S. gallons (10 barrels $\times 42$ gallons/barrel $=420$ gallons). 
Table B1. Motric Conversion Factors

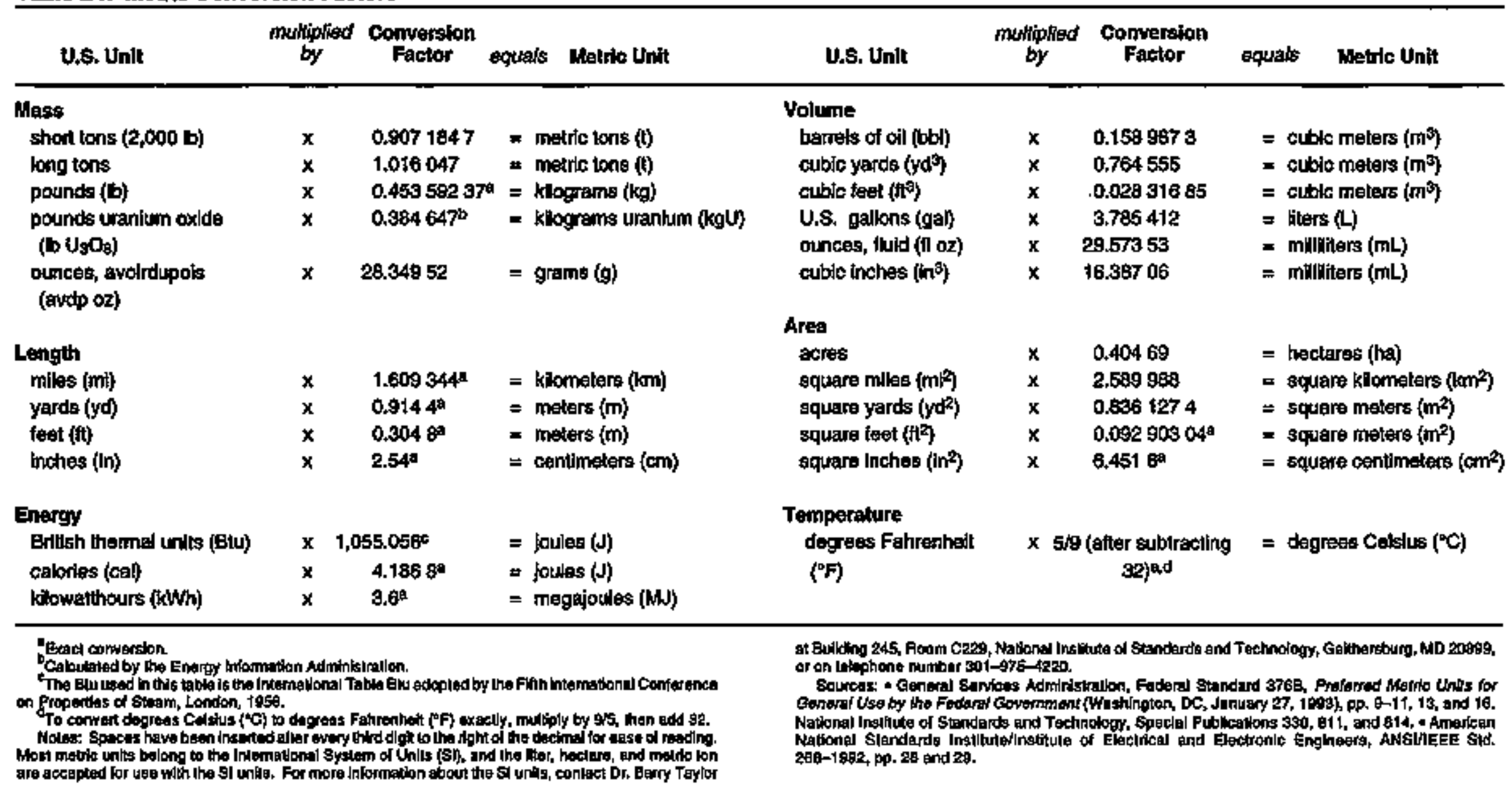


Table B2. Metrlc Prefixes

\begin{tabular}{|c|c|c|c|c|c|}
\hline $\begin{array}{l}\text { Untit } \\
\text { Mutiple }\end{array}$ & Prefix & Symbol & $\begin{array}{l}\text { Unit } \\
\text { Mustiple }\end{array}$ & Preflx & Symbol \\
\hline $10^{1}$ & deka & $\mathrm{da}$ & $10^{-1}$ & deat & d \\
\hline $10^{2}$ & hecto & h & $10^{-2}$ & centht & c \\
\hline $10^{3}$ & kilo & $k$ & $10^{3}$ & milli & $m$ \\
\hline $10^{5}$ & mega & $M$ & $10^{-8}$ & miloro & $\mu$ \\
\hline $10^{\circ}$ & giga & C & $10^{-9}$ & namo & n \\
\hline $10^{12}$ & lera & $\tau$ & $10^{-12}$ & pioo & p \\
\hline $10^{15}$ & pota & $\mathbf{P}$ & $10^{-16}$ & ferto & $f$ \\
\hline $10^{10}$ & exa & E & $10^{-18}$ & atto & $\mathbf{a}$ \\
\hline $10^{21}$ & zetta & $z$ & $10^{-21}$ & zepla & $z$ \\
\hline $10^{24}$ & yotila & $\gamma$ & $10^{-24}$ & yocio & $y$ \\
\hline
\end{tabular}

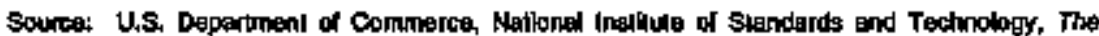

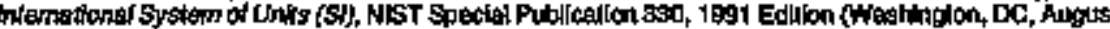
1901), p. 10 .

\section{Table E3. Other Physlcal Converslon Factors}

\begin{tabular}{|c|c|c|c|c|c|}
\hline Energy Source & $\begin{array}{c}\text { Originet } \\
\text { Unit }\end{array}$ & $\begin{array}{c}\text { multiplied } \\
\text { by }\end{array}$ & $\begin{array}{l}\text { Convorsion } \\
\text { Factor }\end{array}$ & equats & $\begin{array}{l}\text { FInal } \\
\text { Unit }\end{array}$ \\
\hline Petroleum & barels (bbl) & $\mathbf{x}$ & $42^{\circ}$ & $=1$ & U.S. gallans (gal) \\
\hline \multirow[t]{3}{*}{ Co:l } & short tons & $\mathbf{x}$ & $2,000^{a}$ & $=F$ & pounds $\{(t)$ \\
\hline & lang lons & $x$ & $2,240^{\circ}$ & $=\mathrm{F}$ & pouncls $\{(b)$ \\
\hline & metric tons (t) & $x$ & $1,000^{9}$ & $=k$ & kllograms (kg) \\
\hline \multirow[t]{2}{*}{ Wood } & cords (cd) & $x$ & $1.25^{b}$ & $=8$ & short tons \\
\hline & $\operatorname{cords}(\operatorname{cod})$ & $x$ & 1280 & $=c$ & cublc teet $\left(t^{3}\right)$ \\
\hline
\end{tabular}

Everest conturention

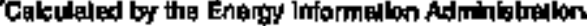

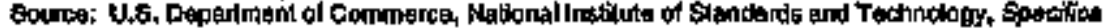

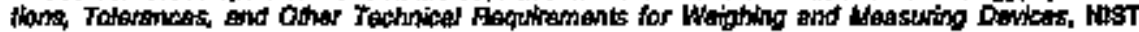
Handbook 44, 1964 Edition (Htashingtor, OC, Oclober 19p3). Pp. B-10, C-17, and C-21. 


\section{Carbon Dioxide Emission Factors for Coal}

The need for accurate estimates of carbon dioxide emissions produced toring the combustion of coal has led the Energy Information Administration (EIA) to dovelop basic emission factors. Basic emission factors reflect the carbon-to-heat-content ratio of coal, a ratio which meastres carton dioxide omissions per unit of energy (pounds per million Btu), assuming complete combustion. These basic factors are derived from 5,426 samplo analyses maintained in EIA's Coal Analysis File. Variations in the carbon-to-heat-content ratios of different coals were observed to follow coal tank and geographic origin, leading EIA to develop basic emission factors specific to the rank and the State of origin of the coal.

On the basis of these rank- and State-specific basic emission factors for coal, EIA has also developed emission factors by sector. Theso sectoral emission factors weight the coal consumed in a given sector by its rank and State of origin. Table C1 presents the U.S. average carbon dioxide emission factors for coal by sector. Emission factors differ among sectors and within a given sector over time for a number of reasons:
- A bigher average emission factor in the residential and commercial sector can be attributed to the steady consumpton of bituminous coal and anthracite (presumably for home heating).

- Virtually all of the coal consumed by coke plants comes from only a few States in the Appalachian Coal Basin (West Virginia, Virginia, and eastem Kentucky). Hence, the emission factors for this sector have remained fairly constant.

- Other industrial users of coal (not coke plants) increased consumption of low-rank, high-enission western coals, which has contributed to a rise in their average emission factor.

- Electric utilities, which account for most U.S. coal consumption, have shifted over time away from high-rank, low-emission bituminous coal to low-rank, high-emission subbituminous coal and lignite as reflected in a gradually rising weighted-average carbon dioxide emisstion factor.

Table CT. Average Carbon Dioxide Emission Factors for Coal by Coar-Consuming Sector, 1990-1994 (Pounds of Carbon Dloxlde per Million Btu)

\begin{tabular}{|c|c|c|c|c|c|}
\hline \multirow[b]{2}{*}{ Year } & \multirow{2}{*}{$\begin{array}{l}\text { Residtential and } \\
\text { Commerclal }\end{array}$} & \multicolumn{2}{|c|}{ motusirial } & \multirow[b]{2}{*}{ Electric Utillties } & \multirow[b]{2}{*}{ U, Averaget } \\
\hline & & Coke Plants" & Olher Coal & & \\
\hline 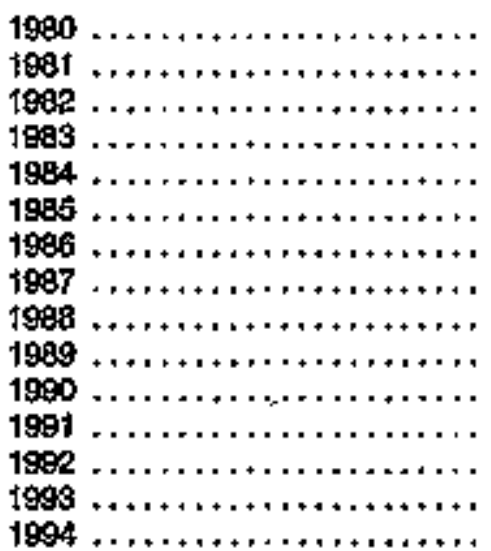 & $\begin{array}{l}210.6 \\
212.0 \\
210.4 \\
209.2 \\
209.5 \\
209.3 \\
209.2 \\
209.4 \\
209.1 \\
209.7 \\
209.5 \\
210.2 \\
211.2 \\
209.9 \\
209.8\end{array}$ & $\begin{array}{l}205.8 \\
205.8 \\
205.7 \\
205.6 \\
205.6 \\
205.6 \\
205.4 \\
205.2 \\
205.3 \\
205.3 \\
206.2 \\
206.2 \\
206.2 \\
200.2 \\
206.3\end{array}$ & $\begin{array}{l}205.9 \\
205.9 \\
206.0 \\
205.9 \\
206.2 \\
206.4 \\
203.5 \\
206.4 \\
206.4 \\
206.6 \\
206.8 \\
206.9 \\
207.1 \\
207.0 \\
207.2\end{array}$ & $\begin{array}{l}206.7 \\
206.9 \\
207.0 \\
207.1 \\
207.1 \\
207.3 \\
207.3 \\
207.9 \\
207.6 \\
207.6 \\
207.6 \\
207.7 \\
207.7 \\
207.9 \\
207.9\end{array}$ & $\begin{array}{l}200.5 \\
206.7 \\
206.9 \\
207.0 \\
207.0 \\
207.1 \\
207.1 \\
207.2 \\
207.3 \\
207.3 \\
207.4 \\
207.5 \\
207.6 \\
207.7 \\
207.8\end{array}$ \\
\hline
\end{tabular}




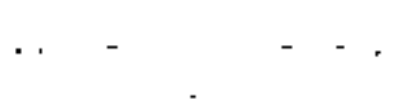


Appendlx D

\section{Energy Units in Perspective}

\section{Using Appendix D}

The two tables in this appendix are intended to help the nontechnical reader understand the value of the vatious energy units used in the Annual Energy Review. The values shown here (especially the equivalents in Table D2) are approximations intended to conyey a general idea of the magnitude of energy units. The tables can be used to relate a familiar measure of energy, such as gallons, to energy measures used in this report. For example, using information from Table D1, the reader can calculate that 8 gallons of motor gasoline was, on average, about a six-and-a-half-day supply per capita in 1995. Table D2 indicates that 8 gallons of motor gasoline equals about 10 therms of patural gas or approximately 1 million British thermal units (see Glossary).
Tabto 01. U.S. Daily Per Caplta Consumptlon of Energy by Type, 1975,1995 , and 1995

\begin{tabular}{|c|c|c|c|c|c|c|}
\hline \multirow[b]{2}{*}{ Type of Energy } & \multirow[b]{2}{*}{ Type of Lnit } & \multirow[b]{2}{*}{1976} & \multirow[b]{2}{*}{1995} & \multicolumn{3}{|c|}{$\begin{array}{r}\text { Percent Change } \\
1975-1989=\end{array}$} \\
\hline & & & & 1996 & 1985 & 1995 \\
\hline Petroteum Products & gallons & 3.2 & 2.8 & 2.8 & .12 .9 & 2.2 \\
\hline Hotor Gasoline & gallons & 1.3 & 1.2 & 1.2 & -7.7 & 3.3 \\
\hline Natural Gas (diry) & cublc leet & 246 & 198 & 226 & .20 .2 & 13.6 \\
\hline Cogl & pounds & 14.3 & 18.8 & 19.6 & 31,2 & 4.5 \\
\hline Hydroelectrictity & kilowalthours & 3.0 & 3.2 & 3.1 & -15.4 & -5.3 \\
\hline Nuclaar Elecirtely & kikwalthours & 22 & 4.4 & 7.0 & 100.5 & 59.2 \\
\hline Total Elecirichty & kilowatthours & 24,4 & 28.3 & 31,2 & 16.3 & 10.1 \\
\hline Total Energy & thousand Btu & 897 & 649 & 945 & .5 .3 & 11.3 \\
\hline
\end{tabular}

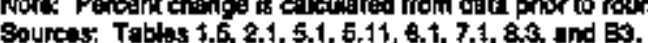


Table D2. Energy Equivalents

\begin{tabular}{|c|c|c|}
\hline \multirow{2}{*}{$\begin{array}{l}\text { Unit of Enorgy } \\
1 \text { Ehu of enargy . . }\end{array}$} & \multicolumn{2}{|r|}{ Energy Equivalent } \\
\hline & 1 & makch tip \\
\hline & 250 & calories (Intemational Steam Table) \\
\hline \multirow{6}{*}{1 millon Bhu of ensrgy . ......... } & 0,25 & kilocalories (lood calories) \\
\hline & 90 & pounds of conl \\
\hline & 8 & galloris of motor gasoline \\
\hline & 10 & thems of dry natural gas \\
\hline & 11 & gallons of propane \\
\hline & 1.1 & $\begin{array}{l}\text { days of U.S. energy consumption per } \\
\text { capita }\end{array}$ \\
\hline \multirow[t]{7}{*}{1 quadrillon' Elw of energy, ...... } & 45 & million shoet tons of coal \\
\hline & 60 & milton shont tons of owen-dried hardwood \\
\hline & 1 & trillon cubic feet of dry natural gas \\
\hline & 170 & mallion barrels of crude oi \\
\hline & 470 & $\begin{array}{l}\text { thousand barrels of crude oll per day for } \\
1 \text { year }\end{array}$ \\
\hline & 19 & days of U.S. pelroleum imports \\
\hline & 24 & days of U.S. motor gasolline use \\
\hline \multirow[t]{4}{*}{1 barred of arude oll ........... } & 15 & $\begin{array}{l}\text { days of U.S. petroleum } \\
\text { consumption per ceapliz }\end{array}$ \\
\hline & 5.6 & thousend pubic feat of chy nalural gas \\
\hline & 0.26 & shert tons (520 poumds) of cots \\
\hline & $\begin{array}{r}1.7 \\
102\end{array}$ & thousend killowatthour of electritilyo \\
\hline \multirow{3}{*}{1 short ton of coal ... } & 3.8 & barrels of chucte oij \\
\hline & 21 & thousend cubtc teet of dy rahural gas \\
\hline & 6.5 & thausand klowathours of elaptritity \\
\hline \multirow[t]{2}{*}{$\begin{array}{l}\text { 1,000 cubic toet } \\
\text { of natural gas }, \ldots \ldots \ldots \ldots \ldots+\text {, }\end{array}$} & 4.4 & $\begin{array}{l}\text { days of U.S. natural gas } \\
\text { consumptian per capita }\end{array}$ \\
\hline & 300 & klowalihours of eleciricityc \\
\hline $\begin{array}{l}1,000 \text { billowathours } \\
\text { of etaclicity........ }\end{array}$ & $\$ 2$ & days of U.S. electrklyy use per capite \\
\hline
\end{tabular}

\footnotetext{
Equlvalenls are appoxirnals.

One quadrilion equats $1,000,000,000,000,000$.

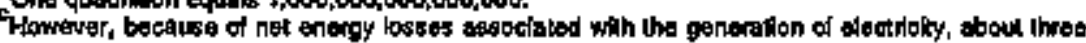

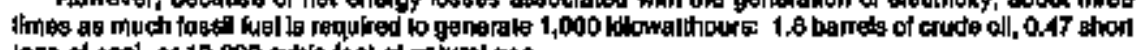
lons of coal, or 10,000 cuble feel of makthal gas.

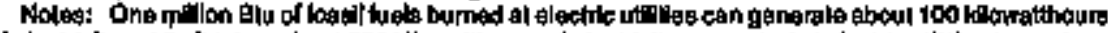

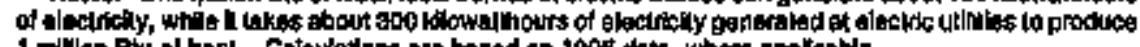

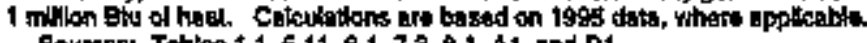

Soures: Tables $\uparrow .1,6.11,6.1,7,3,0.1, A 1$, and D1.
} 


\section{Appendix E}

\section{Gross Domestic Product and Implicit Price Deflators}

Table E1. Grosk Domestic Product and Implicit Price Deflators, 1949-1995

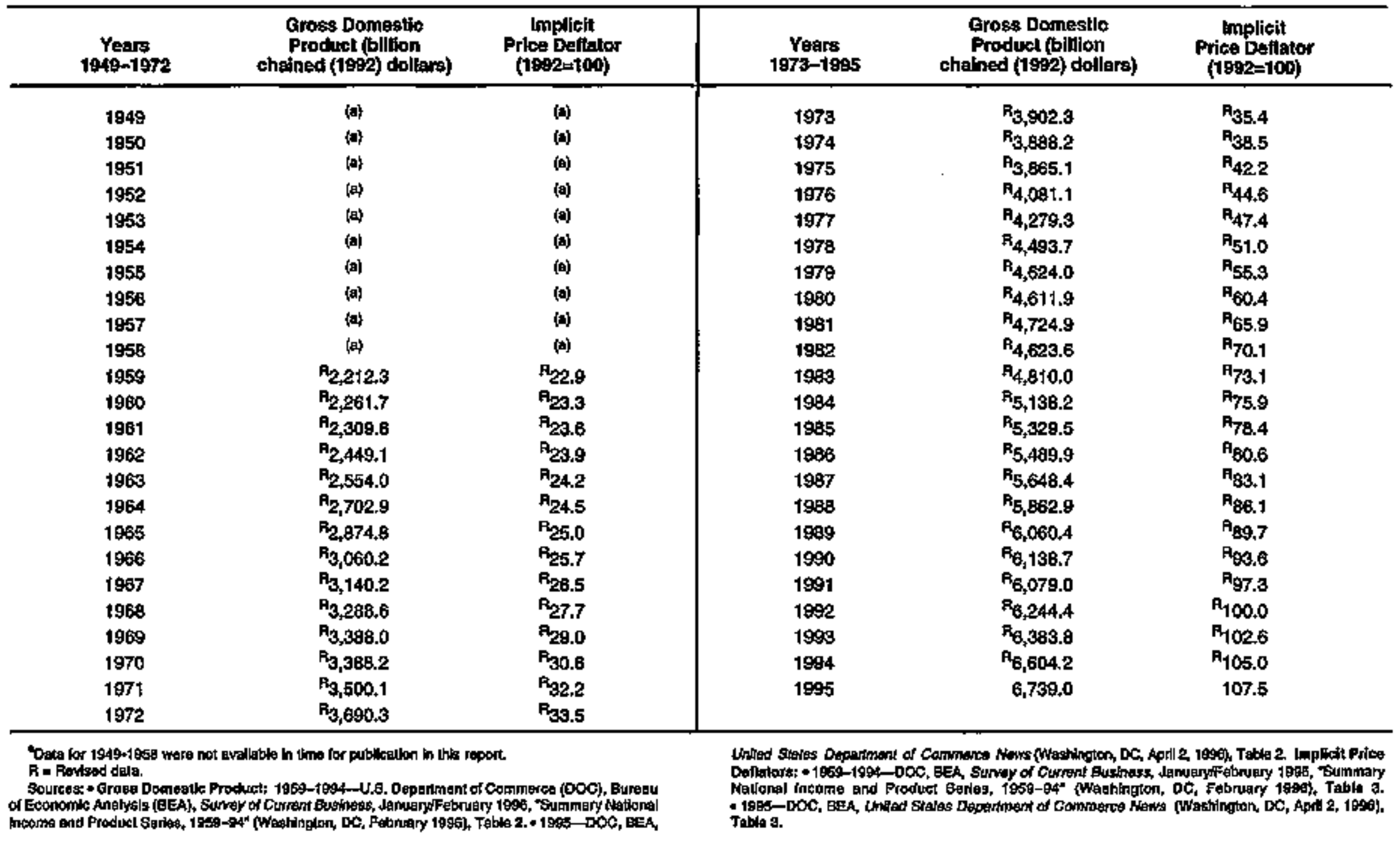





\section{U.S. Census Regions and Divisions}

Figure 1. U.S. Census Reglons and Dlvisions
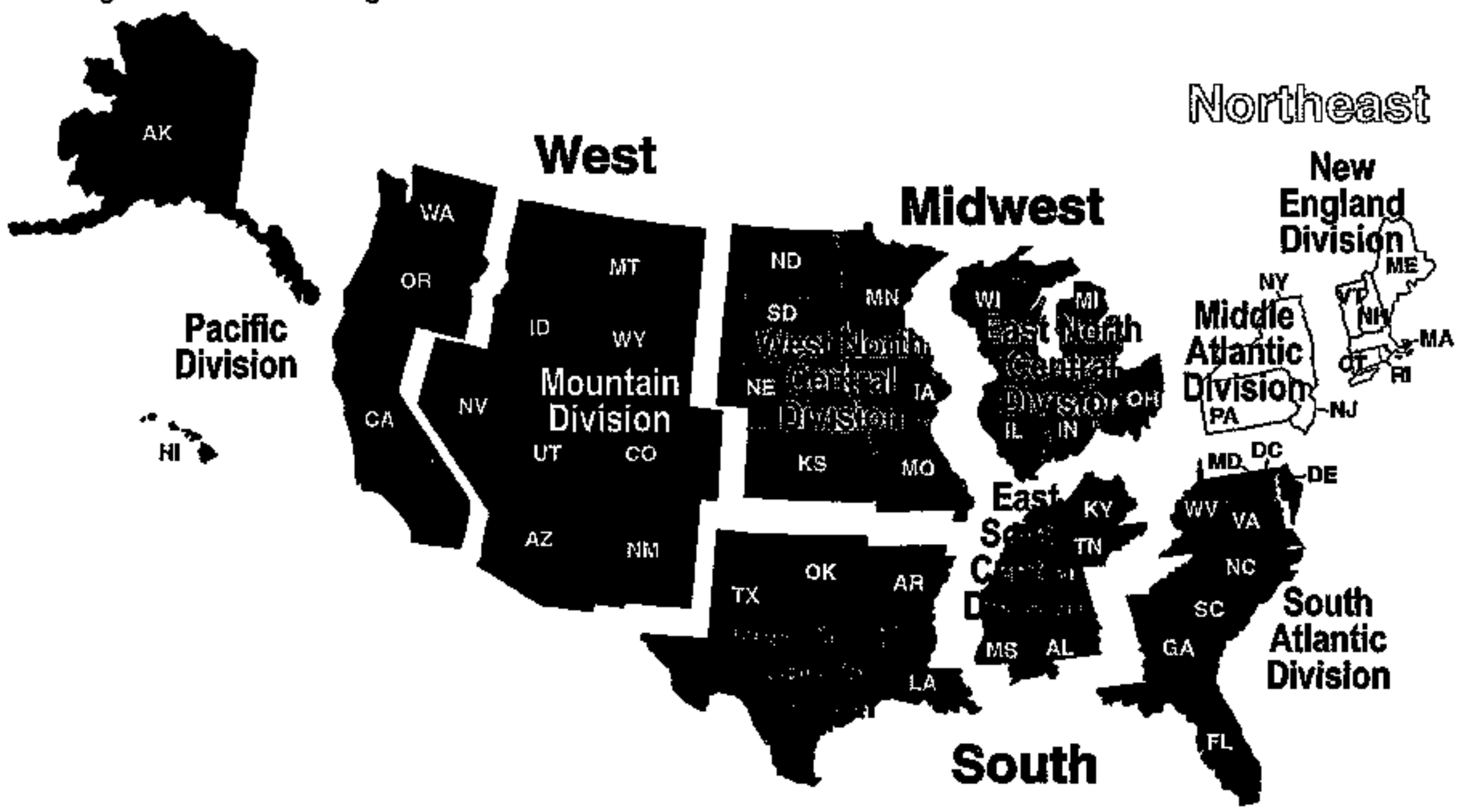

Source: U.S. Department of Comurnerce. Buweau of the Census, Statistical Abstract of the Uniled States 1995 (Washingkon, DC, Seplember 1995), Figure 1. 



\section{Glossary}

Account of Others (natural gas): Natural gas deliveries for the account of others are deliveries to customers by transporters that do not own the natural gas but deliver it for others for a fee. Incladed are quantities covered by long-term contracts and quantities involved in short-term or spot market sales.

Additions to Property: The current year's expenditures on property, plant, and equipment. The amount is predicated upon each reporting company's accounting practices. That is, accounting practices with regard to capitalization of certain items may differ across companies, and, therefore, this figure is a function of each reporting company's policy.

Alcohol: The family name of a group of organic chemical compounds composed of carbon, hydrogen, and oxygen. The series of molecules vary in chain length and are composed of a hydrocarbon plus a hydroxyl group; $\mathrm{CH}_{3}-\left(\mathrm{CH}_{2}\right)_{n}-\mathrm{OH}$ (e.g., methanol, ethanol, and tertiary butyl alcohol).

Anthracite: A hard, black, lustrous coal containing a high percentage of fixed carbon and a low percentage of volatile matter. Often referred to as hard coal. It conforms to ASTM Specification D388-84 for anthracite, meta-anthracite, and semianthracite.

API: The American Petroleum Institute, a trade association.

API Gravity: An arbitrary scale expressing the gravity or density of liquid petroleum products. The measuring scale is calibrated in terms of degrees API. A lighter, less dense product has a higher API gravity.

Apparent Consumption, Natural Gas (international): The total of an individual nation's marketed natural gas production plus imports less exports.

Apparent Consumption, Petroleum (international): Consumption which includes internal consumption, refinery tuel and loss, and bunkering. For countries in the Organization for Economic Cooperation and Development (OECD), apparent consumption is derived from refined product output plus refined product imports minus refined product exports plus reftned product stock changes plus other oil consumption (such as direct use of crude oil). For countries outside the OECD, apparent consumption is either a reported figure or is derived from refined product output plus refined product imports minus refined product exports, with stock levels assumed to remain the same. Apparent consumption also includes, where available, liquefied petroIeum gases sold directly from natural gas processing plants, for fuel or chemical uses.

Asphalt: A dark-brown-to-black cement-like material containing bitumens as the predominant constituents. It is obtained by petroleum processing. The definition includes crude asphalt as well as the following finished products: cements, fluxes, the asphait content of emulisions (exclusive of water), and petroleum distillates blended with asphalt to make cutback asphalts.

\section{ASTM: The American Society for Testing and Materials.}

Avtation Gasoline Blending Components: Naphthas that are used for blending or compounding into finished aviation gasoline (e.g. straight-run gasoline, alkylats, and reformate). Excluded are oxygenates (alcohols, ethers), butane, and pentanes plus.

Aviation Gasoline, Finished: All special grades of gasoline for use in aviation reciprocating engines, as given in ASTM Specification D910 and Military Specification MIL-G-5572. Excludes blending components that will be used in blending or compounding into finished aviation gasoline.

Barrel (petroleum): A unit of volume equal to 42 U.S. gallons.

Barrels per Calendar Day (operable refinery capacity): The maximum number of banrels of input that can be processed during a 24-hon period after making allowances for the following limitations: the capability of downstream facilities to absorb the output of crude oil processing facilities of a given retinery (no reduction is made when a planned distribution of intermedjate streams through other than downstrean facilities is part of a refinery's normal operation); the types and grades of inputs to be processed; the types and grades of products to be manufactured; the environmental constraints associated with refinery operations; the reduction of capacity for scheduled downtime, such as routine inspection, mechanical problems, maibtenance, repairs, and 
turnaround; and the reduction of capacity for unscheduled downtime, such as mechanical problems, repairs, and slowdowns.

Base (Cushion) Gas: The volume of gas needed as a permanent inventory to maintain adequate underground storage teservoit pressures and deliverability rates throughout the withdrawal season. All native gas is included in the base gas volume.

Btofnels: Fiselwood, wood byproducts, waste wood, municipal solid waste, manufacturing process waste, and alcohol fuels.

Bituminous Coal: A dense black coal, often with well-defined bands of bright and dull material, with a moisture content usually less than $\mathbf{2 0}$ percent. Often referred to as soft coal. It is the most common coal and is used primarily for generating electricity, making coke, and space heating. It conforms to ASTM Specification D388-84 for bituminous coal. In this report, bituminous coal includes subbituminous coal.

Brttish Thermal Unit (Btu): The quantity of heat needed to taise the temperature of 1 pound of water by $1^{\circ} \mathrm{F}$ at or near $39.2^{\circ} \mathrm{F}$. (See Heat Content of a Quantity of Froel, Gross, and Heat Content of a Quantity of Fuel, Net.)

Bntane: A normally gaseous straight-chain or branched-chain hydrocarbon $\left(\mathrm{C}_{4} \mathrm{H}_{10}\right)$. It is extracted from natural gas or refinery gas streams. It includes isobutane and normal butane and is designated in ASTM Specification D1835 and Gas Processors Association Speciffcations for commercial butane. Isobutane: A normally gaseous branched-chain hydrocarbon. It is a colorless paraffinic gas that boils at a temperature of $10.9^{\circ} \mathrm{F}$. It is extracted from natural gas or refinery gas streams. Normal Butane: A normally gaseous straight-chain hydrocarbon. It is a colorless paraffinic gas that boils at a temperature of $31.1^{\circ} \mathrm{F}$. It is extracted from natural gas or refinery gas streams.

Butylene: An olefinic hydrocarbon $\left(\mathrm{C}_{4} \mathrm{H}_{8}\right)$ recovered from refinery processes.

Capacity Factor: The ratio of the electrical energy produced by a generating unit for a given period of time to the electrical energy that coald have been produced at continuous full-power operation during the same period.
Chained Dollars: A measure used to express real prices. Real prices are those that have been adjusted to remove the effect of changes in the purchasing power of the dollar; they usually reflect buying power relative to a reference year. Prior to 1996, real prices were expressed in constant dollars, a measure based on the weights of goods and services in a single year, usually a recent year. In 1996, the U.S. Department of Cormerce introduced the chained-dollar measure. The new measure ts based on the average weights of goods and serv. ices in successive pairs of years. It is "chained" because the second year in each pair, with its weights, becomes the first year of the next pait. The advantage of using the chained-dollar measure is that it is more closely related to any given pertod covered and is therefore subject to less distortion over time.

\section{CIF: See Cost, Insurance, Freight.}

City Gate: A point or measuring station at which a distribution gas utility receives gas from a natural gas pipeline company or transmission system.

Class A Electric Utility: An electric utility having annual electric operating revenues of $\$ 2.5$ million or more. (Use of this term ceased on December 31, 1983.)

Class B Electric Utility: An electric utility having annual electric operating revenues of $\$ 1.0$ million or more but less than $\$ 2.5$ million. (Use of this term ceased on December 31,1983 .)

Coal: A black or brownish-black solid, combustible substance formed by the partial decomposition of vegetable matter without access to air. The rank of coal, which includes anthracite, bituminous coal, subbituminous coal, and lignite, is based on fixed carbon, volatile matter, and heating value. Coal rank indicates the progressive alteration, or coalification, from lignite to anthracite. Lignite contains approximately 9 to 17 million Btu per ton. The heat contents of subbituminous and bituminous coal range from 16 to 24 million Bth per ton, and from 19 to 30 million Btu per ton, respectively. Anthracite contains approximately 22 to 28 million Btu per ton. 
Coalhed Methane: Methane that is produced from coalbeds in the same manner as natural gas produced from other strata. Methane is the principal component of natural gas.

Coal Coke: A hard, porous product made from baking bituminous coal in ovens at temperatures as high as $2,000^{\circ} \mathrm{F}$. It is used both as a fuel and as a reducing agent in smelting iron ore in a blast fumace.

Cogenerator: A generating facility that produces electricity and anather form of useful thermal energy (such as heat or steam) used for industrial, commercial, heating, and cooling purposes. See Nonutility Power Producer.

Commercial Bullding: A building with more than 50 percent of its floorspace used for commercial activities. Commercial buildings include, but are not limited to, stores, offices, schools, churches, gymnasiums, libraries, museums, hospitals, clinics, warehouses, and jails. Goverument buildings are included, except buildings on miljtary bases or reservations.

Commercial Sector: The commercial sector, as defined economically, consists of bustiness establishments that are not engaged in transportation or in manufacturing or other types of industrial activity (agriculture, mining, or construction). Commercial establishments inelude hotels, motels, restaurants, wholesale businesses, retail stores, laundries, and other service enterprises; religious and nonprofit organizations; tealth, social, and educational institutions; and Federal, State, and local governments. Street lights, pumps, bridges, and public services are also included if the establishment operating them is considered commercial. Standard Industrial Classification (SIC) codes used to classify an establishment as commercial are 50 through 87,89 , and 91 through 97 .

Completion: The installation of permanent equipment for the production of oil or gas. If a well is equipped to produce only oil or gas from one zone or reservoir, the definition of a well (classified as an oil well or gas well) and the definition of a completion are identical. However, if a well is equipped to produce oil and/or gas separately from more than one reservoir, a well is not synonymous with a completion.

\section{Constant Dollars: See Chained Dollars.}

Conversion Factor: A number that translates units of one system into corresponding values of another system. Conversion factors can be used to translate physical units of measure for various fuels into Btu equivalents.

Cost, Insurance, Freight (CIF): A type of sale in which the buyer of the product agrees to pay a unit price that inciudes the f.o.b. value of the product at the point of origin, plus all costs of insurance and transportation. This type of transaction differs from a "delivered" purchase in that the buyer accepts the quantity as determined at the loading port (as certified by the Bill of Loading and Quality Report) rather than pay on the basis of the quantity and quality ascertained at the unloading port. It is similar to the terms of an f.o.b. sale, excepe that the seller, as a service for which he is compensated, arranges for transportation and insurance.

Crade Oil f.o.b. Price: The crude oil price actually charged at the oil-producing country's port of loading. Includes deductions for any rebates and discounts or additions of premiums, where applicable. It is the actual price paid with no adjustment for credit terms.

Crude Oil (Including Lease Condensate): A mixture of hydrocarbans that exists in liquid phase in underground reservoirs and remains liquid at atmospheric pressure after passing through surface separating facilities. Included are lease condensate and liquid hydrocarbons produced from tar sands, gilsonite, and oil shale. Drip gases are also inctuded, but topped crude oil (residual oil) and other unfinished oils are excluded. Where identifiable, liquids produced at natural gas processing plants and mixed with crude oil are likewise excluded.

Crude Oil Landed Cost: The price of crude oil at the port of discharge, including charges associated with the purchase, transporting, and insuring of a cargo from the purchase point to the port of discharge. The cost does not include charges incurred at the discharge port (e.g., import tariffs or fees, wharfage charges, and demurrage).

Crude Oil Refinery lopat: The total crude oil put into processing units at refineries. 
Crude Oil Stocks: Stocks of crude oil and lease condensate held at refineries, in pipelines, at pipeline cerminals, and on leases.

Crude Oil Usted Directly: Crude oil consumed as fuel by crude oil pipelines and on crude oil leases.

Cubie Foot (natural gas): A unit of volume equal to 1 cubic foot at a pressure base of 14.73 pounds standard per square inch absolute and a temperature base of $60^{\circ} \mathrm{F}$.

\section{Current Dollars: See Nominal Dollars.}

Degree-Days, Cooling (CDD): The number of degrees per day that the daily average temperature is above $65^{\circ} \mathrm{F}$. The daily average temperature is the mean of the maximum and minimum temperatures for a 24-hour period.

Degree-Days, Eleating (HDD): The number of degrees per day that the daily average temperature is below $65^{\circ} \mathrm{F}$. The daily average temperature is the mean of the maximum and minimum temperatures for a 24-hour period.

Degree-Days, Population-Wefghted: Heattng or cooling degreedays weighted by the population of the area in which the degreeddays are recorded. To compute State population-weighted degree-days, each State is divided into from one to nine climatically homogeneous divisions, which are assigned weights based on the ratio of the population of the division to the total population of the State. Degree-day readings for each division are multiplied by the corresponding population weight for each division and those products are then summed to arrive at the State population-weighted degreedday figure. To compute national population-weighted degree-days, the Nation is divided into nine Census regions, each comprising from three to eight States, which are assigned weights based on the ratio of the population of the region to the total population of the Nation. Degree-day readings for each region are multiplied by the corresponding population weight for each region and those products are then summed to arrive at the nationat population-weighted degree-day figure.

Demnonstrated Reserve Base (coal): A collective term for the sum of coal in both measured and indicated resource categories of reliability, representing 100 percent of the in-place coal in those categories as of a certain date. Includes beds of bituminous coal and anthracite 28 or more inches thick and beds of subbituminous coal 60 or more inches thick that can occur at depths of up to 1,000 feet. Includes beds of lignite $\mathbf{6 0}$ or more inches thick that can be surface mined. Includes also thinner and/or deeper beds that currently are being mined or for which there is evidence that they could be mined commercially at a given time. Represents that portion of the identified coal resource from which reserves are calculated,

Design Electrical Rating, Net: The nominal net electrical output of a nuclear unit as specified by the electric utitity for the purpose of plant design.

Development Well: A well drilled within the proved area of an oil or gas reservoit to the depth of a stratigraphic hortzon known to be productive.

Distillate Fuel Oil: A general classiftcation for one of the petroleum fractions produced in conventional distillation operations. Included are products known as No. 1, No. 2, and No. 4 fuel oils and No. 1, No. 2 , and No. 4 diesel fuels. It is used primarily for space heating, on-and off-highway diesel engine fuel (including railroad engine fuel and fuel for agricultural machinery), and electric power generation.

Distillation Unit (atmospheric): The primary distilation unit that processes crude oil (including mixtures of other hydrocarbons) at approximately atmospheric conditions. It includes a pipe still for vaporizing the crude oil and a fractionation tower for separating the vaporized hydrocarbon components in the cuude oil into fractions with different boiling ranges. This is done by continuously vaporizing and condensing the components to separate higher boiling point material. The selected boiling ranges are set by the processing scheme, the properties of the crude oil, and the product specifications.

District Heat; Steam or hot water from an outside source used as an snergy source in a building. The steam or hot water is produced in a central plant and piped into the building. The district heat may be purchased from a utility or provided by a physical plant in a separate 
building that is part of the same facility (for example, a hospital complex or vniversity).

Dry Hole: An exploratory or development well found to be incapable of producing either oil or gas in sufficient quantities to justify completion as an oil or gas well.

Dry Naturad Gas Production (as a decrement from gas reserves): The volume of natural gas withdrawn from reservoirs during the report year less (1) the volume returned to such reservoirs in cycling, repressuring of oil reservoirs, and conservation operations; (2) shrinkage resulting from the removal of lease condensate and plant liquids; and (3) nonhydrocatbon gases, where they occur in sufficient quantity to render the gas unmarketable. Volumes of gas withdrawn from gas storage reservoirs and native gas that has been transferred to the storage category are not considered in production. This is not the same as marketed production, since the latter also excludes vented and flared gas but contains liquids.

Dry Natural Gas Production (as an increment to gas supply): Gross withdrawals from production reservoirs less gas used in reservoir repressuring, amounts vented and flared, nonhydrocarbons removed, and various natural gas constituents, such as ethane, propane, and butane, removed at natural gas processing plants. The parameters for measurement are $60^{\circ} \mathrm{F}$ and 14.73 pounds standard per square inch absolute.

Electrical System Energy Lossest The amount of energy lost during generation, transmission, and distribution of electricity, including plant and unaccounted-for uses.

Electricity Generation: The process of producing electric energy or transforming other forms of energy into electric energy. Also, the amount of electric energy produced or expressed in watthours (Wh).

Electricity Generation, Gross: The total amount of electric energy produced by a generating facility, as measured at the generator terminals.

Electricity Generation, Net: Gross generation minus plant use from all electric utility-owned plants. The energy required for pumping at a pumped-storage hydroelectric plant is regarded as plant use and must be deducted from the gross generation.

EIectricity Production: Net electricity (gross electricity output measured at generator terminals minus power plant use) generated by publicly and privately owned electric utilities. Excludes industrial electricity generation (except autogeneration of hydroelectric power).

Electricity Sales: The amount of kilowatthours sold in a given period of time; usually grouped by classes of service, such as residential, commercial, industrial, and other. "Other" sales include sales for public street and highway lighting and other sales to public authorities and railways, and interdepartmental sales.

Electric Power Plant: A station containing prime movers, electric generators, and auxiliary equipment for converting mechapical, chemical, and/or fission energy into electric energy.

Electric Utilities: All privately owned companies and all publicly owned agencies engaged in the generation, transmission, or distribution of electric power for public use. Publicly owned agencies include municipal electric utilities; Fexleral power projects, such as the Tennessee Valley Authority (TVA); rural electrification cooperatives; power districts; and State power projects.

Glectric Utility: A corporation, person, agency, antherity, or other legal entity or instrumentality that owns and/or operates facilities within the United States, its territories, or Puerto Rico for the generation, transmission, distribution, or sale of electric energy, primarily for use by the public, and that files forms listed in the Code of Federal Regulations, Title 18, Part 141. Facilities that qualify as cogenerators or small power producers under the Public Utility Regulatory Policies Act are not considered electric utilities.

Electric Utility Sector: The electric utility sector consists of privately and publicly owned establishments that generate, transmit, distribute, or sell electricity primarily for use by the public and that meet the definition of an electric utility. Nonutility power producers are not included in the electric utility sector. 
Eliminations: Revenues and expenses resulting from transactions between segments. Consolidated company accounts do not include intersegment revenues and expenses. Therefore, such intersegment transactions must be eliminated.

End-Use Sectors: The residential, commercial, industrial, and transportation sectors of the economy.

Energy: The capacity for doing work as measured by the capability of doing work (potential energy) or the conversion of this capability to motion (kinetic energy). Energy has several forms, some of which are easily convertible and can be changed to another form useful for work. Most of the world's convertible energy comes from fossil fuels that are bumed to produce heat that is then used as a transfer medium to mochanical or other means in order to accomplish tasks. Electrical energy is usually measured in kilowatthours, while heat energy is usually measured in British thermal units.

Energy Consnmption: The use of energy as a source of heat or power or as an input in the manufacturing process.

Energy Consnmption, End-Use: The sum of fossi] foel consumption by the four end-use sectors (residential, commercial, industrial, and transportation) plus electric utility sales to those sectors and generation of hydroelectric power by nonelectric utilities. Net end-use energy consumption excludes electrical system energy losses. Total end-use energy consumption includes electrical system energy losses.

Energy Consumption, Total: The sum of fossil fuel consumed by the five sectors (residential, commercial, industrial, transportation, and electric utility) plus hydroelectric power, nuclear electric power, net imports of coal coke, and electricity generated for distribution from wood, waste, geothermal, wind, photovoltaic. and solat thermal energy.

Energy Expenditures: The money directly spent by consumers to purchase energy. Expenditures equal the amount of energy used by the consumer times the price per unit paid by the consumer.

Energy Source: A substance, such as petroleum, natural gas, or coal, that supplies heat or power. In Energy Information Administration
(EIA) reports, electricity and renewable forms of energy, such as biomass, geothermal, wind, and solar, are considered to be energy sources.

Energy-Weighted Industrial Output: The weighted sum of real output for all two-digit Standard Industrial CIassification (SIC) manufacturing tindustries, plus agriculture, construction, and mining. The weight for each industry is the ratio of the cuantity of end-use energy consumption to the vaiue of real output. The base year for those weights is either 1981 or 1982 , depending on data availability.

Ethane: A normaily gaseous straight-chain hydrocarbon $\left(\mathrm{C}_{2} \mathrm{H}_{6}\right)$. It is a colorless, paraffinic gas that boils at a temperature of $-127.48^{\circ} \mathrm{F}$. It is extracted from natural gas and refinery gas streams.

Ethylene: An olefinic hydrocarbon $\left(\mathrm{C}_{2} \mathrm{H}_{4}\right)$ recovered from refinery processes or petrochemical processes.

Exploratory Well: A well drilled to find and produce oil or gas in an unproved area, to find a new reservoir in a field previously found to be productive of oil or gas in another reservoir, or to extend the limit of a known oil or gas reservoir.

Exports: Shipments of goods from the 50 States and the District of Columbia to foreign countries and to Puerto Rico, the Virgin Islands, and other U.S. possessions and territories.

Extraction Loss: The reduction in volume of natural gas due to the removal of natural gas constituents, such as ethane, propane, and butane, at natural gas processing plants.

\section{f.a.s.: See Free Alongside Ship.}

Federal Energy Regulatory Commission (FERC): The Federa] agency with jurisdiction over interstate electricity sales, wholesale electric rates, hydroelectric licensing, natural gas pricing, oil pipeline rates, and gas pipeline certification. FERC is an independent regulatory agency within the Department of Energy and is the successor to the Federal Power Commission. 
Federal Power Commission (FPC): The predecessor agency of the Federal Energy Regulatory Commission. The Federal Power Commission was created by an Act of Congress under the Federal Water Power Act on June 10, 1920. It was charged originally with tegulating the electric power and natural gas industries. It was abolished on September 30, 1977, when the Department of Energy was created. Its functions were divided between the Department of Energy and the Federal Energy Regulatory Commission, an independent regulatory agency.

First Purchase Price: The marketed first sales price of domestic crude oil, consistent with the removal price defined by the provisions of the Windfall Profits Tax on Domestic Crude Oil (Public Law 96223, Sec. 4998 [c]].

Fiscal Year: The U.S. Government's fiscal year runs from October 1 through September 30. The fiscal year is designated by the calendar year in which it ends; e.g., fiscal year 1992 begins on October 1, 1991, and ends on September 30, 1992.

Flared Natural Gas: Natural gas burned in flares on the base site or at gas processing plants.

Floorspace: All the area enclosed by the exterior walls of a bujlding, inchuding indoor parking facilities, basements, hallways, lobbies, stairways, and elevator shafts. For aggregate floorspace statistics, square footage was summed or aggregated over all buildings in a category (such as all office buildings in the United States).

C.o.b.: See Free on Board.

Former U.S.S.R.: See U.S.S.R.

Pootage Drilled: Total footage for wells in various categoties, as reported for any specified period, includes (1) the deepest total depth (length of well bores) of all wells drilled from the surface, (2) the total of all bypassed footage drilled in connection with reported wells, and (3) all new footage drilled for directional sidetrack welis. Footage reported for directional sidetrack wells does not include footage in the cornmon bore, which is reported as footage for the original well. In the case of old wells drilled deeper, the reported footage is that which was drilled below the total depth of the old well.

Forward Costs: The operating and capital costs still to be incurred in the production of uranium from estimated reserves; such costs are used in assigning the uranium reserves to cost categories. Those costs include labor, materials, power and fuel, royalties, payroll and producton taxes, insurance, and applicable general and administrative costs. They exclude expenditures prior to reserve estimates, for example, for property acquisition, exploration, mine development, and mill construction from the forward cost determinations, as well as income taxes, profit, and the cost of money. Forward costs are neither the full costs of production nor the market price at which the uranium will be sold.

Fossil Fuel: Any naturally occurring organic fuel formed in the Earth's crust, such as petroleum, coal, and natural gas.

Fossil Fuel Steam-Electric Power Plant: An electricity generation plant in which the prime mover is a turbine rotated by high-pressure stean produced in a boiler by heat from burning fossil fuels.

Free Alongside Ship (f.a.s.): The value of a commodity at the port of exportation, generally including the purchase price, plus all charges incurred in placing the commodity alongside the carrier at the port of exportation.

Free on Board (f.o.b.): A transaction whereby the seller makes the product available within an agreed-on period at a given port at a given price. It is the responsibjlity of the buyer to arrange for the transportation and insurance,

Foel Ethanol: An anhydrous, denatured aliphatic alcohol $\left(\mathrm{C}_{2} \mathrm{H}_{3} \mathrm{OH}\right)$ intended for motor gasoline blending. See Oxygenates.

Fuel-Switching Capability: The short-term capability of a manufacturing establishment to have used substitute energy sources in place of those actually consumed. Capabillty to use substitute energy sources means that the establishment's combustors (for example. boilers, furnaces, ovens, and blast furnaces) had the machinery or equipment either in place or available for installation so that 
substitutions could actuatly have been introduced within 30 days without extensive modifications. Fuel-\$witching capability does not depend on the relative prices of energy sources; it depends only on the characteristics of the equjpment and certain legal constraints.

Ful-Power Operation: Operation of a nuclear generating unit at 100 percent of its design capacity. Full-power operation precedes commercial operation.

Gasohol: A blend of finished motor gasoline (leaded or unleaded) and alcohol (generally ethanol but sometimes methanol) limited to 10 percent by volume of alcohol. Gasohol is included in finished leaded and unleaded motor gasoline.

Gas-Turbine Electric Power Plant: A plant in which the prime mover is a gas turbine. A gas turbine typically consists of an axialflow air compressor and one or more cornbustion chambers where liquid or gaseous fuel is burned. The hot gases expand to drive the generator and then are used to run the compressor.

Gas Well: A well completed for the production of natural gas from one or more gas zones or reservoits. (Wells producing both crude oil and natural gas are classified as oil wells.)

Gas Well Productivity: Derived annually by dividing gross natural gas withdrawals from gas wells by the number of producing gas wells on December 31 and then dividing the quotient by the number of days in the year.

Geothermal Energy: Energy from the internal beat of the Earth, which may be residual heat, friction heat, or a result of radioactive decay. The heat is found in rocks and fluids at various depths and can be extracted by ditling and/or pumping.

Geothermal Energy (as used at electric utilities): Hot water or steam, extracted from geothermal reservoirs in the Earth's crust, and supplied to steam turbines at electric utilities that drive generators to produce electricity.

Grosss Domestic Product (GDP): The total value of goods and seryices produced by labor and property located in the United States. As long as the labor and property are located in the United States, the supplier (that is, the workers and, for property, the owners) may be either U.S. residents or residents of foreign countries.

Gross Domestic Product (GDP) Implicit Price Deflator: A measure used to convert nominal prices to real prices. See Chained Dollars.

\section{Gross Electricity Generation: See Electricity Generation, Gross.}

Gross Input to Atmospheric Crude Oll Distillation Units: Total input to atmospheric crude oil distillation units. Inctudes all crude oil, lease condensate, natural gas plant liguids, unfinished oils, liquefied refinery gases, slop oils, and other liquid hydrocarbons produced from tar sands, gilsonite, and oil shale.

Heat Content of a Quantity of Fuel, Gross: The total amount of heat released when a fuel is burned. Coal, crude oil, and natural gas all include chemical compounds of carbon and hydrogen. When those fuels are burned, the carbon and hydrogen combine with oxygen in the air to produce carbon djoxide and water. Some of the energy released in burning goes into transforming the water into steam and is usually lost. The antount of heat spent in transforming the water into steam is counted as part of gross heat content but is not counted as part of net content. Also referred to as the higher heating value. Btu conversion factors typically used by EIA represent gross heat content.

Heat Content of a Quantity of Fuel, Net: The amount of ușable heat energy released when a fuel is burned under conditions similar to those in which it is normally used. Also referred to as the lower heating valure. Btu conversion factors typically used by EIA ropresent gross heat content.

Heavy Oil: The fuel oils remaining after the lighter oils have been distilled off during the refining process. Except for start-up and flame stabilization, virtually all petroleum used ju steam-electric power plants is heavy oil.

Household: A family, an individual, or a group of up to nine unrelated persons occupying the same hotrsing unit. Occupy means the housing unit was the person's usual or permanent place of residence. 
Thie household includes bables, lodgers, boarders, employed persons who live in the housing unit, and persons who usually live in the household but are away traveling or in a hospital. The household does not include persons who are normally members of the household but who are away from home as college students or members of the armed forces. The household does not include persons temporarily visiting with the household if they have a place of residence elsewhere, persons who take their meals with the household but usually lodge or sleep elsewhere, domestic employees or other persons employed by the household who do not sleep in the same housing unit, or persons who are former members of the household, but have since become inmates of correctional or penal institutions, mental institutions, homes for the aged or needy, homes or hospitals for the chronically ill or handicapped, nursing homes, convents or monssteries, or other places in which residents may remain for long periods of time. By definition, the number of households is the same as the number of occupied housing units.

Housing Unit: A structure or part of a structure where a household lives. It has access from the oxtside of the building either directly or through a common hall. Housing tuits do not include group quarters, such as prisons or nursing homes where 10 or more unrelated persons live. Hotel and motel rooms are considered housing units if occupied as the usual or permanent place of residence.

Hydrocarbon: An organic chemical compound of hydrogen and carbon in the gaseous, liquid, or solid phase. The molecular structure of hydrocarbon compounds varies from the simplest (methane, a constituent of natural gas) to the very heavy and very complex.

Hydroelectric Power: The production of electricity from the kinetic energy of falling water.

Hydroelectric Power Plant: A plant in which the turbine generators are driven by falling water.

Implicit Price Deflator: See Gross Domestic Product (GDP) Implicit Price Deflator.
Imports: Receipts of goods into the 50 States and the District of Columbia from foreign countries and from Puerto Rico, the Virgin Islands, and other U.S. possessions and territories.

Independent Power Producer: Wholesale electricity producers (other than qualifying facilities under the Public Utilities Regulatory Policjes Act of 1978) that are unaffiliated with franchised utilities in the area in which the independent power producers are selling power and that lack significant narketing power. Unlike traditional electric utilities, independent power producers do not possess transmission facilities that are essential to their customers and do not sell power in any retail service territory where they have a franchise. Ses Nonutility Power Producer.

Indicated Resources, Coal: Coal for which estimates of the rank quality, and quantity are based partly on sample analyses and measurements and partly on reasonable geologic projections. Indicated resources are computed partly from specified measurements and partly from projection of visible data for a reasonable distance on the basis of geologic evidence. The points of observation are $1 / 2$ to 1-1/2 miles apart. Indicated coal is projected to extend as a $1 / 2$-mile-wide beit that lies more than $1 / 4$ mile from the outcrop or points of observation or measurement.

Industrial Sector: The industrial sector comprises manufacturing industries which make up the largest part of the sector along with mining, construction, agriculture, fisheries, and forestry. Establishments in this sector range from steel mills, to suall farms, to companies assembling electronic components. The SIC codes used to classify establishrments as industrial are 1 through 39.

Internal Combustion Electric Power Plant: A power plant in which the prime mover is an internal combustion engine. Diesel or gas-fired engines are the principal types used in electric power plants. The plant is usually operated during periods of high demand for electricity.

International Bunkers: Storage compartments, found on vessels and aircraft engaged in international commerce, where fuel to be used by the vessel or aircraft is stored. 
Jet Fuel: The term includes kerosene-type jet fuel and naphtha-type jet fuel. Kerosene-type jet fuel is a kerosene-quality product used primarily for commercial turbojet and turboprop aircraft engines. Naphthe-type jet fuel is a fuel in the heavy naphthas range used primarily for military turbojet and turboprop aircraft engines.

Kerosene: A petroleum distillate that has a maximum distillation temperature of $401^{\circ} \mathrm{F}$ at the 10 -percent recovery point, a final boiling point of $572^{\circ} \mathrm{F}$, and a minimum flash point of $100^{\circ} \mathrm{F}$. Included are the two grades designated in ASTM D3699 (No. 1-K and No. 2-K) and all grades of kerosene called range or stove oil. Kerosene is used in space heaters, cook stoves, and water heaters; it is suitable for use as an illuminant when bumed in wick lamps.

Lease and Plant Fuel: Natural gas used in woll, field, and lease operations (such as gas used in drilling operations, heaters, dehydrators, and field compressors), and as fuel in matural gas processing plants.

Lease Condensate: A natural gas liquid recovered from gas well gas (associated and non-associated) in lease separators or natural gas field facitities. Lease condensate consists primarily of pentanes and heavier hydrocarbons.

Light Oil: Lighter fuel oils distilled off during the refining process. Virtually all petroleum used in internal combustion and gas-turbine engines is light oil.

Lignite: A brownish-black coal of low rank with a bigh content of moisture and volatile matter. Often referred to as brown coal. It is used almost exclusively for electric power generation. It conforms to ASTM Specification D388-84 for lignite.

Line-Miles of Seismic Exploration: The distance along the Earth's surface that is covered by seismic surveying.

Liquefied Natoral Gas (LNG): Natural gas (primarily methane) that has been liquefled by reducing its temperature to $-260^{\circ} \mathrm{F}$ at atmospheric pressure.

Liquefied Petroleum Gases (LPG): Ethane, ethylene, propane, propylene, normal butane, butylene, and isobutane produced at refineries or nattra] gas processing plants, including plants that fractionate new natural gas plant liquids.

Liquefied Refinery Gases (LRG): Liquefied petroleum gases fractionated from refinery or still gases. Through compression and/or refrigeration, they are retained in the liguid state. The reported categories are ethane/ethylene, propane/propylene, normal butane/butylene, and isobutane. Excludes still gas.

Low-Power Testing: The period of time between a nuclear generating unit's initial fuel loading date and the issuance of its operating (fullpower) license. The maximum level of operation during that period is 5 percent of the unit's design thermal rating.

Lubricants: Substances used to reduce friction between bearing surfaces or as process materials ejther incorporated into other materials used as processing aids in the manufacturing of other products or as carriers of other materials. Petroleum lubricants may be produced either from distillates or residues. Other substances may be added to impart or improve certain required properties. Excluded are byproducts of lubricating oil refining, such as aromatic extracts derived from solvent extraction or tars derived from deasphalting. Lubricants in clude all grades of lubricating oils from spindle oil to cylinder oil and those used in greases. Lubricant categories include paraffinic and naphthenic.

Main Cooking Fael: Fuel most often ased for cooking.

Main Heating Equipment: Equipment used primarily for heating ambient air in a housing unit.

Main Heating Fuel; Fuel that powers the main beating equipment.

Major Electric Utility: A utility that, in the last 3 consecutive calendar years, had sales or transmission services exceeding one of the following: (1) 1 million megawatthours of total annual sales; (2) 100 megawathours of annual sales for resale; (3) 500 megawatthours of annual gross interchange out; or (4) 500 megaw atthours of wheeling (deliveries plus losses) for others. 
Major Fuels: The energy sources or fuels for which consumption and expenditure data were collected on the 1986 Nonresidential Building Energy Consumption Survey. Those fuels or energy sources are as follows: electricity, fuel oil, tiquefied petroleum gases, natural gas, district steam, district hot water, and district chilled water.

Manufacturing Establishment: An economic unit at a single physical location where the mechanical or chemical transformation of materials or substances into new products is performed. Those operations are generally conducted in facilities described as plants, factories, or mills and characteristically use power-driven machines and material handling equipment. In addition, the assembly of comporents of manufactured products is considered manufacturing, as is the blending of materials, such as lubricating oil, plastics, resins, or liquors. Manufacturing establishments are covered by SIC codes 20 through 39.

Manufacturing Sector: The universe of manufacturing establishments within the 50 States and the District of Columbia.

Measured Resources, Coal: Coal resources for which estimates of the rank, quality, and quantity have been computed, within a margin of error of less than 20 percent, from sample analyses and measurements from closely spaced and geologically well known sample sites. Measured resources are computed from dimensions revealed in outcrops, trenches, mine workings, and drill holes. The points of observation and measurement are so closely spaced and the thickness and extent of coals are so well defined that the tonnage is judged to be accurate within 20 percent. Although the spacing of the point of observation necessary to demonstrate continuity of the coal differs from region to region, according to the character of the coalbeds, the points of observation are no greater than $1 / 2$ mile apart. Measured coal is projected to extend as a belt $1 / 4$ mile wide from the cutcrop or points of observation or measurement.

Metallurgical Coal: Coal that meets the requirements for making coke. It must be low in ash and sulfur and form a coke that is capable of supporting the charge of iron ore and limestone in a blast furnace. A blend of two or more bituminous coals is usually requited to make coke.
Methanol: A light, volatile alcohol $\left(\mathrm{CH}_{3} \mathrm{OH}\right)$ eligible for motor gasotine blending. See Oxygenates.

Metropoliten: Refers to bujldings Jocated within Metropolitan Statistical Areas (MSA's) is defined in the 1980 Census. Except in New England, an MSA is a county or a group of contiguous counties that contains at least one city of 50,000 inhabitants or more, or twin cities with a combined population of 50,000 or more. The contiguous counties are included in an MSA if they are essentially metropolitan in character and are socially and economically integrated with the central city. In New England, MSA's consist of towns and cities rather than coupties.

Miscellaneous Petroleum Products: All finished petroleum products not classified elsewhere, for example, petrolatum, lube refining byproducts (aromatic extracts and tars), absorption oils, ram-jet fuel, petroleum rocket fuels, synthetic natural gas feedstocks, and specialty oils.

Motor Gasoline: A complex mixture of relatively volatile hydrocatbons, with or without small quantities of additives, obtained by blending appropriate refinery streams to form a fuel suitable for use in spark-ignition engines. Motor gasoline includes both leaded and unleaded grades of finished motor gasoline, blending components, and gasohol.

Motor Gasoline Blending Components: Naphthas that will be used for blending or compounding into finished motor gasoline (e.g. straight-run gasoline, alkylite, reformate, benzene, toluene, and xylene). Excluded are oxygenates (alcohols and ethers), butane, and pentanes plus.

Motor Gasoline, Finished: A complex mixture of relatively volatile bydrocarbons, with or without small quantities of additjves, that has been blended to form a fuel suitable for use in spark-ignition engines. Motor gasoline, as given in ASTM Specification D439 or Federal Specification VV-Gr1690B, includes a range in distillation temperatures from $122^{\circ}$ to $158^{\circ} \mathrm{F}$ at the 10 percent recovery point and from $365^{\circ}$ to $374^{\circ} \mathrm{F}$ at the 90 -percent recovery point. Moto gasoline includes reformulated motor gasoline, oxygenated motor 
gasoline (Environmental Protection Agency [EPA] approved), and other firisined motor gasoline. Blendstock is excluded until blending has been completed.

- Reformulated Motor Gasoline: Motor gasoline, formulated for use in motor vehicles, the composition and properties of which tre certified as "reformulated motor gasoline" by the EPA.

- Oxygenated Motor Gasoline (EPA Approved): Motor gasoline, formulated for use in motor vehicles, that is intended for use in the EPA carbon monoxide nonattainsment program. Reformulated motor gasoline is excluded.

- Other Finished: Motor gasoline that is not included in the refor mulated or oxygenated categcries.

Motor Gasoline, Finished Gasobol: A bjend of finished motor gasoline (leaded or unleaded) and alcohol (generally ethanol, but sometimes methanol) in which 10 percent or more of the product is alcohol.

Motor Gasoline, Finished Leaded: Motor gasoline that contains more than 0.05 gram of lead per gallon or more than 0.005 gram of phosphorus per gallon. Premium and regular grades are included, depending on the octane rating. Inchides leaded gasohol. Blendstock is excluded until blending has been completed. Alcohol that is to be used in the blending of gasohol is also excluded.

Motor Gasolinc, Finished Leaded Premium: Motor gasoline having an antiknock index, calculated as $(R+M) / 2$, greater than 90 and containing more than 0.05 gram of lead per gallon or mare than 0.005 gram of phosphorus per galton.

Motor Gasoline, Finished Leaded Regular: Motor gasoline having an antiknock index, calculated as $(R+M) / 2$ greater than or equal to 87 and less than or equal to 90 and containing prore than $0.05 \mathrm{gram}$ of lead or 0,005 gram of phosphorus per gallon.

Motor Gasoline, Finished Unieaded: Motor gasoline containing not more than 0.05 grair of lead per gallon and not mere than 0.005 gram of phosphorus per gallon. Premium and regular grades are included, depending on the octane rating. Includes unleaded gasohol. Blendstock is excluded until blending has been completed. Alcohol that is to be used in the blending of gasohol is also oxcluded.
Motor Gasoline, Finished Unleaded Midgrade: Motor gasoline having an antiknock index calculated as $(R+M) / 2$, greater than or equat to 88 and less than or equal to 90 and containing not more than 0.05 gram of phosphorus per gallon.

Motor Gasoline, Finished Unleaded Premium: Motor gasoline having an antiknock index calculated as $(\mathrm{R}+\mathrm{M}) / 2$, greater than 90 and containing not more than 0.05 gram of lead or $0.005 \mathrm{gram}$ of phosphonus per gallon.

Motor Gasoline, Finished Unleaded Regular: Motor gasoline having an antiknock index, calculated as $(R+M) / 2$, of 87 and containing not more than 0.05 gram of lead per gallon and not more than 0.005 gram of phosphorus per gallon.

Motor Gasoline, Leaded: Motor gasoline that contains more than $0.05 \mathrm{gram}$ of lead per gallon or more than $0.005 \mathrm{gram}$ of phosphorus per gatlon. Premitum and regular grades are included.

Motor Gasoline Retajl Prices: Motor gasoline prices calculated each month by the Bureau of Labor Statistics (BLS) in conjunction with the construction of the Consumer Price Index (CPI). Those prices are collected in 85 urben areas selected to represent all uban consumers-about 80 percent of the total U.S. population. The service stations are selected initially, and on a replacement basts, in such a way that they represent the purchasing habits of the CPI population. Service stations in the current sample include those providing all types of service (i.e., full-, mini-, and self-service).

Motor Gasoline, Total: Includes finished leaded motor gasoline (premium and regular), finished unleaded motor gasoline (premium, midgrade, and regular), motor gasoline blending components, and gasohol.

Motor Gasoline, Unleaded: Gasoline that contains not more than 0.05 gram of lead per gallon and not more than 0.005 gram of phosphorus per gallon. Premium and regular grades are included, depending on the octane rating.

MTBE (Methyl Tertiary Butyl Ether): An ether, $\left(\mathrm{CH}_{3}\right)_{3} \mathrm{COCH}_{3}$, intended for motor gasoline blending. See Oxygenates. 
Naphtha: A generic term applied to a petroleum fraction with an approximate boiling range between $122^{\circ}$ and $400^{\circ} \mathrm{F}$.

Native Gas: The total volume of natural gas indigenous to the storage reservoir at the time the storage started.

Natural Gas: A mixture of hydrocarbons (principally methane) and small quantities of various nonhydrocarbons existing in the gaseous phase or in solution with crade oil in underground reservoirs.

Natural Gas, Dry: The marketable portion of natural gas production, which is obtained by subtracting extraction losses, including natural gas liquids removed at natural gas processing plants, from total production.

Natural Gas Gross Withdrawals: Full well stream volume of produced natural gas, excluding condensate separated at the lease.

Natural Gas Liquids (NGL): Those hydrocartons in natural gas that are separated as liquids from the gas. Natural gas liquids include natural gas plant liquids (primarity ethane, propane, butane, and isobutane), and lease condensate (primarily pentanes produced from natural gas at lease separators and fjeld facilities.)

Natural Gas Marketed Production: Gross withdrawals of natural gas from production teservoirs, less gas used for reservoir repressuring; nonhydrocarbon gases removed in treating and processing operations; and quantities vented and flared.

Natural Gas Plant Liquids (NGPL): Natural gas liquids recovered from natural gas in processing plants and, in some situations, from natural gas field facilities, as well as those extracted by fractionators. Natural gas plant liquids are defined according to the published specifications of the Gas Processors Association and the American Society for Testing and Materials as follows: ethane, propane, normal butane, isobutane, pentanos plus, and other products from natural gas processing plants (i.e., products meeting the standards for finished petroleum procucts produced at natural gas processing plants, such as finished motor gasoline, finished aviation gasoline, specjal naphthas, kerosene. distillate fuel oil, and miscellaneous products).
Natural Gas Wellhead Price: The wellhead price of natural gas is calculated by dividing the total reported value at the wellhead by the total quantity produced as reported by the appropriate agencies of individual producing States and the U.S. Minerals Management Service. The price includes all costs prior to shipment from the lease, including gathering and compression costs, in addition to State production, severance, and similar charges.

Natural Gas, Wet: Natural gas prior to the extraction of liquids and other misceilaneous products.

\section{NERC: See North American Electric Reliability Council.}

\section{Net Electricity Generation: See Electricity Generation, Net.}

Net Income: Operating income plus earnings from unconsolidated affiliates; gains from disposition of property, plant, and equipment; minority interest income; and foreign curtency translation effects less income taxes, extraordinary items, and the cumulative effect of accounting changes.

Net Ownership Interest: The sum of net working interest and royalty interest. Net ownership interest applies to both production and reserves.

Net Property Investment: The original cost of property, plant, and equipment (PP\&E), less accumulated depreciation.

Net Summer Capability: The steady hourly output that generating equipment is expected to supply to system load, exclusive of auxiliary power, as demonstrated by testing at the time of summer peak demand.

Net Working Interest: A company's working interest, not including any basic royalty or overriding royalty interests.

Nominal Dollars: A measure used to express nominal prices.

Nominal Price: The price paid for goods or services at the time of the transaction. Nominal prices are those that have not been adjusted to remove the offect of changes in the purchasing power of 
the dollar; they reflect buying power in the year in which the transaction occurred.

Nonhydrocarbon Gases: Typical nonhydrocarbon gases that may be present in reservoir natural gas are carbon dioxide, helium, hydrogen sulfide, and nitrogen.

Nonmetropolitan: Refers to buildings not located within Metropolitan Statistical Areas as defined in the 1980 Census.

Nontraceables: Those revenues, costs, assays, and liabilities that cannot be directly attributed to a type of business by use of a reasonable allocation method developed on the basis of operating-leve! utilities.

Nonutility Power Producer: A corporation, person, agency, authority, or other legal entity or instrumentality that owns electric generating capacity and is not an electric utility. Nonutility power producers include qualifying cogenerators, qualifying small power producers, and other nonutility generators (including independent power producers) without a designated, franchised service area that do not file forms listed in the Code of Federal Regulations, Title 18, Part 141. See Cogenerator; Independent Power Producer; and Small Power Producer.

North American Electric Reliability Council (NERC): A council formed in 1968 by the electric utility industry to promote the reliability and adequacy of bulk power supply in the electric utility systems of North America. The NERC consists of nine regional reliability councils and encompasses essentially all the power systems of the contiguous United States and Canada. The NERC regions are as follows: (1) East Central Area Reliability Coordination Agreement (ECAR); (2) Electric Reliability Council of Texas (ERCOT); (3) MidAperica Interpol Network (MAIN); (4) Mid-Atlantic Area Council (MAAC); (5) Mid-Continent Area Power Pool (MAPP); (6) Northeast Power Coordinating Cotncil (NPCC); (7) Southeastem Electric Reliability Council (SERC); (8) Southwest Potwer Pool (SPP); and (9) Western Systems Coordinating Council (WSCC).
Nuclear Electric Power: Electricity generated by an electric power plant whose turbines are driven by steam generated in a reactor by heat from the frssioning of nuclear fuel.

Nuclear Electric Power Plant: A single-unit or multi-unit facility in which heat produced in one or more reactors by the fissioning of nuclear fuel is used to drive one or more steam turbiness.

Nuclear Reactor: An apparatus in which the nuclear fission chain can be initiated, maintained, and controlled so that energy is released at a specific rate. The reactor includes fissionable material (fuel), such as uranium or plutonium; fertile material; moderating material (unless it is a fast reactor); a heavy-walled pressure vessel; shielding to protect personnel; provision for heat removal; and control elements and instrumentation.

Offshore: That geographic area that lies seaward of the coastline. In general, the coastline is the line of ordinary low water along with that portion of the coast that is in direct contact with the open sea or the line marking the seaward limit of inland water.

\section{Oil: See Crude Oil (Including Lease Condensate).}

Oil Well: A well completed for the production of crude oil from one or more oil zones or reservoirs. Wells producing both crude oil and natural gas are classifted as oil wells.

Operable (nuclear): A. U.S. nuclear generating unit is considered operable after it completes low-power testing and is issued a fullpower operating license by the Nuclear Regulatory Commission. A foreign nuclear generating unit is considered operable once it has generated electricity to the grid.

Operable Refineries: Refineries that were in one of the following three categories at the beginning of a given yeart in operation; not in operation and not under active repair, but capable of being placed into operation within 30 days; or not in operation, but under active repair that could be completed within 90 days.

Operating Income: Operatiog revenues less operating expenses. Excludes items of other revenue and expense, such as equity in earnings of 
unconsolidated affiliates, dividends, interest incorne and expense, income taxes, extraordinary items, and cumulative effect of accounting changes.

Organization for Economic Cooperation and Development (OECD): Current members are Australia, Austria, Belgium, Canada, Denmark, Finland, France, Germany, Greece, Iceland, Ireland, Italy, Japan, Luxembourg, Mexico, the Netherlands, New Zealand, Norway, Portugal, Spain, Sweden, Switzerland, Turkey, the United Kingdom, and the United States and its territories (Guam, Puerto Rico, and the Virgin Islands).

Organization of Petroleum Exporting Countries (OPEC): Countries that have organized for the purpose of negotiating with oil companies on matters of oil production, prices, and future concession rights. Current members are Algeria, Gabon, Indonesia, Iran, Iraq, Kuwait, Libya, Nigeria, Qatar, Saudi Arabia, the United Arab Emirates, and Venezuela.

Other Hydracarbons (petroleum): Other materials processed at refineries. Includes coal tar derivatives, hydrogen, gilsonite, and natural gas received by the refinery for reforming into hydrogen.

\section{Oxygenated Motor Gasoline: See Motor Gasoline, Finished.}

Oxygenates: Any substance which, when added to motor gasoline, increases the amount of oxygen in that motor gasoline blend. Through a series of waivers and interpretive rules, the Eavironmental Protection Agency (EPA) has determined the allowable limits for oxygenates in unleaded gasoline. The "Substantially Similar" Interprettve Rules (56 FR [February 11, 1991]) allows blends of aliphatic alcohols other than methanol and aliphatic ethers, provided the oxygen content does not exceed 2.7 percent by weight. The "Substantially Similar" Interpretive Rules also provide for blends of methanol up to 0.3 percent by volume exclusive of other oxygenates, and butanol or alcohols of a higher molecular weight up to 2.75 percent by weight. Individual waivers pertaining to the use of oxygenates in unleaded motor gasoline have been issued by the EPA. They include the following:

- Fuel Ethanol: Blends of up to 10 percent by volume anhydrous ethanol (200 proof).
- Metharol: Blends of metbanol and gasolìne-grade tertiary butyl alcohol (GTBA) such that the total oxygen content does not exceed 3.5 percent by weight and the ratio of methatol to GTBA is less than or equal to 1 . It is also specified that this blended fuel anust meet ASTM volatility specifications. Blends of up to 5.0 percent by volume methanol with a minimum of 2.5 percent by volume cosolvent alcohols having carbon number of 4 or less (i.e., ethanol, propanot, butanol, and/or GTBA). The total oxygen must not exceed 3.7 percent by weight, and the blend must meet ASTM volatility specfications as well as phase separation and alcohol purity specifications.

- MTBE (Methyl tertiary butyl ether): Blends up to 15.0 percent by volume MTBE that must meet the ASTM D4814 specifications. Blenders must take precautions that the blends are not used as base gasolines for other oxygenated blends.

Pentanes Plas: A mixture of hydrocarbons, mostly pentanes and heavier, extracted from natural gas. Inciudes isopentane, natural gasoline, and plant condensate.

Petrochemical Feedstocks: Chemical feedstocks derived from petroleum principally for the manufacture of chemicals, synthetic rubber, and a variety of plastics. The categories reported are naphthas less than $401^{\circ} \mathrm{F}$ endpoint and other oils equal to or greater than $401^{\circ} \mathrm{F}$ endpoint.

Petroleum: A generic term applied to ofl and oil products in alt forms, such as crude oil, lease condensate, unfinished oils, petroleum products, natural gas plant liquids, and nonhydrocarbon compounds blended into finished petroleum products.

Petroleum Coke: A residue that is the final product of the condensation process in cracking. The product is either marketable petroleum coke or catalyst petroleurn coke.

Petroleum Coke, Catalyst: The carbonaceous residue that is deposited on and deactivates the catalyst used in many catalytic operations (e.g., catalytic cracking), Carbon is deposited on the catalyst, thus deactivating the catalyst. The catalyst is reactivated by burning of the 
carbon, which is used as a fuel in the refining process. That carbon or coke is not recoverable in a concentrated form.

Petroleum Coke, Marketable: Those grades of coke produced in delayed or fluid cokers that may be recovered as relatively pure carbon. Marketable petroleum coke may be sold as is or further purified by calcining.

Petroleum Consumption: The sum of all refined petroleum products supplied. For each refined petroleum product, the amount supplied is calculated by adding production and imports, then subtracting changes in primary stocks (net withdrawals are a plus quantity and net additions are a minus quantity) and exports.

Petroleum Imports: Imports of petroleum into the 50 States and the District of Columbia from foreign countries and from Puetto Rico, the Virgin Islands, and other U.S. territories and possessions. Included are imports for the Strategic Petroleum Reserve and withdrawals from bonded warehouses for onshore consumption, offshore bunker use, and military use. Excluded are receipts of foreign petroleum into bonded warehouses and into U.S. territories and U.S. Foreign Trade Zones.

Petroleum Products: Products obtained from the processing of crude oil (including lease condensate), natural gas, and other hydrocarbon compounds. Petroleum products include unfinished oils, liquefied petroleum gases, pentanes plus, aviation gasoline, motor gasoline, naphtha-type jet fuel, kerosene-type jet fuel, kerosene, distillate fuel oil, residual fuel oil, petrochemical feedstocks, special naphthas, lubricants, waxes, petroleum coke, asphalt, road oil, still gas, and miscellaneous products.

\section{Petroleum Products Supplied: See Petroleum Consumption.}

Petroleum Stocks, Primary: For individetal products, quantities that are held at refineries, in pipelines, and at bulk terminals that have a capacity of 50,000 barrels or more, or that are in transit thereto. Stocks held by product retailers and resellers, as wel] as tertiary stocks held at the point of consumption, are excluded, Stocks of individual products held at gas processing plants are excluded from individual product estimates but are included in other oil estimates and total.

Photovoltaic and Solar Mhermal Energy (as used at electric utilitfes): Energy radiated by the sun as electromagnetic waves (electromagnetic radiation) that is converted at electric utilities into electricity by means of solar (photovoltaic) cells or concentrating (focusing) collectors.

Photovoltaic Module: A group of photovoltajc cells. (Cells are solid-state devices that produce electricity when exposed to sunlight,) The electricity is used primarily in applications requiring remote power, such as radio communication, cathodic protection, and navigattonal aids.

Pipeline, Natural Gas: A continuous pipe conduit, complete with such equipment as valves, compressor stations, communications systems, and meters, for transporting batural gas and/or supplementa] gascous fuels from one point to another, usually from a point in or beyond the producing field or processing plant to another pipeline or to points of utilization. Also refers to a company operating such facilities.

Pipeline, Petroleum: Crude oil and product pipelines (including interstate, intrastate, and intracompany pipelines) useo to transport crude oil and petroleum products, respectively, within the 50 States and the District of Colambia.

Plant Condensate: One of the natural gas fiquids, mostly pentanes and heavier hydrocarbons, recovered and separated as liguids at gas inlet separators or scrubbers in processing plants.

Primary Energy Consumption Expenditures: Expenditures for energy consumed in each of the four major end-use sectors, excluding energy in the form of electricity, plus expenditures by the electric utilities sector for energy used to generate electricity. There are no fue]-associated expenditures for hydroelectric power, geothermal energy, photovoltaic and solar energy, or wind energy. Also excluded are the quantifiable consumption expenditures that are an integral part of process fuel consumption. 
Process Fuel: All energy consumed in the acquisition, processing, and transportation of energy. Quantifiable process fuel includes three categories: natural gas lease and plant operations, natural gas pipeline operations, and oil refinery operations.

Pracessing Gain: The amount by which total volume of refinery output is greater than the volume of input for a given period of time. The processing gain arises when crude oil and other hydrocarbons are processed into products that are, on average, less dense than the input.

Processing Loss: The amount by which total volume of refinery output is less than input for a given period of time. The processing loss arises when crude oil and other hydrocatbons are processed into products that are, on average, more dense than the input.

Processing Plant (natural gas): A surface installation designed to separate and recover natural gas líquids from a stream of produced natural gas through the processes of condensation, absorption, refrig. eration, or other methods, and to control the quality of natural gas marketed or returned to oil or gas reservoirs for pressure maintenance, repressuring, or cycling.

Propane: A normally gaseous straight-chain hydrocarbon $\left(\mathrm{C}_{3} \mathrm{H}_{8}\right)$. It is a colorless paraffinic gas that boils at a temperature of $-43.67^{\circ} \mathrm{F}$. It is extracted from natural gas or xefinery gas streams. It includes all products designated in ASTM Specification D1835 and Gas Processors Association Specifications for commercial propane and HD.5 propane,

Propylene: An olefinic hydrocerbon $\left(\mathrm{C}_{3} \mathrm{H}_{6}\right)$ recovered from refinery or petrochemical processes.

Proved Reserves, Crude On: The estimated quantities of all liquids defined as crude oil that geological and engineering data demonstrate with reasonable certainty to be recoverable in future years from known reservoirs under existtng economic and operating conditions.

Proved Reserves, Lease Condensate: The volumes of lease condensale expected to be recovered in future years in conjunction with the production of proved reserves of natural gas based on the recovery efficiency of lease and or field separation facilities installed.
Proved Reserves, Natural Gas: The estimated quantities of natural gas that analysis of geological and engineering data demonstrate with reasonable certainty to be recoverable in future years from known reservoirs under existing economic and operating conditions.

Proved Reserves, Natural Gas Liquids: Those volumes of natural gas liquids (including lease condensate) demonstrated with reasonable certainty to be separable in the future from proved natural gas reserves, under existing economic and operating conditions.

Real Price: A price that has been adjusted to remove the effect of changes in the purchasing power of the dollar. Real prices, which are expressed in chained dollars in this report, reflect buying power relative to a reference year. See Chained Dollars.

Refiner Acquisition Cost of Crude Oil: The cost af crude oil to the refiner, jncluding transportation and fees. The composite cost is the weighted average of domestic and imported crude oil costs.

Refinery Input: The raw materials and intermediate materials processed at refineries to produce finished petroleum products. They inctude crude oil, products of natural gas processing plants, unfinished olls, other hydrocarbons and alcohol, motor gasoline and aviation gasoline blending components, and finished petroleum products.

Refinery Output: The total amount of petroleum products produced at a refinery. Includes petroleum consumed by the reftnery.

Refinery (petroleum): An installation that manufactures finished petroleum products from crude oil, unfinished oils, natural gas liquids, other hydrocatbons, and alcohol.

Renewable Energy: Energy obtained from sources that are essentially inexhaustible (unlike, for example, the fossil fuels, of which there is a finite supply). Renewable sources of energy include wood, waste, geothermal, wind, photovoltaic, and solar thermal energy.

Reservoir Repressuring: The injection of a pressurized fluid (such as air, gas, or water) into oil and gas reservoir formations to effect greater ultimate recovery. 
Residential Buftding: A structure used primarily as a dwelling for one or more households.

Residential Sector: The residential sector is considered to consist of all private residences, whether occupied or vacant, owned or rented, including single-family homes, multifamily housing units, and mobile homes. Secondary homes, such as summer homes, are also included. Institutional housing, such as-school dormitories, hospitals, and military barracks, generaily are not included in the residential sector; they are included in the commercial sector. The Standard Industrfal Classification (SIC) code used to classify an establishment as residential is 88 (Household).

Residential Vehicles: Motorized vehicles used by U.S. households for personal transportation. Excluded are motorcycles, mopeds, large trucks, and buses. Included are automobiles, station wagons, passenger vans, cargo vans, motor homes, pickup trucks, and jeeps or similar vehicles. In order to be included, vehicles must be: (1) owned by members of the household, or (2) company cars not owned by household members but regularly available to household members for their personal use and ordinatily kept at home, or (3) rented or leased for 1 month or more.

Residual Fuel Oil: The heavier oils that remain after the distillate fuel oils and lighter hydrocarbons are distilled away in refinery operations and that conform to ASTM Specifications D396 and D975. Included are No, 5, a residual fuel oil of medium viscosity; Navy Special, for use in steam-powered vessels in government service and in shore power plants; and No. 6 , which includes Bunker $C$ fuel oil and is used for commercial and industrial heating, electricity generation, and to power ships. Imports of residual fuel oil include imported crude oil burned as fuel.

Road Oil: Any heavy petroleum oil, including residual asphaltic oil, used as a dust palliative and surface treatment on roads and bighways. It is generally produced in six grades, from 0 , the most liquid, to $S$, the most viscous.

Rotary Rig: A machine used for drilling wells that employs a rotating tube attached to a bit for boring holes through rock.
Royalty Interest: An interest in a mineral property provided through a royalty contract.

Rural Area: A place that had a population of less than 2,500 as of the 1980 U.S. Census.

Short Ton (coal): A unit of weight equal to 2,000 pounds.

\section{SIC: See Standard Industrial Classification.}

Small Power Producer: Under the Public Utility Regulatory Policies Act, a small power production facility (small power producer) generates electricity by using waste or renewable energy (biomass, conventional hydroelectric, wind, solar, and geothermal) as a primary energy source. Fossil fuels can be used, but renewable resources must provide at least 75 percent of the total energy input. See Nonutility Power Producer.

Solar Collector: Eguipment that actively concentrates thermal energy from the sun. The energy is usually used for space heating, for water heating, or for heating swimming pools. Ejther air or liquid is the working fluid.

Solar Energy: The radiant energy of the sun that can be converted into other forms of energy, such as heat or electricity.

Solar Thermal Collector: A device designed to receive solar radiation and convert it into thermal energy. Normatly, a solar therma] collector inclurdes a frame, glazing, and an absorber, together with appropriate insulation. The heat collected by the solar thermal collector may be used immediately or stored for later use.

Solar Thermal Collector, High-Temperature: A collector that generally operates at temperatures above $180^{\circ} \mathrm{F}$.

Solar Thermal Collector, Low-Temperature: A collector that generally operates at temperatures bolow $110^{\circ} \mathrm{F}$. Typically, it has no glazing or insulation and is made of plastic or nubber, although some are made of metal. 
Solar Thermal Collector, Medinm-Temperature: A collector that generally operates at temperatures of $140^{\circ}$ to $180^{\circ} \mathrm{F}$ but can also operate at temperatures as low as $110^{\circ} \mathrm{F}$. Typically, tt has one or two glazings, a metal frame, a metal absorption panel with integral flow channels or attached tubing (liquid collector) or with integral ducting (air collector) and insulation on the sides and back of the panel.

Solar Thermal Collector, Special: An evacuated tube collector or a concentrating (focusing) collector. \$pectal collectors operate in the temperature range from just above ambient temperature (low concentration for pool heating) to several hundred degrees Fahrenheit (high concentration for ajr conditioning and specialized industrial processes).

Space Heating: The use of mechanical equipment (including wood stoves and active solar heating devices) to heat all, or part, of a building to at least $50^{\circ} \mathrm{F}$.

Special Naphthas: All finished products within the naphtha boiling range that are used as paint thinners, cleaners, or solvents. Those products are refined to a specified flash point. Special naphthas include all commercial hexane and clearing solvents conforming to ASTM Specifications D1836 and D484, respectively. Naphthas to be blended or marketed as motor gasoline or aviation gasoline, or that are to be used as petrochemical and synthetic natural gas (SNG) feedstocks, are excluded.

Spot Market Price: A transaction price concluded "on the spot," that is, on a one-time, prompt basis; usually the transaction involves only one specific quantity of product. This contrasts with a term contract sale price, which obligates the seller to deliver a product at an agreed frequency and price over an extended period.

Standard Industrial Classification (SIC): A set of codes developed by the Office of Managenent and Budget which categorizes industries according to groups with similar economic activities.

Startup Test Phase of Nuclear Power Plant: A nuclear power plant that has been hicensed by the Nuclear Regulatory Commission to operate but is still in the initial testing phase, during which the production of electricity may not be continuous. In general, when the electric utility is satisfied with the plant's performance, it formally accepts the plant from the manufacturer and places it in commercial operation status. A request is then stbmitted to the appropriate utilty rate commission to include the power plant in the tate base calculation.

Steam-Electric Power Plant: A plant in which the prime mover is a steam turbine. The steam used to drive the turbine is produced in a boiler where fossil fuels are burned.

Still Gas (refinery gas): Any form or mixture of gas produced in refitheries by distillation, cracking, reforming, and other processes. The principal constituents are rtethane, ethane, ethylene, normal butane butylene, propane, and propylene. It is used primarily as refinery fuel and petrochemical feedstock.

Strategic Petroleum Reserve (SPR): Petroleum stocks maintained by the Federal Government for use during periods of major supply interruption.

Stripper Well (natural gas): A well that produces 60 thousand cubic feet per day or less of gas-well gas, for a period of 3 consecutive months while producing at its maximum rate flow. In determining abandonments, a stripper well is one that produced less than 22.5 million cubic feet in its last 12 months of production.

Stripper Well Property (petroleum): A property whase averago daily production of crude oil per well (excluding condensate recovered in nonassociated natural gas production) did not exceed an average of 10 barrels per day during any preceding consecutive 12 month period beginning after December $31,1972$.

Subbituminous Coal: A dutl, black coal of rank intermediate between lignite and bituminous coal. It conforms to ASTM Specification D388-84 for subbituminous coal. In this report, subbituminous coal is included in bituminous coal.

Supplemental Gaseous Fuels: Any gaseous substance that, introduced into or commingled with natural gas, jpcreases the volume available for disposition. Such substances include, but are not limited to, propane-air, refinery gas, coke oven gas, still gas, manufactured gas, biomass gas, or air or inert gases added for But stabilization. 
Synthetic Natural Gas (SNG): A manufactured product chemically similar in most respects to natural gas, resulting from the conversion or reforming of petroleum hydrocarbons. It may easily be substituted for, or interchanged with, pipeline quality natural gas. Also referred to as substitute natural gas.

Transportation Sector: The transportation sector consists of private and public vehicles that move people and commodities. Included are automobiles, trucks, buses, motorcycles, railroads, and railways (including streetcars), aircraft, ships, barges, and natural gas pipelines. The SIC codes used to classify establishments as belonging to the transportation sector are 40 through 49 .

Unaccounted-for Crude Oil: Represents the arithmetic difference between the calculated supply and the calculated disposition of crude oil. The calculated supply is the sum of crude oil production and imports, less changes in crude oil stocks. The calculated disposition of crude oil is the sum of crude oil input to refineries, crude oil exports, crude oil bumed as fuel. and crude oil losses.

Unaccounted-for Natnral Gas: Quantities lost, the net result of flow data metered at varying temperature and pressure conditions and converted to a standard tomperature and pressure base; metering inaccuracies; differences between the billing cyclo and calendar period timeframes; the effect of variations in company accounting and billing practices; and imbalances from the merger of data reporting systems which vary in scope, format, definitions, and type of respondents.

Undergronnd Storage: The storage of natural gas in underground reservoirs at locations other than those from which it was produced.

Undiscovered Recoverable Reserves (crude oil and natural gas): Those economic resources of crudo oil and natural gas, yet undiscovered, that are estimated to exist in favorable geologic settings.

Unfintshed Olls: All oils requiring futther refinery processing, except those requiring only mechanical blending. Includes naphthas and lighter oils, kerosene and light gas oils, heavy gas oils, and residuum.
Unfractionated Streams: Mixtures of unsegregated natural gas liq uid components, excluding those in plant condensate. This product is extracted from natural gas.

United States: Unless otherwise noted, United States in this publication means the 50 States and the District of Columbia. U.S. exports include shipments to U.S. tertitories, and imports include receipts from U.S. territories.

Uranium: A heavy, naturally radioactive, metallic element (atomic number 92). Its two principally occurring isotopes are uranium-235 and uranium-238. Uranjum-235 is indispensable to the nuclear industry, because it is the only isotope existing in nature to any appreciable extent that is fissionable by thermal neutrons. Uranjum-238 is also important, because it absorbs neutrons to produce a radioactive isotope that subsequently decays to plutonium-239, an isotope that also is fissionable by thermal neutrons.

Uranium Ore: Rock containing uranium mineralization (typically 1 to 4 pounds of $\mathrm{U}_{3} \mathrm{O}_{8}$ per ton or 0.05 percent to 0.2 percent $\mathrm{U}_{3} \mathrm{O}_{5}$ ) that can be mined economically.

Uranium Oxide: Uranium concentrate or yellowcake.

Uranium Resources: Uranium resource estimates are divided into three separate categories reflecting different levels of confidence in the quantities estimated: reasonable assured resources, stimated additional resources, and speculative resources. Reasonably assured resources refers to uranium in known mineral deposits of such size, grade, and configuration that it could be recovered within the given cost ranges with currently proven mining and processing technology. Estimated arditional resources refers to uranium in addition to reasonably assured resources that is expected, mostly on the basis of direct geological evidence, to occur in extensions of well-explored deposits and in depostts in which geological continuity has been well established, as well as in deposits believed to exist in well-defined geologic trends ar areas of mineraltzation with known deposits. Deposits in this category can be discovered and delineated and the urantum subsequently recovered, all within the given cost range. Speculative resources refers to uranium in 
addition to estimated additional resources that are thought to exist, mostly on the basis of indirect evidence and geological extrapolations.

Urban Area: A place that had a population of 2,500 or more as of the 1970 U.S. Census.

U.S.S.R.: The Union of Soviet Socialist Republics consisted of 15 constituent republics: Armenia, Azerbaijan, Belarus, Estonia, Georgia, Kazakstan, Kyrgyz Republic, Latvia, Lithuania, Moldova, Russia, Tajikistan, Turkmenistan, Ukraine, and Uzbekistan. As a political entity, the U.S.S.R. ceased to exist as of December 31, 1991.

Yented Natural Gas: Gas released into the air on the base site or at processing plants.

Vessel: Tankers used to transport crude oil and petroleum products. VesseI categories are as follows: Uttra Large Cruce Carrier (ULCC), Very Large Crude Carrier (VLCC), Other Tanker, and Specialty Ships * (LPG/LNG).

Waxes: Solid or semisolid materials derived from petroleum distillates or residues. Waxes are light-colored, more or less translucent crystalline masses, slightly greasy to the touch, consisting of a mixture of solid hydrocarbons in which the paraffin series predominates. Included are all marketable waxes, whether crude scale or fully refined. Waxes are used primarily as industrial coating for surface protection.

Well: A hole drilled in the Earth for the purpose of finding or producing crude oil or natural gas; or providing services related to the production of crude oil or natural gas. Wells are classifjed as oil wells, gas welis, dry holes, stratigraphic test wells, or service wells. The latter two types of wells are counted for Federal Reporting System data reporting. Oil wells, gas wells, and dry holes are classified as exploratory wells of development wells. Exploratory wells are subclassified as new-pool wildcats, deeper-pool tests, shallow-pool tests, and outpost (extension) tests. Well classifications reftect the status of wells after drilling has been completed.
Wellhead Price: The value of crude oil or natural gas at the mouth of the well.

Well Servicing Unit: Truck-mounted equipment generally used for downhole services after a well is drilled. Services include well completions and recompletions, maintenance, repairs, workovers, and well plugging and abandonments. Jobs range from minor operations, such as pulling the rods and rod pumps out of an oil well, to major workovers, such as milling out and repairing collapsed casing. Well depth and characterlstics determine the type of equipment used.

Wind Energy (as used at electric utilities): The kinetic energy of wind converted at electric utilities into mechanical energy by wind turbines (i.e., blades rotating from a hub) that drive generators to produce electricity for distribution.

Wood and Waste (as used at electric utilities): Wood energy, garbage, bagasse, sewerage gas, and other industrial, agricultural, and urban refuse used to generate electricity for distribution.

Wood Energy: Wood and wood products used as fuel, including round wood (cord wood), limb wood, wood chips, bark, sawdust, forest residues, charcoal, pulp waste, and spent pulping liquor.

Working Gas: The gas in a reservoir that is in addition to the base (cushion) gas. It may or may not be completely withdrawn during any particular withdrawat season. Conditions pemitting, the total working capacity could be used more than once during any given season.

Working Interest: An interest in a mineral property that entitles the owner to explore, develop, and operate a property. The working interest owner bears the costs of exploration, development, and operation of the property and, in return, is entitled to a share of the mineral production from the property or to a share of the proceeds.

Yellowcake: A uranium oxide concentrate that results from milling (concentrated) uranium ore. It is the final precipitate formed in the milling process. $\mathrm{U}_{3} \mathrm{O}_{3}$, a common form of triuranium oxjde, is the powder obtained by evaporating an ammonia solution of the oxide. Yellowcake typically contains 80 percent to 90 percent $\mathrm{U}_{3} \mathrm{O}_{8}$. 


\title{
Publication Order Form for Annual Energy Review 1995
}

Published: July 1996

Energy Information Adininistration

GPO Stock No. 061-008-00962-0

Price per copy: $\$ 25.00$

Personal Name or Altention Line:

Company Name, if applicable:

Street Address:

City. Stale, Zip Code:

Daytime Phone Number (area colte first);

Purchase Order No:

Nay we make your mante and address available to other mailers? $\square$ yes $\square$ no

Please include payment with this order form.

Allow a mmimum of 4 weeks for domestic delivery and an additional 6 weeks for intemational delvery.

Quantity $x \$ 25.00=$ total dus: (Intemational customers add 25\%)

$\square$ Check payable to Superintendent of Documents

$\square$ GPO Deposit Account No.

VISA or MasterCard Account No.

Authorizing Signature

Credlt Card Expiration Date

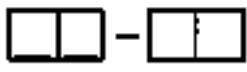

Note: Price includes regular domestc postage and handling. It is subfect to change.

\author{
Wall order form to: U.S. Government Printing Office \\ P.O. Box 371254 \\ Plitsburgh, PA 15250-7054 \\ Or fax order form to: $\quad 202-512-2250$
}

Thank you for your order! 


\section{Introducing the Energy InfoDisc....}

How much oil does the U.S. import from the Persian Gulf?

How many U.S. households use personal computers?

What's the long range outlook for nuclear power, and how will it affect other fuels?

How are clean alr regulations affecting emissions in the electric power industry?

Find answers to all your energy questions with Energy InfoDisc, the new CD-ROM providing the most comprehensive collectlon of energy informatton and analysis tools available today. Energy InfoDisc is a valuable resource for industry and govemment analysts, forecasters, journalists, and academic researchers- almost aryone needing access to current or historical energy information.

The Energy InfoDisc comes with advanced seach capability to find the information you need in seconds from over 180 of the most current periodicals and analytical publications of the Energy information Administration (EIA), the independent statstical and analytical agency within the U.S. Department of Energy. With Energy InfoDisc, you also heve instant accesss to ElA's wide range of national energy databases and special analysis applications. Dan't be whthout this important resource; subsctibe today.

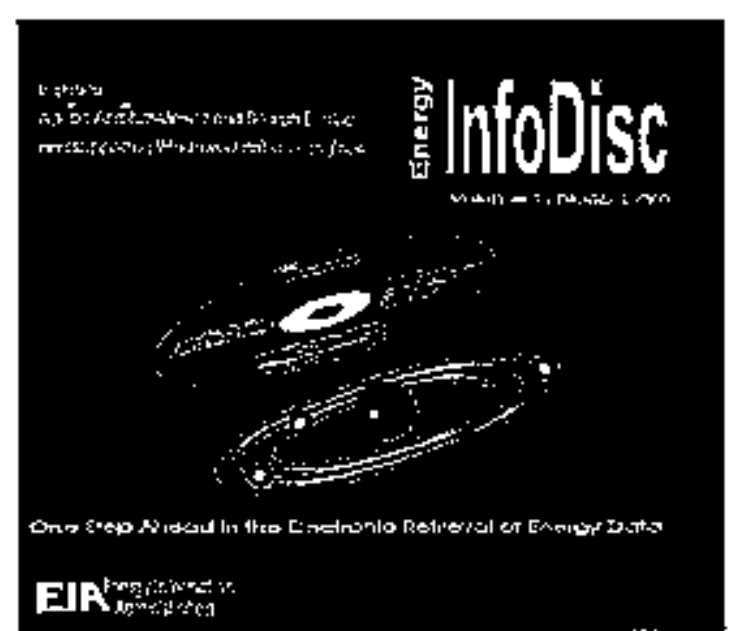

NOTE: Documents en be bocesged using either Mherosoft Windows or Madintosh System 7 opersthe oystems, Databastes and applleations on only be ecceses using Microsoft Windows.

\section{STAT-USAOrderForm}

Yes, entermy order for the Energy InfoDisc CD-RON:

Number of copies:

D singlo issue (U.S., Canada, \& Mexico): \$4B

Single lasue outelde the U, S., Canada \& Moxico: \$80

Quarterly subscription in the U.S., Canada, 8 Mexipo: \$100

Quarteriy subscription outside the U.S., Canada

\& Nexico: $\$ 160$

Contact or personal name

(please type or print)

Company

Street tadress

Additionala

Clty. State, ZtP Codo

Daytime phone

Faxnumber
Charge your order, It's easyf

To fax your orders: $(202) \mathbf{4 8 2 - 2 1 6 4}$

To phone your orders: (202)482-1986

For privacy protection, check the box below:

Do not make my name available to requesters.

Check method of payment:

$\square$ AMEX $\square$ Discover $\square$ MasterCard $\square$ VISA

Account Number:

\begin{tabular}{|l|l|l|l}
\hline & & & \\
\hline
\end{tabular}

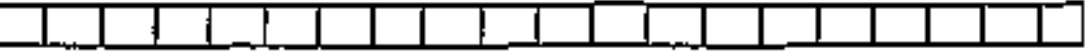

Thank you for yourorderl

Authorizing signature

Date

\section{Check payable to STAT-USA}

Mail to: U.S. Depariment of Commerce

STAT-USA, RoOM H-4BB5

Washington, DC 20230 